NUREG/CR-0200

ORNL/NUREG/CSD-2/R4-Vol.3

Vol. 3, Rev. 4

\title{
SCALE: A Modular Code System for Performing Standardized Computer Analyses for Licensing Evaluation
}

\section{Miscellaneous}

Manuscript Completed: November 1994

Date Published: April 1995

Prepared by

L. M. Petrie, W. C. Jordon, A. L. Edwards, ${ }^{1}$ P. T. Williams,

J. C. Ryman, O. W. Hermann, N. F. Landers, J. A. Bucholz,

J. R. Knight, C. V. Parks, J. C. Turner, R. M. Westfall,

J. T. West, ${ }^{2}$ M. B. Emmett, N. M. Greene

Oak Ridge National Laboratory

Managed by Martin Marietta Energy Systems, Inc.

Oak Ridge National Laboratory

Oak Ridge, TN 37831-6285

\section{Prepared for}

Division of Industrial and Medical Nuclear Safety

Office of Nuclear Material Safety and Safeguards

U.S. Nuclear Regulatory Commission

Washington, DC 20555-0001

NRC Job Code B0009

\footnotetext{
1Lawrence Livermore National Laboratory, Livermore, CA

2Formerly with Oak Ridge National Laboratory
} 


\section{AVAILABILITY NOTICE}

Availability of Reference Materials Cited in NRC Publications

Most documents cited in NRC publications will be available from one of the following sources:

1. The NRC Public Document Room, 2120 L Street, NW., Lower Level, Washington, DC 20555-0001

2. The Superintendent of Documents, U.S. Government Printing Office, P. O. Box 37082, Washington, DC 20402-9328

3. The National Technical Information Service, Springfield, VA 22161-0002

Although the listing that follows represents the majority of documents cited in NRC publications, it is not intended to be exhaustive.

Referenced documents avallable for inspection and copying for a fee from the NRC Public Document Room include NRC correspondence and internal NRC memoranda; NRC bulletins, circulars, information notices, inspection and investigation notices; licensee event reports; vendor reports and correspondence; Commission papers; and applicant and licensee documents and correspondence.

The following documents in the NUREG series are available for purchase from the Government Printing Office: formal NRC staff and contractor reports, NRC-sponsored conference proceedings, international agreement reports, grantee reports, and NRC booklets and brochures. Also available are regulatory guides, NRC regulations in the Code of Federal Regulations, and Nuclear Regulatory Commission Issuances.

Documents avallable from the National Technical Information Service include NUREG-series reports and technical reports prepared by other Federal agencies and reports prepared by the Atomic Energy Commission, forerunner agency to the Nuclear Regulatory Commission.

Documents avallable from public and special technical libraries include all open literature items, such as books, journal articles, and transactlons. Federal Register notices. Federal and State legislation, and congressional reports can usually be obtained from these libraries.

Documents such as theses, dissertations, foreign reports and translations, and non-NRC conference proceedings are available for purchase from the organization sponsoring the publication cited.

Single copies of NRC draft reports are available free, to the extent of supply, upon written request to the Office of Administration, Distribution and Mail Services Section, U.S. Nuclear Regulatory Commission, Washington, DC 20555-0001.

Copies of industry codes and standards used in a substantive manner in the NRC regulatory process are maintained at the NRC Library. Two White Flint North, 11545 Rockville Pike. Rockville, MD 20852-2738, for use by the public. Codes and standards are usually copyrighted and may be purchased from the originating organization or, If they are American National Standards, from the American National Standards Institute, 1430 Broadway, New York, NY 10018-3308.

\section{DISCLAIMER NOTICE}

This report was prepared under an international cooperative agreement for the exchange of technical information. Neither the United States Government nor any agency thereof, nor any of their employees, makes any warranty, expressed or implied, or assumes any legal liability or responsibility for any third party's use, or the results of such use, of any information, apparatus, product, or process disclosed in this report, or represents that its use by such third party would not infringe privately owned rights.

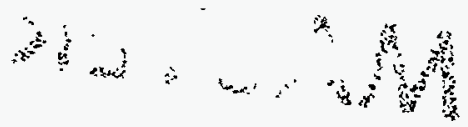




\section{DISCLAIMER}

Portions of this document may be illegible in electronic image products. Images are produced from the best available original document. 


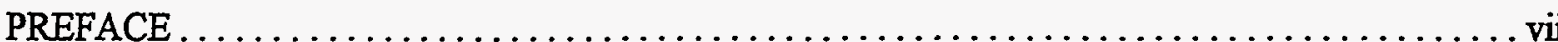

\section{Volume 1: Control Modules}

C1* CSAS1: A ONE-DIMENSIONAL CRITICALITY SAFETY ANALYSIS MODULE

C2* CSAS2: A MULTIDIMENSIONAL CRITICALITY SAFETY ANALYSIS MODULE

C3** CSAS3: AN OPTIMUM CONCENTRATION CRITICALITY SAFETY ANALYSIS MODULE (to be included in Sect. $\mathrm{C} 4$ at a later date)

C4 CSAS: AN ENHANCED CRITICALITY SAFETY ANALYSIS MODULE WITH SEARCH OPTIONS (N. F. Landers, L. M. Petrie)

S1 SAS1: A ONE-DIMENSIONAL SHIELDING ANALYSIS MODULE (J. R. Knight, C. V. Parks, S. M. Bowman, L. M. Petrie, J. A. Bucholz)

S2 SAS2H: A COUPLED ONE-DIMENSIONAL DEPLETION AND SHIELDING ANALYSIS MODULE (O. W. Hermann, C. V. Parks)

S3 SAS3: AN AUTOMATED MONTE CARLO SHIELDING ANALYSIS MODULE (J. T. West)

S4 SAS4: A MONTE CARLO CASK SHIELDING ANALYSIS MODULE USING AN AUTOMATED BIASING PROCEDURE (J. S. Tang)

H1 HTAS1: A TWO-DIMENSIONAL HEAT TRANSFER ANALYSIS OF FUEL CASKS, VERSION 4.0 (G. E. Giles)

\section{Volume 2, Part 1: Functional Modules}

Fl BONAMI: RESONANCE SELF-SHIELDING BY THE BONDARENKO METHOD (N. M. Greene)

F2 NITAWL-II: SCALE SYSTEM MODULE FOR PERFORMING RESONANCE SHIELDING AND WORKING LIBRARY PRODUCTION (N. M. Greene, L. M. Petrie, R. M. Westfall)

*Obsolete with SCALE-4.0 release.

**Not included in SCALE-4.2 release. 
F3 XSDRNPM: A ONE-DIMENSIONAL DISCRETE-ORDINATES CODE FOR TRANSPORT ANALYSIS (N. M. Greene, L. M. Petrie)

F4 XSDOSE: A MODULE FOR CALCULATING FLUXES AND DOSE RATES AT POINTS OUTSIDE A SHIELD (J. A. Bucholz)

F5* KENO IV/S: AN IMPROVED MONTE CARLO CRITICALITY PROGRAM

F6 COUPLE: SCALE SYSTEM MODULE TO PROCESS PROBLEM-DEPENDENT CROSS SECTIONS AND NEUTRON SPECTRAL DATA FOR ORIGEN-S DATA ANALYSES (O. W. Hermann)

F7 ORIGEN-S: SCALE SYSTEM MODULE TO CALCULATE FUEL DEPLETION, ACTINIDE TRANSMUTATION, FISSION PRODUCT BUILDUP AND DECAY, AND ASSOCIATED RADIATION SOURCE TERMS

(O. W. Hermann, R. M. Westfall)

F8 ICE: MODULE TO MIX MULTIGROUP CROSS SECTIONS

(N. M. Greene, L. M. Petrie, S. K. Fraley)

Volume 2, Part 2: Functional Modules (continued)

F9 MORSE-SGC FOR THE SCALE SYSTEM (J. T. West, T. J. Hoffman, M. B. Emmett)

F10 HEATING 7.2 USER'S MANUAL (K. W. Childs)

F11 KENO V.a: AN IMPROVED MONTE CARLO CRITICALITY PROGRAM WITH SUPERGROUPING (L. M. Petrie, N. F. Landers)

F12* JUNEBUG-II: A THREE-DIMENSIONAL GEOMETRY PLOTTING CODE

F13* HEATPLOT-S: A TEMPERATURE DISTRIBUTION PLOTTING PROGRAM FOR HEATING

F14* REGPLOT6: A PLOTTING PROGRAM TO VERIFY HEATING INPUT DATA

F15** PLORIGEN: A PLOTTING PROGRAM FOR ORIGEN-S OUTPUT (O. W. Hermann)

F16 OCULAR: A RADIATION EXCHANGE FACTOR COMPUTER PROGRAM (C. B. Bryan, G. E. Giles)

*Obsolete with SCALE-4.0 release.

**Not included in SCALE-4.2 release. 
Volume 3: Miscellaneous

M1 SCALE SYSTEM DRIVER (L. M. Petrie)

M2 SCALE SUBROUTINE LIBRARY (L. M. Petrie)

M3 SCALE FREE-FORM READING ROUTINES (L. M. Petrie)

M4 SCALE CROSS-SECTION LIBRARIES (W. C. Jordan)

M5 THERMAL MATERIAL PROPERTIES LIBRARY (A. L. Edwards, P. T. Williams)

M6 ORIGEN-S DATA LIBRARIES (J. C. Ryman, O. W. Hermann)

M7 THE MATERIAL INFORMATION PROCESSOR FOR SCALE (N. F. Landers, L. M. Petrie, J. A. Bucholz)

M8 STANDARD COMPOSITION LIBRARY (J. A. Bucholz, J. R. Knight, C. V. Parks, L. M. Petrie, J. C. Turner, R. M. Westfall)

M9 MARS: A MULTIPLE ARRAY SYSTEM USING COMBINATORIAL GEOMETRY (J. T. West, M. B. Emmett)

M10 FIDO INPUT SYSTEM (L. M. Petrie)

M11* SCALE INTERACTIVE INPUT PROCESSOR

M12* CESAR: A CRITICALITY EXPERIMENT STORAGE AND RETRIEVAL PROGRAM

M13 PICTURE: A PRINTER PLOT PACKAGE FOR MAKING 2-D PICTURES OF MARS GEOMETRIES (M. B. Emmett)

M14 COMPOZ DATA GUIDE (J. R. Knight, L. M. Petrie)

M15 USER'S GUIDE FOR UTILITY MODULES (N. M. Greene)

M16 COMMENT DATA GUIDE (L. M. Petrie)

*Obsolete with SCALE-4.0 release. 


\section{PREFACE}

\section{Background}

This Manual represents Revision 4 of the user documentation for the modular code system referred to as SCALE. The history of the SCALE code system dates back to 1969 when the current Computing Applications Division at Oak Ridge National Laboratory (ORNL) began providing the transportation package certification staff at the U.S. Atomic Energy Commission with computational support in the use of the new KENO code for performing criticality safety assessments with the statistical Monte Carlo method. From 1969 to 1976 the certification staff relied on the ORNL staff to assist them in the correct use of codes and data for criticality, shielding, and heat transfer analyses of transportation packages. However, the certification staff learned that, with only occasional use of the codes, it was difficult to become proficient in performing the calculations often needed for an independent safety review. Thus, shortly after the move of the certification staff to the U.S. Nuclear Regulatory Commission (NRC), the NRC staff proposed the development of an easyto-use analysis system that provided the technical capabilities of the individual modules with which they were familiar. With this proposal, the concept of the Standardized Computer Analyses for Licensing Evaluation (SCALE) code system was born.

The NRC staff provided ORNL with some general development criteria for SCALE: (1) focus on applications related to nuclear fuel facilities and package designs, (2) use well-established computer codes and data libraries, (3) design an input format for the occasional or novice user, (4) prepare "standard" analysis sequences (control modules) that will automate the use of multiple codes (functional modules) and data to perform a system analysis, and (5) provide complete documentation and public availability. With these criteria the ORNL staff laid out the framework for the SCALE system and began development efforts. The initial version (Version 0) of the SCALE Manual was published in July 1980. Then, as now, the Manual is divided into three volumes - Volume 1 for the control module documentation (Sections C4, S1- S4, and H1), Volume 2 for the functional module documentation (Sections F1-F16), and Volume 3 for the documentation of the data libraries and subroutine libraries (Sections M1-M16).

\section{System Overview}

The original concept of SCALE was to provide "standardized" sequences where the user had very few analysis options in addition to the geometry model and materials. Input for the control modules has been designed to be free-form with extensive use of keywords and engineering-type input requirements. The more flexible functional modules have a more difficult input logic and require the user to interface the data sets necessary to run the modules in a stand-alone fashion. As the system has grown in popularity over the years and additional options have been requested, the control modules have been improved to allow sophisticated users additional access to the numerous capabilities within the functional modules. However, the most important feature of the SCALE system remains the capability to simplify the user knowledge and effort required to prepare material mixtures and to perform adequate problem-dependent cross-section processing.

The modules available in Version 0 of SCALE were for criticality safety analysis sequences (CSAS) that provided automated material and cross-section processing prior to a one-dimensional (1-D) or multidimensional criticality analysis. Since that time the capabilities of the system have been significantly expanded to provide additional CSAS capabilities, new shielding analysis sequences (SAS) that also include depletion/decay capabilities for spent fuel characterization, and a heat transfer analysis sequence (HTAS). At the center of the CSAS and SAS sequences is the library of subroutines referred to as the Material Information Processor or MIPLIB (see Section M7). The purpose of MIPLIB is to allow users to specify problem materials using easily remembered and easily recognizable keywords that are associated with mixtures, elements, and nuclides provided in the Standard Composition Library (see Section M8). MIPLIB also uses other keywords 
and simple geometry input specifications to prepare input for the modules that perform the problem-dependent cross-section processing: BONAMI, NITAWL-II, and XSDRNPM. A keyword supplied by the user selects the cross-section library from a standard set provided in SCALE (see Section M4) or designates the reference to a user-supplied library. Several utility modules from AMPX ${ }^{1}$ have been added to this version of SCALE to provide users with the capability to edit the cross-section data and reformat user-supplied libraries for use in SCALE.

Over the history of the project several modules have been removed from the system because they are no longer supported by the development staff at ORNL. Tables 1 and 2 provide a iummary of the major applications of each of the control modules and functional modules currently in the SCALE code system. The control modules were designed to provide the system analysis capability originally requested by the NRC staff. The CSAS module (sometimes denoted as the CSAS4 module and documented in Section C4) is currently the only control module designed for the calculation of the neutron multiplication factor of a system. Eight sequences enable general analysis of a 1-D system model or a multidimensional system model, capabilities to search on geometry spacing, and problem-dependent cross-section processing for use in executing stand-alone functional modules. The SAS1 and SAS3 modules (see Sections S1 and S3, respectively) provide general 1-D deterministic and 3-D Monte Carlo analysis capabilities. The SAS2 module (see Section S2) was originally developed to perform a depletion/decay calculation to obtain spent fuel radiation source terms that were subsequently input automatically to a 1-D, radial shielding analysis in a cylindrical geometry. Over time the depletion/decay portion of the SAS2 module has been significantly enhanced and interfacing to the other shielding modules has been provided. The SAS4 module (see Section S4) enables automated particle biasing for a Monte Carlo analysis of a transportation package-type geometry. The HTASl module (see Section H1) is the only heat transfer control module and uses the various capabilities of the HEATING code to perform different sequences of steady-state and transient analysis that enable the normal and accident conditions of a transportation package to be evaluated. Like SAS4, the HTAS1 module is limited to a package-type geometry.

\section{Portability}

Version 4.2 of the SCALE system has been developed to ensure portability among various computing platforms. The system is maintained and enhanced at ORNL under quality assurance and configuration management plans. The system has been routinely tested on IBM mainframe and IBM workstations. In addition, the system has been applied at ORNL on DEC and SUN workstations. Information needed to install SCALE on each of these systems is included with the software package distributed by the code centers. Advice for installation on HP workstations is also included in the software package. A separate SCALE software package, designated SCALE-PC, is available for the execution of select portions of the SCALE system on a personal computer.

\section{Related Developments}

The definition of "easy-to-use" has changed considerably since the late 1970s. As funding has allowed, the ORNL development staff has sought to develop user interfaces that provide a distinct aid to novice or occasional users of the system. These full-screen input processors were developed to work on a personal computer and provide interactive help to the user in preparing accurate input for a SCALE module. Currently, input processors are available only for the criticality control sequences ${ }^{2}$ and the ORIGEN-S functional module. ${ }^{3}$

The capability to perform a point-kernel shielding analysis within the SCALE system has been developed ${ }^{4}$ and will be provided within SCALE-PC in the next release of the software package.

A 238-energy-group neutron cross-section library based on ENDF/B-V has recently been prepared for the SCALE system. ${ }^{s}$ All the nuclides that are available in ENDF/B-V are in the library. A 44-group 
library has been collapsed from this 238-group library and validated against numerous critical measurements. ${ }^{6}$ These libraries are available as separate data packages from the software distribution centers.

\section{Availability}

The SCALE code system and the other software designated under Related Developments have been packaged by the Radiation Shielding Information Center (RSIC) under cooperative agreement with the Energy Science and Technology Sc.tware Center. The SCALE system and the related software may be obtained by contacting either

Energy Science and Technology Software Center

P.O. Box 1020

Oak Ridge, TN 37831-1020

Telephone: (615) 576-2606

FAX: (615) 576-2865

or

Radiation Shielding Information Center

Oak Ridge National Laboratory

P.O. Box 2008

Oak Ridge, TN 37831-6362

Telephone: (615) 574-6176

FAX: (615) 574-6182

\section{Acknowledgments}

The SCALE system is maintained at ORNL and enhanced to keep pace with normal technical advancements in the analysis areas of interest. Although the NRC continues its role as the controlling sponsor of the SCALE system, the U.S. Department of Energy (DOE) began assisting in the maintenance of the SCALE system in 1987. Over the years numerous individuals within these sponsoring organizations have played key roles in ensuring that the SCALE system remained a readily available, relishle system for the analysis of nuclear fuel facilities and packages. The individuals who have worked with the ORNL staff to coordinate maintenance and development activities include $\mathrm{R}$. H. Odegaarden (NRC, ret.), G. H. Bidinger (NRC, ret.), C. Mauck (DOE, ret.), E. P. Easton (NRC), W. H. Lake (NRC and DOE), M. E. Wangler (DOE), and M. G. Bailey (NRC).

As demonstrated by this Manual, there are also numerous individuals from the ORNL staff who have contributed significantly to the development and enhancement of the SCALE system. Most are credited by their authorship of the sections in this Manual that correspond to their work. A few individuals have been essential to the development and maintenance of SCALE but are not credited by authorship. These individuals include: S. M. Bowman, who is responsible for proper configuration and testing of the development and production systems at ORNL and is the principal contact for general user assistance and training; S. K. Martin, who is responsible for implementing system changes; C. H. Shappert, who provided the editorial review of this Manual; and L. F. Norris, who prepared the entire manuscript. Special acknowledgement is also due to R. M. Westfall and G. E. Whitesides who, together with R. H. Odegaarden of the NRC, developed the concept and long-range goals of the SCALE system in the late 1970s. Finally, this Project Leader will always be grateful to L. M. Petrie, who for nearly 20 years has consistently provided consultation and advice on the technical 
direction that should be taken in development of nearly every module and cross-section library that are in the present system.

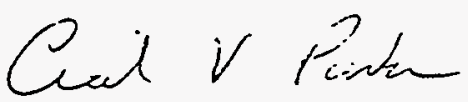

Cecil V. Parks

SCALE Project Manager

March 1995

\section{References}

1. Greene; N. M., Ford, W. E., III, Petrie, L. M., and Arwood, J. W., AMPX-77: A Modular Code System for Generating Coupled Multigroup Neutron-Gamma Cross-Section Libraries from ENDF/B-IV and/or ENDF/B-V, ORNL/CSD/TM-283, Martin Marietta Energy Systems, Inc., Oak Ridge Natl. Lab., October 1992.

2. S. M. Bowman OFFSCALE: A PC Input Processor for the SCALE Code System - The CSASIN Processor for the Criticality Sequences, NUREG/CR-6182, Vol. 1 (ORNL/TM-12263/V1), U.S. Nuclear Regulatory Commission, November 1994.

3. S. M. Bowman OFFSCALE: A PC Input Processor for the SCALE Code System - The ORIGNATE Processor for ORIGEN-S, NUREG/CR-6182, Vol. 2 (ORNL/TM-12263/V2), U.S. Nuclear Regulatory Commission, November 1994.

4. Broadhead, B. L., QADS: A Multidimensional Point Kernel Analysis Module, NUREG/CR-5468 (ORNL/CSD/TM-270), U.S. Nuclear Regulatory Commission, May 1990.

5. N. M. Greene, J. W. Arwood, R. Q. Wright, C. V. Parks, The LAW Library-A Multigroup CrossSection Library for Use in Radioactive Waste Analysis Calculations, ORNL/TM-12370, Martin Marietta Energy Systems, Inc., Oak Ridge Natl. Lab., August 1994.

6. M. D. DeHart and S. M. Bowman, Validation of the SCALE Broad Structure 44-Group ENDF/B-V Cross-Section Library for Use in Criticality Safety Analyses, NUREG/CR-6102 (ORNL/TM-12460), U.S. Nuclear Regulatory Commission, September 1994. 
Table 1 Analysis capabilities summary of the SCALE control modules

\begin{tabular}{|c|c|c|c|}
\hline $\begin{array}{l}\text { Control } \\
\text { module }\end{array}$ & Analysis function(s) & $\begin{array}{l}\text { Functional modules } \\
\text { executed }\end{array}$ & $\begin{array}{c}\text { Section } \\
\text { reference }\end{array}$ \\
\hline CSAS & $\begin{array}{l}\text { 1-D deterministic calculation of neutron multiplication } \\
\text { 3-D Monte Carlo calculation of neutron multiplication } \\
\text { Problem-dependent cross-section processing } \\
\text { Multiplication search or spacing }\end{array}$ & $\begin{array}{l}\text { BONAMI } \\
\text { NITAWL-II } \\
\text { XSDRNPM } \\
\text { KENO V.a } \\
\text { ICE }\end{array}$ & $\mathrm{C} 4$ \\
\hline SAS1 & $\begin{array}{l}\text { 1-D deterministic calculation of radiation transport through } \\
\text { shield and dose evaluation at a point } \\
\text { Calculation of dose at detector based on leakage from } \\
\text { critical volume }\end{array}$ & $\begin{array}{l}\text { BONAMI } \\
\text { NITAWL-II } \\
\text { XSDRNPM } \\
\text { XSDOSE }\end{array}$ & S1 \\
\hline SAS2 & $\begin{array}{l}\text { Point depletion/decay of nuclear fuel } \\
\text { 1-D radial shielding analysis in cylindrical geometry }\end{array}$ & $\begin{array}{l}\text { BONAMI } \\
\text { NITAWL-II } \\
\text { XSDRNPM } \\
\text { COUPLE } \\
\text { ORIGEN-S } \\
\text { XSDOSE }\end{array}$ & S2 \\
\hline SAS3 & Dose evaluation using MORSE Monte Carlo code & $\begin{array}{l}\text { BONAMI } \\
\text { NITAWL-II } \\
\text { XSDRNPM } \\
\text { MORSE-SGC }\end{array}$ & S3 \\
\hline SAS4 & $\begin{array}{l}\text { Calculation of dose outside of transportation package using } \\
\text { MORSE code and automated biasing techniques }\end{array}$ & $\begin{array}{l}\text { BONAMI } \\
\text { NITAWL-II } \\
\text { XSDRNPM } \\
\text { MORSE-SGC }\end{array}$ & S4 \\
\hline HTASI & $\begin{array}{l}\mathrm{R}-Z \text { steady-state and transient analyses of a transportation } \\
\text { package }\end{array}$ & $\begin{array}{l}\text { OCULAR } \\
\text { HEATING }\end{array}$ & $\mathrm{HI}$ \\
\hline
\end{tabular}


Table 2 Analysis capabilities summary of the SCALE functional modules

\begin{tabular}{|c|c|c|}
\hline Module & Function & $\begin{array}{l}\text { Section } \\
\text { reference }\end{array}$ \\
\hline BONAMI & Resonance self-shielding of cross sections with Bondarenko factors & $\mathrm{Fl}$ \\
\hline NITAWL-II & Resonance self-shielding of cross sections with resolved resonance data & F2 \\
\hline XSDRNPM & $\begin{array}{l}\text { General 1-D, discrete-ordinates code for: } \\
\text { - zone-weighting of cross sections } \\
\text { - eigenvalue calculations for neutron multiplication } \\
\text { - fixed-source calculation for shielding analysis } \\
\text { - adjoint calculation for determining importance functions }\end{array}$ & F3 \\
\hline XSDOSE & $\begin{array}{l}\text { Module for calculation of dose at a point based on the 1-D leakage flux } \\
\text { from a finite shield }\end{array}$ & F4 \\
\hline COUPLE & $\begin{array}{l}\text { Interface module for preparation of cross-section and spectral data for } \\
\text { ORIGEN-S }\end{array}$ & F6 \\
\hline ORIGEN-S & $\begin{array}{l}\text { General-purpose point-depletion and decay code to calculate isotopic, } \\
\text { decay heat, radiation source terms, and curie levels }\end{array}$ & F7 \\
\hline ICE & Cross-section utility module for mixing cross sections & F8 \\
\hline MORSE-SGC & $\begin{array}{l}\text { Monte Carlo code with combinatorial and array geometry features used to } \\
\text { perform radiation shielding analysis }\end{array}$ & F9 \\
\hline HEATING7.2 & $\begin{array}{l}\text { Finite-volume, multidimensional code for conduction and radiation heat } \\
\text { transfer }\end{array}$ & F10 \\
\hline KENO V.a & Monte Carlo code for calculation of neutron multiplication factors & F11 \\
\hline OCULAR & Calculation of radiation exchange factors & F16 \\
\hline
\end{tabular}


NUREG/CR-0200

Revision 4

Volume 3, Section M1

ORNL/NUREG/CSD-2/R4

Computing Applications Division

SCALE SYSTEM DRIVER

L. M. Petrie

Previously Published: December 1984

Date Published: April 1995

Prepared for the

Office of Nuclear Material Safety and Safeguards

U.S. Nuclear Regulatory Commission

Washington, DC 20555

Under Interagency Agreement DOE 1886-8000-9B

NRC JCN No. B0009

Prepared by the

OAK RIDGE NATIONAL LABORATORY

managed by

MARTIN MARIETTA ENERGY SYSTEMS, INC.

for the

U.S. DEPARTMENT OF ENERGY

under contract DE-AC05-84OR21400 
、 


\begin{abstract}
The SCALE driver was designed to allow implementation of a modular code system consisting of control modules, which determine the calculation path, and functional modules, which perform the basic calculations. The user can either select a control module and have that module determine the execution path, or the user can select functional modules directly by input.
\end{abstract}




\section{M1.1 DESCRIPTION}

The SCALE driver was designed to allow implementation of a modular code system consisting of control modules, which determine the calculation path, and functional modules, which perform the basic calculations. The user can either select a control module and have that module determine the execution path, or the user can select functional modules directly by input.

The driver obtains the name of the module to be accessed from the module specification card, the first card in the user input data file. It then transfers data cards from the input file to unit 5 until it finds an END card (a separate card with the characters END in columns 1 through 3 ). The driver accesses the module named on the first card, passing four arguments to it. These arguments allow the module to return control information to the driver and indicate what the next task will be. These tasks may include transferring more cards from the input file to unit 5, accessing a string of up to five functional modules and/or terminating this module and checking the input file for another module name to be accessed. SCALE uses subroutines GETMS and RESETM to communicate these arguments between the driver and labeled commons. This isolates the exact mechanism for communicating these arguments to.the driver and the two subroutines. This mechanism is one of the system-dependent parts of the SCALE system. Another system-dependent function the driver needs is the means to initiate the execution of another program.

When the driver accesses a functional module, the condition code returned by the module is checked against the value supplied by the control module. If the returned code is greater, the access string is terminated. When a string of functional module accesses is finished, the driver again accesses the control module to determine its next function.

Whenever a module finishes, the driver attempts to perform certain cleanup functions so that execution of subsequent modules may proceed. This includes closing data sets left open by the module and releasing storage that was allocated but not freed by the module.

Table M1.1 describes the four arguments the driver passes to a control module. The arguments of $\mathrm{JP}$ and $\mathrm{JD}$ are message strings, IC is an integer array, and $\mathrm{AC}$ is a real array. On IBM mainframes, JP and JD are used to pass a parameter string and a list of ddnames to system utilities. JP is the string defined by the PARM $=$ field on the module specification card.

By default, the driver reads input on SYSIN, prints a record of primary module accesses and input data on PRINT, and writes the input on FT05F001 (IBM mainframe) or INPUT (UNLX systems).

On IBM mainframes, these ddnames can be changed by specifying the overriding values in a PARM field for the driver. The ddnames should be specified in the following order: data output, data input, and print. Each ddname should be terminated by either a comma or the end of the parameter string. A zero-length entry (for example, consecutive commas) avoids redefining that entry. 
JP(1) PARM ficld, string length starts on a half-word boundary followed by a character string.

$\mathrm{JD}(1)$

DDNAME table, length of table starts on a halfword boundary, then 8-character names follow, binary zeros nullify.

IC(1) Control module access count, termination flag

IC(2) Allowed STOP return code numbers corresponding to the code module name list $\mathrm{AC}(2)-\mathrm{AC}(6)$ below.

IC(6)

\section{IC(7) Task completion flag, 0 - completed} successfully, $\neq 0$ - failure.

IC(8) User input data transfer flag (0 - no; 1 - transfer data and access module specified by control module; 2 - transfer data and access the special processor named on the first card (A8); $>2$ transfer data only).

IC(9) Individual code module task completions.

IC(10) Reserved for future driver control.

IC(11) Reserved for control module use.
Can be passed to the main program as a parameter.

Needed for system routine use.

If 1 , read data from unit 5 , save, set 0 for subsequent case, $<0$ for termination; $<1$ upon entry indicates an error condition.

Set here.

If $\neq 0$, execute wrap-up procedures.

Set to anticipate needs.

Probably set 0 at the start of each separate case nonzero upon first access indicates previous calculations have been done, perhaps under control of this or another control module.
(None)

(None)

Initialize as 0 whenever user input instructs access of a control module, add 1 prior to each access of a control module, seek new use input instructions if 0 , terminate if $<0$.

Used here.

Store STOP return number from code module here if it exceeds that allowed.

If $>0$, move a block to unit 5 , no other tasks if $>2$; set to zero on successful data transfer.

Add 1 after each acceptable return from a code module excluding the control module.

If $5376 \leq$ IC $(10) \leq 5631$, driver will print a functional module access record along with the control module access and input record. 
Table M1.1 (continued)

\begin{tabular}{|c|c|c|c|}
\hline Item & Use & Control module action & Driver action \\
\hline $\mathrm{AC}(1)$ & 8-character control module name. & (None) & Set here. \\
\hline $\begin{array}{l}\mathrm{AC}(2- \\
\mathrm{AC}(6)\end{array}$ & 8-character code module names. & $\begin{array}{l}\text { Set functional module access order here, end with } \\
\text { a blank if }<5 \text { entries. }\end{array}$ & Initialize blank. \\
\hline $\mathrm{AC}(7)$ & Reserved for future driver control. & & Initialize blank. \\
\hline$A C(8)$ & Latest input data header name. & Used here, then set blank. & $\begin{array}{l}\text { Initialize blank, set here unless first record read } \\
\text { encounters end-of-file. }\end{array}$ \\
\hline $\begin{array}{l}\mathrm{AC}(9)- \\
\mathrm{AC}(10)\end{array}$ & Reserved for future driver control. & & \\
\hline $\begin{array}{l}\mathrm{AC}(11)- \\
\mathrm{AC}(40)\end{array}$ & Reserved for control module use. & & \\
\hline
\end{tabular}

A control module will not be summoned under the apparent error conditions of unsuccessful transfer of data to unit 5 ; a terminator flag in the input data is required. The driver processes the user input file seeking a subsequent request for access to a control module. The elements in the $\mathrm{IC}$ array are set zero and in array $A C$ are set "BLANK" initially by the driver, and prior to a subsequent access of any control module, IC(1) - IC(8) and IC(10) are set zero and $A C(1)-A C(10)$ set "BLANK." Upon entry to a control module, $\mathrm{AC}(1)$ will contain its access name, IC(1) will be 1 , IC(8) is a task completion flag set for transfer of the controlmodule input data, IC(9) remains the code-module access count. 
NUREG/CR-0200

Revision 4

Volume 3, Section M2

ORNL/NUREG/CSD-2/V3/R4

Computing Applications Division

SCALE SUBROUTINE LIBRARY

\author{
L. M. Petrie
}

Previously Published: December 1984

Revised Manuscript Completed: November 1994

Date Published: April 1995

\author{
Prepared for the \\ Office of Nuclear Material Safety and Safeguards \\ U. S. Nuclear Regulatory Commission \\ Washington, DC 20555 \\ Under Interagency Agreement DOE 1886-8000-9B \\ NRC JCN No. B0009
}

Prepared by the

OAK RDGE NATIONAL LABORATORY

managed by

MARTIN MARIETTA ENERGY SYSTEMS, INC.

for the

U.S. DEPARTMENT OF ENERGY

under contract DE-AC05-84OR21400 



\begin{abstract}
A number of subroutines have been developed which are used by more than one of the SCALE program modules. The subroutines have been collected together in a library. This section contains a brief description of the function and the arguments of each subroutine.
\end{abstract}




\section{CONTENTS}

ABSTRACT

M2.iii

ACKNOWLEDGMENT

M2.ix

M2.1 INTRODUCTION

M2.1.1

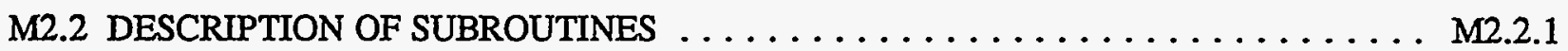

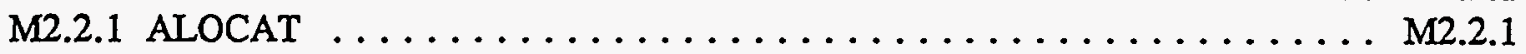

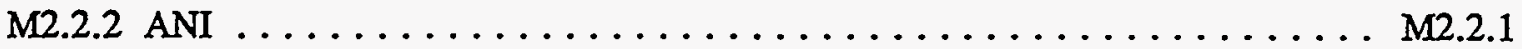

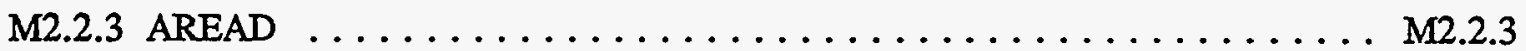

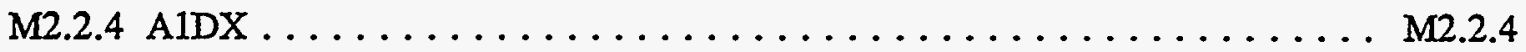

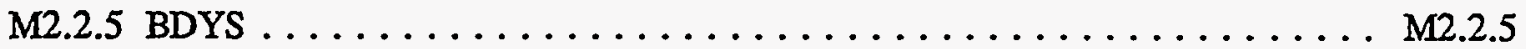

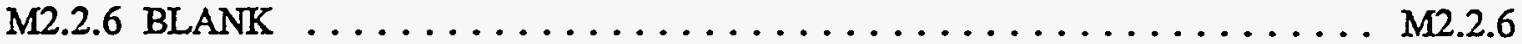

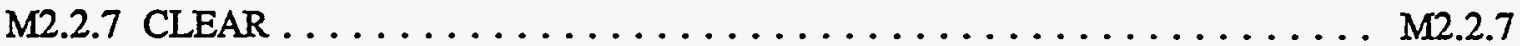

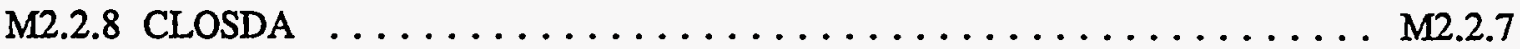

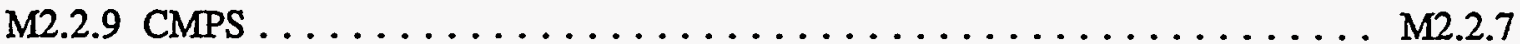

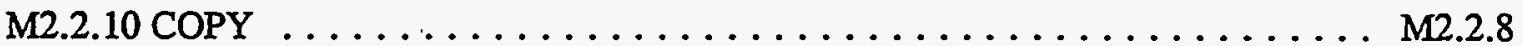

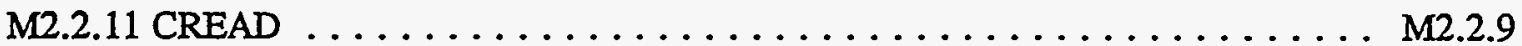

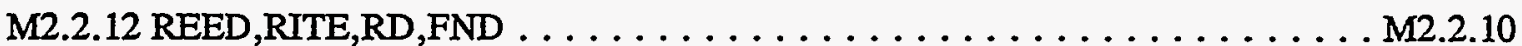

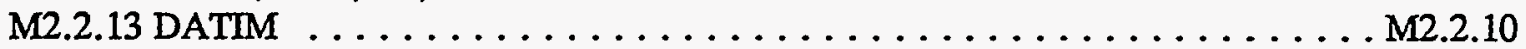

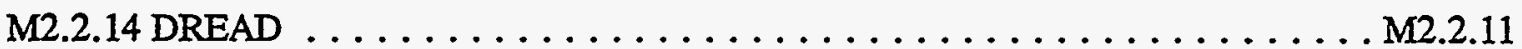

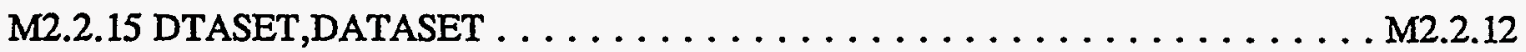

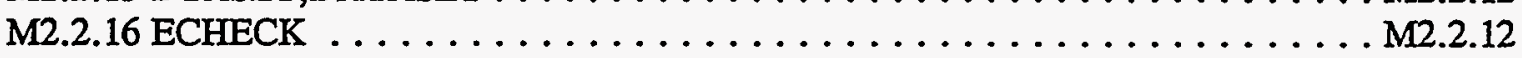

M2.2.17 ENERGY $\ldots \ldots \ldots \ldots \ldots \ldots \ldots \ldots \ldots \ldots \ldots \ldots \ldots \ldots \ldots \ldots \ldots \ldots \ldots \ldots \ldots \ldots .2 .13$

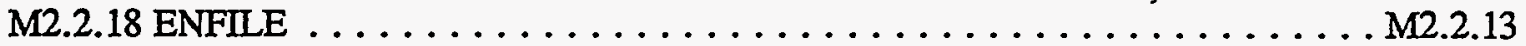

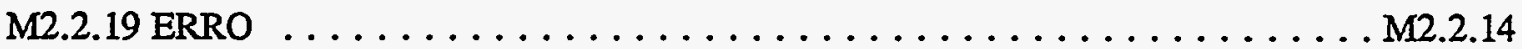

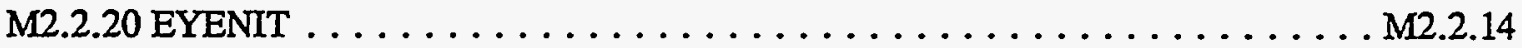

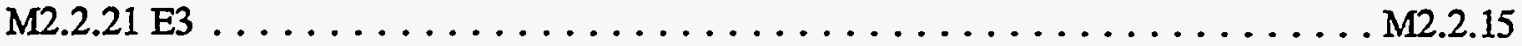

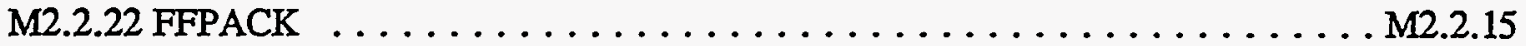

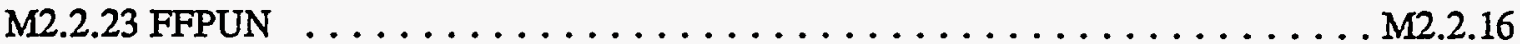

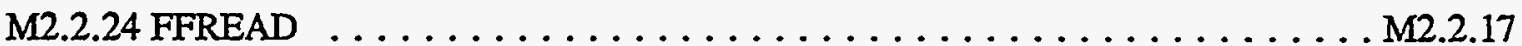

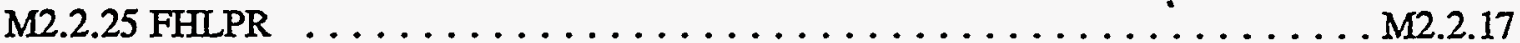

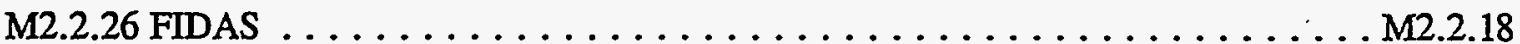

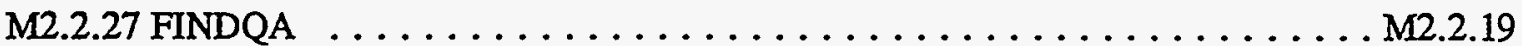

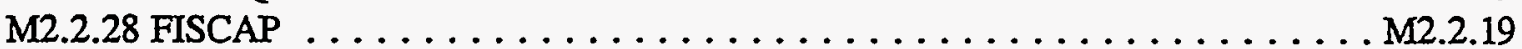

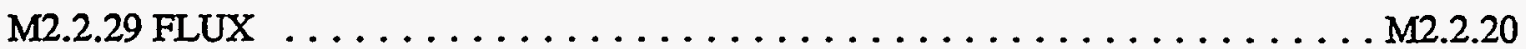

M2.2.30 FPUNCH $\ldots \ldots \ldots \ldots \ldots \ldots \ldots \ldots \ldots \ldots \ldots \ldots \ldots \ldots \ldots \ldots \ldots \ldots \ldots .2 .21$

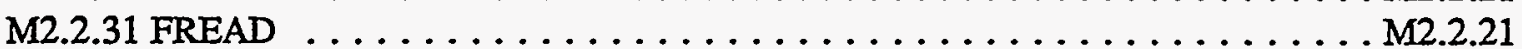

M2.2.32 FREECR $\ldots \ldots \ldots \ldots \ldots \ldots \ldots \ldots \ldots \ldots \ldots \ldots \ldots \ldots \ldots \ldots \ldots \ldots \ldots \ldots \ldots .2 .22$

M2.2.33 GETMS $\ldots \ldots \ldots \ldots \ldots \ldots \ldots \ldots \ldots \ldots \ldots \ldots \ldots \ldots \ldots \ldots \ldots \ldots \ldots \ldots \ldots \ldots .2 .22$

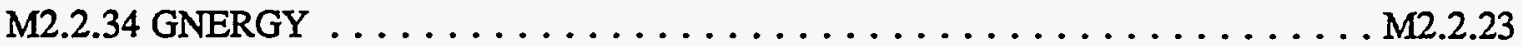

M2.2.35 ICOMPA $\ldots \ldots \ldots \ldots \ldots \ldots \ldots \ldots \ldots \ldots \ldots \ldots \ldots \ldots \ldots \ldots \ldots \ldots \ldots \ldots \ldots .2 .23$

M2.2.36 INQUIR $\ldots \ldots \ldots \ldots \ldots \ldots \ldots \ldots \ldots \ldots \ldots \ldots \ldots \ldots \ldots \ldots \ldots \ldots \ldots \ldots \ldots \ldots .2 .24$ 
CONTENTS (continued)

Page

M2.2.37 INTIME,PRTIME . . . . . . . . . . . . . . . . . . M2.2.25

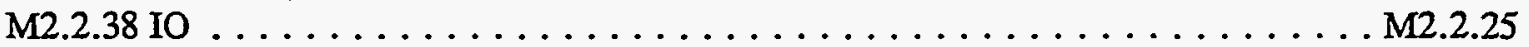

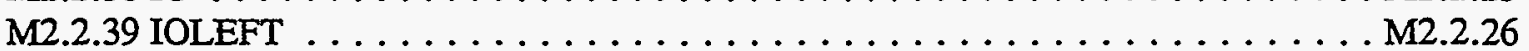

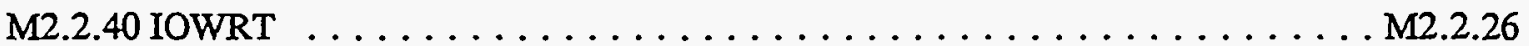

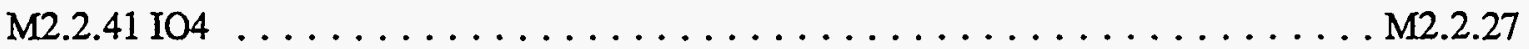

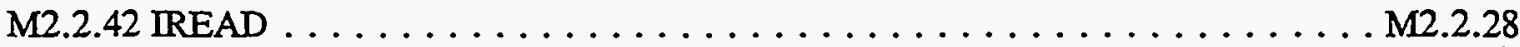

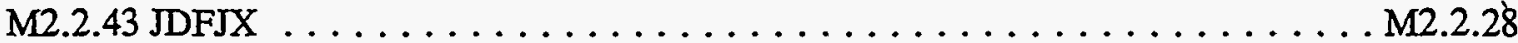

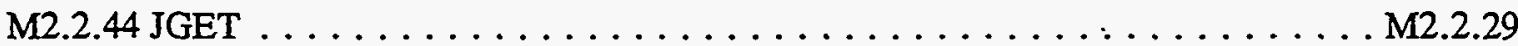

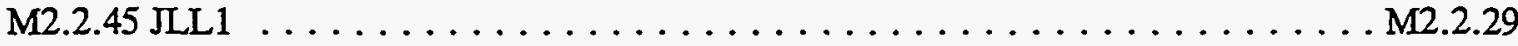

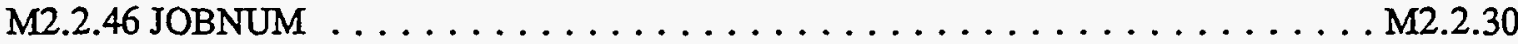

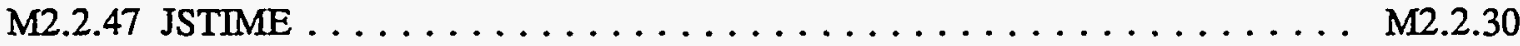

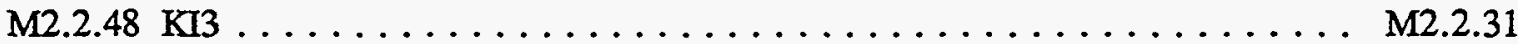

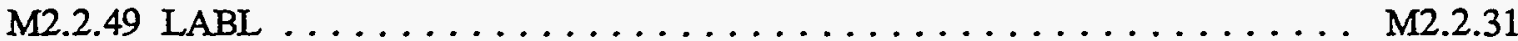

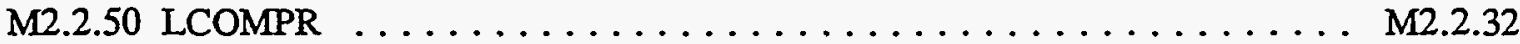

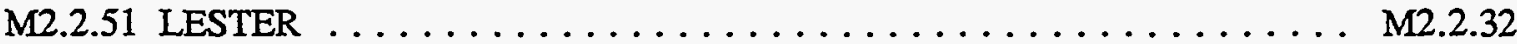

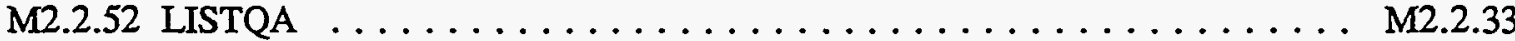

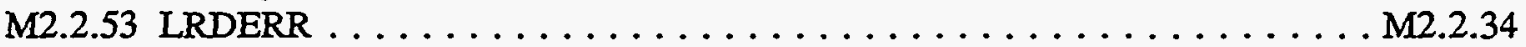

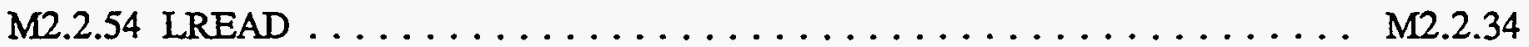

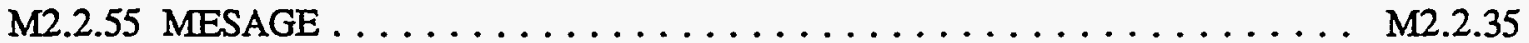

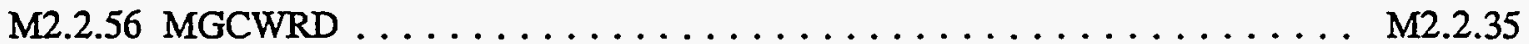

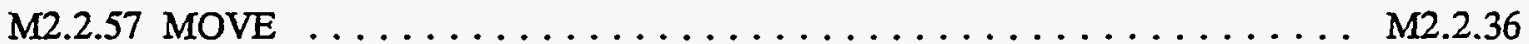

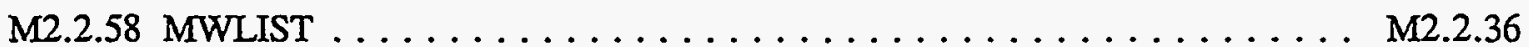

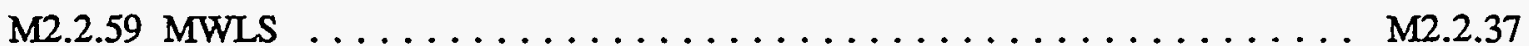

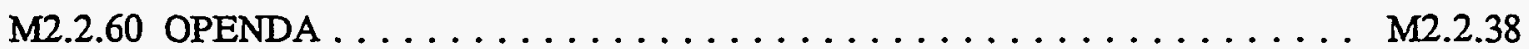

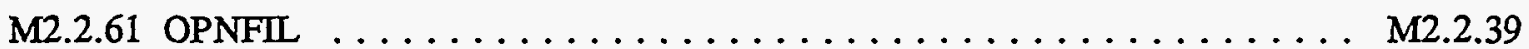

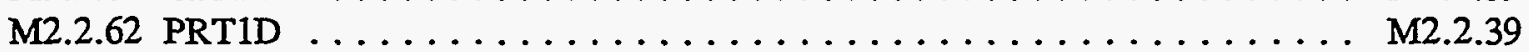

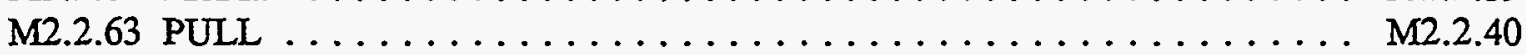

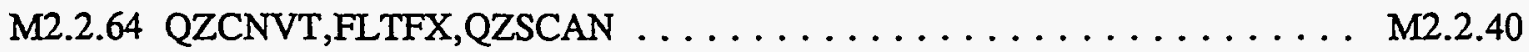

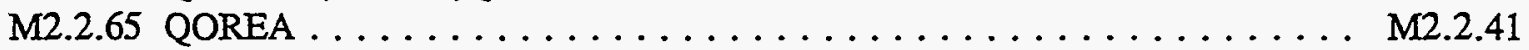

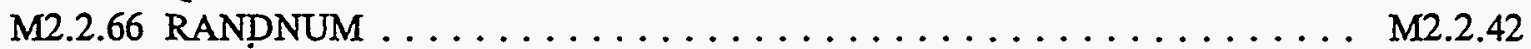

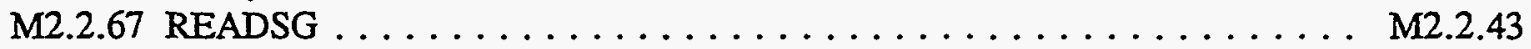

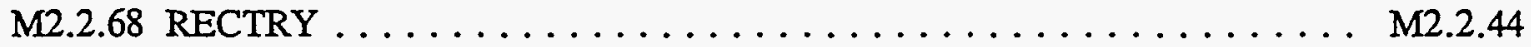

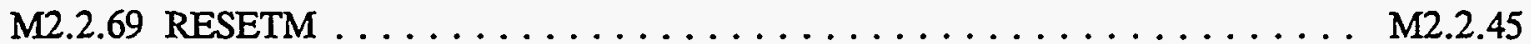

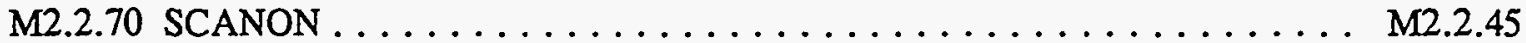

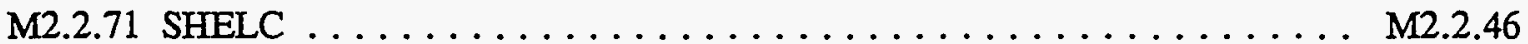

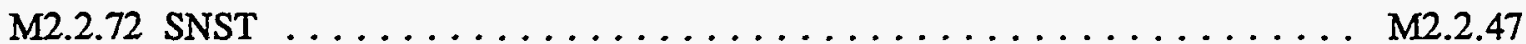

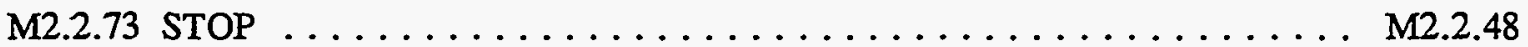

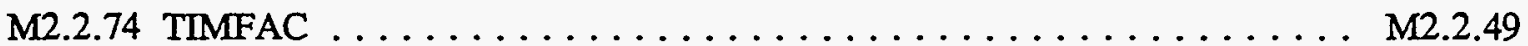

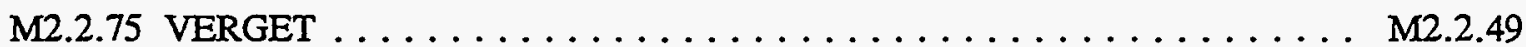

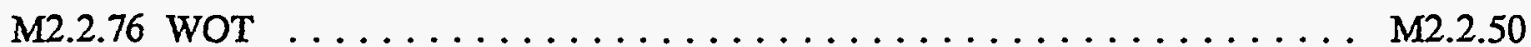

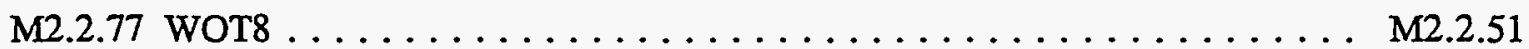

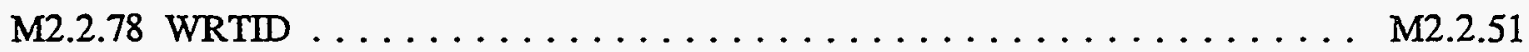

NUREG/CR-0200,

Vol. 3, Rev. 4

M2.vi 


\section{CONTENTS (continued)}

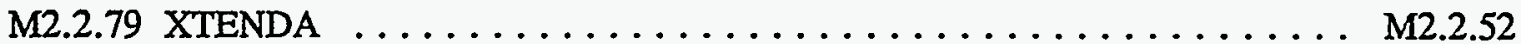

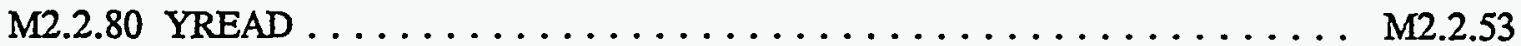

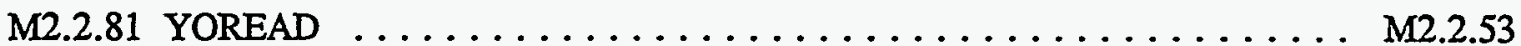

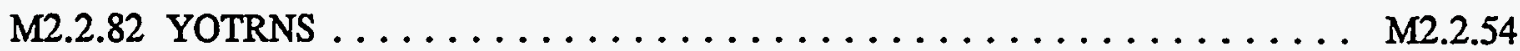

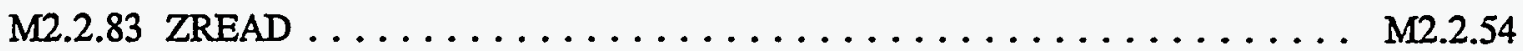

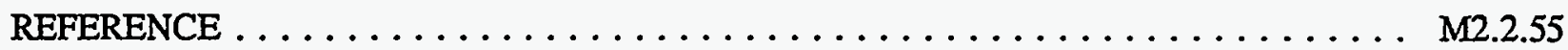

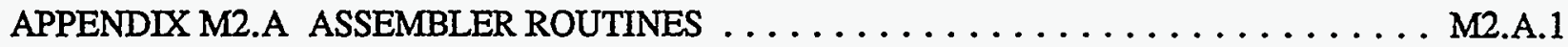
APPENDIX M2.B UNIX SPECIFIC SUBROUTINES $\ldots \ldots \ldots \ldots \ldots \ldots \ldots \ldots \ldots$ M2.B.1 APPENDIX M2.C UNICOS CRAY SPECIFIC SUBROUTINES $\ldots \ldots \ldots \ldots \ldots \ldots \ldots$ M2.C.1

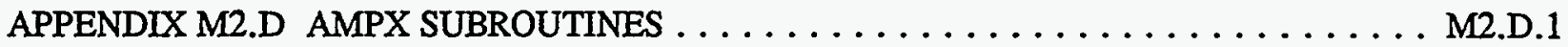




\section{ACKNOWLEDGMENT}

Many of the subroutines described here were contributed by N. M. Greene. Numerous other people have also contributed to the library. 


\section{M2.1 INTRODUCTION}

The SCALE subroutine library is a collection of subroutines, each of which performs a function that may be useful to more than a single program. These subroutines have been collected into a library so that a program can easily access those it needs. In the description that follows the calling sequence, a brief description of the function, a brief description of the arguments, and the programming language used for each subroutine in the library are given. This section is written from the point of view of aiding a programmer in using these subroutines in a program. Section M3.2 gives more information on how a user inputs data to the SCALE free-form reading package. Section M10 gives similar information on using FIDO-type input.

The programming language for the subroutines refers to the IBM mainframe version. Most of the subroutines are programmed in FORTRAN, with the rest being programmed in IBM assembler language. There were two reasons for using assembler: (1) the functionality needed by the routine was not available in FORTRAN; or (2) the routine needed to be more efficient than FORTRAN. All the assembler routines have FORTRAN or $\mathrm{C}$ versions for the UNIX systems. For the routines needing extra functionality, either this was provided by making calls to system library routines, or a reduced functionality was provided entirely in FORTRAN. Appendix M2.A contains a list of the assembler routines with comments on the impact of writing the routine totally in FORTRAN and using only standard FORTRAN functions. Appendices M2.B and M2.C describe subroutines developed specifically for UNIX and UNICOS Cray systems, respectively.

A number of AMPX ${ }^{1}$ subroutines are included in the SCALE subroutine library for use with the AMPX modules included in SCALE. These subroutines are not described here, but are listed in Appendix M2.D, along with the modules that use them. 


\section{M2.2 DESCRIPTION OF SUBROUTINES}

\section{M2.2.1 ALOCAT}

\section{CALLING SEQUENCE:}

CALL ALOCAT(PROG,LMAC, *NSRET)

FUNCTION:

ALOCAT is used to dynamically allocate an array and pass it, along with its dimensions, to a subroutine ' supplied as an argument. ALOCAT makes a variable-length request for storage to the system. The maximum length requested can be supplied by the user. The system returns the largest storage array available, but not larger than the maximum requested. ALOCAT then frees a portion of this space for use by the system and passes the rest to a subroutine supplied by the calling program. The user can also supply the amount of storage to be freed for use by the system.

\section{ARGUMENTS:}

PROG is the subroutine ALOCAT is to call. The call is of the form CALL PROG(D,LIM), where D is an array of length LIM. D starts on a double-word boundary, and LIM is the number of single words in D.

LMAX is an optional argument specifying storage management options. If it is omitted, a positive value of $4,194,302$ ( 8000000 on UNIX systems) is assumed. LMAX $>0$ means the maximum value of $L I M=L M A X$. LMAX $=0$ means the maximum possible value of LIM will be returned to the called program as LMAX. PROG will not be called. LMAX $<0$ means the maximum array size will be reduced by LMAX to define LIM. By default, the maximum array size is reduced by 12800 to determine LIM.

*NSRET is an optional alternative return that will be used, if present, when the largest array available was smaller than the amount by which the array was to be reduced. ALOCAT returns to this alternative return without calling PROG.

\section{LANGUAGE:}

ASSEMBLER

\section{M2.2.2 ANIS}

\section{CALLING SEQUENCE:}

CALL ANIS(EG,UG,EN,UN,IDE,CX,C,MSC,MSCM,ID,IHT,IHS,ITL,MMCR,NOU,NPU,NT4, NT9,IFCT) 


\section{FUNCTION:}

ANIS is used to convert an AMPX working format library to an ANISN format library (either binary or punched card).

\section{ARGUMENTS:}

EG is an array into which the gamma energy group boundaries are read.

UG is an array into which the gamma lethargy group boundaries are read.

EN is an array into which the neutron energy group bounds are read.

UN is an array into which the neutron lethargy group bounds are read.

$\mathrm{IDE}$ is an array of length 50 into which the nuclide identifier record from the AMPX library is read.

CX is a scratch array used to hold the cross sections from the AMPX working library.

C is an array used to construct the ANISN-formatted cross section in. Its length is ITL*(IGM + IPM), where IGM is the number of neutron groups and IPM is the number of gamma groups.

MSC is an array containing the MT numbers of the extra 1-D cross sections to be output on the ANISN library.

MSCM is the number of extra 1-D cross sections to be output on the ANISN library.

ID is the ANISN cross-section identifier. ANIS increments this by one for every set. If $\mathrm{ID}<0$ when ANIS is called, it is set to 0 . The first cross-section set will have an identifier of the initial ID +1

IHT is the position of the total cross section in the ANISN cross-section table. If IHT is 3 or greater, position IHT-1 will contain $v \sigma_{f}$, and position IHT-2 will contain $\sigma_{a}$ by default. Positions 1 to MSCM will contain the cross sections specified in the MSC array.

IHS is the position of the within-group scattering cross section in the ANISN cross-section table. If the cross sections contain upscatter elements, positions for the values must be left between IHT and IHS.

ITL is the table length of the ANISN cross sections. The value should be IHS plus the number of downscatters allowed.

MMCR specifies the format of the output ANISN library. If MMCR $=1$, the ANISN library will be punched card format. If $M M C R=2$, the ANISN library will be unformatted binary.

NOU is the logical unit number to print messages and list cross sections on. 
NPU is the logical unit number to punch the cross sections on.

NT4 is the logical unit number for the AMPX working library.

NT9 is the logical unit number for the binary ANISN library.

IFCT is a listing control flag. The ANISN cross sections are listed through order of $L=$ IFCT. If IFCT $<-1$, only the $\mathrm{P}_{\mathrm{o}}$ cross sections are output on the ANISN library.

SUBROUTINES CALLED:

CLEAR,IO,A1DX,SNST,WOT,FFPUN

LANGUAGE:

FORTRAN

M2.2.3 AREAD

CALLING SEQUENCE:

WORD $=$ AREAD $($ IBR,IRET $)$

FUNCTION:

AREAD is a CHARACTER*4 function used to read character data in free format. AREAD returns four characters at a time. Depending on its arguments, AREAD can return the first four characters of a new record, the next four characters from the current record, or it can skip blanks and then return up to four characters. After having skipped to a nonblank character, AREAD will return up to the next four characters, but will stop and pad with blanks if it detects a blank (or double blank, depending on the argument). AREAD, on the next reference, can return the next four characters, but it remembers if a blank (or double blank) has been detected, and it will return a blank word in this case. The double blank allows a string of characters with embedded single blanks to be returned as entered.

\section{ARGUMENTS:}

IBR is an option flag determining the mode of reading data.

IBR $=0$ returns the next four characters in the input record.

$\mathrm{IBR}=1$ reads a new record and returns the first four characters.

IBR $=2$ returns four characters starting with the first nonblank character and stopping if there are two consecutive blanks. Padding is with blanks if necessary. 
IBR $=3$ returns four characters but stops with a double (or single) blank, depending on whether the preceding call to $\mathrm{AREAD}$ had IBR $=2$ or IBR $=4$.

IBR $=4$ returns four characters starting with the first nonblank character and stopping with a single blank.

$\mathrm{IBR}=-1$ returns the last character scanned.

IRET is a flag returned to the calling program if the scan-ahead feature has been activated (see SCANON, also see Sect. M3). If IRET $=2$ when AREAD is called, it prints a message and terminates. Otherwise, it sets IRET $=0$ and continues. If the scan ahead feature is activated, and 'END' is found when scanning, IRET is set to 1 . If an end of file is detected while scanning ahead, IRET is set to 2 .

\section{SUBROUTINES CALLED:}

ENFILE,YOREAD

COMMONS:

UNIT,QRDBUF

\section{LANGUAGE:}

FORTRAN

M2.2.4 A1DX

CALLING SEQUENCE:

CALL AIDX(CX,N,IGP,IA,C,ITL,MSC,MSCM,IHT,GR,IGM,ITRG)

\section{FUNCTION:}

AlDX finds the 1-D cross sections from an AMPX working library (see Sect. F2.4) and moves them to the correct positions in an ANISN library. It has a default set of reaction types which can be supplemented in the argument list.

\section{ARGUMENTS:}

CX is an array containing the 1-D cross sections from an AMPX working library.

$\mathrm{N}$ is the number of different 1-D cross sections in CX.

IGP is the number of groups +1 in the AMPX cross sections. 
IA is the offset to be added to the group number in the AMPX library to obtain the group index in the ANISN library. This offset will be zero for neutron groups, and will be the number of neutron groups for the gamma groups in a coupled library. The offset will be zero for a gamma-only library.

C is the array for the ANISN library.

ITL is the table length of the ANISN cross sections.

MSC is the array containing the identifiers of extra processes to be put in the ANISN library.

MSCM is the number of extra processes to be put into the ANISN library.

IHT is the position of the total cross section in the ANISN library. By default, $v \sigma_{\mathrm{f}}$ is in position IHT-1, $\sigma_{2}$ is in IHT-2, and the extra cross sections are lined up sequentially in positions 1 to MSCM. An "extra" cross section will override the default process if the positions overlap.

GR is a vector into which A1DX will place the difference between the cross section placed in position IHT and the total cross section. This difference is then used to correct the within-group scattering position of the transfer array.

IGM is the number of groups in the ANISN cross sections.

ITRG is a flag determining whether the cross sections are for neutrons or gammas ( 0 is neutrons, 1 is gammas).

\section{LANGUAGE:}

FORTRAN

\section{M2.2.5 BDYS}

\section{CALLING SEQUENCE:}

\section{CALL BDYS(E,IGM,N6,NTYPE,IVER,NWT)}

\section{FUNCTION:}

BDYS searches a group boundary library for a particular group structure, type, and version, and then reads the corresponding boundaries from the library into E. If the particular set asked for cannot be found, BDYS will generate a default set using an equal lethargy spacing. The default neutron structure will be from 0.00001 to $1.49 \mathrm{E}+7 \mathrm{eV}$; the default gamma structure will be from 1.E+4 to $1 . \mathrm{E}+7 \mathrm{eV}$. 


\section{ARGUMENTS:}

E is the array returning the group boundaries.

IGM is the number of groups.

N6 is the logical unit number for the printed output.

NTYPE is a flag determining whether a neutron or a gamma group structure is needed.

0 - neutrons

1 - gammas

IVER is the version number desired.

NWT is the logical unit number of the group boundary library.

\section{LANGUAGE:}

FORTRAN

\section{M2.2.6 BLANK}

\section{CALLING SEQUENCE:}

CALL BLANK (LC,NL)

\section{FUNCTION:}

BLANK sets a character string to blanks.

\section{ARGUMENTS:}

LC is the character string.

NL is the number of characters in the string.

\section{LANGUAGE:}

FORTRAN 


\section{M2.2.7 CLEAR}

\section{CALLING SEQUENCE:}

CALL CLEAR (LD,N)

FUNCTION:

CLEAR sets an array to zero.

ARGUMENTS:

LD is the array to be zeroed.

$\mathrm{N}$ is the number of words to be zeroed.

\section{LANGUAGE:}

FORTRAN

\section{M2.2.8 CLOSDA}

\section{CALLING SEQUENCE:}

CALL CLOSDA (NU)

FUNCTION:

CLOSDA is used to close a random access file opened by OPENDA.

\section{ARGUMENTS:}

NU is the logical unit number of the file to be closed.

\section{LANGUAGE:}

FORTRAN

\section{M2.2.9 CMPS}

CALLING SEQUENCE:

CALL CMPS (C,L,IGM,IPM,IFTG,N,IHT,CODE) 


\section{FUNCTION:}

CMPS is used to convert an expanded transfer array that allows space for all possible values to a compressed form containing magic words and with zeroes suppressed such as is used on AMPX cross-section libraries.

\section{ARGUMENTS:}

C is the array to be compressed.

$\mathrm{L} \quad$ is the compressed dimension of $\mathrm{C}$ upon exiting CMPS.

IGM is the number of neutron groups.

IPM is the number of gamma groups.

IFTG is the first thermal group.

$\mathrm{N}$ is an array that points to the magic word position in the expanded array.

IHT is the number of 1-D cross-section positions in the array.

CODE is a flag determining whether a group can be completely compressed out of the array $(0.0$ is yes, 1.0 is no).

\section{LANGUAGE:}

FORTRAN

\section{M2.2.10 COPY}

\section{CALLING SEQUENCE:}

CALL COPY (X,N,II,IO,IGO)

\section{FUNCTION:}

COPY is used to copy a record from unit II to unit IO.

\section{ARGUMENTS:}

$\mathrm{X}$ is an array used in the copy.

$\mathrm{N}$ is the number of words to be copied.

NUREG/CR-0200,

Vol. 3, Rev. 4 
II is the input logical unit number.

IO is the output logical unit number.

IGO is a flag keying whether the records are self-defining or not. IGO $=1$ means $N$ must be supplied by the calling program. IGO $=2$ means $N$ is supplied by the record to be copied.

LANGUAGE:

FORTRAN

M2.2.11 CREAD

CALIING SEQUENCE:

WORD $=$ CREAD $(I B R, I R E T)$

FUNCTION:

CREAD is a CHARACTER*8 function used to return eight characters according to the argument IBR.

See AREAD for more details:

\section{ARGUMENTS:}

IBR is an option flag determining the mode of reading data.

$\mathrm{IBR}=0 \quad$ returns the next eight characters in the input record.

$\mathrm{IBR}=1$ reads a new record and returns the first eight characters.

$\mathrm{IBR}=2$ returns eight characters starting with the first nonblank character and stopping if

there are two consecutive blanks. Padding is with blanks if necessary.

$\mathrm{IBR}=3$ returns eight characters but stops with a double (or single) blank depending on

whether the preceding call to $A R E A D$ had IBR $=2$ or IBR $=4$.

$\mathrm{IBR}=4 \quad$ returns eight characters starting with the first nonblank character and stopping with a single blank.

$\mathrm{IBR}=-1 \quad$ returns the last character scanned.

IRET is a flag returned to the calling program if the scan ahead feature has been activated (see SCANON, also see Sect. M3). If IRET $=2$ when AREAD is called, it prints a message and terminates. Otherwise, it sets IRET $=0$ and continues. If the scan ahead feature is activated, and 'END' is found when scanning, IRET is set to 1 . If an end of file is detected while scanning ahead, IRET is set to 2 .

SUBROUTINES CALIED:

AREAD 
LANGUAGE:

FORTRAN

\section{M2.2.12 REED,RITE,RD}

\section{CALLING SEQUENCE:}

CALL REED (X,L,NU,NP)

CALL RITE (X,L,NU,NP)

CALL RD (LP,X,L,NP,NU)

\section{FUNCTION:}

REED is used to read an array, $X$ of length $L$, from the random access file pointed to by logical unit number NU, starting at block number NP. RITE is used to write X on NU at NP. RD is used to read $X$ from NU starting with LPth word of block NP.

\section{ARGUMENTS:}

$\mathrm{X}$ is the array into which or from which data are read or written.

$\mathrm{L}$ is the number of words to be read or written.

NU is the logical unit number of the random-access file.

NP is the block number at which data transfer is to start.

LP is the first word of block NP to be transferred to X.

\section{LANGUAGE:}

FORTRAN

\section{M2.2.13 DATIM}

CALLING SEQUENCE:

CALL DATIM (DATE,TIME)

FUNCTION:

DATIM returns the date and time of day as two eight-character strings suitable for printing.

NUREG/CR-0200,

Vol. 3, Rev. 4

M2.2.10 


\section{ARGUMENTS:}

DATE is an eight-character string in which the date is returned in the form $\mathrm{mm} / \mathrm{dd} / \mathrm{yy}$, where $\mathrm{mm}$ is the month, dd is the day, and yy is the year.

TIME is an eight-character string in which the time of day is returned in the form hh.mm.ss, where hh is the hour, $\mathrm{mm}$ is the minutes, and ss is the seconds.

LANGUAGE:

ASSEMBLER

\section{M2.2.14 DREAD}

CALLING SEQUENCE:

WORD $=$ DREAD $($ IBR, IRET $)$

FUNCTION:

DREAD is used to read numbers in free-form format. It returns a double-precision floating-point number. This routine is the basic number reading routine for the free-form reading package.

\section{ARGUMENTS:}

IBR can have two values.

$\mathrm{IBR}=1$ - read a new record and return the first number found.

$\mathrm{IBR}=0$ - return the next number found.

IRET $=2$ will cause DREAD to terminate.

IRET $\neq 0$ will cause a 0.0 to be returned. If the scan-ahead feature is activated and an 'END' is found while scanning, IRET will be set to 1 . If an end of file is sensed while scanning, IRET will be set to 2 .

\section{SUBROUTINES CALLED:}

ENFILE,YOREAD

CÖMMONS:

UNIT,QRDBUF

\section{LANGUAGE:}

FORTRAN 


\section{M2.2.15 DTASET,DATASET}

\section{CALLING SEQUENCE:}

\section{CALL DTASET (LOG,DSN, VOL)}

CALL DATASET (DDN,DSN,VOL)

\section{FUNCTION:}

DTASET and DATASET return the data set name and volume serial number pointed to by a DD card specified as an argument. DTASET generates the ddname of the DD card from a FORTRAN logical unit number; DATASET uses a ddname supplied as an argument.

\section{ARGUMENTS:}

LOG is the FORTRAN logical unit number of the DD card.

DDN is the 8-character ddname of the DD card.

DSN is the 44-character data set name returned.

VOL is the 8-character volume serial number returned.

\section{LANGUAGE:}

ASSEMBLER

\section{M2.2.16 ECHECK}

\section{CALLING SEQUENCE:}

CALL ECHECK (E,IGM,N6)

FUNCTION:

ECHECK verifies that the energy boundaries of a group structure are in descending order.

\section{ARGUMENTS:}

$\mathrm{E}$ is the array containing the group boundaries.

IGM is the number of energy groups.

N6 is the logical unit number on which the error messages are printed. 


\section{LANGUAGE:}

FORTRAN

\section{M2.2.17 ENERGY}

CALLING SEQUENCE:

CALL ENERGY (E,IGM,N6)

\section{FUNCTION:}

ENERGY determines a set of energy-group boundaries for an IGM group neutron structure by calling subroutine BDYS. The boundaries are expected to reside on logical 47.

\section{ARGUMENTS:}

$\mathrm{E}$ is the array of group boundaries.

IGM is the number of energy groups.

N6 is the message unit number.

\section{SUBROUTINES CALLED:}

BDYS

\section{LANGUAGE:}

FORTRAN

\section{M2.2.18 ENFILE}

CALLING SEQUENCE:

CALL ENFILE

\section{FUNCTION:}

ENFILE is used by the free-form reading package to print an end-of-file message and stop when an end-of-file has been sensed. 
COMMONS:

UNIT

LANGUAGE:

FORTRAN

\section{M2.2.19 ERRO}

CALLING SEQUENCE:

CALL ERRO (A,J)

FUNCTION:

ERRO is used to print an error message and stop.

ARGUMENTS;

A is a four-character error identifier.

$\mathrm{J}$ is an integer containing information relating to the error.

\section{LANGUAGE:}

FORTRAN

\section{M2.2.20 EYENIT}

CALLING SEQUENCE:

CALL EYENIT (NBLK,LBLK,NUNT,D,LSKIP,BAL)

FUNCTION:

EYENIT is called to initialize a set of direct-access blocks. It is necessary on IBM systems, but may not be necessary on other systems.

ARGUMENTS:

NBLK number of blocks

LBLK length of each block

NUREG/CR-0200,

Vol. 3, Rev. 4

M2.2.14 
NUNIT FORTRAN logical unit number

D scratch buffer array of length LBLK

LSKIP number of blocks already existing

BAL 12-byte area where system data will be saved. This area should be saved from the creation of the file to the destruction of the file.

\section{LANGUAGE:}

\section{ASSEMBLER}

\section{$\mathrm{M} 2.2 .21 \mathrm{E3}$}

\section{CALLING SEQUENCE:}

$$
\mathrm{Y}=\mathrm{E} 3(\mathrm{X})
$$

FUNCTION:

E3 returns the value of the $E_{3}$ function at the point $x . E_{3}(x)=\int_{1}^{\infty} \frac{e^{-x u}}{u^{3}} d u$.

\section{ARGUMENTS:}

$\mathrm{X}$ is the point at which the value of the $\mathrm{E}_{3}$ function is desired.

\section{LANGUAGE:}

FORTRAN

\section{M2.2.22 FFPACK}

\section{CALLING SEQUENCE:}

\section{CALL FFPACK (ISTRNG,ICHAR,IPOS)}

\section{FUNCTION:}

FFPACK is used to insert a character into a string of characters at a given position. FFPACK is used by the FIDO reading package (see Sect. M10) when transmitting character data.

\section{ARGUMENTS:}


ISTRNG is the string of 8 characters.

ICHAR is the character to be inserted.

IPOS is the position in ISTRNG at which ICHAR is to be inserted.

LANGUAGE:

FORTRAN

M2.2.23 FFPUN

CALLING SEQUENCE:

CALL FFPUN $(X, N, N 2)$

FUNCTION:

FFPUN is used to punch a floating-point array in free-format input form. The data are punched on unit NPU, the first variable in COMMON /PUNIT/. The default unit number is 7.

\section{ARGUMENTS:}

$\mathrm{X}$ is the array to be punched.

$N$ is the number of words to be punched.

N2 columns 73-76.

SUBROUTINES CALLED:

FLTFX

COMMONS:

PUNIT

LANGUAGE:

FORTRAN 
M2.2.24 FFREAD

\section{CALLING SEQUENCE:}

CALL FFREAD (IN,K,V,NF,N5,N6,IPRTRG)

\section{FUNCTION:}

FFREAD is the free and fixed-field card translator for the FIDO input package. It reads a card at a time, returning the data and the number of entries read.

\section{ARGUMENTS:}

IN is the array used to hold the first subfield value of the three-subfield arrangement used by the FDO input scheme. It generally contains the number of repeats, the array number, etc.

$\mathrm{K}$ is the array used to hold the second subfield in FIDO input scheme. It generally contains an operator, such as $\mathrm{R}$ for repeat, * for a floating-point array, etc.

$\mathrm{V}$ is an array used to hold the third subfield in the FIDO input scheme. It most often contains a data value.

$\mathrm{NF}$ is the number of entires in $\mathrm{IN}, \mathrm{K}$, and $\mathrm{V}$.

N5 is the input logical unit number.

N6 is the print logical unit number.

IPRTRG is a print trigger flag signaling whether the input card images should be echoed to the print unit.

$=0$ - do not echo.

$>0$ - do echo.

\section{SUBROUTINES CALLED:}

FFPACK

\section{LANGUAGE:}

FORTRAN

\section{M2.2.25 FHLPR}

CALLING SEQUENCE:

CALL FHLPR (CC,A,NOU) 


\section{FUNCTION:}

FHLPR prints an eight-character block letter line.

\section{ARGUMENTS:}

$\mathrm{CC}$ is the carriage control character to be printed with the first line.

A is the eight-character string to be printed in block letters.

NOU is the logical unit number for the print.

\section{COMMONS:}

LETTER

LANGUAGE:

FORTRAN

\section{M2.2.26 FIDAS}

CALLING SEQUENCE:

CALL FIDAS (D,LD,LPN,LOF,NER,N5,N6)

\section{FUNCTION:}

FIDAS reads a FIDO-type input data block into an arbitrary array. (See Sect. M10 for a description of FIDO-type input.)

\section{ARGUMENTS:}

$D, L D$ are the arrays into which the floating point and the integer numbers are stored. These arrays would normally be the same.

LPN is the array containing the pointers to the beginning of each FIDO array in D and LD.

LOF is the offset to the $1 \$$ or $1^{*}$ array pointer in LPN.

NER is returned as the count of errors found in reading the current data block.

N5 is the input logical unit number.

N6 is the print logical unit number.

NUREG/CR-0200,

Vol. 3, Rev. 4 


\section{SUBROUTINES CALLED:}

FFREAD

LANGUAGE:

FORTRAN

M2.2.27 FINDQA

CALLING SEQUENCE:

CALL FINDQA (PROGRAM,DATE,LIBRARY)

FUNCTION:

FINDQA returns the name of the current program, the date it was created, and the library it comes from. These data are used to print a QA table.

ARGUMENTS:

PROGRAM eight-character name of the current program

DATE eight-character date PROGRAM was created

LIBRARY 44-character dataset name of the library containing PROGRAM

\section{LANGUAGE:}

ASSEMBLER

\section{M2.2.28 FISCAP}

CALLING SEQUENCE:

CALL FISCAP (ZA,EPF,EPC)

\section{FUNCTION:}

FISCAP is used to supply default values of energy per fission and energy per capture for a selected set of nuclides. It returns EPF and EPC unchanged if it has no data for the ZA specified. If EPF and/or EPC already have positive values, FISCAP will not change them. 


\section{ARGUMENTS:}

$\mathrm{ZA}$ is $1000^{*} \mathrm{Z}+\mathrm{A}$ for the nuclide for which data are to be supplied.

EPF is the energy per fission in watt-s/fission.

EPC is the energy per capture in watt-s/capture.

\section{LANGUAGE:}

FORTRAN

\section{M2.2.29 FLUX}

\section{CALLING SEQUENCE:}

$$
X=\text { FLUX (E,EMAX,T,C2,EF,THETA,C1,IOPT) }
$$

\section{FUNCTION:}

FLUX supplies a flux value at $\mathrm{E}$ based on the other arguments. If IOPT $=1$, the value is interpolated from a fast reactor spectrum. Otherwise, the spectrum is a combination of a fission spectrum to $1 / \mathrm{E}$ to Maxwellian at thermal.

\section{ARGUMENTS:}

E is the energy in $\mathrm{eV}$ at which the flux is desired.

EMAX is the upper energy in $\mathrm{eV}$ at which a Maxwellian spectrum is to be used.

$\mathrm{T} \quad$ is the thermal temperature in $\mathrm{eV}$ of the Maxwellian spectrum.

C2 is the normalization factor for the Maxwellian spectrum.

$\mathrm{EF} \quad$ is the upper limit in $\mathrm{eV}$ of the $1 / \mathrm{E}$ portion of the spectrum.

THETA is the temperature in $\mathrm{eV}$ of the fission spectrum used at high energies.

C1 is the normalization factor used for the fission spectrum.

IOPT selects the flux spectrum to be used. IOPT $=1$ selects a ZPPR default spectrum. Otherwise, a Maxwellian-1/E-fission spectrum is used.

\section{LANGUAGE:}

FORTRAN

NUREG/CR-0200,

Vol. 3, Rev. 4 


\section{M2.2.30 FPUNCH}

CALLING SEQUENCE:

\section{CALL FPUNCH (N,L,LABL,IFORM)}

\section{FUNCTION:}

FPUNCH is used to punch in free format the array $\mathrm{N}$ according to the data type specified by IFORM. ARGUMENTS:

$\mathrm{N}$ is the array to be punched on unit NPU, the first variable in COMMON /PUNIT/. The default unit number is 7 .

$\mathrm{L}$ is the length of the array.

LABL is an identifier to be punched on the output cards. If $L A B L<0$, then the $L A B L$ and sequence number are not punched.

IFORM selects whether the data are to be punched as integers or floating-point numbers. IFORM $=0$ selects integers

IFORM $=1$ selects floating point

\section{COMMONS:}

PUNIT

SUBROUTINES CALLED:

FLTFX, QZCNVT, BLANK

\section{LANGUAGE:}

FORTRAN

M2.2.31 FREAD

CALLING SEQUENCE:

WORD $=$ FREAD(IBR,IRET)

\section{FUNCTION:}

FREAD returns a floating-point number read in free format. 
ARGUMENTS:

See DREAD.

SUBROUTINES CALLED:

DREAD, YOREAD

COMMONS:

UNIT, QRDBUF

LANGUAGE:

FORTRAN

M2.2.32 FREECR

CALLING SEQUENCE:

CALL FREECR (LL)

FUNCTION:

Releases some of the array acquired by ALOCAT. This mechanism allows a program to keep only the amount of storage it needs to run.

ARGUMENTS:

$\mathrm{LL}$ is the negative of the number of words to be freed.

LANGUAGE:

ASSEMBLER

\section{M2.2.33 GETMS}

CALLING SEQUENCE:

CALL GETMS

\section{FUNCTION:}

GETMS is used to transfer the data the SCALE driver supplies to labeled commons. It is called by SCALE control programs to isolate the communications with the driver. After the call to GETMS, the driver data are loaded into two labeled commons.

NUREG/CR-0200,

Vol. 3, Rev. 4

M2.2.22 
COMMON/CDATA/AC(40),IC(80),JPL,JDL

DOUBLE PRECISION AC

COMMON/CCDATA/JP,JD

CHARACTER JP*144,JD*96

AC, JC, JP, and JD are described in Sect. M1. JPL is the number of characters supplied in JP, and JDL is the number of characters supplied in JD.

COMMONS:

CDATA, CCDATA

LANGUAGE:

ASSEMBLER

\section{M2.2.34 GNERGY}

CALLING SEQUENCE:

CALL GNERGY (E,IGM,N6)

FUNCTION:

GNERGY sets the group boundaries of a gamma-group structure in E. It calls subroutine BDYS to access the boundaries that are expected to reside on logical 47 .

\section{ARGUMENTS:}

E is the array of group boundaries.

IGM is the number of groups.

N6 is logical unit number for printed output.

SUBROUTINES CALLED:

BDYS

LANGUAGE:

FORTRAN

\section{M2.2.35 ICOMPA}

CALLING SEQUENCE:

$\mathrm{N}=\operatorname{ICOMPA}(\mathrm{S} 1, \mathrm{~S} 2, \mathrm{LEN})$ 


\section{FUNCTION:}

ICOMPA compares character string S1 of length LEN characters with string $S 2$ and returns a value 1 , 0 , or $-1-$, depending on whether $S 1$ is greater than, equal to, or less than $S 2$ in the collating sequence. $S 1$ is defined as equal to $S 2$ if every character in $S 1$ is equal to the corresponding character in S2. S1 is greater than S2 if the first character that is not equal to the corresponding character in $S 2$ is further down the collating sequence.

\section{ARGUMENTS:}

S1 is the first-character string.

S2 is the second-character string.

LEN is the number of characters in $\$ 2$ and $\$ 2$.

\section{LANGUAGE:}

ASSEMBLER

\section{M2.2.36 INQUIR}

CALLING SEQUENCE:

CALL INQUIR (NUNIT,NXTREC)

\section{FUNCTION:}

INQUIR returns value of the next record on the direct-access file connected to NUNIT.

\section{ARGUMENTS:}

NUNIT FORTRAN logical unit number of the file.

NXTREC Next record on the file.

\section{LANGUAGE:}

FORTRAN 


\section{M2.2.37 INTIME,PRTIME}

\section{CALLING SEQUENCE:}

CALL INTIME (IO)

CALL PRTIME (IO)

\section{FUNCTION:}

INTIME initializes the argument IO with the time left in the job step.

PRTIME computes the time used since IO and prints it in units of minutes.

\section{ARGUMENTS:}

IO is the time left in the job step in hundredths of a second at the call to INTIME.

\section{SUBROUTINES CALLED:}

JSTIME

\section{LANGUAGE:}

FORTRAN

M2.2.38 IO

CALLING SEQUENCE:

CALL IO (X,L,JUMP,NU)

\section{FUNCTION:}

IO is used to do short list input/output.

\section{ARGUMENTS:}

$\mathrm{X}$ is the array to be read or written.

$\mathrm{L}$ is the number of words in X.

JUMP selects reading or writing and whether or not the record is self-defining.

1 is a simple read.

2 is a self-defining read.

3 is a simple write.

4 is writing a self-defining record.

A self-defining record contains $\mathrm{L}$ as the first word. 
NU is the logical unit number for the input/output.

\section{LANGUAGE:}

FORTRAN

\section{M2.2.39 IOLEFT}

\section{CALLING SEQUENCE:}

\section{CALL IOLEFT(LEFT)}

\section{FUNCTION:}

IOLEFT returns the number of input/output requests left before the system cancels the job. This routine performs a specialized function for the local Oak Ridge computer systems. A dummy routine returning a constant value of LEFT $>0$ is supplied with SCALE.

\section{ARGUMENTS:}

LEFT is the number of input/output requests left to the job before the system cancels it.

\section{LANGUAGE:}

FORTRAN

\section{M2.2.40 IOWRT}

\section{CALLING SEQUENCE:}

CALL IOWRT (OUTPT,PARNAM,IO,HOLLID)

\section{FUNCTION:}

IOWRT is used to print a line of information identifying the dataset connect to a logical unit number.

ARGUMENTS:

OUTPT is the unit where the line is printed.

PARNAM is a four-character identifier that indicates the input variable name used to set the logical unit number.

IO is the logical unit number.

NUREG/CR-0200,

Vol. 3, Rev. 4

M2.2.26 
HOLLID is a character string printed at the end of the line to further identify IO (less than 35 characters).

\section{SUBROUTINES CALLED:}

DTASET

\section{LANGUAGE:}

FORTRAN

\section{M2.2.41 IO4}

\section{CALLING SEQUENCE:}

CALL IO4 (MTX,LX,NLX,NTX,LEN,JUMP,NU)

FUNCTION:

IO4 is used to read or write the descriptor records for the transfer (2-D) arrays.

\section{ARGUMENTS:}

MTX is the array of mt numbers identifying the 2-D arrays.

LX is the array of maximum lengths of the 2-D arrays corresponding to MTX.

NLX is the array specifying the order of scattering of the 2-D arrays corresponding to MTX.

NTX is the array containing the number of temperatures of the 2-D arrays corresponding to MTX.

LEN is the number of entires in MTX, LX, NLX, and NTX.

JUMP selects whether the call is a read or a write (see IO).

NU is the logical unit number to be used.

\section{LANGUAGE:}

FORTRAN 
M2.2.42 IREAD

CALIING SEQUENCE:

$\mathrm{NUM}=\mathrm{IREAD}(\mathrm{IBR}, \mathbb{R E T})$

FUNCTION:

IREAD returns an integer read in free format.

ARGUMENTS:

See DREAD.

SUBROUTINES CALLED:

DREAD,YOREAD

COMMONS:

UNIT,QRDBUF

LANGUAGE:

FORTRAN

\section{M2.2.43 JDFJX}

CALIING SEQUENCE:

CALL JDFJX (ID,NGN,NGG)

FUNCTION:

JDFJX is used to zero entries in the AMPX master library nuclide identifier record.

\section{ARGUMENTS:}

ID is the array containing control information about an AMPX master library nuclide.

NGN is the number of neutron groups.

NGG is the number of gamma groups.

NUREG/CR-0200,

Vol. 3, Rev. 4 


\section{LANGUAGE:}

FORTRAN

\section{M2.2.44 JGET}

CALLING SEQUENCE:

$$
\mathrm{I}=\mathrm{JGET}(\mathrm{X})
$$

\section{FUNCTION:}

JGET returns an integer stored in a floating-point variable.

\section{ARGUMENTS:}

$\mathrm{X}$ is the integer typed as floating point in the calling program.

\section{LANGUAGE:}

FORTRAN

\section{M2.2.45 JLL1}

\section{CALLING SEQUENCE:}

\section{CALL JLL1 (IGM,IPM,IFTG,N,IHT)}

\section{FUNCTION:}

JLL1 constructs an array, $\mathrm{N}$; pointing to the beginning of each group in an expanded transfer array.

\section{ARGUMENTS:}

IGM is the number of neutron groups.

IPM is the number of gamma groups.

IFTG is the first thermal group.

$\mathrm{N} \quad$ is the array of pointers returned.

IHT is the number of 1-D cross sections stored in the expanded array for each group. 
LANGUAGE:

FORTRAN

\section{M2.2.46 JOBNUM}

CALLING SEQUENCE:

CALL JOBNUM (JNAME)

FUNCTION:

JOBNUM returns the eight-character jobname of the current job.

ARGUMENTS:

JNAME is the eight-character jobname.

LANGUAGE:

ASSEMBLER

M2.2.47 JSTIME

CALLING SEQUENCE:

CALL JSTIME(I)

FUNCTION:

JSTIME returns the cpu time (in hundredths of a second) remaining in the current job step before the system cancels the job.

\section{ARGUMENTS:}

I returns the remaining cpu time.

\section{LANGUAGE:}

ASSEMBLER 
M2.2.48 KI3

CALLING SEQUENCE:

$\mathrm{Y}=\mathrm{KI} 3(\mathrm{X})$

FUNCTION:

KI3 returns the third-order Bickley function evaluated at its argument.

ARGUMENTS:

$\mathrm{X}$ is the point at which $\mathrm{KI} 3$ is evaluated.

\section{LANGUAGE:}

FORTRAN

\section{M2.2.49 LABL}

CALLING SEQUENCE:

CALL LABL (N,X,HEAD1,HEAD2)

\section{FUNCTION:}

LABL is used to print a page header, indexed table of an array.

\section{ARGUMENTS:}

$\mathrm{N}$ is the number of entries to be printed.

$\mathrm{X}$ is the array containing the entries to be printed.

HEAD1 and HEAD2 form the 16-character heading for each column printed.

COMMONS:

UNIT

\section{LANGUAGE:}

FORTRAN 


\section{M2.2.50 LCOMPR}

\section{CALLING SEQUENCE:}

LFLAG = LCOMPR(STRING,CARRAY,NEL,INDX)

FUNCTION:

LCOMPR searches an array CARRAY for a match with STRING, and returns a value of true if a match is found. Only the number of characters supplied in STRING are compared. If a match is found, INDX is set to the index in CARRAY, where the match occurred, and STRING is set equal to CARRAY(INDX).

\section{ARGUMENTS:}

STRING is the string for which a match is checked.

CARRAY is the array of strings containing possible matches.

NEL is the number of elements in CARRAY.

INDX is the index at which a match occurred.

LANGUAGE:

FORTRAN

\section{M2.2.51 LESTER}

CALLING SEQUENCE:

CALL LESTER (E,MAXG,P,IOPT,T,THETA,AKT,FCUT)

\section{FUNCTION:}

LESTER is used to generate a flux spectrum based on the arguments in an arbitrary group structure.

\section{ARGUMENTS:}

$\mathrm{E} \quad$ is the array of energy bounds.

MAXG is the number of groups.

$P \quad$ is the array of fluxes. 
IOPT selects the basic spectrum. IOPT $=0$ selects a fission to $1 / \mathrm{E}$ to Maxwellian spectrum. IOPT $=1$ selects a fast reactor spectrum.

T is the temperature for the Maxwellian in Kelvin.

THETA is the temperature for the fission spectrum in $\mathrm{eV}$.

AKT is the multiplier on $\mathrm{kT}$ for the Maxwellian-1/E joining point.

FCUT is the fission-1/E joining point.

SUBROUTINES CALLED:

FLUX

LANGUAGE:

FORTRAN

M2.2.52 LISTQA

CALLING SEQUENCE:

CALL LISTQA (OUTPT)

FUNCTION:

LISTQA prints a table of information useful for QA purposes.

ARGUMENTS:

OUTPT is the unit number the table will be printed on.

SUBROUTINES CALLED:

FINDQA, JOBNUM, DATIM

LANGUAGE:

FORTRAN 


\section{M2.2.53 LRDERR}

CALLING SEQUENCE:

LFLAG $=$ LRDERR( )

FUNCTION:

LRDERR returns the current value of the free-form reading error flag, and resets it to false.

ARGUMENTS:

None.

COMMONS:

QRDBUF

LANGUAGE:

FORTRAN

M2.2.54 LREAD

CALIING SEQUENCE:

LFLAG $=$ LREAD(IBR,IRET)

FUNCTION:

LREAD returns a true value if the next character in the free-form reading package buffer is a numeric digit. Otherwise, it returns a false value.

ARGUMENTS:

IRET $=2$ will cause LREAD to print a message and stop. Other values of the arguments are ignored.

LANGUAGE:

FORTRAN

NUREG/CR-0200,

Vol. 3, Rev. 4

M2.2.34 


\section{M2.2.55 MESAGE}

\section{CALLING SEQUENCE:}

CALL MESAGE (LINE1,NOU)

FUNCTION:

MESAGE prints a banner page in block letters consisting of the eight-character LINE1, the jobname, the date, and the time of day. This page is followed by a table of information useful for QA purposes.

\section{ARGUMENTS:}

LINE1 is an eight-character name printed as the first line of block letters on the banner page.

NOU is the logical unit number of the print file.

SUBROUTINES CALLED:

FHLPR,JOBNUM,DATIM,LISTQA

\section{LANGUAGE:}

FORTRAN

\section{M2.2.56 MGCWRD}

\section{CALLING SEQUENCE:}

CALL MGCWRD (MW,IIG,IMX,IMN,M)

\section{FUNCTION:}

MGCWRD is used to either decipher or construct a magic word.

\section{ARGUMENTS:}

MW is the magic word. If it is not zero, MGCWRD sets the other arguments by deciphering it. If it is zero, MGCWRD constructs.a new magic word from the other arguments: $\mathrm{MW}=\mathrm{IMN} * 1000000+\mathrm{IMX} * 1000+\mathrm{IIG}$.

IIG is the current group number.

IMX is the maximum group number that can scatter to IIG.

IMN is the minimum group number that can scatter to IIG. 
$M$ is the length of the cross-section string for IIG:

$\mathrm{M}=\mathrm{MMX}-\mathrm{MMN}+1$.

LANGUAGE:

FORTRAN

M2.2.57 MOVE

CALLING SEQUENCE:

CALL MOVE (A,B,L)

FUNCTION:

MOVE is used to move $\mathrm{L}$ words from $\mathrm{B}$ to $\mathrm{A}$.

ARGUMENTS:

$A$ is the destination of the move.

$B$ is the source for the move.

$\mathrm{L}$ is the number of words to be moved.

LANGUAGE:

ASSEMBLER

M2.2.58 MWLIST

CALLING SEQUENCE:

CALL MWLIST (X,LA,IHT,ITRG)

\section{FUNCTION:}

MWLIST is used to print an AMPX-formatted transfer array.

All arguments must be supplied by the calling program.

\section{ARGUMENTS:}

$\mathrm{X}$ is the array to be printed.

LA is the length of the array.

NUREG/CR-0200,

Vol. 3, Rev. 4 
IHT is the position of the total cross section in each group string.

ITRG is a flag selecting whether the whole array or only the 1-D cross sections will be printed. ITRG = 0 prints the whole array, ITRG $=1$ prints only the $1-D$ cross sections in the array.

SUBROUTINES CALLED:

MGCWRD

LANGUAGE:

FORTRAN

M2.2.59 MWLS

CALLING SEQUENCE:

CALL MWLS (X,LA,IHT,TEV,MT,NOU,NL,IDR)

FUNCTION:

MWLS is used to title and print an AMPX-formatted transfer array.

All arguments must be supplied by the calling program.

\section{ARGUMENTS:}

$\mathrm{X}$ is the array to be printed.

LA is the length of the array.

IHT is the position of the total cross section within a group string.

TEV is the temperature of the matrix.

MT is the identifier of the array to be printed.

NOU is the logical unit number of the print file.

NL is the order of Legendre expansion for the array to be printed.

IDR is the ID record for the array to be printed.

\section{SUBROUTINES CALLED:}

MGCWRD 


\section{LANGUAGE:}

FORTRAN

\section{M2.2.60 OPENDA}

\section{CALLING SEQUENCE:}

\section{CALL OPENDA (NBLKS,LBLKS,TYPE,ASSVAR,NUNIT,BUFFER)}

\section{FUNCTION:}

OPENDA is used to open a file for the random-access package and to initialize the file if necessary. It can return the length of a block when used to open an old file. Although written in FORTRAN, there are still system dependencies that must be dealt with in this routine.

\section{ARGUMENTS:}

NBLKS ' is the number of blocks of direct access space to be initialized. If TYPE $=$ ' $O$ ', the number of blocks in the dataset is returned here.

LBLKS is the size of a block. If TYPE $=$ ' $O{ }^{\prime}$, the size is returned here in units of words.

TYPE selects the type of open to be done. TYPE $=$ ' $O$ ' selects opening an old dataset. No initialization is done. TYPE $=$ ' $U$ ' selects the size unit to be in words. If the dataset already exists, OPENDA checks that enough blocks of the right size already exist. If not, enough new blocks are initialized to reach the correct total. TYPE $=$ ' $L$ ' or ' $E^{\prime}$ selects the size unit to be in bytes. Otherwise, this is the same as ' $U$ '.

ASSVAR is the associated variable for this file.

NUNIT is the logical unit number for this file.

BUFFER is a scratch array used in initializing the file. It must be at least LBLKS long.

\section{SUBROUTINES CALLED:}

EYENIT

\section{LANGUAGE:}

FORTRAN 
M2.2.61 OPNFIL

CALIING SEQUENCE:

CALL OPNFIL (NUN,STATUS,FORM,FILE)

FUNCTION:

OPNFIL is used to isolate open statements so that all system dependencies can be contained in a single subroutine.

ARGUMENTS:

NUN is the unit number to be opened.

STATUS is the status of open (i.e, 'NEW', 'OLD', 'UNKNOWN').

FORM is the format of data, 'FORMATTED' or 'UNFORMATTED'.

FIIL is the filename for unit.

Not used on IBM, for other systems.

'DEFAULT' - generates a filename based on NUN.

' $\$ X X X '$ - generates a unique filename, _XXXnonn, where nnnn is a number making the name unique.

Anything else is used as a filename.

LANGUAGE:

FORTRAN

M2.2.62 PRT1D

CALLING SEQUENCE:

CALL PRT1D (X,NG,NX,NOU)

FUNCTION:

PRTID is used to print a 1-D array of cross sections (total absorption, etc.) with their identifiers. It will compress multiple lines that are the same to reduce the amount of output.

\section{ARGUMENTS:}

$\mathrm{X}$ is the array of $1-\mathrm{D}$ cross sections.

NG is the first dimension of $X . N G$ is the number of groups +1 . 
$\mathrm{NX}$ is the number of $1-\mathrm{D}$ cross-section sets in $\mathrm{X}$.

NOU is the logical unit number of the print file.

\section{LANGUAGE:}

FORTRAN

\section{M2.2.63 PULL}

\section{CALLING SEQUENCE:}

CALL PULL (MIN,SEC, ${ }^{*}$ RETN)

\section{FUNCTION:}

PULL is used to set a cpu time interval. When the interval expires, an interrupt occurs which allows execution to be continued along a different path.

\section{ARGUMENTS:}

MIN refers to minutes to be set in the interval.

SEC refers to seconds to be set in the interval if MIN and SEC are 0, a previously set interval is cancelled.

*RETN is a statement where execution is to be transferred when the interval expires.

\section{LANGUAGE:}

ASSEMBLER

\section{M2.2.64 QZCNVT,FLTFX,QZSCAN}

\section{CALLING SEQUENCE:}

CALL QZCNVT (I,LDATA,LL,PLS)

CALL FLTFX (X,IX,IEX)

CALL QZSCAN (LDATA,LL,LT,IEX)

\section{FUNCTION:}

QZCNVT is used to convert a binary number to EBCDIC.

FLTFX is used to convert a floating-point number to an integer and an exponent.

NUREG/CR-0200,

Vol. 3, Rev. 4
M2.2.40 
QZSCAN is used to delete trailing zeroes by modifying the exponent.

\section{ARGUMENTS:}

I is the number to be converted to EBCDIC.

LDATA is the character string into which the answer is stored.

LL is the length of the answer.

PLS is the character to be used as a plus sign.

$\mathrm{X}$ is the floating-point number.

IX is the integer derived from $\mathrm{X}$.

IEX is the exponent derived from $\mathrm{X}$.

LT is the length of the string from which trailing zeroes are to be dropped.

LANGUAGE:

ASSEMBLER

M2.2.65 Q0READ

CALLING SEQUENCE:

CALL QOREAD (D,LP,LOF,NER,NIN,NOU)

FUNCTION:

QOREAD is used to read a data block from a binary file with FIDO-type array identifiers.

\section{ARGUMENTS:}

D is the array into which the numbers are to be read.

LP is the array of pointers to the beginning of each array in D.

LOF is the offset to the number 1 array in LP.

NER returns the number of errors encountered in reading the data block.

NIN is the logical unit number of the binary file. 
NOU is the logical unit number of the print file.

SUBROUTINES CALLED:

IO

LANGUAGE:

FORTRAN

\section{M2.2.66 RANDNUM}

ENTRIES:

FLTRN,RNDIN,RNDOUT,AZIRN,GTISO,EXPRN,SFLRA,ANORM

CALLING SEQUENCE:

$\mathrm{X}=$ FLTRN ()

$\mathrm{X}=\mathrm{EXPRN}($ )

$\mathrm{X}=\mathrm{SFLRA}()$

$\mathrm{X}=\mathrm{ANORM}()$

CALL RNDIN(R)

CALL RNDOUT(R)

CALL AZIRN(S,C)

CALL GTISO(U,V,W)

CALL DAZIRN(DS,DC)

CALL DGTISO(DU,DV,DW)

\section{FUNCTION:}

FLTRN returns a pseudo double-precision random number uniformly distributed between 0.0 and 1.0.

EXPRN returns an exponentially distributed double-precision random number.

SFLRA returns a double-precision random number uniformly distributed between -1.0 and 1.0 .

ANORM returns a normally distributed random number of mean 0.0 and half width 1.0 .

AZIRN returns the sine and cosine of a uniformly distributed random azimuthal angle.

DAZIRN returns the double-precision sine and cosine of a uniformly distributed random azimuthal angle.

GTISO returns the direction cosines of an isotropically distributed random direction.

DGTISO returns the double-precision direction cosines of an isotropically distributed random direction. NUREG/CR-0200,

Vol. 3, Rev. 4 
RNDIN sets the seed for the next random number.

RNDOUT returns the seed for the next random number.

All functions may be typed as double precision.

\section{ARGUMENTS:}

The function arguments are not used.

$\mathrm{R}$ is the seed. It is an eight-byte number, of which only the low-order six bytes are used or returned.

$S, C$ are the sine and cosine of a random azimuthal angle.

$\mathrm{U}, \mathrm{V}, \mathrm{W}$ are the isotropically distributed direction cosines.

DS,DC are the double-precision sine and cosine of a random azimuthal angle.

DU,DV,DW are the isotropically distributed double-precision direction cosines.

\section{LANGUAGE:}

ASSEMBLER

\section{M2.2.67 READSG}

\section{CALLING SEQUENCE:}

CALL READSG (X,M,NIN,IFORM)

\section{FUNCTION:}

READSG is used to read an array of cross sections from an ANISN cross-section library.

\section{ARGUMENTS:}

$\mathrm{X}$ is the array of ANISN-formatted cross sections.

M is the size of the array.

NIN is the logical unit number from which the array is read.

IFORM selects the form of the ANISN cross sections on NIN.

IFORM $>0$ means the cross sections are in fixed FIDO format.

IFORM $=0$ means the cross sections are in free-field FIDO format.

IFORM $<-0$ means the cross sections are in binary form.

\section{SUBROUTINES CALLED:}

IONUMS,RCRDLN,FREAD,AREAD 
COMMONS:

RETCDE

LANGUAGE:

FORTRAN

\section{M2.2.68 RECTRY}

CALLING SEQUENCE:

CALL RECTRY (X,LIM,NOU,NT1,NT2,NS,NT)

\section{FUNCTION:}

RECTRY is used to write a correct table of contents on an AMPX master library NT1 and/or an AMPX working library NT2.

ARGUMENTS:

$\mathrm{X}$ is a scratch array.

LIM is the length of $\mathrm{X}$.

NOU is the logical unit number of the print file.

NT1 is the logical unit number of the master library (0 means skip).

NT2 is the logical unit number of the working library (0 means skip).

NS,NT are logical unit numbers of scratch files.

SUBROUTINES CALLED:

IOLEFT,JSTIME,COPY,JDFJX,JGET

LANGUAGE:

FORTRAN 


\section{M2.2.69 RESETM}

\section{CALLING SEQUENCE:}

CALL RESETM

FUNCTION:

RESETM is used by control programs to reset the data communicated between the SCALE driver and the program. See GETMS.

COMMONS:

CDATA,CCDATA

LANGUAGE:

ASSEMBLER

\section{M2.2.70 SCANON}

ENTRIES:

SCANON,SCANOF,ALLOWC,RESETC,SETBIN, RESETB,IONUMS,RCRDLN, GETPTR, RSTPTR

\section{CALLING SEQUENCE:}

CALL SCANON

CALL SCANOF

CALL ALLOWC

CALL RESETC

CALL SETBIN

CALL RESETB

CALL IONUMS(NIN,NOU,NINOLD,NOUOLD)

CALL RCRDLN(LEN,LENOLD)

CALL GETPTR(PTR)

CALL RSTPTR(PTR)

FUNCTION:

SCANON turns on the feature in the free-form reading package to scan ahead to the next entry and check if it is 'END'.

SCANOF turns off the scan-ahead feature. 
ALLOWC turns off the invalid character check when reading numbers. With the check turned off, any character not valid in a numeric field will act as a terminator for the field.

RESETC turns the invalid character check on. With the check turned on, any character not valid in a numeric field will cause an error message to be printed and the character will be replaced by a 0.

SETBIN turns on the binary reading flag.

RESETB turns off the binary reading flag. This mode is for reading free-form data punched on cards.

IONUMS sets new input and output unit numbers and returns the previous unit numbers.

RCRDLN sets a new logical record length, and returns the previous one.

GETPTR returns the current pointer in the input buffer.

RSTPTR sets the current pointer in the input buffer.

\section{ARGUMENTS:}

NIN is the new input logical unit number.

NOU is the new output logical unit number.

If NIN or NOU is 0 , the unit number is not changed.

NINOLD is where the previous input logical unit number is returned.

NOUOLD is where the previous output logical unit number is returned.

LEN is the new logical record length (LEN <255).

LENOLD is where the previous logical record length is returned.

PTR is the pointer in the input buffer.

LANGUAGE:

FORTRAN

\section{M2.2.71 SHELC}

CALLING SEQUENCE:

CALL SHELC (R,TAU,TOI,TOO)

NUREG/CR-0200,

Vol. 3, Rev. 4

M2.2.46 


\section{FUNCTION:}

SHELC is used to generate the transmission probabilities for a cylindrical shell.

\section{ARGUMENT:}

$\mathbf{R}$ is the ratio of inner radius to outer radius of the shell.

TAU is the thickness of the shell (in mean-free paths).

TOI is the transmission from the outside to the inside of the shell.

TOO is the transmission from the outside to the outside of the shell.

SUBROUTINES CALLED:

$\mathrm{KI} 3, \mathrm{COS}, \mathrm{SQRT}$

LANGUAGE:

FORTRAN

\section{M2.2.72 SNST}

\section{CALIING SEQUENCE:}

\section{CALL SNST (CX,L,C,ITL,IHT,IHS,ITOT,GR,LL)}

\section{FUNCTION:}

SNST is used to move cross-section data from an AMPX-formatted transfer array to an ANISN-formatted array. It can also make a transport correction to the within-group scatter cross section.

\section{ARGUMENTS:}

$\mathrm{CX}$ is the magic word 2-D array.

$\mathrm{L}$ is the length of $\mathrm{CX}$.

C is the ANISN array.

ITL is the table length of the ANISN array.

IHT is the position of the total cross section in a cross-section string of the ANISN array. 
IHS is the position of the within-group scatter cross section within a cross-section string of the ANISN array.

ITOT is the number of groups.

GR is the array containing the transport corrections to be applied to the within-group cross sections.

LL is the order of scattering of the array.

\section{SUBROUTINES CALLED:}

MGCWRD

LANGUAGE:

FORTRAN

\section{M2.2.73 STOP}

\section{CALLING SEQUENCE:}

CALL STOP (MESSAGE,STPCDE,NOU,TRCFLG,P1,..PN)

\section{FUNCTION:}

STOP is used to print a message, optionally print a trace back, print optional data, and optionally stop.

\section{ARGUMENTS:}

MESSAGE is the message to be printed. It can be no longer than 132 characters. If it is less than 132 characters, it must be terminated by a $\$$ symbol. This argument is required, but the calling sequence can be terminated after this argument, or any subsequent argument, in which case defaults are supplied for the missing arguments.

STPCDE is a stop number, defaulted to 0 . If it is greater than 0 , STOP will execute a stop instead of returning to the calling program.

NOU is the logical unit number of the print file. The default is the standard error message file.

TRCFLG selects a trace back if it is greater than 0 . The default is 0 .

$\mathrm{P} 1, \ldots, \mathrm{PN} \quad$ are optional arguments which will be printed following MESSAGE.

\section{LANGUAGE:}

\section{ASSEMBLER}

NUREG/CR-0200,

Vol. 3, Rev. 4

M2.2.48 
M2.2.74 TIMFAC

CALLING SEQUENCE:

CALL TIMFAC(FACTOR)

FUNCTION:

TIMFAC supplies a machine-dependent factor used to scale cpu times in a program so that roughly equivalent amounts of computation can be done on different machines using the same input time limit. The SCALE version sets FACTOR $=1.0$.

ARGUMENTS:

FACTOR is the machine-dependent factor used to scale the time.

\section{LANGUAGE:}

FORTRAN

\section{ARGUMENTS:}

FACTOR is the machine-dependent factor used to scale the time.

\section{LANGUAGE:}

FORTRAN

\section{M2.2.75 VERGET}

\section{CALLING SEQUENCE:}

L=VERGET(PGM,CDATE,CLIB,SYSTEM,SVERS,PROG,PVERS)

\section{FUNCTION:}

VERGET is used to return the system name, system version, program name, and program version for a given module created on a given date and residing in a given library.

\section{ARGUMENTS:}

PGM is the accessed name of the module.

CDATE is the date PGM was created. 
CLIB is the name of the library where PGM resides.

SYSTEM is the name of the system.

SVERS is the version of the system.

PROG is the program name of PGM.

PVERS is the version of PGM.

\section{LANGUAGE:}

ASSEMBLY

\section{M2.2.76 WOT}

\section{CALLING SEQUENCE:}

CALL WOT(X,NCOL,NROW,LG,TOP1,TOP2,TOP3)

\section{FUNCTION:}

WOT is used to print a 1-, 3-, or 3-D array in a columnar output form with headings supplied as TOP1, TOP2, and TOP3. It will compress out lines that are the same to reduce the amount of output.

\section{ARGUMENTS:}

$\mathrm{X}$ is the array to be printed.

NCOL is the number of columns in $\mathrm{X}$ ( 1 if $\mathrm{X}$ is a vector).

NROW is the number of rows in $\mathrm{X}$.

LG is the third dimension of $X$ ( 1 if $X$ is less than 3 dimensions).

TOP1 is the heading for the row index.

TOP2 is the heading for the columns.

TOP3 is the page heading for the third dimension.

\section{LANGUAGE:}

FORTRAN

NUREG/CR-0200,

Vol. 3, Rev. 4 


\section{M2.2.77 WOT8}

\section{CALLING SEQUENCE:}

CALL WOT8 (A1,L1,A2,L2,A3,L3,A4,L4,A5,L5,A6,L6,A7,L7,A8,L8,NOU)

FUNCTION:

WOT8 is used to print up to eight arbitrary-length vectors as eight columns down a page.

\section{ARGUMENTS:}

An is the $n t h$ vector.

In is the length of the $n t h$ vector. If $\operatorname{Ln}=0$, then the $n t h$ vector is omitted.

NOU is the logical unit number of the print file.

\section{LANGUAGE:}

FORTRAN

\section{M2.2.78 WRTID}

CALLING SEQUENCE:

CALL WRTID (ID,N6)

\section{FUNCTION:}

WRTID is used to print a labeled table of the data in an AMPX master library nuclide identifier record.

\section{ARGUMENTS:}

ID is the ID record from an AMPX master library.

N6 is the logical unit number of the print file.

\section{LANGUAGE:}

FORTRAN 


\section{M2.2.79 XTENDA}

\section{CALLING SEQUENCE:}

CALL XTENDA (BUFFER,NBLK,NUNIT)

FUNCTION:

XTENDA is used to add blocks to (extend) a random-access file.

\section{ARGUMENTS:}

BUFFER is a scratch array used to initialize the new blocks. Whatever data are in BUFFER will be written into the new blocks. BUFFER must be at least as long as a block.

NBLK is the number of new blocks to be added.

NUNIT is the logical unit number of the random-access file.

\section{SUBROUTINES CALLED:}

EYENIT

\section{LANGUAGE:}

FORTRAN

\section{M2.2.80 YREAD}

CALIING SEQUENCE:

CALL YREAD (DD,LD,LIM,IT,LERR)

FUNCTION:

YREAD is used to read an array using the free-form reading package while allowing interpolation, filling, skipping, multiple repeats, and arbitrary indexing. (See Sect. M3 for a more complete description.)

\section{ARGUMENTS:}

$\mathrm{DD}, \mathrm{LD}$ is the array to be read. $\mathrm{DD}$ is used for floating-point numbers and $L D$ for integers.

LIM is the number of entries in the array.

IT selects what kind of data are being read.

IT $=0$ selects integers.

NUREG/CR-0200,

Vol. 3, Rev. 4 
IT $=1$ selects single-precision floating-point numbers.

IT $=2$ selects double-precision floating-point numbers.

LERR logical flag that is set true if an attempt is made to store data outside the DD or LD array.

SUBROUTINES CALLED:

DREAD,AREAD

COMMONS:

UNIT,QRDBUF

LANGUAGE:

FORTRAN

\section{M2.2.81 YOREAD}

CALLING SEQUENCE:

CALL YOREAD (CBUF,LBUF,IRET)

FUNCTION:

YOREAD is used to read the next logical record for the free-form reading package.

ARGUMENTS:

CBUF is the array into which the record is read.

LBUF is the length of the record.

IRET is set to 2 if scan ahead is activated and an end of file is sensed.

SUBROUTINES CALLED:

ENFILE

COMMONS:

UNIT,QRDBUF

LANGUAGE:

FORTRAN 


\section{M2.2.82 YOTRNS}

CALLING SEQUENCE:

CALL YOTRNS(CARD,LBUF)

FUNCTION:

YOTRNS translates a character array from upper to lower case on the CRAY and from lower to upper case on the IBM.

\section{ARGUMENTS:}

CARD is the character array to be translated.

LBUF is the number of characters in CARD.

\section{LANGUAGE:}

FORTRAN

\section{M2.2.83 ZREAD}

\section{CALLING SEQUENCE:}

$\mathrm{D}=\mathrm{ZREAD}($ IBR,IRET)

\section{FUNCTION:}

ZREAD is used to read a hexadecimal number in free form and return it as a double-precision number.

\section{ARGUMENTS:}

See DREAD.

SUBROUTINES CALLED:

YOREAD,ENFILE

COMMONS:

UNIT,QRDBUF

NUREG/CR-0200,

Vol. 3, Rev. 4 


\section{LANGUAGE:}

FORTRAN

\section{REFERENCE}

1. N. M. Greene, W. E. Ford III, L. M. Petrie, and J. W. Arwood, AMPX-77: A Modular Code System for Generating Coupled Multigroup Neutron-Gamma Cross-Section Libraries From ENDF/B-IV and/or ENDF/B-V, ORNL/CSD/TM-283, Martin Marietta Energy Systems, Inc., Oak Ridge Natl. Lab., October 1992. 


\section{M2.A ASSEMBLER ROUTINES}

ALOCAT, performs storage management. The FORTRAN version calls library routines to perform this FREECR function

DATIM, return information about the job, program, and datasets being used which are then printed, DTASET, providing a QA trace. The FORTRAN versions call library routines for the necessary FINDQA, information.

JOBNUM

VERGET

EYENIT is needed on IBM to initialize the direct-access data files. For other systems, the FORTRAN replacement may be all that is needed.

ICOMPA, are in assembler for efficiency reasons. The FORTRAN provides the same functionality. MOVE, FLTFX, QZSCAN, QZCNT

JSTIME is used to do timings. The FORTRAN version calls a library routine to obtain the times needed.

PULL is used to prevent infinite loops in KENO. This functionality is lost in FORTRAN, but the impact is small.

FLTRN, Random-number FORTRAN replacements work well, with some loss of efficiency, provided SFLRA, there is a uniform random-number generator available to be called. MORSE and KENO require AZIRN, that this package be available.

GTISO, ANORM, DGTISO, DAZIRN, RNDJN, RNDOUT

GETMS, interface the control programs to the driver. The communications mechanisms define whether RESETM these routines can be in FORTRAN or not.

STOP the FORTRAN replacement works with some minor loss in functionality. 


\title{
M2.B UNIX SPECIFIC SUBROUTINES
}

The following routines are provided for UNIX systems. They may require modification to work correctly on different UNIX systems.

\author{
CALACT - $\quad$ A C language routine to provide an interface between ALOCAT and the UNIX system \\ malocs routine \\ ERRTRA - $\quad$ A replacement for an IBM routine that gives a traceback \\ FILNAM - $\quad$ A routine that generates unique filenames for output files \\ GETFLE - $\quad$ A routine that returns the path for a given filename \\ GETMTM - $\quad$ A C language routine that returns the creation date of a file \\ GETNAM - $\quad$ A C language routine to return the login name of the user \\ H7LIB - $\quad$ C language routines for HEATING7 \\ LNBLNK - $\quad$ A function to return the position of the last nonblank character in a string \\ PUTENV - $\quad$ A C language routine to set an environment variable \\ RETNTM - $\quad$ A C language routine to return the current date and time \\ XUFLOW - $\quad$ A dummy replacement for an IBM routine to cause underflows to be ignored
}




\section{M2.C UNICOS CRAY SPECIFIC SUBROUTINES}

The following routines are provided for CRAY systems. They are no longer supported at ORNL, and they may require modification to work correctly.

CSEVL - needed for ERF and ERFC which are in the IBM standard mathematics library.

ERF,ERFC - mathematics functions that are needed in the Dancoff calculations.

ERRTRA - a standard IBM library routine to provide a traceback.

FILNAM - a routine that generates unique filenames for output files.

INITS - $\quad$ needed by ERF and ERFC.

RIMACH - provides machine-dependent constants for ERF and ERFC.

XUFLOW - a standard IBM library routine to turn on or off trapping exponential underflow.

SEGNFO - a C language routine returning the date an executable was created. 
M2.D AMPX SUBROUTINES

\begin{tabular}{ll} 
Subroutine & \multicolumn{1}{c}{ Used by these modules } \\
\cline { 2 - 2 } BSQ & ALE \\
EBLIST & RADE \\
END & LAVA \\
FILL & \\
FILLY & ALE, AJAX, ALPO, RADE, WAX \\
LEGE & RADE \\
NCK & ALE, AJAX, ALPO, WAX \\
NOTE & AJAX, WAX \\
P1D & ALE \\
RD4 & RADE \\
SUMX & RADE
\end{tabular}


Computing Applications Division

\title{
SCALE FREE-FORM READING ROUTINES
}

\author{
L. M. Petrie \\ Previously Published: December 1984 \\ Revised Manuscript Completed: November 1993 \\ Date Published: April 1995 \\ Prepared for the \\ Office of Nuclear Material Safety and Safeguards \\ U.S. Nuclear Regulatory Commission \\ Washington, DC 20555 \\ Under Interagency Agreement DOE 1886-8000-9B \\ NRC JCN No. B0009
}

\author{
Prepared by the \\ OAK RIDGE NATIONAL LABORATORY \\ managed by \\ MARTIN MARIETTA ENERGY SYSTEMS, INC. \\ for the \\ U.S. DEPARTMENT OF ENERGY \\ under contract DE-AC05-84OR21400
}




\begin{abstract}
The SCALE free-form reading routines are a set of subroutines for use by programs in the SCALE system to read input from cards in an unstructured manner. This document provides information for a programmer who wishes to use these routines.
\end{abstract}





\section{CONTENTS}

ABSTRACT $\ldots \ldots \ldots \ldots \ldots \ldots \ldots \ldots \ldots \ldots \ldots \ldots \ldots \ldots \ldots \ldots \ldots \ldots \ldots \ldots \ldots$ LIST OF TABLES $\ldots \ldots \ldots \ldots \ldots \ldots \ldots \ldots \ldots \ldots \ldots \ldots \ldots \ldots \ldots \ldots \ldots$ ACKNOWLEDGMENTS $\ldots \ldots \ldots \ldots \ldots \ldots \ldots \ldots \ldots \ldots \ldots \ldots \ldots \ldots \ldots \ldots$ M3. $\ldots \ldots \ldots$ M3.1 INTRODUCTION $\ldots \ldots \ldots \ldots \ldots \ldots \ldots \ldots \ldots \ldots \ldots \ldots \ldots \ldots \ldots \ldots \ldots \ldots .1$

M3.2 DATA INPUT CONSIDERATIONS $\ldots \ldots \ldots \ldots \ldots \ldots \ldots \ldots \ldots \ldots \ldots \ldots \ldots . .1$

M3.3 PROGRAMMING CONSIDERATIONS $\ldots \ldots \ldots \ldots \ldots \ldots \ldots \ldots \ldots \ldots \ldots . \ldots \ldots$ 


\section{LIST OF TABLIES}

Page

M3.1 Routines to activate features $\ldots \ldots \ldots \ldots \ldots \ldots \ldots \ldots \ldots \ldots \ldots \ldots \ldots \ldots .2$

M3.2 Alphanumeric reading routines $\ldots \ldots \ldots \ldots \ldots \ldots \ldots \ldots \ldots \ldots \ldots \ldots$

M3.3 Alphanumeric reading arguments $\ldots \ldots \ldots \ldots \ldots \ldots \ldots \ldots \ldots \ldots \ldots \ldots$

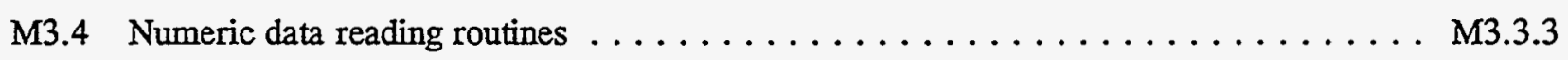

M3.5 Numeric reading arguments $\ldots \ldots \ldots \ldots \ldots \ldots \ldots \ldots \ldots \ldots \ldots \ldots \ldots . . \ldots \ldots$

M3.6 Miscellaneous reading routines $\ldots \ldots \ldots \ldots \ldots \ldots \ldots \ldots \ldots \ldots \ldots \ldots \ldots$

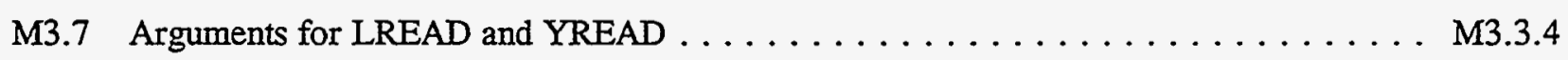

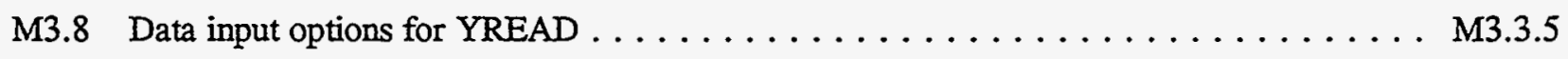

Vol. 3, Rev. $4 \quad$ M3.vi 


\section{ACKNOWLEDGMENTS}

The many helpful comments and suggestions of N. F. Landers during the development of this package are gratefully acknowledged. 


\section{M3.1 INTRODUCTION}

A set of free-form data reading routines has been developed to facilitate the use of free-formatted data input. These routines are used by the control programs to read the standard composition data and related data. Some of the functional modules such as KENO V.a and HEATING also make extensive use of these routines. This document is intended to provide guidance to a programmer desiring to use these routines in a program. Section M3.2 explains the conventions used to input data, and Sect. M3.3 contains information necessary for a programmer to use the routines. 


\section{M3.2 DATA INPUT CONSIDERATIONS}

The free-form reading routines allow alphanumeric data, floating-point data, and integer data to be entered in a free-formatted manner. All 80 columns of any card may be used; and data, with certain exceptions noted below, can start or end in any column. A single data entry cannot be started on one card and extend onto the next card, however.

Any alphanumeric data entry is terminated by one or more blanks or an equal sign, depending on the first argument supplied to the reading routine. Any numeric data entry will be terminated when a blank or a comma is encountered. The use of an $\mathrm{E}$ as an exponent does allow a single imbedded blank after the $\mathrm{E}$. An exponent is limited to two digits, and the number being read is terminated with the second digit. Therefore, for this case only, another number can be started immediately following the second digit of the exponent without an intervening blank or comma. Decimal data may be entered as in FORTRAN input: e.g., 1.733-4, $1.733 \mathrm{E}-04$, or 0.0001733 are the same as $1.733 \times 10^{-4} ; 1.733+4,1.733 \mathrm{E}+4,1.733 \mathrm{E} 4$, and 17330.0 are the same as $1.733 \times 10^{4}$. Integers may be entered for floating-point data (i.e., 10 will be interpreted as 10.0 ). Similarly, floating-point data may be entered for integers. Thus, $1.733 \mathrm{E}+4$ would be interpreted as 17330 , and $1.733 \mathrm{E}-4$ would be interpreted as zero.

The free-form routines have provisions for multiple entries of the same data value. This step is done by entering the number of repeats, followed by an $\mathrm{R}$, *, or $\mathrm{S}$, followed by the data value to be repeated. For example, $5 R 2,5 * 2$, or $5 \$ 2$ enters five successive $2 \mathrm{~s}$ in the input data. Blanks are not allowed between the number of repeats and the repeat flag $(R, *, \$)$. However, a blank is allowed between the repeat flag and the data item to be repeated. Multiple zeros may be specified by entering $n Z$, where $n$ is the number of zeros to be repeated. No blanks should be placed between the $n$ and the $Z$, but the $n Z$ must be separated from the rest of the data by or more blanks.

All numeric data are read in double precision and are then converted to the desired form. Exponent indicators can be either a $\mathrm{D}$ or an $\mathrm{E}$. The default method of terminating a data field is one or more blanks or a comma. A comma must immediately follow the number if it is used as a terminator (i.e., 5.6, should be used to enter the number 5.6 as data; 5.6 , results in two numbers, 5.6 and 0 ). Thus, commas can be used to enter zeros. $5.6,,,, 8.0$ enters 6 numbers as data-5.6, four zeros, and 8.0 (the comma immediately after the 5.6 terminates that number and does not cause an entry of zero into the data). Similarly, both $5.6,,,, 8.0$ and $5.6,,,,, 8.0$ enter seven numbers as data-5.6, five zeros and 8.0. 


\section{M3.3 PROGRAMMING CONSIDERATIONS}

When using the free-form reading routines in a program, it is important to be aware of the different types of routines that are available in the package. Routines are available to activate desired features, to do the actual reading, and "transparent" routines that are used internally. These routines and their arguments are listed in Tables M3.1 through M3.7.

If the programmer desires to use the word END to terminate a block of data, SCANON must be called to activate the scan-ahead feature. Once SCANON has been activated, the scan-ahead feature remains in effect until it is inactivated by calling SCANOF. If the scan-ahead feature is active, the second argument, IRET, of the reading routine (see Tables M3.2 and M3.5) will be returned with a value of 1 whenever the next piece of data to be read is the word END. The argument IRET will be returned with a value of 2 if an end-offile is the next piece of information to be read. Note: IRET should be initialized to zero before the very first read is done.

The first argument, IC, is used to communicate to the reading routine information regarding the means of reading data. This step is explained in greater detail in Tables M3.2 and M3.4. It may be advantageous to create a common that contains preset values of IC for use in the call statements.

Subroutine ALLOWC can be called to force termination of a numeric entry whenever any character that is illegal in a numeric field is encountered. Once invoked, this feature remains in effect until it is inactivated by calling RESETC.

The default card length is set at 80 columns. If it becomes desirable to set the card length at some value less than or equal to 80 , this can be accomplished by calling RCRDLN. The new card length remains in effect until RCRDLN is called to set a different card length.

Under certain conditions it is desirable to be able to read unformatted data. This can be achieved by calling SETBIN. Once activated, this feature remains in effect until it is inactivated by calling RESETB. When this feature has been activated, unformatted records of the current card length are read from the input file. The reading routines then do no conversion, but simply return the next word (or two words for double precision) from the record.

Subroutine YREAD allows reading a whole array of numbers using free-form input. In addition to repeating numbers, capabilities are provided for various sequence repeats, interpolations, filling the array, and entering or overriding specific locations in the array in a manner similar to FIDO-type input (see Sect. M10). Table M3.8 lists the various data entry options. 
Table M3.1 Routines to activate features

\begin{tabular}{|c|c|c|}
\hline Subroutine name & Means of utilization & Purpose \\
\hline SCANON & CALL SCANON & $\begin{array}{l}\text { This routine is used to activate the scan-ahead feature } \\
\text { that allows the program to scan ahead for an 'END' }\end{array}$ \\
\hline SCANOF & CALL SCANOF & This disables the scan-ahead feature \\
\hline IONUMS & $\begin{array}{l}\text { CALL IONUMS } \\
(I I, J J, K K, L L)\end{array}$ & $\begin{array}{l}\text { This subroutine is used to change the input and output } \\
\text { unit numbers } \\
\text { II is the unit to be used for input } \\
\text { (new input unit, default }=5 \text { ) } \\
\mathrm{JJ} \text { is the unit number to be used for output } \\
\text { (new print unit, default }=6 \text { ) } \\
\text { KK is used to return the old input unit number } \\
\text { LL is used to return the old output unit number }\end{array}$ \\
\hline RCRDLN & $\begin{array}{l}\text { CALL RCRDLN } \\
(\mathrm{LIN}, \mathrm{LO})\end{array}$ & $\begin{array}{l}\text { This subroutine is used to change the number of } \\
\text { columns in a card and thereby ignore any information } \\
\text { past column LIN } \\
\text { LIN is the new number of columns to be considered } \\
\text { on a card ( }<81 \text { ) } \\
\text { LO is the previous value of the number of columns on } \\
\text { a card (default }=80 \text { ) }\end{array}$ \\
\hline SETBIN & CALL SETBIN & $\begin{array}{l}\text { This subroutine is used to set a flag that causes data } \\
\text { reading to be unformatted. This feature remains in } \\
\text { effect until RESETB is called }\end{array}$ \\
\hline RESETB & CALL RESETB & $\begin{array}{l}\text { This subroutine sets a flag that causes data reading to } \\
\text { be free-form (disables the SETBIN feature) }\end{array}$ \\
\hline ALLOWC & CALL ALLOWC & $\begin{array}{l}\text { A call to this subroutine causes the termination of a } \\
\text { numeric data field whenever any character that is } \\
\text { illegal in a numeric field is encountered; i.e., it treats } \\
\text { all such characters the way it treats a comma during } \\
\text { normal numeric reading. This feature remains in } \\
\text { effect until RESETC is called }\end{array}$ \\
\hline RESETC & CAIL RESETC & $\begin{array}{l}\text { This subroutine resets a flag to disable the ALLOWC } \\
\text { feature }\end{array}$ \\
\hline
\end{tabular}


Table M3.2 Alphanumeric reading routines

\begin{tabular}{lll} 
Function name & Means of utilization & Type of data \\
\hline \multirow{2}{*}{ AREAD } & $\begin{array}{l}\text { Variable name }= \\
\text { AREAD(IC,IRET) }\end{array}$ & Alphanumeric data, 4 characters at a time \\
\multirow{2}{*}{ CREAD } & $\begin{array}{l}\text { Variable name }= \\
\text { CREAD(IC,IRET })\end{array}$ & Alphanumeric data, 8 characters at a time \\
\hline
\end{tabular}

Table M3.3 Alphanumeric reading arguments

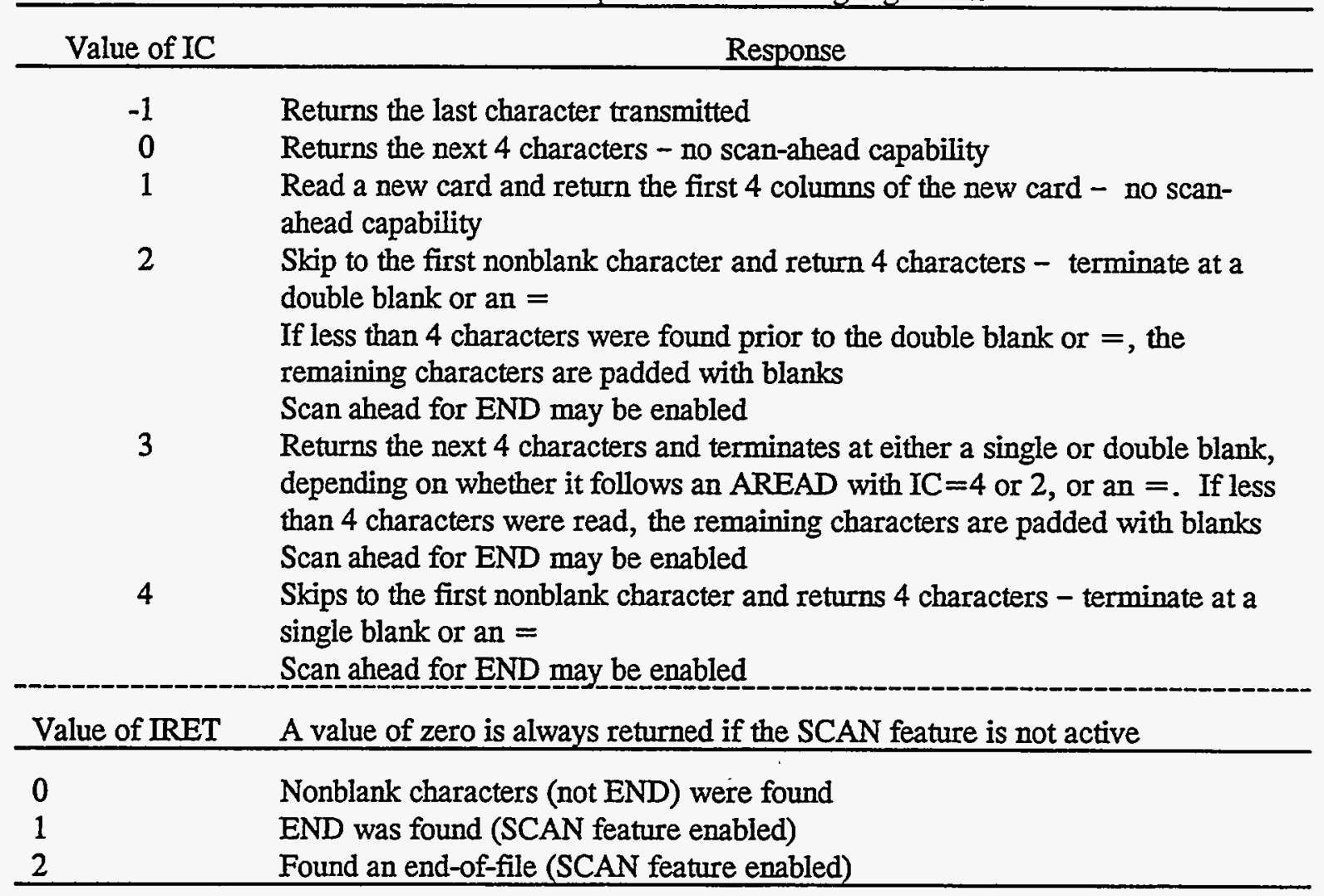

Table M3.4 Numeric data reading routines

\begin{tabular}{lll}
\hline Function name & \multicolumn{1}{c}{ Means of utilization } & \multicolumn{1}{c}{ Type of data } \\
\hline DREAD & Variable = DREAD(IC,IRET) & Double-precision data \\
FREAD & Variable = FREAD(IC,IRET) & Floating-point data \\
IREAD & Variable = IREAD(IC,IRET) & Integer data \\
ZREAD & Variable = ZREAD(IC,IRET) & Double-precision hexadecimal data \\
\hline
\end{tabular}


Table M3.5 Numeric reading arguments

\begin{tabular}{ll}
\hline Value of IC & Response \\
\hline 0 & Returns the next number \\
1 & Reads a new card and returns the next number \\
\hline Value of IRET & A value of zero is always returned if the SCAN feature is not enabled \\
\hline 0 & Nonblank characters (not END) were found near the current number \\
1 & END was found as the next entry after the current number \\
2 & An end-of-file was encountered in scanning for END \\
\hline
\end{tabular}

Table M3.6 Miscellaneous reading routines

\begin{tabular}{cll}
\hline Name & \multicolumn{1}{c}{ Means of utilization } & \multicolumn{1}{c}{ Purpose } \\
\hline LREAD & Variable = LREAD(IC,IRET) & $\begin{array}{l}\text { This logical function returns a true if the next } \\
\text { character is a numeric character and false if the } \\
\text { next character is nonnumeric. It does not do any } \\
\text { actual reading }\end{array}$ \\
YREAD & $\begin{array}{l}\text { CALL } \\
\text { YREAD(A,A,NUM,ITP) }\end{array}$ & $\begin{array}{l}\text { To load an array of numeric data that consists of } \\
\text { integer or floating-point data in single or double } \\
\text { precision. A is the array and is entered in the } \\
\text { argument list twice. NUM is the length of the } \\
\text { array }\end{array}$ \\
\hline
\end{tabular}

Table M3.7 Arguments for LREAD and YREAD

\begin{tabular}{ll} 
Argument & Explanation \\
\hline IC & This argument is not used \\
IRET & If IRET $=2$, ENFILE is called; otherwise, this argument is ignored \\
The array to be loaded by YREAD, integer, or floating point \\
The length of the array A
\end{tabular}


Table M3.8 Data input options for YREAD

\begin{tabular}{|c|c|c|c|}
\hline $\begin{array}{l}\text { Count } \\
\text { field }\end{array}$ & $\begin{array}{c}\text { Option } \\
\text { field }\end{array}$ & $\begin{array}{l}\text { Data } \\
\text { field } \\
\end{array}$ & Function \\
\hline \multirow{15}{*}{$\mathrm{i}$} & & $\mathbf{j}$ & Stores $\mathrm{j}$ at the current position in the array \\
\hline & $\mathrm{F}$ & $\mathbf{j}$ & $\begin{array}{l}\text { Fills the remainder of the array with the number } j \text {, starting with the } \\
\text { current position in the array }\end{array}$ \\
\hline & A & \multirow[t]{2}{*}{$\mathbf{j}$} & Sets the current position in the array to $j$ \\
\hline & $S$ & & $\begin{array}{l}\text { Increments the current position in the array by } i \text {. (This allows skipping } \\
\text { i positions. i may be positive or negative) }\end{array}$ \\
\hline & Q & $\mathbf{j}$ & Repeats the previous $j$ entries $i$ times. The default value of $i$ is 1 \\
\hline & $\mathbf{N}$ & $\mathbf{j}$ & $\begin{array}{l}\text { Repeats the previous } j \text { entries } i \text { times inverting the sequence each time. } \\
\text { The default value of } i \text { is } 1\end{array}$ \\
\hline & B & j & $\begin{array}{l}\text { Back } i \text { entries. From that position, repeat the previous } j \text { entries in } \\
\text { reverse order. The default value of } i \text { is } 1\end{array}$ \\
\hline & $\mathbf{I}$ & $\mathrm{j} \mathbf{k}$ & $\begin{array}{l}\text { Provides the end points, } \mathrm{j} \text { and } \mathrm{k} \text {, with } \mathrm{i} \text { entries linearly interpolated } \\
\text { between them (i.e., a total of } \mathrm{i}+2 \text { points). At least one blank must } \\
\text { separate } \mathrm{j} \text { and } \mathrm{k} \text {. When used for an integer array, the I option should } \\
\text { only be used to generate integer steps [i.e., }(\mathrm{k}-\mathrm{j}) /(\mathrm{i}+1) \text { should be a } \\
\text { whole number] }\end{array}$ \\
\hline & $\mathbf{L}$ & $\mathrm{j} k$ & $\begin{array}{l}\text { Provides the end points, } j \text { and } k \text {, with } i \text { entries logarithmically } \\
\text { interpolated between them (i.e., a total of } i+2 \text { points). At least one } \\
\text { blank must separate } j \text { and } k\end{array}$ \\
\hline & $\mathbf{Z}$ & & Enters i zeros \\
\hline & $\mathbf{R}$ & $\mathbf{j} \mathbf{k}$ & Repeat j i times \\
\hline & * & j & Repeat j i times \\
\hline & $\$$ & $\mathrm{j}$ & Repeat j i times \\
\hline & $\mathbf{P}$ & $\mathrm{j}$ & Alternately stores $j$ and $-j$ in the next $i$ positions of the array \\
\hline & $\mathbf{T}$ & & Terminates the data reading for the array \\
\hline
\end{tabular}


Computing Applications Division

\title{
SCALE CROSS-SECTION LIBRARIES
}

\author{
W. C. Jordan
}

Manuscript Revised: November 1994

Date Published: April 1995

Prepared for the

Office of Nuclear Material Safety and Safeguards

U.S. Nuclear Regulatory Commission

Washington, DC 20555

Under Interagency Agreement DOE 1886-8000-9B

NRC JCN No. B0009

Prepared by the

OAK RIDGE NATIONAL LABORATORY

managed by

MARTIN MARIETTA ENERGY SYSTEMS, INC.

for the

U.S. DEPARTMENT OF ENERGY

under contract DE-AC05-84OR21400 
$\ldots$ $\ldots$

. 


\begin{abstract}
This document briefly describes the cross-section libraries available in the SCALE code system. Included are the background of each library, the intended use of the library, and information relating to general experience with the library. The energy group bounds of the library are given in a manner that allows a quick comparison of the different libraries available. This document is intended as a companion document and supplement to Sect. M8, which describes the Standard Composition Library.
\end{abstract}




\section{CONTENTS}

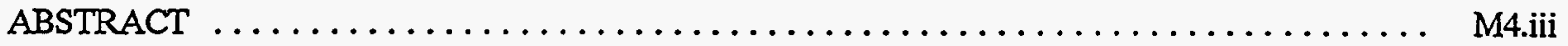

LIST OF TABLES $\ldots \ldots \ldots \ldots \ldots \ldots \ldots \ldots \ldots \ldots \ldots \ldots \ldots \ldots \ldots \ldots \ldots \ldots \ldots \ldots \ldots \ldots$

ACKNOWLEDGMENTS $\ldots \ldots \ldots \ldots \ldots \ldots \ldots \ldots \ldots \ldots \ldots \ldots \ldots \ldots \ldots \ldots \ldots \ldots \ldots$ M4.vii

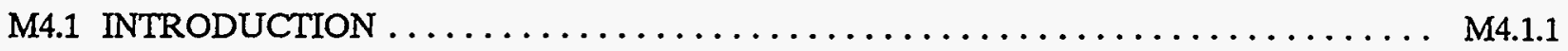

M4.2 DESCRIPTION OF THE SCALE CROSS-SECTION LIBRARIES $\ldots \ldots \ldots \ldots \ldots \ldots \ldots$ M4.2.1

M4.2.1 THE 218-GROUP ENDF/B-IV LIBRARY (218GROUPNDF4) $\ldots \ldots \ldots \ldots \ldots$ M4.2.1

M4.2.2 THE 27-GROUP ENDF/B-IV LIBRARY (27GROUPNDF4) ........... M4.2.1

M4.2.3 THE HANSEN-ROACH LIBRARY (HANSEN-ROACH) . . . . . . . . M4.2.12

M4.2.4 THE 123-GROUP GAM-THERMOS LIBRARY (123GROUPGMTH) $\ldots \ldots \ldots$.

M4.2.5 THE 18-GROUP GAMMA LIBRARY (18GROUPGAMMA) . . . . . . . . M4.2.13

M4.2.6 THE 22n-18g STRAKER-MORRISON LIBRARY (22N-18COUPLE) . . . . . M4.2.17

M4.2.7 THE 27n-18g COUPLED LIBRARY (27N-18COUPLE) $\ldots \ldots \ldots \ldots \ldots \ldots \ldots$

M4.2.8 THE 27-GROUP DEPLETION LIBRARY (27BURNUPLIB) $\ldots \ldots \ldots \ldots \ldots$ M4.2.17

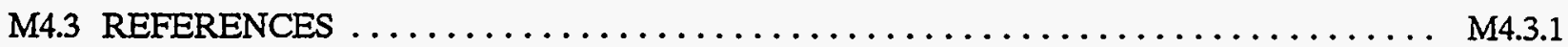

APPENDIX M4.A TABLE OF CONTENTS LISTING FOR SCALE LIBRARIES

M4.A.1 THE 218-GROUP ENDF/B-IV LIBRARY $\ldots \ldots \ldots \ldots \ldots \ldots \ldots \ldots \ldots \ldots$ M4.A.2

M4.A.2 THE 27-GROUP ENDF/B-IV LIBRARY $\ldots \ldots \ldots \ldots \ldots \ldots \ldots \ldots \ldots \ldots$ M4.A.4

M4.A.3 THE 16-GROUP HANSEN-ROACH LIBRARY $\ldots \ldots \ldots \ldots \ldots \ldots \ldots \ldots$ M4.A.6

M4.A.4 THE 123-GROUP GAM-THERMOS LIBRARY $\ldots \ldots \ldots \ldots \ldots \ldots \ldots \ldots \ldots$ M4.A.8

M4.A.5 THE 18-GROUP GAMMA LIBRARY $\ldots \ldots \ldots \ldots \ldots \ldots \ldots \ldots \ldots$ M4.A.11

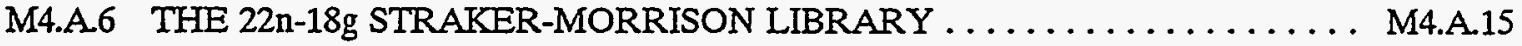

M4.A.7 THE $27 n-18 g$ COUPLED ENDF/B-IV LIBRARY $\ldots \ldots \ldots \ldots \ldots \ldots \ldots \ldots$ M4.A.16

M4.A.8 THE 27-GROUP BURNUP LIBRARY $\ldots \ldots \ldots \ldots \ldots \ldots \ldots \ldots \ldots \ldots$ M4.A.18

APPENDIX M4.B LOCAL EXPERIENCE WITH THE 27-GROUP

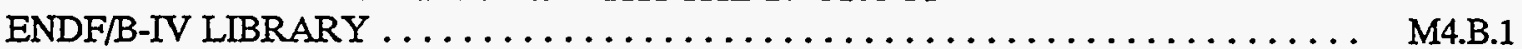

M4.B.1 BIAS DUE TO POOR CARBON CROSS SECTIONS $\ldots \ldots \ldots \ldots \ldots \ldots \ldots$ M4.B.1

M4.B.2 BIAS DUE TO ABSENCE OF BONDARENKO DATA

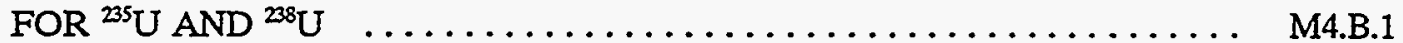

M4.B.3 BLAS IN ${ }^{239} \mathrm{Pu}$ THERMAL SYSTEMS $\ldots \ldots \ldots \ldots \ldots \ldots \ldots \ldots \ldots \ldots \ldots$ M4.B.1

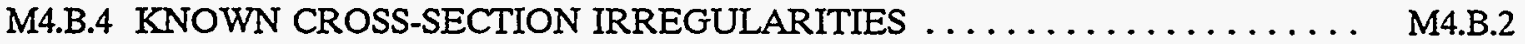

M4.B.5 THERMAL-SCATTERING DATA LIMITATION $\ldots \ldots \ldots \ldots \ldots \ldots \ldots$ M4.B.2

M4.B.6 GENERAL COMMENTS ON THE SCALE 27-GROUP LIBRARY . . . . . M4.B.2 


\section{LIST OF TABLES}

Table

Page

M4.1.1 SCALE cross-section libraries $\ldots \ldots \ldots \ldots \ldots \ldots \ldots \ldots \ldots \ldots \ldots \ldots \ldots \ldots \ldots \ldots \ldots \ldots \ldots .1$

M4.2.1 SCALE neutron energy group structure $\ldots \ldots \ldots \ldots \ldots \ldots \ldots \ldots \ldots \ldots \ldots \ldots \ldots \ldots .2 .2$

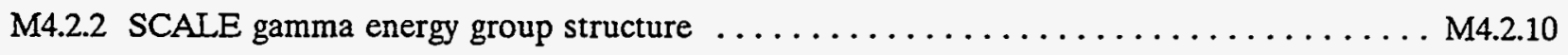

M4.2.3 Resonance nuclides found on the 27GROUPNDF4 and

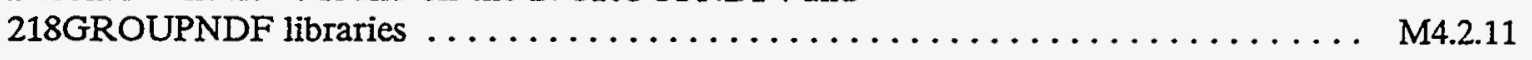

M4.2.4 Nuclides in ENDF/B-IV libraries with multiple sets of thermal-scattering data $\ldots \ldots \ldots \ldots \ldots \ldots \ldots \ldots \ldots \ldots \ldots \ldots \ldots \ldots \ldots \ldots \ldots \ldots .2 .12$

M4.2.5 Resonance nuclides found on the Hansen-Roach library $\ldots \ldots \ldots \ldots \ldots \ldots \ldots \ldots$ M4.2.14

M4.2.6 Nuclides in Hansen-Roach library with multiple sets of

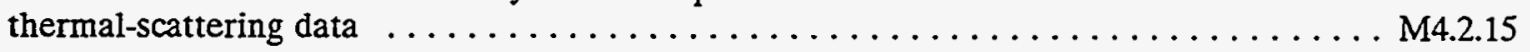

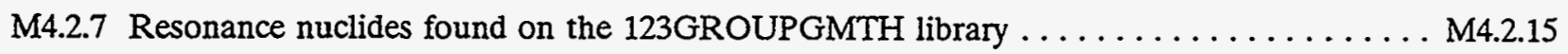

M4.2.8 Nuclides in the 123GROUPHGMTH library with multiple sets of thermal-scattering data $\ldots \ldots \ldots \ldots \ldots \ldots \ldots \ldots \ldots \ldots \ldots \ldots \ldots \ldots \ldots \ldots \ldots \ldots .2 .16$

M4.2.9 List of nuclides in the $27 \mathrm{n}-18 \mathrm{~g}$ library with no gamma-ray production cross sections $\ldots \ldots \ldots \ldots \ldots \ldots \ldots \ldots \ldots \ldots \ldots \ldots \ldots \ldots \ldots \ldots \ldots \ldots \ldots .2 .18$

NUREG/CR-0200,

Vol. 3, Rev. 4 


\section{ACKNOWLEDGMENTS}

I would like to acknowledge all those who participated in developing and implementing the SCALE cross-section libraries for their assistance in preparing this document. Special thanks go to J. A. Bucholz, N. M. Greene, J. R. Knight, L. M. Petrie, and R. M. Westfall. 


\section{M4.1 INTRODUCTION}

The SCALE control modules are designed to allow complex analyses using simple input descriptions. Each shielding or criticality control module (1) uses the Standard Composition Library (see Sect. M8) for specifying the materials and mixtures used in a calculation and (2) provides automatic problem-dependent cross-section preparation prior to problem execution via the functional modules. This section describes the cross-section libraries currently available in the SCALE system.

There are eight cross-section libraries automatically available in the SCALE system. Four of these libraries were designed primarily for criticality analysis, three were developed as shielding libraries, and one library was configured for use in depletion analyses. The library is selected by specifying the appropriate alphanumeric name (which in turn points to the appropriate unit number for the cross-section data). Alternative libraries can be used easily with a minimum of additional job control specifications. Table M4.1.1 lists the standard SCALE cross-section libraries, along with the alphanumeric name and associated unit number. Also listed is the main source of data for each library.

The SCALE control modules are designed to read AMPX master format libraries. ${ }^{1}$ These libraries are very general and many include temperature-dependent cross-section data as well as resonance data. The master format libraries are used as a basis for creating an AMPX working format library that has problem-dependent (user-specified) temperature dependence and appropriate resonance processing. The SCALE control module sequences access BONAMI first to process nuclides with Bondarenko data. The master library output from BONAMI is input to NITAWL-II, where resonance data are processed via the Nordheim treatment and an AMPX working format library is produced. The SCALE criticality and shielding functional modules are all designed to use an AMPX working library format.

One significant difference between Version 4 of the SCALE system and all previous versions of SCALE is in the structure of the AMPX master format libraries. Earlier versions of SCALE used a cross-section library structure that was generated by AMPX prior to XLACS-77 and that is compatible with the NITAWL code. The current version of SCALE uses cross sections having a data structure compatible with XLACS-77 (and later versions of XLACS) and processed by NITAWL-II. The cross sections are the same in both cases; however, the data are represented in the manner that allows correct interface with the two different implementations of the Nordheim Integral Treatment found in NITAWL and NITAWL-II. This modification should be invisible to the SCALE user in most situations. However, it should be cautioned that cross sections compatible with NITAWL cannot be properly processed by NITAWL-II, and vice versa.

Table M4.1.1. SCALE cross-section libraries

\begin{tabular}{lll}
\hline Alphanumeric name & $\begin{array}{l}\text { IBM } \\
\text { unit }\end{array}$ & Primary source \\
\hline HANSEN-ROACH & 81 & Hansen-Roach 16 group library \\
27GROUPNDF4 & 82 & ENDF/B-IV 218-group library \\
123GROUPGMTH & 83 & GAM-THERMOS 123-group library \\
218GROUPNDF4 & 84 & ENDF/B-IV \\
22N-18COUPLE & 85 & Straker-Morrison \\
18GROUPGAMMA & 86 & OGRE point-data library \\
27BURNUPLIB & 87 & ENDF/B-IV,ENDF/B-V \\
27N-18COUPLE & 88 & ENDF/B-IV 27-group library/ \\
& & 18GROUPGAMMA library \\
Anything else & 70 & User-supplied library \\
\hline
\end{tabular}




\section{M4.2 DESCRIPTION OF THE SCALE CROSS-SECTION LIBRARIES}

The neutron energy group structure of each of the SCALE neutron libraries is given in Table M4.2.1. Five different neutron energy group structures are available in the SCALE system: the Hansen-Roach 16-group structure, the Straker-Morrison 22-group structure, the 27-group subset of the 218-group library, the 123-group structure of the GAM-THERMOS library, and the 218-group structure of the ENDF/B-IV reference library. The latter is commonly referred to as the 218-group Criticality Safety Reference Library, or 218-group CSRL. The 22n-18g Straker-Morrison library is primarily a shielding library. The other libraries are considered to be general-purpose criticality analysis libraries. The energy group structure of the gamma cross-section libraries is given in Table M4.2.2. Each of the SCALE cross-section libraries is discussed in the following sections.

\section{M4.21 THE 218-GROUP ENDF/B-IV LIBRARY (218GROUPNDF4)}

The 218-group ENDF/B-IV library is one of the most complete libraries available in SCALE. The source of the data was ENDF/B-IV, and the processing of the cross sections by XLACS in the AMPX system is well documented..$^{23}$ The weighting function used in the $P_{3}$ cross-section generation was a fission-1/E $\sigma_{\mathrm{t}}$-Maxwellian weighting (except for resonance nuclides, which were weighted $1 / E$ instead of $1 / E \sigma_{\mathrm{t}}$ ). One of the features of the library is that explicit resonance data carried with it can be used to generate problem-dependent, resonance-region group cross sections using NITAWL-II. This capability allows great flexibility in the use of the library as a general-purpose criticality analysis library. The library has 140 fast groups and 78 thermal groups (below $3 \mathrm{eV}$ ). The group structure was designed to fit the cross-section variation and reaction thresholds of the light and intermediate nuclides and to fit the major resonances of the intermediate and heavy nuclides. No unresolved resonance data are carried in the library. The unresolved resonance region was processed at a $\sigma_{\mathrm{p}}=50,000$. This fixed $\sigma_{\mathrm{p}}$ is too high for most water-moderated uranium systems and is largely the reason why validation against low-enriched, water-moderated criticals indicate 1 to $2 \%$ underprediction that gradually disappears as the systems become more thermal (where the unresolved contribution is negligible).

The 218-group library has not been routinely validated because of its size and the related costs. However, the 27-group ENDF/B-IV library was derived directly from the 218-group library and has been validated against a large number of critical experiments (see Sect. M4.2.2). The 218-fine-group structure of the library generally will give either the same or more precise results than its companion 27-broad-group library.

An obvious advantage of a fine-group library over a broad-group library is that the library is less sensitive to the weighting spectrum used to generate the library. The cross sections more closely represent the base data, and the group structure allows a more detailed determination of the energy dependence of the flux. In past validations, it has been found useful to compare a fine-group calculation against a broad-group calculation when bias is observed. Tables M4.2.3 and M4.2.4 show 218-group nuclides that have resonance data and/or thermal data.

\section{M4.22 THE 27-GROUP ENDF/B-IV LIBRARY (27GROUPNDF4)}

The 27-group ENDF/B-IV library is the broad-group companion library to the 218-group ENDF/B-IV library. The 218-group library was flux collapsed using MALOCS and the MT 1099 flux file carried with each of the nuclide's fine-group cross sections. (This flux file is the group representation of the original weighting spectrum used to generate the 218-group cross sections from ENDF/B data.) The library has 14 fast groups and 13 thermal groups (below $3 \mathrm{eV}$ ). The group structure was chosen to match the 16-group Hansen-Roach structure with two additional fast groups and seven additional thermal groups. The additional groups were chosen such that, for the systems considered, the broad-group calculations meet an acceptance criterion of $\Delta \mathrm{k}_{\text {erf }} / \mathrm{k}_{\text {eff }}<0.3 \%$ when compared with the reference 218-group calculation using the XSDRN code. ${ }^{4}$ This 
Table M4.2.1 SCALE neutron energy group structure

\begin{tabular}{|c|c|c|c|c|c|c|}
\hline $\begin{array}{l}\text { CSRL } \\
\text { 218-group }\end{array}$ & $\begin{array}{l}\text { CSRL } \\
\text { 27-group }\end{array}$ & $\begin{array}{l}\text { Hansen-Roach } \\
\text { 16-group }\end{array}$ & $\begin{array}{l}\text { GAM-THERMOS } \\
\text { 123-group }\end{array}$ & $\begin{array}{l}\text { Straker- } \\
\text { Morrison } \\
\text { 22-group }\end{array}$ & $\begin{array}{l}\text { Upper } \\
\text { energy } \\
(\mathrm{eV})\end{array}$ & $\begin{array}{l}\text { Upper } \\
\text { lethargy }\end{array}$ \\
\hline \multirow[t]{10}{*}{1} & 1 & & & & $2.0000+7^{a}$ & $(-0.693)$ \\
\hline & & & 1 & 1 & $1.4918+7$ & $(-0.40)$ \\
\hline & & & 2 & & $1.3499+7$ & $(-0.30)$ \\
\hline & & & 3 & 2 & $1.2214+7$ & $(-0.20)$ \\
\hline & & & 4 & & $1.1052+7$ & $(-0.10)$ \\
\hline & & 1 & 5 & 3 & $1.0000+7$ & 0.0 \\
\hline & & & 6 & & $9.0484+6$ & 0.10 \\
\hline & & & 7 & 4 & $8.1873+6$ & 0.200 \\
\hline & & & 8 & & $7.4082+6$ & 0.30 \\
\hline & & & 9 & & $6.7032+6$ & 0.40 \\
\hline \multirow[t]{5}{*}{2} & 2 & & & & $6.4340+6$ & 0.441 \\
\hline & & & & 5 & $6.3600+6$ & 0.453 \\
\hline & & & 10 & & $6.0653+6$ & 0.50 \\
\hline & & & 11 & & $5.4881+6$ & 0.60 \\
\hline & & & 12 & 6 & $4.9659+6$ & 0.70 \\
\hline \multirow[t]{2}{*}{3} & & & & & $4.8000+6$ & 0.734 \\
\hline & & & 13 & & $4.4933+6$ & 0.80 \\
\hline \multirow[t]{5}{*}{4} & & & & & $4.3040+6$ & 0.843 \\
\hline & & & 14 & 7 & $4.0657+6$ & 0.90 \\
\hline & & & 15 & & $3.6788+6$ & 1.00 \\
\hline & & & 16 & & $3.3287+6$ & 1.10 \\
\hline & & & 17 & 8 & $3.0119+6$ & 1.20 \\
\hline \multirow[t]{2}{*}{5} & 3 & 2 & & & $3.0000+6$ & 1.204 \\
\hline & & & 18 & & $2.7253+6$ & 1.30 \\
\hline \multirow[t]{2}{*}{6} & & & & & $2.4790+6$ & 1.395 \\
\hline & & & 19 & 9 & $2.4660+6$ & 1.40 \\
\hline \multirow[t]{4}{*}{7} & & & & & $2.3540+6$ & 1.446 \\
\hline & & & & 10 & $2.3500+6$ & 1.448 \\
\hline & & & 20 & & $2.2313+6$ & 1.50 \\
\hline & & & 21 & & $2.0190+6$ & 1.60 \\
\hline \multirow[t]{3}{*}{8} & 4 & & & & $1.8500+6$ & 1.687 \\
\hline & & & 22 & 11 & $1.8268+6$ & 1.70 \\
\hline & & & 23 & & $1.6530+6$ & 1.80 \\
\hline \multirow[t]{2}{*}{9} & & & & & $1.5000+6$ & 1.897 \\
\hline & & & 24 & & $1.4957+6$ & 1.90 \\
\hline 10 & 5 & 3 & & & $1.4000+6$ & 1.966 \\
\hline \multirow[t]{2}{*}{11} & & & & & $1.3560+6$ & 1.998 \\
\hline & & & 25 & & $1.3534+6$ & 2.00 \\
\hline 12 & & & & & $1.3170+6$ & 2.027 \\
\hline \multirow[t]{2}{*}{13} & & & & & $1.2500+6$ & 2.079 \\
\hline & & & 26 & & $1.2246+6$ & 2.10 \\
\hline \multirow[t]{2}{*}{14} & & & & & $1.2000+6$ & 2.120 \\
\hline & & & 27 & 12 & $1.1080+6$ & 2.20 \\
\hline 15 & & & & & $1.1000+6$ & 2.207 \\
\hline
\end{tabular}

NUREG/CR-0200,

Vol. 3, Rev. 4

M4.2.2 
Table M4.2.1 (continued)

\begin{tabular}{|c|c|c|c|c|c|c|}
\hline $\begin{array}{l}\text { CSRL } \\
\text { 218-group }\end{array}$ & $\begin{array}{l}\text { CSRL } \\
\text { 27-group }\end{array}$ & $\begin{array}{l}\text { Hansen-Roach } \\
\text { 16-group }\end{array}$ & $\begin{array}{l}\text { GAM-THERMOS } \\
\text { 123-group }\end{array}$ & $\begin{array}{l}\text { Straker- } \\
\text { Morrison } \\
\text { 22-group }\end{array}$ & $\begin{array}{c}\text { Upper } \\
\text { energy } \\
\text {. }(\mathrm{eV})\end{array}$ & $\begin{array}{l}\text { Upper } \\
\text { lethargy }\end{array}$ \\
\hline 16 & & & & & $1.0100+6$ & 2.293 \\
\hline & & & 28 & & $1.0026+6$ & 2.30 \\
\hline 17 & & & & & $9.2000+5$ & 2.386 \\
\hline & & & 29 & & $9.0718+5$ & 2.386 \\
\hline 18 & 6 & 4 & & & $9.0000+5$ & 2.408 \\
\hline 19 & & $\cdot$ & & & $8.7500+5$ & 2.436 \\
\hline 20 & & & & & $8.6110+5$ & 2.452 \\
\hline & & & 30 & & $8.2085+5$ & 2.50 \\
\hline 21 & & & & & $8.2000+5$ & 2.501 \\
\hline 22 & & & & & $7.5000+5$ & 2.590 \\
\hline & & & 31 & & $7.4274+5$ & 2.60 \\
\hline 23 & & & & & $6.7900+5$ & 2.69 \\
\hline & & & 32 & & $6.7206+5$ & 2.70 \\
\hline 24 & & & & & $6.7000+5$ & 2.703 \\
\hline & & & 33 & & $6.0810+5$ & 2.80 \\
\hline 25 & & & & & $6.0000+5$ & 2.813 \\
\hline 26 & & & & & $5.7300+5$ & 2.859 \\
\hline & & & 34 & 13 & $5.5023+5$ & 2.90 \\
\hline 27 & & & & & $5.5000+5$ & 2.900 \\
\hline 28 & & & & & $4.9952+5$ & 2.997 \\
\hline & & & 35 & 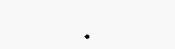 & $4.9787+5$ & 3.00 \\
\hline 29 & & & & & $4.7000+5$ & 3.058 \\
\hline & & & 36 & & $4.5049+5$ & 3.10 \\
\hline 30 & & & & & $4.4000+5$ & 3.124 \\
\hline 31 & & & & & $4.2000+5$ & 3.170 \\
\hline & & & 37 & & $4.0762+5$ & 3.20 \\
\hline 32 & 7 & 5 & & & $4.0000+5$ & 3.219 \\
\hline & & & 38 & & $3.6883+5$ & 3.30 \\
\hline & & & 39 & & $3.3373+5$ & 3.40 \\
\hline 33 & & & & & $3.3000+5$ & 3.411 \\
\hline & & & 40 & & $3.0197+5$ & 3.50 \\
\hline & & & 41 & & $2.7324+5$ & 3.60 \\
\hline 34 & & & & & $2.7000+5$ & 3.612 \\
\hline & & & 42 & & $2.4724+5$ & 3.70 \\
\hline & & & 43 & & $2.2371+5$ & 3.80 \\
\hline & & & 44 & & $2.0242+5$ & 3.90 \\
\hline 35 & & & $\ddots$ & & $2.0000+5$ & 3.912 \\
\hline & & & 45 & & $1.8316+5$ & 4.00 \\
\hline & & & 46 & & $1.6573+5$ & 4.10 \\
\hline 36 & & & & & $1.5000+5$ & 4.200 \\
\hline & & & 47 & & $1.4996+5$ & 4.20 \\
\hline & & & 48 & & $1.3569+5$ & 4.30 \\
\hline 37 & & & & & $1.2830+5$ & 4.356 \\
\hline & & & 49 & . & $1.2277+5$ & 4.40 \\
\hline
\end{tabular}


Table M4.2.1 (continued)

\begin{tabular}{|c|c|c|c|c|c|c|}
\hline $\begin{array}{l}\text { CSRL } \\
\text { 218-group }\end{array}$ & $\begin{array}{l}\text { CSRL } \\
\text { 27-group }\end{array}$ & $\begin{array}{l}\text { Hansen-Roach } \\
\text { 16-group }\end{array}$ & $\begin{array}{l}\text { GAM-THERMOS } \\
\text { 123-group }\end{array}$ & $\begin{array}{l}\text { Straker- } \\
\text { Morrison } \\
\text { 22-group }\end{array}$ & $\begin{array}{c}\text { Upper } \\
\text { energy } \\
(\mathrm{eV})\end{array}$ & $\begin{array}{l}\text { Upper } \\
\text { lethargy }\end{array}$ \\
\hline & & & 50 & 14 & $1.1109+5$ & 4.50 \\
\hline \multirow[t]{2}{*}{38} & 8 & 6 & & & $1.0000+5$ & 4.605 \\
\hline & & & 51 & & $8.6517+4$ & 4.75 \\
\hline 39 & & & & & $8.5000+4$ & 4.768 \\
\hline 40 & & & & & $8.2000+4$ & 4.804 \\
\hline 41 & & & & & $7.5000+4$ & 4.893 \\
\hline \multirow{2}{*}{42} & & & & & $7.3000+4$ & 4.920 \\
\hline & & & 52 & & $6.7379+4$ & 5.00 \\
\hline \multirow[t]{2}{*}{43} & & & & & $6.0000+4$ & 5.116 \\
\hline & & & 53 & & $5.2475+4$ & 5.25 \\
\hline 44 & & & & & $5.2000+4$ & 5.259 \\
\hline 45 & & & & & $5.0000+4$ & 5.298 \\
\hline \multirow[t]{3}{*}{46} & & & & & $4.5000+4$ & 5.404 \\
\hline & & & 54 & & $4.0868+4$ & 5.50 \\
\hline & & & 55 & & $3.1828+4$ & 5.75 \\
\hline 47 & & & & & $3.0000+4$ & 5.809 \\
\hline \multirow[t]{3}{*}{48} & & & & & $2.5000+4$ & 5.991 \\
\hline & & & 56 & & $2.4788+4$ & 6.00 \\
\hline & & & 57 & & $1.9305+4$ & 6.25 \\
\hline \multirow[t]{2}{*}{49} & 9 & 7 & & & $1.7000+4$ & 6.377 \\
\hline & & & 58 & & $1.5034+4$ & 6.50 \\
\hline \multirow[t]{2}{*}{50} & & & & & $1.3000+4$ & 6.645 \\
\hline & & & 59 & & $1.1709+4$ & 6.75 \\
\hline \multirow[t]{2}{*}{51} & & & & & $9.5000+3$ & 6.959 \\
\hline & & & 60 & & $9.1188+3$ & 7.00 \\
\hline \multirow[t]{2}{*}{52} & & & & & $8.0300+3$ & 7.127 \\
\hline & & & 61 & & $7.1017+3$ & 7.25 \\
\hline \multirow[t]{3}{*}{53} & & & & & $6.0000+3$ & 7.419 \\
\hline & & & 62 & & $5.5308+3$ & 7.50 \\
\hline & & & 63 & & $4.3074+3$ & 7.75 \\
\hline 54 & & & & & $3.9000+3$ & 7.849 \\
\hline \multirow[t]{2}{*}{55} & & & & & $3.7400+3$ & 7.891 \\
\hline & & & 64 & 15 & $3.3546+3$ & 8.00 \\
\hline \multirow[t]{2}{*}{56} & 10 & 8 & & & $3.0000+3$ & 8.112 \\
\hline & & & 65 & & $2.6126+3$ & 8.25 \\
\hline 57 & & & & & $2.5800+3$ & 8.263 \\
\hline 58 & & & & & $2.2900+3$ & 8.382 \\
\hline \multirow[t]{2}{*}{59} & & & & & $2.2000+3$ & 8.422 \\
\hline & & & 66 & & $2.0347+3$ & 8.50 \\
\hline \multirow[t]{2}{*}{60} & & & & & $1.8000+3$ & 8.623 \\
\hline & & & 67 & & $1.5846+3$ & 8.75 \\
\hline 61 & & & & & $1.5500+3$ & 8.772 \\
\hline \multirow[t]{2}{*}{62} & & & & & $1.5000+3$ & 8.805 \\
\hline & & & 68 & & $1.2341+3$ & 9.00 \\
\hline
\end{tabular}

NUREG/CR-0200,

Vol. 3, Rev. 4

M4.2.4 
Table M4.2.1 (continued)

\begin{tabular}{|c|c|c|c|c|c|c|}
\hline $\begin{array}{l}\text { CSRL } \\
\text { 218-group }\end{array}$ & $\begin{array}{l}\text { CSRL } \\
27 \text {-group }\end{array}$ & $\begin{array}{l}\text { Hansen-Roach } \\
\text { 16-group }\end{array}$ & $\begin{array}{l}\text { GAM-THERMOS } \\
\text { 123-group }\end{array}$ & $\begin{array}{l}\text { Straker- } \\
\text { Morrison } \\
\text { 22-group }\end{array}$ & $\begin{array}{c}\text { Upper } \\
\text { energy } \\
\text { (ev) }\end{array}$ & $\begin{array}{l}\text { Upper } \\
\text { letharg }\end{array}$ \\
\hline 63 & & & & & $1.1500+3$ & 9.071 \\
\hline & & & 69 & & $9.6112+2$ & 9.25 \\
\hline 64 & & & & & $9.5000+2$ & 9.262 \\
\hline & & & 70 & & $7.4852+2$ & 9.50 \\
\hline 65 & & & & & $6.8300+2$ & 9.592 \\
\hline 66 & & & & & $6.7000+2$ & 9.611 \\
\hline & & & 71 & 16 & $5.8295+2$ & 9.75 \\
\hline 67 & 11 & 9 & & & $5.5000+2$ & 9.808 \\
\hline & & & 72 & & $4.5000+2$ & 10.00 \\
\hline & & & 73 & & $3.5357+2$ & 10.25 \\
\hline 68 & & & & & $3.0500+2$ & 10.25 \\
\hline 69 & & & & & $2.8500+2$ & 10.466 \\
\hline & & & 74 & & $2.7536+2$ & 10.50 \\
\hline 70 & & & & & $2.4000+2$ & 10.637 \\
\hline & & & 75 & & $2.1445+2$ & 10.75 \\
\hline 71 & & & & & $2.1000+2$ & 10.771 \\
\hline 72 & & & & & $2.0750+2$ & 10.783 \\
\hline 73 & & & & & $1.9250+2$ & 10.858 \\
\hline 74 & & & & & $1.8600+2$ & 10.892 \\
\hline & & & 76 & & $1.6702+2$ & 11.00 \\
\hline & & & 77 & & $1.3007+2$ & 11.25 \\
\hline 75 & & & & & $1.2200+2$ & 11.314 \\
\hline 76 & & & & & $1.1900+2$ & 11.339 \\
\hline 77 & & & & & $1.1500+2$ & 11.373 \\
\hline 78 & & & & & $1.0800+2$ & 11.436 \\
\hline & & & 78 & 17 & $1.0130+2$ & 11.50 \\
\hline 79 & 12 & 10 & & & $1.0000+2$ & 11.513 \\
\hline 80 & & & & & $9.0000+1$ & 11.618 \\
\hline 81 & & & & & $8.2000+1$ & 11.711 \\
\hline 82 & & & & & $8.0000+1$ & 11.736 \\
\hline & & & 79 & & $7.8893+1$ & 11.75 \\
\hline 83 & & & & & $7.6000+1$ & 11.787 \\
\hline 84 & & & & & $7.2000+1$ & 11.841 \\
\hline 85 & & & & & $6.7500+1$ & 11.906 \\
\hline 86 & & & & & $6.5000+1$ & 11.944 \\
\hline & & & 80 & & $6.1442+1$ & 12.00 \\
\hline 87 & & & & & $6.1000+1$ & 12.007 \\
\hline 88 & & & & & $5.9000+1$ & 12.041 \\
\hline 89 & & & & & $5.3400+1$ & 12.140 \\
\hline 90 & & & & & $5.2000+1$ & 12.167 \\
\hline 91 & & & & & $5.0600+1$ & 12.194 \\
\hline 92 & & & & & $4.9200+1$ & 12.222 \\
\hline 93 & & & & & $4.8300+1$ & 12.241 \\
\hline$\cdot$ & & & 81 & & $4.7851+1$ & 12.25 \\
\hline
\end{tabular}


Table M4.2.1 (continued)

\begin{tabular}{|c|c|c|c|c|c|c|}
\hline $\begin{array}{l}\text { CSRL } \\
\text { 218-group }\end{array}$ & $\begin{array}{l}\text { CSRL } \\
\text { 27-group }\end{array}$ & $\begin{array}{l}\text { Hansen-Roach } \\
\text { 16-group }\end{array}$ & $\begin{array}{l}\text { GAM-THERMOS } \\
\text { 123-group }\end{array}$ & $\begin{array}{l}\text { Straker- } \\
\text { Morrison } \\
\text { 22-group }\end{array}$ & $\begin{array}{c}\text { Upper } \\
\text { energy } \\
(\mathrm{eV})\end{array}$ & $\begin{array}{l}\text { Upper } \\
\text { lethargy }\end{array}$ \\
\hline 94 & & & & & $4.7000+1$ & 12.268 \\
\hline 95 & & & & & $4.5200+1$ & 12.307 \\
\hline 96 & & & & & $4.4000+1$ & 12.334 \\
\hline 97 & & & & & $4.2400+1$ & 12.371 \\
\hline 98 & & & & & $4.1000+1$ & 12.405 \\
\hline 99 & & & & & $3.9600+1$ & 12.439 \\
\hline 100 & & & & & $3.9100+1$ & 12.452 \\
\hline \multirow[t]{2}{*}{101} & & & & & $3.8000+1$ & 12.481 \\
\hline & & & 82 & & $3.7267+1$ & 12.50 \\
\hline 102 & & & & & $3.7000+1$ & 12.507 \\
\hline 103 & & & & & $3.5500+1$ & 12.549 \\
\hline 104 & & & & & $3.4600+1$ & 12.574 \\
\hline 105 & & & & & $3.3750+1$ & 12.599 \\
\hline 106 & & & & & $3.3250+1$ & 12.614 \\
\hline 107 & & & & & $3.1750+1$ & 12.660 \\
\hline 108 & & & & & $3.1250+1$ & 12.676 \\
\hline \multirow[t]{2}{*}{109} & 13 & 11 & & & $3.0000+1$ & 12.717 \\
\hline & & & 83 & 18 & $2.9023+1$ & 12.75 \\
\hline 110 & & & & & $2.7500+1$ & 12.804 \\
\hline \multirow{2}{*}{111} & & & & & $2.5000+1$ & 12.899 \\
\hline & & & 84 & & $2.2603+1$ & 13.00 \\
\hline 112 & & & & & $2.2500+1$ & 13.005 \\
\hline 113 & & & & & $2.1000+1$ & 13.074 \\
\hline 114 & & & & & $2.0000+1$ & 13.122 \\
\hline 115 & & & & & $1.9000+1$ & 13.174 \\
\hline \multirow[t]{2}{*}{116} & & & & & $1.8500+1$ & 13.200 \\
\hline & & & 85 & & $1.7603+1$ & 13.25 \\
\hline 117 & & & & & $1.7000+1$ & 13.285 \\
\hline 118 & & & & & $1.6000+1$ & 13.346 \\
\hline 119 & & & & & $1.5100+1$ & 13.403 \\
\hline 120 & & & & & $1.4400+1$ & 13.451 \\
\hline \multirow[t]{2}{*}{121} & & & & & $1.3750+1$ & 13.497 \\
\hline & & & 86 & & $1.3710+1$ & 13.50 \\
\hline 122 & & & & & $1.2900+1$ & 13.561 \\
\hline 123 & & & & & $1.1900+1$ & 13.642 \\
\hline \multirow[t]{2}{*}{124} & & & & & $1.1500+1$ & 13.676 \\
\hline & & & 87 & 19 & $1.0677+1$ & 13.75 \\
\hline 125 & 14 & 12 & & & $1.0000+1$ & 13.816 \\
\hline \multirow{2}{*}{126} & & & & & $9.1000+0$ & 13.910 \\
\hline & & & 88 & & $8.3153+0$ & 14.000 \\
\hline 127 & & & & & $8.1000+0$ & 14.026 \\
\hline 128 & & & & & $7.1500+0$ & 14.151 \\
\hline 129 & & & & & $7.0000+0$ & 14.172 \\
\hline 130 & & & & & $6.7500+0$ & 14.209 \\
\hline
\end{tabular}

NUREG/CR-0200,

Vol. 3, Rev. 4

M4.2.6 
Table M4.2.1 (continued)

\begin{tabular}{|c|c|c|c|c|c|c|}
\hline $\begin{array}{l}\text { CSRL } \\
\text { 218-group }\end{array}$ & $\begin{array}{l}\text { CSRL } \\
\text { 27-group }\end{array}$ & $\begin{array}{l}\text { Hansen-Roach } \\
\text { 16-group }\end{array}$ & $\begin{array}{l}\text { GAM-THERMOS } \\
\text { 123-group }\end{array}$ & $\begin{array}{l}\text { Straker- } \\
\text { Morrison } \\
\text { 22-group }\end{array}$ & $\begin{array}{l}\text { Upper } \\
\text { energy } \\
(\mathrm{eV})\end{array}$ & $\begin{array}{l}\text { Upper } \\
\text { lethargy }\end{array}$ \\
\hline 131 & & & & & $6.5000+0$ & 14.246 \\
\hline & & & 89 & & $6.4760+0$ & 14.250 \\
\hline 132 & & & & & $6.2500+0$ & 14.286 \\
\hline 133 & & & & & $6.0000+0$ & 14.326 \\
\hline 134 & & & & & $5.4000+0$ & 14.432 \\
\hline & & & 90 & & $5.0435+0$ & 14.500 \\
\hline 135 & & & & & $5.0000+0$ & 14.509 \\
\hline 136 & & & & & $4.7500+0$ & 14.560 \\
\hline 137 & & & & & $4.0000+0$ & 14.732 \\
\hline & & & 91 & & $3.9279+0$ & 14.750 \\
\hline 138 & & & & & $3.7300+0$ & 14.802 \\
\hline 139 & & & & & $3.5000+0$ & 14.865 \\
\hline 140 & & & & & $3.1500+0$ & 14.971 \\
\hline & & & 92 & & $3.0590+0$ & 15.00 \\
\hline & & & & 20 & $3.0590+0$ & 15.00 \\
\hline 141 & 15 & & & & $3.0500+0^{b}$ & 15.03 \\
\hline 142 & & 13 & & & $3.0000+0$ & 15.019 \\
\hline 143 & & & & & $2.9700+0$ & 15.030 \\
\hline 144 & & & & & $2.8700+0$ & 15.064 \\
\hline 145 & & & & & $2.7700+0$ & 15.099 \\
\hline 146 & & & & & $2.6700+0$ & 15.136 \\
\hline 147 & & & & & $2.5700+0$ & 15.174 \\
\hline 148 & & & & & $2.4700+0$ & 15.214 \\
\hline & & & 93 & & $2.3824+0$ & 15.250 \\
\hline 149 & & & & & $2.3800+0$ & 15.251 \\
\hline 150 & & & & & $2.3000+0$ & 15.285 \\
\hline 151 & & & & & $2.2100+0$ & 15.325 \\
\hline 152 & & & & & $2.1200+0$ & 15.367 \\
\hline 153 & & & & & $2.0000+0$ & 15.425 \\
\hline 154 & & & & & $1.9400+0$ & 15.455 \\
\hline 155 & & & 94 & & $1.8600+0^{\circ}$ & 15.498 \\
\hline 156 & 16 & & & & $1.7700+0$ & 15.547 \\
\hline & & & 95 & & $1.7100+0$ & 15.582 \\
\hline 157 & & & & & $1.6800+0$ & 15.599 \\
\hline 158 & & & & & $1.5900+0$ & 15.654 \\
\hline & & & 96 & & $1.5600+0$ & 15.673 \\
\hline 159 & & & & & $1.5000+0$ & 15.713 \\
\hline 160 & & & & & $1.4500+0$ & 15.747 \\
\hline & & & 97 & & $1.4400+0$ & 15.753 \\
\hline 161 & & & & & $1.4000+0$ & 15.782 \\
\hline 162 & & & & & $1.3500+0$ & 15.818 \\
\hline 163 & 17 & & & & $1.3000+0$ & 15.856 \\
\hline & & $\bullet$ & 98 & & $1.2900+0$ & 15.863 \\
\hline
\end{tabular}


Table M4.2.1 (continued)

\begin{tabular}{|c|c|c|c|c|c|c|}
\hline $\begin{array}{l}\text { CSRL } \\
\text { 218-group }\end{array}$ & $\begin{array}{l}\text { CSRL } \\
\text { 27-group }\end{array}$ & $\begin{array}{l}\text { Hansen-Roach } \\
\text { 16-group }\end{array}$ & $\begin{array}{l}\text { GAM-THERMOS } \\
\text { 123-group }\end{array}$ & $\begin{array}{l}\text { Straker- } \\
\text { Morrison } \\
\text { 22-group }\end{array}$ & $\begin{array}{l}\text { Upper } \\
\text { energy } \\
(\mathrm{eV})\end{array}$ & $\begin{array}{l}\text { Upper } \\
\text { lethargy }\end{array}$ \\
\hline 164 & & & & & $1.2500+0$ & 15.895 \\
\hline 165 & & & & & $1.2250+0$ & 15.915 \\
\hline 166 & & & & & $1.2000+0$ & 15.936 \\
\hline 167 & & & & & $1.1750+0$ & 15.957 \\
\hline 168 & & & & & $1.1500+0$ & 15.978 \\
\hline 169 & & & & & $1.1400+0$ & 15.987 \\
\hline \multirow[t]{2}{*}{170} & 18 & & & & $1.1300+0$ & 15.996 \\
\hline & & & 99 & & $1.1250+0$ & 16.00 \\
\hline 171 & & & & & $1.1200+0$ & 16.005 \\
\hline 172 & & & & & $1.1100+0$ & 16.014 \\
\hline 173 & & & & & $1.1000+0$ & 16.023 \\
\hline 174 & & & & & $1.0900+0$ & 16.032 \\
\hline 175 & & & & & $1.0800+0$ & 16.041 \\
\hline 176 & & & & & $1.0700+0$ & 16.050 \\
\hline 177 & & & & & $1.0600+0$ & 16.060 \\
\hline 178 & & & & & $1.0500+0$ & 16.069 \\
\hline 179 & & & & & $1.0400+0$ & 16.079 \\
\hline 180 & & & & & $1.0300+0$ & 16.089 \\
\hline 181 & & & & & $1.0200+0$ & 16.098 \\
\hline \multirow[t]{2}{*}{182} & & & & & $1.0100+0$ & 16.108 \\
\hline & & & 100 & & $1.0000+0$ & 16.118 \\
\hline 183 & 19 & 14 & & & $1.0000+0$ & 16.118 \\
\hline 184 & & & & & $9.7500-1$ & 16.143 \\
\hline 185 & & & & & $9.5000-1$ & 16.169 \\
\hline 186 & & & & & $9.2500-1$ & 16.196 \\
\hline \multirow[t]{2}{*}{187} & & & & & $9.0000-1$ & 16.223 \\
\hline & & & 101 & & $8.7600-1$ & 16.250 \\
\hline 188 & & & & & $8.5000-1$ & 16.281 \\
\hline \multirow{2}{*}{189} & 20 & & & & $8.0000-1$ & 16.341 \\
\hline & & & 102 & & $7.7600-1$ & 16.372 \\
\hline 190 & & & & & $7.5000-1$ & 16.406 \\
\hline 191 & & & & & $7.0000-1$ & 16.475 \\
\hline 192 & & & 103 & & $6.5000-1$ & 16.549 \\
\hline 193 & & & & & $6.0000-1$ & 16.629 \\
\hline \multirow[t]{2}{*}{194} & & & 104 & & $5.5000-1$ & 16.716 \\
\hline & & & & 21 & $5.3159-1$ & 16.750 \\
\hline 195 & & & & & $5.0000-1$ & 16.811 \\
\hline \multirow[t]{2}{*}{196} & & & 105 & & $4.5000-1$ & 16.917 \\
\hline & & & & $22^{d}$ & 4.1400-1 & 17.000 \\
\hline 197 & 21 & 15 & & & $4.0000-1$ & 17.034 \\
\hline 198 & & & & & $3.7500-1$ & 17.099 \\
\hline 199 & & & 106 & & $3.5000-1$ & 17.168 \\
\hline 200 & 22 & & & & $3.2500-1$ & 17.242 \\
\hline 201 & & & 107 & $\bullet$ & $3.0000-1$ & 17.322 \\
\hline
\end{tabular}

NUREG/CR-0200,

Vol. 3, Rev. 4

M4.2.8 
Table M4.2.1 (continued)

\begin{tabular}{|c|c|c|c|c|c|c|}
\hline $\begin{array}{l}\text { CSRL } \\
\text { 218-group }\end{array}$ & $\begin{array}{l}\text { CSRL } \\
\text { 27-group }\end{array}$ & $\begin{array}{l}\text { Hansen-Roach } \\
\text { 16-group }\end{array}$ & $\begin{array}{l}\text { GAM-THERMOS } \\
\text { 123-group }\end{array}$ & $\begin{array}{l}\text { Straker- } \\
\text { Morrison } \\
\text { 22-group }\end{array}$ & $\begin{array}{c}\text { Upper } \\
\text { energy } \\
(\mathrm{eV})\end{array}$ & $\begin{array}{l}\text { Upper } \\
\text { lethargy }\end{array}$ \\
\hline 202 & & & & & $2.7500-1$ & 17.409 \\
\hline 203 & & & 108 & & $2.5000-1$ & 17.504 \\
\hline 204 & 23 & & & & $2.2500-1$ & 17.610 \\
\hline \multirow[t]{2}{*}{205} & & & 109 & & $2.0000-1$ & 17.728 \\
\hline & & & 110 & & $1.8000-1$ & 17.833 \\
\hline 206 & & & & & $1.7500-1$ & 17.861 \\
\hline \multirow[t]{3}{*}{207} & & & 111 & & $1.6000-1$ & 17.95 \\
\hline & & & & & $1.5000-1$ & 18.015 \\
\hline & & & 112 & & $1.4000-1$ & 18.084 \\
\hline \multirow[t]{2}{*}{208} & & & & & $1.2500-1$ & 18.198 \\
\hline & & & 113 & & $1.2000-1$ & 18.238 \\
\hline 209 & 24 & 16 & 114 & & $1.0000-1$ & 18.421 \\
\hline 210 & & & & & $9.0000-2$ & 18.526 \\
\hline 211 & & & 115 & & $8.0000-2$ & 18.644 \\
\hline 212 & & & 116 & & $7.0000-2$ & 18.777 \\
\hline 213 & & & 117 & & $6.0000-2$ & 18.932 \\
\hline 214 & 25 & & 118 & & $5.0000-2$ & 19.114 \\
\hline 215 & & - & 119 & & $4.0000-2$ & 19.337 \\
\hline 216 & 26 & & 120 & & $3.0000-2$ & 19.625 \\
\hline \multirow[t]{3}{*}{217} & & & & & $2.5300-2$ & 19.795 \\
\hline & & & 121 & & $2.0000-2$ & 20.030 \\
\hline & & & 122 & & $1.5000-2$ & 20.318 \\
\hline $218^{c}$ & $27^{e}$ & & 123 & & $1.0000-2$ & 20.723 \\
\hline
\end{tabular}

${ }^{\circ}$ Read as $2.0000 \times 10^{-7}$.

${ }^{b}$ Top energy for CSRL thermal energy range.

Top energy for THERMOS thermal energy range.

${ }^{d}$ Bottom energy for 123- and 22-group libraries group is $5.0000 \times 10^{-3} \mathrm{eV}$.

${ }^{\circ}$ Bottom energy CSRL 218- and 27-group libraries for group is $1.0000 \times 10^{-5} \mathrm{eV}$. 
Table M4.2.2. SCALE gamma energy group structure

\begin{tabular}{cc}
\hline $\begin{array}{c}\text { SCALE } \\
\text { gamma structure }\end{array}$ & $\begin{array}{c}\text { Upper } \\
\text { energy } \\
(\mathrm{eV})\end{array}$ \\
\hline 1 & $1.0000+7$ \\
2 & $8.0000+6$ \\
3 & $6.5000+6$ \\
4 & $5.0000+6$ \\
5 & $4.0000+6$ \\
6 & $3.0000+6$ \\
7 & $2.5000+6$ \\
8 & $2.0000+6$ \\
9 & $1.6600+6$ \\
10 & $1.3300+6$ \\
11 & $1.0000+6$ \\
12 & $8.0000+5$ \\
13 & $6.0000+5$ \\
14 & $4.0000+5$ \\
15 & $3.0000+5$ \\
17 & $2.0000+5$ \\
18 & $1.0000+5$ \\
& $5.0000+4$ \\
& $1.0000+4$ \\
\hline
\end{tabular}

${ }^{a}$ Lower energy boundary of gamma libraries.

NUREG/CR-0200,

Vol. 3, Rev. 4

M4.2.10 
Table M4.2.3. Resonance nuclides found on the 27GROUPNDF4 and 218GROUPNDF4 libraries

\begin{tabular}{lc}
\hline Standard composition & Nuclide ID \\
alphanumeric name & No. \\
\hline $\mathrm{Na}$ & 11023 \\
$\mathrm{Mn}$ & 25055 \\
$\mathrm{Fe}$ & 26000 \\
$\mathrm{Co}$ & 27059 \\
$\mathrm{Co}-59$ & 27059 \\
$\mathrm{Cu}$ & 29000 \\
$\mathrm{Br}-79$ & 35079 \\
$\mathrm{Br}-81$ & 35081 \\
$\mathrm{ZIRCALLOY}$ & 40302 \\
$\mathrm{Nb}-93$ & 41093 \\
$\mathrm{Mo}$ & 42000 \\
$\mathrm{Ag}-107$ & 47107 \\
Ag-109 & 47109 \\
In-113 & 49113 \\
In-115 & 49115 \\
$\mathrm{Cs}-133$ & 55133 \\
Gd & 64000 \\
$\mathrm{Dy}-164$ & 66164 \\
Lu-175 & 71175 \\
Lu-176 & 71176 \\
Ta-181 & 73181 \\
W-182 & 74182 \\
W-183 & 74183 \\
W-184 & 74184 \\
W-186 & 74186 \\
Re-185 & 75185 \\
Re-187 & 75187 \\
Au & 79197 \\
Th-232 & 90232 \\
Pa-233 & 91233 \\
U-233 & 92233 \\
U-234 & 92234 \\
U-236 & 92235 \\
U-238 & 92236 \\
Np-237 & 92238 \\
Pu-238 & 93237 \\
Pu-239 & 94238 \\
Pu-240 & 94239 \\
Pu-241 & 94240 \\
Pu-242 & 94241 \\
Am-241 & 94242 \\
Cm-244 & 95241 \\
\hline & 95423 \\
\hline & 96244 \\
\hline
\end{tabular}


Table M4.2.4 Nuclides in ENDF/B-IV libraries with multiple sets of thermal-scattering data

\begin{tabular}{llll}
\hline $\begin{array}{l}\text { Cross-section } \\
\text { library } \\
\text { specified by user }\end{array}$ & $\begin{array}{c}\text { Standard } \\
\text { composition } \\
\text { alphanumeric } \\
\text { name }\end{array}$ & $\begin{array}{c}\text { Nuclide } \\
\text { ID } \\
\text { No. }\end{array}$ & $\begin{array}{c}\text { Temperatures (K) for which } \\
\text { different sets of thermal } \\
\text { scattering cross-section } \\
\text { data are available }\end{array}$ \\
\hline 27GROUPNDF4 & H & 1001 & 293,550 \\
& D & 1002 & 293,550 \\
218GROUPNDF4 & Be & 4009 & $296,900,1000,1200$ \\
Or & B-10 & 5010 & 293,550 \\
27BURNUPIB & B-11 & 5011 & 293,550 \\
& C & 6012 & $293,900,1000,1200$ \\
\hline
\end{tabular}

criterion was relaxed to $1 \%$ for ${ }^{238} \mathrm{U}$ in systems where the median fission energy was greater than $1 \mathrm{eV}$ and less than $100 \mathrm{eV}$. The resonance data carried with the 27-group libraryand the 218-group library are the same and are processed by NITAWL-II. The library was conceived as a general-purpose criticality analysis library with a special interest in applicability toward shipping cask analysis and thermal neutron systems.

The 27-group library has been extensively validated against critical experiments. ${ }^{S-13}$ Areas of validation include highly enriched uranium-metal, compound and solution systems, moderated low-enriched uranium, heterogeneous and homogeneous systems, and plutonium metal and solution systems. The 27-group ENDF/B-IV cross-section set is known to have a 1 to $2 \%$ positive bias for highly thermal ${ }^{239} \mathrm{Pu}$ systems. Negative bias of 1 to $2 \%$ has been observed for light-water-reactor (LWR) fuel lattice depending on the degree of lattice moderation (see discussion in Sect. M4.2.1). Other areas of bias tend to be geometry and composition dependent (the reader is referred to the various validation reports for specific areas of applicability). Refer to Appendix M4.B for more information on ORNL experience with the 27-group ENDF/B-IV library.

\section{M4.2.3 THE HANSEN-ROACH LIBRARY (HANSEN-ROACH)}

The Hansen-Roach 16-group library is based on the original Los Alamos report by Hansen and Roach. ${ }^{14}$ Important nuclides not available in the original library were added by collapsing the 218-group ENDF/B-IV library to the 16-group structure. Table M4.A.3 in Appendix M4.A gives a complete list of the nuclides available in this library and the source of the data.

Resonance nuclides in the original Hansen-Roach library had cross sections tabulated at several $\gamma_{p}$ values. To make these cross sections compatible with the SCALE system, an infinite dilution library was defined for each resonance nuclide and Bondarenko data were generated for the remaining values of $\sigma_{\mathrm{p}}$. The implementation of the Hansen-Roach library in SCALE departs significantly from historical use of the Hansen-Roach library. In the past the shielded cross-section set used in a Hansen-Roach calculation was determined by calculating a $\sigma_{\mathrm{p}}$ value using a single value of the potential scatter cross section for each nuclide. As implemented in SCALE, $\sigma_{\mathrm{p}}$ is calculated on a group-wise basis using the total cross-section. Cross-section shielding is then done on a group-wise basis. The original Hansen-Roach library did not carry total cross sections, per se, but had a total cross section that included a transport correction. In order to implement the Hansen-Roach library in SCALE, an infinite dilute 16-group total cross-section was generated from the SCALE 27-group library and added to the Hansen-Roach library as MT-201. The Bondarenko iteration in

NUREG/CR-0200,

Vol. 3, Rev. 4

M4.2.12 
BONAMI automatically uses MT-201 when it is present in a library. This allowed the SCALE control modules to perform automatic problem-dependent cross-section processing using BONAMI.

The Hansen-Roach library was developed primarily for fast systems. There are 12 fast groups and 4 thermal groups (groups below $3 \mathrm{eV}$ ). However, thermal upscatter is not included in the original Hansen-Roach data. The cross sections are generally $P_{0}$ cross sections that are transport corrected to account for leakage. The exceptions are hydrogen and deuterium, which are $P_{1}$ transport-corrected cross sections. All of the nuclides added to the original library were generated to $P_{3}$. One significant modification was made to ${ }^{238} \mathrm{U}$ in the original library such that the library more accurately calculated low-enriched uranium systems. This was the Knight modification to the $\sigma_{\mathrm{p}}$ data for ${ }^{238} \mathrm{U}$ such that the $2 \%$ enriched green block experiments were accurately calculated. ${ }^{15}$

While the library was originally developed for fast systems, the Knight modification has allowed it to be successfully used as a general-purpose library. The areas of applicability have been periodically documented at the Oak Ridge facilities in validations against critical experiments. ${ }^{5-11,16-18}$ The library continues to be widely used because it is well known. Areas of validation include highly enriched uranium-metal, compounds and solutions, moderated low-enriched uranium systems, and plutonium-metal and solution systems. The Hansen-Roach cross-section set is-known-to have a 1.5 to $2 \%$ negative bias (underpredicts $k_{\text {eff }}$ for some highly enriched uranyl nitrate systems) and to have a 1 to $1.5 \%$ positive bias for highly thermal ${ }^{29} \mathrm{Pu}$ systems. Other areas of bias tend to be geometry and composition dependent (the reader is referred to the various validation reports for specific areas of applicability). Tables M4.2.5 and M4.2.6 show Hansen-Roach nuclides that have resonance and/or thermal data.

\section{M4.24 THE 123-GROUP GAM-THERMOS LIBRARY (123GROUPGMTH)}

The 123-group GAM-THERMOS library is a hybrid library composed of fast data taken from libraries prepared for the GAM-II code ${ }^{19}$ and thermal data based on cross-section data from the THERMOS code. ${ }^{20}$ The library contains 93 fast groups and 30 thermal groups (below $1.86 \mathrm{eV}$ ). The group structure in the thermal region was developed by the reactor physics group at ORNL in the late 1960s. The library structure in the fast groups tends to be based on even lethargy intervals rather than on energy (as in the 218-group library). The original GAM library was obtained from General Atomic in 1964. Since that time, the library has been expanded and improved by individuals at ORNL. Some ENDF/B data processed by SUPERTOG ${ }^{21}$ have been added to the library. The thermal data from THERMOS also came from a number of sources. The majority of the structural materials and heavy elements have kernels calculated with a free-gas model. Bound hydrogen or water kernels are based on the Nelkin model and crystalline moderator material kernels (i.e., graphite was calculated with the SUMMIT code. ${ }^{2}$

The 123-group library was developed for use with the original XSDRN ${ }^{23}$ code for general criticality analysis. Resonance data are carried in the master library and are processed by NITAWL-II. Six nuclides have unresolved resonance data that may be important in low-enriched, undermoderated systems: ${ }^{232} \mathrm{Th},{ }^{234} \mathrm{U},{ }^{236} \mathrm{U}$, ${ }^{228} \mathrm{U},{ }^{240} \mathrm{Pu}$, and ${ }^{242} \mathrm{Pu}$. The library has been widely used and tailored toward thermal reactor-type calculations. The library has been formally validated at ORNL for only a few critical systems. ${ }^{12}$

There has been a format change in the 123-group library between SCALE-3 and SCALE-4. In SCALE-3, the unresolved resonance cross-section data were processed by NITAWL. In SCALE-4, NITAWL-II has replaced NITAWL and the unresolved resonance processing capability has been removed. Bondarenko data have been generated for the affected nuclides and will now be processed in BONAMI.

Tables M4.2.7 and M4.2.8 give 123-group nuclides that have resonance or thermal data. Note the absence of resonance data for ${ }^{235} \mathrm{U}$ (a fixed preshielded value corresponding to nearly infinite dilution is included) can cause significant biases for some high-enriched systems. 
Table M4.2.5 Resonance nuclides found on the Hansen-Roach library

\begin{tabular}{ll}
\hline $\begin{array}{c}\text { Standard composition } \\
\text { alphanumeric name }\end{array}$ & $\begin{array}{c}\text { Nuclide ID } \\
\text { No. }\end{array}$ \\
\hline Mn & 25055 \\
Ag-107 & 47107 \\
Ag-109 & 47109 \\
In-113 & 49113 \\
In-115 & 49115 \\
Dy-164 & 66164 \\
Lu-175 & 71175 \\
Lu-176 & 71176 \\
W-182 & 74182 \\
W-183 & 74183 \\
W-184 & 74184 \\
W-186 & 74186 \\
Re-185 & 75185 \\
Re-187 & 75187 \\
Au & 79197 \\
Th-232 & $90232^{\circ}$ \\
Pa-233 & 91233 \\
U-233 & $92233^{\circ}$ \\
U-234 & 92234 \\
U-235 & $92235^{\circ}$ \\
U-236 & 92236 \\
U-238 & $92238^{\circ}$ \\
Np-237 & 93237 \\
Pu-238 & $94338^{\circ}$ \\
Pu-239 & $94239^{\circ}$ \\
Pu-240 & $94240^{\circ}$ \\
Pu-241 & 94241 \\
Pu-242 & 94242 \\
Am-241 & 95241 \\
Am-243 & 95243 \\
Cm-244 & 96244 \\
& \\
\hline & \\
& \\
\hline & \\
\hline
\end{tabular}

${ }^{a}$ Denotes nuclides having Bondarenko data in lieu of resonance parameters. 
Table M4.2.6 Nuclides in Hansen-Roach library with multiple sets of thermal scattering data

\begin{tabular}{lccc}
\hline $\begin{array}{l}\text { Cross-section } \\
\text { library }\end{array}$ & $\begin{array}{c}\text { Standard } \\
\text { composition } \\
\text { alphanumeric } \\
\text { name }\end{array}$ & $\begin{array}{c}\text { Nuclide } \\
\text { ID } \\
\text { No. }\end{array}$ & $\begin{array}{c}\text { Temperature (K) for which } \\
\text { different sets of thermal } \\
\text { scattering cross-section } \\
\text { data are available }\end{array}$ \\
\hline HANSEN-ROACH & B-10 & 5010 & 293,550 \\
& B-11 & 5011 & 293,550 \\
\hline
\end{tabular}

Table M4.2.7 Resonance nuclides found on the 123GROUPGMTH library

\begin{tabular}{lc}
\hline $\begin{array}{l}\text { Standard composition } \\
\text { alphanumeric name }\end{array}$ & $\begin{array}{c}\text { Nuclide ID } \\
\text { No. }\end{array}$ \\
\hline Th-232 & 90232 \\
U-234 & 92234 \\
U-236 & 92236 \\
U-238 & 92238 \\
Pu-240 & 94240 \\
Pu-242 & 94242 \\
\hline
\end{tabular}


Table M4.2.8 Nuclides in the 123GROUPGMTH library with multiple sets of thermal scattering data

\begin{tabular}{|c|c|c|c|}
\hline $\begin{array}{l}\text { Cross-section } \\
\text { library } \\
\text { specified by user }\end{array}$ & $\begin{array}{l}\text { Standard } \\
\text { composition } \\
\text { alphanumeric } \\
\text { name }\end{array}$ & $\begin{array}{c}\text { Nuclide } \\
\text { ID } \\
\text { No. }\end{array}$ & $\begin{array}{l}\text { Temperature }(\mathrm{K}) \text { for which } \\
\text { different sets of thermal- } \\
\text { scattering cross-section } \\
\text { data are available }\end{array}$ \\
\hline 123GROUPGMTH & $\begin{array}{l}\mathrm{H} \\
\mathrm{D} \\
\mathrm{Li}-6 \\
\mathrm{Li}-7 \\
\mathrm{Be} \\
\mathrm{B}-11 \\
\mathrm{C} \\
\mathrm{O} \\
\mathrm{F} \\
\mathrm{Na} \\
\mathrm{Al} \\
\mathrm{Cr} \\
\mathrm{Fe} \\
\mathrm{Ni} \\
\mathrm{Cu} \\
\mathrm{Zr} \\
\mathrm{Ne}-93 \\
\mathrm{Mo} \\
\mathrm{Sn} \\
\mathrm{Pa}-231 \\
\mathrm{U}-234 \\
\mathrm{U}-235 \\
\mathrm{U}-236 \\
\mathrm{U}-238 \\
\mathrm{~Np}-237 \\
\mathrm{Pu}-238 \\
\mathrm{Pu}-239 \\
\mathrm{Pu}-240 \\
\mathrm{Pu}-241 \\
\mathrm{Pu}-242\end{array}$ & $\begin{array}{l}1001 \\
1002 \\
3006 \\
3007 \\
4009 \\
5011 \\
6012 \\
8016 \\
9019 \\
11023 \\
13027 \\
24000 \\
26000 \\
28000 \\
29000 \\
40000 \\
41093 \\
42000 \\
50000 \\
91231 \\
92234 \\
92235 \\
92236 \\
92238 \\
93237 \\
94238 \\
94239 \\
94240 \\
94241 \\
94242\end{array}$ & $\begin{array}{l}295,345 \\
294,345,361 \\
294,800900,1000 \\
294,800,850,900,950,1000 \\
294,800,850900,950,1000 \\
300,600,900,1200 \\
589,627,675,800,850,900,950,100 \\
294,345,361,900,1165 \\
294,800,850,900,950,1000 \\
294,900 \\
627,900 \\
295,627,900 \\
295,627,900 \\
295,627,900 \\
295,900 \\
627,900 \\
627,900 \\
627,900 \\
627,900 \\
900,1165 \\
900,1000,1165 \\
295,900,1000,1165 \\
900,1000,1165 \\
295,900,1165 \\
900,1165 \\
900,1165 \\
900,1165 \\
900,1165 \\
900,1165 \\
900,1165\end{array}$ \\
\hline
\end{tabular}

\section{M4.25 THE 18-GROUP GAMMA LIBRARY (18GROUPGAMMA)}

The 18-group gamma energy group structure available in SCALE is given in Table M4.2.2. The SCALE gamma energy group structure is available in the stand-alone 18-group gamma library (18GROUPGAMMA), the $27 \mathrm{n}-18 \mathrm{~g}$ coupled library (27N-18COUPLE), and the $22 \mathrm{n}-18 \mathrm{~g}$ coupled library (22N-18COUPLE).

The standard SCALE 18-group gamma library was originally based on the OGRE point-data library. ${ }^{25}$ The OGRE library, in turn, was originally based on photon cross sections available through the National

NUREG/CR-0200,

Vol. 3, Rev. 4 
Bureau of Standards. The OGRE library was periodically updated as ENDF/B data became available. The group cross sections were generated by the SMUG1 code. At the time the data were generated for the 18-group gamma cross sections, the OGRE library contained the same data as the HPICE library, DLC-7E. ${ }^{26}$ Subsequently, data in the HPICE library were approved as ENDF/B-IV by the Cross Section Evaluation Working Group (CSEWG). In SCALE-4, the gamma data released in the 22n-18g Straker-Morrison library are ENDF/B-V data processed by SMUG. Both of these libraries have been widely used in shielding applications. No formal validation has been done for these libraries against experiments or analytic benchmarks.

\section{M4.26 THE 22n-18g STRAKER-MORRISON LIBRARY (22N-18COUPLE)}

The 22-group neutron library was developed and introduced in conjunction with air-over-ground radiation transport studies done in the late $1960 \mathrm{~s}^{24}$ The library is a $\mathrm{P}_{3}$ radiation shielding library with secondary gamma-ray production data coupled to an 18-group gamma library. The source of the neutron cross sections was the ENDF/B-II library. The neutron cross sections were generated at infinite dilution (1/E weighting) into a 104 fine-group structure using SUPERTOG. ${ }^{21}$ The 104-group structure was then collapsed to the 22 broad-group structure using the flux from a fine-group ANISN ${ }^{27}$ calculation for a uranium-water mixture. ${ }^{28}$ There are 19 fast groups, tailored to weapons radiation transport, and 3 thermal groups (below $3 \mathrm{eV}$ ). The 22-neutron group structure is essentially a subset of the 123-group structure over the fast range (above $3.059 \mathrm{eV}$ ). The 18-group gamma data are discussed in Sect. M4.2.5. The gamma-ray data were generated for SCALE 4 so as to preserve the pair-production cross section. This cross section is needed by the Klein-Nishina estimator in MORSE-SGC.

The $22 \mathrm{n}-18 \mathrm{~g}$ library is a widely used radiation shielding library. No resonance data are located in the library, and the group collapse of the cross sections has tailored the cross sections to water-filled shipping-cask-type calculations. The library used in SCALE was converted from an ANISN working format to an AMPX master format library. The library should not be expected to give good results for general criticality calculations or in shielding calculations where fission neutrons are important.

\section{M4.27 THE 27n-18g COUPLED LIBRARY (27N-18COUPLE)}

The $27 \mathrm{n}$-18g library is a coupled 27 neutron group, 18 gamma-ray group library for shielding calculations. The neutron data were taken from the 27-group ENDF/B-IV library discussed in Sect. M4.2.8, and the gamma-ray data were taken from the standard SCALE gamma library discussed in Sect. M4.2.5. Secondary gamma production data from ENDF/B-IV were processed by LAPHNGAS and added to the library. As shown in Table M4.2.9, several potentially important nuclides have no gamma-ray production matrices because ENDF/B-IV provided no production data for these nuclides.For many problems in which these nuclides occur, this will not cause a problem, but the user should be aware that these nuclides have no gamma production matrices and should verify that this is not important for the particular problem of interest. The neutron library used in this coupled library is primarily a criticality analysis library and has only one group in the 6to $20-\mathrm{MeV}$ range. Thus the user should determine that the group structure is adequate for the particular shielding application being considered. A recent shielding analyses study ${ }^{29}$ that compared the $27 \mathrm{n}-18 \mathrm{~g}$ library structure against other group structures indicated that the $27 \mathrm{n}-18 \mathrm{~g}$ library performs satisfactorily for LWR spent fuel sources. This library also has been widely used in LWR spent fuel shielding applications. No formal validation has been done against experiments or analytic benchmarks.

\section{M4.2.8 THE 27-GROUP DEPLETION LIBRARY (27BURNUPLIB)}

The 27-group depletion library is a general-purpose library originally developed for use in the SAS2 depletion/shielding control module. The library consists of the 27-group ENDF/B-IV library discussed in Sect. M4.2.2 supplemented with data from $E N D F / B-V$ for a large number of fission products. This library is the preferred library for use with SAS2 (Shielding Analysis Sequence 2) because of the large number of 
Table M4.2.9 List of nuclides in the $27 \mathrm{n}-18 \mathrm{~g}$ library with no gamma-ray production cross sections

\begin{tabular}{ll}
\hline $\begin{array}{c}\text { Standard composition } \\
\text { alphanumeric }\end{array}$ & Nuclide ID \\
\hline He & \\
B-11 & 2004 \\
Br-79 & 5011 \\
Br-81 & 35079 \\
Ag-107 & 35081 \\
Ag-109 & 47107 \\
Cd & 47109 \\
In-113 & 48000 \\
In-115 & 49113 \\
Sn & 49115 \\
Xe-135 & 50000 \\
Cs-133 & 54135 \\
Gd & $55133^{\circ}$ \\
Dy-164 & 64000 \\
Lu-175 & 66164 \\
Lu-176 & 71175 \\
Hf & 71176 \\
Re-185 & 72000 \\
Re-187 & 75185 \\
Au-197 & 75187 \\
Th-232 & 79197 \\
Pa-233 & 90232 \\
U-233 & $91233^{\circ}$ \\
U-234 & 92233 \\
U-236 & 92234 \\
Np-237 & 92236 \\
Pu-238 & $93237^{\circ}$ \\
Pu-241 & 94238 \\
Pu-242 & 94241 \\
Am-241 & 94242 \\
Am-243 & $95241^{a}$ \\
Cm-244 & $95243^{a}$ \\
& $96244^{a}$ \\
& \\
\hline & \\
\hline & \\
\hline & \\
\hline
\end{tabular}

${ }^{a}$ These nuclides have no gamma-ray data at all.

nuclides that can be processed explicitly in XSDRNPM for use in the ORIGEN-S depletion code. This processing eliminates the cross-section dependence on the ORIGEN library used for those nuclides that are treated in XSDRNPM. Because the base library was the 27-group ENDF/B-IV library, all the comments in Sects. M4.2.2 and M4.2.7 are directly applicable here.

NUREG/CR-0200,

Vol. 3, Rev. 4

M4.2.18 


\section{M4.3 REFERENCES}

1. N. M. Greene et al., AMPX-II: A Modular Code System for Generating Coupled Multigroup NeutronGamma Libraries from ENDF/B, PSR-63, ORNL/TM-3706, Union Carbide Corp., Nucl. Div., Oak Ridge Natl. Lab., March 1976.

2. W. E. Ford, III et al., A 218-Group Neutron Cross-Section Reference Library in the AMPX Master Interface Format for Criticality Safety Studies, DLC-43 ORNL/CSD/TM-4, Union Carbide Corp., Nucl. Div., Oak Ridge Natl. Lab., July 1976.

3. W. E. Ford III et al., "A 218-Neutron-Group Master Cross-Section Library for Criticality Safety Studies," TANSAO 22, 290-291 (1975).

4. R. M. Westfall et al., "Procedures for Determining Broad-Group Energy Structure for Criticality Safety Calculations," TANSAO 22, 291-292 (1975).

5. R. M. Westfall and J. R. Knight, "SCALE System Cross Section Validation with Shipping Cask Critical Experiments," TANSAO 33, 368 (1979).

6. J. R. Knight, Validation of the Monte Carlo Criticality Program KENO V.a for Highly Enriched Uranium Systems, ORNL/CSD/TM-221, Martin Marietta Energy Systems, Inc., Oak Ridge Natl. Lab., 1984.

7. M. E. Easter, Validation of KENO V.a and Two Cross-Section Libraries for Criticality Calculations of Low-Enriched Uranium Systems, ORNL/CSD/T-223, K/HS-74, Martin Marietta Energy Systems, Inc., Oak Ridge Natl. Lab., 1985.

8. L. M. Petrie and J. T. Thomas, Assessment of Computational Performance in Nuclear Criticality, ORNL/CSD/TM-224, Martin Marietta Energy Systems, Inc., Oak Ridge Natl. Lab., 1985.

9. W. C. Jordan et al., Validation of KENO V.a Comparison with Critical Experiments, ORNL/CSD/TM-238, Martin Marietta Energy Systems, Inc., Oak Ridge Natl. Lab., December 1986.

10. M. E. Easter and R. T. Primm, III, Validation of the SCALE Code System and Two Cross-Section Libraries for Plutonium Benchmark Experiments, ORNL/TM-9402, Martin Marietta Energy Systems, Inc., Oak Ridge Natl. Lab., January 1985.

11. H. R. Dyer, Recalculation of a Few Bare Plutonium Critical Arrays,- ORNL/CDS/TM-242, Martin Marietta Energy Systems, Inc., Oak Ridge Natl. Lab., April 1987.

12. H. R. Dyer and R. M. Westfall, "KENO V.a Validation of Fuel Pin Experiments," TANSAO 55, 382-385 (1987).

13. G. R. Smolen and H. Funabashi, "Validation Studies Performed with Low-Concentration Mixed Pu+U Aqueous Critical Experiments," TANSAO 55, 380-381 (1987).

14. G. E. Hansen and W. H. Roach, Six and Sixteen Group Cross-Sections for Fast and Intermediate Critical Assemblies, LA-2543-MS, Los Alamos Scientific Laboratory, November 1961.

NUREG/CR-0200; 
15. J. T. Mihalczo et al., Preliminary Rpeort on $2 \%{ }^{235} \mathrm{U}$ Enriched $U F_{4} C_{25} \mathrm{H}_{25}$ Critical Assemblies, ORNL/CF-59-4-120, Union Carbide Corp., Nucl. Div., Oak Ridge Natl. Lab., 1956.

16. G. R. Handley and C. M. Hopper, Validation of the KENO Code for Nuclear Criticality Safety Calculations of Moderated Low-Enriched Uranium Systems, Y-1948, Union Carbide Corp., Nucl. Div., Oak Ridge Y-12 Plant, 1974.

17. G. R. Handley et al., Validation of the Monte Carlo Criticality Program KENO IV and the HansenRoach Sixteen-Energy-Group Cross Sections for High Assay Uranium Systems, Y-2234, Union Carbide Corp., Nucl. Div., Oak Ridge Y-12 Plant, 1981.

18. R. L. Sanders, Validation of the SCALE Code System and One Cross-Section Library for Plutonium and Gadolinium Systems, ORNL/CFRP-84/20, Martin Marietta Energy Systems, Inc., Oak Ridge Natl. Lab., July 1985.

19. G. D. Joanou and J. S. Dudek, GAM-II: $A B_{3}$ Code for the Calculation of Fast Neutron Spectra and Associated Multigroup Constants, GA-4265, General Atomic, September 1963.

20. H. C. Honeck, THERMOS: A Thermalization Transport Theory Code for Reactor Lattice Calculations, BNL-5826, Brookhaven National Laboratory, September 1961.

21. R. Q. Wright et al., SUPERTOG: A Program to Generate Fine Group Constants and $P_{n}$ Scattering Matrices From ENDF/B, ORNL/TM-2679, Union Carbide Corp., Nucl. Div., Oak Ridge Natl. Lab., 1969.

22. J. L. Bell, SUMMIT: An IBM-7090 Program for the Computation of Crystalline Scattering Kernels, GA-2492, General Atomic, February 1962.

23. N. M. Greene and C. W. Craven, XSDRN: A Discrete Ordinates Spectral Averaging Code, ORNL/TM-2500, Union Carbide Corp., Nucl. Div., Oak Ridge Natl. Lab., July 1969.

24. E. A Straker and M. L. Gritzner, Neutron and Secondary Gamma-Ray Transport in Infinite Homogeneous Air, ORNL-4464, Union Carbide Corp., Nucl. Div., Oak Ridge Natl. Lab., December 1969.

25. RSIC Computer Code Collection, OGRE, General-Purpose Monte Carlo Gamma-Ray Transport Code System, CCC-46, Union Carbide Corp., Nucl. Div., Oak Ridge Nati. Lab. (updated July 1981).

26. RSIC Data Library Collection, HPICE: Evaluated Photon Interaction Library ENDF/B File 23 Format, DCL-7, Martin Marietta Energy Systems, Inc., Oak Ridge Natl. Lab. (updated September 1986).

27. W. W. Engle, Jr., A User's Manual for ANISN: A One-Dimensional Discrete Ordinates Transport Code With Anisotropic Scattering, K-1693, Union Carbide Corp., Nucl. Div., Oak Ridge Gaseous Diffusion Plant, March 1967.

28. RSIC Data Library Collection, CASK-81: 22-Neutron, 18-Gamma-Ray Group, $P_{3}$ Cross Sections for Shipping Cask Analysis, DLC-23, Martin Marietta Energy Systems, Inc., Oak Ridge Natl. Lab. (updated September 1987).

NUREG/CR-0200,

Vol. 3, Rev. 4 
29. C. V. Parks et al., "Intercomparision of Cross-Section Libraries Used for Spent Fuel Cask Shielding Analyses," pp. 559-569 in Proceedings of Theory and Practices in Radiation Protection and Shielding, Knoxville, Tenn., April 22-24, 1987. 
M4.A TABLE OF CONTENTS LISTING FOR SCALE LIBRARIES

M4.A.1 THE 218-GROUP ENDF/B-IV LIBRARY $\ldots \ldots \ldots \ldots \ldots \ldots \ldots \ldots \ldots \ldots$ M4.A.2

M4.A.2 THE 27-GROUP ENDF/B-IV LIBRARY $\ldots \ldots \ldots \ldots \ldots \ldots \ldots \ldots \ldots \ldots \ldots$

M4.A.3 THE 16-GROUP HANSEN-ROACH LIBRARY $\ldots \ldots \ldots \ldots \ldots \ldots \ldots \ldots \ldots$ M4.A.6

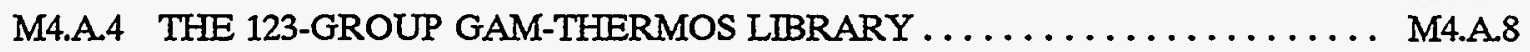

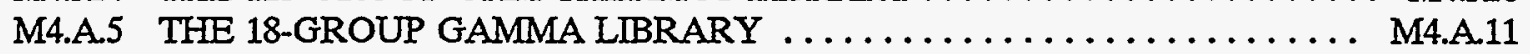

M4.A.6 THE 22n-18g STRAKER-MORRISON LIBRARY $\ldots \ldots \ldots \ldots \ldots \ldots \ldots \ldots$ M4.A.15

M4.A.7 THE 27n-18g COUPLED ENDF/B-IV LIBRARY $\ldots \ldots \ldots \ldots \ldots \ldots \ldots \ldots$ M4.A.16

M4.A.8 THE 27-GROUP BURNUP LIBRARY $\ldots \ldots \ldots \ldots \ldots \ldots \ldots \ldots \ldots \ldots$ M4.A.18 


\section{M4.AI THE 218-GROUP ENDF/B-IV LIBRARY}

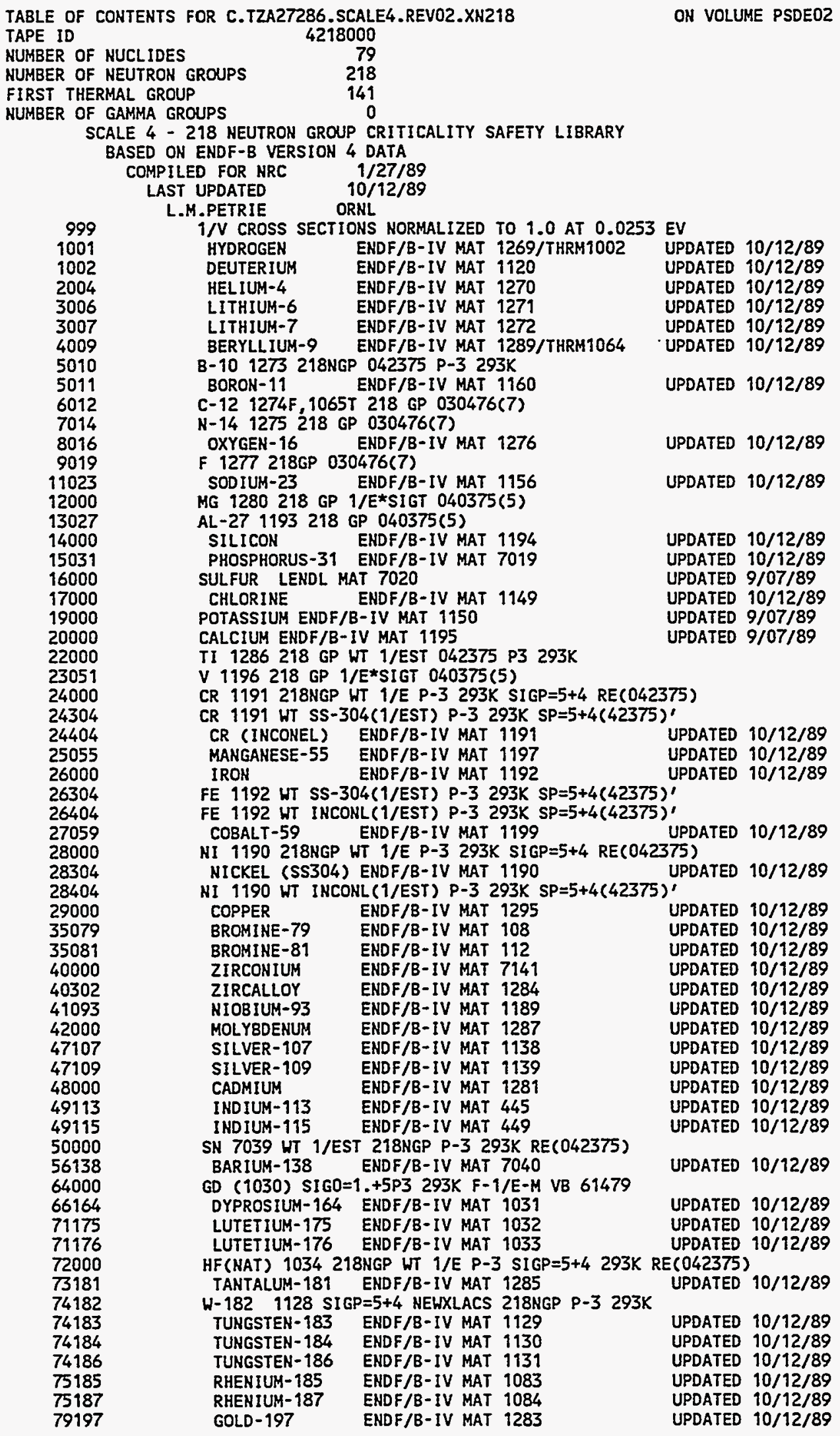

NUREG/CR-0200, 


\begin{tabular}{|c|c|c|c|c|}
\hline $\begin{array}{l}82000 \\
90232 \\
91233 \\
92233 \\
92234 \\
92235 \\
92236 \\
92238 \\
93237 \\
94238 \\
94239 \\
94240 \\
94241 \\
94242 \\
95241 \\
95243 \\
96244\end{array}$ & $\begin{array}{l}\text { PB } 1288218 N G \\
\text { THORIUH-232 } \\
\text { PALADIUH-231 } \\
\text { U-233 } 1260 \text { SIG } \\
\text { U-234 } 1043 \text { SIGO } \\
\text { URANIUH-235 } \\
\text { URANIUH-236 } \\
\text { URANIUH-238 } \\
\text { NEPTUNIUH-237 } \\
\text { PLUTONIUH-238 } \\
\text { PLUTONIUH-239 } \\
\text { PLUTONIUH-240 } \\
\text { PLUTONIUH-241 } \\
\text { PLUTONIUM-242 } \\
\text { AM-241 } 1056 \text { SIG } \\
\text { AM-243 } 1057218 \\
\text { CURIUM-244 }\end{array}$ & 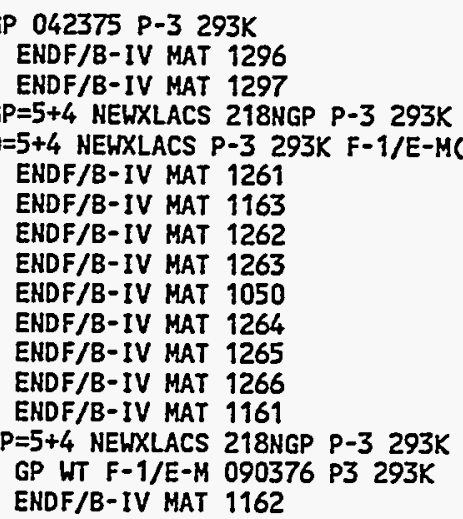 & $\begin{array}{l}1 .+5) \\
\text { UPDATED } \\
\text { UPDATED } \\
\text { UPDATED } \\
\text { UPDATED } \\
\text { UPDATED } \\
\text { UPDATED } \\
\text { UPDATED } \\
\text { UPDATED } \\
\text { UPDATED }\end{array}$ & $\begin{array}{l}10 / 12 / 89 \\
10 / 12 / 89 \\
10 / 12 / 89 \\
10 / 12 / 89 \\
10 / 12 / 89 \\
10 / 12 / 89 \\
10 / 12 / 89 \\
10 / 12 / 89 \\
10 / 12 / 89\end{array}$ \\
\hline
\end{tabular}


M4.A2 THE 27-GROUP ENDF/B-IV LIBRARY

TABLE OF CONTENTS FOR C.TZA27286.SCALE4.REV02.XN27 TAPE ID 4027000

NUMBER OF NUCLIDES

83

NUMBER OF NEUTRON GROUPS 27

FIRST THERMAL GROUP

NUMBER OF GAMMA GROUPS

15

SCALE 4 - 27 NEUTRON GROUP CRITICALITY SAFETY LIBRARY BASED ON ENDF-B VERSION 4 DATA

COMPILED FOR NRC $1 / 27 / 89$

LAST UPDATED $10 / 12 / 89$

L.M.PETRIE ORNL

$\begin{array}{lllll}900 & \text { DOSE FACTORS FROM ANSI/ANS }-6.1 .1-1977 & \text { UPDATED } 9 / 07 / 89 \\ 999 & \text { IN CROSS SECTIONS NORMALIZED TO } 1.0 \text { AT } 0.0253 & \text { EV } & \\ 1001 & \text { HYDROGEN } & \text { ENDF/B-IV MAT } 1269 / \text { THRM1002 } & \text { UPDATED } 10 / 12 / 89 \\ 1002 & \text { DEUTERIUM } & \text { ENDF/B-IV MAT } 1120 & \text { UPDATED } 10 / 12 / 89 \\ 2004 & \text { HELIUH-4 } & \text { ENDF/B-IV MAT } 1270 & \text { UPDATED } 10 / 12 / 89\end{array}$

3006 LI-6 1271218 GP $1 /$ E*SIGT 040375(5)

3007 LI $-71272218 \mathrm{GP}$ 1/E*SIGT 040375(5)

4009

5010

5011

6012

7014

8016

9019

11023

12000

13027

14000

15031

16000

17000

19000

20000

22000

23051

24000

24304

24404

25055

26000

26304

26404

27059

28000

LI-7 1272218 GP $1 /$ E*SIGT $040375(5)$
BERYLLIUM-9 ENDF/B-IV MAT 1289/

B-10 1273 218NGP 042375 P-3 293K

BORON-19 ENDF/B-IV MAT 1160

CARBON-12 ENDF/B-IV HAT 1274/THRH1065

NITROGEN-14 ENDF/B-IV MAT 1275

OXYGEN-16 ENDF/B-IV MAT 1276

FLUORINE ENDF/B-IV MAT 1277

SODIUM-23 ENDF/B-IV MAT 1156

MG 1280218 GP $1 / E *$ SIGT 040375 (5)

AL-27 1193218 GP $040375(5)$

SILICON ENDF/B-IV MAT 1194

P-31 7019 218NGP WT 1/EST 042375 P3 293K

SULFUR LENDL MAT 7020

CHLORINE ENDF/B-IV MAT 1149

POTASSIUM ENDF/8-IV MAT 1150

CALCIUM ENDF/B-IV MAT 1195

TITANIUN ENDF/B-IV MAT 1286
$V 1196218$ GP 1/E*SIGT $040375(5)$

CR 1191 218NGP WT $1 / E$ P-3 293K SIGP $=5+4$ RE(042375)

CR 1191 WT SS-304(1/EST) $P-3 \quad 293 K \quad S P=5+4(42375)^{\prime}$

CR 1191 UT INCONL (1/EST) P-3 293K SP=5+4(42375)

MANGANESE-55 ENDF/B-IV MAT 1197 UPDATED $10 / 12 / 89$

IRON ENDF/B-IV MAT $1192 \quad$ UPDATED $10 / 12 / 89$

FE 1192 ITT SS-304(1/EST) P-3 293K SP=5+4(42375)'

FE 1192 WT INCONL(1/EST) P-3 293K SP =5+4(42375)'

COBALT-59 ENDF/B-IV MAT 1199 UPDA

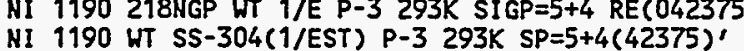

NI 1190 WT INCONL(1/EST) P-3 293K SP=5+4(42375)

COPPER ENDF/B-IV MAT 1295

BROMINE-79 ENDF/B-IV MAT 108

UPDATED $10 / 12 / 89$

28404

35079

35081

BROMINE-81

ENDF/B-IV MAT 112

ZIRCONIUM ENDF/B-IV MAT 7141

ZIRCALLOY ENDF/B-IV MAT 1284

NIOBIUM-93 ENDF/B-IV MAT 1189

41093

MO (1287) SIGP $=5+4$ NEWXLACS 218NGP F-1/E-M P-3

SILVER-107 ENDF/B-IV MAT 1138

SILVER-109 ENDF/B-IV MAT 1139

CD 1281 WT 1/EST 218NGP P-3 293K RE(042375)

INDIUM-113 ENDF/B-IV MAT 445

INDIUM-115 ENDF/B-IV MAT 449

SN 7039 WT 1/EST 218NGP P-3 293K RE(042375)

XENON-135 ENDF/B-IV MAT 1294

CESIUM-133 ENDF/B-IV MAT 1141

BA-138 7040 218NGP WT 1/EST 042375 P3 293K

GD (1030) SIGD=1.+5P3 293K F-1/E-M VB 61479

DYPROSIUM- 164 ENDF/B-IV MAT 1031

LUTETIUM-175 ENDF/B-IV MAT 1032

LUTETIUM-176 ENDF/B-IV MAT 1033

HF(NAT) 1034 218NGP WT 1/E P-3 SIGP

TANTALUM-181 ENDF/B-IV MAT 1285

TUNGSTEN-182 ENDF/B-IV MAT 1128

TUNGSTEN-183 ENDF/B-IV MAT 1129

TUNGSTEN-184 ENDF/B-IV MAT 1130

UPDATED $10 / 12 / 89$

UPDATED $10 / 12 / 89$

UPDATED $10 / 12 / 89$

UPDATED $10 / 12 / 89$

UPDATED $10 / 12 / 89$

ENDF/B-IV MAT 1130
ENDF/B-IV MAT 1131

UPDATED $10 / 12 / 89$

UPDATED $10 / 12 / 89$

UPDATED $10 / 12 / 89$

UPDATED $10 / 12 / 89$

UPDATED $10 / 12 / 89$

UPDATED $10 / 12 / 89$

UPDATED $10 / 12 / 89$

UPDATED $10 / 12 / 89$

UPDATED $10 / 12 / 89$

73181

74183

74184

TUNGSTEN-186

UPDATED $10 / 12 / 89$

UPDATED $10 / 12 / 89$

UPDATED $10 / 12 / 89$

UPDATED $10 / 12 / 89$

UPDATED $10 / 12 / 89$

NUREG/CR-0200,

Vol. 3, Rev. 4

M4.A.4 


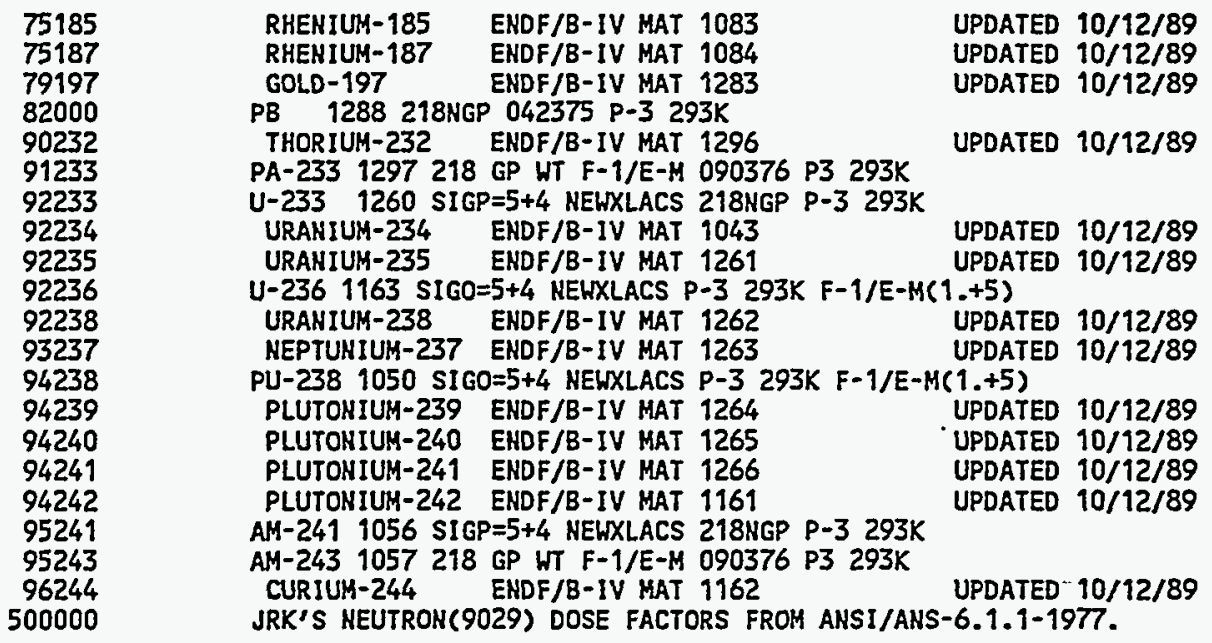




\section{M4.A.3 THE 16-GROUP HANSEN-ROACH LIBRARY}

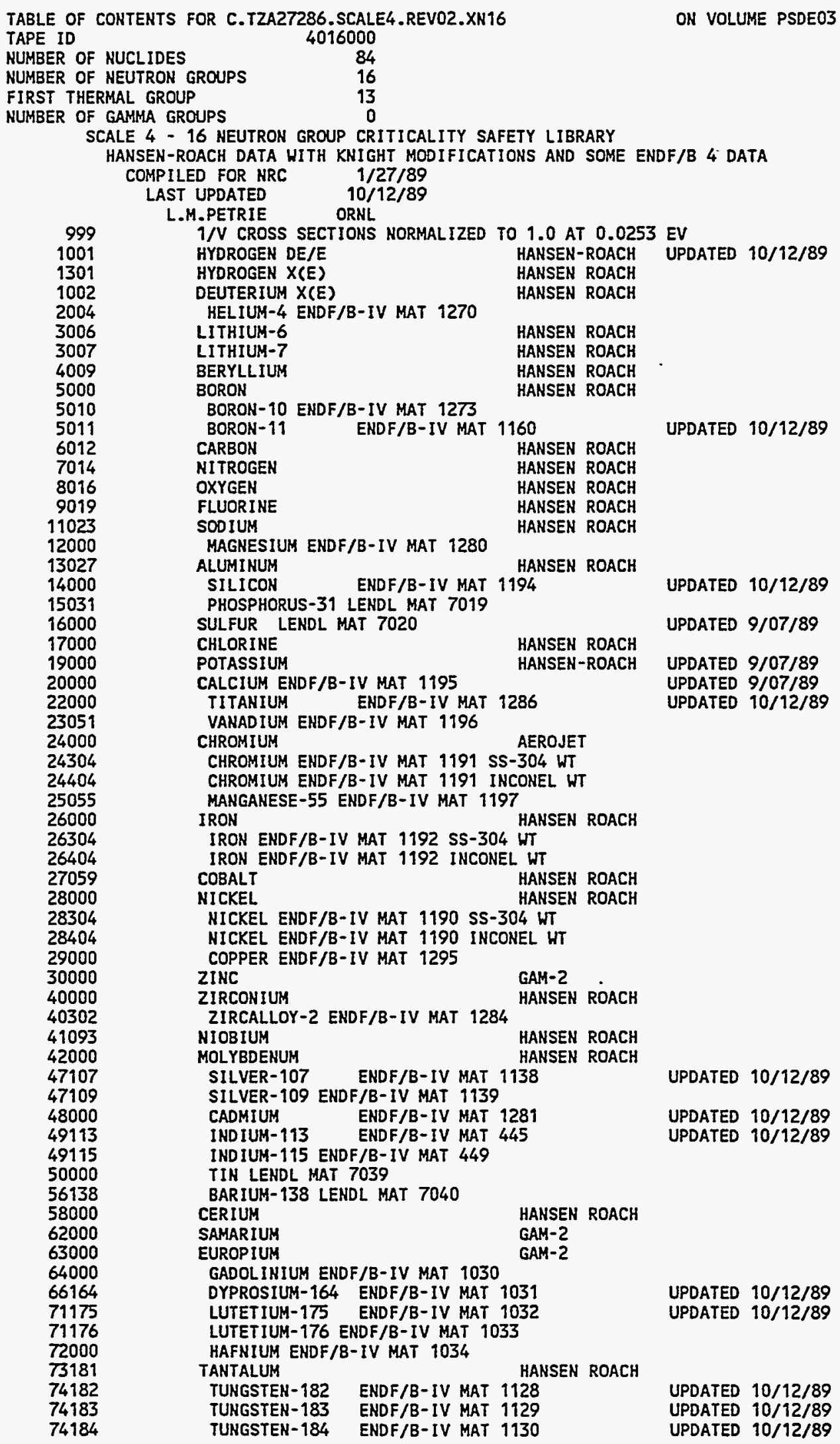

NUREG/CR-0200, 


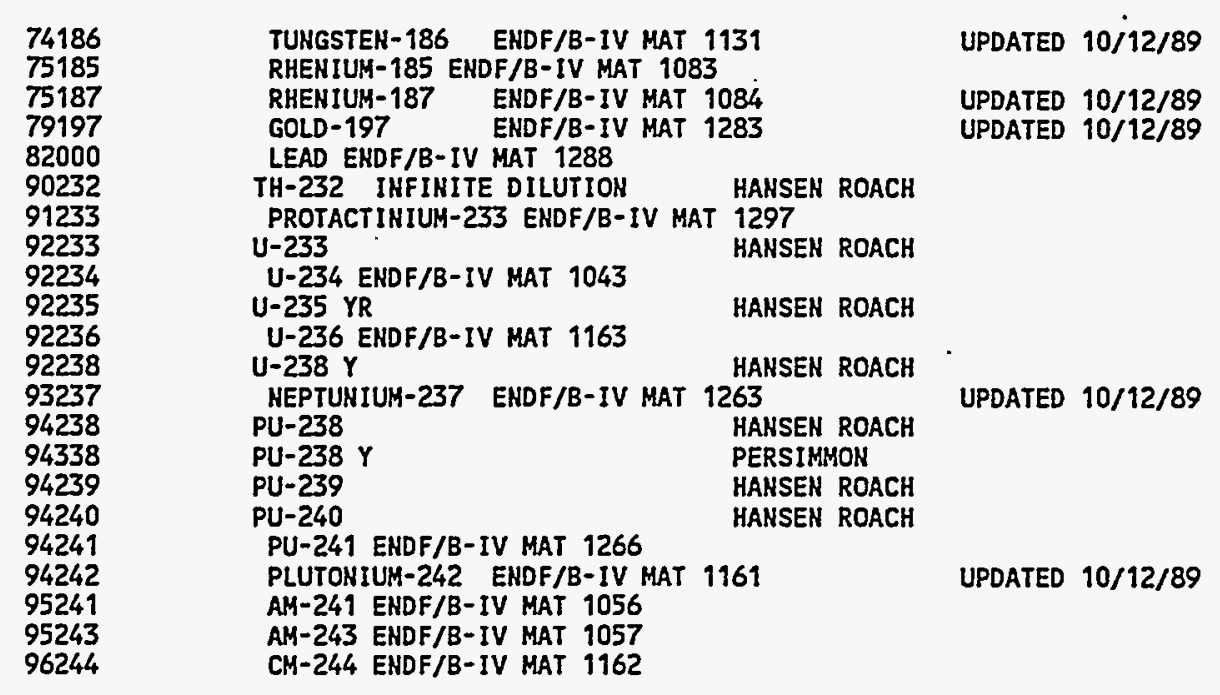

NUREG/CR-0200,

Vol. 3, Rev. 4 


\section{M4.A.4 THE 123-GROUP GAM-THERMOS LIBRARY}

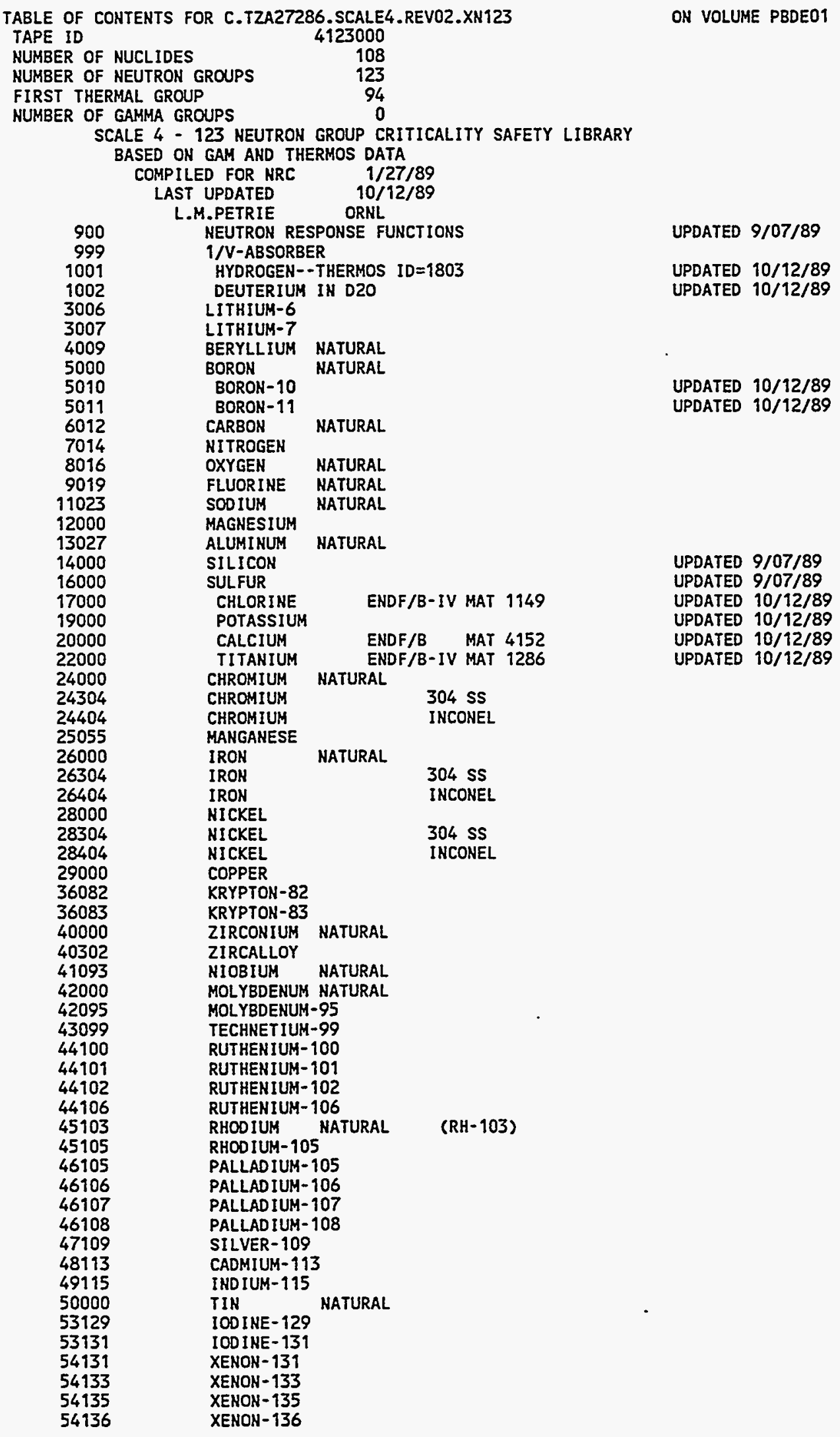

NUREG/CR-0200,

Vol. 3, Rev. 4 


\begin{tabular}{|c|c|c|}
\hline $\begin{array}{l}55133 \\
55134 \\
55135 \\
57139 \\
59141 \\
59143 \\
60143 \\
60144 \\
60145 \\
60148 \\
61147 \\
61148 \\
61548 \\
62147 \\
62148 \\
62149 \\
62150 \\
62151 \\
62152 \\
62154 \\
63153 \\
63154 \\
63155 \\
64000 \\
64155 \\
64157 \\
74000 \\
75187 \\
79197 \\
82000 \\
90232 \\
91231 \\
91233 \\
92233 \\
92234 \\
92235 \\
92236 \\
92238 \\
93237 \\
93239 \\
94238 \\
94239 \\
94240 \\
94241 \\
94242 \\
500000\end{array}$ & 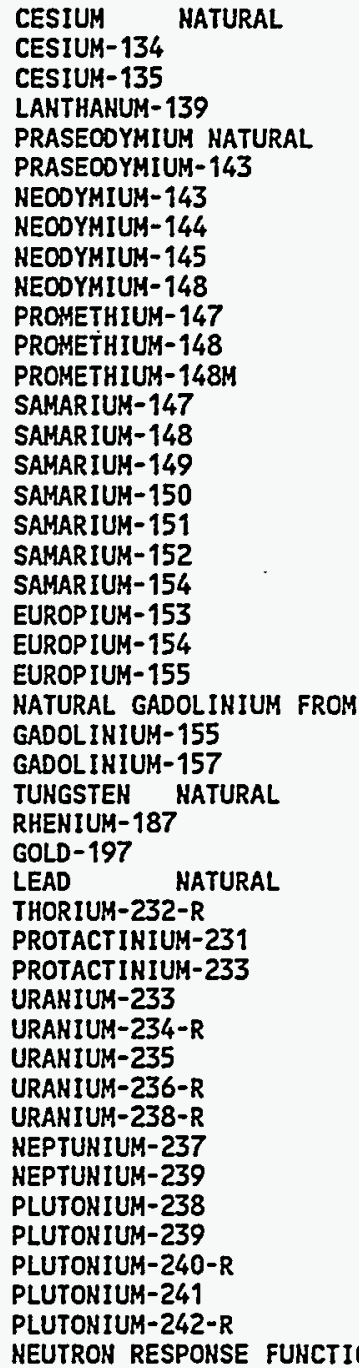 & 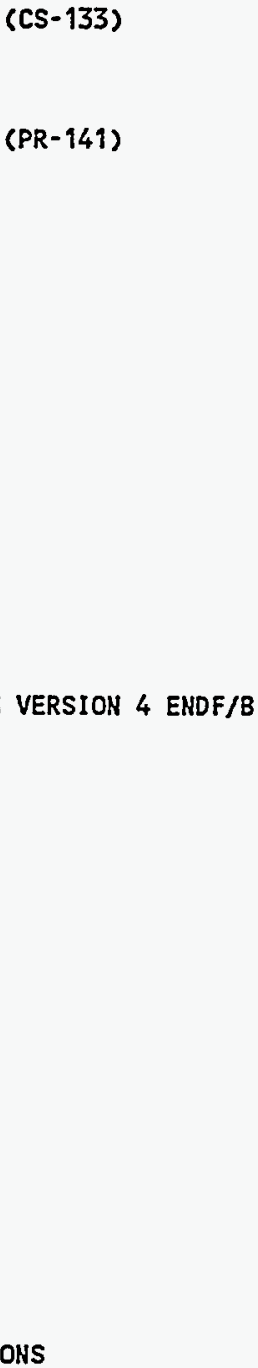 \\
\hline
\end{tabular}

NUREG/CR-0200, 
M4.A.5 THE 18-GROUP GAMMA LIBRARY

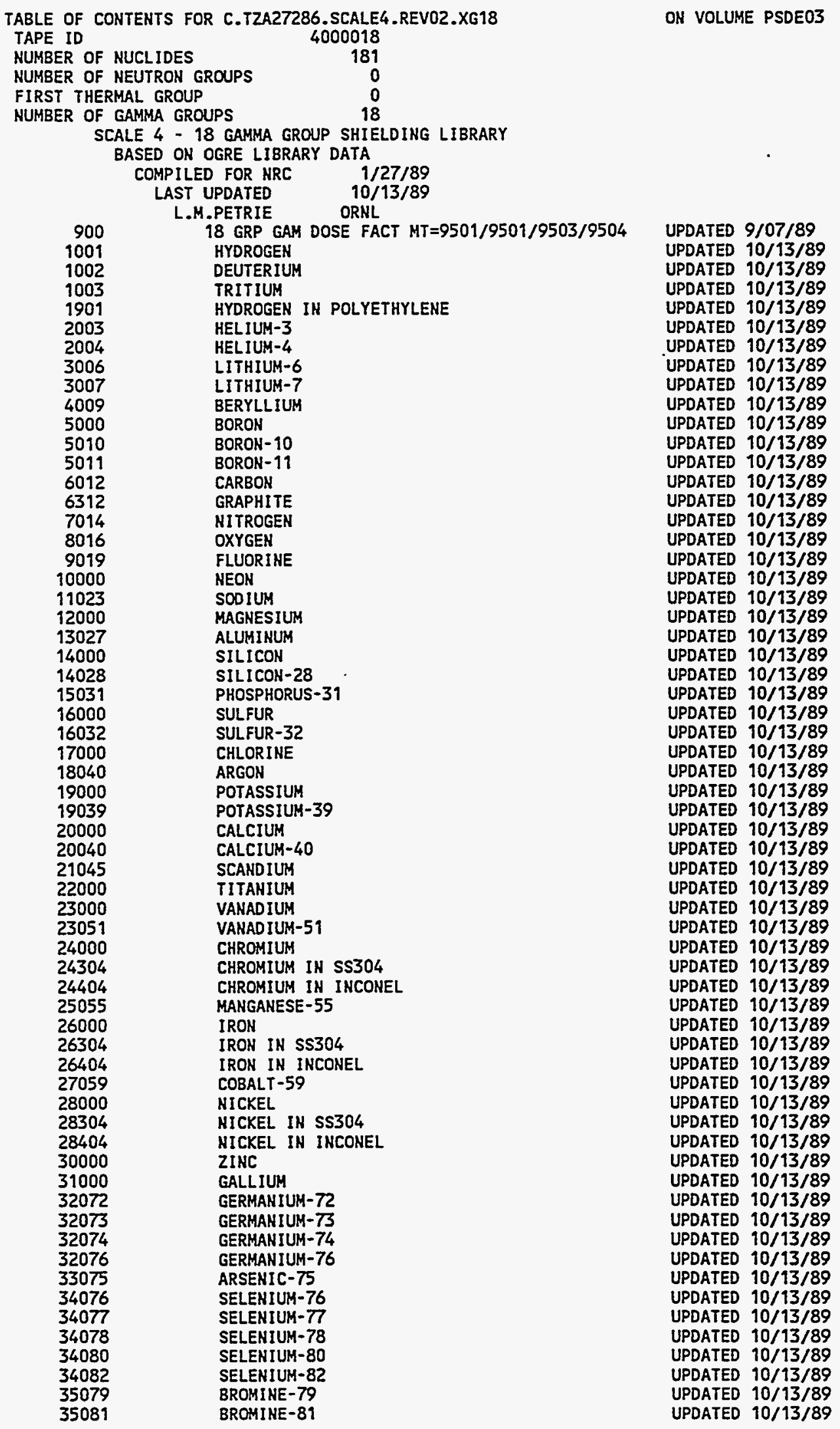

NUREG/CR-0200,

Vol. 3, Rev. 4

M4.A.10 


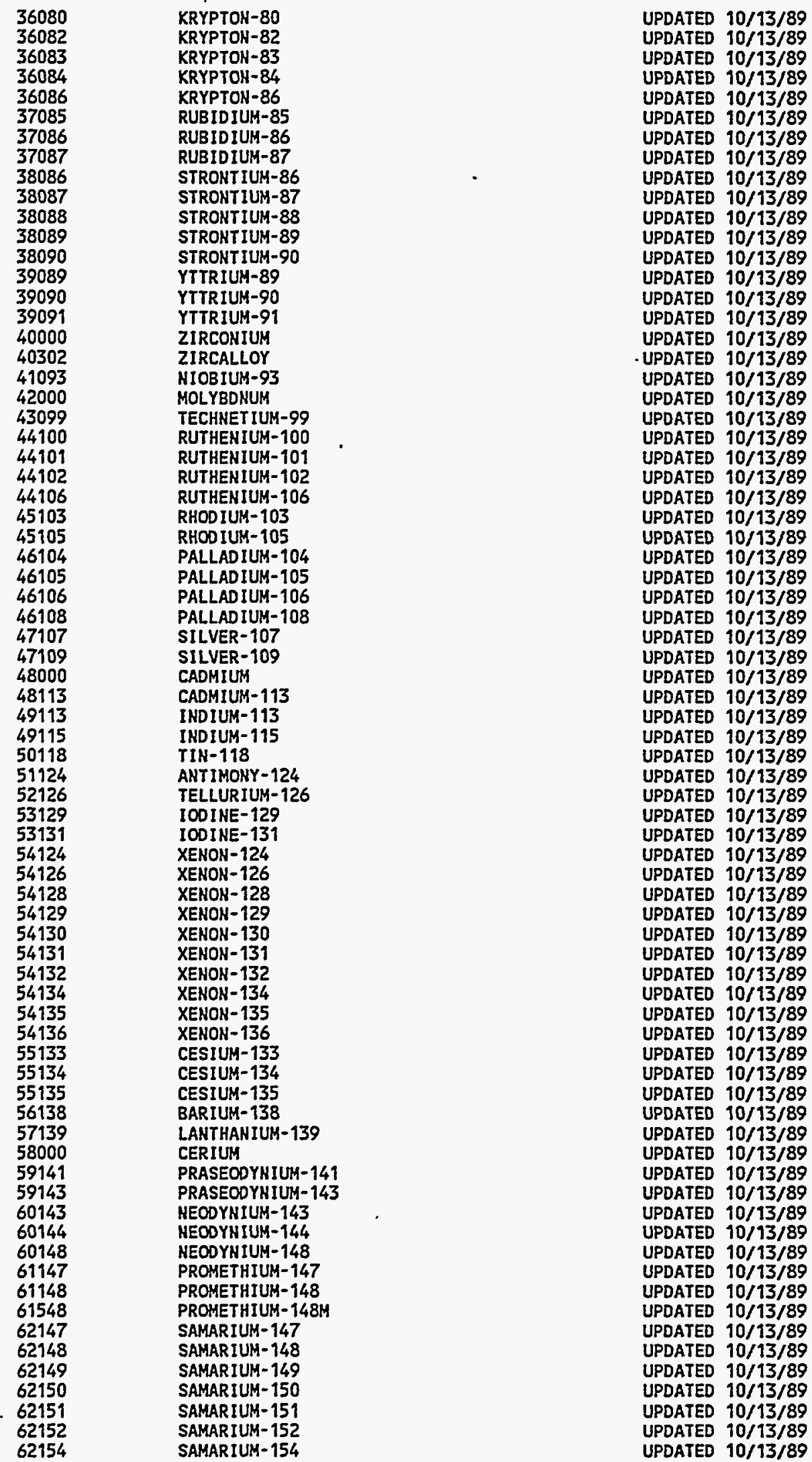




\section{M4.A.6 THE 22n-18g STRAKER-MORRISON LIBRARY}

TABLE OF CONTENTS FOR C.TZA27286.SCALE4.REV02.XN22G18

TAPE ID 4022018

ON VOLUME PSDE01

NUMBER OF NUCLIOES

NUMBER OF NEUTRON GROUPS

FIRST THERMAL GROUP

NUMBER OF GAMMA GROUPS

$$
\begin{aligned}
& 36 \\
& 22 \\
& 22
\end{aligned}
$$

- 22 MEUTRON 18 GAYMA GROUP SHIEIDING LIBRARY

BASED ON STRAKER-MORRISON DATA WITH REGENERATED GAMMA CROSS SECTIONS COMPILED FOR NRC $1 / 27 / 89$

LAST UPDATED $10 / 13 / 89$

$$
\text { L.M.PETRIE ORNL }
$$

1001

2004

3006

3007

4009

5010

5011

6012

7014

8016

9019

11023

12000

13027

14000

17000

19000

20000

22000

24000

25055

26000

28000

29000

40000

42000

50000

73181

74000

82000

92235

92238

94239

94240

500000

$$
\begin{array}{r}
\text { DOSE FACTORS } \\
\text { HYDROGEN }
\end{array}
$$

HELIUM

LITHIUM-6

LITHIUM-7

BERYLLIUM

BORON-10

BORON-11

CARBON

NITROGEN

OXYGEN

FLUORINE

SODIUM

MAGNESIUN

ALUHINUM

SILICON

CHLORINE

POTASSIUM

CALCIUM

TITAMIUM

CHROMIUH

MANGANESE

IRON

NICKEL

COPPER

MOLYBDENUM

TIN

TANTALUM

TUNGSTEN

LEAD

URANIUM-235

URANIUM-238

PLUTONIUM-239

PLUTONIUM-240

FAKE DATA SET W/DOSE FACTORS 10-17- 77 (1)

UPDATED $9 / 07 / 89$

UPDATED $10 / 13 / 89$

UPDATED $10 / 13 / 89$

UPDATED $10 / 13 / 89$

UPDATED $10 / 13 / 89$

UPDATED $10 / 13 / 89$

UPDATED $10 / 13 / 89$

UPDATED $10 / 13 / 89$

UPDATED $10 / 13 / 89$

UPDATED $10 / 13 / 89$

UPDATED $10 / 13 / 89$

UPDATED $10 / 13 / 89$

UPDATED $10 / 13 / 89$

UPDATED $10 / 13 / 89$

UPDATED $10 / 13 / 89$

UPDATED $10 / 13 / 89$

UPDATED $10 / 13 / 89$

UPDATED $10 / 13 / 89$

UPDATED $10 / 13 / 89$

UPDATED 10/13/89

UPDATED $10 / 13 / 89$

UPDATED 10/13/89

UPDATED $10 / 13 / 89$

UPDATED $10 / 13 / 89$

UPDATED 10/13/89

UPDATED $10 / 13 / 89$

UPDATED $10 / 13 / 89$

UPDATED $10 / 13 / 89$

UPDATED $10 / 13 / 89$

UPDATED $10 / 13 / 89$

UPDATED $10 / 13 / 89$

UPDATED $10 / 13 / 89$

UPDATED $10 / 13 / 89$

UPDATED $10 / 13 / 89$

UPDATED $10 / 13 / 89$ 
M4.A.7 THE 27n-18g COUPLED ENDF/B-IV LIBRARY

TABLE OF CONTENTS FOR C.TZA27286.SCALE4.REV03.XN27G18

TAPE ID

4027018

NUMBER OF NUCLIDES

NUMBER OF NEUTRON GROUPS

FIRST THERHAL GROUP

HUMBER OF GAMMA GROUPS

83

27

15

SCALE4 - 27 NEUTRON 18 GAMMA GROUP SHIELDING LIBRARY

BASED ON ENDF-B VERSION 4 DATA

COMPILED FOR NRC $1 / 27 / 89$

LAST UPDATED $\quad 9 / 19 / 90$

900

ORNL

1001

DOSE FACTORS

$1 / \mathrm{V}$ CROSS SECTIONS NORMALIZED TO 1.0 AT 0.0253 EV

HYDROGEN ENDF/B-IV MAT 1269/THRM1002

DEUTERIUM ENDF/B-IV MAT 1120

HELIUM-4 ENDF/B-IV MAT 1270

LITHIUM-6 ENDF/B-IV MAT 1271

LITHIUM-7 ENDF/B-IV MAT 1272

BERYLLIUM-9

ENDF/B-IV MAT 1289/TH

BORON-10 ENDF/8-IV MAT 1273

CARBON-12

ENDF/B-IV MAT 1274/THRM1065

NITROGEN-14 ENDF/B-IV MAT 1275

OXYGEN-16 ENDF/B-IV MAT 1276

FLUORINE ENDF/B-IV MAT 1277

SODIUM-23 ENDF/B-IV MAT 1156

MAGNESIUM ENDF/B-IV MAT 1280

ALUMINUM ENDF/B-IV MAT 1193

SILICON ENDF/B-IV MAT 1194

PHOSPHORUS-31 LENDL MAT 7019

SULFUR LENDL MAT 7020

CHLORINE ENDF/B-IV MAT 1149

POTASSIUM ENDF/B-IV MAT 1150

CALCIUM ENDF/B-IV MAT 4152

TITANIUM ENDF/B-IV MAT 1286

VANADIUM ENDF/B-IV MAT 1196

CHROMIUM ENDF/B-IV MAT 1191

CHROMIUM(SS304)ENDF/B-IV MAT 1191

CHROMIUM(INCONLENDF/B-IV MAT 1191

MANGANESE ENDF/B-IV MAT 1197

IRON ENDF/B-IV MAT 1192

IRON(SS304) ENDF/B-IV MAT 1192

IRON(INCONEL) ENDF/B-IV MAT 1192

COBALT-59 ENDF/B-IV MAT 1199

NICKEL ENDF/B-IV MAT 1190

NICKEL(SS304) ENDF/B-IV MAT 1190

MICKEL (INCONEL)ENDF/B - IV MAT 1190

COPPER ENDF/B-IV MAT 1295

BROMINE-79

ENDF/B-IV MAT 108

BROMINE-81

ENDF/B-IV MAT 112

ZIRCONIUM

ENDF/B-IV MAT 7141

2IRCALLOY

ENDF/B-IV MAT 1284

40302

ENDF/B-IV MAT 1189

NIOBIUM-93

ENDF/B-IV MAT 1287

SILVER-107

SILVER-109

CADMIUH

ENDF/B-IV MAT 1138

47107

47109

ENDF/B-IV MAT 1139

INDIUM-113

ENDF/B-IV MAT 1281

49113

49115

50000

INDIUM-115

ENDF/B-IV MAT 445

TIN

ENDF/B-IV MAT 449

XENON-135

54135

ENDF/B-IV MAT 7039

CESIUH-133

ENDF/B-IV MAT 1294

64000

66164

GADOLINIUM

ENDF/B-IV MAT 1030

DYPROSIUM-164 ENDF/B-IV MAT 1031

LUTETIUM-175 ENDF/B-IV MAT 1032

LUTETIUM-176 ENDF/B-IV MAT 1033

HAFNIUH

ENDF/B-IV MAT 1034

TANTALUM-181 ENDF/B-IV MAT 1285

TUNGSTEN-182 ENDF/B-IV MAT 1128

TUNGSTEN-183 ENDF/B-IV MAT 1120

TUNGSTEN-184 ENDF/B-IV MAT 1130

TUNGSTEN-186 ENDF/B-IV MAT 1131

ON VOLUME PSDEO2

UPDATED $9 / 07 / 89$

UPDATED $10 / 13 / 89$

UPDATED $10 / 13 / 89$

UPDATED $10 / 13 / 89$

UPDATED $10 / 13 / 89$

UPDATED $10 / 13 / 89$

UPDATED $10 / 13 / 89$

UPDATED $10 / 13 / 89$

UPDATED $10 / 13 / 89$

UPDATED $10 / 13 / 89$

UPDATED $10 / 13 / 89$

UPDATED $10 / 13 / 89$

UPDATED $10 / 13 / 89$

UPDATED $10 / 13 / 89$

UPDATED $10 / 13 / 89$

UPDATED $10 / 13 / 89$

UPDATED $10 / 13 / 89$

UPDATED $9 / 19 / 90$

UPDATED $9 / 19 / 90$

UPDATED $9 / 19 / 90$

UPDATED $9 / 19 / 90$

UPDATED $10 / 13 / 89$

UPDATED $10 / 13 / 89$

UPDATED $10 / 13 / 89$

UPDATED $10 / 13 / 89$

UPDATED $10 / 13 / 89$

UPDATED $10 / 13 / 89$

UPDATED $10 / 13 / 89$

UPDATED $10 / 13 / 89$

UPDATED $10 / 13 / 89$

UPDATED $10 / 13 / 89$

UPDATED $10 / 13 / 89$

UPDATED $10 / 13 / 89$

UPDATED $10 / 13 / 89$

UPDATED 10/13/89

UPDATED $10 / 13 / 89$

UPDATED 10/13/89

UPDATED $10 / 13 / 89$

UPDATED 10/13/89

UPDATED $10 / 13 / 89$

UPDATED $10 / 13 / 89$

UPDATED $10 / 13 / 89$

UPDATED 10/13/89

UPDATED 10/13/89

UPDATED 10/13/89

UPDATED $10 / 13 / 89$

UPDATED $10 / 13 / 89$

UPDATED $10 / 13 / 89$

UPDATED $10 / 13 / 89$

UPDATED $10 / 13 / 89$

UPDATED 10/13/89

UPDATED 10/13/89

UPDATED $10 / 13 / 89$

UPDATED $10 / 13 / 89$

UPDATED $10 / 13 / 89$

UPDATED $10 / 13 / 89$

UPDATED 10/13/89

UPDATED 10/13/89

UPDATED 10/13/89

UPDATED 10/13/89

UPDATED $10 / 13 / 89$

NUREG/CR-0200,

Vol. 3, Rev. 4

M4.A.14 
RHENIUM-185 ENDF/B-IV MAT 1083 RHENIUM-187 ENDF/B-IV MAT 1084 GOLD-197 ENDF/B-IV MAT 1283 LEAD THORIUM-232 ENDF/B-IV MAT 1288 ENDF/B-IV MAT 1296 PA-233 1297218 GP WT F-1/E-M 090376 P3 293K URANIUH-233 ENDF/B-IV MAT 1269 URANIUM-234 ENDF/B-IV MAT 1043 URANIUH-235 ENDF/B-IV MAT 1261 URANIUH-235 ENDF/B-IV MAT 1163 URANIUM-238 ENDF/B-IV MAT 1262 NEPTUNIUM-237 ENDF/B-IV HAT 1263 PLUTONIUM-238 ENDF/B-IV MAT 1050 PLUTONIUM-239 ENDF/B-IV MAT 1264 PLUTONIUH-240 ENDF/B-IV MAT 1265 PLUTONIUH-241 ENDF/B-IV HAT 1266 PLUTONIUM-242 ENDF/B-IV MAT 1161 AM-241 1056 SIGP $=5+4$ NEWXLACS 218NGP P-3 293K AM-243 1057218 GP WT F-1/E-H 090376 P3 293K CURIUM-244

FAKE DATA SET OF DOSE FACTORS
UPDATED $10 / 13 / 89$

UPDATED $10 / 13 / 89$ UPDATED $10 / 13 / 89$

UPDATED $10 / 13 / 89$ UPDATED $10 / 13 / 89$

UPDATED $10 / 13 / 89$ UPDATED $10 / 13 / 89$ UPDATED $10 / 13 / 89$ UPDATED $10 / 13 / 89$ UPDATED $10 / 13 / 89$ UPDATED $10 / 13 / 89$ UPDATED $10 / 13 / 89$ . UPDATED $10 / 13 / 89$ UPDATED $10 / 13 / 89$ UPDATED $10 / 13 / 89$ UPDATED $10 / 13 / 89$

UPDATED $10 / 13 / 89$ 
M4.A.8 THE 27-GROUP BURNUP LIBRARY TABLE OF CONTENTS FOR C.TZA27286.SCALE4.REV02.XN27BURN
TAPE ID 4027000

$\begin{array}{lr}\text { NUMBER OF NUCLIDES } & 252 \\ \text { NUMBER OF NEUTRON GROUPS } & 27 \\ \text { FIRST THERMAL GROUP } & 15 \\ \text { NUMBER OF GAMMA GROUPS } & 0\end{array}$

SCALE 4 - 27 NEUTRON GROUP BURNUP LIBRARY

BASED ON ENDF-B VERSION 4 DATA

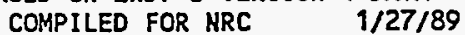

DEUTERIUM ENDF/B-IV MAT 1120 UPDATED 10/13/89

3007 LI -71272218 GP $1 / E^{\star}$ SIGT $040375(5)$
4009
BERYLIUM-9 ENDF/B-IV MAT 1289/THF

16000

17000

19000

20000

22000

23051

24000

24304

24404

25055

26000

26304

26404

27059

28000

28304

28404

29000

32072

32073

32074

32076

33075

34076

34077

34078

34080

34082

35079

35081

36080

36082

36083

36084

36085

36086

37085

37086

37087

38086

38087

38088 ENDF/B-IV MAT 1289/THRM1064

B-10 1273 218NGP 042375 P-3 293K

BORON-11 ENDF/B-IV MAT 1160

CARBON-12 ENDF/B-IV MAT 1274/THRM1065

NITROGEN-14 ENDF/B-IV MAT 1275

$\begin{array}{ll}\text { OXYGEN-16 } & \text { ENDF/B-IV MAT } 1276 \\ \text { FLUORINE } & \text { ENDF/B-IV MAT } 1277\end{array}$

SODIUM-23 ENDF/B-IV MAT 1156

HG 1280218 GP 1/E*SIGT 040375(5)

AL-27 1193218 GP 040375(5)

SILICON ENDF/B-IV MAT 1194

P-31 7019 218NGP WT 1/EST 042375 P3 293K

SULFUR LENDL MAT 7020

CHLORINE ENDF/B-IV MAT 1149

POTASSIUM ENDF/B-IV MAT 1150

CALCIUM ENDF/8-IV MAT 1195

TITANIUM ENDF/B-IV MAT 1286

V 1196218 GP 1/E*SIGT 040375(5)

CR 1191 218NGP WT 1/E P-3 293K SIGP=5+4 RE(042375)

CR 1191 WT SS-304(1/EST) $P-3$ 293K SP $=5+4(42375)$ '

CR 1191 WT INCONL(1/EST) $P-3$ 293K SP=5+4(42375)

MANGANESE-55 ENDF/8-IV MAT 1197 UPDATED $10 / 13 / 89$

IRON ENDF/B-IV MAT 1192 UPDATED 10/13/89

FE 1192 WT SS-304(1/EST) $P-3$ 293K SP=5+4(42375)

FE 1192 WT INCONL(1/EST) P-3 293K SP=5+4(42375)' COBALT-59 ENDF/B-IV MAT 1199

UPDATED $10 / 13 / 89$

NI 1190 218NGP HT 1/E P-3 293K SIGP=5+4 RE(042375)

NI 1190 WT SS-304(1/EST) P-3 293K SP $=5+4(42375)$ '

NI 1190 UT INCONL(1/EST) $P-3$ 293K $S P=5+4(42375)$

COPPER . ENDF/B-IV MAT 1295 UPDATED 10/13/89

GE-72 MT=102 UPDATED $10 / 13 / 89$

GE-73 MT $=102$ UPDATED $10 / 13 / 89$

GE-74 MT=102 UPDATED $10 / 13 / 89$

GE-76 HT=102 UPDATED $10 / 13 / 89$

AS-75 MT $=102 \quad$ UPDATED $10 / 13 / 89$

$\begin{array}{lll}\text { SE-76 MT }=102 & \text { UPDATED } 10 / 13 / 89\end{array}$

$\begin{array}{lll}S E-77 & M T=102 & \text { UPOATED } 10 / 13 / 89\end{array}$

SE-78 MT $=102$ UPDATED $10 / 13 / 89$

SE-80 MT $=102$

SE-82 MT $=102$

BROMINE-81 ENDF/B-IV MAT 112 UPDATED $10 / 13 / 89$

$K R-80$

$K R-82$

$\mathrm{KR}-83$

$K R-84$

$\mathrm{KR}-85$

$\mathrm{KR}-86$

$\mathrm{RB}-85$

$R B-86$

RB -87

$\mathrm{SR}-86$

SR -87

SR -88

SR -89

$M T=102,103,104,105,106,107$

$M T=102,103,104,105,106,107$

MT $=102,103,103,105,106,107$ UPDATED $10 / 13 / 89$

$M T=102,103,104,105,106,107$

$M T=102$

$M T=102,103,104,105,107$

$M T=102$

$M T=102 \quad$ UPDATED $10 / 13 / 89$

UPDATED $10 / 13 / 89$

$\begin{array}{lll}M T= & 102 & \\ M T=102 & \end{array}$

102

UPDATED $10 / 13 / 89$

NUREG/CR-0200, 


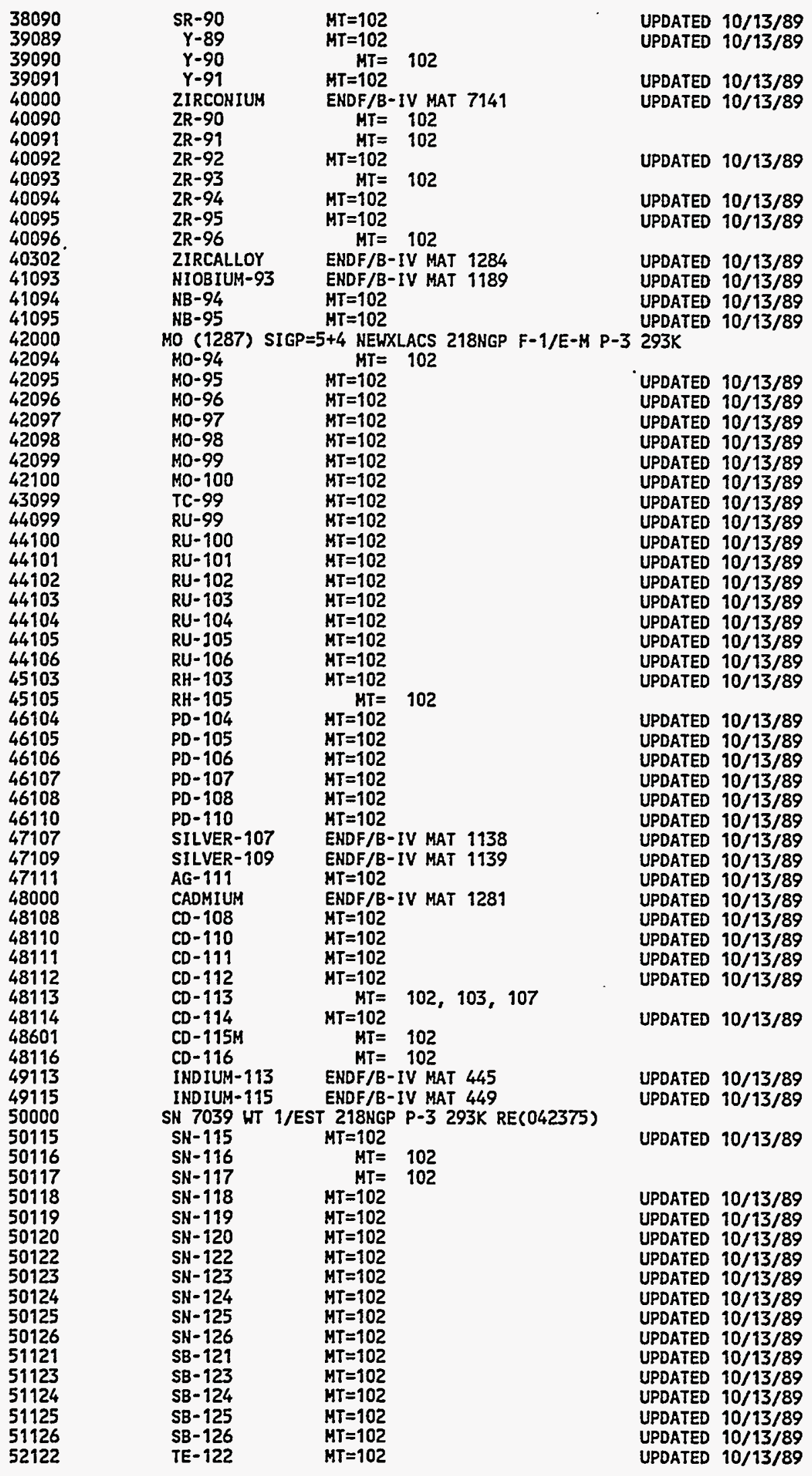

NUREG/CR-0200, Vol. 3, Rev. 4 


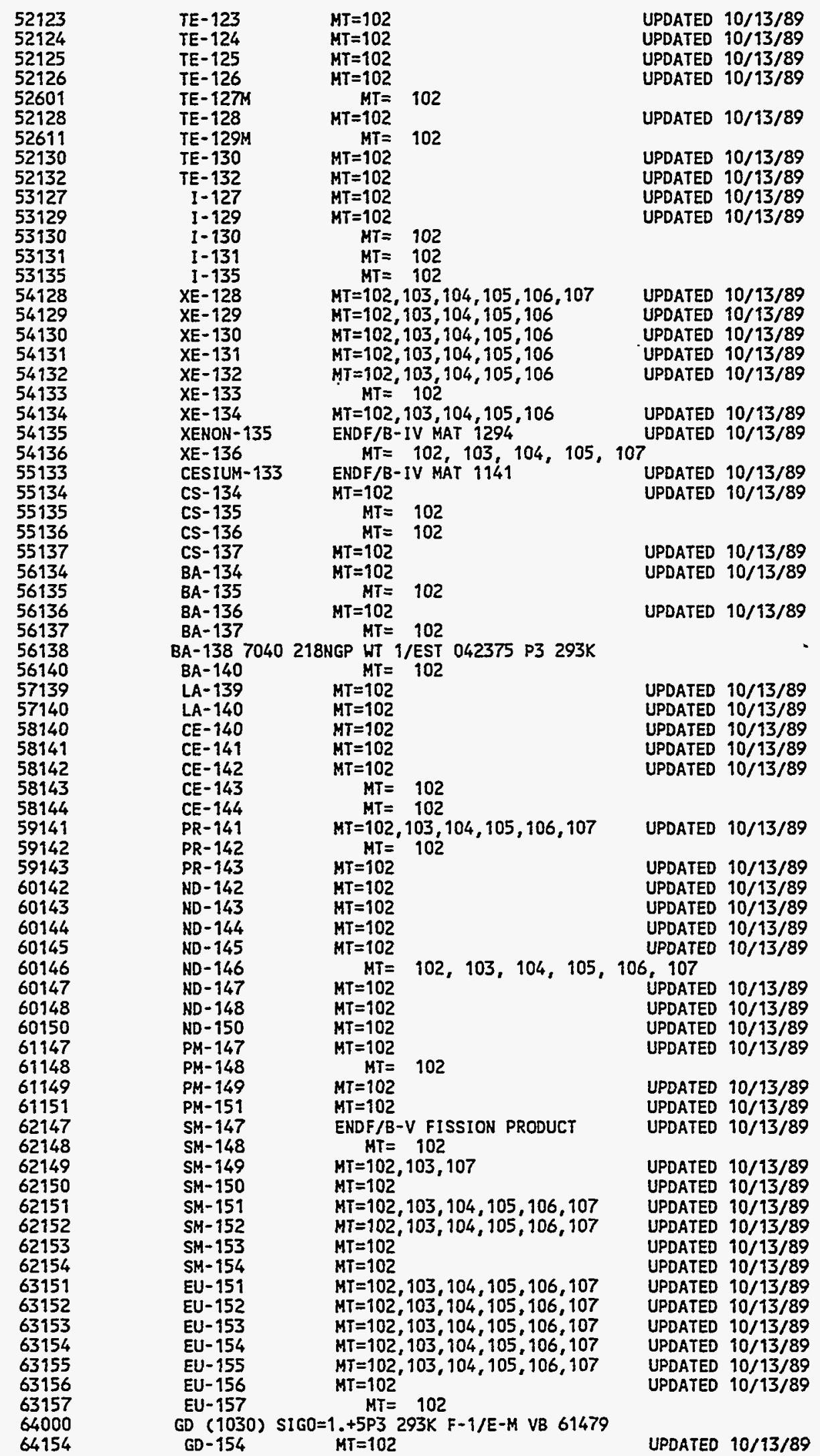

NUREG/CR-0200,

Vol. 3, Rev. 4

M4.A.18 


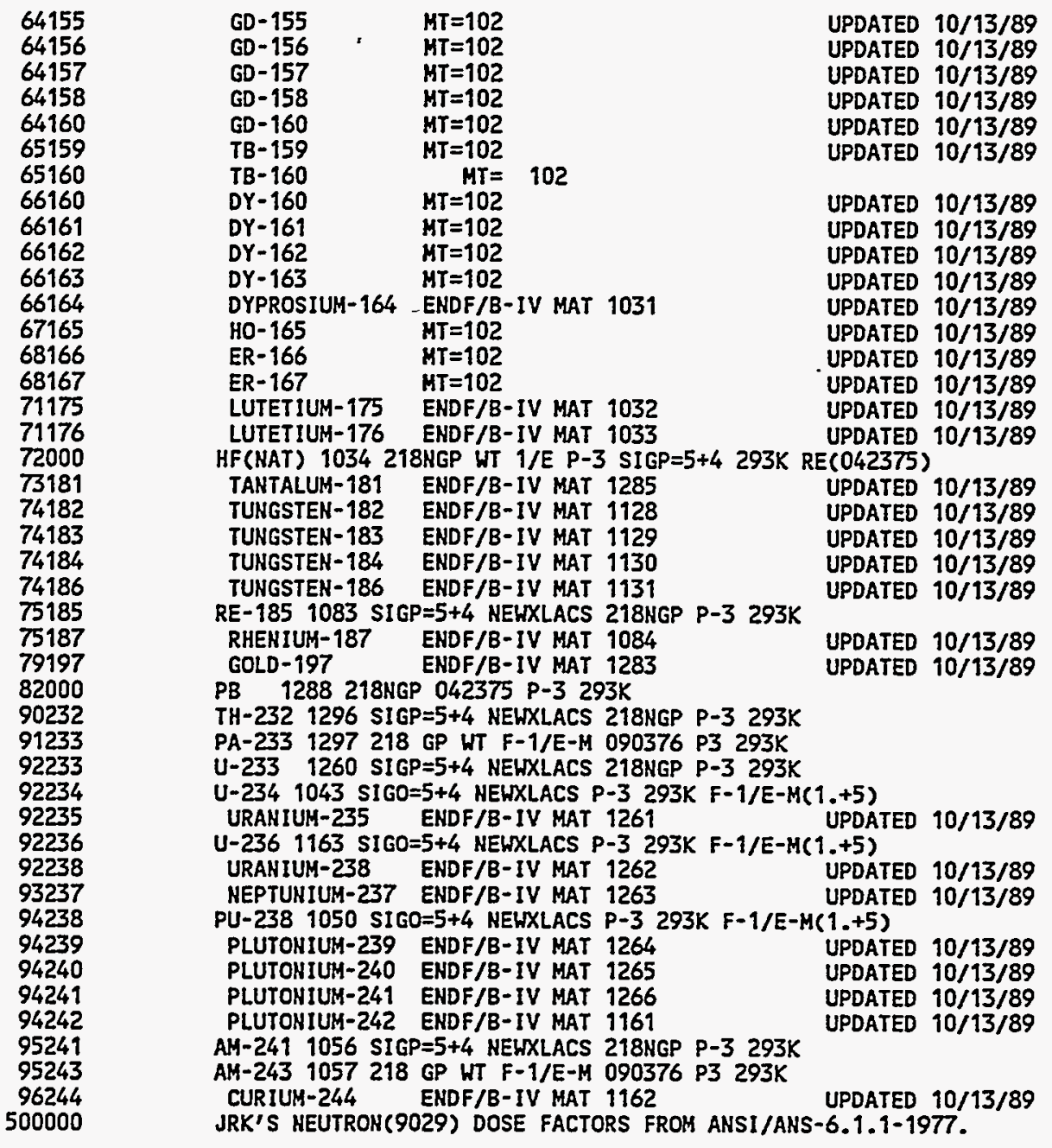




\section{M4.B LOCAL EXPERIENCE WITH THE 27-GROUP ENDF/B-IV LIBRARY}

Continuous efforts are made at ORNL to identify the cause of any calculational bias observed when using the SCALE system. Bias exists when a calculated value differs from an experimental value or a value calculated by another code or cross-section library for the same system. Cross-section bias is routinely studied when two calculations of the same system or a calculation of an experiment disagree by more than about $0.5 \%$. (Agreement between calculation and experiment to about $0.5 \%$ appears to be an acceptable limit considering that the SCALE codes and cross sections are intended for very general applications.) One way to study cross-section bias is to change suspected cross sections and then demonstrate that the bias diminishes or disappears. This process has led to discovery of some deficiencies in the 218- and 27-group ENDF/B-IV libraries currently in SCALE. These deficiencies are discussed in this section.

\section{M4.B.1 BIAS DUE TO POOR CARBON CROSS SECTIONS}

Negative bias of up to $2.5 \%$ has been observed for numerical benchmark comparison between the 27-group ENDF/B-IV library and the Hansen-Roach and 27-group ENDF/B-V libraries for carbon systems. Calculations with the 218-group library also showed a significant bias. Analysis of the 218-group data indicated abnormalities in the 1099 flux file. (This file contains the 218-group flux representing the flux spectrum used to generate the fine group data.) Examination of the group 10 cross section of the 27-group library indicated an incorrect scatter matrix, which caused a significant flux depression in this group. Carbon was regenerated from ENDF/B-IV data, and the bias disappeared.

\section{M4.B.2 BIAS DUE TO ABSENCE OF BONDARENKO DATA FOR ${ }^{235} U$ AND ${ }^{238} U$}

Negative bias of up to $2 \%$ has been observed between the 27- and 218-group ENDF/B-IV libraries compared with the Hansen-Roach, 123-group, and 27-group ENDF/B-V libraries for low-enriched uranium oxide rods closely spaced in borated water. The bias was traced to inadequate cross sections in the unresolved resonance region of ${ }^{238} \mathrm{U}$. (Unresolved resonance cross sections in the SCALE ENDF/B-IV libraries were generated at $\sigma_{\mathrm{p}}=50,000$. This might be compared with values of $\sigma_{\mathrm{p}}=3500$ for ${ }^{235} \mathrm{U}$ and $\sigma_{\mathrm{p}}=65$ for ${ }^{238} \mathrm{U}$ in a typical light-water-reactor lattice.) Unresolved resonance data were generated from ENDF/B-IV and added to ${ }^{255} \mathrm{U}$ and ${ }^{238} \mathrm{U}$ in the revised libraries. The bias was reduced by about $70 \%$. Study of the remaining bias indicated that the resolved resonance region cross sections for ${ }^{238} \mathrm{U}$ were inadequate. (One of the major revisions between ENDF/B-IV and ENDF/B-V for ${ }^{238} U$ was in the resolved resonance region.)

\section{M4.B.3 BIAS IN ${ }^{239} \mathrm{Pu}$ THERMAL SYSTEMS}

A positive bias of 1.15 to $2 \%$ has been routinely observed in validation of the SCALE 27-group library on thermal ${ }^{239} \mathrm{Pu}$ systems. Investigation of the bias indicated that the $0.3-\mathrm{eV}$ resonance of ${ }^{239} \mathrm{Pu}$ significantly overlapped the Maxwellian used in cross-section generation. A hybrid thermal library was generated from ENDF/B-IV and used to construct a flux-weighting file. The flux file was used to collapse the thermal library to a 27-group library. The bias was eliminated for the system under consideration. More extensive review of ${ }^{239} \mathrm{Pu}$ thermal systems indicated that the 27-group structure was inadequate to account for flux changes (as a function of $\mathrm{Pu}$ concentration) across the $0.3-\mathrm{eV}$ resonance. An intermediate 41-group library was collapsed from the 218 -group library for use on thermal ${ }^{239} \mathrm{Pu}$ systems. 


\section{M4.B.4 KNOWN CROSS-SECTION IRREGULARITIES}

The hafnium cross-section data available in the 218- and 27-group ENDF/B-IV libraries are not ENDF/B-IV data (ENDF/B-IV did not include hafnium). Known irregularities are present in the cross section, and no resonance data are available with the nuclide. The cross sections are infinite dilution (1/E weighting) across the resonance range. Use of the above sets of hafnium data should be done with caution.

Systems containing gadolinium have not calculated well with the 27-group library. The problem stems from the characteristic of the gadolinium data in the thermal range. Gadolinium has low-energy resonance data down to $10^{-5} \mathrm{eV}$. The resonances are so broad that the implementation of the Nordheim treatment in NITAWL-II fails to have a mesh point in group 27 of the 27-group structure. This has been addressed by setting the bottom energy of the resonance data to that of group 26 and carrying infinite dilution cross sections in group 27 of the master library. Use of the gadolinium in the SCALE system, especially for very dilute systems, should be done with caution.

\section{M4.B.5 THERMALSCATTERING DATA LIMITATION}

A discrepancy was discovered in comparing KENO V.a calculations using the 27-group library and CASMO- $3^{1}$ calculations for LWR fuel assemblies in a storage configuration as a function of temperature. The two codes were in relative agreement at low temperatures $\left(20^{\circ} \mathrm{C}\right)$ and small water gaps between assemblies. However, as the temperature of the system was increased to $120^{\circ} \mathrm{C}$, the CASMO calculations gave increasingly larger values of $k_{\text {eff }}$ relative to KENO. Larger water gaps (between assemblies) enhanced the temperature effects on calculated $\mathrm{k}_{\mathrm{efr}}$. The KENO results were as much as $3 \%$ lower than CASMO at $120^{\circ} \mathrm{C}$.

The cause of this discrepancy has been identified as a limitation in processing the thermal-scattering data when NITAWL makes a working library. The SCALE 27-group ENDF/B-IV hydrogen has scattering matrices at $293 \mathrm{~K}$ and $550 \mathrm{~K}\left(20^{\circ} \mathrm{C}\right.$ and $\left.277^{\circ} \mathrm{C}\right)$. When NITAWL processes hydrogen, the scattering matrix with a temperature closest to that specified is used. It was determined that the temperature dependence of the scattering can increase the multiplication factor by as much as $2.5 \%$. Users should be aware of this problem and ensure that the hydrogen-scattering matrices used in their analyses are either appropriate or conservative with respect to $k_{e n t}$.

With regard to the other criticality libraries in SCALE, hydrogen has kernels at $295 \mathrm{~K}$ and $345 \mathrm{~K}$ in the 123-group library and only at room temperature in the Hansen-Roach library. Information on the thermal kernels for other nuclides may be found in Tables M4.2.4, M4.2.6, and M4.2.8.

No changes are planned for any of the existing SCALE-4 cross-section libraries, but there are plans to eventually release new ENDF/B-V cross-section libraries that will have hydrogen kernels at 296,350 , $400,450,500,600,800$, and $1000 \mathrm{~K}$

\section{M4.B.6 GENERAL COMMENTS ON THE SCALE 27-GROUP LIBRARY}

The 27-group ENDF/B-IV library has given good results for a broad range of calculations of critical experiments. The bias discussed above applies to very specific systems (as do the cross-section modifications to correct the bias). Analysis and correction of the bias in the cross sections gives considerable insight into the considerations and requirements that will be given to the next generation of SCALE cross-section libraries.

\section{REFERENCE OF APPENDIX B}

1. M. Edenius, A Ahlin, and B. Forssen, "CASMO-3G, A Fuel Assembly Burnup Program," User's Manual, STUDSVIK/NFA-86/7, November 1986.

NUREG/CR-0200, 
NUREG/CR-0200

Revision 4

Volume 3, Section M5

ORNL/NUREG/CSD-2/V3/R4

Computing Applications Division

\title{
THERMAL MATERIAL PROPERTIES LIBRARY
}

\author{
A. L. Edwards* \\ P. T. Williams
}

Manuscript Completed: August 1989

Date Published: April 1995

Prepared for theOffice of Nuclear Material Safety and SafeguardsU. S. Nuclear Regulatory CommissionWashington, DC 20555Under Interagency Agreement DOE 1886-8000-9BNRC JCN No. B0009

Prepared by the

OAK RIDGE NATIONAL LABORATORY managed by MARTIN MARIETTA ENERGY SYSTEMS, INC.

for the

U.S. DEPARTMENT OF ENERGY

under contract DE-AC05-84OR21400

"Lawrence Livermore National Laboratory. 


\begin{abstract}
The thermal property data compiled and prepared at Lawrence Livermore National Laboratory by Dr. A. L. Edwards have long been used in conjunction with the HEATING series of codes. The thermal property data including density, specific heat, and thermal conductivity were tabulated against temperature, transition temperatures, and latent heats of transition for more than 1000 materials. These data were collected from over 50 references, most of which contain extensive data tabulations and bibliographies. In addition to the data obtained from the sources listed, estimates were also made for many materials for which data could not be found. These estimates were done wherever the estimates appeared to be as accurate as measured values for similar materials. The data library is arranged such that materials are identified numerically according to a general and flexible classification system. An accompanying alphabetical index describes each material, assigns it an identification number, references the sources of the data by code number, and codes the quality or reliability of the data.

This collection of thermal data makes up the thermal material properties library distributed with the SCALE system for use by the HEATING and HTAS1 modules. This section of the SCALE Manual relies heavily on the text of UCRL-50589 to provide SCALE users with a thorough description of the available thermal material properties library.
\end{abstract}




\section{CONTENTS}

Page

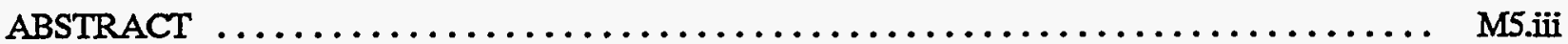

IIST OF TABLES $\ldots \ldots \ldots \ldots \ldots \ldots \ldots \ldots \ldots \ldots \ldots \ldots \ldots \ldots \ldots \ldots \ldots \ldots \ldots \ldots \ldots \ldots \ldots$

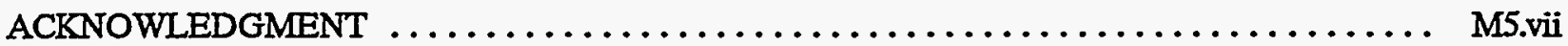

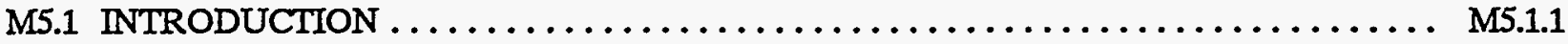

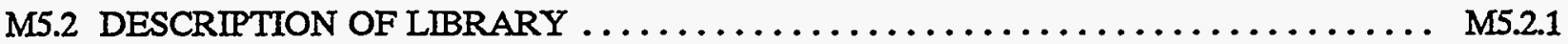

M5.3 LIBRARY DATA SOURCES $\ldots \ldots \ldots \ldots \ldots \ldots \ldots \ldots \ldots \ldots \ldots \ldots \ldots \ldots \ldots \ldots \ldots \ldots \ldots \ldots \ldots .1$

M5.4 MATERIAL CLASSIFICATION SYSTEM $\ldots \ldots \ldots \ldots \ldots \ldots \ldots \ldots \ldots \ldots \ldots \ldots \ldots . \ldots \ldots .1$

M5.5 QUALITY INDICATOR SYSTEM $\ldots \ldots \ldots \ldots \ldots \ldots \ldots \ldots \ldots \ldots \ldots \ldots \ldots \ldots \ldots .1$

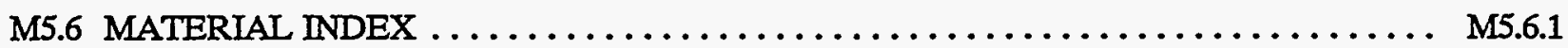

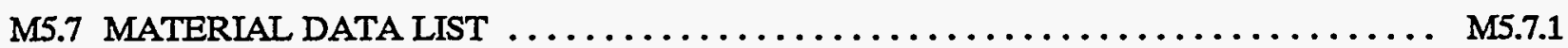

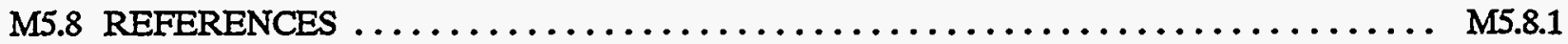


LIST OF TABLES

Table

Page

M5.3.1 Data sources $\ldots \ldots \ldots \ldots \ldots \ldots \ldots \ldots \ldots \ldots \ldots \ldots \ldots \ldots \ldots \ldots \ldots \ldots \ldots \ldots \ldots .2$

M5.4.1 Material classification system $\ldots \ldots \ldots \ldots \ldots \ldots \ldots \ldots \ldots \ldots \ldots \ldots \ldots \ldots \ldots \ldots \ldots .2$

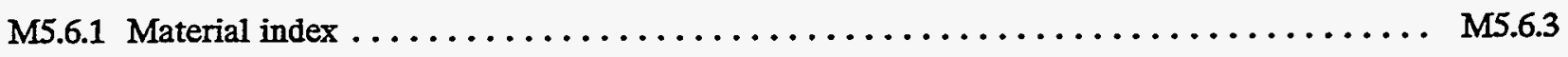

NUREG/CR-0200,

Vol. 3, Rev. $4 \quad$. M5.vi 


\section{ACKNOWLEDGMENT}

The developers of HEATING and the SCALE system gratefully acknowledge A. L. Edwards' consent to use an edited version of his earlier published document, $A$ Compilation of Thermal Property Data for Computer Heat-Conduction Calculations, UCRL-50589 (1969), as the basis for this section of the SCALE Manual. 


\section{M5.1 INTRODUCTION}

The availability of computer programs for solving problems in transient and steady-state heat conduction makes it possible to rapidly and accurately. solve large numbers of problems involving a wide variety of materiais, provided that accurate input data are used. In particular, the thermal properties of the materials, including density, specific heat, and thermal conductivity and the dependence of these properties on temperature, temperatures, latent heats of transition, and the temperature ranges for specific applications, should be known as accurately as possible. Some of these properties are difficult to measure and may vary from sample to sample, depending on the method of fabrication and previous history. Therefore, when used in calculations, the possible inaccuracy or variability of thermal data should be accounted for in interpreting the results. For this reason, Dr. A. L. Edwards of the Lawrence Livermore National Laboratory (LLNL) compiled a library of thermal property data (see Ref. 1) in the late 1960s that is still being widely used in heat transfer calculations.

For many years, this LLNL library of thermal material properties has been used by the HEATING series of codes developed at Oak Ridge National Laboratory (ORNL). Therefore, this library was selected for inclusion in, and subsequent distribution with, the SCALE computational system that contains HEATING as one of its functional modules (see Sect. F10). The HTAS1 control module (see Sect. H1), which accesses HEATING, also uses the material properties library. The HEATING and HTAS1 programs give the user the option of inputting thermal data for a problem on the material input cards or of allowing the program to extract the properties from the LLNL material properties library. The material properties available in the library are density, thermal conductivity, specific heat, transition temperature, and latent heat. The density of the material is typically either the value at or near room temperature or the lowest temperature for which specific heat or conductivity is tabulated, whichever is highest. The thermal conductivity and specific heat of the material are given if they are constant or if the temperature dependence is unknown. When a table of thermal conductivity or specific heat vs temperature is listed in the library, the table will be stored and used as a tabular function by HEATING. The transition temperature is the temperature at which either a phase change or a solid-state transition occurs. The latent heat is the amount of heat absorbed by the material when the temperature is increased past the transition temperature.

The material properties library is available in SCALE with the centimeter gram second-calorie-degrees Celcius (cgs-cal- ${ }^{\circ} \mathrm{C}$ ) system. Conversion to any other unit system can be controlled through HEATING (see Sect. F10) input data. HEATING accesses logical unit IMATLB (currently equal to 78) whenever the input specifies that data be extracted from the material properties library. Conversion to the English units employed in HTAS1 is handled automatically.

This section of the SCALE Manual provides documentation on the format and contents of the LLNL thermal material properties library provided with the SCALE system. Information and tables describing the format and contents are taken directly from Ref. 1 with the permission of the author, Dr. A. L. Edwards. 


\section{M5.2 DESCRIPTION OF THE LIBRARY}

Thermal property data for over 1000 materials have been compiled in the material properties library. The compilation includes (1) a numbered list of data sources, primarily those containing extensive data tabulations and bibliographies; (2) a numerical classification system used as a guide in assigning a permanent identification number to each material included in the system; (3) a system of quality indicators used to show the general reliability or accuracy of data included in the compilation; (4) thermal property data sheets for each material, including all tabular and graphical data collected or estimated by A. L. Edwards and converted to a standard system of units; (5) an alphabetical index of materials that includes the identification number assigned to each material, an alphanumeric designator for auxiliary identification, a list of data sources by number, and a quality indicator for each type of data given for the material; and (6) a list of material property data arranged according to the material identification numbers. These material properties data include the material identification number and alphanumeric designator, density, specific heat, thermal conductivity, phasechange or transition temperature, latent heat effect, and tables of specific heat and thermal conductivity vs temperature.

The data compilation described herein was completed about 1969 and, even at that time, no claim of completeness or comprehensiveness was made. However, developers of the HEATING codes never updated the library. 'Analysts should check subsequent tables in this document for the source of the data for a given material to be used. Also, the analysts can disregard the material properties library and input original or updated data into HEATING. Thermal data for new or special materials not in the library should also be obtained by the analyst. 


\section{MS.3 LIBRARY DATA SOURCES}

The sources for most of the data included in the compilation and several other general sources are listed in abbreviated form in Table M5.3.1. The numbers of the first column are used in the alphabetical material index to cross-reference the sources. Asterisks indicate the data sources actually used for the compilation. Classified data sources were omitted from Ref. 1 and this report. The source used most extensively for the compilation is that edited by Touloukian (No. 20) of Table M5.3.1.

Reference 1 provides an estimate of the thermal properties for a large number of materials for which no reliable data could be found. These estimates have been included whenever the estimates appeared to be as accurate as available data for similar materials.

Many errors were found in the literature and corrected before including the data in the original compilation (Ref. 1). Most of these errors were introduced by incorrect conversion from one unit system to another, incorrect labelling or interpretation of axes labels or scales on graphs, and confusion between units of mass or gram-molecular weight used for specific heats. 
Table M5.3.1 Data sources

\begin{tabular}{|c|c|c|c|}
\hline & MATERIAI PROPERTIES F & FERENCES. & \\
\hline 1 & * PERRY J H & CHEMICAL ENGINEERS HANDBOOK 4TH ED & 1963 \\
\hline 2 & * MCADAMS W H & HEAT TRANSMISSION 3RD ED & 1954 \\
\hline 3 & * & LIQUMD METALS HANDBOOK 2ND ED & 1952 \\
\hline 4 & * MARKS L S & MECHANICAI ENGINEERS HANDBOOK 5TH ED & 1951 \\
\hline 5 & * FLEMUNG P & PRIVATE COLIECTION OF PLASTICS DATA & 1968 \\
\hline 6 & * & MATERIALS ENGR MATL SELECTOR ISSUE & 1967 \\
\hline 7 & PFEIFER H & PRIVATE COLLECTION OF MATERIALS DATA & 1968 \\
\hline 8 & * JAMES E & PROPERTIES OF CHEMICAL EXPLOSIVES UCRL 14592 & 1965 \\
\hline 9 & & ASRE DATA BOOK & \\
\hline 10 & & AIRPLANE AIR CONDITIONING ENGR DATA & 1952 \\
\hline 11 & & INTERNATIONAL CRITICAL TABLES & 1926 \\
\hline 12 & JOHNSON A I & THERMAL CONDUCTIVITY CHART FOR GASES & 1954 \\
\hline 13 & HWSENRATH J & TABLES OF THERMAL PROPERTIES OF GASES NBS 564 & 1955 \\
\hline 14 & - TIPTON CR JR & THE REACTOR HANDBOOK 2ND ED VOL 1 & 1960 \\
\hline 15 & KUONG J F & THERMAL PROPERTIES OF LIQUIDS & 1963 \\
\hline 16 & & THE REACTOR HANDBOOK VOL 3 ENGINEERING & 1963 \\
\hline 17 & & ENGLISH TRANSL OF HANDBUCH DER PHYSIC & 1962 \\
\hline 18 & HOYT S L & METAL DATA & 1952 \\
\hline 19 & AVDUYEVSKTY V S & FUNDLS OF HEAT TRANSFER IN AV AND RKT ENGR & 1962 \\
\hline 20 & - TOULOUKIAN Y S & THERMOPHYSICAL PROP OF HIGH TEMP SOLID MATLS & 1967 \\
\hline 21 & & PRELIM REPT ON THE PROP OF LI BE MG AL NBS6297 & 1959 \\
\hline 22 & & TH PROP OF SELD IIGHT ELEMENT CPDS NBS7437 & 1962 \\
\hline 23 & KOWALCZYK I S & THERMAL COND AND ITS VARN WITH T AND P & 1955 \\
\hline 24 & JOHNSON V J & A COMPDM OF PROP OF MATL AT LOW TEMP NBS & 1960 \\
\hline 25 & & JANAF THERMOCHEMICAL TABLES & \\
\hline 26 & KELIEY K K & ENTROPIES OE ELEMENTS AND INORG CPDS BM592 & 1961 \\
\hline 27 & * WEAST R C & HANDBOOK OF CHEMISTRY AND PHYSICS 4TTH ED & 1966 \\
\hline 28 & * JESTER M & PRIVATE COLLECTION OF LIQUID METAL PROPERTIES & 1968 \\
\hline 29 & WICKS CE & THERMODYN PROP OF 65 ELEMENTS BU MINES 605 & 1963 \\
\hline 30 & * PETERS R I & MATERIALS DATA NOMOGRAPHS & 1965 \\
\hline 31 & - THOMPSON B & ENERGY CONTENT VS TEMP FOR D-PU A-PU AND U & \\
\hline 32 & * KELIEY K K & ENTHALPY PLOTS DWG K38745 BU MINES 584 & 1960 \\
\hline 33 & - KELLEY K K & BU MINES 371 & 1939 \\
\hline 34 & - LABER D & BMI FINAL REPT ON SANL TASKS 309/032A 401/027 & 1967 \\
\hline 35 & & Y-12 DATA SHEETS & \\
\hline 36 & * SCHAUER D & WEAPONS MATL DATA BOOK & \\
\hline 37 & * SCHORSCH R H & ENGINEERING PROPERTIES OF SELECTED MATLS & 1966 \\
\hline 38 & & MODERN PLASTICS ENCYCLOPEDIA & 1968 \\
\hline 39 & & HANDBOOK OF MOLDED AND EXIR RUBBER GOODYEAR & \\
\hline 40 & • & MACHINE DESIGN REFERENCE ISSUE PLASTICS & 1964 \\
\hline 41 & * & METALS HANDBOOK 8TH ED & 1961 \\
\hline 42 & * STULL D R & THERMODYNAMIC PROPERTIES OF THE ELEMENTS ACS & 1956 \\
\hline 43 & * HAMPEL C A & RARE METAIS HANDBOOK 2ND ED & 1961 \\
\hline 44 & * MOYER J & PRIVATE COLIECTION OF THERMAL DATA & 1968 \\
\hline 45 & * HODGE A W & PROP OF HIGH TEMP TI ALLOYS DMIC MEMO 230 & 1968 \\
\hline 46 & * CARSLAW H JAEGER J & CONDUCTION OF HEAT IN SOLIDS 2ND ED OXFORD & 1959 \\
\hline 47 & - SMITHELIS C J & METALS REFERENCE BOOK 4TH ED VOL 3 & 1967 \\
\hline 48 & * LYNCH J F RUDERER & ENGR PROP OF SEL CERAM KATIS BMI AM CER SOC & 1966 \\
\hline 49 & & PROP OF KENNAMETAL HARD CARBIDE AIIOYS & 1963 \\
\hline 50 & & PROP HANDBOOK CARBOLOY ETC GE MET PROD & 1958 \\
\hline 51 & * CLARK S P JR & HANDBOOK OF PHYSICAL CONSTANTS GEOL SOC AMER & 1966 \\
\hline 52 & * STEPHENS D R MAIMO & THE THERMAL COND OF ROCK SALT UCRL 6894-II & 1964 \\
\hline 53 & * SEDDON B J & PHYS PROP OF PU CERAMIC CPDS TRG1601 & 1968 \\
\hline 54 & * STORMS EK & THE REFRACTORY CARBIDES & 1967 \\
\hline
\end{tabular}

NUREG/CR-0200,

Vol. 3, Rev. 4

M5.3.2 


\section{M5.4 MATERIAL CLASSIFICATION SYSTEM}

The material classification system tabulated in Table M5.4.1 was used to assign identification numbers to the materials included in this report. The classification of many materials was arbitrary. The range of numbers in each category of materials is sufficient to include most materials of interest and importance. Many unused numbers remain within each category for new materials that can be included in the compilation.

The alphanumeric identifiers assigned to each material aid in identifying the materials on the material data list. In the cases of the elements and most simple compounds, the atomic or molecular formulae are used. In most other cases, acronyms or mnemonics are used. 
Table M5.4.1 Material classification system

\begin{tabular}{|c|c|c|}
\hline \multirow[t]{4}{*}{1000} & \multicolumn{2}{|l|}{ ELEMENTS } \\
\hline & $1001-1499$ & SOLIDS, LIQUIDS \\
\hline & $1501-1599$ & GASES \\
\hline & 1601-1999 & NOT USED \\
\hline \multirow[t]{8}{*}{2000} & \multicolumn{2}{|l|}{ ALLOYS } \\
\hline & 2001-2099 & ALUMINUM ALLOYS \\
\hline & $2101-2399$ & COPPER ALLOYS \\
\hline & $2401-2499$ & MAGNESIUM ALLOYS \\
\hline & $2501-2599$ & NICKEL ALLOYS \\
\hline & $2601-2699$ & COBALT ALLOYS \\
\hline & $2701-2799$ & TITANIUM ALLOYS \\
\hline & $2801-2999$ & NOT USED \\
\hline \multirow[t]{16}{*}{3000} & \multicolumn{2}{|c|}{ ALLOYS (CONTINUED) } \\
\hline & $3001-3099$ & IRON ALLOYS \\
\hline & 3101-3299 & STEELS \\
\hline & $3301-3499$ & SUPER AILOYS (CR-NI-FE) \\
\hline & $3501-3599$ & BERYLLIUM ALLOYS \\
\hline & $3601-3649$ & LEAD, TIN, AND INDIUM ALLOYS \\
\hline & $3651-3679$ & NOLYBDENUM ALLOYS \\
\hline & $3681-3699$ & NIOBIUM (COLUMBIUM) ALLOYS \\
\hline & 3701-3749 & PLUTONIUM ALIOYS \\
\hline & $3751-3779$ & SILVER ALLOYS \\
\hline & $3781-3799$ & TANTALUM ALLOYS \\
\hline & $3801-3829$ & TUNGSTEN ALLOYS \\
\hline & 3831-3859 & URANIUM ALLOYS \\
\hline & 3861-3879 & ZINC ALLOYS \\
\hline & 3881-3899 & ZIRCONIUM ALLOYS \\
\hline & 3901-3999 & MISCELLANEOUS ALLOYS \\
\hline \multirow[t]{14}{*}{4000} & \multicolumn{2}{|c|}{ INORGANIC COMPOUNDS } \\
\hline & $4001-4199$ & OXIDES (SINGLE) \\
\hline & $4201-4299$ & OXIDES (MIXED) \\
\hline & $4301-4399$ & SILICATES \\
\hline & $4401-4499$ & NITRIDES \\
\hline & $4501-4599$ & CARBIDES \\
\hline & $4601-4699$ & BORIDES \\
\hline & $4701-4739$ & BERYLLIDES \\
\hline & $4741-4759$ & SULFIDES \\
\hline & $4761-4769$ & PHOSPHIDES \\
\hline & $4771-4799$ & SILICIDES \\
\hline & $4801-4899$ & HALIDES \\
\hline & $4901-4949$ & INTERMETALLICS, METALLOIDS \\
\hline & $4951-4999$ & MISCELLANEOUS COMPOUNDS \\
\hline \multirow[t]{7}{*}{5000} & \multicolumn{2}{|c|}{ INORGANIC MIXTURES } \\
\hline & $5001-5199$ & GLASSES \\
\hline & $5201-5299$ & CERAMICS, BRICKS \\
\hline & $5301-5399$ & NOT USED \\
\hline & $5401-5499$ & CERMETS \\
\hline & $5501-5799$ & GAS MIXTURES \\
\hline & $5801-5999$ & NOT USED \\
\hline \multirow[t]{3}{*}{6000} & \multicolumn{2}{|c|}{ INORGANIC COMPOSIIES } \\
\hline & $6001-6099$ & ROCKS, MINERAIS, SANDS, SOILS \\
\hline & $6101-6999$ & NOT USED \\
\hline \multirow[t]{4}{*}{7000} & \multicolumn{2}{|c|}{ ORGANIC COMPOUNDS AND MIXTURES } \\
\hline & 7001-7499 & POLYMERS (INCLUDING FOAMS) \\
\hline & $7501-7599$ & HIGH EXPLOSIVES (INCLUDING MOCK H. E.) \\
\hline & 7601-7699 & NOT USED \\
\hline \multirow[t]{4}{*}{8000} & \multicolumn{2}{|c|}{ ORGANIC COMPOSITES AND NATURAL MATERIALS } \\
\hline & $8001-8499$ & MISCELLANEOUS \\
\hline & $8501-8599$ & WOODS \\
\hline & $8601-8999$ & NOT USED \\
\hline 9000 & MISCELLA & \\
\hline & $9001-9099$ & IDEALIZED MATERIALS \\
\hline & $9101-9999$ & NOT USED \\
\hline
\end{tabular}

NUREG/CR-0200, Vol. 3, Rev. 4 


\section{M5.5 QUALITY INDICATOR SYSTEM}

The data for each material were chosen as the best values. For cases in which conflicting or inaccurate data were found in the literature, Ref. 1 provided the best values available for each material. The numerical quality indicators are necessarily crude and general but may be interpreted approximately as follows:

\section{Quality Type 0 (or Blank)}

Data were good, or no statement was made in data source restricting their accuracy. No conflicting data were found in any other data sources. Most data in this category are probably accurate to within $1-2 \%$ for density, $5-10 \%$ for specific heat, and $10-20 \%$ for thermal conductivity. When tables or specific heat vs temperature or thermal conductivity vs temperature are included, the constant values are included only for information and generally apply only to temperatures ranging from $0-100^{\circ} \mathrm{C}$ or at the lower end of the indicated temperature range of the table, whichever is higher.

\section{Quality Type 1}

Good data but specific heat or thermal conductivity were reported only for a limited temperature range. The temperature range has been extended by extrapolation, and the resulting values are probably as accurate as reported values.

\section{Quality Type 2}

Either the accuracy of the data was poor, or values reported by different sources disagreed. The best values were used whenever a judgment could be made, or average values were used with consideration given to data for similar materials.

\section{Quality Type 3}

No data could be found in the literature; however, the author made an estimate based on theoretical or empirical grounds or on data for similar materials. These estimates were included whenever they appeared to be about as accurate as reported data for similar materials.

\section{Quality Type 4}

No data could be found in the literature, and no accurate estimate could be made. The data, therefore, are considered to be a rough estimate based, in most cases, on data for similar materials.

\section{Quality Type 5}

No data could be found in the literature, and no estimate was made. A minimum requirement for inclusion of a material in the alphabetical index and material data list is the availability of at least estimated constant values of density, specific heat, and thermal conductivity. 


\section{M5.6 MATERIAL INDEX}

Table M5.6.1 is an alphabetical index of material descriptions that are available in the library. The format used for the information on each card-image record is as follows:

\section{Columns 1-5}

Alphanumeric identifier that always starts in column 1 and begins with a letter. This identifier is provided as an aid in identifying the material on the material data list. The atomic or molecular formulae are used for all elements and most simple compounds; short names, abbreviations, acronyms, or mnemonics are used in other cases.

\section{Column 6}

Always left blank.

\section{Columns 7-10}

Material identification number, in the range from 1001-9999, and never exactly divisible by 1000 . Each material is assigned its own identification number.

\section{Column 11}

Always left blank

\section{Columns 12-50}

Material description, including as much information as necessary to identify the specific material. Many abbreviations are used, such as these examples: HP (hot pressed), SINT (sintered), $89 \mathrm{D}$ (89\% of theoretical density), 22 P (22\% porosity), PRSD (pressed), FRD (fired), and HT (hot treated). A number of other standard abbreviations also are used for special alloys. Mass percentages follow component names. Atomic percentages precede the name of the molecular species.

\section{Column 51}

Normally left blank except when more than one card is used to list the data source numbers. In these cases, the additional cards have a + in column 51.

\section{Columns 52-72}

Data source numbers, specified in the list of data sources or other information identifying the sources of the compiled data. No classified data sources are listed. For all data estimated by the author or obtained from unknown data sources, a data source number is not indicated.

\section{Columns 73-79}

The numerical quality indicators for the data. One column is provided for each of the following properties: density (b), constant specific heat (c), constant thermal conductivity ( $k$ ), temperature of transition or maximum service temperature $(\mathrm{t})$, latent heat of transition $(\mathrm{h})$, table of specific heat vs 
temperature (c), and table of thermal conductivity vs temperature (k). The one-letter abbreviation for each property is listed in Table M5.6.1 over the column containing the corresponding quality indicator.

\section{$\underline{\text { Column } 80}$}

Always left blank.

Many materials appear more than once in the index. The reason for this duplication is that several common names exist for the same material or additional identifying information is included under separate entries. 
Table M5.6.1 Material index

\begin{tabular}{|c|c|c|c|c|}
\hline ID & No. & Material & References & $\begin{array}{l}\text { Quality } \\
\text { Index } \\
\text { DCKTHCK }\end{array}$ \\
\hline ALOXD & 4012 & ALUMINUM OXIDE (AL203) (POLYXTAL 100 D) & $1,20,27,32,47,48,51$ & 200 \\
\hline ALOXP & 4014 & ALUMINUM OXIDE (AL203) (POLYXTAL, 55 D) & $1,20,27,32,47,48,51$ & 200 \\
\hline ALOXS & 4016 & ALUMINUM OXIDE (AI203) (SINGLE XTAL) & $1,20,27,32,47,48,51$ & 202 \\
\hline ALCR1 & 5412 & ALUMINUM OXIDE + CR (AL203 23, CR T7) & 20,48 & 302530 \\
\hline AICR2 & 5413 & ALUMINUM OXIDE + CR (AL203 70, CR 30) & 20,48 & 302535 \\
\hline ANDAL & 4312 & ALUMINUM SILICATE (AL203.SIO2) (ORTHO) & $20,27,47,51$ & 20505 \\
\hline KYAN & 4314 & ALUMINUM SILICATE (AL203.SIO2) (TRICL) & $20,27,47,51$ & 500 \\
\hline MULL & 4316 & ALUMINUM SILICATE (3AL203.2SIO2) (100 D) & $20,27,47,48,51$ & 500 \\
\hline $\mathbf{A M}$ & 1430 & AMERICIUM & 20,27 & 342555 \\
\hline NH3 & 4881 & AMMONLA (NH3) (GAS) & $1,27,47$ & 0 \\
\hline NH3LQ & 4880 & AMMONLA (NH3) (LIQUID UNDER PRESSURE) & $1,27,47$ & 500 \\
\hline NH4BR & 4812 & AMMONIUM BROMIDE (NH4BR) (PRSD $8 \mathrm{~KB}$ ) & 27,47 & 300530 \\
\hline NH4CL & 4814 & AMIMONIUM CHIORIDE (NH4CL) (PRSD $8 \mathrm{~KB}$ ) & 27,47 & 10 \\
\hline ANALC & 4329 & ANALCIIE (NA20.AL203.4SIO2.4H2O) (XTAL) & 27,51 & 305555 \\
\hline ANDAI & 4312 & ANDALUSITE (AL203.SIO2) (ORTHO XTAL) & $20,27,51$ & 20505 \\
\hline SB & 1006 & ANTIMONY & $20,1,32,42,27$ & 0 \\
\hline SBLIQ & 1007 & ANTIMONY (LIQUID) & $1,47,42,27,20,14$ & 0 \\
\hline SBTEC & 4913 & ANTIMONY TEL LURIDE (SB2TE3) (CPR, N DR) & 20,27 & 300555 \\
\hline SBTEP & 4912 & ANTIMONY TELLURIDE (SB2TE3) (POLYXTAI) & 20,27 & 300555 \\
\hline ARGAS & 1501 & ARGON (GAS) & $27,2,42,41$ & 0 \\
\hline AS & 1008 & ARSENIC, GREY & $1,27,41,42$ & 40005 \\
\hline ASTEX & 4914 & ARSENIC TELLURIDE (ASZTE3) (V ZONE MLT) & 20 & 3305555 \\
\hline ART1 & 9001 & ARTIFICAL MATERIAL $1(\mathrm{D}=\mathrm{C}=\mathrm{K}=0)$ & & 0 \\
\hline ART2 & 9002 & ARTIFICAL MATERIAL $2\left(\mathrm{D}=\mathrm{C}=0, \mathrm{~K}=10^{* * 9}\right)$ & & $\mathbf{0}$ \\
\hline ART3 & 9003 & ARTIFICAL MATERIAL $3(\mathrm{D}=\mathrm{C}=\mathrm{K}=1)$ & & $\mathbf{0}$ \\
\hline ART4 & 9004 & ARTIFICAL MATERIAI $4\left(\mathrm{D}=\mathrm{C}=1, \mathrm{~K}=10^{* *}=9\right)$ & & 0 \\
\hline ART5 & 9005 & ARTIFICAL MATERIAI $5\left(\mathrm{D}=1, \mathrm{C}=\mathrm{K}=10^{* * 9)}\right.$ & & 0 \\
\hline ART6 & 9006 & ARTIFICAL MATERIAL $6(\mathrm{D}=\mathrm{C}=\mathrm{K}=\mathrm{TM}=\mathrm{HM}=1)$ & & 0 \\
\hline ART7 & 9007 & ARTIFICAL MATERIAL 7 (DCKTM $=1, \mathrm{HM}=10 * * 91$ & & $\mathbf{0}$ \\
\hline AT & 1437 & ASTIIINE & 42 & 3343335 \\
\hline BRTOL & 7501 & BARATOL H.E. (TNT 26, BA NITRATE 76) & 8 & 555 \\
\hline BA & 1241 & BARIUM & $20,27,29,42,43$ & 40005 \\
\hline BAB6 & 4612 & BARIUM BORIDE (BABG) & 27,48 & 300555 \\
\hline BAF2 & 4816 & BARIUM FLUORIDE (BAF2) (SINGLE CRYSTAL) & $20,27,51$ & 300230 \\
\hline BANO3 & 4952 & BARIUM NITRATE (BA(NO3)2) (PRSD 8 K8) & 1,27 & 300050 \\
\hline BASO4 & 4954 & BARIUM SULFATE (BASO4) (CRYSTAL) & 27,51 & 300550 \\
\hline BATIS & 4213 & BARIUM TITANATE (BAO.TIO2) (SINTERED) & $20,27,48$ & 500 \\
\hline BATIT & 4212 & BARIUM TITANATE (BAO.TIO2) (100 D) & $20,27,48$ & 500 \\
\hline BATMM & 4214 & BARIUM TITANATE (BAO.TIO2) (+MN,NB OX) & $20,27,48$ & 500 \\
\hline BK & 1440 & BERKEIIUM & 27 & 4445555 \\
\hline BERYL & 4318 & BERYL (3BEO.AL203.6SIO2) & $20,27,51$ & 320502 \\
\hline $\mathrm{BE}$ & 1011 & BERYLIIUM & $20,6,1,32,34,27,36,42$ & 22 \\
\hline BEBEO & 5420 & BERYLLIUM + BEO (BE, BEO 0.6-1.7) & 20 & 3300 \\
\hline BE96A & 3501 & BERYLIIUM ALLOY (BE96.5) (AS RECEIVED) & 20 & 303331 \\
\hline BE96H & 3502 & BERYLIIUM ALIOY (BE96.5) (ANNEALED) & 20 & 303331 \\
\hline BE98A & 3503 & BERYLITUM ALLOY (BE98.5) (AS RECEIVED) & 20 & 303331 \\
\hline BE98H & 3504 & BERYLIIUM ALLOY (BE98.5) (ANNEALED) & 20 & 303331 \\
\hline BE995 & 3505 & BERYLIIUM ALLOY (BE99.5) & 20 & 3033313 \\
\hline BERYL & 4318 & BERYLINUM ALUMMOSIICATE (BERYL) & $20,27,51$ & 320502 \\
\hline BE2C & 4512 & BERYLIIUM CARBDE (BE2C) (HP OR SNT) & $14,20,28,47$ & 2220022 \\
\hline CUBER & 2181 & BERYLLIUM COPPER (CU BAL, BE 0.38-0.55) & 1 & 331 \\
\hline CUBEH & 2182 & BERYLIIUM COPPER (CU BAL, BE1.7-1.9) & $1,6,41$ & 2335 \\
\hline BE3N2 & 4414 & BERYLIIUM NITRIDE (BE3N2) (PRSD $3.4 \mathrm{~KB})$ & 20,47 & 5 \\
\hline BEOXP & 4024 & BERYLIIUM OXIDE (BEO) (76 PC DENS) & $14,20,27,36,43,44$ & 0 \\
\hline BEOXP & 4024 & BERYLIIUM OXIDE (BEO) (76 PC DENS) & $+47,48,51$ & 0 \\
\hline
\end{tabular}


Table M5.6.1 (continued)

\begin{tabular}{|c|c|c|c|c|}
\hline D & No. & Material & References & $\begin{array}{l}\text { Quality } \\
\text { Index } \\
\text { DCKTHCK }\end{array}$ \\
\hline BEO & 4022 & BERYLIIUM OXIDE (BEO) (96 PC DENS) & $14,20,27,36,43,44$ & 0 \\
\hline BEO & 4022 & BERYLIIUM OXIDE (BEO) (96 PC DENS) & $+47,48,51$ & 0 \\
\hline BEOBE & 5414 & BERYLIIUM OXIDE + BE (BEO, BE 3-12) & 20 & 5500 \\
\hline BEOMO & 5416 & BERYLLIUM OXIOE + BE + MO (BE 7, MO 7) & 20 & 5501 \\
\hline BEOSI & 5418 & BERYLLIUM OXIDE + BE + SI & 20 & 305530 \\
\hline PORBE & 5280 & BERYLIIUM OXIDE PORCELAIN 4811 & 20 & 305530 \\
\hline BSPOD & 4320 & BETA-SPODUMENE (LT20.AL203.4SIO2) (TET) & $20,27,51$ & 305550 \\
\hline BI & 1016 & BISMUTH & $2,1,27,43,41,42,47$ & 0 \\
\hline BIIIQ & 1017 & BISMUTH (LIQUID) & $1,14,27,43,47$ & 0 \\
\hline BITEP & 4916 & BISMUTH TELIURIDE (BLTE3-P) (PLANE DR) & 20,47 & 220522 \\
\hline BITES & 4918 & BISMUTH TELIURIDE SULFIDE (BLTE2S) & 20 & 3305550 \\
\hline ZRB2Z & 5498 & BORIDE Z CERMET (ZRB2 81-87, MOSD2 13) & 47,48 & .2000500 \\
\hline ZRB2B & 5496 & BOROLITE 101 CERMET (ZRB2 93-96, B 4-7) & 47,48 & 505 \\
\hline BORON & 1266 & BORON & $20,27,30,42,43,48$ & 20205 \\
\hline B4C-D & 4514 & BORON CARBIDE (BAC) (DENSE) & $20,27,48$ & 2002500 \\
\hline B4C-P & 4515 & BORON CARBIDE (BAC) (POROUS) & $20,27,48$ & 2002500 \\
\hline BN & 4416 & BORON NITRIDE (BN) (PERP PR AXIS, 95 D) & $20,27,36,47,48$ & 500 \\
\hline BNPPA & 4418 & BORON NITRIDE (BN) (PRS AXIS, 94 D) & $20,27,36,47,48$ & 500 \\
\hline BNAC & 4424 & BORON NITRIDE (BN 80, C 20) (PRS AXIS) & 20 & 5500 \\
\hline BNOX2 & 4420 & BORON NITRIDE (BN 97, BN2O3 2) (PERP P) & 20 & 5500 \\
\hline BNOXP & 4422 & BORON NITRIDE (BN 97, BN2O3 2) (PRS AX) & 20 & 5500 \\
\hline SIBA & 4614 & BORON SILICIDE (B4SI) & 27,48 & 300530 \\
\hline BRAIM & 2101 & BRASS, ALUMINUM (CU76, ZN22, AI2) & 1 & 555 \\
\hline BRCAR & 2105 & BRASS, CARTRIDGE (CU70, ZN30) & $1,2,20,41,46$ & 500 \\
\hline BRPBL & 2111 & BRASS, LEADED & 6,41 & 3555 \\
\hline BRMUM & 2116 & BRASS, MUNTZ METAL & 1,41 & 5555 \\
\hline BRRDC & 2121 & BRASS, RED, CAST (CU85, ZN5, PB5, SN3) & 1,41 & 3555 \\
\hline BRRDW & 2122 & BRASS, RED, WROUGHT (CU85, ZN15) & 1,41 & 20555 \\
\hline BRTIN & 2126 & BRASS, TIN (NAVAL AND ADMIRALTY) & $1,2,41$ & 2555 \\
\hline BRYEL & 2131 & BRASS, YELIOW (CU65, ZN35) & $1,6,41$ & 555 \\
\hline BRICR & 5232 & BRICK, CHROME (CR203 32) & $1,27,41$ & 5530 \\
\hline BRCRM & 5234 & BRICK, CHROME MAGNESITE (SEE REF 47) & 20,47 & 330 \\
\hline DIATA & 5246 & BRICK, DIATOMACEOUS EARTH (ACCR STRATA) & 4 & 305530 \\
\hline DIATH & 5249 & BRICK, DIATOMACEOUS EARTH (HIGH BURN) & 4 & 305530 \\
\hline DIATM & 5248 & BRICK, DLATOMACEOUS EARTH (MOLDED, FRD) & 4 & 305530 \\
\hline DLATP & 5247 & BRICK, DIATOMACEOUS EARTH (PRLI STRATA) & 4 & 305530 \\
\hline DIATT & 5251 & BRICK, DIATOMACEOUS EARTH (USE TO 1100) & 4 & 305530 \\
\hline DIATL & 5250 & BRICK, DLATOMACEOUS EARTH (USE TO 850C) & 4 & 305530 \\
\hline BRIEF & 5256 & BRICK, EGYPIIAN FIRE (SIO2 6471) & 20 & 2323532 \\
\hline BRICF & 5224 & BRICK, FIRED CARBON & $1,20,27,42,47$ & 5505 \\
\hline BRIFR & 5262 & BRICK, FORSTERITE (MGO 58 SIO2 38)(20P) & 20,47 & 335 \\
\hline BRALF & $\$ 212$ & BRICK, FUSED ALUMINA (AL203 96)(22 P) & $1,20,47$ & 2330 \\
\hline BRISI & 5294 & BRICK, HARD FIRED SIIICA (SIO2 94-95) & 20 & 330 \\
\hline BRAL1 & 5214 & BRICK, HIGH ALUMINA (AL203 53) (20 P) & 47 & 322335 \\
\hline BRAL2 & 5215 & BRICK, HIGH ALUMINA (AL203 83 ) (28 P) & 47 & 322335 \\
\hline BRAL3 & 5216 & BRICK, HIGH ALUMINA (AI203 87) (22 P) & 20 & 303330 \\
\hline BRIKB & 5265 & BRICK, KAOLIN INSULATING (D $=0.30)$ & 1,20 & 5510 \\
\hline BRIKA & 5264 & BRICK, KAOLIN INSULATING $(D=0.43)$ & 1,20 & 5510 \\
\hline MAGNP & 5267 & BRICK, MAGNESITE (MGO 87) & $1,20,27,47,48$ & 330 \\
\hline MAGNA & 5268 & BRICK, MAGNESITE A (MGO 90) (14.5 P) & $1,20,27,47,48$ & 330 \\
\hline MAGNB & 5269 & BRICK, MAGNESITE B (MGO 93) (22.6 P) & $1,20,27,47,48$ & 330 \\
\hline MAGNC & 5270 & BRICK, MAGNESITE C (MGO 86) (17.8 P) & $1,20,27,47,48$ & 330 \\
\hline MAGNS & 5266 & BRICK, MAGNESITE SPALI RES (MGO 89) & $1,20,27,47,48$ & 335 \\
\hline BRIMM & 5218 & BRICK, MASONRY, MEDIUM & $1,2,27,46$ & 2025535 \\
\hline BRIFM & 5259 & BRICK, MISSOURI FIRECLAY & 1,47 & 3300530 \\
\hline
\end{tabular}

NUREG/CR-0200, Vol. 3, Rev. 4 
Table M5.6.1 (continued)

\begin{tabular}{|c|c|c|c|c|}
\hline ID & No. & Material & References & $\begin{array}{l}\text { Quality } \\
\text { Index } \\
\text { DCKTHCK }\end{array}$ \\
\hline BRIFN & 5258 & BRICK, NORMAL FIRECLAY (22 P) & 47 & 535 \\
\hline BRISL & 5296 & BRICK, SILICEOUS (SIO2 89 AL203 9)(25P) & 47 & 335 \\
\hline BRIFS & 5260 & BRICK, SIIICEOUS FIRECLAY (23 P) & 47 & 535 \\
\hline BRISK & 5298 & BRICK, SILIIMANTTE (22 PC POROSITY) & 20 & 300530 \\
\hline BRIDS & 5254 & BRICK, STABLIZED DOLOMITE (22 P) & 1,47 & 530 \\
\hline VERMI & 4986 & BRICK, VERMICULITE & 20 & 305550 \\
\hline BRGAS & 1546 & BROMINE (GAS) & $27,1,42$ & 0 \\
\hline BRONZ & 2141 & BRONZE (CU75, SN25) & 1,2 & 305555 \\
\hline BROAL & 2146 & BRONZE, ALUMINUM (CU92, AL8) & $1,6,41$ & 2000555 \\
\hline BROAR & 2151 & BRONZE, ARCHITECTURAL & 1,41 & 2300555 \\
\hline BROCM & 2156 & BRONZE, COMMERCIAL & $1,2,38,41$ & 555 \\
\hline BROMN & 2161 & BRONZE, MANGANESE & 1,41 & 555 \\
\hline BROPH & 2166 & BRONZE, PHOSPHER 10 PERCENT & 1,41 & 5555 \\
\hline BROPL & 2168 & BRONZE, PHOSPHER 1.25 PERCENT & 6,41 & 555 \\
\hline BROPM & 2167 & BRONZE, PHOSPHER 5 PERCENT & 6,41 & 555 \\
\hline BRSIF & 2171 & BRONZE, SILICON, HIGH & $1,6,41$ & 550 \\
\hline BRSIL & 2172 & BRONZE, SIIICON, LOW & $1,6,41$ & 555 \\
\hline BRSNH & 2176 & BRONZE, TIN (CAST), HIGH LEADED & 6,41 & 23555 \\
\hline BRSNL & 2177 & BRONZE, TIN (CAST), LEADED & 6 & 3555 \\
\hline BUACR & 7026 & BUTADIENE-ACRYLONITRIEEUBBER +C & 20 & 5555 \\
\hline BUTYR & 7031 & BUTYL RUBBER & 6,39 & 555 \\
\hline CD & 1041 & CADMMUM & $2,1,32,42,43,27,41,47$ & 0 \\
\hline CDLIQ & 1042 & CADMIUM (LIQUT) & $2,1,32,42,43,27,41,47$ & 0 \\
\hline CACCP & 4957 & CALCITE (CACO3) (CRYSTAL) (C AXIS) & $1,27,51$ & 0 \\
\hline CACCS & 4958 & CALCITE (CACO3) (CRYSTAI) (A AXIS) & $1,27,51$ & 0 \\
\hline CA & 1305 & CALCIUM & $27,1,42,43,41$ & 5 \\
\hline CAB6 & 4616 & CALCTUM BORIDE (CABO) & 27,48 & 300555 \\
\hline CACCP & 4957 & CALCIUM CARBONATE (CACO3) (CALCITE) (C) & $1,27,51$ & 0 \\
\hline CACCS & 4958 & CALCIUM CARBONATE (CACO3) (CALCTIE) (A) & $1,27,51$ & 0 \\
\hline CACON & 4956 & CALCIUM CARBONATE (CACO3) (NATURAI) & $1,27,51$ & 5 \\
\hline CAF2A & 4820 & CALCIUM FLUORDE (CAFZ) (MINERAL AGGR) & $1,20,27,47,51$ & 205 \\
\hline CAF2 & 4818 & CALCIUM FLUORIE (CAF2) (SINGLE XTAL) & $1,20,27,47,51$ & 200 \\
\hline DOLOM & 4960 & CALCIUM MAGNESIUM CARBONATE (CAMGC200) & $1,27,51$ & 20515 \\
\hline CAO & 4026 & CALCIUM OXIDE (CAO) (PRESSED, 91 DENS) & $1,20,27,47,48,51$ & 200 \\
\hline CAOPP & 4028 & CALCIUM OXIDE (CAO) (PACKED PWD, 50 D) & $1,20,27,47,48$ & 200 \\
\hline GYPSM & 4962 & CALCIUM SULFATE DIFYDRATE (CASO4.4H2O) & $1,27,51$ & 555 \\
\hline CATIT & 4216 & CALCIUM TITANATE (CAO.TTO2) & $20,27,48,51$ & 500 \\
\hline CE & 1443 & CALIFORNIUM & & 4445555 \\
\hline CAMOR & 1071 & CARBON, AMORPHOUS (CARBON STOCK) & 27,1 & 22 \\
\hline CGEMI & 1061 & CARBON, DIAMOND GEM QUALITY TYPE 1 & $1,20,27$ & 500 \\
\hline CGRAF & 1066 & CARBON, GRAPHITE (TYPICAL K) & $1,2,20,27,32,42,51$ & 2000002 \\
\hline BRICF & 5224 & CARBON BRICK, FIRED & $1,20,27,42,47$ & 5505 \\
\hline $\mathrm{CO} 2$ & 4027 & CARBON DIOXIDE & $1,2,27$ & 0 \\
\hline COGAS & 4029 & CARBON MONOXIDE & 1,27 & 300030 \\
\hline CELA2 & 7037 & CELLULOSE ACETATE (HIGH K) & 6,38 & 20555 \\
\hline CELA1 & 7036 & CELLULOSE ACETATE (LOW K) & 6,38 & 20555 \\
\hline CEAB2 & 7042 & CELLULOSE ACETATE BUTYRATE (HIGH $\mathrm{K}$ ) & 6,38 & 225555 \\
\hline CEAB1 & 7041 & CELLULOSE ACETATE BUTYRATE (LOW K) & 6,38 & 225555 \\
\hline CENIP & 7046 & CELLULOSE NITRATE (PYROXYLIN) & 6,38 & 200555 \\
\hline CEPR1 & 7051 & CELLULOSE PROPRIONATE (LOW K) & 6,38 & 225555 \\
\hline CEPR2 & 7052 & CELLULOSE PROPRIONATE (HIGH K) & 6,38 & 225555 \\
\hline CETRA & 7056 & CELLULOSEE TRIACETATE & 38 & 5555 \\
\hline $\mathrm{CE}$ & 1356 & CERTUM & $41,27,20,42$ & 20205 \\
\hline CEB6 & 4626 & CERIUM BORIDE (CEBG) (99.0 PC DENSE) & 48 & 300555 \\
\hline CEO2 & 4030 & CERIUM OXIDE (CEO2) (PRSD, SNTRD, 86 D) & $1,20,47$ & 201 \\
\hline
\end{tabular}


Table M5.6.1 (continued)

\begin{tabular}{|c|c|c|c|c|}
\hline $\mathbf{I D}$ & No. & Material & References & $\begin{array}{l}\text { Quality } \\
\text { Index } \\
\text { DCKTHCK }\end{array}$ \\
\hline CES & 4742 & CERIUM SULFIDE (CES) & 20,48 & 22505 \\
\hline CE2S3 & 4744 & CERIUM SULFIDE (CE2S3) & 20,48 & 20512 \\
\hline CS & 1231 & CESIUM & $1,14,27,28,32,43,47$ & 40005 \\
\hline CSLIQ & 1232 & CESIUM (LIQUID) & $14,27,28,32,43,47$ & 22 \\
\hline CHAIK & 6018 & CHALK (AV PROP) & 1,46 & 25555 \\
\hline CLGAS & 1506 & CHILORINE (GAS) & $27,1,42,2$ & 0 \\
\hline CRALM & 4973 & CHROME ALUM (CR2(SO4)3.K2SO4.24H2O) & 1,27 & 550 \\
\hline BRICR & 5232 & CHROME BRICK (CR2O3 32) & $1,27,41$ & 5530 \\
\hline BRCRM & 5234 & CHROME MAGNESITE BRICK (SEE REF 47) & 20,47 & 330 \\
\hline CNISA & 3312 & CHROME-NICKEL-IRON SUPERAILOYS & 6 & 555 \\
\hline $\mathbf{C R}$ & 1201 & CHROMTUM & $20,1,27,32,43,42$ & 0 \\
\hline CHCNI & 5422 & CHROMIUM CARBIDE + NI (CR(X)C(Y), NI) & 48 & 2000555 \\
\hline CUCHR & 2183 & CHROMIUM COPPER (CU BAL, CRO.5) & $6,20,47$ & 2330 \\
\hline CRN & 4426 & CHROMIUM NITRDE (CRN) (PRSD, 100 PC D) & $27,47,48$ & 505 \\
\hline CR2N & 4428 & CHROMIUM NITREE (CR2N) (PRSD, $100 \mathrm{D})$ & $27,47,48$ & 200505 \\
\hline CRSD & 4772 & CHROMIUM SIIICIDE (CRSI2) & $20,27,48$ & 500 \\
\hline $\mathrm{Co}$ & 1046 & COBALT & $20,27,1,32,43,30,41$ & 0 \\
\hline $\mathrm{CO}$ & 1046 & COBALT & +42 & 0 \\
\hline COCRW & 2646 & COBAIT AILOY (CO64,CR30,W6) & 20 & 330333 \\
\hline $\mathrm{CO}$ & & & 20 & 3300 \\
\hline $\mathrm{COH} 21$ & 2614 & COBALT ALLOY HS-21 (AS CAST) & $1,14,20,41$ & 310 \\
\hline $\mathrm{COH} 2 \mathrm{~A}$ & 2615 & COBALT ALLOY HS-21 (AGED) & $1,14,20,41$ & 310 \\
\hline COH23 & 2616 & COBALT ALLOY HS- 23 & 14,20 & 303330 \\
\hline $\mathrm{COH} 25$ & 2618 & COBAIT ALLOY HS-25 (L-605) (WROUGHT) & $1,14,41$ & 330 \\
\hline $\mathrm{COH} 27$ & 2620 & COBALT ALIOY HS-27 (AS CAST) & 14,20 & 303330 \\
\hline COH30 & 2622 & COBALT ALLOY HS-30 (422-19) (AS CAST) & 14,20 & 333333 \\
\hline $\mathrm{COH} 31$ & 2624 & COBALT ALLOY HS-31 $(X-40)$ (AS CAST) & $1,14,20,41$ & 300330 \\
\hline $\mathrm{COH} 36$ & 2626 & COBALT ALLOY HS-36 (CAST) & $1,14,20$ & 333 \\
\hline COJG3 & 2628 & COBALT ALLOY JESSOP G-32 & 20 & 303330 \\
\hline COJ15 & 2630 & COBALT ALLOY J-1570 & 20 & 3333330 \\
\hline COK42 & 2632 & COBALT ALLOY K-42B & 14 & 3323332 \\
\hline COMTL & 2636 & COBALT ALLOY MULTMMT (N-155) (LOW C) & $1,14,20,41$ & 330 \\
\hline COMTM & 2634 & COBALT ALLOY MULTIMET (N-155) (WROUGHT) & $1,14,20,41$ & 330 \\
\hline $\cos 59$ & 2638 & COBALT ALLOY S-590 (WROUGHT) & 14,41 & 330 \\
\hline $\cos 81$ & 2640 & COBALT ALLOY S-816 (WROUGHT) & $1,14,20,41$ & 330 \\
\hline cov36 & 2642 & COBALT AILOY V-36 (WROUGHT) & 41 & 333333 \\
\hline cow52 & 2644 & COBALT ALLOY WI-52 & 20 & 3333330 \\
\hline Cow5G & 2645 & COBALT ALLOY WI-52 (CR COATED SAMPLE) & 20 & 3333330 \\
\hline CNLOX & 4218 & COBALT NICKEL OXIDE (46COO.46NIO.8LIO) & 20,27 & 3305555 \\
\hline COBOX & 4034 & COBALT OXIDE (COO) & $20,27,47,48$ & 2005 \\
\hline $\cos$ & 4774 & COBALT SILICIDE (COS) & 20,48 & 305555 \\
\hline NBTAW & 3681 & COLOMBIUM ALLOY (CB61,TA28,W10,ZR0.5) & 20 & 3300 \\
\hline NBWMO & 3684 & COLOMBIUM ALIOY (CB80, W15, MO5) & 20 & 3300 \\
\hline NBTIZ & 3682 & COLOMBIUM ALLOY (CBSS, TI10, ZRS) & 20 & 3300 \\
\hline NBTAS & 3683 & COLOMBIUM ALLOY (CB95, TAS) & 20 & 3303330 \\
\hline CMB-3 & 7502 & COMPOSIIION B-3 H.E. (RDX 60, TNT 40) & 8 & 555 \\
\hline $\mathrm{CMC}-4$ & 7503 & COMPOSITION C-4 H.E. (RDX 90, BINDERS) & 8 & 5555 \\
\hline CONCN & 5240 & CONCRETE, CINDER & $1,2,20,27,46$ & 25535 \\
\hline CONLW & 5243 & CONCRETE, LIGHTWEIGHT & $1,2,20,27,46$ & 5530 \\
\hline CONCS & 5241 & CONCRETE, STONE (1-2-4 MIX) & $1,2,20,27,46$ & 25535 \\
\hline CON14 & 5242 & CONCRETE, 1-4 DRY & $1,2,20,27,46$ & 25535 \\
\hline $\mathrm{CU}$ & 1051 & COPPER & $20,1,27,32,34,37,42$ & 0 \\
\hline $\mathrm{CU}$ & 1051 & COPPER & +47 & 0 \\
\hline CUWGT & 2191 & COPPER, WROUGHT (ETP, DHP, TE0.5, PBI) & 41 & 3535 \\
\hline CUBER & 2181 & COPPER ALLOY (CU BAI, BE 0.38-0.55) & 1 & 331 \\
\hline
\end{tabular}

NUREG/CR-0200, Vol. 3, Rev. 4 
Table M5.6.1 (continued)

\begin{tabular}{|c|c|c|c|c|}
\hline $\mathbf{D}$ & No. & Material & References & $\begin{array}{c}\text { Quality } \\
\text { Index } \\
\text { DCKTHCK }\end{array}$ \\
\hline CUBEH & 2182 & COPPER ALLOY (CU BAL, BE 1.7-1.9) & $1,6,41$ & $2335^{\circ}$ \\
\hline CUCHR & 2183 & COPPER ALLOY (CU BAL, CR0.5) & $6,20,47$ & 2330 \\
\hline CUPR3 & 2203 & COPPER ALLOY (CU70, NI30) & $1,6,41$ & 2555 \\
\hline CUPR1 & 2202 & COPPER ALLOY (CU90, N110) & $1,6,41$ & 2555 \\
\hline CUALI & 2201 & COPPER ALLOY (CU99.4, AL0.3, ZR0.27) & 20 & 3303331 \\
\hline NICON & 2506 & COPPER ALLOY CONSTANTAN (CUS5, NI45) & $1,2,14,41,47$ & 331 \\
\hline CUMAN & 2195 & COPPER ALLOY MANGANIN & 2 & 3305550 \\
\hline cUNIs & 2185 & COPPER ALLOY NCKEL SILVER (NI 10-20) & $1,2,6,41,47$ & 2222555 \\
\hline CUGZN & 2186 & COPPER GIIDING METAL (CU95, ZNS) & 1,41 & 555 \\
\hline CUOLI & 4220 & COPPER LITHIUM OXIDE (96CUO.4LIO) & 20,27 & 3305550 \\
\hline cuo & 4036 & COPPER OXIDE (CUO) (TENORITE) & $1,20,27,47,51$ & 2002220 \\
\hline CUSO4 & 4966 & COPPER SULFATE (CUUSO4) (CRYSTAL) & 27 & 550 \\
\hline BLUEV & 4967 & COPPER SULFATE HYDRATE (CUS04.5H2O) & $1,27,51$ & 555 \\
\hline CORDR & 4322 & CORDIERTIE (2MGO.2AL203.5SIO2) & 20,51 & 5510 \\
\hline CORKG & 8514 & CORK, GROUND & 2,46 & 5555 \\
\hline CORKR & 8515 & CORK, GROUND, REGRANULATED & 2,46 & 5555 \\
\hline CUPR3 & 2203 & CUPRONICKEL (CU70, NI30) & $1,6,41$ & 2555 \\
\hline CUPR1 & 2202 & CUPRONICKEL (CU90, NI10) & $1,6,41$ & 2555 \\
\hline CM & 1446 & CURTOM & 20,27 & 4445555 \\
\hline DAN35 & 3901 & DANDELION 35 & 34,36 & 5500 \\
\hline DATB & 7504 & DATB H.E. (DIANINO TRINITROBENZENE) & 8 & 300555 \\
\hline D-GAS & 1551 & DEUTERRUM & 27 & 3305530 \\
\hline D20 & 4118 & DEUTERTOM OXIDE (D2O) (LIQUID) & 14,27 & 300 \\
\hline DIABG & 5020 & DIABASIC GLASS (ARTIFICIAL) & 27,51 & 3305530 \\
\hline DAPON & 7061 & DIALLYL PHTHALATE (DAPON) & 35 & 2025555 \\
\hline DLATA & 5246 & DIATOMACEOUS EARTH BRICK (ACCR STRATA) & 4 & 305530 \\
\hline DIATH & 5249 & DIATOMACEOUS EARTH BRICK (HGH BURN) & 4 & 305530 \\
\hline DIATM & 5248 & DIATOMACEOUS EARTH BRICK (MOLDED, FRD) & 4 & 305530 \\
\hline DLATP & 5247 & DIATOMACEOUS EARTH BRICK (PRLL STRATA) & 4 & 305530 \\
\hline DLATT & 5251 & DIATOMACEOUS EARTH BRICK (USE TO $11000^{\circ}$ & 4 & 305530 \\
\hline DLATL & 5250 & DIATOMACEOUS EARTH BRICK (USE TO 850C) & 4 & 305530 \\
\hline DOLOM & 4960 & DOLOMITE (CAMG(CO3)2) (AVG PROP) & $1,27,51$ & 20555 \\
\hline BRIDS & 5254 & DOLOMTE BRICK, STABIIZED (22 P) & 1,47 & 530 \\
\hline DY & 1391 & DYSPROSIUM & $41,27,20,42$ & 35 \\
\hline BRIEF & 5256 & EGYPTIAN FLRE BRICK (SIO2 64-71) & 20 & 2323532 \\
\hline ES & 1449 & EINSTEINIUM & & 4445555 \\
\hline EPCR1 & 7066 & EPOXY, DER 332 (C), HYSOL 6000-OP (K) & $6,20,38$ & 2220505 \\
\hline EPGFM & 7071 & EPOXY, GLASS FIBER FILLED (MOLDED) & 20,38 & 25552 \\
\hline EPSFC & 7076 & EPOXY, SKICA FLLED, CAST & 38 & 2225555 \\
\hline EPUNC & 7081 & EPOXY, UNFILLED, CAST & 38 & 2025555 \\
\hline EPSOM & 4971 & EPSOMITE (MGSO4.7H2O) (CRYSTAL) & $1,27,51$ & 555 \\
\hline ER & 1401 & ERBIUM & $41,27,20,42$ & 5 \\
\hline ETHCE & 7086 & ETHYL CELLULOSE (WIDE RANGE OF C, $K$ ) & 6,38 & 225555 \\
\hline ETHVA & 7091 & ETHYL VINYL ACETATE & 38 & 25555 \\
\hline EU & 1376 & EUROPIUM & $20,27,41,43$ & 30005 \\
\hline EUB6 & 4634 & EUROPIUM BORTE (EUBO) (93.0 PC DENSE) & 48 & 305555 \\
\hline FM & 1452 & FERMIUM & & 4445555 \\
\hline FBRFX & 8201 & FIBERRAX PAPER (CARBORUNDUM CO.) & 44 & 5500 \\
\hline BRIFM & 5259 & FIRECLAY BRICK, MISSOURI & 1,47 & 3300530 \\
\hline BRIFN & 5258 & FIRECLAY BRICK, NORMAL (22 P) & 47 & 535 \\
\hline BRIFS & 5260 & FIRECLAY BRICK, SILICEOUS (23 P) & 47 & 535 \\
\hline FLINT & 5022 & FLINT GLASS & $1,27,46$ & 25532 \\
\hline ART5 & 9005 & FLUID, HEAT SINK (D=1, C=K=10**9) & & 0 \\
\hline ART4 & 9004 & FLUID, WELL STIRRED $(D=C=1, K=10 * * 9)$ & & 0 \\
\hline F-GAS & 1511 & FLUORINE (GAS) & 27,42 & 0 \\
\hline
\end{tabular}

NUREG/CR-0200, 
Table M5.6.1 (continued)

\begin{tabular}{|c|c|c|c|c|}
\hline $\mathbf{m}$ & No. & Material & References & $\begin{array}{c}\text { Quality } \\
\text { Index } \\
\text { DCKTHCK }\end{array}$ \\
\hline FCCTF & 7101 & FLUOROCARBONS, CFE AND CTFE & 6,38 & 555 \\
\hline FCFEP & 7106 & FLUOROCARBONS, FEP & 6,38 & 555 \\
\hline FCTFE & 7111 & FLUOROCARBONS, TFE (TEFLON) & $1,6,20,38$ & 2500 \\
\hline GLASF & 5024 & FOAMED GLASS $(D=0.144)$ & 1 & 305532 \\
\hline FORST & 4324 & FORSTERTTE (2MGO.SIO2) (100 PC DENSE) & $1,20,27,51$ & 0 \\
\hline BRIFR & 5262 & FORSTERITE BRICK (MGO 58 SIO2 38)(20 P) & 20,47 & 335 \\
\hline FR & 1455 & FRANCIUM & 42 & 4343335 \\
\hline SIO2 & 4062 & FUSED SILICA GLASS & $1,20,27,47,51$ & 2200 \\
\hline SIO2 & 4062 & FUSED QUARTZ GLASS (SIO2) & $1,20,27,47,51$ & 2200 \\
\hline GD & 1381 & GADOLINIUM & $41,27,20,42$ & 5 \\
\hline GDB6 & 4636 & GADOLINIUM BORIDE (GDBG) (95.6 PC DENS) & 48 & 300555 \\
\hline GD203 & 4038 & GADOLINIUM OXIDE (GD203) (MONOC) (98 D) & $20,47,48$ & 2000505 \\
\hline GA & 1311 & GALLIUM & $27,42,43,1$ & 20005 \\
\hline GALIQ & 1312 & GALIIUM (LIQUID) & $1,14,27,43,47$ & 20005 \\
\hline GE-IP & 1261 & GERMANIUM (INTRINSIC, P-TYPE) & $20,27,42,43,1,48$ & 2 \\
\hline GE-N & 1262 & GERMANIUM (N-TYPE) & $20,27,42,43,1,48$ & 0 \\
\hline GLASS & 5012 & GLASS (SEE REP 27, PP E5-E8) (AVG PROP) & 27 & 2225555 \\
\hline GLABC & 5014 & GLASS, BOROSIICATE CROWN & 27,51 & 25502 \\
\hline PYRC6 & 5018 & GLASS, CERAMIC, PYROCERAM 9606 & 20 & 5500 \\
\hline PYRC8 & 5019 & GLASS, CERAMIC, PYROCERAM 9608 & 20 & 5500 \\
\hline DIABG & 5020 & GLASS, DIABASE (ARTIFICIAI) & 27,51 & 3305530 \\
\hline FLINT & 5022 & GLASS, FLINT & $1,27,46$ & 25532 \\
\hline GLASF & 5024 & GLASS, FOAMED (D $=0.144)$ & 1 & 305532 \\
\hline SIO2 & 4062 & GLASS, FUSED QUARTZ (SIOZ) & $1,20,27,47,51$ & 2200 \\
\hline $\mathrm{SIO} 2$ & 4062 & GLASS, FUSED SILICA OR VITROUS SILICA & $1,20,27,47,51$ & 2200 \\
\hline GLASL & 5026 & GLASS, IEAD & 20 & 305530 \\
\hline GLASW & 5028 & GLASS, LIME WINDOW & 20 & 305530 \\
\hline OBSID & 5030 & GLASS, OBSIDIAN & 27,51 & 305530 \\
\hline PYREX & 5016 & GLASS, PYREX & $2,20,27,51$ & 500 \\
\hline GLASP & 5034 & GLASS, SODA PLATE & 20,51 & 305532 \\
\hline GLASC & 5032 & GLASS, SODA-IIME & 20,27 & 3325532 \\
\hline VYCOR & 5036 & GLASS, VYCOR & 20,27 & 500 \\
\hline AU & 1056 & GOLD & $20,6,1,32,27,42,41,2$ & 0 \\
\hline AULIQ & 1057 & GOLD (LIQUID) & $14,20,27,42,43$ & 40005 \\
\hline GRNTM & 6014 & GRANITE (AV PROP) (SEE REF S1) & $1,2,27,46,51$ & 25555 \\
\hline GRNTH & 6013 & GRANIIE (HIGH K) & $1,2,27,46,51$ & 25555 \\
\hline GRNTL & 6012 & GRANITE (LOW K) & $1,2,27,46,51$ & 25555 \\
\hline GYPSM & 4962 & GYPSUM (CASO4.4H2O) (MINERAL) (HIGH D) & $1,27,51$ & 555 \\
\hline GYPSA & 4964 & GYPSUM (CASO4.4H2O) (ARTIFICIAI) & 1,27 & 555 \\
\hline HIF & 1271 & HAFNIUM & $20,32,27,42,43,41$ & 0 \\
\hline HFB2 & 4618 & HAFNIUM BORIDE (HFB2) & $20,27,48$ & 20502 \\
\hline HFC & 4518 & HAFNIUM CARBIDE (HFC) & $20,27,48,54$ & 22502 \\
\hline HFN & 4430 & HAFNIUM NITRIDE (HIFN) (HP STRD 78-92 D) & $20,27,48$ & 2020502 \\
\hline HFO2 & 4040 & HAFNIUM OXIDE (HFO2) (MONOC) (94 D) & $20,27,48$ & 21 \\
\hline D2O & 4118 & HEAVY WATER (D2O) (LIQUID) & 14,27 & 300 \\
\hline HEGAS & 1516 & HEIIUM (GAS) & $27,1,2,42$ & 0 \\
\hline FE203 & 4042 & HEMATITE (FE203) & $1,27,32,47,48,51$ & 20505 \\
\hline Ho & 1396 & HOLMIUM & $20,27,41,42,43$ & 30005 \\
\hline H-GAS & 1521 & HYDROGEN (GAS) & $27,2,42,1$ & 0 \\
\hline ICE & 4116 & ICE (H2O) (SOLID) & $27,46,51$ & 0 \\
\hline IN & 1211 & INDIUM & $1,27,43,30,42,41$ & 20005 \\
\hline INLIQ & 1212 & INDIUM (LIQUD) & $1,42,43,47$ & 5 \\
\hline SOLD1 & 3611 & INDIUM ALLOY (IN25, SN37.5, PB37.5) & 36 & 3355 \\
\hline INSBP & 4920 & INDIUM ANTIMONIDE (INSB) (IMP 0.16) & 20,27 & 3000000 \\
\hline INSBS & 4921 & INDIUM ANTIMONDE (INSB) (IMP 0.33-1.2) & 20,27 & 3000000 \\
\hline
\end{tabular}

NUREG/CR-0200, Vol. 3, Rev. 4 
Table M5.6.1 (continued)

\begin{tabular}{|c|c|c|c|c|}
\hline $\mathbf{m}$ & No. & Material & References & $\begin{array}{c}\text { Quality } \\
\text { Index } \\
\text { DCKTHCK }\end{array}$ \\
\hline INASP & 4922 & INDIUM ARSENIDE (INAS) (POLYX, IMP 3.0) & 20,27 & 3000500 \\
\hline INASS & 4923 & RDIUM ARSENDE (RNAS) (PURE, S-DOPED) & 20,27 & 3000500 \\
\hline INTE & 4924 & INDIUM TELIURIDE (IN2TE3) & 20,27 & 300550 \\
\hline I-SOL & 1316 & IODINE (SOLID) & $27,42,41,1$ & 5 \\
\hline $\mathbf{R}$ & 1276 & IRIDIUM & $27,41,20,42,43$ & 20002 \\
\hline FEFUR & 1083 & IRON (0 TO 3000 DEG C) & $20,1,32,27,42,44,51$ & $\cdot 0$ \\
\hline FECRY & 1082 & RON (-273 TO 763 DEG C) & $20,1,32,27,42,44,51$ & 0 \\
\hline FE & 1081 & IRON (-51 TO 1537 DEG C) & $20,1,32,27,42,44,51$ & 0 \\
\hline INDO2 & 3022 & IRON, DUCTILE (MG CONTAINING) & 1 & 300355 \\
\hline INDO3 & 3023 & IRON, DUCTIEE (MG CONTAINING, HEAT RES) & 1 & 300355 \\
\hline INDOI & 3021 & IRON, DUCTILE (0.06 MG) & 1,6 & 323333 \\
\hline GCIO1 & 3001 & IRON, GREY CAST, FERRITIC (2.3-3.0 C) & $1,2,6,20,27,33,46$ & 3300 \\
\hline GCIO2 & 3002 & IRON, GREY CAST, FERRITIC $3.2-3.8 \mathrm{C}$ & $1,2,6,20,27,33,46$ & 303330 \\
\hline GCIO3 & 3003 & GREY CAST, PEARIIIIC (2.3-3.0 C) & $1,2,6,20,27,33,46$ & 303330 \\
\hline GCIO4 & 3004 & IRON, GREY CAST, PEARIITIC (3.0-3.2 C) & $1,2,6,20,27,33,46$ & 303330 \\
\hline GCIOS & 3005 & IRON, GREY CAST, PEARLITIC (3.4 C) & $1,2,6,20,27,33,46$ & 303330 \\
\hline GCIO6 & 3006 & IRON, GREY CAST, PEARLITIC (3.7-3.8 C) & $1,2,6,20,27,33,46$ & 303330 \\
\hline GCIO7 & 3007 & IRON, GREY CAST, PEARLITIC (4.12 C) & $1,2,6,20,27,33,46$ & 303330 \\
\hline FE & 1081 & IRON, INGOT (FE99.9+) & $1,20,27,32,42,44$ & 0 \\
\hline KOVAR & 3031 & IRON, NI-HARD TYPES 1 AND 2 (KOVAR) & 1,20 & 200320 \\
\hline INNRD & 3035 & IRON, NI-RESIST, TYPE D2 (CAST) & 1 & 300355 \\
\hline INNR3 & 3033 & IRON, NI-RESIST, TYPE 3 (CAST) & 1 & 355 \\
\hline INNR4 & 3034 & IRON, NI-RESIST, TYPE 4 (CAST) & 1 & 355 \\
\hline INNIR & 3032 & IRON, NI-RESIST, TYPES 1 AND 2 (CAST) & 1,20 & 325 \\
\hline INNIT & 3041 & IRON, NI-TENSYLIRON (CAST, HEAT TREAT) & 1 & 300355 \\
\hline INCFB & 3026 & IRON, NODULAR CAST, FERRIIIC BASE & $1,2,20$ & 303330 \\
\hline INCPB & 3027 & IRON, NODULAR CAST, PEARLITIC BASE & $1,2,20$ & 303330 \\
\hline INKAI & 3036 & IRON, MALLEABLE (2.5 C) & 1,6 & 5555 \\
\hline INWRT & 3037 & IRON, WROUGHT (VARIOUS) & $1,2,6,27$ & 2330 \\
\hline NINVR & 2501 & IRON ALLOY INVAR (FE64, NI36) & $6,41,47$ & 20355 \\
\hline FE2O3 & 4042 & IRON OXIDE (FE2O3) (HEMATITE) & $1,27,32,47,48,51$ & 20505 \\
\hline FE3O4 & 4044 & RON OXIDE (FEO.FE2O3) (MAGNATIIE) & $20,27,47,51$ & 2000005 \\
\hline FES2 & 4746 & IRON SULFIDE (FES2) (SINGLE CRYSTAI) & $27,47,51$ & 505 \\
\hline BRIKB & 5265 & KAOLIN BRICK, INSULATING (D $=0.30)$ & 1,20 & 5510 \\
\hline BRIKA & 5264 & KAOLIN BRICK, INSULATING (D $=0.43$ ) & 1,20 & 5510 \\
\hline KRGAS & 1556 & KRYPTON (GAS) & $27,1,42$ & 0 \\
\hline KYAN & 4314 & KYANITE (AL2O3.SIO2) (TRICL CRYSTAI) & $20,27,51$ & 500 \\
\hline LA & 1351 & LANTHANUM & $41,27,1,20,42$ & 5 \\
\hline LAB6 & 4624 & LANTHANUM BORIDE (LAB6) (99.5 PC DENSE) & 48 & 300555 \\
\hline $\mathbf{L W}$ & 1491 & LAWRENCIUM & & 4445555 \\
\hline PB & 1091 & LEAD & $2,1,32,27,37,42$ & 0 \\
\hline PBLIQ & 1092 & LEAD (LIQUID) & $1,2,14,27,37,42,43,47$ & 2 \\
\hline PB & 1091 & LEAD $(0.07 \mathrm{CA})$ & 36 & 0 \\
\hline PBANT & 3601 & LEAD, ANTIMONIAL (PB, SB 4-G) (HARD) & $1,6,41$ & 355 \\
\hline PBSBH & 3602 & LEAD, ANTIMONIAL (PB, SB 8-9) & $1,6,41$ & 355 \\
\hline PB & 1091 & LEAD, ANTIMONIAI (PB, SB1) & 1,41 & 0 \\
\hline PB & 1091 & LEAD, TELIURIUM & 1 & 0 \\
\hline SOLD1 & 3611 & LEAD ALLOY (PB37.5, SN37.5, IN25) & 36 & 3355 \\
\hline SOLD2 & 3612 & LEAD ALLOY (PB39.2, SN60.8) (SOLDER) & 34,41 & 5 \\
\hline SOLD4 & 3613 & LEAD ALLOY (PBSO, SN50) (SOLDER) & 1,41 & 50 \\
\hline SOLD3 & 3614 & LEAD ALLOY (PB60, SN40) (SOLDER) & 1,41 & 55 \\
\hline GLASL & 5026 & LEAD GLASS & 20 & 305530 \\
\hline PBO & 4046 & LEAD OXIDE (PBO) (YELLOW) & $1,20,27,32,47$ & 201 \\
\hline PBTEP & 4927 & LEAD TELLURME (PBTE) (POLYXTAL) & 20,27 & 300550 \\
\hline PBTES & 4926 & LEAD TELLURIDE (PBTE) (SNGLE CRYSTAL) & 20,27 & 300550 \\
\hline
\end{tabular}


Table M5.6.1 (continued)

\begin{tabular}{|c|c|c|c|c|}
\hline ID & No. & Material & References & $\begin{array}{c}\text { Quality } \\
\text { Index } \\
\text { DCKTHCK }\end{array}$ \\
\hline LMST & 6016 & LIMESTONE (DENSE, DRY) & $1,2,27,46,51$ & 5555 \\
\hline LIMSW & 6017 & LMMESTONE (H2O 15.3) & $1,2,27,46,51$ & 5555 \\
\hline LI & 1216 & LITHIUM & $1,27,28,41,43,42,47$ & 0 \\
\hline LILIQ & 1217 & LITHIUM (LIQUID) & $1,27,28,41,42,43,47$ & 202 \\
\hline BSPOD & 4320 & LITHIUM ALUMINUN SILICATE (B-SPODUMENE) & $20,27,51$ & 305550 \\
\hline CNLOX & 4218 & LITHUM COBALT NICKEL OXIDE (8-46-46 M) & 20,27 & 3305555 \\
\hline CUOLI & 4220 & LTHHUM COPPER OXIDE (4LIO.96CUO) & 20,27 & 3305550 \\
\hline LIH & 4882 & LTHIUM HYDRIDE (LIH) (CAST, VAC VOIDS) & 20 & 200 \\
\hline LIH & 4882 & LITHIUM FYDRIDE (LIF) (POWDER COMPACT) & 20 & 200 \\
\hline IIHCG & 4884 & LITHIUM HYDRIDE (LIH) (CAST GAS VOIDS) & 20 & 200 \\
\hline LIF & 4822 & LITHIUM FLUORIDE (LIF) (SINGLE CRYSTAL) & $1,20,27,47,51$ & 20202 \\
\hline IIFPB & 4824 & LITHIUM FLUORIDE (LIF 96) (PLASTIC BND) & $1,20,27,47,51$ & 200 \\
\hline MNSEL & 4928 & LITHIUM MANGANESE SELENIDE (9TMN.3LI.-) & 20,27 & 3305530 \\
\hline NIOLI & 4222 & IITHIUM NICKEL OXIDE (5LIO.95NIO) & 20,27 & 3305550 \\
\hline LITBR & 4968 & IITHIUM TETRABORATE (LI2O.2B2O3) (EPOX) & 27 & 555 \\
\hline LU & 1416 & LUTETIUM & $20,27,41$ & 230025 \\
\hline LX041 & 7505 & LX-04-1 H.E. (HMX 85, VITON A 15) & 8 & 200551 \\
\hline FE304 & 4044 & MAGNATITE (FEO.FE203) & $20,27,47,51$ & 2000005 \\
\hline MAGNA & 5268 & MAGNESITE A BRICK (MGO 90) (14.5 P) & $1,20,27,47,48$ & 330 \\
\hline MAGNB & 5269 & MAGNESITE B BRICK (MGO 93) (22.6 P) & $1,20,27,47,48$ & 330 \\
\hline MAGNP & 5267 & MAGNESITE BRICK (MGO 87) & $1,20,27,47,48$ & 330 \\
\hline MAGNS & 5266 & MAGNESTTE BRICK, SPALL RES (NGO 89) & $1,20,27,47,48$ & 335 \\
\hline MAGNC & 5270 & MAGNESITE C BRICK (MGO 86) (17.8 P) & $1,20,27,47,48$ & 330 \\
\hline MG & 1096 & MAGNESIUM & $20,1,32,27,42$ & 0 \\
\hline MGLIQ & 1097 & MAGNESIUM (LIQUID) & $1,14,20,27,32,43$ & 30005 \\
\hline MG042 & 2462 & MAGNESIUM ALLOY (MG,AG2.5,CE2,ZR0.6) & 47 & 333 \\
\hline MG001 & 2421 & MAGNESIUM ALLOY AM100A (CASTING) & 41 & 33 \\
\hline $\mathrm{MGO02}$ & 2422 & MAGNESIUM ALLOY AZ31(X,S) (WROUGHT) & $14,20,47$ & 10 \\
\hline NGOO3 & 2423 & MAGNESIUM ALLOY AZ31B(P,S) (WROUGHT) & $1,20,41$ & $\mathbf{0}$ \\
\hline MG004 & 2424 & MAGNESIUM ALLOY AZ61A(X), AZM (WROUGHI) & $14,41,47$ & 33 \\
\hline MG005 & 2425 & MAGNESIUM ALLOY AZ63A(AC,F) (CASTING) & 14,41 & 33 \\
\hline MG006 & 2426 & MAGNESIUM ALIOY AZSOA(X,FRGD) (WROUGHT) & $1,20,37,41$ & 303 \\
\hline MG007 & 2427 & MAGNESIUM ALLOY AZ81A(T4) (CASTING) & 41 & 300333 \\
\hline MG008 & 2428 & MAGNESIUM ALLOY AZ855(X) (WROUGHT) & 47 & 333 \\
\hline MG009 & 2429 & MAGNESIUM ALIOY AZ91A,B (DC) (CASTING) & $1,14,41,47$ & 31 \\
\hline MG010 & 2430 & MAGNESIUM ALLOY AZ91C(AC) (CASTING) & 1,41 & 33 \\
\hline MG011 & 2431 & MAGNESIUM ALLOY AZ92A(AC) (CASTING) & $1,14,41$ & 33 \\
\hline MG012 & 2432 & MAGNESIUM ALLOY A3A (WROUGHT) & 41 & 33333 \\
\hline MG013 & 2433 & MAGNESTUM AILOY A8(AC OR ST) (CASTING) & 47 & 333 \\
\hline MG014 & 2434 & MAGNESIUM ALLOY BZ33A(AC,AH) (CASTING) & 1 & 333 \\
\hline MG015 & 2435 & MAGNESIUM ALLOY EK30A, H812 (CASTING) & 20,41 & 31 \\
\hline MG017 & 2437 & MAGNESIUM ALLOY EK33A, H811 (CASTING) & 20,41 & 32 \\
\hline MG016 & 2436 & MAGNESIUM ALLOY EK41A(T5,T6) (CASTING) & 41 & 333 \\
\hline MG018 & 2438 & MAGNESTUM ALIOY HK31A(H24) (CASTING) & $1,20,41$ & 0 \\
\hline MG019 & 2439 & MAGNESIUM ALLOY HK31A(O) (CASTING) & $1,20,41$ & $\mathbf{0}$ \\
\hline MG020 & 2440 & MAGNESIUM ALLOY HK31A(T6) (CASTING) & $1,20,41$ & 0 \\
\hline MG021 & 2441 & MAGNESIUM ALLOY HM21A(O,H24) (WROUGHT) & 41 & 313 \\
\hline $\operatorname{MGO22}$ & 2442 & MAGNESIUM ALLOY HM31A (WROUGHT) & 20,41 & 3 \\
\hline MG023 & 2443 & MAGNESIUM ALLOY HZ32A(AC),ZT1 (CASTING) & $1,20,41,47$ & 33 \\
\hline $\mathrm{MGO24}$ & 2444 & MAGNESIUM ALLOY MAGNOX A12(X) (WROUGHT) & 47 & 333 \\
\hline MG025 & 2445 & MAGNESIUM ALLOY MI(AC) (CASTING) & 14,47 & 333 \\
\hline MG026 & 2446 & MAGNESIUM ALIOY MI $(\mathrm{x}, \mathrm{s})$ (WROUGHT) & 14,47 & 333 \\
\hline MG027 & 2447 & MAGNESIUM ALLOY MIA (WROUGHT) & 41 & 33 \\
\hline MGO28 & 2448 & MAGNESIUM ALLOY PE (WROUGHT) & 41 & 30033 \\
\hline MG029 & 2449 & MAGNESIUM ALIOY ZA(AC) (CASTING) & 47 & 3333 \\
\hline
\end{tabular}

NUREG/CR-0200, Vol. 3, Rev. 4 
Table M5.6.1 (continued)

\begin{tabular}{|c|c|c|c|c|}
\hline ID & No. & Material & References & $\begin{array}{c}\text { Quality } \\
\text { Index } \\
\text { DCKTHCK }\end{array}$ \\
\hline MG030 & 2450 & MAGNESIUM ALLOY ZE10A(O,H24) (WROUGHT) & 41 & 33 \\
\hline MG031 & 2451 & MAGNESIUM ALIOY ZEA1A(T5,HT) (CASTING) & $20,41,47$ & 330 \\
\hline NG032 & 2452 & MAGNESIUM ALLOY ZH42 (CASTING) & 41 & 33 \\
\hline MG033 & 2453 & MAGNESIUM ALLOY ZH62A(AC),TZ6 (CASTING) & $20,41,47$ & 31 \\
\hline MG034 & 2454 & MAGNESIUM ALLOY ZK20A (WROUGHT) & 20,41 & 3303333 \\
\hline MG035 & 2455 & MAGNESIUM ALLOY ZK51A, H807 (CASTING) & $20,41,47$ & 0 \\
\hline MG036 & 2456 & MAGNESIUM ALLOY ZK60A, B, ZW6 (CASTING) & $1,14,20,41,47$ & 1 \\
\hline MG037 & 2457 & MAGNESIUM ALIOY ZREO (EZ30) (CASTING) & 20 & 303331 \\
\hline NG038 & 2458 & MAGNESIUM AILOY ZRE1(AA) (CASTING) & 47 & 333 \\
\hline MG039 & 2459 & MAGNESIUM ALLOY ZTY $(X)$ (HK11) (WROUGHT) & 20,47 & 331 \\
\hline MG040 & 2460 & MAGNESIUM ALLOY ZW1(X) (ZK11) (WROUGHT) & 47 & 333 \\
\hline MG041 & 2461 & MAGNESIUM ALLOY ZW3(X) (ZKK31) (WROUGHT) & 47 & 333 \\
\hline MG043 & 2463 & MAGNESIUM ALIOY 1959 (MG,CE4.33) & 20 & 3303335 \\
\hline MG044 & 2464 & MAGNESIUM ALLOY 1960 (MG,CE6.7) & 20 & 3303330 \\
\hline MG045 & 2465 & MAGNESIUM ALLOY 1961 (MG,CE11.85) & 20 & 3303330 \\
\hline MG046 & 2466 & MAGNESIUM ALLOY 1964 (MG,CES,CO2,MN0.8) & 20 & 3303330 \\
\hline MG047 & 2467 & MAGNESTUM ALLOY 1992 (MG,CE4.45,CO3) & 20 & 3303330 \\
\hline SPINX & 4224 & MAGNESIUM ALUMINATE (MGO.AL2O3) (XTAL) & $20,27,47,48,51$ & 500 \\
\hline SPINL & 4225 & MAGNESIUM ALUMINATE (MGO.AI203) (100 D) & $20,27,47,48,51$ & 500 \\
\hline CORDR & 4322 & MAGNESIUM ALUMINUM SILICATE (CORDIERIT) & 20,51 & 5510 \\
\hline MGOPX & 4050 & MAGNESIUM OXIDE (MGO) (POLYXTAI, 100 D) & $1,20,27,47,48,51$ & 2000 \\
\hline MGOX & 4048 & MAGNESIUM OXIDE (MGO) (SINGLE CRYSTAL) & $1,20,27,47,48$ & 0 \\
\hline FORST & 4324 & MAGNESIUM SMYCATE (2MGO.SIO2) (100 D) & $1,20,27,51$ & 0 \\
\hline STEAT & 4326 & MAGNESIUM SIIICATE (MGO.SIO2) (COMMERC) & $1,20,27,51$ & 505 \\
\hline MG2SI & 4776 & MAGNESIUM SIICIDE (MG2SI) & $20,27,48$ & 300530 \\
\hline MGSO4 & 4970 & MAGNESIUM SULFATE (MGSO4) (CRYSTAL) & 1,27 & 50 \\
\hline EPSOM & 4971 & MAGNESIUM SULFATE HYDRATE (MGSO4.7H2O) & $1,27,51$ & 555 \\
\hline PORMT & 5283 & MAGNESIUM TITANATE PORCELAIN & 20,48 & 305530 \\
\hline MNCRY & 1101 & MANGANESE & $20,1,32,27,43,42$ & 0 \\
\hline MNO & 4052 & MANGANESE OXIDE (MNO) (SINGLE XTAL) & $1,27,48$ & 5 \\
\hline $\mathrm{MN3O4}$ & 4054 & MANGANESE OXIDE (MN3O4) (87 PC DENSE) & $20,27,48,51$ & 22005 \\
\hline MANSEL & 4928 & MANGANESE SELENIDE (97MNSE.3LISE) & 20,27 & 3305530 \\
\hline MNSI2 & 4778 & MANGANESE SILICIDE (MNSI) & $20,27,48$ & 300530 \\
\hline MNTEA & 4930 & MANGANESE TELIURIDE (95MNTE.5MNAS) & 20 & 3305530 \\
\hline MNTEN & 4931 & MANGANESE TELLURIDE (99MNTE.NATE) & 20 & 3305530 \\
\hline CUMAN & 2195 & MANGANIN (CU84, NI4, MN12) & 2 & 3305550 \\
\hline MARBL & 6021 & MARBLE (AV PROP) (SEE REF 51) & $1,27,51$ & 25555 \\
\hline MARBD & 6020 & MARBLE DIELECTRIC (XTAL) (CACO3-99.99) & $1,27,51$ & 5550 \\
\hline MELM2 & 7122 & MELAMINE (HIGH DENS, HIGH K) & 6,38 & 2022555 \\
\hline MELM1 & 7121 & MELAMINE (LOW DE14S, LOW K) & 6,38 & 2022555 \\
\hline MELAC & 7123 & MELAMINE, ALPHA CELIULOSE FILLED & 38 & 22555 \\
\hline MELAS & 7124 & MELAMINE, ASBESTOS FILIED (MST 95-205) & 38 & 2022555 \\
\hline MELAF & 7125 & MELAMINE, CELLULOSE FILLED (MST 95-205) & 38 & 22555 \\
\hline MELFF & 7127 & MELAMINE, FABRIC OR FLOCK FIILED & 6,38 & 555 \\
\hline MELGF & 7126 & MELAMINE, GLASS FIBER FILIED (MST 205) & 6,38 & 555 \\
\hline MD & 1461 & MENDELEVIUM & & 4445555 \\
\hline HGLIQ & 1207 & MERCURY (LIQUID) & $1,27,28,42,43,47,14$ & 0 \\
\hline HGCL2 & 4826 & MERCURY CHIORDE (HGCL2) (PRSD 8 KB) & $1,27,47$ & 10 \\
\hline CH4 & 4890 & METHANE (CH4) (GAS) & 1,27 & 0 \\
\hline MEMAC & 7131 & METHYL METHACRYLATE & 1,38 & 25550 \\
\hline MICAX & 4982 & MICA (SINGLE CRYSTAL) (A OR B AXES) & 20,51 & 305555 \\
\hline MICAC & 4983 & MICA (SINGLE CRYSTAI) (C AXIS) & 20,51 & 305555 \\
\hline MICAS & 4984 & MICA (SINGLE CRYSTAL) (SYNTHETIC) (98D) & 20 & 305550 \\
\hline MICAB & 4985 & MICA BRICK (RED OR WHITE) (AVG PROP) & 20 & 305552 \\
\hline MICAP & 4987 & MICA INSULATING POWDER & 20 & 305550 \\
\hline
\end{tabular}

NUREG/CR-0200, 
Table M5.6.1 (continued)

\begin{tabular}{|c|c|c|c|c|}
\hline ID & No. & Material & References & $\begin{array}{l}\text { Quality } \\
\text { Index } \\
\text { DCKTHCK }\end{array}$ \\
\hline HEM01 & 7514 & MOCK H.E. LM-04-0 H4-048-A294-3 & 5,8 & 5530 \\
\hline HEMO2 & 7515 & MOCK H.E. LM-04-0 H7-048-A522.1 & 5,8 & 5500 \\
\hline HEM03 & 7506 & MOCK H.E. RM-04-BG (LX-04-1 MECH MOCK) & 8 & 5555 \\
\hline HEM04 & 7507 & MOCK H.E. 90010 (PBX-9404 MECH MOCK) & 8 & 5555 \\
\hline MO & 1106 & MOLYBDENUM & $20,6,1,32,41,43,42$ & 0 \\
\hline MO & 1106 & MOLYBDENUM & $+47,14$ & 0 \\
\hline MOAFE & 3672 & MOLYBDENUM ALLOY (MO BAL, FE 0.25) & 20 & 333311 \\
\hline Mow30 & 3673 & MOLYBDENUM ALLOY (MO70, W30) & 20 & 3300 \\
\hline MOATI & 3671 & MOLYBDENUM ALLOY (MO99.5, TI0.5) & $1,6,41$ & 300 \\
\hline MOBED & 4712 & MOLYBDENUM BERYLIIDE (MOBE12) & 20,48 & 500 \\
\hline $\mathrm{MO} 2 \mathrm{C}$ & 4520 & MOLYBDENUM CARBIDE (MO2C) & $20,27,48$ & 2022502 \\
\hline MO2N & 4432 & MOLYBDENUM NTRIDE (MO2N) (PR SRD $100 \mathrm{D}$ ) & 47,48 & 2000505 \\
\hline MOSE2 & 4932 & MOLYBDENUM SELENIDE (MOSE2) & 20 & 3303555 \\
\hline MOSI2 & 4780 & MOLYBDENUM SIIICIDE (MOSI2) & $20,27,48$ & 2500 \\
\hline MOTE2 & 4934 & MOLYBDENUM TELLURIDE (MOTE2) & 20 & 3305555 \\
\hline MULBY & 3831 & MULBERRY (U90, NB7.5, ZR2.5) & $34,36,37$ & 0 \\
\hline MULI & 4316 & MULIITE (3AI2O3.2SIO2) (100 PC DENSE) & $20,27,48,51$ & 500 \\
\hline ND & 1366 & NEODYMIUM & $41,20,42$ & 30225 \\
\hline NDB6 & 4630 & NEODYMIUM BORIE (NDBG) (97.3 PC DENSE) & 48 & 300555 \\
\hline NEGAS & 1526 & NEON (GAS) & $27,2,1,42$ & 20000 \\
\hline NEOPR & 7136 & NEOPRENE RUBBER & $6,38,39$ & 555 \\
\hline NP & 1464 & NEPTUNIUM & 20,27 & 2440555 \\
\hline NI & 1111 & NICKEL & $20,2,1,32,37,41,42,51$ & 2 \\
\hline NIAL3 & 2588 & NICKEL ALLOY (NI35,CR20,FE45) & 41 & 5533 \\
\hline NIAL2 & 2586 & NICKEI ALIOY (NI60,CR16,FE24) & 41 & 5533 \\
\hline NIALI & 2584 & NICKEL ALLOY (NI62,CR12,FE26) & 2,41 & 3305533 \\
\hline NT995 & 2590 & NICKEL ALLOY (NI99.5) LOW C, 220,225 & 1,14 & 320 \\
\hline NICKA & 2503 & NICKEL ALLOY A (NI99.4) (ANNEAIED) & $1,14,20$ & 2 \\
\hline NICAN & 2502 & NICKEL ALLOY CALITE N & 14 & 333 \\
\hline NICH3 & 2504 & NICKEL ALLOY CHLORIMET 3 & 14 & 3333 \\
\hline NICON & 2506 & NICKEL ALLOY CONSTANTAN (NI45, CU55) & $1,2,14,41,47$ & 331 \\
\hline NICOD & 2508 & NICKEL ALLOY CORROSIST & 14 & 333 \\
\hline NIDAE & 2592 & NICKEI ALLOY D AND E & 1 & 30 \\
\hline NIDUH & 2512 & NICKEL ALIOY DURANICKEI (AND-R) (HARD) & $1,14,47$ & 333 \\
\hline NIDUS & 2510 & NICKEL ALLOY DURANICKEI (AND -R) (SOFT) & $1,14,47$ & 333 \\
\hline NI20 & 2514 & NICKEL ALLOY DURIMET 20 (CAST) & 1 & 303333 \\
\hline NIHSA & 2516 & NICKEL ALLOY HASTELLOY A (ANNEALED) & $1,14,20$ & 20332 \\
\hline NIHSB & 2518 & NICKEL ALLOY HASTELLOY B & $1,14,20,41,47$ & 300 \\
\hline NIHSC & 2520 & NICKEL ALLOY HASTELIOY C & $1,14,41,47$ & 302 \\
\hline NIHSD & 2522 & NICKEL ALLOY HASTELLOY D & $1,14,41,47$ & 333 \\
\hline NIHSN & 2523 & NICKEL ALLOY HASTELLOY N AND INOR-8 & 20,41 & 330 \\
\hline NIHSR & 2524 & NICKEL ALLOY HASTELLOY R-235 & $1,14,20$ & 300 \\
\hline NIHSX & 2526 & NICKEL ALLOY HASTELLOY X & $1,14,20,41$ & 330 \\
\hline NIH80 & 2528 & NICKEL ALLOY HY MU 80 & 14 & 200333 \\
\hline NIILG & 2530 & NICKEL ALLOY IILIUM $G$ & $1,14,20,41,47$ & 2002333 \\
\hline NIILR & 2532 & NICKEL ALLOY IIIIUM $R$ & $1,14,41,47$ & 2000333 \\
\hline NINCL & 2534 & NICKEL AILOY INCOLOY & 1,14 & 323 \\
\hline NINC9 & 2536 & NICKEL ALLOY INCOLOY 901 & 1,20 & 3310 \\
\hline NINCN & 2540 & NICKEL ALLOY INCONEL (CAST) & $1,14,20,41,47$ & 302 \\
\hline NINCA & 2538 & NICKEL AILOY INCONEL (WROUGET, ANNLD) & $1,14,20,41,47$ & 302 \\
\hline NINCW & 2542 & NICKEI ALLOY INCONEL W & 1 & 333 \\
\hline NINCX & 2544 & NICKEL ALLOY INCONEL X AND X-750 & $1,20,41$ & 301 \\
\hline NINC6 & 2545 & NICKEL ALLOY INCONEL 600 (ANNEALED) & 1,47 & 2003330 \\
\hline NANC7 & 2546 & NICKEL ALLOY INCONEL 700 & $1,14,20,41$ & 330 \\
\hline NINC2 & 2543 & NICKEL ALLOY INCONEI 702 (ANNEALED) & 1,20 & 3320 \\
\hline
\end{tabular}

NUREG/CR-0200, Vol. 3, Rev. 4 
Table M5.6.1 (continued)

\begin{tabular}{|c|c|c|c|c|}
\hline ID & No. & Material & References & $\begin{array}{l}\text { Quality } \\
\text { Index } \\
\text { DCKTHCK }\end{array}$ \\
\hline NIN7C & 2547 & NICKEL ALLOY INCONEL 713C (CAST) & 1,20 & 200320 \\
\hline NDNVR & 2501 & NICKEL ALLOY INVAR (HOT-ROLLED OR FRGD) & $6,41,47$ & 20355 \\
\hline $\operatorname{coK} 42$ & 2632 & NICKEL ALLOY K-42B & 14 & 3323332 \\
\hline NIMOC & 2551 & NICKEL ALLOY MONEL (CAST) & 1,41 & 200333 \\
\hline NIMOU & 2549 & NICKEL ALLOY MONEL (COLD-DRAWN) & $1,14,20,41$ & 333 \\
\hline NIMON & 2548 & NICKEL ALLOY MONEL (HOT-ROLLED) & $1,14,41,44,47$ & $\mathbf{0}$ \\
\hline NIMIH & 2552 & NICKEL ALLOY MONEL, H (AS CAST) & 1,41 & 220333 \\
\hline NIMHU & 2555 & NICKEL ALLOY MONEI, H (CAST, VAR COMP) & $1,20,41$ & 220333 \\
\hline NIMLK & 2554 & NICKEL ALLOY MONEL, K (ANNEALED) & $1,14,20,41,44$ & 200300 \\
\hline NIMKR & 2556 & NICKEL ALLOY MONEL, KR (ANNEALED) & 1,14 & 200333 \\
\hline NIMLR & 2558 & NICKEL ALLOY MONEL, R (HOT-ROLLED) & $1,20,41$ & 200330 \\
\hline NIMIS & 2560 & NICKEL AILOY MONEL, S (CAST, ALL COND) & $1,14,20$ & 200330 \\
\hline NIMOW & 2553 & NICKEL ALLOY MONEL WELDABLE ALLOY & 1 & 200333 \\
\hline NIM4H & 2557 & NICKEL ALLOY MONEL 400 & 47 & 205533 \\
\hline NIMLA & 2550 & NICKEL ALLOY MONEL 403 (HOT-ROLLED) & 1 & 203333 \\
\hline COMTL & 2636 & NICKEL ALLOY MULTIMET (N-155) (LOW C) & $1,14,20,41$ & 330 \\
\hline COMTM & 2634 & NICKEL ALLOY MULTIMET (N-155) (WROUGHT) & $1,14,20,41$ & 330 \\
\hline NIM25 & 2561 & NICKEI AILOY M-252 (GE J-1500) & 20 & 3310 \\
\hline NICHR & 2562 & NICKEI ALLOY NICHROME V (NI80, CR 20) & 1,47 & 23302 \\
\hline NIMND & 2564 & NICKEL ALLOY NIMONIC DS & 47 & 303333 \\
\hline NIM15 & 2575 & NICKEI ALLOY NIMONIC 105 & 47 & 3330 \\
\hline NIM75 & 2566 & NICKEL ALLOY NIMONIC 75 & $1,14,20$ & 330 \\
\hline NIMSO & 2568 & NICKEL AILOY NIMONIC 80 & $1,14,20,41,47$ & 330 \\
\hline NIM8A & 2570 & NICKEL ALLOY NIMONIC BOA & $1,20,41,47$ & 330 \\
\hline NIM90 & 2572 & NICKEL ALLOY NIMONIC 90 & $1,14,20,41$ & 330 \\
\hline NM95 & 2573 & NICKEI ALLOY NIMONIC 95 & 20,47 & 303330 \\
\hline NIPER & 2574 & NICKEI ALIOY PERMANICKEL & 1,14 & 335 \\
\hline NIREN & 2576 & NICKEL ALLOY RENE 41 & 20,41 & 303320 \\
\hline NIUDM & 2578 & NICKEL ALLOY UDIMET 500 (WROUGHT) & $1,20,41$ & 300330 \\
\hline NIWSP & 2580 & NICKEL ALLOY WASPALLOY & $1,20,41$ & 300330 \\
\hline NL330 & 2582 & NICKEL ALIOY 330 (NI99.55) (ANNEALED) & 1 & 335 \\
\hline CNLOX & 4218 & NICKEI COBALT OXIDE (46NIO.46COO.8LIO) & 20,27 & 3305555 \\
\hline NIOLI & 4222 & NICKEL LITHIUM OXIDE (95NIO.5LIO) & 20,27 & 3305550 \\
\hline NIOPL & 4060 & NICKEL OXIDE (NIO) (POLYXTAL, 68-74 D) & $20,27,32,47,48,51$ & 0 \\
\hline NIOPX & 4058 & NICKEL OXIDE (NIO) (POLYXTAL, 88-100 D) & $20,27,32,47,48,51$ & 0 \\
\hline No & 4056 & NICKEL OXIDE (NIO) (SINGLE XTAL) & $20,27,32,47,48,51$ & 5 \\
\hline CUNIS & 2185 & NICKEL SILVER (CU BAL, NI 10-20) & $1,2,6,41,47$ & 2222555 \\
\hline NIZNF & 4226 & NICKEL ZINC FERRITE (NI(ZN)O.FE2O3) & 20 & 2025502 \\
\hline $\mathrm{NB}$ & 1246 & NIOBIUM & $20,27,32,43,44,42$ & 0 \\
\hline NBTAW & 3681 & NIOBIUM AILOY (NB61, TA28, W10, ZR0.5) & 20 & 3300 \\
\hline NBWMO & 3684 & NIOBIUM ALLOY (NB80, W15, MO5) & 20 & 3300 \\
\hline NBTZ & 3682 & NIOBIUM ALIOY (NB85, TI10, ZRS) & 20 & 3300 \\
\hline NBTA5 & 3683 & NIOBIUM ALLOY (NB95, TAS) & 20 & 3303330 \\
\hline NBBED & 4714 & NIOBIUM BERYLLIDE (NBBE12) (HP, 93-97D) & 20,48 & 2000500 \\
\hline NBBE8 & 4716 & NIOBIUM BERYLLIDE (NB2BE17) & 20,48 & 300530 \\
\hline NBB2 & 4620 & NIOBIUM BORIDE (NBB2) (PRESSED, SNTRD) & $20,27,48$ & 2500 \\
\hline NBC & 4522 & NIOBIUM CARBIDE (NBC) & $20,27,48,54$ & 20502 \\
\hline NBN & 4434 & NIOBIUM NITRIDE (NBN) & $20,47,48$ & 505 \\
\hline NB2N & 4436 & NIOBIUM NITRIDE (NB2N) & $20,47,48$ & 300535 \\
\hline NBSL & 4782 & NIOBIUM SIIICIDE (NBSE) & 20,27 & 300535 \\
\hline NOGAS & 4061 & NITRIC OXIDE (NO) (GAS) & 1,27 & 500 \\
\hline NITRR & 7141 & NITRIIE RUBBER & 6,39 & 5555 \\
\hline NIIRC & 7508 & NITROCELLULOSE H.E. (12.7 N) & 8 & 305555 \\
\hline N-GAS & 1531 & NITROGEN (GAS) & $27,2,42,1$ & 0 \\
\hline No & 1467 & NOBELIUM & & 4445555 \\
\hline
\end{tabular}


Table M5.6.1 (continued)

\begin{tabular}{|c|c|c|c|c|}
\hline ID & No. & Material & References & $\begin{array}{c}\text { Quality } \\
\text { Index } \\
\text { DCKTHCK }\end{array}$ \\
\hline NYLON & 7151 & NYLON $6,11,66,610$ (POLYCAPROLACTAM) & $1,6,38$ & 500 \\
\hline NYLGF & 7156 & NYLON, GLASS FILLED & & 202555 \\
\hline OBSID & 5030 & OBSIDLAN GLASS & 27,51 & 305530 \\
\hline ORTHC & 4328 & ORTHOCLASE (K2O.AL2O3.6SIO2) (CRYSTAL) & 27,51 & 325555 \\
\hline os & 1114 & OSMIUM & $27,20,42,41$ & 0 \\
\hline O-GAS & 1536 & OXYGEN (GAS) & $27,42,1,2$ & 0 \\
\hline PD & 1236 & PALLADIUM & $20,41,42,27,43$ & 0 \\
\hline E9011 & 7509 & PBX-9011 H.E. (HMX 90, ESTANE 10) & 8 & 555 \\
\hline E9404 & 7510 & PBX-9404-03 H.E. (FIMX 94, NC 3, BIND 3) & 8,44 & 511 \\
\hline PETN & 7511 & PETN H.E. & 8 & 555 \\
\hline PHCAF & 7172 & PHENOLIC, CAST, ASBESTOS FILLER & 6,38 & 2555 \\
\hline PHCNF & 7171 & PHENOLIC, CAST, NO FILIER & 6,38 & 222555 \\
\hline PHMHID & 7177 & PHENOLIC, MOLDED (HIGH DENSITY, K) & 6 & 22555 \\
\hline PHMID & 7176 & PHENOLIC, MOLDED (LOW DENSITY, K) & 6 & 22555 \\
\hline PHRPD & 7181 & PHENOLIC RESIN, PRESSED, TYPES 40, 50 & 20 & 305555 \\
\hline PFPPF & 7161 & PHENOL-FORMALDEHYDE + PHENOL-FURFURAL & 20 & 2225555 \\
\hline PHNXY & 7191 & PHENOXY & 6,38 & 2000555 \\
\hline $\mathbf{P}$ & 1321 & PHOSPHORUS (WHITE) & 27 & 40005 \\
\hline PLASL & 4963 & PLASTER, BUILDING (MOLDED, DRY) & 1,27 & 555 \\
\hline PLAMT & 7201 & PLASTIC LAMINATE, VARIOUS TYPES & 6,20 & 2222555 \\
\hline GLASP & 5034 & PLATE GLASS & 20,51 & 305532 \\
\hline PT & 1116 & PLATINUM & $20,1,32,27,41,43,42$ & 0 \\
\hline PU & 1121 & PLUTONIUM & $20,31,3,27,43,42,41$ & 0 \\
\hline PU & 1121 & PLUTONIUM & $+36,44$ & 0 \\
\hline PUSTD & 3701 & PLUTONIUM ALLOY (DELTA PHASE) & $20,27,31,44$ & 200 \\
\hline PUC & 4524 & PLUTONIUM CARBIDE (PUC) (ARCM OR CAST) & $20,48,53,54$ & 2025502 \\
\hline PUN & 4438 & PLUTONIUM NITRIDE (PUN) & $27,48,53$ & 300530 \\
\hline PUP & 4762 & PLUTONIUM PHOSPHIDE (PUP) (90 PC DENSE) & 53 & 500 \\
\hline PUS & 4747 & PLUTONIUM SULFIDE & 53 & 550 \\
\hline UPUOX & 4242 & PLUTONIUM URANIUM OXIDE (PUO2.4UO2) SEE & 53 & 303530 \\
\hline PO & 1473 & POLONIUM & 20,27 & 20005 \\
\hline PALLO & 7211 & POLYALLOMER & 6,38 & 22555 \\
\hline PCARB & 7221 & POLYCARBONATE, VARIOUS FILLERS & 6,38 & 2022555 \\
\hline PESTG & 7231 & POLYESTER, GLASS FIBER REINFORCED, TAC & 20 & 2555 \\
\hline PETHH & 7243 & POLYETHYLENE, HIGH DENSITY & 6,38 & 2555 \\
\hline PETHI & 7241 & POLYETHYLENE, LOW DENSITY & 6,38 & 2555 \\
\hline PETHM & 7242 & POLYETHYLENE, MEDIUM DENSITY & 6,38 & 2555 \\
\hline PIMIHF & 7251 & POLYMIIDE, H-FIIM, KAPTON & 6,40 & 555 \\
\hline MEMAC & 7131 & POLYMETHYL METHACRYLATE & 1,38 & 25550 \\
\hline PPROC & 7262 & POLYPROPYLENE, COPOLYMER & 6,38 & 20555 \\
\hline PPROP & 7263 & POLYPROPYLENE, FILLED & 6 & 20555 \\
\hline PPROM & 7261 & POLYPROPYLENE, MOPLIN & 6,38 & 555 \\
\hline PSTYF & 7271 & POLYSTYRENE, FOAMED-IN-PLACE, RIGID & 6 & 2020555 \\
\hline PSTYG & 7276 & POLYSTYRENE, GENERAI PURPOSE & $6,20,38$ & 2550 \\
\hline PSTYM & 7281 & POLYSTYRENE, MODIFIED & 6 & 22555 \\
\hline PSTYP & 7286 & POLYSTYRENE, PREFOAMED, RIGID, DOW Q103 & 6,20 & 2002550 \\
\hline PSTYL & 7287 & POLYSTYRENE FOAM $(D=0.038)(1$ ATM $)$ & 1 & 20552 \\
\hline PSTYV & 7289 & POLYSTYRENE FOAM $(D=0.046)$ (VACUUM) & 1 & 20552 \\
\hline PSTYH & 7288 & POLYSTYRENE FOAM $(D=0.046)(1$ ATM $)$ & 1 & 20552 \\
\hline PSULF & 7291 & POLYSULFONE & $5,6,38$ & 555 \\
\hline PURRF & 7302 & POLYURETHANE FOAMED-IN-PLACE, RIGID & 6,20 & 2320555 \\
\hline PUREF & 7301 & POLYURETHANE FOAM, FLEXIBLE & $6,20,38$ & 2020555 \\
\hline PURER & 7311 & POLYURETHANE RUBBER L-100 & 6,38 & 20555 \\
\hline PVINA & 7321 & POLYVINYL ALCOHOL & 6 & 5555 \\
\hline PVINB & 7331 & POLYVINYL BUTYRAL & 6,38 & 555 \\
\hline
\end{tabular}

NUREG/CR-0200,

Vol. 3, Rev. 4 
Table M5.6.1 (continued)

\begin{tabular}{|c|c|c|c|c|}
\hline ID & No. & Material & References & $\begin{array}{c}\text { Quality } \\
\text { Index } \\
\text { DCKTHCK }\end{array}$ \\
\hline PVINC & 7341 & POLYVINYL CARBAZOLE & 20 & 5555 \\
\hline PVCAF & 7356 & POLYVINYL CHILORIDE ACYTATE, FLEXIBLE & 38 & 2225555 \\
\hline PVCAR & 7357 & POLYVINYL CHIORIDE ACYTATE, RIGID & 38 & 2225555 \\
\hline PVCFL & 7351 & POLYVINYL CHIOORIDE, FLEXIBLE & $6,38,20$ & 2222555 \\
\hline PVCRD & 7352 & POLYVINYL CHIORIDE, RIGID & $6,38,20$ & 2222555 \\
\hline PVTPX & 7371 & POLYVINYL TPX-R & 5,38 & 5555 \\
\hline PVDCM & 7362 & POLYVINYLIDENE CHLORIDE & 6,38 & 22555 \\
\hline PVDCF & 7361 & POLYVINYLIDENE CHLORIDE FILM & 6,38 & 555 \\
\hline PVDCK & 7366 & POLYVINYLIDENE FLUORIDE (KYNAR) & 5,38 & 5555 \\
\hline PORAI & 5281 & PORCELAIN, HIGH ALUMINA & 20 & 3005500 \\
\hline PORZR & 5282 & PORCEILAIN, HIGH ZIRCON & 20 & 305535 \\
\hline PORMT & 5283 & PORCELAIN, MAGNESIUM TITANATE & 20,48 & 305530 \\
\hline PORCE & 5286 & PORCELAIN, ORDINARY & 1,20 & 3325535 \\
\hline PORBE & 5280 & PORCELANN 4811 (BEO) & 20 & 305530 \\
\hline PORC5 & 5284 & PORCELAIN 576 & 20 & 325535 \\
\hline $\mathbf{K}$ & 1226 & POTASSIUM & $1,27,28,42,41,43,51$ & 0 \\
\hline KLIQ & 1227 & POTASSIUM (LIQUID) & $14,27,28,43,47,51$ & 22 \\
\hline KALUM & 4972 & POTASSIUM ALUM (K2SO4.AL2(SO4)3.24H2O) & 1,27 & 550 \\
\hline ORTHC & 4328 & POTASSIUM ALUMINUM SIIICATE (ORTHOCLAS) & 27,51 & 325555 \\
\hline KBR & 4828 & POTASSIUM BROMIDE (KBR) (PRSD 8 KB) & $1,27,47$ & 210 \\
\hline KBRX & 4830 & POTASSIUM BROMIDE (KBR) (SINGLE XTAL) & $1,27,47,51$ & 210 \\
\hline KBR50 & 4833 & POTASSIUM BROMIDE (KBR 50, KCL 50) & $1,27,47,51$ & 3303330 \\
\hline KBR75 & 4832 & POTASSIUM BROMIDE (KBR 75, KCL 25) & $1,27,47,51$ & 3303330 \\
\hline KCL & 4836 & POTASSIUM CHLORIDE (KCL) (PRSD 8 KB) & $1,27,47,51$ & 10 \\
\hline KCLSY & 4837 & POTASSIUM CHILORIDE (KCL) (SYLVITE XTAL) & $1,27,47,51$ & 10 \\
\hline KBR50 & 4833 & POTASSIUM CHLORIDE (KCL 50, KBR 50) & $1,27,47,51$ & 3303330 \\
\hline KCLSO & 4838 & POTASSIUM CHLORIDE (KCL 50, NACL 50) & $1,27,47,51$ & 303330 \\
\hline KCL75 & 4834 & POTASSIUM CHIORIDE (KCL 75, KBR 25) & $1,27,47,51$ & 3303330 \\
\hline KCL90 & 4835 & POTASSIUM CHLORIDE (KCL 90, KBR 10) & $1,27,47,51$ & 3303330 \\
\hline KCROM & 4233 & POTASSIUM CHROMATE (K2O.2CRO3) (M AXIS) & 1,27 & 300050 \\
\hline KCROX & 4232 & POTASSIUM CHROMATE (KOO.2CRO3) (S AXIS) & 1,27 & 300050 \\
\hline KF & 4840 & POTASSIUM FLUORIDE (KF) (PRSD $8 \mathrm{~KB}$ ) & $1,27,47$ & 10 \\
\hline KI & 4842 & POTASSIUM IODIDE (KI) (PRSD $8 \mathrm{~KB}$ ) & $1,27,47$ & 10 \\
\hline KFECN & 4974 & POTASSIUM FERROCYANIDE (K4FE(CN)6.3H2O) & 1,27 & 550 \\
\hline KNO3 & 4976 & POTASSIUM NITRATE (KNO3) (PR $8000 \mathrm{~KB})$ & 1,27 & 0 \\
\hline PR & 1361 & PRASEODYMIUM & $41,27,20,42$ & 205 \\
\hline PRB6 & 4628 & PRASEODYMIUM BORIDE (PRBG) (95 PC DENS) & 48 & 305555 \\
\hline PM & 1421 & PROMETHIUM & $20,27,42$ & 3332035 \\
\hline PA & 1476 & PROTACTINIUM & 20,27 & 30005 \\
\hline PYREX & 5016 & PYREX GLASS & $2,20,27,51$ & 500 \\
\hline PYRC6 & 5018 & PYROCERAM 9606 CERAMIC GLASS & 20 & 5500 \\
\hline PYRC8 & 5019 & PYROCERAM 9608 CERAMIC GLASS & 20 & 5500 \\
\hline PYROP & 4990 & PYROPHYLIITE (PARALCEL TO BEDDING) & 27,51 & 2305530 \\
\hline PYRON & 4991 & PYROPHYLLITE (PERPEND. TO BEDDING) & 27,51 & 2305530 \\
\hline SIO2A & 4066 & QUARTZ CRYSTAL, A AXIS (SIO2) & $1,2,20,27,37,47,51$ & 2200 \\
\hline SIO2C & 4064 & QUARTZ CRYSTAI, C AXIS (SIO2) & $1,2,20,27,37,47,51$ & 2200 \\
\hline SANQF & 6032 & QUARTZ FLOUR, FINE (DRY) & 51 & 305535 \\
\hline SANQN & 6033 & QUARTZ FLOUR, FINE (H2O 21 PC) & 51 & 305555 \\
\hline $\mathrm{SIO} 2$ & 4062 & QUARTZ GLASS, FUSED (SIO2) & $1,20,27,47,51$ & 2200 \\
\hline SANQP & 6039 & QUARTZ POWDER, COARSE (H2O 24) & 51 & 305555 \\
\hline SANDY & 6034 & QUARTZ SAND (DRY) (AV PROP) (SEE REF) & 51 & 2325555 \\
\hline SANDQ & 6036 & QUARTZ SAND (WET) (H2O 4-23) (AV PROP) & 51 & 2325555 \\
\hline RA & 1479 & RADIUM & 27 & 2040025 \\
\hline RNGAS & 1561 & RADON GAS & 27 & 40505 \\
\hline RATTN & 8211 & RATTAN & 44 & 25555 \\
\hline
\end{tabular}


Table M5.6.1 (continued)

\begin{tabular}{|c|c|c|c|c|}
\hline ID & No. & Material & References & $\begin{array}{l}\text { Quality } \\
\text { Index } \\
\text { DCKTHCK }\end{array}$ \\
\hline RE & 1251 & RHENIUM & $27,43,41,42$ & 2 \\
\hline RH & 1281 & RHODIUM & $20,27,43,42,41$ & 0 \\
\hline ROCKS & 6022 & ROCK OR STONE (AVERAGE PROPERTIES) & 1,46 & 3335555 \\
\hline STBRC & 7431 & RUBBER, BUNA, WITH CARBON BLACK & $6,20,39$ & 200555 \\
\hline BUTYR & 7031 & RUBBER, BUTYL & 6,39 & 555 \\
\hline RUBBD & 7382 & RUBBER, DIELECTRYC MIX & 6,20 & 550 \\
\hline RUBBK & 7383 & RUBBER, HIGH K & 6,20 & 550 \\
\hline RUBBN & 7381 & RUBBER, NATURAI & 6 & 555 \\
\hline RUBBF & 7386 & RUBBER, NATURAL, FOAM & 6,20 & 320555 \\
\hline NEOPR & 7136 & RUBBER, NEOPRENE & $6,38,39$ & 555 \\
\hline NITRR & 7141 & RUBBER, NTRTIE & & 5555 \\
\hline PURER & 7311 & RUBBER, POLYURETHANE ELASTOMER L-100 & 6,38 & 20555 \\
\hline RB & 1291 & RUBDIUM & $1,27,28,42,43,47$ & 40024 \\
\hline RBLIQ & 1292 & RUBDIUM (LIQUID) & $1,14,27,28,43,47$ & 20022 \\
\hline RBCL & 4844 & RUBIDIUM CHLORIDE (RBCL) (PRSD $8 \mathrm{~KB}$ ) & $1,27,47$ & 10 \\
\hline RBI & 4846 & RUBIDIUM IODIDE (RBD) (PRSD 8 KB) & $1,27,47$ & 10 \\
\hline RU & 1301 & RUTHENTUM & $20,42,1,27$ & 202020 \\
\hline SM & 1371 & SAMARIUM & $20,27,41,42,43$ & 30205 \\
\hline SMB6 & 4632 & SAMARIUM BORIDE (SMB)) (96.8 PC DENSE) & 48 & 300555 \\
\hline SMS & 4748 & SAMARIUM SULFIDE (SMS) & 20,48 & 300550 \\
\hline SANDY & 6034 & SAND (DRY) (D = 1.36 TO 1.84) (AV PROP) & 51 & 2325555 \\
\hline SANDN & 6038 & SAND, NORTHWAY (H2O 410) (AV PROP) & 51 & 2325555 \\
\hline SANDQ & 6036 & SAND, QUARTZ (WET) (H2O 423) (AV PROP) & 2,51 & 2325555 \\
\hline SANDM & 6026 & SANDSTONE (AV PROP) (SEE REF S1) & $2,27,46,51$ & 25555 \\
\hline SANDL & 6025 & SANDSTONE (LOW DENSITY) & $2,27,46,51$ & 25555 \\
\hline ALOXD & 4012 & SAPPHIRE (AL203) (POLYXTAL) (100 PC D) & $1,20,27,32,47,48,51$ & 200 \\
\hline AlOXS & 4016 & SAPPHIRE (AL2O3) (SINGLE XTAI) (AV DIR) & $1,20,27,32,47,48,51$ & 202 \\
\hline sc & 1341 & SCANDIUM & $20,27,41,43$ & 30005 \\
\hline SE & 1326 & SELENIUM (GREY) & $27,43,42,1$ & 20005 \\
\hline SHALE & 6028 & SHALE (AV PROP) (SEE REF 51) & 51 & 2225555 \\
\hline BRISI & 5294 & SILICA BRICK, HARD FIRED (SIO2 94-95) & 20 & 330 \\
\hline $\mathrm{SIO} 2$ & 4062 & SUICA GLASS, FUSED OR VITROUS & $1,20,27,47,51$ & 2200 \\
\hline BRISL & 5296 & SLICEOUS BRICK (SIO2 89, AL2O3 9)(25P) & 47 & 335 \\
\hline SI & 1256 & SIIICON & $20,1,27,41,43,42,48$ & 0 \\
\hline SIB4 & 4614 & SIIICON BORIDE (SIB4) & 27,48 & 300530 \\
\hline SICAL & 4539 & SUICON CARBIDE (SIC) (BRICK AL203 1.7) & $20,27,32,47$ & 2500 \\
\hline SICCF & 4535 & SILICON CARBDE (SIC) (CARBOFRAX BRICK) & $20,27,32,47$ & 2500 \\
\hline SICFV & 4542 & SLICON CARBIDE (SIC) (FOAM, IN VACUUM) & $20,32,47$ & 2500 \\
\hline SICFB & 4536 & SILICON CARBIDE (SIC) (FRIT BND BRICK) & $20,27,32,47$ & 2500 \\
\hline SICKT & 4534 & SIICON CARBIDE (SIC) (KT GRADE) & $20,27,32,47,48$ & 2500 \\
\hline SICNB & 4541 & SIIICON CARBIDE (SIC) (NITRIDE BONDED) & $20,32,47,48$ & 2503 \\
\hline SICPA & 4543 & SILICON CARBIDE (SIC) (POWDER, IN AIR) & $20,32,47$ & 2500 \\
\hline SICPH & 4544 & SIIICON CARBDE (SIC) (POWDER, IN HE) & $20,32,47$ & 2500 \\
\hline SICRD & 4540 & SIICON CARBIDE (SIC) (REFRACTORY D-30) & $20,27,32,47$ & 2500 \\
\hline SICRP & 4538 & SIICON CARBIDE (SIC) (REXTAL, 65-70 D) & $1,20,27,32,47$ & 2500 \\
\hline SICRX & 4537 & SIIICON CARBIDE (SIC) (REXTAI, 80-100 D) & $20,27,32,47,48$ & 2500 \\
\hline sicxi & 4531 & SIIICON CARBIDE (SIC) (SINGLE XTAL) & $20,27,32,47$ & 22500 \\
\hline $\operatorname{sic} \times 2$ & 4532 & SIIICON CARBIDE (SIC) (SINGLE XTAL) & $20,32,47,48$ & 22505 \\
\hline SICSB & 4533 & SUICON CARBIDE (SIC) (SLF BND, HE ATM) & $20,27,32,47$ & 2500 \\
\hline SICSI & 5424 & SIIICON CARBIDE + SI (SIC 76, SI 24) & 20 & 3305550 \\
\hline SI3NL & 4444 & SIIICON NITRIDE (SIBN4) (70 PC DENSE) & $20,27,47,48$ & 20502 \\
\hline SEN4 & 4442 & SHICON NITRIDE (SIBN4) (85 PC DENSE) & $20,27,47,48$ & 20502 \\
\hline SIO2F & 4068 & SILICON OXIDE (SIO2) (FOAM, 1 ATM AIR) & $1,20,27,47$ & 2200 \\
\hline SIO2 & 4062 & SILICON OXME (SIO2) (FUSED QUARTZ) & $1,20,27,47,51$ & 2200 \\
\hline SIO2A & 4066 & SIIICON OXIDE (SIO2) (QUARTZ, A AXIS) & $1,2,20,27,37,47,51$ & 2200 \\
\hline
\end{tabular}

NUREG/CR-0200, Vol. 3, Rev. 4 
Table M5.6.1 (continued)

\begin{tabular}{|c|c|c|c|c|}
\hline $\mathbf{D}$ & No. & Material & References & $\begin{array}{l}\text { Quality } \\
\text { Index } \\
\text { DCKTHCK }\end{array}$ \\
\hline SIO2C & 4064 & SIIICON OXIDE (SIO2) (QUARTZ, C AXIS) & $1,2,20,27,37,47,51$ & 2200 \\
\hline SITE & 4936 & SILICON TELLURIDE (SITE) & 20 & 305555 \\
\hline SLFF & 7401 & SILICONE FOAM, FLEXIBLE (LRL) & 6,20 & 2022555 \\
\hline SLFR & 7402 & SIIICONE FOAM, RIGD, VARIOUS & 6,20 & 2022555 \\
\hline SLRH & 7423 & SILICONE RUBBER, HIGH K (SEE REF 5) & $5,6,41,44$ & 220555 \\
\hline SILRL & 7421 & SIICONE RUBBER, LOW K (SEE REF 5 ) & $5,6,41,44$ & 220555 \\
\hline SILRM & 7422 & SIICONE RUBBER, MEDIUM K (SEE REF S) & $5,6,41,44$ & 220555 \\
\hline SILRI & 7424 & SIIICONE RUBBER, RTV 521 AND 093-009 & $5,6,41,44$ & 220555 \\
\hline SILMD & 7411 & SLICONE, MOLDED, VARIOUS FILLERS & $6,20,38$ & 2222555 \\
\hline BRISK & 5298 & SILLIMANITE BRICK (22 PC POROSITY) & 20 & 300530 \\
\hline AG & 1126 & SILVER & $20,6,1,27,2,32,42,47$ & 0 \\
\hline AG & 1126 & SILVER & $+14,43$ & 0 \\
\hline AGLIQ & 1127 & SILVER (LIQUID) & $27,32,42,43$ & 30005 \\
\hline SILVA & 3751 & SILVER ALLOYS, STERLING AND COIN & 1 & 325 \\
\hline SNTE2 & 4940 & SILVER ANTIMONY TELLUURDE (SNTE 25 PC) & 20 & 3305555 \\
\hline AGCL & 4848 & SILVER CHLORIDE (AGCL) (SINGLE CRYSTAL) & $27,47,51$ & 15 \\
\hline AG2SE & 4942 & SILVER SELENDE (AG2SE) & $20,27,47$ & 20502 \\
\hline SLATE & 6030 & SLATE (AV PROP) (SEE REF 51) & 51 & 2225555 \\
\hline GLASC & 5032 & SODA-LIME GLASS & 20,27 & 3325532 \\
\hline NA & 1221 & SODIUM & $2,1,27,28,41,42,43,51$ & 0 \\
\hline NALIQ & 1222 & SODIUM (LIQUID) & $1,14,27,28,42,43,47$ & 1 \\
\hline NALIQ & 1222 & SODIUM (LIQUID) & +51 & 1 \\
\hline ANALC & 4329 & SODIUM ALUMINUM SIICATE HYDRATE (XTAL) & 27,51 & 305555 \\
\hline NABR & 4850 & SODIUM BROMDE (NABR) (PRSD $8 \mathrm{~KB}$ ) & $1,27,47$ & 10 \\
\hline NACLO & 4978 & SODIUM CHLORATE (NACLO3) (CRYSTAL) & $1,27,51$ & 505 \\
\hline NACL & 4852 & SODIUM CHLORDE (NACL) (CLEAR CRYSTAL) & $1,27,47,51,52$ & 10 \\
\hline NACLR & 4854 & SODIUM CELORIDE (NACL) (OPAQUE, IMPURE) & $1,27,47,51,52$ & 10 \\
\hline KCL50 & 4838 & SODIUM CELORDE (NACL 50, KCL 50) & $1,27,47,51$ & 303330 \\
\hline NAF & 4856 & SODIUM FLUORIDE (NAF) (PRSD $8 \mathrm{~KB}$ ) & $1,27,47$ & 10 \\
\hline SOILS & 6046 & SOIL (AV PROPS) (SEE REFS) & $2,46,51$ & 2225555 \\
\hline soll 3 & 6044 & SOIL, CLAY (WET) & 51 & 2225555 \\
\hline SANQF & 6032 & SOII, FINE QUARTZ FLOUR (DRY) & 51 & 305535 \\
\hline SANQW & 6033 & SOII, FINE QUARTZ FLOUR (H2O 21 PC) & 51 & 305555 \\
\hline solli & 6042 & SOII, LOAM (DRY) (AV PROP) (SEE REFS) & 2,51 & 2225555 \\
\hline soll2 & 6043 & SOII, LOAM (H2O 4-27 PC) (AV, SEE REFS) & 2,51 & 2225555 \\
\hline SOIIM & 6048 & SOIL, MARS SURFACE (SEE UCRL-50309) & & 5555 \\
\hline SOLID & 6050 & SOIL, SANDY DRY & 46 & 5555 \\
\hline soIlw & 6052 & SOIL, SANDY (H2O 8) & 46 & 5555 \\
\hline ART & 7007 & SOLD, REGULATING $\left(\mathrm{D}=\mathrm{C}=\mathrm{K}=\mathrm{TM}=1, \mathrm{HM}=10^{* * 9}\right)$ & & $\mathbf{0}$ \\
\hline ART6 & 9006 & SOLI, UNIT LATENT HEAT ( $\mathrm{D}=\mathrm{C}=\mathrm{K}=\mathrm{TM}=\mathrm{HM}=1)$ & & $\mathbf{0}$ \\
\hline ART3 & 9003 & SOLD, UNTT PROPERTY $(\mathrm{D}=\mathrm{C}=\mathrm{K}=1)$ & & $\mathbf{0}$ \\
\hline SNOWF & 8231 & SNOW, FRESH & 2,27 & 55 \\
\hline SNOWP & 8232 & SNOW, PACKED & 27,46 & 55 \\
\hline SOLD1 & 3611 & SOLDER (PB37.5, SN37.5, IN25) & 36 & 3355 \\
\hline SOLD2 & 3612 & SOLDER (PB39.2, SN60.8) & 34,41 & 5 \\
\hline SOLD4 & 3613 & SOLDER (PB50, SN50) & 1,41 & 50 \\
\hline SOLD3 & 3614 & SOLDER (PB60, SN40) & 1,41 & 55 \\
\hline SPINX & 4224 & SPINEI (MGO.AL2O3) (SINGLE CRYSTAL) & $20,27,47,48,51$ & 500 \\
\hline SPINL & 4225 & SPINEL (MGO.AL203) (100 PC DENSE POLYX) & $20,27,47,48,51$ & 500 \\
\hline H2OGS & 4113 & STEAM (H2O) (GAS) (SATD) & $1,2,14,27,46$ & 205550 \\
\hline H2OG1 & 4112 & STEAM (H2O) (GAS) (1 ATM) & $1,2,14,27,46$ & 200050 \\
\hline STEAT & 4326 & STEATITE (MGO.SIO2) (COMMERCIAL GRADES) & $1,20,27,51$ & 505 \\
\hline STALL & 3101 & STEEL, ALLOY AND MIID $(4130,4340)$ & $6,41,46$ & 3302 \\
\hline STALC & 3106 & STEEE, ALLOY, CAST & 6 & 3355 \\
\hline STCAR & 3116 & STEEL, CARBON, TYPE $1020(0.2-0.6 \mathrm{C})$ & $1,20,37$ & 300 \\
\hline
\end{tabular}


Table M5.6.1 (continued)

\begin{tabular}{|c|c|c|c|c|}
\hline ID & No. & Material & References & $\begin{array}{c}\text { Quality } \\
\text { Index } \\
\text { DCKTHCK }\end{array}$ \\
\hline STCFC & 3111 & STEEL, FREE CUTTING, EUTECTOID & $2,4,6,20,41$ & 300 \\
\hline STHSP & 3121 & STEEI, HIGH SPEED (M1, M10, M-2, TI) & 20 & 3303355 \\
\hline COMTL & 2636 & STEEL, MULTIMET (N-155) (LOW C) & $1,14,20,41$ & 330 \\
\hline COMTM & 2634 & STEEL, MULTIMET (N-155) (WROUGHT) & $1,14,20,41$ & 330 \\
\hline STST4 & 3141 & STEEI, STAINLESS (CR 12-13, NI 0-3) & $1,2,4,14,20$ & 300 \\
\hline STST3 & 3131 & STEEL, STAINLESS (CR 16-26, NI 8-36) & $1,2,4,6,20,37$ & 2023333 \\
\hline sSc08 & 3208 & STEEL, STAINLESS CA15, CA40 (CAST) & 1 & 355 \\
\hline ssc09 & 3209 & STEEL, STANLLESS CB30, CC50 (CAST) & 1 & 355 \\
\hline SSC13 & 3213 & STEEL, STAINLESS CK, CH, HI (CAST) & 1 & 355 \\
\hline SsC12 & 3212 & STEEL, STANLESS CF (CAST) & 1 & 355 \\
\hline ssc04 & 3204 & STEEL, STAINLESS CN-7M (CAST) & 1 & 355 \\
\hline ssco6 & 3206 & STEEL, STAINLESS HA (CAST) & 1 & 355 \\
\hline ssc07 & 3207 & STEEL, STANNLESS HC, HD (CAST) & 1 & 355 \\
\hline ssc11 & 3211 & STEEI, STAINLESS HE (CAST) & 1 & 355 \\
\hline sscos & 3205 & STEEI, STARLESS HF (CAST) & 1 & 355 \\
\hline sscio & 3210 & STEEL, STANLESS HH, HI, HK (CAST) & 1 & 355 \\
\hline ssco3 & 3203 & STEEL, STAINLESS HT (CAST) & 1 & 355 \\
\hline ssco2 & 3202 & STEEL, STANLESS HU (CAST) & 1 & 355 \\
\hline SSCO1 & 3201 & STEEI, STAINLESS HW (CAST) & 1 & 355 \\
\hline STST3 & 3131 & STEEL, STANLESS SERIES 300 & $1,2,4,6,20,37$ & 2023333 \\
\hline STST4 & 3141 & STEEI, STANILESS SERIES 400 & $1,2,4,20$ & 300 \\
\hline STPH4 & 3171 & STEEI, STANLESS 17-4PH & 20,14 & 23302 \\
\hline STPH7 & 3176 & STEEL, STAINLESS 17-7PH & 20,14 & 2003300 \\
\hline ST199 & 3186 & STEEL, STANLESS 19-9DL & 41 & 2300 \\
\hline STST2 & 3126 & STEEL, STAINLESS 201 AND 202 & 1 & 3355 \\
\hline ST304 & 3133 & STEEL, STAINLESS 304 & $1,4,37$ & 300 \\
\hline ST347 & 3135 & STEEL, STAINLESS 321 AND 347 & $1,2,4,20,37,14$ & 300 \\
\hline STS4A & 3146 & STEEL, STAINLESS 430, 430F, AND 431 & $1,2,4,6,20,14$ & 302 \\
\hline STS4B & 3151 & STEEL, STAINLESS 446 & $1,14,20$ & 302 \\
\hline STST5 & 3161 & STEEL, STAINLESS 501 AND 502 & 2,4 & 2303330 \\
\hline wCCO2 & 5453 & STEEL, TOOL, TUNGSTEN CARBIDE CA2 & 20 & 3300530 \\
\hline WCCO1 & 5452 & STEEL, TOOL, TUNGSTEN CARBIDE CA4 & 20 & 3300530 \\
\hline STUHS & 3181 & STEEL, ULTRA HIGH STRENGTH TYPE 300-M & 1 & 355 \\
\hline SR & 1296 & STRONTIUM & $20,28,42,27$ & 240024 \\
\hline SRS04 & 4980 & STRONTIUM SULFATE (SRSO4) (CRYSTAL) & $1,27,51$ & 550 \\
\hline SRTTT & 4234 & STRONTIUM TITANATE (SRO.TIO2) (100 D) & 20,48 & 500 \\
\hline SRTIP & 4235 & STRONTIUM TITANATE (SRO.TIO2) (80 D) & 20,48 & 500 \\
\hline STCOI & 5426 & STRONTIUM TITANATE + CO (CO 10) & 20 & 3300535 \\
\hline STCO2 & 5427 & STRONTIUM TITANATE + CO (CO 20) & 20 & 3300535 \\
\hline STCO3 & 5428 & STRONTIUM TITANATE + CO (CO 30) & 20 & 3300535 \\
\hline STCO4 & 5429 & STRONTIUM TITANATE + CO (CO 40) & 20 & 3300535 \\
\hline STBRC & 7431 & STYRENE-BUTADIENE RUBBER + CARBON BLK & $6,20,39$ & 200555 \\
\hline $\mathbf{S}$ & 1331 & SULFUR & $27,1,42,30,2,41$ & 10001 \\
\hline SO2 & 4071 & SULFUR DIOXIDE (SO2) (GAS) & 1 & 5500 \\
\hline TALC & 4994 & TALC & $20,27,51$ & 5505 \\
\hline TA & 1161 & TANTALUM & $20,1,27,32,37,43$ & 20002 \\
\hline TANBV & 3784 & TANTAIUM ALLOY (TA62, NB30, V7.5) & 20 & 3300 \\
\hline TAWHF & 3785 & TANTALUM ALLOY (TA89, W9, HF2) & 20 & 300 \\
\hline TA10W & 3781 & TANTALUM ALLOY (TA90, W10) & 20,36 & 500 \\
\hline TACUZ & 3783 & TANTALUM ALLOY (TA98, CUO.7, ZRO.7) & 20 & 3300 \\
\hline TANB1 & 3782 & TANTALUM ALLOY (TA99.5, NBO.5) & 20 & 3303330 \\
\hline TASB & 4944 & TANTALUM ANTIMONIDE (TASB) & 20 & 3305552 \\
\hline TABED & 4718 & TANTALUM BERYLIIDE (TABE12) (HP) & 20,48 & \\
\hline TABED & 4720 & TANTALUM BERYLIDE (TA2BE17) & 20,48 & 500 \\
\hline TAB & 4642 & TANTALUM BORIDE (TAB) (PSD, SNTR, 85D) & $20,27,47,48$ & 500 \\
\hline
\end{tabular}

NUREG/CR-0200,

Vol. 3, Rev. 4 
Table M5.6.1 (continued)

\begin{tabular}{|c|c|c|c|c|}
\hline ID & No. & Material & References & $\begin{array}{c}\text { Quality } \\
\text { Index } \\
\text { DCKTHCK }\end{array}$ \\
\hline TAB2 & 4644 & TANTALUM BORIDE (TAB2) & $20,27,47,48$ & 2020502 \\
\hline TAC & 4562 & TANTALUM CARBIDE (TAC) & $20,27,48,54$ & 2020502 \\
\hline wccos & 5456 & TANTALUM CARBIDE + WC.CERMET K601 & 49 & 300530 \\
\hline TAN & 4446 & TANTALUM NITRIDE (TAN) & $20,27,48$ & 2220525 \\
\hline TA2N & 4448 & TANTALUM NIIRIDE (TA2N) & $20,27,48$ & 2220522 \\
\hline TASL2 & 4784 & TANTALUM SIIICIEE (TASI2) & 20,27 & 300535 \\
\hline TC & 1164 & TECHNICIUM & 27,42 & 40025 \\
\hline FCTEE & 7111 & TEFLON & $1,6,20,38$ & 2500 \\
\hline FCTFR & 7112 & TEFLON, REINFORCED & 20 & 2500 \\
\hline TE & 1488 & TELLURIUM & $27,20,42,41,1$ & 20002 \\
\hline TB & 1386 & TERBIUM & $20,27,41,42,43$ & 30205 \\
\hline TBB6 & 4638 & TERBIUM BORIDE (TBB6) (94.3 PC DENSE) & 48 & 305555 \\
\hline TEIRL & 7512 & TETRYL.H.E.- & 8 & 300555 \\
\hline TL & 1336 & THALIIUM & $41,27,1,42,47$ & 0 \\
\hline TLLIQ & 1337 & THALIIUM (LIQUID) & $1,14,27,42,43,47$ & 55 \\
\hline TH & 1166 & THORIUM & $20,32,34,27,37,43,44$ & 2 \\
\hline $\mathbf{T H}$ & 1166 & THORIUM & +41 & 2 \\
\hline THB4 & 4646 & THORIOM BORIDE (THB4) & $20,27,48$ & 2002502 \\
\hline THB6 & 4648 & THORIUM BORDE (THBG) & $20,27,48$ & 2000535 \\
\hline THC & 4564 & THORIUM CARBIDE (THC) (80 PC DENSE) & $20,27,48,54$ & 300530 \\
\hline THC2 & 4565 & THORIUM CARBIDE (THC2) (69 PC DENSE) & $20,27,48,54$ & 300530 \\
\hline TH02 & 4072 & THORIUM OXIDE (THO2) (96-100 PC DENSE) & $1,20,27,47,48,51$ & 2002300 \\
\hline TM & 1406 & THULIUM & $20,27,41,42,43$ & 30005 \\
\hline SN & 1171 & TIN & $2,1,27,32,42,41,47$ & 0 \\
\hline SNLIQ & 1172 & TIN (LIQUID) & $1,14,27,32,41,42,43$ & 0 \\
\hline SOLD1 & 3611 & TIN ALLOY (SN37.5, PB37.5, IN25) & 36 & 3355 \\
\hline SOLD3 & 3614 & TIN ALLOY (SN40, PB60) (SOLDER) & 1,41 & 55 \\
\hline SOLD4 & 3613 & TIN ALLOY (SN50, PB50) (SOLDER) & 1,41 & 50 \\
\hline SOLD2 & 3612 & TIN ALLOY (SN60.8, PB39.2) (SOLDER) & 34,41 & 5 \\
\hline SNO2 & 4074 & TIN OXIDE (SNO2) (93-95 PC DENSE) & $1,20,27,47,48$ & 2300 \\
\hline SNTE2 & 4940 & TIN TELLURIDE (SNTE 25, AGSBTE2 75) & 20 & 3305555 \\
\hline SNTE6 & 4939 & TIN TELLURIDE (SNTE 60, AGSBTE2 40) & 20 & 3305555 \\
\hline SNTE8 & 4938 & TIN TELLURIDE (SNTE 80, AGSBTE2 20) & 20 & 3305555 \\
\hline $\mathbf{T I}$ & 1176 & TITANIUM & $20,27,32,37,42,43,41$, & 20002 \\
\hline TI & 1176 & TITANIUM & +1 & 20002 \\
\hline TLALI & 2712 & TITANIUM ALLOY (TI BAL, AL2, MN2) & 20 & 3303330 \\
\hline TLAI3 & 2716 & TITANIUM ALLOY (TI BAL, ALA, CU2, ZR2) & 20 & 3303330 \\
\hline TIALT & 2730 & TITANIUM ALIOY (TI BAI, ALA, CU4, SN2) & 20 & 3303330 \\
\hline TIA11 & 2732 & TITANIUM ALIOY (TI BAL, ALA, MO3, V1) & 20 & 3233323 \\
\hline TLAIS & 2720 & TITANIUM ALLOY (TI BAL, ALA, V1, MOO.) & 20 & 3303330 \\
\hline TLAL2 & 2714 & TITANIUM ALLOY (TI BAL, ALA, V2, MO1) & 20 & 3303330 \\
\hline TIAL4 & 2718 & TITANIUM ALLOY (TI BAL, ALA, V3, MO1.5) & 20 & 3303330 \\
\hline TIAL6 & 2728 & TITANIUM AILOY (TI BAL, ALA, ZR3.5) & 20 & 3303330 \\
\hline TIA12 & 2736 & TITANIUM ALLOY (TI BAL, AL5, SN2.5) & 41,45 & 303330 \\
\hline TI555 & 2738 & TITANIUM ALLOY (TI BAL, AL5, SNS, ZRS) & 45 & 303330 \\
\hline TIAL3 & 2740 & TITANIUM ALLOY (TI BAL, AL6, V4) & $20,37,45$ & 300 \\
\hline TLA15 & 2742 & TITANIUM ALLOY (II BAI, AL8, MO1, V1) & 45 & 3330 \\
\hline TLA14 & 2746 & TITANIUM ALLOY (TI BAL, CR3.4, MO2.1) & 20 & 3303330 \\
\hline TIALS & 2752 & TITANIUM ALLOY (II BAI, SN4.8, AL4.5) & 20 & 3303330 \\
\hline TIAL9 & 2754 & TITANIUM ALLOY (II BAI, SN5.5, AI2) & 20 & 3303330 \\
\hline TIV14 & 2768 & TITANIUM ALLOY (II BAL, V14, CR10, AIA) & 20 & 3003300 \\
\hline TIV15 & 2766 & TITANIUM ALIOY (TI BAL, V15, AI2.8) & 20 & 3003300 \\
\hline TLA10 & 2770 & TITANIUM ALIOY (TI BAL, ZR3, AI2) & 20 & 3303330 \\
\hline TI100 & 2750 & TITANIUM AIIOY CIOOM (RC130A) (MN7.9) & 20 & 203320 \\
\hline TIH40 & 2722 & TITANIUM ALLOY HYLITE 40 C130AM,RC130B & $1,20,41$ & 303330 \\
\hline
\end{tabular}


Table M5.6.1 (continued)

\begin{tabular}{|c|c|c|c|c|}
\hline ID & No. & Material & References & $\begin{array}{c}\text { Quality } \\
\text { Index } \\
\text { DCKTHCK }\end{array}$ \\
\hline TIH50 & 2724 & TITANIUM ALIOY HYLITE 50 (IMI550) & 20,45 & 303330 \\
\hline THES1 & 2726 & TITANIUM AILOY HYLITE 51 (IMIS51) & 45 & 303330 \\
\hline THH55 & 2760 & TITANIUM ALLOY HYLITE 55 (IMI) & 20,45 & 303330 \\
\hline TIH60 & 2758 & TITANIUM ALLOY HYLITE 60 (MMI) & 20,45 & 303330 \\
\hline TIH65 & 2756 & TITANIUM ALLOY HYLITE 65 (IMI) & 45 & 303330 \\
\hline T1679 & 2764 & TITANIUM ALLOY IMI 679 (SNI1, ER5, AL2) & 45 & 303330 \\
\hline TI680 & 2762 & TITANIUM ALLOY IMI 680 (SN11, M04, AI2) & 45 & 303330 \\
\hline TI140 & 2748 & TITANIUM ALIOY TI140A (FE2, CR2, MO2) & 20 & 3303330 \\
\hline TI150 & 2744 & TITANIUM ALIOY TII50A (CR2.7, FE1.4) & 20 & 3003300 \\
\hline T1155 & 2734 & TITANIUM ALLOY TIL5SA (ALS,FE2,CR1,MO1) & 1,20 & 3303330 \\
\hline TIBED & 4722 & TITANIUM BERYLLIDE (TIBE12) (HP, 95D) & 20,48 & 2500 \\
\hline TIB2 & 4650 & TITANIUM BORIDE (TIB2) (HP, 95 PC DENS) & $20,27,47,48$ & 500 \\
\hline TIC93 & 4567 & TITANIUM CARBIDE (TIC) (93 PC DENSE) & $20,27,47,48,54$ & 22502 \\
\hline TIC96 & 4566 & TIIANIUM CARBIDE (TIC) (96 PC DENSE) & $20,27,47,48,54$ & 22502 \\
\hline $\operatorname{TICC2}$ & 5431 & TITANIUM CARBIDE + CO (CO18 NBC,TAC15) & 20 & 3305535 \\
\hline TICC1 & 5430 & TITANIUM CARBIDE + CO (TIC 80, CO 20) & 20 & 305535 \\
\hline TICC3 & 5432 & TITANIUM CARBIDE + NBC + NI & 20 & 3305535 \\
\hline TICCR & 5442 & TITANIUM CARBIDE + NI OR CO (AVG PROP) & 48 & 2220555 \\
\hline $\operatorname{TICC5}$ & 5434 & TITANIUM CARBIDE CERMET K138A & 49 & 305530 \\
\hline TICC6 & 5435 & TITANIUM CARBIDE CERMIET K151A & 49 & 305530 \\
\hline TIC10 & 5439 & TITANIUM CARBIDE CERMIET K161B & 20 & 3005500 \\
\hline TICC4 & 5433 & TITANIUM CARBIDE CERMET K162B & 49 & 305530 \\
\hline TICC7 & 5436 & TITANIUM CARBIDE CERMET K163B1 & 49 & 305530 \\
\hline TICC8 & 5437 & TITANIUM CARBIDE CERMET K164B & 49 & 305530 \\
\hline TICC9 & 5438 & TITANIUM CARBIDE CERMET K165 & 49 & 305530 \\
\hline TINIT & 4452 & TITANIUM NITRIDE (TIN) (HP, 70-90 DENS) & $20,27,47,48$ & 2020502 \\
\hline TIO2A & 4084 & TITANIUM OXIDE (TIO2) (RUTILE, A AXIS) & $1,20,27,32,47,48,51$ & 20202 \\
\hline TIO2C & 4082 & TITANIUM OXIDE (TIO2) (RUTILE, C AXIS) & $1,20,27,32,47,48,51$ & 20202 \\
\hline T1O2 & 4086 & TITANIUM OXIDE (TIO2) (RUTILE, $100 \mathrm{D})$ & $1,20,27,32,47,48,51$ & 200 \\
\hline TNT & 7513 & TNT H.E. (2, 4, 6-TRINITROTOLUENE) (CAST) & 8 & 555 \\
\hline TOPAZ & 4301 & TOPAZ (2ALFO.SIO2) (A-AXIS) & 27,51 & 305550 \\
\hline TOPAC & 4302 & TOPAZ (2AIFO.SIO2) (C-AXIS) & 27,51 & 305551 \\
\hline TOURM & 4996 & TOURMALINE & 27,51 & 305550 \\
\hline T-GAS & 1566 & TRITIUM GAS & & 3335533 \\
\hline w & 1181 & TUNGSTEN & $20,1,32,34,27,37,42$, & 0 \\
\hline $\mathrm{W}$ & 1181 & TUNGSTEN & $+41,43$ & 0 \\
\hline W25RE & 3801 & TUNGSTEN ALLOY (W75, RE25) & & 3303330 \\
\hline WNICU & 3802 & TUNGSTEN ALLOY (W90, NI6, CU2-4) & 20 & 303330 \\
\hline WB & 4652 & TUNGSTEN BORIDE (WB) & $20,27,47,48$ & 2500 \\
\hline wc & 4568 & TUNGSTEN CARBIDE (WC) & $20,27,47,48,54$ & 2500 \\
\hline wCC12 & 5463 & TUNGSTEN CARBIDE CERMET CARBOLOY 883 & 50 & 300530 \\
\hline WCC11 & 5462 & TUNGSTEN CARBIDE CERMET CARBOLOY 905 & 50 & 300530 \\
\hline wcc10 & 5461 & TUNGSTEN CARBIDE CERMET CARBOLOY 999 & 50 & 300530 \\
\hline WCCO2 & 5453 & TUNGSTEN CARBIDE CERMET CA2 TOOL STEEL & 20 & 3300530 \\
\hline WCCO1 & 5452 & TUNGSTEN CARBIDE CERMET CA4 TOOL STEEI & 20 & 3300530 \\
\hline WCCO3 & 5454 & TUNGSTEN CARBIDE CERMET K6 AND K96 & 20,49 & 300530 \\
\hline wccos & 5456 & TUNGSTEN CARBIDE CERMET K601 & 49 & 300530 \\
\hline wccos & 5459 & TUNGSTEN CARBDE CERMET X701 & 49 & 300530 \\
\hline wccog & 5460 & TUNGSTEN CARBDE CERMET K801 (WC + ND) & 49 & 300530 \\
\hline wCCO7 & 5458 & TUNGSTEN CARBIDE CERMET K92 & 49 & 300530 \\
\hline WCCO6 & 5457 & TUNGSTEN CARBIDE CERMET K94 AND K1 & 49 & 300530 \\
\hline WO3 & 4092 & TUNGSTEN OXIDE (WO3) (POLYXTAL. POROUS) & $20,27,47,48$ & 20305 \\
\hline WSE2 & 4946 & TUNGSTEN SELENIDE (WSE2) & 20,27 & 3303550 \\
\hline WSI2 & 4786 & TUNGSTEN SILICIDE (WSI) (HP, 95 DENSE) & $20,27,48$ & 2002500 \\
\hline WTE2 & 4947 & TUNGSTEN TELLURIDE (WTE2) & 20,27 & 3303555 \\
\hline
\end{tabular}

NUREG/CR-0200, Vol. 3, Rev. 4 
Table M5.6.1 (continued)

\begin{tabular}{|c|c|c|c|c|}
\hline ID & No. & Material & References & $\begin{array}{c}\text { Quality } \\
\text { Index } \\
\text { DCKTHCK }\end{array}$ \\
\hline WTIC5 & 5470 & TUNGSTEN TITANIUM CARBDE KM & 49 & 300530 \\
\hline WCCO4 & 5465 & TUNGSTEN TITANIUM CARBIDE K2S & 20,49 & 300530 \\
\hline WTIC7 & 5472 & TUNGSTEN TITANIUM CARBDE K21 & 49 & 300530 \\
\hline WTIC6 & 5471 & TUNGSTEN TITANIUM CARBDE K4H & 49 & 300530 \\
\hline WTIC4 & - 5469 & TUNGSTEN TITANIUM CARBIDE KSH & 49 & 300530 \\
\hline WTIC3 & 5468 & TUNGSTEN TITANIUM CARBIDE K81 & 49 & 300530 \\
\hline WTIC2 & 5467 & TUNGSTEN TITANIUM CARBIDE K84 & 49 & 300530 \\
\hline WTIC1 & 5466 & TUNGSTEN TITANIUM CARBIDE K86, K7H, K3H & 49 & 300530 \\
\hline $\mathbf{U}$ & 1186 & URANIUM & $20,31,32,36,27,37,42$ & 0 \\
\hline U & 1186 & URANIUM & $+41,43,44,34$ & 0 \\
\hline MULBY & 3831 & URANIUM ALIOY MULBERRY & $34,36,37$ & 0 \\
\hline $\mathrm{U} 18 \mathrm{ZR}$ & 3833 & URANIUM ALIOY (U82, ZR18) & 20,34 & 303330 \\
\hline U9OFS & 3837 & URANIUM ALLOY (U90, FS10) & 20 & 303330 \\
\hline U10MO & 3832 & URANIUM ALIOY (U90, MO10) & $20,35,36$ & 300 \\
\hline UFSZR & 3838 & URANIUM ALIOY (U93, FS5, ZR2) & 20 & 303330 \\
\hline UCREU & 3835 & URANIUM ALLOY (U94.4, CR5.6) (EUTECTIC) & 20 & 3003300 \\
\hline UZRO5 & 3840 & URANIUM ALIOY (U95, ZRS) & 20 & 30303330 \\
\hline UOANB & 3834 & URANIUM ALIOY (U96, NB4) & 20,34 & 303330 \\
\hline U97FS & 3836 & URANIUM ALIOY (U97, FS3) & 20 & 303330 \\
\hline UZRO2 & 3839 & URANIUM ALLOY (U98.5, ZR1.5) & 20 & 303330 \\
\hline UBE13 & 4724 & URANIUM BERYLIIDE (UBE13) (SNTRD, 61D) & 20,48 & 305550 \\
\hline UB4 & 4654 & URANIUM BORIDE (UB4) & 20,48 & 300555 \\
\hline UCAMC & 4572 & URANIUM CARBIDE (UC) (ARCM OR CAST,99D) & $20,48,53,54$ & 2502 \\
\hline UCAVG & 4574 & URANIUM CARBIDE (UC) (AVG, VAR. TYPES) & $20,48,53,54$ & 2502 \\
\hline UCSNT & 4573 & URANIUM CARBIDE (UC) (SINTERED, 90D) & $20,48,53,54$ & 2502 \\
\hline $\mathrm{UC2}$ & 4576 & URANIUM CARBDE (UC2) & $20,27,48,54$ & 2000500 \\
\hline UN & 4454 & URANIUM NITRIDE (UN) (HP, 95-98 DENSE) & $20,27,48$,PWAC481-65 & 2500 \\
\hline UO2PX & 4096 & URANIUM OXIDE (UO2) (POLYXTAL, 97 DENS) & $20,27,47,48,51$ & 500 \\
\hline UO2 & 4094 & URANIUM OXIDE (UO2) (SINGLE CRYSTAI) & $20,27,47,48,51$ & 500 \\
\hline U308L & 4099 & URANIUM OXTDE (U3O8) (PRSD AT 100 PSD) & $1,20,27,47,48$ & 2002500 \\
\hline U308H & 4098 & URANIUM OXIDE (U308) (PRSD AT 4200 PSD) & $1,20,27,47,48$ & 2002500 \\
\hline $\mathrm{UO} 2 \mathrm{CR}$ & 5482 & URANIUM OXIDE + CR (UO2 80 VOL) (97 D) & 20 & 4305550 \\
\hline UOMO3 & 5486 & URANIUM OXIDE + MO (UO2 70 VOL) (92 D) & 20 & 4305550 \\
\hline UOMO2 & 5485 & URANIUM OXIDE + MO (UO2 80 VOL) (91 D) & 20 & 4305550 \\
\hline UOMOI & 5484 & URANIUM OXIDE + MO (UO2 80 VOL) (94 D) & 20 & 4305550 \\
\hline UO2NB & 5488 & URANIUM OXDE + NB (UO2 80 VOL) & 20 & 4305550 \\
\hline UO2S1 & 5490 & URANIUM OXIDE + ST STEEL (UO2 70 VOL) & 20 & 4305550 \\
\hline UO2S2 & 5491 & URANIUM OXIDE + ST STEEL (UO2 80 VOI) & 20 & 4305550 \\
\hline vO2Z1 & 5492 & URANIUM OXMDE + ZR (UO2 43,ZR 57)(59 P) & 20 & 4305530 \\
\hline UO2Z2 & 5493 & URANIUM OXIDE + ZR (UO2 80,ZR 20) & 20 & 305535 \\
\hline UPUOX & 4242 & URANIUM PLUTONIUM OXIDE (4UO2.PUO2) SEE & 53 & 303530 \\
\hline U3SI & 4788 & URANIUM SILICIDE (U3SI) & 20,48 & 20525 \\
\hline URFMA & 7442 & UREA-FORMAIDEHYDE, ALPHA CELLULOSE FLIR & 38 & 25555 \\
\hline URFMN & 7441 & UREA-FORMAIDEHYDE, MOLDED & 38 & 25555 \\
\hline ART2 & 9002 & VACUUM, CONDUCTING $(D=C=0, K=10 * 9)$ & & 0 \\
\hline ART1 & 9001 & VACUUM, INSULATING $(\mathrm{D}=\mathrm{C}=\mathrm{K}=0)$ & & 0 \\
\hline $\mathrm{v}$ & 1286 & VANADIUM & $20,32,27,41,42,43$ & 0 \\
\hline VBE12 & 4726 & VANADIUM BERYLLIDE (VBE12) (85 PC DENS) & 20,48 & 505 \\
\hline VB2 & 4656 & VANADIUM BORIDE (VB2) & $20,27,48$ & 20555 \\
\hline ve & 4578 & VANADIUM CARBDE (VC) & $20,27,47,48,54$ & 2022502 \\
\hline VN & 4456 & VANADIUM NITRIDE (VN) (PR, STRD, $100 \mathrm{D})$ & $20,27,47,48$ & 22505 \\
\hline VERM2 & 5292 & VERMICULITE, EXPANDED (D $=0.19-0.25)$ & 20 & 305530 \\
\hline VERM3 & 5293 & VERMICULITE, EXPANDED $(D=0.3)$ & 20 & 305530 \\
\hline VERMI & 4986 & VERMICULITE BRICK & 20 & 305550 \\
\hline VERMP & 4988 & VERMICULITE INSULATING POWDER & 20 & 305550 \\
\hline
\end{tabular}


Table M5.6.1 (continued)

\begin{tabular}{|c|c|c|c|c|}
\hline ID & No. & Material & References & $\begin{array}{l}\text { Quality } \\
\text { Index } \\
\text { DCKTHCK }\end{array}$ \\
\hline SIO2 & 4062 & VITROUS SIIICA GLASS & $1,20,27,47,51$ & 2200 \\
\hline VYCOR & 5036 & VYCOR GLASS & 20,27 & 500 \\
\hline H2OGS & 4113 & WATER (H2O) (GAS) (SATD) & $1,2,14,27,46$ & 205550 \\
\hline H2OG1 & 4112 & WATER (H2O) (GAS) (1 ATM) & $1,2,14,27,46$ & 200050 \\
\hline WATER & 4114 & WATER (H2O) (LIQUID) & $2,14,27,46$ & 0 \\
\hline ICE & 4116 & WATER (H2O)(SOLID) (ICE) & $27,46,51$ & 0 \\
\hline D20 & 4118 & WATER, HEAVY (D20) (LIQUD) & 14,27 & 300 \\
\hline GLASW & 5028 & WINDOW GLASS, LIME & 20 & 305530 \\
\hline BALS1 & 8516 & WOOD, BALSA (ACROSS GRAIN) & $1,2,27$ & 305555 \\
\hline BALS2 & 8517 & WOOD, BALSA (ACROSS GRAIN) & $1,2,27$ & 305555 \\
\hline CYPRS & 8518 & WOOD, CYPRESS (ACROSS GRAIN) & 1,27 & 305555 \\
\hline MAHOG & 8520 & WOOD, MAHOGANY (ACROSS GRAIN) & 1,27 & 305555 \\
\hline MAPLE & 8522 & WOOD, MAPLE (ACROSS GRATN) & $1,2,27$ & 305555 \\
\hline PINEW & 8526 & WOOD, NORWAY PINE (ACROSS GRAIN) & $1,2,27$ & 305555 \\
\hline OAKLD & 8525 & WOOD, OAK, RED, BLACK (ACROSS GRAIN) & $1,2,27$ & 05555 \\
\hline OAKHD & 8524 & WOOD, OAK, WHTTE, LIVE (ACROSS GRAN) & $1,2,27$ & 05555 \\
\hline PINEL & 8527 & WOOD, OREGON PINE (ACROSS GRAIN) & $1,2,27$ & 305555 \\
\hline PINEW & 8529 & WOOD, PINE (WTTH GRAIN) & $1,2,27$ & 305555 \\
\hline WOOD2 & 18513 & WOOD, SPRUCE (ACROSS GRAIN) & 46 & 5555 \\
\hline WOOD1 & 8512 & WOOD, SPRUCE (WTTH GRAIN) & 46 & 5555 \\
\hline TEAK & 8530 & WOOD, TEAK (ACROSS GRAN) & 1,2 & 305555 \\
\hline PINEV & 8528 & WOOD, VIRGINIA PINE (ACROSS GRAIN) & $1,2,27$ & 305555 \\
\hline FIRWH & 8532 & WOOD, WHITE FIR (ACROSS GRAIN) & 1,2 & 305555 \\
\hline PINEA & 8534 & WOOD, WHITE PINE (ACROSS GRAIN) & $1,2,27$ & 305555 \\
\hline $\mathrm{XE}$ & 1541 & XENON & 27,42 & 30000 \\
\hline YB & 1411 & YTTERBIUM & $20,27,41,42,43$ & 30205 \\
\hline YBB6 & 4640 & YTTERBIUM BORIDE (YBBG) (90.6 PC DENS) & 48 & 305555 \\
\hline $\mathbf{Y}$ & 1346 & YTTRIUM & $41,27,1,20,42,43$ & 20005 \\
\hline YB6 & 4622 & YTTRIUM BORIDE (YBG) (98.4 PC DENSE) & 48 & 300555 \\
\hline Y2O3 & 4102 & YTTRIUM OXIDE (Y2O3) (96-100 PC DENSE) & $20,27,47,48$ & 300 \\
\hline ZNFEO & 4252 & ZINC FERRITE (ZNO.FE203) (PR, FRD, VAC) & 20,27 & 500 \\
\hline ZNO & 4104 & ZINC OXIDE (ZNO) (PRSD, FIRED, $100 \mathrm{D})$ & $1,20,27,47,48,51$ & 2000 \\
\hline ZNS & 4750 & ZINC SULFIDE (ZNS) (CUBIC CRYSTAL) & $1,27,47,48,51$ & 310 \\
\hline ZINC3 & 3863 & ZINC-ALUMINUM ALLOY ASTM 23 & $1,6,41$ & 355 \\
\hline ZINC4 & 3864 & ZINC-ALUMMNUM-COPPER ALLOY ASTM 25 & $1,6,41$ & 355 \\
\hline ZIRCN & 4330 & ZIRCON (ZRO2.SIO2) (SINGLE CRYSTAL) & $20,27,48,61$ & 2505 \\
\hline PORZR & 5282 & ZIRCON PORCELAIN, HIGH & 20 & 305535 \\
\hline ZR & 1196 & ZIRCONIUM & $20,27,32,37,43,42,41$ & 20002 \\
\hline ZR3ZI & 3882 & ZIRCONIUM ALLOY 3ZI (ZR97,AL1,SN1,MO1) & 20 & 303330 \\
\hline ZIRCA & 3881 & ZIRCONIUM ALLOYS ZIRCAIIOY 2 AND 3 & $1,6,14$ & 200355 \\
\hline ZRBET & 4728 & ZIRCONIUM BERYLLIDE (ZRBE13) & 20,48 & 500 \\
\hline ZRB2 & 4658 & ZIRCONIUM BORIDE (ZRB2) (HP, 97 PC DEN) & $20,27,47,48$ & 20502 \\
\hline ZRB2B & 5496 & ZIRCONIUM BORDE + BORON (BOROLITE 101) & 47,48 & 505 \\
\hline ZRB2Z & 5498 & ZIRCONIUM BORIDE + MOSI (BORIDE Z) & 47,48 & 2000500 \\
\hline ZRC & 4580 & ZIRCONIUM CARBIDE (ZRC) (HP OR SNT,94D) & $20,27,48,54$ & 22502 \\
\hline ZRH12 & 4892 & ZIRCONIUM HYDRDE (ZRH + ZRH2) & 20 & 2225522 \\
\hline ZRNPF & 4458 & ZRRCONIUM NITRIDE (ZRN) (PR SR 88-90 D) & $20,27,47,48$ & 500 \\
\hline ZRNPS & 4459 & ZIRCONIUM NITRIDE (ZRN) (PR SR 93 D) & $20,27,47,48$ & 20502 \\
\hline ZROYZ & 5495 & ZIRCONIUM OXIDE (Y203 12, ZR 8) (97 D) & 20 & 4305530 \\
\hline ZRO2 & 4106 & ZIRCONIUM OXIDE (ERO2) (NONOC., $100 \mathrm{D}$ ) & $1,20,27,47,48,51$ & 0 \\
\hline ZRO2C & 4108 & ZIRCONIUM OXIDE (ZRO2 96, CAO 6, 91 D) & $1,20,27,47,48,51$ & 0 \\
\hline ZROTI & 5494 & ZIRCONIUM OXIDE + TI CERMET ZT-15-M & 20 & 5500 \\
\hline ZIRCN & 4330 & ZIRCONIUM SILICATE (ZRO2.SIO2) (XTAL) & $20,27,48,61$ & 2505 \\
\hline ZIRCP & 4332 & ZIRCONIUM SIIICATE (ZRO2.SIO2) (100 D) & $20,27,48,61$ & 2500 \\
\hline
\end{tabular}

"See text description of columns 73-79 for explanation of property abbreviation used in each column.

NUREG/CR-0200,

Vol. 3, Rev. 4

M5.6.22 
The data for each material are contained on one to seven card-image records. A listing of the material data in the cgs-cal- ${ }^{\circ} \mathrm{C}$ units system may be found in Ref. 1 or read from the appropriate file in the SCALE code package. The following format is used:

\section{MATERIAL IDENTIFICATION CARD:}

\section{Columns 1-5}

Alphanumeric identifier (same as in material index).

\section{Column 6}

Always left blank.

\section{Columns 7-10}

Material identification number (same as in material index).

\section{Columns 11-20}

Always left blank. (Used in TRUMP program ${ }^{2}$ to specify identification numbers of any chemical reactants associated with the material. Such numbers, if required, must be added manually.

\section{Columns 21-25}

Number of data pairs listed in the table of specific heat vs temperature. This number does not exceed 12. If the number is not zero, it is always two or more.

\section{Columns 26-30}

Number of data pairs listed in the table of thermal conductivity vs temperature. This number does not exceed 12. If this number is not zero, it is always two or more.

\section{Columns 31-40}

Density of material in grams per cubic centimeter $\left(\mathrm{g} / \mathrm{cm}^{3}\right)$. This value is normally the value at or near room temperature or the lowest temperature for which specific heat or thermal conductivity is tabulated, whichever is highest. For.use in codes that assume a fixed geometry, both the density and specified dimensions should correspond to the same conditions of temperature and pressure.

\section{Columns 41-50}

Specific heat of the material, in cal/g- ${ }^{\circ} \mathrm{C}$, if constant or if the temperature dependence is unknown. When a table of specific heat vs temperature is listed, the value given here is normally the value at or near room temperature or at the lowest temperature tabulated, whichever is higher. 


\section{Columns 51-60}

Thermal conductivity of the material, in cal $/ \mathrm{s}-\mathrm{cm}-{ }^{\circ} \mathrm{C}$, if constant or if the temperature dependence is unknown. When a table of thermal conductivity vs temperature is listed, the value given here is normally the value at or near room temperature or the lowest temperature listed in the table, whichever is higher.

\section{Columns 61-70}

Transition temperature of maximum temperature, in ${ }^{\circ} \mathrm{C}$, at which material may be used. If a latent heat is specified in columns $71-80$, this is the transition temperature at which either a phasechange or solid-state transition occurs. If a material has more than one transition with a latentheat effect, others are included in the table of specific heat vs temperature as a triangular peak superimposed over the actual specific heat curve.' This triangular peak has a base width of $10^{\circ} \mathrm{C}$ and a height of 115 of the latent heat of transition, in cal/g, and is centered at the transition temperature.

\section{Columns 71-80}

Latent heat absorbed by the material, in cal/g, when the temperature is increased past the transition temperature specified in columns $61-70$. Other latent-heat effects may be included in the specific heat table as described in the previous description (columns 61-70).

\section{SPECIFIC HEAT TABLE CARDS}

Only included if at least two data pairs are listed (no blank cards are needed).

\section{Column 1}

Always left blank.

Columns 2-10

Specific heat of the material, in $\mathrm{cal} / \mathrm{g}-{ }^{\circ} \mathrm{C}$, at the temperature specified in columns $11-20$.

\section{Columns 11-20}

Temperature, in ${ }^{\circ} \mathrm{C}$, at which the material has the specific heat specified in columns 2-10.

\section{Columns 21-30}

Specific heat of the material, in cal $/ \mathrm{g}-{ }^{\circ} \mathrm{C}$, at the temperature specified in columns $31-40$.

\section{Columns $31-40$}

Temperature, in ${ }^{\circ} \mathrm{C}$, at which the material has the specific heat specified in columns $21-30$. Always equal to or greater than the preceding temperature in the table. 
The specific heat table card may list up to four data pairs using ten columns for each value of specific heat or temperature. As many as three cards with the same format can be used to list the number of data pairs specified in columns 21-25.

\section{THERMAL CONDUCTIVITY TABLE CARDS}

Only included if at least two data pairs are listed (no blank cards are needed).

\section{Column 1}

Always left blank.

\section{Columns 2-10}

Thermal conductivity of the material, in $\mathrm{cal} / \mathrm{s}-\mathrm{cm}-{ }^{\circ} \mathrm{C}$, at the temperature specified in columns 11-20.

Columns 11-20 2-10.

Temperature, in ${ }^{\circ} \mathrm{C}$, at which the material has the thermal conductivity specified in columns

\section{Columns 21-30}

Thermal conductivity of the material, in $\mathrm{cal} / \mathrm{s}-\mathrm{cm}-{ }^{\circ} \mathrm{C}$, at the temperature specified in columns $31-40$.

\section{Columns $31-40$}

Temperature, in ${ }^{\circ} \mathrm{C}$, at which the material has the thermal conductivity specified in columns 21-30. Always equal to or greater than the preceding temperature in the table.

The thermal conductivity table card may list up to four data pairs using ten columns for each value of thermal conductivity. As many as three cards with the same format can be used to list the number of data pairs specified in columns 26-30. 


\section{M5.8 REFERENCES}

1. A. L. Edwards, $A$ Compilation of Thermal Property Data for Computer Heat-Conduction Calculations, UCRL-50589, University of California Lawrence Radiation Laboratory, February 24, 1969.

2. A. L. Edwards, TRUMP: A Computer Program for Transient and Steady-State Temperature Distributions in Multidimensional Systems, UCRL-14754, Rev. 3, University of California Lawrence Livermore Laboratory, September 1, 1972.

NUREG/CR-0200, 
NUREG/CR-0200

Revision 4

Volume 3, Section M6

ORNL/NUREG/CSD-2/V3/R4

Computing Applications Division

\title{
ORIGEN-S DATA LIBRARIES
}

\author{
J. C. Ryman \\ O. W. Hermann
}

Previously Published: December 1984

Revised Manuscript Completed: November 1994

Date Published: April 1995

Prepared for the

Office of Nuclear Material Safety and Safeguards

U.S. Nuclear Regulatory Commission

Washington, DC 20555

Under Interagency Agreement DOE 1886-8000-9B

NRC JCN No. B0009

Prepared by the

OAK RIDGE NATIONAL LABORATORY

managed by

MARTIN MARIETTA ENERGY SYSTEMS, INC.

for the

U.S. DEPARTMENT OF ENERGY

under contract DE-AC05-84OR21400 


\begin{abstract}
The ORIGEN-S code can use three major kinds of data libraries: the nuclear and photon card-image data libraries, the binary data libraries, and the Master Photon Data Base.

The basic data necessary to run ORIGEN-S are contained in two files of the card-image nuclear data libraries. The first file includes decay parameters, natural abundances of nuclides, and radioactivity concentration guides. The second file contains cross sections and fission-product yields for four kinds of reactors (HTGR, LWR, LMFBR, and MSBR) in a light-element library (for 689 nuclides), an actinide library (for 129 nuclides), and a fission-product library (for 879 nuclides).

Card-image photon-yield libraries for light-element, actinide, and fission-product nuclides contain multigroup photon spectra for decay gamma and X-rays, for prompt and equilibrium fission-product gamma rays from spontaneous fission, for gamma rays associated with $(\alpha, n)$ reactions, and for bremsstrahlung from decay beta (negatron and positron) particles slowing down in a $\mathrm{UO}_{2}$ fuel matrix.

Another kind of library developed especially for ORIGEN-S is the binary (unformatted) data library. It contains the same kinds of data as the card-image nuclear data and photon yield libraries, but for only one kind of reactor. The ORIGEN-S code is normally run with a multiburnup binary data library, since a binary library has many advantages as compared with the card-image libraries. The principal advantage is that the cross sections in a binary library can be replaced with cross sections derived from a detailed multigroup neutronics calculation. Cross-section updating is performed with the COUPLE code which reads the multigroup cross sections from an AMPX or SCALE weighted cross-section library. Automated generation of time-dependent (i.e., burnup-dependent) binary data libraries can be performed with the SAS2 control module (see Sect. S2). Another advantage is that any portion of the photon yield data from the ORNL Master Photon Data Base can be placed in a binary library with any desired energy group structure. A further advantage is that any item of data in a binary library can be replaced (using COUPLE) by a user-specified value.

The last kind of library is the ORNL Master Photon Data Base, originally developed for the ORIGEN2 code. It contains decay gamma- and X-ray line data, spectra for gamma rays accompanying spontaneous fission and $(\alpha, n)$ reactions, and bremsstrahlung spectra from decay beta (negatron and positron) particles slowing down both in a $\mathrm{UO}_{2}$ fuel matrix and in water. This is the most comprehensive and up-to-date photon library available to ORIGEN-S. It can be used to generate multigroup photon source spectra, to make cardimage photon yield libraries, or to update photon yield data in a binary data library. The multigroup source spectra and photon yield data can be generated in any energy group structure for all light-element, actinide, and fission-product nuclides having photon data. The ORNL Master Photon Data Base is available in both card-image and binary formats.

Noteworthy improvements to ORIGEN-S data libraries in the SCALE 4.2 release are in both the structures of library files and the decay data. The card-image libraries were reduced from six to two files, using a file structure such that all ORIGEN-S card-image data files are now uniform for all computers. The SAS2 method of producing burnup-dependent binary libraries has been improved so that all the data are combined into a single file. Decay data, including physical half-lives, branching fractions, and recoverable decay energies, were updated for all but 18 nuclides, chiefly from ENDF/B-VI data.

This document describes the formats, data sources, and uses of the libraries outlined above.
\end{abstract}





\section{CONTENTS}

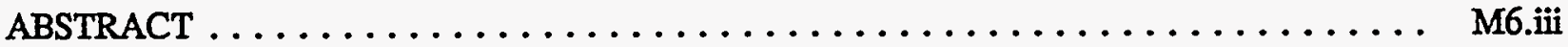

LIST OF TABLES $\ldots \ldots \ldots \ldots \ldots \ldots \ldots \ldots \ldots \ldots \ldots \ldots \ldots \ldots \ldots \ldots \ldots \ldots$

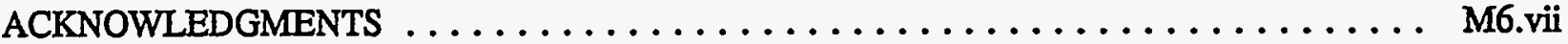

M6.1 INTRODUCTION . .......................... M6.1.1

M6.1.1 FILE STRUCTURE OF CARD-IMAGELIBRARIES . . . . . . .

M6.1.2 MULTIBURNUP BINARY DATA LIBRARY FILE $\ldots \ldots \ldots \ldots \ldots \ldots$ M6.1.3

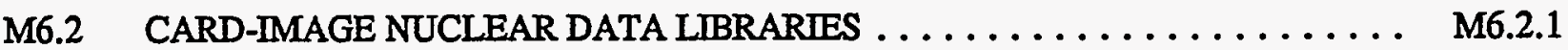

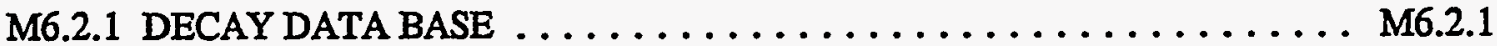

M6.2.2 LIGHT-ELEMENT CROSS-SECTION LIBRARY $\ldots \ldots \ldots \ldots \ldots \ldots$ M6.2.2

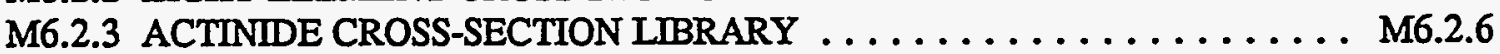

M6.2.4 FISSION-PRODUCT CROSS-SECTION AND FISSION-

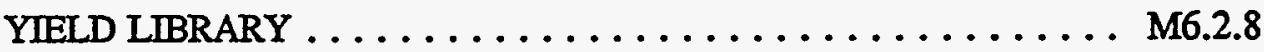

M6.2.5 CONSTRUCTION OF THE TRANSITION MATRIX $\ldots \ldots \ldots \ldots \ldots \ldots$ M6.2.9

M6.2.6 SOURCES OF DECAY DATA $\ldots \ldots \ldots \ldots \ldots \ldots \ldots \ldots \ldots \ldots \ldots \ldots \ldots \ldots \ldots .2 .11$

M6.2.7 SOURCES OF CROSS-SECTION DATA $\ldots \ldots \ldots \ldots \ldots \ldots \ldots \ldots \ldots .2 .13$

M6.2.8 SPECIAL TREATMENT OF CERTAIN NUCLIDES . . . . . . . . M6.2.14

M6.3 CARD-IMAGE PHOTON YIELD LIBRARIES $\ldots \ldots \ldots \ldots \ldots \ldots \ldots \ldots \ldots$ M6.3.1

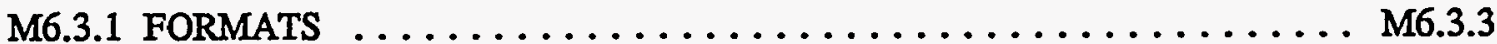

M6.3.2 SOURCE OF DATA $\ldots \ldots \ldots \ldots \ldots \ldots \ldots \ldots \ldots \ldots \ldots \ldots \ldots \ldots .3 .4$

M6.4 DATA PROGRAMMED INTO ORIGEN-S AND COUPLE $\ldots \ldots \ldots \ldots \ldots \ldots$ M6.4.1

M6.5 MASTER PHOTON DATA BASE $\ldots \ldots \ldots \ldots \ldots \ldots \ldots \ldots \ldots \ldots \ldots \ldots . \ldots \ldots . \ldots \ldots$

M6.5.1. CARD-IMAGE DATA BASES $\ldots \ldots \ldots \ldots \ldots \ldots \ldots \ldots \ldots \ldots \ldots .5 .1$

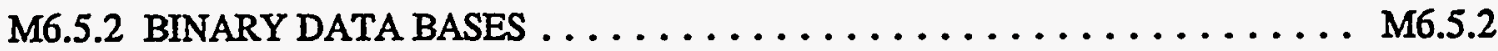

M6.6 ENDF/B-IV FISSION-PRODUCT DATA BASE $\ldots \ldots \ldots \ldots \ldots \ldots \ldots \ldots$ M6.6.1

M6.7 BINARY ORIGEN-S DATA LIBRARIES $\ldots \ldots \ldots \ldots \ldots \ldots \ldots \ldots \ldots \ldots \ldots \ldots .7 .1$

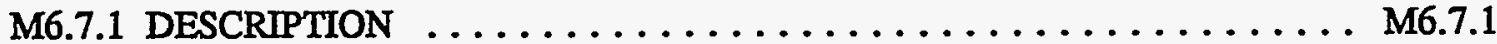

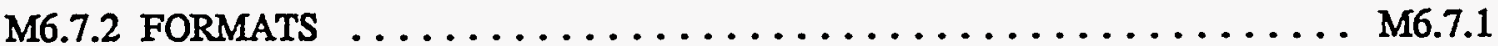

M6.7.3 GENERATION OF SOME USEFUL LIBRARIES $\ldots \ldots \ldots \ldots \ldots \ldots$ M6.7.6

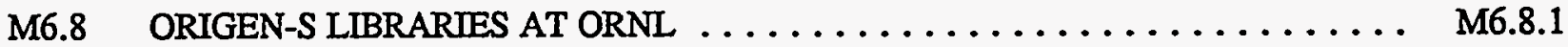

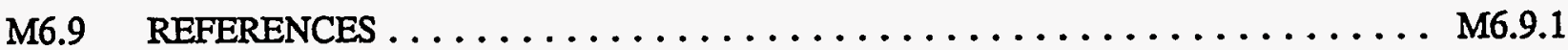




\section{LIST OF TABLES}

Tahle

Page

M6.2.1 Units of half-life indicated by the variable IU

M6.2.3

M6.2.2 Definitions of branching fraction variables

M6.2.3

M6.2.3 Definitions of nuclear data variables in light-element libraries for a thermal reactor $\ldots \ldots \ldots \ldots \ldots \ldots \ldots \ldots \ldots \ldots \ldots \ldots . \ldots \ldots \ldots$

M6.2.4 Reactor type as a function of variable IT $\ldots \ldots \ldots \ldots \ldots \ldots \ldots \ldots \ldots$

M6.2.5 Definitions of spectral indices for thermal reactors $\ldots \ldots \ldots \ldots \ldots$ M6.2.6

M6.2.6 Definitions of nuclear data variables in the actinide library for a

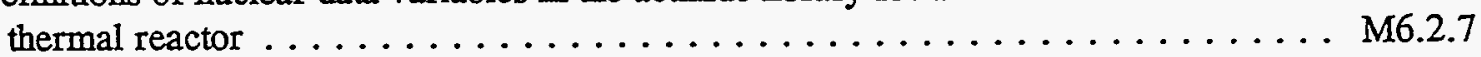

M6.2.7 Fissionable nuclides having yield data $\ldots \ldots \ldots \ldots \ldots \ldots \ldots \ldots \ldots$

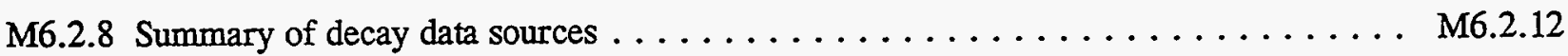

M6.2.9 Nuclides updated with decay data from ENSDF $\ldots \ldots \ldots \ldots \ldots \ldots \ldots \ldots . . \ldots \ldots$

M6.2.10 Nuclides changed to stable or not updated with decay data $\ldots \ldots \ldots \ldots \ldots \ldots$ M6.2.13

M6.3.1 Group structures for original photon yield libraries $\ldots \ldots \ldots \ldots \ldots \ldots . \ldots \ldots$

M6.3.2 Group structures for ORIGEN-S photon yield libraries $\ldots \ldots \ldots \ldots \ldots \ldots \ldots .2$

M6.3.3 FORMATS for original photon yield libraries $\ldots \ldots \ldots \ldots \ldots \ldots \ldots . \ldots \ldots$

M6.3.4 FORMATS for current ORIGEN-S photon yield libraries $\ldots \ldots \ldots \ldots \ldots . \ldots \ldots$

M6.7.1 Data in first record of binary data library $\ldots \ldots \ldots \ldots \ldots \ldots \ldots \ldots . \ldots \ldots$ M6.2

M6.7.2 Structure of binary data library $\ldots \ldots \ldots \ldots \ldots \ldots \ldots \ldots \ldots \ldots \ldots . \ldots \ldots$

M6.7.3 Initial uranium composition of typical PWR assembly $\ldots \ldots \ldots \ldots \ldots \ldots \ldots \ldots$. . . . . . . 10

M6.7.4 Nuclides with updated cross sections in typical BWR libraries . . . . . . . . . M6.7.10

M6.7.5 Generic PWR and BWR library parameters . . . . . . . . . . . M6.7.12

M6.8.1 Card-image ORIGEN-S libraries at ORNL $\ldots \ldots \ldots \ldots \ldots \ldots \ldots \ldots .1$

M6.8.2 Some binary ORIGEN-S libraries at ORNL $\ldots \ldots \ldots \ldots \ldots \ldots \ldots \ldots .2$ NUREG/CR-0200,

Vol. 3, Rev. 4

M6.vi 


\section{ACKNOWLEDGMENTS}

Special thanks are due to A. G. Croff, S. B. Ludwig, K. J. Notz, and C. W. Alexander of the Oak Ridge National Laboratory (ORNL) Chemical Technology Division, who provided the ORNL Master Photon Data Base and sponsored the updating of decay data for both ORIGEN2 and ORIGEN-S. The authors are grateful to P. R. Daniel of the University of Florida, who produced libraries updated from ENDF/B-VI decay data, in addition to M. A. Bjerke, R. W. Roussin, and J. E. White for their help in accessing the ENDF decay data.

The authors would like to acknowledge M. J. Bell, who developed the original ORIGEN libraries, and C. W. Kee, G. W. Morrison, and R. E. Schenter, who developed the large light-element and/or fissionproduct libraries for ORIGEN.

Many colleagues at ORNL provided helpful suggestions and advice. In particular, the authors would like to thank S. M. Bowman, L. M. Petrie, J. P. Renier, N. M. Greene, K. F. Eckerman, and S. B. Watson. They would like to acknowledge the encouragement and supervision provided by G. E. Whitesides, R. M. Westfall, and, especially, C. V. Parks. They are further indebted to C. V. Parks and S. M. Bowman for their review of the manuscript.

At the U.S. Nuclear Regulatory Commission (NRC), the authors would like to thank R. H. Odegaarden (formerly of the NRC) and other staff members for sponsoring and directing the development of ORIGEN-S. Special thanks are also due to P. Worthington and others of the NRC Division of Engineering Technology for sponsoring the updating of the card-image nuclear data libraries.

The authors are indebted to $\mathrm{L}$. Norris, who retyped the complete manuscript for this revision. 


\section{M6.1 INTRODUCTION}

The original version of the ORIGEN code ${ }^{1}$ used two kinds of data libraries in card-image format. The muclear data libraries contained decay data, natural abundances of nuclides, radioactivity concentration guides, cross sections, and fission yields. The photon yield libraries contained multigroup photon yields (photons per disintegration) for decay gamma and $\mathrm{X}$ rays, for bremsstrahlung from beta particles slowing down in a $\mathrm{UO}_{2}$ fuel matrix, and for some gammas accompanying $(\alpha, n)$ reactions in oxide fuels. There were three libraries of each kind: one for 253 light-element nuclides (structural materials and activation products), one for 101 actinide nuclides (fuel materials, transplutonium nuclides, and decay daughters), and one for 461 fissionproduct muclides. The nuclear data libraries included cross sections and fission yields for four reactor types: the high-temperature gas-cooled reactor (HTGR), the light-water reactor (LWR), the liquid metal fast breeder reactor (LMFBR), and the molten salt breeder reactor (MSBR). Since the original ORIGEN code and its libraries were primarily intended for use in generic studies of spent fuel and waste characteristics, cross sections for a number of muclides were adjusted to give agreement between calculated and measured fuel mass balances.

As the ORIGEN code became widely used for more complex applications, two additional data libraries were added. A large light-element library ${ }^{23}$ for 674 nuclides was created, with cross sections for HTGRs and LWRs. At about the same time, a large fission-product library ${ }^{3,4}$ for 821 nuclides, with cross sections and fission yields for LWRs and LMFBRs, was generated from ENDF/B-IV data. ${ }^{5}$ These libraries were included in the releases of SCALE-1.0 through SCALE-4.0, inclusive. In SCALE-4.1, the small (461 nuclides) fissionproduct library was removed and the LWR fission-product yields of the large (821 nuclides) library for all muclides except tritium were updated from ENDF/B-V. ${ }^{6}$ New tritium yields were taken from Boumahraz ${ }^{7}$ and from Wagemans et al. ${ }^{8}$

A further expansion in the size of the ORIGEN-S libraries and an update ${ }^{9}$ in the decay, energy, and fission-product yield data are included in the SCALE-4.2 release. The sizes of the libraries were increased to 689 light-element nuclides, 129 actinides, and 879 fission products; all smaller libraries were removed. Decay data, chiefly from ENDF/B-VI, ${ }^{10}$ were used to update half-lives, branching fractions of the modes of decay, and gamma and total recoverable energies per disintegration. Fission-product yields for all of the fissile nuclides included in the four reactor libraries (HTGR, LWR, LMFBR, and MSBR) were updated from ENDF/B-V. Although the decay data update was undertaken primarily for the ORIGEN2 code, the resulting decay data base is now used to generate decay libraries with the same nuclides for ORIGEN-S and ORIGEN2.

The major revision to the card-image nuclear data libraries has been the inclusion of new decay data. Nearly all the cross-section data have been left the same as in the original ORIGEN libraries. Updating of cross-section data for the binary data libraries discussed later is performed with the COUPLE code (Sect. F6), using problem-dependent multigroup cross sections from a detailed neutronics calculation. The photon-yield libraries have data taken from the ORNL Master Photon Data Base ${ }^{11}$ discussed later. In addition to using the photon-yield libraries described in this report, the user of ORIGEN-S can generate photon-yield libraries in any desired energy-group structure (Sect. F7.6).

In addition to the card-image nuclear data and photon-yield libraries, the ORIGEN-S code can read data from three other kinds of libraries: a binary (unformatted) data library, an ENDF/B-IV fission-product data base, and the ORNL Master Photon Data Base.

The use of a binary library is perhaps the most significant feature of ORIGEN-S. A binary data library is generated with the COUPLE code (Sect. FO). It contains, in a single library, the same kinds of data as the card-image nuclear data and photon-yield libraries, but for only one reactor type. The ORIGEN-S code is typically run with a multiburnup binary data library for the reactor type of interest. The binary data library has many advantages over the card-image data libraries. Its principal advantage is that the cross sections 
within the library can be replaced with cross sections derived from a detailed multigroup neutronics (e.g., unit cell) calculation. Cross-section updating is performed with the COUPLE code which reads the multigroup cross sections from an AMPX ${ }^{12}$ weighted (working) cross-section library (Sect. F2.3.8). Automated generation of time-dependent (i.e., burnup-dependent) binary data libraries can be performed with the SAS2 control module (Sect. S2), which invokes the BONAMI, NITAWL-II, XSDRNPM, COUPLE, and ORIGEN-S codes (Sects. F1, F2, F3, F6, and F7, respectively). Another advantage is that any portion of the photon-yield data from the ORNL Master Photon Data Base can be placed in the binary library with any desired energy group structure. Furthermore, any item of data in a binary library can be replaced (using COUPLE) by a user-specified value.

The ENDF/B-IV fission-product data base used by ORIGEN-S contains fission-product decay data in ENDF/B-IV card-image (BCD) format. ${ }^{13}$ These data were compiled from file (MF) 1, reaction type (MT) 457 data of the ENDF/B-IV fission-product tapes. ${ }^{5}$ They can be used by ORIGEN-S to generate multigroup fission-product photon source spectra or to make a card-image photon-yield library for fission products (Sect. F7.6). For either use, the photon energy group structure can be specified by the user. The ENDF/B-IV photon-yield library is nearly obsolete because improved and more complete data described below are available.

The ORNL Master Photon Data Base ${ }^{11}$ was originally developed for the ORIGEN2 code. ${ }^{14}$ In its cardimage form, it consists of six data files for six kinds of photon sources. One file contains decay gamma- and $\mathrm{X}$-ray line data from the Evaluated Nuclear Structure Data File (ENSDF). ${ }^{15,16}$ Another file contains spectra for gamma rays accompanying spontaneous fission and $(\alpha, n)$ reactions. Two files contain bremsstrahlung spectra from decay beta (negatron and positron) particles slowing down in a $\mathrm{UO}_{2}$ fuel matrix. The last two files contain bremsstrahlung spectra from decay betas slowing down in water. These files can be concatenated in any user-chosen combination to form a card-image master photon data base for use with ORIGEN-S. In addition, ORIGEN-S can be used (Sect. F7.6) to create a binary (unformatted) master photon data base, containing data from any combination of the card-image data files, for use in subsequent ORIGEN-S runs. It has been customary at ORNL to run ORIGEN-S with a binary master photon data base, since execution is somewhat more efficient for that mode of operation. The ORNL Master Photon Data Base is the most comprehensive and up-to-date photon library available to ORIGEN-S. It can be used (Sect. F7.6) to generate multigroup photon source spectra, to make card-image photon-yield libraries, or to update photon-yield data in a binary data library. The spectra and photon-yield data can be generated in any energy group structure for all light-element, actinide, and fission-product nuclides having photon data.

The remainder of this document describes in detail the file structures, formats, data sources, and uses of the different kinds of ORIGEN-S libraries outlined above.

\section{M6.1.1 FILE STRUCTURE OF CARD-IMAGE LIBRARIES}

The ORIGEN-S card-image libraries consist of the following:

1. the decay data base,

2. the light-element cross-section library,

3. the actinide cross-section library,

4. the fission-product cross-section and yield library,

5. the light-element photon-yield library,

6. the actinide photon-yield library, and

7. the fission-product photon-yield library.

NUREG/CR-0200,

Vol. 3, Rev. 4

M6.1.2 
Starting with the release of SCALE 4.2, there has been a significant change in the file structure of the seven libraries. Decay data for all nuclides are now in a separate file. The other six libraries are now combined in another file.

Prior to SCALE 4.2, a different file was used for each of the last six libraries. Decay data were in the first three files. The libraries were read as six sequential files on an IBM mainframe. On a Cray computer or on a workstation, the six files were combined into one file, with embedded end-of-file markers separating libraries. This conversion from the IBM format to the workstation format was performed with a special utility code, ORSLIB. In SCALE 4.2, the library file structure is identical for all types of computers; the ORSLIB utility code is no longer required.

The card-image libraries are divided into two major categories: nuclear data (the first four libraries) and photon-yield data (the last three libraries). The nuclear data and the photon-yield libraries are described in detail in Sects. M6.2 and M6.3, respectively.

\section{M6.1.2 MULTIBURNUP BINARY DATA LIBRARY}

The recommended method of running ORIGEN-S is to use a multiburnup binary data library.

To produce a proper multiburnup library, the card-image libraries should be converted to a binary ORIGEN-S library for a specified type of reactor. Then, starting with this binary library, the SAS2H control module should be executed to update the cross sections of all the nuclides having data on the SCALE 27-group depletion library in the production of a preliminary SAS2 binary data library. This preliminary library, in turn, becomes the standard input ORIGEN-S binary data library for SAS2 cases for the same reactor type. A multicase job containing input data, and either job control language or a UNIX script to produce a preliminary SAS2 binary data library, is provided on the SCALE tape.

The main function of SAS2 (alias SAS2H) is to perform a depletion analysis of a fuel assembly to produce isotopic inventories and radiation sources of discharged or cooled spent fuel. A secondary function of the SAS2H case is the production (in a single file) of a multiburnup ORIGEN-S binary data library. Such libraries contain cross-section data (for user-specified nuclides) for each burnup interval or cycle given in the power history input to the case. The multiburnup binary library is useful as input to ORIGEN-S cases that apply a variety of power histories, different nuclide concentration units, different energy group structures of radiation sources, or various decay times. Further details of the binary ORIGEN-S libraries are presented in Sect. M6.7. 


\section{M6.2 CARD-IMAGE NUCLEAR DATA LIBRARIES}

The card-image muclear data libraries consist of three cross-section libraries and the decay data base. The cross-section libraries are (1) a light-element library for 689 nuclides, (2) an actinide library for 129 muclides, and (3) a fission-product library for 879 nuclides. The decay data base contains (for all nuclides in the three cross-section libraries) decay data, percent natural abundances, and radioactivity concentration guides. The decay data for a muclide include the half-life, branching fractions, recoverable energy per decay, and the fraction of recoverable energy from photons. The data for each nuclide in the cross-section libraries are contained on five card-image records. The first card-image record contains information identifying the muclide. The last four card images contain cross-section, and for fission-product nuclides, fission-yield data for four reactor types (HTGR, LWR, LMFBR, and MSBR), with one card image for each reactor type.

The card-image nuclear data libraries are the basic libraries for ORIGEN-S. The code can be run using these libraries directly, or it can be run from a binary data library which (prior to any cross-section or other muclear data updating) was created by running the COUPLE code (Sect. F6) to convert one or more of these card-image libraries.

When ORIGEN-S is run with these card-image libraries, the customary procedure is to use the lightelement library, the actinide library, and the fission-product library. However, ORIGEN-S can be run with only one or two nuclear data libraries if the user wishes (Sect. F7.6). All the decay data are obtained from a separate data file referenced by logical unit No. 27. The card-image cross-section data and photon-yield libraries are referenced by another logical unit number. The libraries are read in the following order: lightelement, actinide, and fission-product decay and cross-section data libraries, followed by light-element, actinide, and fission-product photon-yield libraries.

The remainder of this section is devoted to describing the data formats and sources for the decay data base and the three cross-section data libraries. Much of the description has been taken from the original ORIGEN report.

\section{M6.2.1 DECAY DATA BASE}

The decay data base contains decay data, atom percent natural abundances, and radioactivity concentration guides for both air and water. These data for light elements, actinides, and fission products are in a single data file. There is an exact one-to-one correspondence in the order of the decay-data-base nuclides and those in the three cross-section libraries. In processing these nuclear data libraries, first the nuclide identification (ID) number is read into variable NUCL(I) from the cross-section library, next the data from the decay data base for the same nuclide are read, and then the cross-section data for the specified type of reactor are read. The decay data are read with a list-directed read statement as follows:

READ(LIBDEC, *) LIB, NUC1, IU, HALFL, FB1, FP, FPI, FA, FT, LI2,

$\star_{F S F}, F N, Q(I), A B U N D(1), A M P C(I), \operatorname{WMPC}(I), L I 3, F G(I), F B$

During the processing, the muclide data are stored in several arrays at locations indicated by the index $\mathrm{I}$. The value of the ID number in both NUCL(I) and NUC1 is given by

$$
\operatorname{NUCL}(\mathrm{I})=\mathrm{Z} * 10000+\mathrm{W} * 10+\mathrm{IS} \text {, }
$$


where $\mathrm{Z}$ is the atomic number, $\mathrm{W}$ is the atomic mass number, and IS is 0 for a ground state or 1 for the first metastable state. In principle, IS could be greater than 1 for a nuclide in a higher metastable state, but none of the libraries currently contain data for any such nuclides.

The variable HALFL is the physical half-life in units designated by the variable $I U$, as shown in Table M6.2.1. The definitions of eight variables for branching fractions are given in Table M6.2.2.

The variable $Q(I)$ is the total amount of recoverable energy $(\mathrm{MeV})$ per disintegration released by radioactive decay. It does not include the energy of neutrinos emitted during beta decay transitions.

The variable $F G(I)$ is the fraction of recoverable energy per disintegration that comes from gamma and $\mathrm{X}$ rays. In the ORIGEN-S libraries this fraction includes the energy from all decay gamma and $\mathrm{X}$ rays and from all gamma rays associated with spontaneous fission. Using an approximation ${ }^{11}$ for the combined spectra of prompt and equilibrium fission-product gamma rays from spontaneous fission, a value of 12.56 $\mathrm{MeV}$ per spontaneous fission transition was calculated for use in determining FG for any nuclide having a spontaneous fission fraction exceeding $10^{-7}$. Note that the definition of FG is not the same as that for the original ORIGEN libraries. In those libraries, ${ }^{1} \mathrm{FG}$ included only those photons with energies greater than $200 \mathrm{keV}$. In addition, it included the bremsstrahlung radiation from beta particles slowing down in a $\mathrm{UO}_{2}$ fuel matrix. Bremsstrahlung radiation is not included in the values of FG in the ORIGEN-S libraries, since the bremsstrahlung spectrum depends on the medium that contains the decaying nuclide. Neither is the energy from gamma rays accompanying $(\alpha, n)$ reactions included, since it too depends on the medium.

The variable $A B U N D(I)$ is the atom percent abundance of naturally occurring isotopes. It is read by ORIGEN-S for light-element libraries but is ignored for the actinide and fission-product libraries.

The variables WMPC(I) and AMPC(I) are the radioactivity concentration guides for continuous ingestion (from water) and inhalation (from air) in unrestricted areas, in units of curies per cubic meter $\left(\mathrm{Ci} \mathrm{m}^{-3}\right)$. The RCG values, as defined in the pre-1991 version of Part 10, Title 20, of the Code of Federal Regulations ${ }^{17}$ (10CFR20), specify the maximum permissible concentrations of an isotope in soluble and insoluble forms, for both ingestion and inhalation, and for occupational and unrestricted exposure. When the activity (in curies) of a given isotope is divided by WMPC (or AMPC) for that isotope, the result is the volume of water (or air) required to dilute that quantity of the isotope to its maximum permissible concentration. The dilution volume is a measure of the radioactive toxicity of the nuclide for cases of direct ingestion or inhalation. The values of WMPC and AMPC are defined to be the smaller (i.e., more toxic) of the values for soluble and insoluble forms of the isotope.

The variables LIB, LI2, and LI3 contain the library ID numbers read first from each card image. They are for accounting purposes and may be ignored.

\section{M6.2.2 LIGHT-ELEMENT CROSS-SECTION LIBRARY}

The light-element card-image cross-section data library contains data for structural materials, activation products, and their decay daughters. The library has data for 879 nuclides.

As indicated earlier, there are five card-image records for each nuclide. The first record contains the nuclide ID mumber defined by Eq. (M6.2.1) in an I7 format plus other information not used by the code. The next four records contain data for neutron-induced reactions, with one record for each of the four reactor

types. The data in these four records are referred to collectively as cross-section data, even though some items are not cross sections. The data are read using the following READ statement and FORMAT:

NUREG/CR-0200,

Vol. 3, Rev. 4

M6.2.2 
Table M6.2.1 Units of half-life indicated by the variable $\mathrm{IU}$

\begin{tabular}{ll}
\hline IU & Units of half-life \\
\hline 1 & seconds \\
2 & minutes \\
3 & hours \\
4 & days \\
5 & years \\
6 & stable \\
7 & $10^{3}$ years \\
8 & $10^{6}$ years \\
9 & $10^{9}$ years \\
\hline
\end{tabular}

Table M6.2.2 Definitions of branching fraction variables

\begin{tabular}{|c|c|}
\hline Variable name & Definition \\
\hline FB & $\begin{array}{l}\text { Fraction of decay transitions that take place by beta } \\
\text { (negatron) emission and lead to a product nuclide in the } \\
\text { ground state }\end{array}$ \\
\hline FB1 & $\begin{array}{l}\text { Fraction of decay transitions that take place by beta } \\
\text { (negatron) emission and lead to a product nuclide in an } \\
\text { excited (metastable) nuclear state }\end{array}$ \\
\hline FP & $\begin{array}{l}\text { Fraction of decay transitions that take place by positron } \\
\text { emission or orbital electron capture and lead to a product } \\
\text { nuclide in the gorund state }\end{array}$ \\
\hline FP1 & $\begin{array}{l}\text { Fraction of decay transitions that take place by positron } \\
\text { emission or orbital electron capture and lead to a product } \\
\text { nuclide in an excited (metastable) nuclear state }\end{array}$ \\
\hline FA & $\begin{array}{l}\text { Fraction of decay transitions that take place by } \\
\text { alpha particle emission }\end{array}$ \\
\hline FT & $\begin{array}{l}\text { Fraction of decay transitions that take place by } \\
\text { isomeric transition }\end{array}$ \\
\hline FSF & $\begin{array}{l}\text { Fraction of decay transitions that take place by spontaneous } \\
\text { fission }\end{array}$ \\
\hline FN & $\begin{array}{l}\text { Fraction of decay transitions that take place by the } \\
\text { emission of both a beta (negatron) particle and a neutron }\end{array}$ \\
\hline
\end{tabular}

M6.2.3

NUREG/CR-0200, Vol. 3, Rev. 4 
150 READ(L, 11500) SIGTH, FNG1, FNA, FNP, RITH, FINA,

*FINP, SIGHEV, FN2N1, FFNA, FFNP, IT

11500 FORMAT(7X, F9.2, 3F5.3, F9.2, 2F5.3, F9.2, 3F5.3, 5X, 11) .

Definitions of the muclear data variables are given in Table M6.2.3 for the case of a thermal reactor (HTGR, LWR, or MSBR). For an LMFBR, the cross-section variables have different definitions than those of Table M6.2.3. In that case, either SIGTH or RITH is the spectrum-averaged radiative capture (n, $\gamma$ ) cross section. When one is nonzero, the other is always zero. The variable SIGMEV is the sum of the spectrumaveraged $(n, 2 n),(n, \alpha)$, and $(n, p)$ cross sections.

Table M6.2.3 Definitions of nuclear data variables in light-element libraries for a thermal reactor

\begin{tabular}{|c|c|}
\hline Variable name & Definition \\
\hline SIGTH & $\begin{array}{l}\text { Total absorption cross section (barns) for thermal }(2200 \mathrm{~m} / \mathrm{s}) \\
\text { neutrons }\end{array}$ \\
\hline FNG1 & $\begin{array}{l}\text { Fraction of radiative capture }(n, \gamma) \text { reactions that produce a product } \\
\text { nuclide in an excited (metastable) nuclear state }\end{array}$ \\
\hline FNA & Fraction of SIGTH that produces $(n, \alpha)$ reactions \\
\hline FNP & Fraction of SIGTH that produces $(n, p)$ reactions \\
\hline \multirow[t]{2}{*}{ RITH } & $\begin{array}{l}\text { Resonance integral (barns) for all epithermal (above } 0.5 \mathrm{eV} \text { ) } \\
\text { neutron absorption, }\end{array}$ \\
\hline & $\int_{0.5 \mathrm{ev}}^{\infty} \frac{1}{\mathrm{E}} \sigma_{\mathrm{a}}(\mathrm{E}) \mathrm{dE}$ \\
\hline FINA & Fraction of RITH that produces $(n, \alpha)$ reactions \\
\hline FINP & Fraction of RITH that produces $(n, p)$ reactions \\
\hline SIGMEV & $\begin{array}{l}\text { Fission-spectrum-averaged cross section (barns) for all reactions } \\
\text { with a threshold above } 1 \mathrm{MeV}\end{array}$ \\
\hline FN2N1 & $\begin{array}{l}\text { Fraction of }(n, 2 n) \text { reactions that produce a product nuclide } \\
\text { in an excited (metastable) nuclear state }\end{array}$ \\
\hline FFNA & Fraction of SIGMEV that produces $(n, \alpha)$ reactions \\
\hline FFNP & Fraction of SIGMEV that produces $(\mathrm{n}, \mathrm{p})$ reactions \\
\hline
\end{tabular}

NUREG/CR-0200,

Vol. 3, Rev. 4

M6.2.4 
The last variable on the card-image record, IT, is used to indicate the reactor type for which the data have been compiled. Possible values are shown in Table M6.2.4. In the original ORIGEN libraries, a value of zero for IT indicated that no data were present for that reactor type. In the ORIGEN-S libraries, a nonzero value is always used, even if all other data on the card-image record are zero. This gives the same number of nuclides for every reactor type, which is necessary for full utilization of the blended fuel option in ORIGEN-S.

Table M6.2.4 Reactor type as a function of variable IT

\begin{tabular}{ll}
\hline IT & Reactor type \\
\hline 1 & HTGR \\
2 & LWR \\
3 & LMFBR \\
4 & MSBR \\
\hline
\end{tabular}

Three additional pieces of data are computed from the data on the card image, as shown in the following equations:

$$
\begin{aligned}
\text { FNG } & =1.0-\text { FNA }- \text { FNP }, \\
\text { FING } & =1.0-\text { FINA }- \text { FINP },
\end{aligned}
$$

and

$$
\text { FN2N }=1.0-\text { FFNA }- \text { FFNP }
$$

In these equations, FNG and FING are the fractions of SIGTH and RITH, respectively, which produce (n, $\gamma)$ reactions. The variable FN2N is the fraction of SIGMEV which produces $(n, 2 n)$ reactions.

For all reactor types, the effective one-group cross sections are obtained by weighting the cross sections from the card-image record, as described below. The $(n, \alpha),(n, p),(n, \gamma)$, and $(n, 2 n)$ cross sections are given by

$$
\begin{gathered}
\sigma_{\mathrm{n}, \alpha}=\text { THERM } * \text { SIGTH } * \text { FNA + RES } * \text { RITH } * \text { FINA + FAST } * \text { SIGMEV } * \text { FFNA, } \\
\sigma_{\mathrm{n}, \mathrm{p}}=\text { THERM } * \text { SIGTH } * \text { FNP + RES } * \text { RITH } * \text { FINP + FAST } * \text { SIGMEV } * \text { FFNP }, \\
\sigma_{n, \gamma}=\text { THERM } * \text { SIGTH } * \text { FNG + RES } * \text { RITH } * \text { FING },
\end{gathered}
$$

and

$$
\sigma_{\mathrm{n}, 2 \mathrm{n}}=\mathrm{FAST} * \mathrm{SIGMEV} * \mathrm{FN} 2 \mathrm{~N}
$$


The $(n, \gamma)$ and $(n, 2 n)$ cross sections are further divided into cross sections for product nuclides in ground and excited states by using the variables FNG1 and FN2N1. The total capture cross section is computed from the relation

$$
\sigma_{c}=\sigma_{n, \alpha}+\sigma_{n, p}+\sigma_{n, \gamma}+\sigma_{n, 2 n}
$$

For thermal reactors, the variables THERM, RES, and FAST in Eqs. (M6.2.6) through (M6.2.9) are spectral indices (weight factors) defined in Table M6.2.5. It can be seen that all reaction rates for thermal reactors are computed with the thermal neutron flux. A more complete discussion of THERM, RES, and FAST for thermal reactors and alternative definitions based upon the use of multigroup neutron fluxes and cross sections are given in both the COUPLE (Sect. F6.2.1) and ORIGEN-S (Sects. F7.2.6 and F7.2.12) documentation.

Table M6.2.5 Definitions of spectral indices for thermal reactors

\begin{tabular}{cl}
\hline Index (weight factor) & \multicolumn{1}{c}{ Definition } \\
\hline THERM & $\begin{array}{l}\text { Ratio of the neutron reaction rate for a } 1 / \mathrm{v} \text { absorber with a } \\
\text { population of neutrons that has a Maxwell-Boltzmann distribution } \\
\text { at absolute temperature } \mathrm{T}, \text { to the reaction rate given by the } \\
\text { product of the thermal neutron flux and the } 2200 \mathrm{~m} / \mathrm{s} \text { cross } \\
\text { section }\end{array}$ \\
RES & $\begin{array}{l}\text { Ratio of the resonance neutron flux per unit lethargy to the } \\
\text { thermal neutron flux }\end{array}$ \\
FAST & $\begin{array}{l}1.45 \text { times the ratio of the neutron flux above } 1 \mathrm{MeV} \text { to the } \\
\text { thermal neutron flux }\end{array}$ \\
\hline
\end{tabular}

For the LMFBR, the spectral indices are all equal to 1.0 since the cross sections are already spectrumaveraged. In this case, all reaction rates are computed with the total neutron flux. The values of FNA, FNP, FINA, and FINP are always zero for the LMFBR, since SIGTH (or RITH) is only the ( $n, \gamma$ ) cross section.

Three steps are used in reading the nuclear data for each nuclide in the library. First, the card-image record containing only the nuclide ID number is read from the cross-section library. Second, the decay data are read from the decay library. Then, the card-image records containing cross-section data are read from the cross-section library until the value of the variable IT is equal to the value of the input parameter NLIBE (Sect. F7.6.10). The remaining records, if any, containing cross-section data are then processed as described in Sect. M6.2.5. When data for all nuclides in the library have been read, processing of the actinide and/or fission-product libraries begins.

\section{M6.2.3 ACTINIDE CROSS-SECTION LIBRARY}

The actinide library contains data for 129 fuel, transplutonium, and decay daughter nuclides. Again, the first card-image record for each nuclide contains the $\mathrm{ID}$ and the last four records contain cross-section data for four reactor types. These cross-section data are read with the following READ and FORMAT statements:

NUREG/CR-0200,

Vol. 3, Rev. 4

M6.2.6 


\footnotetext{
READ(L, 11700) SIGNG, RING, FNG1, SIGF, RIF, SIGFF,

*SIGN2N, FH2N1, SIGN3H, IT

11700 FORMAT(7X, 2F9.2, F5.3, 4F9.2, F4.3, F9.2,11) .
}

Definitions of the muclear data variables for thermal reactors are given in Table M6.2.6. For an LMFBR, the variables RING, RIF, and SIGFF are not used. In addition, the variables SIGNG, SIGF, SIGN2N, and SIGN3N are then reactor-spectrum-averaged cross sections for $(n, \gamma)$, fission, $(n, 2 n)$, and $(n, 3 n)$ reactions, respectively.

Table M6.2.6 Definitions of nuclear data variables in the actinide library for a thermal reactor

\begin{tabular}{|c|c|}
\hline Variable name & Definition \\
\hline SIGNG & $\begin{array}{l}\text { Radiative capture }(\mathrm{n}, \gamma) \text { cross section (barns) for thermal } \\
(2200 \mathrm{~m} / \mathrm{s}) \text { neutrons }\end{array}$ \\
\hline RING & Resonance integral (barns) for $(n, \gamma)$ reaction \\
\hline FNG1 & $\begin{array}{l}\text { Fraction of }(n, \gamma) \text { reactions that produce a product nuclide in an } \\
\text { excited (metastable) nuclear state }\end{array}$ \\
\hline SIGF & Thermal neutron (n,fission) cross section (barns) \\
\hline RIF & Resonance integral (barns) for (n,fission) reaction \\
\hline SIGFF & $\begin{array}{l}\text { Fission-spectrum-averaged ( } \mathrm{n} \text {,fission) cross section (barns) for } \\
\text { nuclides having a high-energy threshold for fission }\end{array}$ \\
\hline SIGN2N & Fission-spectrum-averaged (n,2n) cross section (barns) \\
\hline FN2N1 & $\begin{array}{l}\text { Fraction of ( } n, 2 n) \text { reactions that produce a product nuclide in an } \\
\text { excited (metastable) nuclear state }\end{array}$ \\
\hline SIGN3N & Fission-spectrum-averaged ( $\mathrm{n}, 3 \mathrm{n}$ ) cross section (barns) \\
\hline
\end{tabular}

The variable IT identifies the reactor type, as explained in Sect. M6.2.2 (Table M6.2.4).

If the input variable LPU (Sect. F7.6.10) is greater than zero, the cross-section data for LPU actinide nuclides, whose ID numbers are specified in the input array NEWCX, are read from cards in the input stream. These data are read with a READ statement and FORMAT identical to the ones for the card-image library, as described above.

Again, the effective one-group cross sections are obtained by weighting the cross sections from the card-image record. The $(n, \gamma)$, (n,fission), $(n, 2 n)$, and $(n, 3 n)$ cross sections are given by 


$$
\begin{gathered}
\sigma_{\mathrm{a}, y}=\text { THERM } * \text { SIGNG + RES } * \text { RING }, \\
\sigma_{\mathrm{f}}=\text { THERM } * \text { SIGF + RES } * \text { RIF }+ \text { FAST } * \text { SIGFF }, \\
\sigma_{n, 2 n}=\text { FAST } * \text { SIGN } 2 N,
\end{gathered}
$$

and

$$
\sigma_{n, 3 \mathrm{~m}}=\mathrm{FAST} * \operatorname{SIGN} 3 \mathrm{~N} .
$$

As for the light-element library, the $(n, \gamma)$ and $(n, 2 n)$ cross sections are divided into cross sections for product muclides in ground and excited states by using the variables FNG1 and FN2N1. The total capture cross section is found from

$$
\sigma_{\mathrm{c}}=\sigma_{\mathrm{n}, \mathrm{y}}+\sigma_{\mathrm{f}}+\sigma_{\mathrm{n}, 2 \mathrm{n}}+\sigma_{\mathrm{n}, 3 \mathrm{n}} \text {. }
$$

For thermal reactors, the variables THERM, RES, and FAST are the spectral indices, as defined in Table M6.2.5. Again, these indices are all 1.0 for an LMFBR, since the cross sections on the card-image record are already spectrum-averaged.

The muclear data records for the actinide library are read and processed in the same manner as those for the light-element library.

\section{M6.2.4 FISSION-PRODUCT CROSS-SECTION AND FISSION-YIELD LIBRARY}

The fission-product library contains data for 879 fission-product nuclides. As for the light-element and actinide libraries, the first card-image record for each nuclide contains the ID. In the fission-product libraries, the last four records contain fission yield as well as cross-section data. These data are read with the following READ and FORMAT statements:

620 READ(L, 11800) SIGNG, RING, FNG1, $(Y(I), I=1,5)$, IT 11800 FORMAT $(7 X, 2 F 9.2, F 5.3,5 F 9.2,4 X, 11)$.

All the nuclear data variables except $Y$ have the same definitions as for the actinide library (Table M6.2.6). Radiative capture is the only neutron absorption reaction considered for fission products, and the effective one-group $(n, \gamma)$ cross section is given by Eq. (M6.2.11). As in the actinide library, the variable RING is not used for the LMFBR, and the spectral indices are all 1.0 for that reactor. As before, the variable FNG1 is used to divide the one-group $(n, \gamma)$ cross section into cross sections for product nuclides in ground and excited states.

The array $Y$ contains energy-dependent direct fission-product yields for five fissionable nuclides. The fissionable nuclides for the four reactor types are shown in Table M6.2.7.

NUREG/CR-0200,

Vol. 3, Rev. 4 
Table M6.2.7 Fissionable nuclides having yield data

\begin{tabular}{llllll}
\hline Reactor & $\mathrm{Y}(1)$ & $\mathrm{Y}(2)$ & $\mathrm{Y}(3)$ & $\mathrm{Y}(4)$ & $\mathrm{Y}(5)$ \\
\hline HTGR & ${ }^{233} \mathrm{U}$ & ${ }^{235} \mathrm{U}$ & ${ }^{232} \mathrm{Th}^{a}$ & ${ }^{238} \mathrm{U}^{a}$ & ${ }^{239} \mathrm{Pu}$ \\
LWR & ${ }^{233} \mathrm{U}$ & ${ }^{235} \mathrm{U}$ & ${ }^{241} \mathrm{Pu}$ & ${ }^{238} \mathrm{U}^{a}$ & ${ }^{239} \mathrm{Pu}$ \\
LMFBR & ${ }^{241} \mathrm{Pu} a$ & ${ }^{235 U} a$ & ${ }^{240} \mathrm{Pu} a$ & ${ }^{238} \mathrm{U}^{a}$ & ${ }^{239} \mathrm{Pu}$ \\
MSBR & ${ }^{233 \mathrm{U}}$ & ${ }^{235 U}$ & ${ }^{232} \mathrm{Th} a$ & ${ }^{238 \mathrm{U}_{a}}$ & ${ }^{239} \mathrm{Pu}$ \\
\hline
\end{tabular}

'Yield is for fission-sp ectrum-energy neutrons.

In the table, any yields not footnoted " $a$ " are for thermal-neutron-induced fission. All fission-product yields for all nuclides except ${ }^{3} \mathrm{H},{ }^{6} \mathrm{Li},{ }^{7} \mathrm{Li},{ }^{9} \mathrm{Be},{ }^{10} \mathrm{Be}$, and ${ }^{14} \mathrm{C}$ are from ENDF/B-V. The tritium yield from ${ }^{238} \mathrm{U}$ fission is the average of data from Boumahraz. ${ }^{7}$ The tritium yields from fission of ${ }^{223} \mathrm{U},{ }^{235} \mathrm{U}$, ${ }^{229} \mathrm{Pu}$, and ${ }^{241} \mathrm{Pu}$ are from measurements described by Wagemans et al. ${ }^{8}$ Yield data for ${ }^{6} \mathrm{Li},{ }^{7} \mathrm{Li},{ }^{9} \mathrm{Be},{ }^{10} \mathrm{Be}$, and ${ }^{14} \mathrm{C}$ were taken from the ORIGEN2 fission-product yield library. ${ }^{14}$

The muclear data records for the fission-product libraries are read and processed in the same manner as for the light-element and actinide libraries.

\section{M6.2.5 CONSTRUCTION OF THE TRANSITION MATRIX}

In general, the ORIGEN-S code solves a coupled set of linear, nonhomogeneous, first-order differential equations with constant coefficients (Sect. F7.2) which can be written in matrix form as

$$
\underset{\sim}{\mathbb{N}}=\underset{\approx}{\mathrm{A}} \underset{\sim}{\mathbb{N}}+\underset{\sim}{\mathrm{B}}
$$

In this equation, $\underset{\sim}{N}$ is a vector of muclide concentrations, $\underset{\approx}{\mathrm{A}}$ is the transition matrix, and $\underset{\sim}{\mathrm{B}}$ is a vector of userspecified rate changes (which are zero if the chemical processing options are not used).

In the transition matrix, each element $a_{i j}$ is the first-order rate constant for the formation of nuclide $i$ from nuclide $j$. Each rate constant is defined by one of the following equations:

$$
\begin{aligned}
& a_{i j}=\ell_{i j} \lambda_{j}, \\
& a_{i j}=f_{i j} \sigma_{j} \phi,
\end{aligned}
$$

or

$$
a_{i i}=-\left(\lambda_{i}+\sigma_{i} \phi\right)
$$

In these equations, $\lambda_{i}$ is the radioactive decay constant $\left(\mathrm{s}^{-1}\right)$ for nuclide $j, \sigma_{i}$ is the effective one-group neutron absorption (total capture) cross section $\left(\mathrm{cm}^{2}\right)$, and $\phi$ is the neutron flux $\left(\mathrm{cm}^{-2} \mathrm{~s}^{-1}\right)$. The variables $\ell_{\mathrm{ij}}$ and $\mathrm{f}_{\mathrm{ij}}$ are the fractions of radioactive decay and neutron absorption of nuclide $j$ which lead to the formation of nuclide $i$. Note that the term $f_{i j} \sigma_{j}$ in Eq. (M6.2.18) is general enough to include the formation of fission-product nuclides as well as the daughter products of any other kind of neutron capture reaction. 
The transition matrix elements are constructed from the information in the card-image nuclear data libraries described in the preceding subsections. In addition, the nuclear data in an ORIGEN-S binary data library are stored in transition matrix format. Therefore, this subsection is devoted to a description of how the transition matrix and its associated nuclide locator vectors are constructed. These operations are performed in subroutine XNUDAT of ORIGEN-S or COUPLE.

Since the transition matrix is normally very sparse, and since straightforward construction of this matrix would require the storage of a very large number of matrix elements $(-2.9$ million words for the large libraries), a different approach was taken when the original ORIGEN code ${ }^{1}$ was developed. Only the diagonal elements and nonzero off-diagonal elements of the matrix are stored. The location of each nonzero offdiagonal element (i.e., row and column in the full transition matrix) is recorded using three nuclide locator vectors.

The information needed to construct the diagonal elements $\mathrm{a}_{\mathrm{ii}}$ is stored in two one-dimensional (1-D) arrays. The radioactive decay constant $\lambda_{i}$, computed from the half-life, is stored in array element DIS(I). The total capture cross section for nuclide $i$ is stored in array element TOCAP(I).

The processing of information for the nonzero off-diagonal elements $a_{i j}$ is described below. The firstorder rate constant for a decay transition is calculated by multiplying the decay constant $\lambda_{j}$ of the parent muclide by the fraction of transitions to the final state of interest. Next, the product nuclide of the transition is identified by addition of a suitable constant to the six-digit identification number NUCL(J). For example, NUCL(J) +10000 identifies the product nuclide following $\beta^{-}$decay of nuclide $j$, and NUCL(J)- 1 identifies the product of isomeric transition. Two temporary arrays are constructed. In the first, each element NPROD(M, $J)$ contains the six-digit identifier of the product nuclide formed by transition $M$ of nuclide $J$. In the second array, the element $\operatorname{COEFF}(M, J)$ contains the first-order rate constant for the corresponding transition.

For nonfission neutron capture transitions, a slightly different procedure is followed. Since the neutron flux is not known, only that portion of the rate constant given by $f_{i j} \sigma_{j}$ is computed. For example, the product of FN2N1 and the one-group $(n, 2 n)$ cross section gives $f_{i j} \sigma_{j}$ for an $(n, 2 n)$ transition from nuclide $j$ to metastable product nuclide i. Again, the product nuclide identifier is found by adding a suitable constant to the six-digit parent nuclide identifier NUCL(J). For the example under consideration, the metastable product muclide from the $(n, 2 n)$ reaction is given by NUCL(J)-9. As before, the temporary array element NPROD(M, J) contains the six-digit product nuclide identifier. For neutron capture transitions, the element COEFF(M, $J)$ of the second array contains only the $\mathrm{f}_{\mathrm{jij}} \sigma_{\mathrm{j}}$ portion of the rate constant.

After the arrays NPROD and COEFF have been constructed, a search is made of the NPROD array to identify all the parents of a given muclide $I$. Nuclide $J$ is a parent of I if NPROD(M,J) equals NUCL(I) for any reaction type $M$. When a parent of nuclide $I$ has been located, the value of the corresponding transition matrix element $a_{\bar{i}}$ is just $\operatorname{COEFF}(M, J)$. The nonzero, off-diagonal matrix elements $a_{i j}$ are stored sequentially in a 1-D array $A$. Each time a matrix element is stored in array element $A(N)$, the index $N$ is incremented by one. At the same time, the value of $J$ identifying the parent nuclide is stored in array element $L O C(N)$ of a second 1-D array. The total number of parents for production of nuclide $I$ is stored in array element $I$ of a third array NONO. Finally, the number of parents for production of nuclide I by radioactive decay is stored in array element $I$ of the last locator vector $K D$.

When the nonzero, off-diagonal matrix elements for nuclide I are stored in array A, all those for radioactive decay transitions are grouped first. These elements are followed by those for formation of $I$ by neutron capture. The number of neutron capture transitions for formation of nuclide I is given by NONO(I)$\mathrm{KD}(\mathrm{I})$.

Since the matrix elements for nuclide I are grouped by transition type, the information in the locator vectors $L O C, N O N 0$, and $K D$ is sufficient to identify the location of any array element $A(N)$ in the expanded transition matrix. Note that NONO(I) is the number of nonzero, off-diagonal elements in row I of the expanded matrix and LOC(N) is the column number of array element $A(N)$.

NUREG/CR-0200,

Vol. 3, Rev. 4

M6.2.10 
After the matrix elements for all nuclides have been stored, the elements of the NONO array are converted (in subroutine XORIGN of ORIGEN-S) to indicate the cumulative number of matrix elements for all muclides up to and including the muclide of interest. The array element NONO(I+1) is set equal to NONO(I) + NONO(I +1) for all I greater than 1. The elements of the KD array are also adjusted such that NONO(I) $\mathrm{KD}(1)$ still gives the number of neutron capture transitions for formation of nuclide $\mathrm{I}$.

The construction of the matrix elements $a_{4}$ corresponding to the production of fission-product nuclides is slightly different. When the yield $Y_{\bar{y}}$ (for direct formation of muclide $i$ from fission of nuclide $j$ ) is multiplied by the fission cross section $\sigma_{f, j}$, the result is just the $f_{j i} \sigma_{j}$ portion of the first-order rate constant $a_{i j}$. The product $Y_{\mathfrak{j}} \sigma_{f j}$ is entered directly into the proper array element $A(N), J$ is entered into $L O C(N)$, and there is no need for the temporary arrays NPROD and COEFF.

\section{M6.2.6 SOURCES OF DECAY DATA}

An extensive decay-data update ${ }^{9}$ was completed prior to the release of the SCALE-4.2 version of ORIGEN-S. The primary source of the radioactive decay data was ENDF/B-VI. ${ }^{10}$ Approximately $90 \%$ of the library nuclides either are stable or were completely updated with decay half-lives, branching fractions, recoverable energy per decay, and gamma energy per decay from ENDF/B-VI. The decay data for most of the remaining muclides were taken from ENSDF. ${ }^{15,16}$ All or part of the decay data from only 20 nuclides were not updated. In referring to "number of nuclides" here, it means the number of nuclide positions or locations in the libraries. The "number of unique nuclides" would be smaller because some isotopes or isomers are included in more than one of the three libraries.

Improved decay data were installed in the ORIGEN-S and ORIGEN2 libraries during the same project. ${ }^{2}$ The decay data libraries of both codes were made the same size, and the same data were put into each library, with one exception. The ORIGEN2 data for each nuclide are read from two card images. A third card image is added in the ORIGEN-S library containing the library $\mathrm{ID}$, the $\beta^{-}$(negatron) branching fraction, and the fraction of the recoverable photon energy per decay. ORIGEN2 (at the time this is written) calculates the negatron branching fraction from the other branching fractions and does not compute total nuclide recoverable photon energies. However, all decay data common to both codes are identical.

Table M6.2.8 summarizes nuclides according to their change status (updated or unchanged), their decay data source, and their stability (stable or radioactive). ${ }^{18-20}$ The stability status of one nuclide was changed to stable. The large majority of the nuclides were updated from nine ENDF/B-VI files. Nuclides that were updated from ENSDF data are listed in Table M6.2.9.

All the remaining muclides that were not completely updated or were given special treatment, are listed in Table M6.2.10. Although these include the 25 muclides in the listing in Table M6.2.8, note that only 21 are shown in Table M6.2.10. The reason for the difference in numbers is because four of the different nuclides in Table M6.2.10 are in two libraries, and the values in Table M6.2.8 represent the number of nuclide positions in the entire library. The fake muclides ${ }^{1550} \mathrm{Gd}$ and ${ }^{250} \mathrm{~S}$ are not actually for nuclides, but are locations for neutron counters used by ORIGEN2. Also, the special purpose of ${ }^{4} \mathrm{H}$ is explained in Sect. M6.2.8. The decay data for nuclides in Table M6.2.10 which are not specifically footnoted were taken from either the library for the original version of ORIGEN ${ }^{1}$ or the first expansion of the light-element and fission-product libraries. ${ }^{2,4}$ The source of most of the decay data in those libraries was either the Table of Isotopest or the Chart of the Nuclides, ${ }^{2}$ although the source of some of the data remains unknown.

A part of the recoverable energy per decay not included in the ENDF/B-VI and ENSDF data was that from spontaneous fission. This quantity was calculated as the product of spontaneous fission branching fraction and energy per fission and, then, added to the given recoverable energy. A value (consistent with that used 
Table M6.2.8 Summary of decay data source

\begin{tabular}{cl}
\hline $\begin{array}{c}\text { Number of } \\
\text { nuclides }\end{array}$ & \multicolumn{1}{c}{$\begin{array}{c}\text { Stability, change status, } \\
\text { and data source }\end{array}$} \\
\hline 404 & Stable, unchanged \\
1 & Stable, updated (Table of Radioactive Isotopes") \\
1128 & Radioactive, updated (ENDF/B-VI $\left.{ }^{10}\right)$ \\
140 & Radioactive, updated (ENSDF $\left.{ }^{15,19.20}\right)$ \\
20 & Radioactive, partial or no change (prior ORIGEN2 ${ }^{5}$ ) \\
4 & Special purpose or "fake" positions, unchanged \\
\hline 1697 & Total, library size \\
\hline Taken from Ref. 18. \\
'Taken from Ref. 11.
\end{tabular}

Table M6.2.9 Unique nuclides updated with decay data from ENSDF

\begin{tabular}{|c|c|c|c|c|}
\hline $\begin{array}{lll}4 \mathrm{BEE} & 11 \\
5 & \mathrm{~B} & 12 \\
7 & \mathrm{~N} & 13 \\
6 \mathrm{C} & 15 \\
11 \mathrm{NA} & 24 \mathrm{M} \\
11 \mathrm{NA} & 25 \\
13 \mathrm{AI} & 29 \\
13 \mathrm{AI} & 30 \\
14 \mathrm{SI} & 32 \\
15 & \mathrm{P} & 33 \\
15 & \mathrm{P} & 34 \\
16 & \mathrm{~S} & 35 \\
16 & \mathrm{~S} & 37 \\
17 \mathrm{CI} & 38 \mathrm{M} \\
17 \mathrm{CL} & 38 \\
19 & \mathrm{~K} & 43 \\
19 & \mathrm{~K} & 44 \\
21 \mathrm{SC} & 46 \mathrm{M} \\
20 \mathrm{CA} & 49 \\
21 \mathrm{SC} & 49 \\
21 \mathrm{SC} & 50 \\
23 & \mathrm{~V} & 53 \\
23 & \mathrm{~V} & 54 \\
24 \mathrm{CR} & 55\end{array}$ & $\begin{array}{ll}25 \mathrm{MN} & 57 \\
25 \mathrm{MN} & 58 \\
27 \mathrm{CO} & 58 \mathrm{M} \\
27 \mathrm{CO} & 61 \\
27 \mathrm{CO} & 62 \\
28 \mathrm{NI} & 65 \\
28 \mathrm{NI} & 66 \\
29 \mathrm{CU} & 67 \\
30 \mathrm{ZN} & 69 \mathrm{M} \\
30 \mathrm{ZN} & 69 \\
31 \mathrm{GA} & 70 \\
30 \mathrm{ZN} & 71 \\
30 \mathrm{ZN} & 71 \mathrm{M} \\
32 \mathrm{GE} & 71 \\
32 \mathrm{GE} & 71 \mathrm{M} \\
35 \mathrm{BR} \quad 86 \mathrm{M} \\
45 \mathrm{RH} 102 \\
47 \mathrm{AG} 106 \\
55 \mathrm{CS} 131 \\
56 \mathrm{BA} 131 \\
56 \mathrm{BA} 131 \mathrm{M} \\
55 \mathrm{CS} 132 \\
56 \mathrm{BA} 133 \mathrm{M} \\
58 \mathrm{CE} 137\end{array}$ & $\begin{array}{l}\text { 58CE139 } \\
\text { 58CE139M } \\
\text { 59PR139 } \\
\text { 59PR140 } \\
60 N D 141 \\
63 E U 149 \\
66 \mathrm{DY157} \\
66 \mathrm{DY159} \\
67 \mathrm{HO1} 163 \\
68 \mathrm{ER} 163 \\
\text { 68ER165 } \\
\text { 68ER169 } \\
\text { 70YB169 } \\
\text { 69TM170 } \\
\text { 68ER171 } \\
\text { 69TM171 } \\
\text { 68ER172 } \\
\text { 69TM172 } \\
\text { 69TM173 } \\
\text { 70YB175 } \\
\text { 72HF175 } \\
\text { 71LU176M } \\
\text { 70YB177 } \\
\text { 71LU177M }\end{array}$ & 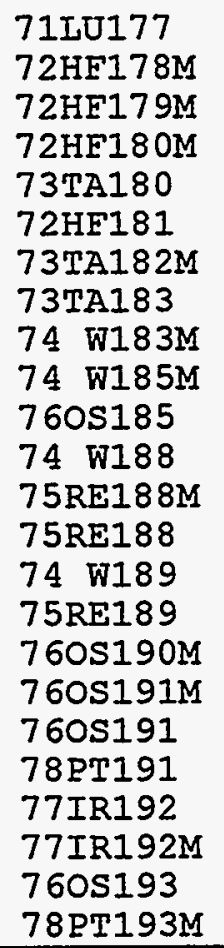 & $\begin{array}{l}\text { 77IR194M } \\
\text { 78PT195M } \\
\text { 78PT197M } \\
78 \text { PT197 } \\
\text { 80HG197M } \\
89 \mathrm{HG197} \\
78 \mathrm{PT} 199 \mathrm{M} \\
78 \mathrm{PT} 199 \\
79 \mathrm{AU} 199 \\
79 \mathrm{AU} 200 \\
\text { 80HG205 } \\
\text { 84PO211M } \\
\text { 88RA222 } \\
\text { 90TH226 } \\
\text { 92 U230 } \\
\text { 92 U231 } \\
\text { 91PA235 } \\
\text { 93NP235 } \\
\text { 95AM239 } \\
\text { 93NP241 } \\
\text { 94PU246 } \\
\text { 95AM246 } \\
\text { 96CM251 } \\
\text { 99ES254 }\end{array}$ \\
\hline
\end{tabular}

NUREG/CR-0200,

Vol. 3, Rev. 4

M6.2.12 
Table M6.2.10 Nuclides changed to stable or not updated with decay data

\begin{tabular}{|c|c|c|c|c|}
\hline $\begin{array}{l}1 \mathrm{H} \quad 4^{a} \\
4 \mathrm{BE} \quad 8^{b} \\
23 \mathrm{~V} 5^{c} \\
34 \mathrm{SE} 85 \mathrm{M} \\
58 \mathrm{CE} 137 \mathrm{M} c\end{array}$ & $\begin{array}{l}\text { 58CE142 } \\
62 \mathrm{SM} 149 \\
65 \mathrm{~TB} 162 \mathrm{M} \\
\text { 64GD155M }{ }^{2} \\
65 \mathrm{~TB} 163 \mathrm{M}\end{array}$ & $\begin{array}{l}69 \text { TM170M } \\
70 \text { YB175M } \\
92 \text { U241 } \\
82 \text { PB204 } \\
96 \text { CM250 }\end{array}$ & $\begin{array}{l}\text { 97BK251 } \\
\text { 98CF254 } \\
\text { 99ES254M e } \\
\text { 98CF255 } \\
\text { 99ES255 }\end{array}$ & $\mathrm{S} 250^{\circ}$ \\
\hline
\end{tabular}

"Fake "special purpose" with no physical decay data.

${ }^{6} \mathrm{Half}$-life increased from $6.7 \times 10^{-17} \mathrm{~s}$ to $2 \times 10^{-6} \mathrm{~s}$ to require fewer changes in $\mathrm{PC}$ version.

\%Half-lives and recoverable energies from ENSDF.

"The "radioactivity/stability status" was specified as "stable" in the Table of Radioactive

lsotopes.

'Gamma energies from the Table of Radioactive Isotopes.

in unchanged data) of $200 \mathrm{MeV}$ per fission ${ }^{11}$ was assumed. A value of $12.56-\mathrm{MeV}$ gamma energy per fission ${ }^{11}$ was used in computing the fraction of recoverable energy from photons.

In addition to radioactive decay data, the decay data base contains two other kinds of data. Atom percent natural isotopic abundances were taken from Holden, ${ }^{23}$ and maximum permissible radioactivity concentration guides (RCGs) for air and water were taken from the Code of Federal Regulations, 10 CFR $20 .{ }^{17}$

\section{M6.2.7 SOURCES OF CROSS-SECTION DATA}

With the exception of the nuclides discussed later, all cross-section and fission-yield data for the HTGR, LMFBR; and MSBR were taken from the ORIGEN libraries. ${ }^{14}$ However, some rearrangement of these data was undertaken, as explained below.

Cross sections were transferred from the small light-element library to the large light-element library for those nuclide and reactor-type combinations that previously had no cross-section data in the large lightelement library.

The cross sections for those nuclide and reactor-type combinations that were already present in the large light-element library were transferred to the small light-element library, since these data are from more recent sources ${ }^{2,4}$ than those data originally in the small library.

Cross sections for ${ }^{129} I$ were transferred from the original small fission-product library to the large (now the only) fission-product library for the HTGR and MSBR, since the large library had no data for these cases.

When data were transferred from the large to the small libraries, the transfers were performed only for those nuclides originally in the small libraries. No nuclides were added. As mentioned earlier in Sect. M6.2.2, 13 muclides from the small light-element library were added to the original large light-element library during the updating.

The net result of all the transfers of cross-section data was to make the small light-element library a subset of the large light-element library. Now, the small libraries have been retired.

Later, cross-section data for ${ }^{133} \mathrm{Cs}$ were replaced for the HTGR, LWR, and MSBR in the large lightelement and fission-product libraries. Values of the thermal $(2200 \mathrm{~m} / \mathrm{s})(\mathrm{n}, \gamma)$ cross section and the $(\mathrm{n}, \gamma)$ resonance integral were taken from an ENDF/B-V compilation. ${ }^{24}$ For the LWR only, those cross sections were adjusted slightly to give an effective one-group $(n, \gamma)$ cross section of $117 \mathrm{~b}$ for ${ }^{133} \mathrm{Cs}$ when used with the 
"typical" values of 0.632 for THERM and 0.333 for RES. This one-group cross section is more representative of a modern LWR than the old value, which consistently led to an overestimate of the afterheat power from ${ }^{134}$ Cs.

The value of FINP for ${ }^{3} \mathrm{He}$ in the old light-element libraries was erroneously given as zero. The correct value of 1.0 was used for the new libraries.

The values of $(n, \alpha)$ cross sections for the HTGR and LWR in the old light-element libraries were replaced for the following 11 maclides: ${ }^{1} \mathrm{H},{ }^{2} \mathrm{H},{ }^{6} \mathrm{Li},{ }^{7} \mathrm{Li},{ }^{9} \mathrm{Be},{ }^{10} \mathrm{~B},{ }^{11} \mathrm{~B},{ }^{12} \mathrm{C},{ }^{14} \mathrm{~N},{ }^{16} \mathrm{O}$, and ${ }^{19} \mathrm{~F}$. The sum of the $(n, \alpha)$ and the $(n, 2 n)$ cross sections from the original reference ${ }^{25}$ had been misinterpreted as just the $(n, \alpha)$ cross section, leading to erroneously high values for the $(n, \alpha)$ cross sections in the libraries. New cross-section data were taken either from a compilation ${ }^{26}$ of ENDF/B-IV thermal cross sections and resonance integrals or from a collapse of the SCALE 218-group library (Sect. M4). A 1/E weighting in the resonance region and a fission spectrum weighting in the fast region were used for the collapse.

The thermal cross sections and resonance integrals for the $(n, \gamma)$ and (n,fission) reactions were updated for the following muclides in the actinide library: ${ }^{242 \mathrm{Am}} \mathrm{Am}{ }^{242} \mathrm{Am},{ }^{242} \mathrm{Cm},{ }^{243} \mathrm{Cm}$, and ${ }^{245} \mathrm{Cm}$. New values were placed in the library for the HTGR, LWR, and MSBR. The new data were taken from an ENDF/B-V compilation. ${ }^{24}$ Cross sections for these nuclides are often not updated before running an ORIGEN-S case, and the new values should give better nuclide concentrations and neutron sources than those from the old actinide library.

\section{M6.2.8 SPECIAL TREATMENT OF CERTAIN NUCLIDES}

The data for certain muclides in the ORIGEN-S card-image nuclear data libraries are not the same as the data taken from the original sources. Because this situation is potentially confusing to the user, explanations of these cases are presented here.

The first special case is that of the fictitious nuclide ${ }^{4} \mathrm{H}$. This nuclide has been added to the lightelement library, so the following reaction can be represented for the HTGR and LWR:

$$
{ }_{3}^{7} \mathrm{Li}+{ }_{0}^{1} \mathrm{n}-{ }_{1}^{3} \mathrm{H}+{ }_{2}^{4} \mathrm{He}+{ }_{0}^{1} \mathrm{n} \text {. }
$$

Since this fictitious nuclide is represented as being stable with a large $\left(9.9 \times 10^{10} \mathrm{~b}\right)(\mathrm{n}, 2 \mathrm{n})$ cross section, the reaction of Eq. (M6.2.20) can be represented by the following two reactions:

$$
\begin{aligned}
& { }_{3}^{7} \mathrm{Li}+{ }_{0}^{1} \mathrm{n} \rightarrow{ }_{1}^{4} \mathrm{H}+{ }_{2}^{4} \mathrm{He}, \\
& { }_{1}^{4} \mathrm{H}+{ }_{0}^{1} \mathrm{n} \rightarrow 2{ }_{0}^{1} \mathrm{n}+{ }_{1}^{3} \mathrm{H} .
\end{aligned}
$$

If the reaction of Eq. (M6.2.21) is given the same cross section as that of Eq. (M6.2.20), then the sum of the reactions of Eqs. (M6.2.21) and (M6.2.22) is a good approximation of the reaction in Eq. (M6.2.20).

The second special case is that of ${ }^{92} \mathrm{Nb}$ in the light-element library. The decay data shown for ${ }^{92} \mathrm{Nb}$ are actually the data for ${ }^{92 \mathrm{~m}} \mathrm{Nb}$, which is formed by the reaction

$$
{ }_{42}^{92} \mathrm{Mo}+{ }_{0}^{1} \mathrm{n} \rightarrow{ }_{1}^{1} \mathrm{H}+{ }_{41}^{92 m} \mathrm{Nb} \text {. }
$$

Since there is no provision for representing an $(\mathrm{n}, \mathrm{p})$ reaction leading to a metastable product nuclide, ${ }^{92 \mathrm{~m}} \mathrm{Nb}$ has been represented as ${ }^{22} \mathrm{Nb}$.

NUREG/CR-0200,

Vol. 3, Rev. 4

M6.2.14 
The third special treatment of certain nuclides involves the request for the option to solve for the time integral of fission-product concentrations (Sect. F7.2.7) during the decay-only type of time interval. The option is requested in ORIGEN-S input by specifying a nonzero value for NVERT, the 32nd entry in the $3 \$$ data array (Sect. F7.6.10). Programming considerations required that fission-product nuclides do not decay by the $(\beta, n)$ or the $\alpha$ modes of decay. If the integral option is requested, the code sets the $\alpha$ decay and the $(\beta, n)$ decay branching fractions to zero when processing the card-image libraries and does not change other branching fractions of the decay of the muclide. The option is not permitted during irradiation, when the $(\beta, n)$ emission can be important. Following the first hour after a reactor power shutdown, the nuclides that have $(\beta, n)$ emission have diminished to insignificance because their half-lives do not exceed 1 minute. The fission products that decay by $\alpha$ emission are ${ }^{142} \mathrm{Ce},{ }^{144} \mathrm{Nd},{ }^{146} \mathrm{Sm},{ }^{147} \mathrm{Sm},{ }^{148} \mathrm{Sm},{ }^{149} \mathrm{Sm}$, and ${ }^{152} \mathrm{Gd}$. The shortest halflife of these nuclides (for ${ }^{146} \mathrm{Sm}$ ) exceeds $10^{8}$ years. 


\section{M6.3 CARD-IMAGE PHOTON YIELD LIBRARIES}

The original card-image photon yield libraries for ORIGEN ${ }^{1}$ contained multigroup photon yields (photons per disintegration) for decay gamma and $\mathrm{X}$ rays, for bremsstrahlung from decay beta rays slowing down in a $\mathrm{UO}_{2}$ fuel matrix, and for some gammas accompanying $(\alpha, n)$ reactions in oxide fuels. The yields for light elements and fission products were given in the 12-group structure of the PHOEBE code. ${ }^{27}$ For the actinide library, the lowest energy group was divided into seven smaller groups with energies down to $20 \mathrm{keV}$, giving 18 groups in all. The group structures are shown in Table M6.3.1.

Table M6.3.1. Group structures for original photon yield libraries

\begin{tabular}{|c|c|c|c|}
\hline \multicolumn{2}{|c|}{ Group number } & \multirow{2}{*}{$\begin{array}{c}\text { Lower energy } \\
(\mathrm{MeV})\end{array}$} & \multirow{2}{*}{$\begin{array}{c}\text { Average energy } \\
(\mathrm{MeV})\end{array}$} \\
\hline LE,FP & ACT & & \\
\hline & 1 & 0.020 & 0.03 \\
\hline & 2 & 0.035 & 0.04 \\
\hline & 3 & 0.050 & 0.06 \\
\hline & 4 & 0.075 & 0.10 \\
\hline & 5 & 0.125 & 0.15 \\
\hline & 6 & 0.175 & 0.20 \\
\hline 1 & 7 & $0.2^{a}, 0.25^{b}$ & 0.30 \\
\hline 2 & 8 & 0.400 & 0.63 \\
\hline 3 & 9 & 0.900 & 1.10 \\
\hline 4 & 10 & 1.350 & 1.55 \\
\hline 5 & 11 & 1.800 & 1.99 \\
\hline 6 & 12 & 2.200 & 2.38 \\
\hline 7 & 13 & 2.600 & 2.75 \\
\hline 8 & 14 & 3.000 & 3.20 \\
\hline 9 & 15 & 3.500 & 3.70 \\
\hline 10 & 16 & 4.000 & 4.22 \\
\hline 11 & 17 & 4.500 & 4.70 \\
\hline 12 & 18 & $\begin{array}{c}5.000 \\
10.000^{c}\end{array}$ & 5.25 \\
\hline
\end{tabular}

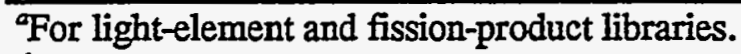

${ }^{b}$ For actinide library.

Upper limit of last group.

These group structures are programmed directly into ORIGEN-S and COUPLE, which can still read the original photon yield libraries.

There are three card-image photon yield libraries which were generated specifically for ORIGEN-S: (1) a light-element library for 324 nuclides, (2) an actinide library for 114 nuclides, and (3) a fission-product library for 298 nuclides. The photon yields in these libraries include decay gamma and X rays, prompt and equilibrium fission-product gamma rays from spontaneous fission, gamma rays accompanying $(\alpha, n)$ reactions in oxide fuel, and bremsstrahlung from decay beta rays slowing down in a $\mathrm{UO}_{2}$ fuel matrix. The light-element and fission-product photon yields were generated in a 12-group structure, and the actinide photon yields are given in an 18-group structure. Both group structures are shown in Table M6.3.2. 
Table M6.3.2 Group structures for ORIGEN-S photon yield libraries

\begin{tabular}{|c|c|c|c|}
\hline \multicolumn{2}{|c|}{ Group No. } & $\begin{array}{c}\text { Lower energy } \\
(\mathrm{MeV})\end{array}$ & $\begin{array}{c}\text { Average energy } \\
(\mathrm{MeV})\end{array}$ \\
\hline & 1 & 0.00 & 0.02 \\
\hline & 2 & 0.02 & 0.04 \\
\hline & 3 & 0.04 & 0.07 \\
\hline & 4 & 0.07 & 0.10 \\
\hline & 5 & 0.10 & 0.14 \\
\hline & 6 & 0.14 & 0.20 \\
\hline 1 & 7 & 0.20 & 0.40 \\
\hline 2 & 8 & 0.40 & 0.90 \\
\hline 3 & 9 & 0.90 & 1.35 \\
\hline 4 & 10 & 1.35 & 1.80 \\
\hline 5 & 11 & 1.80 & 2.20 \\
\hline 6 & 12 & 2.20 & 2.60 \\
\hline 7 & 13 & 2.60 & 3.00 \\
\hline 8 & 14 & 3.00 & 3.50 \\
\hline 9 & 15 & 3.50 & 4.00 \\
\hline 10 & 16 & 4.00 & 4.50 \\
\hline 11 & 17 & 4.50 & 5.00 \\
\hline 12 & 18 & 5.00 & 6.00 \\
\hline
\end{tabular}

The lower energy bounds for the light-element and fission-product libraries are the same as in the original ORIGEN libraries (Table M6.3.1). For the actinide library, the lower bounds are the same as in the original library for groups 8 to 18 , but the group bounds have been revised for the seven lowest energy groups. The revised boundaries were chosen to give a relatively flat spectrum in these low energy groups.

On an IBM mainframe, the card-image libraries can be referenced by a single logical unit number with different FORTRAN sequence numbers (FTnnF004 to FTnnF006 for the photon libraries) or by different logical unit mumbers. The standard setup for all computers is for the three nuclear data libraries and the three photon yield libraries to reside in a single data file, separated by blank cards, and to be referenced by a single logical unit number.

If the input variable INPT (Sect. F7.6.10) is one, the photon yield libraries will be read from cards in the input stream. In this case, each of the three libraries must be followed by one or more blank cards (determined from the format required to read the library) to indicate the end of the library.

Note that the user can generate his own card-image photon yield libraries by the use of various options in ORIGEN-S (Sect. F7.6.10). Because of programming considerations, the number of energy groups in the light-element and fission-product libraries must be less than or equal to 12 , and the number of groups in the actinide library must be in the range 10 to 18 . Any energy group boundaries can be used.

Other ORIGEN-S options (Sect. F7.6.10) allow multigroup photon yield data to be placed in a binary data library (Sect. M6.7). In a binary data library, there are no limits on the number of energy groups which can be used.

The remainder of this section is devoted to describing (1) the data formats for the original libraries and for the ORIGEN-S photon libraries and (2) the data source for the ORIGEN-S libraries.

NUREG/CR-0200,

Vol. 3, Rev. 4

M6.3.2 


\section{M6.3.1 FORMATS}

following:

The photon yields are read from the card-image libraries with a READ statement such as the

READ(NDSET, FOR, END=350) NUCLID，(GFRAC(N), N=1, NGP)

where NUCLID is the muclide identification number of Eq. (M6.2.1), GFRAC(N) is the yield in group N, and NGP is the number of groups. The READ statement used for photon libraries in the input stream does not have the "END $=$ " option. The FORMAT used is given in array FOR and varies according to the library being read. The FORMATS used for the original ORIGEN libraries are given in Table M6.3.3.

Table M6.3.3 FORMATS for original photon yield libraries

\begin{tabular}{ll}
\hline \multicolumn{1}{c}{ Library } & \multicolumn{1}{c}{ FORMAT } \\
\hline Light element or fission product & $(\mathrm{I6,12F6.4)}$ \\
Actinide & $(16,9 \mathrm{E} 8.2,2 \mathrm{X} / 6 \mathrm{X}, 9 \mathrm{E} 8.2)$ \\
\hline
\end{tabular}

If the value of NUCLID on the first card is negative, subroutine XPHOLB assumes that an ORIGEN-S photon yield library is being used. The number of groups is -NUCLID. The FORMAT to be used in the READ statement above is then read in with the following statements:

READ(NDSET, 11000) FOR

11000 FORMAT (18A4)

The FORMAT read into array FOR is read from the second card of an ORIGEN-S light-element or fissionproduct library. In an ORIGEN-S actinide photon library, the second card is ignored, and the FORMAT of array FOR is read from the third card.

Once the proper FORMAT has been set, the remaining cards of a photon yield library are read by the first READ statement given above, for both the original ORIGEN and the ORIGEN-S libraries.

Any format compatible with the number of energy groups can be used for an ORIGEN-S photon yield library. The current ORIGEN-S libraries were generated by ORIGEN-S itself, using the FORMATS shown in the following table.

Table M6.3.4 FORMATS for current ORIGEN-S photon yield libraries

\begin{tabular}{ll}
\hline \multicolumn{1}{c}{ Library } & \multicolumn{1}{c}{ FORMAT } \\
\hline Light element & $(16,6 \mathrm{E} 12.5,2 \mathrm{X} / 6 \mathrm{X}, 6 \mathrm{E} 12.5)$ \\
Actinide & $(16,6 \mathrm{E} 12.5,2 \mathrm{X} / 6 \mathrm{X}, 6 \mathrm{E} 12.5,2 \mathrm{X} / 6 \mathrm{X}, 6 \mathrm{E} 12.5)$ \\
Fission product & $(16,6 \mathrm{E} 12.5,2 \mathrm{X} / 6 \mathrm{X}, 6 \mathrm{E} 12.5)$ \\
\hline
\end{tabular}




\section{M6.3.2 SOURCE OF DATA}

The ORIGEN-S card-image photon yield libraries were generated by ORIGEN-S itself from data in the ORNL Master Photon Data Base described in Sect. M6.5.

As an aid to those who may wish to generate their own libraries, and for completeness in documentation, the ORIGEN-S input data to generate these libraries are presented below:

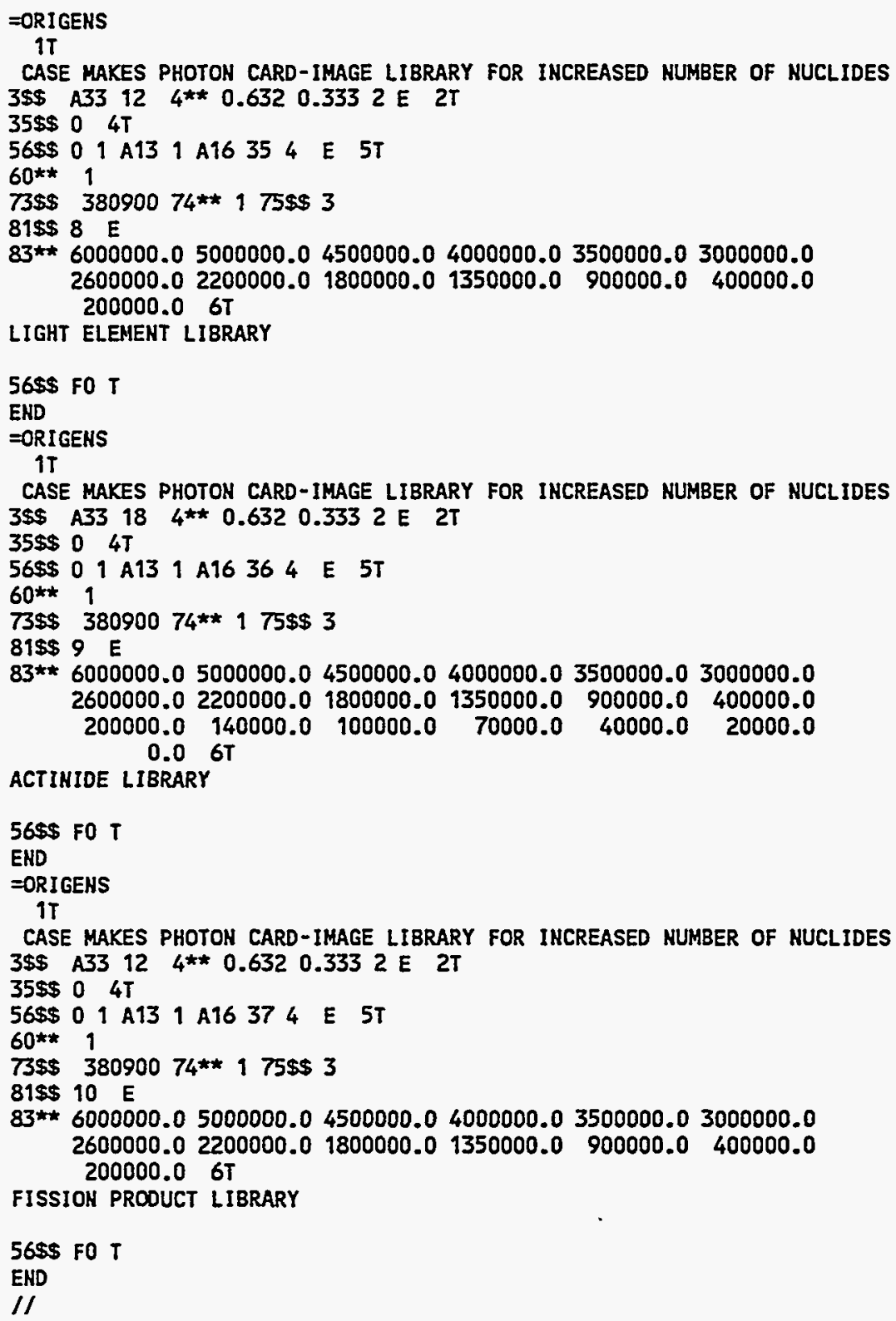

All three cases shown in the input data are run back to back. Each case simulates a 1-second decay of some nuclide in the library of interest since ORIGEN-S must perform some calculation before generating a new library. The large light-element, actinide, and fission-product nuclear data libraries are read on logical unit

NUREG/CR-0200,

Vol. 3, Rev. 4 
28. The card-image master photon data base for these runs was formed by concatenating the data sets for (1) decay gamma and $\mathrm{X}$ rays, (2) gamma rays accompanying spontaneous fission and ( $\alpha, n)$ reactions, (3) bremsstrahlung for negatrons slowing down in $\mathrm{UO}_{2}$. This card-image master photon data base is read on logical unit 60. The light-element, actinide, and fission-product card-image photon yield libraries are written on logical units 35, 36, and 37, respectively. Further details of the input data may be found by studying Sect. F7.6 of the ORIGEN-S documentation.

When the data from the ORNL Master Photon Data Base ${ }^{11}$ (Sect. M6.5) are converted to multigroup yields by ORIGEN-S, the intensities of the photons are adjusted to conserve energy by using the following equation:

$$
I_{g}=I_{a}\left(E_{s} / E_{g}\right)
$$

where

$$
\begin{aligned}
& \mathrm{I}_{\mathrm{g}}=\text { group photon intensity (photons per disintegration), } \\
& \mathrm{I}_{2}=\text { actual photon intensity from the ORNL Master Photon Data Base (photons per disintegration), } \\
& \mathrm{E}_{2}=\text { actual photon energy (MeV), } \\
& \mathrm{E}_{\mathrm{g}}=\text { average energy of the group }(\mathrm{MeV}) .
\end{aligned}
$$

The intensities are adjusted to ensure conservation of the photon energy release rates calculated by ORIGEN-S. 


\section{M6.4 DATA PROGRAMMED INTO ORIGEN-S AND COUPLE}

Several items of muclear data are programmed directly into ORIGEN-S and COUPLE. Descriptions of these data are presented here. Although these data are not part of the ORIGEN-S libraries, the user may on occasion wish to change these data or to understand explicitly how they are used.

The arrays EACTGP and EGROUP are defined by DATA statements in subroutine FLXDIM in ORIGEN-S and in subroutine CARDIM in COUPLE. The array EACTGP contains the average energies of the 18 groups in the original card-image actinide photon yield library. The array EGROUP contains the average energies of the 12 groups in the original card-image light-element and fission-product photon yield libraries. These are the average energies of Table M6.3.1. Note that the arrays EACTGP, EGROUP, and EFPGRP can be read as imput data in the 36*, 37*, and 39* arrays of ORIGEN-S (Sect. F7.6.10) or COUPLE (Sect. F6.5.8). When read as input data, these arrays contain the energy group boundaries (not the average group energies) for the card-image light-element, actinide, and fission-product photon yield libraries. These data should be read in only when the user has made his own card-image photon yield libraries to be read using the original ORIGEN library FORMATS of Table M6.3.3, and then only if different energy group boundaries have been used. These data should not be read when photon yield libraries with the new ORIGEN-S variable FORMATS are used.

A number of data in the ORIGEN-S COMMON/SPECDT/ are defined by DATA statements in the BLOCK DATA ORGENS subroutine of ORIGEN-S. These data, used in the calculation of spontaneous fission and $(\alpha, n)$ neutron sources in $\mathrm{UO}_{2}$ (Sect. F7.2.8), are described below in their order of appearance in the COMMON block.

1. The variable NGAL is the number of energy groups in which neutron spectra data are provided for $(\alpha, n)$ neutron sources due to ${ }^{242} \mathrm{Cm},{ }^{244} \mathrm{Cm}$, and ${ }^{238} \mathrm{Pu}$.

2. The variable NGSP is the number of energy groups in which neutron spectra data are provided for spontaneous fission neutron sources from ${ }^{242} \mathrm{Cm}$ and ${ }^{244} \mathrm{Cm}$.

3. The array GRPAL contains the energy group boundaries (MeV) for neutron spectra from $(\alpha, n)$ reactions.

4. The array GRPSP contains the energy group boundaries (MeV) for neutron spectra from spontaneous fission.

5. The array SA38 contains the neutron spectrum from $(\alpha, n)$ reactions due to alpha decays in ${ }^{238} \mathrm{Pu}$.

6. The array SA42 contains the neutron spectrum from $(\alpha, n)$ reactions due to alpha decays in ${ }^{242} \mathrm{Cm}$.

7. The array SA44 contains the neutron spectrum from $(\alpha, n)$ reactions due to alpha decays in ${ }^{244} \mathrm{Cm}$.

8. The array $S S 42$ contains the neutron spectrum from spontaneous fission of ${ }^{242} \mathrm{Cm}$.

9. The array SS44 contains the neutron spectrum from spontaneous fission of ${ }^{244} \mathrm{Cm}$.

10. The array EALPH contains the mean alpha energies (MeV) for those actinides which decay by alpha emission.

11. The array FA contains the alpha decay branching fractions for the actinides.

12. The array SPONU contains the values of the spontaneous fission yield, $v_{\mathrm{SF}}$, for those actinides that have measured data.

13. The array HALFSP contains spontaneous fission half-lives (years) for a number of actinides.

14. The array AEK contains data for an empirical formula used to estimate the spontaneous fission yield for those actinides having no measured value of $v_{\mathrm{SF}}$. 
Data having the same variable names as those in COMMON/SPECDT/ are also present in COMMON/SPEBOR/. They are defined by DATA statements in the BLOCK DATA BORSIL subroutine of ORIGEN-S. These data are used in the calculation of $(\alpha, n)$ neutron sources in borosilicate glass.

The arrays YLD1, YLD2, YLD3, YLD4, and YLD5 from COMMON/NEUTYL/ of ORIGEN-S are defined in the BLOCK DATA BORSIL subroutine. These arrays contain spectrally dependent $(\alpha, n)$ neutron yields in borosilicate glass for the 54 lightest elements in the ORIGEN-S libraries.

The arrays ST1, ST2, ST3, ST4, ST5, and ST6 from COMMON/STPOWR/ of ORIGEN-S are also defined in the BLOCK DATA BORSIL subroutine. They contain spectrally dependent stopping power data for alpha particles for the 99 elements in the ORIGEN-S libraries.

The array MSRS in subroutine FLXDI1 in ORIGEN-S, and in subroutine CARDIM in COUPLE, contains the identification mumbers of the fissionable muclides which have fission-product yield data in the cardimage nuclear data libraries (Table M6.2.7).

A mumber of arrays defined by DATA statements in subroutine POWERF in ORIGEN-S contain data used to compute the recoverable energy (MeV per fission) for converting power to flux. The array IDL contains the identification numbers of ten light-element nuclides having values of recoverable energy per neutron capture in the array QCLIT. The array QNFISS contains values of recoverable energy per (n,fission) reaction for 30 actinides whose identification numbers are given in array IDA. The array QCACT contains values of recoverable energy per neutron capture for the same 30 actinides. The array IDF has identification numbers for 30 fission products whose values of recoverable energy per neutron capture are given in the array QCFPR. The recoverable energy values in arrays QCLIT, QCACT, QNFISS, and QCFPR were taken primarily from ENDF. ${ }^{5,6}$ The recoverable energy per neutron capture is assumed to be $5.0 \mathrm{MeV}$ for all nuclides for which data are not given in the DATA statements.

Finally, the arrays YTNEUT, YRNEUT, and YFNEUT are defined by DATA statements in subroutine XNUDAT in ORIGEN-S and in COUPLE. These arrays contain values of $v$ (neutrons per fission) for the thermal, resonance, and fast energy groups, respectively, for all 129 nuclides. These values are used in ORIGEN-S if the option to compute the infinite medium neutron multiplication factor has been invoked. The user has the option to read in his own values as input data in the $121^{*}, 122^{*}$, and 123* arrays of ORIGEN-S (Sect. F7.6.10).

NUREG/CR-0200,

Vol. 3, Rev. 4
M6.4.2 


\section{M6.5 MASTER PHOTON DATA BASE}

The ORNL Master Photon Data Base ${ }^{11}$ was originally developed for the ORIGEN2 code. It is maintained as six card-image data sets for ease in updating. However, ORIGEN-S can be used (Sect. F7.6.10) to create a binary (unformatted) master photon data base for use in subsequent ORIGEN-S runs. It has been customary at ORNL to run ORIGEN-S with a binary master photon data base, since execution is somewhat more efficient for that mode of operation. The ORNL Master Photon Data Base is the most comprehensive and up-to-date photon library available to ORIGEN-S. It can be used (Sect. F7.6.10) to generate multigroup photon source spectra, to make card-image photon yield libraries, or to update photon yield data in a binary data library. The spectra and photon yield data can be generated in any energy group structure for all lightelement, actinide, and fission-product nuclides having photon data. The ORNL Master Photon Data Base is described in detail in Ref. 11. The remainder of this section is devoted to a summary description of the formats, data sources, and uses of this data base.

\section{M6.5.1 CARD-IMAGE DATA BASES}

There are six card-image data sets for six categories of photon sources. The first data set contains decay gamma and X-ray line data from ENSDF. 15,16

The second data set contains spectra for gamma rays accompanying spontaneous fission and for gamma rays accompanying $(\alpha, n)$ reactions in oxide fuels. The combined spectra for prompt and equilibrium fission-product gamma rays from spontaneous fission are computed from the following approximation: ${ }^{11}$

$$
\begin{array}{rlrl}
\mathrm{N}(\mathrm{E}) & \approx 11.5 & , & 0.1 \leq \mathrm{E} \leq 0.6 \mathrm{MeV}, \\
& \approx 35.4 \exp (-1.78 E), & 0.6 \leq \mathrm{E} \leq 1.5 \mathrm{MeV}, \\
& \approx 12.6 \exp (-1.09 E), & 1.5 \leq \mathrm{E} \leq 10.5 \mathrm{MeV}, \\
& \simeq 0 \quad, \mathrm{E}<0.1 ; \mathrm{E}>10.5 \mathrm{MeV},
\end{array}
$$

where

$$
\mathrm{N}(\mathrm{E})=\text { number of photons per unit energy per fission (photons } \mathrm{MeV}^{-1} \text { per fission) at energy } \mathrm{E} \text {, }
$$

and

$$
\mathrm{E}=\text { photon energy }(\mathrm{MeV}) \text {. }
$$

The spectrum of gamma rays accompanying $(\alpha, n)$ reactions is computed from the following approximation: ${ }^{11}$

$$
\mathrm{N}(\mathrm{E}) \simeq 2.13 \times 10^{-8} \exp (-1.38 \mathrm{E}),
$$

where

$$
\begin{aligned}
& N(E)= \text { number of photons per unit energy per alpha decay (photons } \mathrm{MeV}^{-1} \text { per } \\
& \text { disintegration) at energy } \mathrm{E} \text {, }
\end{aligned}
$$


and

$$
\mathrm{E}=\text { photon energy }(\mathrm{MeV})
$$

Two data sets contain bremsstrahlung spectra from decay negatrons and positrons slowing down in a $\mathrm{UO}_{2}$ fuel matrix. The last two data sets contain bremsstrahlung spectra from decay negatrons and positrons slowing down in water. According to Ref. 11, all bremsstrahlung spectra were calculated using a computer program developed by Dillman et al. ${ }^{28}$ using beta spectra derived from ENSDFF' decay data with a computer program written by Gove and Martin. ${ }^{29}$

The six data sets described above can be concatenated in any user-chosen combination to form a cardimage master photon data base for use with ORIGEN-S. All six data sets are constructed in the same cardimage format. The data are read in subroutine GSMAST of ORIGEN-S by READ and FORMAT statements such as

\footnotetext{
READCNLIB, $10000, E N D=320)$ NUC, $(R E(J), R I(J), J=1,3)$ 1000 FORMAT $(16,4 X, 6 F 10.0)$.
}

In the READ statement, NUC is the nuclide identification number, RE is the photon energy (MeV), and RI is the photon intensity (photons per disintegration).

There are several cards for each nuclide. The first card contains a nonzero value of NUC, and zero values for all the RE and RI entries. The remaining cards for a nuclide contain a zero entry for NUC and nonzero entries for the RE and RI values. These cards are repeated until all photon data for a nuclide have been given.

\section{M6.5.2 BINARY DATA BASES}

As mentioned earlier, a binary master photon data base can be created by ORIGEN-S from any combination of the six card-image data sets. All data in a binary master photon data base are read in subroutine GSMAST of ORIGEN-S by the following unformatted READ statement:

READ(NLIB, END=310) NUC, LINES, (RE(J), RI(J), J=1, LINES).

In this READ statement, LINES is the total number of entries for the nuclide. The variables NUC, RE, and RI have the same meanings as for a card-image master photon data base.

Three binary master photon data bases have been generated for use at ORNL. Each contains decay gamma and X-ray line data and the spectra for gamma rays accompanying spontaneous fission and $(\alpha, n)$ reactions. One contains no bremsstrahlung data, another contains bremsstrahlung spectra for a $\mathrm{UO}_{2}$ fuel matrix, and the last contains bremsstrahlung spectra for a water medium.

The ORIGEN-S input data to create a binary master photon data base are given below. A card-image master photon data base of the user's choice is read on logical unit 60 . The card-image data base is then converted to a binary master photon data base written on logical unit 35 . The large light-element, actinide, and large fission-product card-image nuclear data and photon yield libraries are read on logical unit 28. Details of the input data can be determined by studying Sect. F7.6.10 of the ORIGEN-S documentation. 
=ORIGENS

$0 \$ \$ A 4$ A 028 A9 60 A11 35 E 1 T

ORIGEN-S CARD-IMAGE NUCLEAR DATA LIBRARIES

$3 \$ \$ 28 \quad A 33 \quad 12 \quad E$

$4 * * 0.632 \quad 0.333 \quad 2$ E $2 T$

$4 \mathrm{~T}$

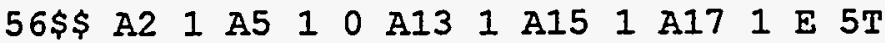

DECAY OF U238 FOR 1 SECOND

$60 * * 1 \quad 73 \$ \$ 92238074 * * 175 \$ 2 \quad 81 \$ \$ 15 \mathrm{E}$ 6T

MAKING BINARY MASTER PHOTON DATA BASE

$1 \$ \$ 0 ~ 1 T$

END 


\section{M6.6 ENDF/B-IV FISSION-PRODUCT DATA BASE}

The ENDF/B-IV fission-product data base contains fission-product decay data in ENDF/B-IV cardimage (BCD) format. ${ }^{13}$ These data were processed from file (MF) 1 , reaction type (MT) 457 data of the ENDF/B-IV fission-product tapes. ${ }^{5}$

This library can be used by ORIGEN-S (Sect. F7.6.10) to generate multigroup fission-product photon source spectra, to make a card-image photon yield library for fission products, or to make a binary (unformatted) photon yield library for fission products. Any energy group structure can be used for a source spectrum or photon yield library.

A description of the data variables and formats can be found in Ref. 13. The header records of the ENDF/B-IV fission-product tapes ${ }^{5}$ give the sources of the decay data.

These data are normally not used since the Master Photon Data Base described in the preceding section contains newer and more complete data. The user should note that the routines which read these data will not work for decay data in $\mathrm{ENDF} / \mathrm{B}-\mathrm{V}^{6}$ or $\mathrm{ENDF} / \mathrm{B}-\mathrm{VI}^{10}$ formats. 


\section{M6.7 BINARY ORIGEN-S DATA LIBRARIES}

The use of a binary data library is perhaps the most significant feature of ORIGEN-S. A binary data library is made or updated with the COUPLE code (Sect. F6). It contains, in a single library, the same kinds of data as the card-image nuclear data and photon yield libraries, but for only one reactor type. The ORIGEN-S code is normally run with one or more (time-dependent) binary data libraries for the reactor type of interest, since a binary data library has many advantages over the card-image libraries. Its principal advantage is that the cross sections in the library can be replaced by cross sections derived from a detailed multigroup neutronics (e.g., unit cell) calculation. Cross-section updating is performed by COUPLE, which reads the multigroup cross sections from an $\mathrm{AMPX}^{12}$ weighted (working) cross-section library (Sect. F2.3.8). Automated generation of a multitime-dependent (i.e., multiburnup-dependent) binary data library can be performed with the SAS2 control module (Sect. S2) which invokes the BONAMI, NITAWL, XSDRNPM, COUPLE, and ORIGEN-S codes (Sects. F1, F2, F3, F6, and F7, respectively). Another advantage is that any portion of the photon yield data from the ORNL Master Photon Data Base can be placed in the binary data library with any energy group structure. In addition, any item of data other than $v$ in a binary data library can be replaced by a user-specified value by using COUPLE (Sect. F6.5.8).

The remainder of this section gives the description and formats of the two kinds of binary data libraries, as well as the input data necessary to generate some of the binary data libraries in use at ORNL.

\section{M6.7.1 DESCRIPTION}

There are two kinds of binary data libraries. A binary master library contains all the kinds of data present in the card-image muclear data and photon yield libraries for a single reactor type. It does not contain one-group flux-weighted cross sections, so it cannot be used as an input library to run ORIGEN-S. A master library can be made by direct conversion from card-image libraries or by updating another master library using COUPLE with card-image data input by the user.

A binary working library contains all the data of a master library. In addition, it contains effective one-group flux-weighted cross sections that apply at one or more burnups so it can be used as an input library to run ORIGEN-S. It can be made by direct conversion from card-image libraries, by direct conversion from a master library, by updating either form of binary library with data input from card images, or by updating either form of binary library with cross sections from an AMPX weighted cross-section library. A multiburnup binary working library may be produced by the SAS2 control module (Sect. S2) of SCALE.

Every binary data library has a library identification mumber given by the variable NEWID. A master library has a value of NEWID $<950$. A working library has a value of NEWID $>1000$.

A binary data library is subdivided (unless deleted by special options) into three kinds of libraries: Library 1 for light elements, Library 2 for actinides, and Library 3 for fission products. The designations of Library 1,2, or 3 are used in the discussion of different updating options in COUPLE (Sect. F6.5.8).

Additional details about the definitions, uses, and updating of binary data libraries are given in Sect. F6.5 of the COUPLE documentation.

\section{M6.7.2 FORMATS}

A master library contains 36 binary (unformatted) records; at least 40 binary records are found in a working library. A working library is identical to a master library except for the addition of at least four 
records containing effective one-group flux-weighted data. A working library produced by converting a cardimage library contains only one set of an additional four records. However, if the library is produced during a SAS2 case, there is an additional set of four records for each burnup interval or cycle specified in the power history input to the SAS2 case.

The first records of a binary data library contain the header information described in Table M6.7.1. A summary description of the data in all the records of a binary data library is given in Table M6.7.2. Most of these data have been described in earlier sections of this report.

Table M6.7.1 Data in first record of binary data library

\begin{tabular}{ll}
\hline Variable name & \multicolumn{1}{c}{ Description } \\
\hline ITOT or ITMAX & Total number of nuclides in library \\
IITE or ILMAX & Number of light-element nuclides in library \\
IACT or IAMAX & Number of actinide nuclides in library \\
IFP or IFMAX & Number of fission-product nuclides in library \\
NON or IZMAX & Number of nonzero off-diagonal elements in the transition \\
& matrix \\
NREACT & Maximum number of transitions for any single nuclide \\
NFISO & Number of fissionable nuclides for which fission-product yields \\
& are given \\
NELEM & Largest atomic number of nuclides in library \\
NMO & Month library was made \\
NDAY & Day of month library was made \\
NYR & Year library was made \\
NENAC & Number of energy groups for actinide photon yields \\
NENLE & Number of energy groups for light-element photon yields \\
NENFP & Number of energy groups for fission-product photon yields \\
THERM & Thermal group flux weighting factor \\
RES & Resonance group flux weighting factor \\
FAST & Fast-group flux weighting factor \\
ERR & Truncation error limit below which values computed by \\
IDREFS & ORIGEN-S are considered to be zero \\
& ID number of nuclide in AMPX weighted cross-section library \\
NEWID & containing the weighting spectrum used to obtain the flux \\
& weighting factors THERM, RES, and FAST \\
\hline
\end{tabular}


Table M6.7.2 Structure of binary data library

\begin{tabular}{|c|c|c|c|}
\hline \multicolumn{2}{|c|}{ Record length ${ }^{a}$} & \multirow{2}{*}{ Array } & Description \\
\hline 1 & 20 & & Header information of Table M6.7.1 \\
\hline 2 & $20 * \mathrm{NTIT}^{b}$ & TITLE & Title cards containing descriptive information \\
\hline 3 & NFISO & NUCFIS & $\begin{array}{l}\text { ID numbers of fissionable nuclides having fission- } \\
\text { product yields }\end{array}$ \\
\hline 4 & $3 *$ NFISO & SIGFIS & $\begin{array}{l}\text { Three-group fission cross sections for nuclides in } \\
\text { NUCFIS array in the order ((SIGFIS(N,I), } \\
N=1,3), I=1, N F I S O)\end{array}$ \\
\hline 5 & ITOT & NUCL & I numbers for all nuclides in library \\
\hline 6 & ITOT & $\mathrm{KD}^{\circ}$ & $\begin{array}{l}\mathrm{KD}(\mathfrak{)}) \text { is the number of parents for production of } \\
\text { nuclide I by decay transitions }\end{array}$ \\
\hline 7 & ITOT & NONO ${ }^{c}$ & $\begin{array}{l}\text { NONO(I) is the total number of parents for } \\
\text { nuclide I }\end{array}$ \\
\hline 8 & NON & LOC $^{c}$ & $\begin{array}{l}\text { LOC(J) is the position in array NUCL of the } \\
\text { parent of the transition stored in position J of the } \\
\text { compressed transition matrix A }\end{array}$ \\
\hline 9 & NON & $A_{1}^{c}$ & $\begin{array}{l}\text { Compressed transition matrix for thermal group } \\
\text { neutron capture transitions }\end{array}$ \\
\hline 10 & ITOT & $\operatorname{TOCAP}_{1}^{c}$ & Thermal group total capture cross sections \\
\hline 11 & IACT & FISS $_{1}$ & Thermal group fission cross sections \\
\hline 12 & ILITE+IACT & GENNEU $_{1}$ & $\begin{array}{l}\text { Thermal group neutron yields, expressed as the } \\
\text { sum of the product of neutrons per capture } \\
\text { reaction times the capture cross section for that } \\
\text { reaction, summed over all neutron-producing } \\
\text { reactions }\end{array}$ \\
\hline 13 & NON & $A_{2}{ }^{c}$ & $\begin{array}{l}\text { Compressed transition matrix for resonance group } \\
\text { neutron capture transitions }\end{array}$ \\
\hline 14 & ITOT & $\operatorname{TOCAP}_{2}^{c}$ & Resonance group total capture cross sections \\
\hline 15 & IACT & FISS $_{2}$ & Resonance group fission cross sections \\
\hline 16 & ILITE+IACT & GENNEU $_{2}$ & Resonance group neutron yields \\
\hline 17 & NON & $\mathrm{A}_{3}{ }^{\mathrm{c}}$ & $\begin{array}{l}\text { Compressed transition matrix for fast group } \\
\text { neutron capture transitions }\end{array}$ \\
\hline 18 & ITOT & $\operatorname{TOCAP}_{3}{ }^{c}$ & Fast group total capture cross sections \\
\hline 19 & IACT & $\mathrm{FISS}_{3}$ & Fast group fission cross sections \\
\hline 20 & ILITE+IACT & $\mathrm{GENNEU}_{3}$ & Fast group neutron yields \\
\hline 21 & NON & $\mathrm{A}_{\lambda}{ }^{c}$ & Compressed transition matrix for decay transitions \\
\hline 22 & ITOT & Dİs & Radioactive decay constants \\
\hline $23^{e}$ & NON & $\mathrm{A}^{c, d}$ & $\begin{array}{l}\text { Compressed transition matrix for effective one- } \\
\text { group neutron capture transitions of first burnup and } \\
\text { for decay transitions }\end{array}$ \\
\hline $24^{e}$ & ITOT & TOCAP $^{c, d}$ & $\begin{array}{l}\text { Effective one-group capture cross sections of first } \\
\text { burnup }\end{array}$ \\
\hline $25^{e}$ & IACT & FISS $^{d}$ & $\begin{array}{l}\text { Effective one-group fission cross sections of first } \\
\text { burnup }\end{array}$ \\
\hline $26^{\circ}$ & ITOT+IACT & GENNEU $^{d}$ & Effective one-group neutron yields of first burnup \\
\hline
\end{tabular}


Table M6.7.2 (continued)

\begin{tabular}{|c|c|c|c|}
\hline \multicolumn{2}{|c|}{ Record length ${ }^{c}$} & \multirow{2}{*}{$\frac{\text { Array }}{Q^{\prime}}$} & Description \\
\hline 27 & ITOT & & Recoverable energy values \\
\hline 28 & ITOT & FG & Fractions of Q-values due to photons \\
\hline 29 & ITOT & AMPC & RCG values for air \\
\hline 30 & ITOT & WMPC & RCG values for water \\
\hline 31 & ILITE & ABUND & Natural abundances of light-element nuclides \\
\hline 32 & IACT & SPONF & $\begin{array}{l}\text { Values of the product of the decay constant times } \\
\text { the spontaneous fission branching fraction times } \\
\text { Avagadro's number (no longer used) }\end{array}$ \\
\hline 33 & IACT & ALPHAN & $\begin{array}{l}\text { Values of the product of the decay constant times } \\
\text { the alpha decay branching fraction times } \\
\text { Avagadro's number times the number of } \\
\text { neutrons per alpha decay (no longer used) }\end{array}$ \\
\hline 34 & NENLE + 1 & EGROUP & $\begin{array}{l}\text { Mean photon group energies (NENLE values) for } \\
\text { light-element photon yield data, ordered from low } \\
\text { energy to high. The last value is the lower energy } \\
\text { bound of group } 1 \text {. }\end{array}$ \\
\hline 35 & NENAC + 1 & EACTGP & $\begin{array}{l}\text { Mean photon group energies (NENAC values) } \\
\text { for actinide photon yield data, ordered from low } \\
\text { energy to high. The last value is the lower } \\
\text { energy bound of group } 1 .\end{array}$ \\
\hline 36 & $\mathrm{NENFP}+1$ & EFPGRP & $\begin{array}{l}\text { Mean photon group energies (NENFP values) for } \\
\text { fission-product photon yield data, ordered from low } \\
\text { energy to high. The last value is the lower energy } \\
\text { bound of group } 1 \text {. }\end{array}$ \\
\hline 37 & NENAC & SFGAMA & $\begin{array}{l}\text { Multigroup photon yields for gamma rays } \\
\text { accompanying spontaneous fission, in the group } \\
\text { structure specified by EACTGP. See Sect. } \\
\text { M6.4 for details. }\end{array}$ \\
\hline 38 & NENLE*ILITE & GAMGRP & $\begin{array}{l}\text { Multigroup light-element photon yields, in the } \\
\text { order ((GAMGRP(N,I),N=1,NENLE),I=1,ILITE) }\end{array}$ \\
\hline 39 & NENFP $*$ IFP & GFPGRP & $\begin{array}{l}\text { Multigroup fission-product photon yields, in the } \\
\text { order ((GFPGRP(N,I),N=1,NENFP),I=1,IFP) }\end{array}$ \\
\hline 40 & NENAC*IACT & ACTGRP & $\begin{array}{l}\text { Multigroup actinide photon yields, in the order } \\
\text { ((ACTGRP(N,I),N=1,NENAC),I=1,IACT) }\end{array}$ \\
\hline $41^{e . g}$ & NON & $\mathrm{A}^{c, d}$ & $\begin{array}{l}\text { Compressed transition matrix for effective one-group } \\
\text { neutron capture transitions of the second burnup and } \\
\text { for decay transitions }\end{array}$ \\
\hline $42^{e, 8}$ & ITOT & TOCAP $^{c, d}$ & $\begin{array}{l}\text { Effective one-group capture cross sections of second } \\
\text { burnup }\end{array}$ \\
\hline
\end{tabular}

NUREG/CR-0200, 
Table M6.7.2 (contimued)

\begin{tabular}{|c|c|c|c|}
\hline \multicolumn{2}{|c|}{ Record length } & \multirow{2}{*}{ Array } & Description \\
\hline $43^{c, 8}$ & IACT & & $\begin{array}{l}\text { Effective one-group_fission cross sections of second } \\
\text { burnup }\end{array}$ \\
\hline $44^{c, 8}$ & ILITE+IACT & GENNEU $^{d}$ & $\begin{array}{l}\text { Effective one-group neutron yields of second burnup'. } \\
\text {. } \\
\text {. }\end{array}$ \\
\hline \multicolumn{4}{|c|}{$\begin{array}{l}\text { (This lastset of four records is continued for the third, fourth, and/or higher burnup intervals or cycles } \\
\text { of the SAS2 power history producing the library, until the last burnup interval is completed.) }\end{array}$} \\
\hline \multicolumn{4}{|c|}{$\begin{array}{l}\text { Length in single-precision words. } \\
\text { 'NTIT is the number of title cards. } \\
\text { These arrays are discussed in Sect. M6.2.5. } \\
{ }^{d} \text { Effective one-group values for the burnup interval given. } \\
\text { 'Records } 23 \text { through } 26 \text { and records } 41 \text { and above are present only in a binary working library. } \\
\text { fThese variables are defined in Sect. M6.2.1. }\end{array}$} \\
\hline
\end{tabular}




\section{M6.7.3 GENERATION OF SOME USEFUL LIBRARIES}

As an aid to the beginning user, this section presents the input data for COUPLE, ORIGEN-S, and SAS2 cases to generate some binary data libraries that have been useful at ORNL.

The user may find this section helpful in understanding part of the installation of a new version of SCALE on a computer. After the SCALE system is installed, it is typically executed by using a predefined procedure (e.g., a script). Some data for SCALE, required to be in the card-image mode for portability, are more efficiently utilized after conversion to the binary mode. Indeed, SCALE cases will not execute properly unless certain required files have been made. Several cases using COUPLE, ORIGEN-S, and SAS2, required to install SCALE, have been combined into two somewhat large cases to make the various binary libraries referenced in a SCALE procecture. The user does not need to know the details or purposes of the large cases to perform the SCALE installation. The user needs to change only items such as names of files or volumes and other installation-dependent parameters in the case's job control language or script for the case to run properly. However, the user who would like to understand the purposes of the conversion cases may wish to read this section and the input instructions of the codes. Although the examples given here may not be precisely the same as the cases used in the installation of SCALE, the purposes of the cases are the same.

The first example contains back-to-back runs of COUPLE and ORIGEN-S. The first COUPLE case converts the data in the card-image library to a binary working library for an LWR. The flux weighting factors used are THERM $=0.632, \mathrm{RES}=0.333$, and $F A S T=2.0$. The card-image cross-section data and photon-yield libraries are read from logical unit 28 , and the decay data base is read from logical unit 27 . The binary working library generated by this case is written on logical unit 42 . The second COUPLE case generates an edit of the cross-section transitions in the binary working library on logical unit 43.

The ORIGEN-S case replaces the photon yield data in the binary working library with 18-group photon yields for the light elements, actinides, and fission products. The 18-group energy boundaries are those of Table M6.3.2. The photon yield data are read from a binary master photon data base on logical unit 26 which includes decay gamma and $X$ rays, gamma rays accompanying spontaneous fission and $(\alpha, n)$ reactions, and bremsstrahlung for a $\mathrm{UO}_{2}$ fuel matrix. The input binary working library from COUPLE is read from logical unit 43. The final binary working library is written by ORIGEN-S on logical unit 21 . This library has an ID of 1107 and is known at ORNL as the Basic LWR ORIGEN-S Binary Working Library. Details of the input data given below can be determined by studying Sect. F6.5.8 of the COUPLE document and Sect. F7.6.10 of the ORIGEN-S document.

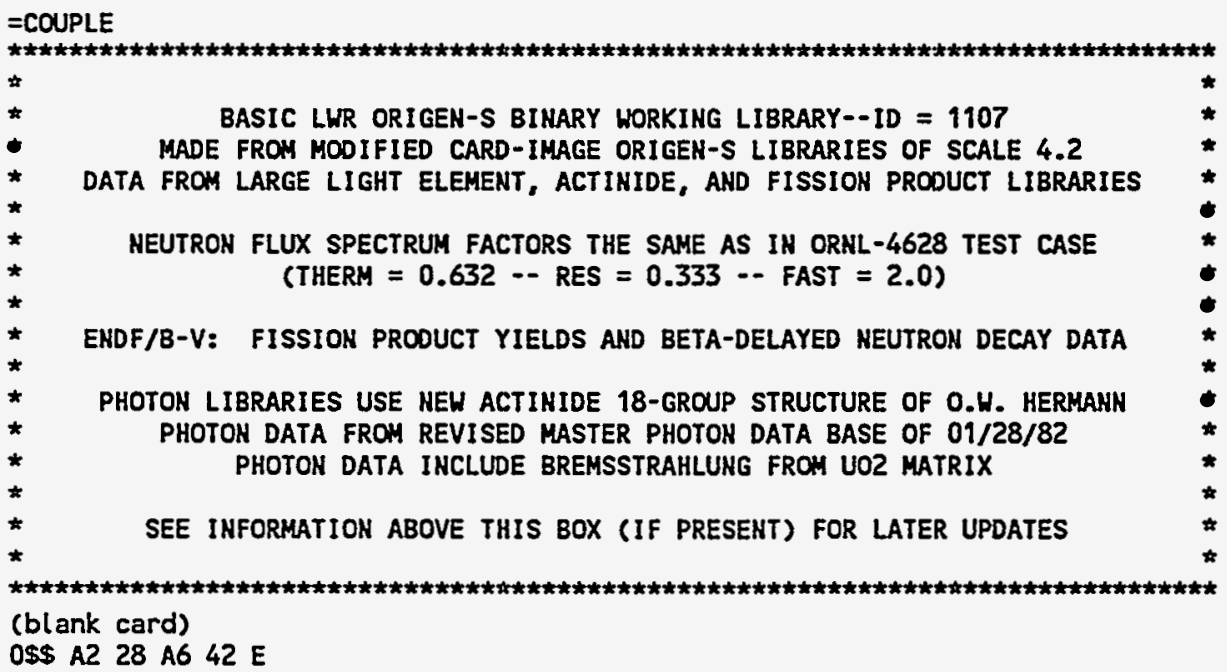

NUREG/CR-0200,

Vol. 3, Rev. 4

M6.7.6 
1\$\$ 2R1 A11 1107 E 2** A2 0.6320 .333 2.0 E IT

$3 \$ \$ 28$ E $5 \$ \$ 23 T$

$35 \$ \$ 0 ~ 5 T$

EDIT

(blank card)

OSS A4 $42 \mathrm{E}$

ISS A2 1 A5 1 A13 -1 E IT

DONE

END

$=$ ORIGENS

OS\$ A4 42 AB 26 A11 21 E IT

(blank card)

$3 \$ \$ 42$ A3 1 A6 1 A33 18 2T

$4 T$

56\$S A2 1 A5 22 A13 1 A17 I E 5T

$60^{\star \star} 173 \$ \$ 92238074^{* *} 175 \$ \$ 2$ 81\$\$ 11 A3 261 E $82 \$ \$ \$ 21$

$83 * * 6+6 \quad 5+6 \quad 4.5+6 \quad 4+6 \quad 3.5+6 \quad 3+6 \quad 2.6+6 \quad 2.2+6 \quad 1.8+6 \quad 1.35+6 \quad 9+5$

$4+5 \quad 2+5 \quad 1.4+5 \quad 1+5 \quad 7+4 \quad 4+4 \quad 2+4 \quad 0 \quad 6 T$

I\$S 0 IT

END

The second example is a SAS2 run commonly known as a "preSAS" case. The purpose of a preSAS case is to make the Preliminary LWR ORIGEN-S Binary Working Library to be input to subsequent SAS2 cases for LWR fuel assembly depletion analyses. The case updates all of the (more than 200) nuclides having cross-section data on the SCALE 27-group depletion library, using the input design data for a typical modern PWR. Most SAS2 cases update only a fraction of the nuclides having data available in the SCALE depletion library. Thus, the remaining nuclides, updated on the preliminary library, will have data that are substantially improved over that on the initial card-image nuclear data libraries.

The SAS2 case in the second example generates a single-burnup-interval binary working library at the mid-time of an 800-day cycle for a $466.3-\mathrm{kgU}, 17 \times 17$ pin assembly. The total burnup is $31.69 \mathrm{GWd} / \mathrm{MTU}$, and the initial ${ }^{235} \mathrm{U}$ enrichment of the fuel is $3.0 \mathrm{wt} \%$. Densities, temperatures, design dimensions, and standard composition specifications for the nuclides to be updated are shown in the input for the case given below:

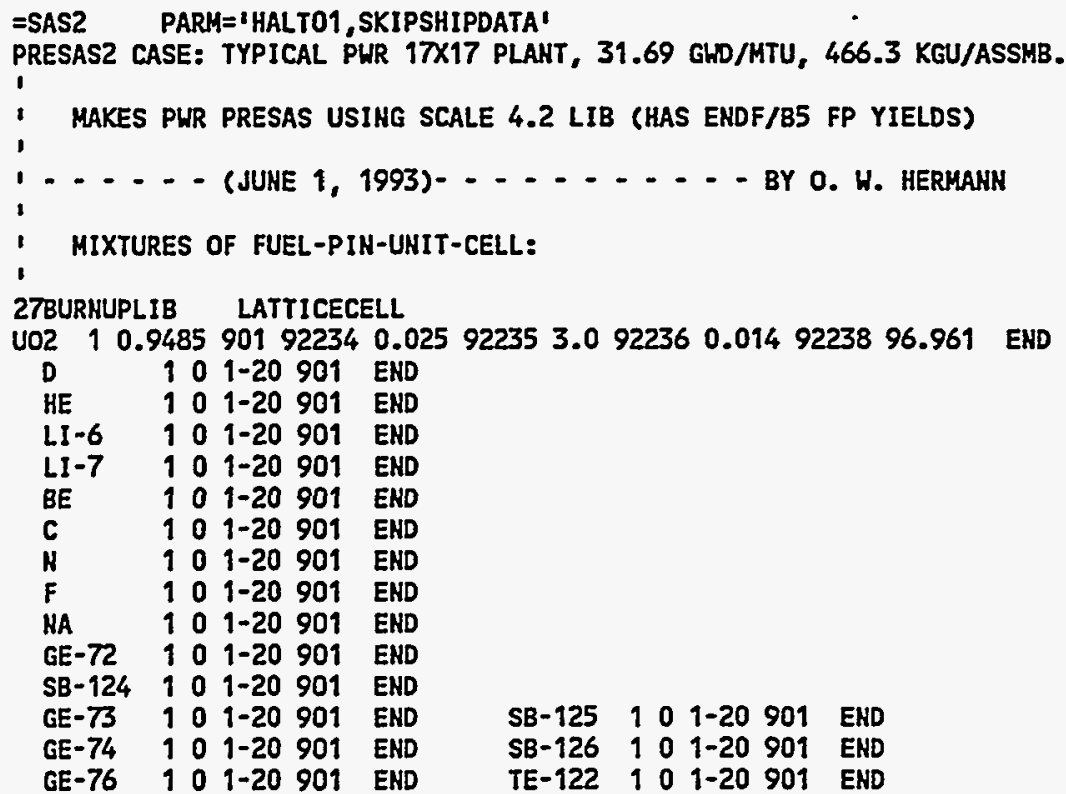




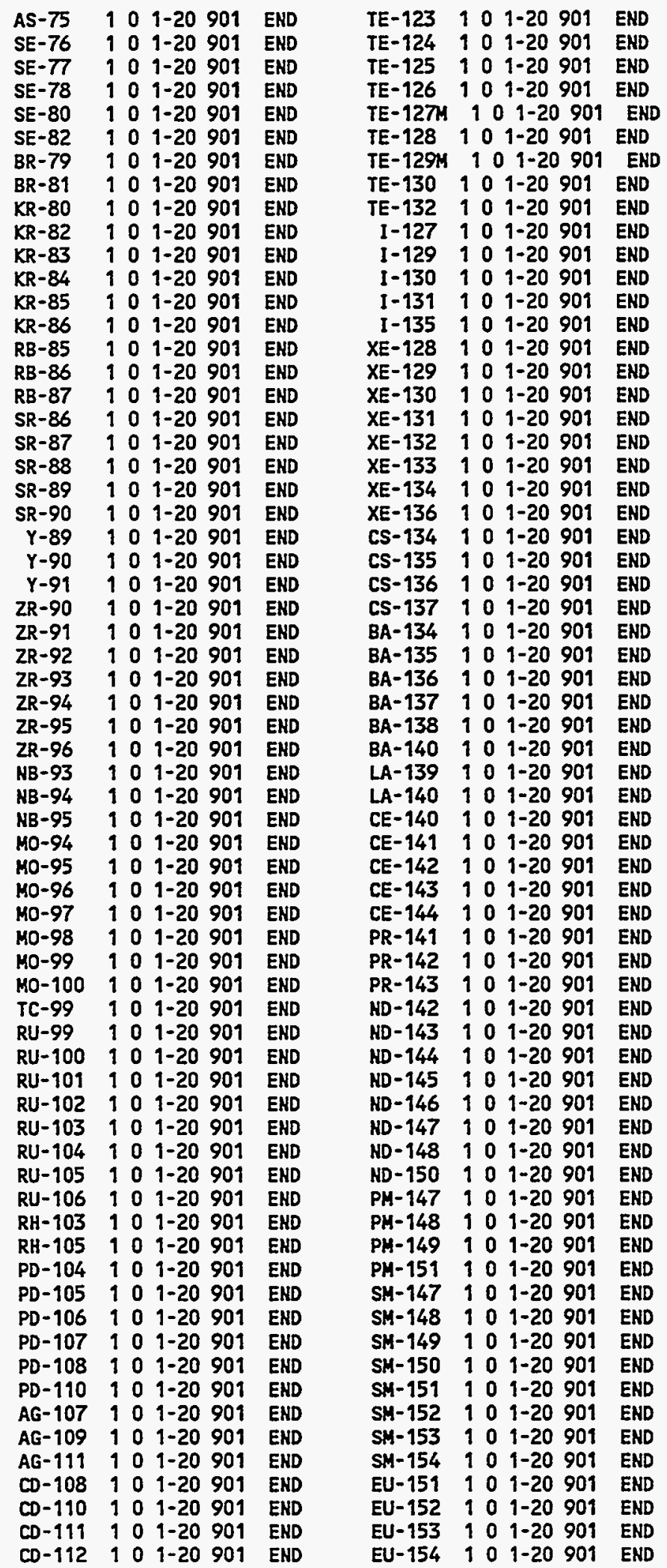

NUREG/CR-0200,

Vol. 3, Rev. 4

M6.7.8 


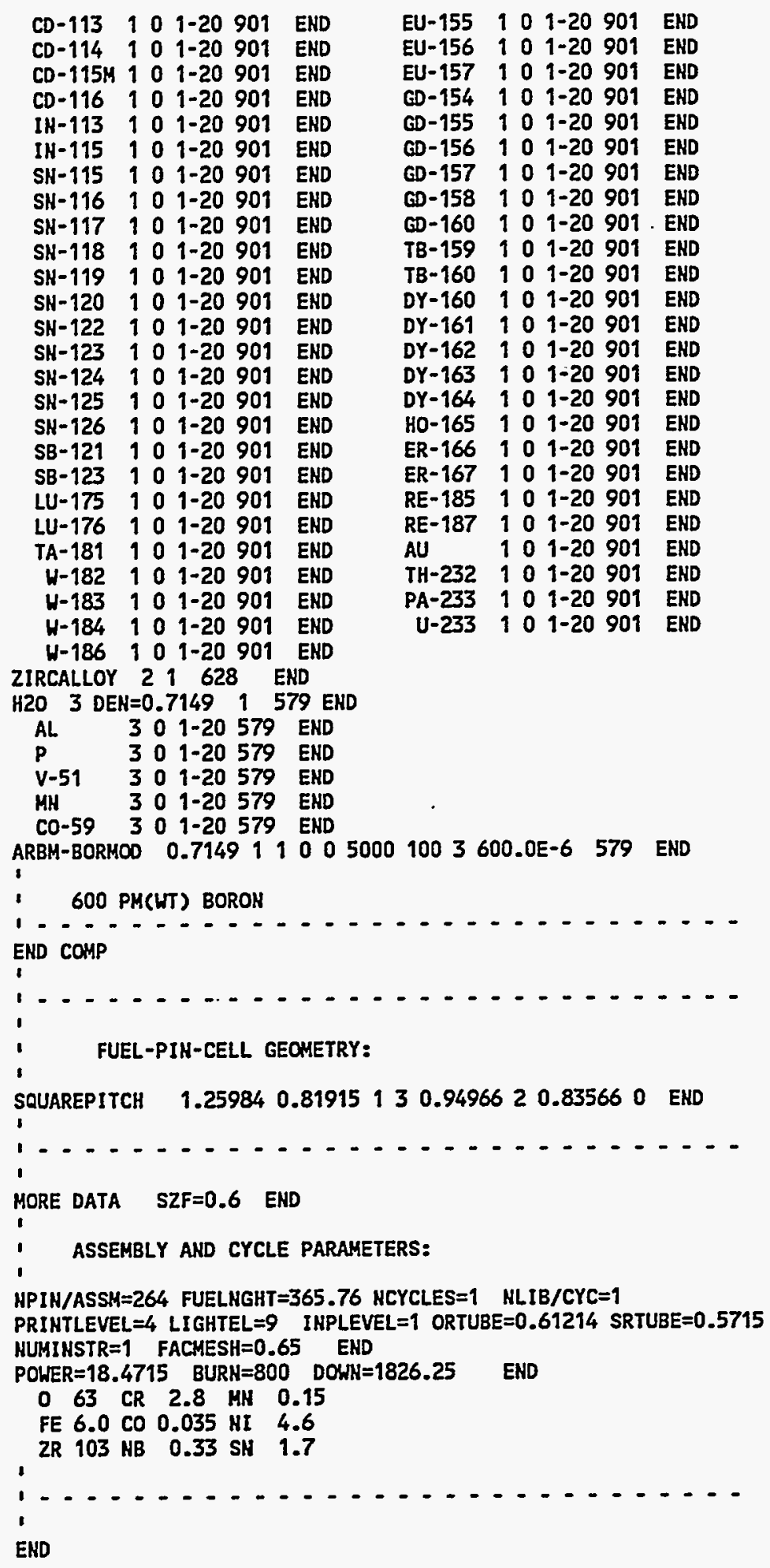


The third example is a SAS2 run to generate a three-burnup-interval binary working library for a "typical" PWR fuel assembly with a burnup of $33 \mathrm{GWD} / \mathrm{MTU}$ and the initial uranium composition of Table M6.7.3. The irradiation history is divided into three cycles having $80 \%$ full power irradiation at $37.5 \mathrm{MW} / \mathrm{MTU}$ and $20 \%$ downtime. Updated cross sections are computed from a 27-group unit cell calculation, at the midpoint of each irradiation cycle, for the nuclides given in Table M6.7.4. The resonance cross-section processing and unit cell calculations are performed for the geometry and operating conditions of a $17 \times 17$ PWR fuel assembly. The cross sections used in the calculations are read from the SCALE 27group ENDF/B-IV burnup library (Sect. M4) on logical unit 87. The input binary library is the Preliminary LWR ORIGEN-S Binary Working Library generated in the second example outlined above, which is read on logical unit 21. The burnup-dependent binary working libraries for cycles 1,2, and 3 are written on logical unit 33. None of these libraries can be used within the integral option. Details of the SAS2 method and input data requirements can be found in Sects. S2.2 and S2.5, respectively, of the SAS2 documentation.

Table M6.7.3 Initial uranium composition of typical PWR assembly

\begin{tabular}{cc}
\multicolumn{2}{c}{ typical PWR assembly } \\
\hline Nuclide & Weight percent \\
\hline${ }^{234} \mathrm{U}$ & 0.029 \\
${ }^{235} \mathrm{U}$ & 3.200 \\
${ }^{236} \mathrm{U}$ & 0.016 \\
${ }^{238} \mathrm{U}$ & 96.755 \\
\hline
\end{tabular}

Table M6.7.4 Nuclides with updated cross sections in typical PWR and BWR libraries

\begin{tabular}{cccc}
${ }^{1} \mathrm{H}$ & ${ }^{105} \mathrm{Rh}$ & ${ }^{144} \mathrm{Ce}$ & ${ }^{235} \mathrm{U}$ \\
${ }^{10} \mathrm{~B}$ & ${ }^{106} \mathrm{Ru}$ & ${ }^{145} \mathrm{Nd}$ & ${ }^{236} \mathrm{U}$ \\
${ }^{11} \mathrm{~B}$ & ${ }^{124} \mathrm{Sb}$ & ${ }^{147} \mathrm{Nd}$ & ${ }^{237} \mathrm{~Np}$ \\
${ }^{16} \mathrm{O}$ & ${ }^{131} \mathrm{Xe}$ & ${ }^{147} \mathrm{Pm}$ & ${ }^{238} \mathrm{Pu}$ \\
${ }^{85} \mathrm{Kr}$ & ${ }^{132} \mathrm{Xe}$ & ${ }^{147} \mathrm{Sm}$ & ${ }^{239} \mathrm{Pu}$ \\
${ }^{90} \mathrm{Sr}$ & ${ }^{135} \mathrm{Xe}$ & ${ }^{149} \mathrm{Sm}$ & ${ }^{240} \mathrm{Pu}$ \\
${ }^{89} \mathrm{Y}$ & ${ }^{133} \mathrm{Cs}$ & ${ }^{151} \mathrm{Sm}$ & ${ }^{241} \mathrm{Pu}$ \\
${ }^{94} \mathrm{Zr}$ & ${ }^{134} \mathrm{Cs}$ & ${ }^{152} \mathrm{Sm}$ & ${ }^{242} \mathrm{Pu}$ \\
${ }^{95} \mathrm{Zr}$ & ${ }^{137} \mathrm{Cs}$ & ${ }^{153} \mathrm{Eu}$ & ${ }^{243} \mathrm{Am}$ \\
${ }^{94} \mathrm{Nb}$ & ${ }^{136} \mathrm{Ba}$ & ${ }^{154} \mathrm{Eu}$ & \\
${ }^{99} \mathrm{Tc}$ & ${ }^{139} \mathrm{La}$ & ${ }^{155} \mathrm{Eu}$ & \\
${ }^{103} \mathrm{Rh}$ & ${ }^{143} \mathrm{Pr}$ & ${ }^{234} \mathrm{U}$ & \\
\hline
\end{tabular}

NUREG/CR-0200, 
The input data for this SAS2 case are given below.

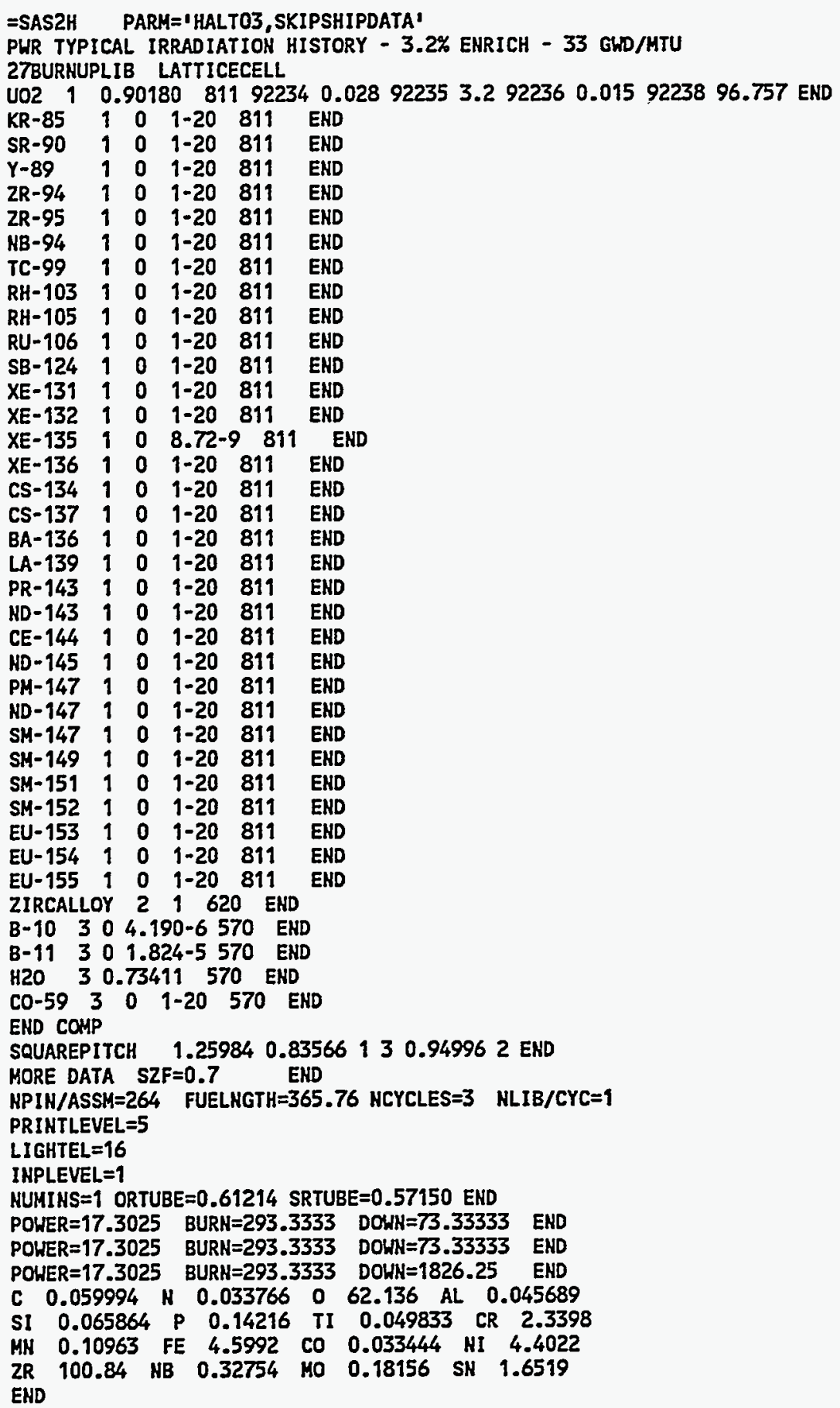




\section{M6.7.4 GENERIC BWR AND PWR LIBRARIES}

There are 36 sets of ORIGEN-S burnup-dependent binary libraries included in SCALE 4.2. These libraries were generated with SAS2 for a proposed revision to the NRC Regulatory Guide 3.54 on radioactive decay heat. ${ }^{30}$ The libraries are categorized by (1) reactor type (PWR or BW.R), (2) fuel enrichment, (3) power, and (4) burnup range, as shown below.

Table M6.7.5 Generic BWR and PWR library parameters

\begin{tabular}{|c|c|c|}
\hline \multirow{2}{*}{ Renctor Type PWR } & \multicolumn{2}{|c|}{ Power (MW/MTU) } \\
\hline & & $\begin{array}{l}18 \\
28 \\
40\end{array}$ \\
\hline $\begin{array}{l}\text { Enrichment/maximum burnup } \\
\text { (wt \% U-235) (GWd/MTU) }\end{array}$ & \multicolumn{2}{|r|}{$\begin{array}{l}\text { Burnup per cycle } \\
\text { (MWd/MTU) }\end{array}$} \\
\hline $\begin{array}{ll}2.4 \text { wt \% / } & 25 \\
2.8 \text { wt \% / } & 30 \\
3.2 \text { wt \% / } & 35 \\
3.6 \text { wt \% / } & 40 \\
3.9 \text { wt \% / } & 45 \\
4.2 \text { wt \% / } & 50\end{array}$ & $\begin{array}{l}3 \\
3 \\
4 \\
4 \\
5 \\
5\end{array}$ & $\begin{array}{r}8,333 \\
10,000 \\
8,750 \\
10,000 \\
9,000 \\
10,000\end{array}$ \\
\hline Reactor Type,BWR & \multicolumn{2}{|c|}{$\begin{array}{l}12 \\
20 \\
30\end{array}$} \\
\hline $\begin{array}{l}\text { Enrichment/maximum burnup } \\
\text { (wt \% U-235) (GWd/MTU) }\end{array}$ & Number of cycles & $\begin{array}{c}\text { Burnup per cycle } \\
\text { (MWd/MTU) }\end{array}$ \\
\hline $\begin{array}{ll}1.9 w t \% / & 20 \\
2.3 w t \% / / & 25 \\
2.7 w t \% / & 30 \\
3.1 w t \% / & 35 \\
3.4 w t \% / & 40 \\
3.8 w t \% / & 45\end{array}$ & $\begin{array}{l}3 \\
3 \\
4 \\
4 \\
5 \\
5\end{array}$ & $\begin{array}{l}6,667 \\
8,333 \\
7,500 \\
8,750 \\
8,000 \\
9,000\end{array}$ \\
\hline
\end{tabular}

NUREG/CR-0200,

Vol. 3, Rev. 4

M6.7.12 
The naming convention for these 36 datasets is

$$
\text { rbuspLIB.DATA }
$$

where the lower case letters represent the following:

$$
\begin{aligned}
& r=\text { reactor type }(\mathrm{P}=\mathrm{PWR} \text { or } \mathrm{B}=\mathrm{BWR}) \\
& b u=\text { maximum burnup in } \mathrm{GWd} / \mathrm{MTU} \text { (i.e., } \mathrm{MWd} / \mathrm{MTU} / 1000), \\
& s p=\text { specific power in } \mathrm{MW} / \mathrm{MTU}
\end{aligned}
$$

The nearest enrichment should be the criterion for choosing the enrichment/maximum burnup. The maximum burnup is simply an upper bound for which cross sections are available. The burnup range is the criterion for selecting the library on the dataset (variable NTYPE in the ORIGEN-S $3 \$$ array.)

A depletion subcase that exceeds the lower or upper burnup limit by no more than 5 or $10 \%$ is acceptable. For some fuel cycles, it may be necessary to break up the cycle into two or more subcases to match the burnup ranges of the depletion libraries. An example would be a $3.6 \mathrm{wt} \%$ PWR fuel assembly that accumulates $18 \mathrm{GWd} / \mathrm{MTU}(18,000 \mathrm{MWd} / \mathrm{MTU})$ of burnup at an average power of $28 \mathrm{MW} / \mathrm{MTU}$ in its first cycle. This would require one subcase from 0 to $10 \mathrm{GWd} / \mathrm{MTU}$ and a second from 10 to $18 \mathrm{GWd} / \mathrm{MTU}$. The dataset name for the library for these depletion steps is P4028.lib.data. For the first depletion from 0 to 10 GWd/MTU, NTYPE $=1$, and for the second depletion from 10 to $18 \mathrm{GWd} / \mathrm{MTU}, \mathrm{NTYPE}=2$, since they use the first and second libraries, respectively, from the dataset.

These libraries are being supplied to enable ORIGEN-S users to perform analyses for a wide range of light water reactor fuel calculations without having to generate their own cross-section libraries with SAS2. These libraries may be selected from menus in ORIGNATE, the PC input processor for setting up ORIGEN-S input decks. ${ }^{31}$

The libraries are in BCD format and must be restored to binary form to be useable by the ORIGEN-S computer code. OSBIRE restores the converted libraries to binary format. OSBICO converts the binary libraries to BCD format. The scripts osbireb.jcl and osbirep.jcl run OSBIRE to restore the BWR and PWR libraries, respectively. The restored binary libraries will be written to /scale/datalib/origen/binrylib. The naming convention is the same as the BCD datasets, except that the ".data" is dropped from the end of the data (e.g., P4028.lib.data is restored to P4028.lib).

The input for OSBIRE and OSBICO is as follows:

1

1

1

where line one contains an integer which specifies the number of libraries to convert which is followed by twice that number of lines which have a / in column one. To convert or restore five libraries, the input looks like the following:

5
1
1
1
1
1
1

M6.7.13

NUREG/CR-0200, Vol. 3, Rev. 4 
The maximum number of datasets which can be converted/restored with one execution of OSBICO/OSBIRE is twenty. Binary datasets are automatically allocated and incremented by 1 , beginning at file 30 ( $\mathrm{ft} 30 \mathrm{fO01}$ ) and going to a maximum of file 49 ( $\mathrm{ft} 49 \mathrm{f001}$ ). BCD files are automatically allocated and incremented by 1 beginning at file 50 (ft50f001) and going to a maximum of 69 (ft69f001).

To use a binary library dataset in ORIGEN-S, it should be allocated to the file number specified by NDSET in the $\$ 3$ array. Because the BWR and PWR libraries are contained in multiple-library datasets, then the position of the library within the dataset must be specified by NTYPE in the $\$ 3$ array. 


\section{M6.8 ORIGEN-S LIBRARIES AT ORNL}

This section gives a summary description of the card-image and binary ORIGEN-S libraries available on ORNL computing systems. Complete descriptions of most of these libraries were given in earlier sections of this report.

All libraries are maintained as members of partitioned data sets on IBM mainframe computing systems and as separate data files on workstations. Names and descriptions of card-image libraries are given in Table M6.8.1; those for binary libraries are given in Table M6.8.2.

Table M6.8.1 Card-image ORIGEN-S libraries at ORNL

\begin{tabular}{|c|c|}
\hline Library name ${ }^{a}$ & Description \\
\hline END6DEC & Decay data base for the light elements, actinides, and fission products \\
\hline ENDFB4FP & ENDF/B-IV fission-product decay library in ENDF format \\
\hline MPBRH2OM & Master photon data for bremsstrahlung from negatrons slowing down in water \\
\hline MPBRH2OP & Master photon data for bremsstrahlung from positrons slowing down in water \\
\hline MPBRUO2M & Master photon data for bremsstrahlung from negatrons slowing down in $\mathrm{UO}_{2}$ \\
\hline MPBRUO2P & Master photon data for bremsstrahlung from positrons slowing down in $\mathrm{UO}_{2}$ \\
\hline MPDKXGAM & Master photon decay $X$ - and gamma-ray line data \\
\hline MPSFANGM & Master photon gamma ray spectra from spontaneous fission and $(\alpha, n)$ reactions \\
\hline XSECTPHO & $\begin{array}{l}\text { Nuclear data libraries and photon-yield libraries for the light elements, actinides, and } \\
\text { fission products }\end{array}$ \\
\hline
\end{tabular}

${ }^{a}$ Member name on an IBM mainframe or filename on a workstation. 
Table M6.8.2 Some binary ORIGEN-S libraries at ORNL

Library name ${ }^{a}$ Description

PRLIMLWR Preliminary LWR ORIGEN-S Binary Working Library described in Sect. M6.7.3. It has $(\beta, n)$ decay data for fission products, so it cannot be used with the integral option

BASLMFBR Basic LMFBR ORIGEN-S Binary Working Library. This library was converted from the large light-element, actinide, and large fission-product card-image nuclear data libraries. It has the same $(\beta, n)$ decay data and photon yield data as the Basic LWR Binary Working Library. It cannot be used with the integral option

MAPHH2OB Binary Master Photon Library with the photon data from members MPDKXGAM, MPSFANGM, MPBRH2OM, and MPBRH2OP of the cardimage library

MAPHNOBR Binary Master Photon Library with the photon data from members MPDKXGAM and MPSFANGM of the card-image library

MAPHUO2B Binary Master Photon Library with the photon data from members MPDKXGAM, MPSFANGM, MPBRUO2M, and MPBRUO2P of the cardimage library

PWR33GWD Multi-burnup binary working library producted from the typical PWR 33GWd/MTU SAS2H case described in Sect. M6.7.3

\footnotetext{
${ }^{a}$ Member name on an IBM mainframe or filename on a workstation.
}

NUREG/CR-0200, 


\section{M6.9 REFERENCES}

1. M. J. Bell, ORIGEN-The ORNL Isotope Generation and Depletion Code, ORNL-4628, Union Carbide Corp., Nucl. Div., Oak Ridge Natl. Lab., May 1973.

2. C. W. Kee, $A$ Revised Light Element Library for the ORIGEN Code, ORNL/TM-4896, Union Carbide Corp., Nucl. Div., Oak Ridge Natl. Lab., May 1975.

3. Radiation Shielding Information Center (Oak Ridge National Laboratory) Data Package DLC38/ORYX-E, ORIGEN Yields and Cross Sections-Nuclear Transmutation and Decay Data From $E N D F / B$, contributed by Oak Ridge National Laboratory, September 1979.

4. G. W. Morrison, C. R. Weisbin, and C. W. Kee, "Decay Heat Analysis for an LMFBR Fuel Assembly Using ENDF/B-IV Data," Nuclear Cross Sections and Technology, Proceedings of a Conference, Washington, DC, March 3-7, 1975, NBS Special Publication 425, Vol. 1, U.S. Department of Commerce, National Bureau of Standards, October 1975.

5. ENDF/B-IV Fission Product Library Tapes 414-419, National Neutron Cross Section Center, Brookhaven Natl. Lab. (December 1974, and Rev. 1 December 1975).

6. ENDF/B-V Library Tapes 513, 515, 521, 522, 532, and 541-546, National Neutron Cross Section Center, Brookhaven Natl. Lab.

7. L. Boumahraz, Enrichissement et Separation Isotopique du Tritium entre l'Hydrogene el l'Eau Liquide dans un Reacteur a Lit Fixe Arrose, Thesis, DE87-701990 (INIS-mf-10814), Centre d'Etudes Nucleaires et Solaires, Algeria, September 1986.

8. C. Wagemans, P. D'Hondt, P. Schillebeeckx, and R. Brissot, "Triton and Alpha Emission in the Ternary Fission of the Actinides," Proceedings of the XV-th International Symposium on Nuclear Physics-Nuclear Fission, ZfK-592, Technical University of Dresden, Gaussig, Germany (GDR), April 1986.

9. P. R. Daniel, "Analysis of Effects of Updated Decay and Fission Yield Data on ORIGEN2 Results," Trans. Am. Nucl. Soc. 68(A), 92 (1993).

10. ENDF/B-VI Radioactive Decay Data Sublibrary Tapes 200-208, National Neutron Cross-Section Center, Brookhaven National Laboratory.

11. A. G. Croff, R. L. Haese, and N. B. Gove, Updated Decoy and Photon Libraries for the ORIGEN Code, ORNL/TM-6055, Union Carbide Corp., Nucl. Div., Oak Ridge Natl. Lab., February 1979.

12. N. M. Greene et al., AMPX: A Modular Code System for Generating Coupled Multigroup NeutronGamma Libraries From ENDF/B-IV and/or ENDF/B-V, ORNL/CSD/TM-283, Martin Marietta Energy Systems, Inc., Oak Ridge Natl. Lab., October 1992. 
13. D. Garber, C. Dunford, and S. Pearlstein, Data Formats and Procedures for the Evaluated Nuclear Data File, ENDF, BNL-NCS-50496 (ENDF-102) Brookhaven Natl. Lab., October 1975.

14. A. G. Croff, ORIGEN2-Revised and Updated Version of the Oak Ridge Isotope Generation and Depletion Code, ORNL-5621, Union Carbide Corp., Nucl. Div., Oak Ridge Natl. Lab., July 1980.

15. W. B. Ewbank, M. R. Schmorak, F. E. Bertrand, M. Feliciano, and D. J. Horen, Nuclear Structure Data File: A Manual for Preparation of Data Sets, ORNL-5054, Union Carbide Corp., Nucl. Div., Oak Ridge Natl. Lab., June 1975.

16. W. B. Ewbank, "Evaluated Nuclear Structure Data File (ENSDF) for Basic and Applied Research," Fifth International CODATA Conference, Boulder, Colorado, June 1976.

17. Code of Federal Regulations, Title 10, Part 20 (pre-1991 version).

18. Edgardo Browne, Richard Firestone, and V. S. Shirley (Editor), Table of Radioactive Isotopes, John Wiley and Sons, 1986.

19. M. J. Martin (Ed.), Nuclear Decay Data for Selected Radionuclides, ORNL-5114, Union Carbide Corp., Nucl. Div., Oak Ridge Natl. Lab., March 1976.

20. Thomas W. Burrows, The Program RADLST, BNL-NCS-52142, Brookhaven Natl. Lab., February $29,1988$.

21. C. M. Lederer, J. M. Hollander, and S. Perlman, Table of Isotopes, 6th ed., Wiley, New York, 1967.

22. D. T. Goldman and J. R. Rosser, Chart of the Nuclides, 9th ed., General Electric Company, July 1966.

23. N. E. Holden, Isotopic Composition of the Elements and Their Variation in Nature: A Preliminary Report, BNL-NCS-50605, Brookhaven Natl. Lab.. March 1977.

24. T. R. England, W. B. Wilson, R. E. Schenter, and F. M. Mann, Summary of ENDF/B-V Data for Fission Products and Actinides, EPRI NP-3787 (LA-UR 83-1285) (ENDF-322), Electric Power Research Institute (December 1984).

25. H. Alter and C. W. Weber, "Production of Hydrogen and Helium in Metals During Reactor Irradiation," J. Nucl. Mat. 16 (1965).

26. D. J. Garber and C. Brewster, ENDF/B Cross Sections, BNL-17100 (ENDF-200), 2nd ed., Brookhaven Natl. Lab., 1975.

27. E. D. Arnold, PHOEBE-A Code for Calculating Beta and Gamma Activity and Spectra for ${ }^{235} U$ Fission Products, ORNL-3931, Union Carbide Corp., Nucl. Div., Oak Ridge Natl. Lab., July 1966.

NUREG/CR-0200,

Vol. 3, Rev. 4

M6.9.2 
28. L. T. Dillman, W. S. Snyder, and M. R. Ford, "Nuclear Data Compilation of Utility in Medical and Biological Applications," Proceedings of the Symposium on Application of Nuclear Data in Science and Technology, IAEA-FM-170/43, Vol. 2, pp. 529-39 (March 1973).

29. N. B. Gove and M. J. Martin, "Log-f Tables for Beta Decay," Nucl. Data Tables 10, 206 (1971).

30. O. W. Hermann, C. V. Parks, and J. P. Renier, Technical Support for a Proposed Decay Heat Guide Using SAS2H/ORIGEN-S Data, NUREG/CR-5625 (ORNL-6698), Martin Marietta Energy Systems, Inc., Oak Ridge Natl. Lab. (1994).

31. S. M. Bowman, OFFSCALE: A PC Input Processor for the SCALE Code System - The ORIGNATE Processor for ORIGEN-S, NUREG/CR-6182, Vol. 2 (ORNL/TM-12263), Martin Marietta Energy Systems, Inc., Oak Ridge Natl. Lab. (November 1994). 
NUREG/CR-0200

Revision 4

Volume 3, Section M7

ORNL/NUREG/CSD-2/R4

Computing Applications Division

THE MATERIAL INFORMATION PROCESSOR FOR SCALE

\author{
N. F. Landers \\ L. M. Petrie \\ J. A. Bucholz
}

Manuscript Revised: November 1994

Date Published: April 1995

\author{
Prepared for the \\ Office of Nuclear Material Safety and Safeguards \\ U.S. Nuclear Regulatory Commission \\ Washington, DC 20555 \\ Under Interagency Agreement DOE 1886-8000-9B \\ NRC JCN No. B0009
}

Prepared by the

OAK RIDGE NATIONAL LABORATORY

managed by

MARTIN MARIETTA ENERGY SYSTEMS, INC.

for the

U.S. DEPARTMENT OF ENERGY

under contract DE-AC05-84OR21400 


\begin{abstract}
The Material Information Processor was developed to utilize free-form input data consisting of easily visualized engineering parameters to derive and prepare input data for many of the functional modules used in SCALE. The processor creates an AMPX master format cross-section library that contains only those nuclides utilized in the problem. This library can then be used to create a problem-dependent cross-section library in the AMPX working format for use by SCALE modules.
\end{abstract}




\section{CONTENTS}

Page

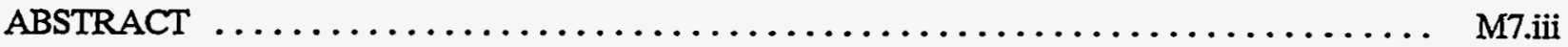

LIST OF FIGURES $\ldots \ldots \ldots \ldots \ldots \ldots \ldots \ldots \ldots \ldots \ldots \ldots \ldots \ldots \ldots \ldots \ldots \ldots \ldots \ldots \ldots \ldots \ldots$

LIST OF TABLES $\ldots \ldots \ldots \ldots \ldots \ldots \ldots \ldots \ldots \ldots \ldots \ldots \ldots \ldots \ldots \ldots \ldots \ldots \ldots \ldots$

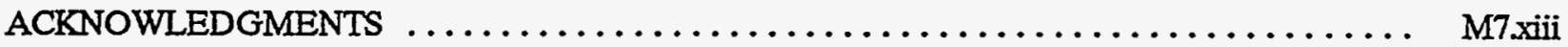

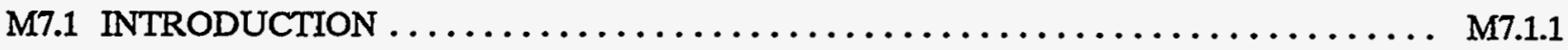

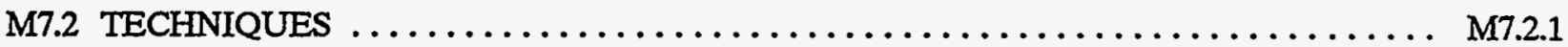

M7.2.1 MATERIAL INFORMATION PROCESSOR FEATURES $\ldots \ldots \ldots \ldots \ldots \ldots$ M7.2.1

M7.2.2 APPLICABILITY OF THE MATERIAL INFORMATION

M7.2.3 NUMBER DENSITY CRITERIA OF THE MATERIAL INFORMATION

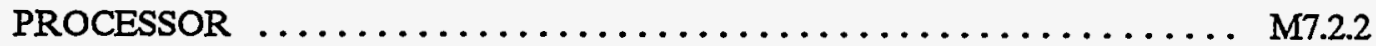

M7.2.4 GEOMETRICAL CRITERIA OF THE MATERIAL INFORMATION

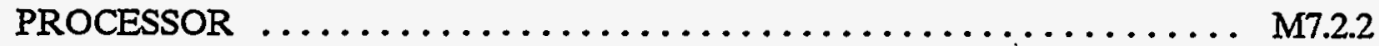

M7.2.4.1 Infinite Homogeneous Medium Treatment (INFHOMMEDIUM) $\ldots$.. M7.2.3

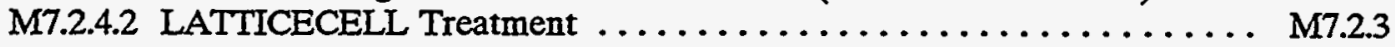

M7.2.4.3 MULTIREGION Treatment $\ldots \ldots \ldots \ldots \ldots \ldots \ldots \ldots \ldots \ldots \ldots$ M7.2.4

M7.2.5 APPLICABILITY OF PROBLEM-DEPENDENT CROSS-SECTION
PREPARATION $\ldots \ldots \ldots \ldots \ldots \ldots \ldots \ldots \ldots \ldots \ldots \ldots \ldots \ldots \ldots \ldots \ldots \ldots \ldots \ldots \ldots$

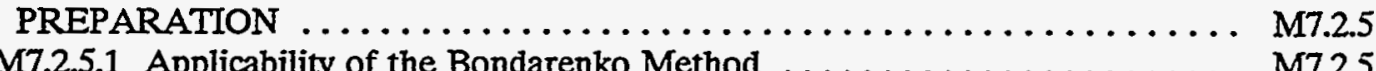

M7.2.5.2 Applicability of the Nordheim Integral Method ........... M7.2.6

M7.2.5.3 Applicability of the Dancoff Factor . ............... M7.2.7

M7.2.5.4 The One-Dimensional Approximation With/Without Buckling . . . . M7.2.11

M7.2.5.5 Use of XSDRNPM by the Material Information Processor . . . . . . M7.2.12

M7.2.5.6 The Automatic Mesh Generator . . . . . . . . . . . . . . M7.2.12

M7.2.5.7 The Automatic Quadrature Generator . . . . . . . . . . . . M7.2.13

M7.2.5.8 XSDRNPM Convergence Criteria ......................

M7.3 THE LOGICAL PROGRAM FLOW $\ldots \ldots \ldots \ldots \ldots \ldots \ldots \ldots \ldots \ldots \ldots \ldots \ldots \ldots \ldots . \ldots \ldots$

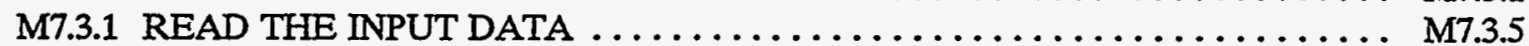

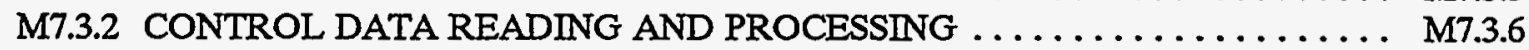

M7.3.3 READ THE STANDARD COMPOSITION SPECIFICATION DATA . . . . . . M7.3.8

M7.3.4 READ THE LATTICE CELL UNIT CELL SPECIFICATION . . . . . . . . . . M7.3.9

M7.3.5 READ THE MULTIREGION UNIT CELL SPECIFICATION $\ldots \ldots \ldots \ldots \ldots$.

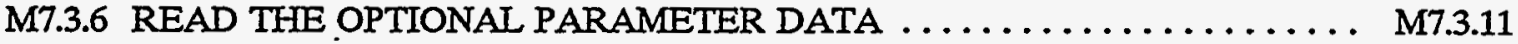

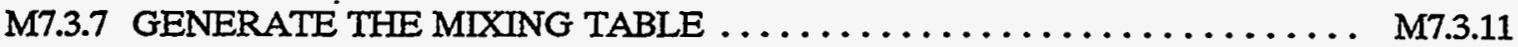

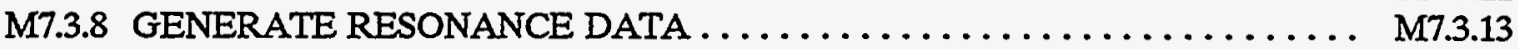

M7.3.9 COLLAPSE THE ENERGY GROUP STRUCTURE $\ldots \ldots \ldots \ldots \ldots \ldots \ldots$ M7.3.15

M7.4 INPUT DATA GUIDE $\ldots \ldots \ldots \ldots \ldots \ldots \ldots \ldots \ldots \ldots \ldots \ldots \ldots \ldots \ldots \ldots \ldots \ldots \ldots \ldots .1$

M7.4.1 INPUT DATA SUMMARY FOR EXPERIENCED USERS $\ldots \ldots \ldots \ldots \ldots \ldots$ M7.4.2

M7.4.2 PARAMETERS FOR DATA CHECKING AND SPACE

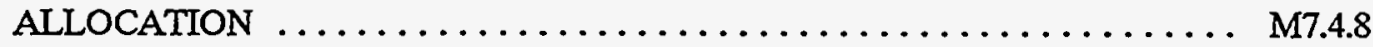


M7.4.3 MATERIAL INFORMATION PROCESSOR DATA $\ldots \ldots \ldots \ldots \ldots \ldots \ldots$ M7.4.8

M7.4.4 STANDARD COMPOSITION SPECIFICATION DATA ........... M7.4.11

M7.4.5 OPTIONAL UNIT CELL SPECIFICATION FOR INFINITE

HOMOGENEOUS PROBLEMS $\ldots \ldots \ldots \ldots \ldots \ldots \ldots \ldots \ldots \ldots \ldots$ M7.4.18

M7.4.6 UNIT CELL SPECIFICATION FOR LATTICE CELL PROBLEMS . . . . . . . M7.4.19

M7.4.7 UNIT CELL SPECIFICATION FOR MULTIREGION PROBLEMS . . . . . . . M7.4.26

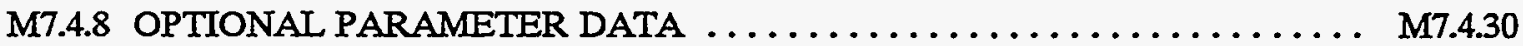

M7.5 NOTES ABOUT THE MATERIAL INFORMATION PROCESSOR . . . . . . . . . . M7.5.1

M7.5.1 USE OF THE MATERIAL INFORMATION PROCESSOR $\ldots \ldots \ldots \ldots \ldots \ldots$ M7.5.1

M7.5.2 MATERIAL INFORMATION PROCESSOR TITLE $\ldots \ldots \ldots \ldots \ldots \ldots \ldots \ldots$ M7.5.1

M7.5.3 CROSS-SECTION LIBRARY NAME $\ldots \ldots \ldots \ldots \ldots \ldots \ldots \ldots \ldots \ldots \ldots$ M7.5.1

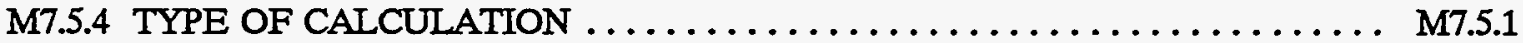

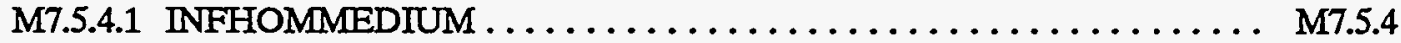

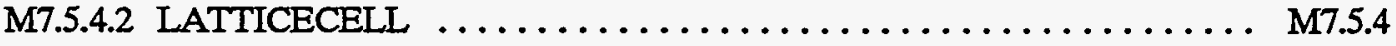

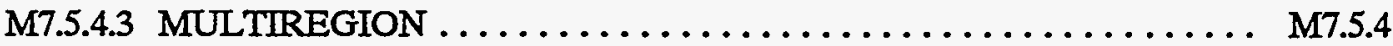

M7.5.5 STANDARD COMPOSITION SPECIFICATION DATA $\ldots \ldots \ldots \ldots \ldots \ldots$ M7.5.5

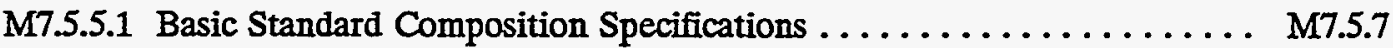

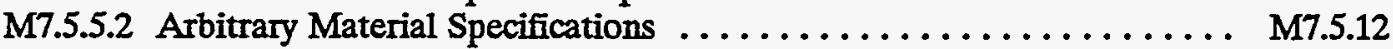

M7.5.5.3 Solution Specifications ....................... M7.5.17

M7.5.5.4 Combinations of Basic Standard Compositions to Define a

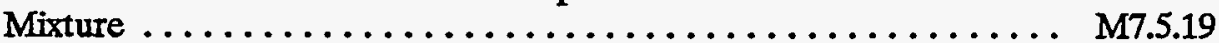

M7.5.5.5 Combinations of Arbitrary Materials to Define a Mixture ........ M7.5.22

M7.5.5.6 Combination of Solutions to Define a Mixture .............. M7.5.24

M7.5.5.7 Combinations of Basic and Arbitrary Standard Compositions to

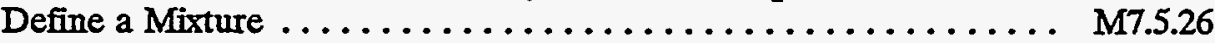

M7.5.5.8 Combinations of Basic and Solution Standard Compositions to

Define a Mixture .....................................

M7.5.5.9 Combinations of Arbitrary Material and Solution to Define a

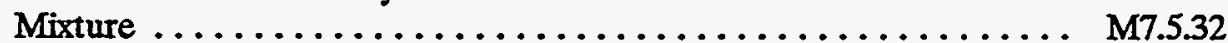

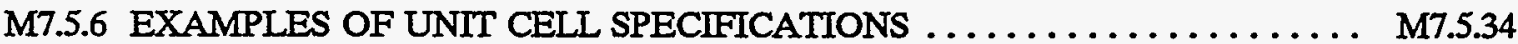

M7.5.6.1 Infinite Homogeneous Medium Unit Cell Data ........... M7.5.34

M7.5.6.2 Lattice Cell Unit Cell Data . . . . . . . . . . . . . . . M7.5.35

M7.5.6.3 Multiregion Unit Cell Data .................... M7.5.46

M7.5.7 OPTIONAL PARAMETER DATA OR MORE DATA ........... M7.5.52

M7.5.7.1 Sample Optional Parameter Data . . . . . . . . . . . . . M7.5.55

M7.5.8 EXAMPLES OF COMPLETE MATERIAI INFORMATION

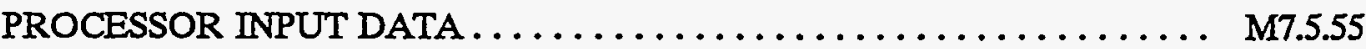

M7.5.8.1 Infinite Homogeneous Medium Input Data $\ldots \ldots \ldots \ldots \ldots \ldots$ M7.5.55

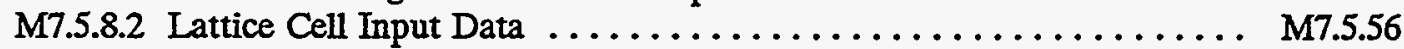

M7.5.8.3 Multiregion Input Data . . . . . . . . . . . . . . . . . M7.5.58

M7.5.9 THREE METHODS OF SPECIFYING A SOLUTION .............. M7.5.59

M7.5.9.1 Comparison of Number Densities from the Three Methods . . . . . . M7.5.63

M7.5.10 MULTIPLE FISSILE CELLS IN A SINGLE PROBLEM . . . . . . . . . . . M7.5.63

M7.5.11 MULTIPLE FISSILE MIXTURES IN A SINGLE PROBLEM . . . . . . . M7.5.65

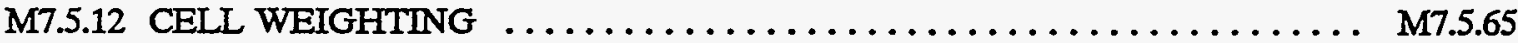

M7.5.12.1 Cell weighting an infinite homogeneous problem $\ldots \ldots \ldots \ldots \ldots$ M7.5.66

M7.5.12.2 Cell weighting a lattice cell problem ............... M7.5.66

M7.5.12.3 Cell weighting a multiregion problem $\ldots \ldots \ldots \ldots \ldots \ldots \ldots$ M7.5.67

NUREG/CR-0200,

Vol. 3, Rev. 4 


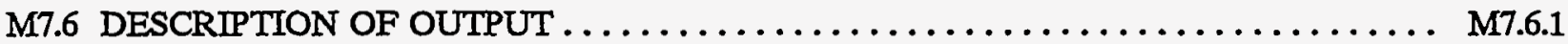

M7.6.1 PROBLEM TITLE $\ldots \ldots \ldots \ldots \ldots \ldots \ldots \ldots \ldots \ldots \ldots \ldots \ldots \ldots \ldots \ldots, \quad$ M7.6.1

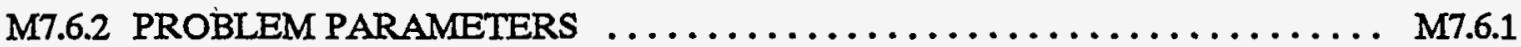

M7.6.3 PROBLEM COMPOSITION DESCRIPTION $\ldots \ldots \ldots \ldots \ldots \ldots \ldots \ldots \ldots$, M7.6.2

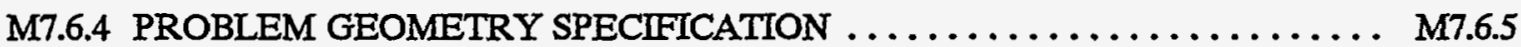

M7.6.4.1 Problem Geometry Description for an Infinite Homogeneous

Medium ................................ M7.6.5

M7.6.4.2 Problem Geometry Description for a Lattice Cell ............. M7.6.5

M7.6.4.3 Problem Geometry Description for a Muitiregion Cell ........... M7.6.6

M7.6.5 OPTIONAL PARAMETER DATA OR MORE DATA $\ldots \ldots \ldots \ldots \ldots \ldots \ldots$, M7.6.6

M7.6.6 ZONE SPECIFICATIONS FOR A LATTICE CELL $\ldots \ldots \ldots \ldots \ldots \ldots \ldots, \quad$ M7.6.7

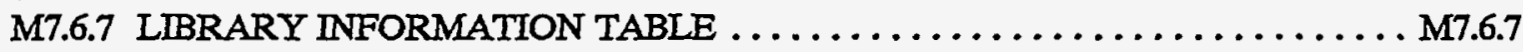

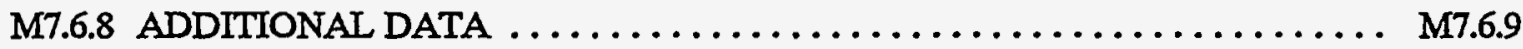

M7.6.8.1 Mixing Table Data ............................. M7.6.9

M7.6.8.2 Resonance Data for NTTAWL $\ldots \ldots \ldots \ldots \ldots \ldots \ldots \ldots \ldots \ldots$ M7.6.9

M7.6.8.3 Additional Data for NITAWL, XSDRNPM, and BONAMI ....... M7.6.11

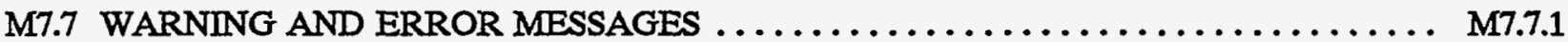

M7.7.1 MATERIAL INFORMATION PROCESSOR MESSAGES $\ldots \ldots \ldots \ldots \ldots \ldots$ M7.7.1

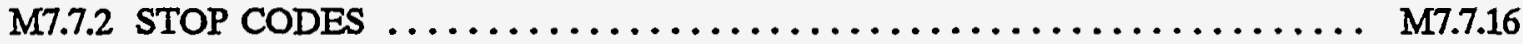

M7.7.3 MESSAGES ASSOCIATED WITH STOP 20 IN CSAS $\ldots \ldots \ldots \ldots \ldots \ldots \ldots$ M7.7.17

M7.7.4 UNNUMBERED MESSAGES $\ldots \ldots \ldots \ldots \ldots \ldots \ldots \ldots \ldots \ldots \ldots, \quad M 7.7 .18$

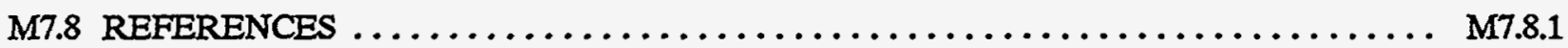

M7.A NOTES ON SOME ELEMENTARY RESONANCE SELF-SHIELDING

TECHNIQUES USED IN SCALE $\ldots \ldots \ldots \ldots \ldots \ldots \ldots \ldots \ldots \ldots \ldots \ldots \ldots \ldots \ldots \ldots . .1$

M7.A1 THE NORDHEIM INTEGRAL METHOD FOR THE TWO-

REGTON PROBLEM $\ldots \ldots \ldots \ldots \ldots \ldots \ldots \ldots \ldots \ldots \ldots \ldots \ldots \ldots \ldots$, M7.A.1

M7.A.2 EXACT IMPRESSIONS FOR THE FIRST-FLIGHT

ESCAPE PROBABILITY USED IN THE NORDHEIM

INTEGRAL METHOD, AND THE ROLE OF THE

DANCOFF FACTOR (C) IN LATTICECELI CALCULATIONS ....... M7.A.6

M7.A3 APPROXIMATE EXPRESSIONS FOR THE FIRST-FLIGHT

ESCAPE PROBABILITY, THE DEFINITION OF THE

ESCAPE CROSS SECTIONS, AND THE RELATIONSHIP

BETWEEN THE TWO QUANTTTIES $\ldots \ldots \ldots \ldots \ldots \ldots \ldots \ldots \ldots$ M7.A8

M7.A.4 THE NARROW-RESONANCE APPROXIMATION FOR

THE FLUX, AS DERIVED FROM A GENERALIZED

FORM OF THE NORDHEIM INTEGRAL EQUATION $\ldots \ldots \ldots \ldots \ldots$ M7.A.12

M7.A5 THE NARROW-RESONANCE/INFINITE-MASS

APPROXIMATION FOR THE FLUX, AS DERIVED

FROM THE NORDHEIM INTEGRAL EQUATION $\ldots \ldots \ldots \ldots \ldots \ldots$ M7.A.14

M7.A.6 THEORETICAL BASIS FOR THE BASIC BONDARENKO

METHOD IN THE ABSENCE OF OVERLAPPING

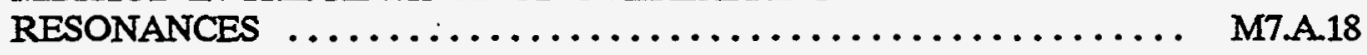

M7.A.7 THE EFFECT OF RESONANCE OVERLAP ON THE

GROUP-AVERAGED CROSS SECTIONS $\ldots \ldots \ldots \ldots \ldots \ldots \ldots \ldots$ M7.A.21 
M7.A.8 THE ITERATTVE BONDARENKO METHOD AND HOW IT PARTLALIY ACCOUNTS FOR RESONANCE OVERLAP USING A MODIFIED DEFINITION OF THE BACKGROUND

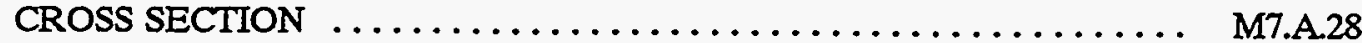

M7.A.9 SOME GENERAL COMMENTS ON THE GENERATION OF BONDARENKO SELF-SHIELDING FACTORS . . . . . . . . . . M7.A.31

M7.A.10 DERIVATION OF THE SELF-SHIELDING FACTORS FOUND IN THE ORIGINAI HANSEN-ROACH CROSS-SECTION

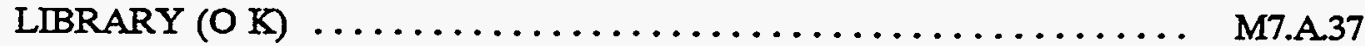

M7.A.11 THE EFFECT OF RESONANCE SCATTERING ON THE GROUP-AVERAGED CROSS SECTIONS

M7.A.12 THE EFFECT OF DOPPLER BROADENING ON THE GROUP-AVERAGED CROSS SECTIONS

M7.A.12.1 Temperature Dependence of the Doppler-Broadened, Energy-Dependent, Cross-Section Data: A Qualitative Explanation and a Mathematical Description in Terms of the $\psi$ and $\chi$ Functions . . . . . . . . . . . . . .

M7.A.12.2 Temperature Dependence of the Resonance-Self-Shielded Group-Averaged Cross Sections: A Mathematical Description in Terms of the J Functions, a Qualitative Explanation Using a Simplified Model, and a Quantitative Assessment with Numerical Examples ............. M7.A.52

M7.A.13 THE KNIGHT-MODIFIED HANSEN-ROACH CROSSSECTION LIBRARY ......................... M7.A.64

M7.A.13.1 Modifications Made by J. R. Knight to the ${ }^{238} \mathrm{U}$ Capture Cross Section for Concentrated Systems $\left(\sigma_{0}<400\right.$ barns) $\ldots \ldots$ M7.A.64

M7.A.13.2 Brief Description of the Experiments Upon Which the Knight Modifications Were Based .............. M7.A.66 


\section{LIST OF FIGURES}

Figure

Page

M7.2.1 Representation of a lump and its neighbors for cylindrical pins in

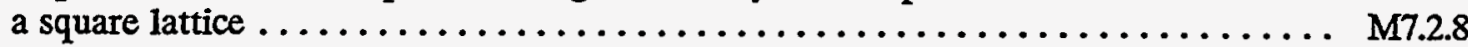

M7.2.2 Representation of a lump and its neighbors for cylindrical pins in a

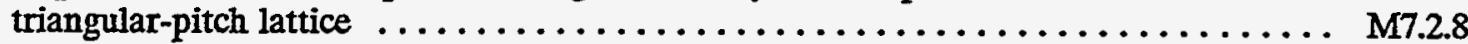

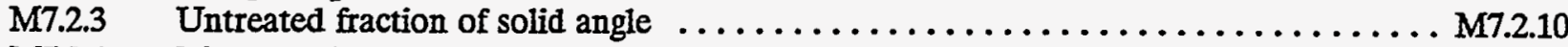

M7.2.4 Mesh spacing scheme used in material zone $\ldots \ldots \ldots \ldots \ldots \ldots \ldots \ldots \ldots \ldots$ M7.2.13

M7.2.5 Angular directions associated with an $\mathrm{S}_{6}$ Gauss-Chebyschev quadrature

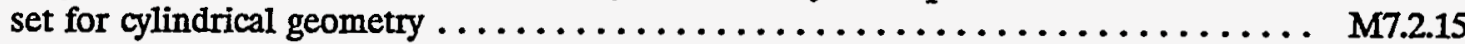

M7.3.1 Flow chart of the Material Information Processor $\ldots \ldots \ldots \ldots \ldots \ldots \ldots \ldots \ldots \ldots$ M7.3.2

M7.3.2 Read the Material Information Processor input data $\ldots \ldots \ldots \ldots \ldots \ldots \ldots \ldots \ldots \ldots$ M7.3.5

M7.3.3 Control Material Information Processor data reading and processing $\ldots \ldots \ldots \ldots \ldots$ M7.3.7

M7.3.4 Flow chart for reading the Standard Compositions Specification data . . . . . . . . . M7.3.8

M7.3.5 Flow chart for reading the unit cell specification for lattice cell $\ldots \ldots \ldots \ldots \ldots \ldots$ M7.3.9

M7.3.6 Flow chart for reading the unit cell specification for multiregion . . . . . . . . . M7.3.10

M7.3.7 Flow chart for reading the optional parameter data $\ldots \ldots \ldots \ldots \ldots \ldots \ldots \ldots \ldots \ldots$ M7.3.11

M7.3.8 Flow chart for generating the mixing table $\ldots \ldots \ldots \ldots \ldots \ldots \ldots \ldots \ldots \ldots \ldots \ldots$ M7.3.12

M7.3.9 Flow chart for generating resonance data $\ldots \ldots \ldots \ldots \ldots \ldots \ldots \ldots \ldots \ldots \ldots \ldots \ldots . . .13$

M7.3.10 Collapse the energy group structure for shielding analytical

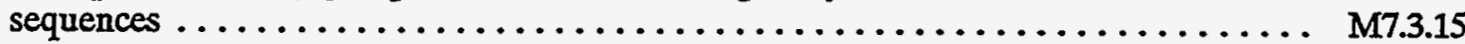

M7.4.1 Arrangement of materials in a SQUAREPITCH and SPHSQUAREP

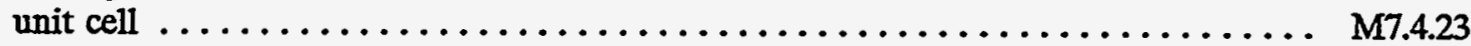

M7.4.2 Arrangement of materials in a TRIANGPITCH and SPHTRIANGP

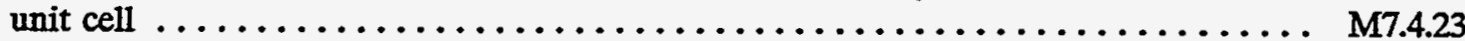

M7.4.3 Arrangement of materials in a SYMMSLABCELL unit cell having

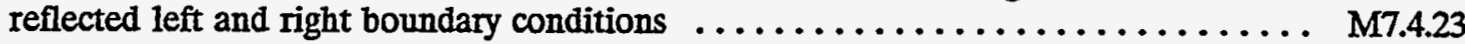

M7.4.4 Arrangement of materials in an ASQUAREPITCH or ASPHSQUAREP

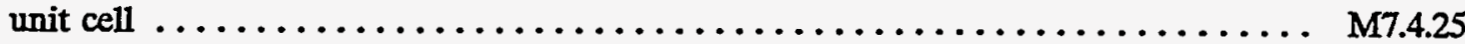

M7.4.5 Arrangement of materials in an ATRIANGPITCH or ASPHTRIANGP

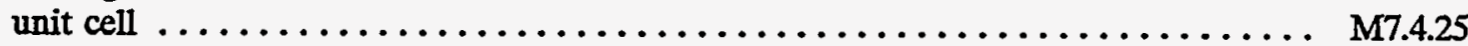

M7.4.6 Arrangement of materials in an ASYMSLABCELL unit cell $\ldots \ldots \ldots \ldots \ldots \ldots \ldots$ M7.4.25

M7.6.1 Example of problem title and problem parameters $\ldots \ldots \ldots \ldots \ldots \ldots \ldots \ldots \ldots$ M7.6.1

M7.6.2 Example of standard composition printout $\ldots \ldots \ldots \ldots \ldots \ldots \ldots \ldots \ldots \ldots \ldots$ M7.6.3

M7.6.3 Example of geometry description printout for infinite homogeneous medium ...... M7.6.5

M7.6.4 Example of geometry description printout for lattice cell $\ldots \ldots \ldots \ldots \ldots \ldots \ldots \ldots$ M7.6.5

M7.6.5 Example of geometry description printout for multiregion cell $\ldots \ldots \ldots \ldots \ldots \ldots$ M7.6.6

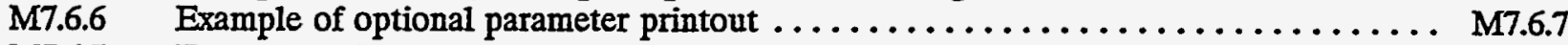

M7.6.7 Example of lattice cell zone specifications $\ldots \ldots \ldots \ldots \ldots \ldots \ldots \ldots \ldots \ldots \ldots \ldots \ldots \ldots .7 \ldots \ldots \ldots$

M7.6.8 Example of data library information table $\ldots \ldots \ldots \ldots \ldots \ldots \ldots \ldots \ldots \ldots \ldots \ldots$ M7.6.7

M7.6.9 Mixing table and parameters from the Material Information

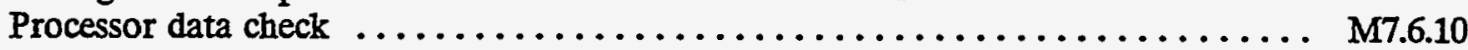

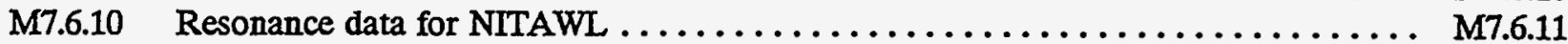

M7.6.11 Additional data for NITAWL, XSDRNPM, and BONAMI . . . . . . . . . M7.6.12

M7.A.1 Elastic scattering into $\mathrm{dE}$ about $\mathrm{E}$ when $\mathrm{E}$ lies inside a narrow resonance $\ldots \ldots \ldots$ M7.A.3

M7.A2 Transmission of an uncollided neutron through a lattice $\ldots \ldots \ldots \ldots \ldots \ldots \ldots \ldots$ M7.A.7 
M7.A.3 The escape probability $\left(\mathrm{P}_{\mathrm{FO}}\right)$ and Wigner's rational approximation, as functions of the characteristic dimension $\left[\ell \Sigma_{\mathrm{kF}}(\mathrm{E})\right] \ldots \ldots \ldots \ldots \ldots \ldots \ldots$ M7.A.10

M7.A.4 Elastic scattering into $\mathrm{dE}$ about $\mathrm{E}$ when $\mathrm{E}$ lies inside a narrow resonance ....................................... M73

M7.A.5 Elastic scattering into $\mathrm{dE}$ about $\mathrm{E}$ when $\mathrm{E}$ lies inside a broad

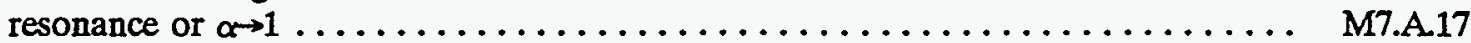

M7.A.6 Well-separated resonances in a mixture of $\mathrm{UO}_{2} \ldots \ldots \ldots \ldots \ldots \ldots \ldots \ldots$ M7.A.19

M7.A7 Hypothetical case of resonance overlap in $\mathrm{UO}_{2} \ldots \ldots \ldots \ldots \ldots \ldots \ldots \ldots \ldots$ M7.A.22

M7.A.8a Resonance overlap for ${ }^{232} \mathrm{Th},{ }^{233} \mathrm{U}$, and ${ }^{238} \mathrm{U}$ in the 4- to $10-\mathrm{eV}$

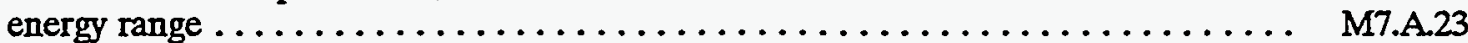

M7.A.8b Resonance overlap for ${ }^{232} \mathrm{Th},{ }^{232} \mathrm{U},{ }^{235} \mathrm{U}$, and ${ }^{238} \mathrm{U}$ in the $10-$

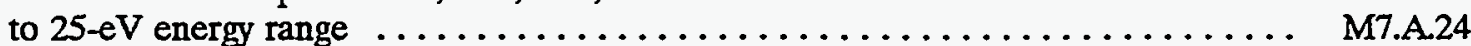

M7.A.8c Resonance overlap for ${ }^{255} \mathrm{U},{ }^{238} \mathrm{U},{ }^{239} \mathrm{Pu},{ }^{240} \mathrm{Pu},{ }^{241} \mathrm{Pu}$, and

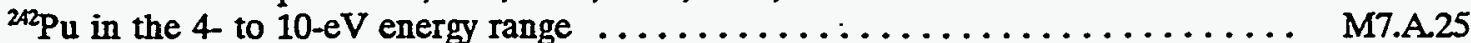

M7.A.8d Resonance overlap for ${ }^{235} \mathrm{U},{ }^{238} \mathrm{U},{ }^{239} \mathrm{Pu},{ }^{240} \mathrm{Pu},{ }^{241} \mathrm{Pu}$, and

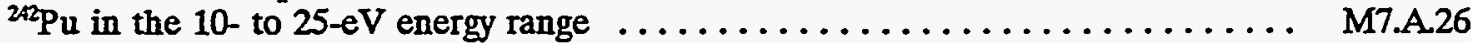

M7.A\&e Resonance overlap for ${ }^{235} \mathrm{U},{ }^{28} \mathrm{U},{ }^{239} \mathrm{Pu},{ }^{240} \mathrm{Pu},{ }^{241} \mathrm{Pu}$, and

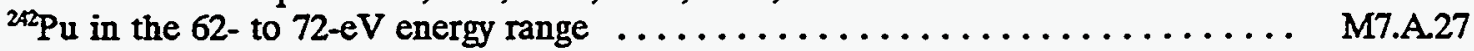

M7.A.9 Resonance self-shielded group-averaged $(\eta, \gamma)$ capture cross section for ${ }^{288} \mathrm{U}$ as a function of the background cross

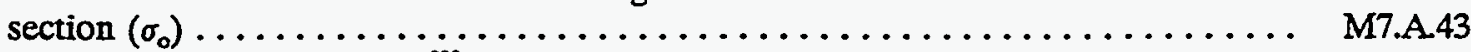

M7.A.10 Doppler broadening of the ${ }^{28} \mathrm{U}$ capture cross section near

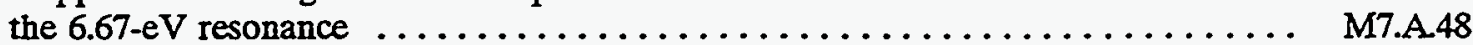

M7.A.11a Actual profiles of the Doppler-broadened ${ }^{288} \mathrm{U}$ capture cross section near the $6.67-\mathrm{eV}$ resonance . . . . . . . . . . . . . . . . . . . M7.A8

M7.A.11b Idealized rectangular profiles for the Doppler-broadened ${ }^{238} \mathrm{U}$ capture cross section near the $6.67-\mathrm{eV}$ resonance $\ldots \ldots \ldots \ldots \ldots \ldots \ldots \ldots$ M7.A.58

NUREG/CR-0200, 


\section{LIST OF TABLES}

Table

$\underline{\text { Page }}$

M7.2.1 Control sequences and their associated functional modules $\ldots \ldots \ldots \ldots \ldots \ldots \ldots \ldots$ M7.2.1

M7.2.2 Dancoff factor equations algorithms for various geometries $\ldots \ldots \ldots \ldots \ldots \ldots \ldots \ldots$ M7.2.9

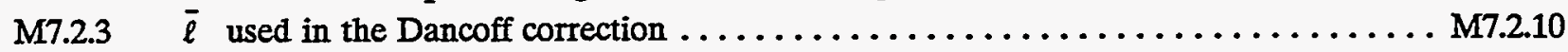

M7.4.1 Description of $\mathrm{I} / \mathrm{O}$ units utilized by the Material Information Processor $\ldots \ldots \ldots$ M7.4.1

M7.4.2 Outline of Material Information Processor data $\ldots \ldots \ldots \ldots \ldots \ldots \ldots \ldots \ldots$ M7.4.2

M7.4.3 Tables of Material Information Processor data requirements ............ M7.4.3

M7.4.4 Outline of Material Information Processor data $\ldots \ldots \ldots \ldots \ldots \ldots \ldots \ldots \ldots$ M7.4.9

M7.4.5 Outline of standard composition specification data $\ldots \ldots \ldots \ldots \ldots \ldots \ldots \ldots \ldots$ M7.4.12

M7.4.6 Optional unit cell specification for INFHOMMEDIUM problems . . . . . . . . . M7.4.19

M7.4.7 Unit cell specification for lattice cell problems $\ldots \ldots \ldots \ldots \ldots \ldots \ldots \ldots \ldots \ldots \ldots$ M7.4.21

M7.4.8 Geometry specification for multiregion problems $\ldots \ldots \ldots \ldots \ldots \ldots \ldots \ldots \ldots$ M7.4.27

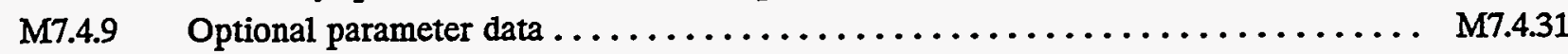

M7.5.1 Organization of notes about the Material Information Processor . . . . . . . . M7.5.2

M7.7.1 STOP codes used in Material Information Processor . . . . . . . . . . . . M7.7.17

M7.A.1 Recommended " $A$ " factors used in the modified Wigner approximation ........ M7.A11

M7.A.2 Comparison of the Dresner and Hansen-Roach resonance integrals

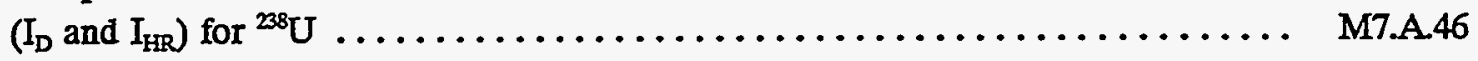

M7.A.3a Energy group structure used by Bondarenko, and some infinitely

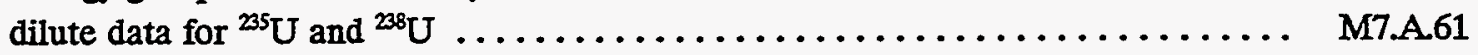

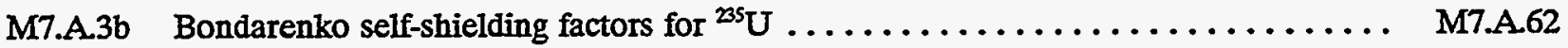

M7.A.3C Bondarenko self-shielding factors for ${ }^{238} \mathrm{U} \ldots \ldots \ldots \ldots \ldots \ldots \ldots \ldots \ldots \ldots \ldots$ M7.A.63

M7.A.4 Values of the background cross section $\left(\sigma_{0}^{28}\right)$ for several different

experiments in which $k_{\infty}$ of the homogeneous mixture was measured

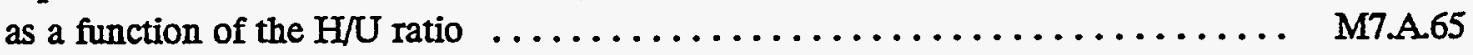

M7.B.1 Alphabetical index of Material Information Processor routines . . . . . . . . . M7.B.1

M7.B.2 Commons used in the Material Information Processor $\ldots \ldots \ldots \ldots \ldots \ldots \ldots$ M7.B.13 


\section{ACKNOWLEDGMENTS}

The concept of a Material Information Processor using alphanumeric material specifications was initially proposed and developed by R. M. Westfall. J. R. Knight and J. A. Bucholz expanded and refined the Material Information Processor. J. R. Knight developed the Standard Composition Library and many of the associated data-processing routines. He also developed routines to calculate the Dancoff factor and other resonance parameters needed by the Material Information Processor. J. A Bucholz implemented the Material Information Processor in CSAS1 and CSAS2. This work forms the basis of the current version of the Material Information Processor.

Special appreciation is expressed to L. F. Norris for her efforts in preparing this document and to Y. Y. Chan, J. R. Knight, R. C. Robinson, and W. C. Jordan for reviewing it. 


\section{M7.1 INTRODUCTION}

The Material Information Processor was developed to utilize standardized engineering-type input data and standardized procedures to provide data to create problem-dependent cross-section libraries for use by the SCALE functional modules. Information provided by the Standard Compositions Library is used by the Material Information Processor to calculate the number densities (atoms/b-cm) of each material specified in the problem, to develop data used by the resonance processors, and to utilize the automatic mesh-generator to calculate the mesh intervals used in the cell-weighting calculation. 


\section{M7.2 TECHNIQUES}

\section{M7.21 MATERIAL INFORMATION PROCESSOR FEATURES}

The Material Information Processor reads and checks a unified set of engineering-type data and performs the calculations that are necessary to create binary input data files for use by the codes BONAMI, NITAWL, and, optionally, XSDRNPM and/or ICE to provide a problem-dependent cross-section library. If the control sequence that activates the Material Information Processor activates XSDRNPM, the eigenvalue for the designated problem is calculated. The control sequences that utilize the Material Information Processor and the codes they activate are listed in Table M7.2.1. The engineering-type data read by the Material Information Processor include (1) the standard composition data (a standardized alphanumeric name, mixture number, and other data to define materials, including volume fraction or percent theoretical density, temperature, and isotopic distribution) which is used in the standardized number density calculations, and (2) a unit cell description defining the materials, dimensions, and boundary conditions of the geometry that will be used in the Dancoff factor calculations, the resonance self-shielding calculations, and the flux-weighting cell calculations used in cross-section processing.

Table M7.2.1 Control sequences and their associated functional modules

\begin{tabular}{|c|c|c|c|c|c|c|}
\hline \multirow{3}{*}{$\begin{array}{l}\begin{array}{l}\text { Control } \\
\text { sequence }\end{array} \\
\text { CSASI } \\
\text { CSASIX }\end{array}$} & \multicolumn{4}{|c|}{ Cross-section processing codes } & \multicolumn{2}{|c|}{$\begin{array}{l}\text { Criticality, shielding, and } \\
\text { burnup/decay codes }\end{array}$} \\
\hline & BONAMI-S & NITAWL-II & & ICE-S & & \\
\hline & BONAMI-S & NITAWL-II & XSDRNPM-S & ICE-S & & \\
\hline CSASN & BONAMI-S & NITAWL-II & & & & \\
\hline CSAS1X & BONAMI-S & NITAWL-II & XSDRNPM-S & & & \\
\hline CSAS25 & BONAMI-S & NITAWL-II & & & KENO V.a & \\
\hline $\operatorname{CsAS} 2 x$ & BONAMI-S & NITAWL-II & XSDRNPM-S & & KENO V.a & \\
\hline CSAS4 & BONAMI-S & NITAWL-II & & & KENO Va & MODIFY' \\
\hline CSAS4X & BONAMI-S & NITAWL-II & XSDRNPM-S & & KENO V.a & MODIFY \\
\hline SAS1 & BONAMI-S & NITAWL-II & & & XSDRNPM-S & XSDOSE \\
\hline SAS1X & BONAMI-S & NITAWL-II & XSDRNPM-S & & XSDRNPM-S & XSDOSE \\
\hline SAS2 & BONAMI-S & NITAWL-II & XSDRNPM-S & & COUPLE & $\begin{array}{l}\text { ORIGEN-S XSDRNPM-S } \\
\text { XSDOSE }\end{array}$ \\
\hline SAS3 & BONAMIS & NITAWL-II & XSDRNPM-S & ICE-S & MORSE-SGCS & \\
\hline SAS4 & BONAMI-S & NITAWL-II & XSDRNPM-S & & MORSE-SGCS & \\
\hline
\end{tabular}

-Although the text of this section (MT) refers only to NITAWL, the version available beginning with the SCALE-4 release is NITAWL-II.

${ }^{b}$ MODIFY is a control module.

\section{M722 APPLICABILITY OF THE MATERIAL INFORMATION PROCESSOR}

The Material Information Processor is primarily used to prepare data for creating the problem-dependent cross-section libraries required by the criticality safety and/or shielding sequences listed in Table M7.2.1. The Material Information Processor creates the binary input files for the cross-section processing codes. It provides only a limited set of code options to these codes; thus, the options that are exercised are considerably more limited than when the codes are executed in a "stand-alone" mode. These problem-dependent cross-section libraries can be used with any code that requires (1) a microscopic or macroscopic AMPX working format library or (2) a Monte Carlo formatted 
macroscopic cross-section library in the MORSE/KENO format. The Material Information Processor is particularly applicable for large homogeneous systems and large regular lattices of slabs, pins, or spheres. In the case of large regular lattices, it can prepare data that allow the cross-section processing codes to create a homogenized cell-weighted cross section, denoted as mixture 500, that is capable of representing a heterogeneous array of cells as a homogeneous mixture. This capability allows the three-dimensional (3-D) heterogeneous system to be modeled as a single region composed of mixture 500, the homogenized cell-weighted mixture. The Material Information Processor can create data for only one cell-weighted mixture per problem. Other limitations are discussed in this section.

\section{M7.23 NUMBER DENSITY CRITERIA OF THE MATERIAL INFORMATION PROCESSOR}

A primary function of the Material Information Processor is to calculate the "number density" (atoms $/ \mathrm{b}-\mathrm{cm}$ ) of every nuclide in each mixture defined in the problem. Known limitations in this process are listed below:

1. The available nuclides are limited to those nuclides that are included in the Standard Composition Library, and then only to those available in the specified cross-section library with the correct nuclide identifier (ID). Table M8.2.1 lists the available nuclides and the libraries containing them. A new Standard Composition Library containing additional nuclides can be created by using COMPOZ. See Sect. M14 for additional information.

2. No more than one multi-isotope nuclide can be utilized in a standard composition specification. The multi-isotope nuclides are listed in Table M8.4.1 of the standard composition section of the SCALE document.

3. Temperature data are not available for any of the solution standard compositions except uranyl nitrate (SOLNUO2(NO3)2). Data for all other solutions are given at room temperature. Note that if the specific gravity of the solution is known at a temperature other than room temperature, and it is entered in the standard composition specification using SPG $=$, the temperature effect is accounted for in the calculated number densities. The temperature should still be entered in the standard composition data so it can be used in the resonance calculations for the individual nuclides. A solution standard composition is one whose standard composition name begins with SOLN. The available solutions are listed in Table M8.3.1 of the standard composition section of the SCALE document.

4. Mixed-oxide (MOX) solutions are particularly difficult to describe in a manner that will provide correct number densities. It is possible to obtain correct number densities if the specific gravity and molarity of the mixed solution are known and the mixture is described using a SOLN standard composition name for both solutions. The volume fractions of the two SOLN standard composition specifications must sum to 1.000 . The volume fraction of the uranium solution must be entered as the weight fraction of the fuel density that is uranium, and the volume fraction of the plutonium solution must be entered as the weight fraction of the fuel density that is plutonium. See Sect. M7.5.5.6, example 1, for a MOX solution specification.

\section{M7.24 GEOMETRICAL CRITERIA OF THE MATERIAL INFORMATION PROCESSOR}

The Material Information Processor offers three types of calculations: infinite homogeneous medium, lattice cell, and multiregion. The method of specifying the desired calculation type is described in Sects. M7.4.3 and M7.5.4.

NUREG/CR-0200, 
The Material Information Processor utilizes a unit cell description to provide information for the resonance self-shielding corrections and the Dancoff corrections that are applied to the cross sections to create a problem-dependent cross-section library.

\section{M724.1 Infinite Homogeneous Medium Treatment (INFHOMMEDIUM)}

The infinite homogeneous medium treatment is best suited to large masses of materials where the size of each material is large compared with the average mean-free path of the material or where the fraction of the material that is a mean-free path of the surface of the material is very small. When the infinite homogeneous medium treatment is specified, every material specified in the problem is treated as an infinite lump. Systems composed of small fuel lumps should not be treated as an infinite homogeneous medium.

\section{M7.24.2 LATTICECELL Treatment}

The lattice cell treatment is appropriate for large arrays of slabs, fuel pins, or spherical pellets. Examples showing the use of the lattice cell treatment are given in Sect. M7.5.6.2. The input data are described in Sect. M7.4.6. When the lattice cell treatment is used, the mixtures specified in the cell have resonance self-shielding with Dancoff corrections applied to the cross sections of the nuclides utilized in the cell. All other mixtures and their nuclides are treated as infinite homogeneous media unless the appropriate resonance and Dancoff data are explicitly entered in the optional parameter data as described in Sects. M7.4.8, M7.5.7, and M7.5.10. Limitations of the lattice cell treatment are listed below:

1. The cell description is limited to a one-dimensional (1-D) cell. Most physical systems consist of 3-D geometry, but in many instances a 1-D representation is adequate, as in the case of a large array of spheres in a regular lattice, a large array of slabs, or a large array of long uniform pins in a regular lattice. A 1-D representation is inadequate for systems that exhibit a two-dimensional (2-D) or 3-D spatial dependence.

2. Only one cell description is allowed in a problem. This limitation can be circumvented by entering the appropriate data in the optional parameter data. See Sects. M7.4.8 and M7.5.10 for details.

3. The LATTICECELL treatment assumes an infinite array of 1-D cells. This assumption is an excellent approximation for large arrays of long fuel pins or large arrays of spherical pellets. The approximation becomes less rigorous for short fuel pins and/or small arrays where multidimensional spatial dependence can become important.

4. The choices of cell configurations are strictly limited. The available options are described in detail in Sect. M7.4.6 and are summarized below:

a. The first option is an infinite planar array of pin cells or an infinite array of spherical pellets. Cylindrical pins or spherical pellets consist of fuel, gap, clad, and moderator where the gap and clad are optional. The configuration of the cell requires that the innermost region must be the fuel, with subsequent regions being the gap, clad, and moderator in that order. The moderator fills the volume between the pins or pellets and the outer boundaries of the cell. The gap is the only component of the unit cell that can be a void, specified as mixture 0 .

b. The second option is an infinite planar array of annular pin cells or an infinite array of annular spherical pellets. The annular cylindrical pins or annular spherical pellets have 
an annular fuel region with an optional gap and/or optional ciad on both sides of the fuel. The second moderator is defined to be the innermost region, and the first moderator is present outside the other regions and inside the outer boundaries of the cell. The thickness and material of the gap are required to be the same on both sides of the fuel, as are the thickness and material of the clad. The moderator materials and the thicknesses of the two moderators need not be the same.

c. The third option is an infinite symmetric array of slabs, called a symmetrical slab cell. The configuration of a symmetric slab cell requires the fuel region to be the innermost region with an optional gap and/or optional clad outside the fuel region followed by a moderator region. The cell is defined to extend from the centerline of the fuel region to the center of the moderator region.

d. The fourth option is an infinite asymmetric array of slabs, called an asymmetrical slab cell. The configuration of an asymmetric slab cell requires the fuel region to be the innermost region with an optional gap and/or optional clad outside the fuel region. A moderator region exists on each side of the fuel/gap/clad region. The moderator materials and the thickness of the two moderators need not be the same. The cell is defined to extend from the centerline of one moderator region to the centerline of the second moderator region.

\section{M7.2.3.3 MULTIREGION Treatment}

The multiregion treatment is appropriate for 1-D geometric regions where the geometry effects may be important, but the infinite homogeneous media treatment or lattice cell treatment are inappropriate. The multiregion unit cell allows more flexibility in the placement of the fuel, but requires all regions of the cell to have the same geometric shape (i.e., slab, cylinder, sphere, buckled siab, or buckled cylinder). See Sects. M7.4.7 and M7.5.6.3 for more details. Limitations of the multiregion cell treatment are listed below:

1. A multiregion cell is limited to a 1-D approximation of the system being represented. This constraint is appropriate for a sphere, an infinitely long cylinder, a slab, or an infinite array of slabs.

2. The shape of the outer boundary of the multiregion cell is the same as the shape of the inner regions. Cells with curved outer surfaces cannot be stacked to represent arrays.

3. The boundary conditions available in a multiregion problem include vacuum (eliminated at the boundary), reflected (reflected about the normal to the surface at the point of impact), periodic (a particle exiting the surface effectively enters an identical cell having the same orientation and continues traveling in the same direction), and white (isotropic return about the point of impact). Reflected and periodic boundary conditions on a slab can represent a real physical situation, but are not valid on a curved outer surface.

4. A multiregion cell represents a single cell if the outer boundary has a vacuum boundary condition applied to it. The cross-section treatment then uses an interlump Dancoff factor of zero in the geometric correction calculations. 
5. If the outer boundary of a multiregion cell has a boundary condition other than vacuum, the interlump Dancoff correction is approximated by homogenizing the adjacent zones and computing the transmission through the homogenized material. This value is correct for a slab having a reflected or periodic boundary condition, but is inexact for a curved surface.

6. The interlump Dancoff factor is determined using homogenized interior zones.

\section{M7.2.5 APPLICABILITY OF PROBLEM-DEPENDENT CROSS-SECTION PREPARATION}

Cross-section processing is briefly discussed here because the Material Information Processor is indirectly involved in cross-section processing by virtue of providing binary input data files to the cross-section processing codes. The problem-dependent AMPX working format cross-section library is created by executing BONAMI and NITAWL and, optionally, ICE and/or XSDRNPM.

The cross-section processing in SCALE utilizes the Bondarenko (or shielding factor) method ${ }^{1}$ and the Nordheim Integral Treatment. ${ }^{2}$ With the exception of the 16-group Hansen-Roach library, SCALE uses BONAMI primarily to shield unresolved resonances, while NITAWL is used for the resolved resonances. The assumptions and limitations shared by these methods include:

1. The simple two-zone model used in the formulation is not valid where strong 2-D effects occur [boiling-water reactor (BWR) fuel assemblies] or where double levels of heterogeneity exist (fuel grains in some gas reactor fuels).

2. The assumption of a spatially flat flux may not be good, especially at the peak of a large resonance.

3. Thermal upscatter into the resonance range cannot be accounted for. This may be important for the $0.3-\mathrm{eV}$ resonance in ${ }^{239} \mathrm{Pu}$ and/or the $1.0-\mathrm{eV}$ resonance in ${ }^{240} \mathrm{Pu}$. For example, at $550 \mathrm{~K}$, hydrogen may supply the $0.3-\mathrm{eV}^{239} \mathrm{Pu}$ resonance with approximately $40 \%$ as many neutrons via upscatter as via downscatter. Incoherent scattering with hydrogen may scatter neutrons up as high as $2.0 \mathrm{eV}$. Upscatter effects are also important when the moderating nuclide is bound in a crystalline lattice such as graphite or beryllium.

\section{M7.2.5.1 Applicability of the Bondarenko Method}

The Bondarenko method is basically an "infinite medium" method that parameterizes cross sections for a nuclide as a function of temperature, $T$, and $\sigma_{0}$, the "background" cross section of all the other nuclides mixed with the nuclide. Section F1.2 contains a more-detailed discussion of this method. Simplistically, if the temperature and cross-section values are known, the self-shielded cross sections are determined by interpolating the tabulated parameterized data. Because self-shielding causes changes in the background cross sections that apply to a nuclide, an iterative procedure is used for each nuclide in the problem.

To account for geometric effects, the $\sigma_{0}$ value is augmented by an escape cross section, $\sigma_{c}$. This escape cross-section value is a function of the geometry and the total cross-section value in the medium. Many implementations of this approach use either the Wigner rational approximation $\left(\sigma_{c}=1 / \ell \mathrm{N}_{\mathrm{i}}\right)$, or a modified form. BONAMI uses "exact" values of escape probabilities for the three simple geometries (slabs, cylinders, and spheres) as developed by Case, de Hoffman, and Placzek. ${ }^{3}$ These "exact" values are based on the assumption that the flux in each region is spatially flat and the scattering is isotropic. Multizone situations such as reactor lattices are accounted for by the use of Dancoff factors, which are used to modify the escape probability and, hence, the value of $\sigma_{e}$. 
Several of the approximations used in the Bondarenko method are known to be inadequate in some situations. At low energies, many nuclides have resonances that are wide when compared with the scattering ranges for the mixtures in a particular configuration. This discrepancy typically leads to crosssection values that are too high in the resonances. Systems with nuclides whose resonances overlap also cause inaccuracies. In SCALE, the Bondarenko factors are used primarily in the unresolved energy region where the resonances are too narrow to be resolved into sets of resonance parameters. Although the flat flux and isotropic scattering approximations used to determine escape probabilities may have an effect on the group-averaged values, a potentially larger effect is possible because of the procedures used to generate the original Bondarenko factor tables. These tables may not have included all of the resonanceresonance overlap terms. However, given proper Bondarenko factors for the unresolved range, the treatment is probably adequate for treating an "unresolved" region.

SCALE uses the Bondarenko method to shield its 16-group Hansen-Roach cross-section library. As originally distributed, this library contained several sets of data for importance resonance nuclides that were characterized by various values of background cross sections, $\sigma_{0}$. The basic sets were generated using narrow resonance approximations, and were adjusted to make them accurately calculate the multiplication factor for a variety of critical experiments. This adjustment accounts for the success of the Hansen-Roach library in accurately calculating many types of criticality problems. This library was converted into Bondarenko format by dividing the "shielded" cross-section sets by a reference infinite dilution set. Advantages of converting them to Bondarenko format include:

1. The user does not have to determine the appropriate value of $\sigma_{0}$ because BONAMI does it automatically.

2. Because $\sigma_{0}$ varies as a function of energy, the user is not restricted to a single set of data.

3. The $\sigma_{0}$ values can be interpolated rather than using only a set of discrete values.

4. $\sigma_{0}$ is modified to account for lattice and two-region geometrical effects.

Although there are many approximations in the basic cross sections used to create the 16-group Bondarenko factors, the Bondarenko treatment has significantly increased its utility for SCALE users.

\section{M7.252 Applicability of the Nordheim Integral Method}

The Nordheim Integral treatment is discussed in detail in Sect. F2.2. It is basically a two-region integral transport theory method for a fuel lump surrounded by a moderator region. The moderator region is assumed to have an asymptotic (1/E) flux at all energies and over all space. Escape probabilities are used to account for coupling between the two regions. As with BONAMI, NITAWL uses exact escape probabilities for slabs, cylinders, and spheres as developed by Case, de Hoffman, and Placzek, ${ }^{3}$ but which are based on the assumption of a flat flux and isotropic scattering in the fuel lump. To account for lattice effects, a Dancoff factor can be specified, though it is a single value that must be used at all energies. The Nordheim Integral Treatment considers only one resonance nuclide in its calculation (i.e., the overlap between resonances of different nuclides is not treated), and a separate calculation is performed for each resonance using the assumption that the resonances of a nuclide do not overlap.

Because NITAWL does not include resonance-resonance overlap, it does not accurately treat nuclides having large low-energy resonances $\left({ }^{223} \mathrm{U}\right.$ and $\left.{ }^{241} \mathrm{Pu}\right)$ or multinuclide systems that contain many overlapping resonances such as (1) systems containing MOXs of uranium and plutonium and (2) advanced thorium converter systems. For fast reactor systems, the effects are not as severe as might be expected for criticality studies because the most important energy region is high relative to the resolved energy regions for most nuclides. For systems involving primarily ${ }^{235} \mathrm{U}$ and ${ }^{238} \mathrm{U}$, such as the light-water

NUREG/CR-0200,

Vol. 3, Rev. 4 
reactor (LWR), the Nordheim treatment is quite good because the resonance overlap effect for these two nuclides is small.

An area in which the Nordheim method is particularly weak is that of calculating small, tightly packed lattices, where the flux in the moderator is significantly different from the assumed asymptotic value, for example, gas-reactor fuel where tiny fuel pellets are coated with a graphite moderator.

The use of escape probabilities based on the flat flux and isotropic scattering assumptions used in NITAWL introduce errors in some cases. Fix-ups ${ }^{4,5}$ (not available in NITAWL) involving the use of transport corrections to the scattering have been tried but have not been entirely satisfactory. Cohen ${ }^{6}$ derived probabilities based on a hyperbolic cosine-shaped source which should be more accurate for some cases.

The fact that the Nordheim method only treats free atom elastic scattering may introduce errors where inelastic sources are important or where upscattering effects for low-energy resonances are important. The Nordheim treatment as implemented in SCALE has been shown to be adequate for treating a variety of critical experiment problems and other problems. The user should be aware of the limitations inherent in the Material Information Processor and the cross-section processing performed by $S C A L E$ and use them accordingly.

\section{M7.25.3 Applicability of the Dancoff Factor}

The Nordheim method was designed to treat a single fuel lump in an infinite moderator. To account for the heterogeneous effects of a lattice of fuel lumps, a correction known as the Dancoff factor is applied to the leakage probability from the lump. The interlump Dancoff factor $(C)$ is the probability that a neutron emitted isotropically from the surface of one absorber lump will pass through the external media and enter a nearby absorber lump. In the case of an annular region, the total Dancoff factor is a weighted sum of the interlump factor and the probability of a neutron emitted on the inner surface of the annulus reentering the annulus without experiencing a collision. The weighting factors are the inner and outer surface areas of the annular region.

$$
C=\left(A_{0} C_{0}+A_{i} C_{1}\right) /\left(A_{0}+A_{i}\right)
$$

where

C is the total Dancoff factor,

$A_{0}$ is the outer surface area of the region,

$\mathrm{C}_{\mathrm{o}}$ is the Dancoff factor associated with the outer surface,

$A_{i}$ is the inner surface area of the region,

$\mathrm{C}_{\mathrm{i}}$ is the Dancoff factor associated with the inner surface.

Interaction probabilities are calculated for lattices of spheres, infinitely long cylinders, or infinite slabs. The algorithms used in SCALE for LATTICECELL problems were developed in SUPERDAN, ${ }^{7}$ a program that uses a double numerical integration to analytically determine the Dancoff factor of spheres, cylinders, and slabs. In each case, the program accounts for any cladding that might be present. For a particular fuel lump, the total Dancoff factor (C) is calculated for the appropriate lattice. The overshadowing of one neighboring lump by another is accounted for analytically and includes all nearest and second-nearest neighbors. Figure M7.2.1 represents cylindrical pins in a square lattice, and Fig. M7.2.2 represents cylindrical pins in a triangular lattice. The Dancoff factor is the summation of the 


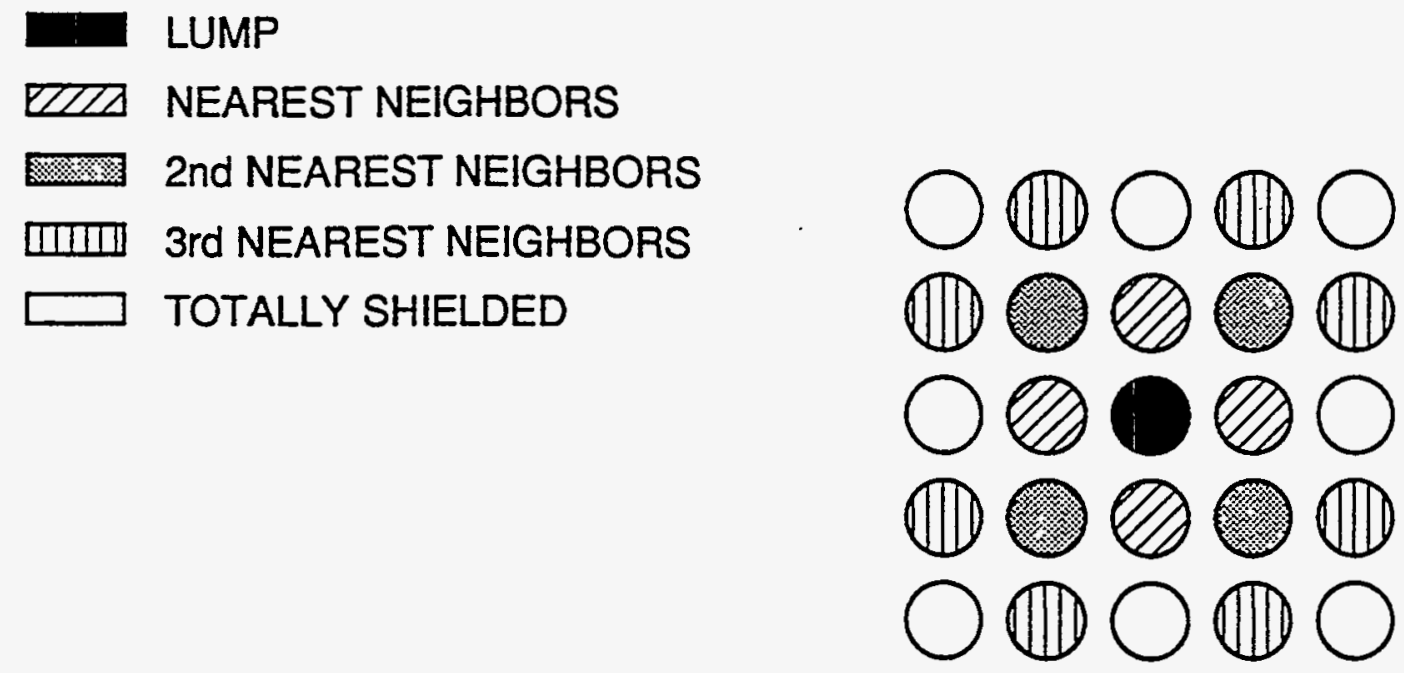

Figure M7.2.1. Representation of a lump and its neighbors for cylindrical pins in a square lattice

LUMP

EII NEAREST NEIGHBORS

2nd NEAREST NEIGHBORS

IIIIII) 3rd NEAREST NEIGHBORS

TOTALLY SHIELDED

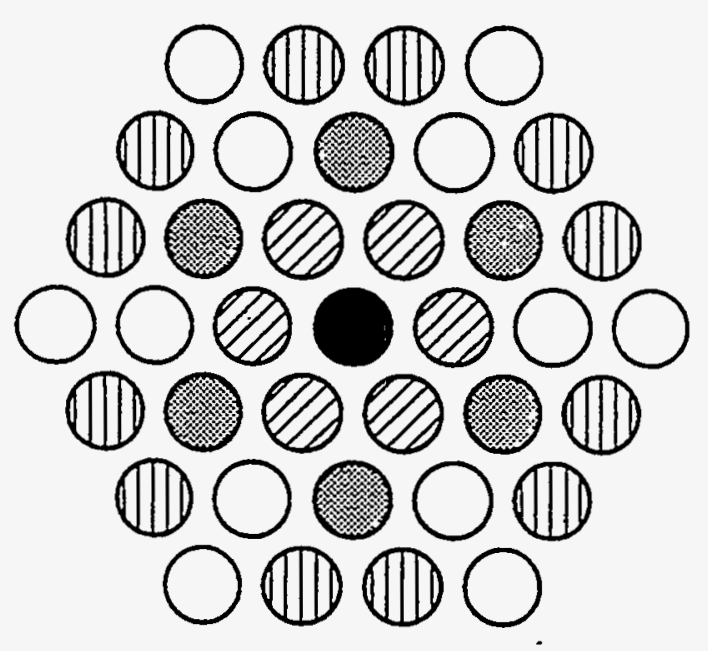

Figure M7.2.2 Representation of a lump and its neighbors for cylindrical pins in a triangularpitch lattice 
Table M7.2.2 Dancoff factor equations for various geometries

\begin{tabular}{|c|c|c|c|c|c|}
\hline \multirow[b]{2}{*}{ Fuel lump } & \multirow[b]{2}{*}{$\begin{array}{l}\text { Type of } \\
\text { lattice pitch }\end{array}$} & \multicolumn{3}{|c|}{ Number of neighbors } & \multirow[b]{2}{*}{ Dancoff } \\
\hline & & Nearest & $\begin{array}{l}\text { Second } \\
\text { nearest }\end{array}$ & $\begin{array}{l}\text { Third } \\
\text { nearest }\end{array}$ & \\
\hline Cylinder & Square & 4 & 4 & $8^{a}$ & $c=\sum_{i=1}^{8} c_{1}$ \\
\hline Cylinder & Triangular & 6 & 6 & $12^{a}$ & $C=\sum_{i=1}^{12} C_{i}$ \\
\hline Sphere & Square & 6 & 12 & 8 & $c=\sum_{i=1}^{26} c_{i}$ \\
\hline Sphere & Triangular & 12 & 6 & 8 & $C=\sum_{i=1}^{26} C_{i}$ \\
\hline Slab & - & 2 & - & - & $C=\sum_{i=1}^{2} C_{i}$ \\
\hline
\end{tabular}

${ }^{a}$ Not included in the SUPERDAN treatment.

Dancoff factors of all fuel regions visible to the lump. See Table M7.2.2 for the appropriate equations used to determine the Dancoff factor.

In order to treat the interaction to the third and subsequent nearest neighbors, a correction factor, $\mathrm{CF}$, is added to the Dancoff factor, $\mathrm{C}$, calculated using the SUPERDAN algorithm. The CF is determined by repeating the Dancoff calculation using a void in the place of the moderator. This computation yields a Dancoff factor, $\mathrm{D}_{0}$, which represents the fraction of the solid angle that is being treated by the SUPERDAN algorithm. Since the true solid angle should be 1.0, the untreated solid angle is $1.0-D_{0}$. An exponential attenuation based on the total cross section, $\Sigma_{\mathrm{T}}$, of the moderating media and an estimated distance $\bar{\ell}$ is applied to the untreated solid angle, that is,

$$
\begin{gathered}
C F=\left(1.0-D_{0}\right) e^{-\Sigma_{I_{m}} \bar{l}}, \\
D F=C+C F,
\end{gathered}
$$

where $\bar{\ell}$ is given in Table M7.2.3 and the untreated fraction of the solid angle is shown graphically in Fig. M7.2.3.

The magnitude of the correction, $\mathrm{CF}$, and the effect on a calculated $\mathrm{k}_{\mathrm{eff}}$ will depend on both the geometry of the system and the moderator cross section. This Dancoff treatment calculates the correct limits for cases in which the particle size and/or the moderator cross section are very small. The ratio $\mathrm{CF} /(1-\mathrm{DF})$ provides a quantity that can be used to estimate the importance of the correction. For a 
Table M7.2.3 $\bar{l}$ used in the Dancoff correction

\begin{tabular}{ll}
\hline System geometry & \multicolumn{1}{c}{$\bar{\ell}$} \\
\hline Cylindrical square pitch & Pitch $\times \sqrt{5}$ \\
Cylindrical triangular pitch & Pitch $\times \sqrt{7}$ \\
Spherical square pitch & Pitch $\times(\sqrt{5}+\sqrt{7}) / 2$ \\
Spherical triangular pitch & Pitch $\times \sqrt{3}$ \\
\hline
\end{tabular}

\section{Untreated fraction of solid angle}

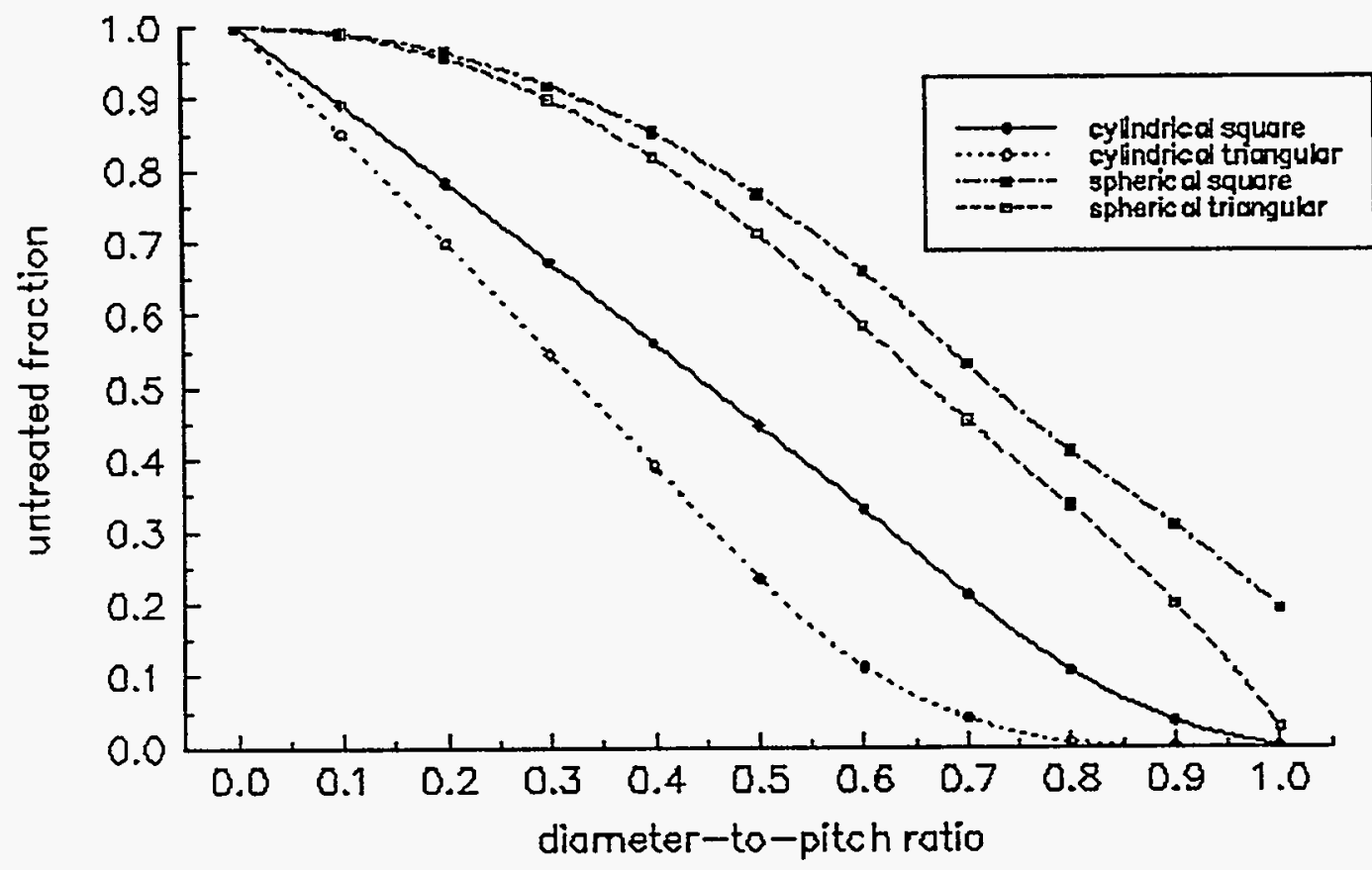

Figure M7.2.3 Untreated fraction of solid angle 
typical LWR lattice, this ratio is on the order of $10^{-3}$, with a change in $k_{\infty}$ of $<10^{-5}$. Other studies with LWR fuel indicate ratios less than 0.01 lead to changes in $k_{\infty}$ less than $0.1 \%$, and ratios less than 0.2 lead to changes in $\mathrm{k}_{\infty}$ of less than $2 \%$.

\section{M7.25.4 The One-Dimensional Approximation With/Without Buckling}

The Material Information Processor assumes that the physical system may be adequately represented in one dimension. For most lattice cell calculations, this is a reasonable approximation since the leakage out the ends of a fuel rod is almost negligible and the effect of neighboring fuel rods may be accounted for by using the appropriate boundary condition. For multiregion calculations, however, the implications of the approximation should be examined more carefully. In 1-D calculations, cylinders are assumed to be infinitely long and slabs are assumed to be of infinite extent in both of the transverse directions. Hence, a true 1-D calculation in these geometries would tend to overestimate the $k_{\text {eff }}$ of the physical system.

To partially alleviate this difficulty, it is possible to use a buckling correction that accounts for the leakage out of the system in the transverse direction(s). To do this, the leakage in each group is calculated as $\mathrm{D}_{\mathrm{g}} \mathrm{B}_{\mathrm{g}}{ }^{2} \phi_{\mathrm{g}}$ and treated as an absorption term in the transport equation. Here, $\mathrm{D}_{\mathrm{g}}$ is the diffusion coefficient:

$$
D_{8}=1 /\left(3 \Sigma_{T R_{8}}\right)
$$

and the buckling, $B_{g}^{2}$, is given by

$$
\mathrm{B}_{g}^{2}=\left(\pi / \mathrm{DY} \mathrm{g}_{\mathrm{g}}^{*}\right)^{2}+\left(\pi / \mathrm{DZ} \mathrm{g}_{\mathrm{g}}^{*}\right)^{2}
$$

in slab geometry, and

$$
\mathrm{B}_{8}^{2}=(\pi / \mathrm{DY})_{8}^{*}
$$

in cylindrical geometry. $\mathrm{DY}_{\mathrm{g}}^{*}$ and $\mathrm{DZ} Z_{\mathrm{g}}^{*}$ are the extrapolated dimensions of the assembly defined by

$$
D Y_{g}^{*}=D Y+2 d_{g}
$$

and

$$
\mathrm{DZ}_{\mathrm{g}}^{*}=\mathrm{DZ}+2 \mathrm{~d}_{\mathrm{g}}
$$

where DY and DZ are the actual dimensions of the assembly and $d_{g}$ is the extrapolation distance from the surface of the assembly. For a semi-infinite system in planar geometry, the analytic solution to the Milne problem yields $d=(0.710446) \lambda_{\mathrm{TR}}$. For smaller systems, $d$ can be shown to lie between $(0.7104) \lambda_{\mathrm{TR}}$ and (1.3333) $\lambda_{\text {IR. }}$. Within the XSDRNPM code, $d$ is calculated as

$$
\mathrm{d}_{\mathrm{B}}=(1 / 2)(\mathrm{BKL}) \lambda_{\mathrm{TR}_{\mathrm{z}}}=(1 / 2)(\mathrm{BKL})\left(1 / \Sigma_{\mathrm{TR}_{\mathrm{z}}}\right)
$$


where $B K L$ is an optional parameter that the user may supply. A default value of $B K L=1.420892$ is typically supplied by the control module. Even though it is true that underestimating the extrapolation distance (i.e., using a value of BKL that is too small) will cause a buckling-corrected transport calculation to underestimate $\mathrm{k}_{\text {er }}$ by a slight amount, that is nearly always a second- or third-order effect. In systems with transverse dimensions small enough for $d$ to be much greater than $(0.7104) \lambda_{I R}$, the 1-D approximation is no longer valid and a 2-D model of the physical system is probably required.

\section{M7.2.5.5 Use of XSDRNPM by the Material Information Processor}

The Material Information Processor prepares data that are used by the 1-D discrete-ordinates code XSDRNPM. XSDRNPM performs the dual functions of (1) criticality safety analyses and (2) crosssection processing to create a homogenized cell-weighted mixture cross section. The Material Information Processor utilizes an automatic mesh generator and an automatic quadrature generator to supply data for XSDRNPM. The automatic mesh generator creates a mesh across the material zones used to calculate the fluxes that are used in calculating $\lambda$, the neutron muitiplication factor, and in creating the homogenized cell-weighted mixture cross section. The angular quadrature is used to divide the directions of the angular flux into discrete bins defined by the direction cosines. Appropriate weights are defined to be used in the numerical integtation of the angular-dependent flux to obtain a scalar flux used in the calculation.

\section{M7.25.6 The Automatic Mesh Generator}

The Material Information Processor determines the number and location of mesh boundaries within a zone using an algorithm based on the total epithermal cross section and asymptotic diffusion length in each mixture. The number of mesh intervals used in a calculation may be increased or decreased by entering a value for the parameter $\mathrm{SZF}=$ in the optional parameter data.

Within a particular material zone, the mesh boundaries are logarithmically symmetric about the midpoint of the zone as shown in Fig. M7.2.4.

Assuming a total of $N$ mesh intervals in a zone, the size of each mesh interval $\left(\Delta r_{n}\right)$ is given by

$$
\Delta \mathrm{r}_{\mathrm{n}}=0.5\left(\mathrm{r}_{\mathrm{o}} \mathrm{I}_{\mathrm{i}}\right) \log _{10}\{[\mathrm{~N}+18(\mathrm{n})] /[\mathrm{N}+18(\mathrm{n}-1)]\} . \mathrm{n}=1,2, \ldots, \mathrm{N} / 2
$$

This logarithmically symmetric distribution has the advantage of providing more mesh intervals near the material zone interfaces where greater flux gradients are likely to exist. To determine $\mathrm{N}$, the size of the largest mesh interval must be less than some specified number of mean free paths or asymptotic diffusion lengths. Specifically, $\mathrm{N}$ is determined by applying the requirement that

$$
\begin{aligned}
& \left(\Delta r_{\max }\right) \leq(S Z F)(0.06)\left(\lambda_{T}\right) \text { for LATTICECELL calculations, or } \\
& \left(\Delta r_{\max }\right) \leq(S Z F)(0.15)(L) \text { for MULTIREGION calculations, }
\end{aligned}
$$

where the size factor (SZF) is an optional control parameter that may be specified by the user, and $L$ is the asymptotic diffusion length for the mixture defined by

$$
(1 / L)^{2}=3 \Sigma_{\mathrm{A}} \Sigma_{\mathrm{S}}(1-\bar{\mu})\left(1-4 \Sigma_{\mathrm{A}} / 5 \Sigma_{\mathrm{T}}\right)
$$

The asymptotic diffusion length is computed using epithermal cross-section data from the Standard Composition Library (see Sect. M8). The constants [0.06 and 0.15 in Eq. (M7.2.11)] were chosen to ensure an adequate mesh size when SZF is set to its default value of 1.0. The size of the largest mesh

NUREG/CR-0200,

Vol. 3, Rev. 4

M7.2.12 
interval can be adjusted by entering a value for SZF in the optional parameter data. For LATTICECELL calculations, the number of mesh intervals in a zone is given by

$$
N=18 /\left(10^{x}-1\right)
$$

where

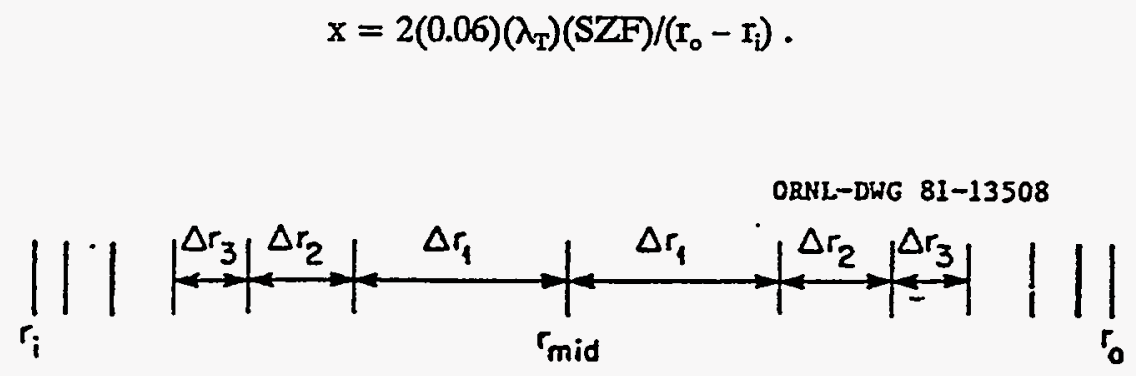

Figure M7.2.4. Mesh spacing scheme used in material zone

A similar expression is obtained for the multiregion case. For optically thin regions such as voids or thin cladding, $\mathbf{N}$ is assigned a value of 4 whenever the equation yields a smaller value. $N$ is always defaulted to 1 for an infinite-homogeneous-media calculation.

\section{M7.2.5.7 The Automatic Quadrature Generator}

The discrete-ordinates code, XSDRNPM, solves for the angular flux $\left(\psi_{\mathrm{m}}\right)$ in a number of discrete directions $\left(\bar{\Omega}_{m}=\mu_{m} \bar{i}+\eta_{m} \bar{j}+\xi_{m} \bar{k}\right)$ in each spatial mesh. The scalar flux in each mesh $(\phi)$ is then computed using a numerical quadrature of the form:

$$
\phi=\underset{\mathrm{m}}{\mathbf{\Sigma}} \mathrm{W}_{\mathrm{m}} \psi_{\mathrm{m}}
$$

where $W_{m}$ is the weight associated with direction $\overline{\mathbf{Q}}_{\mathrm{m}}$.

XSDRNPM automatically calculates the direction cosines and the associated weights for the specified geometry. The number of discrete directions (MM) generated for a quadrature of order ISN is given by

and

$$
M M=I S N+1 \quad \text { for slab or spherical geometry }
$$

$$
\mathrm{MM}=\mathrm{ISN}^{*}(\mathrm{ISN}+4) / 4 \text { for cylindrical geometry. }
$$

In spherical geometry, the calculated directions and weights correspond to those of a simple Gaussian quadrature set of order ISN. In slab geometry, XSDRNPM calculates a Gaussian quadrature set of

More precisely: $\mu_{i}= \pm X_{j}$, where $\left\{x_{j}\right\}$ are the $(m / 2)$ positive roots of $P_{m}(x)=0.0$, where $m=I S N$; and $w_{i}=W_{j} / 2$, where $\left\{W_{j}\right\}$ are the Gaussian weights associated with $\left\{x_{j}\right\}$. The starting direction, $\mu_{o}=$ -1 , is assigned a zero weight. 
order ISN/2, compresses it from $180^{\circ}$ down to $90^{\circ}$ (for symmetry), and uses this compressed quadrature in combination with its mirror image." (In both slab and spherical geometry, one additional direction having an associated weight of 0.0 is also included.) In cylindrical geometry, the polar angles $(\theta)$ correspond to the positive angles of a Gaussian quadrature of order ISN while the azimuthal angles $(\phi)$ are equally spaced as shown in Fig. M7.2.5." This equal spacing of the azimuthal angles corresponds to a Chebyschev quadrature in $\phi$. Note that one additional angular direction having an associated weight of 0.0 is also included for each of the polar angles $(\theta)$.

The quadrature order (ISN) is an optional control parameter that may be specified by the user. The SCALE criticality safety analysis sequences normally default to ISN $=8$. The user may increase or decrease the quadrature order to verify the accuracy of a particular calculation. ISN $=8$ has been found to be adequate for most LATTICECELL calculations. In MULTIREGION calculations having a reflector, ISN $=8$ will generally be adequate, although the user may wish to compare the resulting $k_{\text {efr }}$ and/or scalar fluxes with those of another calculation using ISN $=12$. Accurate determination of the scalar fluxes deep in a thick shield may require ISN $=16$.

\section{M7.25.8 XSDRNPM Convergence Criteria}

The convergence criteria for the XSDRNPM calculation used to create the cell-weighted cross sections are the optional control parameters EPS and PTC in the Material Information Processor input. Terms useful in describing the convergence criteria are defined below:

$$
\begin{aligned}
& Q \quad \equiv \text { total fixed source in system } \\
& \text { F } \quad \text { = total fission neutron source } \\
& D \equiv \text { total outscatter }=\sum_{i} \sum_{\mathbf{g}} \sum_{g^{\prime} \neq g} \phi_{i, g} \sigma_{g \rightarrow g^{\prime}} V_{i} \\
& \phi_{\mathrm{ig}} \equiv \text { scalar flux in group } \mathrm{g} \text {, interval } \mathrm{i} \\
& V_{i} \equiv \text { volume of interval } \mathrm{i} \\
& \sigma_{g \rightarrow g^{\prime}} \equiv \text { group } \mathrm{g} \text { to group } \mathrm{g}^{\prime} \text { transfer cross section } \\
& \text { IGM } \equiv \text { number of energy groups } \\
& \mathrm{q}_{\mathrm{g}} \quad \equiv \text { fixed source in group } \mathrm{g} \\
& \mathrm{f}_{\mathrm{g}} \equiv \text { fission source in group } \mathrm{g}
\end{aligned}
$$

"More precisely: $\mu_{i}= \pm\left(1 \pm x_{j}\right) / 2$; where $\left\{x_{j}\right\}$ are the $(m / 2)$ positive roots of $P_{m}(x)=0.0$, where $\mathrm{m}=\mathrm{ISN} / 2$; and $\mathrm{w}_{\mathrm{i}}=\mathrm{W}_{\mathrm{j}} / 4$, where $\left\{\mathrm{W}_{\mathrm{j}}\right\}$ are the Gaussian weights associated with $\left\{\mathrm{x}_{\mathrm{j}}\right\}$. The starting direction, $\mu_{0}=-1$, is assigned a zero weight.

“.More precisely: $\eta_{\mathrm{i}}=\cos \left(\theta_{\mathrm{i}}\right)$ are the $(\mathrm{m} / 2)$ positive roots of $\mathrm{P}_{\mathrm{m}}(\eta)=0.0$ where $\mathrm{m}=\mathrm{ISN} ; \mu_{\mathrm{ij}}= \pm$ $\sqrt{1-\eta_{i}^{2}} \cos [\pi(j-0.5) / 2 i]$ where $j=1,2, \ldots, i$; and $w_{i j}=W_{j} /(2 i)$ where $\left\{w_{i}\right\}$ are the Gaussian weights associated with $\left\{\eta_{i}\right\}$. The starting direction, $\mu_{i, o}=-\sqrt{1-\eta_{i}^{2}}$, is assigned a zero weight. 


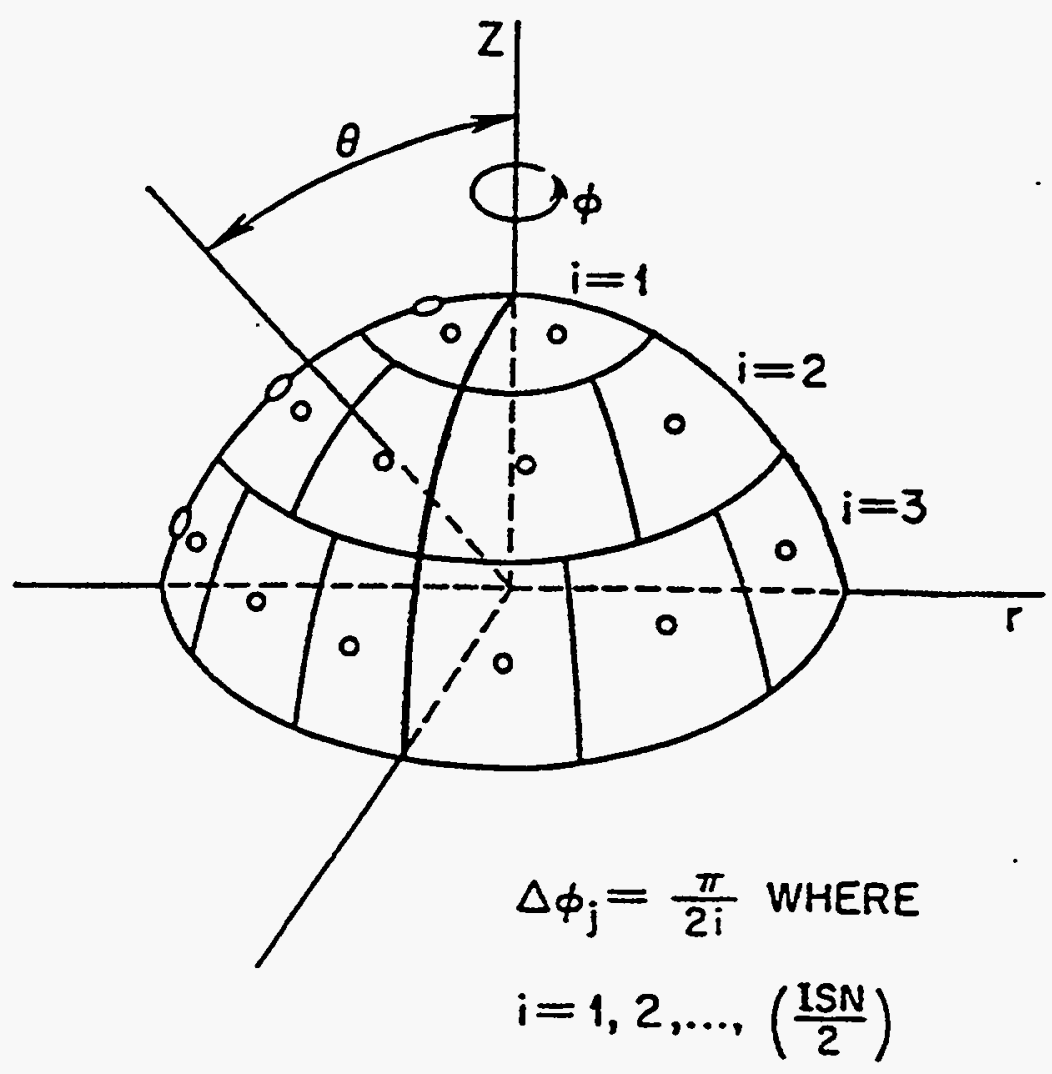

Figure M7.2.5. Angular directions associated with an $\mathrm{S}_{6}$ Gauss-Chebyschev quadrature set for cylindrical geometry

$$
\begin{aligned}
& \epsilon_{\mathrm{p}}^{\prime}=\left(\frac{\mathrm{q}_{\mathrm{g}}+\mathrm{f}_{\mathrm{g}}}{\mathrm{IGM}}\right) \text { EPS } \\
& k \quad \equiv \text { outer iteration number (do not confuse with the multiplication factor) } \\
& \lambda_{k} \equiv \frac{Q+F_{k}}{Q+F_{k-1}} \text { (SOURCE RATIO in output) } \\
& G_{k} \equiv \frac{D_{k}}{Q+F_{k}}
\end{aligned}
$$




$$
\begin{aligned}
& \lambda_{k}^{\prime} \equiv \frac{G_{k-1}}{G_{k}} \quad \text { (SCATTER RATIO in output) } \\
& U_{k} \equiv \text { total upscatter rate }=\sum_{i} \sum_{g} \sum_{g^{\prime}<g} \phi_{i, g} \sigma_{g-g^{\prime}} V_{i} .
\end{aligned}
$$

An inner iteration consists of sweeping one time through the entire spatial mesh and calculating the flux for all the $S_{n}$ angles in one energy group. A sweep through all energy groups is called an outer iteration.

When the fluxes for a particular group are being calculated, the inner iterations will continue until (1) the number of inner iterations in this outer exceed IIM (the inner iteration maximum), or (2) until the following criteria are met:

(1) $\sum_{i}\left|\left(\phi_{i, g}^{k}-\phi_{i, g}^{k-1}\right)\right| \sigma_{g-g^{\prime}} V_{i} \leq \epsilon_{g}^{\prime}$

(2) $\sum_{i}\left|\left(\phi_{i, g}^{k}-\phi_{i, g}^{k-1}\right)\right|\left(\sigma_{t}-\sigma_{g \rightarrow g^{\prime}} V_{i} \leq \epsilon_{g}^{\prime}\right.$

If PTC (the point flux convergence criteria) is greater than zero, XSDRNPM also requires

$$
\max _{i}\left|\frac{\phi_{i, g}^{k}-\phi_{i, g}^{k-1}}{\phi_{i, g}^{k}}\right| \leq \text { PTC }
$$

At the end of an outer iteration, the following checks are made:

(4) $\left|1.0-\lambda_{t}\right| \leq$ EPS

(5) $R\left|1.0-\lambda_{k}^{\prime}\right| \leq$ EPS

(6) $\mathrm{R}\left|1.0-\frac{\mathrm{U}_{k-1}}{\mathrm{U}_{k}}\right| \leq \mathrm{EPS}$

$R$ is a convergence relaxation factor that is automatically set to 0.5 within XSDRNPM. If all the convergence criteria are met or if the maximum allowed number of outer iterations is reached, the XSDRNPM calculation will terminate with full output. Otherwise, another outer iteration will be started. 


\section{M73 THE LOGICAL PROGRAM FLOW}

The general flow of the Material Information Processor is given in this section. An abbreviated representation, rather than a formal flow chart, is used to outline the program flow. A flow chart may show a subroutine or library routine only once, even though it may be called several times. The text usually states when multiple calls are made to a subroutine or library routine. Each flow chart is accompanied by an explanation of the purpose of that segment of the program and text describing the subroutines referenced in the flow chart.

The segment of the program shown in Fig. M7.3.1 activates the Material Information Processor. The Material Information Processor reads data that specify the cross-section library, defines the materials to be used in the problem, and provides data used to apply resonance corrections to the cross sections. The data are read and checked, and calculations are performed to create a mixing table and provide data to the functional modules that are invoked by the control module.

CADATA - This is the subroutine through which the Material Information Processor is activated. It opens the units that will be used to pass data to the functional modules. Throughout the subroutine, pointers are defined for various types of data, and STOP is called to write a message if the data arrays require more storage than is available. The call to subroutine KNIGHT initiates the reading and preparation of data for use in the functional modules involved in cross-section preparation. All other subroutines called by C4DATA carry out operations to prepare and check data that will be used by the functional modules activated by the sequence.

AXSDRN - This subroutine is used by the SAS4 sequence and is replaced by a dummy for the CSAS sequences.

STOP - $\quad$ This library routine may be called many times from C4DATA. If the computer storage is insufficient to contain the data arrays, it is called to write an error message. Depending on the arguments passed to it, this routine can also do any or all of the following: print a traceback, execute a stop, or return to the calling program.

KNIGHT - This subroutine initiates the preparation of data for use in the functional modules involved in cross-section preparation. It is described in more detail in Sect. M7.3.1.

CINIT - $\quad$ This subroutine is called to clear the offsets into the pointer storage array and set the CSAS and KENO V.a offsets. OPENDA is called to open the random access units or devices, RITE writes the offsets on a random access unit, and INQUIR returns the number of the next random access block.

SMMTBA - This subroutine is called to set the unit number corresponding to the specified master cross-section library.

SHORTX - The purpose of this subroutine is to copy only those nuclides utilized in the standard composition specification data to unit 11 for processing by the functional module BONAMI and to print the Data Information Table. LOGID determines if the composition name from the standard composition library was specified in the standard composition specification data. OPNFIL is used to open the specified cross-section library and unit 11. COPY is used to copy the cross-section data to unit 11. 


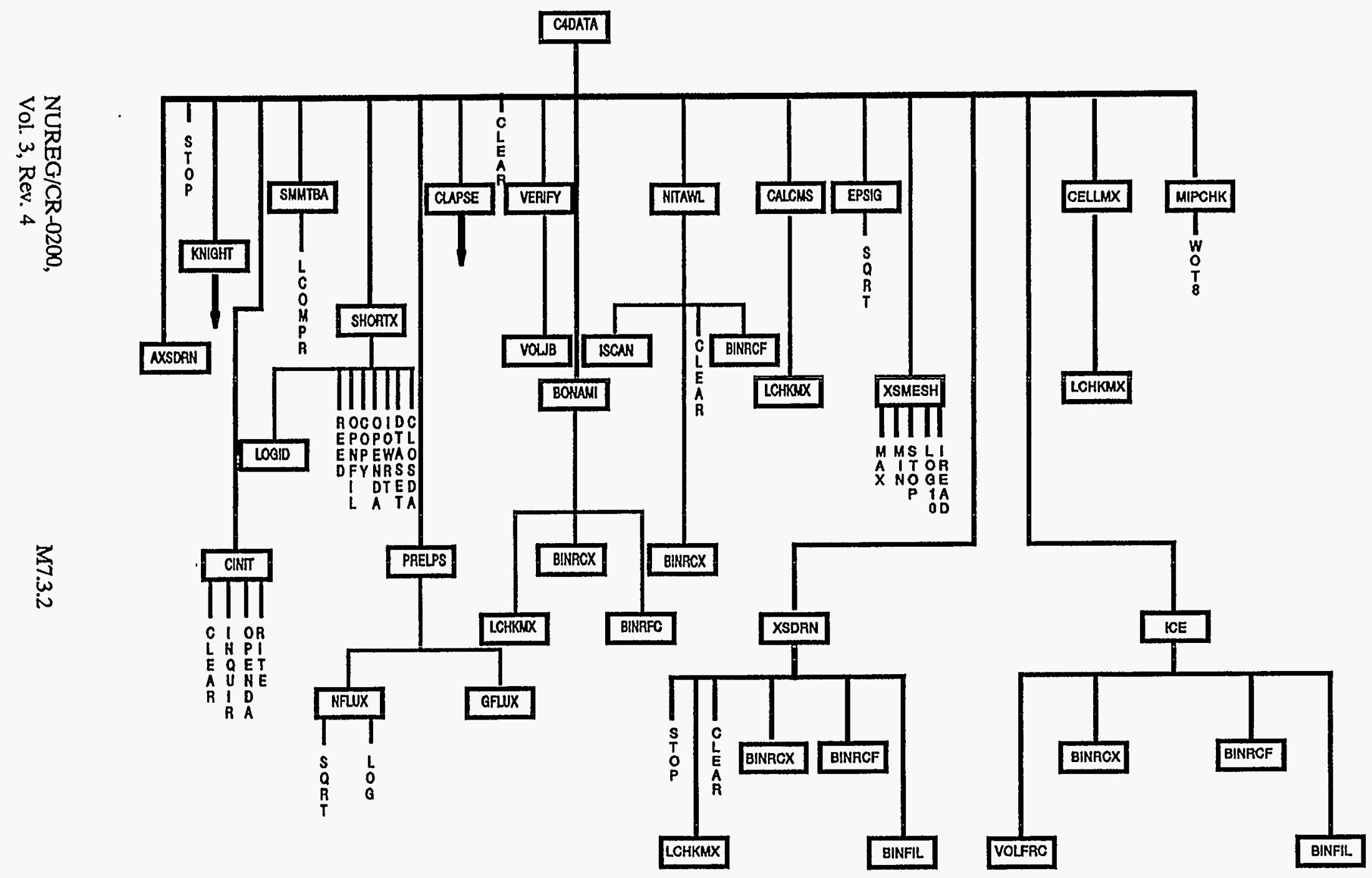

Figure M7.3.1. Flow chart of the Material Information Processor 
The library routine OPENDA is called to open the direct-access data set. IOWRT is a library routine that prints the data set name and the volume where the data set resides for the specified unit number. It is called several times to generate and print portions of the Data Library Information Table. The library routine DTASET is called to set the data set name and volume serial number associated with a specified unit number. The library routine CLOSDA is called to close the direct-access data set.

PRELPS - This subroutine defines the collapsed group structure for the shielding analytical sequences. It should not be used in the criticality safety analytical sequences. The call to PRELPS is triggered by entering COLL in MORE DATA. PRELPS calls NFLUX to generate a neutron flux spectrum and GFLUX to generate a gamma flux spectrum.

CLAPSE - This subroutine controls the collapsing of the appropriate AMPX master format library to the new group structure. It is described in more detail in Sect. M7.3.9.

CLEAR - This library routine is called to zero the volume fraction array.

VERIFY - This subroutine checks the mixture-by-zone array. A warning message is written if the same mixture number is specified for more than one zone. It also determines the number of void zones in the 1-D model for use in the BONAMI mixing table.

VOLJB - This function is used in calculating volume fractions. It returns the volume for a sphere, the volume per unit height for a cylinder, and the thickness for a slab.

BONAMI - This subroutine prepares binary input data for the functional module BONAMI-S. The binary data are written on unit 96 by subroutines BINRCX and BINRCF.

LCHKIMX - This logical function returns a value of true if a variable is referenced. BONAMI, NITAWL, CALCMS, and CELLMX utilize this function to determine if a mixture is referenced in the mixture-by-zone array.

BINRCX - $\quad$ Each time this subroutine is called, it writes a binary integer data array on a specified data file. This data array is part of the binary input data used by certain functional modules for processing the cross sections. BINRCX is called with six arguments. The first argument is the array identification number for FIDO-type data. The second argument is the starting point of the data to be written in the array defined by the first argument. The third argument is the end point of the data to be written in the array defined by the first argument. The fourth argument is the offset of the first location of the array defined by the first argument, from the beginning of the base array. The fifth argument is the name of the base array that contains the data to be written. The sixth argument is the unit number where the data is to be written. For example, arguments of $(13,1,4,0, L, 40)$ writes the first four entries of array $L$ on unit 40 as the first four entries of the $13 \$ \$$ array. Arguments of $(13,1,4,20, L, 40)$ would write entries 21 through 24 of array $L$ on unit 40 as the first four entries in the $13 \$ \$$ array.

BINRCF - Each time this subroutine is called, it writes a binary floating-point data array on a specified data file. This array is part of the binary data used by certain functional modules for processing the cross sections. BINRCF is called with six arguments that are identical in function to those for BINRCX. For example, arguments of $(13,1,4,0, B, 40)$ write the first four entries of array $B$ on unit 40 as the first four entries of the 13** array. Arguments of $(13,1,4,20, B, 40)$ would write entries 21 through 24 of array B on unit 40 as the first four entries in the $13^{* *}$ array. 
NITAWL - This subroutine prepares binary input data for the functional module NITAWL-II. Subroutine ISCAN is called to return the nuclide number. The library routine CLEAR is called to zero the data array before loading data. The binary data are written on unit 97 for NITAWL-II by subroutines BINRCX and BINRCF.

CALCMS - This subroutine corrects the mixing table length to account for mixtures that are to be passed through XSDRNPM-S without being cell-weighted. LCHKMX is used to determine whether a mixture occurs in the mixture-by-zone array.

EPSIG - $\quad$ This subroutine is called only if a cell-weighted mixture is to be created. It calculates the total epithermal cross section and the corresponding asymptotic relaxation factor for use in determining the number of spatial mesh intervals. SQRT is used in determining the asymptotic relaxation factor.

XSMESH - This subroutine is called only if a cell-weighted mixture is to be created. It calculates the number of spatial intervals and their corresponding locations for XSDRNPM-S. STOP is called if more storage is required than is available. LOG10 is used in determining the interval boundary locations. MAX and MIN are used to determine the larger of two values and the smaller of two values, respectively.

XSDRN - This subroutine is called only if a cell-weighted mixture is to be created. It prepares binary input data for the functional module XSDRNPM-S. The binary input data are written on unit 98. LCHKMIX is used to determine if a mixture is in the mixture-by-zone array, STOP is called if an error is recognized, CLEAR is used to zero arrays, BINRCX is used to write the binary integer data arrays, BINRCF is used to write the binary floating-point data arrays, and BINFIL is used to load an array with a specified number and write it on a specified unit number.

ICE - This subroutine is called only when the control modules CSASI and CSASIX are executed. It prepares binary input data for the functional module ICE-S. VOLFRC returns the volume fraction of a mixture in a cell. BINRCX writes the binary integer data arrays, BINRCF writes the binary floating-point data arrays, and BINFIL is used to fill an array with a number and write it on the specified unit number. The binary input data for ICE-S are written on unit 92.

VOLFRC - This function is used to determine the volume fraction of a mixture in the cell.

CELLMX - This subroutine is used to determine the number of components in a cell-weighted mixture. LCHKMXX is used to determine if a mixture is in the mixture-by-zone array.

MIPCHK - This subroutine is activated if PARM $=$ CHECK is specified on the analytical sequence indicator as shown by the following example:

$=$ CSAS25 PARM $=$ CHECK

MIPCHK prints additional information including the mixing table, resonance data, data for BONAMI-S and NITAWL-II, and all KENO V.a data that are printed prior to creating the initial source distribution. The library routine WOT8 is used to print part of the data.

NUREG/CR-0200, 


\section{M7.3.1 READ THE INPUT DATA}

Figure M7.3.2 illustrates the beginning of the data reading and processing segment of the program known as the Material Information Processor.

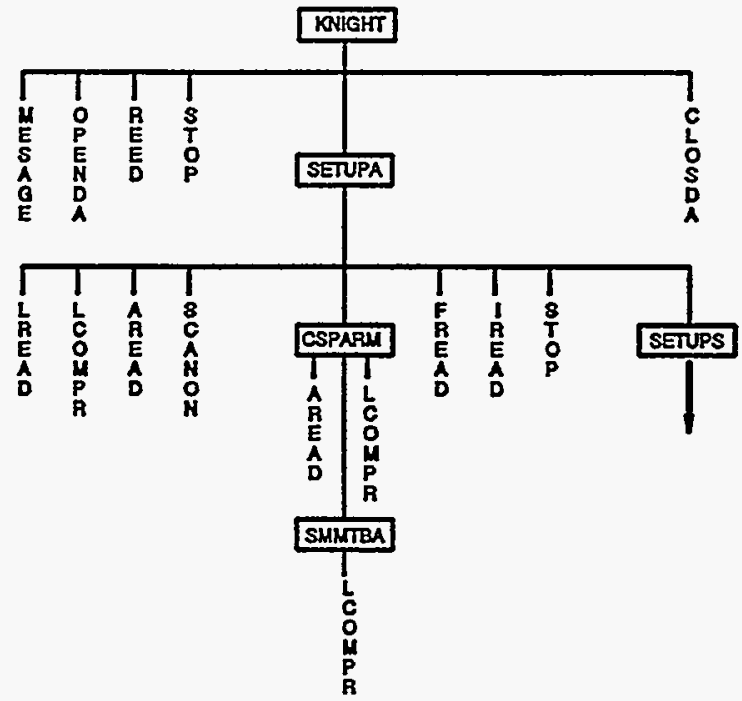

Figure M7.3.2 Read the Material Information Processor input data

KNIGHT - This subroutine initiates the data-reading portion of the Material Information Processor. It defines the output unit for the analytical sequence and sets up storage for various data arrays needed by the Material Information Processor. STOP is called if the available storage is too small to contain the data arrays. Data from the Standard Composition Library (see Sect. M8) are loaded for use by the Material Information Processor. SETUPA is called to control the data reading. CLOSDA is called to close out the standard compositions specification data file when the Material Information Processor is finished.

MESAGE - This library routine is called with two arguments: an eight-character hollerith argument and an output unit. Additional library routines are called from MESAGE to print a header page in block letters and the Program Verification Information Table for qualityassurance purposes. The header page includes the eight-character hollerith argument defining the analytical sequence being executed, the date and time execution was begun, and the job name. The program verification information table includes the program name, its creation date, the library name, the job name, and the date and time of execution.

OPENDA - This library routine initializes the direct-access files.

REED - This library routine is called to load data from the Standard Composition Library into data arrays. 
SETUPA - This subroutine is responsible for reading the standard composition specification data and geometry description data from the input unit and determining the number of mixtures specified in the data, the number of standard composition specifications entered as data, the number of solutions specified in the standard composition specification data, and the number of material zones to be used by XSDRNPM-S. The input unit is rewound so it can be read by subroutine SETUPB. Then the problem parameters are printed, and pointers are established for subsequent information storage. The library routine STOP is called to print a message if more computer storage is required for the problem.

AREAD - This library routine is used to read the standard composition names and other alphanumeric data.

SCANON - This library routine is called to activate the feature that allows scanning for the word END, when reading data.

CSPARM - This subroutine uses the library routine AREAD to read the problem title, cross-section library name, and type of calculation to be performed. It is called twice from SETUPA: once at the beginning, and again before calling SETUPB.

SMMTBA - This subroutine sets the logical cross-section unit number based on the cross-section library specified in the input data.

LCOMPR - This library routine is called from CSPARM to verify that the cross-section library name specified in the data matches one of the available libraries. It is called from SETUPA to determine if infinite homogeneous cell data and/or optional parameter data are to be read.

FREAD - This library routine is called as needed to read floating-point data in the standard composition specification data and geometry description data.

IREAD - This library routine is used to read integer data in the standard composition specification data and geometry description data.

LREAD - This library routine returns a value of "true" if the next character in a free-form reading buffer is a numeric digit. It is called from SETUPA to determine if DEN= or SPG= was entered in the standard composition data.

SETUPB - $\quad$ This subroutine is described in more detail in the following section.

\section{M73.2 CONTROL DATA READING AND PROCESSING}

Figure M7.3.3 illustrates the control of the data reading and processing for the Material Information Processor. 


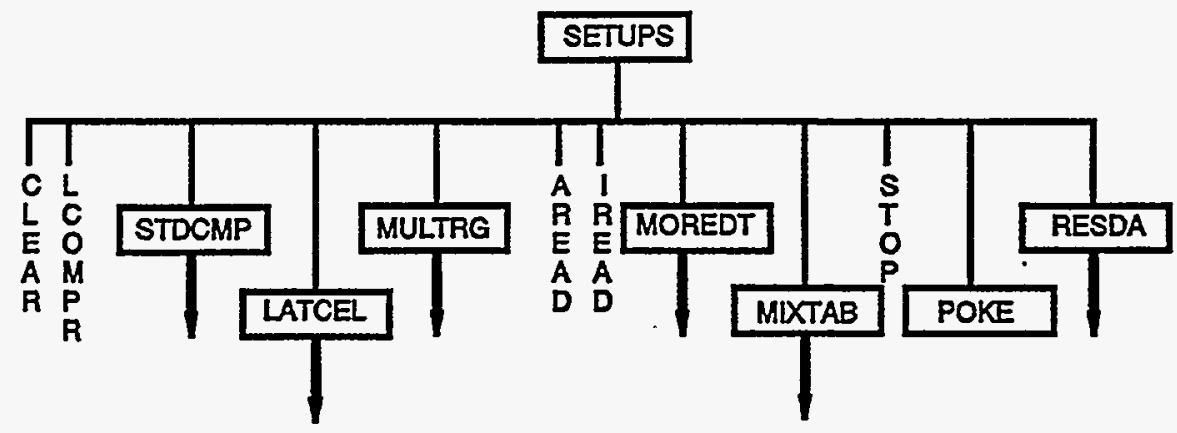

Figure M7.3.3 Control Material Information Processor data reading and processing

SETUPB - This subroutine controls reading the standard composition data, the unit cell specification data, and the optional parameter data. It is responsible for generating the mixing table information and determining the resonance parameters required for NITAWL-S. Various consistency checks are made as the data are read and processed. STOP is called if more storage is needed for the resonance treatment data arrays than is available.

CLEAR - This library routine is called to clear storage arrays.

LCOMPR - This library routine is called many times to compare character strings of input data with the allowed data names specified in the program. It compares as many characters as are supplied in the input data, thus allowing terse input of variable length.

STDCMP - This subroutine is called from SETUPB to read the standard compositions data. See Sect. M7.3.3 for more details.

LATCEL - This subroutine reads the unit cell specification associated with a lattice cell problem. See Sect. M7.3.4 for more details.

MULTRG - This subroutine reads the unit cell specification for a multiregion problem. See Sect. M7.3.5 for more details.

AREAD - This library routine is called from SETUPB to read the alphanumeric data used to define the cell mixture for an infinite homogeneous medium problem.

IREAD - $\quad$ This library routine is called from SETUPB to read the mixture number used in the cell mixture definition in an infinite homogeneous medium problem.

MOREDT - This subroutine reads the optional parameter data as described in Sect. M7.3.6.

MIXTAB - This subroutine is called to generate mixing table information. It is described in more detail in Sect. M7.3.7.

STOP - $\quad$ This library routine is called to write error messages.

POKE - $\quad$ This subroutine uses the geometry description data to calculate the outer boundary of each zone. The zone boundary and mixture by zone data are then loaded in the appropriate arrays. 
RESDA - This subroutine creates the resonance data required by NITAWL-S. It is described in more detail in Sect. M7.3.8.

\section{M7.3.3 READ THE STANDARD COMPOSITION SPECIFICATION DATA}

Figure M7.3.4 illustrates the program flow for reading the standard composition specification data. The data format is discussed in Sect. M7.4.4.

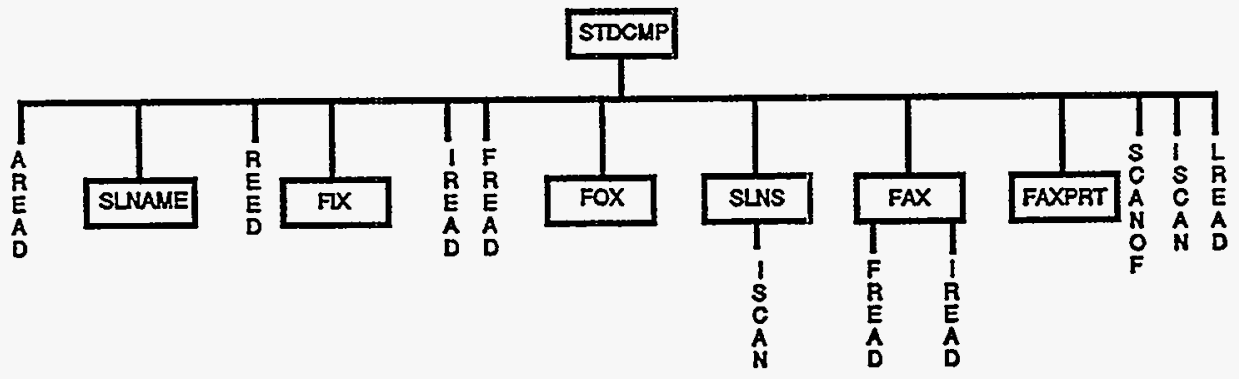

Figure M7.3.4. Flow chart for reading the Standard Compositions Specification data

STDCMP - This subroutine is called from SETUPB to read and process the standard composition specification data for a problem.

AREAD - This library routine is called to read the standard composition names, the END for each standard composition, and the END COMP that terminates the standard composition specification data.

SLNAME - This subroutine returns the standard composition name of the fuel used in a solution.

REED - This library routine is used to load the table of contents from the Standard Composition Library into temporary storage before calling subroutines FIX and FOX.

FIX - This subroutine loads the data for an arbitrary material into the appropriate data arrays.

IREAD - This library routine is used to read integer data encountered in the standard composition specification data and the unit cell specification data.

FREAD - This library routine is used to read floating-point data encountered in the standard composition specification data and unit cell specification data.

LREAD - This library routine is used to determine if the next character is a numeric digit. A value of true is returned if it is a numerical digit. Otherwise, a value of false is returned.

ISCAN - This subroutine is used to determine if a nuclide ID specified in the input data is found on the specified cross-section library. The cross-section library is scanned, and a value of true is returned if a match is found. Otherwise, a value of false is returned.

NUREG/CR-0200,

Vol. 3, Rev. 4

M7.3.8 
FOX - This subroutine is called to provide the nuclide IDs and corresponding natural abundance in weight percent if the isotopic distribution is not specified in the input data.

SLNS - When a solution is specified in the standard composition specification data, this subroutine is used to calculate the volume fraction corresponding to the water, acid, and heavy metal according to the empirical formula applicable to the specified solution.

FAX - $\quad$ This subroutine is called from SETUPB to read the standard composition information for an arbitrary material. IREAD is used to read the integer data, and FREAD is used to read the floating-point data. Entry FAXPRT prints the standard composition specification data for an arbitrary material.

FAXPRT - This subroutine is responsible for printing the arbitrary material specifications of a standard composition in the Material Information Processor output.

SCANOF - This library routine is called to disable the ability to scan ahead for the word END.

\section{M7.3.4 READ THE LATTICE CELL UNIT CELL SPECIFICATION}

Figure M7.3.5 shows the program flow for reading the unit cell specification for a lattice cell problem. The input data for this option are described in Sect. M7.4.6.

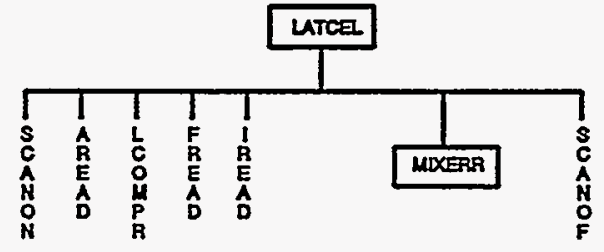

Figure M7.3.5. Flow chart for reading the unit cell specification for lattice cell

LATCEL - This subroutine is called from SETUPB to control reading and processing the unit cell specification for a lattice cell problem.

SCANON - This library routine is used to activate the feature that allows scanning for the word END while reading data.

AREAD - This library routine is called from LATCEL to read the type of cell to be used in a lattice cell problem.

LCOMPR - This library routine is used to compare the type of cell entered in the data with the allowed cell names. It checks as many characters as are entered in the input data. A value of true is returned if a match is found.

FREAD - $\quad$ This library routine is used to read the floating-point data encountered in the unit cell description of a lattice cell problem. 
IREAD - This library routine is used to read the integer data encountered in the unit cell description of a lattice cell problem.

MIXERR - This subroutine is used to verify that mixture numbers utilized in the geometry description data have been defined in the standard composition specification data.

SCANOF - This library routine is called to disable the ability to scan ahead for the word END.

\section{M73.5 READ THE MULTIREGION UNIT CELL SPECIFICATION}

Figure M7.3.6 shows the program flow for reading the unit cell specification for a multiregion problem. The input data for this option are described in Sect. M7.4.7.

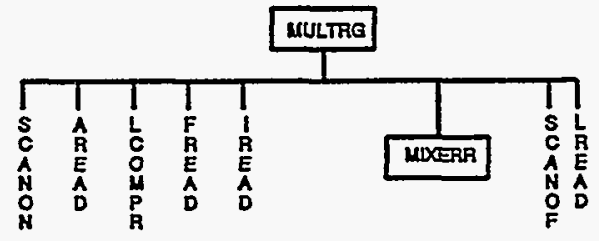

Figure M7.3.6 Flow chart for reading the unit cell specification for multiregion

MULTRG - This subroutine is called from SETUPB to control reading and processing the unit cell specification for a multiregion problem.

SCANON - This library routine is used to activate the feature that allows scanning for the word END while reading data.

AREAD - This library routine is called from MULTRG to read the type of cell to be used in a multiregion problem.

LCOMPR - This library routine is used to compare the type of cell entered in the data with the allowed cell names. It checks as many characters as are entered in the input data. A value of true is returned if a match is found.

FREAD - This library routine is used to read the floating-point data encountered in the unit cell description of a multiregion problem.

IREAD - This library routine is used to read the integer data encountered in the unit cell description of a multiregion problem.

LREAD - This library routine returns a value of true if the next data entry is a numeric digit. It is used to test whether the optional moderator index data are present.

MIXERR - This subroutine is used to verify that mixture numbers utilized in the geometry description data have been defined in the standard compositions specification data.

SCANOF - This library routine is called to disable the ability to scan ahead for the word END.

NUREG/CR-0200,

Vol. 3, Rev. 4

M7.3.10 


\section{M73.6 READ THE OPTIONAL PARAMETER DATA}

The optional parameter data in the CSAS4 family of control modules allow certain parameters to be adjusted as described in Sect. M7.4.8. The program flow for this option is given in Fig. M7.3.7. This portion of the code is entered if the words MORE DATA are encountered after reading all of the other Material Information Processor data.

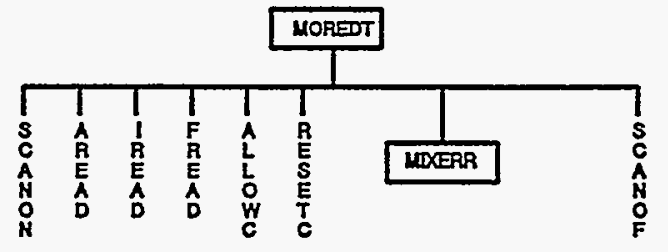

Figure M7.3.7 Flow chart for reading optional parameter data

SCANON - This library routine is used to activate the feature that allows scanning for the word END while reading data.

AREAD - This library routine is used to read the parameter names and other alphanumeric data used in the optional parameter data.

IREAD - This library routine is used to read integer data in the standard composition specification data and geometry description data.

FREAD - $\quad$ This library routine is called as needed to read floating-point data in the standard composition specification data and geometry description data.

ALLOWC - This library routine is called to cause the numeric data reading routines to terminate a number when a non-numerical character is encountered.

RESETC - This library routine is called to reset the numeric data reading routines to cause a number to be terminated only when a blank or a comma is encountered.

MIXERR - This subroutine is used to verify that mixture numbers specified in the resonance and/or Dancoff parameter data have been defined in the standard composition specification data.

SCANOF - This library routine is called to disable the ability to scan ahead for the word END.

\section{M73.7 GENERATE THE MIXING TABLE}

Figure M7.3.8 shows the subroutines used in generating the mixing table for the Material Information Processor. 


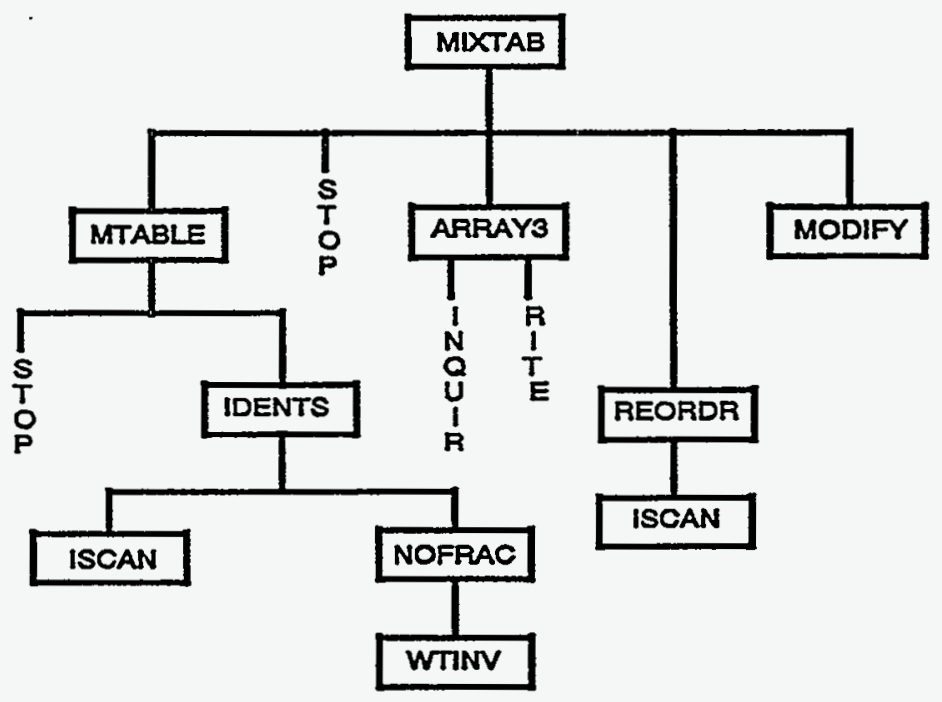

Figure M7.3.8 Flow chart for generating the mixing table

MIXTAB - This subroutine is responsible for generating the mixing table information required for the analytical sequence. It uses information from the Standard Composition Library and standard composition specification data to calculate the number density in atoms/b-cm for each nuclide in each mixture. STOP is called if the code needs more computer storage than is available. The final mixing table consists of a mixture number array, a nuclide ID array, and a number density array.

MTABLE - This subroutine is responsible for generating a mixing table containing a set of data for every isotope in every mixture. Each set of data consists of a mixture number, nuclide $\mathrm{ID}$, and number density in atoms $/ \mathrm{b}-\mathrm{cm}$. Some nuclides may occur more than once in a mixture. STOP is called if the code needs more computer storage than is available. IDENTS is called to calculate the number density for each nuclide in each mixture.

IDENTS - $\quad$ This subroutine calculates the number density for each occurrence of each nuclide. ISCAN is used to locate the input nuclide in the Standard Composition Library. NOFRAC calculates the number fraction for each isotope in an element from the weight fraction data and atomic mass.

ISCAN - $\quad$ This function scans a vector to locate a matching component.

NOFRAC - This subroutine is called for compounds containing multiple isotope elements. It uses the weight fractions and atomic masses to determine the number fraction of each isotope in an element. Subroutine WTINV inverts the matrix.

WTINV - This subroutine inverts the weight-fraction matrix using the Gauss-Jordan reduction.

ARRAY3 - This subroutine divides the mixing table into separate arrays for the mixture number array, the nuclide ID array, and the number density array. It also compacts the mixing

NUREG/CR-0200, Vol. 3, Rev. 4

M7.3.12 
table, combining the number densities for duplicate nuclide IDs that appear in the same mixture.

REORDR - This subroutine reorders the mixing table based on isotope rather than mixture number. Therefore, all entries for a given isotope are loaded consecutively.

ISCAN - This function is used by subroutine REORDR to determine if a nuclide ID occurs in the Standard Composition Library.

MODIFY - This subroutine modifies the nuclide ID array portion of the mixing table to provide unique IDs for each appearance of a resonance nuclide and/or a nuclide for which multiple sets of thermal-scattering data are available.

\section{M7.3.8. GENERATE RESONANCE DATA}

Figure M7.3.9 shows the portion of the Material Information Processor that is responsible for generating the resonance data required by the analytical sequence.

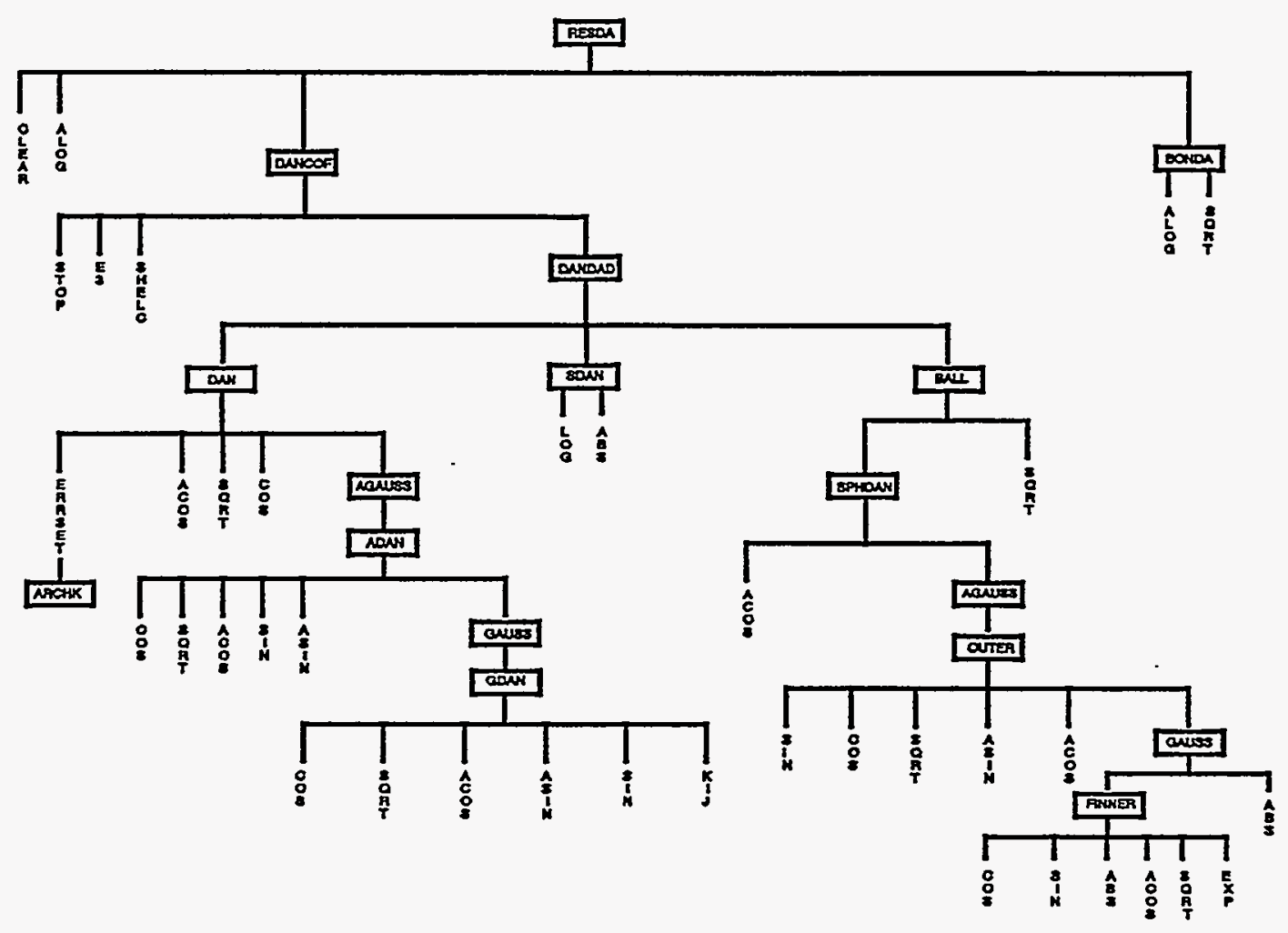

Figure M7.3.9 Flow chart for generating resonance data 
RESDA - This subroutine is responsible for determining the resonance data required by NITAWL-II and BONAMI for each nuclide having resonance information in the master cross-section library. CLEAR is called to clear arrays. ALOG is used in calculating the average logarithmic slowing-down decrement for determining the first and second moderator for NITAWL-II. DANCOF is called to provide Dancoff factors ${ }^{1,8}$ for resonance materials. BONDA is called to provide a factor to be used in calculating the escape cross section for materials having Bondarenko data.

DANCOF - This subroutine controls the calculation of the Dancoff factors for the different zones in the cell. It determines the Dancoff factor across the inner surface for a curvilinear coordinate system and calculates the Dancoff factor to an outer curved surface that has a white boundary condition applied to it. E3 is used to determine the Dancoff factor for slabs, and SHELC is used to determine the Dancoff factor across cylindrical shells. DANDAD is called to provide the Dancoff factor for a lattice cell problem.

E3 -

This library routine is a third-order exponential integral function.

SHELC - $\quad$ This library routine evaluates the transmission probabilities for a cylindrical shell.

DANDAD - This subroutine provides Dancoff factors between fuel lumps in a lattice cell calculation. DAN provides Dancoff factors for cylindrical geometry; SDAN, for slab geometry; and BAIL, for spherical geometry. The Dancoff factors are part of the resonance data required by NITAWL-II and BONAMI to reduce the effective escape probability from the fuel in a heterogeneous lattice. See Sect. M7.2.5.3 for additional information concerning Dancoff factors.

DAN - This subroutine provides the Dancoff factors for the nearest and next-nearest cylinders in an array having a square or triangular pitch. ERRSET is used to trap errors caused by invalid arguments to the arcsine or arccosine routines by invoking subroutine ARCHK. ACOS, SQRT, and COS are used in determining the limits for the outer integration loop to be provided to AGAUSS.

ARCHK - $\quad$ This subroutine is called by ERRSET to determine if the invalid argument is due to roundoff, in which case standard fix-up procedures are implemented. Otherwise, an error message is written, an error flag is set, and execution is continued using standard fix-up procedures. If the error flag is set, data reading and processing will continue, but none of the functional modules will be executed.

AGAUSS - This subroutine uses a Gaussian quadrature to numerically evaluate the outer integral of the double integral defining the Dancoff factor.

ADAN - $\quad$ This function provides point-by-point values of the outer integral of the Dancoff equation for cylindrical geometry. COS, SQRT, ACOS, SIN, and ASIN are used in evaluating this Dancoff equation. ADAN also provides the limits for the inner integration.

GAUSS - $\quad$ This subroutine uses a Gaussian quadrature to numerically evaluate the inner integral of the double integral defining the Dancoff factor.

GDAN - This subroutine provides point-by-point values of the inner integral of the Dancoff equation for cylindrical geometry. COS, SQRT, ACOS, SIN, and ASIN are used in evaluating the Dancoff equation. The library routine $\mathrm{KI} 3$ is used to evaluate the

NUREG/CR-0200,

Vol. 3, Rev. 4

M7.3.14 
third-order Bickley function, which evaluated the effect of the moderating material between the cylinders.

SDAN - $\quad$ This subroutine determines the Dancoff factor for slab geometry. ALOG and ABS are used in this determination.

BALL - This subroutine computes the Dancoff factor for spherical geometry in an array having a square or triangular pitch.

SPHDAN - This subroutine sets up the double integration required in the evaluation of the Dancoff factor in spherical geometry.

OUTER - This function provides point-by-point values for the outer integral of the Dancoff equation for spherical geometry.

FINNER - This function provides point-by-point values for the inner integral of the Dancoff equation for spherical geometry. COS, SIN, ABS, ACOS, SQRT, and EXP are utilized in this evaluation.

BONDA - This subroutine provides a geometry-dependent factor that is used in calculating the escape cross section for isotopes having Bondarenko data associated with them. ALOG and SQRT are utilized in the calculations.

\section{M7.3.9. COLLAPSE THE ENERGY GROUP STRUCTURE}

Figure M7.3.10 illustrates the portion of the Material Information Processor that collapses the master library to the specified group structure for the SAS sequences.

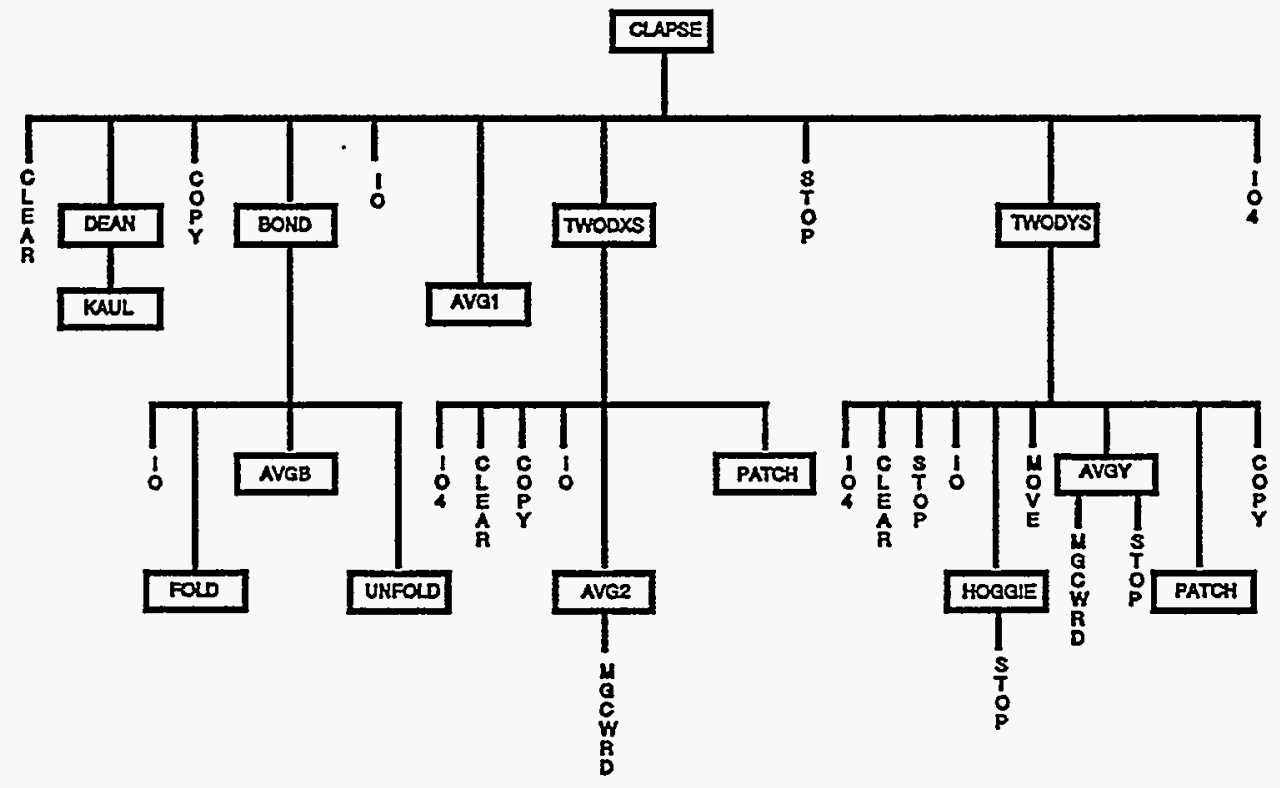

Figure M7.3.10 Flow chart for collapsing the energy group structure for shielding analytical sequences 
CLAPSE - This subroutine is responsible for collapsing the master library to the specified group structure for the Shielding Analytical Sequences. It should not be invoked by the Criticality Safety Analytical Sequences. The call to CLAPSE is triggered by entering COLL in MORE DATA. See Sect. M7.4.8 for input data details.

CLEAR - This library routine is used to zero the work space.

DEAN - $\quad$ This subroutine reads the energy group boundaries.

KAUL - This subroutine generates the collapsed energy group boundaries and the collapsed flux spectrum. It is called once to process neutron data and once to process gamma data.

COPY - $\quad$ This library routine is used to copy data from one library to another.

BOND - This subroutine controls processing the Bondarenko data to obtain collapsed Bondarenko data.

IO -

This library routine is called several times to read and write data.

FOLD - $\quad$ This subroutine multiplies the Bondarenko factors by the cross sections.

AVGB - This subroutine collapses the folded Bondarenko factors and the cross sections.

UNFOLD - This subroutine divides the collapsed and folded Bondarenko factors by the collapsed cross sections to obtain collapsed Bondarenko factors.

AVG1 - This subroutine collapses the 1-D neutron and gamma cross sections.

TWODXS - This subroutine collapses the 2-D neutron and gamma cross sections. IO4 is used to read and write the 2-D scattering matrix directory. COPY is used several times to copy data from the old library to a scratch file and from the scratch file to the new library. CLEAR is used to zero working arrays. IO is used several times reading and writing data to various units.

AVG2 - This subroutine is used to collapse the 2-D scattering or transfer arrays. The library routine MGCWRD is used to decipher "magic" words that define the contents of subsequent cross-section data strings.

PATCH - $\quad$ This subroutine defines the first group transfer of every empty array to be zero.

TWODYS - This subroutine governs the collapsing of the gamma production arrays. IO4 is used to read and write the production array directory. MOVE is called to move data from one array to another. STOP is called to write error messages. IO is used several times for reading and writing data. CLEAR is used to zero arrays and COPY is used to copy the weighted yield libraries from the scratch unit to the new library.

HOGGIE - This subroutine generates flux integrated fine- and broad-group cross sections for converting the yield arrays to cross-section arrays. STOP is called to write an error message.

NUREG/CR-0200,

Vol. 3, Rev. 4

M7.3.16 
AVGY - This subroutine collapses the 2-D gamma production array. The library routine MGCWRD is used to decipher "magic" words within cross-section arrays. These words define the contents of subsequent data strings. STOP is called to write an error message. 


\section{M7.4 INPUT DATA GUIDE}

This section describes the input data required for the Material Information Processor.

All data are entered in free form, allowing alphanumeric data, floating-point data, and integer data to be entered in an unstructured manner. Eighty columns of data entry are allowed, simulating a card of data. Data can usually start or end in any column. Each data entry must be followed by one or more blanks to terminate the data entry. For numeric data, either a comma or a blank can be used to terminate each data entry. Integers may be entered for floating values. For example, 10 will be interpreted as 10.0. Imbedded blanks are not allowed within a data entry unless an $E$ precedes a single blank as in an unsigned exponent in a floating-point number. For example, 1.0E 4 would be correctly interpreted as $1.0 \times 10^{4}$.

The word "END" is a special data item. An "END" may have a name or label associated with it. The name or label associated with an "END" is separated from the "END" by a single blank and is a maximum of 12 characters long. At least 2 blanks MUST follow every labeled and unlabeled "END." It is the user's responsibility to assure compliance with this restriction. Failure to observe this restriction can result in the use of incorrect or incomplete data without the benefit of waming or error messages.

Multiple entries of the same data value can be achieved by specifying the number of times the data value is to be entered, followed by either $R,{ }^{*}$, or $\$$, followed by the data value to be repeated. Imbedded blanks are not allowed between the number of repeats and the repeat flag. For example, 5R12, $5^{*} 12,5 \$ 12$, or $5 R 12$, etc., will enter five successive 12's in the input data. Multiple zeros can be specified as $\mathrm{nZ}$ where $\mathbf{n}$ is the number of zeroes to be entered. The SCALE free-form reading routines are described in more detail in Sect. M3.

The major function of the Material Information Processor is to create binary input data files for BONAMI, NITAWL, and XSDRNPM and/or ICE. Table M7.4.1 lists the I/O units for the cross-section libraries, Standard Composition Library, temporary files, and the binary input data files. Optional files that can be defined include (1) the unit from which XSDRNPM may read fluxes, (2) the unit on which XSDRNPM may write fluxes, (3) unit 7, where ICE may write a card-image ANISN library, and (4) the unit on which ICE may write a binary ANISN library (see Sect. M7.4.8 on optional parameter data).

Table M7.4.1 Description of I/O units utilized by the Material Information Processor

\begin{tabular}{|c|c|c|}
\hline $\begin{array}{l}\text { Unit } \\
\text { No. }\end{array}$ & Type of data & Type-of file \\
\hline 5 & Input & Sequential \\
\hline 11 & Short master xsec library & Sequential \\
\hline 70 & User-supplied xsecs & AMPX Master Format Library \\
\hline 81 & 16-Group xsecs & AMPX Master Format Library \\
\hline 82 & 27-Group xsecs & AMPX Master Format Library \\
\hline 83 & 123-Group xsecs & AMPX Master Format Library \\
\hline 84 & 218-Group xsecs & AMPX Master Format Library \\
\hline 85 & 22 Neutron-18 gamma xsecs & AMPX Master Format Library \\
\hline 86 & 18 Gamma xsecs & AMPX Master Format Library \\
\hline 87 & 27-Group xsecs for burnup & AMPX Master Format Library \\
\hline 88 & 27 Neutron-18 gamma xsecs & AMPX Master Format Library \\
\hline 89 & Standard Composition Library & Direct or random access data file \\
\hline 90 & Scratch file & Direct or random access \\
\hline 92 & ICE input data & Sequential \\
\hline 96 & BONAMI input data & Sequential \\
\hline 97 & NITAWL input data & Sequential \\
\hline 98 & XSDRNPM input data & Sequential \\
\hline 99 & Printed output & Sequential \\
\hline
\end{tabular}




\section{M7.4.1 INPUT DATA SUMMARY FOR EXPERIENCED USERS}

Section M7.4.1 is provided for the convenience of experienced users. Other users should skip to Sect. M7.4.2, p. M7.4.8.

All the input data for the Material Information Processor are summarized in Table M7.4.2 and presented in more detail in Table M7.4.3. Each component table of Table M7.4.3 is repeated and discussed in detail in Sects. M7.4.3 through M7.4.8.

The Material Information Processor allows terse data input for all data except the standard composition names and the keyword entries in the optional parameter data (MORE DATA). Terse data entry requires the user to enter only as many characters as are necessary to uniquely define the data entry. However, as many characters as are specified by the user must match the name allowed by the code. For example, refer to Table M7.4.2, Outline of Material Information Processor data, data position 3. The available choices for the type of calculation are: INFHOMMEDIUM, LATTICECELL, and MULTIREGION. Therefore, I would be sufficient to specify an infinite homogeneous medium, I would be sufficient for lattice cell, and $M$ would specify multiregion. If it is desirable to use more characters, the user is free to do so. However, as many characters as are entered must match the name allowed by the code. For example, if INFHOMMEDIUM is to be specified, INFH is correct, but INFI is not.

WARNING: If several choices begin with the same letters, sufficient characters should be entered to uniquely define the name. For example, ASPHSQUAREP and ASPHTRIANGP are identical through the first four characters. If only ASPH is entered, the code will accept the first name whose first four characters are ASPH. This may not be the one the user intended to use.

Table M7.4.2 Outline of Material Information Processor data (see Sect. M7.4.3 for details)

\begin{tabular}{|c|c|c|c|}
\hline $\begin{array}{l}\text { Data } \\
\text { position }\end{array}$ & Type of data & Data entry & Comments \\
\hline 1 & TITLE & Enter a title & 80 characters \\
\hline 2 & $\begin{array}{l}\text { Cross-section } \\
\text { library name }\end{array}$ & $\begin{array}{l}\text { HANSEN-ROACH } \\
\text { 27GROUPNDF4 } \\
\text { 123GROUPGMTH } \\
\text { 218GROUPNDF4 } \\
\text { 27BURNUPLIB } \\
\text { etc. }\end{array}$ & $\begin{array}{l}\text { The currently available libraries are listed in } \\
\text { Table M4.1.1. }\end{array}$ \\
\hline 3 & Type of calculation & $\begin{array}{l}\text { INFHOMMEDIUM } \\
\text { LATTICECELL } \\
\text { MULTIREGION }\end{array}$ & $\begin{array}{l}\text { These are the available options. See the } \\
\text { explanation in Sect. M7.4.3. }\end{array}$ \\
\hline 4 & $\begin{array}{l}\text { Standard Composition } \\
\text { specificaiton data }\end{array}$ & $\begin{array}{l}\text { Enter the appropriate } \\
\text { data }\end{array}$ & $\begin{array}{l}\text { Terminate this data block with END COMP. } \\
\text { See Sect. M7.4.4. }\end{array}$ \\
\hline 5 & $\begin{array}{l}\text { Unit cell } \\
\text { geometry } \\
\text { specification }\end{array}$ & $\begin{array}{l}\text { Enter the appropriate } \\
\text { data (optional for } \\
\text { INFHOMMMEIUM) }\end{array}$ & $\begin{array}{l}\text { Optional for INFHOMMEDIUM. } \\
\text { See Sect. M7.4.5 for INFHOMMEDIUM. } \\
\text { See Sect. M7.4.6 for LATTICECELL. } \\
\text { See Sect. M7.4.7 for MULTIREGION. }\end{array}$ \\
\hline 6 & Optional parameter data & Enter the desired data & $\begin{array}{l}\text { Precede this data block by MORE DATA if } \\
\text { more parameter data are to be entered. } \\
\text { Otherwise, omit these data entirely. } \\
\text { See Sect. M7.4.8. }\end{array}$ \\
\hline
\end{tabular}

NUREG/CR-0200,

Vol. 3, Rev. 4

M7.4.2 
Table M7.4.3 Tables of Material Information Processor data requirements

Outline of standard compositions specification data (see Sect. M7.4.4 for details)

\begin{tabular}{|c|c|c|c|c|}
\hline $\begin{array}{l}\text { Entry } \\
\text { No. }\end{array}$ & $\begin{array}{l}\text { Variable } \\
\text { name }\end{array}$ & Type of data & $\begin{array}{l}\text { Entry } \\
\text { requirement }\end{array}$ & Comments \\
\hline 1 & SC & $\begin{array}{l}\text { Standard composition } \\
\text { component name }\end{array}$ & Always & $\begin{array}{l}\text { Enter once for each standard compasition. } \\
\text { Enter the alphanumeric description from Table } \\
\text { M8.2.1. Additional allowed names include } \\
\text { those beginning with ARBM for arbitrary } \\
\text { materials, and SOLN for solutions. }\end{array}$ \\
\hline A1 & ROTH & $\begin{array}{l}\text { Theoretical density } \\
\text { of material }(g / c c)\end{array}$ & ARBM & $\begin{array}{l}\text { Enter once for each standard composition } \\
\text { component that is an arbitrary material. }\end{array}$ \\
\hline A2 & NEL & $\begin{array}{l}\text { Number of elements } \\
\text { in the material }\end{array}$ & ARBM & $\begin{array}{l}\text { Enter once for each standard composition } \\
\text { component that is an arbitrary material. }\end{array}$ \\
\hline A3 & IVIS & $\begin{array}{l}\text { Multiple-isotope } \\
\text { indicator }\end{array}$ & ARBM & $\begin{array}{l}\text { Enter once for each standard composition com- } \\
\text { ponent that is an arbitrary material. Enter } 0 \\
\text { for a material that does not contain multiple- } \\
\text { isotope elements. Enter } 1 \text { if the material con- } \\
\text { tains a multiple-isotope element. An arbitrary } \\
\text { material cannot have more than one multiple- } \\
\text { isotope element. If necessary, several arbitrary } \\
\text { materials may be used in a single mixture. }\end{array}$ \\
\hline A4 & ICP & Compound indicator & ARBM & $\begin{array}{l}\text { Enter once for each standard composition } \\
\text { component that is an arbitrary material. } \\
\text { Enter } 1 \text { for a compound, } 0 \text { for alloys, mixtures, } \\
\text { etc. }\end{array}$ \\
\hline A5 & IRS & Resonance indicator & ARBM & $\begin{array}{l}\text { Enter once for each standard composition } \\
\text { component that is an arbitrary material. } \\
\text { Enter } 0 \text { if all the nuclides in the material are } \\
\text { non-resonance nuclides; enter } 1 \text { if one or more } \\
\text { have resonance data. See Sect. M8.2, Table } \\
\text { M8.2.1. }\end{array}$ \\
\hline A6 & NCZA & $\begin{array}{l}\text { ID number (from far } \\
\text { right column of } \\
\text { Table M8.2.1) }\end{array}$ & ARBM & $\begin{array}{l}\text { Repeat the sequences } A 6 \text { and } A 7 \text { for each ele- } \\
\text { ment in the arbitrary material before entering } \\
\text { entry number } 2 \text { Enter the number from the } \\
\text { far right column of Table M8.2.1. (Premixed } \\
\text { standard compositions cannot be used in an } \\
\text { arbitrary material definition.) }\end{array}$ \\
\hline A7 & ATPM & $\begin{array}{l}\text { Number of atoms of } \\
\text { this element per } \\
\text { molecule of arbitrary } \\
\text { material }\end{array}$ & $\begin{array}{l}\text { ARBM } \\
\& \\
I C P=1\end{array}$ & $\begin{array}{l}\text { Repeat the sequence } \mathrm{A} 6 \text { and } \mathrm{A} 7 \text { for each ele- } \\
\text { ment in the arbitrary material before entering } \\
\text { entry number } 2 \text {. Do not enter a value unless } \\
\mathrm{ICP}=1 \text {. }\end{array}$ \\
\hline & & $\begin{array}{l}\quad \text { or } \\
\text { Weight percent of this } \\
\text { element in this } \\
\text { arbitrary material }\end{array}$ & $\begin{array}{l}\text { or } \\
\text { ARBM } \\
\& \\
\text { ICP }=0\end{array}$ & $\begin{array}{l}\text { or } \\
\text { Repeat the sequence } A 6 \text { and } A 7 \text { for each ele- } \\
\text { ment in the arbitrary material before entering } \\
\text { entry number } 2 \text {. Do not enter a value unless } \\
\text { ICP }=0 \text {. }\end{array}$ \\
\hline
\end{tabular}

NUREG/CR-0200, 
Table M7.4.3 (continued)

Outline of standard compositions specification data (continued)

\begin{tabular}{|c|c|c|c|c|}
\hline $\begin{array}{l}\text { Entry } \\
\text { No. }\end{array}$ & $\begin{array}{l}\text { Variable } \\
\text { name }\end{array}$ & Type of data & $\begin{array}{l}\text { Entry } \\
\text { requirement }\end{array}$ & Comments \\
\hline 2 & $\mathrm{MXX}$ & Mixture ID number & Always & Enter once for each standard composition component. \\
\hline SI & FD & $\begin{array}{l}\text { Fuel density (grams of } U \\
\text { or Pu per liter of solution) }\end{array}$ & SOLN & Enter once for a solution. \\
\hline S2 & AML & $\begin{array}{l}\text { Acid molarity of the } \\
\text { solution }\end{array}$ & SOLN & $\begin{array}{l}\text { Enter once for a solution. } A M L=0 \text { if there is no } \\
\text { acid in the solution. }\end{array}$ \\
\hline 01 & SPGR & $\begin{array}{l}\text { Specific gravity of the } \\
\text { solution }\end{array}$ & Optional & $\begin{array}{l}\text { If the specific gravity (SPGR) of the solution is } \\
\text { known, it should be entered as SPG = SPGR. }\end{array}$ \\
\hline & or & $\begin{array}{l}\text { or } \\
\text { Density of the basic } \\
\text { standard composition }\end{array}$ & & $\begin{array}{l}\text { or } \\
\text { If the density of a basic standard composition } \\
\text { (ROTH) is to be entered, use DEN = ROTH. }\end{array}$ \\
\hline 3 & VF & Density multiplier & $\begin{array}{l}\text { See } \\
\text { comment } \\
\text { column }\end{array}$ & $\begin{array}{l}\text { Enter the density multiplier (density fraction, volume } \\
\text { fraction, or a combination). Default value is } 1 \text {. This } \\
\text { item can be omitted if entries } 4,5,6 a \text {, and } 6 \mathrm{~b} \text { are } \\
\text { also omitted. VF }=0 \text { is not allowed for SOLN or } \\
\text { ARBM. }\end{array}$ \\
\hline 4 & ADEN & $\begin{array}{l}\text { Number density (atoms/b- } \\
\mathrm{cm} \text { ) for the nuclide }\end{array}$ & $V F=0$ & Enter only if $\mathrm{VF}=\mathbf{0 . 0}$ \\
\hline 5 & TEMP & Temperature, in degrees $\mathrm{K}$ & $\begin{array}{l}\text { See comment } \\
\text { column }\end{array}$ & $\begin{array}{l}\text { Default value is } 293 \mathrm{~K} \text {. This entry can be } \\
\text { omitted if entries } 6 \mathrm{a} \text { and } 6 \mathrm{~b} \text { are also omitted. }\end{array}$ \\
\hline $6 a$ & IZA & Isotope's ZA number & $\mathrm{VF} \neq 0$ & $\begin{array}{l}\text { Enter for each isotope in the standard composition } \\
\text { component. Omit if VF }=0 \text {. Entries } 6 \mathrm{a} \text { and } 6 \mathrm{~b} \text { are } \\
\text { entered in pairs until each isotope in the component } \\
\text { is defined. }\end{array}$ \\
\hline $6 \mathrm{~b}$ & WTP & $\begin{array}{l}\text { Weight percent of the } \\
\text { isotope }\end{array}$ & $\mathrm{VF} \neq 0$ & $\begin{array}{l}\text { Enter for each isotope in the standard composition } \\
\text { component. Omit if } \mathrm{VF}=0.0 \text {. Entries } 6 \mathrm{a} \text { and } 6 \mathrm{~b} \text { are } \\
\text { entered in pairs until each isotope in the component } \\
\text { is defined. }\end{array}$ \\
\hline \multirow[t]{2}{*}{7} & END & $\begin{array}{l}\text { Terminate a standard } \\
\text { composition }\end{array}$ & Always & $\begin{array}{l}\text { Enter once for each standard composition component. } \\
\text { This terminates the data for a standard composition } \\
\text { component. Enter END to terminate the component. } \\
\text { Repeat entries } 1 \text { through } 7 \text { until all the mixtures have } \\
\text { been defined. At least two blanks must separate } \\
\text { entry } 7 \text { from the next entry. }\end{array}$ \\
\hline & END COMP & Terminate the data block & Terminus & $\begin{array}{l}\text { Enter once for a problem. Enter the words END } \\
\text { COMP when all the standard composition } \\
\text { components have been described. At least two } \\
\text { blanks must follow the END COMP. }\end{array}$ \\
\hline
\end{tabular}

NOTE: Entry 7 should not begin in column 1 unless a name is associated with it. At least two blanks should separate the last entry 7 from the END COMP.

NUREG/CR-0200, Vol. 3, Rev. 4 
Table M7.4.3 (continued)

Optional unit cell specifications for INFHOMMEDIUM problems (see Sect. M7.4.5 for details)

\begin{tabular}{|c|c|c|c|c|}
\hline $\begin{array}{l}\text { Entry } \\
\text { number }\end{array}$ & $\begin{array}{l}\text { Variable } \\
\text { name }\end{array}$ & Type of data & $\begin{array}{l}\text { Data } \\
\text { entry }\end{array}$ & Comments \\
\hline 1 & NAME & Keyword & CELLMIX & Initiate reading cell data for INFHOMMEDIUM \\
\hline 2 & MFUEL & $\begin{array}{l}\text { Moture number } \\
\text { in the cell }\end{array}$ & $\begin{array}{l}\text { Misture } \\
\text { number }\end{array}$ & $\begin{array}{l}\text { Specilies the misture aumber to be used in the cell. Defaults to the } \\
\text { emalleat minture number entered in the Standard Composition Data }\end{array}$ \\
\hline
\end{tabular}

NOTE: Unit cell data are necessary for INFHOMMEDIUM Onfy if a misture sumber other than the smallest minture pumber is to be used in the cell and a control sequence that executes XSDRNPM bas been specilied. If mitures 1, 2, and 3 are specilied and minture 3 is to be used in the cell, enter CRILMIX 3.

Unit cell specification for latticecell problems (see Sect. C4.4.6 for details)

\begin{tabular}{|c|c|c|c|c|c|}
\hline $\begin{array}{l}\text { Entry } \\
\text { number }\end{array}$ & $\begin{array}{l}\text { Variable } \\
\text { name }\end{array}$ & Type of data & $\begin{array}{l}\text { Entry } \\
\text { requirement }\end{array}$ & Data entry & Comments \\
\hline 1 & CTP & Type of latice & Always & $\begin{array}{l}\text { SQUAREPICH } \\
\text { ASQUAREPITCH } \\
\text { ASQP } \\
\text { TRIANGPITCH } \\
\text { ATRIANGITCH } \\
\text { ATRP } \\
\text { SPHSQUAREP } \\
\text { ASPHSQUAREP } \\
\text { ASSP } \\
\text { SPHIRIANGP } \\
\text { ASPHTRIANGP } \\
\text { ASTP } \\
\text { SYMMSLABCELL } \\
\text { ASYMSLABCELL }\end{array}$ & 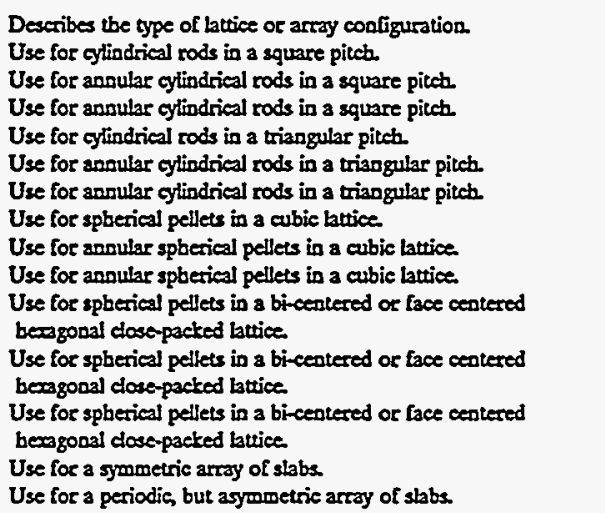 \\
\hline 2 & PITCH & Array pitch $(\mathrm{cm})$ & Always & $\begin{array}{l}\text { Appropriate } \\
\text { dimension }\end{array}$ & 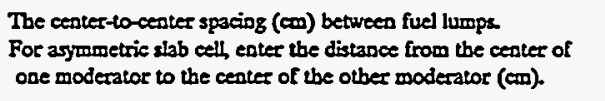 \\
\hline 3 & FUELOD & $\begin{array}{l}\text { Outside dimension } \\
\text { of fued (लm) }\end{array}$ & Always & $\begin{array}{l}\text { Approptiate } \\
\text { dimension }\end{array}$ & $\begin{array}{l}\text { Outide diameter of fuel }(\mathrm{cm}) \text {, or the thickness of the fuel in a } \\
\text { slab. }\end{array}$ \\
\hline 4 & MFUEL & Fuel minture number & Always & Mioture number & Meture number representing the fuel. \\
\hline 5 & MMOD & $\begin{array}{l}\text { Moderator miture } \\
\text { number }\end{array}$ & Always & Mirture number & Micure number representing the moderator \\
\hline 6 & MMOD2 & $\begin{array}{l}\text { 2nd moderator } \\
\text { mibsure number }\end{array}$ & Anoular cell & Miture Dumber & Mirture number represeatiog the second moderator. \\
\hline 7 & TKMOD2 & $\begin{array}{l}\text { 2nd moderator thickness } \\
\text { or } \\
\text { 2nd moderator diameter } \\
\text { (cm) }\end{array}$ & $\begin{array}{l}\text { ASYMSLABCELL } \\
\text { or } \\
\text { annular cell }\end{array}$ & $\begin{array}{l}\text { Thickness } \\
\text { or } \\
\text { Diameter }\end{array}$ & $\begin{array}{l}\text { Thictness of the second moderator (cm) for ASYMSLABCELL. } \\
\text { or } \\
\text { Diameter of inner woderatos (cm) for otber anoular cells. }\end{array}$ \\
\hline 8 & CLADOD & $\begin{array}{l}\text { Outside diameter } \\
\text { of clad (œ्) }\end{array}$ & If clad & Cad OD & $\begin{array}{l}\text { OMIT IF NO CLAD. For a slab, CLADOD is the sum of } \\
\text { thiciness of the fuel, gap, and dad. }\end{array}$ \\
\hline 9 & MCLAD & Cad miture number & If clad & Mature number & OMIT IF NO CLAD. Mure number represeating the chad. \\
\hline 10 & CLADID & $\begin{array}{l}\text { Inside diameter of } \\
\text { clad (ळ) }\end{array}$ & If gap & $C_{3 d}$ ID & OMIT IF NO GAP between the fuel and clad. \\
\hline 11 & MGAP & Gap mixture number & If gap & Moure number & $\begin{array}{l}\text { OMIT IF NO GAP between the fuel and clad. } \\
\text { A wisture number of zero is ofles used. }\end{array}$ \\
\hline 12 & END & Terminate Latticecell data & Always & END & $\begin{array}{l}\text { Terminate the latticecell input data by eatering the word END. } \\
\text { Do not start in column } 1 \text { Al least two blanks must follow edtry } \\
\text { No. } 12\end{array}$ \\
\hline
\end{tabular}


Table M7.4.3 (continued)

Unit cell specification for multiregion problems (see Sect. C4.4.7 for details)

\begin{tabular}{|c|c|c|c|c|c|}
\hline $\begin{array}{l}\text { Entry } \\
\text { number }\end{array}$ & $\begin{array}{l}\text { Variable } \\
\text { name }\end{array}$ & Type of data & $\begin{array}{l}\text { Entry } \\
\text { requirement }\end{array}$ & Data eatry & Comments \\
\hline 1 & Cs & Type of geometry & Always & $\begin{array}{l}\text { SLAB } \\
\text { CYLINDRICAL } \\
\text { SPHERICAL } \\
\text { BUCKLEDSLAB }\end{array}$ & $\begin{array}{l}\text { Describes the type of geometry. The options are listed below. } \\
\text { Use for slab geometry. } \\
\text { Use for cylindrieal geometry. } \\
\text { Use for spherical geometry. } \\
\text { Use for stab geometry with a buetling correction for the two } \\
\text { transverse direetions. }\end{array}$ \\
\hline & & & & BUCKIEDCYL & $\begin{array}{l}\text { Use for cylindrieal geometry with a buclling correction in the axial } \\
\text { direction }\end{array}$ \\
\hline 2 & BR & $\begin{array}{l}\text { Right boundary } \\
\text { condition }\end{array}$ & $\begin{array}{l}\text { Required for } \\
\text { BUCKIEDSLAB } \\
\quad \text { \& } \\
\text { BUCKLEDCYL } \\
\text { Optional for other } \\
\text { geometries }\end{array}$ & $\begin{array}{l}\text { VACUUM } \\
\text { REFLECIED } \\
\text { PERIODIC } \\
\text { WHIE }\end{array}$ & $\begin{array}{l}\text { Default is VACUUM. Describes the right/outside boundary } \\
\text { condition. } \\
\text { This grovides a non-return condition at the boundary. } \\
\text { Do not use for gylindrieal or spherieal } \\
\text { Do not use for cylindrical or spherical } \\
\text { This provides isotopic return at the boundary. }\end{array}$ \\
\hline 3 & BL. & $\begin{array}{l}\text { Left boundary } \\
\text { condition }\end{array}$ & $\begin{array}{l}\text { Reguired for } \\
\text { BUCKIEDSLAB } \\
\quad \& \\
\text { BUCKLEDCYL } \\
\text { Optional for otber } \\
\text { geometries }\end{array}$ & $\begin{array}{l}\text { VACUUM } \\
\text { REFLECTED } \\
\text { PERIODIC } \\
\text { WHTTE }\end{array}$ & $\begin{array}{l}\text { Defaut is REFLECTED. Describes the left boundary condition. } \\
\text { This provides a non-return condition at the boundary. } \\
\text { Recommended for cylindrical or spberical. } \\
\text { Do not use for cylindrical or spberieal. } \\
\text { This provides irotropic return at the boundary. }\end{array}$ \\
\hline 4 & ORGN & $\begin{array}{l}\text { Location of left } \\
\text { boundary on the } \\
x-a x i s(c \infty)\end{array}$ & $\begin{array}{l}\text { BUCKLEDSLAB } \\
\text { BUCKIEDCYL } \\
\text { Optional for other } \\
\text { geometries }\end{array}$ & $\begin{array}{l}\text { Appropriate } \\
\text { dimension }\end{array}$ & $\begin{array}{l}\text { Default is } Q, Q \text {. Should not be changed for cylindrical or spherieal } \\
\text { geometry. A value must be entered if subsequent data are to be } \\
\text { entered. }\end{array}$ \\
\hline 5 & DY & Buctling beigtt $(\mathrm{cm})$ & $\begin{array}{l}\text { BUCKIEDSLAB } \\
\& \\
\text { BUCKLEDCYL }\end{array}$ & $\begin{array}{l}\text { Appropriate } \\
\text { dimension }\end{array}$ & $\begin{array}{l}\text { OMIT FOR SLAB, CYLINDRICAL, and SPHERICAL } \\
\text { This corresponds to one of the transwerse dimensions of an setual } \\
\text { 3-D slab assembly or to the lengtb of a finite cylinder. }\end{array}$ \\
\hline 6 & $\mathrm{DZ}$ & Buckling depth $(\mathrm{cm})$ & BUCKLEDSLAB & $\begin{array}{l}\text { Appropriate } \\
\text { dimension }\end{array}$ & $\begin{array}{l}\text { OMIT UNLESS BUCKI.RDSLAB WAS SPECIFIED. } \\
\text { This is the buckling depth correspondiog to the secood traneverse } \\
\text { dimension of a 3-D stab assembly. }\end{array}$ \\
\hline 7 & END & $\begin{array}{l}\text { End geometry } \\
\text { parameters }\end{array}$ & Always & END & $\begin{array}{l}\text { Eoter the word END. Do not start in column } 1 \text { At least two } \\
\text { blanits must separate entry } 7 \text { from the first eatry } 8\end{array}$ \\
\hline 8 & $\mathbf{M D Z}$ & $\begin{array}{l}\text { Micture number in } \\
\text { the zone }\end{array}$ & Always & $\begin{array}{l}\text { Mithre } \\
\text { number }\end{array}$ & $\begin{array}{l}\text { Repest enty numbers } 8-10 \text { until all zones are defined. } \\
\text { Enter the mixure number for this zone. }\end{array}$ \\
\hline 9 & $\mathbf{R Z}$ & $\begin{array}{l}\text { Outside radius of the } \\
\text { zone (con) }\end{array}$ & Akways & $\begin{array}{l}\text { Appropriate } \\
\text { dimension }\end{array}$ & $\begin{array}{l}\text { Repeat entry numbers } 8-10 \text { until all zones are defined. } \\
\text { Enter the outside dimension of the zone }(\mathrm{cm}) \text {. }\end{array}$ \\
\hline \multirow[t]{2}{*}{10} & XMOD & $\begin{array}{l}\text { External moderator } \\
\text { index }\end{array}$ & Optional & $\begin{array}{l}\text { NOEXTERMOD } \\
\text { ONEEXTERMOD } \\
\text { TWOEXIERMOD }\end{array}$ & $\begin{array}{l}\text { Repeat entry numbers } 8-10 \text { until all zones are defined. } \\
\text { Entry } 10 \text { is optional and ean be omitted. If it is omitted, repeat } \\
\text { entry numbers } 8 \text { and } 9 \text { until all zones are defined. } \\
\text { No moderating materials in the adjacent zoner. } \\
\text { A moderatiog material is present is one adjacent zone. } \\
\text { Moderating materials are present in two adjacent zones. }\end{array}$ \\
\hline & END ZONE & Terminate zone data & & END ZONE & $\begin{array}{l}\text { Bnter when all zones have been defined by repeating entry } \\
\text { numbers } 8 \text { through } 10 \text { for each zone. At least two blantes must } \\
\text { follow this entry. }\end{array}$ \\
\hline
\end{tabular}

NUREG/CR-0200,

Vol. 3, Rev. 4

M7.4.6 
Table M7.4.3 (continued)

Summary of available optional parameter data (see Sect. C4.4.8)

\begin{tabular}{|c|c|c|c|c|}
\hline $\begin{array}{l}\text { Entry } \\
\text { number }\end{array}$ & $\begin{array}{l}\text { Keyword } \\
\text { name }\end{array}$ & Type of data & $\begin{array}{l}\text { Applieable } \\
\text { module }\end{array}$ & Commenis \\
\hline 1 & MORE DATA & Input flag & & $\begin{array}{l}\text { This signals that optional parameter data will be cotered. Enter only } \\
\text { those parameters you wish to change. }\end{array}$ \\
\hline 2 & $\mathrm{ISN}=$ & Order of angular quadrawre & XSDRNPM & The default value is 8 . This allows using another value. \\
\hline 3 & $\mathrm{SZF}=$ & Spatial mesb size factor & XSDRNPM & $\begin{array}{l}\text { The defaule value is } 10 \\
0<S Z F<10 \text { gives a finer mesh. } \\
S Z F>10 \text { gives a coarser mesh }\end{array}$ \\
\hline 4 & $\mathbb{I M}=$ & $\begin{array}{l}\text { Max number of } \\
\text { inner iterations }\end{array}$ & XSDRNPM & The default value is 20 . This allows using another value. \\
\hline 5 & $\mathrm{ICM}=$ & $\begin{array}{l}\text { Max number of } \\
\text { outer iterations }\end{array}$ & XSDRNPM & The default value is 25 . This allows using another value. \\
\hline 6 & EPS $=$ & Overall convergence criteria & XSDRNPM & The default value is 0,0001 . This allows using another value \\
\hline 7 & $\mathrm{PTC}=$ & Point convergence criteria & XSDRNPM & The default value is 00001 This allows using anotber value. \\
\hline 8 & $\mathrm{BKC}=$ & Buctling factor & XSDRNPM & $\begin{array}{l}\text { The default value is } 1420892 \\
\text { Use ONLY for a multiregion problem that specifies BUCKLEDSLAB } \\
\text { or BUCKLEDCYL }\end{array}$ \\
\hline 9 & IUS $=$ & Upscatter scaling factor & XSDRNPM & $\begin{array}{l}\text { The default value is zera. } \\
\text { IUS }=0 \text { doesn't utilize upseatter sealing. IUS }=1 \text { uses upseatter sealing } \\
\text { to aceelerate the solution and/or speed corvergence. }\end{array}$ \\
\hline 10 & RES $=$ & Resonance data & $\begin{array}{l}\text { BONAMI } \\
\text { NITAWL }\end{array}$ & $\begin{array}{l}\text { Enter the minture number, geometry type (SLAR, CYLNDER, } \\
\text { SPLERE) and the thicksess of the slab or radius of the spbere or } \\
\text { glinder, in col. }\end{array}$ \\
\hline \multirow[t]{2}{*}{11} & $\operatorname{DAN}(\mathrm{mm})=$ & $\begin{array}{l}\text { Dancolf factor for the } \\
\text { specified minture }\end{array}$ & $\begin{array}{l}\text { BONAMI } \\
\text { NITAWL }\end{array}$ & $\begin{array}{l}\text { Eoter the miture number, mon, to which the Dancoff factor applies } \\
\text { inside the parentheses; enter the Daneoff factor after the equal sign. }\end{array}$ \\
\hline & & & & 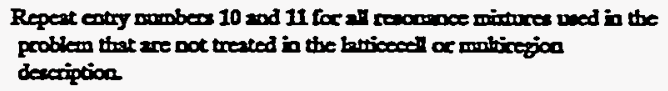 \\
\hline 12 & $\mathrm{BAL}=$ & Key to print balance tables & XSDRNPM & $\begin{array}{l}\text { The defaule value is FINE. } B A L=\text { NONE suppresses priating the } \\
\text { balance table. BAL }=A L L \text { prints all balance tables } B A L=F I N E \text { prints } \\
\text { only the tine-group balance tables. }\end{array}$ \\
\hline 13 & $D Y=$ & First transverse dimension & XSDRNPM & $\begin{array}{l}\text { The first transverse dimension, in com, used in a buckling correction to } \\
\text { caleulate leakage nomal to the principal calculation direction (ien, the } \\
\text { beight of a slab or a cylinder). }\end{array}$ \\
\hline 14 & $\mathrm{DZ}=$ & Second transverse dimension & XSDRNPM & $\begin{array}{l}\text { The second transverse dimension in centimeters used for a buckling } \\
\text { correction (ie, the ridth of a stab). }\end{array}$ \\
\hline 15 & $\mathrm{COF}=$ & $\begin{array}{l}\text { Diffusion coefficient option for } \\
\text { transverse leakage corrections }\end{array}$ & XSDRNPM & The default is 0. See Sect. F3.5, 35 array, variable IPN. \\
\hline 16 & FRD $=$ & $\begin{array}{l}\text { Unit from which lines will be } \\
\text { read }\end{array}$ & XSDRNPM & $\begin{array}{l}\text { Eoter the unit number from which the flux guess for XSDRNPM will } \\
\text { be read. }\end{array}$ \\
\hline 17 & $F W R=$ & $\begin{array}{l}\text { Unit on which flutes will be } \\
\text { written }\end{array}$ & XSDRNPM & $\begin{array}{l}\text { Enter the unit number where the binary alues from XSDRNPM will be } \\
\text { witten. }\end{array}$ \\
\hline 18 & $\mathrm{DAB}=$ & $\begin{array}{l}\text { Number of direct access data } \\
\text { blocks }\end{array}$ & MIP* & The default is 200 Number of blocks allocated for direct access unit 90 \\
\hline 19 & $A X S=$ & $\begin{array}{l}\text { Unit on which a mired ANISN } \\
\text { library will be written }\end{array}$ & ICE & Enter the unit number where ICE is to write a mired ANISN tibrary. \\
\hline 20 & COLL & $\begin{array}{l}\text { Key to activate collapse of } \\
\text { thermal groups }\end{array}$ & MIP• & $\begin{array}{l}\text { Enter COLL to collapse all thermal groups into one group for the } \\
\text { shielding segueaces }\end{array}$ \\
\hline 21 & END & Terminus & & $\begin{array}{l}\text { Terminate the optional parameter data Do not start in column } 1 \text { At } \\
\text { least two blaniss must follow entry number } 21 \text {. }\end{array}$ \\
\hline
\end{tabular}

MIP is the Material Information Processor. 


\section{M7.4.2 PARAMETERS FOR DATA CHECKING AND SPACE ALLOCATION}

To check the Material Information Processor input data, run CSASN and specify PARM $=$ CHECK or PARM $=$ CHK starting after column 10 of the analytical sequence specification as shown below.

$$
\begin{array}{ll}
=\text { CSASN } & \text { PARM }=\text { CHK } \\
\text { or } & \\
\text { \#CSASN } & \text { PARM }=\text { CHK }
\end{array}
$$

The data are checked, the problem description is printed, appropriate error and warning messages are printed, and a table of additional data is printed. These data include the mixing table, resonance data, NITAWL data, CSAS(XSDRN) data, and BONAMI data. An example of this output is given in Sect. M7.6. The region size for a problem can be specified by the user by entering PARM=SIZE=nnnn starting after column 10 of the analytical sequence specification. The region size, nnnn, is specified in words. The following examples run CSASN and set the region size to 120,000 words.

$$
\begin{array}{ll}
=C S A S N & \text { PARM }=S T Z E=120000 \\
\# C S A S N & \text { PARM }=S I Z E=120000
\end{array}
$$

To run CSASN and utilize data checking with the region size set to 120,000 words, enter an analytical sequence specification as shown below. PARM should start after column 10.

$$
\begin{array}{ll}
=\text { CSASN } & \text { PARM }=(\text { CHECK,SIZE }=120000) \\
=\text { CSASN } & \text { PARM }=(\text { SIZE }=120000, \text { CHECK }) \\
=\text { CSASN } & \text { PARM }=\text { 'CHECK,SIZE }=120000^{\prime} \\
=\text { CSASN } & \text { PARM }=\text { 'SIZE }=120000, C H E C K '
\end{array}
$$

\section{M7.4.3 MATERIAL INFORMATION PROCESSOR DATA}

The Material Information Processor reads the standard composition specification data and the unit cell geometry specifications. It then produces the mixing table and unit cell information necessary for processing the cross sections. Table M7.4.4 outlines the input data for the Material Information Processor.

The input data for the Material Information Processor are identical to the input for CSAS1 of SCALE 3.1 and older versions of SCALE with the following exceptions:

- The analytical sequence card is considered to be part of the overall data input.

- Items 2, 3, 4, 6, and 7 from Sect. C1.6 of SCALE 3.1 and older versions of SCALE are omitted from the parameter card.

- The words END COMP are entered to signal the completion of the standard composition specification data.

- The multiregion zone description data are terminated by the words END ZONE.

- If optional control parameters are entered, the words MORE DATA must precede the first optional parameter data entry.

Note that the CSAS1 program is not included in SCALE beginning with the SCALE-4 release.

NUREG/CR-0200,

Vol. 3, Rev. 4 
Table M7.4.4 Outline of Material Information Processor data

Outline of Material Information Processor Data (see Sect. C4.4.3 for details)

\begin{tabular}{|c|c|c|c|}
\hline $\begin{array}{l}\text { Data } \\
\text { position }\end{array}$ & Type of data & Data entry & Comments \\
\hline 1 & TITLE & Enter a title & 80 characters \\
\hline 2 & $\begin{array}{l}\text { Cross-section } \\
\text { library name }\end{array}$ & $\begin{array}{l}\text { HANSEN-ROACH } \\
\text { 27GROUPNDF4 } \\
\text { 123GROUPGMTH } \\
\text { 218GROUPNDF4 } \\
\text { 27BURNUPLIB } \\
\text { etc. }\end{array}$ & $\begin{array}{l}\text { The currently available libraries } \\
\text { are listed in Table M4.1.1 and } \\
\text { Table M8.8.2. }\end{array}$ \\
\hline 3 & Type of calculation & $\begin{array}{l}\text { INFHOMMEDIUM } \\
\text { LATTICECELL } \\
\text { MULTIREGION }\end{array}$ & $\begin{array}{l}\text { These are the available } \\
\text { options. See the explanation } \\
\text { in Sect. M7.4.3. }\end{array}$ \\
\hline 4 & $\begin{array}{l}\text { Standard Composition } \\
\text { specification data }\end{array}$ & $\begin{array}{l}\text { Enter the appropriate } \\
\text { data }\end{array}$ & $\begin{array}{l}\text { Terminate this data block with } \\
\text { END COMP. See Sect. M7.4.4. }\end{array}$ \\
\hline 5 & $\begin{array}{l}\text { Unit cell } \\
\text { geometry } \\
\text { specification }\end{array}$ & $\begin{array}{l}\text { Enter the appropriate } \\
\text { data (optional for } \\
\text { INFHOMMEDIUM) }\end{array}$ & $\begin{array}{l}\text { Optional for INFHOMMEDIUM. } \\
\text { See Sect. M7.4.5 for } \\
\text { INFHOMMEDIUM. } \\
\text { See Sect. M7.4.6 for LATTICECELL. } \\
\text { See Section M7.4.7 for } \\
\text { MULTIREGION. }\end{array}$ \\
\hline 6 & $\begin{array}{l}\text { Optional parameter } \\
\text { data }\end{array}$ & $\begin{array}{l}\text { Enter the desired } \\
\text { data }\end{array}$ & $\begin{array}{l}\text { Precede this data block by } \\
\text { MORE DATA if more parameter } \\
\text { data are to be entered. } \\
\text { Otherwise, omit these data } \\
\text { entirely. See Sect. M7.4.8. }\end{array}$ \\
\hline
\end{tabular}

The Material Information Processor allows terse data input for all data except the standard composition names and the keyword entries in the optional parameter data (MORE DATA). Terse data entry requires the user to enter only as many characters as are necessary to uniquely define the data entry. However, as many characters as are specified by the user must match the name allowed by the code. For example, refer to Table M7.4.4, Outline of Material Information Processor data, data position 3. The available choices for the type of calculation are: INFHOMMEDIUM, LATTICECELL, and MULTIREGION. Therefore, it would be sufficient to specify I for an infinite homogeneous medium, $I$ for lattice cell, and $M$ for multiregion. If it is desirable to use more characters, the user is free to do so. However, as many characters as are entered must match the name allowed by the code. For example, if INFHOMMEDIUM is to be specified, INFH is correct, but INFI is not.

WARNING: If several choices begin with the same letters, sufficient characters should be entered to uniquely define the name. For example, ASPHSQUAREP and ASPHTRIANGP are identical through the first four characters. If only ASPH is entered, the code will accept the first name whose first four characters are ASPH. This may not be the one the user intended to use. 
The types of data required for the Material Information Processor are given in Table M7.4.4. The individual entries are explained in the text following the table.

1. TITLE...An 80-character title is required. The title is the first 80 characters of the Material Information Processor data.

2. CROSS-SECTION LIBRARY NAME... This item specifies the cross-section library that is to be used in the calculation. See Sect. M4, Table M4.1.1, or Sect. M8, Table M8.2.2, for a discussion of the available libraries.

3. TYPE OF CALCULATION...The options are INFHOMMEDIUM, LATTICECELL, and MULTIREGION.

INFHOMMEDIUM is used for an infinite homogeneous medium. It provides cross sections to represent large homogeneous pieces. The cross sections are treated as if each mixture is infinite. Thus, the self-shielding calculations will not account for any geometrical effects. By default, the smallest mixture number will be used in the cell. A different mixture can be specified as described in Sect. M7.4.5 and Table M7.4.6.

LATTICECELL is used when the geometry can be described as a lattice. It is especially suited for arrays of cylindrical rods or spherical pellets. The use of LATTICECELL requires the entry of additional geometry information (unit cell specification), which is described in Sect. M7.4.6 and Table M7.4.7. When the problem consists of an array of fuel bundles or similar geometry, the cross sections are corrected for resonance self-shielding, including geometry effects. If cell-weighted cross sections are desired, an appropriate control sequence must be used (CSAS2X, for example). A flux disadvantage factor is then applied to the cross sections of the materials that are used in the unit cell.

MULTIREGION may be used to define a geometric configuration that is more complicated than that allowed by LATTICECELL. It can also be used for a system involving large geometric regions where geometry effects may be minimal. The cross sections utilized in the unit cell are corrected for resonance self-shielding, and an appropriate Dancoff factor is applied (see Sect. M7.2.4.3). If a cell-weighted mixture is generated, it is derived from homogenizing the entire MULTIREGION unit cell. The additional geometry information (Unit Cell Specification) required for a MULTIREGION problem is described in Sect. M7.4.7 and Table M7.4.8.

4. STANDARD COMPOSITIONS...These data are used to define the mixtures that will be used in the problem. See Sect. M7.4.4 and Table M7.4.5 for a description of the standard composition specification data. These data are required for every problem.

5. CELL GEOMETRY SPECIFICATION...See Sect. M7.4.5, and Table M7.4.6 for an explanation of the optional unit cell data associated with an INFHOMMEDIUM problem. See Sect. M7.4.6 and Table M7.4.7 for an explanation of the data associated with LATTICECELL problems. Section M7.4.7 and Table M7.4.8 explain the data required for a MULTIREGION problem.

6. OPTIONAI PARAMETER DATA...This option allows certain defaulted parameters to be respecified by the user. Omit these data unless they are needed. If data are to be entered, see Sect. M7.4.8 and Table M7.4.9 for assistance.

NUREG/CR-0200, 


\section{M7.4.4 STANDARD COMPOSITION SPECIFICATION DATA}

The standard composition specification data are used to define mixtures that are to be utilized in the problem. These data can be considered to be a mixing table that defines mixtures in terms of standard composition specification data (available from Sect. M8.2, Table M8.2.1). The required input for the standard composition specification data varies, depending on the standard composition component name. However, every standard composition specification must include the following:

1. a standard composition component name (SC),

2. the mixture that contains this component $(\mathrm{MX})$, and

3. a terminator for the standard composition specification data (enter the word END).

Enter as many standard composition specifications as necessary to define all the mixtures needed for the problem. When all the necessary mixtures have been described, enter the words END COMP to signal the completion of this type of data.

The data required to define a standard composition specification are contained in Table M7.4.5. In the column entitled "Entry Requirement," "ARBM" is used to denote entries required only for arbitrary materials, and "SOLN" is used for entries required only for solutions.

The input data for standard composition specifications are arranged with entry numbers 1 through 7 that apply to all standard composition data. Entries A1 through A7 apply only to arbitrary materials. Entries S1 and S2 apply only to solutions. Entry $\mathrm{O} 1$ is optional information that applies to both basic standard composition and solutions. The individual entries specified in Table M7.4.5 are explained in more detail in the text following the table.

1. $\mathrm{SC}$

STANDARD COMPOSITION COMPONENT NAME...The names of the standard composition components (the alphanumeric identifiers) may be (1) chosen from Table M8.2.1 of Sect. M8.2, which contains the list of elements, compounds, and alloys found in the Standard Composition Library, (2) chosen from the table of available solutions, Sect. M8.3, or (3) designated as an arbitrary material (ARBM). An error message will be printed if the user enters an invalid standard composition component name as if the composition does not exist in the specified library.

For standard compositions taken from Table M8.2.1 of the Standard Composition Library (basic standard composition), certain data such as the volume fraction or theoretical density and other engineering-type data may need to be entered. For standard compositions containing more than one isotope of an element (such as $\mathrm{UO}_{2}$ ),

the user is free to specify the weight percent for each isotope, such that they total $100 \%$. See Sect. M7.5.5.1 for examples of basic standard compositions.

Solutions require the specification of the density of the heavy metal in the solution and the acid molarity of the solution. The alphanumeric specification of a solution starts with the four characters "SOLN." Some common fissile solutions are SOLNUO2(NO3)2, SOLNPU(NO3)4, and SOLNUO2F2. See Sect. M8.3 for a complete listing of the available solutions.- Sections M7.5.5.3 and M7.5.9 contain examples of the input data for solutions. 
Table M7.4.5 Outline of standard composition specification data

Outline of standard compasitions specification data

\begin{tabular}{|c|c|c|c|c|}
\hline $\begin{array}{l}\text { Entry } \\
\text { No. }\end{array}$ & $\begin{array}{l}\text { Variable } \\
\text { name }\end{array}$ & Type of data & $\begin{array}{l}\text { Entry } \\
\text { requirement }\end{array}$ & Comments \\
\hline 1 & SC & $\begin{array}{l}\text { Standard composition } \\
\text { component name }\end{array}$ & Always & $\begin{array}{l}\text { Enter once for each standard composition. Enter the } \\
\text { alphanumeric description from Table M8.21. Additional } \\
\text { allowed names include those beginning with ARBM for } \\
\text { arbitrary materials, and SOLN for solutions. }\end{array}$ \\
\hline A1 & ROTH & $\begin{array}{l}\text { Theoretical density of } \\
\text { material }(g / c c)\end{array}$ & ARBM & $\begin{array}{l}\text { Enter once for each standard composition component that is an } \\
\text { arbitrary material. }\end{array}$ \\
\hline A2 & NEL & $\begin{array}{l}\text { Number of elements in the } \\
\text { material }\end{array}$ & ARBM & $\begin{array}{l}\text { Enter once for each standard composition component that is an } \\
\text { arbitrary material. }\end{array}$ \\
\hline$A 3$ & TVIS & Multiple-isotope indicator & ARBM & $\begin{array}{l}\text { Enter once for each standard composition component that is an } \\
\text { abitrary material. Enter } 0 \text { for a material that does not contain } \\
\text { multiple-isotope elements. Enter } 1 \text { if the material contains a } \\
\text { multiple-isotope element. An arbitrary material cannot have } \\
\text { more than one multiple-isotope element If necessary, several } \\
\text { arbitrary materials may be used in a single mixture. }\end{array}$ \\
\hline A4 & ICP & Compound indicator & ARBM & $\begin{array}{l}\text { Enter once for each standard composition component that is an } \\
\text { arbitrary material. Enter } 1 \text { for a compound, } 0 \text { for alloys, } \\
\text { mixtures, etc. }\end{array}$ \\
\hline A5 & IRS & Resonance indicator & ARBM & $\begin{array}{l}\text { Enter once for each standard composition component that is an } \\
\text { arbitrary material. Enter } 0 \text { if all the nuclides in the material } \\
\text { are non-resonance nuclides; enter } 1 \text { if one or more have } \\
\text { resonance data. See Sect. M8.2 Table M8.21. }\end{array}$ \\
\hline A6 & NCZA & $\begin{array}{l}\text { ID number (from far right } \\
\text { column of Table M8.21) }\end{array}$ & ARBM & $\begin{array}{l}\text { Repeat the sequences } A 6 \text { and } A 7 \text { for each element in the } \\
\text { arbitrary material before entering entry } 2 \text { Enter the number } \\
\text { from the far right column of Table M8.21. (Premired standard } \\
\text { compositions cannot be used in an arbitrary material } \\
\text { definition.) }\end{array}$ \\
\hline$A 7$ & ATPM & $\begin{array}{l}\text { Number of atoms of this } \\
\text { element per molecule of } \\
\text { arbitrary material } \\
\text { or } \\
\text { Weight percent of this } \\
\text { element in this arbitrary } \\
\text { material }\end{array}$ & $\begin{array}{l}\text { ARBM } \\
\& \\
\text { ICP }=1 \\
\quad \text { or } \\
\text { ARBM } \\
\& \\
I C P=0\end{array}$ & $\begin{array}{l}\text { Repeat the sequences } A 6 \text { and } A 7 \text { for each element in the } \\
\text { arbitrary material before entering entry number } 2 \\
\text { Do not enter a value unless ICP }=1 \text {. } \\
\text { or } \\
\text { Repeat the sequences } A 6 \text { and } A 7 \text { for each element in the } \\
\text { arbitrary material before entering entry number } 2 \text { Do not enter } \\
\text { a value unless ICP }=0 \text {. }\end{array}$ \\
\hline
\end{tabular}

NUREG/CR-0200, 
Table M7.4.5 (continued)

Outline of standard compositions specification data (continued)

\begin{tabular}{|c|c|c|c|c|}
\hline $\begin{array}{l}\text { Entry } \\
\text { No. }\end{array}$ & $\begin{array}{l}\text { Variable } \\
\text { name }\end{array}$ & Type of data & $\begin{array}{l}\text { Entry } \\
\text { requirement }\end{array}$ & Comments \\
\hline 2 & MX & Mixture ID number & Always & Enter once for each standard composition component. \\
\hline \$1 & FD & $\begin{array}{l}\text { Fuel density (grams of } U \\
\text { or Pu per liter of solution) }\end{array}$ & SOLN & Enter once for a solution. \\
\hline S2 & AML & $\begin{array}{l}\text { Acid molarity of the } \\
\text { solution }\end{array}$ & SOLN & $\begin{array}{l}\text { Enter once for a solution. AML }=0 \text { if there is no } \\
\text { acid in the solution. }\end{array}$ \\
\hline \multirow[t]{2}{*}{01} & SPGR & $\begin{array}{l}\text { Specific gravity of the } \\
\text { solution }\end{array}$ & Optional & $\begin{array}{l}\text { If the specific gravity (SPGR) of the solution is } \\
\text { known, it should be entered as SPG }=S P G R \text {. }\end{array}$ \\
\hline & or & $\begin{array}{l}\text { or } \\
\text { Density of the basic } \\
\text { standard composition }\end{array}$ & & $\begin{array}{l}\text { or } \\
\text { If the density of a basic standard composition } \\
\text { (ROTH) is to be entered, use DEN=ROTH. }\end{array}$ \\
\hline 3 & VF & Density multiplier & $\begin{array}{l}\text { See } \\
\text { comment } \\
\text { column }\end{array}$ & $\begin{array}{l}\text { Enter the density multiplier (density fraction, volume } \\
\text { fraction, or a combination). Default value is } 1 \text {. This } \\
\text { item can be omitted if entries } 4,5,6 \mathrm{a} \text {, and } 6 \mathrm{~b} \text { are } \\
\text { also omitted. VF }=0 \text { is not allowed for SOLN or } \\
\text { ARBM. }\end{array}$ \\
\hline 4 & ADEN & $\begin{array}{l}\text { Number density (atoms/b- } \\
\mathrm{cm} \text { ) for the nuclide }\end{array}$ & $\mathrm{VF}=0$ & Enter only if VF $=0.0$ \\
\hline 5 & TEMP & Temperature, in degrees $\mathrm{K}$ & $\begin{array}{l}\text { See comment } \\
\text { column }\end{array}$ & $\begin{array}{l}\text { Default value is } 293 \mathrm{~K} \text {. This entry can be } \\
\text { omitted if entries } 6 \mathrm{a} \text { and } 6 \mathrm{~b} \text { are also omitted. }\end{array}$ \\
\hline 6a & IZA & Isotope's ZA number & $\mathrm{VF} \neq 0$ & $\begin{array}{l}\text { Enter for each isotope in the standard composition } \\
\text { component. Omit if VF }=0 \text {. Entries } 6 \mathrm{a} \text { and } 6 \mathrm{~b} \text { are } \\
\text { entered in pairs until each isotope in the component } \\
\text { is defined. }\end{array}$ \\
\hline $6 b$ & WTP & $\begin{array}{l}\text { Weight percent of the } \\
\text { isotope }\end{array}$ & $\mathrm{VF} \neq 0$ & $\begin{array}{l}\text { Enter for each isotope in the standard composition } \\
\text { component. Omit if VF }=0 \text {. Entries } 6 \mathrm{a} \text { and } 6 \mathrm{~b} \text { are } \\
\text { entered in pairs until each isotope in the component } \\
\text { is defined. }\end{array}$ \\
\hline \multirow[t]{2}{*}{7} & END & $\begin{array}{l}\text { Terminate a standard } \\
\text { composition }\end{array}$ & Always & $\begin{array}{l}\text { Enter once for each standard composition component. } \\
\text { This terminates the data for a standard composition } \\
\text { component. Enter END to terminate the component. } \\
\text { Repeat entries } 1 \text { through } 7 \text { until all the mixtures have } \\
\text { been defined. At least two blanks must separate } \\
\text { entry } 7 \text { from the next entry. }\end{array}$ \\
\hline & END COMP & Terminate the data block & Terminus & $\begin{array}{l}\text { Enter once for a problem. Enter the words END } \\
\text { COMP when all the standard composition } \\
\text { components have been described. At least two } \\
\text { blanks must follow the END COMP. }\end{array}$ \\
\hline
\end{tabular}

NOTE: Entry number 7 should not begin in column 1 unless a name is associated with it. At least two blanks should separate the last entry 7 from the END COMP. 
Arbitrary materials require the user to provide all the information normally found in the Standard Composition Library. The arbitrary material option allows specifying a compound or alloy not available in the Standard Composition Library by utilizing the standard composition available in the library. Table M8.2.1 indicates which nuclides require a resonance self-shielding calculation.

An arbitrary material name must start with the four characters "ARBM." A maximum of twelve characters is allowed for the standard composition component name. Imbedded blanks are not allowed in a standard composition component name. Section M7.5.5.2 contains input data for arbitrary materials.

An additional example of an arbitrary material specification is given below:

Consider a mixture of boral having $35 \mathrm{wt} \% \mathrm{~B}_{4} \mathrm{C}, 65 \mathrm{wt} \% \mathrm{Al}$ and an overall density of $2.64 \mathrm{~g} / \mathrm{cc}$. If neither BORAL nor B4C were available in the Standard Composition Library, the components BORON, C, and AI could be used as basic standard compositions to describe the boral. The necessary volume fractions would have to be determined as shown in Sect. M7.5.5.4, examples 3 and 4. By utilizing the arbitrary material option, both $\mathrm{B}_{4} \mathrm{C}$ and $\mathrm{Al}$ can be described as a component of the same mixture (assume it is desired to be mixture 3), both have a density of $2.64 \mathrm{~g} / \mathrm{cc}$ and the volume fractions are 0.35 for the $\mathrm{B}_{4} \mathrm{C}$ and 0.65 for the $\mathrm{Al}$. The resulting standard composition specification data do not require any calculations (see example 1, Sect. M7.5.5.5 for a similar situation) and could be entered as:

ARBMTL-B4C $2.642110500046012130 .35 \mathrm{END}$

ARBMTL-AL $2.64100013027100 .030 .65 \mathrm{END}$

A1. ROTH THEORETICAL DENSITY OF MATERIAL...Enter ONLY for arbitrary materials. The density of the arbitrary material is entered in units of $\mathrm{g} / \mathrm{cc}$.

NOTE: ROTH can be entered for a basic standard composition as shown by entry $O 1$.

A2. NEL NUMBER OF ELEMENTS IN THE MATERIAL...Enter ONLY for arbitrary materials. Enter the number of components from the Standard Composition Library that are to be used to define this arbitrary material. In the above example, the ARBMTL-B4C contains two components, the $B$ and the $C$. Therefore, NEL is 2 for the $\mathrm{B}_{4} \mathrm{C}$ arbitrary material. The ARBMTL-AL contains only one component, so NEL is 1 for it.

A3. IVIS MULTIPLE-ISOTOPE INDICATOR...Enter ONLY for an arbitrary material. An arbitrary material cannot have more than one multiple-isotope element. If more than one is needed, define additional arbitrary materials. Enter a zero if none of the elements in the arbitrary material have multiple isotopes. In the above example, the boron is a multiple-isotope element, so IVIS is 1 for the $\mathrm{B}_{4} \mathrm{C}$ arbitrary material. The arbitrary material describing the aluminum contains no multiple-isotope elements, so IVIS is zero for it.

A4. ICP COMPOUND INDICATOR...Enter ONLY for arbitrary materials. A compound is a substance containing more than one constituent element and having properties different from those which their constituents had as elementary substances. The composition of a pure compound is perfectly definite and is always the same, regardless of the method of formation. Examples of compounds are: $\mathrm{H}_{2} \mathrm{O}, \mathrm{B}_{4} \mathrm{C}, \mathrm{CO}_{2}, \mathrm{Ca}(\mathrm{OH})_{2}, \mathrm{C}_{2} \mathrm{H}_{6}, \mathrm{Fe}_{2} \mathrm{~S}_{3}$,

NUREG/CR-0200,

Vol. 3, Rev. 4

M7.4.14 
A5. IRS

$\mathrm{Cr}_{2} \mathrm{O}_{3}$, etc. ICP is 1 for a compound. ICP is 0 for alloys (stainless steel, Monel, etc.), and conglomerates or mixtures such as concrete.

In the $\mathrm{B}_{4} \mathrm{C}$ arbitrary material example, ICP is 1 ; in the aluminum arbitrary material example, ICP is 0 . These examples are given in the explanation of entry number $1, \mathrm{SC}$.

RESONANCE INDICATOR...Enter ONLY for arbitrary materials. If any of the nuclides in the arbitrary material have resonance data associated with them, set IRS to 1. If all the nuclides are nonresonance nuclides, set IRS to zero. Table M8.2.1 lists the nuclides that have resonance data associated with them. An entry of 1 is acceptable even for nonresonance nuclides. For example, NCZA is 1001 for hydrogen, 8016 for oxygen, and 92235 for ${ }^{235} \mathrm{U}$. For elements for which the natural abundance is acceptable, NCZA can be entered as $1000^{*} Z$; for example, 92000 for uranium or 5000 for boron.

IRS is zero for both the $\mathrm{B}_{4} \mathrm{C}$ and $\mathrm{Al}$ arbitrary material examples given in the explanation of entry 1.

A6. NCZA ID NUMBER... Enter ONLY for arbitrary materials. This is the "ZA" ID number for the element or isotope. Usually, $N C Z A=A+1000^{*} Z$, where $A$ is the atomic mass or weight of the nuclide, and $Z$ is the atomic number.

If the arbitrary material contains an element that has multiple isotopes, that element MUST be the first element specified in the arbitrary material. Furthermore, that element MUST be listed in the Isotope Distribution Table, Table M8.4.1. Uranium (92000), plutonium ( 94000$)$, and boron (5000) are multiple-isotope elements.

For example:

ARBMTL-B4C 2.642110500046012130 .35 END is correct;

ARBMTL-B4C 2.642110601215000 430.35 END is incorrect because the multipleisotope element is not listed first.

REPEAT THE SEQUENCE NCZA and ATPM (A6 and A7) FOR EVERY ELEMENT IN THE ARBITRARY MATERIAL.

A7. ATPM Enter ONLY for arbitrary materials. Repeat the sequence A6 and A7 for every element in the arbitrary material before going on to entry 2 .

If ICP is 1 (entry A4) enter the NUMBER OF ATOMS PER MOLECULE. If the arbitrary material is a compound (entry A4, ICP is 1), enter the number of atoms of this element per molecule of arbitrary material.

If ICP is 0 (entry A4) enter the WEIGHT PERCENT OF THIS ELEMENT IN THE ARBITRARY MATERIAI. If the arbitrary material is not a compound (entry A4, ICP is 0 ), enter the weight percent of this element in the arbitrary material. If ICP is 0 , the sum of all the weight percents for the arbitrary material MUST be 100.0.

2. MX MIXTUREID NUMBER...A mixture number is required on every standard composition specification. It defines the mixture that contains the material defined by the standard composition specification data. The mixture numbers are utilized in the Unit Cell Specification for INFHOMMEDIUM, LATTICECELL, or MULTIREGION problems and the KENO V.a geometry data. 
S1. FD

FUEL DENSITY...Enter ONLY for a solution. The standard composition component name for a solution starts with the four characters "SOLN." The available solution names are listed in Sect. M8.3. Enter the fuel density in units of grams of heavy metal (fissile material) per liter of solution.

S2. AMI ACID MOLARITY...Enter ONLY for a solution. If there is no acid in the solution, enter zero. If acid is present in the solution, enter the molarity of the solution.

O1. SPGR or

OPTIONAL DATA..Does NOT apply to ARBITRARY MATERIALS. These ROTH optional data can be entered for a solution or for a basic standard composition using a keyword in the form: $S P G=S P G R, D E N=S P G R, D E N=R O T H$, or $S P G=R O T H$. The keywords SPG = and DEN= are interchangeable. SPGR is the specific gravity of the fuel solution. If the standard composition name begins with SOLN and the specific gravity of the solution is known, it should be entered. Otherwise the code has to interpolate in a table to obtain a specific gravity to use in the calculation. ROTH is the specified density of the standard composition in $\mathrm{g} / \mathrm{cc}$ and can be entered if desired. The interaction between ROTH, the density of the standard composition, and VF (entry 3) is demonstrated in Sect. M7.5.5.

3. VF VOLUME FRACTION...The default value of the volume fraction is 1.0 . It can be omitted if entries $4,5,6 \mathrm{a}$, and $6 \mathrm{~b}$ are also omitted. The volume fraction can be interpreted as:

a. the volume fraction of this standard composition component in the mixture,

b. the density of the standard composition component in this application, divided by the theoretical density listed in the Standard Composition Library (Sect. M8.2, Table M8.2.1), or

c. the product of (a) and (b).

Section M7.5.5 discusses the interaction between ROTH and VF. For example, assume a homogenized mixture representing the water moderator and Zircaloy cladding around a fuel pin is to be described. If the volume of the clad is $5.32 \mathrm{cc}$ and the volume of the water moderator is $44.68 \mathrm{cc}$, the mixture can be described using $\mathrm{H}_{2} \mathrm{O}$ with a volume fraction of 0.8936 [i.e., $44.68 /(44.68+5.32)$ ] and ZIRCALOY with a volume fraction of 0.1064 [i.e., $5.32 /(44.68+5.32)]$.

For $\mathrm{UO}_{2}$ fuel at $95 \%$ theoretical density, the volume fraction is 0.95 . For the coolant water in an operating PWR, the volume fraction might typically be 0.71 .

To describe a mixed-oxide fuel pin with a density of $10.5 \mathrm{~g} / \mathrm{cc}$, that is $17.8 \mathrm{wt} \% \mathrm{PuO}_{2}$ and $82.2 \mathrm{wt} \% \mathrm{UO}_{2}$, two standard composition specifications must be entered: one for the $\mathrm{PuO}_{2}$ component and one for the $\mathrm{UO}_{2}$ component. From the Standard Composition Library, Table M8.2.1, the theoretical density of the $\mathrm{PuO}_{2}$ is $11.46 \mathrm{~g} / \mathrm{cc}$, and that of the $\mathrm{UO}_{2}$ is $10.96 \mathrm{~g} / \mathrm{cc}$. Therefore, the volume fraction for the $\mathrm{PuO}_{2}$ is 0.1631 (i.e., $0.178 * 10.50 / 11.46$ ), and the volume fraction for the $\mathrm{UO}_{2}$ is 0.7875 (i.e., $0.822 * 10.50 / 10.96)$.

Occasionally, a special mixture will be desired for which the determination of the component volume fractions will not be so straightforward. Consider a mixture of boral having $35 \mathrm{wt} \% \mathrm{~B}_{4} \mathrm{C}, 65 \mathrm{wt} \% \mathrm{Al}$, and an overall density of $2.64 \mathrm{~g} / \mathrm{cc}$. Assume that neither BORAL nor $\mathrm{B}_{4} \mathrm{C}$ is in the Standard Composition Library. The volume fractions corresponding to BORON, C, and AL may be computed as illustrated in Sect. M7.5.5.4,

NUREG/CR-0200,

Vol. 3, Rev. 4

M7.4.16 
examples 3 and 4. Note that the calculation is complicated by the fact that $\mathrm{B}_{4} \mathrm{C}$ is a compound and boron has two isotopes. It might be simpler to enter $\mathrm{B}_{4} \mathrm{C}$ and $\mathrm{Al}$ as arbitrary materials as illustrated in example 1 of Sect. M7.5.5.5. Examples 1 and 2 of Sect. M7.5.5.4 illustrate the use of $\mathrm{B}_{4} \mathrm{C}$ and aluminum to describe a boral mixture. If the volume fraction is set to 0.0 , the user can enter the number density for the nuclide (in atoms per barn-cm) for entry 4. Number densities cannot be entered for standard compositions that represent multiple nuclides.

4. ADEN NUMBER DENSITY...Enter a value for the number density ONLY if the volume fraction (VF, entry 3) was entered as zero. The number density is entered in units of atoms per barn-cm.

5. TEMP TEMPERATURE...The default value of the temperature is $293 \mathrm{~K}$. The temperature can be omitted if entries $6 a$ and $6 b$ are also omitted.

The temperature is used for Doppler broadening and/or the selection of the proper set of thermal scattering data.

The resonance self-shielding calculation performed by NITAWL uses the Nordheim Integral Method and can account for Doppler broadening of the resonances at any specified temperature. If this material is known to contain a resonance nuclide, the user should enter a rough estimate of the temperature of the material. To determine whether resonance data are available for any of the nuclides in a material,

a. check Table M8.2.1 if entry 1 is not a solution, SOLN;

b. check Table M8.3.1 if entry 1 denotes a solution, SOIN.

For each of the light nuclides (A $\leq 20$ a.m.u.), the master cross-section library may contain one or more sets of thermal-scattering data, each set corresponding to a different temperature. Tables M4.2.4, M4.2.6, and M4.2.8 list, respectively, the available sets of data for the 27-group ENDF/B-IV library, the 16-group Hansen-Roach library, and the 123-group GAM-THERMOS library. Scattering matrices for nuclides in media at elevated temperatures are generally fuller than those at lower temperatures. Tables M8.2.1 and M8.3.1 indicate the isotopes, elements, compounds, solutions, and alloys for which multiple sets of thermal-scattering data are currently available. If multiple sets of thermal-scattering data are available, the user should enter a rough estimate of the temperature of the material. The code will then use the set of cross-section data that is nearest to the input temperature.

6a. IZA ISOTOPE ZA NUMBER...Enter a value for each isotope in the standard composition component, entry 1. Do not enter a value if the volume fraction, VF, is zero (entry 3 ).

The ZA number of the isotope is entered if the user wishes to specify the isotopic distribution. This is done by entering $6 a$ and $\sigma b$ for each isotope until all the desired isotopes have been described. The " $\mathrm{ZA}$ " ID number is $\left(A+1000^{*} \mathrm{Z}\right)$, where $\mathrm{A}$ is the atomic mass or weight of the isotope, and $\mathrm{Z}$ is the atomic number.

Entries $6 a$ and $6 \mathrm{~b}$ can be skipped if the default values listed in the Isotope Distribution Table, Table M8.4.1, are acceptable. 
6b. WTP

WEIGHT PERCENT OF THE ISOTOPE...Do not enter a value if the volume fraction, VF, entry 3 , is zero. If entry $6 a$ is entered, a value must also be entered for $6 \mathrm{~b}$. The weight percent of the isotope is the percent of this isotope in the element.

The user need not input entries $6 \mathrm{a}$ and $6 \mathrm{~b}$ for each isotope listed for the element in Table M8.4.1. The only requirement is that the sum of entries $6 \mathrm{~b}$ for the element must sum to 100.0. Thus, uranium could be specified as 922353.29223896 .8 to represent $3.2 \%$ enriched uranium and ignore the 234 and 236 isotopes. However, 922353.0 and 9223896.8 would not be correct because the 3.0 and 96.8 do not sum to 100.0. 92235 3.0922340 .29223896 .8 would be correct.

REPEAT THE SEQUENCE $6 a$ and $6 b$ until all the isotopes of the element have been defined as desired.

7. END The word END is entered to terminate the input data for a standard composition component. This END can have a label associated with it that can be as long as 12 characters. The label is optional, and if entered is separated from the END by a single blank. At least two blanks must separate item 7 from the next data entry.

END COMP The words END COMP are entered only once for a problem. Their purpose is to signal the end of all the standard composition specification data that will be used in the problem. At least two blanks should separate entry 7 from the END COMP. Note that COMP is a label associated with this END. This label can be as long as 12 characters, but the first four characters must be COMP.

\section{M7.4.5 OPTIONAL UNIT CELL SPECIFICATION FOR INFINITE HOMOGENEOUS PROBLEMS}

This section describes the unit cell data that can be entered for an INFHOMMEDIUM problem (data position 3 of Table M7.4.4). By default, the smallest mixture number is the mixture that will be used for the cell in XSDRNPM. In order to calculate the eigenvalue of the system, the mixture should contain fissionable material. Unit cell data are required for an infinite homogeneous medium problem ONLY if XSDRNPM is utilized by the control sequence and a mixture number other than the smallest mixture number is to be used in the cell. Control sequences that end in X, (CSAS1X, etc.) utilize XSDRNPM. Additional information is available in Sect. M7.5.12.

The data required to specify the unit cell for an INFHOMMEDIUM problem are given in Table M7.4.6. The individual entries are explained in the text following the table.

NUREG/CR-0200, 
Table M7.4.6 Optional unit cell specification for INFHOMMEDIUM problems

\begin{tabular}{ccccc}
\hline $\begin{array}{l}\text { Entry } \\
\text { No. }\end{array}$ & $\begin{array}{c}\text { Variable } \\
\text { name }\end{array}$ & $\begin{array}{c}\text { Type of } \\
\text { data }\end{array}$ & $\begin{array}{c}\text { Data } \\
\text { entry }\end{array}$ & \multicolumn{1}{c}{ Comments } \\
\hline 1 & NAME & Keyword & CELLMTX & $\begin{array}{l}\text { Initiates reading cell data for } \\
\text { INFHOMMEDIUM. }\end{array}$ \\
2 & MFUEL & $\begin{array}{l}\text { Mixture } \\
\text { number } \\
\text { in the cell }\end{array}$ & $\begin{array}{l}\text { Mixture } \\
\text { number }\end{array}$ & $\begin{array}{l}\text { Specifies the mixture number to be used in the } \\
\text { cell. Defaults to the smallest mixture number } \\
\text { entered in the Standard Composition Data. }\end{array}$ \\
\hline
\end{tabular}

1. NAME KEYWORD...The keyword CELLMIX is entered to indicate that unit cell data will be entered. If this entry is entered, entry 2 must also be entered. These data can be entered ONLY if entry 3, the Type of Calculation from Table M7.4.4, is entered as INFHOMMEDIUM.

2. MFUEL MIXTURE NUMBER...The mixture number that defines the mixture to be used in the cell. The default value is the smallest mixture number specified in the standard composition specification data. If either item 1 or 2 is entered, the other must also be entered.

To enter the above data, enter the keyword CELLMIX, one or more blanks, and the desired mixture number, MFUEL, as shown below.

\section{CELLMTX MFUEL}

To specify mixture 5 to be used in the cell, enter the following data.

\section{CELLMIX 5}

WARNING: If unit cell data are to be entered for an infinite homogeneous problem, the word CELLMTX must be spelled correctly. If it is misspelled, the code will not give an error message and will attempt to use the smallest mixture number. The input data will get out of phase for CSAS and SAS sequences that expect to read data after the unit cell specification.

\section{M7.4.6 UNIT CEIL SPECIFICATION FOR LATTICE CELX PROBLEMS}

This section describes the unit cell data that must be entered for a LATTICECELL problem (data position 3 of Table M7.4.4). Additional information is available in Sects. M7.5.4, M7.5.4.2, M7.5.6.2, and M7.5.8.2. The lattice cell description is especially suited to large arrays of identical cells. The code is limited to a single unit cell description for each problem. The unit cell data are used to provide the lump shape and dimensions for resonance cross-section processing, to provide lattice corrections for cross-section processing, and to provide data used by XSDRNPM to create cell-weighted cross sections. Thus the unit cell specification plays a major role in providing problem-dependent cross sections. The configuration of the unit cell is determined by the specified "type of lattice." The unit cells are limited to infinitely long cylindrical rods in a square or triangular lattice, spheres in a cubic or triangular lattice, a symmetric array of slabs, or an asymmetric array of slabs. Two distinct types of cells ("Regular" and "Annular") are available to be used in a lattice cell problem. "Regular" cells allow a concentric spherical, cylindrical, or symmetric slab configuration constrained to a central fuel region 
surrounded by an optional gap, an optional clad, and an external moderator. The outer boundary of the cell is limited to provide an array having a square or triangular pitch. "Annular" cells allow a concentric spherical, cylindrical, or asymmetric slab configuration constrained to a central (second) moderator region surrounded by a fuel region having an optional gap and optional clad on each side of the fuel. The gap, if present, is identical on both sides of the fuel. The clad, if present, is identical in dimension and composition on both sides of the fuel. The outer region of the cell is filled with an external (first) moderator. The outer boundary of the cell is limited to provide an array having a square or triangular pitch.

Regular cells are: SQUAREPITCH, TRIANGPITCH, SPHSQUAREP, SPHTRIANGP, and SYMMSLABCELL.

Annular cells are: ASQUAREPITCH, ASQP, ATRIANGPITCH, ATRP, ASPHSQUAREP, ASSP, ASPHTRIANGP, ASTP, and ASYMSLABCELL

The unit cell data are utilized by the code to define the geometric and resonance self-shielding corrections that will be applied to the cross sections. Cell-weighted cross sections are created only if XSDRNPM is invoked by executing a control sequence ending in X, (CSAS1X, CSAS2X, etc.). The cell-weighted cross sections have a flux disadvantage factor applied to them. Because this weighting is applied to each mixture used in the cell, these cell-weighted mixtures should not be used in the geometry description of a subsequent code. However, the cell-weighted mixture that is created is always assigned a mixture number of 500 and can be used in a subsequent code.

The unit cell geometry data required to specify a LATTICECELL problem are given in Table M7.4.7. The individual entries are explained in the text accompanying the table. 
Table M7.4.7 Unit cell specification for lattice cell problems

\begin{tabular}{|c|c|c|c|c|c|}
\hline $\begin{array}{l}\text { Entry } \\
\text { number }\end{array}$ & $\begin{array}{l}\text { Variable } \\
\text { name }\end{array}$ & Type of dats & $\begin{array}{l}\text { Entry } \\
\text { requiresoent }\end{array}$ & Data entry & Comments \\
\hline 1 & CIP & Type of lattice & Always & $\begin{array}{l}\text { SQUAREPITH } \\
\text { ASQUAREPITCH } \\
\text { ASQP } \\
\text { TRIANGPITCH } \\
\text { ATRIANGPITCH } \\
\text { ATRP } \\
\text { SPHSQUAREP } \\
\text { ASPHSQUAREP } \\
\text { ASSP } \\
\text { SPHTRIANGP } \\
\text { ASPHTRLANGP } \\
\text { ASTP } \\
\text { SYMMSLABCELL } \\
\text { ASYMSLABCELL }\end{array}$ & 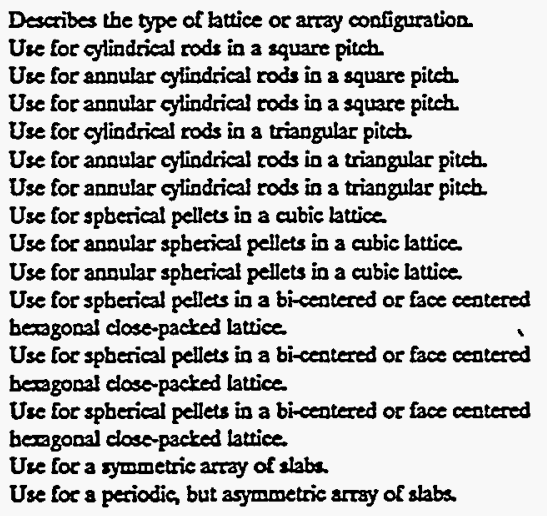 \\
\hline 2 & PITCH & Array pilch $(\mathrm{cm})$ & Always & Appropriate dimension & $\begin{array}{l}\text { The center-to-center spacing }(\mathrm{cm}) \text { between fuel lumps. } \\
\text { For asymmetric stab cell, enter the distance from the } \\
\text { ceater of one moderator to the center of the other } \\
\text { moderator }(\mathrm{cm}) \text {. }\end{array}$ \\
\hline 3 & FUELOD & $\begin{array}{l}\text { Outside dimension } \\
\text { of fuel }(\mathrm{cm})\end{array}$ & Atways & Appropriate dimension & $\begin{array}{l}\text { Outside drameter of fuel }(\mathrm{cm}) \text {, or the thictaness of the fuel } \\
\text { in } 3 \text { stab. }\end{array}$ \\
\hline 4 & MFUEL & Fuel mixure number & Always & Mincure number & Misture number representing the fuel \\
\hline 5 & MMOD & $\begin{array}{l}\text { Moderator miture } \\
\text { number }\end{array}$ & Ahways & Micure sumber & Mixture number representing the moderator \\
\hline 6 & MMOD2 & $\begin{array}{l}\text { 2nd moderator } \\
\text { mixure number }\end{array}$ & Anoular cell & Misere number & Miture number representing the second moderator. \\
\hline 7 & TKMOD2 & 2nd moderator thickness & ASYMSLABCELL & Thickness & $\begin{array}{l}\text { Thickness of the second moderator (cm) for } \\
\text { ASYMSLABCELL. }\end{array}$ \\
\hline & & $\begin{array}{l}\text { or } \\
\text { 2nd moderator diameter } \\
\text { (co) }\end{array}$ & $\begin{array}{c}\text { or } \\
\text { anoular cell }\end{array}$ & $\begin{array}{c}\text { or } \\
\text { Diameter }\end{array}$ & $\begin{array}{l}\text { or } \\
\text { Diameter of inner moderator }(\mathrm{cm}) \text { for other annular celle. }\end{array}$ \\
\hline 8 & CLADOD & $\begin{array}{l}\text { Outside diameter } \\
\text { of clad (cos) }\end{array}$ & If clad & Cad OD & $\begin{array}{l}\text { OMIT IR NO CLAD. For a slab, CLADOD is the sum } \\
\text { of thickness of the fuel, gap, and clad. }\end{array}$ \\
\hline 9 & MCLAD & Clad misture number & If clad & Misure number & $\begin{array}{l}\text { OMTT IF NO CLAD. Mirture number representing the } \\
\text { clad. }\end{array}$ \\
\hline 10 & CLADID & $\begin{array}{l}\text { Inside diameter of } \\
\text { clad (cm) }\end{array}$ & If g\&p & Cad ID & OMIT IF NO GAP between the fuel and clad \\
\hline 11 & MGAP & Gap minture number & $I_{\text {gap }}$ & Mrowure sumber & $\begin{array}{l}\text { OMIT IF NO GAP between the fuel and clad. } \\
\text { A minure number of zero is often used. }\end{array}$ \\
\hline 12 & END & $\begin{array}{l}\text { Terminate latticecell } \\
\text { data }\end{array}$ & Always & END & $\begin{array}{l}\text { Terminate the latticecell input data by enteriag the word } \\
\text { END. Do sot start in columo } 1 \text {. At least two blants } \\
\text { must follow entry number } 12\end{array}$ \\
\hline
\end{tabular}

1. CTP

TYPE OF LATTICE...This defines the type of lattice or array configuration. Any one of the following alphanumeric descriptions may be used. Note that the alphanumeric description must be separated from subsequent data entries by one or more blanks. Figures M7.4.1 through M7.4.6 are used to illustrate the type of lattice configurations available in a LATTICECELL problem. The fuel region is labeled $F$; the gap, $\mathrm{G}$; the clad, $\mathrm{C}$; and the moderator, $\mathrm{M}$. If two moderators are present, $M 1$ is the first moderator, and $M 2$ is the second moderator. Both "regular" 
and "annular" unit cells are available. The arrangement of the materials in the unit cell is strictly constrained. Regular cells are limited to a minimum of two regions and a maximum of four regions. The innermost region must be fuel, which is surrounded by an optional gap and/or optional clad. The outer region is moderator. Annular cells are limited to a minimum of three regions. The innermost region must be the second moderator. The annular fuel region is outside the second moderator. If a clad is present, it must be identical in thickness and composition on both sides of the fuel. If a gap is present, it is the same thickness on both sides of the fuel. If the first and second moderators are the same material at the same density and temperature, and do not contain resonance nuclides, the same mixture number can be used for both moderators. Otherwise, different mixture numbers must be used for the two moderators.

Regular and annular cell configurations are specified as shown below.

\title{
Regular Cells
}

SQUAREPITCH is used for an array of cylinders arranged in a square lattice, as shown in Fig. M7.4.1. The clad and/or gap can be omitted.

TRIANGPITCH is used for an array of cylinders arranged in a triangular-pitch lattice as shown in Fig. M7.4.2. The clad and/or gap can be omitted.

SPHSQUAREP is used for an array of spheres arranged in a square-pitch lattice. A cross-section view through a cell is represented by Fig. M7.4.1. The clad and/or gap can be omitted.

SPHTRIANGP is used for an array of spheres arranged in a triangular-pitch (dodecahedral) lattice. A cross-section view through a cell is represented by Fig. M7.4.2. The clad and/or gap can be omitted.

SYMMSLABCELL is used for an infinite array of symmetric slab cells, as shown in Fig. M7.4.3. The clad and/or gap can be omitted.

\author{
Annular Cells
}

ASQUAREPITCH or ASQP is used for annular cylindrical rods in a square-pitch lattice as shown in Fig. M7.4.4. The gap on both sides of the fuel must be identical, as must the clad. The clad and/or gap can be omitted.

ATRIANGPITCH or ATRP is used for annular cylindrical rods in a triangularpitch lattice as shown in Fig. M7.4.5. The gap on both sides of the fuel must be identical, as must the clad. The clad and/or gap can be omitted. 


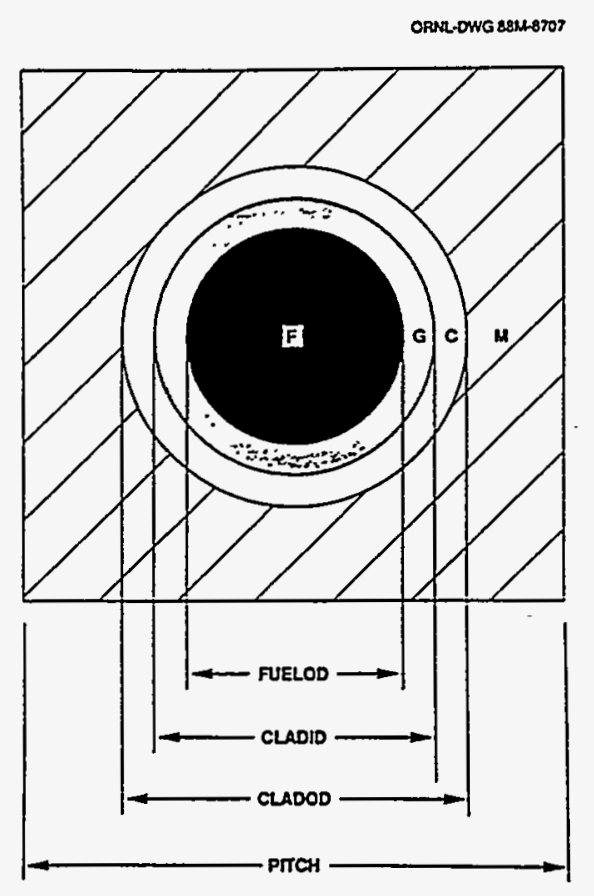

Figure M7.4.1 Arrangement of materials in a SQUAREPITCH and SPHSQUAREP unit cell

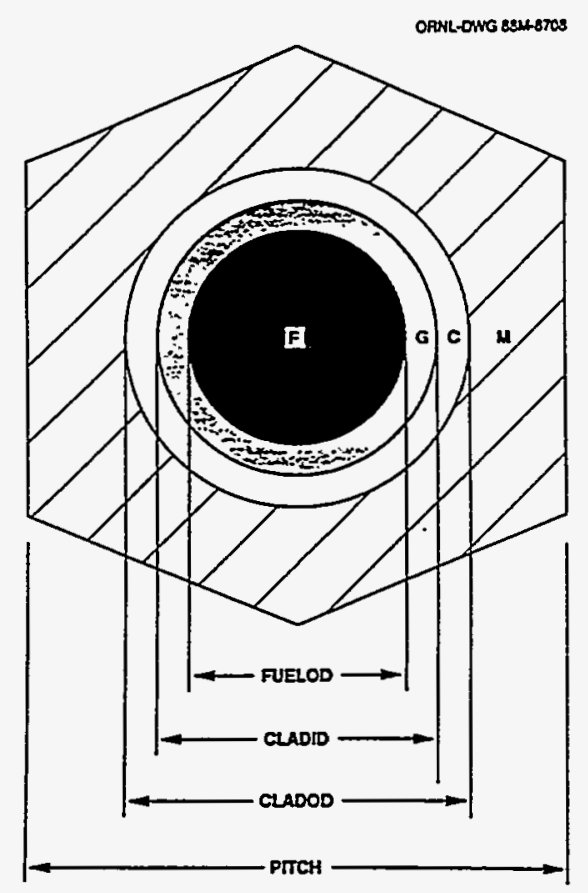

Figure M7.4.2 Arrangement of materials in a TRIANGPITCH and SPHTRIANGP unit cell

ORPL-Dingesuros

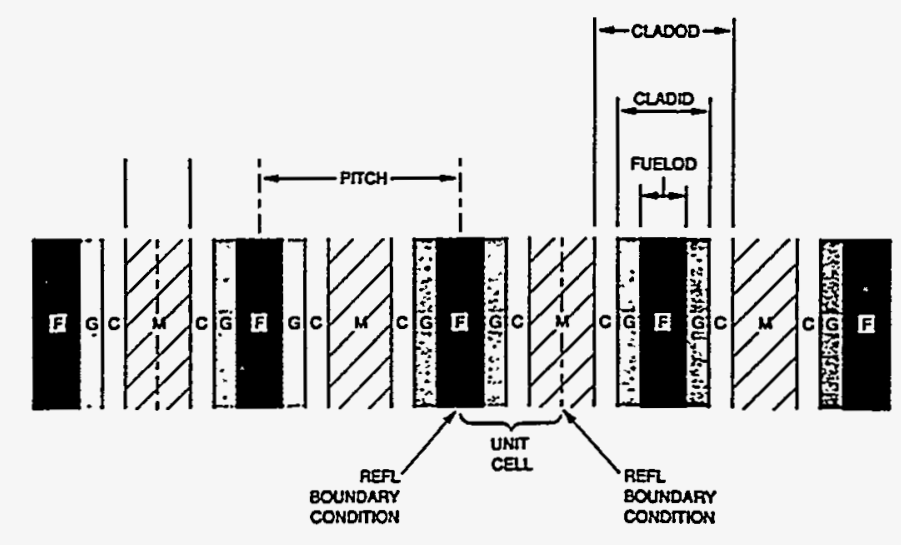

Figure M7.4.3 Arrangement of materials in a SYMMSLABCELL unit cell having reflected left and right boundary conditions 
ASPHSQUAREP or ASSP is used for spherical shells in a square-pitch lattice as shown in Fig. M7.4.4. The gap on both sides of the fuel must be identical, as must the clad. The clad and/or gap can be omitted.

ASPHTRIANGP or ASTP is used for spherical shells in a triangular-pitch (dodecahedral) lattice as shown in Fig. M7.4.5. The gap on both sides of the fuel must be identical, as must the clad. The clad and/or gap can be omitted.

ASYMSLABCELL is used for a periodic, but asymmetric, array of slabs as shown in Fig. M7.4.6. The gap on both sides of the fuel must be identical, as must the clad. The clad and/or gap can be . omitted.

\section{PITCH}

3. FUELOD

4. MFUEL

5. MMOD

6. $\mathrm{MMOD} 2$

7. TKMOD2

8. CLADOD

9. MCLAD

10. CLADID

ARRAY PITCH...This is the center-to-center spacing between the fuel lumps (rods, pellets, or slabs) in $\mathrm{cm}$, as shown in Figs. M7.4.1 through M7.4.6. For an ASYMSLABCELL, enter the distance from the center of one moderator to the center of the other moderator. (See Fig. M7.4.6.)

OUTSIDE DIMENSION OF FUEL...This is the outside diameter of the fuel in $\mathrm{cm}$, as shown in Figs. M7.4.1 through M7.4.6. In slab geometry, enter the thickness of the fuel (see Figs. M7.4.1 through M7.4.6).

FUEL MIXTURE NUMBER...This is the mixture number representing the fuel (F in Figs. M7.4.1 through M7.4.6).

MODERATOR MIXTURE NUMBER...This is the mixture number representing the moderator (M or M1 in Figs. M7.4.1 through M7.4.6).

SECOND MODERATOR MIXTURE NUMBER...Enter ONLY for annular cells. This is the mixture number representing the second moderator (M2 in Figs. M7.4.4 through M7.4.6).

SECOND MODERATOR THICKNESS...Enter ONLY for annular cells. This is the thickness or diameter of the second moderator in cm (see Figs. M7.4.4 through M7.4.6).

OUTSIDE DIAMETER OF CLAD...Enter ONLY if a clad is present. Enter the thickness of the clad in cm. For a slab, CLADOD is the sum of the fuel thickness, twice the gap thickness, and twice the clad thickness. See Figs. M7.4.1 through M7.4.6.

CLAD MIXTURE NUMBER...Enter ONLY if a clad is present. Enter the mixture number that represents the clad ( $C$ in Figs. M7.4.1 through M7.4.6).

INSIDE DIAMETER OF CLAD...Enter ONLY if a gap is present between the fuel and the clad. Omit if there is no gap. If a gap is present, enter the inside diameter of the clad in $\mathrm{cm}$. This corresponds to the outside diameter of the gap. In slab geometry, CLADID is the sum of the fuel thickness and twice the gap thickness. See Figs. M7.4.1 through M7.4.6. 


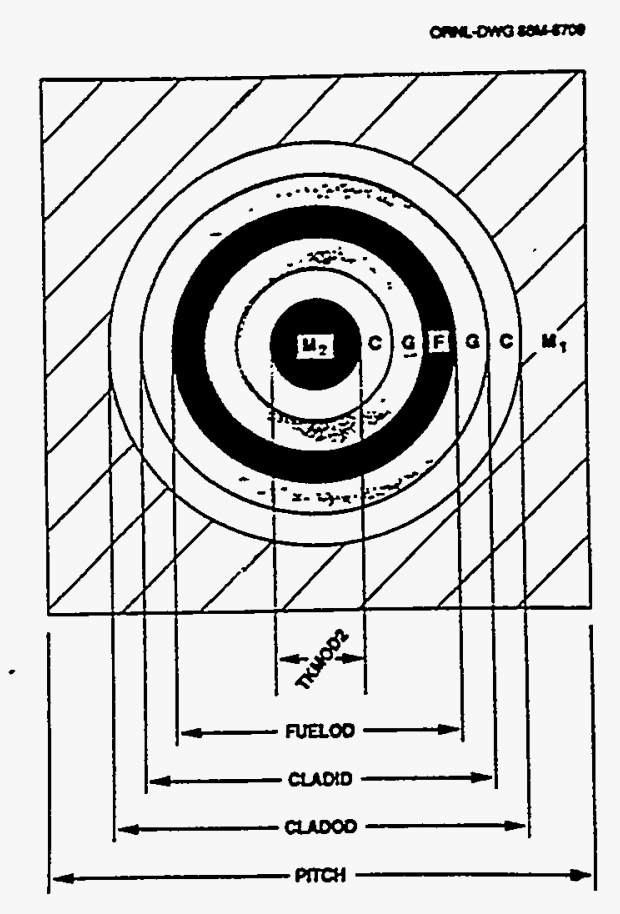

Figure M7.4.4 Arrangement of materials in an ASQUAREPITCH or ASPHSQUAREP unit cell

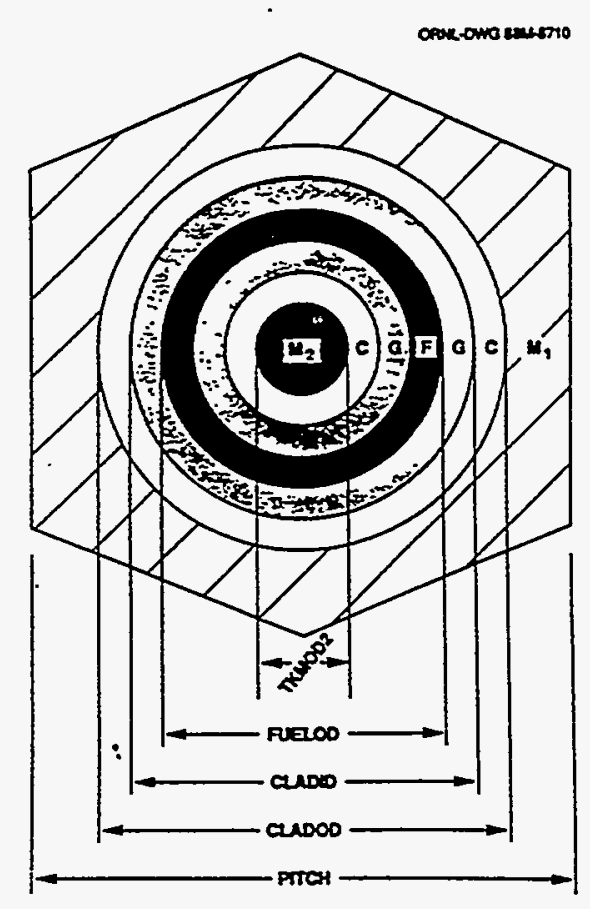

Figure M7.4.5 Arrangement of materials in an ATRIANGPITCH or ASPHTRIANGP unit cell

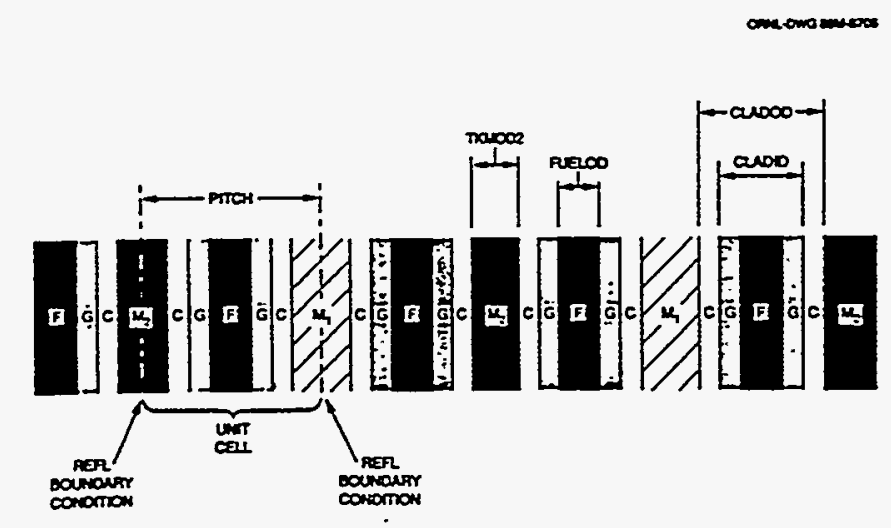

Figure M7.4.6 Arrangement of materials in an ASYMSLABCELL unit cell 

the clad. Omit if there is no gap. Enter the mixture number representing the gap ( $G$ in Figs. M7.4.1 through M7.4.6). Zero is often used to represent a void.

12. END

The word END is entered to terminate the LATTICECELL data. An optional label can be associated with this END. The label can be as many as 12 characters long and is separated from the END by a single blank. At least two blanks must follow entry number 12 .

\section{M7.4.7 UNIT CEIL SPECIFICATION FOR MULTIREGION PROBLEMS}

These data are entered only if the problem is defined as a multiregion problem. They describe the additional geometry data that are required for a MULTIREGION problem (data postition 3 of Table M7.4.4). A multiregion problem can be used to define a geometric arrangement that is more complicated than is allowed by a lattice cell. It can also be used for large geometric regions where the geometry effects for the cross sections are minimal. Additional information is available in Sects. M7.5.4, M7.5.4.3, M7.5.6.3, and M7.5.8.3. BE FULLY AWARE THAT CROSS SECTIONS GENERATED USING MUITIREGION IGNORE THE LATTICE GEOMETRY EFFECTS IN PROCESSING THE RESONANCE CORRECTIONS.

The additional data required for a MULTIREGION problem are given in Table M7.4.8 and explained in the text following the table.

NUREG/CR-0200,

Vol. 3, Rev. 4 
Table M7.4.8 Geometry specification for multiregion problems

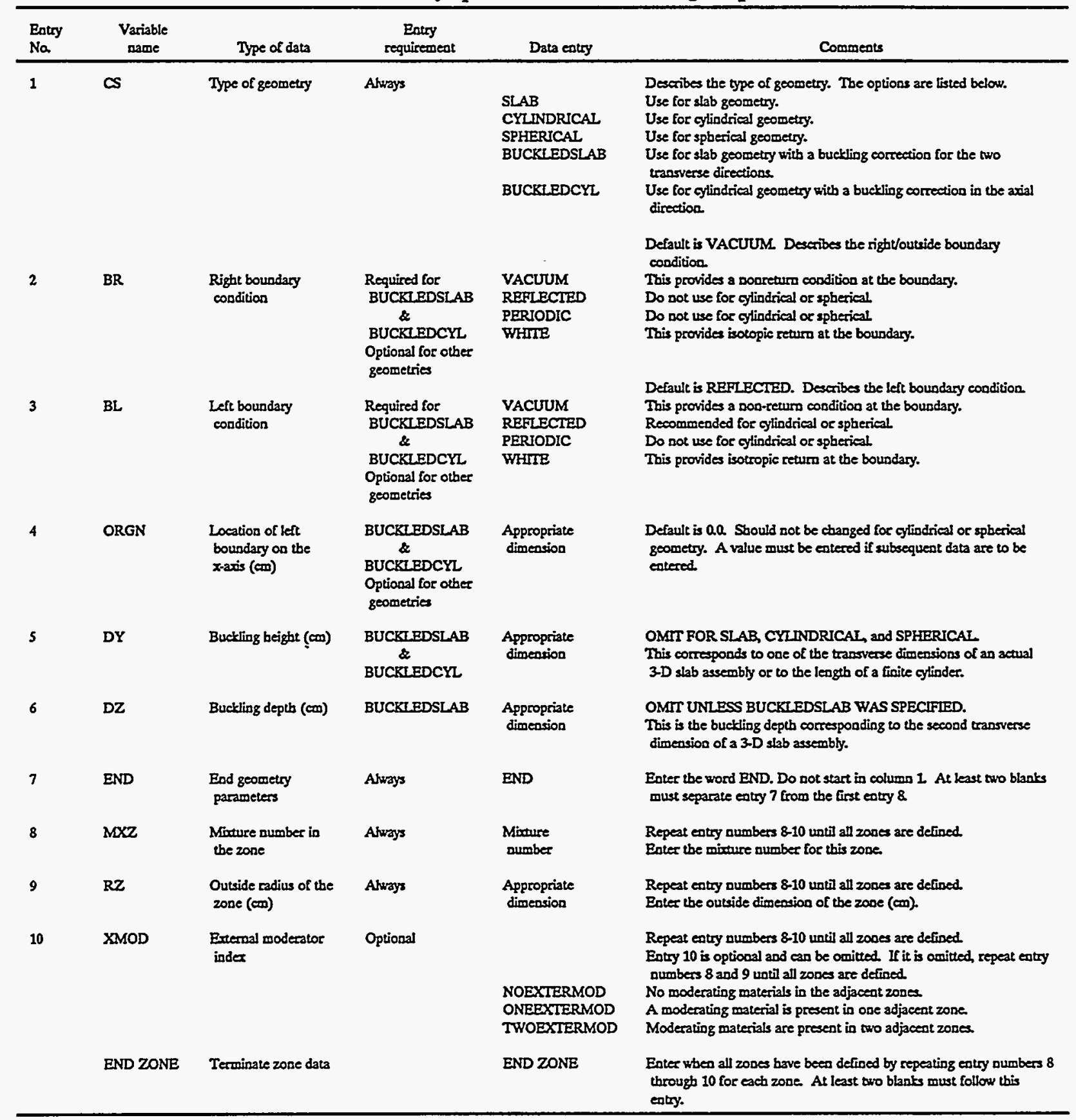


1. CS TYPE OF GEOMETRY...The type of geometry must always be specified for a MULTIREGION problem. The cross-section corrections do not account for lattice effects. The available geometry options are listed below.

SLAB...This is used to describe a slab geometry.

CYLINDRICAL....This is used to describe cylindrical geometry.

SPHERICAL...This is used to describe spherical geometry.

BUCKLEDSLAB...This is used for slab geometry with a buckling correction for the two transverse directions.

BUCKLEDCYL...This is used for cylindrical geometry with a buckling correction in the axial direction.

2. BR RIGHT BOUNDARY CONDITION...This is defaulted to vacuum. A value for BR MUST be entered for BUCKLEDSLAB and BUCKLEDCYL, but is optional for SLAB, CYLINDRICAL, or SPHERICAL. The available options and their qualifications are listed below:

VACUUM...This imposes a vacuum at the boundary of the system.

REFLECTED...This imposes mirror image reflection at the boundary. Do not use for CYLINDRICAL or SPHERICAL.

PERIODIC...This imposes petiodic reflection at the boundary. Do not use for CYLINDRICAL or SPHERICAL.

WHITE...This imposes isotropic return at the boundary.

3. BL LEFT BOUNDARY CONDITION...This is defaulted to reflected. A value for BL MUST be entered for BUCKLEDSLAB, but is optional for SLAB, CYLINDRICAL, or SPHERICAL. The available options and their qualifications are listed below:

VACUUM...This imposes a vacuum at the boundary of the system.

REFLECTED...This imposes mirror image reflection at the boundary. For CYLINDRICAL or SPHERICAL, this is the only valid boundary condition because the left boundary corresponds to the centerline.

PERIODIC...This imposes periodic reflection at the boundary.

WHITE...This imposes isotropic return at the boundary.

4. ORGN LOCATION OF LEFT BOUNDARY ON THE ORIGIN...The default value of ORGN is 0.0 . This is the only value allowed for CYLINDRICAL or SPHERICAL geometry. Enter the location of the left boundary on the $\mathrm{x}$-axis perpendicular to the slab (in $\mathrm{cm}$ ).

NUREG/CR-0200,

Vol. 3, Rev. 4

M7.4.28 
5. DY BUCKLING HEIGHT...Enter ONLY for BUCKLEDSLAB or BUCKLEDCYL. This is the buckling height in $\mathrm{cm}$. It corresponds to one of the transverse dimensions of an actual 3-D slab assembly or the length of a finite cylinder.

6. DZ BUCKLING DEPTH...Enter ONLY for BUCKLEDSLAB. This is the buckling width in $\mathrm{cm}$. It corresponds to the second transverse dimension of an actual 3-D slab assembly.

7. END The word END is entered to terminate these data before entering the zone description data. It must not be entered in columns 1 through 3 and at least two blanks must separate it from the zone description. A label can be associated with this END. The label can be a maximum of 12 characters and is separated from the END by a single blank. At least two blanks must follow entry number 7.

The zone description data are entered at this point. Entries 8,9, and 10 are entered for each zone, and the sequence is repeated until all the desired zones have been described. To terminate the data, enter the words END ZONE.

8. MXZ MIXTURE NUMBER IN THE ZONE...Enter the mixture number of the material that is present in the zone. Enter a zero for a void. Repeat the sequence of entries 8 through 10 for each zone.

9. RZ OUTSIDE RADIUS OF THE ZONE...Enter the outside dimension of the zone in $\mathrm{cm}$. In slab geometry, $R Z$ is the location of the zone's right boundary on the $x$-axis. Repeat the sequence of entries 8 through 10 for each zone.

10. XMOD Optional EXTERNAL MODERATOR INDEX...This optional entry describes the conditions existing in the zones adjacent to the present zone. Appropriate conditions are provided by default. The available options are listed below:

NOEXTERMOD...This means there are no moderating materials between this zone and either boundary.

ONEEXTERMOD...This means one of the zones between this zone and one of the boundaries contains a material.

TWOEXTERMOD...This indicates that at least one zone on either side of this zone contains a material.

CAUTION: User-provided entries do not always supersede the default values.

(1) For SLAB geometry, user-supplied values will be used everywhere except zone 1. If the left boundary is reflected, the default value of ONEEXTERMOD will be used unless NOEXTERMOD is specified.

(2) For SPHERICAL and CYLINDRICAL geometry, default values will be used for all zones unless NOEXTERMOD is specified. NOEXTERMOD allows the user to "turn off" geometric corrections.

Repeat the sequence of entries 8 and 9 or 8 through 10 for each zone. When all the zones have been described, enter the words END ZONE. 
END ZONE is used to terminate the muitiregion zone data. Enter the words END ZONE when all the zones have been described. Note that ZONE is a label associated with this END. This label can be as long as 12 characters, but the first four characters must be ZONE. At least two blanks must follow this entry.

\section{M7.4.8 OPTIONAL PARAMETER DATA}

Most of the parameter data for the Material Information Processor are determined by the code and cannot be adjusted. However, certain parameters can be altered. If the default parameters are acceptable, this section of input data should be omitted in its entirety. Nondefault values for one or more of the parameters can be specified by entering the words MORE DATA followed by the desired keyworded parameters and their associated values. One or more of the parameters can be entered in any order. Default values are used for parameters that are not entered. Each parameter is entered by spelling its name, followed immediately by an equal sign and the value to be entered. There should not be a blank between the parameter name and the equal sign. Each parameter specification must be separated from the rest by at least one blank. For example:

$$
\text { MORE DATA ISN }=16 \text { EPS }=0.00008 \text { END- }
$$

would result in using an S16 angular quadrature set and tightening the convergence criteria to 0.00008 in the XSDRNPM calculation.

Table M7.4.9 describes the optional parameters that can be entered as data and the code or codes where the parameters apply. A description of each entry is given. 
Table M7.4.9 Optional parameter data

\begin{tabular}{|c|c|c|c|c|}
\hline $\begin{array}{l}\text { Entry } \\
\text { No. }\end{array}$ & $\begin{array}{l}\text { Keyword } \\
\text { name }\end{array}$ & Type of data & $\begin{array}{l}\text { Applicable } \\
\text { module }\end{array}$ & Comments \\
\hline 1 & MORE DATA & Input flag & & $\begin{array}{l}\text { This signals that optional parameter data will be } \\
\text { entered. Enter only those parameters you wish } \\
\text { to change. }\end{array}$ \\
\hline 2 & $\mathrm{ISN}=$ & $\begin{array}{l}\text { Order of angular } \\
\text { quadrature }\end{array}$ & XSDRNPM & $\begin{array}{l}\text { The default value is } 8 \text {. This allows using } \\
\text { another value. }\end{array}$ \\
\hline 3 & $\mathrm{SZF}=$ & $\begin{array}{l}\text { Spatial mesh } \\
\text { size factor }\end{array}$ & XSDRNPM & $\begin{array}{l}\text { The default value is } 1.0 \text {. } \\
0<S Z F<1.0 \text { gives a finer mesh. } \\
S Z F>1.0 \text { gives a coarser mesh. }\end{array}$ \\
\hline 4 & $\mathrm{mM}=$ & $\begin{array}{l}\text { Max number of } \\
\text { inner iterations }\end{array}$ & XSDRNPM & $\begin{array}{l}\text { The default value is } 20 \text {. This allows using } \\
\text { another value. }\end{array}$ \\
\hline 5 & $\mathrm{ICM}=$ & $\begin{array}{l}\text { Max. number of } \\
\text { outer iterations }\end{array}$ & XSDRNPM & $\begin{array}{l}\text { The default value is } 25 \text {. This allows using } \\
\text { another value. }\end{array}$ \\
\hline 6 & $\mathrm{EPS}=$ & $\begin{array}{l}\text { Overall convergence } \\
\text { criteria }\end{array}$ & XSDRNPM & $\begin{array}{l}\text { The default value is } 0.0001 \text {. This allows using } \\
\text { another value. }\end{array}$ \\
\hline 7 & $\mathrm{PTC}=$ & $\begin{array}{l}\text { Point convergence } \\
\text { criteria }\end{array}$ & XSDRNPM & $\begin{array}{l}\text { The default value is } 0.0001 \text {. This allows using } \\
\text { another value. }\end{array}$ \\
\hline 8 & $\mathrm{BKI}=$ & Buckling factor & XSDRNPM & $\begin{array}{l}\text { The default value is } 1.420892 \\
\text { Use ONLY for a multiregion problem that } \\
\text { specifies BUCKLEDSLAB or BUCKLEDCYL. }\end{array}$ \\
\hline 9 & IUS $=$ & $\begin{array}{l}\text { Upscatter scaling } \\
\text { factor }\end{array}$ & XSDRNPM & $\begin{array}{l}\text { The default value is zero. } \\
\text { IUS }=0 \text { doesn't utilize upscatter scaling. IUS }=1 \\
\text { uses upscatter scaling to accelerate the solution } \\
\text { and/or speed convergence. }\end{array}$ \\
\hline 10 & RES $=$ & $\begin{array}{l}\text { Resonance } \\
\text { data }\end{array}$ & $\begin{array}{l}\text { BONAMI } \\
\text { NITAWL }\end{array}$ & $\begin{array}{l}\text { Enter the mixture number, geometry type } \\
\text { (SLAB, CYLINDER, SPHERE) and the } \\
\text { thickness of the slab or radius of the sphere or } \\
\text { cylinder, in cm. }\end{array}$ \\
\hline 11 & $\operatorname{DAN}(\mathrm{mm})=$ & $\begin{array}{l}\text { Dancoff factor } \\
\text { for the specified } \\
\text { mixture }\end{array}$ & $\begin{array}{l}\text { BONAMI } \\
\text { NITAWL }\end{array}$ & $\begin{array}{l}\text { Enter the mixture number, mm, to which the } \\
\text { Dancoff factor applies inside the parentheses; } \\
\text { enter the Dancoff factor after the equal sign. }\end{array}$ \\
\hline & & . & & $\begin{array}{l}\text { Repeat entries } 10 \text { and } 11 \text { for all resonance } \\
\text { mixtures used in the problem that are not } \\
\text { treated in the latticecell or multiregion } \\
\text { description. }\end{array}$ \\
\hline
\end{tabular}

NUREG/CR-0200, 
Table M7.4.9 (continued)

\begin{tabular}{|c|c|c|c|c|}
\hline $\begin{array}{l}\text { Entry } \\
\text { No. }\end{array}$ & $\begin{array}{l}\text { Keyword } \\
\text { name }\end{array}$ & Type of data & $\begin{array}{l}\text { Applicable } \\
\text { module }\end{array}$ & Comments \\
\hline 12 & $\mathrm{BAL}=$ & $\begin{array}{l}\text { Key to print } \\
\text { balance tables }\end{array}$ & XSDRNPM & $\begin{array}{l}\text { The default value is FINE. BAL }=\text { NONE } \\
\text { suppresses printing the balance table. } \\
\text { BAL=AIL prints all balance tables. } \\
\text { BAL=FINE prints only the fine-group balance } \\
\text { tables. }\end{array}$ \\
\hline 13 & $\mathrm{DY}=$ & $\begin{array}{l}\text { First transverse } \\
\text { dimension }\end{array}$ & XSDRNPM & $\begin{array}{l}\text { The first transverse dimension, in } \mathrm{cm} \text {, used in a } \\
\text { buckling correction to calculate leakage normal } \\
\text { to the principal calculation direction (i.e., the } \\
\text { height of a slab or a cylinder). }\end{array}$ \\
\hline 14 & $\mathrm{DZ}=$ & $\begin{array}{l}\text { Second transverse } \\
\text { dimension }\end{array}$ & XSDRNPM & $\begin{array}{l}\text { The second transverse dimension, in } \mathrm{cm} \text {, used } \\
\text { for a buckling correction (i.e., the width of a } \\
\text { slab). }\end{array}$ \\
\hline 15 & $\mathrm{COF}=$ & $\begin{array}{l}\text { Diffusion coefficient } \\
\text { option for } \\
\text { transverse } \\
\text { leakage correction }\end{array}$ & XSDRNPM & $\begin{array}{l}\text { The default is } 0 \text {. See Sect. F3.5, } 3 \$ \text { array, } \\
\text { variable IPN. }\end{array}$ \\
\hline 16 & $F R D=$ & $\begin{array}{l}\text { Unit from which } \\
\text { fluxes will be read }\end{array}$ & XSDRNPM & $\begin{array}{l}\text { Enter the unit number from which the flux } \\
\text { guess for XSDRNPM will be read. }\end{array}$ \\
\hline 17 & $\mathrm{FWR}=$ & $\begin{array}{l}\text { Unit on which fluxes } \\
\text { will be written }\end{array}$ & XSDRNPM & $\begin{array}{l}\text { Enter the unit number where the binary fluxes } \\
\text { from XSDRNPM will be written. }\end{array}$ \\
\hline 18 & $\mathrm{DAB}=$ & $\begin{array}{l}\text { Number of direct } \\
\text { access data blocks }\end{array}$ & MIP & $\begin{array}{l}\text { The default is } 200 \text {. Number of blocks allocated } \\
\text { for direct access unit } 90 \text {. }\end{array}$ \\
\hline 19 & $A X S=$ & $\begin{array}{l}\text { Unit on which a } \\
\text { mixed ANISN } \\
\text { library will be } \\
\text { written }\end{array}$ & ICE & $\begin{array}{l}\text { Enter the unit number where ICE is to write a } \\
\text { mixed ANISN library. }\end{array}$ \\
\hline 20 & COLL & $\begin{array}{l}\text { Key to activate } \\
\text { collapse of thermal } \\
\text { groups }\end{array}$ & MIP" & $\begin{array}{l}\text { Enter COLL to collapse all thermal groups into } \\
\text { one group for the shielding sequences. }\end{array}$ \\
\hline 21 & END & Terminus & & $\begin{array}{l}\text { Terminate the optional parameter data. Do not } \\
\text { start in column } 1 \text {. At least two blanks must } \\
\text { follow entry number } 21 \text {. }\end{array}$ \\
\hline
\end{tabular}

MIP is the Material Information Processor.

NUREG/CR-0200,

Vol. 3, Rev. 4

M7.4.32 
1. MORE DATA...These words, followed by one or more blanks, are entered ONLY if optional parameter data are to be entered. They must precede all other optional parameter data. Entries 2 through 19 can be entered in any order.

2. ISN ORDER OF ANGULAR QUADRATURE FOR XSDRNPM...Quadrature sets are geometry-dependent quantities that are defaulted to order 8 by the Material Information Processor. See Sects. M7.2.5.7 and M7.5.7 for a more detailed explanation.

3. SZF SPATIAL MESH SIZE FACTOR FOR XSDRNPM...The size of the largest mesh interval can be adjusted by entering a value for SZF. The default value is 1.0 . A value between zero and 1.0 yields a finer mesh; a value greater than 1.0 yields a coarser mesh. See Sects. M7.2.5.6 and M7.5.7 for more details.

4. IIM MAXIMUM NUMBER OF INNER ITERATIONS FOR XSDRNPM...This is the maximum number of inner iterations to be used in the XSDRNPM calculation. The default value is 20. See Sect. M7.5.7 for a more detailed explanation:

5. ICM MAXIMUM NUMBER OF OUTER ITERATIONS FOR XSDRNPM...This is the maximum number of outer iterations to be used in the XSDRNPM calculation. The default value is 25 . If the calculation reaches the outer iteration limit, a larger value should be used. See Sect. M7.5.7 for a more detailed explanation.

6. EPS OVERALI CONVERGENCE CRITERIA FOR XSDRNPM...This is used by XSDRNPM after each outer iteration to determine if the problem has converged. The default value of EPS is 0.0001 . A value less than 0.0001 tightens the convergence criteria; a larger value loosens the convergence criteria. See Sects. M7.2.5.8 and M7.5.7 for additional information.

7. PTC POINTWISE CONVERGENCE CRITERIA FOR XSDRNPM...This is the point flux convergence criteria used by XSDRNPM to determine if convergence has been achieved after an inner iteration. The default value is 0.0001 . A smaller value tightens convergence; a larger value loosens it. See Sects. M7.2.5.8 and M7.5.7 for a more detailed explanation.

8. BKL BUCKIING FACTOR FOR XSDRNPM...A buckling factor should be used ONLY for a multiregion BUCKLEDSLAB or BUCKLEDCYL problem. Because cylinders are assumed to be infinitely long and slabs are assumed to be infinite in both transverse directions, the analytic sequence may tend to overestimate the total flux for a finite system. A buckling correction can be used to approximate the leakage from the system in the transverse direction(s). The extrapolation distance factor, BKL, is defaulted to 1.420892. See Sects. M7.2.5.4 and M7.5.7 for additional details.

9. IUS UPSCATTER SCALING FLAG FOR XSDRNPM...This option allows the use of upscatter scaling to accelerate the solution or force convergence. The default value is zero, in which case upscatter scaling is not used. IUS $=1$ facilitates upscatter scaling. Guidelines are not available to indicate when upscatter scaling is needed. Some problems will not converge with it, and some will not converge without it. See Sect. M7.5.7 for a more detailed explanation.

10. RES RESONANCE DATAFOR BONAMI AND NITAWL...This parameter allows overriding the default resonance data for materials that are not-used in the unit cell. The default 
resonance data are infinite homogeneous media, which may not accurately represent the geometry (for example, a thin clad or container region). The resonance data are entered in the form:

RES = mixture number geometry type thickness.

The mixture number is the material for which the resonance data apply. The geometry type can be a sphere, slab, or cylinder, and defines the third entry of the $3^{*}$ array in NITAWL. The thickness is the thickness of a slab or the radius of a sphere or cylinder in $\mathrm{cm}$ and defines the fourth entry of the $3^{*}$ array in NITAWL. This entire data sequence should be entered for each material for which the default data are inadequate. See Sect. M7.5.7 for additional details. WARNING: If this parameter is used to enter resonance data for a mixture that is used in the unit cell specification, it will NOT be used. Information provided in the unit cell data will be used instead.

11. DAN(mm) = DANCOFF FACTOR for the specified mixtures. This allows entering a Dancoff factor to be used in the resonance correction for the specified mixture. The Dancoff data are entered in the form:

$\operatorname{DAN}(\mathrm{mm})=$ Dancoff factor

Note that the parentheses must be entered as part of the data. The mixture number, $\mathrm{mm}$, to which the Dancoff factor applies, must be enclosed in the parentheses. The Dancoff factor to be used is entered after the equal sign. See Sect. M7.5.7 for additional details.

Items 10 and 11 should be entered for each resonance mixture that is not specified in the lattice cell or multiregion unit cell specification data. See Sect. M7.5.10.

12. BAL BALANCE TABLE PRINT FLAG FOR XSDRNPM...This allows control of the balance table print from XSDRNPM. The default value is FINE. BAL=NONE suppresses the balance table print. $\mathrm{BAL}=\mathrm{ALL}$ prints all of the balance tables. $\mathrm{BAL}=\mathrm{FINE}$ prints only the fine-group balance tables. See Sect. M7.5.7 for additional details.

13. $D Y=$ FIRST TRANSVERSE DIMENSION FOR XSDRNPM...This is the first transverse dimension, in centimeters, used in a buckling correction to calculate the leakage normal to the principal calculation direction (the height of a slab or cylinder). It should only be entered if XSDRNPM is to create cell-weighted cross sections and/or calculate the eigenvalue of a cylinder or slab system of finite height for a lattice cell problem. DY= is defaulted to an infinite height, or is set to DY for a buckled multiregion cell description. See Sects. M7.2.5.4 and M7.5.7 for additional details. A value entered here overrides any buckling height value entered in the multiregion data.

14. $\mathrm{DZ}=$ SECOND TRANSVERSEDIMENSION FOR XSDRNPM...This is the second transverse dimension, in centimeters, used for a buckling correction for a slab of finite width. It should only be entered if XSDRNPM is to create cell-weighted cross sections and/or calculate the eigenvalue of a lattice cell slab of finite width. $D Z=$ is defaulted to an infinite width, or is set to $\mathrm{DZ}$ for a buckled multiregion slab cell of finite width.

See Sects. M7.2.5.4 and M7.5.7 for additional details. A value entered here overrides any buckling depth value entered in the multiregion data.

NUREG/CR-0200,

Vol. 3, Rev. 4

M7.4.34 
15. $C O F=$ DIFFUSION COEFFICIENT FOR TRANSVERSE LEAKAGE CORRECTIONS IN XSDRNPM...The default value is 0 . The available options are:

$\mathrm{COF}=0$ sets a transport-corrected cross section for each zone

$\mathrm{COF}=1$ use a spatially averaged diffusion coefficient for each zone

$\mathrm{COF}=2$ use a diffusion coefficient for all zones that is one-third the diffusion coefficient determined from the spatially averaged transport cross section for all zones

$\mathrm{COF}=3$ use a flux and volume weighting across all zones

See Sect. M7.5.7 or Sect. F3.5, $3 \$$ array, variable IPN for more details.

16. FRD $=$ UNIT FROM WHICH FLUXES ARE READ FOR XSDRNPM...If fluxes are to be used for the initial flux guess, enter the unit number from which they are to be read. The user is responsible for supplying job control language data that are necessary for reading the flux data set. See Sect. M7.5.7 for more details.

17. FWR $=$ UNIT ON WHICH FLUXES WILL BE WRITTEN FOR XSDRNPM...If binary fluxes are to be saved from this XSDRNPM calculation, enter the unit number where they will be written. The user is responsible for supplying job control language data that are necessary for creating and saving the flux data set. See Sect. M7.5.7 for more details.

18. $D A B=$ NUMBER OF DIRECT-ACCESS DATA BLOCKS FOR THE MATERIAL INFORMATION PROCESSOR...These are the number of blocks allocated for direct access on unit 90. The default is 200. See Sect. M7.5.7 for additional details. If the job fails in the Material Information Processor with an LMP005 DA ERROR, then DAB must be used to enter a larger value. See Sect. M7.7.3 for additional details.

19. $A X S=$ LOGICAL UNIT NUMBER FOR ICE... Write a mixed ANISN library on this unit. The default is zero (no library). If the unit number is input as 7, the ANISN library will be in free-form card image. For any other unit number, the library will be binary. The user is responsible for supplying job control language data that are necessary for creating and saving the ANISN cross-section library. An ANISN cross section can only be created by the control sequences CSASI, CSASIX, and SAS3. See Sect. M7.5.7 for additional details.

20. COLL ACTIVATE COLLAPSE OF THERMAL GROUPS...This parameter should only be used with the shielding analysis sequences (SAS1, etc.). It causes the Material Information Processor to instruct XSDRNPM to collapse all thermal groups into one group. See Sect. M7.5.7 for additional details.

21. END The word END is entered to terminate the optional parameter data. A label can be associated with this END. The label can be as long as 12 characters and is separated from the END by a single blank. If this END is entered without a label, it must not begin in column 1. At least two blanks must follow this entry. 


\section{M7.5 NOTES ABOUT THE MATERIAL INFORMATION PROCESSOR}

This section provides tips about the use of the Material Information Processor utilized by many of the SCALE modules. To assist in locating specific data in this section, see Table M7.5.1.

\section{M7.5.1 USE OF THE MATERTAL INFORMATION PROCESSOR}

The Material Information Processor performs the functions of (1) reading user-specified input data about material specifications and unit cell geometry pertinent to cross-section processing and (2) accessing information from the Standard Composition Library to determine nuclide atom densities and resonance data.

\section{M7.5.2 MATERIAL INFORMATION PROCESSOR TITLE}

The first information required by the Material Information Processor is a title. The title is a maximum of 80 characters and is the first entry after the Analytical Sequence Indicator record. The Analytical Sequence Indicator begins in column 1. The title also begins in column 1. An example is

$=$ CSASN

THIS IS THE TITLE

\section{M7.5.3 CROSS-SECTION LIBRARY NAME}

There are several cross-section libraries available for use with SCALE. They are in the AMPX master library format and are specified as the first data following the Material Information Processor title. The libraries that are available in SCALE are discussed in Sect. M4. The available libraries include:

$$
\begin{aligned}
& \text { HANSEN-ROACH } \\
& \text { 27GROUPNDF4 } \\
& \text { 123GROUPGMTH } \\
& \text { 218GROUPNDF4 } \\
& \text { 27BURNUPLIB } \\
& \text { 27N-18COUPLE } \\
& \text { 22N-18COUPIE } \\
& \text { 18GROUPGAMMA }
\end{aligned}
$$

The first four libraries listed above are criticality safety libraries, and the last three are shielding libraries. The 27BURNUPLIB library is used for depletion analyses or criticality safety analyses where higher-arder actinides or fission products are needed. Terse input is accepted for the cross-section library name, so only the number of characters necessary to uniquely define the library need be entered. However, the entered name must be an exact match for the number of characters that are entered. Thus, 27G is sufficient to define the 27GROUPNDF4 library. Entering 27GRP is incorrect because the fifth character does not match, but $27 \mathrm{GR}$ or $27 \mathrm{GRO}$ are correct.

\section{M7.5.4 TYPE OF CALCULATION}

The type of calculation specifies the basic geometry description that is used for cross-section processing. The type of calculation is very important because it can substantially affect the calculated results. The available options are: 
Table M7.5.1 Organization of notes about the Material Information Processor

\begin{tabular}{|c|c|c|}
\hline Page & & Section and topic \\
\hline M7.5.1 & M7.5.1 & USE OF THE MATERIAI INFORMATION PROCESSOR \\
\hline M7.5.1 & M7.5.2 & MATERIAI INFORMATION PROCESSOR TITLE \\
\hline M7.5.1 & M7.5.3 & CROSS-SECTION LIBRARY NAME \\
\hline M7.5.1 & M7.5.4 & TYPE OF CALCULATION \\
\hline M7.5.4 & & M7.5.4.1 INFHOMMEDIUM \\
\hline M7.5.4 & & M7.5.4.2 LATTICECELL \\
\hline M7.5.4 & & M7.5.4.3 MULTIREGION \\
\hline M7.5.5 & M7.5.5 & STANDARD COMPOSITION SPECIFICATION DATA \\
\hline M7.5.7 & & M7.5.5.1 Basic Standard Composition Specifications \\
\hline M7.5.7 & & GENERIC EXAMPLE \\
\hline M7.5.8 & & EXAMPLE 1. Material name is given \\
\hline M7.5.8 & & EXAMPLE 2. Material name and density $\left(\mathrm{g} / \mathrm{cm}^{3}\right)$ are given \\
\hline M7.5.9 & & EXAMPLE 3. Material name and number density (atoms/b-cm) are given \\
\hline M7.5.9 & & EXAMPIE 4. Material name, density $\left(\mathrm{g} / \mathrm{cm}^{3}\right)$, and isotopic abundance are given \\
\hline M7.5.10 & & EXAMPLE 5. Material name, density $\left(\mathrm{g} / \mathrm{cm}^{3}\right)$, and isotopic abundance are given \\
\hline M7.5.10 & & EXAMPLE 6. Material name and isotopic abundance are given \\
\hline M7.5.11 & & EXAMPLE 7. Material name, density $\left(\mathrm{g} / \mathrm{cm}^{3}\right)$, and isotopic abundance are given \\
\hline M7.5.12 & & EXAMPLE 8. Material name, density $\left(\mathrm{g} / \mathrm{cm}^{3}\right)$, and istotopic abundance are given \\
\hline M7.5.12 & & M7.5.5.2 Arbitrary Material Specifications \\
\hline M7.5.12 & & GENERIC EXAMPLE \\
\hline M7.5.14 & & EXAMPLE 1. Density and weight percents are given \\
\hline M7.5.14 & & EXAMPLE 2. Density, weight percents, and isotopic abundance are given \\
\hline M7.5.16 & & EXAMPLE 3. Density and chemical equation are given \\
\hline M7.5.16 & & EXAMPLE 4. Density and chemical equation are given \\
\hline M7.5.17 & & M7.5.5.3 Solution Specifications \\
\hline M7.5.17 & & GENERIC EXAMPLE \\
\hline M7.5.18 & & EXAMPLE 1. Fuel density, specific gravity, excess acid, and isotopic abundance are given \\
\hline M7.5.19 & & M7.5.5.4 Combinations of Basic Standard Compositions to Define a Mixture \\
\hline M7.5.19 & & EXAMPLE 1. Boral from $\mathrm{B}_{4} \mathrm{C}$ and Aluminum \\
\hline M7.5.20 & & EXAMPLE 2. Boral from $\mathrm{B}_{4} \mathrm{C}$ and Aluminum \\
\hline M7.5.20 & & EXAMPLE 3. Boral from Boron, Carbon, and Aluminum \\
\hline M7.5.22 & & EXAMPLE 4. Boral from ${ }^{10} \mathrm{~B},{ }^{11} \mathrm{~B}$, Carbon, and Aluminum \\
\hline M7.5.22 & & EXAMPLE 5. Specify all of the number densities in a mixture \\
\hline M7.5.23 & & M7.5.5.5 Combinations of Arbitrary Materials to Define a Mixture \\
\hline M7.5.23 & & EXAMPLE 1. Specify boral using two arbitrary materials \\
\hline M7.5.24 & & M7.5.5.6 Combinations of Solutions to Define a Mixture \\
\hline M7.5.25 & & EXAMPLE 1. Solution of uranyl nitrate and plutonium nitrate \\
\hline M7.5.26 & & M7.5.5.7 Combinations of Basic and Arbitrary Standard Compositions to Define a Mixture \\
\hline M7.5.26 & & EXAMPLE 1. Burnable poison from $\mathrm{B}_{4} \mathrm{C}$ and $\mathrm{Al}_{2} \mathrm{O}_{3}$ \\
\hline M7.5.27 & & EXAMPLE 2. Borated water from $\mathrm{H}_{3} \mathrm{BO}_{3}$ and water \\
\hline M7.5.30 & & M7.5.5.8 Combinations of Basic and Solution Standard Compositions to Define a Mixture \\
\hline M75.30 & & EXAMPLE 1. Uranyl nitrate solution containing gadolinium \\
\hline M7.5.32 & & M7.5.5.9 Combinations of Arbitrary Material and Solution to Define a Mixture \\
\hline M7.5.32 & & EXAMPLE 1. Uranyl nitrate solution with gadolinium nitrate \\
\hline M7.5.34 & M7.5.6 & EXAMPLES OF UNIT CELL SPECIFICATIONS \\
\hline M7.5.34 & & M7.5.6.1 Infinite Homogeneous Medium Unit Cell Data \\
\hline M7.5.35 & & EXAMPLE 1. A single mixture \\
\hline M7.5.35 & & EXAMPLE 2. Two mixtures \\
\hline M7.5.35 & & EXAMPLE 3. Two mixtures and specify the cell \\
\hline M7.5.35 & & M7.5.6.2 Lattice Cell Unit Cell Data \\
\hline M7.5.37 & & EXAMPLE 1. SQUAREPITCH (cylindrical pins in a square-pitched array) \\
\hline M7.5.38 & & EXAMPLE 2. TRIANGPITCH (cylinders in a triangular-pitched array) \\
\hline
\end{tabular}

NUREG/CR-0200, Vol. 3, Rev. 4 
Table M7.5.1 (continued)

\begin{tabular}{|c|c|c|}
\hline Page & & Section and topic \\
\hline$\overline{M 7.5 .38}$ & & SPHSQUAREP (spheres in a square-pitched array) \\
\hline M7.5.39 & & SPHTRIANGP (spheres in a triangular-pitched array) \\
\hline M7.5.40 & & EXAMPLE 5. SYMMSLABCELL (slabs repeated in a symmetric fashion) \\
\hline M7.5.40 & & EXAMPLE 5a. SYMMSLABCELL (slabs repeated in a symmetric fashion) \\
\hline M7.5.41 & & EXAMPLE 6. ASQUAREPITCH (annular cylindrical rods in a square-pitched array) \\
\hline M7.5.42 & & EXAMPLE 6a. ASQUAREPITCH (annular cyindrical rods in a square-pitched array) \\
\hline M7.5.42 & & $\begin{array}{l}\text { EXAMPLE 7. ATRIANGPITCH (annular cylindrical rods in a triangular-pitched } \\
\text { array) }\end{array}$ \\
\hline M7.5.43 & & EXAMPLE 8. $\quad$ ASPHSOUAREP (spherical annuli in a square-pitched array) \\
\hline M7.5.44 & & EXAMPLE 9. $\quad$ ASPHTRIANGP (spheres in a triangular-pitched array) \\
\hline M7.5.44 & & $\begin{array}{l}\text { EXAMPLE 10. ASYMSLABCELI (repeated slabs having different moderator } \\
\text { conditions) }\end{array}$ \\
\hline M7.5.45 & & $\begin{array}{l}\text { EXAMPLE 10a. ASYMSLABCELL (repeated slabs having different moderator } \\
\text { conditions) }\end{array}$ \\
\hline M7.5.46 & & M7.5.6.3 Multiregion Unit Cell Data \\
\hline M7.5.48 & & EXAMPLE 1. SLAB \\
\hline M7.5.49 & & EXAMPLE 2. CYLINDRICAI \\
\hline M7.5.50 & & EXAMPLE 3. SPHERICAL \\
\hline M7.5.50 & & EXAMPLE 4. BUCKLEDSLAB \\
\hline M7.5.51 & & EXAMPLE 5. BUCKIEDCYL \\
\hline M7.5.57 & M7.5.7 & OPTIONAL PARAMETER DATA OR MORE DATA \\
\hline M7.5.55 & & M7.5.7.1 Sample Optional Parameter Data \\
\hline M7.5.55 & M7.5.8 & $\begin{array}{l}\text { EXAMPLES OF COMMPLETE MATERIAL INFORMATION PROCESSOR INPUT } \\
\text { DATA }\end{array}$ \\
\hline M7.5.55 & & M7.5.8.1 Infinite Homogeneous Medium Input Data \\
\hline M7.5.55 & & EXAMPLE 1. Default Cell Definition \\
\hline M7.5.56 & & EXAMPLE 2. Specify the Cell Definition \\
\hline M7.5.57 & & M7.5.8.2 Lattice Cell Input Data \\
\hline M7.5.57 & & EXAMPLE 1. SQUAREPITCH \\
\hline M7.5.57 & & EXAMPLE 2. SQUAREPITCH \\
\hline M7.5.57 & & EXAMPLE 3. SPHTRIANGP \\
\hline M7.5.58 & & M7.5.8.3 Multiregion Input Data \\
\hline M7.5.58 & & EXAMPLE 1. SPHERICAL \\
\hline M7.5.59 & & EXAMPLE 2. BUCKIEDSLAB \\
\hline M7.5.59 & M7.5.9 & THREE METHODS OF SPECIFYING A SOLUTION \\
\hline M7.5.60 & & METHOD 1 \\
\hline M7.5.61 & & METHOD 2 \\
\hline M7.5.62 & & METHOD 3 \\
\hline M7.5.63 & & M7.5.9.1 Comparison of Number Densities from the Three Methods \\
\hline M7.5.63 & M7.5.10 & MULTIPLE FISSILE CELLS IN A SINGLE PROBLEM \\
\hline M7.5.65 & M7.5.11 & MULTIPLE FISSILE MIXTURES IN A SINGLE PROBLEM \\
\hline M7.5.66 & M7.5.12 & CELL-WEIGHTING \\
\hline M7.5.66 & & M7.5.12.1 Cell-weighting an infinite homogeneous problem \\
\hline M7.5.66 & & EXAMPLE 1 \\
\hline M7.5.66 & & M7.5.12.2 Cell-weighting a lattice cell problem \\
\hline M7.5.66 & & EXAMPLE 1 \\
\hline M7.5.67 & & M7.5.12.3 Cell-weighting a multiregion problem \\
\hline M7.5.67 & & EXAMPLE 1 \\
\hline
\end{tabular}

NUREG/CR-0200, 


\section{INFHOMMEDIUM \\ LATTICECELL MULTIREGION}

Terse input is accepted so only the number of characters necessary to uniquely define the type of calculation need be entered. However, the entered name must be an exact match for the number of characters that are entered. Thus, $I$ is sufficient to specify an infinite homogeneous medium treatment. However, it may be more informative to use names such as INF, LAT or MULT.

\section{M7.5.4.1 INFHOMMEDIUM}

The choice of infinite homogeneous medium means that the cross sections are treated as if each mixture is an infinite lump. Thus the self-shielding calculations do not account for any geometrical effects. Because the geometric effect to the cross-section resonance correction is a surface effect, infinite homogeneous medium is an appropriate choice if the surface of the material is very large. The fraction of the fuel that is within a mean-free path of the surface is the governing consideration. If the fraction is large, the geometric effect is very important. If the fraction is very small, the geometric effect is unimportant. Therefore, infinite homogeneous medium is a good choice if the size of the material is large relative to the mean-free path in the material. Infinite homogeneous medium is a very poor choice for large arrays of small lumps or fuel pins where the geometric correction for each fuel pin is extremely important. The unit cell specification is optional in an infinite homogeneous medium problem. If it is to be entered, it follows the standard compositions specification data. Examples of INFHOMMEDIUM unit cell specifications are given in Sect. M7.5.6.1. Examples of problems using the infinite homogeneous medium treatment are given in Sect. M7.5.8.1.

\section{M7.5.4.2 LATTICECELL}

The choice of LATTICECELL is used when the geometry can be described as a lattice. The LATTICECELL treatment assumes an infinite array of identical cells. It is especially suited for large arrays of cylindrical rods or spherical pellets. The use of LATTICECEIL requires a unit cell specification following the last entry of the standard composition specification data. The use of LATTICECELL assures that the cross sections are corrected for both geometric and resonance self-shielding. The geometric correction for a LATTICECELL specification utilizes the Dancoff correction factor in order to approximate the effects of a lattice of fuel lumps. NOTE THAT ONLY ONE UNIT CELL SPECIFICATION IS ALLOWED IN A PROBLEM. Thus if a problem utilizes more than one kind of fuel pin (different dimensions, different enrichments, etc.) special procedures must be invoked to assure adequate cross-section treatment as described in Sect. M7.5.10. The unit cell specification associated with the choice of LATTICECEIL is used to provide information used in processing the cross sections. Only those mixtures used in the unit cell specification have geometric corrections applied to their cross sections. ALL OTHER MTXTURES SPECIFIED IN THE PROBLEM ARE TREATED AS INFINITE HOMOGENEOUS MEDIA unless otherwise specified as described in Sect. M7.5.7 using the parameter keywords RES $=$ and DAN( ()$=$. Section M7.5.10 demonstrates this procedure. The unit cell configurations available as a LATTICECELL specification are described in Sect. M7.5.6.2.

\section{M7.5.4.3 MULTIREGION}

MULTIREGION can be used for a system of geometric regions where the geometry effects may be important but infinite homogeneous media treatment or lattice cell treatment are inappropriate. It can also be used to define a geometric configuration that is more complicated than that allowed by the LATTICECELL. The MULTIREGION treatment assumes a single cell and does not allow a true lattice

NUREG/CR-0200,

Vol. 3, Rev. 4

M7.5.4 
geometry. Therefore, the cross sections are corrected for resonance self-shielding and the geometric size and shape, but the Dancoff factor is an approximation. The use of MULTIREGION requires a unit cell specification following the standard composition specification data. Only one unit cell specification is allowed in a problem. Examples of multiregion geometries are given in Sect. M7.5.6.3.

\section{M7.5.5 STANDARD COMPOSITION SPECIFICATION DATA}

The standard composition specification data are used to define mixtures using standardized engineering data entered in a free-form format. The Material Information Processor uses the standard composition specification data and information from the Standard Composition Library to provide number densities for each nuclide of every defined mixture according to Eq. (M7.5.1):

$$
\mathrm{NO}=\frac{\mathrm{RHO} \times \mathrm{AVN} \times \mathrm{C}}{\mathrm{AWT}},
$$

where

NO is the number density of the nuclide in atoms/b-cm,

RHO is the actual density of the nuclide in $\mathrm{g} / \mathrm{cm}^{3}$,

AVN is Avogadro's number in atoms/mol,

C is a constant, $10^{24} \mathrm{~cm}^{2} / \mathrm{b}$,

AWT is the atomic or molecular weight of the nuclide in $\mathrm{g} / \mathrm{mol}$.

The actual density, RHO, is defined by

$$
\mathrm{RHO}=\mathrm{ROTH} \times \mathrm{VF} \times \mathrm{WGTF},
$$

where

RHO is the actual density of the standard composition in $\mathrm{g} / \mathrm{cm}^{3}$,

ROTH is either the specified density of the standard composition or the theoretical density of the standard composition in $\mathrm{g} / \mathrm{cm}^{3}$,

VF is a density multiplier compatible with ROTH as defined by Eq. (M7.5.3),

WGTF is the weight fraction of the nuclide in the standard composition. This value is automatically obtained by the code from the Standard Composition Library. WGTF is 1.0 for a single nuclide standard composition.

$$
\mathrm{VF}=\mathrm{DFRAC} \times \mathrm{VFRAC}
$$

where

VF is the density multiplier, 
DFRAC is the density multiplier,

VFRAC is the volume fraction.

To illustrate the interaction between ROTH and VF, consider an Inconel having a density of $8.5 \mathrm{~g} / \mathrm{cm}^{3}$. It is $7.0 \%$ by weight iron, $15.5 \%$ chromium, and $77.5 \%$ nickel. The Inconel occupies a volume of $4 \mathrm{~cm}^{3}$.

Method 1: To describe the iron, enter 8.5 for ROTH and 0.07 for VF.

To describe the nickel, enter 8.5 for ROTH and 0.155 for VF.

To describe the chromium, enter 8.5 for ROTH and 0.775 for VF.

Method 2: Do not enter the density, and by default the theoretical density of each component will be used for ROTH. DFRAC will be the ratio of the specified density to the theoretical density. The specified density of each component is the density of the Inconel $\times$ the weight fraction of that component.

Thus, the density of the iron is $8.5 \times 0.07=0.595 \mathrm{~g} / \mathrm{cm}^{3}$ chromium is $8.5 \times 0.155=1.318 \mathrm{~g} / \mathrm{cm}^{3}$

nickel is $8.5 \times 0.775=6.588 \mathrm{~g} / \mathrm{cm}^{3}$

To calculate DFRAC, the theoretical density of each material must be obtained from Table M8.2.1. These values are

$7.874 \mathrm{~g} / \mathrm{cm}^{3}$ for iron

$8.902 \mathrm{~g} / \mathrm{cm}^{3}$ for nickel

$7.190 \mathrm{~g} / \mathrm{cm}^{3}$ for chromium

The DFRAC entered for the iron is $0.595 / 7.874=0.0756$

for the nickel is $1.318 / 8.902=0.1481$

for the chromium is $6.588 / 7.190=0.9163$

Since there are no volumetric corrections, VFRAC is 1.0 and the values of DFRAC are entered for VF.

Method 3: Assume the Inconel, which occupies $4 \mathrm{~cm}^{3}$, is to be spread over a volume of $5 \mathrm{~cm}^{3}$. Then the volume fraction, VFRAC, is $4 \mathrm{~cm}^{3} / 5 \mathrm{~cm}^{3}=0.8$ and can be combined with the density fraction, DFRAC, to obtain the density multiplier, VF, according to Eq. (M7.5.3).

To describe the iron, enter 8.5 for ROTH and $0.07 \times 0.8=0.056$ for VF

for nickel, enter 8.5 for ROTH and $0.155 \times 0.8=0.124$ for VF

for chromium, enter 8.5 for ROTH and $0.775 \times 0.8=0.620$ for VF

Alternatively, the volume fraction can be applied to the density before it is entered. Then the ROTH can be entered as $8.5 \mathrm{~g} / \mathrm{cm}^{3} \times 0.8=6.8 \mathrm{~g} / \mathrm{cm}^{3}$, and DFRAC is entered for the density multiplier, VF.

To describe the iron, enter 6.8 for ROTH and 0.07 for VF

for nickel, enter 6.8 for ROTH and 0.155 for VF

for chromium, enter 6.8 for ROTH and 0.775 for VF

NUREG/CR-0200,

Vol. 3, Rev. 4

M7.5.6 
Method 4: Assume the Inconel, which occupies $4 \mathrm{~cm}^{3}$, is to be spread over a volume of $5 \mathrm{~cm}^{3}$. Then the volume fraction, VFRAC, is $4 \mathrm{~cm}^{3} / 5 \mathrm{~cm}^{3}=0.8$. Do not enter the density, and by default the theoretical density of each component will be used for ROTH.

VF is then entered as the product of VFRAC and DFRAC according to Eq. (M7.5.3). The specified density of each component is the density of the Inconel $\times$ the weight fraction of that component.

Thus, the density of the iron is $8.5 \times 0.07=0.595 \mathrm{~g} / \mathrm{cm}^{3}$

chromium is $8.5 \times 0.155=1.318 \mathrm{~g} / \mathrm{cm}^{3}$

nickel is $8.5 \times 0.775=6.588 \mathrm{~g} / \mathrm{cm}^{3}$

To calculate DFRAC, the theoretical density of each material must be obtained from Table M8.2.1. These values are

$7.874 \mathrm{~g} / \mathrm{cm}^{3}$ for iron

$8.902 \mathrm{~g} / \mathrm{cm}^{3}$ for nickel

$7.190 \mathrm{~g} / \mathrm{cm}^{3}$ for chromium

Then DFRAC for the iron is $0.595 / 7.874=0.0756$

for nickel is $1.318 / 8.902=0.1481$

for chromium is $6.588 / 7.190=0.9163$

Then VF is DFRAC $\times$ VFRAC

$\mathrm{VF}$ for the iron is $0.0756 \times 0.8=0.0605$

for nickel is $0.1481 \times 0.8=0.1185$

for chromium is $0.9163 \times 0.8=0.7330$

The number densities calculated by the Material Information Processor are used in processing the problem-specific working format cross-section libraries created for use by many of the SCALE functional modules. Three types of input data are allowed for the standard composition specification data: basic, arbitrary materials, and solutions. Each standard composition is terminated by entering the word END. The code continues to read standard composition data until the words END COMP are encountered. The basic data are described in Sect. M7.5.5.1, the arbitrary materials are described in Sect. M7.5.5.2, and the solutions are described in Sect. M7.5.5.3. Many mixtures can be described using only basic, arbitrary, or solution specifications. However, the description of some mixtures can be greatly simplified by using a combination of those specifications as shown in Sects. M7.5.5.4 through M7.5.5.9.

\section{M7.5.5.1 Basic Standard Composition Specifications}

Basic standard compositions are those whose standard composition name is found in the Standard Composition Library. The input data for basic standard compositions are discussed in more detail in Sect. M7.4.4. Examples of basic standard compositions are given below.

\section{GENERIC EXAMPLE}

Input data for the basic standard compositions are entered as follows:

SC MX DEN=ROTH VF ADEN TEMP $\left(\mathrm{IZA}_{i} \mathrm{WTP}_{\mathrm{i}}\right)$ END

or 


\section{SC MX SPG=ROTH VF ADEN TEMP $\left(\right.$ IZA $\left._{i} W_{T P}\right)$ END}

where

SC is the standard composition component name (see Table M8.2.1).

MX is the mixture number (defined by the user).

ROTH is the density of the material. THESE DATA ARE OPTIONAL AND ARE ENTERED USING THE KEYWORD SPG $=$ or DEN=.

VF is the density multiplier for this standard composition (enter 0 if the number density is to be entered for this standard composition).

$\mathrm{ADEN}$ is the number density (atoms/b-cm). Enter only if VF $=0$.

TEMP is the temperature in Kelvin.

IZA is the isotope $\mathrm{D}$ number (see Table M8.4.1).

WTP is the weight percent of the isotope in the material. WTP must be between 0 and 100 .

Repeat the sequence IZA WTP until the sum of the WTPs sum to 100. IZA and WTP are used to specify the isotopic abundance of a standard composition that has multiple isotopes. IZA identifies the isotope, and WTP specifies its abundance in weight percent. The sequence IZA WTP is repeated until all of the desired isotopes have been specified.

EXAMPLE 1. Material name is given.

Create a mixture 3 that is Plexiglas. Since no other information is given, the information on the Standard Composition Library can be assumed to be adequate. Therefore, the only data to be entered are the standard composition name and the mixture number. The minimum generic input specification for the Plexiglas follows:

SC MX END

where

SC is the standard composition component name (PLEXIGLAS; see Table M8.2.1).

$\mathrm{MX}$ is the mixture number (enter a 3 ). The input data for the Plexiglas are given below.

\section{PLEXIGLAS 3 END}

EXAMPLE 2. Material name and density $\left(\mathrm{g} / \mathrm{cm}^{3}\right)$ are given.

Create a mixture 3 that is Plexiglas at a density of $1.15 \mathrm{~g} / \mathrm{cm}^{3}$. Since no other data are specified, the defaults from the Standard Composition Library will be used. Therefore, the only data to be entered are the standard composition name, the mixture number, and the density. The minimum generic input specification for the Plexiglas is given below:

SC MX DEN=ROTH END

NUREG/CR-0200,

Vol. 3, Rev. 4

M7.5.8 
where

SC is the standard composition component name (PLEXIGLAS; see Table M8.2.1).

$\mathrm{MX}$ is the mixture number (enter a 3).

ROTH is the density of the material (enter $\mathrm{DEN}=1.15$ ).

The input data for the Plexiglas are given below.

\section{PLEXIGLAS 3 DEN=1.15 END}

EXAMPLE 3. Material name and number density (atoms/b-cm) are given.

Create a mixture 2 that is aluminum having a number density of 0.060244 .

The generic standard composition specification is

\section{SC MX VF ADEN END}

where

SC $\quad$ is the standard composition component name (AL; see Table M8.2.1).

$\mathrm{MX}$ is the mixture number (2).

VF is the density multiplier (enter 0 because the number density is to be used).

ADEN is the number density of the standard composition (0.060244).

The input data for the aluminum are given below:

\section{AL 20.060244 END}

EXAMPLE 4. Material name, density $\left(\mathrm{g} / \mathrm{cm}^{3}\right)$ and isotopic abundance are given.

Create a mixture 1 that is uranium metal at $18.76 \mathrm{~g} / \mathrm{cm}^{3}$ whose isotopic composition is $93.2 \%_{\mathrm{wt}}{ }^{235} \mathrm{U}, 5.6 \%_{\mathrm{wt}}{ }^{238} \mathrm{U}$, and $1.0 \%_{\mathrm{wt}}{ }^{234} \mathrm{U}$, and $0.2 \%_{\mathrm{wt}}{ }^{266} \mathrm{U}$. This example uses the $\mathrm{DEN}=$ keyword to enter the density and define the standard composition. Example 5 demonstrates another method of defining the standard composition.

The generic standard composition specification is

SC MX DEN=ROTH VF TEMP $\left(\mathrm{IZA}_{i} \mathrm{WTP}_{\mathrm{i}}\right)$ END

where

SC is the standard composition component name (URANIUM; see Table M8.2.1).

MX is the mixture number (enter a 1 ).

ROTH is the density of the material (enter DEN $=18.76$ ).

NUREG/CR-0200, 
VF is the density multiplier (enter 1 because the density was entered using $D E N=$ ).

TEMP is the temperature in Kelvin (293).

IZA is the isotope $\mathrm{ID}$ number $\left(92235\right.$ for ${ }^{235} \mathrm{U}, 92238$ for ${ }^{238} \mathrm{U}, 92234$ for ${ }^{234} \mathrm{U}$, and 92236 for ${ }^{236} \mathrm{U}$ ).

WTP is the weight percent of the isotope in the material $\left(93.2\right.$ for ${ }^{235} \mathrm{U}, 5.6$ for ${ }^{238} \mathrm{U}$, 1.0 for ${ }^{234} \mathrm{U}$, and 0.2 for ${ }^{236} \mathrm{U}$ ). Repeat the sequence IZA WTP until the sum of the WTPs sum to 100 .

The input data for the uranium metal follow:

URANIUM 1 DEN=18.76 $12939223593.292238 \quad 5.692234 \quad 1.092236 \quad 0.2$ END

EXAMPLE 5. Material name, density $\left(\mathrm{g} / \mathrm{cm}^{3}\right)$ and isotopic abundance are given. Create a mixture 1 that is uranium metal at $18.76 \mathrm{~g} / \mathrm{cm}^{3}$ whose isotopic composition is $93.2 \%$ wt ${ }^{235} \mathrm{U}, 5.6 \%$ wt ${ }^{238} \mathrm{U}$, and $1.0 \%$ wt ${ }^{234} \mathrm{U}$, and $0.2 \%$ wt ${ }^{266} \mathrm{U}$. This method illustrates the standard composition specification without using the DEN= option.

The generic standard composition specification is

$$
\text { SC MX VF TEMP (IZA } \left.\text { WTP }_{i}\right) \text { END }
$$

where

SC is the standard composition component name (URANIUM; see Table M8.2.1).

$\mathrm{MX}$ is the mixture number (enter a 1 ).

VF is the density multiplier (the density multiplier is the ratio of actual to theoretical density $(18.76 / 19.05=0.985)$. The theoretical density $\left(19.05 \mathrm{~g} / \mathrm{cm}^{3}\right)$ is obtained from Table M8.2.1.

TEMP is the temperature in Kelvin (293).

IZA is the isotope ID number (92235 for ${ }^{235} \mathrm{U}, 92238$ for ${ }^{238} \mathrm{U}, 92234$ for ${ }^{234} \mathrm{U}$, and 92236 for ${ }^{236} \mathrm{U}$ ).

WTP is the weight percent of the isotope in the material (93.2 for ${ }^{235} \mathrm{U}, 5.6$ for ${ }^{238} \mathrm{U}$, 1.0 for ${ }^{224} \mathrm{U}$, and 0.2 for ${ }^{266} \mathrm{U}$ ). Repeat the sequence IZA WTP until the sum of the WTPs sum to 100 .

The input data for the uranium metal follow:

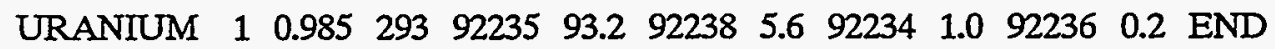

EXAMPLE 6. Material name and isotopic abundance are given.

Create a mixture 6 defining $\mathrm{B}_{4} \mathrm{C}$ at theoretical density. The boron is $40 \%{ }_{\mathrm{wt}}{ }^{10} \mathrm{~B}$ and $60 \%{ }_{\mathrm{wt}}{ }^{11} \mathrm{~B}$. The minimum generic input specification for this standard composition is 
SC MX VF TEMP (IZA WTP $\left._{\mathfrak{i}}\right)$ END

where

SC is the standard composition component name (B4C; see Table M8.2.1).

$\mathrm{MX}$ is the mixture number (6).

VF is the density multiplier (use 1.0 since the theoretical density of $\mathrm{B}_{4} \mathrm{C}$ is to be accepted as the density).

TEMP is the temperature in Kelvin (293).

IZA is the isotope ID number (5010 for ${ }^{10} \mathrm{~B}$ and 5011 for $\left.{ }^{11} \mathrm{~B}\right)$.

WTP is the weight percent of the isotope in the material (40 for ${ }^{10} \mathrm{~B}$ and 60 for ${ }^{11} \mathrm{~B}$ ). Repeat the sequence IZA WTP until the sum of the WTPs sum to 100.

The input data for this basic standard composition are given below.

B4C 61293501040.0501160 .0 END

Note that the free-form reading routines allow the user to enter an integer 1 for VF as readily as a 1.0 .

EXAMPLE 7. Material name, density $\left(\mathrm{g} / \mathrm{cm}^{3}\right)$ and isotopic abundance are given. Create a mixture 7 defining $\mathrm{B}_{4} \mathrm{C}$ with a density of $2.45 \mathrm{~g} / \mathrm{cm}^{3}$. The boron is $40 \%{ }_{\mathrm{kxt}}{ }^{10} \mathrm{~B}$ and $60 \%_{\mathrm{wt}}{ }^{11} \mathrm{~B}$. This example utilizes the DEN $=$ keyword. Example 8 illustrates an alternative description. The minimum generic input specification for this standard composition is

SC MX DEN=ROTH VF TEMP ( IZA WTP $\left._{i}\right)$ END

where

SC is the standard composition component name (B4C; Table M8.2.1).

$\mathrm{MX} \quad$ is the mixture number (7).

$\mathrm{ROTH}$ is the density of the material (enter $\mathrm{DEN}=2.45$ ).

VF is the density multiplier (enter 1.0 because the density was entered).

TEMP is the temperature in Kelvin (293).

IZA is the isotope ID number (5010 for ${ }^{10} \mathrm{~B}$ and 5011 for ${ }^{11} \mathrm{~B}$ ).

WTP is the weight percent of the isotope in the material ( 40 for ${ }^{10} \mathrm{~B}$ and 60 for ${ }^{11} \mathrm{~B}$ ). Repeat the sequence IZA WTP until the sum of the WTPs sum to 100 .

The input data for the $\mathrm{B}_{4} \mathrm{C}$ are given below. 
$\mathrm{B} 4 \mathrm{C} 7 \mathrm{DEN}=2.451 .0293501040 .0501160 .0$ END

EXAMPLE 8. Material name, density $\left(\mathrm{g} / \mathrm{cm}^{3}\right)$ and isotopic abundance are given.

Create a mixture 7 defining $\mathrm{B}_{4} \mathrm{C}$ with a density of $2.45 \mathrm{~g} / \mathrm{cm}^{3}$. The boron is $40 \%{ }_{\mathrm{wt}}{ }^{10} \mathrm{~B}$ and $60 \%{ }_{\mathrm{wt}}{ }^{11} \mathrm{~B}$. This example incorporates the known density into the density multiplier, $\mathrm{VF}$, rather than using the $\mathrm{DEN}=$ keyword. The minimum generic input specification for this standard composition is

\section{SC MX VF TEMP (IZA $\left.A_{i} W_{T}\right)$ END}

where

SC is the standard composition component name (B4C; Table M8.2.1).

$M X \quad$ is the mixture number (7).

VF is the density multiplier (the density multiplier is the ratio of actual to theoretical density $(2.45 / 2.52=0.9722)$. The theoretical density $\left(2.52 \mathrm{~g} / \mathrm{cm}^{3}\right)$ is obtained from Table M8.2.1.

TEMP is the temperature in Kelvin (293).

$\mathrm{IZA}$ is the isotope $\mathrm{D}$ number $\left(5010\right.$ for ${ }^{10} \mathrm{~B}$ and 5011 for ${ }^{11} \mathrm{~B}$ ).

WTP is the weight percent of the isotope in the material ( 40 for ${ }^{10} \mathrm{~B}$ and 60 for ${ }^{11} \mathrm{~B}$ ). Repeat the sequence IZA WTP until the sum of the WTPs sum to 100.

The input data for the $\mathrm{B}_{4} \mathrm{C}$ are given below.

B4C 70.9722293501040 .0501160 .0 END

\section{M7.5.5.2 Arbitrary Material Specifications}

The arbitrary material option allows the user to specify materials that are not found in the Standard Composition Library. To define an arbitrary material, the first four characters of the standard composition component name must be ARBM. The remaining characters of the standard composition component name are chosen by the user. The maximum length of the standard composition name is 16 characters. All the information that would normally be found in the Standard Composition Library must be entered in the arbitrary material specification. Section M7.4.5 contains data input details for arbitrary materials.

\section{GENERIC EXAMPLE}

The generic input data for arbitrary materials are entered as follows:

SC ROTH NEL IVIS ICP IRS (NCZA ATPM $)_{i}$ MX VF TEMP (IZA WTP $\left._{j}\right)$ END where 
$\mathrm{SC}$ is the standard composition component name (maximum length is 16 characters, the first four characters must be ARBM, the remaining characters are determined by the user).

ROTH is the density of the compound in $\mathrm{g} / \mathrm{cm}^{3}$.

NEL is the number of elements in the material.

IVIS is the multiple-isotope indicator (the multiple-isotope nuclides are listed in Table M8.4.1) ONLY ONE MULTIPLE-ISOTOPE NUCLIDE CAN BE USED IN AN ARBITRARY MATERIAL.

ICP is the compound indicator (enter a 1 for a compound represented by a chemical formula; a 0 for an alloy or mixture).

IRS is the resonance indicator ( 1 if any of the isotopes/nuclides have resonance data; 0 if none of them have resonance data, see Table M8.2.1).

NCZA is the isotope $\mathrm{ID}$ number (see Table M8.2.1 to determine the isotope $\mathrm{ID}$ number). For example, aluminum has a standard composition component of $\mathrm{AL}$ and an isotope ID number of 13027 so 13027 would be entered for aluminum. If a multiple-isotope nuclide is to be used, enter $Z^{*} 1000$ where $Z$ is the atomic number. For example, 92000 would be entered for uranium or 5000 would be entered for boron (see Table M8.4.1 for a list of allowed multipleisotope nuclides).

ATPM is the weight percent of the isotope (NCZA) in this material.

Repeat the sequence NCZA ATPM until the NEL elements in the arbitrary material have been specified.

MX is the mixture number (chosen by the user).

VF is the fraction of this arbitrary material in the mixture. (The relationship between VF and ROTH is given in Sect. M7.5.5.)

TEMP is the temperature in Kelvin.

IZA is the isotope ID number. ENTER ONLY IF IVIS $>0$, in which case one of the NCZAs was a multiple-isotope nuclide. Then IZA and WTP are used to specify the isotopic abundance of the multiple-isotope nuclide.

WTP is the weight percent of the isotope (NCZA) in the multiple-isotope nuclide.

Repeat the sequence IZA WTP until the sum of the WTPs sum to 100. IZA and WTP are used to specify the isotopic abundance of the multiple-isotope nuclide. IZA identifies the isotope, and WTP specifies its abundance in weight percent. The sequence IZA WTP is repeated until all of the desired isotopes have been specified.

EXAMPLE 1. Density and weight percents are given.

Create a mixture 5 that defines a borated aluminum that is 2.5 wt \% natural boron. The density of the borated aluminum is $2.65 \mathrm{~g} / \mathrm{cm}^{3}$. The minimum generic input specification for this arbitrary material is

NUREG/CR-0200, 


\section{SC ROTH NEL IVIS ICP IRS (NCZA $\left.A_{i} A T P M_{i}\right)$ MX END}

where

SC is the standard composition component name. (ARBMBAL is used as the standard composition name in this example. The first 4 characters MUST be ARBM. The remaining characters are chosen by the user.)

$\mathrm{ROTH}$ is the density of the compound in $\mathrm{g} / \mathrm{cm}^{3}$ (enter 2.65 ).

NEL is the number of elements in the material (enter a 2; aluminum and boron).

IVIS is the multiple-isotope indicator (enter 1 because boron is a multiple-isotope nuclide).

ICP is the compound indicator (enter 0 because this material is not defined by a chemical formula).

IRS is the resonance indicator (enter 0 because neither the boron nor the aluminum are resonance materials). (See Table M8.2.1.)

NCZA is the isotope ID number [enter 5000 for the boron $\left(1000^{*} Z\right.$ is entered for multiple-isotope nuclides)]. (Enter 13027 for the aluminum.) Note: The multiple-isotope nuclide must be entered first.

ATPM is the weight percent of the isotope in the material (enter 2.5 for the boron and 97.5 for the aluminum). Repeat the sequence NCZA ATPM until the NEL elements in the arbitrary material have been specified.

$\mathrm{MX}$ is the mixture number (enter 5).

Because natural boron was specified in the problem, no further data need be specified. EXAMPLE 2 illustrates the situation where the isotopic abundance of boron must be specified.

The input data for this arbitrary material are given below.

\section{ARBMBAL $2.652 \begin{array}{lllllllll}2 & 0 & 0 & 5000 & 2.5 & 13027 & 97.5 & 5 & \text { END }\end{array}$}

EXAMPLE 2. Density, weight percents, and isotopic abundance are given.

Create a mixture 5 that defines a borated aluminum that is $2.5 \mathrm{wt} \%$ boron. The boron is $90 \%_{\mathrm{wr}}{ }^{10} \mathrm{~B}$ and $10 \%_{\mathrm{wt}}{ }^{11} \mathrm{~B}$. The density of the borated aluminum is $2.65 \mathrm{~g} / \mathrm{cm}^{3}$. The minimum generic input specification for this arbitrary material is

SC ROTH NEL IVIS ICP IRS (NCZA ATPM $\left._{i}\right)$ MX VF TEMP (IZA WTP $\left._{j}\right)$ END where

SC is the standard composition component name. The first 4 characters MUST be ARBM (enter ARBMBAL).

NUREG/CR-0200, 
ROTH is the density of the compound in $\mathrm{g} / \mathrm{cm}^{3}$ (enter 2.65).

NEL is the number of elements in the material (enter 2).

IVIS is the multiple-isotope indicator. (Enter 1 because boron is a multiple-isotope nuclide.)

ICP is the compound indicator. (Enter 0 because this material is not defined by a chemical formula.)

IRS is the resonance indicator. (Enter 0 because neither the boron nor the aluminum are resonance materials. See Table M8.2.1.)

NCZA is the isotope ID number [Enter 5000 for the boron $\left(1000^{*} Z\right.$ is entered for multiple-isotope nuclides). Enter 13027 for the aluminum.] Note: The multiple-isotope nuclide must be entered first.

ATPM is the weight percent of the isotope in the material. (Enter 2.5 for the boron and 97.5 for the aluminum.)

Repeat the sequence NCZA ATPM until the NEL elements in the arbitrary material have been specified.

MX is the mixture number (enter 5).

VF is the density multiplier (use 1 or 1.0 since the density of the material was entered as the theoretical density, ROTH).

TEMP is the temperature in Kelvin. (Enter 293. The temperature must be entered because the isotopic abundance of boron must be specified.)

IZA is the isotope ID number for the isotopes in the multiple-isotope nuclide (enter 5010 for ${ }^{10} \mathrm{~B}$ and 5011 for ${ }^{11} \mathrm{~B}$ ).

WTP is the weight percent of the isotope in the multiple-isotope nuclide (enter 90 for ${ }^{10} \mathrm{~B}$ and 10 for ${ }^{11} \mathrm{~B}$ ).

Repeat the sequence IZA WTP until the sum of the WTPs sum to 100 and all of the isotopes present in the multiple-isotope nuclide have been entered.

The input data for this arbitrary material are given below.

ARBMBAL $2.652 \begin{array}{lllllllllllll}2 & 0 & 5000 & 2.5 & 13027 & 97.5 & 5 & 1 & 293 & 5010 & 90.5011 & 10 . & \text { END }\end{array}$

EXAMPLE 3. Density and chemical equation are given.

Create a mixture 3 that is a hydraulic fluid, $\mathrm{C}_{2} \mathrm{H}_{0} \mathrm{SiO}$, with a density of $0.97 \mathrm{~g} / \mathrm{cm}^{3}$. The minimum generic input specification for this arbitrary material is

SC ROTH NEL IVIS ICP IRS (NCZA ATPM $\left._{i}\right)$ MX END

where

NUREG/CR-0200, 
SC is the standard composition component name. The first 4 characters MUST be ARBM (enter ARBMC2H6SIO).

ROTH is the theoretical density of the compound in $\mathrm{g} / \mathrm{cm}^{3}(0.97)$.

NEL is the number of elements in the material (there are 4 elements in this material, $\mathrm{C}, \mathrm{H}, \mathrm{Si}$, and $\mathrm{O}$ ).

IVIS is the multiple-isotope indicator. (Enter a 0 because there are no multipleisotope nuclides in this material. Multiple-isotope nuclides are listed in Table M8.4.1)

ICP is the compound indicator (enter a 1 because this material is defined by a chemical formula).

IRS is the resonance indicator. (Enter a 0 because none of the nuclides are resonance nuclides. Table M8.2.1 indicates whether a nuclide has resonance data available.)

NCZA is the element ID number. (Table M8.2.1 lists the element ID numbers. Enter 6012 for carbon, 1001 for hydrogen, 14028 for silicon and 8016 for oxygen.)

ATPM is the number of atoms of this element per molecule of arbitrary material. (Enter 2 for carbon, 6 for hydrogen, 1 for silicon and 1 for oxygen.)

Repeat the NCZA ATPM sequence until the chemical formula of a molecule has been defined.

MX is the mixture number (3).

The input data for this arbitrary material are given below:

ARBMC2H6SIO 0.97400110601221001614000118016113 END

EXAMPLE 4. Density and chemical equation are given.

Create a mixture 7, TBP, also known as phosphoric acid tributyl ester or tributylphosphate, $\left(\mathrm{C}_{4} \mathrm{H}_{9} \mathrm{O}\right)_{3} \mathrm{PO}$, having a density of $0.973 \mathrm{~g} / \mathrm{cm}^{3}$.

SC ROTH NEL IVIS ICP IRS $\left(\mathrm{NCZA}_{i} \mathrm{ATPM}_{\mathrm{i}}\right) \mathrm{MX}$ END

where

SC is the standard composition component name. The first 4 characters MUST be ARBM (enter ARBMTBP).

ROTH is the theoretical density of the compound in $\mathrm{g} / \mathrm{cm}^{3}(0.973)$.

NEL is the number of elements in the material. (There are 4 elements in TBP, C, $\mathrm{H}, \mathrm{O}$, and $\mathrm{P}$.)

NUREG/CR-0200,

Vol. 3, Rev. 4

M7.5.16 
IVIS is the multiple-isotope indicator. (Enter a 0 because there are no multipleisotope nuclides in TBP.)

ICP is the compound indicator. (Enter a 1 because TBP is defined by a chemical formula.)

IRS is the resonance indicator. (Enter a 0 because TBP does not contain resonance nuclides.)

NCZA is the nuclide/isotope ID number. (Table M8.2.1 lists the nuclide/isotope $\mathrm{DD}$ numbers. Use 1001 for hydrogen, 6012 for carbon, 8016 for oxygen and 15031 for phosphorus.)

ATPM is the number of atoms of each element in the arbitrary material. (Enter 27 for hydrogen, 12 for carbon, 4 for oxygen, and 1 for phosphorus.)

Repeat the NCZA ATPM sequence until the NEL elements have been described.

$\mathrm{MX}$ is the mixture number (7).

The input data for the TBP are given below:

ARBMTBP $0.973 \quad 4 \quad 010100127601212801641503117$ END

\section{M7.5.5.3 Solution Specifications}

Solutions of fissile materials are available in the Material Information Processor. A list of the available solutions are given in Table M8.3.1. When the Material Information Processor processes a solution, it breaks the solution up into its component parts (basic standard composition specifications) and uses the specific gravity to calculate the volume fractions. If the specific gravity is not explicitly entered in the solution specification, the Material Information Processor uses a fitted equation to determine the specific gravity. The specific gravity should be entered if it is known. Section M7.4.4 contains data input details for solutions. See Sect. M7.5.9 for a comparison of three different methods of specifying a uranyl nitrate solution.

\section{GENERIC EXAMPLE}

The generic input data for solutions are entered as follows:

or

SC MX FD AML SPG=SPGR VF TEMP (IZA WTP $\left._{i}\right)$ END

or

SC MX FD AML DEN=SPGR VF TEMP (IZA WTP $\left._{i}\right)$ END

SC MX FD AML VF TEMP (IZA WTP $_{i}$ ) END

where

SC is the standard composition component name. 
$\mathrm{MX}$ is the mixture number.

FD is the fuel density in grams of $\mathrm{U}$ or $\mathrm{Pu}$ per liter of solution.

AMI is the acid molarity of the solution.

SPGR is the specific gravity of the solution. THESE DATA ARE OPTIONAL AND ARE ENTERED USING THE KEYWORD SPG $=$ or DEN $=$.

VF is the density multiplier (ratio of actual to theoretical density of the solution).

TEMP is the temperature in Kelvin.

IZA is the isotope ID number.

WTP is the weight percent of the isotope in the material.

Repeat the sequence IZA WTP until the sum of the WTPs sum to 100.

Examples of solution specifications follow:

EXAMPLE 1. Fuel density, specific gravity, excess acid and isotopic abundance are given. Create a mixture 2 that is highly enriched uranyl nitrate solution at $415 \mathrm{~g} / \mathrm{L}$, a specific gravity of 1.555 and $0.39 \mathrm{mg}$ of excess nitrate per gram of solution. The uranium isotopic content is $92.6 \%_{\mathrm{wt}}{ }^{235} \mathrm{U}, 5.9 \%_{\mathrm{wt}}{ }^{238} \mathrm{U}, 1.0 \%_{\mathrm{wt}}{ }^{234} \mathrm{U}$, and $0.5 \%_{\mathrm{wt}}{ }^{236} \mathrm{U}$.

A generic input specification for this solution is

SC MX FD AML SPG=SPGR VF TEMP $\left(\operatorname{IZA}_{i} W_{T}\right)$ END

where

SC is the standard composition component name from Table M8.3.1 of Sect. M8.3 (enter SOLNUO2(NO3)2).

$\mathrm{MX}$ is the mixture number (enter 2).

FD is the fuel density in grams of $U$ or $\mathrm{Pu}$ per liter of solution (enter 415).

AML is the acid molarity of the solution. The molecular weight of the $\mathrm{NO}_{3}$ is 61.9895. The molarity is $(0.39 \mathrm{mg}$ nitrate $/ \mathrm{g} \mathrm{soln}) \times\left(1000 \mathrm{~cm}^{3}\right.$ soln $/ \mathrm{L}$ soln $) \times$ $(1 \mathrm{~g} / 1000 \mathrm{mg}) \times\left(1.555 \mathrm{~g} \mathrm{soln} / \mathrm{cm}^{3}\right.$ soln $)=0.60645 \mathrm{~g}$ excess nitrate $/ \mathrm{L}$ soln. $(0.60645 \mathrm{~g}$ nitrate $/ \mathrm{L}$ soln $) /(61.9895 \mathrm{~g}$ nitrate $/ \mathrm{mol}$ nitrate $)=9.783 \times 10^{-3} \mathrm{mols}$ nitrate/L soln. The mols of nitrate per liter is identical to mols of acid per liter, which is identical to molarity.

SPGR is the specific gravity of the solution. The specific gravity is optional data and is entered using the keyword SPG=spgr or DEN=spgr. (Enter $\mathrm{SPG}=1.555$ or $\mathrm{DEN}=1.555$.) 
VF is the density multiplier of the solution in the mixture. (Enter a 1 because this mixture is composed entirely of this solution.)

TEMP is the temperature in Kelvin (293).

IZA is the isotope ID number. (Enter 92235 for ${ }^{235} \mathrm{U}, 92238$ for ${ }^{28} \mathrm{U}, 92234$ for ${ }^{234} \mathrm{U}$, and 92236 for ${ }^{236} \mathrm{U}$.)

WTP is the weight percent of the isotope in the material. (Enter 92.6 for ${ }^{255} \mathrm{U}, 5.9$ for ${ }^{238} \mathrm{U}, 1.0$ for ${ }^{234} \mathrm{U}$, and 0.5 for ${ }^{236} \mathrm{U}$.)

Repeat the sequence IZA WTP until the sum of the WTPs sum to 100.

The input data for the uranyl nitrate solution are

SOLNUO2(NO3)2 2415 9.783-3 SPG=1.555 1.02939223592.692238 5.9922341.0922360.5 END

\section{M7.5.5.4 Combinations of Basic Standard Compositions to Define a Mixture}

Frequently more than one standard composition is required to define a mixture. This section contains such examples.

EXAMPLE 1. Boral from $\mathrm{B}_{4} \mathrm{C}$ and Aluminum.

Create a mixture 6 that is boral, $15 \%_{\mathrm{wr}} \mathrm{B}_{4} \mathrm{C}$ and $85 \%_{\mathrm{kr}} \mathrm{Al}$, having a density of $2.64 \mathrm{~g} / \mathrm{cm}^{3}$. Natural boron is used in the $\mathrm{B}_{4} \mathrm{C}$. Boral can be described in several ways. Example 1 of Sect. M7.5.5.5 illustrates how to describe boral using arbitrary materials. Because both $\mathrm{B}_{4} \mathrm{C}$ and $\mathrm{Al}$ are available in the Standard Composition Library, it is not necessary to use arbitrary materials. Using basic standard compositions is much easier as shown by this example. Example 2 demonstrates the use of the keyword DEN $=$ to enter the density of the mixture and avoid having to look up the theoretical density from Table M8.2.1 and calculate the density multiplier (VF). The generic specification for this example is

\section{SC MX VF END}

where

$\mathrm{SC}$ is the standard composition component name (enter $\mathrm{B} 4 \mathrm{C}$ for $\mathrm{B}_{4} \mathrm{C}$ and $\mathrm{Al}$ for aluminum).

MX is the mixture number (enter 6).

VF is the density multiplier. (The density multiplier is the ratio of actual to theoretical density. For $\mathrm{B}_{4} \mathrm{C}$, the density multiplier is $(0.15 \times 2.64) / 2.52$, and for the aluminum the density multiplier is $(0.85 \times 2.64) / 2.6989$. The theoretical density $\left(2.52 \mathrm{~g} / \mathrm{cm}^{3}\right.$ for $\mathrm{B}_{4} \mathrm{C}$ and $2.6989 \mathrm{~g} / \mathrm{cm}^{3}$ for aluminum) is obtained from Table M8.2.1.

The standard compositions input data for the boral are given below.

B4C 60.1571 END

AL 60.8314 END 
EXAMPLE 2. Boral from $\mathrm{B}_{4} \mathrm{C}$ and Aluminum.

This is the same problem as example 1 using a different method of specifying the input data. Create a mixture 6 that is boral, $15 \%_{\mathrm{wt}} \mathrm{B}_{4} \mathrm{C}$ and $85 \%_{\mathrm{wt}}$ Al, having a density of $2.64 \mathrm{~g} / \mathrm{cm}^{3}$. Natural boron is used in the $B_{4} C$. Boral can be described in several ways. Example 1 of Sect. M7.5.5.5 illustrates how to describe boral using arbitrary materials. Because both $\mathrm{B}_{4} \mathrm{C}$ and $\mathrm{Al}$ are available in the Standard Composition Library, it is not necessary to use arbitrary materials. Using standard compositions is much easier as shown by this example. The generic specification for this problem is

$$
\text { SC MX DEN=ROTH VF END }
$$

where

$\mathrm{SC}$ is the standard composition component name (enter $\mathrm{B} 4 \mathrm{C}$ for $\mathrm{B}_{4} \mathrm{C}$ and $\mathrm{AL}$ for aluminum).

$\mathrm{MX}$ is the mixture number (enter 6).

$\mathrm{ROTH}$ is the density of the material. (Enter $\mathrm{DEN}=2.64$ for both $\mathrm{B}_{4} \mathrm{C}$ and $\mathrm{Al}$ ).

VF is the weight fraction of the mixture that is this standard composition. (Enter 0.15 for $\mathrm{B}_{4} \mathrm{C}$ and 0.85 for $\mathrm{Al}$.)

The standard composition input data for the boral are given below:

$$
\begin{aligned}
& \text { B4C } 6 \text { DEN }=2.640 .15 \text { END } \\
& \text { AL } 6 \mathrm{DEN}=2.640 .85 \text { END }
\end{aligned}
$$

EXAMPLE 3. Boral from Boron, Carbon, and Aluminum

If neither boral nor $\mathrm{B}_{4} \mathrm{C}$ were available in the Standard Composition Library, boral could be described as follows:

Create a mixture 2 that is boral composed of $35 \% \%_{\mathrm{wr}} \mathrm{B}_{4} \mathrm{C}$ and $65 \%$ aluminum with an overall density of $2.64 \mathrm{~g} / \mathrm{cm}^{3}$. The boron is natural boron. The generic specification for this problem is

\section{SC MX VF END}

where

$\mathrm{SC}$ is the standard composition name (enter BORON for boron, $\mathrm{C}$ for carbon, and $\mathrm{AL}$ for aluminum).

$\mathrm{MX}$ is the mixture number ( 2 for each standard composition).

VF is the density multiplier. (The density multiplier is the ratio of actual to theoretical density. From the Standard Composition Library, Table M8.2.1, the theoretical density of aluminum is $2.6989 \mathrm{~g} / \mathrm{cm}^{3}$; boron is $2.373 \mathrm{~g} / \mathrm{cm}^{3}$; and carbon is $2.30 \mathrm{~g} / \mathrm{cm}^{3}$. The density multiplier, VF, for $\mathrm{Al}$ is $(0.65)(2.64) / 2.6989=0.63581$. From Table M8.4.1 of Sect. M8.4, the natural boron is $18.3022 \%{ }_{\mathrm{ut}}{ }^{10} \mathrm{~B}$ at $10.0129 \mathrm{amu}$ and $81.6978 \%_{\mathrm{wt}}{ }^{11} \mathrm{~B}$ at $11.0096 \mathrm{amu}$. $\mathrm{C}$ is $12.000 \mathrm{amu}$. Convert the weight percents to

NUREG/CR-0200,

Vol. 3, Rev. 4

M7.5.20 
atom percents for the natural boron where $w$ denotes weight fraction, a denotes atom fraction, and $M$ denotes atomic mass:

$$
\begin{gathered}
w_{10_{B}}=0.183022=\frac{a_{{ }_{10} B} M_{10_{B}}}{a_{{ }_{10} B} M_{{ }_{10} B}+a_{1_{B}} M_{1_{B}}}= \\
\frac{a_{{ }_{10} B}(10.0129)}{a_{10_{B}}(10.0129)+\left(1-a_{10_{B}}\right)(11.0096)} \\
a_{10}\left[\left(\frac{10.0129}{0.183022}\right)-10.0129+11.0096\right]=11.0096 \\
a_{10_{B}}=0.19764=19.764 \text { atom \% . }
\end{gathered}
$$

Similarly,

$$
a_{11_{B}}=80.236 \text { atom \%. }
$$

The mass of the $\mathrm{B}_{4} \mathrm{C}$ molecule is $[(0.19764 \times 4 \times 10.0129)+(0.80236 \times 4 \times 11.0096)+(12.000)]=55.25045 \mathrm{amu}$. The mass of the boron is $(55.25045-12.000)=43.25045 \mathrm{amu}$.

The VF of boron would be $\left(\frac{43.25045}{55.25045}\right)\left[\frac{(0.35)(2.64)}{2.373}\right]=0.30481$.

The VF of $C$ would be $\left(\frac{12.000}{55.25045}\right)\left[\frac{(0.35)(2.64)}{2.30}\right]=0.08725$.

The standard composition input data for the boral follow:

$\begin{array}{llll}\text { AL } & 2 & 0.63581 & \text { END } \\ \text { BORON } & 2 & 0.30481 & \text { END } \\ \text { C } & 2 & 0.08725 & \text { END }\end{array}$

EXAMPLE 4. Boral from ${ }^{10} \mathrm{~B},{ }^{11} \mathrm{~B}$, Carbon, and Aluminum Create a mixture 2 that is boral composed of $35 \%_{\mathrm{wt}} \mathrm{B}_{4} \mathrm{C}$ and $65 \%$ aluminum. The boral density is $2.64 \mathrm{~g} / \mathrm{cm}^{3}$. The boron is natural boron. The generic specification for this problem is

SC MX VF END 
where

$\mathrm{SC}$ is the standard composition name (enter $\mathrm{B}-10$ for ${ }^{10} \mathrm{~B}, \mathrm{~B}-11$ for ${ }^{11} \mathrm{~B}, \mathrm{C}$ for carbon, and AL for aluminum).

$\mathrm{MX}$ is the mixture number ( 2 for each standard composition).

VF is the density multiplier. Enter 0.63581 for $\mathrm{AL}$ and 0.08725 for $\mathrm{C}$ as explained in Example 3 above. From the Standard Composition Library, Table M8.2.1, the theoretical density of ${ }^{10} \mathrm{~B}$ is $2.195 \mathrm{~g} / \mathrm{cm}^{3}$ and ${ }^{11} \mathrm{~B}$ is $2.413 \mathrm{~g} / \mathrm{cm}^{3}$. As computed in Example 3, the mass of the $\mathrm{B}_{4} \mathrm{C}$ molecule is $55.25045 \mathrm{amu}$, and the boron is 19.764 atom $\%{ }^{10} \mathrm{~B}$ and 80.236 atom $\%{ }^{11} \mathrm{~B}$. The mass of ${ }^{10} \mathrm{~B}$ is $10.0129 \mathrm{amu}$ and the ${ }^{11} \mathrm{~B}$ is 11.0096. Thus, the VF of ${ }^{10} \mathrm{~B}$ is

$$
\left[\frac{(4)(0.19764)(10.0129)}{55.25045}\right]\left[\frac{(0.35)(2.64)}{2.195}\right]=0.06031 \mathrm{y}
$$

The VF of ${ }^{11} \mathrm{~B}$ is

$$
\left[\frac{(4)(0.80236)(11.0096)}{55.25045}\right]\left[\frac{(0.35)(2.64)}{2.413}\right]=0.24489 \text {. }
$$

The standard composition input data for the boral are given as

$\begin{array}{llll}\mathrm{AL} & 2 & 0.63581 & \text { END } \\ \mathrm{B}-10 & 2 & 0.06031 & \text { END } \\ \text { B-11 } & 2 & 0.24489 & \text { END } \\ \mathrm{C} & 2 & 0.08725 & \text { END }\end{array}$

EXAMPLE 5. Specify all of the number densities in a mixture.

Create a mixture 1 that is vermiculite, defined as

$\begin{array}{ll}\text { hydrogen } & \text { at a number density of } 6.8614-4 \text { atoms } / \mathrm{b}-\mathrm{cm} \\ \text { oxygen } & \text { at a number density of } 2.0566-3 \text { atoms } / \mathrm{b}-\mathrm{cm} \\ \text { magnesium } & \text { at a number density of } 3.5780-4 \text { atoms } / \mathrm{b}-\mathrm{cm} \\ \text { aluminum } & \text { at a number density of } 1.9816-4 \text { atoms } / \mathrm{b}-\mathrm{cm} \\ \text { silicon } & \text { at a number density of } 4.4580-4 \text { atoms } / \mathrm{b}-\mathrm{cm} \\ \text { potassium } & \text { at a number density of } 1.0207-4 \text { atoms } / \mathrm{b}-\mathrm{cm} \\ \text { iron } & \text { at a number density of } 7.7416-5 \text { atoms } / \mathrm{b}-\mathrm{cm}\end{array}$

The generic standard composition specification is

$$
\text { SC MX VF ADEN END }
$$

where

SC is the standard composition component name.

$\mathrm{MX}$ is the mixture number.

NUREG/CR-0200,

Vol. 3, Rev. 4

M7.5.22 
VF is the density multiplier (enter 0 because number densities are to be used).

ADEN is the number density of the standard composition.

The standard composition input data for the vermiculite are given below:

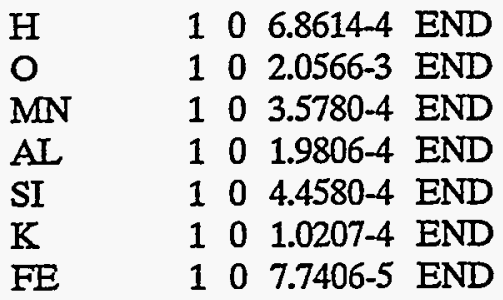

\section{M7.5.5.5 Combinations of Arbitrary Materials to Define a Mixture}

Mixtures can usually be created using only basic standard composition specifications. Occasionally, it is convenient to create two or more arbitrary materials for a given mixture. This procedure is demonstrated in the following example.

EXAMPLE 1. Specify boral using two arbitrary materials.

Create a mixture 6 that is boral, $15 \%_{\mathrm{wz}} \mathrm{B}_{4} \mathrm{C}$ and $85 \%_{\mathrm{st}} \mathrm{Al}$, having a density of $2.64 \mathrm{~g} / \mathrm{cm}^{3}$. Natural boron is used in the $\mathrm{B}_{4} \mathrm{C}$. Boral can be described in several ways. For demonstration purposes, it will be described as an arbitrary material. This is not necessary, because both $\mathrm{B}_{4} \mathrm{C}$ and $\mathrm{Al}$ are available as standard compositions. A method of describing the boral without using arbitrary materials is given in Examples 1 and 2 of Sect. M7.5.5.4. The minimum generic input specification for this arbitrary material is

\section{SC ROTH NEL IVIS ICP IRS (NCZA $A_{i}$ ATPM $\left._{i}\right)$ MX VF END}

where

SC is the standard composition component name. The first four characters must be $\mathrm{ARBM}$ (enter $\mathrm{ARBM}-\mathrm{B} 4 \mathrm{C}$ for $\mathrm{B}_{4} \mathrm{C}$ and $\mathrm{ARBM}-\mathrm{AL}$ for aluminum).

ROTH is the theoretical density of the compound $\left(2.64 \mathrm{~g} / \mathrm{cm}^{3}\right)$.

NEL is the number of elements in the material (there are two elements in $\mathrm{B}_{4} \mathrm{C}, \mathrm{B}$ \& $C$; there is one element in aluminum).

IVIS is the multiple-isotope indicator (enter a 1 for the $\mathrm{B}_{4} \mathrm{C}$ because the boron is a multiple-isotope nuclide; enter a 0 for the aluminum because it is not a multiple-isotope nuclide; multiple-isotope nuclides are listed in Table M8.4.1).

ICP is the compound indicator (enter a 1 for the $\mathrm{B}_{4} \mathrm{C}$ because it is defined by a chemical formula; enter a 0 for the aluminum because it is not defined by a chemical formula).

IRS is the resonance indicator (enter $\mathrm{a} 0$ because neither $\mathrm{B}_{4} \mathrm{C}$ nor aluminum contain 
resonance nuclides; Table M8.2.1 indicates whether a nuclide has resonance data available).

NCZA is the isotope ID number (Table M8.2.1 lists the isotope ID numbers) (enter 5000 for boron, 6012 for carbon, and 13027 for aluminum).

ATPM is the number of atoms of each element in the arbitrary material. For the $\mathrm{B}_{4} \mathrm{C}$ enter 4 for the boron and 1 for the carbon. For the aluminum, ATPM is the weight percent of the element in the arbitrary material. Repeat the NCZA ATPM sequence until the chemical formula of $B_{4} C$ has been defined. Repeat the NCZA ATPM sequence until the weight percents sum to 100 .

MX is the mixture number (enter 6).

VF is the density multiplier. (Use 0.15 for the $\mathrm{B}_{4} \mathrm{C}$ and 0.85 for the $\mathrm{Al}$ because the density of the boral, $2.64 \mathrm{~g} / \mathrm{cm}^{3}$, was entered as the theoretical density, ROTH.)

The input data for the boral are given below:

ARBM-B4C 2.642211105000460121160 .15 END

ARBM-AL $2.6411000013027 \quad 100.0 \quad 6 \quad 0.85$ END

\section{M7.5.5.6 Combination of Solutions to Define a Mixture}

This section demonstrates the use of more than one solution definition to describe a single mixture. The assumptions used in processing the cross sections are likely to be inadequate for solutions of mixed oxides of uranium and plutonium (see Sect. M7.2.5.2). Therefore, this section is given purely for demonstration purposes. The use of this method is not recommended and should be carefully evaluated for each specific application. The input data for a solution are entered as follows:

\section{SC MX FD AML SPG=SPGR VF TEMP $\left(\right.$ IZA $_{i}$ WTP $\left._{i}\right)$ END}

where

SC is the standard composition component name from Table M8.3.1 of Sect. M8.3.

MX is the mixture number.

FD is the fuel density in grams of $\mathrm{U}$ or $\mathrm{Pu}$ per liter of solution.

AML is the acid molarity of the solution.

SPGR is the specific gravity of the solution.

VF is the density multiplier (ratio of actual to theoretical density of the solution).

TEMP is the temperature in Kelvin.

IZA is the isotope ID number from Table M8.3.1.

WTP is the weight percent of the isotope in the material.

NUREG/CR-0200,

Vol. 3, Rev. 4

M7.5.24 
Repeat the sequence IZA WTP until the sum of the WTPs sum to 100 .

EXAMPLE 1. Solution of uranyl nitrate and plutonium nitrate.

Note that the assumptions used in processing the cross sections are likely to be inadequate for mixed-oxide solutions. This example is given purely for demonstration purposes.

Create a mixture 1 consisting of a mixture of plutonium nitrate solution and uranyl nitrate solution. The specific gravity of the mixed solution is 1.4828 . The solution contains $325.89 \mathrm{~g}(\mathrm{U}+\mathrm{Pu}) / \mathrm{L}$ soln. The acid molarity of the solution is 0.53 . The solution is $77.22 \%$ uranium. The isotopic abundance of the uranium is $0.008 \%{ }^{234} \mathrm{U}$, $0.7 \%{ }^{235} \mathrm{U}, 0.052 \%{ }^{236} \mathrm{U}$, and $99.24 \%{ }^{238} \mathrm{U}$. The isotopic abundance of the plutonium is $0.028 \%{ }^{238} \mathrm{Pu}, 91.114 \%{ }^{239} \mathrm{Pu}, 8.34 \%{ }^{240} \mathrm{Pu}, 0.426 \%{ }^{241} \mathrm{Pu}$, and $0.092 \%{ }^{242} \mathrm{Pu}$.

The generic input specification for this solution is

SC MX FD AML SPG=SPGR VF TEMP $\left(\mathrm{IZA}_{i} \mathrm{WTP}_{\mathrm{i}}\right)$ END

where

SC is the standard composition name from Table M8.3.1 (enter SOLNPU(NO3)4 for the plutonium nitrate and SOLNUO2(NO3)2 for the uranyl nitrate).

$\mathrm{MX}$ is the mixture number (enter 1 for both solutions).

FD is the fuel density in grams of $\mathrm{U}$ or $\mathrm{Pu}$ per liter of solution (enter 325.89 for the plutonium nitrate and 325.89 for the uranyl nitrate).

AML is the acid molarity (enter 0.53 for both solutions).

SPGR is the specific gravity of the solution (enter $\mathrm{SPG}=1.4828$ for both solutions).

VF is the density multiplier (ratio of actual to theoretical density of the solution).

TEMP is the temperature in Kelvin (enter 293).

IZA is the isotope ID number from Table M8.3.1 (enter 94238 for ${ }^{238} \mathrm{Pu}, 94239$ for ${ }^{239} \mathrm{Pu}, 94240$ for ${ }^{240} \mathrm{Pu}, 94241$ for ${ }^{241} \mathrm{Pu}, 94242$ for ${ }^{242} \mathrm{Pu}, 92234$ for ${ }^{234} \mathrm{U}, 92235$ for ${ }^{235} \mathrm{U}, 92236$ for ${ }^{236} \mathrm{U}$, and 92238 for ${ }^{238} \mathrm{U}$ ).

WTP is the weight percent of the isotope in the material (enter 0.028 for ${ }^{238} \mathrm{Pu}, 91.114$ for ${ }^{209} \mathrm{Pu}, 8.34$ for ${ }^{240} \mathrm{Pu}, 0.426$ for ${ }^{241} \mathrm{Pu}, 0.092$ for ${ }^{242} \mathrm{Pu}, 0.008$ for ${ }^{24} \mathrm{U}, 0.7$ for ${ }^{235} \mathrm{U}, 0.052$ for ${ }^{236} \mathrm{U}$, and 99.24 for ${ }^{238} \mathrm{U}$ ).

SOLNPU(NO3)4 $1325.89 \quad 0.53 \quad$ SPG=1.4828 0.2278 293. $94238 \quad 0289423991.11494240 \quad 8.34$ 94241.42694242 .092 END

$\begin{array}{llllllllllll}\text { SOLNUO2(NO3)2 } & 1 & 325.89 & 0.53 & \text { SPG }=1.4828 & 0.7722 & 293.92234 & 008 & 92235 & .700 & 92236 & .052\end{array}$ 9223899.240 END 
M75.5.7 Combinations of Basic and Arbitrary Standard Compositions to Define a Mixture

EXAMPLE 1. Burnable poison from $\mathrm{B}_{4} \mathrm{C}$ and $\mathrm{Al}_{2} \mathrm{O}_{3}$.

Create a mixture 6 that is a burnable poison with a density of $3.7 \mathrm{~g} / \mathrm{cm}^{3}$ and composed of $\mathrm{Al}_{2} \mathrm{O}_{3}$ and $\mathrm{B}_{4} \mathrm{C}$. The material is $1.395 \%$ wt $\mathrm{B}_{4} \mathrm{C}$. The boron is natural boron. This material can be easily specified using a combination of an arbitrary material to describe the $\mathrm{Al}_{2} \mathrm{O}_{3}$ and a simple standard composition to define the $\mathrm{B}_{4} \mathrm{C}$. The minimum generic input specification for this arbitrary material and the standard composition are

SC ROTH NEL IVIS ICP IRS (NCZA ATPMi $)$ MX VF END

SC MX VF END

where

SC is the standard composition component name (enter ARBMPOIS1 for the $\mathrm{Al}_{2} \mathrm{O}_{3}$ and enter $\mathrm{B} 4 \mathrm{C}$ for $\mathrm{B}_{4} \mathrm{C}$ ).

ROTH is the theoretical density of the compound $\left(3.70 \mathrm{~g} / \mathrm{cm}^{3}\right)$.

NEL is the number of elements in the material (there are 2 elements in $\mathrm{Al}_{2} \mathrm{O}_{3}$ ).

IVIS is the multiple-isotope indicator (enter a 0 because there are no multipleisotope nuclides in A1203; multiple-isotope nuclides are listed in Table M8.4.1).

ICP is the compound indicator (enter a 1 for the $\mathrm{Al}_{2} \mathrm{O}_{3}$ because it is defined by a chemical formula).

IRS is the resonance indicator (enter a 0 because the $\mathrm{Al} 2 \mathrm{O} 3$ does not contain resonance nuclides; Table M8.2.1 indicates whether a nuclide has resonance data available).

NCZA is the isotope $\mathrm{ID}$ number. Table M8.2.1 lists the isotope $\mathrm{ID}$ numbers. (Enter 13027 for aluminum and 8016 for oxygen.)

ATPM is the number of atoms of each element in the arbitrary material (enter 2 for aluminum and 3 for oxygen).

$\mathrm{MX}$ is the mixture number (6).

VF is the density multiplier (the density multiplier of the $\mathrm{B}_{4} \mathrm{C}$ is the density of the material times the weight percent, divided by the theoretical density of $\mathrm{B}_{4} \mathrm{C}$ $((3.7 \times 0.01395) / 2.52)$ or 0.02048 ; the density multiplier of the $\mathrm{Al}_{2} \mathrm{O}_{3}$ is 1.0 0.01395 or 0.98605 (the theoretical density of $\mathrm{B}_{4} \mathrm{C}$ was obtained from Table M8.2.1).

The input data for the burnable poison are given below:

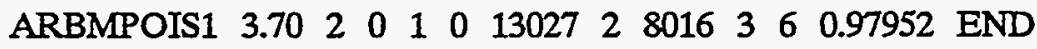
B4C 6 2.048-2 END

NUREG/CR-0200,

Vol. 3, Rev. 4

M7.5.26 
The input can be specified using the $\mathrm{DEN}=$ parameter as shown below:

\section{ARBMPOIS1 3.702001013027280163360 .98605 END}

$\mathrm{B} 4 \mathrm{C} 6 \mathrm{DEN}=3.70 .01395 \mathrm{END}$

The density of the $\mathrm{Al}_{2} \mathrm{O}_{3}$ can be calculated. The fraction of $\mathrm{B}_{4} \mathrm{C}$ in the mixture is $((3.7 \times 0.01395) / 2.52)=0.02048$. The fraction of $\mathrm{Al}_{2} \mathrm{O}_{3}$ in the mixture is $1.0-0.02048=0.979518$.

$$
\begin{aligned}
& \mathrm{P}_{\mathrm{Al}_{2} \mathrm{O}_{3}} * \text { Density } \\
& \text { Density } \\
& \text { Dens } \mathrm{Al}_{2} \mathrm{O}_{3} \\
& \text { Input data using the density of } \mathrm{Al}_{2} \mathrm{O}_{3} \text { are given below: }
\end{aligned}
$$

\section{ARBMPOIS1 $3.7246720010013027228016 \quad 3 \quad 6 \quad 0.97952$ END B4C 6 2.048-2 END}

EXAMPLE 2. Borated water from $\mathrm{H}_{3} \mathrm{BO}_{3}$ and water.

Create a mixture 2 that is borated water at 4350 parts per million by weight, resulting from the addition of boric acid, $\mathrm{H}_{3} \mathrm{BO}_{3}$ to water. The density of the borated water is $1.0078 \mathrm{~g} / \mathrm{cm}^{3}$ (see Ref. 9). The solution temperature is $15^{\circ} \mathrm{C}$ and the boron is natural boron.

An easy way to describe this mixture is to use a combination of an arbitrary material to describe the boric acid, and a basic composition to describe the water.

\section{STEP 1. INPUT DATA TO DESCRIBE THE ARBITRARY MATERIAL}

The generic input data for the boric acid arbitrary material are given below. The actual input data are derived in steps 2 through 5.

\section{SC ROTH NEL IVIS ICP IRS (NCZA ATPM $\left._{i}\right)$ MX VF TEMP END}

where

SC is the standard composition component name.

ROTH is the theoretical density of the compound (enter 0.025066 and see.step 2 auxiliary calculations for the arbitrary material input data below).

NEL is the number of elements in the material (enter 3, for the $\mathrm{H}, \mathrm{B}$, and $\mathrm{O}$ ).

IVIS is the multiple-isotope indicator (enter 1 because boron is a multiple-isotope nuclide; see Table M8.4.1).

ICP is the compound indicator (enter 1 because the boric acid is defined by a chemical formula, $\mathrm{H} 3 \mathrm{BO} 3$ ).

IRS is the resonance indicator (enter 0 because none of the nuclides have resonance data; see Table M8.2.1). 
NCZA is the isotope ID number obtained from Table M8.2.1 (enter 5000 for boron, 1001 for hydrogen, 8016 for oxygen). Note: Boron is a multiple-isotope nuclide, so the ID number is obtained from Table M8.4.1.

ATPM is the number of atoms of this element per molecule of arbitrary material (enter 1 for boron, 3 for hydrogen, and 3 for oxygen).

Repeat the NCZA ATPM sequence until the NEL elements in the arbitrary material have been specified.

$\mathrm{MX}$ is the mixture number (enter 2).

VF is the density multiplier (enter 1 since the density of the $\mathrm{H} 3 \mathrm{BO} 3$ in the borated water is used as the theoretical density).

TEMP is the temperature in Kelvin (enter 288.15).

The input data for this arbitrary material are given below.

$\begin{array}{lllllllllllllll}A R B M H 3 B O 3 & 0.025066 & 3 & 1 & 1 & 0 & 5000 & 1 & 1001 & 3 & 8016 & 3 & 2 & 1 & 288.15 \\ \mathrm{END}\end{array}$

STEP 2. AUXILIARY CALCULATIONS FOR THE ARBITRARY MATERIAL INPUT DATA

In calculating the molecular weights, use the atomic weights from SCALE, which are available in the output from COMPOZ. COMPOZ is used to create the Standard Composition Library for SCAIE. The atomic weights used in SCALE may differ from some periodic tables. The SCALE atomic weights used in this problem are listed below:

$\begin{array}{cc}\mathrm{H} & 1.0078 \\ \mathrm{O} & 15.9954 \\ { }^{10} \mathrm{~B} & 10.0129 \\ { }^{11} \mathrm{~B} & 11.0096\end{array}$

The natural boron abundance obtained from Table M8.4.1 in Sect. M8.4 is given in weight percent:

$$
\begin{array}{ll}
{ }^{10} \mathrm{~B} & 18.30219 \\
{ }^{11} \mathrm{~B} & 81.69782
\end{array}
$$

The molecular weight of natural boron is given by:

$$
\begin{aligned}
\text { DEN nat B/AWT nat } \mathrm{B} & =\mathrm{DEN}^{10} \mathrm{~B} / \mathrm{AWT}{ }^{10} \mathrm{~B}+\mathrm{DEN}^{11} \mathrm{~B} / \mathrm{AWT}{ }^{11} \mathrm{~B} \\
\text { DEN }{ }^{10} \mathrm{~B} & =\mathrm{WTF}^{10} \mathrm{~B} \times \mathrm{DEN} \text { nat } \mathrm{B} \\
\text { DEN }{ }^{11} \mathrm{~B} & =\mathrm{WTF}^{11} \mathrm{~B} \times \mathrm{DEN} \text { nat } \mathrm{B}
\end{aligned}
$$

where

DEN is density in $\mathrm{g} / \mathrm{cm}^{3}$,

NUREG/CR-0200, 
AWT is the atomic weight in $\mathrm{g} / \mathrm{mol}$,

WTF is the weight fraction of the isotope.

Substituting,

$\mathrm{DEN}$ nat $\mathrm{B} / \mathrm{AWT}$ nat $\mathrm{B}=\mathrm{DEN}$ nat $\mathrm{B} \times\left(\left(\mathrm{WTF}^{10} \mathrm{~B} / \mathrm{AWT}{ }^{10} \mathrm{~B}\right)+\left(\mathrm{WTF}^{11} \mathrm{~B} / \mathrm{AWT}{ }^{11} \mathrm{~B}\right)\right)$

Solving for AWT nat $B$ yields:

AWT nat $B=1 /\left(\left(W_{T F}{ }^{10} B / A W T{ }^{10} B\right)+\left(W T F{ }^{11} B / A W T{ }^{11} B\right)\right)$

The atomic weight of natural boron is thus

$1.0 /\left(\left(0.1830219 \mathrm{~g}{ }^{10} \mathrm{~B} / \mathrm{g}\right.\right.$ nat $\left.\mathrm{B} / 10.0129 \mathrm{~g}{ }^{10} \mathrm{~B} / \mathrm{mol}^{10} \mathrm{~B}\right)+$

$\left(0.8169782 \mathrm{~g}{ }^{11} \mathrm{~B} / \mathrm{g}\right.$ nat $\left.\left.\mathrm{B} / 11.0096 \mathrm{~g} / \mathrm{mol}^{11} \mathrm{~B}\right)\right)=10.81261 \mathrm{~g}$ nat $\mathrm{B} / \mathrm{mol}$ nat $\mathrm{B}$

The molecular weight of the boric acid, $\mathrm{H}_{3} \mathrm{BO}_{3}$ is given by:

$$
(3 \times 1.0078)+10.81261+(3 \times 15.9954)=61.8222
$$

Calculate the grams of boric acid in a gram of solution:

Boric acid, $\mathrm{H}_{3} \mathrm{BO}_{3}$ is $61.8222 \mathrm{~g} / \mathrm{mol}$

Natural boron is $10.81261 \mathrm{~g} / \mathrm{mol}$

$\left(4350 \times 10^{-6} \mathrm{~g} \mathrm{~B} / \mathrm{g} \mathrm{soln}\right) \times(1 \mathrm{~mol} / 10.81261 \mathrm{~g} \mathrm{~B}) \times(61.8222 \mathrm{~g}$ boric acid $/ \mathrm{mol})=$ $0.024872 \mathrm{~g}$ boric acid/g soln (2.4872 wt \%)

Interpolating from ref. 9, the specific gravity of the boric acid solution at 2.4872 weight percent is 1.0087 . This value is based on water at $15^{\circ} \mathrm{C}$. The density of pure air free water at $15^{\circ} \mathrm{C}$ is $0.99913 \mathrm{~g} / \mathrm{cm}^{3}$. Therefore, the density of the boric acid solution is $1.0087 \times 0.99913 \mathrm{~g} / \mathrm{cm}^{3}=1.0078 \mathrm{~g}$ soln $/ \mathrm{cm}^{3}$.

Calculate ROTH, the theoretical density of the boric acid.

$1.0078 \mathrm{~g} \mathrm{soln} / \mathrm{cm}^{3} \times 0.024872 \mathrm{~g}$ boric acid $/ \mathrm{g}$ soln $=0.025066 \mathrm{~g}$ boric acid $/ \mathrm{cm}^{3}$

Calculate TEMP, the temperature in Kelvin:

$273.15+15=288.15$

\section{STEP 3. DESCRIBE THE BASIC STANDARD COMPOSITION INPUT DATA}

The generic input data for the basic standard composition are given below:

SC MX VF TEMP END

where

SC is the standard composition component name from Table M8.2.1 (enter H2O). 
$\mathrm{MX}$ is the mixture number (enter 2).

VF is the density multiplier (enter the volume fraction, 0.984507 , and see step 4 auxiliary calculations for the basic standard composition input data below).

TEMP is the temperature in Kelvin (enter 288.15).

The input data for this standard composition are given below.

$\mathrm{H} 2 \mathrm{O} \quad 2 \quad 0.984507288 .15$ END

\title{
STEP 4. AUXILIARY CALCULATIONS FOR THE BASIC STANDARD
} COMPOSITION INPUT DATA

Calculate the volume fraction of the water in the solution. Each gram of solution contains $0.024872 \mathrm{~g}$ of boric acid, so there is $0.975128 \mathrm{~g}$ of water in each gram of solution. The volume fraction of water is then given by:

$\left(1.0078 \mathrm{~g} \mathrm{soln} / \mathrm{cm}^{3} \times 0.975128 \mathrm{~g}\right.$ water $/ \mathrm{g}$ soln $) / 0.9982 \mathrm{~g}$ water $/ \mathrm{cm}^{3}=0.984506$

The 0.9982 is the theoretical density of water from Table M8.2.1.

Calculate TEMP, the temperature in Kelvin:

$$
273.15+15=288.15
$$

STEP 5. CREATE THE MIXTURE FOR BORATED WATER

\author{
ARBMH3BO3 0.025066311105000111001380163221288 .15 END \\ $\mathrm{H} 2 \mathrm{O} \quad 20.984506288 .15$ END
}

\section{M75.5.8 Combinations of Basic and Solution Standard Compositions to Define a Mixture}

The solution specification is the easiest way of specifying the solutions listed in Table M8.3.1. A combination of solution and basic standard compositions can be used to describe a mixture that contains more than just a solution as demonstrated in the following example.

EXAMPLE 1. Uranyl nitrate solution containing gadolinium.

Create a $4.306 \%$ enriched uranyl nitrate solution containing $0.184 \mathrm{~g}$ gadolinium per liter. The uranium in the nitrate is $95.65 \%{ }^{238} \mathrm{U}, 0.022 \%{ }^{236} \mathrm{U}, 4.306 \%{ }^{235} \mathrm{U}$, and $0.022 \%{ }^{234} \mathrm{U}$. The uranium concentration is $195.8 \mathrm{~g} \mathrm{U} / \mathrm{L}$ and the specific gravity of the uranyl nitrate is 1.254. There is no excess acid in the solution. The presence of the gadolinium is assumed to produce no significant change in the solution density. The solution is defined to be mixture 3 .

The input data for a solution are entered as follows:

SC MX FD AML SPG=SPGR VF TEMP (IZA WTP $\left._{i}\right)$ END

where

$\mathrm{SC} \quad$ is the standard composition component name from Table M8.3.1 (enter SOLNUO2(NO3)2).

NUREG/CR-0200,

Vol. 3, Rev. 4

M7.5.30 
$\mathrm{MX}$ is the mixture number (enter 3).

FD is the fuel density in grams of $\mathrm{U}$ or Pu per liter of solution (enter 195.8).

AMI is the acid molarity of the solution (enter 0 because there is no excess acid in the solution).

SPGR is the specific gravity of the solution (enter SPGR=1.254).

VF is the density multiplier, the volume fraction of the solution that is uranyl nitrate (enter 1.0).

TEMP is the temperature in Kelvin (enter 293).

IZA is the isotope ID number from Table M8.31 (enter 92238 for ${ }^{238} \mathrm{U}, 92236$ for ${ }^{236} \mathrm{U}, 92235$ for ${ }^{235} \mathrm{U}$, and 92234 for ${ }^{234} \mathrm{U}$ ).

WTP is the weight percent of the isotope in the material (enter 95.65 for ${ }^{238} \mathrm{U}, 0.022$ for ${ }^{236} \mathrm{U}, 4.306$ for ${ }^{235} \mathrm{U}$, and 0.022 for ${ }^{234} \mathrm{U}$ ).

Repeat the sequence IZA WTP until the sum of the WTPs sum to 100 .

The input data for the uranyl nitrate solution are given as

SOLNUO2(NO3)2 $3 \quad 195.80 \mathrm{SPG}=1.2541 .02939223895 .65922360 .022$

922354.306922340 .022 END

The input data for a basic standard composition are entered as follows:

SC MX VF TEMP END

where

SC is the standard composition component name from Table M8.2.1 (enter GD for gadolinium).

$\mathrm{MX}$ is the mixture number (enter 3).

VF is the density multiplier or the ratio of actual to theoretical density. (From Table M8.2.1, the theoretical density of gadolinium is 1.0. The density of the gadolinium is $0.184 \mathrm{~g} / \mathrm{L}$ or $0.000184 \mathrm{~g} / \mathrm{cm}^{3}$. Therefore, enter $0.000184 / 1.0=$ 0.000184.)

TEMP is the temperature in Kelvin (293).

The input data for basic standard composition are entered as follows:

GD 30.000184293 END

The input data for the mixture are given as: 
SOLNUO2(NO3)2 $3 \quad 195.8 \quad 0 \quad$ SPG=1.254 1.02939223895 .65

922360.022922354 .306922340 .022

GD $\quad 30.000184293$ END

\section{M7.5.5.9 Combinations of Arbitrary Material and Solution to Define a Mixture}

The solution specification is the easiest way of specifying the solutions listed in Table M8.3.1. A solution specification and an arbitrary material specification can be used to describe a mixture that contains more than just a solution as demonstrated in the following example.

EXAMPLE 1. Uranyl nitrate solution with gadolinium nitrate.

Create a $4.306 \%$ enriched uranyl nitrate solution containing gadolinium in the form of $\mathrm{Gd}\left(\mathrm{NO}_{3}\right)_{3}$. The uranium in the nitrate is $95.65 \%{ }^{238} \mathrm{U}, 0.022 \%{ }^{236} \mathrm{U}, 4.306 \%{ }^{235} \mathrm{U}$, and $0.022 \%{ }^{234} \mathrm{U}$. The uranium concentration is $195.8 \mathrm{~g} \mathrm{U} / \mathrm{L}$ and the specific gravity of the uranyl nitrate is 1.254 . There is no excess acid in the solution. The concentration of the gadolinium is $0.184 \mathrm{~g} / \mathrm{L}$. The solution is defined to be mixture 3 .

The input data for a solution are entered as follows:

SC MX FD AML SPG=SPGR VF TEMP $\left(\right.$ IZA $_{i}$ WTP $\left._{\mathrm{i}}\right)$ END

where

$\mathrm{SC}$ is the standard composition component name from Table M8.3.1 (SOLNUO2(NO3)2).

$\mathrm{MX}$ is the mixture number (3).

FD is the fuel density in grams of $\mathrm{U}$ or Pu per liter of solution (195.8).

AML is the acid molarity of the solution ( 0 because there is no excess acid in the solution).

SPGR is the specific gravity of the solution ( $\mathrm{SPG}=1.254$ ).

VF is the volume fraction of the mixture that is uranyl nitrate $(0.99985=1.254$ / $(1.254+0.000184))$.

TEMP is the temperature in Kelvin (293).

IZA is the isotope ID number from Table M8.2.1 (enter 92238 for ${ }^{238} \mathrm{U}, 92236$ for ${ }^{236} \mathrm{U}, 92235$ for ${ }^{235} \mathrm{U}$, and 92234 for ${ }^{234} \mathrm{U}$ ).

WTP is the weight percent of the isotope in the material (enter 95.65 for ${ }^{238} \mathrm{U}, 0.022$ for ${ }^{236} \mathrm{U}, 4.306$ for ${ }^{235} \mathrm{U}$, and 0.022 for ${ }^{234} \mathrm{U}$ ).

Repeat the sequence IZA WTP until the sum of the WTPs sum to 100.

The input data for the uranyl nitrate solution are given as

NUREG/CR-0200,

Vol. 3, Rev. 4

M7.5.32 
SOLNUO2(NO3)2 $3195.80 \mathrm{SPG}=1.2540 .99852939223895 .65922360 .02292235$ 4.306922340 .022 END

The generic input specification for an arbitrary material is given as:

SC ROTH NEL IVIS ICP IRS (NCZA ATPM $\left._{i}\right)$ MX VF TEMP $\left(\right.$ IZA $_{j}$ WTP $\left._{j}\right)$ END where

SC is the standard composition component name. The first four characters MUST be ARBM (enter ARBMGD(NO3)3).

ROTH is the theoretical density of the compound. (In this case, the density of gadolinium nitrate in the solution will be used. The calculated density is 0.0004016 . See the density calculation given below.)

NEL is the number of elements in the material. (Enter 3. This material contains gadolinium, nitrogen, and oxygen.)

IVIS is the multiple-isotope indicator (enter 0 because none are multiple-isotope nuclides).

ICP is the compound indicator [enter 1 because the gadolinium nitrate is defined by a chemical formula, $\left.\mathrm{Gd}\left(\mathrm{NO}_{3}\right)_{3}\right]$.

IRS is the resonance indicator (enter 1 because gadolinium is a resonance nuclide; see Table M.8.2.1).

NCZA is the isotope ID number from Table M8.2.1. (Enter 64000 for gadolinium, 7014 for nitrogen, and 8016 for oxygen.)

ATPM is the number of atoms of each element in the arbitrary material (enter 1 for gadolinium, 3 for nitrogen, and 9 for oxygen).

Repeat the sequence NCZA ATPM until the NEL elements in the arbitrary material have been specified.

$\mathrm{MX}$ is the mixture number (enter 3).

VF is the density multiplier [enter 1.0 for the volume fraction because the density of the $\mathrm{Gd}\left(\mathrm{NO}_{3}\right)_{3}$ in the solution was entered as ROTH; thus the contribution to the overall mixture was already accounted for in ROTH].

TEMP is the temperature in Kelvin (293).

IZA is not entered because there are no multiple-isotope nuclides in this arbitrary material.

WTP is not entered because there are no multiple-isotope nuclides in this arbitrary material. 
The density of the gadolinium is given as $0.184 \mathrm{~g} / \mathrm{L}$. To describe the arbitrary material, the density of the $\mathrm{Gd}\left(\mathrm{NO}_{3}\right)_{3}$ is needed. The atomic weights used by $\mathrm{COMPOZ}$ to create the Standard Composition Library are:

$\begin{array}{ll}\text { Gd } & 157.25 \\ \mathrm{~N} & 14.0033 \\ \mathrm{O} & 15.9945\end{array}$

Therefore, the density of the $\mathrm{Gd}\left(\mathrm{NO}_{3}\right)_{3}=0.000184 \mathrm{~g} \mathrm{Gd} / \mathrm{cm}^{3} \times(157.25+3(14.0033+$ $3(15.9945)) / 157.25)=0.0004016 \mathrm{~g} / \mathrm{cm}^{3}$.

The input data for this arbitrary material are given below:

ARBMGD(NO3)3 .0004016300116400011701438016931293 END

The input data for the mixture of uranyl nitrate and gadolinium nitrate are given as:

SOLNUO2(NO3)2 3195.80 SPG=1.2540.99852939223895.65922360.022922354.306922340.022 END

ARBMGD(NO3)3 .00040163011640001701438016931293 END

Note: $\quad$ Since the default temperature $(293 \mathrm{~K})$ is to be used, it can be omitted from the arbitrary material standard composition. The temperature must be entered if the standard composition contains a multiple-isotope nuclide whose isotopic abundance is to be specified.

\section{M7.5.6 EXAMPLES OF UNIT CELL SPECIFICATIONS}

The data that are entered as a unit cell specification are determined by the type of calculation as discussed in Scct. M7.5.4. Examples of the unit cell data follow.

\section{M7.5.6.1 Infinitc Homogeneous Medium Unit Cell Data}

Unit cell data are not required for INFHOMMEDIUM. All the materials specified in the standard composition specification data are treated as infinite homogeneous media for the cross-section processing performed by BONAMI and/or NITAWL.

Cell-weighted cross sections are created by XSDRNPM when an analytical sequence that ends in X (CSAS1X, etc.) is executed. The unit cell used by XSDRNPM is assumed to consist entirely of the smallest defined mixture number. All other materials are assumed to have a number density of 1.0E-20. The most plausible reason for using XSDRNPM for an infinite homogeneous medium is to obtain the eigenvalue for an infinite mass of material. Since XSDRNPM calculates the eigenvalue for the mixture in the cell, that mixture should contain fissile material. If the smallest mixture number in the standard composition data does not contain fissile material, the mixture for the unit cell should be specified. If the unit cell does not contain fissile material, XSDRNPM will execute and calculate the eigenvalue using the 1.0E-20 number densities for the fuel.

Warning: If unit cell data are to be entered as in example 3 below, the word CELLMIX must be spelled correctly. If it is misspelled, the code will not give an error message and will attempt to use the smallest mixture number. The input data will get out of phase for CSAS and SAS sequences that expect to read data after the unit cell specification. For example, CSAS25 expects to read KENO data after the unit

NUREG/CR-0200,

Vol. 3, Rev. 4

M7.5.34 
cell specification. If CELLMTX is misspelled, the code assumes that it is reading the KENO title card and the data reading gets out of phase.

EXAMPLE 1. A single mixture.

Consider a cylindrical configuration of $10 \%$ enriched $\mathrm{UO}_{2}$ having a radius of $35 \mathrm{~cm}$ and a height of $20 \mathrm{~cm}$.

Because this problem defines only one mixture, unit cell data do not need to be specified. XSDRNPM will calculate the eigenvalue of an infinite mass of $10 \%$ enriched $\mathrm{UO}_{2}$.

EXAMPLE 2. Two mixtures.

Consider a cylindrical steel container filled with $10 \%$ enriched $\mathrm{UO}_{2}$. The inside radius is $35 \mathrm{~cm}$ and inside height is $20 \mathrm{~cm}$. The wall thickness of the steel is $0.32 \mathrm{~cm}$. The $\mathrm{UO}_{2}$ is defined as mixture 1 , and the steel is defined as mixture 2 .

Because this problem defines the fuel to be the smallest mixture number, unit cell data need not be specified. XSDRNPM will calculate the eigenvalue of an infinite mass of $10 \%$ enriched $\mathrm{UO}_{2}$.

EXAMPLE 3. Two mixtures and specify the cell.

Consider a cylindrical steel container filled with $10 \%$ enriched $\mathrm{UO}_{2}$. The inside radius is $35 \mathrm{~cm}$, and inside height is $20 \mathrm{~cm}$. The wall thickness of the steel is $0.32 \mathrm{~cm}$. The steel is defined as mixture 1 , and the $\mathrm{UO}_{2}$ is defined as mixture 2 .

If this problem is run using an analytical sequence that does not perform a cell-weighting calculation, unit cell data need not be specified.

If this problem is run using an analytical sequence that performs a cell-weighting calculation, unit cell data should be specified so XSDRNPM can calculate the eigenvalue, fluxes, and cell-weighted cross sections for the $10 \%$ enriched $\mathrm{UO}_{2}$. The necessary cell data are CELLMIX 2.

\section{M7.5.6.2 Lattice Cell Unit Cell Data}

Unit cell data are always required for LATTICECELL calculations. Only one unit cell can be defined in a problem. This unit cell is always one-dimensional; infinitely long cylinders, spheres, slabs. The configuration of the unit cell is determined by the specified "type of lattice." Both "regular" and "annular" cells are allowed. The "regular" cells allow spherical, cylindrical, or symmetric siab fuel regions that are constrained to a central fuel region surrounded by an optional gap, an optional clad, and an external moderator material. The "annular" cells for spherical, cylindrical, or asymmetric slab configurations are constrained to a central (second) moderator material surrounded by a fuel region having an optional gap and optional clad on both sides of the fuel with an external (first) moderator material.

"Regular" cells are specified using SQUAREPITCH, TRIANGPITCH, SPHSQUAREP, SPHTRIANGP, or SYMMSLABCELL.

"Annular" cells are specified using ASQUAREPITCH, ASQP, ATRIANGPITCH, ATRP, ASPHSQUAREP, ASSP, ASPHTRIANGP, ASTP, or ASYMSLABCELL.

The unit cell data in a LATTICECELL problem are used (1) to provide the dimensions and shape of the lump and the moderator material for resonance cross-section processing, (2) to provide 
lattice corrections for the cross-section processing, and (3) to provide information used in creating cell-weighted cross sections when XSDRNPM is executed for cross-section processing.

BONAMI and/or NITAWL perform resonance cross-section processing for the materials used in the unit cell, utilizing the shape and dimensions defined in the cell. A Dancoff correction is applied to account for lattice effects. Materials that are not used in the unit cell are treated as infinite homogeneous media. If cell-weighted cross sections are to be created by XSDRNPM, an analytical sequence ending with an X must be used. XSDRNPM calculates the eigenvalue of the cell assuming a white boundary condition. The resultant fluxes are used to weight the cross sections of the materials in the cell and to create a homogenized cell-weighted cross section having the characteristics of the heterogeneous cell configuration. This cell-weighted cross section is always labeled mixture 500 . Whenever XSDRNPM is executed for cross-section processing, mixtures used in the cell description cannot be used in the heterogeneous geometry data for other codes. If they are needed in the other code, additional mixtures with identical specifications must be defined in the standard composition data.

The general input data for a lattice cell unit cell follow:

\section{CTP PITCH FUELOD MFUEL MMOD MMOD2 TKMOD2 CLADOD MCLAD CLADID MGAP END}

where

CTP is the type of lattice. This defines both the shape of the fuel lump and the spacing configuration of the lattice. The lattice cell configurations are listed below.

(1) "Regular cells"

$\begin{array}{ll}\text { SQUAREPITCH } & \text { - cylindrical fuel in a square-pitched array } \\ \text { TRIANGPITCH } & \text { - cylindrical fuel in a triangular-pitched array } \\ \text { SPHSQUAREP } & \text { - spherical fuel in a square-pitched array } \\ \text { SPHTRIANGP } & \text { - spherical fuel in a square-triangular array } \\ \text { SYMMSLABCELL } & \text { - fuel slabs identically moderated on each side }\end{array}$

(2) "Annular cells"

$\begin{array}{ll}\text { ASQUAREPITCH } & \text { - annular cylinders in a square-pitched array } \\ \text { ASQP } & \text { - annular cylinders in a square-pitched array } \\ \text { ATRIANGPITCH } & \text { - annular cylinders in a triangular-pitched array } \\ \text { ATRP } & \text { - annular cylinders in a triangular-pitched array } \\ \text { ASPHSQUAREP } & \text { - annular spherical fuel in a square-pitched array } \\ \text { ASSP } & \text { - annular spherical fuel in a square-pitched array } \\ \text { ASPHTRIANGP } & \text { - annular spherical fuel in a triangular-pitched array } \\ \text { ASTP } & \text { - annular spherical fuel in a triangular-pitched array } \\ \text { ASYMSLABCELL } & \text { - fuel slabs moderated differently on each side }\end{array}$

PITCH is the center-to-center spacing of the fuel lumps (in centimeters).

FUELOD is the outside dimension (diameter or thickness) of the fuel in centimeters.

MFUEL is the mixture number of the fuel.

MMOD is the mixture number of the moderator or first moderator.

NUREG/CR-0200,

Vol. 3, Rev. 4

M7.5.36 
MMOD2 is the mixture number of the second moderator. ENTER ONLY FOR ANNULAR CELLS.

TKMOD2 is the dimension (diameter or thickness) of the second moderator in centimeters. ENTER ONLY FOR ANNULAR CELLS.

CLADOD is the outside dimension of the clad in centimeters. OMIT IF NO CLAD.

MCLAD is the mixture number of the clad. OMIT IF NO CLAD.

CLADID is the outside dimension of the gap or the inside dimension of of the clad in centimeters. OMIT IF NO GAP.

MGAP is the mixture number. OMIT IF NO GAP.

Examples of "regular" LATTICECELL unit cells are given in Examples 1-5, and examples of "annular" LATTICECELL unit cells are given in Examples 6-10 below.

EXAMPLE 1. SQUAREPITCH (infinitely long cylindrical pins in a square-pitched array). Consider a large array of $\mathrm{UO}_{2}$ fuel pins having a fuel O.D. of $0.79 \mathrm{~cm}$, a $0.015-\mathrm{cm}$ gap, and a $0.06-\mathrm{cm}$-thick aluminum clad. The array is a square-pitched array with a center-to-center spacing of $1.60 \mathrm{~cm}$ and is completely flooded with water. In the standard composition data, $\mathrm{UO}_{2}$ is defined to be mixture 1 , the aluminum clad is defined to be mixture 2 , and the water moderator is defined to be mixture 3 .

The input data for this lattice cell description are entered as follows:

CTP PITCH FUELOD MFUEL MMOD CLADOD MCLAD CLADID MGAP END

where

CTP is the type of lattice (SQUAREPITCH)

$\mathrm{PITCH}$ is the center-to-center spacing in $\mathrm{cm}(1.60)$

FUELOD is the outside diameter of the fuel in $\mathrm{cm}(0.79)$

MFUEL is the fuel mixture number (1)

MMOD is the moderator mixture number (3)

CLADOD is the outside diameter of the clad in $\mathrm{cm}(0.79+2 * 0.015+2 * 0.06=$ 0.94)

MCLAD is the clad mixture number (2)

CLADID is the inside diameter of the clad or the outside diameter of the gap in $\mathrm{cm}(0.79+2 * 0.015=0.82)$

MGAP is the gap mixture number (enter 0 for a void)

M7.5.37

NUREG/CR-0200, Vol. 3, Rev. 4 
EXAMPLE 2. TRIANGPITCH (infinitely long cylinders in a triangular-pitched array).

Consider an array of $\mathrm{UO}_{2}$ pins with a diameter of $0.635 \mathrm{~cm}$. The outside diameter of the clad is $0.78 \mathrm{~cm}$. There is no gap between the fuel and clad. The array is a triangular-pitched array with a center-to-center spacing of $5.0 \mathrm{~cm}$ and is flooded with water. In the standard composition data, the $\mathrm{UO}_{2}$ is defined to be mixture 1 , the aluminum is defined to be mixture 2 , and the water moderator is defined to be mixture 3.

The input data for this lattice cell description are entered as follows:

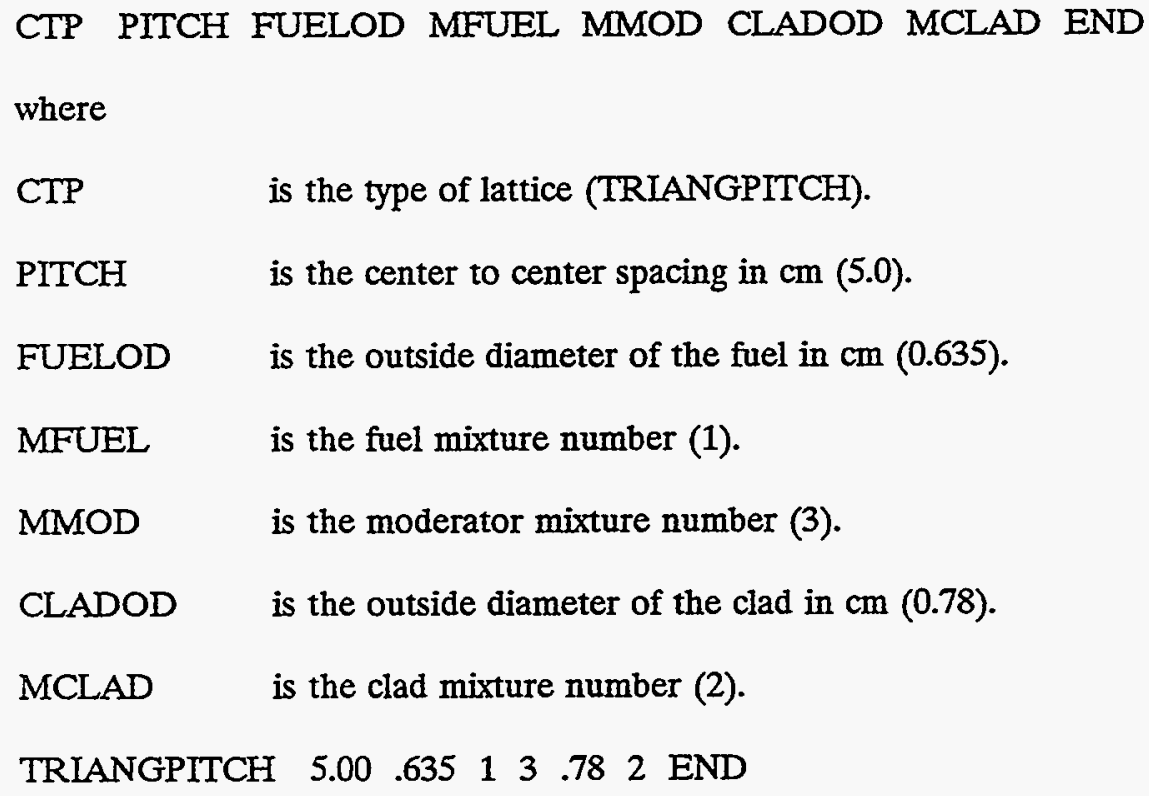

EXAMPLE 3. SPHSQUAREP (spheres in a square-pitched array).

Consider a large array of $\mathrm{U}_{3} \mathrm{O}_{8}$ spheres having a fuel O.D. of $18.6 \mathrm{~cm}$, with an aluminum clad that is $0.18 \mathrm{~cm}$ thick. The array is a triangular-pitched array with a center-to-center yspacing of $19.0 \mathrm{~cm}$ and is unmoderated. In the standard composition data, the aluminum is defined to be mixture 1 and the $U_{3} \mathrm{O}_{8}$ is defined to be mixture 2 . There is no moderator material, so 0 will be used to represent a void.

The input data for this lattice cell description are entered as follows:

$$
\text { CTP PITCH FUELOD MFUEL MMOD CLADOD MCLAD END }
$$

where

CTP is the type of lattice (SPHSQUAREP).

PITCH is the center-to-center spacing in $\mathrm{cm}$ (19.0).

FUELOD is the outside diameter of the fuel in $\mathrm{cm}$ (18.6).

NUREG/CR-0200, 
MFUEL is the fuel mixture number (2).

MMOD is the moderator mixture number (0).

CLADOD is the outside diameter of the clad in $\mathrm{cm}(18.6+2 * 0.18=18.96)$.

MCLAD is the clad mixture number (1).

SPHSQUAREP $\quad \begin{array}{lllllll}19.0 & 18.6 & 2 & 0 & 18.96 & 1 & \text { END }\end{array}$

EXAMPLE 4. SPHTRIANGP (spheres in a triangular-pitched array).

Consider a large array of $\mathrm{U}_{3} \mathrm{O}_{8}$ spheres having a fuel O.D. of $18.6 \mathrm{~cm}$, with an aluminum clad that is $0.18 \mathrm{~cm}$ thick. The array is a triangular-pitched array with a center-to-center spacing of $19.0 \mathrm{~cm}$ and is flooded with water. In the standard composition data, the aluminum is defined to be mixture 1 , the $U_{3} \mathrm{O}_{8}$ is defined to be mixture 2, and the water moderator is defined to be mixture 3 .

The input data for this lattice cell description are entered as follows:

CTP PITCH FUELOD MFUEL MMOD CLADOD MCLAD END

where

CTP is the type of lattice (SPHTRIANGP).

PITCH is the center-to-center spacing in $\mathrm{cm} \mathrm{(19.0).}$

FUELOD is the outside diameter of the fuel in $\mathrm{cm}(18.6)$.

MFUEL is the fuel mixture number (2).

MMOD is the moderator mixture number (3).

CLADOD is the outside diameter of the clad in $\mathrm{cm}(18.6+2 * 0.18=18.96)$.

MCLAD is the clad mixture number (1).

$\begin{array}{llllllll}\text { SPHTRIANGP } & 19.0 & 18.6 & 2 & 3 & 18.96 & 1 & \text { END }\end{array}$

EXAMPLE 5. SYMMSLABCELL (slabs repeated in a symmetric fashion).

Consider a system of alternating slabs of $\mathrm{U}_{3} \mathrm{O}_{8}$ and low-density water. Each $\mathrm{U}_{3} \mathrm{O}_{8}$ region is $1.27 \mathrm{~cm}$ thick, and each water region is $15.0 \mathrm{~cm}$ thick. In the standard composition data, the $\mathrm{U}_{3} \mathrm{O}_{8}$ is defined to be mixture 1 , and the low-density water is defined to be mixture 2 .

The input data for this lattice cell description are entered as follows:

CTP PITCH FUELOD MFUEL MMOD END

where

NUREG/CR-0200, 
CTP is the type of lattice (SYMMSLABCELL).

PITCH is the center-to-center spacing in $\mathrm{cm}(15.0+1.27=16.27)$.

FUELOD is the outside diameter of the fuel in $\mathrm{cm}$ (1.27).

MFUEL is the fuel mixture number (1).

MMOD is the moderator mixture number (2).

SYMMSLABCELL 16.271 .2712 END

EXAMPLE 5a. SYMMSLABCELL (slabs repeated in a symmetric fashion).

Consider a system of alternating slabs of $\mathrm{U}_{3} \mathrm{O}_{8}$ and low-density water. Each $\mathrm{U}_{3} \mathrm{O}_{8}$ region is $1.27 \mathrm{~cm}$ thick, and each water region is $15.0 \mathrm{~cm}$ thick. The $\mathrm{U}_{3} \mathrm{O}_{8}$ regions have a $0.01-\mathrm{cm}$ gap and $0.24-\mathrm{cm}$-thick aluminum clad on each face. In the standard composition data, the $\mathrm{U}_{3} \mathrm{O}_{8}$ is defined to be mixture 1 , the aluminum is defined to be mixture 2 , and the low-density water is defined to be mixture 3 .

The input data for this lattice cell description are entered as follows:

CTP PITCH FUELOD MFUEL MMOD CLADOD MCLAD CLADID MGAP END

where

CTP is the type of lattice (SYMMSLABCELL).

PITCH is the center-to-center spacing in $\mathrm{cm}(15.0+1.27+2 * 0.01+$ $2 * 0.24=16.77$ ).

FUELOD is the thickness of the fuel in $\mathrm{cm}$ (1.27).

MFUEL is the fuel mixture number (1).

MMOD is the moderator mixture number (3).

CLADOD is the outside dimension of the clad in $\mathrm{cm}(15.0+2 * 0.01+2 * 0.24=$ 15.5).

MCLAD is the clad mixture number (2).

CLADID is the inside dimension of the clad in $\mathrm{cm}(15.0+2 * 0.01=15.02)$.

MGAP is the gap mixture number ( 0 is used to represent a void).

SYMMSLABCELL $\quad 16.77 \quad 1.27 \quad 1 \quad 3 \quad 15.5 \quad 2 \quad 15.02 \quad 0 \quad$ END

NUREG/CR-0200,

Vol. 3, Rev. 4

M7.5.40 
EXAMPLE 6. ASQUAREPITCH (infinitely long annular cylindrical rods in a square-pitched array).

Consider an array of uranium metal pipes having an inside diameter of $5.0 \mathrm{~cm}$ and an outer diameter of $6.75 \mathrm{~cm}$. A gap of $0.025 \mathrm{~cm}$ and a clad of $0.25 \mathrm{~cm}$ exist on both the inner and outer surfaces of the fuel. The fuel rods are arranged in a square-pitched array. The center-to-center spacing is $8.0 \mathrm{~cm}$. The array is completely flooded with water. In the standard composition data, the uranium metal is defined to be mixture 1 , the clad is mixture 2 , the inner moderator is Plexiglas and is mixture 3 , the gap is a void, and the external moderator is water, defined to be mixture 4 .

The input data for this lattice cell description are entered as follows:

CTP PITCH FUELOD MFUEL MMOD MMOD2 TKMOD2 CLADOD MCLAD CLADID MGAP END

where

CTP is the type of lattice (SQUAREPITCH).

PITCH is the center-to-center spacing in $\mathrm{cm}(8.0)$.

FUELOD is the outside diameter of the fuel in $\mathrm{cm}(6.75)$.

MFUEL is the fuel mixture number (1).

MMOD is the moderator mixture number (4, the external moderator).

MMOD2 is the second moderator mixture number $(3$, the moderator material in the innermost region).

TKMOD2 is the diameter of the moderator in the innermost region in $\mathrm{cm}$ (5.0 $2 * 0.025-2 * 0.25=4.45)$ ).

CLADOD is the outside diameter of the clad in $\mathrm{cm}(6.75+2 * 0.025+2 * 0.25=$ 7.30).

MCLAD is the clad mixture number (2).

CLADID is the outside diameter of the gap $(6.75+2 * 0.025=6.80)$.

MGAP is the gap mixture number (enter 0 for a void).

ASQUAREPITCH $\quad 8.0 \quad 6.75 \quad 1 \quad 4 \quad 3 \quad 4.45 \quad 7.3 \quad 2 \quad 6.8 \quad 0 \quad$ END

or

$\begin{array}{lllllllllllll}\text { ASQP } & 8.0 & 6.75 & 1 & 4 & 3 & 4.45 & 7.3 & 2 & 6.8 & 0 & \mathrm{END}\end{array}$

EXAMPLE 6a. ASQUAREPITCH (infinitely long annular cylindrical rods in a square-pitched array).

Consider ayn array of uranium metal pipes having an inside diameter of $5.0 \mathrm{~cm}$ and an outer diameter of $6.75 \mathrm{~cm}$ arranged in a square-pitched array. The 
center-to-center spacing is $8.0 \mathrm{~cm}$. The array is completely flooded with water. In the standard composition data, the uranium metal is defined to be mixture 1 , and the water moderator is defined to be mixture 2 .

The input data for this lattice cell description are entered as follows:

CTP PITCH FUELOD MFUEL MMOD MMOD2 TKMOD2 END

where

CTP is the type of lattice (ASQUAREPITCH).

PITCH is the center-to-center spacing in $\mathrm{cm}(8.0)$.

FUELOD is the outside diameter of the fuel in $\mathrm{cm}$ (6.75).

MFUEL is the fuel mixture number (1).

MMOD is the moderator mixture number (2).

MMOD2 is the second moderator mixture number (2, the moderator material in the innermost region).

TKMOD2 is the diameter of the moderator in the innermost region in $\mathrm{cm}(5.0)$.

ASQUAREPITCH $\quad 8.0 \quad 6.7512220 .0 \quad$ END

or

$\begin{array}{lllllllll}A S Q P & 8.0 & 6.75 & 1 & 2 & 2 & 5.0 & \mathrm{END}\end{array}$

NOTE: This problem uses the same moderator material in the center and outside the uranium pipes. This will cause the code to print a warning message.

EXAMPLE 7. ATRIANGPITCH (infinitely long annular cylindrical rods in a triangular-pitched array).

Consider an array of uranium metal pipes having an inside diameter of $8.0 \mathrm{~cm}$ and a wall thickness of $0.75 \mathrm{~cm}$ arranged in a square-pitched array. The center-to-center spacing is $9.75 \mathrm{~cm}$. The array is completely flooded with water. A Plexiglas rod fills the center of the uranium pipe. In the standard compositions data, the uranium metal is defined to be mixture 1 , the Plexiglas is defined to be mixture 2 , and the external water moderator is mixture 3 .

The input data for this lattice cell description are entered as follows:

CTP PITCH FUELOD MFUEL MMOD MMOD2 TKMOD2 END

where

CTP is the type of lattice (ATRIANGPITCH).

PITCH is the center-to-center spacing in $\mathrm{cm}(9.75)$.

NUREG/CR-0200,

Vol. 3, Rev. 4

M7.5.42 
FUELOD is the outside diameter of the fuel in $\mathrm{cm}(8.0+2 * 0.75=9.5)$.

MFUEL is the fuel mixture number (1).

MMOD is the mixture number of the first (external) moderator (3).

MMOD2 is the mixture number of the second moderator (2, the moderator in the innermost region).

TKMOD2 is the diameter of the moderator in the innermost region in $\mathrm{cm}(8.0)$.

ATRIANGPITCH 9.759 .513328 .0 END

or

ATRP 9.759 .513228 .0 END

EXAMPLE 8. ASPHSQUAREP (spherical annuli in a square-pitched array).

Consider a large array of hollow $\mathrm{U}_{3} \mathrm{O}_{8}$ spheres having a fuel I.D. of $8.0 \mathrm{~cm}$ and O.D. of $18.6 \mathrm{~cm}$. The centers of the spheres are empty. The external moderator is water. The spheres are stacked in a square-pitched array with a center-to-center spacing of $19.0 \mathrm{~cm}$. In the standard composition data, the $\mathrm{U}_{3} \mathrm{O}_{8}$ is defined to be mixture 1 , and the water is defined to be mixture 2. The centers of the spheres are defined to be void, mixture 0 .

The input data for this lattice cell description are entered as follows:

\section{CTP PITCH FUELOD MFUEL MMOD MMOD2 TKMOD2 END}

where

CTP is the type of lattice (SPHSQUAREP).

PITCH is the center-to-center spacing in $\mathrm{cm}(19.0)$.

FUELOD is the outside diameter of the fuel in $\mathrm{cm}$ (18.6).

MFUEL is the fuel mixture number (1).

MMOD is the moderator mixture number (2).

MMOD2 is the mixture number of the second moderator $(0$, the moderator in the innermost region).

TKMOD2 is the diameter of the moderator in the innermost region in $\mathrm{cm}(8.0)$.

$\begin{array}{lllllllll}\text { ASPHSQUAREP } & 19.0 & 18.6 & 1 & 2 & 0 & 8.0 & \mathrm{END}\end{array}$

or

ASSP $\quad 19.018 .6 \quad 122008.0$ END

EXAMPLE 9. ASPHTRIANGP (spheres in a triangular-pitched array).

Consider a large array of hollow $\mathrm{U}_{3} \mathrm{O}_{8}$ spheres having a fuel I.D. of $8.0 \mathrm{~cm}$ and a fuel O.D. of $18.6 \mathrm{~cm}$. A 0.18 -cm-thick aluminum clad exists inside and outside the 
fuel. The interior of each sphere is void. The array is a triangular-pitched array with a center-to-center spacing of $19.0 \mathrm{~cm}$ and is flooded with water. In the standard composition data, the aluminum is defined to be mixture 1 , the $\mathrm{U}_{3} \mathrm{O}_{8}$ is defined to be mixture 2 , and the water moderator is defined to be mixture 3 . The void in the center of each sphere is entered as mixture 0.

The input data for this lattice cell description are entered as follows:

CTP PITCH FUELOD MFUEL MMOD MMOD2 TKMOD2 CLADOD MCLAD END

where

CTP is the type of lattice (ASPHTRIANGP).

PITCH is the center-to-center spacing in $\mathrm{cm}(19.0)$.

FUELOD is the outside diameter of the fuel in $\mathrm{cm}$ (18.6).

MFUEL is the fuel mixture number (2).

MMOD is the moderator mixture number (3).

MMOD2 is the mixture number of the second moderator $(0$, the moderator in the innermost region).

TKMOD2 is the diameter of the moderator in the innermost region in $\mathrm{cm}(8.0$ $2 * 0.18=7.64$ ).

CLADOD is the outside diameter of the clad in $\mathrm{cm}(18.6+2 * 0.18=18.96)$.

MCLAD is the clad mixture number (1).

$\begin{array}{llllllllll}\text { ASPHTRIANGP } & 19.0 & 18.6 & 2 & 3 & 0 & 7.64 & 18.96 & 1 & \text { END }\end{array}$

or

$\begin{array}{llllllllll}\text { ASTP } & 19.0 & 18.6 & 2 & 3 & 0 & 7.64 & 18.96 & 1 & \text { END }\end{array}$

EXAMPLE 10. ASYMSLABCELL (repeated slabs having different moderator conditions on the left and right boundaries).

Consider a system of slabs of $\mathrm{U}_{3} \mathrm{O}_{8}$ reflected by $8.0 \mathrm{~cm}$ of full-density water on the left face and $16.0 \mathrm{~cm}$ of low-density water on the right face. Each $\mathrm{U}_{3} \mathrm{O}_{8}$ region is $1.27 \mathrm{~cm}$ thick. In the standard composition data, the $\mathrm{U}_{3} \mathrm{O}_{8}$ is defined to be mixture 1 , the full density water is defined to be mixture 2 , and the low-density water is mixture 3.

The input data for this lattice cell description are entered as follows:

CTP PITCH FUELOD MFUEL MMOD MMOD2 TKMOD2 END

NUREG/CR-0200,

Vol. 3, Rev. 4

M7.5.44 
where

CTP is the type of lattice (ASYMSLABCELL).

PITCH is the center-to-center spacing between fuel slabs, in $\mathrm{cm}(1.27+8.0 / 2$ $+16.0 / 2=13.27$ )

FUELOD is the outside diameter of the fuel in $\mathrm{cm}$ (1.27).

MFUEL is the fuel mixture number (1).

MMOD is the moderator mixture number (2).

MMOD2 is the second moderator material (3).

TKMOD2 is the thickness of the second moderator in $\mathrm{cm}(8.0)$.

ASYMSLABCELL 13.271 .271238 .0 END

EXAMPLE 10a.

ASYMSLABCELL (repeated slabs having different moderator conditions on the left and right boundaries). Consider a system of slabs of $\mathrm{U}_{3} \mathrm{O}_{8}$ reflected by $8.0 \mathrm{~cm}$ of full-density water on the left face and $16.0 \mathrm{~cm}$ of low-density water on the right face. Each $\mathrm{U}_{3} \mathrm{O}_{8}$ region is $1.27 \mathrm{~cm}$ thick and has a $0.01-\mathrm{cm}$ gap and 0.24-cm-thick aluminum clad on each face. In the standard composition data, the $U_{3} \mathrm{O}_{8}$ is defined to be mixture 1 , the full-density water is defined to be mixture 2 , the low-density water is mixture 3 , and the aluminum is mixture 4 .

The input data for this lattice cell description are entered as follows:

CTP PITCH FUELOD MFUEL MMOD MMOD2 TKMOD2 CLADOD MCLAD CLADID MGAP END

where

CTP is the type of lattice (ASYMSLABCELL).

PITCH is the distance from the center of the first moderator to the center of the second moderator in $\mathrm{cm}(1.27+2 * 0.01+2 * 0.24$ $+8.0 / 2+16.0 / 2=13.77)$.

FUELOD is the fuel thickness in $\mathrm{cm}$ (1.27).

MFUEL is the fuel mixture number (1).

MMOD is the first moderator mixture number (2).

MMOD2 is the second moderator material (3).

TKMOD2 is the thickness of the second moderator in $\mathrm{cm}(8.0)$.

M7.5.45

NUREG/CR-0200, Vol. 3, Rev. 4 
CLADOD is the outside dimension of the clad in $\mathrm{cm}(1.27+2 * 0.01+$ $2 * 0.24=1.77$ ).

MCLAD is the clad mixture number (4).

CLADID is the outside dimension of the gap in $\mathrm{cm}(1.27+2 * 0.01=$ 1.29).

MGAP is the gap mixture number (0).

$\begin{array}{llllllllllll}\text { ASYMSLABCELL } & 13.77 & 1.27 & 1 & 2 & 3 & 8.0 & 1.77 & 4 & 1.29 & 0 & \text { END }\end{array}$

\section{M7.5.6.3 Multiregion Unit Cell Data}

Unit cell data are always required for MULTIREGION calculations. Only one unit cell can be defined in a problem. The LATTICECELL description is rigorously constrained as to the placement of fuel, gap, clad, and moderator. MULTIREGION allows complete freedom in the placement of the materials but is constrained by shape (i.e., only concentric regions of the same shape are allowed). With the exception of the external cell boundary, MULTIREGION is capable of describing all of the configurations available in LATTICECELL. However, it does not account for lattice effects, so it is best used for problems where lattice effects are not important.

The materials specified in the unit cell are treated according to the specified shape, zone dimensions, and the moderator conditions for each zone. The resonance cross-section processing ignores lattice geometry effects.

The general input data for a multiregion unit cell follow:

\section{CS BR BL ORGN DY DZ END (MXZ RZ XMOD) END ZONE}

where

CS is the geometry shape. All regions in a multiregion cell have the same shape and are one-dimensional. There are no restrictions on the placement of materials. The available geometric shapes are the following:

SLAB all regions are slabs

CYLINDRICAL all regions are infinitely long concentric cylinders

SPHERICAI all regions are concentric spheres

BUCKLEDSLAB all regions are slabs having the same finite height.

BUCKLEDCYL all regions are concentric cylinders having the same finite height.

BR is the right (outside) boundary condition. This is required data for a BUCKLEDSLAB or BUCKLEDCYL and is optional for other geometries. The default value is VACUUM. The available choices are

VACUUM Nothing returns at the boundary

NUREG/CR-0200,

Vol. 3, Rev. 4

M7.5.46 
REFLECTED Provides mirror image return at the boundary. DO NOT USE FOR CYLINDRICAL OR SPHERICAL

PERIODIC Provides periodic reflection at the boundary. DO NOT USE FOR CYLINDRICAL OR SPHERICAL

WHITE Provides isotropic return at the boundary.

BL is the left (inside) boundary condition. These data are required for a BUCKLEDSLAB or BUCKLEDCYL and are optional for other geometries. The default value is REFLECTED. The available choices are the following:

VACUUM Nothing returns at the boundary

REFLECTED Provides mirror image return at the boundary. RECOMMENDED FOR CYLINDRICAL OR SPHERICAI

PERIODIC Provides periodic reflection at the boundary. DO NOT USE FOR CYLINDRICAL OR SPHERICAL

WHITE Provides isotropic return at the boundary.

ORGN is the location of the left boundary of a slab relative to the axis that is perpendicular to the slab. The default is 0.0. DO NOT CHANGE FOR SPHERICAL OR CYLINDRICAL GEOMETRY.

DY is the buckling height in centimeters. ENTER ONLY FOR BUCKLEDSLAB OR BUCKLEDCYL.

$\mathrm{DZ}$ is the buckling depth in centimeters. ENTER ONLY FOR BUCKLEDSLAB.

END terminates the geometry parameters.

MXZ is the mixture number of the zone.

$\mathrm{RZ} \quad$ is the outside dimension of the zone.

XMOD is an optional entry specifying the external moderator index. These data were required for older versions of SCAIE but can be omitted for this version. If the user chooses to input this data, a valid option must be specified. The choices are

NOEXTERMOD There are no moderating materials in an adjacent zone.

ONEEXTERMOD There is moderating material in one adjacent zone.

TWOEXTERMOD There are moderating materials in both adjacent zones.

Repeat the sequence (MXZ RZ XMOD) until all of the zones in the geometry have been described.

END ZONE terminates the MULTIREGION unit cell data. 
Examples of MULTIREGION unit cells follow:

EXAMPLE 1. SLAB.

Consider a 5-cm-thick slab of fuel (mixture 1) with $0.5 \mathrm{~cm}$ of aluminum (mixture 3 ) and $15 \mathrm{~cm}$ of water (mixture 2) on each face. The unit cell data for this problem could be entered as follows:

\section{CS BR BL ORGN END (MXZ RZ XMOD) END ZONE}

where

CS is the geometry shape (SLAB).

BR is the right (outside) boundary condition (VACUUM).

BL is the left (inside) boundary condition (REFLECTED because it is easier to describe only half of the system and reflect at the mid-plane of the fuel.

ORGN is the location of the left boundary of a slab in $\mathrm{cm}(0)$.

END terminates the geometry parameters.

MXZ is the mixture number of the zone [ 1 for the first zone (fuel), 3 for the second zone (aluminum), and 2 for the third zone (water)].

$\mathrm{RZ} \quad$ is the outside dimension of the zone. (2.5 for the half thickness of fuel in the first zone, $3.0=2.5+0.5$ for the outer dimension of the aluminum in the second zone, and $18.0=2.5+0.5+15.0$ for the outer dimension of the water in the third zone.)

XMOD is the optional external moderator index and has been omitted.

Repeat the sequence ( $M X Z R Z$ XMOD) until all of the zones in the geometry have been described.

END ZONE

The unit cell data for this problem can be entered as follow:

\section{SLAB VACUUM REFLECTED 0 END}

\section{$\begin{array}{llllllll}1 & 2.5 & 3 & 3.0 & 2 & 18.0 & \text { END } & \text { ZONE }\end{array}$}

EXAMPLE 2. CYLINDRICAL.

Consider a large array of fuel pins. Each pin is $\mathrm{UO}_{2}$ (mixture 1 ) with a radius of $0.465 \mathrm{~cm}$, a $0.009-\mathrm{cm}$ gap (mixture 0), and a Zircaloy clad (mixture 9) $0.062 \mathrm{~cm}$ thick, centered in a water (mixture 8) region surrounded by a flooded support structure represented by homogenized water and Zircaloy (mixture 10). The outer radius of the water-Zircaloy region is $0.844 \mathrm{~cm}$ and it is $0.037 \mathrm{~cm}$ thick. This problem cannot be described as a lattice cell problem because the lattice cell

NUREG/CR-0200,

Vol. 3, Rev. 4 
configuration is limited to fuel-gap-clad-cell boundary and this problem is fuel-gap-clad-moderator-outer region. A white boundary condition on the outer boundary is a reasonable representation of a large array. However, lattice effects are not accounted for when MULTIREGION is used, so the user will have to enter the appropriate Dancoff factor in the optional parameter data.

The unit cell data for this problem could be entered as follows:

CS BR BL ORGN END (MXZ RZ XMOD) END ZONE

where

CS is the geometry shape (CYLINDRICAL).

BR is the right (outside) boundary condition (WHITE).

BL is omitted because the default is REFLECTED and is appropriate for CYLINDRICAL.

ORGN is omitted because it applies only to slabs.

END terminates the geometry parameters.

MXZ is the mixture number of the zone [ 1 for the first zone (fuel), 0 for the second zone (gap), 9 for the third zone (clad), 8 for the fourth zone (water), and 10 for the outer water-Zircalloy region].

$\mathrm{RZ}$ is the outside dimension of the zone. ( 0.465 for the radius of the fuel in the first zone, 0.474 for the outer radius of the gap, 0.536 for the outer radius of the Zircaloy clad, 0.807 for the outer radius of the water moderator, and 0.844 for the outer radius of the outer region.)

XMOD is the optional external moderator index and has been omitted.

Repeat the sequence (MXZ RZ XMOD) until all of the zones in the geometry have been described.

END ZONE

The input data for this unit cell can be entered as follows:

CYLINDRICAL WHITE END $10.465 \quad 0 \quad 0.474 \quad 9 \quad 0.536$

$\begin{array}{llll}8 & 0.807 & 10 & 0.844 \\ \text { END ZONE }\end{array}$

EXAMPLE 3. SPHERICAL.

Describe a bare sphere of uranium metal $8.72 \mathrm{~cm}$ in radius. The uranium metal is defined to be mixture 1 . The unit cell data for this problem could be entered as follows:

CS END (MXZ RZ XMOD) END ZONE 
where

CS is the geometry shape (SPHERICAL). Other geometry parameters need not be entered because the defaults are sufficient.

END terminates the geometry parameters.

MXZ is the mixture number of the zone (1 for the first zone (uranium)).

RZ is the outside dimension of the zone in $\mathrm{cm}$ (8.72 for the radius of the uranium in the first zone).

XMOD is the optional external moderator index and has been omitted.

Repeat the sequence (MXZ RZ XMOD) until all of the zones in the input have been described.

END ZONE

The input data for this unit cell can be entered as follows:

SPHERICAL END 18.72 END ZONE

EXAMPLE 4. BUCKLEDSLAB.

Consider a plate of fuel $4 \mathrm{~cm}$ thick, reflected by $3 \mathrm{~cm}$ of water on both faces. The plate is $32 \mathrm{~cm}$ tall and $16 \mathrm{~cm}$ deep. The fuel is mixture 1 and the water is mixture 2.

The unit cell data for this problem could be entered as follows:

CS BR BL ORGN DY DZ END (MXZ RZ XMOD) END ZONE where

CS is the geometry shape (BUCKLEDSLAB).

BR is the right (outside) boundary condition (VACUUM).

BL is the left boundary condition. (BL must be entered as REFLECTED even though REFLECTED is the default because the buckling height and depth must be entered.)

ORGN is the location of the left boundary on the $x$-axis ( 0.0 this value must be entered even though it is the default value because the buckling height and depth must be entered).

DY is the buckling height in $\mathrm{cm}(32.0)$.

$\mathrm{DZ}$ is the buckling depth in $\mathrm{cm}(16.0)$.

END terminates the geometry parameters.

NUREG/CR-0200, Vol. 3, Rev. 4 
MXZ is the mixture number of the zone ( 1 for the first zone (fuel), and 2 for the second zone (water)).

RZ is the outside dimension of the zone $(2.0 \mathrm{~cm}$ for the half thickness of the fuel in the first zone, and $5.0 \mathrm{~cm}(4 / 2+3)$ for the outer dimension of the water in zone 2).

XMOD is the optional external moderator index and has been omitted.

Repeat the sequence (MXZ RZ XMOD) until all of the zones in the geometry have been described.

END ZONE

The unit cell data for this problem follow:

BUCKLEDSLAB VACUUM REFLECTED $0.0 \quad 32 \quad 16.0$ END

$\begin{array}{llll}1 & 2.0 & 2 & 5.0 \\ \text { END } & \text { ZONE }\end{array}$

EXAMPLE 5. BUCKLEDCYL.

Consider a solution of uranyl nitrate contained in a cylindrical stainless-steel container reflected by $33 \mathrm{~cm}$ of water. The inside dimensions of the steel container are $7.62 \mathrm{~cm}$ in radius and $130.0 \mathrm{~cm}$ tall. The steel is $0.15 \mathrm{~cm}$ thick. The uranyl nitrate is defined to be mixture 1 , the steel is defined to be mixture 2 , and the water is defined to be mixture 3 .

The unit cell data for this problem could be entered as follows:

CS BR BL ORGN DY END (MXZ RZ XMOD) END ZONE

where

CS is the geometry shape (BUCKLEDCYL).

BR is the right (outside) boundary condition (VACUUM).

BL is the left boundary condition. (The left boundary is at the center of the cylinder and must be entered as REFLECTED even though REFLECTED is the default because the buckling height must be entered.)

ORGN is the location of the left boundary on the $x$-axis (enter 0.0 even though it is the default value because data will be specified after it).

DY is the buckling height in $\mathrm{cm}(130.0)$.

END terminates the geometry parameters.

$\mathrm{MXZ}$ is the mixture number of the zone [enter 1 for the first zone (fuel), 2 for the second zone (stainless steel) and 3 for the third zone (water)]. 
$\mathrm{RZ} \quad$ is the outside dimension of the zone in $\mathrm{cm}$. (Enter 7.62 for the radius of the fuel in the first zone, $\mathbf{7 . 7 7}$ for the outer radius of the stainiess container and $40.77 \mathrm{~cm}$ for the outer radius of the water reflector.)

XMOD is the optional external moderator index and has been omitted.

Repeat the sequence (MXZ RZ XMOD) until all of the zones in the geometry have been described.

END ZONE

The unit cell data for this problem follow:

BUCKLEDCYL VACUUM REFLECTED 0.0130 .0 END

$\begin{array}{llllllll}1 & 7.62 & 2 & 7.77 & 3 & 40.77 & \text { END } & \text { ZONE }\end{array}$

\section{M7.5.7 OPTIONAL PARAMETER DATA OR MORE DATA}

The optional parameter data provide a means of providing additional information or alternative data to the cross-section processing codes. The data that are provided to XSDRNPM are used only for cross-section processing. Optional parameter data will be read if the words "MORE DATA" are entered. As many parameters as are needed can be entered. Each parameter entry must be separated from the others by one or more blanks. The optional parameter data are terminated by entering the word "END." The parameter data that can be entered are listed below.

ISN $=\quad$ This keyword allows XSDRNPM to use an order of angular quadrature other than 8 when it is executed to perform cell-weighted cross-section processing. The value entered with this keyword is ISN, the 8th entry of the $1 \$$ array in XSDRNPM. Section M7.2.5.7 describes the automatic quadrature generator.

$\mathrm{SZF}=\quad$ This keyword allows the user to alter the number of XSDRNPM mesh intervals provided by the Material Information Processor. The default value of SZF is 1.0. The Material Information Processor automatically provides the mesh intervals used in XSDRNPM. See Sect. M7.2.5.6 for details about the automatic mesh generator. It is not uncommon for an excessive number of mesh intervals to be generated. The keyword SZF= allows a means of reducing or increasing the number of mesh intervals. A number between zero and 1.0 will provide more mesh intervals, and a number greater than 1.0 will reduce the number of mesh intervals.

IIM = This keyword allows the user to set the maximum number of inner iterations for XSDRNPM. The value entered with this keyword is IM, the 11th entry in the XSDRNPM $1 \$$ array. The default value of IIM is 20.

$\mathrm{ICM}=\quad$ This keyword is used to set the maximum number of outer iterations for XSDRNPM. The value entered with this keyword is ICM, the 12th entry in the XSDRNPM $1 \$$ array. The default value of ICM is 25 .

EPS $=\quad$ This keyword is used to set the overall convergence criteria for XSDRNPM. The default value is 0.0001 . EPS is the first entry in the XSDRNPM 5* array. The convergence criteria are discussed in Sect. M7.2.5.8. 
PTC $=\quad$ This keyword is used to set the point convergence criteria (the scalar flux convergence criteria) for XSDRNPM. The default value is 0.0001 . PTC is the second entry in the XSDRNPM 5* array.

BKL $=\quad$ This keyword is used to set the buckling factor, BF, for XSDRNPM. The default value is 1.420892 and is two times the multiplier on the "extrapolation" distance used to determine where a linearly extrapolated line from the asymptotic flux shape will go to zero. For slabs, the extrapolation distance is approximately $0.71 \lambda_{t r}$ or approximately 1.42. The buckling factor, BF, is the 6th entry in the XSDRNPM $5^{*}$ array.

IUS $=\quad$ This keyword is used to set the upscatter scaling factor for XSDRNPM. The default value is 0 . IUS $=0$ does not utilize upscatter scaling. IUS $=1$ uses upscatter scaling to accelerate the solution and/or speed convergence. IUS $=$ is used to set the 11th entry, IFCT, of the XSDRNPM $3 \$$ array.

RES $=\quad$ This keyword is used to supply resonance data to BONAMI and NITAWL for cross-section processing. This option must be used if the problem needs more than one unit cell description or contains more than one fissile mixture. See Sect. M7.5.10 for an example illustrating the use of this feature.

The data are entered in the form: RES $=\mathrm{mm}$ fgeom dimn

where

$\mathrm{mm}$ is the mixture number, fgeom is the lump shape (SLAB, CYLINDER, SPHERE), and dimn is the dimension, in $\mathrm{cm}$, of the lump (thickness of the slab or radius of the sphere or cylinder).

DAN $(\mathrm{mm})=$ This keyword is used to supply Dancoff data to BONAMI and NITAWL for cross-section processing.

The data are entered in the form: $\mathrm{DAN}(\mathrm{mm})=$ dancoff

where

$\mathrm{mm}$ is the mixture number and dancoff is the Dancoff factor to be applied to mixture $\mathrm{mm}$. The easiest way to obtain the Dancoff factor is to run a CSASN problem and specify PARM=CHECK The Dancoff is printed as part of the RESONANCE DATA. See Sect. M7.5.10 for an example demonstrating the use of this feature.

BAL $=\quad$ This keyword controls the balance table edits in XSDRNPM. The default value is FINE. The available options are listed below.

$\mathrm{BAL}=\mathrm{FINE} \quad$ Prints the fine-group balance tables.

This corresponds to IPBT $=0$ in the XSDRN $2 \$$ array.

$B A L=N O N E \quad$ Suppresses all balance table print.

This corresponds to IPBT $=-1$ in the XSDRN $2 \$$ array.

$\mathrm{BAL}=\mathrm{AIL} \quad$ Prints the fine- and broad-group balance tables.

This corresponds to IPBT $=1$ in the XSDRN $2 \$$ array.

$\mathrm{DY}=\quad$ This keyword allows the user to specify the first transverse dimension in centimeters used in a buckling correction to calculate leakage normal to the principal direction (i.e., the height of a slab or a cylinder). This correction is already included in the unit cell data for a MULTIREGION problem. Therefore, DY should only be specified for a 
LATTICECELL problem. DY= corresponds to DY, the 7th entry in the XSDRN $5^{*}$ array.

$\mathrm{DZ}=\quad$ This keyword allows the user to specify the second transverse dimension in centimeters used in a buckling correction (i.e., the width or depth of a slab). This correction is already included in the unit cell data for a MULTIREGION problem. Therefore, DY should only be specified for a LATTICECELL problem utilizing slab geometry. $D Z=$ corresponds to $\mathrm{DZ}$, the 8th entry in the XSDRN $5^{*}$ array.

$\mathrm{COF}=\quad$ This keyword is used to set the diffusion coefficient option for transverse leakage corrections in XSDRNPM. This variable corresponds to IPN, the 7th variable in the XSDRNPM $3 \$$ array. The default value is 0 . The available options are listed below.
$\mathrm{COF}=0$
$\mathrm{COF}=1$
$\mathrm{COF}=2$
Set a transport cross section for each zone.
Use a spatially averaged diffusion coefficient for all zones.
Use a diffusion coefficient for all zones that is one-third the diffusion coefficient determined from the spatially averaged transport cross section for all zones.
$\mathrm{COF}=3 \quad$ Use a flux and volume weighting across all zones.

$F R D=\quad$ This keyword is used to set the unit number from which the binary flux guess for XSDRNPM will be read. It corresponds to setting IFN, the 4th entry in the XSDRNPM $3 S$ array to a value greater than 3 . In SCALE, it is prudent to choose a unit number in the 30 's, 40 's, or 50's so other necessary data sets are not impacted. The user is responsible for supplying job control language data that are necessary for reading the flux data set.

$F W R=\quad$ This keyword is used to set the unit number on which the fluxes generated by XSDRNPM will be written in binary format. It corresponds to setting ID1, the 2nd entry in the XSDRNPM $2 \$$ array to a value greater than 3. In SCALE, it is prudent to choose a unit number in the 30's, 40's, or 50's so other necessary data sets are not impacted. The user is responsible for supplying job control language data that are necessary for creating and saving the flux data set.

AXS $=\quad$ This keyword is used to set the unit number on which the macroscopic ANISN library is written. If the unit number is input as 7, the ANISN library will be written in a freeform card-image format. For any other unit number, the library will be written in binary format. The user is responsible for supplying job control language data that are necessary for creating and saving the ANISN cross-section library. The only control sequences that can create an ANISN cross-section library are CSASI, CSASIX, and SAS3.

$\mathrm{DAB}=\quad$ This keyword is used to set the number of direct-access data blocks for the Material Information Processor direct-access device on unit 8. The default number of directaccess data blocks is 200 . This feature can be used if the problem fails with the message LMP005 DA ERROR - RELATTVE BLOCK NOT IN DATA SET. RELATIVE $B L O C K N U M B E R$ IS nnn. Set $D A B=$ to a value larger than nnn. For example, if $n n n$ is 201,300 or 400 would be an appropriate value to try.

COLL This keyword is used to activate the collapse of the thermal groups into one group for the shielding sequences. To activate this feature, simply enter COLL in MORE DATA.

NUREG/CR-0200,

Vol. 3, Rev. 4

M7.5.54 
For example, MORE DATA COLL END would activate this feature. MORE DATA EPS $=.00005$ COLL END DATA would tighten the convergence criteria for XSDRNPM and collapse all of the thermal groups into one group.

\section{M75.7.1 Sample Optional Parameter Data}

Consider a problem in which it is desirable to increase the number of inner iterations in XSDRN to 30 and to tighten the overall convergence criteria to a value of 0.000075 . This could be accomplished by entering the data as follows:

\section{MORE DATA IIM=30 EPS $=0.000075$ END}

The order of the data entry is not important. The data must start with MORE or MORE DATA and end with an END. It need not be entered as a single "card," but can be strung out across several "cards." However, a keyword cannot be separated across "card" boundaries. The terminator for the optional parameter data, END, must not begin in column 1 unless you assign a name to it. An alternative method of entering the above data is given below.

MORE DATA

IIM $=30 \quad$ EPS $=0.000075$

END MORE

or

MORE DATA IIM=30 EPS $=0.000075$ END MORE DATA

\section{M7.5.8 EXAMPLES OF COMPLETE MATERIAL INFORMATION PROCESSOR INPUT DATA}

The Material Information Processor data consist of:

(1) TITLE

(2) CROSS-SECTION LIBRARY NAME

(3) TYPE OF CALCULATION

(4) STANDARD COMPOSITIONS SPECIFICATION DATA

(5) UNIT CELL, SPECIFICATION

(6) OPTIONAL PARAMETER DATA (MORE DATA)

Items 1 through 6 have been discussed in Sects. M7.5.1 through M7.5.7.

\section{M7.5.8.1 Infinite Homogeneous Medium Input Data}

Examples of Material Information Processor input data for infinite homogeneous media problems are given below.

EXAMPLE 1. Default Cell Definition. Consider a cylindrical billet of $20 \%$ wt enriched $\mathrm{UO}_{2}$, having a density of $10.85 \mathrm{~g} / \mathrm{cc}$ that is $26 \mathrm{~cm}$ in diameter and $26 \mathrm{~cm}$ tall.

The average mean-free path in the uranium dioxide is on the order of $2.5 \mathrm{~cm}$. Because only a small fraction of the billet is within a mean-free path of the surface, the material can be treated as an infinite homogeneous medium. The Material Information Processor data utilizing the 27-group ENDF/B-IV SCALE cross-section library follows: 


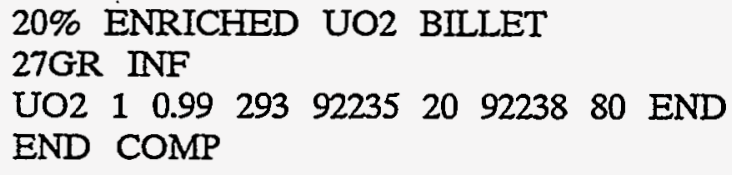

The volume fraction used for the $\mathrm{UO}_{2}, 0.99$, is calculated by dividing the actual density yy the theoretical density obtained from Table M8.2.1 (10.85/10.96). Since the enrichment was specified as $20 \%$, it is reasonable to assume that the remainder is ${ }^{238} \mathrm{U}$.

An alternative input data description follows:

20\% ENRICHED UO2 BILLET

$27 \mathrm{G}$ INF

UO2 $1 \mathrm{DEN}=10.85129392235209223880$ END

END COMP

EXAMPLE 2. Specify the Cell Definition.

Consider a 5-1 Plexiglas bottle with an inner radius of $9.525 \mathrm{~cm}$ and inner height of $17.78 \mathrm{~cm}$ that is filled with highly enriched uranyl nitrate solution at $415 \mathrm{~g} / \mathrm{L}$, a specific gravity of 1.555 , and $0.39 \mathrm{mg}$ of excess nitrate per gram of solution. The uranium isotopic content of the nitrate solution is $92.6 \%_{\mathrm{wt}}{ }^{235} \mathrm{U}, 5.9 \%_{\mathrm{wt}}{ }^{238} \mathrm{U}, 1.0 \%{ }_{\mathrm{wt}}{ }^{234} \mathrm{U}$, and $0.5 \%_{\mathrm{wt}}{ }^{236} \mathrm{U}$.

The size of the nitrate solution is on the order of 16 to $20 \mathrm{~cm}$ in diameter and height. The average mean-free path in the nitrate solution is on the order of $0.5 \mathrm{~cm}$. Therefore, infinite homogeneous medium is an appropriate choice for this problem.

If the Plexiglas is defined to be mixture 1 and the uranyl nitrate solution is defined to be mixture 2, unit cell data must be entered. This is done by entering the word "CELLMIX" followed by the mixture that is to be used to define the cell. The Material Information Processor data for this problem utilizing the 16-group Hansen-Roach cross-section library is given below.

SET UP 5LITER URANYL NITRATE SOLUTION IN A PLEXIGLAS CONTAINER HANSEN-ROACH INFHOMMEDIUM

PLEXIGLAS 1 END

SOLNUO2(NO3)2 2415 9.783-3 SPG=1.555 $1.02939223592 .692238 \quad 5.9$

END COMP

$92234 \quad 1.0 \quad 92236 \quad 0.5 \quad$ END

CELLMIX 2

\section{M7.5.8.2 Lattice Cell Input Data}

below.

Examples of Material Information Processor input data for lattice cell problems are given

EXAMPLE 1. Squarepitch.

Consider an infinite planar array (infinite in $x$ and $y$ and 1 layer in $z$ ) of $20 \%$ wr enriched $\mathrm{U}$ metal rods with a $1-\mathrm{cm}$ pitch. Each fuel rod is bare uranium metal, $0.75 \mathrm{~cm} O D \times$ $30.0 \mathrm{~cm}$ long. The rods are submerged in water. 
Because the diameter of the fuel rod, $0.75 \mathrm{~cm}$, is only slightly larger than the average mean-free path in the uranium metal, approximately 0.5 , and because the configuration is a regular array, LATTICECELL is the appropriate choice for proper cross-section processing. The Material Information Processor data using the 27-group ENDF/B-IV cross-section library follows:

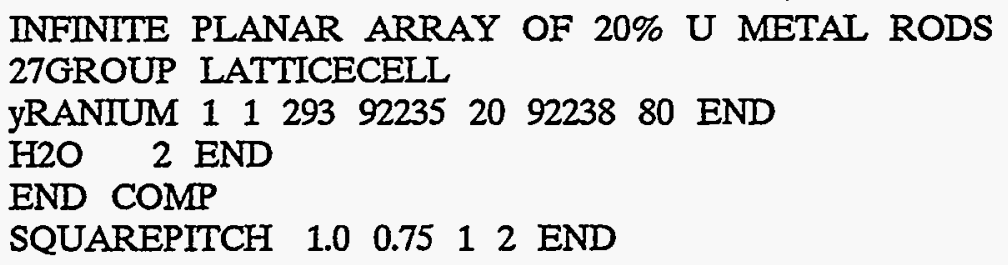

EXAMPLE 2. Squarepitch.

Consider an infinite planar array (infinite in $\mathrm{x}$ and $\mathrm{y}$ and 1 layer in $\mathrm{z}$ ) of PWR-like fuel pins of $2.35 \%$ enriched $\mathrm{UO}_{2}$ clad with zirconium. The density of the $\mathrm{UO}_{2}$ is $9.21 \mathrm{~g} / \mathrm{cc}$. The fuel in each pin is $0.823 \mathrm{~cm}$ in diameter, the clad is $0.9627 \mathrm{~cm}$ in diameter, and the length of each pin is $366 \mathrm{~cm}$. The fuel pins are separated by $0.3124 \mathrm{~cm}$ of water in the horizontal plane.

Because the diameter of the fuel rod, $0.823 \mathrm{~cm}$, is only slightly larger than the average mean-free path in the uranium metal, approximately 0.5 , and because the configuration is a regular array, LATTICECELL is the appropriate choice for proper cross-section processing. The Material Information Processor data using the 16-group Hansen-Roach cross-section library follows:

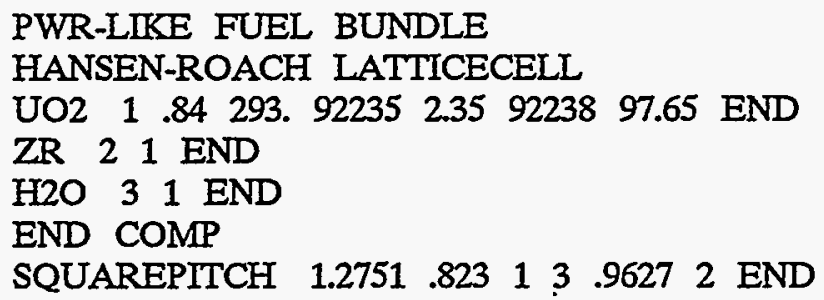

EXAMPLE 3. Sphtriangp.

Consider an infinite array of spherical pellets of $2.67 \%$ enriched $\mathrm{UO}_{2}$ with a density of $10.3 \mathrm{~g} / \mathrm{cc}$ and a diameter of $1.0724 \mathrm{~cm}$ arranged in a "triangular" pitch, flooded with borated water at 4350 WPPM. The boron is natural boron, the borated water is created by adding boric acid, $\mathrm{H}_{3} \mathrm{BO}_{3}$, and has a density of $1.0078 \mathrm{~g} / \mathrm{cc}$. The temperature is $15^{\circ} \mathrm{C}$, and the pitch is $1.1440 \mathrm{~cm}$. The standard composition data for the borated water are given in Example 2 of Sect. M7.5.5.7.

Because the diameter of the fuel pellet, $1.0724 \mathrm{~cm}$, is smaller than the average mean-free path in the $\mathrm{UO}_{2}$ approximately $1.5 \mathrm{~cm}$, and because the configuration is a regular array, LATTICECELL is the appropriate choice for proper cross-section processing.

The density fraction for the $\mathrm{UO}_{2}$ is the ratio of actual to theoretical density $(10.3 / 10.96=0.9398)$. Assume that the $U$ is all ${ }^{235} U$ and ${ }^{238} U$. 
To describe the boric acid, first calculate the grams of boric acid in a gram of solution: Boric acid, $\mathrm{H}_{3} \mathrm{BO}_{3}$, is $61.8222 \mathrm{~g} / \mathrm{mol}$

Natural boron is $10.81261 \mathrm{~g} / \mathrm{mol}$

$\left(4350 \times 10^{-6} \mathrm{~g} \mathrm{~B} / \mathrm{g} \mathrm{soln}\right) \times(1 \mathrm{~mol} / 10.81261 \mathrm{~g} \mathrm{~B}) \times(61.8222 \mathrm{~g}$ boric acid $/ \mathrm{mol})=$ $0.0248715 \mathrm{~g}$ boric acid/g soln.

Then calculate the theoretical density of the boric acid.

$1.0078 \mathrm{~g}$ soln $/ \mathrm{cc} \times 0.024871 \mathrm{~g}$ boric acid $/ \mathrm{g}$ soln $=0: 025066 \mathrm{~g}$ boric acid $/ \mathrm{cc}$

Then calculate the volume fraction of the water in the solution. Each gram of solution contains $0.024871 \mathrm{~g}$ of boric acid, so there is $0.975129 \mathrm{~g}$ of water in each gram of solution.

The volume fraction of water is then given by:

$(1.0078 \mathrm{~g}$ soln $/ \mathrm{cc} \times 0.975129 \mathrm{~g}$ water $/ \mathrm{g}$ soln $) / 0.9982 \mathrm{~g}$ water $/ \mathrm{cc}=0.984507$

The 0.9982 is the theoretical density of water from Table M8.2.1.

The temperature in degrees Kelvin is $273+15=288$.

The Material Information Processor data using the 27-group ENDF/B-IV cross-section library follows:

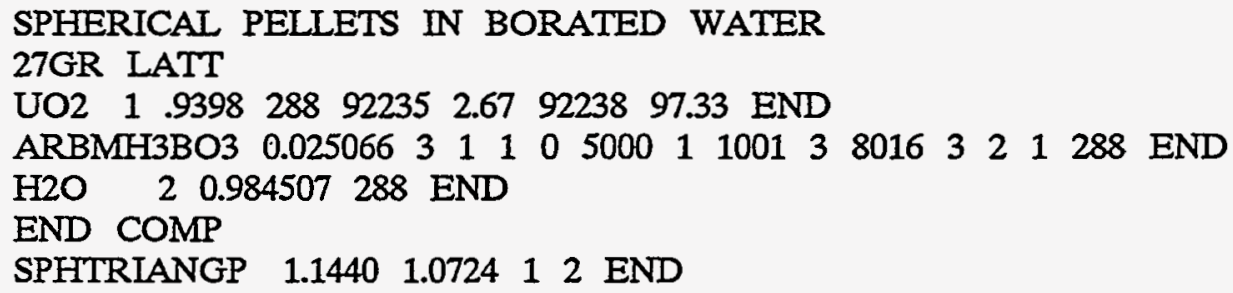

\section{M7.5.8.3 Multiregion Input Data}

below.

Examples of Material Information Processor input data for multiregion problems are given

EXAMPLE 1. Spherical.

Consider a small highly enriched uranium sphere supported by a Plexiglas collar in a tank of water. The uranium metal sphere has a diameter of $13.1075 \mathrm{~cm}$, is $97.67 \%$ enriched, and has a density of $18.794 \mathrm{~g} / \mathrm{cc}$. The cylindrical Plexiglas collar has a $4.1275-\mathrm{cm}$-radius central hole, extends to a radius of $12.7 \mathrm{~cm}$ and is $2.54 \mathrm{~cm}$ thick. The water filled tank is $60 \mathrm{~cm}$ in diameter.

The density fraction of the uranium metal is the ratio of actual to theoretical density, where the theoretical density is obtained from Table M8.2.1. Thus the density multiplier is $18.794 / 19.05=0.9866$. The abundance of uranium is not stated beyond $97.67 \%$ enriched, so it is reasonable to assume the remainder is ${ }^{228} \mathrm{U}$. The Plexiglas collar is not significantly different from water and does not surround the fuel, so it can be ignored. If it is ignored, the problem becomes a one-dimensional geometry that can be defined using the multiregion type of calculation, and the eigenvalue of the system can be obtained without additional data by executing CSAS1X. However, the Plexiglas has been included in this data so it can be passed to a code such as KENO V.a which can

NUREG/CR-0200, 
describe the geometry rigorously. Using the 27-group ENDF/B-IV cross-section library, the Material Information Processor data follow:

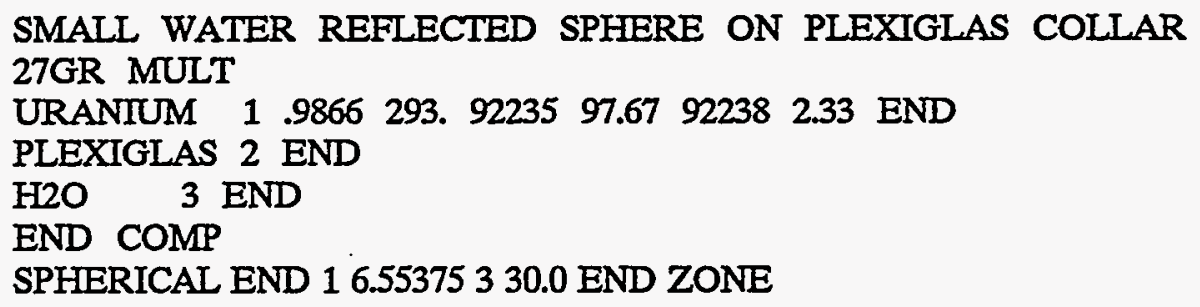

EXAMPLE 2. Buckled slab.

This example features a dense $93.2 \%$ enriched uranyl-fluoride solution inside a Plexiglas container immersed in water. The fissile solution contains $570.8 \mathrm{~g}$ of heavy metal per liter and has no excess acid. The critical thickness of the fuel is $5.384 \mathrm{~cm}$. The finite height of the fuel slab is $147.32 \mathrm{~cm}$, and the depth is $71.58 \mathrm{~cm}$. The Plexiglas container is $1.905 \mathrm{~cm}$ thick and is reflected by $20.32 \mathrm{~cm}$ of water.

The half thickness of the fuel (2.692) will be used with a reflected left boundary and a vacuum right boundary. The Material Information Processor data using the 27-group ENDF/B-IV cross-section library are given below:

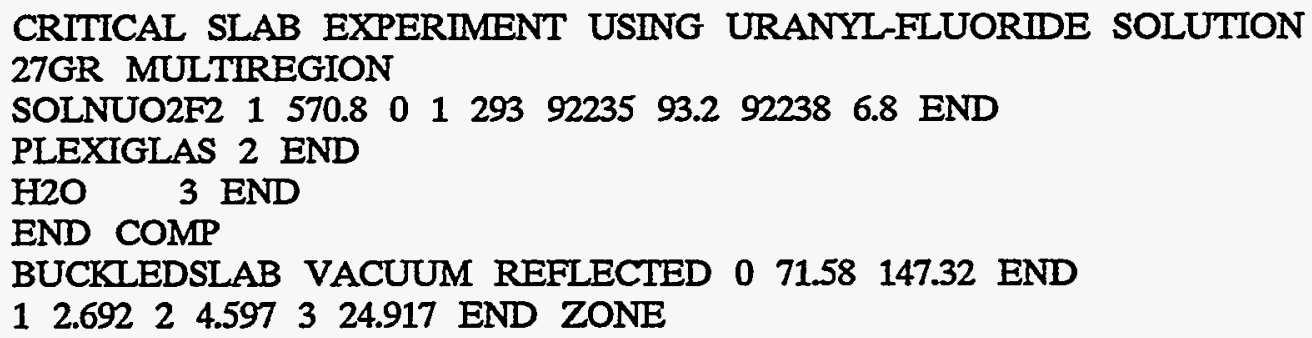

\section{M75.9 THREE METHODS OF SPECIFYING A SOLUTION}

The standard composition specification data offer flexibility in the choice of input data. This section illustrates three methods of specifying the same solution. Section M7.5.9.1 lists the number densities calculated by the Material Information Processor for each method.

Create a mixture 3 that is aqueous uranyl nitrate solution:

$\mathrm{UO}_{2}\left(\mathrm{NO}_{3}\right)_{2}$, sp. gr. $=1.555$

$0.2669 \mathrm{~g} \mathrm{U} / \mathrm{g}$-soln., $0.415 \mathrm{~g} \mathrm{U} / \mathrm{cc}$, excess nitrate $=0.39 \mathrm{mg} / \mathrm{g}$-soln

Uranium isotopic content: $92.6 \mathrm{wt} \%$ U-235 $5.9 \mathrm{wt} \%$ U-238

$1.0 \mathrm{wt} \% \mathrm{U}-234$ and $0.5 \mathrm{wt} \% \mathrm{U}-236$

In calculating the molecular weights, use the atomic weights from SCALE, which are available in the output from COMPOZ. COMPOZ was run to create the Standard Composition Library for SCALE on your computer. The atomic weights used in SCALE may differ from some periodic tables. The SCALE atomic weights used in this problem are listed as follows: 


$\begin{array}{lr}\mathrm{H} & 1.0078 \\ \mathrm{O} & 15.9954 \\ \mathrm{~N} & 14.0033 \\ \mathrm{U}-234 & 234.0406 \\ \mathrm{U}-235 & 235.0442 \\ \mathrm{U}-236 & 236.0458 \\ \mathrm{U}-238 & 238.0510\end{array}$

Three methods of describing the uranyl nitrate solution will be demonstrated. Method 1 is more rigorous, method 2 is easier and is as accurate, and method 3 is approximate.

\section{METHOD 1:}

This method involves breaking the solution into its component parts $\left[\left(\mathrm{HNO}_{3}, \mathrm{UO}_{2}\left(\mathrm{NO}_{3}\right)_{2}\right.\right.$, and $\left.\left.\mathrm{H}_{2} \mathrm{O}\right)\right]$ and entering the basic standard composition specifications for each.

1. Calculate the density of the $\mathrm{HNO}_{3} 0.39 \times 10^{-3} \mathrm{~g} \mathrm{NO}_{3} / \mathrm{g}$ soln $\times\left(\left(62.997 \mathrm{~g} \mathrm{HNO}_{3} / \mathrm{mol}\right.\right.$ $\left.\left.\mathrm{HNO}_{3}\right) /\left(61.990 \mathrm{~g} \mathrm{NO}_{3} / \mathrm{mol} \mathrm{NO}_{3}\right)\right) \times 1.555 \mathrm{~g}$ soln $/ \mathrm{cc}$ soln $=6.16 \times 10^{-4} \mathrm{~g} \mathrm{HNO}_{3} / \mathrm{cc} \mathrm{soln}$.

2. Calculate the density fraction of HNO3 (actual density/theoretical density). In the Standard Composition Library the theoretical density of $\mathrm{HNO}_{3}$ is $1.0 \times 6.16 \times 10^{-4} / 1.0=6.16 \times 10^{-4}$.

3. Calculate the molecular weight of the uranium

The number of atoms in a mol of uranium is the sum of the number of atoms of each isotope in the mol of uranium.

Let $\mathrm{AU}=$ the average molecular weight of uranium, $\mathrm{g} \mathrm{U} / \mathrm{mol} \mathrm{U}$ $\mathrm{GU}=$ the density of uranium in $\mathrm{g} / \mathrm{cc}$

Then the number of atoms in a mol of uranium $=$

$$
\text { or } \quad(6.023 \times 10+23 * 10-24 * \mathrm{GU}) / \mathrm{AU}
$$

The weight fraction of each isotope is the weight $\% * 100$

Therefore, F235 $=0.926$, the weight fraction of U-235 in the U

F238 $=0.059$, the weight fraction of U-238 in the U

$\mathrm{F} 236=0.005$, the weight fraction of U-236 in the U

F234 $=0.010$, the weight fraction of U-234 in the U

$\mathrm{A} 235=235.0442$, the molecular weight of U-235

A238 $=238.0510$, the molecular weight of U-238

A236 $=236.0458$, the molecular weight of U-236

A234 $=234.0406$, the molecular weight of U-234

Then the number of atoms of isotopes in a mol of uranium $=$

$6.023 \times 10+23 * 10-24 *((G U * F 235 / A 235)+(G U *$ F238/A238) +

GU*F236/A236) + (GU*F234/A234) )

or

NUREG/CR-0200,

Vol. 3, Rev. 4

M7.5.60 


$$
\begin{gathered}
0.6023 * \mathrm{GU} *(0.926 / 235.0442+0.059 / 238.0510+ \\
0.005 / 236.0458+0.010 / 234.0406)
\end{gathered}
$$

Because the number of atoms of uranium equals the sum of the atoms of isotopes,

$$
\begin{aligned}
& \begin{array}{r}
0.6023 * \mathrm{GU} / \mathrm{AU}=0.6023 * \mathrm{GU} *(0.926 / 235.0442+0.059 / 238.0510+ \\
0.005 / 236.0458+0.010 / 234.0406)
\end{array} \\
& 1 / \mathrm{AU}=0.926 / 235.0442+0.059 / 238.0510+0.005 / 236.0458+0.010 / 234.0406 \\
& \mathrm{AU}=235.2144
\end{aligned}
$$

4. Calculate the molecular weight of the $\mathrm{UO}_{2}\left(\mathrm{NO}_{3}\right)_{2}$. $235.2144+(8 \times 15.9954)+(2 \times 14.0033)=391.184 \mathrm{~g} \mathrm{UO}_{2}\left(\mathrm{NO}_{3}\right)_{2} / \mathrm{mol}$

5. Calculate the density of $\mathrm{UO}_{2}\left(\mathrm{NO}_{3}\right)_{2}$

$0.415 \mathrm{~g} \mathrm{U} / \mathrm{cc} \times\left(\left(391.184 \mathrm{~g} \mathrm{UO}_{2}\left(\mathrm{NO}_{3}\right)_{2} / \mathrm{mol}\right) /(235.2144 \mathrm{~g} \mathrm{U} / \mathrm{mol})\right)=$ $0.69018 \mathrm{~g} \mathrm{UO}_{2}\left(\mathrm{NO}_{3}\right)_{2} / \mathrm{cc}$ soln.

6. Calculate the density fraction (actual density/theoretical density) of $\mathrm{UO}_{2}\left(\mathrm{NO}_{3}\right)_{2}$

(In the Standard Composition Library the theoretical density of $\mathrm{UO}_{2}\left(\mathrm{NO}_{3}\right)_{2}$ is given as 2.2030 g/cc.)

The density fraction is $0.69018 / 2.2030=0.31329$

7. Calculate the amount of water in the solution

$1.555 \mathrm{~g}$ soln $/ \mathrm{cc}$ soln $-6.16 \times 10^{-4} \mathrm{~g} \mathrm{HNO}_{3} / \mathrm{cc}$ soln $-0.69018 \mathrm{~g} \mathrm{UO}_{2}\left(\mathrm{NO}_{3}\right)_{2} \mathrm{LL} / \mathrm{cc}$ soln $=$ $0.8642 \mathrm{~g} \mathrm{H}_{2} \mathrm{O} / \mathrm{cc}$ soln.

8. Calculate the density fraction (actual density/theoretical density) of water.

(In the Standard Composition Library the theoretical density of water is given as $0.9982 \mathrm{~g} / \mathrm{cc}$.) The density fraction is $0.8642 / 0.9982=0.86575$

The solution specification data follow:

HNO3 $3 \quad 6.16-4 \quad 293$ END

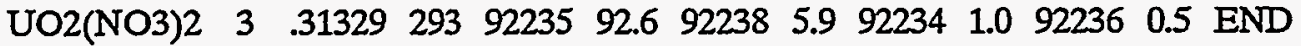
$\mathrm{H} 2 \mathrm{O} \quad 3 \quad .86575 \quad 293$ END

\section{METHOD 2:}

This method utilizes the solution option available in the standard composition specification data. Because the specific gravity is specified in the input data, this method should yield correct number densities that should agree with method 1 except for calculational round-off. The option allowing the specific gravity to be input in the solution data was not available prior to SCALE 4.0.

1. Calculate the fuel density

$0.415 \mathrm{~g} \mathrm{U} / \mathrm{cc}$ is $415 \mathrm{~g} \mathrm{U} / \mathrm{L}$.

2. The molecular weight of nitrate $\mathrm{NO}_{3}$ is 61.9895 . 
3. Calculate the molarity of the solution.

$0.39 \mathrm{mg}$ nitrate $/ \mathrm{g}$ soln $\times 1000 \mathrm{cc}$ soln $/ \mathrm{L}$ soln $\times 1 \mathrm{~g} / 1000 \mathrm{mg} \times 1.555 \mathrm{~g}$ soln $/ \mathrm{cc}$ soln $=0.60645 \mathrm{~g}$ excess nitrate/L soln

A 1-molar solution is $1 \mathrm{~mol}$ of acid/L of solution:

(For nitric acid 1 molar is 1 normal because there is only one atom of hydrogen per molecule of acid in $\mathrm{HNO}_{3}$.)

$(0.60645 \mathrm{~g}$ nitrate $/ \mathrm{L}$ soln $) /\left(61.9895 \mathrm{~g} \mathrm{NO}_{3} / \mathrm{mol} \mathrm{NO}_{3}\right)=9.783 \times 10^{-3} \mathrm{~mol}$ nitrate $/ \mathrm{L}$ is identical to $\mathrm{mol}$ of acid/L is identical to molarity.

4. The density fraction of the solution is 1.0. Do not try to use the density (specific gravity) of the solution divided by the theoretical density of $\mathrm{UO}_{2}\left(\mathrm{NO}_{3}\right)_{2}$ from the Standard Composition Library for your density multiplier. The $\mathrm{UO}_{2}\left(\mathrm{NO}_{3}\right)_{2}$ listed there is the solid, not the solution.

The solution specification data follow:

SOLNUO2(NO3)2 1415 9.783-3 SPG=1.555 1.02939223592 .6922385 .9

$92234 \quad 1.092236 \quad 0.5 \quad \mathrm{END}$

\section{METHOD 3:}

This method utilizes the solution option available in the standard composition specification data without specifying the specific gravity. Because the specific gravity is not specified in the input data, the specific gravity is approximated by the Material Information Processor. The option allowing the specific gravity to be input in the solution data was not available prior to SCALE 4.0.

1. Calculate the fuel density

$0.415 \mathrm{~g} \mathrm{U} / \mathrm{cc}$ is $415 \mathrm{~g} \mathrm{U} / \mathrm{L}$.

2. The molecular weight of nitrate $\mathrm{NO}_{3}$ is 61.9895 .

3. Calculate the molarity of the solution

$0.39 \mathrm{mg}$ nitrate $/ \mathrm{g}$ soln $\times 1000 \mathrm{cc}$ soln $/ \mathrm{L}$ soln $\times 1 \mathrm{~g} / 1000 \mathrm{mg} \times 1.555 \mathrm{~g}$ soln $/ \mathrm{cc}$ soln $=0.60645 \mathrm{~g}$ excess nitrate/L soln.

A 1-molar solution is $1 \mathrm{~mol}$ of acid/L of solution:

(For nitric acid 1 molar is 1 normal because there is only one atom of hydrogen per molecule of acid in $\mathrm{HNO}_{3}$.)

$(0.60645 \mathrm{~g}$ nitrate $/ \mathrm{L}$ soln $) /\left(61.9895 \mathrm{~g} \mathrm{NO}_{3} / \mathrm{mol} \mathrm{NO}_{3}\right)=9.783 \times 10^{-3} \mathrm{mols}$ nitrate $/ \mathrm{L}$ is identical to mols of acid/L is identical to molarity.

4. The density multiplier of the solution is 1.0. Do not try to use the density (specific gravity) of the solution divided by the theoretical density of $\mathrm{UO}_{2}\left(\mathrm{NO}_{3}\right)_{2}$ from the Standard Composition Library for your density fraction. The $\mathrm{UO}_{2}\left(\mathrm{NO}_{3}\right)_{2}$ listed there is the solid, not the solution.

The solution specification data follow:

SOLNUO2(NO3)2 $14415 \quad 9.783-3 \quad 1.0 \quad 293 \quad 92235 \quad 92.692238 \quad 5.9$

$92234 \quad 1.092236 \quad 0.5 \quad \mathrm{END}$

NUREG/CR-0200,

Vol. 3, Rev. 4

M7.5.62 


\section{M7.5.9.1 Comparison of Number Densities from the Three Methods}

The number densities of methods 1 and 2 should agree within the limits of the input data. The density multipliers in method 1 are 5 digits and the density multipliers in method 2 are 4 digits. Therefore, the number densities calculated by the two methods should agree to 4 or 5 digits. Methods 2 and 3 are identical except for the specification of the specific gravity. It is specified as input data in method 2 and is calculated by the Material Information Processor for method 3 . The differences in the two specific gravities are responsible for the difference in the hydrogen and oxygen number densities. It is recommended that method 2 be used when the specific gravity of the solution is given.

METHOD 1

NUCLIDE
NO.

92235

92238

92234

92236

7014

8016

1001

\begin{abstract}
ATOM DENSITY
\end{abstract}

9.84590E-04

6.19407E-05

1.06783E-05

5.29380E-06

2.13089E-03

3.74127E-02

5.77959E-02
METHOD 2

NUCLIDE
NO.

92235

92238

92234

92236

7014

8016

1001

\section{ATOM DENSITY \\ NUCLIDE
NO.}

9.84599E-04

6.19413E-05

1.06784E-05

5.29385E-06

2.13092E-03

3.74130E-02

5.77964E-02
92235

92238

92234

92236

7014

8016

1001

METHOD 3

ATOM

DENSITY

9.84599E-04

6.19413E-05

1.06784E-05

5.29385E-06

2.13092E-03

3.74826E-02

$5.79356 \mathrm{E}-02$

\section{M7.5.10 MULTIPLE FISSIE CEIIS IN A SINGLE PROBLEM}

Consider a problem that involves three different $\mathrm{UO}_{2}$ fuel assemblies: a 1.98\%-enriched assembly, a $2.64 \%$-enriched assembly, and a $2.96 \%$-enriched assembly. All fuel rods are $\mathrm{UO}_{2}$ at $10.138 \mathrm{~g} / \mathrm{cc}$ and are $0.94 \mathrm{~cm}$ in diameter. The Zircaloy $-4 \mathrm{clad}$ has an inside radius of $0.4875 \mathrm{~cm}$ and an outside radius of $0.545 \mathrm{~cm}$. The rod pitch is $1.44 \mathrm{~cm}$. Each fuel assembly is a $15 \times 15$ array of fuel pins with water holes, instrumentation holes, and burnable poison rods. For cross-section processing, the presence of the water holes, instrumentation holes, and burnable poison rods in the assemblies are ignored.

The Material Information Processor allows only one unit cell specification per problem. Therefore, a special effort must be made to provide the correct cross-section processing for the three different fuels. This can be achieved by specifying one of the fuel mixtures in the unit cell and entering the resonance and Dancoff data for the other two mixtures in the optional parameter data (MORE DATA).

To obtain the Dancoff data necessary for correct cross-section treatment of the three different fuels, run CSASN with PARM=CHECK specified. Note that PARM=CHECK must begin beyond column 10. Because all three fuels have the same physical dimensions (gap, clad, moderator and pitch), their Dancoff factors will be identical. Therefore, only one CSASN run is required. Find the Dancoff factors in the output. The final Material Information Processor data will specify one of the fuel mixtures in the unit cell and the Dancoff factors for the other two fuels will be entered in MORE DATA. This is done using the keyword $\mathrm{DAN}()=$. The correct resonance information for the two fuel mixtures that are not specified in the unit cell must also be entered in MORE DATA by specifying the mixture number, physical shape, and fuel lump dimension via the keyword RES=. 
The input data used to determine the Dancoff factors are given below. It is not necessary to specify all three fuel mixtures in the data. Only mixtures that are used in the unit cell data are required for the purpose of determining the Dancoff factors. This problem will determine the Dancoff factors for mixture 3 because it is used in the unit cell data (SQUAREPITCH).

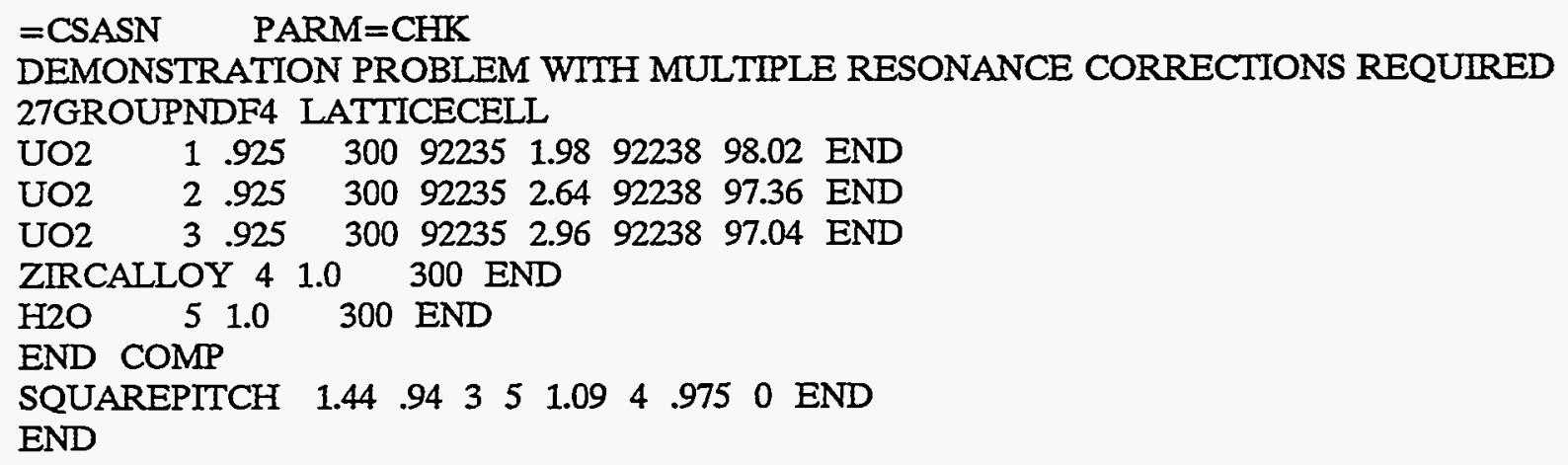

A portion of the computer printout from the above problem is given below. Locate the Dancoff factor for mixture 3 (2.30294E-01). The value 92235 is the ${ }^{235} \mathrm{U}$ of mixture 1,292235 is the ${ }^{235} \mathrm{U}$ of mixture 2, 392235 is the ${ }^{235} \mathrm{U}$ of mixture 3. Notice that Dancoff factors are calculated ONLY for the mixtures that are used in the unit cell data.

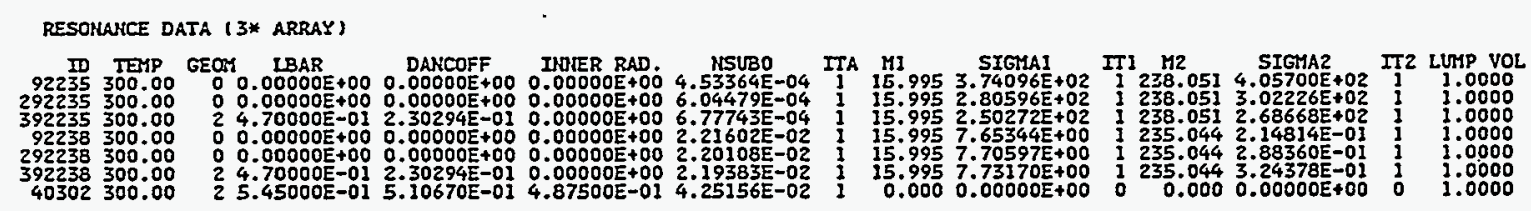

The following Material Information Processor data will calculate the Dancoff factors and resonance data for fuel mixture 1 because they are used in the unit cell data. The Dancoff factor and resonance data provided in MORE DATA will be used for fuel mixtures 2 and 3. Thus, appropriate cross-section processing will be achieved for all three fuel mixtures. The Dancoff factor for mixtures 2 and 3 was determined above. The resonance data are determined from the problem description (cylindrical pins with a radius of $0.47 \mathrm{~cm}$ ).

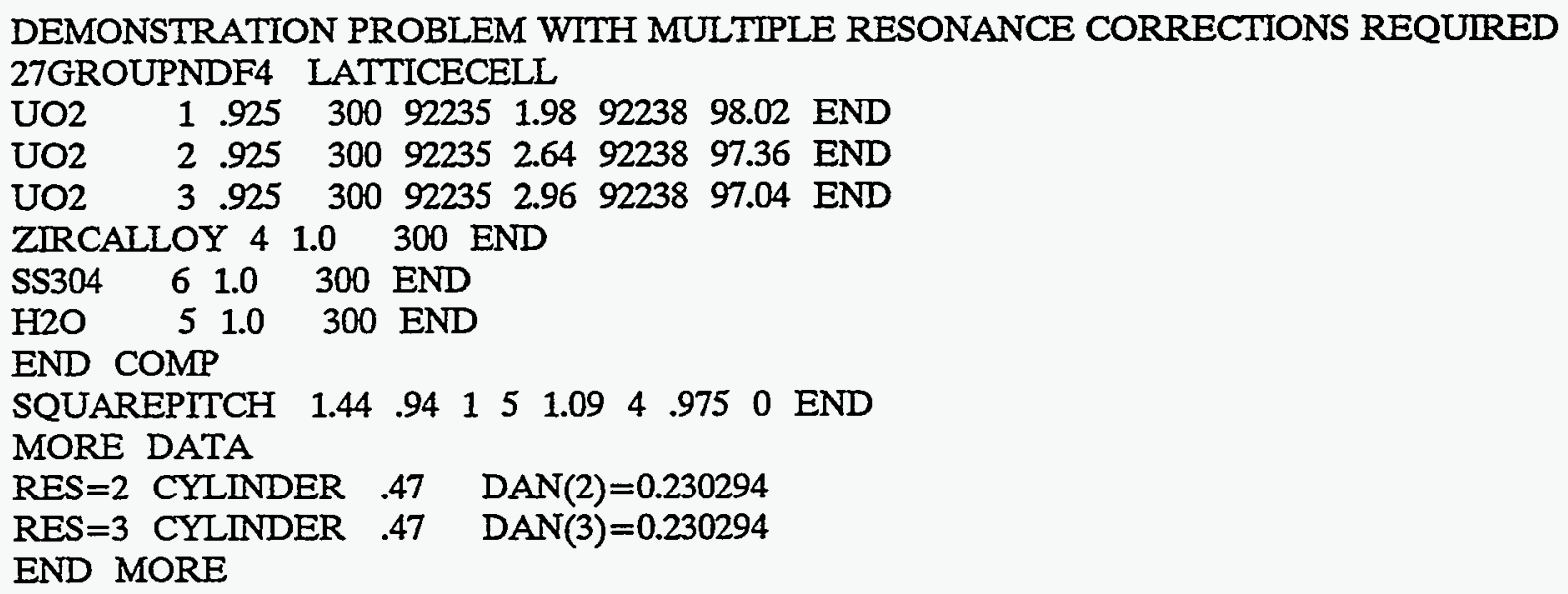


If the geometric configuration or density of the fuel or moderator for each of the three fuel cells is different, a CSASN run should be made for the two configurations that will not be specified in the final unit cell description. These two CSASN runs will provide Dancoff data to be entered in the MORE DATA portion of the final Material Information Processor data. The third configuration is specified in the unit cell data. Thus, two CSASN runs should be made with PARM=CHK specified. The first run specifies the first configuration in the unit cell. The second run specifies the second configuration in the unit cell. The Dancoff factors are located in the CSASN computer printouts and specified in MORE DATA in the final Material Information Processor data using the third fuel cell configuration in the unit cell. In addition, the shape and dimensions of those two fuel lumps must be entered in MORE DATA. In this way, the cross sections are correctly processed for the three different fuel cell configurations.

\section{M7.5.11 MULTIPLE FISSILE MIXTURES IN A SINGLE PROBLEM}

Extreme caution should be exercised when an attempt is made to treat multiple fissile mixtures in a single problem. The Material Information Processor and the SCALE cross-section processing codes do not adequately treat multiple fissile mixtures having significant interaction with each other in the resonance range.

The following problem involves large units having the bulk of their fissile material more than one mean-free path away from the surface of the unit. The interaction between the units that occurs in the resonance range is a very small fraction of the total interaction because an overwhelming percentage of the interaction occurs deep within each unit. Therefore, the resonance range interaction between the units can be ignored, and the cross-section processing in the resonance range can be considered adequate for this particular application.

Consider a problem that consists of four $20.96-\mathrm{kg} 93.2 \%$-enriched uranium metal cylinders, density $18.76 \mathrm{~g} / \mathrm{cc}$, and four 5-1 Plexiglas bottles filled with highly enriched uranyl nitrate solution at $415 \mathrm{~g} / \mathrm{L}$, a specific gravity of 1.555 , and $0.39 \mathrm{mg}$ of excess nitrate per gram of solution. The isotopic content of the uranium metal is $93.2 \%_{\mathrm{wt}}{ }^{235} \mathrm{U}, 5.6 \%_{\mathrm{wt}}{ }^{238} \mathrm{U}, 1.0 \%{ }_{\mathrm{wt}}{ }^{234} \mathrm{U}$, and $0.2 \%_{\mathrm{wt}}{ }^{236} \mathrm{U}$. The uranium isotopic content of the nitrate solution is $92.6 \%_{\mathrm{wt}}{ }^{235} \mathrm{U}, 5.9 \%_{\mathrm{wt}}{ }^{238} \mathrm{U}, 1.0 \%_{\mathrm{wt}}{ }^{234} \mathrm{U}$ and $0.5 \%{ }_{\mathrm{wt}}{ }^{236} \mathrm{U}$. The size of the metal cylinders is between 10 and $12 \mathrm{~cm}$ in diameter and height, and the size of the nitrate solution is on the order of 16 to $20 \mathrm{~cm}$ in diameter and height. The average mean-free path in the uranium metal is on the order of $1.5 \mathrm{~cm}$, and the average mean free path in the nitrate solution is on the order of $0.5 \mathrm{~cm}$. Therefore, infinite homogeneous medium is an appropriate choice for this problem.

See Examples 1 and 3 of Sect. M7.5.5.1 for data input details for the Plexiglas and uranium metal. See Example 1 of Sect. M7.5.5.3 for data input details for the uranyl nitrate solution. The Material Information Processor data for this problem using the 16-group cross-section library follow:

SET UP 4 AQUEOUS 4 METAL IN CSAS25

HANSEN-ROACH INFHOMMEDIUM

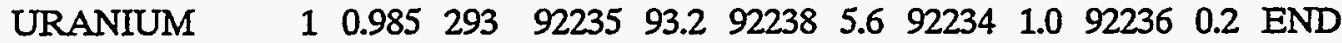

SOLNUO2(NO3)2 2415 9.783-3 SPG=1.555 1.02939223592 .6922385 .9

PLEXIGLAS 3 END

$92234 \quad 1.0 \quad 92236 \quad 0.5 \quad \mathrm{END}$

END COMP

\section{M7.5.12 CELL WEIGHTING}

Cell-weighted cross sections are created by XSDRNPM when an analytical sequence that ends in X (CSAS1X, CSAS2X, etc.) is executed. The unit cell description is then used by XSDRNPM to 
calculate the eigenvalue of the cell. For lattice cell problems, a white boundary condition is assumed. For multiregion problems, the boundary conditions specified in the unit cell are used. The resultant fluxes are used to weight the cross sections of the materials in the cell and create a homogenized cell-weighted cross section having the characteristics of the heterogeneous cell configuration. This cell-weighted cross section is always labeled mixture 500. Whenever XSDRNPM is executed for cross-section processing, mixtures used in the cell description cannot be used in the heterogeneous geometry data for other codes. If they are needed in other codes, additional mixtures with identical specifications must be defined in the standard composition data.

\section{M7.5.12.1 Cell weighting an infinite homogeneous problem}

Cell weighting an infinite homogeneous medium has no effect on the cross sections because there is only one zone and one set of cross sections. However, mixture 500 is created, and if a subsequent code uses the mixture number utilized in the unit cell, a warning message will be printed. However, mixture 500 can be used in a subsequent code, and it is identical to the cell cross section. CSAS1X is usually run to obtain the k-infinity for the mixture and not to obtain a cell-weighted cross section.

\section{EXAMPLE 1}

This problem would probably be run to provide the k-infinity of $20 \%$-enriched $\mathrm{UO}_{2}$.

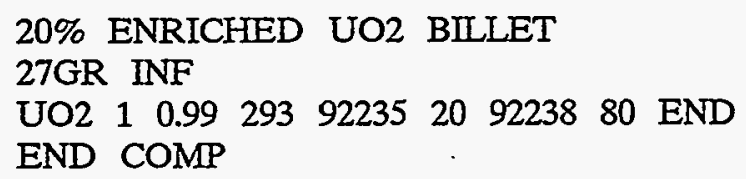

\section{M7.5.122 Cell weighting a lattice cell problem}

Cell weighting used with a lattice cell problem creates cell-weighted homogeneous cross sections that represent the characteristics of the heterogeneous system. This cell-weighted cross section can then be used in a subsequent code for the overall volume where the cells are located without having to mock up the actual three-dimensional heterogeneous array of cells. This cell-weighted homogeneous mixture is always designated as mixture 500 . Note that the mixtures used in the unit cell description cannot be used in a subsequent code because they have been flux weighted to create mixture 500 . Therefore, if a mixture used in the unit cell description is also to be used in a subsequent code, another mixture must be created that is identical except for the mixture number. Every mixture that is to be used in a subsequent code must be defined in the standard composition data.

A byproduct of the cell-weighting calculation is the eigenvalue (k-effective) of an infinite array of the cell described as the unit cell.

\section{EXAMPLE 1}

Consider a cylindrical stainless steel tank filled with spherical pellets of $2.67 \%$-enriched $\mathrm{UO}_{2}$ arranged in a close-packed "triangular" pitch, flooded with borated water at 4350 WPPM. The cylindrical stainless tank is sitting in a larger tank filled with borated water at 4350 WPPM.

The data for the $\mathrm{UO}_{2}$ and borated water were developed in detail in Example 3 of Sect. M7.5.8.2. The stainless steel must be defined, and mixture 3 was chosen because mixture 1 was the $\mathrm{UO}_{2}$ and mixture 2 was the borated water. Because the borated water will be used as a reflector for the stainless steel tank, and has been used in the unit cell data, it must be repeated with a different mixture number (in this case, as mixture 4). 
In the subsequent code, mixture 500 will be used to represent the $\mathrm{UO}_{2}$ pellets in the borated water, mixture 3 will represent the stainless steel tank, and mixture 4 will represent the borated water reflector around the stainless-steel tank.

The Material Information Processor data for creating the cell-weighted cross sections using the 27-group ENDF/B-IV cross-section library follow:

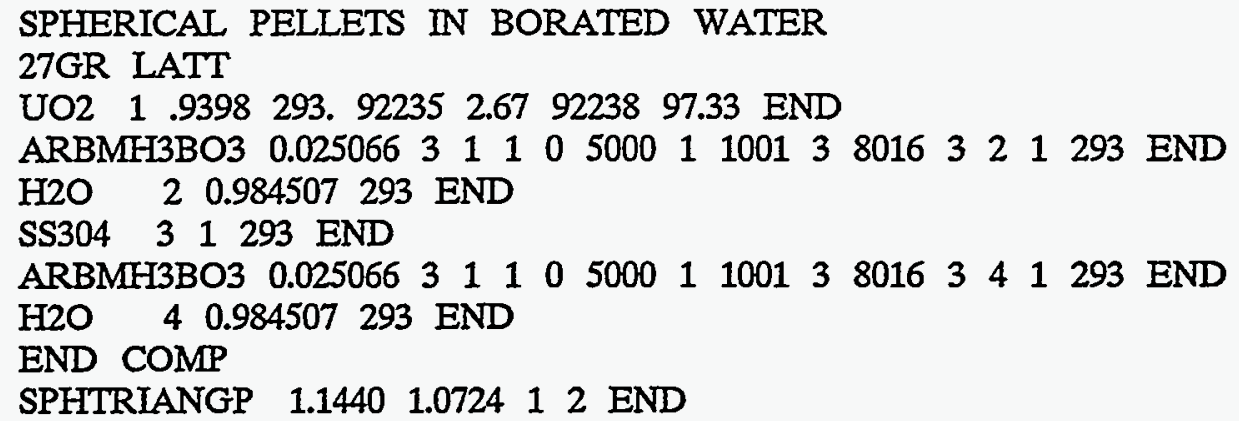

\section{M7.5.12.3 Cell weighting a multiregion problem}

A multiregion problem is cell weighted primarily to obtain a cell-weighted homogeneous cross section that represents the characteristics of the heterogeneous system. The eigenvalue obtained for a multiregion problem with cylindrical or spherical geometry having a white boundary condition specified on the right boundary approximates an infinite array of the cells. A vacuum boundary condition would represent a single cell. A slab with reflected boundary conditions for both boundaries represents an infinite array of slab cells.

The cell-weighted cross sections for spherical or cylindrical geometries with a white right boundary condition do not have a Dancoff correction and thus may not be accurate for representing a large array of the specified units. However, the Dancoff can be specified in the optional parameter data, Sect. M7.5.7, to make the cross sections more accurately represent an array of units.

\section{EXAMPLE 1}

Consider a small, highly enriched uranium sphere supported by a Plexiglas collar in a tank of water. The uranium metal sphere has a diameter of $13.1075 \mathrm{~cm}$, is $97.67 \%$ enriched, and has a density of $18.794 \mathrm{~g} / \mathrm{cc}$. The cylindrical Plexiglas collar has a $4.1275-\mathrm{cm}$ radius central hole, extends to a radius of $12.7 \mathrm{~cm}$ and is $2.54 \mathrm{~cm}$ thick. The water-filled tank is $60 \mathrm{~cm}$ in diameter.

The Plexiglas collar is not significantly different from water and does not surround the fuel, so it will be ignored. Because this makes the problem a one-dimensional geometry, it can be defined using the multiregion type of calculation and the eigenvalue of the system can be obtained without additional data by executing CSAS1X. The abundance of uranium is not stated beyond $97.67 \%$ enriched, so assume the remainder is ${ }^{238} \mathrm{U}$. Using these assumptions and the 27-group ENDF/B-IV cross-section library, the Material Information Processor data follow:

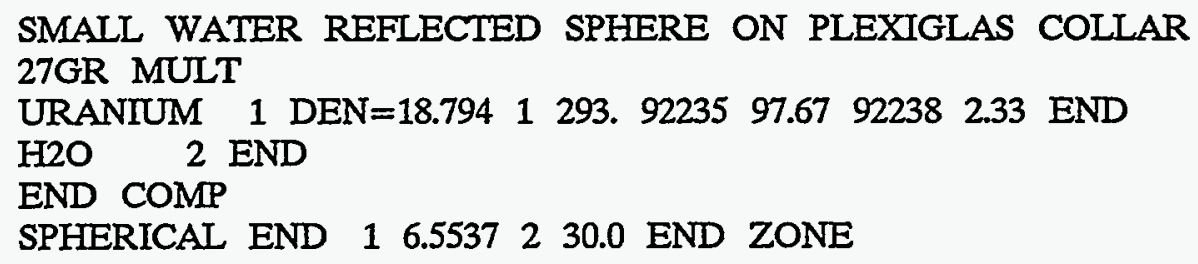




\section{M7.6 DESCRIPTION OF OUTPUT}

This section describes the computer printout from the Material Information Processor. The order of the printout is the following:

1. Title - The title of the problem is printed.

2. Problem Parameters - The parameters used in the problem are listed.

3. Problem Composition Description - All of the standard compositions used in describing the mixtures for the problem are listed.

4. Problem Geometry - The data defining the unit cell for the problem is listed.

5. Optional Parameter Data - If optional parameter data are entered, the optional parameter data table is printed.

6. Library Information Table - A table defining data libraries is printed for quality assurance purposes.

7. Additional Data - These data are printed only if the Material Information Processor is to check the data without executing (PARM $=$ CHECK on the analytical sequence card). Data that will be used in cross-section processing are printed.

\section{M7.6.1 PROBLEM TITLE}

The Problem Title is the first entry printed by the Material Information Processor. It is located immediately above the problem parameters, as shown in Fig. M7.6.1. See Sect. M7.4.3 for the data input requirements.

PROBLEM TO GENERATE MATERIAL INFORMATION PROCESSOR PRINTOUT

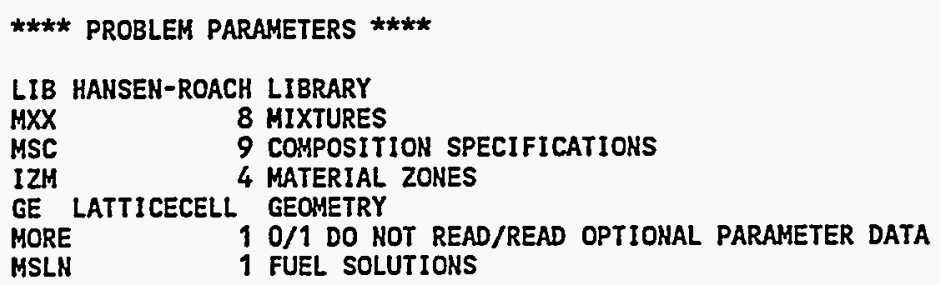

Figure M7.6.1 Example of problem title and problem parameters

\section{M7.6.2 PROBLEM PARAMETERS}

The Problem Parameters is a list of the parameters entered by the user and those counted by the code as the problem input data are processed. Sample input data specifying the title, cross-section library, and type of calculation are given below. 


\section{PROBLEM TO GENERATE MATERIAL INFORMATION PROCESSOR PRINTOUT HANSEN-ROACH LATTICECELI}

The resulting Problem Parameters printout is shown in Fig. M7.6.1. The problem title is printed exactly as it was entered. The cross-section library, LIB, and the geometry, GE, were set by the above data. The other parameters were determined from other data entered for the problem. The left column contains the variable name associated with the data. LIB, the cross-section library, is the first parameter item and is input as data. The data input requirements for LIB are defined in Sect. M7.4.3, item 2, CROSS SECTION LIBRARY NAME. The number of mixtures, MXX, the number of composition specifications, MSC, and the number of material zones, IZM, are determined by the code. The number of mixtures are counted when the standard composition specification data are read and is the total number of mixtures defined in the standard composition specification data. The number of composition specifications is the number of standard composition definitions used in the standard composition specifications data. The geometry type, GE, is input as data and governs the type of geometry data required to define the unit cell. It also influences the type of resonance treatment applied to the cross sections. The data input requirements for GE are given in Sect. M7.4.3, item 3, TYPE OF CALCULATION. The optional parameter flag, MORE, is set by the code. It is set to 1 if optional parameter data are entered. Otherwise, it is zero. The number of fuel solutions, MSLN, is determined by the code from the standard composition specification data and is the number of standard compositions whose name begins with SOLN.

\section{M7.6.3 PROBLEM COMPOSIIION DESCRIPTION}

This portion of the Material Information Processor printout lists all of the standard compositions used in the problem and their associated data, as shown in Fig. M7.6.2. The standard composition data are printed in the order in which the standard compositions are entered. For example, if data for mixture 5 are entered first, and data for mixture 1 are entered last, the standard composition defining mixture 5 will be printed first, and that for mixture 1 will be printed last. Furthermore, if several standard composition specifications are required to define a single mixture, they need not be entered contiguously. They will then be printed in the order in which they were entered, interspersed exactly as they were in the input data.

In each set of data shown in Fig. M7.6.2, the far left column lists the variable name or data name of the input data for each standard composition. These variable names correspond to those used in the Standard Composition input data described in Sect. M7.4.4. The middle column lists the data, and the right column contains either an explanation, or additional data.

The first set of data illustrates the data for a basic standard composition (see Sect. M7.5.5.1 for detailed input data examples) in which the user did not enter the density. The standard composition name is UO2, the mixture number is 1 , the volume fraction is 0.96 , and the theoretical density (obtained by the code from Table M8.2.1), is $10.96 \mathrm{~g} / \mathrm{cc}$. When the code supplies the density, the explanation to the right of the density, ROTH, is stated as THEORETICAL DENSITY. The temperature is 293 degrees Kelvin, and the UO2 is $3.25 \%$ enriched, with the remainder being ${ }^{238} \mathrm{U}$. The isotopic abundance is listed below the temperature with the nuclide $\mathrm{ID}$ printed in the center column and the weight percent printed in the right column. The input data for this entry are shown below.

UO2 10.96293922353 .259223896 .75 END

The second set of data illustrates the same standard composition used as mixture 7 , with a user-supplied density. When the user supplies the density, the explanation to the right of the density, ROTH, is stated as SPECIFIED DENSITY. The input data for this entry are shown below.

UO2 7 DEN=10.5216 1.0293922353.259223896.75 END

NUREG/CR-0200,

Vol. 3, Rev. 4

M7.6.2 
**** PROBLEM COMPOSITION DESCRIPTION ****

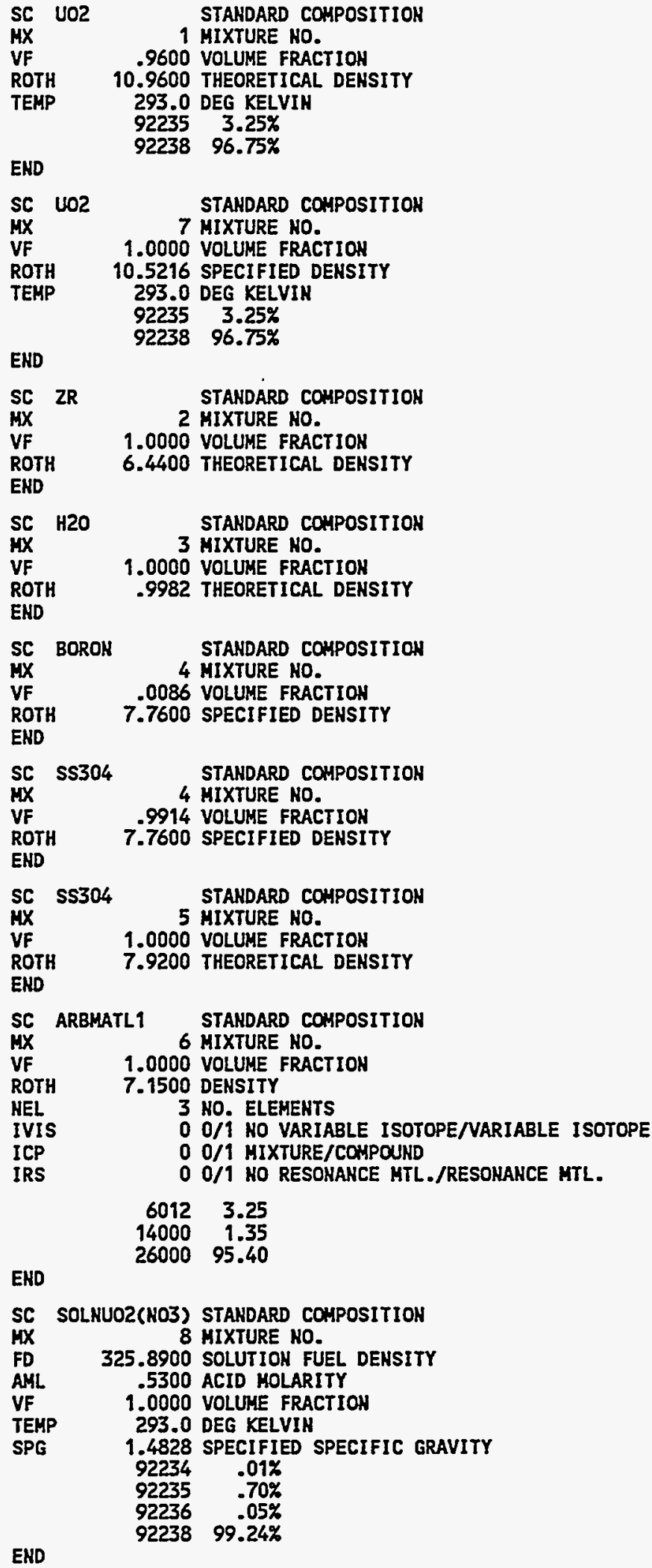

Figure M7.6.2 Example of standard composition printout 
The third and fourth sets of data also illustrate data for basic standard compositions. The third standard composition name is $\mathrm{ZR}$, the mixture number is 2 , the volume fraction is 1.0 , and the theoretical density, obtained from Table M8.2.1 by the code, is $6.44 \mathrm{~g} / \mathrm{cc}$. The fourth standard composition name is H2O, the mixture number is 3 , the volume fraction is 1.0 , and the theoretical density, obtained by the code from Table M8.2.1, is $0.9982 \mathrm{~g} / \mathrm{cc}$. The input data are shown below.

\section{ZR 2 1.0 END \\ H2O 31.0 END}

The fifth and sixth sets of data illustrate the creation of a single mixture using two basic standard compositions (see Sect. M7.5.5.4 for examples). Mixture 4 is borated stainless steel with a density of $7.76 \mathrm{~g} / \mathrm{cc}$, and is $0.86 \%$ wr natural boron. The input data for this mixture are shown below.

\section{BORON 4 DEN $=7.760 .0086$ END \\ SS304 4 DEN=7.76 0.9914 END}

The seventh set of data is another basic standard composition, stainless steel 304. The standard composition name is SS304, the mixture number is 5 , the volume fraction is 1.0 , and the theoretical dnesity, determined by the code, is $7.92 \mathrm{~g} / \mathrm{cc}$. The input data for this mixture are shown below:

\section{SS304 51.0 END}

The eighth set of data illustrates data for an arbitrary material standard composition. Examples of arbitrary material input data are given in Sect. M7.5.5.2. The standard composition name defined by the user is ARBMATL1; the mixture number, $M X$, is 6 ; the volume fraction, VF, is 1.0; the density, ROTH, is always entered by the user for an arbitrary material and for this problem is $7.15 \mathrm{~g} / \mathrm{cc}$. NEL is the number of elements required to define the arbitrary material and is entered as 3 . IVIS, the variable isotope indicator, is 0 because this arbitrary material does not contain multiple-isotope nuclides. The mixture/compound indicator, ICP, is 0 , indicating that the material is defined by weight percents as in an alloy, rather than by a chemical formula. The resonance indicator, IRS, is entered as 0 , indicating that this arbitrary material does not contain resonance nuclides. The data printed after the resonance indicator lists the isotope ID numbers, NCZA, in the center column and the corresponding weight percents, ATPM, in the right column. The input data for this arbitrary material follow.

\section{ARBMATL1 7.150300060123 .25140281 .352600095 .46 END}

If the arbitrary material had been a compound, ICP would have been entered as 1 , and the right column, ATPM, would have contained the number of atoms per molecule.

The ninth and last set of data illustrate data for a solution standard composition. Examples of solution standard composition input data are given in Sect. M7.5.5.3. The standard composition name, SC, for a solution must be chosen from Table M8.3.1. The mixture number, $M X$, is 8; the fuel density, FD, is $325.89 \mathrm{~g}$ U/L soln. The acid molarity, AML, is 0.53 ; the volume fraction, VF, is 1.0; the temperature, TEMP, is 293 degrees Kelvin; and the specific gravity, SPG, is 1.4828. When the user specifies the specific gravity, it is labeled SPECIFIED SPECIFIC GRAVITY. If the code determines the specific gravity, it is labeled DEFAULT SPECIFIC GRAVITY. The last data printed for a solution are the isotope ZA numbers, IZA, and the corresponding weight percent, WTP, of each isotope. IZA is printed in the center column, and WTP is printed to the right. The input data for this solution are given below.

SOLNUO2(NO3)2 $8325.890 .53 \mathrm{SPG}=1.48281 .0293$.

$92234.00892235 .70092236 .0529223899 .240 \mathrm{END}$

NUREG/CR-0200,

Vol. 3, Rev. 4

M7.6.4 


\section{M7.6.4 PROBLEM GEOMETRY SPECIFICATION}

This portion of the Material Information Processor printout lists the geometry description for the problem based on the unit cell description that was entered as data. The unit cell description provides data that are used in processing the cross sections. It follows the standard composition data in the printout. The three types of unit cells are (1) infinite homogeneous medium, (2) lattice cell, and (3) multiregion. The printout for each is shown below.

\section{M7.6.4.1 Problem Geometry Description for an Infinite Homogeneous Medium}

The mixture that is to be used to calculate the eigenvalue if XSDRNPM is to be executed is printed for an infinite homogeneous medium. An example of the printout is given in Fig. M7.6.3. See Sect. M7.4.5 for input data instructions. The input data corresponding to this example are:

\section{CELLMIX 6}

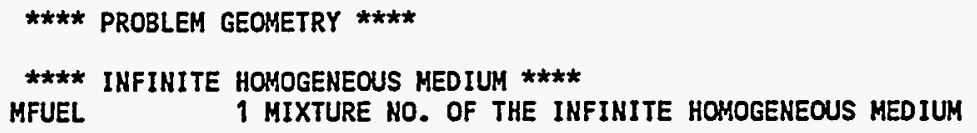

Figure M7.6.3 Example of geometry description printout for infinite homogeneous medium

\section{M7.6.4.2 Problem Geometry Description for a Lattice Cell}

Figure M7.6.4 illustrates the geometry output for a square-pitch lattice. The left column lists the data name corresponding to the input specifications as listed in Sect. M7.4.6 and examples presented in Sect. M7.5.6.2. The input data for this example are given below.

SQUAREPITCH 1.43 .9322131 .07182 .94980 END

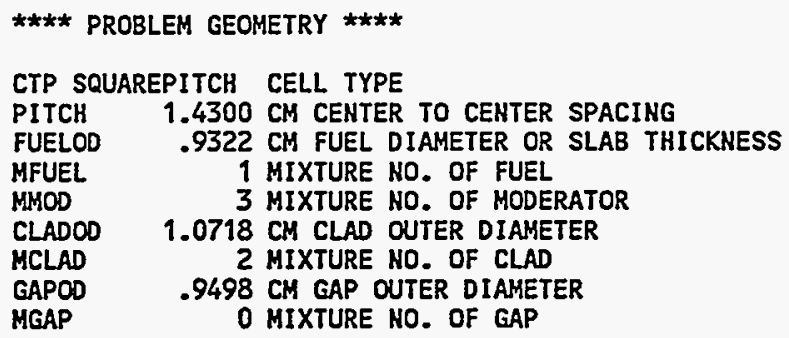

Figure M7.6.4 Example of geometry description printout for lattice cell 


\section{M7.6.4.3 Problem Geometry Description for a Multiregion Cell}

Figure M7.6.5 illustrates the geometry output for a multiregion cell. The left column lists the data name corresponding to the input specifications as listed in Sect. M7.4.7. Examples of multiregion input data are given in Sect. M7.5.6.3. The input data for this example are given below.

\section{BUCKLEDCYL VACUUM REFLECTED 0.0130 .0 END $\begin{array}{llll}17.62 & 27.77 & 3 & 40.77\end{array}$ \\ END ZONE}

The printed results for the above multiregion description are given in Fig. M7.6.5.

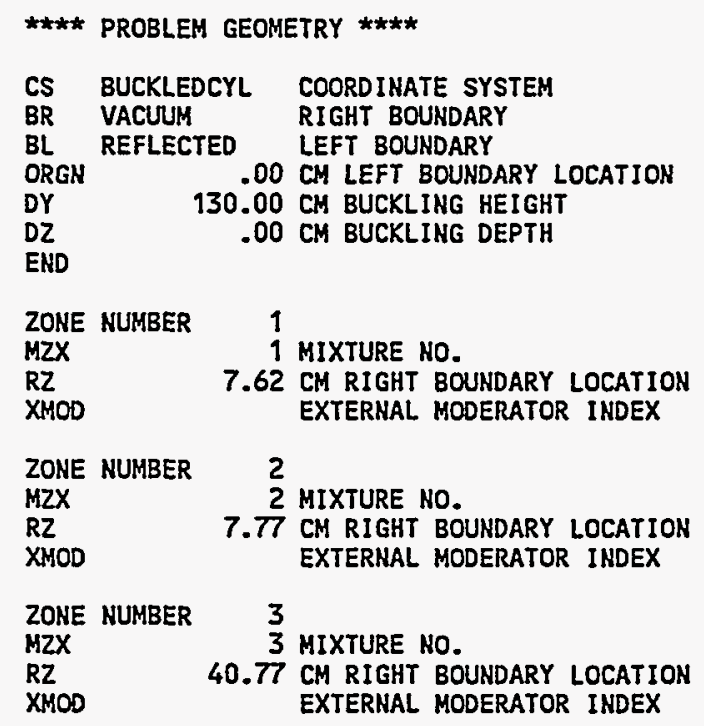

Figure M7.6.5 Example of geometry description printout for multiregion cell

\section{M7.6.5 OPTIONAL PARAMETER DATA OR MORE DATA}

The optional parameter data are printed only if one or more optional parameters are entered. Figure M7.6.6 illustrates the minimum printout when optional parameter data are entered. These eight parameters are printed when the MORE DATA option is activated. See Sect. M7.4.8 for input data instructions and Sect. M7.5.7 for additional details. As many as ten additional parameters can be entered and are printed only if they are entered. The input data for an example that modifies the number of XSDRNPM mesh intervals are given below:

\section{MORE DATA RES $=7$ SLAB 0.5 DAN(7)=0.23 END MORE}

The printed output for this example is given in Fig. M7.6.6.

NUREG/CR-0200,

Vol. 3, Rev. 4 


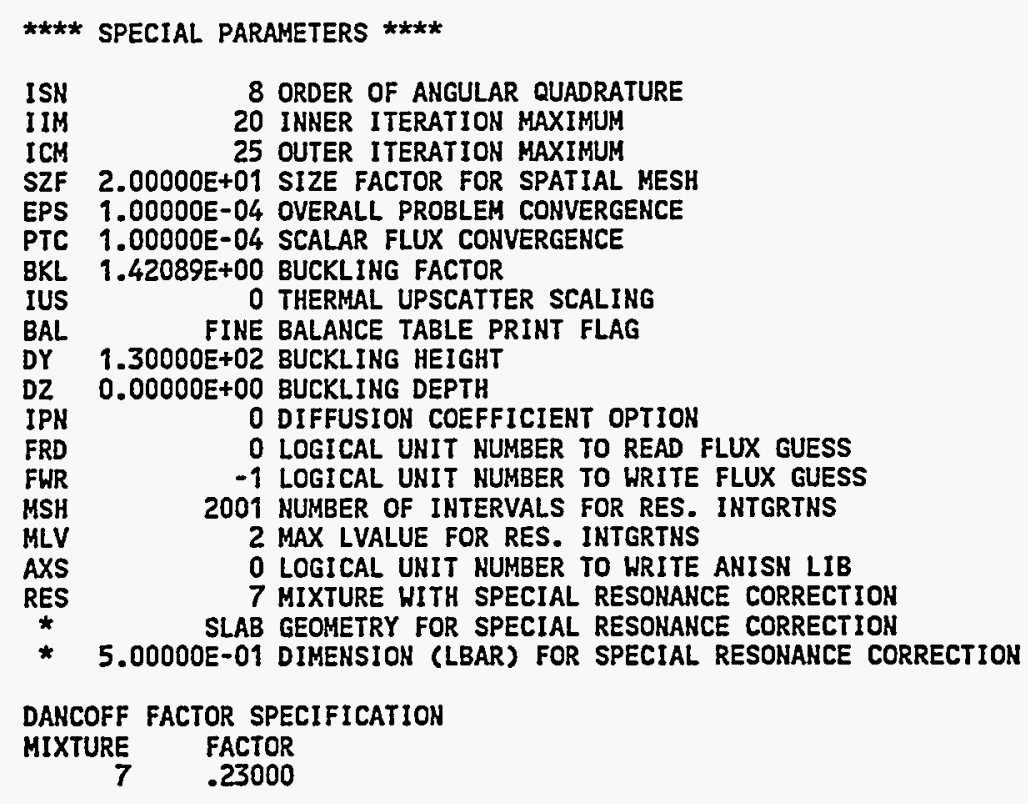

Figure M7.6.6 Example of optional parameter printout

\section{M7.6.6 ZONE SPECIFICATIONS FOR A LATTICE CELL}

The zone specifications for a lattice cell problem are printed after the special parameters (optional parameter data or MORE DATA), described in Sect. M7.6.5. If optional parameter data are not entered in the problem, the zone specifications for a lattice cell are printed immediately after the problem geometry. See Fig. M7.6.7 for an example of the zone specifications for lattice cell geometry. The input data that generated this printout are:

SQUAREPITCH 1.43 .9322131 .07182 .94980 END

ZONE SPECIFICATIONS FOR LATTICECELL GEOMETRY

$\begin{array}{lll}\text { ZONE } & 1 & \text { IS FUEL } \\ \text { ZONE } & 2 & \text { IS GAP } \\ \text { ZONE } & 3 & \text { IS CLAD } \\ \text { ZONE } & 4 & \text { IS MOD }\end{array}$

Figure M7.6.7 Example of lattice cell zone specifications

\section{M7.6.7 LIBRARY INFORMATION TABLE}

The Material Information Processor provides a Library Information Table for quality assurance purposes. An example of this table is given in Fig. M7.6.8. The table contains information about the Standard Composition Library, the master format cross-section library, the short problem-dependent master format cross-section library, and the direct-access dataset for saving input data. The Material Information Processor 


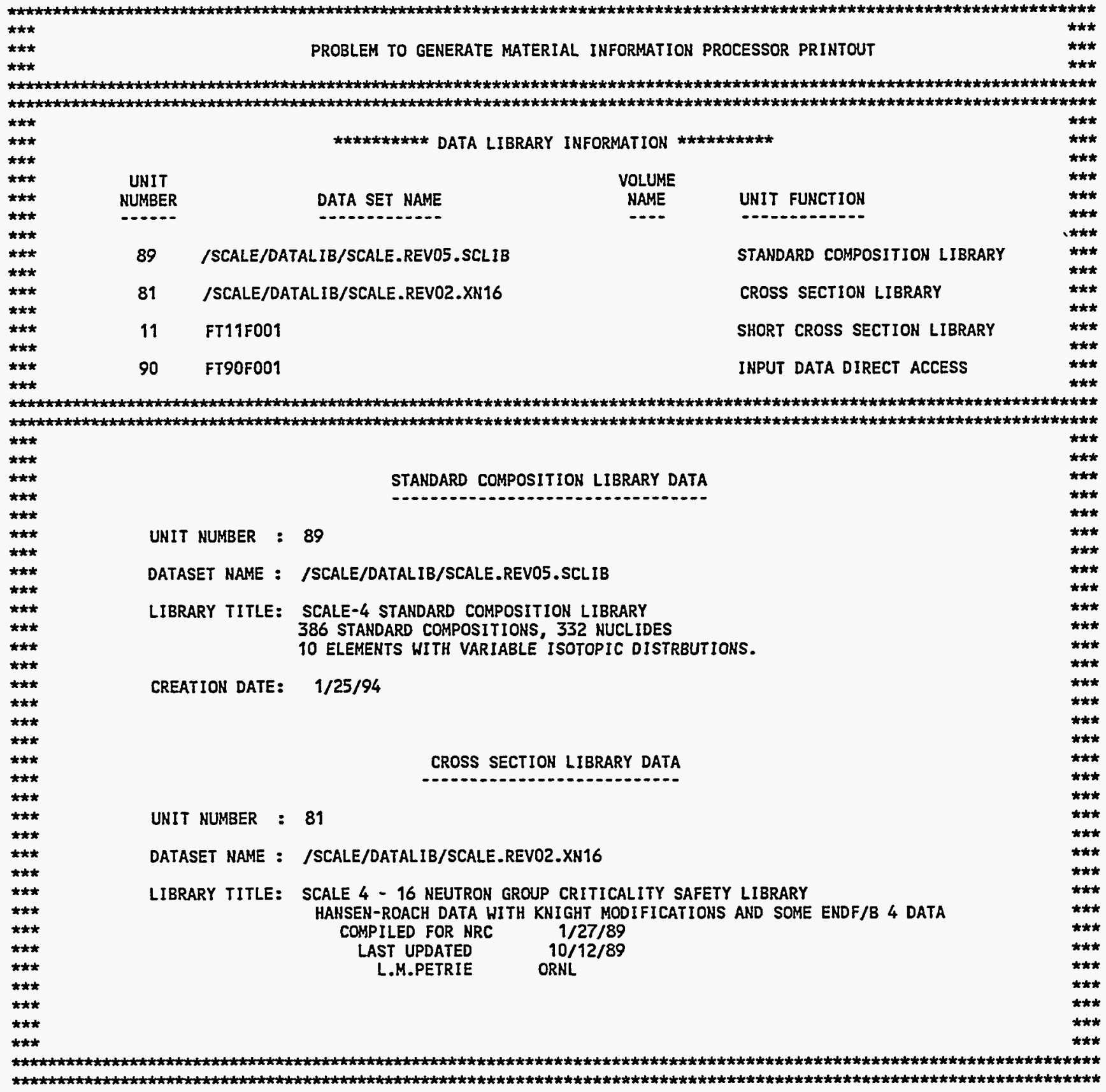

Figure M7.6.8 Example of data library information table

NUREG/CR-0200,

Vol. 3, Rev. 4

M7.6.8 
creates the short cross-section library by copying only the nuclides utilized in the problem from the master format cross-section library. It also saves input data as a direct-access dataset. For these four data libraries, the table lists (1) the unit number used to reference the library, (2) the data set name of the library, (3) the volume where the dataset resides, and (4) the unit function, which is a brief description of the type of library or the library function.

Additional data provided for the Standard Composition Library include the unit number, the dataset name, the title read from the Standard Composition Library, and the date the Standard Composition Library was created. The additional cross-section library data printed in the table include the unit number, the dataset name, and the title read from the master format cross-section library.

\section{M7.6.8 ADDITIONAL DATA}

The Material Information Processor data can be checked by executing CSASN and specifying PARM $=$ CHECK on the analytical sequence indicator. When this is done, the printout will contain additional data as discussed in this section. If $\mathrm{PARM}=\mathrm{CHECK}$ is not specified, the problem printout includes only the printout preceding this section. The data included in the additional data are (1) the mixing table and a table of parameters, (2) resonance data, and (3) NITAWL, XSDRNPM, and BONAMI data.

\section{M7.6.8.1 Mixing Table Data}

The first information printed under the heading additional data is the mixing table generated by the Material Information Processor. Multiple occurrences of the same nuclide are distinguished from each other by adding $100000 \times$ MIXNO to the nuclide ID number, where MIXNO is the mixture number. For example, in Fig. M7.6.9, 8016 is oxygen used in mixture 1 and 308016 is oxygen used in mixture 3. The atom density is given in atoms/barn-cm. The far right column, labeled N.I.T. POINTER, is the internal code pointer to the beginning of the data needed to generate resonance processing data for NITAWL.

The second set of data lists parameters for BONAMI, ICE, NITAWL, and XSDRN. The left column contains the parameter name or variable name. The center column contains the value assigned to the parameter. The right column contains an explanation of the parameter.

\section{M7.6.8.2 Resonance Data for NITAWL}

The data shown in Fig. M7.6.10 are used by NITAWL to provide the cross-section resonance processing to create problem-dependent cross sections. Only nuclides having resonance data are listed in this table. ID is the nuclide ID number. TEMP is the temperature in degrees Kelvin. GEOM specifies the geometry shape, 0/1/2/3 corresponding to homogeneous/slab/cylinder/sphere. LBAR is the absorber lump dimension in centimeters (thickness of a slab, radius of a sphere or cylinder, zero for homogeneous). DANCOFF is the calculated Dancoff factor. INNER RAD is the inner radius of the characteristic absorber lump. NSUBO is the absorber number density in the lump. ITA, IT1, and IT2 are the type of treatment used to determine the contribution in the interior of the absorber lump to the collision density for the absorber, the first moderator, and the second moderator. The available treatment options are: no moderator $(0)$ and Nordheim's integral method (1). M1 and M2 are the mass of the first and second moderator, respectively, for the given nuclide. SIGMA1 and SIGMA2 are the first and second moderator scattering cross section per absorber atom. LUMP VOL is the volume fraction of the absorber lump in the cell. This is used in NITAWL to provide a crude cell weighting in the resonance range. SCALE always sets this to 1.0, which eliminates this weighting in NITAWL. 
MIXING TABLE FROM STANDARD COMPOSITIONS DATA

\begin{tabular}{|c|c|c|c|}
\hline $\begin{array}{c}\text { MIXTURE } \\
\text { NO. } \\
1 \\
7 \\
8 \\
1 \\
7 \\
8 \\
1 \\
7 \\
3 \\
8 \\
2 \\
3 \\
8 \\
4 \\
4 \\
4 \\
5 \\
4 \\
5 \\
4 \\
5 \\
4 \\
5 \\
6 \\
6 \\
6 \\
8 \\
8 \\
8\end{array}$ & $\begin{array}{r}\text { NUCLIDE } \\
\text { NO. } \\
92235 \\
792235 \\
892235 \\
92238 \\
792238 \\
892238 \\
8016 \\
708016 \\
308016 \\
808016 \\
40000 \\
1001 \\
801001 \\
5010 \\
5011 \\
24304 \\
524304 \\
25055 \\
525055 \\
26304 \\
526304 \\
28304 \\
528304 \\
6012 \\
14000 \\
26000 \\
92234 \\
92236 \\
7014\end{array}$ & $\begin{array}{c}\text { ATOM } \\
\text { DENSITY } \\
7.72297 E-04 \\
7.72297 E-04 \\
5.84488 E-06 \\
2.27003 E-02 \\
2.27003 E-02 \\
8.18160 E-04 \\
4.69451 E-02 \\
4.69451 E-02 \\
3.33757 E-02 \\
3.79795 E-02 \\
4.25156 E-02 \\
6.67514 E-02 \\
6.11711 E-02 \\
7.34607 E-04 \\
2.98229 E-03 \\
1.69296 E-02 \\
1.74286 E-02 \\
1.68662 E-03 \\
1.73633 E-03 \\
5.76586 E-02 \\
5.93579 E-02 \\
7.49971 E-03 \\
7.72074 E-03 \\
1.16616 E-02 \\
2.06972 E-03 \\
7.35568 E-02 \\
6.70842 E-08 \\
4.32343 E-07 \\
1.96818 E-03\end{array}$ & $\begin{array}{l}\text { N.I.T. } \\
\text { POINTER } \\
\text { 299 } \\
299 \\
299 \\
302 \\
302 \\
302 \\
25 \\
25 \\
25 \\
25 \\
97 \\
5 \\
5 \\
19 \\
20 \\
48 \\
48 \\
50 \\
50 \\
54 \\
54 \\
59 \\
59 \\
21 \\
31 \\
52 \\
298 \\
300 \\
23\end{array}$ \\
\hline
\end{tabular}

$\begin{array}{lrl}\text { MMT } & 29 \text { NUCLIDES FROM CROSS SECTION LIBRARY } \\ \text { IRES } & 18 \text { RESONANCE NUCLIDES } \\ \text { IBL } & 1 \text { LEFT BDY CONDITION O/1/2/3 VACUUM/REFLECTED/PERIODIC/WHITE } \\ \text { IBR } & 3 \text { RIGHT BDY CONDITION O/1/2/3 VACUUH/REFLECTED/PERIODIC/WHITE } \\ \text { MS } & 29 \text { ENTRIES IN THE MIXING TABLE } \\ \text { ISCT } & 9 \text { ORDER OF SCATTERING } \\ \text { DY } & .0000 \text { FIRST TRANSVERSE BUCKLING DIMENSION } \\ \text { DZ } & .0000 \text { SECOND TRANSVERSE BUCKLING DIMENSION } \\ \text { VSC } & .0000 \text { VOID STREAMING }\end{array}$

Figure M7.6.9 Mixing table and parameters from the Material Information Processor data check

NUREG/CR-0200, 
RESONANCE DATA (3* ARRAY)

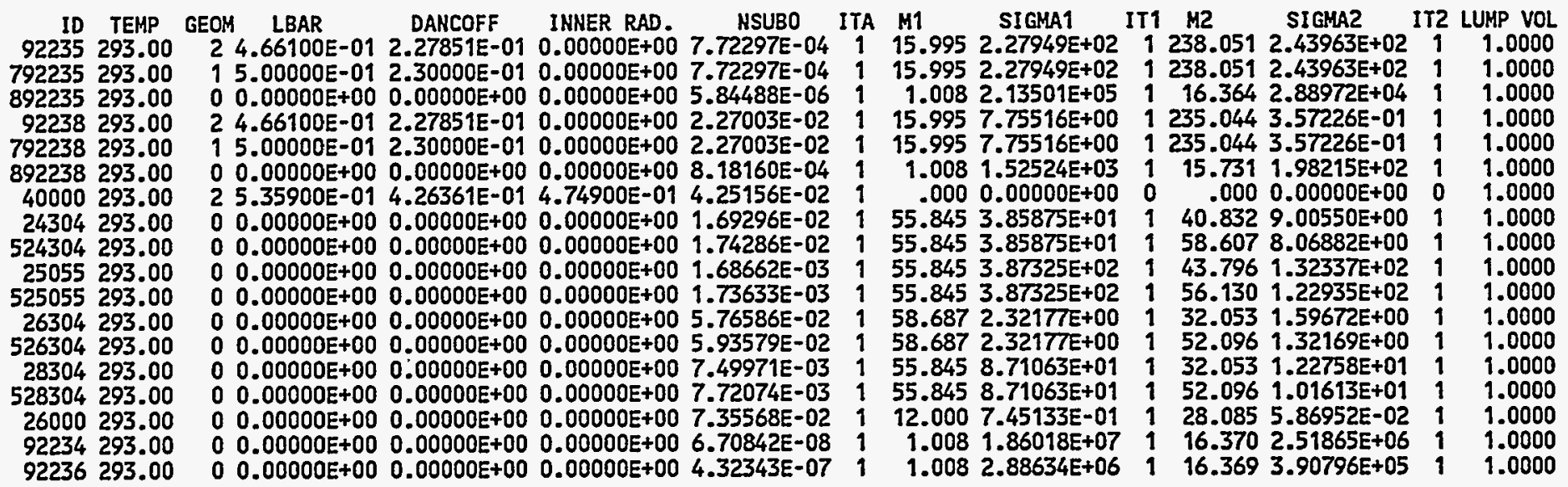

Figure M7.6.10 Resonance data for NITAWL

\section{M7.6.8.3 Additional Data for NITAWL, XSDRNPM, and BONAMI}

The data shown in Fig. M7.6.11 list additional data that are provided by the Material Information Processor for cross-section processing. The NITAWL data are the $2 \$$ and $4 *$ arrays. The CSAS(XSDRN) data include the zone boundaries, mixture by zone, and scatter by zone. The BONAMI data are the extra cross-section data. 
NITAWL DATA

CSAS (XSDRN) DATA

BONAMI DATA

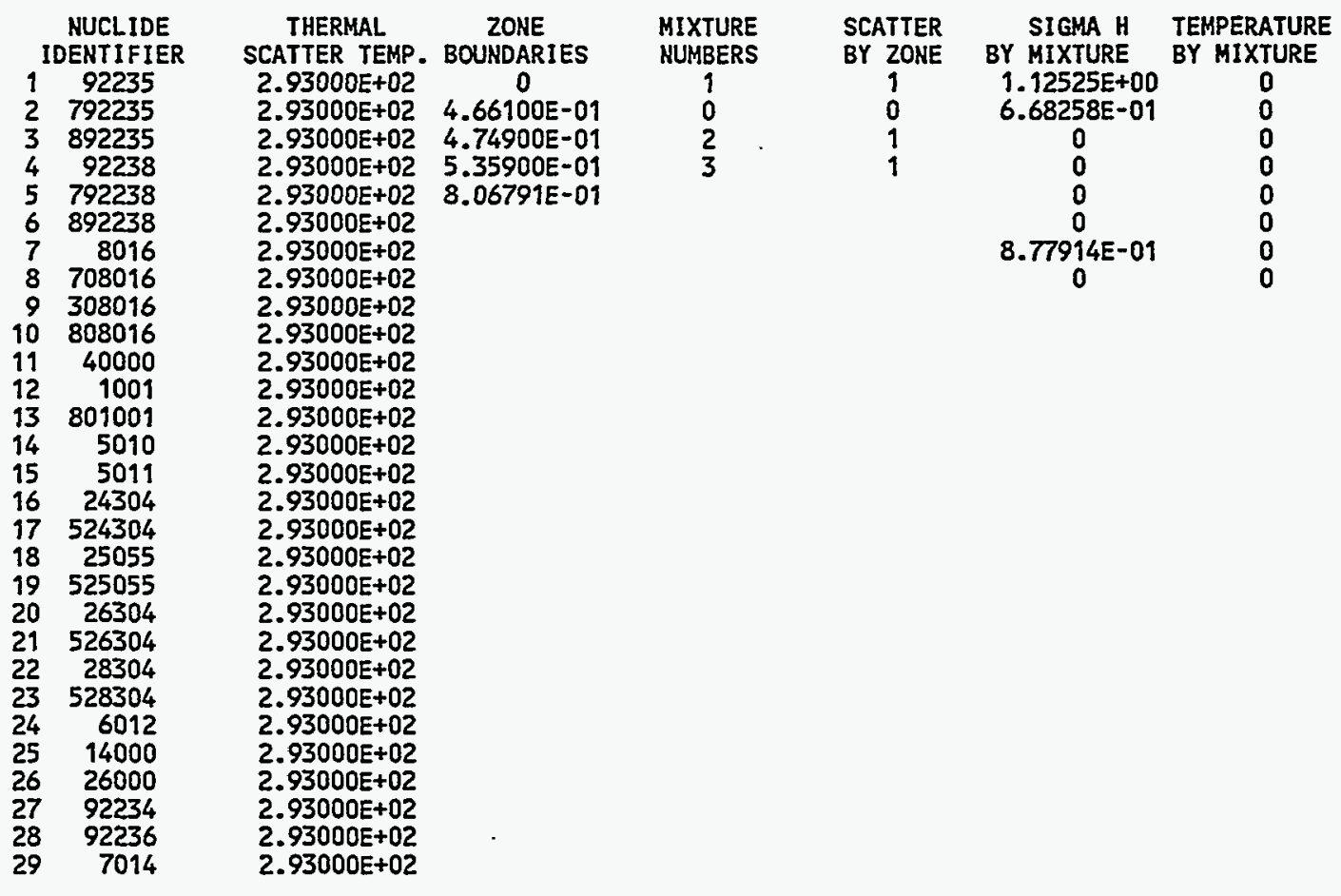

Figure M7.6.11 Additional data for NITAWL, XSDRNPM, and BONAMI

NUREG/CR-0200,

Vol. 3, Rev. 4 


\section{M7.7 WARNING AND ERROR MESSAGES}

The Material Information Processor is responsible for reading and checking the SCALE data used to create a problem-dependent AMPX working format cross-section library. Error messages are printed if the code determines that an error has occurred. Warning messages are printed if the code recognizes a possible error.

It is the responsibility of the user to verify whether the data are correct when a warning message is encountered. The functional modules activated by the control module and related sequences will be executed even though a warning message has been generated.

When an error is recognized, an error message is written and an error flag is set so the functional modules will not be activated. The code stops immediately if the error is too severe to allow continuation of input. However, it will continue to read and check the data if it is able. When the data reading has been completed, execution will be terminated if an error flag was set when the data were being processed. The STOP codes associated with the severe error messages are listed in Sect. M7.7.2.

\section{M7.7.1 MATERIAL INFORMATION PROCESSOR MESSAGES}

The following messages originate in the Material Information Processor, that portion of the analytical sequence that reads the parameter data, standard composition specification data, and geometry data necessary for preparing the required information for the cross-section processing codes.

\section{MP-1 FIRST TWO NUMBERS ARE WORDS OF STORAGE NEEDED AND ALLOCATED. THIRD IS REQUIRED ADDITIONAL WORDS.}

\section{PERTINENT CONSTANTS}

This message from subroutine KNIGHT indicates that the allocated computer storage will not hold the directories and isotope information tables. The first number printed is the amount of storage, in words, needed to hold these data. The second number is the amount of computer storage that was allocated, and the third number is the minimum additional words required to hold the data to this point. Subsequent portions of the program may require even more storage. Increase the region size for the "go step" in the job control language and resubmit the problem. A STOP 300 is executed when this message is printed.

\section{MP-2 FIRST TWO NUMBERS ARE WORDS OF STORAGE NEEDED AND ALLOCATED. THIRD IS REQUIRED ADDITIONAL WORDS.}

\section{PERTINENT CONSTANTS}

This message from subroutine KNIGHT indicates that the allocated computer storage will not hold the directories and isotope information tables. The first number printed is the amount of storage, in words, needed to hold these data. The second number is the amount of computer storage that was allocated, and the third number is the minimum additional words of storage required to hold the data to this point. Subsequent portions of the program may require even more storage. Increase the space allocation using the "SIZE" parameter on the analytical sequence indicator (Sect. M7.4.2) and resubmit the problem. A STOP 310 is executed when this message is printed.

MP-3 FIRST TWO NUMBERS ARE WORDS OF STORAGE NEEDED AND ALIOCATED. THIRD IS REQUIRED ADDITIONAL WORDS.

PERTINENT CONSTANTS 
This message from subroutine KNIGHT indicates that the allocated computer storage will not hold the directories and isotope information tables. The first number printed is the amount of storage, in words, needed to hold these data. The second number is the amount of computer storage that was allocated, and the third number is the minimum additional words of storage required to hold the data to this point. Subsequent portions of the program may require even more storage. Increase the space allocation using the "SIZE" parameter on the analytical sequence indicator (Sect. M7.4.2) and resubmit the problem. A STOP 320 is executed when this message is printed.

MP-4 FIRST TWO NUMBERS ARE WORDS OF STORAGE NEEDED AND ALLOCATED. THIRD IS REQUIRED ADDITIONAL WORDS.

\section{PERTINENT CONSTANTS}

This message from subroutine SETUPA indicates that the allocated computer storage will not hold the directories and isotope information tables. The first number printed is the amount of storage, in words, needed to hold these data. The second number is the amount of computer storage that was allocated, and the third number is the minimum additional words of storage required to hold the data to this point. Subsequent portions of the program may require even more storage. Increase the space allocation using the "SIZE" parameter on the analytical sequence indicator (Sect. M7.4.2) and resubmit the problem. A STOP 330 is executed when this message is printed.

MP-5 ***ERROR*** SYSTEM GEOMETRY NAME INCORRECT. INSTEAD OF ( ), THE USER SHOULD HAVE ENTERED LATTICECELC, MULTIREGION, OR INFHOMMEDIUM AS THE SECOND ITEM ON THE PARAMETER CARD. CHECK SPELIING.

This self-explanatory message is from subroutine SETUPB. The user has misspelled the word defining the type of calculation to be performed or the parameter data preceding it were entered incorrectly. See Sect. M7.7.3 for assistance in correctly specifying the parameter data.

$\mathrm{MP}-6$

***ERROR***

NOT FOUND IN STANDARD COMPOSITION LIBRARY. MAKE SURE THE COMPOSITION NAME USED IS IN THE STANDARD COMPOSITION LIBRARY.

This self-explanatory message from subroutine STDCMP indicates that a standard composition name is misspelled, the standard composition specification data are out of order, or the "END" has been omitted from the preceding standard composition specification. Check the standard composition specification data carefully. See Sect. M7.7.4 for assistance with standard composition specification cards. See Sect. M8 for the materials available in the Standard Composition Library.

MP-7 ***ERROR*** THE USER ENTERED A VOLUME FRACTION (VF) OF 0.0 FOR ONE OF THE STANDARD COMPOSITIONS ( $)$. THIS INDICATES THAT HE INTENDS TO ENTER A NUMBER DENSITY FOR THE STANDARD COMPOSITION. THAT, HOWEVER, CAN ONLY BE DONE WHEN THE STANDARD COMPOSITION NAME REPRESENTS A SINGLE NUCLIDE (LIKE H, O, PB, B-10, U-238, ETC.). CHECK THE STANDARD COMPOSITION LIBRARY.

This self-explanatory message is from subroutine STDCMP. Check the Standard Composition Library, Sect. M8, for the available standard composition names. See Sect. M7.7.4 for the correct method of specifying standard composition specification data.

NUREG/CR-0200,

Vol. 3, Rev. 4

M7.7.2 
MP-8 ***ERROR*** CELL TYPE NAME ( ) IS INCORRECT. CHECK THE SPELLING. THE ALLOWED NAMES ARE: SQUAREPITCH, TRIANGPITCH, SPHSQUAREP, SPHTRIANGP, SYMMSLABCELI, ASYMSLABCELL, ASQUAREPITCH,ATRIANGPITCH, ASPHSQUAREP,ASPHTRIANGP, ASQP, ATRP, ASSP, ASTP.

This self-explanatory message is from subroutine LATCEL. The data are misspelled or out of order. Some data items may be missing or extra ones may have been entered. Errors in the standard composition specification data can cause this message to be printed. See Sect $\mid$ M7.7.6 for additional assistance.

MP-9 ***ERROR*** THE NUMBER OF ZONES (IZM= ) IS INCORRECT FOR ASYMSLABCELL GEOMETRY. FOR AN ASYMMETRIC LATTICECELL CALCULATION, ONE SHOULD HAVE IZM=3, 5, OR 7, DEPENDING ON THE MATERIALS PRESENT.

This self-explanatory message is from subroutine LATCEL. See Sect. M7.7.6 for an explanation of the ASYMSLABCELL geometry data. A code error is responsible for this message.

MP-10 ***ERROR*** INSUFFICIENT DATA SUPPLIED ON THE GEOMETRY DESCRIPTION CARD.

This message from subroutine LATCEL can be caused by having an error in the standard composition specification data, thereby causing the reading routines to get out of phase. If no error messages precede this message, it may indicate that a code error exists. The number of material zones (IZM) has been destroyed or altered in some manner.

\section{MP-11 ***ERROR*** MTXTURE _ IN THE CSAS GEOMETRY DESCRIPTION WAS NOT} SPECIFIED IN THE STANDARD COMPOSITION DATA.

This message from subroutine LATCEL indicates that a mixture number used in the geometry description was not defined in the standard composition specification data. Check the input data for consistency. If the specified mixture number is zero, and the problem is a lattice cell problem using mixture zero for the clad or moderator, it will be necessary to specify a low-density mixture in the standard composition data and use it in the cell specification.

MP-12 ***ERROR*** THE GAP WAS SPECIFIED AS MIXTURE ON THE LATTICECELL. IT SHOULD BE ZERO OR A VALID MIXTURE NUMBER.

This message from subroutine LATCEL indicates that the mixture number used for the GAP was not defined in the standard composition specification data. Check the input data for consistency.

MP-13 **WARNING** NUMBER OF ENTRIES ON THE GEOMETRY DESCRIPTION CARD EXCEEDS THE NUMBER EXPECTED. THIS MESSAGE MAY BE GENERATED IF THE USER FORGOT TO ENTER THE END ON THE GEOMETRY DESCRIPTION CARD.

This message from subroutine LATCEL may result from a code error or from omitting the word "END" from the geometry description card. 

MULTIREGION CAICULATION, THE USER SHOULD HAVE ENTERED SLAB, CYLINDRICAL, SPHERICAI, BUCKLEDSLAB OR BUCKLEDCYL ON THE GEOMETRY DESCRIPTION CARD. CHECK SPELLING.

This self-explanatory message is from subroutine MULTRG.

***ERROR*** ALPHANUMERIC DESCRIPTION OF THE RIGHT-HAND BOUNDARY CONDITION ( ) IS INCORRECT. ONLY VACUUM, REFLECTED, PERIODIC, AND WHITE BOUNDARY CONDITIONS ARE ALLOWED. CHECK SPELLING. CHECK GEOMETRY DESCRIPTION CARD INPUT INSTRUCTIONS FOR ADDITIONAL ASSISTANCE. assistance.

This self-explanatory message is from subroutine MULTRG. See Sect. M7.7.6 for additional

MP-16 ***ERROR*** ALPHANUMERIC DESCRIPTION OF THE LEFT-HAND BOUNDARY CONDITION ( ) IS INCORRECT. ONLY VACUUM, REFLECTED, PERIODIC, AND WHITE BOUNDARY CONDITIONS ARE ALLOWED IN SLAB GEOMETRY. IN THE CASE OF CYLINDRICAL OR SPHERICAL GEOMETRY, ONLY THE REFLECTED BOUNDARY CONDITION IS ALLOWED ON THE LEFT. CHECK SPELLING. CHECK GEOMETRY DESCRIPTION CARD INPUT INSTRUCTIONS FOR ADDITIONAL INSTRUCTIONS. assistance.

This self-explanatory message is from subroutine MULTRG. See Sect. M7.7.6 for additional

MP-17 ***ERROR*** MIXTURE FROM THE MULTIREGION DATA WAS NOT SPECIFIED IN THE STANDARD COMPOSITION DATA.

This message is from subroutine MULTRG. It indicates that a mixture number specified in the multiregion data was not defined in the standard composition specification data. Check the input data for consistency.

MP-18 ***ERROR*** USER MADE AT LEAST DATA ERRORS. PROBLEM WILL NOT BE RUN. HOPEFULLY, EACH OF THESE ERRORS WILL HAVE GENERATED ITS OWN SELF-EXPLANATORY ERROR MESSAGE. IF NOT, CHECK DATA CAREFULLY BEFORE RESUBMITTING.

This self-explanatory message is from subroutine SETUPB. Check through the problem printout and correct all errors that have occurred.

MP-19 FIRST TWO NUMBERS ARE WORDS OF STORAGE NEEDED AND ALLOCATED. THIRD IS REQUIRED ADDITIONAL WORDS.

\section{PERTINENT CONSTANTS}

This message is from subroutine SETUPB. It indicates that the allocated computer storage will not hold the data that must be loaded to calculate the information that must be passed to BONAMI. The first number is the amount of storage, in words, needed to hold these data. The second number is the amount of

NUREG/CR-0200,

Vol. 3, Rev. 4

M7.7.4 
computer storage that is required to hold these data. The third number is the minimum additional words of storage required to hold these data. Subsequent portions of the program may require even more storage. Increase the space allocation using the "SIZE" parameter on the analytical sequence indicator (Sect. M7.4.2) and resubmit the problem. A STOP 390 is executed when this message is printed.

MP-20 ***ERROR*** MIXTURE NUMBER LESS THAN 1.

This message is from subroutine SETUPB. A mixture number specified on a standard composition specification card must always be greater than zero. This message is triggered if a MP-6 message is printed. Fixing the MP-6 error should eliminate this message. If the printed mixture number is a positive number, a code error is responsible for the message.

MP-21 ***WARNING***

STANDARD COMPOSITION CARD NUMBER IMPLIES THAT MIXTURE NUMBER HAS A TEMPERATURE OF DEGREES KELVIN, WHEREAS STANDARD COMPOSITION SPECIFICATION CARD _ IMPLIES THAT MIXTURE NUMBER HAS A TEMPERATURE OF DEGREES KELVIN. (ONE OF THESE MAY HAVE BEEN THE VALUE SPECIFIED BY DEFAULT.) THE CODE WILL ASSUME THE HIGHER OF THE TWO AND PROCEED. IF THIS IS NOT SATISFACTORY, THE USER SHOULD ENTER THE CORRECT TEMPERATURE ON EACH OF THE STANDARD COMPOSITION SPECIFICATION CARDS INDICATED.

This self-explanatory message is from subroutine SETUPB.

MP-22 **WARNING** STANDARD COMPOSITION SPECIFICATION CARD(S) MISSING FOR MIXTURE NUMBER

This message from SETUPB is printed to remind the user that the mixture numbers specified in the standard composition specification data are not contiguous. This may result in wasted storage space, but is not necessarily indicative of an error.

MP-23 FIRST TWO NUMBERS ARE WORDS OF STORAGE NEEDED AND ALLOCATED. THIRD IS REQUIRED ADDITIONAI WORDS.

\section{PERTINENT CONSTANTS}

This message from subroutine MTABLE indicates that the allocated computer storage will not hold the nuclide ID numbers that will be processed by subroutine IDENTS. The first number printed is the amount of storage, in words, needed to hold these data. The second number is the amount of computer storage that was allocated, and the third number is the minimum additional words of storage needed to hold the data to this point. Subsequent portions of the program may require even more storage. Increase the space allocation using the "SIZE" parameter on the analytical sequence indicator (Sect. M7.4.2) and resubmit the problem. A STOP 340 is executed when this message is printed.

MP-24 FIRST TWO NUMBERS ARE WORDS OF STORAGE NEEDED AND ALLOCATED. THIRD IS REQUIRED ADDITIONAL WORDS.

PERTINENT CONSTANTS 
This message from subroutine MIXTAB indicates that the allocated computer storage will not hold the three mixing table arrays that will be processed by subroutine ARRAY3. The first number printed is the amount of storage, in words, needed to hold these data. The second number is the amount of computer storage that was allocated, and the third number is the minimum additional words of storage needed to hold the data to this point. Subsequent portions of the program may require even more storage. Increase the space allocation using the "SIZE" parameter on the analytical sequence indicator (Sect. M7.4.2) and resubmit the problem. A STOP 350 is executed when this message is printed.

\section{MP-25 FIRST TWO NUMBERS ARE WORDS OF STORAGE NEEDED AND ALLOCATED. THIRD IS REQUIRED ADDITIONAL WORDS.}

\section{PERTINENT CONSTANTS}

This message from subroutine MIXTAB indicates that the allocated computer storage will not hold the three mixing table arrays that will be processed by subroutine ARRAY3. The first number printed is the amount of storage, in words, needed to hold these data. The second number is the amount of computer storage that was allocated, and the third number is the minimum additional words of storage needed to hold the data to this point. Subsequent portions of the program may require even more storage. Increase the space allocation using the "SIZE" parameter on the analytical sequence indicator (Sect. M7.4.2) and resubmit the problem. A STOP 360 is executed when this message is printed.

MP-26 FIRST TWO NUMBERS ARE WORDS OF STORAGE NEEDED AND ALLOCATED. THIRD IS REQUIRED ADDITIONAL WORDS.

\section{PERTINENT CONSTANTS}

This message from subroutine MIXTAB indicates that the allocated computer storage will not hold the three mixing table arrays that will be processed by subroutine ARRAY3. The first number printed is the amount of storage, in words, needed to hold these data. The second number is the amount of computer storage that was allocated, and the third number is the minimum additional words of storage needed to hold the data to this point. Subsequent portions of the program may require even more storage. Increase the space allocation using the "SIZE" parameter on the analytical sequence indicator (Sect. M7.4.2) and resubmit the problem. A STOP 370 is executed when this message is printed.

MP-27 ***ERROR*** THE NUMBER OF MIXTURES FOUND IN THE MIXING TABLE IS INCONSISTENT WITH THE INPUT DATA. THE NUMBER FOUND IS BUT THE INPUT DATA INDICATED

This message from subroutine REORDR indicates that an error was found in the mixing table during operations to reorder and load it in permanent storage. The number of mixtures found in the mixing table should be the same as the number indicated by the input data. A code error is the likely cause of this message. A STOP 380 is executed when this message is printed.

MP-28 ***ERROR*** NUCLIDE ID _ SPECIFIED IN THE INPUT DATA WAS NOT FOUND IN THE STANDARD COMPOSITION LIBRARY.

This message is from subroutine IDENTS or subroutine SLNS. A STOP 395 is printed with this message. Check the standard composition specification data, Sect. M7.7.4, and assure that the "ZA" ID numbers were entered correctly. This message is also printed if an arbitrary material specifies a value other than 0 or 1 for the MULTIPLE-ISOTOPE INDICATOR (IVIS in Sect. M7.7.4).

NUREG/CR-0200,

Vol. 3, Rev. 4

M7.7.6 
This message from subroutine ARCHK is indicative of a code error. ARCHK is called from subroutine DAN to assure that proper arguments are supplied to the ARCSIN and ARCCOS functions in determining cylinder Dancoff factors. This error can be caused by specifying a center-to-center spacing that is smaller than is physically possible.

MP-30 ***ERROR***

THE MATRIX WAS SINGULAR WHEN THE NUMBER FRACTION OF AN ISOTOPE IN AN ELEMENT WAS BEING DETERMINED. MAKE SURE THE SPECIFIED ISOTOPE DISTRIBUTION (WEIGHT PERCENT) SUMS TO 100.0.

This message from subroutine NOFRAC is caused by an isotope distribution that does not sum to 100.0 percent for an element. Entry A7 of Sect. M7.4.4 illustrates the correct procedure for specifying the weight percent of the various isotopes in an element.

MP-31 ${ }^{* * *}$ ERROR $* * * \quad$ THE CALCULATED NUMBER FRACTIONS DO NOT REPRODUCE THE WEIGHT PERCENTS ENTERED AS INPUT DATA OR OBTAINED FROM THE STANDARD COMPOSITION LIBRARY.

\section{WTFRAC $=$ nnnnnnnnnn NOFRAC $=$ mmmmmmmmmm $\quad$ MASS $=\ell \ell \ell \ell \ell \ell \ell \ell \ell \ell$}

This message is printed from subroutine NOFRAC. WTFRAC, NOFRAC, and MASS are printed for each isotope in the standard composition. WTFRAC is the specified input weight percent for the isotope converted to weight fraction instead of weight percent. NOFRAC is the adjusted atom percent converted to atom fraction for the isotope corresponding to a total weight percent of $100 \%$ for the isotopes in the standard composition. MASS is the atomic weight of the isotope. The adjusted isotopic weight percents are not printed in MP-31 but can be calculated according to:

$$
\mathrm{ADJ}_{i}=\frac{\text { NOFRAC }_{i} \times \text { MASS }_{i}}{\sum_{i} \text { NOFRAC }_{i} \times \text { MASS }_{i}} \times 100
$$

where

$A D J_{i}$ is the adjusted weight percent of isotope $i$,

NOFRAC $i$ is the number fraction of isotope i printed in MP-31, and

MASS $_{i}$ is the atomic weight of isotope i printed in MP-31.

Message MP-31 is printed if the adjusted weight percent of any individual isotope differs by $0.4 \%$ or more from the isotopic weight percent specified for that particular isotope in the standard composition data. An error flag is set, and the problem will not execute. If the isotopic weight percents specified in the input data do not sum to $100 \%$, the weight percent of the first isotope whose specified weight percent is greater than $0.1 \%$ is adjusted to force the total weight percent to sum to $100 \%$. If this adjustment results in a calculated weight percent for that isotope that is less than $0.4 \%$ different from that specified in the input data, the problem is run using the adjusted data. If message MP-31 is printed, correct the isotopic weight percents specified in the standard composition input data to sum to 100 or specify the isotope with the largest weight percent first, and resubmit the problem. 

WAS READ INSTEAD.

This message from subroutine SETUPA is printed if the data are out of order or the keywords END COMP or END COMPOSITIONS are omitted after the last standard composition specification. An END followed by blanks is also allowed. Check the data and the spelling of the END COMP. See Sect. M7.4.4.

MP-33 ***ERROR*** END OF FILE WAS ENCOUNTERED WHILE READING MULTIREGION ZONE DESCRIPTION. VERIFY THAT THE END ZONE CARD WAS ENTERED.

This self-explanatory message from subroutine SETUPA is printed if the END ZONE is omitted following the multiregion zone description data. See Sect. M7.4.7.

\section{MP-34 ***ERROR*** END ZONE WAS EXPECTED, BUT __ WAS READ INSTEAD.}

This message from subroutine SETUPA is printed if data are out of order or the keywords END ZONE are omitted at the end of the multiregion zone description data. Check the data and the spelling of the END ZONE. See Sect. M7.4.7.

\section{MP-35 ***ERROR*** END OF FILE WAS ENCOUNTERED WHEN THE GEOMETRY DESCRIPTION CARD WAS EXPECTED.}

This self-explanatory message from subroutine SETUPA is printed if data are omitted or out of order. See Sect. M7.4.

MP-36 ***ERROR*** ILLEGAL SOLUTION NAME SOLNUO2F2, SOLNUO2(NO3)2 AND SOLNPU(NO3)4.

This self-explanatory message from subroutines SLNS and SLNAME is printed if a solution name is misspelled or data are out of order. See Sect. M7.4.4 for assistance in specifying solution names correctly.

MP-37 ***ERROR*** IS AN INVALID NAME WHEN READING MORE DATA.

This message is printed from subroutine MOREDT when extra parameter data are to be entered as explained in Sect. M7.4.8. The data are out of order or a parameter name is misspelled.

\section{MP-38 ***ERROR*** INVALID GEOMETRY WORD MULTIREGION, OR LATTICECELL ARE ALLOWED. \\ ONLY INFHOMMEDIUM,}

This self-explanatory message is from subroutine SETUPA. Correct the input data and resubmit the problem. Check the spelling of the geometry word, assure that the data are in order, and resubmit the problem.

\section{MP-39 ***WARNING*** AN END DATA WAS READ BEFORE IT WAS EXPECTED. AN END WAS PROBABLY OMITTED FROM A STANDARD COMPOSITION.}

This message from subroutine SETUPA indicates that an "END" was omitted from a standard composition specification or the END for a standard composition specification was followed by COMP. The first four characters following the END on a standard composition specification card cannot be COMP. The words END COMP terminate the standard composition specification data. Check the standard composition specification data carefully.

NUREG/CR-0200,

Vol. 3, Rev. 4

M7.7.8 
This self-explanatory message is from subroutine REORDR. A STOP 385 is executed in conjunction with this message.

MP-41 ***ERROR***

A NUCLIDE ID OF IS INVALID FOR IN THE FOLLOWING STANDARD COMPOSITION SPECIFICATION.

This message from subroutine STDCMP indicates that a nuclide ID is not compatible with a standard composition name. For example: UO2 3130094240509423850 END would cause this error because plutonium is invalid for a uranium standard composition specification. If this message is printed for a solution, the specific gravity of the solution may have been entered without the required keyword SPG=.

MP-42 ***ERROR*** AN END WAS ENCOUNTERED BEFORE MORE DATA WAS COMPLETED. assistance.

This message from MOREDT indicates incomplete input for MORE DATA See Sect. M7.4.8 for

MP-43 ***WARNING*** BAL= IS AN INVALID BALANCE TABLE SPECIFICATION. ALL BALANCE TABLES WILL BE PRINTED.

This message from subroutine MOREDT indicates that the value entered following $\mathrm{BAL}=$ is incorrect. Available options are NONE, FINE, and ALL. If any other value is entered, this message will be printed.

MP-44 ${ }^{* * * E R R O R * * *}$ NUCLIDE IS NOT A MULTIPLE ISOTOPE NUCLIDE ***ERROR***.

This message from subroutine STDCMP indicates that a value greater than zero was entered for the multiple-isotope indicator (IVIS) in an arbitrary material, and the first ID NUMBER (NCZA) is not a multiple-isotope nuclide (see Entry A6, Sect. M7.4.4). When this message is printed, an error flag is set to prevent execution and IVIS is set to zero to allow the code to continue checking the remaining input data. If an arbitrary material was not specified, this message indicates that the Standard Composition Library is in error for the standard composition printed immediately following this message. INFHOMMEDIUM, LATTICECELL, OR MULTIREGION. EXECUTION IS TERMINATED.

This message from subroutine CSPARM indicates that the TYPE OF CALCULATION (see entry 3 of Sect. M7.4.3) was spelled incorrectly, entered out of order, or was improperly specified.

MP-46 *** ERROR *** THE FUELOD CANNOT BE GREATER THAN THE PITCH.

This self-explanatory message from subroutine LATCEL results from an error in the UNIT CELL SPECIFICATION for a LATTICECELL problem (see Sect. M7.4.6). The value of PITCH must be at least as large as the value of FUELOD. 
This message from subroutine LATCEL indicates an error in the UNIT CELL SPECIFICATION for a LATTICECELL problem. See Sect. M7.4.6 and verify the values of PITCH, FUELOD, and CLADOD.

MP-48 *** ERROR *** THE GAPOD CANNOT BE LESS THAN THE FUELOD, NOR GREATER THAN THE CLADOD.

This message from subroutine LATCEL indicates an error in the UNIT CELL SPECIFICATION for a LATTICECELL problem. See Sect. M7.4.6 and verify the values of FUELOD, CLADOD, and CLADID (note that CLADID is the GAPOD and is equal to FUELOD + twice the gap thickness).

\section{MP-49 *** ERROR *** THE ABOVE RADIUS MUST BE GREATER THAN THE PREVIOUS} RADIUS.

This message from subroutine MULTRG indicates an error in the GEOMETRY SPECIFICATION for a MULTIREGION problem. See Sect. M7.4.7 and check to assure that each value of $R Z$ is greater than the previous value of $R Z$.

MP-50 *** WARNING ***

IN MORE DATA, RESONANCE INFORMATION (RES=) WAS SUPPLIED FOR MIXTURE . IT WILL NOT BE USED BECAUSE THAT MIXTURE OCCURS IN THE CELL DESCRIPTION.

This message from subroutine MOREDT is printed if resonance data (RES $=$ ) are entered for a mixture in MORE DATA (Sect. M7.4.8) and is also used in the cell description (Sects. M7.4.6 and M7.4.7). SPECIFYING RESONANCE DATA. CYLINDER, SPHERE, OR SLAB MUST BE ENTERED.

This message from subroutine MOREDT is printed if resonance data $(R E S=)$ are entered in MORE DATA (Sect. M7.4.8) and an incorrect shape is specified. The correct specification for a sphere of mixture 3 having a radius of $1.5 \mathrm{~cm}$ is: $\mathrm{RES}=3$ SPHERE 1.5

MP-52 *** WARNING ***

IN MORE DATA, DANCOFF INFORMATION (DAN( )=) WAS SUPPLIED FOR MIXTURE _ _ THIS VALUE WILL BE USED INSTEAD OF CALCULATING THE DANCOFF FROM THE CELL DESCRIPTION.

This message from subroutine MOREDT is printed to alert the user that the Dancoff information calculated from the unit cell (Sects. M7.4.6 and M7.4.7) specification is being overridden by the value that was entered in MORE DATA (Sect. M7.4.8).

MP-54 FIRST TWO NUMBERS ARE WORDS OF STORAGE NEEDED AND ALLOCATED. THIRD IS REQUIRED ADDITIONAL WORDS.

\section{PERTINENT CONSTANTS}

This message from subroutine C4DATA indicates that the allocated computer storage will not hold the volume fraction data from subroutine VERIFY. The first number printed is the amount of storage, in 
words, needed to hold this data. The second number is the amount of computer storage that was allocated, and the third number is the minimum additional words of storage required to hold the data to this point. Subsequent portions of the program may require even more storage. Increase the space allocation using the "SIZE" parameter on the analytical sequence indicator (Sect. M7.4.2) and resubmit the problem.

\section{MP-55 FIRST TWO NUMBERS ARE WORDS OF STORAGE NEEDED AND ALLOCATED. THIRD IS REQUIRED ADDITIONAL WORDS.}

\section{PERTINENT CONSTANTS}

This message from subroutine C4DATA indicates that the allocated computer storage will not hold the mixing table data required for subroutine BONAMI. The first number printed is the amount of storage, in words, needed to hold this data. The second number is the amount of computer storage that was allocated, and the third number is the minimum additional words of storage required to hold the data to this point. Subsequent portions of the program may require even more storage. Increase the space allocation using the "SIZE" parameter on the analytical sequence indicator (Sect. M7.4.2) and resubmit the problem.

\section{MP-56 FIRST TWO NUMBERS ARE WORDS OF STORAGENEEDED AND ALIOCATED. THIRD IS REQUIRED ADDITIONAL WORDS.}

\section{PERTINENT CONSTANTS}

This message from subroutine C4DATA indicates that the allocated computer storage will not hold the mixture number, outer radii, temperature, sigma-H, and zone identifiers for each BONAMI zone. The first number printed is the amount of storage, in words, needed to hold these data. The second number is the amount of computer storage that was allocated, and the third number is the minimum additional words of storage required to hold the data to this point. Subsequent portions of the program may require even more storage. Increase the space allocation using the "SIZE" parameter on the analytical sequence indicator (Sect. M7.4.2) and resubmit the problem.

\section{MP-57 FIRST TWO NUMBERS ARE WORDS OF STORAGE NEEDED AND ALIOCATED. THIRD IS REQUIRED ADDITIONAL WORDS.}

\section{PERTINENT CONSTANTS}

This message from subroutine C4DATA indicates that the allocated computer storage will not hold the BONAMI control parameters. The first number printed is the amount of storage, in words, needed to hold these data. The second number is the amount of computer storage that was allocated, and the third number is the minimum additional words of storage required to hold the data to this point. Subsequent portions of the program may require even more storage. Increase the space allocation using the "SIZE" parameter on the analytical sequence indicator (Sect. M7.4.2) and resubmit the problem.

\section{MP-58 FIRST TWO NUMBERS ARE WORDS OF STORAGE NEEDED AND ALIOCATED. THIRD IS REQUIRED ADDITIONAL WORDS.}

\section{PERTINENT CONSTANTS}

This message from subroutine C4DATA indicates that the allocated computer storage will not hold the cross-section data required by subroutines EPSIG and XSMESH. The first number printed is the amount of storage, in words, needed to hold these data. The second number is the amount of computer storage that was allocated, and the third number is the minimum additional words of storage required to hold the data to 
this point. Subsequent portions of the program may require even more storage. Increase the space allocation using the "SIZE" parameter on the analytical sequence indicator (Sect. M7.4.2) and resubmit the problem.

MP-59 FIRST TWO NUMBERS ARE WORDS OF STORAGE NEEDED AND ALLOCATED. THIRD IS REQUIRED ADDITIONAL WORDS.

\section{PERTINENT CONSTANTS}

This message from subroutine C4DATA indicates that the allocated computer storage will not hold the data required by subroutine XSDRN. The first number printed is the amount of storage, in words, needed to hold these data. The second number is the amount of computer storage that was allocated, and the third number is the minimum additional words of storage required to hold the data to this point. Subsequent portions of the program may require even more storage. Increase the space allocation using the "SIZE" parameter on the analytical sequence indicator (Sect. M7.4.2) and resubmit the problem.

MP-60 FIRST TWO NUMBERS ARE WORDS OF STORAGE NEEDED AND ALLOCATED. THIRD IS REQUIRED ADDITIONAL WORDS.

\section{PERTINENT CONSTANTS}

This message from subroutine C4DATA indicates that the allocated computer storage will not hold the data required by subroutine ICE. The first number printed is the amount of storage, in words, needed to hold this data. The second number is the amount of computer storage that was allocated, and the third number is the minimum additional words of storage required to hold the data to this point. Subsequent portions of the program may require even more storage. Increase the space allocation using the "SIZE" parameter on the analytical sequence indicator (Sect. M7.4.2) and resubmit the problem.

MP-61 *** ERROR *** THE CROSS-SECTION LIBRARY NAME ENTERED IN THE MATERIAL INFORMATION PROCESSOR DATA FOR THIS CSAS PROBLEM IS INCORRECT. SEE TABLE M8.2.2 OF THE SCALE MANUAL.

This message from subroutine C4DATA indicates that an invalid CROSS-SECTION LIBRARY NAME (see item 2 of Sect. M7.4.3) was entered. The name was misspelled, out of order, or improperly specified.

MP-62 ***ERROR***

A MIXTURE NUMBER IS OUT OF RANGE. ENTRY IN THE MIXING TABLE IS _ . IT SHOULD FALL BETWEEN 1 AND $\longrightarrow$ THE LARGEST NUMBER USED IN THE STANDARD COMPOSITION DATA.

This message is from subroutine EPSIG. Because the largest mixture number is determined by the code as the input data are read, this message may be the result of a code error introduced when changes were made to the code.

MP-63 ***ERROR***

A POINTER INTO THE NUCLIDE DATA IS OUT OF RANGE. ENTRY IN THE MIXING TABLE IS IT SHOULD FALL BETWEEN 1 AND THE NUMBER OF NUCLIDES IN THE STANDARD COMPOSITION LIBRARY.

This message is from subroutine EPSIG. It may result from a code error introduced when changes were made to the code.

NUREG/CR-0200,

Vol. 3, Rev. 4

M7.7.12 


\section{PERTINENT CONSTANTS}

This message from subroutine SHORTX indicates that the allocated computer storage is insufficient to create the short cross-section library utilized by the Material Information Processor. Increase the space allocation using the "SIZE" parameter on the analytical sequence indicator (Sect. M7.4.2) and resubmit the problem. A STOP 200 is executed when this message is printed.

\section{MP-65 ***** ERROR ***** THE FOLLOWING NUCLIDES WERE NOT FOUND ON THE} MASTER LIBRARY:

This message from subroutine SHORTX indicates that the user specified a standard composition which contains a nuclide that is not available on the specified master library. For example, nuclide ID 25304, which is stainless-steel-weighted manganese, is not available on any of the libraries but is listed in the Standard Composition Library. 25055 could be used instead.

MP-66 ***ERROR*** THE MIX. NO. (MIXZ= OUTSIDE THE RANGE 0 TO MXX=

) ASSIGNED TO ZONE IZ= WAS

This message from subroutine VERIFY indicates that the mixture number is out of range. A code error is the likely cause of this error.

MP-67 **WARNING** MIXTURE WAS ASSIGNED TO ZONES AND
RESONANCE
THIS MAY BE CORRECT IF THE MTXTURE HAS Nō RESONANCE NUCLIDES AND HAS THERMAL SCATTERING DATA AT ONLY ONE TEMPERATURE. USUALLY, UNIQUE MIXTURE NUMBERS SHOULD BE USED IN EACH ZONE, EVEN THOUGH THE MIXTURE SPECIFICATIONS MAY BE IDENTICAL. THIS ALLOWS BONAMI AND NITAWL TO PRODUCE SEPARATE CROSS SECTIONS BASED ON THE APPROPRIATE NUMBER OF EXTERNAL MODERATORS AND THE ACTUAL MEAN CHORD LENGTH FOR EACH SPECIFIED ZONE AS WELL AS THE ACTUAL TEMPERATURE FOR THAT ZONE.

This self-explanatory message is from subroutine VERIFY. The user should verify that the multiple use of the stated mixture number was intentional and correct.

\section{MP-68 ERRONEOUS MIXING TABLE LENGTH FOR XSDRN.}

This message from subroutine XSDRN is indicative of a code error. The computed mixing table length, MS, passed to subroutine XSDRN, does not match the counted length in subroutine XSDRN.

\section{MP-69 FIRST TWO NUMBERS ARE WORDS OF STORAGE NEEDED AND ALLOCATED. THIRD} IS REQUIRED ADDITIONAL WORDS.

\section{PERTINENT CONSTANTS}

This message from subroutine XSMESH indicates that the allocated computer storage will not hold the interval boundaries and zone number for each interval. The first number printed is the amount of storage, in words, needed to hold these data. The second number is the amount of computer storage that was allocated, and the third number is the minimum additional words of storage required to hold the data to this 
point. Subsequent portions of the program may require even more storage. Increase the space allocation using the "SIZE" parameter on the analytical sequence indicator (Sect. M7.4.2) and resubmit the problem. Specification (by the control module) of too many mesh intervals in a given zone is the most frequent cause of failure. In multiregion calculations where one has a large zone containing a strong absorber (such as a tank of uranyl-fluoride solution), it may be necessary to reduce the number of mesh intervals by increasing the size factor (SZF) in the Optional Parameter Data (Sect. M7.7.7). Making this factor large enough (SZF $=10,15$, 20,30 , etc.) will generally allow any problem to run in the space allocated. Once the problem runs, one should check the number density of all strong absorbers to see if they are realistic. Occasionally a user will accidentally specify an unrealistic concentration of a strong absorber in one or more zones. Such a mistake dramatically increases the number of mesh intervals the code thinks it needs.

MP-70 ***ERROR*** MORE THAN ONE ZONE WAS ENCOUNTERED FOR THIS INFINITE HOMOGENEOUS MEDIA PROBLEM.

This self-explanatory message is from subroutine XSMESH. Correct the input data and resubmit the problem.
MP-71 ${ }^{* * *}$ WARNING*** THE TEMPERATURE FOR STANDARD COMPOSITION SPECIFIED AS DEGREES CELSIUS. DENSITY DATA AT 25 DEGREES CELSIUS WILL BE USED FOR THIS SOLUTION.

This message from subroutine SLNS is printed if SOLNUO2F2 or SOLNPU(NO3)4 were specified in the standard composition data with a temperature outside the range of 15 to 30 degrees CELSIUS. The Standard Composition Library does not contain data for these solutions outside that temperature range.
MP-72 *** ERROR *** KEYWORD SPG = OR DEN= TO SPECIFY THE SPECIFIC GRAVITY OF THE SOLUTION WAS EXPECTED. KEYWORD INSTEAD. WAS READ

This message from subroutine STDCMP indicates an error in the specification of solution data in the standard composition specification. If the specific gravity of a solution is to be entered, it is the fourth entry after the solution name. Check the solution input data carefully.

MP-73 ${ }^{* * *}$ ERROR*** EXTERNAL MODERATOR INDEX IS INCORRECT IN ZONE _ OF THE MULTIREGION DATA. ENTER NOEXTERMOD, ONEEXTERMOD, OR TWOEXTERMOD INSTEAD OF CHECK SPELLING.

This self-explanatory message is printed from subroutine MULTRG and subroutine RESDA or subroutine MULTRG. The user has misspelled the word defining the external moderator index of the specified zone or the multiregion data are out of order. See Sect. M7.4.7.

MP-74 *** ERROR *** FIRST MODERATOR HAS NEGATIVE THICKNESS

This message from subroutine DANCOF indicates that the dimensions specified for an ASYMSLABCELL are inconsistent. The array pitch (PITCH) is smaller than the sum of the second moderator thickness (TKMOD2) and $M A X$ where $M A X$ is the outside diameter of the clad (CLADOD) if

NUREG/CR-0200,

Vol. 3, Rev. 4

M7.7.14 
entered; otherwise, $M A X$ is the outside diameter of the fuel (FUELOD). Correct the data and resubmit the problem. See Sect. M7.4.6 and Fig. M7.4.3 for assistance.

\section{MP-75 *** ERROR *** KEYWORD DEN= OR SPG = TO SPECIFY THE DENSITY OF THE BASIC STANDARD COMPOSITION WAS EXPECTED. KEYWORD WAS READ INSTEAD.}

This message from subroutine STDCMP indicates an error in the specification of the density in the basic standard composition data. If the density of the material is to be entered, it is the second entry after the standard composition name. The density is optional data. If the density is entered, it is multiplied by the volume fraction to obtain the density actually used for this composition.

$\begin{array}{ll}\text { MP-76 *** ERROR *** } & \text { THE LOWER BOUND OF XSDRN INTERVAL } \\ \text { MUST BE LESS THAN THE UPPER BOUND OF }\end{array}$

This message from subroutine XSMESH indicates that the specified XSDRN mesh interval is incorrect. Each mesh interval must have a finite positive thickness. This message can be caused by an error in the unit cell data. Either a zero-thick region was specified or the unit cell dimensions were incorrectly specified. Carefully check the unit cell dimensions. If a lattice cell annular cell is specified, verify that the FUELOD is at least as large as TKMOD2+2(CLADOD-FUELOD).

MP-77 ANEGATIVE DIMENSION WAS ENCOUNTERED IN THE UNIT CELLDATA. CHECK AND CORRECT THE GEOMETRY DIMENSION.

This message from subroutine LATCEL is printed if a negative number is read for a cell dimension. Check the printed problem geometry and correct the input data (Sect. M7.4.6).

MP-78 THE FUEL THICKNESS IS NEGATIVE. THE ANNULAR CELLDIMENSIONS FOR TKMOD2, CLADOD, AND FUELOD ARE INCONSISTENT.

This message from subroutine LATCEL indicates an error in the description of a cylindrical or spherical annular cell. The cell description must provide a finite fuel thickness. The inside diameter of the fuel is calculated using the diameter of the second moderator, TKMOD2, and the outer diameter of the clad, CLADOD. If the calculated inside diameter of the fuel is greater than or equal to the specified outer diameter of the fuel, there is no fuel in the cell and this message is printed. The thickness of the gap and clad is $1 / 2$ (CLADOD-FUELOD), so the inside diameter of the fuel is TKMOD2+CLADOD-FUELOD. See Sect. M7.4.6 for data input instructions.

MP-79 *** ERROR *** THE ORIGIN MUST BE 0.0 FOR SPHERICAL OR CYLINDRICAL GEOMETRY.

This message from subroutine MULTRG is printed if the origin, ORGN of Table M7.4.8, Sect. M7.4.7, is nonzero for a cylinder or sphere. Either the multiregion unit cell data are out of order or a nonzero number has been entered for ORGN. Correct the data and resubmit the problem.

MP-80 *** ERROR *** NOT ENOUGH STORAGE IN CLAPSE - FIRST NUMBER IS THE AMOUNT NEEDED, SECOND IS THE AMOUNT AVAILABLE.

PERTINENT CONSTANTS 
This message from subroutine CLAPSE indicates that the allocated computer storage is insufficient to allow collapsing the thermal cross sections to one group for shielding calculations. The first number printed is the amount of storage, in words, needed to hold these data. The second number is the amount of computer storage that was allocated. A STOP 201 is executed when this message is printed.

\section{MP-81 *** ERROR *** DANCOFF FACTOR MUST BE BETWEEN 0.0 AND 1.0}

This message from subroutine MOREDT is printed if $\mathrm{DAN}(\mathrm{n})=$ is specified in MORE DATA with a value greater than 1.0 or less than 0.0 . Dancoff factors must lie between 0 and 1 . The problem will not be run if message MP-81 is printed. Correct the data and resubmit the problem. See Sect. M7.4.7 for assistance.

MP-82 THE FIRST MODERATOR THICKNESS IS NEGATIVE. THE ASYMMETRIC SLAB CELL DIMENSIONS FOR TKMOD2, CLADOD, AND PITCH ARE INCONSISTENT

This message from subroutine LATCEL indicates an error in the description of an asymmetric slab cell. The thickness of the first moderator is not specified in the input data and is calculated as PITCH-TKMOD2/2-CLADOD. If the thickness of the first moderator is negative, this message is printed.

MP-83 *** ERROR *** AN INPUT DATA ERROR HAS BEEN ENCOUNTERED IN THE MATERIAL INFORMATION PROCESSOR DATA ENTERED FOR THIS PROBLEM.

This message from subroutine C4DATA is printed if the subroutine library routine LRDERR returns a value of "TRUE," indicating that a reading error was encountered in the Material Information Processor input data. Locate the unnumbered message stating ${ }^{n * * * * *}$ ERROR IN INPUT. CARD IMAGE PRINTED ON NEXT LINE *****." Correct the data and resubmit the problem.

MP-84 *** WARNING *** FOR MIXTURE _ THE DANCOFF FACTOR OF THE RANGE OF 0 TO 1. IT WILL BE RESET TO THE CLOSER BOUND. IS OUTSIDE

This message from subroutine RESDA is printed when the DANCOFF factor is less than $10^{-4}$ outside the allowed range of 0 to 1 . This is usually due to roundoff in calculating the Dancoff factor.

MP-85 *** ERROR *** FOR MIXTURE __ THE DANCOFF FACTOR OF __ IS OUTSIDE THE RANGE OF 0 TO 1. IT WILL BE RESET TO THE CLOSER BOUND. THE PROBLEM WILL NOT BE EXECUTED.

This message from subroutine RESDA is printed when the Dancoff factor is more than $10^{-4}$ outside the allowed range of 0 to 1 . Check the input data to be sure that the specified Dancoff factor is between 0 and 1. See Sect. M7.4.8 or C4.4.8 for input specifications for the Dancoff factor. If the Dancoff factor was not specified in the optional parameter data, the message is due to a code error.

\section{M7.7.2 STOP CODES}

The STOP codes that are utilized in the Material Information Processor are listed in Table M7.7.1 indicating the subroutine where they occur and the associated error message. A STOP is executed when a fatal error is recognized. Locate the associated message number to determine the appropriate corrective measures. A traceback may be generated whenever subroutine STOP is called to print a message. If no traceback is indicated in the STOP CODE table, a STOP is printed at the completion of the associated message.

NUREG/CR-0200,

Vol. 3, Rev. 4

M7.7.16 
Table M7.7.1 STOP Codes Utilized in Material Information Processor

\begin{tabular}{llll}
\hline $\begin{array}{l}\text { STOP } \\
\text { NUMBER }\end{array}$ & SUBROUTINE & TRACEBACK & $\begin{array}{l}\text { ASSOCIATED } \\
\text { MESSAGE }\end{array}$ \\
\hline 20 & & & see Sect. M7.7.3 \\
200 & SHORTX & No & MP-64 \\
201 & CLAPSE & No & MP-80 \\
300 & KNIGHT & Yes & MP-1 \\
310 & KNIGHT & Yes & MP-2 \\
320 & KNIGHT & Yes & MP-4 \\
330 & SETUPA & Yes & MP-23 \\
340 & MTABLE & Yes & MP-24 \\
350 & MIXTAB & Yes & MP-25 \\
360 & MIXTAB & Yes & MP-26 \\
370 & MIXTAB & Yes & MP-40 \\
380 & REORDR & No & MP-19 \\
385 & REORDR & No & MP-28 \\
390 & SETUPB & Yes & MP-28 \\
395 & IDENTS & No & MP-45 \\
395 & SLNS & No & \\
396 & CSPARM & No & \\
\hline
\end{tabular}

\section{M7.7.3 MESSAGES ASSOCIATED WITH STOP 20 IN CSAS}

The following messages from subroutine library routines will result in a STOP 20 in the material information processor and CSAS.

LMP001 DA ERROR - INVAIID UNIT NUMBER.

THE LOGICAL UNIT NUMBER IS

This message from a subroutine library direct-access routine indicates that an invalid unit number was specified as a direct-access device. In CSAS, this message is indicative of a code error.

LMP002 DA ERROR - FORTRAN USING THIS UNIT. THE LOGICAL UNIT NUMBER IS

This message from a subroutine library direct-access routine indicates that the specified unit number is open as a sequential dataset rather than a direct-access dataset. In CSAS, this error may be caused by entering a direct-access unit number for $F R D=$ or $F W R=$ in MORE DATA. See Sect. M7.4.8.

LMP003 DA ERROR - DCB NOT OPEN.

THE LOGICAL UNIT NUMBER IS

This message from a subroutine library direct-access routine indicates that the program attempted to read or write on a direct-access device but the data control block was not open. In CSAS this message is indicative of a code error.

LMP004 DA ERROR - UNABLE TO OPEN DCB. THE LOGICAL UNIT NUMBER IS 
This message from a subroutine library direct-access routine indicates that the program is unable to open the data control block for the direct-access device. This message indicates that the job control language did not include proper specification of the above named unit.

LMP005

DAERROR - RELATIVE BLOCK NOT IN DATA SET. RELATIVE BLOCK NUMBER IS

This message from a subroutine library direct-access routine indicates that the number of direct-access blocks is too small for the problem. Increase the number of direct-access blocks in MORE DATA by entering the parameter $D A B=n n n$ where nnn is larger. For example, if the relative block number is 201, try increasing the number of direct-access blocks to 300 or more. For CSAS25, CSAS2X, CSAS4, and CSAS4X, it may also be necessary to set NB8=nnn in the KENO parameter data. See Sect. M7.4.8 or C4.4.8, entry number 18, and Sect. F11.4.3, parameter NB8.

LMP006 DA ERROR - INVALID BLOCK LENGTH. THE BLOCK LENGTH IS

This message from a subroutine library direct-access routine indicates that the length of the directaccess blocks is invalid. A valid block length must be positive. In CSAS, this message is indicative of a code error.

LMP007 DA ERROR - DCB ALREADY OPEN. THE LOGICAL UNIT NUMBER IS

This message from a subroutine library direct-access routine indicates that the data control block for the above named unit was previously opened and not closed.

LMP008 DA ERROR - PERMANENT I/O ERROR.

This message from a subroutine library direct-access routine indicates that a permanent I/O error has occurred.

\section{M7.7.4 UNNUMBERED MESSAGES}

Occasionally the code may terminate without printing a message that can be located via the message number. Some of these messages are contained in this section.

\section{***** END OF FILE READ ON UNIT $\mathrm{n} * * * * *$}

This message is from subroutine ENFILE in the Subroutine Library. Unit $\mathbf{n}$ is the device from which data are being read. This message can be caused by lack of a double blank between the END for the last standard composition and the END COMP. It can also be caused by omitting the END COMP or misspelling COMP in the END COMP entry. Other causes include incomplete or missing data. A traceback accompanies this message. Correct the data and resubmit the problem. See Sect. M7.4.4 or C4.4.4 for assistance.

\footnotetext{
***** ERROR IN INPUT. CARD IMAGE PRINTED ON NEXT LINE *****

card image is printed here

ON THE ABOVE CARD, CHARACTER NUMBER m (IMAGE=c) IS NOT VALID.
}

NUREG/CR-0200,

Vol. 3, Rev. 4

M7.7.18 
This message is from the Subroutine Library free-form reading routine DREAD. The character number, $m$, and the character image, $c$, printed in the message are recognized as being invalid for the type of data being read. For example, character data were encountered when numerical data were expected. This message can be caused by missing or incomplete data and by omitting double blanks after a labeled or unlabeled END. A traceback accompanies this message. Correct the data and resubmit the problem. 


\section{M7.8 REFERENCES}

1. I. I. Bondarenko, ed., Group Constants for Nuclear Reactor Calculations, Consultants Bureau, New York, 1964.

2. L. W. Nordheim, "The Theory of Resonance Absorption," Proceedings of Symposia in Applied Mathematics, G. Birkhoff and E. P. Wigner, eds., II, 58, Am. Math. Soc. (1961).

3. K. M. Case, F. de Hoffmann, and G. Placzek, Introduction to the Theory of Neutron Diffusion, Los Alamos Scientific Laboratory, 1953.

4. P. H. Kier, and A. A. Robba, RABBLE, A Program for Computation of Resonance Absorption in Multi-Region Reactor Cells, ANL-7326, Argonne National Laboratory, 1967.

5. M. M. Anderson, The Development and Application of an Interface Currents Technique for TwoDimensional Reactor Cell Calculations, DP-MS-74-3, E. I. du Pont de Nemours \& Co., Savannah River Laboratory, 1974.

6. S. C. Cohen, An Improved Treatment of Scattering Resonances in Slab Geometry, GA-7144, General Atomic Division of General Dynamics, 1966.

7. J. R. Knight, SUPERDAN: Computer Programs for Calculating the Dancoff Factor of Spheres, Cylinders, and Slabs, ORNL/NUREG/CSD-TM-2, Union Carbide Corp., Oak Ridge Natl. Lab., March 1978.

8. S. M. Dancoff and M. Ginsburg, Surface Resonance Absorption in a Close-Packed Lattice, CP-2157, September 1944.

9. "Specific Gravity of Boric Acid Solutions," Handbook of Chemistry, pp.1162, Compiled and Edited by Norbert A. Lange, Ph.D, 1956.

10. G. I. Bell, "A Simple Treatment for Effective Resonance Absorption Cross Sections in Dense Lattices," Nucl. Sci. Eng. 5(2), 138 (February 1959).

11. J. A. Bucholz, A Method of Generating Multigroup Transfer Matrices Using an Analytic Angular Integration Free of Truncation Error, ORNL/NUREG/CSD-8, Union Carbide Corp., Oak Ridge Natl. Lab., September 1978.

12. J. R. Lamarsh, Introduction to Nuclear Reactor Theory, (a) Derivation of Nordheim Integral Equation (Sect. 11-3); (b) Practical Width of a Resonance (Sect. 7-2); (c) Doppler Broadening (Sects. 2-14 and 7-3); Addison-Wesley Pub. Co., Inc., 1966.

13. K M. Case, F. de Hoffman and G. Placzek, Introduction to the Theory of Neutron Diffusion, Vol. 1, U.S. Government Printing Office, Washington, DC, June 1953.

14. J. M. Otter, Escape Probability Approximations in Lumped Resonance Absorbers, NAA-SR-9764, Atomics International, 1963. 
15. S. F. Mughabghab, D.I. Garber, and R. R. Kinsey, Neutron Cross Sections, BNL-325, Brookhaven National Lab., Third Ed., Vol. 1 (June 1973) and Vol. 2 (January 1976).

16. L. M. Petrie and N. F. Cross, KENO IV: An Improved Monte Carlo Criticality Program, ORNL-4938, Union Carbide Corp., Oak Ridge Natl. Lab., November 1975.

17. I. I. Bondarenko, M. N. Nikolaev, L. P. Abagyan, and N. O. Bazazyants, Group Constants for Nuclear Reactor Calculations, Consultants Bureau, New York, 1964.

18. G. E. Hansen and W. H. Roach, Six and Sixteen Group Cross Sections for Fast and Intermediate Critical Assemblies, LAMS-2543, Los Alamos Scientific Lab., November 1961.

19. L. Dresner, Resonance Absorption in Nuclear Reactors, Pergamon Press, 1960.

20. L. Dresner, "The Effective Resonance Integrals of U-238 and Th-232," Nucl Sci. Eng. 1, 68 (March 1956).

21. W. Rothenstein, Collision Probabilities and Resonance Integrals for Lattices, BNL-563, Brookhaven Natl. Lab. (T-151), June 1959.

22. S. J. Raffety and J. T. Mihalczo, "Homogeneous Critical Assemblies of $2 \%$ and $3 \%$ Uranium-235-Enriched Uranium in Paraffin," Nucl. Sci. Eng. 48, 433 (1972).

23. V. I. Neeley and H. E. Handler, Measurement of Multiplication Constant for Slightly Enriched Homogeneous $\mathrm{UO}_{3}$-Water Mixtures and Minimum Enrichment for Criticality, HW-70310, Hanford Atomic Products Operation, August 1961.

24. V. I. Neeley, J. A. Berberet, and R. H. Masterson, $K_{\infty}$ of Three Weight Percent ${ }^{235} U$ Enriched $U_{3}$ and $\mathrm{UO}_{2}\left(\mathrm{NO}_{3}\right)_{2}$ Hydrogeneous Systems, HW-66882, Hanford Atomic Products Operation, September 1961.

25. R. M.. Westfall and J. R. Knight, "SCALE System Cross-Section Validation with Shipping Cask Critical Experiments," Trans. Am. Nucl. Soc. 33, 368 (1979).

NUREG/CR-0200,

Vol. 3, Rev. 4 


\section{M7.A NOTES ON SOME ELEMENTARY RESONANCE SELF-SHIELDING TECHNIQUES USED IN SCALE}

\section{M7.A1 THE NORDHEIM INTEGRAL METHOD FOR THE TWO-REGION PROBLEM}

Multigroup cross-section data must be determined from the basic nuclear data in a fashion that is consistent with the way in which the data are to be used. For most processes (absorption, fission, etc.) that means averaging the actual data over the various energy groups, with the scalar flux (of a similar system) being used as a weighting function:

$$
\sigma^{\mathrm{g}}=\frac{\int_{E^{g}}^{E^{g-1}} \phi(E) \sigma(E) d E}{\int_{E^{g}}^{E^{g-1}} \phi(E) d E} .
$$

Even though slightly different expressions might be used for the transport cross section and/or the group-to-group scattering terms, ${ }^{11}$ it is still necessary to determine the flux spectrum. In the resonance range $\phi(E)$ and $\sigma(E)$ may both vary dramatically, and this weighting, referred to as "resonance self-shielding," is most important.

To determine $\phi(\mathrm{E})$, it is convenient to write an expression for the collision density at energy $\mathrm{E}$ in terms of the scattering density at all higher energies. For energies in the resonance region, virtually all of the slowing-down source is due to elastic scattering. Thus, neutrons of energy $E^{\prime}$ may scatter down to $\alpha^{\prime}$, and the probability of a neutron at energy $E^{\prime}$ scattering down to some energy within $d E$ about $E$ is given by

$$
P\left(E^{\prime} \rightarrow E\right) d E=\left(\frac{1}{1-\alpha}\right)\left(\frac{1}{E^{\prime}}\right) d E,
$$

where

$$
\alpha=\left(\frac{A-1}{A+1}\right)^{2}
$$

For simplicity, let us now consider a two-zone problem with a single nuclide in each zone. In the Nordheim method, ${ }^{3}$ the flux in the fuel $\phi_{F}(E)$ and the flux in the moderator $\phi_{M}(E)$ are assumed to be spatially flat over their respective regions. Gross spatial effects are accounted for by allowing $\mathrm{P}_{\mathrm{F} \rightarrow \mathrm{M}}^{\circ}(\mathrm{E})$ to represent the probability that a neutron of energy $E$ escapes from the fuel without a collision, while $1-\mathbf{P}_{\mathrm{F}-\mathrm{M}}^{\circ}(E)$ represents the probability that the neutron has its next interaction within the fuel. If $V_{F}$ and $V_{M}$ represent the volume of the fuel and moderator regions, then the total collision rate in each region is given by ${ }^{12}$ 


$$
\begin{aligned}
V_{F} \Sigma_{t P}(E) \phi_{F}(E) & =V_{F}\left[1-P_{F-M}^{\circ}(E)\right] \int_{E}^{E / \alpha_{F}} \phi_{F}\left(E^{\prime}\right) \Sigma_{s P}\left(E^{\prime}\right)\left(\frac{1}{1-\alpha_{F}}\right)\left(\frac{1}{E^{\prime}}\right) d E^{\prime} \\
& +V_{M} P_{M-F}^{o}(E) \int_{E}^{E / \alpha_{M}} \phi_{M}\left(E^{\prime}\right) \Sigma_{s M}\left(E^{\prime}\right)\left(\frac{1}{1-\alpha_{M}}\right)\left(\frac{1}{E^{\prime}}\right) d E^{\prime}
\end{aligned}
$$

and

$$
\begin{aligned}
& V_{M} \Sigma_{t M}(E) \phi_{M}(E)=V_{F} P_{F-M}^{\circ}(E) \int_{E}^{E / \alpha_{F}} \phi_{F}\left(E^{\prime}\right) \Sigma_{s P^{\prime}}\left(E^{\prime}\right)\left(\frac{1}{1-\alpha_{F}}\right)\left(\frac{1}{E^{\prime}}\right) d E^{\prime} \\
& \quad+V_{M}\left[1-P_{M-F}^{\circ}(E)\right] \int_{E}^{E / \alpha_{M}} \phi_{M}\left(E^{\prime}\right) \Sigma_{s M}\left(E^{\prime}\right)\left(\frac{1}{1-\alpha_{M}}\right)\left(\frac{1}{E^{\prime}}\right) d E^{\prime}
\end{aligned}
$$

Note that this is a coupled set of integral equations where $\phi_{F}(E)$ depends on $\phi_{M}(E)$ and vice versa. To produce self-shielded cross-section data for the fuel, one must first determine $\phi_{\mathrm{F}}(\mathrm{E})$. Obviously, if one had additional nuclides in the fuel or moderator, one would have additional integrals whose range of integration would be defined by $\alpha_{\mathrm{F}}^{25}, \alpha_{\mathrm{F}}^{28}, \alpha_{\mathrm{F}}^{\mathrm{Oxy}}, \alpha_{\mathrm{M},}^{\mathrm{H}} \alpha_{\mathrm{M}}^{\text {oxy }}$ and whose scattering density would depend on $\Sigma_{\mathrm{sF}}^{25}, \Sigma_{\mathrm{sP}}^{28}, \Sigma_{\mathrm{sF}}^{\mathrm{oxy}}, \Sigma_{\mathrm{sM}}^{\mathrm{H}}, \Sigma_{\mathrm{sM}}^{0 x y}$. Non-resonance nuclides inside the fuel are frequently referred to as "internal moderators," and all nuclides in the moderator region are frequently referred to as "external moderators." In the Nordheim method, the external moderators are accounted for only implicitly, as described below.

Before considering the detailed solution of Eqs. (M7.A.4) and (M7.A.5), it is convenient to note that the asymptotic solutions [i.e., the fluxes $\phi_{F}(E)$ and $\phi_{M}(E)$ in the absence of absorption] are identical. By direct substitution, it can be shown that

$$
\phi_{\mathrm{F}}^{\infty}=\phi_{\mathrm{M}}^{\infty}=\frac{1}{\bar{\xi} \bar{\Sigma}_{S} \mathrm{E}},
$$

where

$$
\bar{\xi} \bar{\Sigma}_{\mathrm{s}} \equiv \frac{1}{\mathrm{~V}}\left(\xi_{\mathrm{F}} \Sigma_{\mathrm{SP}} \mathrm{V}_{\mathrm{F}}+\xi_{\mathrm{M}} \Sigma_{\mathrm{SM}} \mathrm{V}_{\mathrm{M}}\right) \approx \text { constant }
$$

and $\delta$ is defined as the average increase in lethargy per collision. ${ }^{12}$ In the asymptotic range far from resonances, $\Sigma_{\mathrm{sF}}$ is simply the potential scattering cross section, $\Sigma_{\mathrm{pF}}$. 
Armed with knowledge of the asymptotic solution, it is then possible to invoke the Narrow Resonance (NR) approximation for the external moderator, and eliminate the integral(s) over $\phi_{M}(E)$ in Eq. (M7.A.4).

If the average energy loss in an elastic collision with the moderator $\left[1 / 2(1-\alpha) \mathrm{E}_{\text {res }}\right]$ is much larger than the practical width of the resonance $\left(\Gamma_{p}\right)$, then it is very unlikely that a neutron will have a second collision within the resonance. Under these conditions, the contribution to $\Sigma_{\mathrm{FF}}(\mathrm{E}) \phi_{\mathrm{F}}(\mathrm{E})$ due to the integration of $\phi_{M}\left(E^{\prime}\right) \Sigma_{2 M}\left(E^{\prime}\right)$ over the narrow energy range associated with the resonance will be negligible compared to the contribution due to the integration of $\phi_{M}\left(E^{\prime}\right) \Sigma_{s M}\left(E^{\prime}\right)$ over the rest of the range (from just above the resonance $\left[E^{\prime}=E_{2} \approx E\right]$ to $E^{\prime}=E / \alpha$ ). Figure M7.A.1 is an attempt to illustrate this situation. For energies $E^{\prime}$ just above the resonance there is very little absorption, and the flux there assumes the asymptotic form:

$$
\Phi_{M}\left(E^{\prime}\right)=\phi_{m}^{-}=\frac{1}{\bar{\xi} \bar{\Sigma}_{s} E^{\prime}}
$$

\section{ORNL-DWG 81-18144}

\section{RESONANCE}

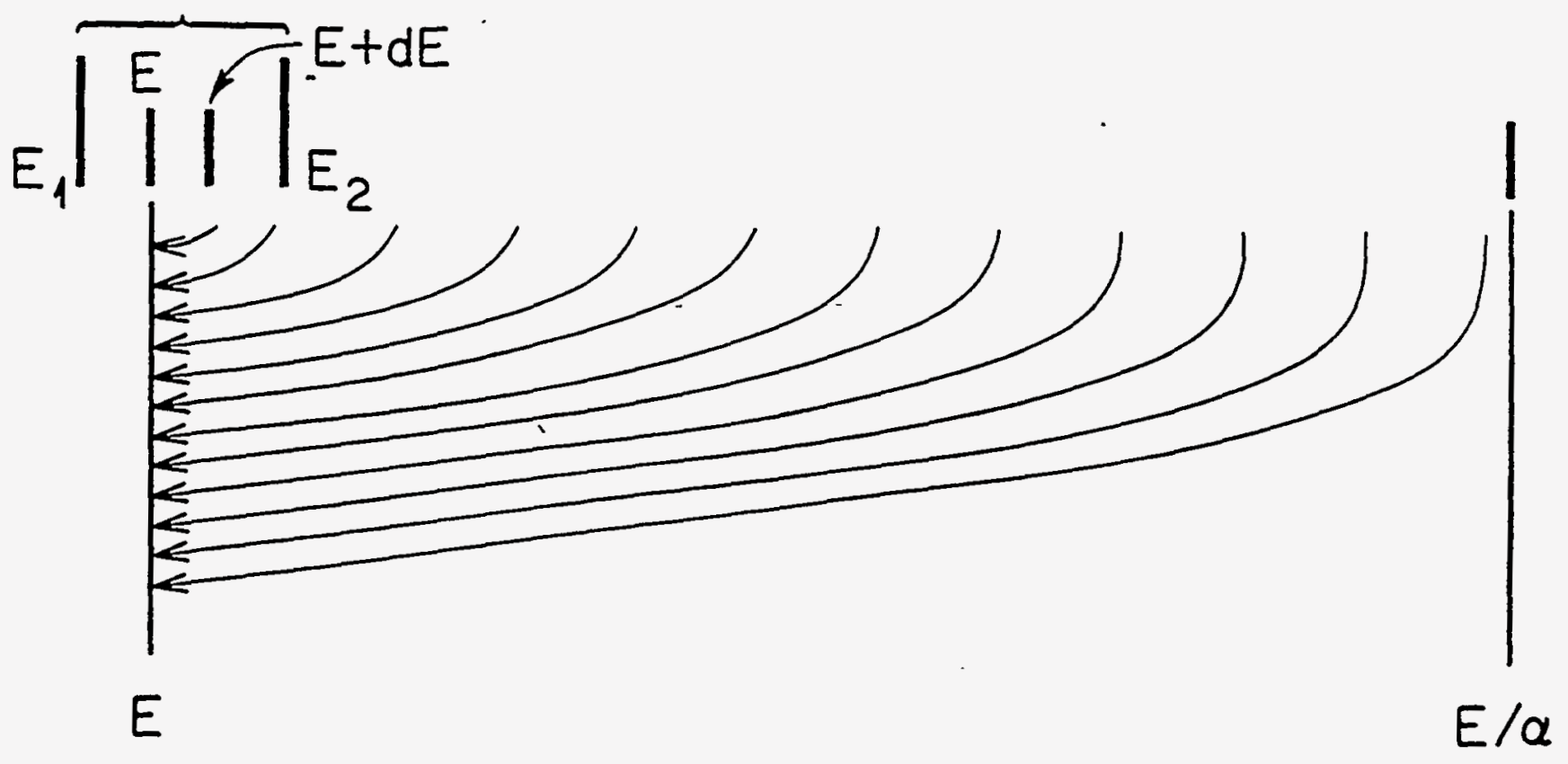

Figure M7.A.1 Elastic scattering into $\mathrm{dE}$ about $\mathrm{E}$ when $\mathrm{E}$ lies inside a narrow resonance 
Substituting this expression in Eq. (M7.A.4) effectively decouples it from Eq. (M7.A.5). More precisely, the expression

$$
\begin{gathered}
\int_{E}^{E / \alpha_{M}} \phi_{M}\left(E^{\prime}\right) \Sigma_{s M}\left(E^{\prime}\right)\left(\frac{1}{1-\alpha_{M}}\right)\left(\frac{1}{E^{\prime}}\right) d E^{\prime} \\
=\int_{E}^{E_{2}=E+\epsilon}[] d E^{\prime}+\int_{E_{2}=E+\epsilon}^{E / \alpha_{M}} \frac{1}{\bar{\xi}_{\bar{\xi}} E_{s}^{\prime}} \Sigma_{s M}\left(\nabla^{\prime}\right)\left(\frac{1}{1-\alpha_{M}}\right)\left(\frac{1}{E^{\prime}}\right) d E^{\prime} \\
=\left(\frac{\Sigma_{s M}}{\bar{\xi} \bar{\Sigma}_{s}}\right)\left(\frac{1}{1-\alpha_{M}}\right) \int_{E}^{E / \alpha_{M}} \frac{1}{x^{2}} d x=\left(\frac{\Sigma_{s M}}{\bar{\xi} \bar{\Sigma}_{s}}\right)\left(\frac{1}{E}\right)
\end{gathered}
$$

is substituted in Eq. (M7.A.4) to yield

$$
\begin{aligned}
& V_{F} \Sigma_{t P}(E) \phi_{F}(E)=V_{F}\left[1-P_{F \rightarrow M}^{o}(E)\right] \int_{E}^{E / \alpha_{F}} \phi_{F}\left(E^{\prime}\right) \Sigma_{S P}\left(E^{\prime}\right)\left(\frac{1}{1-\alpha_{F}}\right)\left(\frac{1}{E^{\prime}}\right) d E^{\prime} \\
& +\mathrm{V}_{M} P_{M-\mathrm{P}}^{0}(\mathrm{E})\left(\frac{\Sigma_{s M}}{\bar{\xi} \bar{\Sigma}_{s}}\right)\left(\frac{1}{E}\right)
\end{aligned}
$$

When the fuel and moderator fluxes are assumed to be flat, it can be shown using the reciprocity theorem that $\mathrm{P}_{\mathrm{F} \rightarrow \mathrm{M}}^{\circ}(\mathrm{E})$ and $\mathrm{P}_{\mathrm{M}-\mathrm{F}}^{\circ}(\mathrm{E})$ are related by the equation

$$
\mathrm{V}_{\mathrm{M}} \mathrm{P}_{\mathrm{M}-\mathrm{F}}^{0}(\mathrm{E}) \Sigma_{\mathrm{SM}}(\mathrm{E})=\mathrm{V}_{\mathrm{F}} \mathrm{P}_{\mathrm{P} \rightarrow \mathrm{M}}^{0}(\mathrm{E}) \Sigma_{\mathrm{tF}}(\mathrm{E})
$$

Substituting this expression into Eq. (M7.A.10) yields 


$$
\begin{gathered}
\Sigma_{\mathrm{tF}}(\mathrm{E}) \phi_{\mathrm{F}}(\mathrm{E})=\left[1-\mathrm{P}_{\mathrm{F} \rightarrow \mathrm{M}}^{0}(\mathrm{E})\right] \int_{\mathrm{E}}^{\mathrm{E} / \alpha_{\mathrm{F}}} \phi_{\mathrm{F}}\left(\mathrm{E}^{\prime}\right) \Sigma_{\mathrm{sP}}\left(\mathrm{E}^{\prime}\right)\left(\frac{1}{1-\alpha_{\mathrm{F}}}\right)\left(\frac{1}{\mathrm{E}^{\prime}}\right) d \mathrm{E}^{\prime} \\
+\frac{\mathrm{P}_{\mathrm{F} \rightarrow \mathrm{M}}^{0}(\mathrm{E}) \Sigma_{\mathrm{tP}}(\mathrm{E})}{\bar{\xi} \bar{\Sigma}_{\mathrm{g}} \mathrm{E}}
\end{gathered}
$$

This integral equation for the flux, $\phi_{\mathrm{F}}(E)$, is the basis of the Nordheim method. Note that the (1/E) slowing down source coming from the external moderator is represented by a single term on the right-hand side of Eq. (M7.A.12). Internal moderators (such as the oxygen in $\mathrm{UO}_{2}$ ) may be accounted for by including additional integrals whose range of integration would be defined by $\alpha_{F}^{25}, \alpha_{F}^{28}, \alpha_{F}^{\alpha x y}$, etc. The Nordheim method as implemented in the NITAWL code allows up to three such integrals - one for the absorber and two for "internal moderators." To solve the Nordheim integral equation, NITAWL expands the integral in a three-point formula corresponding to Simpson's Rule and then marches from the highest to the lowest energy, developing numerical values for the energy-dependent flux and collision density as it goes. For computational efficiency, NITAWL does not carry out this process over all energy but instead it (1) assumes the resonances are well isolated, (2) uses the asymptotic solution for the flux between resonances, and (3) assumes the asymptotic value for the flux $\left[\phi^{\infty}=1 /\left(\xi \Sigma_{s} E\right)\right]$ at the upper end of each resonance.

In the interest of clarity, it must be pointed out that the flux spectrum in an isolated fuel lump $\left[\phi_{\mathrm{P}}(E)\right]$ is independent of the material properties of the surrounding moderator and that the NITAWL code does, in fact, solve Eq. (M7.A.12) without knowledge of the properties of the surrounding moderator. At first glance, this may appear to be contradictory since the term

$$
\bar{\xi} \bar{\Sigma}_{s} \equiv \frac{1}{V}\left(\xi_{F} \Sigma_{s p} V_{F}+\xi_{M} \Sigma_{s M} V_{M}\right) \approx \text { constant }
$$

appears explicitly in the Nordheim integral equation for the flux [cf. Eq. (M7.A.12)]. That equation, you will recall, gives the collision density at energy $E\left[\Sigma_{\mathrm{t}}(E) \phi_{\mathrm{F}}(\mathrm{E})\right]$ in terms of the flux at all higher energies $\left[\phi_{\mathrm{R}}\left(\mathrm{E}^{\prime}\right)\right]$. For energies $(\mathrm{E})$ near the upper end of the highest energy resonance, the flux term appearing in the integrand will correspond to the asymptotic flux given by

$$
\phi_{\mathrm{P}}\left(\mathrm{E}^{\prime}\right)=\phi_{\mathrm{P}}^{\infty}\left(\mathrm{E}^{\prime}\right)=\left(\frac{1}{\overline{\bar{\xi}} \bar{\Sigma}_{\mathrm{s}} \mathrm{E}^{\prime}}\right)
$$

Since the constant $\xi \Sigma_{s}$ appears in both terms on the right-hand side of Eq. (M7.A.12), the flux at all lower energies $\left[\phi_{\mathrm{P}}(E)\right]$ will be directly proportional to $\left(1 / \xi \Sigma_{s}\right)$. That constant will, of course, cancel out when the flux $\left[\phi_{\mathrm{F}}(\mathrm{E})\right]$ is used in Eq. (M7.A.1) to obtain the group-averaged cross sections. The Nordheim integral equation solved by NITAWL is, therefore, frequently written as 


$$
\begin{aligned}
\Sigma_{\mathrm{TP}}(\mathrm{E}) \phi_{\mathrm{F}}(\mathrm{E})=\left[1-\mathrm{P}_{\mathrm{F}-\mathrm{M}}^{0}(\mathrm{E})\right] \int_{\mathrm{E}}^{\mathrm{E} / \alpha_{\mathrm{F}}} \phi_{\mathrm{F}}\left(\mathrm{E}^{\prime}\right) \Sigma_{\mathrm{sP}}\left(\mathrm{E}^{\prime}\right)\left(\frac{1}{1-\alpha_{\mathrm{F}}}\right)\left(\frac{1}{\mathrm{E}^{\prime}}\right) d \mathrm{E}^{\prime} \\
+\left(\frac{1}{\mathrm{E}}\right) \mathrm{P}_{\mathrm{P}-\mathrm{M}}^{\circ}(\mathrm{E}) \Sigma_{\mathrm{LF}}(\mathrm{E})
\end{aligned}
$$

with the initial condition written as simply

$$
\phi_{\mathrm{P}}\left(\mathrm{E}^{\prime}\right) \equiv\left(\frac{1}{\mathrm{E}^{\prime}}\right) \text { at } \mathrm{E}^{\prime}>\mathrm{E}_{\mathrm{res}}^{\max }
$$

In systems having multiple fuel lumps, the material properties of the external moderator will become important only to the extent that they affect the transmission probability through the moderator (i.e., the Dancoff factor, C) and the "effective" escape probability for a typical fuel lump, $P_{F \rightarrow M}(E)$. See Sect. M7.A.2 for additional details.

\section{M7.A.2 EXACT IMPRESSIONS FOR THE FIRST-FLIGHT ESCAPE PROBABILITY USED IN THE NORDHEIM INTEGRAL METHOD, AND THE ROLE OF THE DANCOFF FACTOR (C) IN LATTICECELL CALCULATIONS}

Before leaving our discussion of the Nordheim method as implemented in the NITAWL code, a few words must be said about $\mathrm{P}_{\mathrm{F}-\mathrm{M}}^{\circ}(\mathrm{E})$ and how it is calculated. Obviously, if one had a single fuel lump embedded in an infinite sea of moderator, $\mathrm{P}_{\mathrm{F} \rightarrow \mathrm{M}}^{\circ}(\mathrm{E})$ would simply be the first-flight escape probability for the fuel lump, $P_{\mathrm{FO}}(\mathrm{E})$. Assuming a uniform source of isotropically emitted neutrons, Case, deHoffman and Placzek ${ }^{13}$ have derived exact analytic expressions for $P_{F O}(E)$ as a function of $\Sigma_{\mathrm{F}}(E)$ and the characteristic lump dimension of the fuel, where

$$
\bar{a}=\left\{\begin{array}{l}
t, t=\text { thickness of an infinite slab, } \\
r, r=\text { radius of an infinite cylinder, } \\
r, r=\text { radius of a sphere }
\end{array}\right.
$$

Letting

$$
\mathrm{x}=\overline{\mathrm{a}} \Sigma_{\mathrm{tP}}(\mathrm{E})
$$

these exact analytic expressions for the first-flight escape probability may be written as

NUREG/CR-0200,

Vol. 3, Rev. 4 


$$
\begin{aligned}
& \text { slab: } P_{\mathrm{FO}}(E)=\frac{1}{x}\left[\frac{1}{2}-E_{3}(x)\right] \\
& \text { cylinder: } P_{\mathrm{FO}}(E)=\frac{4}{3}(x)\left\{2\left[x \mathrm{~K}_{1}(x) I_{1}(x)+K_{0}(x) I_{0}(x)-1\right]\right. \\
&\left.+\left(\frac{1}{x}\right) K_{1}(x) I_{1}(x)-K_{0}(x) I_{1}(x)+K_{1}(x) I_{0}(x)\right\} \\
& \text { sphere: } P_{F O}(E)=\left(\frac{3}{8 x^{3}}\right)\left[2 x^{2}-1+(1+2 x) e^{-2 x}\right]
\end{aligned}
$$

Tables of these functions are given in ref. 13. These tables, along with appropriate interpolation schemes, have also been incorporated in the NITAWL code.

In the derivation of Eq. (M7.A.12), $\mathrm{P}_{\mathrm{F}-\mathrm{M}}^{\circ}(\mathrm{E})$ was taken to represent the probability that a neutron born in the fuel will have its next collision in the moderator. In the usual situation where one has a lattice of fuel pins, this probability is not the same as the escape probability from a single fuel rod since some of the escaping neutrons may pass through the moderator without a collision and be absorbed in the next fuel lump or succeeding fuel lumps. Figure M7.A.2 shows the probability that a neutron escaping from a single fuel lump will enter and leave each succeeding fuel lump. It also shows the probability that a neutron escaping from a single fuel lump will experience a collision in each of the succeeding moderator regions. Using $C$ to represent the free-flight transmission probability through the moderator and $P_{t}$ to represent the free-flight transmission probability through the fuel:

$$
P_{\mathrm{F} \rightarrow \mathrm{M}}^{0}(\mathrm{E})=\mathrm{P}_{\mathrm{FO}}(1-\mathrm{C})\left[1+\mathrm{CP}_{\mathrm{t}}+\mathrm{C}^{2} \mathrm{P}_{\mathrm{t}}^{2}+\ldots . .\right]
$$

and

$$
P_{\mathrm{F} \rightarrow \mathrm{M}}^{\circ}(E)=\mathrm{P}_{\mathrm{Fo}}(1-\mathrm{C})\left(\frac{1}{1-\mathrm{CP}_{\mathrm{t}}}\right)
$$

ORNL-DWG 81.18142

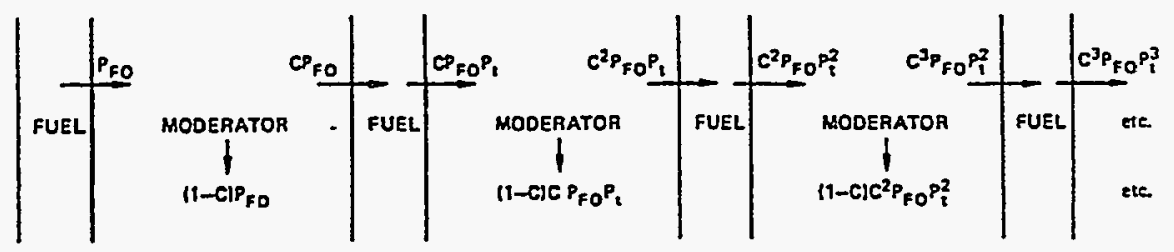

Figure M7.A.2 Transmission of an uncollided neutron through a lattice 
The traditional form of Eq. (M7.A.22) is obtained by writing the transmission probability for the fuel lump, $P_{v}$ in terms of the escape probability, $P_{F O}$. To obtain the approximate relationship typically used, consider a monodirectional beam of neutrons impingent on a slab of thickness $\ell$. The free-flight transmission probability is simply $P_{t}=e^{-\ell \Sigma_{t}}$. Now consider a monodirectional source of neutrons (S) uniformly distributed throughout the slab. The average free-flight escape probability, $P_{F O}$ is then given by

$$
P_{F O}=\frac{\int_{0}^{l} S e^{-x \Sigma_{t}} d x}{\int_{0}^{l} S d x}=\frac{1-e^{-l \Sigma_{t}}}{l \Sigma_{t}}
$$

Rearranging terms, we have

$$
\begin{gathered}
\rightarrow \mathrm{e}^{-\ell \Sigma_{\mathrm{t}}}=1-\ell \Sigma_{\mathrm{t}} \mathrm{P}_{\mathrm{FO}} \\
-\mathbf{P}_{\mathrm{t}}=1-\ell \Sigma_{t} \mathbf{P}_{\mathrm{FO}}
\end{gathered}
$$

Even though this relationship is strictly valid only for a monodirectional source, a reasonable first-order approximation for other cases may be obtained by setting $l$ equal to $\bar{l}$, the mean chord length through the fuel lump. The mean chord length is estimated as $4^{*} V_{F} / S_{F}$.as well. Plugging Eq. (M7.A.25) into Eq. (M7.A.22) yields the standard approximation for $P_{\mathrm{F} \rightarrow \mathrm{M}}^{0}(\mathrm{E})$ :

$$
\mathrm{P}_{\mathrm{F} \rightarrow \mathrm{M}}^{\circ}(E)=\mathrm{P}_{\mathrm{FO}}\left[\frac{1-\mathrm{C}}{1-\left(1-\bar{\ell} \Sigma_{\mathrm{LF}} \mathrm{P}_{\mathrm{FO}}\right) \mathrm{C}}\right]
$$

where $P_{F O}$ and $\Sigma_{t F}$ are energy-dependent $\left[P_{F O}(E)\right.$ and $\left.\Sigma_{t F}(E)\right]$ and where $C$, the free-flight transmission probability through the moderator (also known as the Dancoff factor), depends only on the dimensions and the (relatively constant) cross section for the moderator. Approximations for the Dancoff factor in various types of lattice-cell arrangements are described in Sect. M7.2.4. Equations (M7.A.18-20) are thus used in conjunction with Eq. (M7.A.26) when solving the Nordheim integral equation for the flux.

\section{M7.A3 APPROXIMATE EXPRESSIONS FOR THE FIRST-FLIGHT ESCAPE PROBABILITY, THE DEFINITION OF THE ESCAPE CROSS SECTIONS, AND THE REI.ATIONSHIP BETWEEN THE TWO QUANTITIES}

Before developing an expression for the flux based on the NR approximation and showing how that might be used to determine self-shielding factors for use in the Bondarenko method, it is convenient to make a few additional remarks concerning the first-flight escape probability.

From Eq. (M7.A.23), it is apparent that

$$
\mathrm{P}_{\mathrm{FO}}(\mathrm{E}) \rightarrow \frac{1}{\bar{l} \Sigma_{\mathrm{tF}}(\mathrm{E})}, \bar{\ell} \Sigma_{\mathrm{tP}}(\mathrm{E})>>1
$$

NUREG/CR-0200, 
whenever the fuel lump is very large or very black. While less obvious, it can be shown that Eqs. (M7.A.18-20) obey the same limit. On the other hand, $P_{F O}(E) \rightarrow 1$ whenever the fuel lump is very small. One convenient expression which fits both end-points is Wigner's rational approximation:

$$
\mathrm{P}_{\mathrm{FO}}(\mathrm{E}) \doteq \frac{1}{1+\bar{\ell} \Sigma_{\mathrm{tF}}(\mathrm{E})}
$$

Substituting this expression into Eq. (M7.A.26) and performing a small amount of algebra yields:

$$
\mathrm{P}_{\mathrm{F} \rightarrow \mathrm{M}}^{\mathrm{o}}(\mathrm{E}) \doteq \frac{1}{1+\left(\frac{\bar{l}}{1-\mathrm{C}}\right) \Sigma_{\mathrm{P}}(\mathrm{E})}
$$

Physically this says that the effect of the additional fuel in the lattice is the same as increasing the size of a single equivalent fuel rod.

As shown in Fig. M7.A.3, Wigner's rational approximation for $P_{F O}(E)$ fits the exact results given by Eqs. (M7.A.18-20) fairly well. forms such as

Others, in an attempt to improve the Wigner rational approximation, have suggested alternate

$$
\mathrm{P}_{\mathrm{PO}}(\mathrm{E}) \doteq \frac{1}{1+\mathrm{a} \bar{\ell} \Sigma_{\mathrm{tF}}(E)}
$$

where "a" is a fitted parameter between 0 and 1 which may be a constant, or a weak function of $\bar{\ell} \Sigma_{\mathbb{F}}(E)$. Substituting this expression in Eq. (M7.A.26) yields

$$
\begin{aligned}
P_{\mathrm{F} \rightarrow \mathrm{M}}^{\circ}(\mathrm{E}) & =\frac{1}{1+\mathrm{a}\left(\frac{\bar{l}}{1-\mathrm{C}}\right) \Sigma_{\mathrm{tP}}(\mathrm{E})} \\
& =\frac{\mathrm{N}_{\mathrm{l}}\left(\frac{1-\mathrm{C}}{\left.\mathrm{N}_{\mathrm{F}} \bar{l}\right)}\right)}{\mathrm{N}_{\mathrm{l}}\left(\frac{1-\mathrm{C}}{\left.\mathrm{N}_{\mathrm{F}} \mathrm{a}\right)}\right)+\mathrm{N}_{\mathrm{R}} \sigma_{\mathrm{LP}}(\mathrm{E})}=\frac{\sigma_{\mathrm{esc}}}{\sigma_{\mathrm{esc}}+\sigma_{\mathrm{LF}}(\mathrm{E})}
\end{aligned}
$$

where $\sigma_{e s c}$ is a constant, or a very weak, function of $\bar{\ell} \Sigma_{\mathrm{FF}}(\mathrm{E})$. Otter ${ }^{14}$ has carefully fitted the modified Wigner approximation [cf. Eq. (M7.A.30)] to the exact results given by Eqs. (M7.A.18-20). He claims that using

$$
a=C+\frac{1-C}{A}
$$




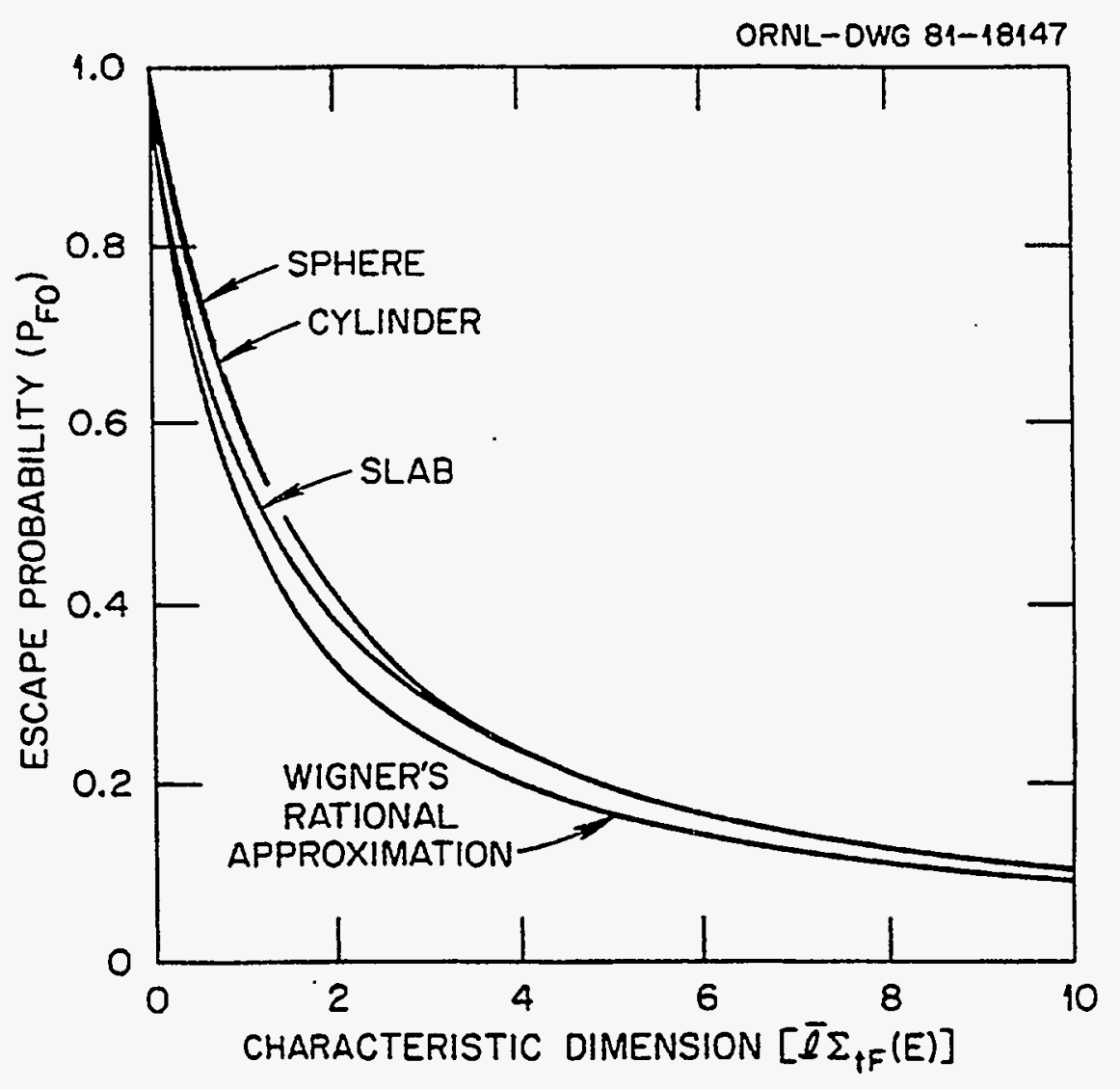

Figure M7.A.3 The escape probability $\left(\mathrm{P}_{\mathrm{FO}}\right)$ and Wigner's rational approximation, as functions of the characteristic dimension $\left[\ell \Sigma_{\mathbb{F}}(E)\right]$ 
[where $A$ is a slowly varying function of $\bar{\ell} \Sigma_{\mathrm{tF}}(E)$ as given in Table M7.A.1] will reproduce the exact escape probabilities to within $\sim 0.5 \%$. Substituting Eq. (M7.A.32) into the expression for the escape cross-section yields

$$
\sigma_{e s c}=\left(\frac{1}{N_{p}}\right)\left(\frac{1-C}{\bar{l}}\right)\left(\frac{A}{1+(A-1) C}\right)
$$

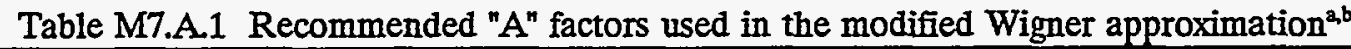

\begin{tabular}{llc}
\hline Range & \multicolumn{1}{c}{ Function } & $\begin{array}{c}\text { Max error } \\
\text { in } \mathrm{P}_{\mathrm{FO}}(\mathrm{E})\end{array}$ \\
\hline$\underline{\text { Plane }}$ & $\mathrm{A}=4 /(1.61593-\ell \mathrm{n}(\Sigma \ell))-\Sigma \ell-0.225(\Sigma \ell)^{2}$ & $0.4 \%$ \\
$0 \leq \Sigma \ell \leq 1.36$ & $\mathrm{~A}=1+1.2978(\Sigma \ell)^{-1}-1.8241(\Sigma \ell)^{-2}$ & $0.75 \%$ \\
$1.36<\Sigma \ell \leq \infty$ & $+0.75275(\Sigma \ell)^{-3}$ & \\
Infinite Cylinder & & \\
$0 \leq \Sigma \ell<2$ & $\mathrm{~A}=1.5013+0.14879(\Sigma \ell)^{1 /}-0.17226 \Sigma \ell$ & \\
$2 \leq \Sigma \ell \leq \infty$ & $\mathrm{A}=1+(\Sigma \ell)^{-1}-(\Sigma \ell)^{-3}$ & $0.5 \%$ \\
Sphere & & $0.5 \%$ \\
$0 \leq \Sigma \ell<1.36$ & $\mathrm{~A}=16 / 9-0.2625 \Sigma \ell+0.0258(\Sigma \ell)^{3}$ & \\
$1.36 \leq \Sigma \ell \leq \infty$ & $\mathrm{A}=1+1.09(\Sigma \ell)^{-1}-0.591(\Sigma \ell)^{-2}$ & $0.2 \%$ \\
\hline
\end{tabular}

'This table was taken directly from ref. 14 by J. M. Otter.

bFor an isolated fuel lump (where $\mathrm{C} \equiv 0$ ), the fitted parameter (a) used in the Modified Wigner Approximation is given by $a=1 / A$; in general, " $a$ " is defined by Eq. (M7.A.32).

To account for the fact that $A$ is a very slowly varying function of $\bar{\ell} \Sigma_{F}(E)$, one typically uses the infinitely dilute group-averaged value, $\Sigma_{\mathrm{tF}}^{\mathrm{g}, \infty}$, to define a group-dependent escape cross section $\sigma_{\mathrm{esc}}^{\mathrm{g}}$. Hence,

$$
P_{\mathrm{F} \rightarrow \mathrm{M}}^{\circ}(\mathrm{E})=\frac{\sigma_{\mathrm{CsC}}^{\mathrm{g}}}{\sigma_{\mathrm{esc}}^{g}+\sigma_{\mathrm{tF}}(\mathrm{E})}
$$

where $\sigma_{e s e}^{8}$ is taken to be constant within any given energy group. 


\section{M7.A4 THE NARROW-RESONANCE APPROXIMATION FOR THE FLUX, AS DERIVED FROM A GENERALIZED FORM OF THE NORDHEIM INTEGRAL EQUATION}

For the sake of argument, let the Nordheim integral equation be written as

$$
\begin{aligned}
& \Sigma_{\mathrm{tF}}(\mathrm{E}) \phi_{\mathrm{P}}(\mathrm{E})+\left[1-\mathrm{P}_{\mathrm{F} \rightarrow \mathrm{M}}^{\circ}(\mathrm{E})\right] \int_{\mathrm{E}}^{\mathrm{E} / \alpha_{\mathrm{F}}^{25}} \phi_{\mathrm{F}}\left(\mathrm{E}^{\prime}\right) \Sigma_{\mathrm{sF}}^{25}\left(\mathrm{E}^{\prime}\right)\left(\frac{1}{1-\alpha_{\mathrm{F}}^{25}}\right)\left(\frac{1}{\mathrm{E}^{\prime}}\right) \mathrm{dE^{ \prime }} \\
& +\int_{E}^{E / \alpha_{F}^{28}} \int_{E}^{E / \alpha_{F}^{28}} \phi_{F}\left(E^{\prime}\right) \Sigma_{\alpha P}^{28}\left(E^{\prime}\right)\left(\frac{1}{1-\alpha_{F}^{28}}\right)\left(\frac{1}{E^{\prime}}\right) d E^{\prime} \\
& +\int_{\mathrm{E}}^{\mathrm{E} / \alpha_{\mathrm{F}}^{16}} \phi_{\mathrm{F}}\left(\mathrm{E}^{\prime}\right) \Sigma_{\mathrm{sP}}^{16}\left(\mathrm{E}^{\prime}\right)\left(\frac{1}{1-\alpha_{\mathrm{F}}^{16}}\right)\left(\frac{1}{\mathrm{E}^{\prime}}\right) d \mathrm{E}^{\prime} \\
& +\frac{P_{\mathrm{F} \rightarrow \mathrm{M}}^{0}(\mathrm{E}) \Sigma_{\mathrm{tP}}(\mathrm{E})}{\bar{\xi} \bar{\Sigma}_{8} \mathrm{E}}
\end{aligned}
$$

where the slowing down due to the ${ }^{235} \mathrm{U},{ }^{238} \mathrm{U}$, and oxygen have all been represented explicitly. Other nuclides present in the fuel could be represented in like fashion.

The most common way to proceed is to assume that the NR approximation applies to each of the nuclides in the fuel $\left({ }^{235} \mathrm{U},{ }^{238} \mathrm{U}, \mathrm{O}\right)$.

If the average energy loss in an elastic collision with a particular fuel nuclide $\left[1 / 2\left(1-\alpha_{\mathrm{F}}^{\mathbf{i}}\right) E_{\mathrm{res}}\right]$ is much larger than the practical width of the response $\left(\Gamma_{\mathrm{p}}\right)$, then it is very unlikely that a neutron will have a second collision within the resonance. Under these conditions, the contribution to $\Sigma_{\mathrm{F}}(E) \phi_{\mathrm{F}}(E)$ due to the integration of $\phi_{F}\left(E^{\prime}\right) \Sigma_{S P}^{i}\left(E^{\prime}\right)$ over the narrow energy range associated with the resonance will be negligible compared to the contribution due to the integration of $\phi_{\mathrm{F}}\left(E^{\prime}\right) \Sigma_{\mathrm{gp}}^{i}\left(E^{\prime}\right)$ over the rest of the range (from just above the resonance $\left[E^{\prime}=E_{2} \approx E\right]$ to $E^{\prime}=E / \alpha$ ). Figure M7.A.4 is an attempt to illustrate this situation. For energies just above the resonance we will, wittingly or not, assume that there is very little absorption such that the flux there may be replaced by its asymptotic form:

$$
\phi_{\mathrm{P}}\left(E^{\prime}\right)=\phi_{\mathrm{F}}^{\infty}=\frac{1}{\bar{\xi} \bar{\Sigma}_{\mathrm{s}} E^{\prime}}
$$

(If indeed there is very little absorption between $E$ and $E / \alpha$, then $\Sigma_{\mathrm{tr}}(\mathrm{E})=\Sigma_{\mathrm{sF}}(\mathrm{E})=$ constant potential scattering cross section at energies above the resonance. Under these conditions, direct substitution of Eq. (M7.A.36) into Eq. (M7.A.35) will show it to be the solution for any and all energies above the resonance). While Eq. (M7.A.8) may be valid for the flux in a nonabsorbing external moderator, Eq. (M7.A.36) is valid for the flux in the fuel only if the resonances are widely spaced. In this particular example, this "widely spaced" assumption would require that neither ${ }^{235} \mathrm{U}$ nor ${ }^{238} \mathrm{U}$ have another resonance 
in the range $\mathrm{E}$ to $\mathrm{E} / \alpha^{25}, \mathrm{E}$ to $\mathrm{E} / \alpha^{28}$, or $\mathrm{E}$ to $\mathrm{E} / \alpha^{16}$. While this last condition is never met and the first two are met only rarely, use of the asymptotic flux [Eq. (M7.A.36)] for energies above the resonance remains a common assumption.

Using the narrow resonance approximation (see Fig. M7.A.4) and invoking Eq. (M7.A.36) for the flux at energies just above the resonance, we may write

$$
\begin{aligned}
& \int_{E}^{E / \alpha^{i}} \int_{E}^{E / \alpha^{\prime}} \phi_{F}\left(E^{\prime}\right) \Sigma_{\alpha F}^{i}\left(E^{\prime}\right)\left(\frac{1}{1-\alpha_{F}^{i}}\right)\left(\frac{1}{E^{\prime}}\right) d E^{\prime}
\end{aligned}
$$

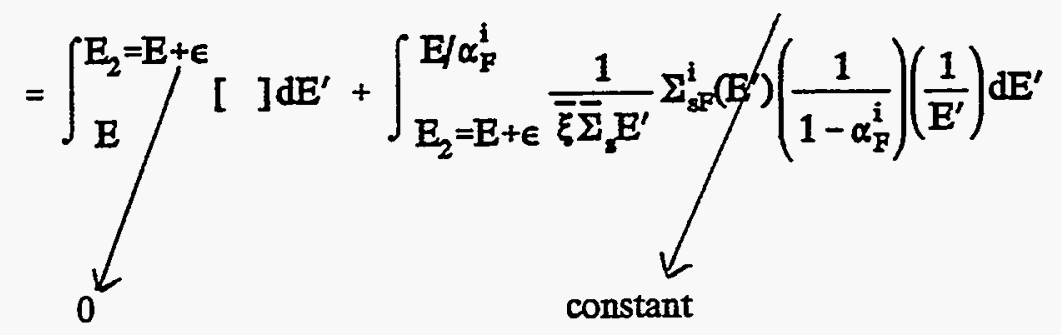

$$
\begin{aligned}
& =\left(\frac{\Sigma_{\mathrm{FF}}^{i}}{\bar{\xi} \bar{\Sigma}_{\mathrm{s}}}\right)\left(\frac{1}{1-\alpha_{F}^{i}}\right) \int_{E}^{E / \alpha_{F}^{i}} \frac{1}{x^{2}} \mathrm{dx}=\left(\frac{\Sigma_{\mathrm{gF}}^{i}}{\overline{\bar{\zeta}} \bar{\Sigma}_{\mathrm{z}}}\right)\left(\frac{1}{\mathrm{E}}\right)
\end{aligned}
$$

\section{ORNL-DWG 81-18144}

\section{RESONANCE}

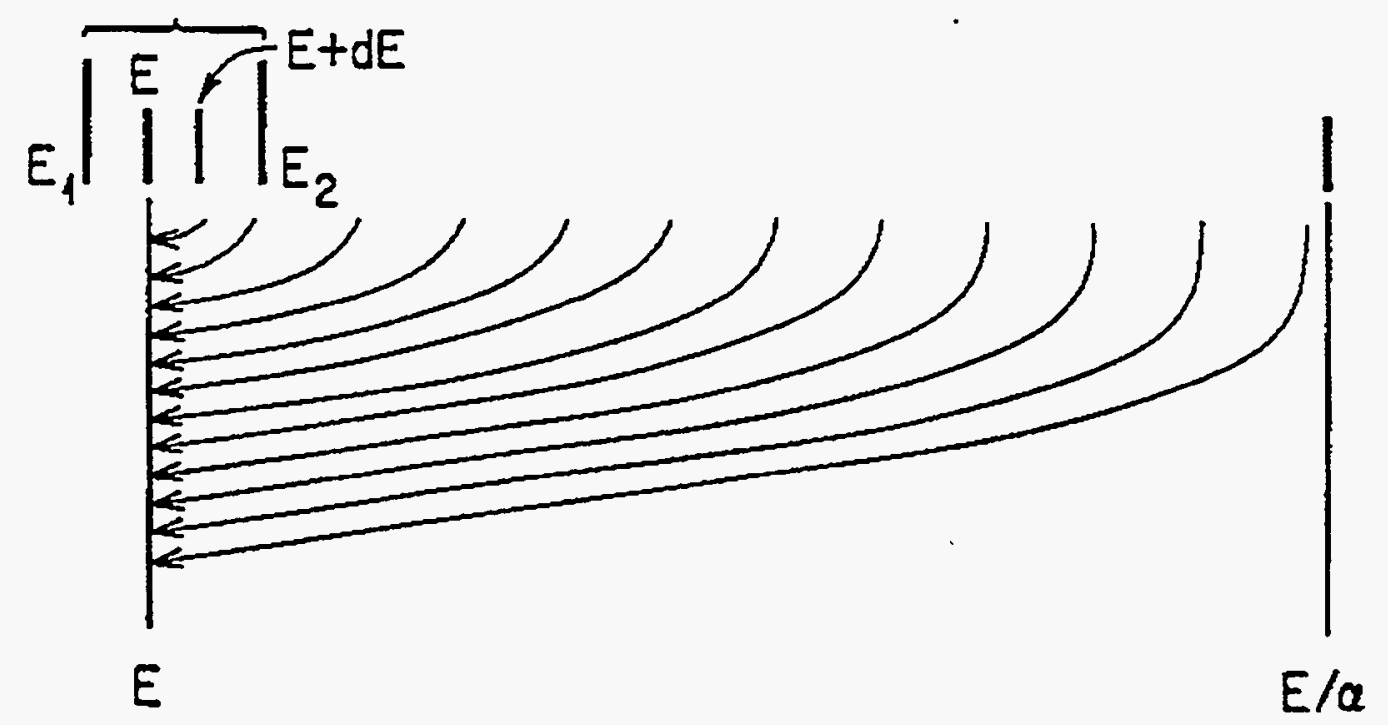

Figure M7.A.4 Elastic scattering into $\mathrm{dE}$ about $\mathrm{E}$ when $\mathrm{E}$ lies inside a narrow resonance 
Substituting this result (for ${ }^{235} \mathrm{U},{ }^{238} \mathrm{U}$, and O) into Eq. (M7.A.35), and recognizing that

$$
1-\mathrm{P}_{\mathrm{F} \rightarrow \mathrm{M}}^{0}(\mathrm{E})=1-\left[\frac{\Sigma_{\mathrm{ess}}}{\Sigma_{\mathrm{esc}}+\Sigma_{\mathrm{tF}}(\mathrm{E})}\right]=\frac{\Sigma_{\mathrm{tP}}(\mathrm{E})}{\Sigma_{\mathrm{esc}}+\Sigma_{\mathrm{tF}}(\mathrm{E})}
$$

yields

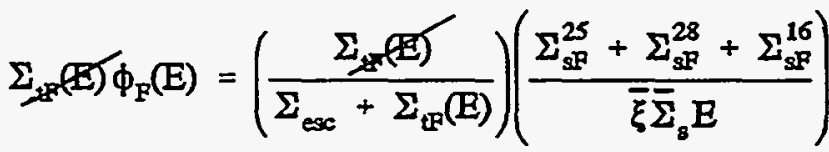

$$
\begin{aligned}
& +\left(\frac{\Sigma_{e s c}}{\Sigma_{e s c}+\Sigma_{t F}(E)}\right)\left(\frac{\Sigma_{c F}(E)}{\bar{\xi} \bar{\Sigma}_{8} E}\right) \\
& \Rightarrow \phi_{\mathrm{P}}(\mathrm{E})=\left(\frac{\Sigma_{\mathrm{sP}}+Z_{\mathrm{esc}}}{\bar{\xi}_{\Sigma_{\mathrm{z}}}}\right)\left(\frac{1}{\Sigma_{\mathrm{FF}}(\mathrm{E})+\Sigma_{\mathrm{esc}}}\right)\left(\frac{1}{\mathrm{E}}\right)
\end{aligned}
$$

To the extent that one has a sequence of widely spaced narrow resonances, this expression accurately described the flux underneath any given resonance and in the region between resonances. Between resonances, for example, $\Sigma_{\mathrm{kF}}(E)=\Sigma_{\mathrm{sF}}(E)=\Sigma_{\mathrm{sF}}=$ constant potential scattering cross section and Eq. (M7.A.40) reduces to the asymptotic solution. As a result, this expression may be used for the flux over an entire energy group.

When $\phi_{F}(E)$ is used as a weighting function to produce group-averaged cross-section data, it appears in both the numerator and the denominator [cf. Eq. (M7.A.1)], such that the leading constant cancels and is of no consequence. For that reason, people frequently write $\phi_{\mathrm{F}}(E)$ as simply

$$
\phi_{\mathrm{P}}(\mathrm{E})=\left(\frac{1}{\Sigma_{\mathrm{tP}}(\mathrm{E})+\Sigma_{\mathrm{esc}}}\right)\left(\frac{1}{\bar{E}}\right)
$$

Expressing the flux as a function of lethargy $\left[u=\ell n\left(E_{d} / E\right)\right]$, Eq. (M7.A.41) would be equivalent to saying that $\phi_{F}(u)$ is constant between resonances, and that $\phi_{F}(u) \Sigma_{\mathrm{F}}(\mathfrak{u})$ is constant underneath a resonance (where $\Sigma_{e s c}=0$ for an infinite system).

\section{M7.A5 THE NARROW-RESONANCE/INFINITE-MASS APPROXIMATION FOR THE FLUX, AS DERIVED FROM THE NORDHEIM INTEGRAL EQUATION}

Before proceeding further, it is necessary to point out that there are instances in which the NR approximation is not valid, that is, instances where 


$$
\Gamma_{\mathrm{P}} \ll<\left(\frac{1}{2}\left(1-\alpha_{\mathrm{P}}^{i}\right) \mathrm{E}_{\mathrm{res}}\right]
$$

is not true, and where Fig. M7.A.4 does not depict the real situation. In the present example $\left(\mathrm{UO}_{2}\right)$, the upper limit of integration $\left(E / \alpha_{F}^{i}\right)$ for the oxygen may lie well outside the resonance where the upper limit for the ${ }^{235} \mathrm{U}$ and ${ }^{238} \mathrm{U}$ integrals may actually lie inside the resonance. (At $\mathrm{E}=10 \mathrm{eV}$, for example, $\mathrm{E} / \alpha^{16}=12.8 \mathrm{eV}$, whereas $\mathrm{E} / \alpha^{25}=\mathrm{E} / \alpha^{28}=10.2 \mathrm{eV}$ ). Before showing how such situations may be handled, let us diverge for a moment to define the practical width $\left(\Gamma_{\mathrm{P}}\right)$ and to identify key instances where the NR approximation is not valid.

The practical width of a resonance in a given mixture $\left(\Gamma_{P}\right)$ is defined as the difference between those energies at which the anomalous cross section given by the single-level Breit-Wigner formula is equal to the potential scattering cross section for the mixture

$$
\frac{N^{i} \sigma_{\text {Tes }}}{1+\left(\frac{2}{\Gamma}\right)^{2}\left(E-E_{\text {res }}\right)^{2}}=\Sigma_{p p}=N^{25} \sigma_{p}^{25}+N^{28} \sigma_{p}^{28}+N^{16} \sigma_{s}^{16}
$$

where $N^{i}$ is the number density of the resonance nuclide $\left({ }^{25} \mathrm{~N}\right.$ or $\left.{ }^{28} \mathrm{~N}\right)$ and $\sigma_{\text {res }}$ the maximum value of the anomalous cross section, is defined by

$$
\sigma_{\text {res }}=4 \pi\left(\frac{2.0722 \times 10^{5} \mathrm{eV} \text { bams }}{\mathrm{E}_{\text {res }}}\right)\left(\frac{\mathrm{A}+1}{\mathrm{~A}}\right)^{2}\left(\frac{\mathrm{gr}_{\mathrm{n}}}{\Gamma}\right)
$$

where the resonance parameters $\left(E_{r e s}, \Gamma\right.$, and $\left.g \Gamma_{n}\right)$ may be found in BNL-325. ${ }^{15}$ [The natural width $(\Gamma)$, of course, is defined as the difference between those energies at which the anomalous cross section is equal to half of its maximum value.] Substituting $E=E_{\mathrm{res}} \pm(1 / 2) \Gamma_{\mathrm{p}}$ into Eq. (M7.A.43) and solving for $\Gamma_{\mathrm{P}}$ yields

$$
\Gamma_{P}=\Gamma \sqrt{\left(\frac{N^{i} \sigma_{r e s}}{\Sigma_{p P}}\right)-1}
$$

As a specific example, consider the $6.67-\mathrm{eV}$ resonance in ${ }^{288} \mathrm{U}$ where $\Gamma=0.0275 \mathrm{eV}$ and $\mathrm{g} \Gamma_{\mathrm{n}}=$ $0.00152 \mathrm{eV}$. Equation (M7.A.44) yields $\sigma_{\mathrm{res}}=21760$ barns. Noting that $\sigma_{\mathrm{p}}^{25} \approx \sigma_{\mathrm{p}}^{28} \approx 10$ barns and that $\sigma_{3}^{16} \approx 3.8$ barns yields

$$
\Gamma_{P}=(0.0275 \mathrm{eV}) \sqrt{\frac{21760}{10+2(3.8)}-1}=0.97 \mathrm{eV}
$$

Thus, $\Gamma_{P}$ is considerably larger than $\Gamma$, making the narrow resonance criterion,

$$
\Gamma_{\mathrm{p}} \ll\left[1 / 2\left(1-\alpha_{\mathrm{p}}^{\mathbf{i}}\right) \mathrm{E}_{\mathrm{res}}\right]
$$


even more difficult to satisfy. Generally speaking, the practical width $\left(\Gamma_{P}\right)$ is about 10 to 30 times larger than the natural width $(\Gamma){ }^{12}$

Using Eqs. (M7.A.44), (M7.A.45), and (M7.A.47) in conjunction with the resonance parameters found in the third edition of BNL-325, one can determine when and where the narrow resonance approximation is applicable. As might be shown by such an exercise, it is quite good for all but the very low-energy resonances. Even then, it is usually applicable for all but the heaviest nuclides where $\alpha_{\mathrm{F}}^{i} \rightarrow 1$. Some of the more outstanding examples of where the narrow resonance approximation is not applicable would include the 21.78 - and $23.43-\mathrm{eV}$ resonances in ${ }^{232} \mathrm{Th}$, the 1.79 - and $10.37-\mathrm{eV}$ resonances in ${ }^{233} \mathrm{U}$, the 6.67-, the 20.9-, and the $36.8-\mathrm{eV}$ resonances in ${ }^{238} \mathrm{U}$, and the $1.056-$ and $20.46-\mathrm{eV}$ resonances in ${ }^{240} \mathrm{Pu}$.

As noted above, many of the heavy nuclides have broad low-energy resonances for which Eq. (M7.A47) cannot be satisfied. In many of those cases, just the reverse is true (i.e., the average energy loss in an elastic collision with a heavy fuel nuclide is much smaller than the practical width):

$$
\left[1 / 2\left(1-\alpha_{\mathrm{F}}^{\mathbf{i}}\right) \mathrm{E}_{\mathrm{res}}\right] \ll \Gamma_{\mathrm{P}}
$$

Fortunately, this type of situation occurs only with the heavy nuclides where $\alpha_{\vec{p}}^{\mathfrak{i}}-1$, as illustrated in Fig. M7.A5. Under such conditions, the range of integration, $E$ to $E / \alpha_{F}^{i}$, becomes so small that $E^{\prime} \approx$ $E$ over the entire range, and

$$
\begin{aligned}
& \operatorname{limit}_{\alpha \rightarrow 1} \int_{E}^{E / \alpha} \phi_{P}\left(E^{\prime}\right) \Sigma_{s p}\left(E^{\prime}\right)\left(\frac{1}{1-\alpha}\right)\left(\frac{1}{E^{\prime}}\right) d E^{\prime} \\
& =\phi_{\mathrm{F}}(\mathrm{E}) \Sigma_{\mathrm{sF}}(\mathrm{E})\left(\frac{1}{\mathrm{E}}\right) \underset{\alpha \rightarrow 1}{\operatorname{limit}}\left(\frac{1}{1-\alpha}\right) \int_{\mathrm{E}}^{\mathrm{E} / \alpha} \mathrm{dE}^{\prime} \\
& =\phi_{\mathrm{F}}(E) \Sigma_{\mathrm{sP}}(E) \operatorname{limit}_{\alpha \rightarrow 1}\left(\frac{\frac{1}{\alpha}-1}{1-\alpha}\right)=\phi_{\mathrm{P}}(E) \Sigma_{\mathrm{sP}}(E)
\end{aligned}
$$




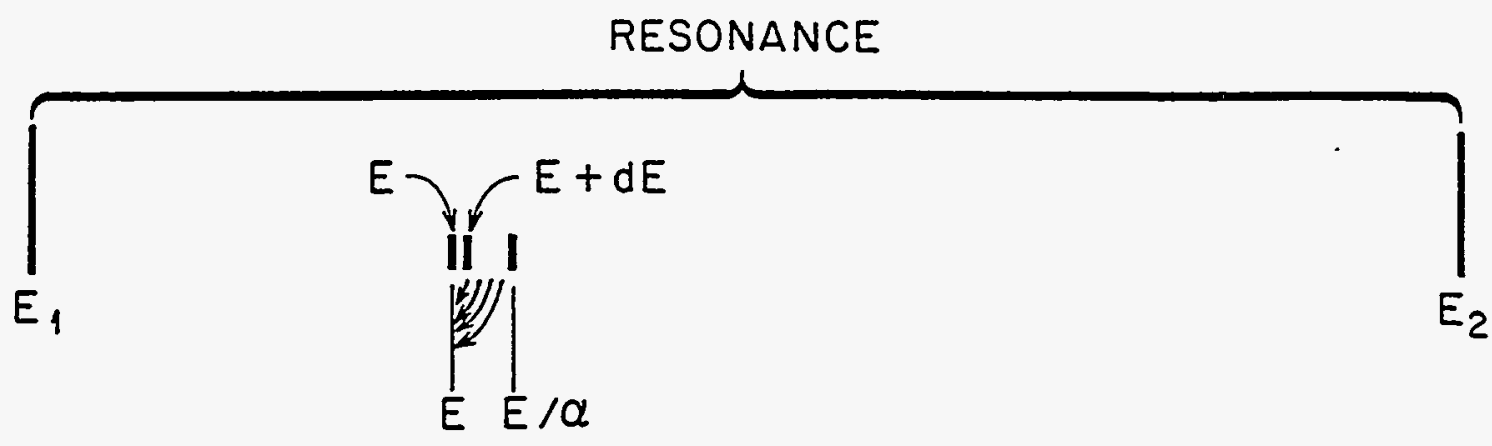

Figure M7.A.5 Elastic scattering into $\mathrm{dE}$ about $\mathrm{E}$ when $\mathrm{E}$ lies inside a broad resonance or $\leftrightarrow 1$

Alternatively, one may take $\phi_{\mathrm{F}}\left(E^{\prime}\right) \Sigma_{\mathrm{sP}}\left(E^{\prime}\right) \approx$ constant over the narrow range from $E$ to $E / \alpha_{\mathrm{F}}^{i}$, and leave the $\left(1 / E^{\prime}\right)$ term inside the integral, in which case

$$
\operatorname{limit}_{\alpha \rightarrow 1}\left(\frac{1}{1-\alpha}\right) \int_{E}^{E / \alpha}\left(\frac{1}{E^{\prime}}\right) d E^{\prime}=\operatorname{limit}_{\alpha \rightarrow 1} \frac{\ln \left(\frac{1}{\alpha}\right)}{1-\alpha}=1
$$

Equation (M7.A.49) is commonly known as the infinite mass (IM) approximation. Substituting this expression into Eq. (M7.A.35), but retaining the narrow resonance approximation for the oxygen term, yields:

$$
\begin{aligned}
& \Sigma_{\mathrm{tP}}(\mathrm{E}) \phi_{\mathrm{F}}(\mathrm{E})=\left(\frac{\Sigma_{\mathrm{qP}}(\mathrm{E})}{\Sigma_{\mathrm{ecc}}+\Sigma_{\mathrm{TF}}(\mathrm{E})}\right)\left[\phi_{\mathrm{F}}(\mathrm{E}) \Sigma_{\mathrm{sP}}^{25}(\mathrm{E})+\phi_{\mathrm{F}}(\mathrm{E}) \Sigma_{\mathrm{sP}}^{28}(\mathrm{E})+\left(\frac{\Sigma_{\mathrm{gP}}^{16}}{\bar{\xi} \bar{\Sigma}_{z}}\right)\left(\frac{1}{\mathrm{E}}\right)\right] \\
& +\left(\frac{\Sigma_{\mathrm{cec}}}{\Sigma_{\mathrm{csc}}+\Sigma_{\mathrm{tP}}(\mathrm{E})}\right)\left(\frac{\Sigma_{\mathrm{tF}}(\mathrm{E})}{\bar{\xi} \bar{\Sigma}_{2}}\right)\left(\frac{1}{\mathrm{E}}\right)
\end{aligned}
$$

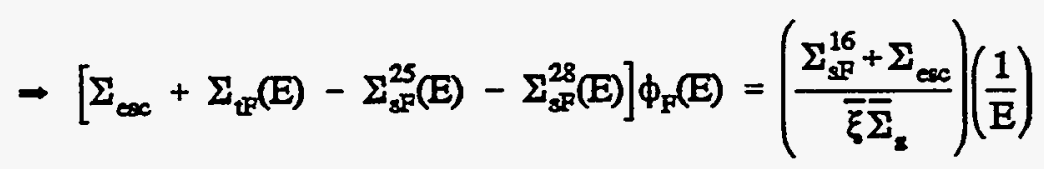




$$
\rightarrow \phi_{\mathrm{P}}(\mathrm{E})=\left(\frac{\Sigma_{\mathrm{sP}}^{16}+\Sigma_{\mathrm{esc}}}{\xi \bar{\Sigma}_{\mathrm{s}}}\right)\left[\frac{1}{\Sigma_{\mathrm{AP}}^{25}(\mathrm{E})+\Sigma_{\mathrm{AF}}^{28}(\mathrm{E})+\Sigma_{\mathrm{tF}}^{16}(\mathrm{E})+\Sigma_{\mathrm{esc}}}\right]\left(\frac{1}{\mathrm{E}}\right)
$$

Except for the leading constant which cancels out when $\phi_{\mathrm{F}}(\mathrm{E})$ is used to produce group-averaged crosssection data, this expression differs from Eq. (M7.A.40) only insofar as the denominator here contains the absorption cross section (rather than the total cross section) for the heavy nuclides in the fuel. Whereas Eq. (M7.A.40) should be used for the flux underneath a narrow resonance, Eq. (M7.A.53) should be used for the flux underneath a broad resonance. Because the narrow resonance approximation was (justifiably) retained for the oxygen term, Eq. (M7.A.53) also assumes that the resonances are widely separated relative to the average energy lost in an elastic collision with the oxygen.

\section{M7A6 THEORETICAL BASIS FOR THE BASIC BONDARENKO METHOD IN THE ABSENCE OF OVERLAPPING RESONANCES}

Having used the narrow resonance approximation to derive an expression for the flux which is valid underneath any given resonance and in the region between resonances [cf. Eq. (M7.A.41)] the group-averaged absorption cross section for resonance nuclide $\mathrm{i}$ may be written as

$$
\sigma_{A}^{i, g}=\frac{\int_{E^{8}}^{E^{g-1}} \sigma_{A}^{i}(E)\left(\frac{1}{\Sigma_{t P}(E)+\Sigma_{e s c}}\right)\left(\frac{1}{E}\right) d E}{\int_{E^{g}}^{E^{8-1}}\left(\frac{1}{\Sigma_{E_{F}}(E)+\Sigma_{c s c}}\right)\left(\frac{1}{E}\right) d E}
$$

Since $\alpha_{A}^{i}(E) \rightarrow 0$ between resonances, the numerator may be replaced by a sum of integrals over the individual resonances of nuclide $i$ lying in group $g$. In the denominator, the integrand vanishes in the vicinity of a resonance such that one need only evaluate the integral between resonances where $\Sigma_{\mathrm{FF}}(\mathrm{E})=\Sigma_{\mathrm{sF}}(\mathrm{E})=\Sigma_{\mathrm{sF}}=$ constant potential scattering cross section. Provided the resonances are very narrow compared to the width of the energy group, the original limits of integration may be retained with little error. To illustrate, consider the expression for $\sigma_{\mathrm{A}}^{25,8}$ in a mixture of $\mathrm{UO}_{2}$ where, for simplicity, we assume the ${ }^{235} \mathrm{U}$ has only two resonances in group $\mathrm{g}$ (cf. Fig. M7.A.6):

$$
\sigma_{\mathrm{A}}^{25,8}=\left[\frac{\Sigma_{\mathrm{sF}}+\Sigma_{\mathrm{esc}}}{\ln \left(\mathrm{E}^{8-1} / \mathrm{E}^{8}\right)}\right] \int_{\substack{\mathrm{Tes} \\ * 1}}\left(\frac{\sigma_{\mathrm{A}}^{25}(\mathrm{E})}{\Sigma_{\mathrm{tP}}(\mathrm{E})+\Sigma_{\mathrm{esc}}}\right) \frac{\mathrm{dE}}{\mathrm{E}}+\int_{\substack{\mathrm{Tes} \\ * 2}}\left(\frac{\sigma_{\mathrm{A}}^{25}(\mathrm{E})}{\Sigma_{\mathrm{tP}}(\mathrm{E})+\Sigma_{\mathrm{esc}}}\right) \frac{\mathrm{dE}}{\mathrm{E}}
$$

NUREG/CR-0200,

Vol. 3, Rev. 4 


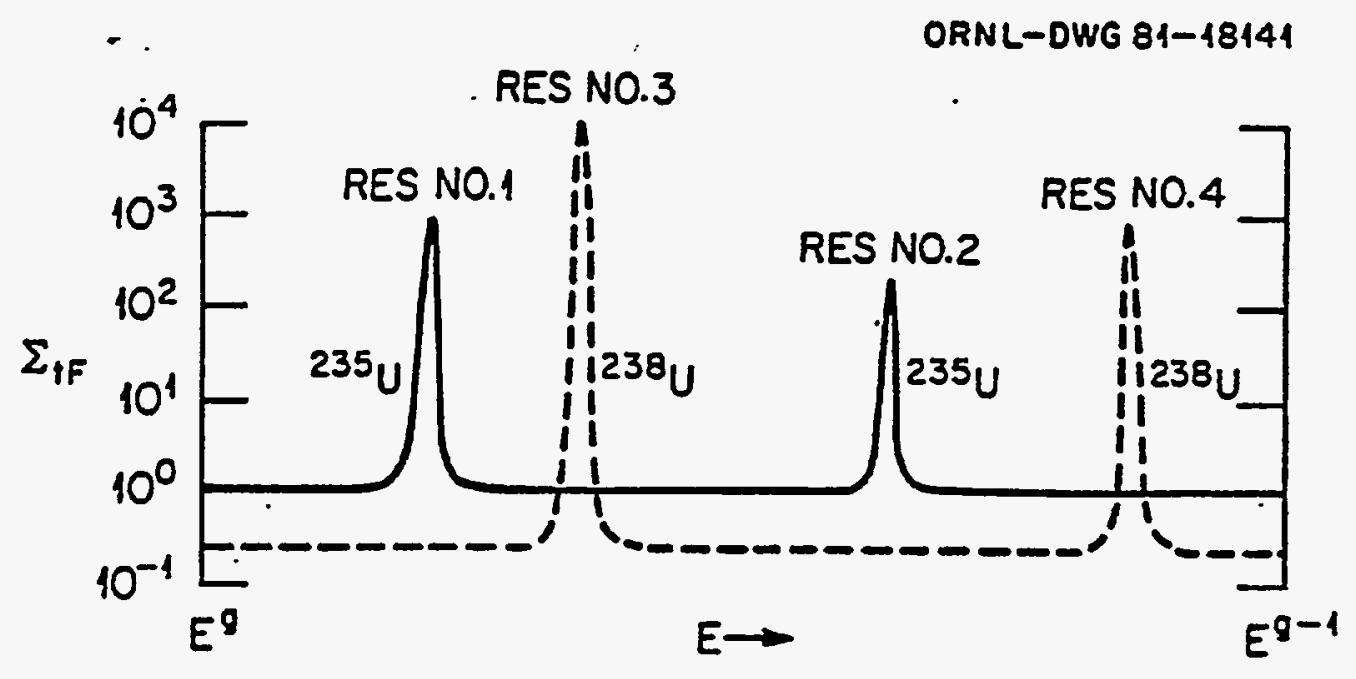

Figure M7.A.6 Well-separated resonances in a mixture of $\mathrm{UO}_{2}$

If the resonances for the mixture are well separated (as required for the narrow resonance approximation to be valid), then $\Sigma_{\mathrm{tF}}^{28}(\mathrm{E}) \approx$ constant underneath resonance 1 , and $\Sigma_{\mathrm{F}}^{28} \approx$ constant underneath resonance 2. [Indeed, under each of the ${ }^{255} \mathrm{U}$ resonances, $\Sigma_{\mathrm{pP}}^{28}(\mathrm{E})=\Sigma_{\mathrm{gP}}^{28}(\mathrm{E})=\Sigma_{\mathrm{gP}}^{28}=$ constant potential scattering cross section.] Under each of the ${ }^{235} U$ resonances, we may then write

$$
\Sigma_{\mathrm{tF}}(\mathrm{E})=\Sigma_{\mathrm{FF}}^{25}(\mathrm{E})+\Sigma_{\mathrm{FF}}^{28}(\mathrm{E})+\Sigma_{\mathrm{TF}}^{16}(\mathrm{E})=\Sigma_{\mathrm{TF}}^{25}(\mathrm{E})+\Sigma_{\mathrm{gP}}^{28}+\Sigma_{\mathrm{sP}}^{16}
$$

or, more generally,

$$
\Sigma_{\mathrm{tP}}(\mathrm{E})=\Sigma_{\mathrm{tF}}^{i}(\mathrm{E})+\Sigma_{\mathrm{gP}}-\Sigma_{\mathrm{SP}}^{i}
$$

Substituting Eq. (M7.A.57) into each term of Eq. (M7.A.55) (and again noting that $\sigma_{A}^{\mathbf{i}}(\mathrm{E}) \rightarrow 0$ between resonances) allows us to recombine the integrals as:

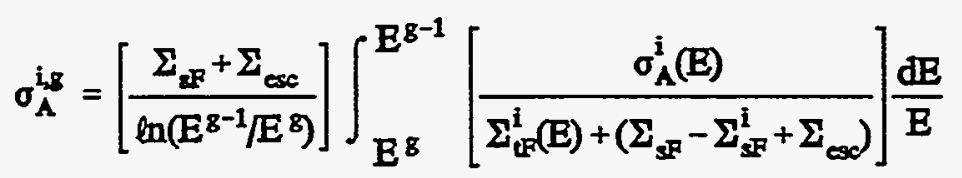

If the concentration of the resonance nuclide (Ni) is so small that 


$$
\Sigma_{\mathrm{tF}}^{\mathrm{i}}(\mathrm{E})<<\Sigma_{\mathrm{gF}}+\Sigma_{\mathrm{esc}} \text { at } \mathrm{E}=\mathrm{E}_{\mathrm{res}}
$$

then Eq. (M7.A.58) yields the "infinitely dilute" cross section, $\sigma_{A}^{i .8}(\infty)$ :

$$
\sigma_{A}^{i, g}(\infty)=\frac{1}{\ln \left(E^{g^{-1}} / E^{8}\right)} \int_{E^{g}}^{E^{g-1}} \sigma_{A}^{i}(E) \frac{d E}{E}=\frac{1}{\Delta u_{g}}\left\langle\sigma_{A}^{i}(u)\right\rangle
$$

where $u=\ell n\left(E_{0} / E\right)$, and $<>$ designates the integral over lethargy. If the resonance nuclide is not infinitely dilute, its very presence affects the way the group-averaged value should be calculated [cf. Eq. (M7.A58)]. Defining $\sigma_{o}^{i}$ as a constant "background" cross section which is independent of energy,

$$
\sigma_{0}^{i}=\left(\frac{1}{N^{i}}\right)\left(\Sigma_{\mathrm{SF}}-\Sigma_{\mathrm{aF}}^{\mathrm{i}}+\Sigma_{\mathrm{CSC}}\right)=\text { constant }
$$

and substituting this into Eq. (M7.A.58) allows the group-averaged value of the absorption cross section to be written as

$$
\sigma_{A}^{i, g}=\left[\frac{\sigma_{s P^{i}}^{i}+\sigma_{0}^{i}}{\ln \left(E^{g^{-1}} / E^{g}\right)}\right] \int_{E^{\mathcal{B}}}^{E^{8-1}}\left[\frac{\sigma_{A}^{i}(E)}{\sigma_{\mathrm{CF}^{i}(E)+\sigma_{0}^{i}}^{i}}\right] \frac{d E}{E}
$$

The point to be made is that the self-shielded, group-averaged cross sections for a resonance nuclide can be tabulated as a function of a single variable $\left(\sigma_{0}^{i}\right)$, even though that nuclide may be in a mixture with other nuclides. Indeed, extensive tables of these group-averaged values do exist for various group structures. Knowing the composition of a given mixture, the user may calculate $\sigma_{0}^{i}$ and then go to the appropriate table to find the self-shielded group-averaged value of $\sigma_{A}^{1,8}$ for that particular mixture.

The procedure described above forms the basis of the Bondarenko method which is described in more detail below. The approach, however, is certainly not new. Users of the KENO 16-group cross-section library ${ }^{16}$ will recall, for example, that it contains over 55 different sets of data for ${ }^{238} U-$ each based on a different value of $\sigma_{0}$ (ranging from $\sigma_{0}=12$ barns to $\sigma_{0}=100,000$ barns). After calculating $\sigma_{0}^{i}$ for the mixture at hand, one would then have to specify the ID number for the appropriate set of data.

The use of precalculated self-shielded cross-section data tabulated as a function of $\sigma_{\circ}$ has also proved to be an attractive alternative to the Nordheim integral method when performing space-time depletion analyses for certain types of reactors (LMFBR's in particular). Even though relatively inexpensive depletion calculations may be performed on a zone-averaged basis using ultra-fine time steps, it is periodically necessary to use the updated number densities to recalculate the power distribution throughout the core and blanket. Prior to performing the spatial flux calculation, it is desirable to produce new self-shielded cross-section data for each zone. The Bondarenko method described above provides a very fast (and therefore very attractive) alternative to solving the Nordheim integral equation on a point-wise basis in energy for each of the (many) spatial zones. 
While the self-shielded group-averaged cross-section data for a given resonance nuclide may be tabulated as a function of the background cross section, $\sigma_{A}^{i, 8}$ is usually expressed as the infinitely dilute value times a self-shielding factor:

$$
\sigma_{A}^{i, 8}=f_{A}^{i, 8}\left(T, \sigma_{\alpha}\right) \sigma_{A}^{i, 8}(\infty)
$$

where the form of the f-factor (or "Bondarenko factor") may be deduced by dividing Eq. (M7.A.62) by Eq. (M7.A.60). The explicit appearance of temperature in the self-shielding factor is in recognition of the fact that the cross sections in Eq. (M7.A.62) $\left[\sigma_{A}^{i}(E)\right.$ and $\left.\sigma_{t p}^{i}(E)\right]$ should be Doppler broadened to the appropriate temperature. In his 1964 book on the subject, ${ }^{2}$ Bondarenko has compiled extensive tables of various self-shielding factors $\left[f_{A}^{i, 8}\left(T, \sigma_{\alpha}\right), f_{C}^{i, 8}\left(T, \sigma_{\alpha}\right), f_{F}^{i, 8}\left(T, \sigma_{o}\right), f_{T}^{i, 8}\left(T, \sigma_{o}\right), f_{l l}^{i, 8}\left(T, \sigma_{\alpha}\right)\right.$, etc. $]$ for most of the important resonance nuclides. In that particular work, 25 fast or epithermal groups were used in conjunction with one thermal (sink) group. A more complete discussion of these resonance self-shielding factors will be presented after some additional comments have been made regarding the limitations of the basic method and the evolution of the "Iterative Bondarenko Method" used in most current computer codes.

\section{M7.A7 THE EFFECT OF RESONANCE OVERLAP ON THE GROUP-AVERAGED CROSS SECTIONS}

The procedure wherein one uses the potential scattering cross section of the various nuclides to calculate the background cross section $\left(\sigma_{0}\right)$ for the mixture, and then applies the appropriate f-factor to obtain the self-shielded group-averaged cross section for the resonance nuclide of interest, might be described as the "Non-Iterative Bondarenko Method." Whereas, Eq. (M7.A.54) or Eq. (M7.A.55) show $\sigma_{A}^{i, 8}$ to be dependent on both the number density and the energy-dependent cross section of all other nuclides in the fuel, the assumption that the resonances were "well separated" allowed $\sigma_{A}^{i, 8}$ (or $f_{A}^{i, g}$ ) to be tabulated as a function of a single variable, $\sigma_{o}^{i}$. The effect of that assumption may be seen by writing Eqs. (M7.A.55) and (M7.A.58) in a similar format and comparing the results in a more realistic case where some resonance overlap is possible. Equation (M7.A.55), which uses the narrow resonance approximation for the flux, may be written as

$$
\left.\sigma_{A}^{25,8}\right|_{\mathrm{Eq} \text { in } \mathrm{M7}, \mathrm{A}, 55}=\left[\frac{\Sigma_{\mathrm{gF}}+\Sigma_{\mathrm{esc}}}{\ln \left(\frac{\mathrm{E}^{8-1}}{E^{8}}\right)}\right] \int_{\mathrm{E}^{8}}^{\mathrm{E}^{8-1}} \frac{\sigma_{\mathrm{A}}^{25}(\mathrm{E})}{\Sigma_{\mathrm{tF}}^{25}(\mathrm{E})+\Sigma_{\mathrm{tF}}^{28}(\mathrm{E})+\Sigma_{\mathrm{tF}}^{16}+\Sigma_{\mathrm{esc}}} \frac{\mathrm{dE}}{\mathrm{E}}
$$

Equation (M7.A.58), which further assumes that the resonances are "well separated," may be written as

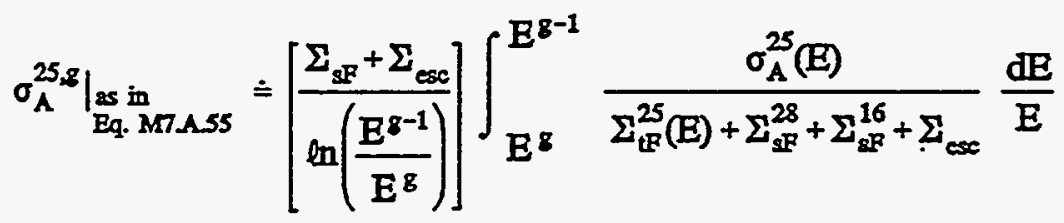


In the case where the resonances are well separated, we have shown these equations to yield the same result. To qualitatively illustrate the effect of resonance overlap, consider the extreme case depicted in Fig. M7.A.7 where one resonance of nuclide A directly overlaps another resonance of nuclide $B$. In this case, $\Sigma_{\mathrm{gP}}^{28}<<\Sigma_{\mathrm{FP}}^{28}(\mathrm{E})$ underneath the ${ }^{235} \mathrm{U}$ resonance and the subsequent use of the potential scattering cross section ( $\Sigma_{\mathrm{gF}}^{28}$ ) in Eq. (M7.A.65) will cause it to overestimate $\sigma_{A}^{25,8}$. Moreover, such a procedure will overestimate $\sigma_{\mathrm{A}}, \sigma_{\mathrm{p}}^{i_{3}}, \sigma_{\mathrm{s}}^{i_{3},}$, etc., whenever the resonances of one nuclide overlap the resonances of another." Figures (M7.A.8a-e) illustrate a few classic examples of resonance overlap in some common fuel mixtures. With the fissile isotopes, the reactivity effect of overestimating $\sigma_{A}^{i, s}$ is partially offset by the fact that $\sigma_{\mathrm{F}}^{\mathrm{is}}$ is also overestimated. Fertile isotopes on the other hand do not fission at resonance energies, and the effect of overestimating $\sigma_{A}^{i, 8}$ can be fairly serious. (More will be said of this later.) From this example, it is also clear that such resonance overlap effects will be more important in concentrated systems where

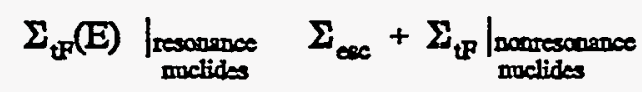

(i.e., where $\sigma_{0}^{i}$ is small), and less important in dilute systems (where $\sigma_{0}^{i}$ is large). As a final point, we parenthetically note that the above conclusions were based on the NR approximation for the flux, but that one could have started with the NRIM approximation for the flux [cf. Eq. (M7.A.53)] and arrived at the same conclusions.
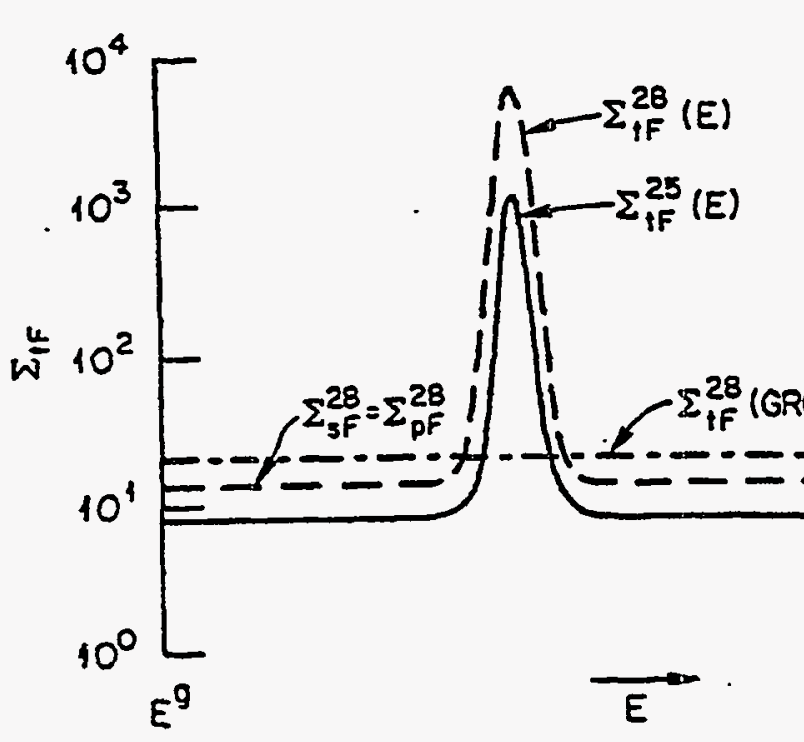

ORNL-DWG $81-18140$

Figure M7.A.7 Hypothetical case of resonance overlap in $\mathrm{UO}_{2}$

'Whereas ${ }^{255} \mathrm{U}$ and ${ }^{238} \mathrm{U}$ have overlapping (or partially overlapping) resonances only at 21 and $6.4 \mathrm{eV}$, ${ }^{235} U{ }^{238} \mathrm{U}{ }^{239} \mathrm{Pu}$ systems have a number of overlapping resonances (cf. 6.4, 12, 15, 21, 66, 75, 102, 165, 190, and $275 \mathrm{eV}$, etc.). Also, ${ }^{232} \mathrm{Th}{ }^{233} \mathrm{U}{ }^{235} \mathrm{U}{ }^{238} \mathrm{U}$ systems, typical of advanced thorium converters, have a number of overlapping resonances (cf. 3.6, 6.4, 16, 19,21, 23.5, 37, and $462 \mathrm{eV}$, etc.). Likewise, ${ }^{235} \mathrm{U}^{238} \mathrm{U}$ ${ }^{209} \mathrm{Pu}{ }^{240} \mathrm{Pu}{ }^{241} \mathrm{Pu}{ }^{242} \mathrm{Pu}$ systems typical of LMFBRs have a larger number of overlapping resonances (cf. $0.28,6.4,8.8,14.5,18,21,26,42,66,75,92,103$, and $275 \mathrm{eV}$, etc.).

NUREG/CR-0200,

Vol. 3, Rev. 4 


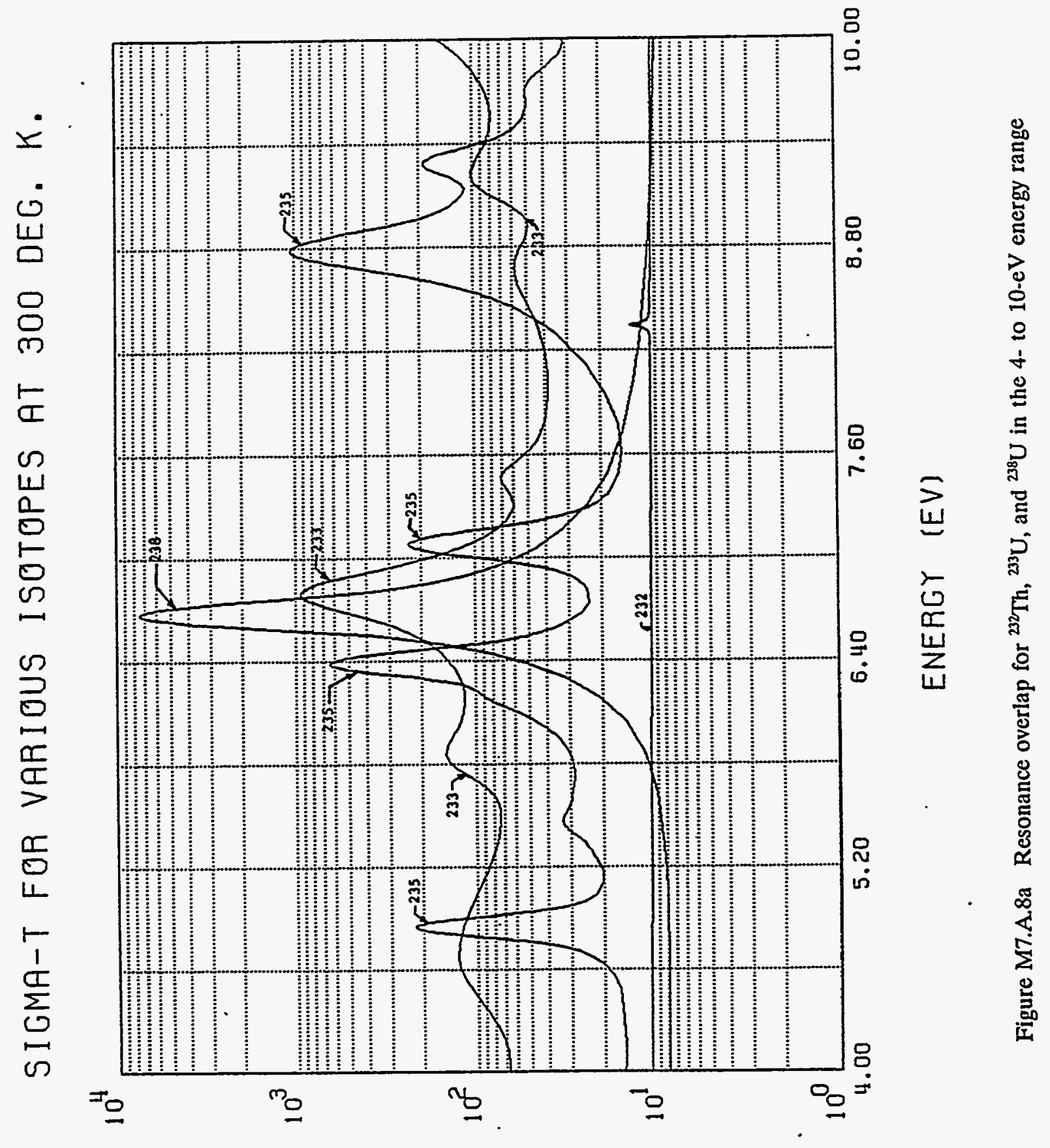

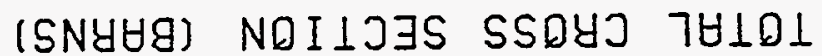




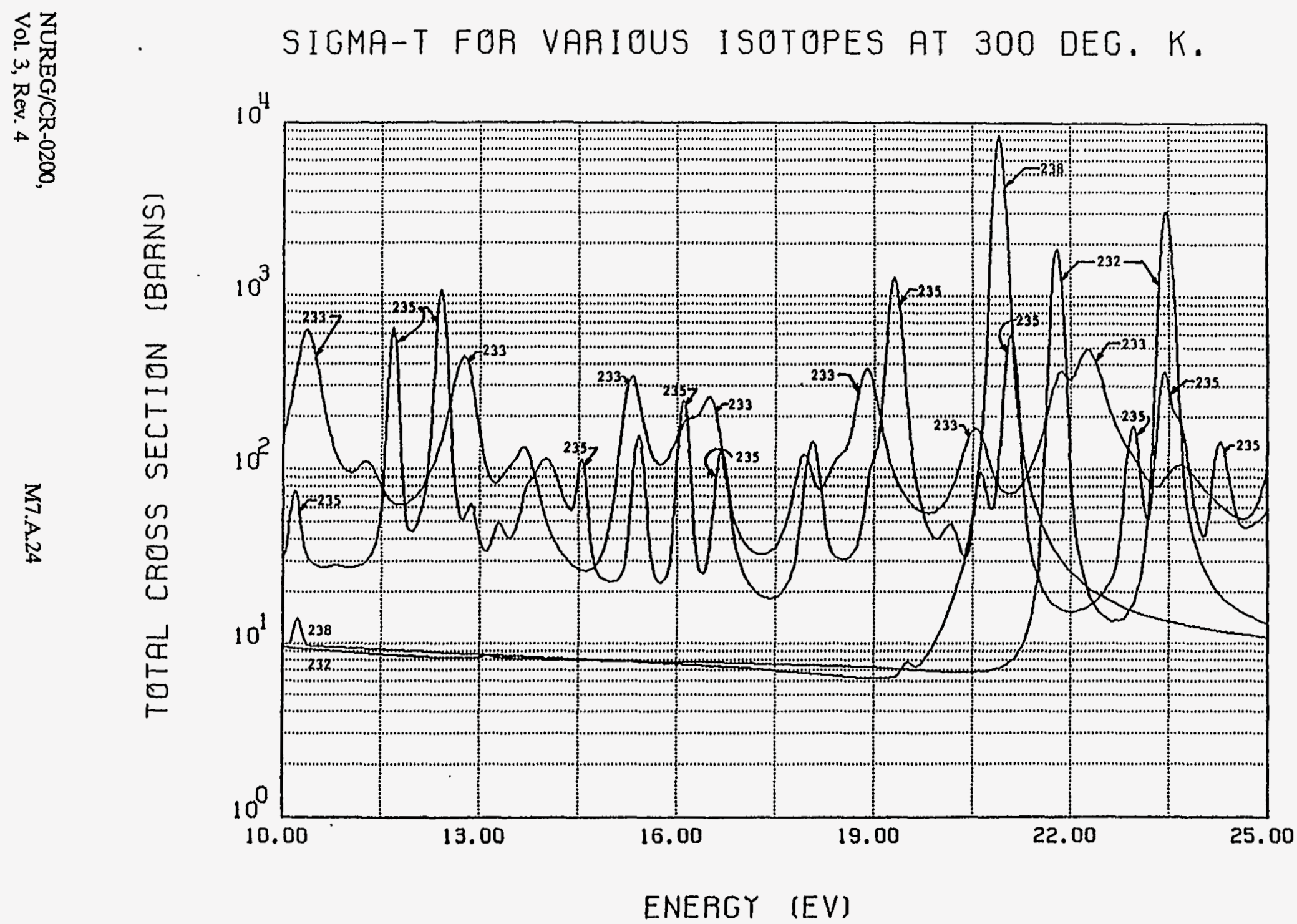

Figure M7.A.8b Resonance overlap for ${ }^{232} \mathrm{Th},{ }^{232} \mathrm{U},{ }^{235} \mathrm{U}$, and ${ }^{238} \mathrm{U}$ in the 10 - to $25-\mathrm{eV}$ energy range 


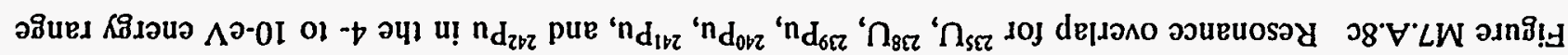

(^ヨ) $\perp 9 y \exists N \exists$

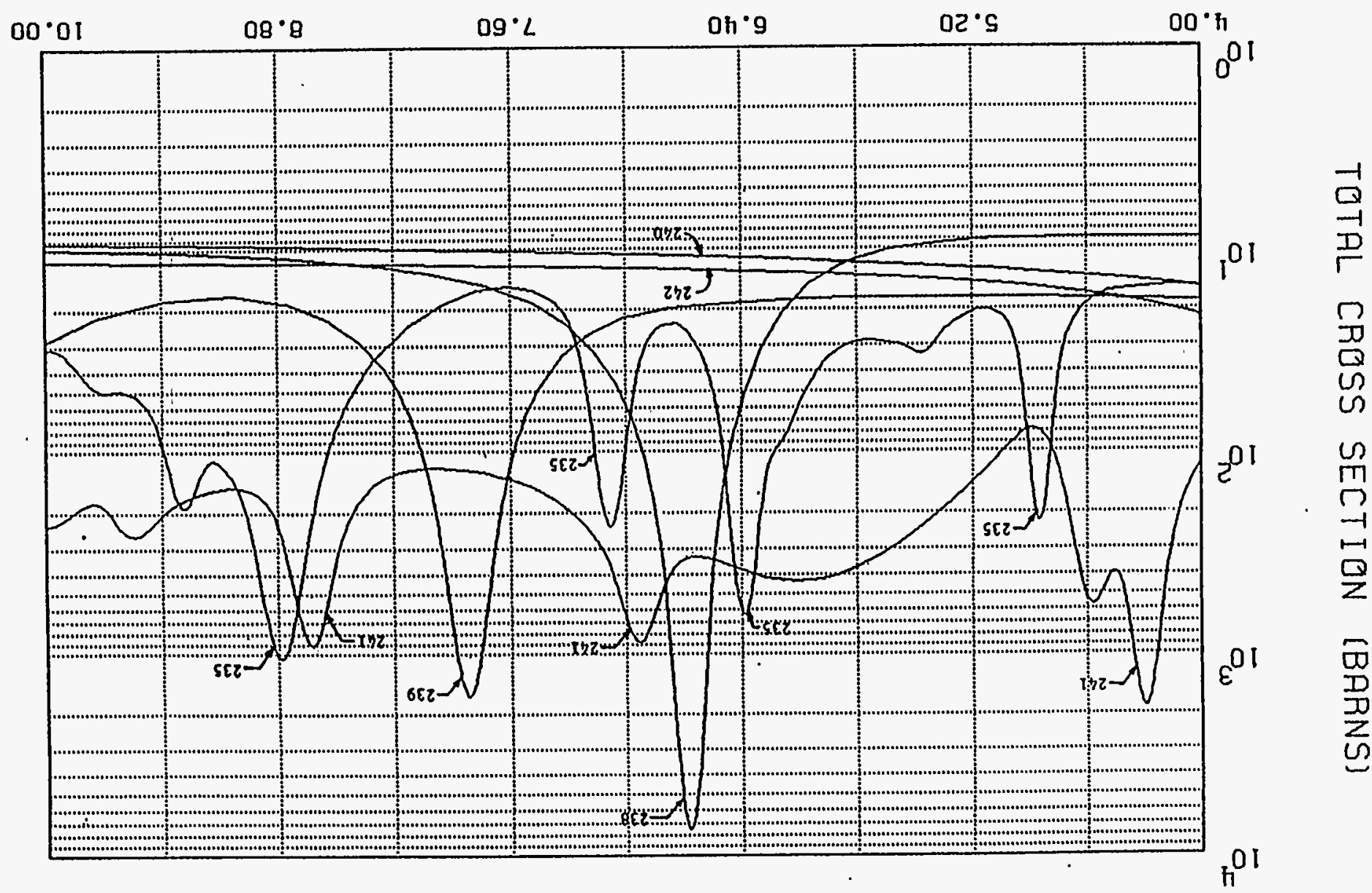

$\stackrel{2}{4}$

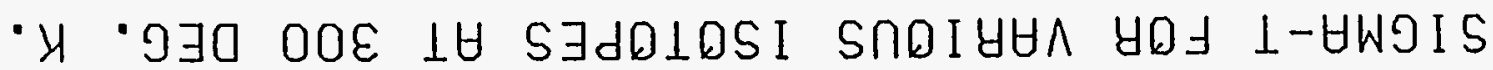




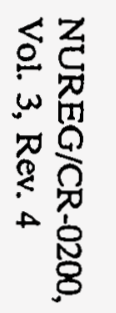

SIGMA-T FOR VARIOUS ISOTOPES AT 300 DEG. $\mathrm{K}$.

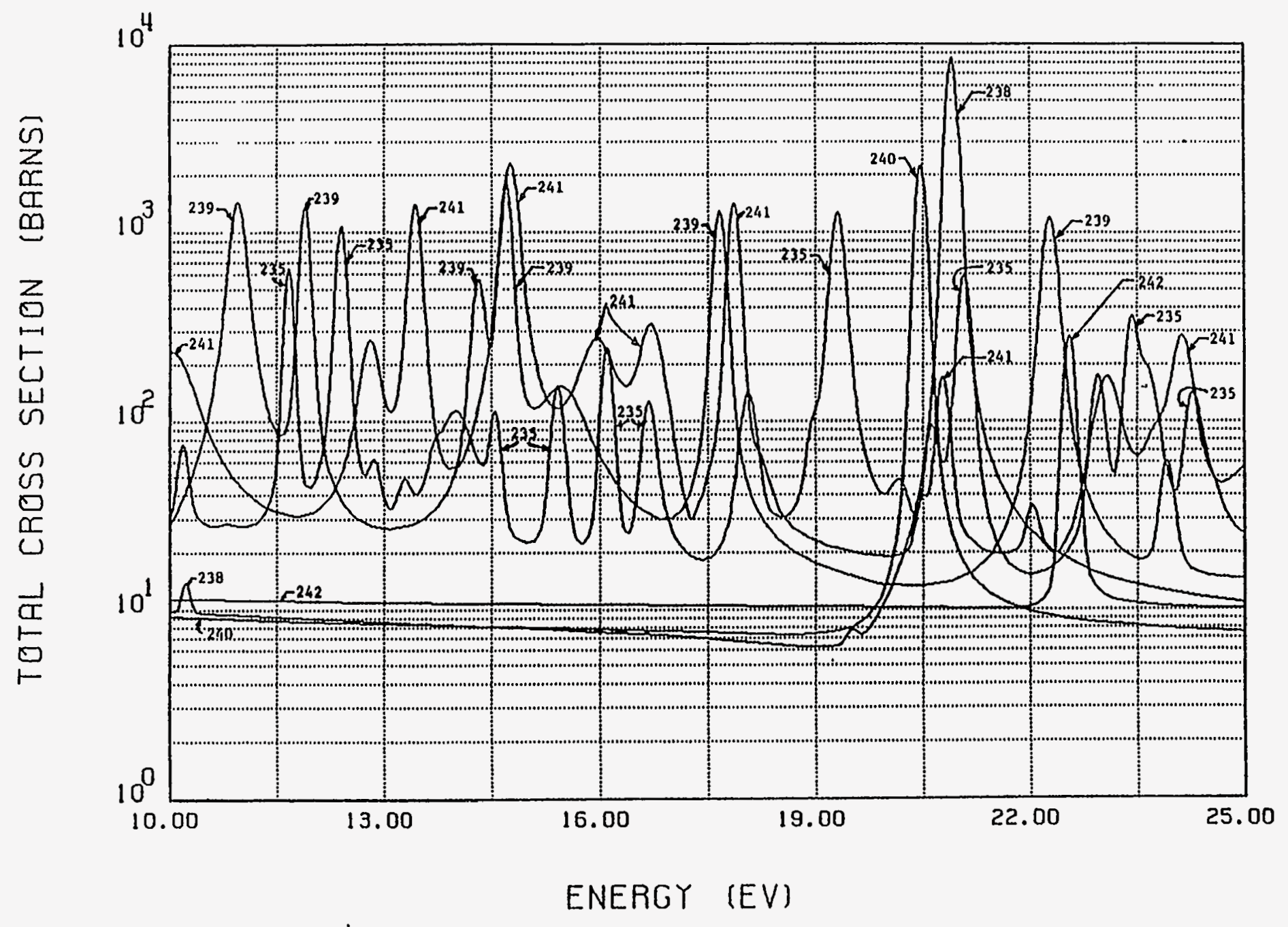

Figure M7.A.8d Resonance overlap for ${ }^{235} \mathrm{U},{ }^{238} \mathrm{U},{ }^{239} \mathrm{Pu},{ }^{240} \mathrm{Pu},{ }^{241} \mathrm{Pu}$, and ${ }^{242} \mathrm{Pu}$ in the $10-1025-\mathrm{eV}$ energy range 


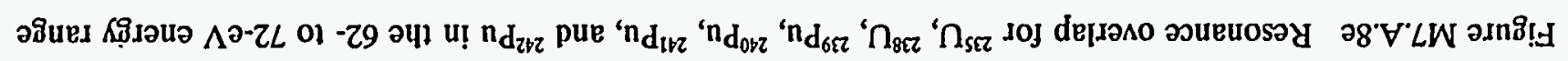

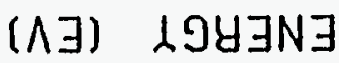

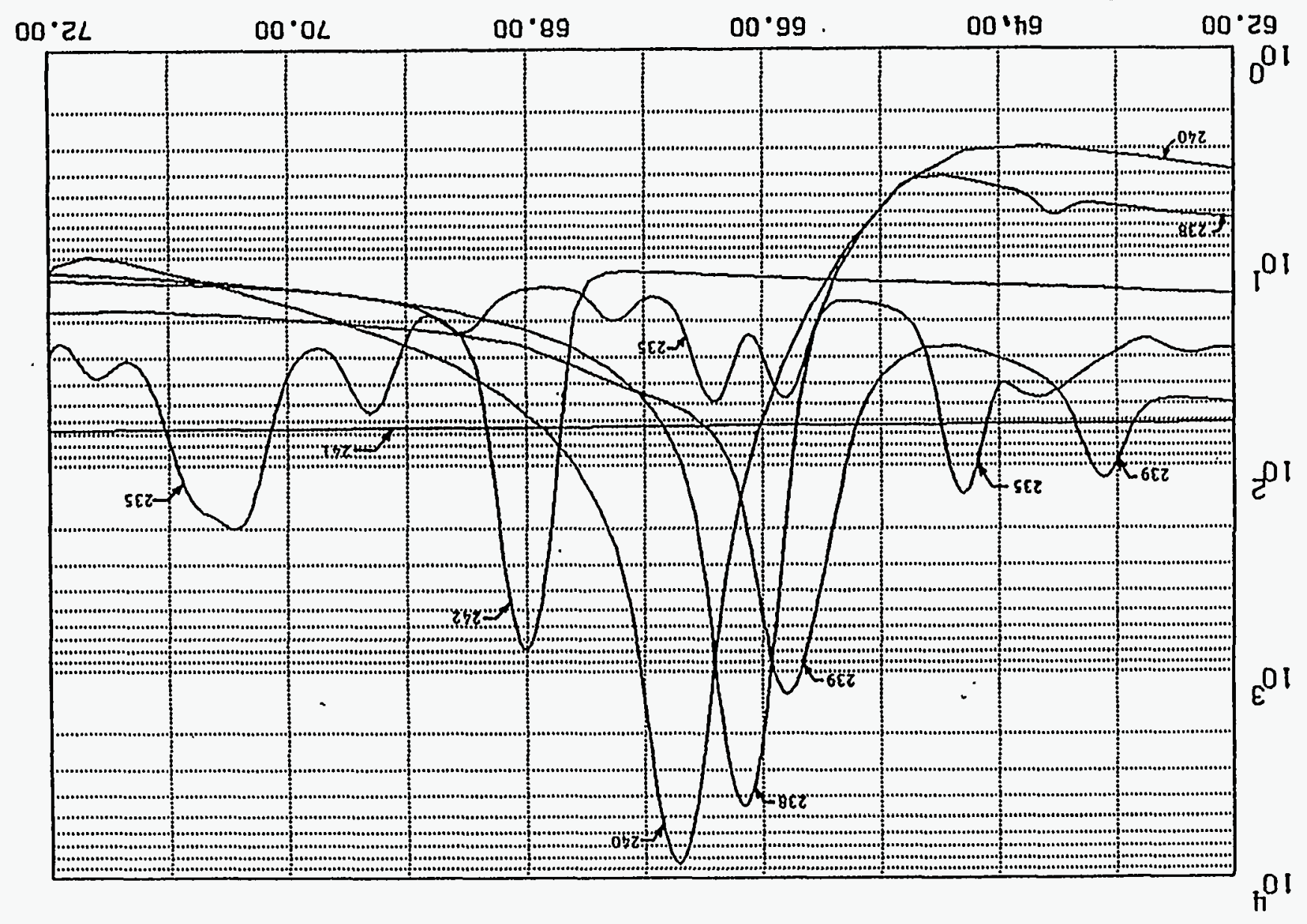

0
0
-1
$D$
$\Gamma$
0
0
0
0
0
0
$m$
0
-1
0
0
2
0
0
$D$
20
2
0

• 


\section{M7.A.8 THE ITERATIVE BONDARENKO METHOD AND HOW IT PARTIALLY ACCOUNTS FOR RESONANCE OVERLAP USING A MODIFIED DEFINITION OF THE BACKGROUND CROSS SECTION}

Having used the narrow resonance approximation to derive an expression for the flux which is valid underneath any given resonance and in the region between responses [cf. Eq. (M7.A.41)], the group-averaged absorption cross section for resonance nuclide $\mathrm{i}$ may be written as

$$
\sigma_{A}^{i, g}=\frac{\int_{E^{8}}^{E^{8-1}} \sigma_{A}^{i}(E)\left(\frac{1}{\Sigma_{t r}(E)+\Sigma_{c s c}}\right)\left(\frac{1}{E}\right) d E}{\int_{E^{8}}^{E^{8-1}}\left(\frac{1}{\Sigma_{t F}(E)+\Sigma_{c s c}}\right)\left(\frac{1}{E}\right) d E}
$$

If the resonances are narrow compared with the width of the energy group, if the resonances for the mixture are well separated, and if $\sigma_{\mathrm{A}}^{i}(\mathrm{E}) \rightarrow 0$ between resonances such that $\boldsymbol{\Sigma}_{\mathrm{tr}}^{\mathbf{i}}(\mathrm{E})=\Sigma_{\mathrm{sp}}^{i}(\mathrm{E})=\Sigma_{\mathrm{sp}}^{i}=$ constant potential scattering cross section (between resonances), then the arguments presented in Sect. M7.A.6 are completely valid, the denominator of Eq. (M7.A.67) may be evaluated analytically, and the group-averaged value of the absorption cross section may be written as

$$
\sigma_{A}^{i, g}=\left[\frac{\sigma_{\mathrm{sP}}^{i}+\sigma_{0}^{i}}{\ln \left(\frac{E^{g-1}}{E^{g}}\right)}\right] \int_{E^{8}}^{E^{g-1}}\left[\frac{\sigma_{A}^{i}(E)}{\sigma_{t F}^{i}(E)+\sigma_{0}^{i}}\right] \frac{d E}{E}
$$

where

$$
\sigma_{0}^{i}=\left(\frac{1}{N^{i}}\right)\left(\Sigma_{S P}-\Sigma_{S P}^{i}+\Sigma_{e s c}\right)=\text { constant }
$$

This was, in fact, a matter of great calculational convenience insofar as it permitted the resonance self-shielded cross sections for a resonance nuclide to be tabulated as a function of a single variable $\left(\sigma_{0}^{i}\right)$, even though that nuclide may be in a mixture with other nuclides.

Starting with Eq. (M7.A.67), it is possible to derive expressions similar to Eqs. (M7.A.68) and (M7.A69) which relax the assumption that $\sigma_{A}^{i}(E) \rightarrow 0$ between resonances and which replace the

NUREG/CR-0200,

Vol. 3, Rev. 4 
potential scattering cross section ( $\Sigma_{\mathrm{sp}}^{\mathbf{i}}$ ) with a constant group-averaged value of the total cross section $\left(\Sigma_{\mathrm{tF}}^{i, 8}\right)$ : Defining the background cross section for a particular energy group as

$$
\sigma_{0}^{i, g} \equiv\left(\frac{1}{N^{i}}\right)\left(\Sigma_{t F}^{g}-\Sigma_{t P}^{i, g}+\Sigma_{e s c}\right)
$$

Eq. (M7.A.67) can then be written as

$$
\sigma_{A}^{i, g}=\frac{\int_{E^{g}}^{E^{g-1}}\left(\frac{\sigma_{A}^{i}(E)}{\sigma_{t F}^{i}(E)+\sigma_{0}^{i, g}}\right)\left(\frac{1}{E}\right) d E}{\int_{E^{g}}^{E^{g-1}}\left(\frac{1}{\sigma_{t F}^{i}(E)+\sigma_{0}^{i, g}}\right)\left(\frac{1}{E}\right) d E}=\frac{\left|\frac{\sigma_{A}^{i}(u)}{\sigma_{\mathrm{tF}}^{i}(u)+\sigma_{0}^{i, g}}\right|_{g}}{\left|\frac{1}{\sigma_{\mathrm{tF}}^{i}(u)+\sigma_{0}^{i, g}}\right|_{g}}
$$

where $u \equiv \ell n\left(E_{\delta} / E\right)$ and $\left\langle>_{g}\right.$ designates the integral over lethargy. In the case of the simple $\mathrm{UO}_{2}$ system used for illustration purposes,

$$
\sigma_{0}^{2 S_{, g}}=\left(\frac{1}{N^{25}}\right)\left(\Sigma_{\mathrm{tP}}^{28, g}+\Sigma_{\mathrm{tP}}^{16,8}+\Sigma_{\mathrm{CSC}}\right)
$$

and

$$
\sigma_{0}^{28,8}=\left(\frac{1}{N^{28}}\right)\left(\Sigma_{\mathrm{tF}}^{25,8}+\Sigma_{\mathrm{tF}}^{16,8}+\Sigma_{e s c}\right)
$$

Formulating $\sigma_{0}^{i, 8}$ in terms of the group-averaged total cross section for the other nuclides in the fuel allows one to partially account for the fact that the absorption cross section in those nuclides may not be negligible compared to their potential scattering cross section. While $\sigma_{A}^{i}(E)$ is often negligible with respect to $\sigma_{\mathrm{s}}^{i}$ for many of the light nuclides, this is not the case with many of the uranium and plutonium isotopes where the wings of adjacent resonances frequently overlap. Indeed, the group-averaged value of the absorption cross section $\left(\sigma_{A}^{i, 8}\right)$ may be several times the potential scattering cross section $\left(\sigma_{s}^{i}\right)$ for

Even though such expressions can be derived and applied as shown in this section, such a feeble attempt to account for the absorption cross section of the other nuclides in the mixture is only partially satisfying. Apart from the obvious shortcoming of having to ignore the detailed energy dependence of $\sigma_{A}^{j}(E)$ for the other nuclides $(j)$ in the mixture [i.e., assuming that $\sigma_{A}^{j}(E)=\sigma_{A}^{j .8}=$ constant], the validity of Eq. (M7.A.67) itself may be questioned when/if the resulting absorption rates are not negligible. Recall, for example, that the narrow resonance approximation for the flux as given by Eq. (M7.A.40) was derived by replacing the flux $\left[\phi_{\mathrm{F}}\left(E^{\prime}\right)\right]$ in Eqs. (M7.A.35) and (M7.A.37) with its asymptotic approximation [cf. Eq. (M7.A.36)] for $\mathrm{E}<\mathrm{E}^{\prime}<\mathrm{E} / \alpha^{1}$. The asymptotic expression given by Eq. (M7.A.36) is, of course, rigorously valid only if the absorption in this range is completely negligible. 
some of the resonance nuclides, thus making the present definition of $\sigma_{0}^{i, 8}$ much more attractive than that used in Sect. M7.A.6.

While the definition of the background cross section $\left(\sigma_{0}^{i, 8}\right)$ has been modified to partially account for absorption by other nuclides, the key point to be made here is that the self-shielded group-averaged cross sections for a resonance nuclide [cf. Eq. (M7.A.71)] can still be tabulated as a function of a single variable $\left(\sigma_{0}^{i, 8}\right)$. Indeed, this data does exist for many multigroup libraries. Typically, $\sigma_{A}^{i, 8}$ is expressed as the infinitely dilute value [cf. Eq. (M7.A.60)] times a self-shielding factor:

$$
\sigma_{A}^{i, g}=f_{A}^{i, g}\left(T, \sigma_{0}^{i, g}\right) \sigma_{A}^{i, g}(\infty)
$$

where the form of the f-factor (or "Bondarenko factor") may be deduced by dividing Eq. (M7.A.71) by Eq. (M7.A60). The explicit appearance of temperature in the self-shielding factor is in recognition of the fact that the cross sections in Eq. (M7.A.71) $\left[\sigma_{A}^{i}(E)\right.$ and $\left.\sigma_{\mathrm{tF}}^{i}(E)\right]$ should be Doppler broadened to the appropriate temperature. Even though expressions for $\sigma_{A}^{i, 8}$ have been used thus far for illustrative purposes, similar expressions may also be written for $\sigma_{t}^{i, 8}, \sigma_{c}^{1,8}, \sigma_{f}^{i, 8}, \sigma_{l}^{i, 8}$, etc. Thus, for example, $\sigma_{t}^{i, 8}$ may be written" as:

$$
\sigma_{t}^{i, g}=\frac{\int_{E^{g}}^{E^{g-1}}\left(\frac{\sigma_{t}^{i}(E)}{\sigma_{\mathrm{tF}}^{i}(E)+\sigma_{0}^{i, g}}\right)\left(\frac{1}{E}\right) d E}{\int_{E^{g}}^{E^{g-1}}\left(\frac{1}{\sigma_{t F}^{i}(E)+\sigma_{0}^{i, g}}\right)\left(\frac{1}{E}\right) d E}=\frac{\left(\frac{\sigma_{t}^{i}(u)}{\sigma_{\mathrm{LF}}^{i}(\mathrm{u})+\sigma_{0}^{i, g}}\right)_{g}}{\left|\frac{1}{\sigma_{\mathrm{tF}}^{i}(\mathrm{u})+\sigma_{0}^{i, g}}\right\rangle_{g}}
$$

or alternatively:

$$
\sigma_{t}^{i, 8}=f_{t}^{i, 8}\left(T, \sigma_{0}^{i, 8}\right) \sigma_{t}^{i, 3}(\infty)
$$

Using expressions similar to Eq. (M7.A.71) or Eq. (M7.A.75), multigroup Bondarenko f-factors have been tabulated for each of the various resonance reactions as a function of $T$ and $\sigma_{\circ}$. Given a library of pretabulated data, one need only apply the various f-factors (evaluated at the appropriate value of $\sigma_{0}^{i, 8}$ ) to obtain the necessary self-shielded cross-section data characteristic of the particular fuel lump. [Note that the size of the fuel lump $(\bar{l})$ and the transparency of the external moderator (as measured by the Dancoff factor) are represented by the escape cross section $\left(\Sigma_{e s c}\right)$, which factors into the background cross section $\left(\sigma_{0}^{i, 8}\right)$ ]. For systems containing more than one resonance nuclide, Eqs. (M7.A.70) and (M7.A.76) must be evaluated in an iterative fashion for each energy group. For a simple mixture of enriched $\mathrm{UO}_{2}$ the iterative procedure would proceed as follows:

"This definition of $\sigma_{t}^{i, s}$ preserves the total reaction rate per unit volume, such that $\sigma_{t}^{i, g} \phi^{g}=\sigma_{t}^{i, g}\langle\phi(u)\rangle=\left\langle\sigma_{t}^{i}(u) \phi(u)\right\rangle$.

NUREG/CR-0200,

Vol. 3, Rev. 4 


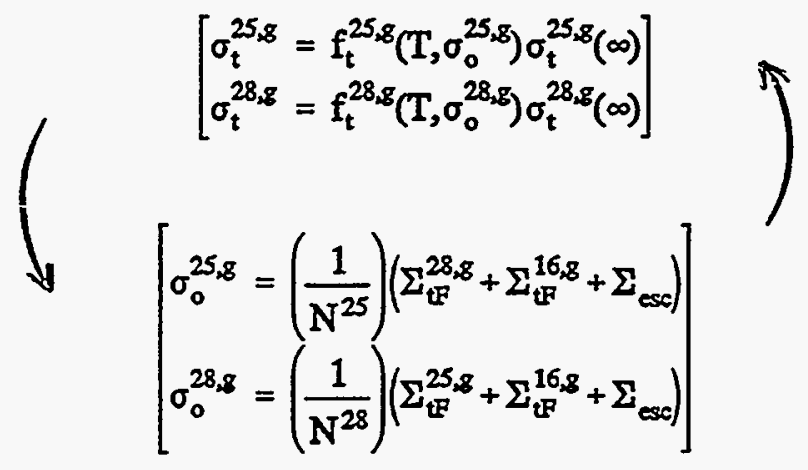

Since the multigroup self-shielding factors, $\mathrm{f}^{8}\left(\mathrm{~T}, \sigma_{0}\right)$ are typically tabulated at only a few discrete values of $\mathrm{T}$ and $\sigma_{\mathrm{o}}$, numerical codes employing the Iterative Bondarenko Method must interpolate to determine the f-factors at the end of each iteration. Simple interpolation formulas such as

$$
f^{g}\left(T, \sigma_{\alpha}\right)=\alpha+\beta \ln T \quad T_{j}<T<T_{j+1}
$$

and

$$
f^{g}\left(T, \sigma_{0}\right)=\alpha^{\prime}+\beta^{\prime} \ln \sigma_{0} \quad \sigma_{k}<\sigma_{0}<\sigma_{k+1}
$$

are still used in some codes. Proceeding in this fashion, the background cross section(s) can be converged to any desired degree of accuracy. Adequate convergence is typically achieved after several iterations. Once the background cross sections are fully converged, the resonance self-shielded values of $\sigma_{t}^{i, 8}, \sigma_{c}^{i, 8}, \sigma_{f}^{i, 8}, \sigma_{l}^{i, 8}$, etc., may be calculated by multiplying the appropriate f-factors by the infinitely dilute values of the respective cross sections. Because the Iterative Bondarenko Method makes use of pretabulated self-shielding factors and requires only a few iterations involving a limited number of algebraic steps, it is very fast and provides an attractive alternative to the Nordheim Integral Method. Even though neither method can properly account for overlapping resonances found in many fuel mixtures, the applicability of the Bondarenko Method is somewhat more limited due to the fact that the self-shielding factors are usually generated using the narrow resonance approximation for the flux [cf. Eq. (M7.A.41)].

\section{M7.A.9 SOME GENERAL COMMENTS ON THE GENERATION OF BONDARENKO SELF- SHIELDING FACTORS}

The generation of Bondarenko self-shielding factors by codes such as ETOX, MINX, ENDRUN, or TABU is a separate calculational step completely divorced from the use and application of that data in codes such as XSRES, SPHINX, TDOWN, or BONAMI which actually generate the resonance self-shielded cross sections for a particular set of mixtures in a particular application. As we have seen in the previous section, however, the approximations that go into the generation of these f-factors ultimately limit the applicability of the method. For completeness, therefore, let us make a few additional remarks concerning the definition of the various f-factors. 
Many nuclear processes involve resonance reactions; the ones of greatest importance in neutronic calculations are fission, radiative capture, and elastic scattering. In multigroup calculations, the corresponding resonance self-shielded cross sections $\left(\sigma_{f}^{i, 8}, \sigma_{c}^{i, 8}, \sigma_{l}^{i, 8}\right)$ should be defined so as to reproduce the integrated reaction rate that one would obtain if he performed the calculation on a point-wise energy basis. Since those reaction rates are given by the product of the scalar flux times, the respective cross sections, the multigroup cross sections should be defined such that

$$
\sigma_{f}^{i, g} \phi^{g}=\sigma_{f}^{i, 8} \int_{E^{g}}^{E^{g-1}} \phi(E) d E=\int_{E^{g}}^{E^{g-1}} \sigma_{f}^{i}(E) \phi(E) d E
$$

Using the narrow resonance approximation for the flux,

$$
\phi(E)=\left(\frac{1}{\Sigma_{\mathrm{tF}}(\mathrm{E})+\Sigma_{\mathrm{esc}}}\right)\left(\frac{1}{\mathrm{E}}\right)
$$

and writing the above expression in terms of lethargy, where

$$
\mathrm{u} \equiv \ln \left(\mathrm{E}_{\mathrm{d}} \mathrm{E}\right), \quad \mathrm{du}=-\left(\frac{1}{\mathrm{E}}\right) \mathrm{dE}
$$

and $\left\langle>_{g}\right.$ denotes the integral over lethargy, we obtain

$$
\begin{aligned}
& \sigma_{f}^{i, g} \phi^{g}=\sigma_{f}^{i, g}\langle\phi(u)\rangle_{g}=\left\langle\sigma_{f}^{i}(u) \phi(u)\right\rangle, \quad \text { or } \\
& \sigma_{f}^{i, g}=\frac{\left\langle\sigma_{f}^{i}(u) \phi(u)\right\rangle_{g}}{\langle\phi(u)\rangle_{g}}=\frac{\left\langle\frac{\sigma_{f}^{i}(u)}{\sigma_{t P}^{i}(u)+\sigma_{o}^{i, g}}\right\rangle}{\left\langle\frac{1}{\sigma_{t F}^{i}(u)+\sigma_{o}^{i, g}}\right\rangle_{g}}
\end{aligned}
$$

where $\sigma_{o}^{i, g}$ is the (constant) background cross section defined by Eq. (M7.A.70). Since the Bondarenko factor is defined as the resonance self-shielded cross section divided by the infinitely dilute value [cf. Eq. (M7.A.60)], the corresponding f-factor would be defined as 


$$
f_{f}\left(T, \sigma_{o}\right)=\frac{\Delta u_{g}}{\left\langle\sigma_{f}^{i}(T, u)\right\rangle_{g}} \frac{\left\langle\frac{\sigma_{f}^{i}(T, u)}{\sigma_{l}^{i}(T, u)+\sigma_{o}}\right\rangle_{g}}{\left\langle\frac{1}{\sigma_{t}^{i}(T, u)+\sigma_{o}}\right\rangle_{g}}
$$

Expressions for $f_{c}\left(T, \sigma_{\circ}\right)$ and $f_{\ell}\left(T, \sigma_{o}\right)$ may be derived in a similar fashion, yielding

$$
f_{c}\left(T, \sigma_{o}\right)=\frac{\Delta u_{g}}{\left\langle\sigma_{c}(T, u)\right\rangle_{g}} \frac{\left\langle\frac{\sigma_{c}^{i}(T, u)}{\sigma_{t}^{i}(T, u)+\sigma_{o}}\right\rangle_{g}}{\left\langle\frac{1}{\sigma_{t}^{i}(T, u)+\sigma_{o}}\right\rangle_{g}}
$$

and

$$
f_{e l}\left(T, \sigma_{\partial}\right)=\frac{\Delta u_{g}}{\left\langle\sigma_{e l}(T, u)\right\rangle_{g}} \frac{\left\langle\frac{\sigma_{e l}(T, u)}{\sigma_{t}^{i}(T, u)+\sigma_{o}}\right\rangle_{g}}{\left|\frac{1}{\sigma_{t}^{i}(T, u)+\sigma_{o}}\right\rangle_{g}}
$$

Although a similar expression may be written for $f_{A}\left(T, \sigma_{0}\right)$, these (superfluous) values are not typically stored in the cross-section data file since, by definition, $\sigma_{A}^{1,8}=\sigma_{f}^{i, 8}+\sigma_{c}^{i, s}$.

The Bondarenko factor for the total cross section $\mathrm{f}_{2}\left(T, \sigma_{0}\right)$ is defined differently by different codes, depending on whether $\sigma_{t}^{i, 8}$ is ultimately to be used in a multigroup transport-theory calculation or a multigroup diffusion-theory calculation. If it is ultimately to be used in a multigroup transport-theory calculation, one should define the resonance self-shielded cross section so that the multigroup calculation accurately reproduces the total collision density per unit path length. If $\psi(\Omega)$ denotes the angular flux, $\sigma_{t}^{i, 8}$ should be defined such that

$$
\sigma_{t}^{i g} \Psi^{g}(\Omega)=\sigma_{t}^{i, g}\langle\Psi(u, \Omega)\rangle_{g}=\left\langle\sigma_{t}^{i}(u) \psi(u, \Omega)\right\rangle_{g}
$$

Integrating over all solid angles and interchanging the order of integration, this again reduces to

$$
\sigma_{\mathfrak{t}}^{i, g}=\frac{\left\langle\sigma_{\mathfrak{t}}^{i}(u) \phi(u)\right\rangle_{g}}{\langle\phi(u)\rangle_{g}}=\frac{\left\langle\frac{\sigma_{\mathfrak{t}}^{i}(u)}{\sigma_{\mathfrak{t}}^{i}(u)+\sigma_{0}^{i, g}}\right\rangle_{g}}{\left\langle\frac{1}{\sigma_{\mathfrak{t}}^{i}(u)+\sigma_{0}^{i, g}}\right\rangle_{g}}
$$


and the corresponding Bondarenko factor is given by

$$
f_{t}^{i}\left(T, \sigma_{0}\right)=\frac{\Delta u_{g}}{\left\langle\sigma_{t}^{i}(T, u)\right\rangle} \frac{\left(\frac{\sigma_{t}^{i}(T, u)}{\sigma_{t}^{i}(T, u)+\sigma_{o}}\right\rangle_{g}}{\left\langle\frac{1}{\sigma_{t}^{i}(T, u)+\sigma_{o}}\right\rangle_{g}}
$$

Indeed, the Bondarenko factors used by BONAMI in the iterative process described by Eqs. (M7.A.77a-d) are defined in exactly this fashion. In point of fact, Bondarenko factors as defined by Eq. (M7.A.90) are somewhat superfluous since $\sigma_{t}^{i, g}$ may be defined in terms of the other resonance self-shielded cross sections. Noting, for example, that

$$
\sigma_{t}^{i, g} \phi^{g}=\sigma_{f}^{i, g} \phi^{g}+\sigma_{c}^{i, g} \phi^{g}+\sigma_{c l}^{i, g} \phi^{g}+\sigma^{i, g} \phi^{g}
$$

all other nonresonance processes

one can write

$$
\sigma_{t}^{i, g}=\sigma_{f}^{i, g}+\sigma_{c}^{i, g}+\sigma_{d}^{i, g}+\sigma^{i, g}
$$

all other nonresonance processes

Noting that the infinitely dilute total cross section is defined as

$$
\sigma_{t}^{i, g}(\infty)=\sigma_{f}^{i, g}(\infty)+\sigma_{c}^{i, g}(\infty)+\sigma_{e \ell}^{i, g}(\infty)+\sigma^{i, g}(\infty) \mid \begin{aligned}
& \text { all other } \\
& \text { nonresonance } \\
& \text { processes }
\end{aligned}
$$

one can combine Eqs. (M7.A.92) and (M7.A.93), and express $\sigma_{t}^{i, 8}$ as 


$$
\sigma_{t}^{i, g}=\sigma_{t}^{i, 8}(\infty)-\sigma_{f}^{i, g}(\infty)-\sigma_{c}^{i, g}(\infty)-\sigma_{e l}^{i, g}(\infty)-\sigma^{i, g}(\infty) \mid \begin{aligned}
& \text { all other } \\
& \text { nonresonance } \\
& \text { processes }
\end{aligned}
$$

$$
+\sigma_{f}^{i, 8}+\sigma_{c}^{i, 8}+\sigma_{e \ell}^{i, 8}+\sigma^{i, g}
$$

all other nonresonance

Noting that processes

$\sigma^{i, 8}\left|\begin{array}{l}\text { i, }(\infty) \\ \text { all other } \\ \text { nonresonance } \\ \text { processes }\end{array}\right| \begin{aligned} & \text { all other } \\ & \text { nonresonance } \\ & \text { processes }\end{aligned}$

$\sigma_{t}^{i, 8}$ can then be written as simply

$$
\sigma_{t}^{i, g}=\sigma_{t}^{i, g}(\infty)+\left[\sigma_{f}^{i, g}-\sigma_{f}^{i, g}(\infty)\right]+\left[\sigma_{c}^{i, g}-\sigma_{c}^{i, g}(\infty)\right]+\left[\sigma_{e l}^{i, g}-\sigma_{e l}^{i, g}(\infty)\right]
$$

For that reason, retention of $f_{t}^{i}\left(T, \sigma_{o}\right)$ in the cross-section data file is somewhat superfluous. As a matter of calculational convenience, however, as $f_{t}^{i}\left(T, \sigma_{0}\right)$ defined by Eq. (M7.A.90) is retained in the input data file for BONAMI and used in the iterative procedure described above. Once the background cross section(s) has been adequately converged and the resonance self-shielded values of $\sigma_{f}^{i, s}, \sigma_{c}^{i, s}$, and $\sigma^{i, 8}$ have been determined, the code actually calculates $\sigma_{t}^{i, 8}$ using Eq. (M7.A.96). Even though this gives essentially the same value that is obtained by multiplying $f_{t}^{i}\left(T, \sigma_{o}\right)$ by the infinitely dilute cross section, the code uses Eq. (M7.A.96) in order to eliminate round-off discrepancies in the output data file.

If, on the other hand, the resonance self-shielding calculation is being performed in order to prepare multigroup cross-section data for use in a diffusion-theory calculation where absorption is negligible and the diffusion coefficient is defined as

$$
D^{\operatorname{sod} M T}=\frac{1}{3 \Sigma_{\mathfrak{t}}^{g_{0} M I X}}
$$

the f-factor, $f_{t}^{i}\left(T, \sigma_{0}\right)$, must be defined in a somewhat different fashion. In such a situation, the quantity to be preserved is the net leakage of particles into or out of the system boundary (i.e., the multigroup calculation should reproduce the leakage rate that one would obtain if the calculation were done on a point-wise energy basis). Mathematically, this requires that

$$
D^{\operatorname{gMx}} \nabla^{2} \phi^{\mathrm{g}}(\mathrm{r})=\left\langle\mathrm{D}^{\mathrm{MIX}}(\mathrm{u}) \nabla^{2} \phi(\mathrm{u}, \mathrm{r})\right\rangle
$$

and 


$$
\begin{aligned}
\frac{1}{3 \Sigma_{\mathrm{t}}^{\mathrm{MX}}(\mathrm{u})}\left\langle-\mathrm{B}^{2} \phi(\mathrm{u}, \mathrm{t})\right\rangle & =\left\langle\frac{1}{3 \Sigma_{\mathrm{t}}^{\mathrm{MIX}}(\mathrm{u})}\left(-\mathrm{B}^{2}\right) \phi(\mathrm{u}, \mathrm{r})\right\rangle \\
\frac{\mathrm{B}^{2}}{3} \frac{\langle\phi(\mathrm{u})\rangle}{\Sigma_{\mathrm{t}}^{\mathrm{MI}}(\mathrm{u})} & =\frac{\mathrm{B}^{2}}{3}\left\langle\frac{\phi(\mathrm{u})}{\Sigma_{\mathrm{t}}^{\mathrm{MIX}}(\mathrm{u})}\right\rangle \\
\Sigma_{\mathrm{t}}^{\mathrm{MI}}(\mathrm{u}) & =\frac{\langle\phi(\mathrm{u})\rangle}{\frac{\phi(\mathrm{u})}{\Sigma_{\mathrm{t}}^{\mathrm{MIX}}(\mathrm{u})}} \\
\Sigma_{\mathrm{t}}^{\mathrm{i}}(\mathrm{u})+\Sigma_{\mathrm{o}} & =\frac{\langle\phi(\mathrm{u})\rangle}{\left\langle\frac{\phi(\mathrm{u})}{\Sigma_{\mathrm{t}}^{\mathrm{i}}(\mathrm{u})+\Sigma_{\mathrm{o}}}\right\rangle}
\end{aligned}
$$

Using the narrow resonance approximation for the flux, this becomes

$$
\Sigma_{\mathrm{t}}^{\mathrm{i}}(\mathrm{u})+\Sigma_{0}=\frac{\left\langle\frac{1}{\Sigma_{\mathrm{t}}^{\mathrm{i}}(\mathrm{u})+\Sigma_{\mathrm{o}}}\right\rangle}{\left(\frac{1}{\left(\Sigma_{\mathrm{t}}^{\mathrm{i}}(\mathrm{u})+\Sigma_{0}\right)^{2}}\right\rangle}
$$

and

$$
\sigma_{t}^{i s}=\frac{\left(\frac{1}{\sigma_{t}^{i}(u)+\sigma_{0}}\right)}{\left(\frac{1}{\left(\sigma_{t}^{i}(u)+\sigma_{0}\right)^{2}}\right\rangle}-\sigma_{0}
$$

Dividing $\sigma_{t}^{i, g}$ by the infinitely dilute value, we then obtain the appropriate expression for $f_{t}^{i}\left(T, \sigma_{\curvearrowright}\right)$ :

$$
f_{t}^{i}\left(T, \sigma_{0}\right)=\frac{\Delta u_{g}}{\left\langle\sigma_{t}^{i}(T, u)\right\rangle_{g}}\left[\frac{\left\langle\frac{1}{\sigma_{t}^{i}(T, u)+\sigma_{o}}\right\rangle_{g}}{\left|\frac{1}{\left(\sigma_{t}^{i}(T, u)+\sigma_{0}\right)^{2}}\right\rangle_{g}}-\sigma_{0}\right]
$$

This, in fact, is the expression originally given by Bondarenko in his classic book on the subject. ${ }^{17}$ Indeed, it is the expression still used in many codes. 
Since Bondarenko self-shielding factors have been generated for numerous multigroup libraries using various cross-section processing codes, the user should be careful to make sure that the Bondarenko factors contained in a given library were generated in a fashion that is consistent with his intended application.

\section{M7.A10 DERIVATION OF THE SEIF-SHIEILING FACTORS FOUND IN THE ORIGINAL HANSEN-ROACH CROSS-SECTION LIBRARY (O K)}

One of the oldest and most useful multigroup libraries used in the United States for criticality analysis is the 16-group Hansen-Roach cross-section library ${ }^{18}$ Originally developed as a six-group library for criticality analysis of fast, heavy-metal systems, the lowest energy group was later divided into ten epithermal energy groups and one thermal energy group so that critical assemblies having an intermediate neutron flux spectrum could be analyzed. Of particular interest here is the fact that the original report (December 1961) contained plots of the resonance self-shielded, group-averaged values of $\sigma_{f}^{8}$ as a function of the background cross section $\left(\sigma_{0}\right)$ for ${ }^{233} \mathrm{U},{ }^{235} \mathrm{U}$, and ${ }^{239} \mathrm{Pu}$, and resonance self-shielded values of $\sigma_{c}^{B}$ (the radiative capture cross section) as a function of the background cross section $\left(\sigma_{0}\right)$ for ${ }^{232} \mathrm{Th}$, ${ }^{23} \mathrm{U},{ }^{235} \mathrm{U},{ }^{238} \mathrm{U},{ }^{239} \mathrm{Pu}$, and ${ }^{240} \mathrm{Pu}$. Because modified versions of this 16-group - library are still in wide use today, the determination of these constants is of historical interest. The determination of the original resonance self-shielded data will be presented in this section. The Knight-Modified Hansen-Roach data currently being disseminated with the SCAIE system will be discussed in Sect. M7.A.13.

While the resonance self-shielded, group-averaged constants reported by Hansen and Roach were calculated in a fashion consistent with Eqs. M7.A.85 or M7.A.86, the closed-form algebraic expression they actually used appears, at first glance, to be significantly different. To arrive at that expression, it is necessary to consider the single-level Breit-Wigner expression for an unbroadened $\left(T=0^{\circ} \mathrm{K}\right)$ isolated resonance, insert those expressions for $\sigma_{c}(E), \sigma_{\mathrm{r}}(\mathrm{E})$, and $\sigma_{\mathrm{t}}(\mathrm{E})$ into Eq. M7.A.71, and carry out the required integration over the particular energy group. In this particular case, the integration is most conveniently carried out in the energy domain rather than lethargy. Before pursuing the details of that integration, however, it is convenient to review some of the simplifying assumptions first introduced in Sect. M7.A6.

Using the narrow resonance approximation for the flux, the resonance self-shielded value of $\sigma_{f}^{i, 8}$ may be written as

$$
\sigma_{f}^{i g}=\frac{\int_{E^{8}}^{E^{g-1}}\left(\frac{\sigma_{f}^{i}(E)}{\sigma_{t}^{i}(E)+\sigma_{o}^{i}}\right)\left(\frac{1}{E}\right) d E}{\int_{E^{8}}^{E^{8-1}}\left(\frac{1}{\sigma_{t}^{i}(E)+\sigma_{o}^{i}}\right)\left(\frac{1}{E}\right) d E}
$$

In the denominator, the integrand vanishes in the vicinity of a resonance such that one need only evaluate that integral between resonances where $\sigma_{t}^{i}(E) \rightarrow \sigma_{p}^{i}$, the potential scattering cross section of nuclide $i$. Assuming that the resonances are very narrow compared with the width of the energy group such that one can retain the original limits of integration, the denominator can then be written as 


$$
\int_{E^{g}}^{E^{g-1}}\left(\frac{1}{\sigma_{t}^{i}(E)+\sigma_{0}^{i}}\right)\left(\frac{1}{E}\right) d E \doteq\left(\frac{1}{\sigma_{p}^{i}+\sigma_{0}^{i}}\right) \int_{E^{8}}^{E^{8-1}}\left(\frac{1}{E}\right) d E=\left(\frac{1}{\sigma_{0}}\right) \ln \left(\frac{E^{g-1}}{E^{8}}\right)=\left(\frac{\Delta u_{g}}{\sigma_{0}}\right)
$$

where

$$
\sigma_{0} \boxminus \sigma_{p}^{i}+\sigma_{0}^{i}
$$

Assuming that the resonances are narrow compared with the width of the energy group and widely spaced such that $\sigma_{f}^{i}(E) \rightarrow 0$ between resonances, the numerator of Eq. (M7.A.103) may be replaced by a sum of integrals over the individual resonances of nuclide $i$ in group $g$. Thus, Eq. (M7.A.103) may be written as

$$
\sigma_{f}^{i, g}=\left(\frac{\sigma_{o}}{\Delta u_{g}}\right) \sum_{\frac{r e g}{j \in g}} \int_{E_{\min }^{\mathrm{res}(j)}}^{\mathrm{E}_{\max }^{\mathrm{res}(j)}}\left(\frac{\sigma_{f}^{i}(E)}{\sigma_{t}^{i}(E)+\sigma_{o}^{i}}\right)\left(\frac{1}{E}\right) d E
$$

Use of the single-level Breit-Wigner equation for an unbroadened ( $T=0 \mathrm{~K}$ ) isolated resonance then permits an analytic evaluation of each of the resonance integrals appearing in Eq. (M7.A.106). Specifically, we note that $\sigma_{f}^{i}(E)$ is given by

$$
\sigma_{f}^{i}\left(E_{c}\right)=\pi \lambda_{\text {res }}^{2} g\left(\frac{E_{\text {res }}}{E_{c}}\right)^{1 / 2} \frac{\Gamma_{n} \Gamma_{f}}{\left(E_{c}-E_{r e s}\right)^{2}+\left(\Gamma^{2} / 4\right)}
$$

where

$$
\begin{aligned}
& E_{\text {res }} \text { denotes a resonance centered about } E=E_{\text {res }} \text {, } \\
& E_{c} \text { denotes the energy of the neutron in the center-of-mass system, } \\
& \Gamma \quad \text { denotes the total width of the resonance, } \\
& \Gamma_{n} \quad \text { denotes the neutron width, } \\
& \Gamma_{\mathrm{f}} \text { denotes the fission width, } \\
& \lambda_{\text {res }} \text { denotes the reduced wavelength of a neutron at } E=E_{r e s} \text { that is, } \lambda_{1}=\bar{h} / \sqrt{2 \mu E_{1}} \text { where } \\
& \mu \text { is the reduced mass of the neutron, or } \\
& \lambda_{1} \doteq 4.55 \times 10^{-10} \mathrm{~cm} / \sqrt{\mathrm{E}_{1}} \text {, where } \mathrm{E}_{1} \text { is in } \mathrm{eV} \text {, } \\
& \text { g denotes the statistical spin factor. }
\end{aligned}
$$


Likewise, the single-level Breit-Wigner formula for radiative capture $(n, \gamma)$ is given as

$$
\sigma_{c}^{i}\left(E_{2}\right)=\pi \lambda_{\text {res }}^{2} g\left(\frac{E_{r e s}}{E_{c}}\right)^{1 / 2} \frac{\Gamma_{n} \Gamma_{\gamma}}{\left(E_{c}-E_{\text {res }}\right)^{2}+\left(\Gamma^{2} / 4\right)}
$$

At $E_{c}=E_{\text {reso }}$ one obtains the maximum cross section for each of these reactions types, denoted here as $\sigma_{f}^{i, 0}$ and $\sigma_{c}^{1,0}$ :

$$
\sigma_{f}^{i, 0}=\sigma_{f}^{i}\left(E_{\text {res }}\right)=4 \pi \lambda_{\text {res }}^{2} g\left(\frac{\Gamma_{n}}{\Gamma}\right)\left(\frac{\Gamma_{f}}{\Gamma}\right)
$$

and

$$
\sigma_{c}^{i, 0}=\sigma_{c}^{i}\left(E_{\text {res }}\right)=4 \pi \lambda_{\text {res }}^{2} g\left(\frac{\Gamma_{n}}{\Gamma}\right)\left(\frac{\Gamma_{y}}{\Gamma}\right)
$$

Although the Breit-Wigner formula for s-wave scattering does have an additional term that produces an asymmetric dip in $\sigma_{e \ell}\left(E_{c}\right)$ at energies just below $E_{r e s}$, the maximum value of $\sigma_{c \ell}\left(E_{c}\right)$ (not including the potential scattering term) is given by

$$
\sigma_{e \ell}^{i, 0}=\sigma_{e \ell}^{i}\left(E_{r e s}\right)=4 \pi \lambda_{r e s}^{2} g\left(\frac{\Gamma_{n}}{\Gamma}\right)\left(\frac{\Gamma_{n}}{\Gamma}\right)
$$

Noting that

$$
\Gamma \equiv \Gamma_{n}+\Gamma_{\gamma}+\Gamma_{f}
$$

the maximum value of the total cross section is given by

$$
\sigma_{t}^{i, 0}=\sigma_{t}^{i}\left(E_{\text {res }}\right)=4 \pi \lambda_{\text {res }}^{2} g\left(\frac{\Gamma_{n}}{\Gamma}\right)
$$

and $\sigma_{\mathrm{t}}^{\mathbf{i}}\left(\mathrm{E}_{\mathrm{d}}\right)$ may (for all practical purposes) be approximated as

$$
\sigma_{i}^{i}\left(E_{c}\right) \doteq \pi \lambda_{r e s}^{2} g\left(\frac{E_{\text {res }}}{E_{c}}\right)^{1 / 2} \frac{\Gamma_{n} \Gamma}{\left(E_{c}-E_{r e s}\right)^{2}+\left(\Gamma^{2} / 4\right)}+\sigma_{p}^{i}
$$

where $\sigma_{p}^{i}$ is the potential scattering cross section for nuclide $i$. Before substituting the various cross sections into Eq. (M7.A.106) and evaluating the various resonance integrals, two additional simplifications can be made: (1) for collisions with intermediate and heavy nuclides, the energy of the neutron in the center-of-mass system $E_{c}$ is essentially the same as the energy in the laboratory system $(E)$; and (2) at energies underneath the (narrow) resonance and in the immediate vicinity of the narrow resonance, 


$$
\frac{\mathrm{E}_{\mathrm{res}}}{\mathrm{E}_{\mathrm{c}}} \doteq \frac{\mathrm{E}_{\mathrm{res}}}{\mathrm{E}} \doteq 1.0
$$

Using these simplifications along with the definitions of $\sigma_{f}^{i, 0}, \sigma_{c}^{i, 0}$, and $\sigma_{t}^{i, 0}$, the energy-dependent cross sections needed in Eq. (M7.A.106) may be written as

$$
\begin{aligned}
& \sigma_{f}^{i}(E)=\frac{\sigma_{f}^{i, 0}}{\left[\left(\frac{2}{\Gamma}\right)\left(E-E_{r e s}\right)\right]^{2}+1} \quad E_{\min }^{\mathrm{res}(j)} \leq E \leq E_{\max }^{\mathrm{res}(j)} \\
& \sigma_{c}^{i}(E)=\frac{\sigma_{c}^{i, 0}}{\left[\left(\frac{2}{\Gamma}\right)\left(E-E_{r e s}\right)\right]^{2}+1} \quad E_{\min }^{\mathrm{res}(j)} \leq E \leq E_{\max }^{\mathrm{res}(j)}
\end{aligned}
$$

and

$$
\sigma_{\mathrm{t}}^{\mathrm{i}}(\mathrm{E})=\frac{\sigma_{\mathrm{t}}^{\mathrm{i}, \mathrm{O}}}{\left[\left(\frac{2}{\Gamma}\right)\left(\mathrm{E}-\mathrm{E}_{\mathrm{res}}\right]^{2}+1\right.}+\sigma_{\mathrm{p}}^{\mathrm{i}} \quad \mathrm{E}_{\min }^{\mathrm{res}(j)} \leq \mathrm{E} \leq \mathrm{E}_{\max }^{\mathrm{res}(j)}
$$

Returning to Eq. (M7.A.106), we need to make one more approximation. Since the integration is over a very narrow band of energies where $E=E_{\text {res, }}$ the (1/E) term appearing in Eq. (M7.A.106) may be replaced by $\left(1 / \mathbb{E}_{\text {res }}\right)$. The integrand may then be written as

$$
\begin{aligned}
& \left(\frac{\sigma_{f}^{i}(E)}{\sigma_{t}^{i}(E)+\sigma_{o}^{i}}\right)\left(\frac{1}{E}\right) d E=\left(\frac{\sigma_{f}^{i, 0}}{\sigma_{t}^{i, 0}+\left(\sigma_{p}^{i}+\sigma_{o}^{i}\right)\left[x^{2}+1\right]}\right)\left(\frac{1}{E_{r e s}}\right) d E \\
& =\left(\frac{\sigma_{f}^{i, 0}}{\sigma_{t}^{i, 0}+\sigma_{o}+\sigma_{o} x^{2}}\right)\left(\frac{1}{E_{r e s}}\right) d E=\left(\frac{1}{E_{r e s}}\right)\left(\frac{\sigma_{f}^{i, 0}}{\sigma_{o}}\right)\left(\frac{1}{a^{2}+x^{2}}\right) d E
\end{aligned}
$$

where 


$$
\begin{gathered}
x=\left(\frac{2}{\Gamma}\right)\left(E-E_{r e s}\right) \\
\sigma_{0}=\sigma_{p}^{i}+\sigma_{0}^{i}
\end{gathered}
$$

and

$$
a^{2}=1+\left(\frac{\sigma_{t}^{i, 0}}{\sigma_{0}}\right)
$$

The resonance integral may then be written as

$$
\int_{E_{\min }^{r e s(j)}}^{E_{\max }^{r e s(j)}}\left(\frac{\sigma_{f}^{i}(E)}{\sigma_{t}^{i}(E)+\sigma_{0}^{i}}\right)\left(\frac{1}{E}\right) d E=\left(\frac{1}{E_{r e s}}\right)\left(\frac{\sigma_{f}^{i, 0}}{\sigma_{0}}\right) \int_{E_{\min }^{r e s}(j)}^{E_{\max }^{r e s(j)}} \frac{1}{\left(\frac{\sigma_{t}^{i, 0}+\sigma_{0}}{\sigma_{0}}\right)+\left[\left(\frac{2}{\Gamma}\right)\left(E-E_{r e s}\right)\right]^{2}} d E
$$

To the extent that the integrand vanishes whenever

$$
\left(\frac{\sigma_{t}^{i, 0}+\sigma_{0}}{\sigma_{0}}\right)+\left[\left(\frac{2}{\Gamma}\right)\left(E-E_{r e s}\right)\right]^{2}>1
$$

the limits of integration may be replaced by $+\infty$ and $-\infty$ with very little residual error. This is certainly true at energies more than a few half-widths away from $E_{\text {zes }}$ that is, whenever

$$
\left[\left(\frac{2}{\Gamma}\right)\left(E-E_{\text {res }}\right)\right]^{2}>1
$$

Thus, in addition to being widely spaced, the (narrow) resonances are assumed to lie well inside the group boundaries. Defining $x=\left(\frac{2}{\Gamma}\right)\left(E-E_{r e s}\right)$, such that $d E=\left(\frac{\Gamma}{2}\right) d x$, the integral is then of the form

$$
\int_{-\infty}^{\infty} \frac{1}{a^{2}+x^{2}} d x=\frac{\pi}{a}, \text { where } a^{2}=1+\left(\frac{\sigma_{t}^{i, 0}}{\sigma_{0}}\right)
$$

The resonance integral may then be expressed as 


$$
\int_{E_{\min }^{\operatorname{res}(j)}}^{E_{\max }^{\operatorname{res}(j)}}\left(\frac{\sigma_{f}^{i}(E)}{\sigma_{t}^{i}(E)+\sigma_{0}^{i}}\right)\left(\frac{1}{E}\right) d E=\left(\frac{1}{E_{\text {res }}}\right)\left(\frac{\sigma_{f}^{i, 0}}{\sigma_{0}}\right)\left(\frac{\Gamma}{2}\right) \frac{\pi}{\sqrt{1+\left(\frac{\sigma_{t}^{i, 0}}{\sigma_{0}}\right)}}
$$

Substituting this result into Eq. (M7.A.106), the resonance self-shielded group-averaged value of $\sigma_{f}^{i, g}$ is then given by

$$
\sigma_{f}^{i, g}=\left(\frac{1}{\Delta u_{g}}\right)\left(\frac{\pi}{2}\right) \sum_{\frac{r e s}{j \in g}} \frac{\left(\frac{\Gamma}{E_{\text {res }}}\right) \sigma_{f}^{i, 0}}{\sqrt{1+\left(\frac{\sigma_{t}^{i, 0}}{\sigma_{0}}\right)}}
$$

Likewise, the resonance self-shielded, group-averaged value of $\sigma_{c}^{i, 8}$ is given by

$$
\sigma_{c}^{i, g}=\left(\frac{1}{\Delta u_{g}}\right)\left(\frac{\pi}{2}\right) \sum_{\substack{\text { ses } \\ j \in g}} \frac{\left(\frac{\Gamma}{E_{\text {res }}}\right) \sigma_{c}^{i, 0}}{\sqrt{1+\left(\frac{\sigma_{t}^{i, 0}}{\sigma_{0}}\right)}}
$$

Using the resonance data available at that time (1961), Hansen and Roach used Eqs. (M7.A.123) and M7.A.124 to tabulate the resonance self-shielded, group-averaged values of $\sigma_{f}^{i, 8}$ and $\sigma_{c}^{i, s}$ as a function of $\sigma_{\circ}$.

Despite the fact that Hansen and Roach ignored the effects of Doppler broadening, resonance scattering, and resonance overlap, their simplified approach did provide a useful set of multigroup cross-section data which accounted for the gross spectral effects of resonance self-shielding. Figure M7.A.9 shows the resonance self-shielded values of the capture cross section $\left(\sigma_{c}^{28,8}, g=8,9,10\right.$, $11,12)$ for ${ }^{28} \mathrm{U}$ as a function of $\sigma_{\mathrm{o}}$. Note that the effect of the resonance self-shielding can be quite significant in certain energy groups. Whereas the group- 12 cross section may have a value of 110 barns in an infinitely dilute mixture such as an aqueous solution of uranylfluoride, its value in an undermoderated $\mathrm{UO}_{2}$ lattice would be considerably less, and its value in a thick uranium-metal shield may be as little as 6 barns. 


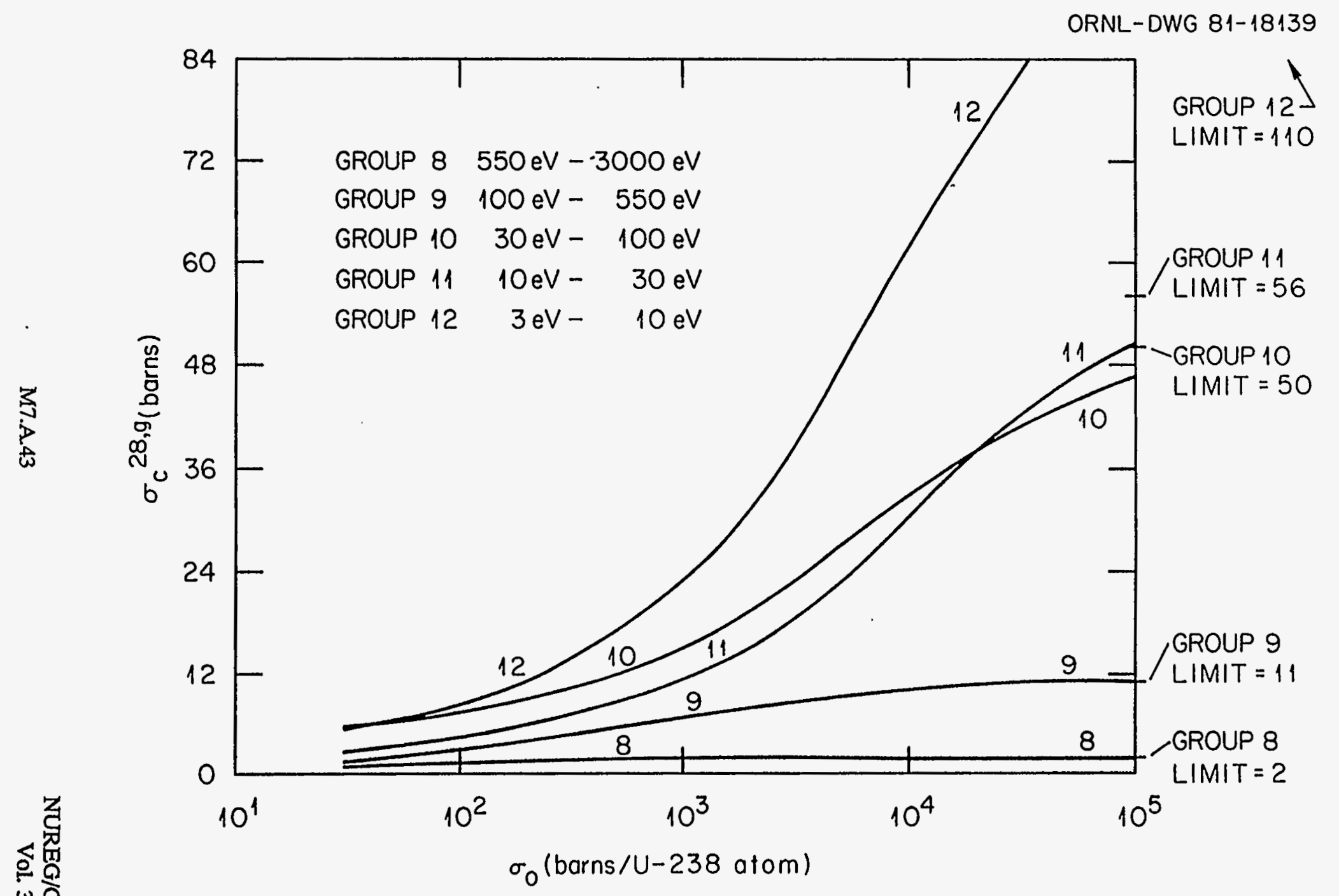

Figure M7.A.9 Resonance self-shielded group-averaged $(\eta, \gamma)$ capture cross section for ${ }^{238} \mathrm{U}$ as a function of the background cross section $\left(\sigma_{0}\right)$ 


\section{M7A11 THE EFFECT OF RESONANCE SCATTERING ON THE GROUP-AVERAGED CROSS SECTIONS}

Somewhat distressing in the derivation of Eqs. (M7.A.123) and (M7.A.124) is the fact that Hansen and Roach ignored the effect of resonance scattering. Indeed, for an unbroadened resonance, its inclusion would have been trivial. Using the Breit-Wigner formula for s-wave scattering, $\sigma_{e f}\left(E_{c}\right)$ may be written as

$$
\begin{aligned}
& \sigma_{e l}^{i}\left(E_{c}\right)=\pi \lambda_{r e s}^{2} g\left(\frac{E_{r e s}}{E_{c}}\right)^{4 / 2}\left[\frac{\Gamma_{n}^{2}}{\left(E_{c}-E_{r e s}\right)^{2}+\left(T^{2} / 4\right)}\right] \\
& +4 \pi \lambda_{r e s} g R \Gamma_{n}\left[\frac{\left(E_{c}-E_{r e s}\right)}{\left(E_{c}-E_{r e s}\right)^{2}+\left(\Gamma^{2} / 4\right)}\right]+\sigma_{p}^{i}
\end{aligned}
$$

where $R$ is the effective radius of the nucleus, and

$$
\sigma_{p}^{i}=4 \pi R^{2}
$$

Incorporating the asymmetric term into the total cross section, we may write

$$
\sigma_{t}^{i}\left(E_{c}\right)=\frac{\sigma_{t}^{i, 0}}{1+x^{2}}+\frac{\sigma_{t}^{i, 0} x d}{1+x^{2}}+\sigma_{p}^{i}
$$

where

$$
\mathrm{d} \equiv\left(\frac{1}{\lambda_{\text {res }}}\right) \sqrt{\frac{\sigma_{p}^{i}}{\pi}}
$$

and

$$
x=\left(\frac{2}{\Gamma}\right)\left(E_{c}-E_{r e s}\right)
$$

Proceeding as before, the integrand in the resonance integral [cf. Eq. (M7.A.106)] may be written as

$$
\left(\frac{\sigma_{f}^{i}(E)}{\sigma_{t}^{i}(E)+\sigma_{o}^{i}}\right)\left(\frac{1}{E}\right) d E=\left(\frac{\Gamma}{2 E_{r e s}}\right)\left(\frac{\sigma_{f}^{i, 0}}{\sigma_{t}^{i, 0}+\sigma_{t}^{i, 0} x d+\left(\sigma_{p}^{i}+\sigma_{0}^{i}\right)\left(1+x^{2}\right)}\right) d x
$$

where

NUREG/CR-0200,

Vol. 3, Rev. 4 


$$
\begin{gathered}
=\left(\frac{1}{2}\right)\left(\frac{\Gamma}{E_{\text {res }}}\right)\left(\frac{1}{x^{2}+b x+c}\right) d x \\
\sigma_{0}=\sigma_{p}^{i}+\sigma_{0}^{i}, b=\left(\frac{\sigma_{t}^{i, 0}}{\sigma_{0}}\right) d \text {, and } c \equiv 1+\left(\frac{\sigma_{t}^{i, 0}}{\sigma_{0}}\right)
\end{gathered}
$$

By "completing the square" in the denominator, the resonance integral may be put in the same standard form as the previous case. To illustrate, consider the following:

$$
x^{2}+b x+c=\left[x^{2}+2\left(\frac{b}{2}\right) x+\left(\frac{b}{2}\right)^{2}\right]+\left[c-\left(\frac{b}{2}\right)^{2}\right]=y^{2}+a^{2} \quad \text { (M7.A.129a) }
$$

where

$$
y=x+\left(\frac{b}{2}\right) \text { and } a^{2}=c-\left(\frac{b}{2}\right)^{2}
$$

Using Eq. (M7.A.128c) for "b," Eq. (M7.A.127b) for "d," and Eq. (M7.A.113) for $\sigma_{t}^{i, 0}$, the quantity $\left(\frac{b}{2}\right)^{2}$ may be written as

$$
\left(\frac{b}{2}\right)^{2}=\left(\frac{\sigma_{t}^{i, 0} \mathrm{~d}}{2 \sigma_{0}}\right)^{2}=\left(\frac{\sigma_{t}^{i, 0}}{\sigma_{0}}\right)^{2}\left(\frac{1}{4}\right)\left(\frac{1}{\lambda_{\mathrm{res}}^{2}}\right)\left(\frac{\sigma_{\mathrm{p}}^{i}}{\pi}\right)
$$

Since $\mathrm{g} \leq 1, \Gamma \mathrm{n} \leq \Gamma$, and $\sigma_{\mathrm{p}}^{i} \leq \sigma_{\mathrm{o}}$, it follows that

$$
\left(\frac{b}{2}\right)^{2} \leq\left(\frac{\sigma_{t}^{i, 0}}{\sigma_{0}}\right)<\left(\frac{\sigma_{t}^{i, 0}}{\sigma_{0}}\right)+1 \equiv c
$$

Hence, the parameter $a^{2}$, defined here as $a^{2}=c-\left(\frac{b}{2}\right)^{2}$, is always positive and

$$
\int_{-\infty}^{\infty} \frac{1}{\left[x+\frac{b}{2}\right]^{2}+\left[c-\left(\frac{b}{2}\right)^{2}\right]} d x=\int_{-\infty}^{\infty} \frac{1}{y^{2}+a^{2}} d y=\frac{\pi}{a}
$$

where 


$$
a=\sqrt{1+\left(\frac{\sigma_{t}^{i, 0}}{\sigma_{0}}\right)\left[1-\left(\frac{g \Gamma_{n}}{\Gamma}\right) \frac{\sigma_{p}^{i}}{\sigma_{0}}\right]}
$$

Thus, the resonance integral found in Eq. (M7.A.106) may be written as

$$
\int_{E_{\max }^{\operatorname{res}(j)}}^{E_{\min }^{\operatorname{res}(j)}}\left(\frac{\sigma_{f}^{i}(E)}{\sigma_{t}^{i}(E)+\sigma_{0}^{i}}\right)\left(\frac{1}{E}\right) d E=\frac{1}{2}\left(\frac{\Gamma}{E_{r e s}}\right)\left(\frac{\sigma_{f}^{i, 0}}{\sigma_{0}}\right) \frac{\pi}{\sqrt{1+\left(\frac{\sigma_{t}^{i, 0}}{\sigma_{0}}\right)\left[1-\left(\frac{g \Gamma_{n}}{\Gamma}\right)\left(\frac{\sigma_{p}^{i}}{\sigma_{0}}\right)\right]}}
$$

Indeed, this form of the resonance integral (for an unbroadened resonance at $\mathrm{T}=0 \mathrm{~K}$ ) was noted by Dresner ${ }^{19}$ some time prior to the release of the original Hansen-Roach cross-section library. Denoting the two forms of the resonance integral as $I_{D}$ and $I_{G R}$, we see that they give essentially the same result whenever the resonance scattering is negligible $\left(\mathrm{g} \Gamma_{\mathrm{n}} \ll \Gamma\right)$, or whenever the resonance nuclide is reasonably dilute $\left(\sigma_{p}^{i} \ll \sigma_{0}\right)$. In a concentrated system, such as a thick uranium-metal shield (where $\sigma_{0} \approx \sigma_{p}^{i}$ ), the more correct form proposed by Dresner [Eq. (M7.A133)] will yield resonance self-shielded, group-averaged cross sections which are consistently larger than those obtained using Eq. (M7.A.122). Table M7.A.2 shows the ratio of the capture integrals $\left(I_{D} / I_{E R}\right)$ for the first few low-energy resonances in ${ }^{238} \mathrm{U}$. In the first case $\left(\sigma_{\mathrm{o}}=45 \mathrm{~b}, \sigma_{\mathrm{p}}=10.7 \mathrm{~b}\right)$, the resonance integrals are within a few percent of each other; in the second case $\left(\sigma_{o}=\sigma_{p}=10.7 \mathrm{~b}\right)$, the resonance integrals are seen to be significantly different. The saving feature, of course, is that many of these low-energy resonances are reasonably broad such that one should in fact use the narrow-resonance/infinite-mass approximation for the flux underneath the resonance (cf. Sect. M7.A.5). Unlike the NR approximation for the flux which has $\sigma_{t}(E)$ in the denominator, the NRIM approximation for the flux has only the absorption cross section $\sigma_{A}^{i}(E)$ in the denominator [cf. Eq. (M7.A.40) and (M7.A.53)]. For broad resonances, therefore, the interference term in the resonance scattering cross section is completely negligible.

Table M7.A.2 Comparison of the Dresner and Hansen-Roach resonance

\begin{tabular}{|c|c|c|c|c|c|}
\hline & & & & $\sigma_{0}=45 \mathrm{~b}$ & $\sigma_{Q}=10.7 \mathrm{~b}$ \\
\hline $\mathrm{E}_{\mathrm{res}}(\mathrm{eV})$ & $\sigma_{t}^{i, 0}$ (barns) & $\mathrm{g} \Gamma_{\mathrm{n}}(\mathrm{MeV})$ & $\Gamma(\mathrm{MeV})$ & $I_{D} / I_{H R}$ & $\mathrm{I}_{\mathrm{D}} / \mathrm{I}_{\mathrm{HR}}$ \\
\hline 6.67 & 21,700 & 1.52 & 27.5 & 1.01 & 1.03 \\
\hline 20.9 & 32,600 & 8.7 & 34.0 & 1.03 & 1.16 \\
\hline 36.8 & 39,500 & 32.0 & 57.0 & 1.08 & 2.27 \\
\hline 66.1 & 20,900 & 26.0 & 48.0 & 1.08 & 1.47 \\
\hline 102.5 & 19,500 & 70.0 & 96.0 & 1.10 & 1.92 \\
\hline 116.8 & 10,300 & 30.0 & 52.0 & 1.08 & 1.54 \\
\hline
\end{tabular}
integrals $\left(I_{D}\right.$ and $\left.I_{H R}\right)$ for ${ }^{238} \mathrm{U}$

NUREG/CR-0200, Vol. 3, Rev. 4 


\section{M7.A12 THE EFFECT OF DOPPLER BROADENING ON THE GROUP-AVERAGED CROSS SECTIONS}

\section{M7.A12.1 Temperature Dependence of the Doppler-Broadened, Energy-Dependent, Cross-Section Data: A Qualitative Explanation and a Mathematical Description in Terms of the $\downarrow$ and $\chi$ Functions}

Somewhat more distressing in the derivation of Eqs. (M7.A.123) and (M7.A.124) is the fact that Hansen and Roach ignored the Doppler broadening of the energy-dependent cross sections at elevated temperatures $(T>0 \mathrm{~K}$ ). While the single-level Breit-Wigner equation does accurately describe the energy-dependent cross sections at $0 \mathrm{~K}$, and while the energy of the neutron in the center-of-mass and laboratory systems may be taken as essentially equal, the vibratory energy associated with the thermal motion of the target nuclide $(E=k T)$ cannot be ignored relative to the width of a narrow resonance $(\Gamma)$. At room temperature, for example, the vibratory energy associated with a ${ }^{238} \mathrm{U}$ nucleus is $0.0253 \mathrm{eV}$. By comparison, the width of the (relatively broad) $6.67-\mathrm{eV}$ resonance is only $0.0275 \mathrm{eV}$. To qualitatively assess the impact of that vibratory motion on the "effective" energy-dependent cross section $\left[\sigma_{c}(E), \sigma_{\mathfrak{f}}(E)\right.$, $\sigma_{\mathrm{t}}(\mathrm{E})$, etc.], let us consider the following analogy:

"Assume that a marksman is consistently firing a steady stream of bullets into a very small bull's-eye painted on a stationary target. Next, assume that the target starts vibrating back and forth with some small amplitude. While the amplitude of the vibratory motion may be very small compared with the trajectory of the bullets (i.e., $\left.\Delta \mathrm{E}<<<\mathrm{E}_{\mathrm{res}}\right)$, it may not be negligible compared with the size of the bull's-eye $(\Delta \mathrm{E} \approx$ $\Gamma)$. As the amplitude of that vibratory motion increases, fewer and fewer bullets traveling along the fixed trajectory $\left(E_{\text {rea }}\right)$ will end up in the bulls-eye. (In the analogy, this would correspond to a decreased absorption probability at $E=E_{\mathrm{res}}$ ). On the other hand, some of the bullets which would have been 'near misses' for the stationary target now land in the bull's-eye (i.e., the absorption probability at $E=E_{\text {nes }} \pm \epsilon$ tends to increase)."

Indeed, the behavior described in the analogy is characteristic of all resonance reactions. Figure M7.A.10 shows the "effective" energy-dependent capture cross section for the 6.67-eV resonance in ${ }^{28} \mathrm{U}$ as a function of temperature. Note that the effective (Doppler-broadened) cross section, $\sigma_{c}^{28}(E, T)$, is substantially lower and substantially wider at elevated temperatures. Note also that it is this Doppler-broadened, energy-dependent cross section (not the Breit-Wigner energy-dependent cross section at $\mathrm{T}=0 \mathrm{~K}$ ) that should be used in Eq. (M7.A.103) when preparing resonance self-shielded, group-averaged cross-section data for a particular application.

To obtain an expression for the Doppler-broadened energy-dependent cross section, we note that it $[\sigma(E, T)]$ should be defined so as to yield the same overall reaction rate (for neutrons of energy $E$ ) that one would obtain if he explicitly integrated over the velocity distribution [N(V)] of all the atoms in the target at temperature $T$. That is, $\sigma(E, T)$ should be defined such that

$$
n v N \sigma(E, T)=\int n|\bar{v}-\bar{V}| N(\bar{V}) \sigma\left(E_{\partial}\right) \bar{d} \bar{V}=\int n v_{r} N\left(V_{z}\right) \sigma\left(E_{\partial}\right) d V_{z}
$$




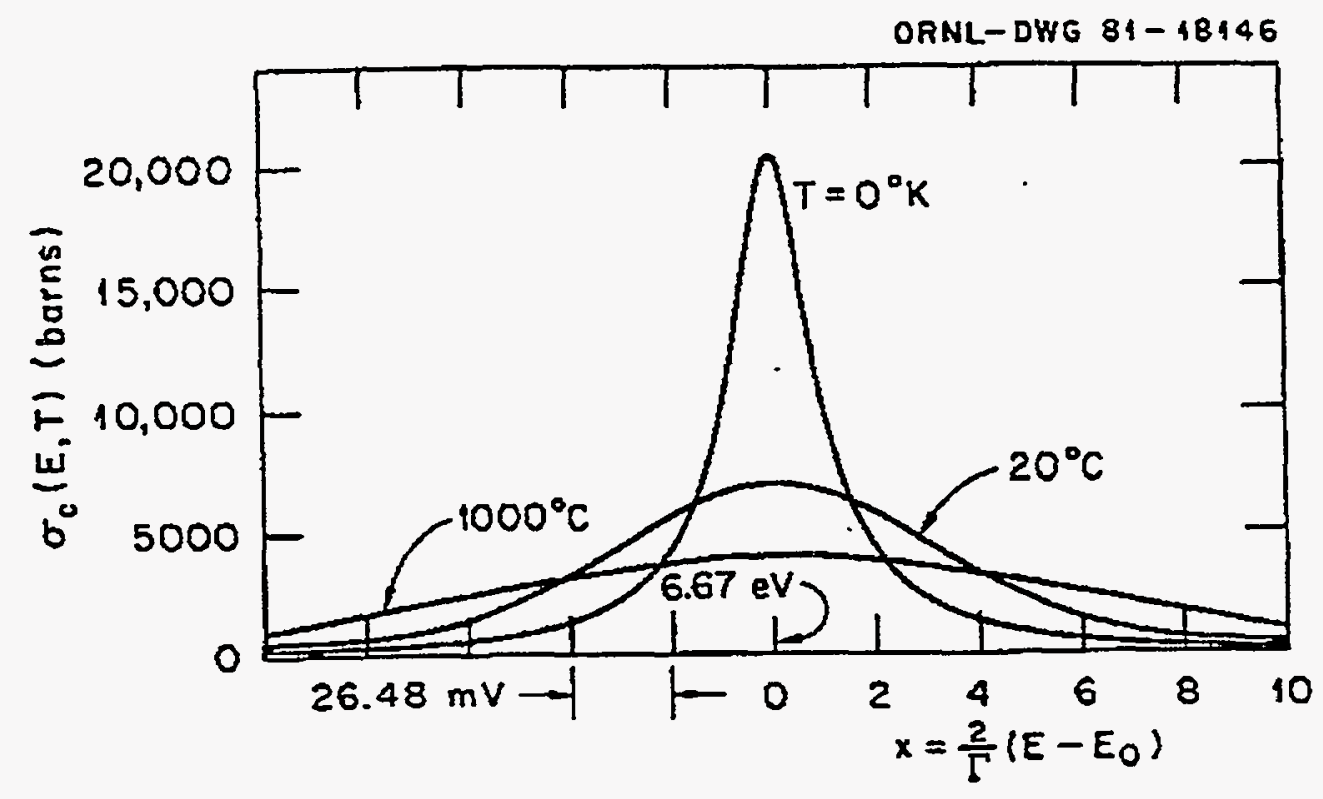

Figure M7.A.10 Doppler broadening of the ${ }^{238} \mathrm{U}$ capture cross section near the $6.67-\mathrm{eV}$ resonance

where $V_{z}=\bar{v} \cdot \bar{v}$ is the component of the target velocity parallel to the flight of the neutron, where the relative speed $v_{r}=|\bar{v}-\bar{V}|$ of the neutron with respect to the target nuclide is essentially the same $e^{*}$ as the speed of the neutron ( $v$ ) in the lab system (such that $n v_{r}=n v=\phi$ ), and where $\sigma\left(E_{c}\right)$ is the energy-dependent cross section as given by the single-level Breit-Wigner equation. Assuming that the velocity distribution of the atoms in the target is Maxwellian

$$
N\left(V_{z}\right)=N\left(\frac{M}{2 \pi k T}\right)^{1 / 2} e^{-\left(\frac{M V_{z}^{2}}{2 K T}\right)}
$$

the Doppler-broadened cross section for neutrons of energy $E$ may be written as

For a ${ }^{238} \mathrm{U}$ nucleus in thermal equilibrium at room temperature $(293 \mathrm{~K})$, its vibrational speed $|\overline{\mathrm{V}}|$ is $\sim 143 \mathrm{~m} / \mathrm{s}$, whereas the speed $|\overline{\mathrm{V}}|$ of a $6.67-\mathrm{eV}$ neutron is $\sim 35,700 \mathrm{~m} / \mathrm{s}$.

NUREG/CR-0200,

Vol. 3, Rev. 4 


$$
\sigma(E, T)=\left(\frac{M}{2 \pi \mathrm{KT}}\right)^{3 / 2} \int_{-\infty}^{\infty} \sigma(\mathrm{E})
$$

or

$$
\sigma_{c}(E, T)=\sigma_{c}^{i, j} \int_{-\infty}^{\infty} \frac{e^{-\left(\frac{M V_{z}^{2}}{2 L T}\right)}}{\left[\left(\frac{2}{\Gamma}\right)\left(E_{c}-E_{r+\infty}\right)\right]^{2}+1}\left(\frac{M}{2 \pi k T}\right)^{1 / 2} d V_{z}
$$

Although it is usually presented in a somewhat different format and tabulated in terms of two dimensionless variables, the integral on the right is the well-known $\psi$ function. When evaluated at a number of different temperatures, the resulting profile of $\sigma_{c}(E, T)$ as a function of $E$ behaves exactly as shown in Fig. M7.A.10. Furthermore, it can be shown that the area under these curves

$$
A=\int_{-\infty}^{\infty} \sigma_{c}(E, T) d E=\sigma_{c}^{i, 0} \pi
$$

is independent of temperature. From this result, we will later show that the resonance self-shielded, group-averaged value of $\sigma_{c}^{i, 8}, \sigma_{f}^{i, 8}, \sigma_{t}^{i, 8}$, etc., will increase with temperature. Before proceeding along those lines, however, it is convenient to put the $\psi$ function of Eq. (M7.A.137) into its standard form. The first step is to write $V_{z}$ in terms of $E$ and $E_{c}$ If $E$ and $E_{A}$ represent the energy of the neutron in the lab system and the vibrational energy of the target nuclide in the lab system $\left(1 / 2 \mathrm{MV}^{2}\right)$, then the energy of the neutron in the center-of-mass system $\left(E_{c}\right)$ may be written as

$$
E_{c}=\left(\frac{M}{m+M}\right) E+\left(\frac{m}{m+M}\right) E_{A}-\left(\frac{m M}{m+M}\right) \bar{v} \cdot \bar{V}
$$

Since $m \ll M$ and $E_{A} \ll E$, this may be written as

$$
E_{c}=E-m v V_{z} \text { where } v=\sqrt{\frac{2 E}{m}} \doteq \sqrt{\frac{2 E_{\text {res }}}{m}}
$$

from which we conclude

$$
\mathrm{dE}_{c}=-\mathrm{mvdV}_{\mathrm{z}} \text { and } \mathrm{dV}_{\mathrm{z}}=-\frac{1}{\mathrm{mv}} \mathrm{dE}_{\mathrm{c}}=-\left(\frac{1}{2 m \mathrm{E}_{\mathrm{rec}}}\right)^{\mathrm{y} / \mathrm{dE}}
$$


Equation (M7.A.140a) may also be rearranged and written as

$$
V_{z}=\left(\frac{1}{m v}\right)(E-E)=\left(\frac{1}{m v}\right)\left[\left(E-E_{\text {res }}\right)-\left(E_{c}-E_{r e s}\right)\right]
$$

from which we conclude that

$$
V_{z}^{2}=\left(\frac{1}{2 m R_{r e s}}\right)\left(\frac{\Gamma^{2}}{4}\right)(x-y)^{2}
$$

where

$$
x \equiv\left(\frac{2}{\Gamma}\right)\left(E-E_{r e s}\right) \text { and } y \equiv\left(\frac{2}{\Gamma}\right)\left(E_{c}-E_{x e s}\right)
$$

Noting that

$$
d y=\frac{2}{\Gamma} \mathrm{dE}_{c}-\mathrm{dE}_{c}=\left(\frac{\Gamma}{2}\right) d y,
$$

Eq. (M7.A.141b) may be written as

$$
d V_{z}=-\left(\frac{\Gamma}{2}\right)\left(\frac{1}{2 \mathrm{mE}_{\mathrm{rez}}}\right)^{3 / 2} \mathrm{dy}
$$

Substituting Eqs. (M7.A.143) and (M7.A.145) into (M7.A.137) yields

$$
\sigma_{c}^{i}(E, T)=\sigma_{c}^{i, 0} \int_{-\infty}^{\infty} \frac{\exp \left[-\left(\frac{M}{2 k T}\right)\left(\frac{1}{2 m E_{r e s}}\right)\left(\frac{\Gamma^{e}}{4}\right)(x-y)^{2}\right]}{y^{2}+1}\left(\frac{\Gamma}{2}\right)\left(\frac{M}{4 \pi m E_{r e s} k T}\right)^{3 / 2} d y \text {. }
$$

Noting that

$$
A=(M / m)
$$

and defining

$$
\Gamma_{D} \equiv \sqrt{\frac{4 \mathrm{KTE}_{\mathrm{ses}}}{A}} \text { and } \xi \equiv \frac{\Gamma}{\Gamma_{\mathrm{D}}}
$$

Eq. (M7.A.146) can then be written as

$$
\sigma_{c}(E, T)=\sigma_{c}^{i, o} \psi(\xi, x),
$$


where the $\psi$ function is formally defined as

$$
\psi(\xi, x)=\frac{\xi}{2 \sqrt{\pi}} \int_{-\infty}^{\infty} \frac{e^{-\left[\xi^{2}(x-y)^{2} / 4\right]}}{1+y^{2}} d y .
$$

Likewise, the Doppler-broadened, energy-dependent fission cross section may be written as

$$
\sigma_{f}^{i}(E, T)=\sigma_{f}^{i, o} \psi(\xi, x),
$$

where

$$
\xi=\left(\frac{\Gamma}{2}\right) \sqrt{\frac{A}{\mathrm{KTE}_{\text {ret }}}} \text { and } x=\left(\frac{2}{\Gamma}\right)\left(E-E_{\text {res }}\right)
$$

Proceeding in the same fashion, the Doppler-broadened, energy-dependent, elastic-scattering cross section may be written as

$$
\sigma_{a}^{i}(E, T)=\left(\frac{\sigma_{t}^{i, 0} \Gamma_{n}}{\Gamma}\right) \Psi(\xi, x)+\sigma_{t}^{i, 0} d \chi(\xi, x)+\sigma_{p}^{i},
$$

where $\sigma_{t}^{i, 0}$ and $d$ are given by Eqs. (M7.A.113) and (M7.A.127b), respectively, and the $\chi$ function is defined as

$$
\chi(\xi, x)=\frac{\xi}{\sqrt{\pi}} \int_{-\infty}^{\infty} \frac{y e^{-\left[\xi^{2}(x-y)^{2} / 4\right]}}{1+y^{2}} d y,
$$

Depending upon whether or not one wishes to account for the asymmetric interference term introduced by the possible presence of resonance scattering, the Doppler-broadened, energy-dependent total cross section may then be written as

$$
\sigma_{i}^{i}(E, T)=\sigma_{i}^{i, 0} \psi(\xi, x)+\sigma_{p}^{i}
$$

or

$$
\sigma_{t}^{i}(E, T)=\sigma_{t}^{i, 0} \Psi(\xi, x)+\sigma_{t}^{i, 0} d \chi(\xi, x)+\sigma_{p}^{i}
$$

Tables of the $\psi$ and $\chi$ functions have been around since the mid-1950's and their properties are well known. ${ }^{12,19,20}$ 
M7.A122 Temperature Dependence of the Resonance-Self-Shielded Group-Averaged Cross Sections: A Mathematical Description in Terms of the J Functions, a Qualitative Explanation Using a Simplified Model, and a Quantitative Assessment with Numerical Examples

Resonance self-shielded, group-averaged cross sections for a material at some elevated temperature may then be evaluated as in Sect. M7.A.10, except that now the energy-dependent cross sections appearing in Eq. (M7.A.106) should be the Doppler-broadened cross sections. That is,

$$
\sigma_{c}^{i g}(T)=\left(\frac{\sigma_{o}}{\Delta u_{g}}\right) \sum_{\frac{1}{j \in g}} \int_{E_{\min }^{\operatorname{res}(j)}}^{E_{\max }^{\operatorname{res}(j)}}\left(\frac{\sigma_{c}^{i}(E, T)}{\sigma_{i}^{i}(E, T)+\sigma_{o}^{i}}\right)\left(\frac{1}{E}\right) d E .
$$

Ignoring the interference term caused by resonance scattering, the resonance integral may then be written as

$$
\begin{gathered}
\int_{E_{\min }^{\operatorname{res}(j)}}^{E_{\operatorname{mex}}^{\operatorname{res}(j)}}\left(\frac{\sigma_{c}^{i}(E, T)}{\sigma_{t}^{i}(E, T)+\sigma_{0}^{i}}\right)\left(\frac{1}{E}\right) d E=\left(\frac{1}{E_{r e s}}\right)\left(\frac{\Gamma}{2}\right) \int_{-\infty}^{\infty} \frac{\sigma_{c}^{i, 0} \Psi(\xi, x)}{\sigma_{t}^{i, 0} \Psi(\xi, x)+\left(\sigma_{p}^{i}+\sigma_{0}^{i}\right)} d x \\
=\left(\frac{1}{E_{r e s}}\right)\left(\frac{\Gamma}{2}\right)\left(\frac{\sigma_{c}^{i, 0}}{\sigma_{t}^{i, 0}}\right) 2 \int_{0}^{\infty} \frac{\psi(\xi, x)}{\Psi(\xi, x)+\left(\frac{\sigma_{p}^{i}+\sigma_{0}^{i}}{\sigma_{t}^{i, 0}}\right)} d x \\
=\left(\frac{\Gamma_{c}}{E_{r e s}}\right) J(\xi, \beta),
\end{gathered}
$$

where

$$
\beta \equiv\left(\frac{\sigma_{0}}{\sigma_{t}^{i, 0}}\right)=\left(\frac{\sigma_{p}^{i}+\sigma_{0}^{i}}{\sigma_{t}^{i, 0}}\right),
$$

and $\mathrm{J}(\xi, \beta)$ is defined as

$$
J(\xi, \beta) \equiv \int_{0}^{\infty} \frac{\psi(\xi, x)}{\psi(\xi, x)+\beta} d x
$$


Note, of course, that $\xi$ and $\beta$ vary from resonance to resonance, and that $\xi$ also depends on the temperature $(T)$. Thus,

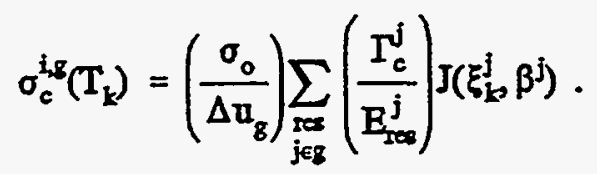

As with the $\psi$ and $\chi$ functions, tables of the J-function have been around since the mid-1950's and its properties are well known. ${ }^{19,20}$

While Eqs. (M7.A.157a,b) are based on the narrow resonance approximation for the flux, a similar expression could be developed for those (low-energy) resonances where the narrow-resonance infinite-mass (NRIM) approximation is more appropriate. Indeed, the only real difference lies in the leading constant and the definition of $\beta$. Using the NRIM approximation for the flux, the resonance self-shielded group-averaged value of $\sigma_{c}^{i, 8}(\mathrm{~T})$ may be written as

$$
\sigma_{c}^{i, g}(T)=\left(\frac{\sigma_{0}^{i}}{\Delta u_{g}}\right) \sum_{r \in g} \int_{E_{j \in g}^{\operatorname{res}(j)}}^{E_{\min }^{\operatorname{res}(j)}}\left(\frac{\sigma_{c}^{i}(E, T)}{\sigma_{A}^{i}(E, T)+\sigma_{o}^{i}}\right)\left(\frac{1}{E}\right) d E,
$$

and the resonance integral may be written as

$$
\begin{aligned}
& \int_{E_{\min }^{r e s(j)}}^{E_{\operatorname{mex}}^{\mathrm{res}(j)}}\left(\frac{\sigma_{c}^{i}(\mathrm{E}, \mathrm{T})}{\sigma_{A}^{i}(\mathrm{E}, \mathrm{T})+\sigma_{0}^{i}}\right)\left(\frac{1}{E}\right) d E \cdot=\left(\frac{1}{E_{x e s}}\right)\left(\frac{\Gamma}{2}\right) \int_{-\infty}^{\infty} \frac{\sigma_{c}^{i, 0} \psi(\xi, x)}{\sigma_{A}^{i, 0} \Psi(\xi, x)+\sigma_{0}^{i}} d x \\
& =\left(\frac{1}{E_{x+0}}\right)\left(\frac{\Gamma}{2}\right)\left(\frac{\sigma_{c}^{i, 0}}{\sigma_{\Lambda}^{i, 0}}\right) 2 \int_{0}^{\infty} \frac{\psi(\xi, x)}{\psi(\xi, x)+\left(\frac{\sigma_{0}^{i}}{\sigma_{\Lambda}^{i, 0}}\right)} d x \\
& =\left(\frac{1}{E_{r e s}}\right)\left(\frac{\Gamma \Gamma_{c}}{\Gamma_{\xi}+\Gamma_{c}}\right) J(\xi, \beta),
\end{aligned}
$$

where $\beta$ is now defined as

Without dwelling on the details, it should be pointed out for the sake of completeness that one can simultaneously account for resonance scattering and Doppler broadening with the tools already developed. Using the narrow resonance approximation for the flux, the resonance integral may then be written as 


$$
\begin{gathered}
\beta=\frac{\sigma_{0}^{i}}{\sigma_{A}^{i, 0}}=\left(\frac{\sigma_{0}-\sigma_{p}^{i}}{\sigma_{t}^{i, 0}}\right)\left(\frac{\Gamma}{\Gamma_{f}+\Gamma_{c}}\right) \\
\int_{E_{\min }^{\operatorname{res}(j)}}^{E_{\operatorname{mix}}^{\operatorname{res}(j)}}\left(\frac{\sigma_{c}^{i}(E, T)}{\sigma_{t}^{i}(E, T)+\sigma_{o}^{i}}\right)\left(\frac{1}{E}\right) d E \\
=\left(\frac{1}{E_{\mathrm{res}}}\right)\left(\frac{\Gamma}{2}\right) \int_{-\infty}^{\infty} \frac{\sigma_{c}^{i, 0} \Psi(\xi, x)}{\sigma_{t}^{i, 0} \Psi(\xi, x)+\sigma_{t}^{i, 0} \mathrm{~d} \chi(\xi, x)+\left(\sigma_{p}^{i}+\sigma_{\partial}^{i}\right)} d x \\
=\left(\frac{\Gamma_{c}}{E_{r e s}}\right) J(\xi, \beta, d),
\end{gathered}
$$

where

$$
\beta \equiv\left(\frac{\sigma_{0}}{\sigma_{t}^{i, 0}}\right)=\left(\frac{\sigma_{p}^{i}+\sigma_{0}^{i}}{\sigma_{t}^{i, 0}}\right),
$$

and the modified $J$-function, $J(\xi, \beta, d)$, is defined as

$$
J(\xi, \beta, d) \equiv \frac{1}{2} \int_{-\infty}^{\infty} \frac{\Psi(\xi, x)}{\Psi(\xi, x)+d \chi(\xi, x)+\beta} d x,
$$

where

$$
d=\left(\frac{1}{t_{\mathrm{res}}}\right) \sqrt{\frac{\sigma_{\mathrm{p}}^{i}}{\pi}}
$$

In an early treatise on the subject, Dresner ${ }^{19}$ has shown that

NUREG/CR-0200,

Vol. 3, Rev. 4
M7.A.54 


$$
\begin{gathered}
\mathrm{J}(\xi, \beta, \mathrm{d}) \doteq \mathrm{J}(\xi \rightarrow \infty, \beta, \mathrm{d})+\mathrm{J}(\xi, \beta)-\mathrm{J}(\xi \rightarrow \infty, \beta) \\
=\mathrm{j}(\xi, \beta)+\left(\frac{\pi}{2}\right)\left[\left(\frac{1}{\beta^{2}+\beta\left[1-\left(\frac{g \Gamma_{\mathrm{n}}}{\Gamma}\right)\left(\frac{\sigma_{p}^{i}}{\sigma_{0}}\right)\right]}\right)^{3 / 2}-\left(\frac{1}{\beta^{2}+\beta}\right)^{4 / /}\right] \text { for } \beta \ll \xi^{2} / 6,
\end{gathered}
$$

and

$$
\mathrm{J}(\xi, \beta, \mathrm{d})=\mathrm{J}(\xi, \beta) \text { for } \xi \ll 1 \text { and } \beta \gg \xi^{2} / 6 .
$$

Other approximations for $\mathrm{J}(\xi, \beta, d)$ have been developed by Rothenstein. ${ }^{21}$ The key facet to be noted, however, is that the effect of resonance scattering becomes less and less important at higher temperatures where the Doppler-broadening effect tends to dominate.

To assess the impact of Doppler broadening on the resonance self-shielded, group-averaged cross sections, it is necessary to examine the behavior of $\mathrm{J}(\xi, \beta)$. In the infinitely dilute case where $\sigma_{0}$ is very large [such that $\left.\beta \equiv\left(\frac{\sigma_{0}}{\sigma_{\mathrm{t}}^{j_{\mathrm{t}}}}\right)>>(\xi, x=0)\right]$,

$$
\begin{aligned}
J(\xi, \beta) & =\operatorname{limit}_{\beta \rightarrow \infty} \int_{0}^{\infty} \frac{\psi(\xi, x)}{\psi(\xi, x)+\beta} d x=\frac{1}{\beta} \int_{0}^{\infty} \psi(\xi, x) d x \\
& =\frac{\xi}{2 \beta \sqrt{\pi}} \int_{0}^{\infty}\left[\int_{-\infty}^{\infty} \frac{e^{-\left[\frac{\xi}{2}(x-y)\right]^{2}}}{1+y^{2}} d y\right] d x .
\end{aligned}
$$

Interchanging the order of integration and defining

$$
\mathbf{u}=\frac{\xi}{2}(\mathrm{x}-\mathrm{y}),
$$

we have 


$$
\begin{gathered}
J(\xi, \beta \rightarrow \infty)=\frac{1}{2 \beta} \int_{-\infty}^{\infty} \frac{1}{1+y^{2}}\left[\operatorname{limit}_{v \rightarrow \infty} \frac{2}{\sqrt{\pi}} \int_{0}^{v} e^{-u^{2}} d u\right] d y \\
=\frac{1}{\beta} \int_{0}^{\infty} \frac{1}{1+y^{2}}\left[\operatorname{limit}_{v \rightarrow \infty} \operatorname{erf}(v)\right] d y=\frac{1}{\beta} \int_{0}^{\infty} \frac{1}{1+y^{2}} d y \\
=\left(\frac{1}{\beta}\right)\left(\frac{\pi}{2}\right)=\left(\frac{\sigma_{t}^{i, 0}}{\sigma_{0}}\right)\left(\frac{\pi}{2}\right) .
\end{gathered}
$$

Note that $\mathrm{J}(\xi, \beta \rightarrow \infty)$ is independent of $\xi$, which was defined as

$$
\xi=\left(\frac{\Gamma}{2}\right) \sqrt{\frac{A}{\mathrm{kTE}_{\mathrm{res}}}} .
$$

Thus, in an infinitely dilute system, the resonance self-shielded, group-averaged cross sections given by Eq. (M7.A.159) will be independent of temperature. Indeed, if we substitute Eq. (M7.A.169) into Eq. (M7.A.159), we obtain

$$
\sigma_{c}^{i, g}=\left(\frac{1}{\Delta u_{g}}\right)\left(\frac{\pi}{2}\right) \sum_{\substack{r e s \\ j \in g}}\left(\frac{\Gamma_{c}}{E_{r e s}}\right) \sigma_{t}^{i, 0}=\left(\frac{1}{\Delta u_{g}}\right)\left(\frac{\pi}{2}\right) \sum_{\substack{r=8 \\ j \in g}}\left(\frac{\Gamma}{E_{r e s}}\right) \sigma_{c}^{i, 0},
$$

which is identical to the result obtained by Hansen and Roach [cf. Eq. (M7.A.124)] as $\sigma_{\circ} \rightarrow \infty$. For all practical purposes, the numerical value thus obtained will be identical to the unshielded, infinitely dilute value given by

$$
\sigma_{c}^{i, g}(\infty) \equiv \frac{1}{\ln \left(E^{8-1} / E^{g}\right)} \int_{E^{8}}^{E^{8-1}} \sigma_{c}^{i}(E) \frac{d E}{E}=\left(\frac{1}{\Delta u_{g}}\right)\left\langle\sigma_{c}^{i}(u)\right\rangle .
$$

Note that this temperature independence will be characteristic of the fission cross section as well as the radiative capture cross section.

In more concentrated mixtures of practical interest, the resonance self-shielded, group-averaged cross sections will be slightly higher at elevated temperatures than at lower temperatures. Note that this is true for the group-averaged values of $\sigma_{f}^{i, 8}(T), \sigma_{c}^{i, 8}(T)$, and $\sigma_{t}^{i / 8}(T)$, despite the fact that $\sigma_{f}^{i}\left(E_{\text {rese }}, T\right)$, $\sigma_{c}^{i}\left(E_{\text {ree }}, T\right)$, and $\sigma_{t}^{i}\left(E_{\text {rege }}, T\right)$ will be considerably lower (cf. Fig. M7.A.10). Even though the point may be proven mathematically, it is probably more instructive to resort to a simplified model of an isolated 
resonance as a function of temperature (cf. Fig. M7.A.11). As shown in Fig. M7.A.11a, the profile of the "effective" energy-dependent cross section $[\sigma(E, T)]$ is substantially flatter at elevated temperatures (i.e., the resonance becomes much wider and the peak value at $E=E_{r e s}$ is substantially reduced). In the simplified model (cf. Fig. M7.A.11b), we shall approximate $\sigma(E, T)$ by a series of rectangular profiles, each becoming shorter and wider as the temperature increases. While the shape of the rectangular profile tends to flatten out at higher temperatures, the area under each profile remains constant and is independent of temperature. That is,

$$
\left[E_{\max }^{\operatorname{res}(i)}-E_{\min }^{\operatorname{res}(1)}\right] \sigma_{c}^{\square}(T)=\int_{E_{\min }^{\operatorname{res}(j)}}^{E_{\max }^{\operatorname{res}(j)}} \sigma_{c}(E, T) d E=\int_{-\infty}^{\infty}\left[\sigma_{c}^{i, 0} \Psi(\xi, x)\right] d x=\pi \sigma_{c}^{i, 0} .
$$

Since this characteristic is crucial to the arguments that follow, it may be worthwhile to prove the point. Using Eqs. (M7.A.148) and (M7.A.149),

$$
\begin{aligned}
& \int_{E_{\min }^{\operatorname{res}(j)}}^{E_{\max }^{\operatorname{res}(j)}} \sigma_{c}(E, T) d E=\int_{-\infty}^{\infty}\left[\sigma_{c}^{i, 0} \Psi(\xi, x)\right] d x \\
& =\sigma_{c}^{i, 0} \frac{\xi}{2 \sqrt{\pi}} \int_{-\infty}^{\infty}\left[\int_{-\infty}^{\infty} \frac{e^{-\left[E^{2}(x-y)^{2} / 4\right]}}{1+y^{2}} d y\right] d x .
\end{aligned}
$$

Interchanging the order of integration and defining

$$
\mathbf{u}=\frac{\xi}{2}(x-y),
$$




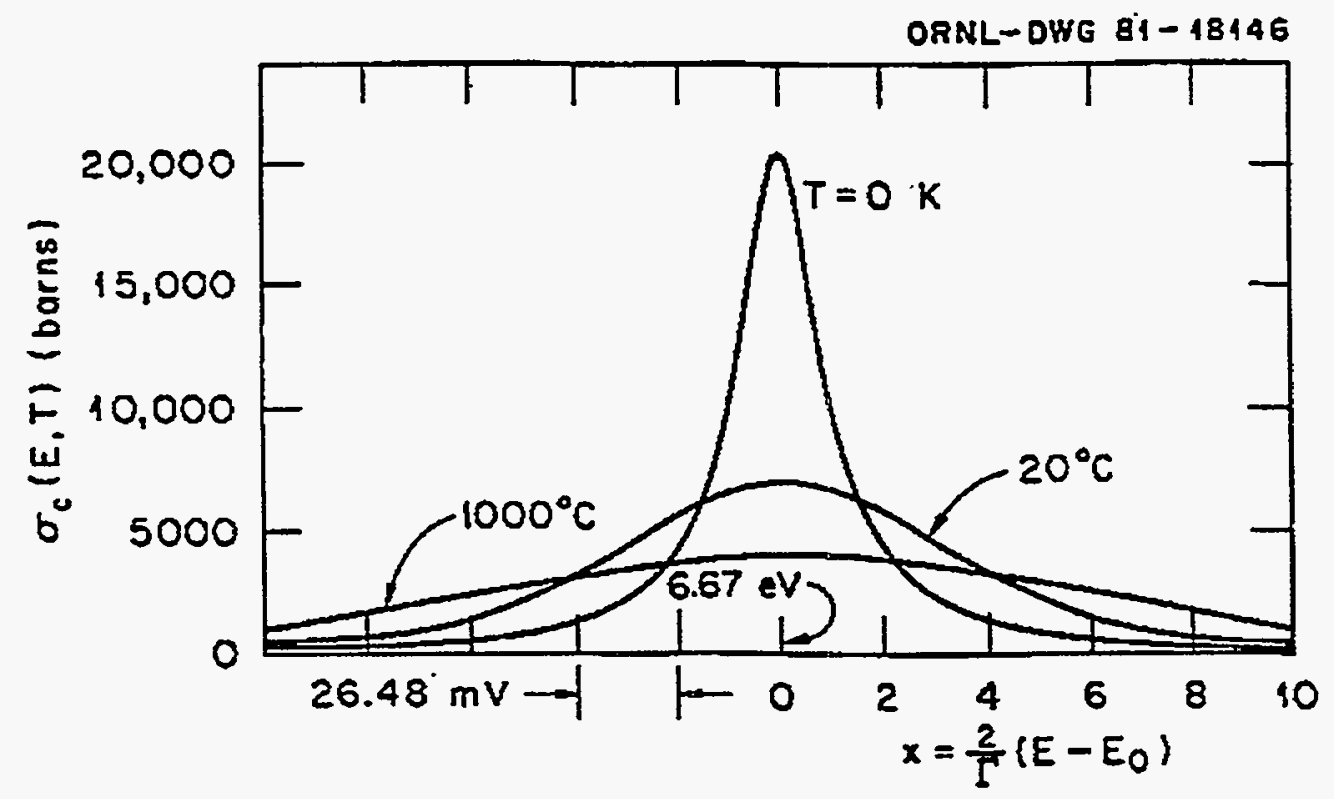

Figure M7.A.11a Actual profiles of the Doppler-broadened ${ }^{238} \mathrm{U}$ capture cross section near the 6.67-eV resonance

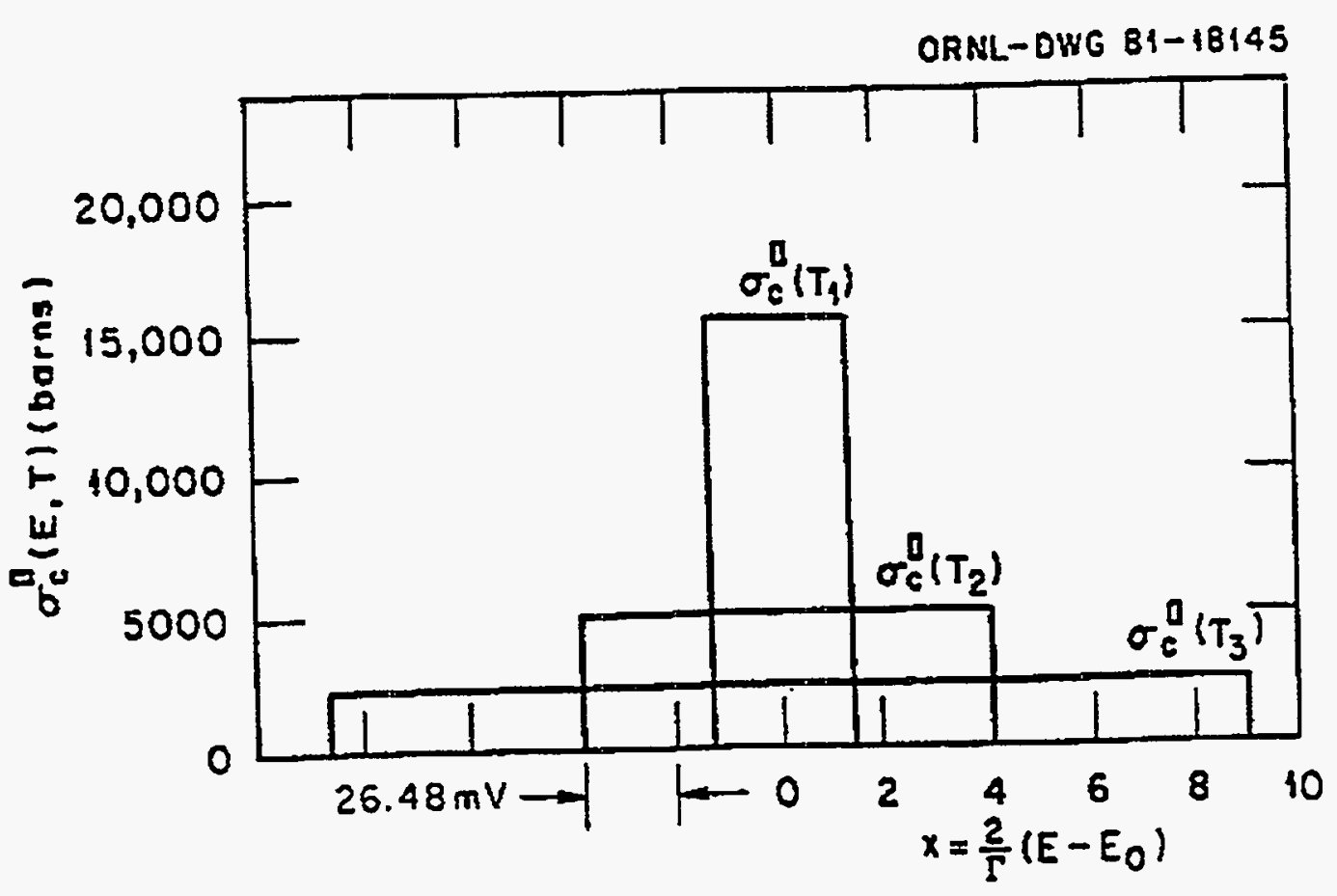

Figure M7.A.11b Idealized rectangular profiles for the Doppler-broadened ${ }^{28} \mathrm{U}$ capture cross section near the $6.67-\mathrm{eV}$ resonance

NUREG/CR-0200,

Vol. 3, Rev. 4

M7.A.58 
we have

$$
\begin{aligned}
\int_{E_{\min }^{\mathrm{xes}(j)}}^{E_{\max }^{\mathrm{xes}(j)}} \sigma_{c}(\mathrm{E}, \mathrm{T}) \mathrm{dE} & =\sigma_{c}^{i, 0} \int_{-\infty}^{\infty} \frac{1}{1+y^{2}}\left[\operatorname{limit}_{\mathrm{v} \rightarrow \infty} \frac{2}{\sqrt{\pi}} \int_{0}^{\mathrm{v}} \mathrm{e}^{-\mathrm{u}^{2}} \mathrm{du}\right] \mathrm{dy} \\
& =\sigma_{c}^{i, 0} \int_{-\infty}^{\infty} \frac{1}{1+\mathrm{y}^{2}}\left[\operatorname{limit}_{\mathrm{v} \rightarrow \infty} \mathrm{erf}(\mathrm{v})\right] \mathrm{dy} \\
& =\sigma_{c}^{i, 0} \int_{-\infty}^{\infty} \frac{1}{1+y^{2}}[1] \mathrm{dy}=\pi \sigma_{c}^{i, 0} .
\end{aligned}
$$

Using the narrow resonance approximation for the flux and the rectangular cross-section profiles shown in Fig. M7.A.11b, the resonance integral may then be written as

$$
\begin{gathered}
\int_{E_{\min }^{\operatorname{res}(j)}}^{E_{\operatorname{mox}}^{\operatorname{res}(j)}}\left(\frac{\sigma_{c}^{i}(E, T)}{\sigma_{t}^{i}(E, T)+\sigma_{0}}\right)\left(\frac{1}{E}\right) d E=\frac{1}{E_{\operatorname{res}}} \int_{E_{\min }^{\operatorname{res}(j)}}^{E_{\operatorname{mix}}^{\operatorname{res}(j)}} \frac{\sigma_{c}^{\square}(T)}{\sigma_{t}^{\square}(T)+\sigma_{0}} d E \\
=\left(\frac{1}{E_{r e s}}\right) \frac{\sigma_{c}^{\square}(T)\left[E_{\max }^{\operatorname{res}(T)}-E_{\min }^{\operatorname{res}(i)}\right]}{\sigma_{t}^{\square}(T)+\sigma_{0}}=\frac{1}{E_{r e s}} \frac{\pi \sigma_{c}^{i, 0}}{\sigma_{t}^{\square}(T)+\sigma_{0}} .
\end{gathered}
$$

Since $\sigma_{t}^{\square}(T)$ gets smaller and smaller at higher temperatures, the resonance integral tends to increase as the temperature increases. Since the resonance self-shielded, group-averaged value of $\sigma_{c}^{i s}(T)$ is defined as

$$
\sigma_{c}^{i, g}(T)=\frac{\sigma_{0}}{\Delta u_{g}} \sum_{\substack{\mathrm{rez} \\ j \in g}} \int_{\mathrm{E}_{\min }^{\operatorname{rag}(j)}}^{E_{\max }^{\mathrm{rag}(j)}}\left(\frac{\sigma_{c}^{i}(E, T)}{\sigma_{t}^{i}(E, T)+\sigma_{0}}\right)\left(\frac{1}{E}\right) \mathrm{dE},
$$

the resonance self-shielded, group-averaged value of $\sigma_{c}^{i, 8}(T)$ tends to increase as the temperature increases. Likewise, the same is also true for $\sigma_{f}^{i, 8}(T), \sigma_{t}^{i, 8}(T)$, etc. The reactivity of a fissile mixture may, of course, increase, decrease, or remain constant, depending on the relative change in the 
capture-to-fission ratio. In low-enriched thermal systems where there is a preponderance of fertile nuclides relative to fissile nuclides, the reactivity typically goes down as the temperature increases.

Having examined the effect of Doppler broadening mathematically, and having used some simplifying assumptions to gain a qualitative feel for the processes involved, it is (at last) necessary to consider some numerical results so that the magnitude of these effects may be kept in proper perspective. As noted above, the resonance self-shielded, group-averaged cross sections for capture, fission, etc., tend to increase as the temperature increases. In his book on resonance absorption ${ }^{19}$ (cf. Tables 4-8, page 106), Dresner indicates that the total capture integral for $\mathrm{UO}_{2}$ at $300 \mathrm{~K}$ may be $10-15 \%$ higher than at $0 \mathrm{~K}$ when $\sigma_{0}$ is $\leq 200$ barns. At temperatures found near the center of a fuel pellet in an operating reactor, the difference may be larger still. In his original book on the subject, Bondarenko ${ }^{17}$ lists his 26-group self-shielding factors for capture, fission, etc., as a function of both temperature (T) and the background cross section $\left(\sigma_{0}\right)$ given in Table M7.A.3a. Tables M7A.3b and M7.A.3c show the corresponding f-factors for ${ }^{235} \mathrm{U}$ and ${ }^{238} \mathrm{U}$ at $300 \mathrm{~K}, 900 \mathrm{~K}$, and $2100 \mathrm{~K}$. In many of the groups the self-shielding factors at $900 \mathrm{~K}$ are $5-10 \%$ higher than at $300 \mathrm{~K}$, and another $5-10 \%$ higher at $2100 \mathrm{~K}$ than at $900 \mathrm{~K}$ This is particularly noticeable for the ${ }^{288} \mathrm{U}$ data in groups $12-18$ when $\sigma_{0}$ is $<1000$ barns. Obviousily in the infinitely dilute case, the f-factors will be independent of temperature. In the more concentrated systems where $\sigma_{0}$ is small, the Doppler effect will be more noticeable. Lastly, we note that while the Doppler effect is very important (increasing $\sigma_{c}^{i, 8}(T), \sigma_{f}^{i, 8}(T)$, etc., by several percent), it may still be regarded as a second-order effect when compared with the rather large adjustment that must be made for $\sigma_{0}$.

\section{M7A.13 THE KNIGHT-MODIFIED HANSEN-ROACH CROSS-SECTION LIBRARY}

\section{M7.A.13.1 Modifications Made by J. R. Knight to the ${ }^{238} \mathrm{U}$ Capture Cross Section for Concentrated Systems $\left(\sigma_{0}<400\right.$ barns $)$}

The original Hansen-Roach library was one of the first multigroup libraries used in the United States for criticality analyses. It was deemed quite useful insofar as it did account for the gross spectral effects of resonance self-shielding (cf. Sect. M7.A.10). Unfortunately, many of the resonance parameters available at that time had not yet been fully refined and, indeed, the methodology used by Hansen and Roach did not account for Doppler broadening, interference effects in resonance scattering, or resonance overlap. When used to analyze well-thermalized critical experiments at room temperature, it was not uncommon to calculate k-effective's between 0.8 and 0.9 . Raffety and Mihalczo ${ }^{22}$ report one case involving a $2 \%$ enriched mixture of $\mathrm{UF}_{4}$ in paraffin $\left(\mathrm{H}^{235} \mathrm{U}=195 ; \sigma_{0}^{28} \approx 120\right)$ where the measured value of $\mathrm{k}_{\infty}$ was $1.195 \pm 0.015$, but the calculated value using the original Hansen-Roach data was 1.114. Characteristically, the original Hansen-Roach data have been found to overestimate the resonance capture in ${ }^{238} \mathrm{U}$." Obviously, in fast systems where the resonance escape probability is less important and the amount of ${ }^{238} \mathrm{U}$ is somewhat reduced, this difficulty is not so apparent.

Interestingly, if one modifies the original Hansen-Roach data to account for Doppler broadening and/or resonance scattering, the capture cross sections for ${ }^{28} U$ would tend to increase, thus making the calculated values for $k_{\infty}$ even worse. The difficulty, therefore, was assumed to lie in the resonance parameters that were used at the time that the original library was compiled.

"Interestingly, if one modifies the original Hansen-Roach data to account for Doppler broadening and/or resonance scattering, the capture cross sections for ${ }^{28} \mathrm{U}$ would tend to increase, thus making the calculated values for $k_{\infty}$ even worse. The difficulty, therefore, was assumed to lie in the resonance parameters that were used at the time the original library was compiled.

NUREG/CR-0200,

Vol. 3, Rev. 4

M7.A.60 
Table M7.A.3a Energy group structure used by Bondarenko, and some infinitely dilute data for ${ }^{235} \mathrm{U}$ and ${ }^{238} \mathrm{U}$

\begin{tabular}{|c|c|c|c|c|c|c|c|c|c|c|c|c|c|c|}
\hline \multirow[b]{2}{*}{ Group } & \multirow[b]{2}{*}{$\mathrm{E}_{\mathrm{n}}$} & \multirow[b]{2}{*}{$\Delta \mathbf{u}$} & \multicolumn{6}{|c|}{ Uranium (U-235) } & \multicolumn{6}{|c|}{ Uranium (U-238) } \\
\hline & & & $\sigma_{\mathrm{t}}$ & $\sigma_{\mathrm{t}}$ & $v$ & $\sigma_{c}$ & $\sigma_{\text {in }}$ & $\sigma_{e}$ & $\sigma_{t}$ & $\sigma_{\mathrm{f}}$ & $\boldsymbol{v}$ & $\sigma_{c}$ & $\sigma_{\text {in }}$ & $\sigma_{c}$ \\
\hline 1 & $6.5-10.5 \mathrm{MeV}$ & 0.48 & 6.30 & 1.75 & 3.40 & 0.02 & 1.03 & 3.50 & 6.30 & 1.00 & 3.48 & 0.00 & 1.80 & 3.50 \\
\hline 2 & 4.0-6.5 MeV & 0.48 & 7.40 & 1.15 & 3.04 & 0.03 & 1.92 & 4.30 & 7.50 & 0.58 & 3.09 & 0.01 & 2.51 & 4.40 \\
\hline 3 & $2.5-4.0 \mathrm{MeV}$ & 0.48 & 7.70 & 1.25 & 2.79 & 0.04 & 1.91 & 4.50 & 7.70 & 0.58 & 2.87 & 0.02 & 2.60 & 4.50 \\
\hline 4 & $1.4-2.5 \mathrm{MeV}$ & 0.57 & 7.00 & 1.28 & 2.63 & 0.06 & 1.76 & 3.90 & 7.10 & 0.49 & 2.67 & 0.06 & 2.25 & 4.30 \\
\hline 5 & $0.8-1.4 \mathrm{MeV}$ & 0.57 & 6.60 & 1.25 & 2.52 & 0.12 & 1.38 & 3.85 & 6.90 & 0.02 & 2.58 & 0.13 & 2.15 & 4.60 \\
\hline 6 & $0.4-0.8 \mathrm{MeV}$ & 0.69 & 7.40 & 1.23 & 2.46 & 0.17 & 1.20 & 4.80 & 7.80 & - & - & 0.13 & 1.65 & 6.02 \\
\hline 7 & $0.2-0.4 \mathrm{MeV}$ & 0.69 & 9.20 & 1.41 & 2.47 & 0.25 & 1.00 & 6.54 & 9.60 & - & - & 0.15 & 1.05 & 8.40 \\
\hline 8 & $0.1-0.2 \mathrm{MeV}$ & 0.69 & 11.2 & 1.70 & 2.45 & 0.40 & 0.60 & 8.50 & 11.5 & - & - & 0.22 & 0.55 & 10.7 \\
\hline 9 & $46.5-100 \mathrm{keV}$ & 0.77 & 12.5 & 2.10 & 2.44 & 0.60 & 0.18 & 9.62 & 12.8 & - & - & 0.35 & 0.19 & 12.3 \\
\hline 10 & $21.5-46.5 \mathrm{keV}$ & 0.77 & 14.0 & 2.65 & 2.43 & 1.00 & 0.06 & 10.3 & 13.5 & - & - & 0.46 & - & 13.0 \\
\hline 11 & $10.0-21.5 \mathrm{keV}$ & 0.77 & 16.0 & 3.40 & 2.42 & 1.50 & - & 11.1 & 14.0 & - & - & 0.60 & - & 13.4 \\
\hline 12 & $4.65-10.0 \mathrm{keV}$ & 0.77 & 19.0 & 4.40 & 2.42 & 2.10 & - & 12.5 & 15.5 & - & - & 0.78 & - & 14.7 \\
\hline 13 & $2.15-4.65 \mathrm{keV}$ & 0.77 & 23.0 & 5.40 & 2.42 & 2.75 & - & 14.8 & 16.5 & - & - & 1.20 & - & 15.3 \\
\hline 14 & $1.0-2.15 \mathrm{keV}$ & 0.77 & 27.0 & 7.30 & 2.42 & 3.80 & - & 15.9 & 18.0 & - & - & 2.10 & - & 15.9 \\
\hline 15 & $465-1000 \mathrm{eV}$ & 0.77 & 32.0 & 11.0 & 2.42 & 6.3 & - & 14.7 & 23.0 & - & - & 3.60 & - & 19.4 \\
\hline 16 & $215-465 \mathrm{eV}$ & 0.77 & 38.0 & 16.0 & 2.42 & 9.5 & - & 12.5 & 18.5 & - & - & 4.50 & - & 14.0 \\
\hline 17 & $100-215 \mathrm{eV}$ & 0.77 & 47.7 & 22 & 2.42 & 13.5 & - & 12.2 & 80.0 & - & - & 17.0 & - & 63.0 \\
\hline 18 & $46.5-100 \mathrm{eV}$ & 0.77 & 69.0 & 35 & 2.42 & 22 & - & 12 & 40.0 & - & - & 15.0 & - & 25.0 \\
\hline 19 & $21.5-46.5 \mathrm{eV}$ & 0.77 & 88.0 & 45 & 2.42 & 31 & - & 12 & 140 & - & - & 58.0 & - & 82.0 \\
\hline 20 & $10.0-21.5 \mathrm{eV}$ & 0.77 & 111 & 45 & 2.42 & 54 & - & 12 & 120 & - & - & 82.0 & - & 38.0 \\
\hline 21 & $4.65-10.0 \mathrm{eV}$ & 0.77 & 93.0 & 37 & 2.42 & 44 & - & 12 & 190 & - & - & 171 & - & 19.0 \\
\hline 22 & $2.15-4.65 \mathrm{eV}$ & 0.77 & 39.0 & 20 & 2.42 & 7 & - & 12 & 9.54 & - & - & 0.54 & - & 9.00 \\
\hline 23 & $1.0-2.15 \mathrm{eV}$ & 0.77 & 61.0 & 35 & 2.42 & 13 & - & 13 & 9.47 & - & - & 0.47 & - & 9.00 \\
\hline 24 & $0.465-1.0 \mathrm{eV}$ & 0.77 & 88.0 & 64 & 2.42 & 10 & - & 14 & 9.58 & - & - & 0.58 & - & 9.00 \\
\hline 25 & $0.215-0.465 \mathrm{eV}$ & 0.77 & 205 & 155 & 2.42 & 35 & - & 15 & 9.90 & - & - & 0.90 & - & 9.00 \\
\hline $\mathrm{T}$ & $0.0252 \mathrm{eV}$ & - & 698 & 582 & 2.42 & 101 & - & 15 & 11.7 & - & - & 2.71 & - & 9.00 \\
\hline
\end{tabular}




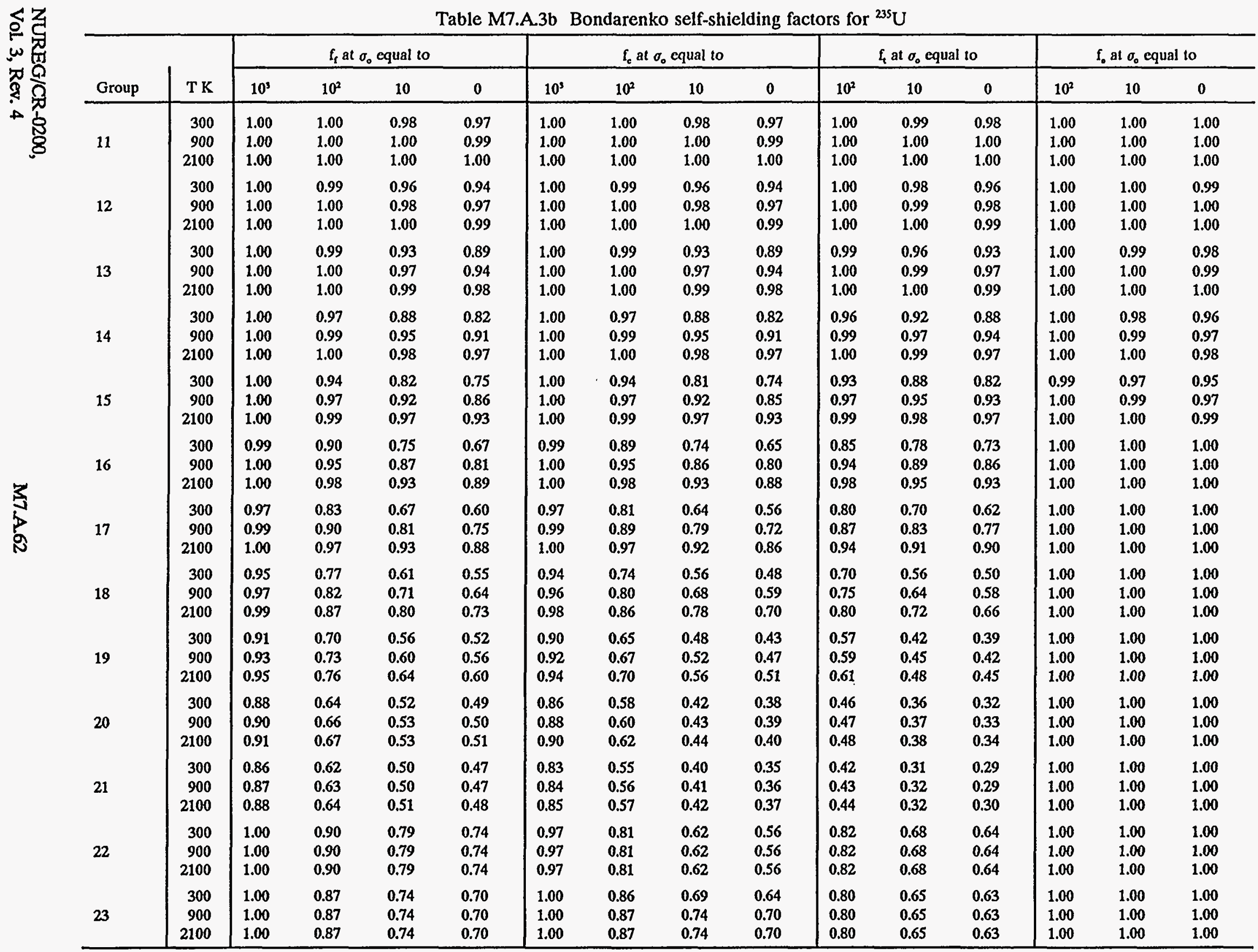


Table M7.A.3c Bondarenko self-shielding factors for ${ }^{238} \mathrm{U}$

\begin{tabular}{|c|c|c|c|c|c|c|c|c|c|c|c|c|c|c|c|}
\hline \multirow[b]{2}{*}{ Group } & \multirow[b]{2}{*}{$\mathrm{TK}$} & \multicolumn{6}{|c|}{$f_{e}$ at $\sigma_{o}$ equal to } & \multicolumn{4}{|c|}{$f_{2}$ at $\sigma_{0}$ equal to } & \multicolumn{4}{|c|}{$f_{0}$ at $\sigma_{0}$ equal to } \\
\hline & & $\infty$ & $10^{4}$ & $10^{3}$ & $10^{2}$ & 10 & 0 & $10^{3}$ & $10^{2}$ & 10 & 0 & $10^{3}$ & $10^{2}$ & 10 & 0 \\
\hline 10 & $\begin{array}{r}300 \\
900 \\
2100\end{array}$ & $\begin{array}{l}1.00 \\
1.00 \\
1.00\end{array}$ & $\begin{array}{l}1.00 \\
1.00 \\
1.00\end{array}$ & $\begin{array}{l}1.00 \\
1.00 \\
1.00\end{array}$ & $\begin{array}{l}0.99 \\
0.99 \\
1.00\end{array}$ & $\begin{array}{l}0.98 \\
0.98 \\
1.00\end{array}$ & $\begin{array}{l}0.93 \\
0.96 \\
0.99\end{array}$ & $\begin{array}{l}1.00 \\
1.00 \\
1.00\end{array}$ & $\begin{array}{l}1.00 \\
1.00 \\
1.00\end{array}$ & $\begin{array}{l}0.98 \\
1.00 \\
1.00\end{array}$ & $\begin{array}{l}0.97 \\
0.98 \\
0.99\end{array}$ & $\begin{array}{l}1.00 \\
1.00 \\
1.00\end{array}$ & $\begin{array}{l}1.00 \\
1.00 \\
1.00\end{array}$ & $\begin{array}{l}0.99 \\
0.99 \\
1.00\end{array}$ & $\begin{array}{l}0.98 \\
0.98 \\
1.00\end{array}$ \\
\hline 11 & $\begin{array}{r}300 \\
900 \\
2100\end{array}$ & $\begin{array}{l}1.00 \\
1.00 \\
1.00\end{array}$ & $\begin{array}{l}1.00 \\
1.00 \\
1.00\end{array}$ & $\begin{array}{l}1.00 \\
1.00 \\
1.00\end{array}$ & $\begin{array}{l}0.98 \\
0.99 \\
1.00\end{array}$ & $\begin{array}{l}0.89 \\
0.95 \\
0.99\end{array}$ & $\begin{array}{l}0.80 \\
0.90 \\
0.97\end{array}$ & $\begin{array}{l}1.00 \\
1.00 \\
1.00\end{array}$ & $\begin{array}{l}0.99 \\
1.00 \\
1.00\end{array}$ & $\begin{array}{l}0.96 \\
0.98 \\
0.99\end{array}$ & $\begin{array}{l}0.92 \\
0.93 \\
0.94\end{array}$ & $\begin{array}{l}1.00 \\
1.00 \\
1.00\end{array}$ & $\begin{array}{l}1.00 \\
1.00 \\
1.00\end{array}$ & $\begin{array}{l}0.97 \\
0.97 \\
0.99\end{array}$ & $\begin{array}{l}0.93 \\
0.95 \\
0.98\end{array}$ \\
\hline 12 & $\begin{array}{r}300 \\
900 \\
2100\end{array}$ & $\begin{array}{l}1.00 \\
1.00 \\
1.00\end{array}$ & $\begin{array}{l}1.00 \\
1.00 \\
1.00\end{array}$ & $\begin{array}{l}0.99 \\
0.99 \\
1.00\end{array}$ & $\begin{array}{l}0.92 \\
0.95 \\
0.98\end{array}$ & $\begin{array}{l}0.75 \\
0.86 \\
0.93\end{array}$ & $\begin{array}{l}0.63 \\
0.77 \\
0.87\end{array}$ & $\begin{array}{l}0.99 \\
1.00 \\
1.00\end{array}$ & $\begin{array}{l}0.98 \\
0.99 \\
1.00\end{array}$ & $\begin{array}{l}0.87 \\
0.89 \\
0.93\end{array}$ & $\begin{array}{l}0.73 \\
0.73 \\
0.73\end{array}$ & $\begin{array}{l}0.99 \\
1.00 \\
1.00\end{array}$ & $\begin{array}{l}0.98 \\
0.98 \\
1.00\end{array}$ & $\begin{array}{l}0.91 \\
0.93 \\
0.95\end{array}$ & $\begin{array}{l}0.85 \\
0.87 \\
0.88\end{array}$ \\
\hline 13 & $\begin{array}{r}300 \\
900 \\
2100\end{array}$ & $\begin{array}{l}1.00 \\
1.00 \\
1.00\end{array}$ & $\begin{array}{l}1.00 \\
1.00 \\
1.00\end{array}$ & $\begin{array}{l}0.96 \\
0.98 \\
1.00\end{array}$ & $\begin{array}{l}0.82 \\
0.89 \\
0.95\end{array}$ & $\begin{array}{l}0.56 \\
0.66 \\
0.79\end{array}$ & $\begin{array}{l}0.46 \\
0.55 \\
0.67\end{array}$ & $\begin{array}{l}0.95 \\
0.96 \\
0.97\end{array}$ & $\begin{array}{l}0.88 \\
0.90 \\
0.94\end{array}$ & $\begin{array}{l}0.75 \\
0.78 \\
0.82\end{array}$ & $\begin{array}{l}0.60 \\
0.61 \\
0.62\end{array}$ & $\begin{array}{l}0.98 \\
0.99 \\
1.00\end{array}$ & $\begin{array}{l}0.94 \\
0.95 \\
0.99\end{array}$ & $\begin{array}{l}0.84 \\
0.87 \\
0.92\end{array}$ & $\begin{array}{l}0.70 \\
0.73 \\
0.76\end{array}$ \\
\hline 14 & $\begin{array}{r}300 \\
900 \\
2100\end{array}$ & $\begin{array}{l}1.00 \\
1.00 \\
1.00\end{array}$ & $\begin{array}{l}0.99 \\
1.00 \\
0.99\end{array}$ & $\begin{array}{l}0.89 \\
0.93 \\
0.97\end{array}$ & $\begin{array}{l}0.63 \\
0.74 \\
0.82\end{array}$ & $\begin{array}{l}0.34 \\
0.43 \\
0.51\end{array}$ & $\begin{array}{l}0.29 \\
0.36 \\
0.42\end{array}$ & $\begin{array}{l}0.91 \\
0.92 \\
0.93\end{array}$ & $\begin{array}{l}0.74 \\
0.78 \\
0.82\end{array}$ & $\begin{array}{l}0.64 \\
0.65 \\
0.68\end{array}$ & $\begin{array}{l}0.50 \\
0.51 \\
0.53\end{array}$ & $\begin{array}{l}0.95 \\
0.97 \\
0.99\end{array}$ & $\begin{array}{l}0.84 \\
0.86 \\
0.91\end{array}$ & $\begin{array}{l}0.74 \\
0.77 \\
0.82\end{array}$ & $\begin{array}{l}0.60 \\
0.63 \\
0.66\end{array}$ \\
\hline 15 & $\begin{array}{r}300 \\
900 \\
2100\end{array}$ & $\begin{array}{l}0.99 \\
1.00 \\
1.00\end{array}$ & $\begin{array}{l}0.97 \\
0.98 \\
1.00\end{array}$ & $\begin{array}{l}0.81 \\
0.87 \\
0.93\end{array}$ & $\begin{array}{l}0.42 \\
0.52 \\
0.60\end{array}$ & $\begin{array}{l}0.23 \\
0.29 \\
0.34\end{array}$ & $\begin{array}{l}0.17 \\
0.21 \\
0.26\end{array}$ & $\begin{array}{l}0.84 \\
0.85 \\
0.87\end{array}$ & $\begin{array}{l}0.60 \\
0.64 \\
0.68\end{array}$ & $\begin{array}{l}0.53 \\
0.54 \\
0.55\end{array}$ & $\begin{array}{l}0.43 \\
0.43 \\
0.44\end{array}$ & $\begin{array}{l}0.86 \\
0.90 \\
0.90\end{array}$ & $\begin{array}{l}0.66 \\
0.70 \\
0.70\end{array}$ & $\begin{array}{l}0.56 \\
0.58 \\
0.60\end{array}$ & $\begin{array}{l}0.48 \\
0.49 \\
0.50\end{array}$ \\
\hline 16 & $\begin{array}{r}300 \\
900 \\
2100\end{array}$ & $\begin{array}{l}0.97 \\
0.99 \\
1.00\end{array}$ & $\begin{array}{l}0.94 \\
0.95 \\
0.97\end{array}$ & $\begin{array}{l}0.65 \\
0.74 \\
0.83\end{array}$ & $\begin{array}{l}0.27 \\
0.35 \\
0.45\end{array}$ & $\begin{array}{l}0.136 \\
0.18 \\
0.23\end{array}$ & $\begin{array}{l}0.106 \\
0.132 \\
0.17\end{array}$ & $\begin{array}{l}0.87 \\
0.92 \\
0.95\end{array}$ & $\begin{array}{l}0.60 \\
0.63 \\
0.66\end{array}$ & $\begin{array}{l}0.50 \\
0.51 \\
0.52\end{array}$ & $\begin{array}{l}0.46 \\
0.46 \\
0.46\end{array}$ & $\begin{array}{l}0.84 \\
0.88 \\
0.92\end{array}$ & $\begin{array}{l}0.73 \\
0.75 \\
0.78\end{array}$ & $\begin{array}{l}0.68 \\
0.70 \\
0.72\end{array}$ & $\begin{array}{l}0.63 \\
0.64 \\
0.65\end{array}$ \\
\hline 17 & $\begin{array}{r}300 \\
900 \\
2100\end{array}$ & $\begin{array}{l}0.95 \\
0.97 \\
0.99\end{array}$ & $\begin{array}{l}0.83 \\
0.86 \\
0.89\end{array}$ & $\begin{array}{l}0.35 \\
0.38 \\
0.44\end{array}$ & $\begin{array}{l}0.13 \\
0.15 \\
0.17\end{array}$ & $\begin{array}{l}0.063 \\
0.071 \\
0.081\end{array}$ & $\begin{array}{l}0.049 \\
0.053 \\
0.063\end{array}$ & $\begin{array}{l}0.38 \\
0.45 \\
0.51\end{array}$ & $\begin{array}{l}0.17 \\
0.17 \\
0.18\end{array}$ & $\begin{array}{l}0.14 \\
0.15 \\
0.16\end{array}$ & $\begin{array}{l}0.070 \\
0.070 \\
0.070\end{array}$ & $\begin{array}{l}0.37 \\
0.38 \\
0.40\end{array}$ & $\begin{array}{l}0.23 \\
0.24 \\
0.25\end{array}$ & $\begin{array}{l}0.19 \\
0.20 \\
0.21\end{array}$ & $\begin{array}{l}0.12 \\
0.12 \\
0.12\end{array}$ \\
\hline 18 & $\begin{array}{r}300 \\
900 \\
2100\end{array}$ & $\begin{array}{l}0.91 \\
0.93 \\
0.95\end{array}$ & $\begin{array}{l}0.81 \\
0.87 \\
0.94\end{array}$ & $\begin{array}{l}0.30 \\
0.33 \\
0.37\end{array}$ & $\begin{array}{l}0.108 \\
0.12 \\
0.13\end{array}$ & $\begin{array}{l}0.052 \\
0.055 \\
0.061\end{array}$ & $\begin{array}{l}0.042 \\
0.044 \\
0.049\end{array}$ & $\begin{array}{l}0.39 \\
0.44 \\
0.48\end{array}$ & $\begin{array}{l}0.29 \\
0.30 \\
0.30\end{array}$ & $\begin{array}{l}0.25 \\
0.25 \\
0.26\end{array}$ & $\begin{array}{l}0.22 \\
0.22 \\
0.22\end{array}$ & $\begin{array}{l}0.54 \\
0.54 \\
0.54\end{array}$ & $\begin{array}{l}0.45 \\
0.45 \\
0.45\end{array}$ & $\begin{array}{l}0.42 \\
0.42 \\
0.42\end{array}$ & $\begin{array}{l}0.38 \\
0.38 \\
0.38\end{array}$ \\
\hline 19 & $\begin{array}{r}300 \\
900 \\
2100\end{array}$ & $\begin{array}{l}0.88 \\
0.90 \\
0.91\end{array}$ & $\begin{array}{l}0.60 \\
0.67 \\
0.75\end{array}$ & $\begin{array}{l}0.19 \\
0.23 \\
0.28\end{array}$ & $\begin{array}{l}0.058 \\
0.060 \\
0.070\end{array}$ & $\begin{array}{l}0.029 \\
0.029 \\
0.029\end{array}$ & $\begin{array}{l}0.023 \\
0.023 \\
0.023\end{array}$ & $\begin{array}{l}0.15 \\
0.16 \\
0.17\end{array}$ & $\begin{array}{l}0.096 \\
0.096 \\
0.096\end{array}$ & $\begin{array}{l}0.078 \\
0.078 \\
0.078\end{array}$ & $\begin{array}{l}0.047 \\
0.047 \\
0.047\end{array}$ & $\begin{array}{l}0.29 \\
0.33 \\
0.37\end{array}$ & $\begin{array}{l}0.17 \\
0.18 \\
0.19\end{array}$ & $\begin{array}{l}0.14 \\
0.14 \\
0.15\end{array}$ & $\begin{array}{l}0.10 \\
0.10 \\
0.10\end{array}$ \\
\hline 20 & $\begin{array}{r}300 \\
900 \\
2100\end{array}$ & $\begin{array}{l}0.86 \\
0.87 \\
0.88\end{array}$ & $\begin{array}{l}0.66 \\
0.73 \\
0.82\end{array}$ & $\begin{array}{l}0.23 \\
0.28 \\
0.36\end{array}$ & $\begin{array}{l}0.065 \\
0.073 \\
0.080\end{array}$ & $\begin{array}{l}0.030 \\
0.030 \\
0.030\end{array}$ & $\begin{array}{l}0.023 \\
0.023 \\
0.023\end{array}$ & $\begin{array}{l}0.17 \\
0.20 \\
0.23\end{array}$ & $\begin{array}{l}0.11 \\
0.11 \\
0.11\end{array}$ & $\begin{array}{l}0.087 \\
0.087 \\
0.087\end{array}$ & $\begin{array}{l}0.075 \\
0.075 \\
0.075\end{array}$ & $\begin{array}{l}0.43 \\
0.47 \\
0.51\end{array}$ & $\begin{array}{l}0.31 \\
0.31 \\
0.32\end{array}$ & $\begin{array}{l}0.28 \\
0.28 \\
0.28\end{array}$ & $\begin{array}{l}0.24 \\
0.24 \\
0.24\end{array}$ \\
\hline 21 & $\begin{array}{r}300 \\
900 \\
2100\end{array}$ & $\begin{array}{l}1.00 \\
1.00 \\
1.00\end{array}$ & $\begin{array}{l}0.71 \\
0.78 \\
0.86 \\
\end{array}$ & $\begin{array}{l}0.27 \\
0.33 \\
0.40 \\
\end{array}$ & $\begin{array}{l}0.084 \\
0.089 \\
0.105\end{array}$ & $\begin{array}{l}0.041 \\
0.041 \\
0.041 \\
\end{array}$ & $\begin{array}{l}0.034 \\
0.034 \\
0.034\end{array}$ & $\begin{array}{l}0.16 \\
0.18 \\
0.21 \\
\end{array}$ & $\begin{array}{l}0.093 \\
0.094 \\
0.095\end{array}$ & $\begin{array}{l}0.072 \\
0.072 \\
0.072\end{array}$ & $\begin{array}{l}0.059 \\
0.059 \\
0.059\end{array}$ & $\begin{array}{l}0.64 \\
0.66 \\
0.69\end{array}$ & $\begin{array}{l}0.54 \\
0.55 \\
0.56\end{array}$ & $\begin{array}{l}0.52 \\
0.52 \\
0.52\end{array}$ & $\begin{array}{l}0.49 \\
0.49 \\
0.49 \\
\end{array}$ \\
\hline
\end{tabular}


To develop a set of data that could be used with good results in the analysis of thermal systems, J. R. Knight and G. E. Whitesides modified the resonance-self-shielded, group-averaged cross sections given by Hansen and Roach as a function of $\sigma_{\circ}$ (cf. Fig. M7.A.9). Given that uncertainties in the resonance parameters or improvements in the calculation of the resonance integrals would affect both the fission and capture cross sections in the same way, and the fact that the resulting changes in the calculated reactivity would tend to cancel, they decided not to modify the reported data for any of the fissile isotopes. This decision was also justified on the grounds that the Hansen-Roach data were known to give fairly good results whenever the background cross $\sigma_{o}^{i}$ was greater than several hundred barns. Obviously in a low-enriched system where $\mathrm{N}^{25} / \mathrm{N}^{\mathrm{U}}<3 \%$, the background cross section for the ${ }^{235} \mathrm{U}$ self-shielding calculation is quite large. That is,

$$
\sigma_{0}^{25} \equiv \frac{1}{N^{25}}\left(N^{25} \sigma_{p}^{25}+N^{28} \sigma_{p}^{28}+\ldots .\right)=(12)\left[1+\left(\frac{N^{28}}{N^{25}}\right)+\ldots\right]
$$

In a 3\% enriched system $\sigma_{0}^{25}$ will be $\geq 400$ barns, and the need for better self-shielding factors for $\sigma_{0}^{25} \leq$ 400 barns was viewed as academic. Consequently, they focused their attention solely on the resonance-self-shielded capture data for ${ }^{238} \mathrm{U}\left(\sigma_{\mathrm{c}}^{28,8}, \mathrm{~g}=8,9,10,11,12\right)$. Noting the good agreement between the Hansen-Roach data for ${ }^{238} \mathrm{U}$ (at $0 \mathrm{~K}$ ) and Dresner's data for ${ }^{238} \mathrm{U}$ (at $300 \mathrm{~K}$ ) whenever $\sigma_{0}^{28}$ was $\geq 200$ barns, and noting that calculated values of $k_{\infty}$ using the Hansen-Roach data were in good agreement with a number of critical experiments whenever $\sigma_{0}^{28}$ was $\geqslant 400$ barns, they then decided to modify the capture data only for those cases where the background cross section $\left(\sigma_{0}^{28}\right)$ was less than 400 barns.

To modify the Hansen-Roach data in a systematic way, Knight et al. relied on a series of experiments ${ }^{23,24}$ in which $k$-infinity $\left(k_{\infty}\right)$ was measured for several different fissile mixtures as a function of the $\mathrm{H} / \mathrm{U}$ ratio. The first set of experimental measurements involved relatively dry mixtures of $\mathrm{UO}_{3}$ and water having $\mathrm{H} / \mathrm{U}$ ratios between 3.7 and 7.5. The second set of measurements involved homogeneous mixtures of $\mathrm{UO}_{3}$ and paraffin having $\mathrm{H} / \mathrm{U}$ ratios between 3.6 and 30.2. The final set of measurements involved homogeneous mixtures of $\mathrm{UO}_{2}\left(\mathrm{NO}_{3}\right)_{2}$ and paraffin having $\mathrm{H} / \mathrm{U}$ ratios between 6.1 and 31.0. In the first set of experiments, the uranium was enriched to $\sim 1 \mathrm{wt} \%{ }^{235} \mathrm{U}$, while in the other two it was enriched to $\sim 3 \mathrm{wt} \%{ }^{235} \mathrm{U}$. Table M7.A.4 shows the explicit $\mathrm{H} / \mathrm{U}$ ratios that were present in each mixture and the corresponding value of the background cross section $\left(\sigma_{0}^{28}\right)$ that should be used to determine the resonance-self-shielded, group-averaged cross sections for the ${ }^{238} \mathrm{U}$ in each case. Attention was eventually focused on just a handful of these experiments $\left(\sigma_{o}^{28}=109 \mathrm{~b}, 157 \mathrm{~b}, 182 \mathrm{~b}, 216 \mathrm{~b}, 267 \mathrm{~b}, 321 \mathrm{~b}\right.$, and 366b). In each case, the Hansen-Roach capture data for ${ }^{238} U$ was numerically scaled up or down until the calculated value of $k_{\infty}$ agreed with the measured value of $k_{\infty}$. To be more precise, these adjusted data (commonly referred to as the Knight-Modified Hansen-Roach data) were defined by multiplying the original Hansen-Roach data by a fudge factor $\left[\mathrm{x}\left(\sigma_{\mathrm{o}}\right)\right]$ which was assumed to be the same for each energy group:

$$
\sigma_{\mathrm{KM}}^{28, g}\left(\sigma_{\mathrm{o}}\right)=x\left(\sigma_{\mathrm{o}}\right) \sigma_{\mathrm{RR}}^{28,8}\left(\sigma_{\mathrm{o}}\right) \quad \mathrm{g}=8,9,10,11,12
$$

The corresponding fudge factors $\left[\mathrm{x}\left(\sigma_{\mathrm{o}}\right), \sigma_{\mathrm{o}}=109 \mathrm{~b}, 157 \mathrm{~b}, 182 \mathrm{~b}, 216 \mathrm{~b}, 267 \mathrm{~b}, 321 \mathrm{~b}\right.$, and $\left.366 \mathrm{~b}\right]$ were then determined by trial and error for each of the seven different experiments, and plotted as a function of $\sigma_{\circ}$. Interestingly, simple extrapolation of $\mathrm{x}\left(\sigma_{\circ}\right)$ to $\sigma_{0}=45 \mathrm{~b}$ yielded a fudge factor very close to that required $(0.77)$ to bring the original Hansen-Roach data into agreement with that obtained using the Doppler-broadened resonance integrals computed by Dresner. That value $\left(0.77\right.$ at $\left.\sigma_{0}=45 \mathrm{~b}\right)$ was therefore taken as an additional anchor point. For values of $\sigma_{\circ} \geqslant 400 \mathrm{~b}, \mathrm{x}\left(\sigma_{\circ}\right)$ was assumed to be 1.0.

NUREG/CR-0200,

Vol. 3, Rev. 4 
Knowing $\mathrm{x}\left(\sigma_{\mathrm{o}}\right)$ as a function of $\sigma_{\circ}$, Knight et al. then made plots of the resonance self-shielded, group-averaged capture cross sections for ${ }^{238} \mathrm{U}$, similar to those shown in Fig. M7.A.9 $\left[\sigma_{c, k M}^{28,8}\left(\sigma_{0}\right), g=\right.$ $8,9,10,11,12]$. Based on that, they later prepared multigroup cross-section sets for many different values of $\sigma_{0}\left(\sigma_{o}=12 ; 15,20,25, \ldots 100 ; 110,120,130,140 ; 160,180, \ldots, 300 ; 330,360\right.$,etc). This Knight-Modified Hansen-Roach data were then released as part of the standard 16-group cross-section library packaged with the KENO IV Monte Carlo code ${ }^{16}$ for criticality analysis. Owing to the wide popularity of the code itself, the availability of the cross-section data and instructions for its use, and the good agreement that people subsequently obtained with still other experiments, ${ }^{2}$ the Knight-Modified Hansen-Roach data became even more popular and were subsequently adopted for use as one of the libraries in the SCALE system for Standardizyed Computer Analyses for Licensing Evaluation. At the time that it was adopted for use in the SCALE system, the infinitely dilute cross sections in each energy group were used to reduce the various background-dependent libraries to Bondarenko factors so that the appropriate resonance-self-shielded, group-averaged cross sections for a given mixture could be obtained automatically by application of the Iterative Bondarenko Method as embodied in the BONAMI code (cf. Sect. M7.A.8). Since that time, results using this library have been benchmarked against dozens of critical experiments, with excellent agreement in each case. ${ }^{25}$

Table M7.A.4 Values of the background cross section $\left(\sigma_{0}^{28}\right)$ for several different experiments in which $k_{\infty}$ of the homogeneous mixture was measured as a function of the $\mathrm{H} / \mathrm{U}$ ratio (shown here in parentheses)

\begin{tabular}{lll}
\hline $\mathrm{UO}_{3} / \mathrm{H}_{2} \mathrm{O}$ & $\mathrm{UO}_{3} / \mathrm{C}_{2} \mathrm{H}_{2}$ & $\mathrm{UO}_{2}\left(\mathrm{NO}_{3}\right)_{2} / \mathrm{C}_{2} \mathrm{H}_{2}$ \\
\hline $109(3.73)^{\mathrm{a}}$ & $110(3.58)$ & -- \\
$139(5.00)$ & -- & -- \\
$157(5.78)^{\mathrm{a}}$ & -- & -- \\
$166(6.16)$ & $165(5.86)$ & -- \\
-- & $177(6.38)$ & -- \\
$182(6.88)^{\mathrm{a}}$ & --- & -- \\
$196(7.50)$ & -- & -- \\
-- & -- & $210(6.10)$ \\
-- & $216(8.01)^{\mathrm{a}}$ & -- \\
-- & $230(8.60)$ & -- \\
-- & $267(10.12)^{\mathrm{a}}$ & -- \\
-- & -- & $275(8.81)$ \\
-- & $321(12.36)^{\mathrm{a}}$ & -- \\
-- & -- & $366(13.02)^{\mathrm{a}}$ \\
-- & $749(30.20)$ & --- \\
-- & -- & $808(31.00)$ \\
\hline
\end{tabular}

ased in generating the Knight-Modified Hansen Roach data. 


\section{M7.A13.2 Brief Description of the Experiments Upon Which the Knight Modifications Were Based}

The original experiments upon which the Knight modifications were based are well documented in refs. 23 and 24. All three sets of experiments described in the two reports were performed at the Physical Constants Testing Reactor in Hanford, Washington. Because the experimental results were reported in terms of $k_{\infty}$ (rather than $k_{\text {eff }}$ for a finite system), the corresponding 0-dimensional spectral calculations performed by Knight were straightforward and free of geometric approximation. To achieve such a measurement, a relatively large sample of the given material was placed in the central cavity of the test reactor. The PCTR was a graphite-moderated assembly driven by highly enriched fuel. It measured $7 \mathrm{ft} \times 7 \mathrm{ft} \times 7 \mathrm{ft}$ and had a central cavity measuring $2 \mathrm{ft} \times 2 \mathrm{ft} \times 3 \mathrm{ft}$. Near the center of the reactor the flux was spatially flat, as it would be in an infinite sample of the test material. The sample section(s) consisted of a central test sample surrounded by a relatively thick "buffer" region which was a layer of material identical to that used in the central test sample. The purpose of the buffer region was to provide a medium in which the neutron spectrum could come into equilibrium with the central test sample. By making the buffer region thick enough, the resulting spectrum in the central test sample would be essentially identical to that which would exist in an infinite system. Measurements of the (infinite) multiplication factor for the central test sample were then made by comparing the behavior of the reactor with the central test sample in place and with a void in the same region. [Since a neutron entering the central void must simply pass through it and come out again, the multiplication factor of the void $\left(k_{\infty}\right)$ is exactly 1.0.] The actual measurements were then made in the following fashion:

1. Adjust the reactor so that it is critical with the buffer and central test sample removed.

2. For a given test sample with a known $\mathrm{H} / \mathrm{U}$ ratio, calculate the amount of poison that is required to yield $\mathbf{k}_{\infty}^{\mathrm{P}}=1.0$ [where $\mathbf{k}_{\infty}^{\mathrm{P}}$ denotes the infinite multiplication factor for the poisoned system (central test sample and buffer)]. Note that a nonfissile $1 / \mathrm{v}$ thermal absorber was used for this purpose.

3. Insert the buffer only, and make minor adjustments in the reactor so that it is again critical with only the buffer in place.

4. Insert control rods to shut down the reactor, and insert the central test sample.

5. Make the reactor slightly supercritical to build up the observable flux, then slowly return the control rods to position (3) and measure the resulting period.

6. If the resulting period is not infinite (i.e., if the reactor is not critical), remove the buffer region and the central test sample, and adjust the amount of poison in both (up or down) as required.

7. Repeat steps $3,4,5$, and 6 until the multiplication factor for the poisoned test sample $\left(\mathbf{k}_{\infty}^{P}\right)$ is 1.0.

8. Knowing the amount of poison required to make $\mathbf{k}_{\infty}^{\mathbf{P}}=1.0$, calculate $\mathrm{k}_{\infty}$ for the unpoisoned sample and report these values.

Because of the difficulty associated with making ultra-fine adjustments in the poison content of the test material, the amount of poison required to make $\mathbf{k}_{\infty}^{\mathrm{P}}$ exactly 1.0 (cf. steps 7 and 8) was ultimately interpolated using results for poisoned test samples having very long positive and negative periods. Details of the calculations required in step 8 are well documented in refs. 23 and 24.

NUREG/CR-0200, Vol. 3, Rev. 4 
Throughout the experiments, bare and cadmium-covered gold foils were placed at various positions in the buffer and the central test sample so as to verify that (a) the flux was spatially flat across the entire region and that (b) the flux spectrum had indeed reached the equilibrium state (corresponding to an infinite system) in the vicinity of the central test sample.

Because these experiments were performed at room temperature $(293 \mathrm{~K})$, and because the Knight-Modified data for ${ }^{238} \mathrm{U}$ was based on these experiments, the 16-group Knight-Modified Hansen-Roach library now found in the SCALE system should (and does) give good results for other critical experiments at room temperatures despite the fact that much of the data for the other resonance nuclides is the original (unbroadened) Hansen-Roach data at $0 \mathrm{~K}$ 


\section{M7.B ALPHABETICAL SUBROUTINE INDEX AND CROSS REFERENCE}

This section provides a convenient alphabetical index of the subroutines and functions and common blocks used in the Material Information Processor.

Table M7.B.1 provides an alphabetical listing of the subroutines and functions that comprise the Material Information Processor. The first column lists the subroutine name, the second column lists the subroutine that calls it, and the third column contains a list of the subroutines it calls.

Table M7.B.2 provides an alphabetical index of the common blocks used in the Material Information Processor.

Table M7.B.1 Alphabetical index of Material Information Processor routines

\begin{tabular}{|c|c|c|}
\hline $\begin{array}{l}\text { SUBROUTINE } \\
\text { CALLED }\end{array}$ & $\begin{array}{l}\text { CALLING } \\
\text { SUBROUTINE }\end{array}$ & $\begin{array}{l}\text { CALLED } \\
\text { SUBROUTINE }\end{array}$ \\
\hline (ACOS) & $\begin{array}{l}\text { ADAN } \\
\text { DAN } \\
\text { FINNER } \\
\text { GDAN } \\
\text { OUTER } \\
\text { SPHDAN }\end{array}$ & \\
\hline$\overline{\mathrm{A}} \overline{\mathrm{D}} \overline{\mathrm{A}} \overline{\mathrm{N}}^{---}$ & $\overline{\mathrm{D}} \overline{\mathrm{AN}}$ & $\begin{array}{l}(\overline{A C O S}) \\
\text { (ASIN) } \\
\text { (COS) } \\
\text { (SIN) } \\
\text { (SQRT) } \\
\text { GAUSS } \\
\text { GDAN }\end{array}$ \\
\hline
\end{tabular}

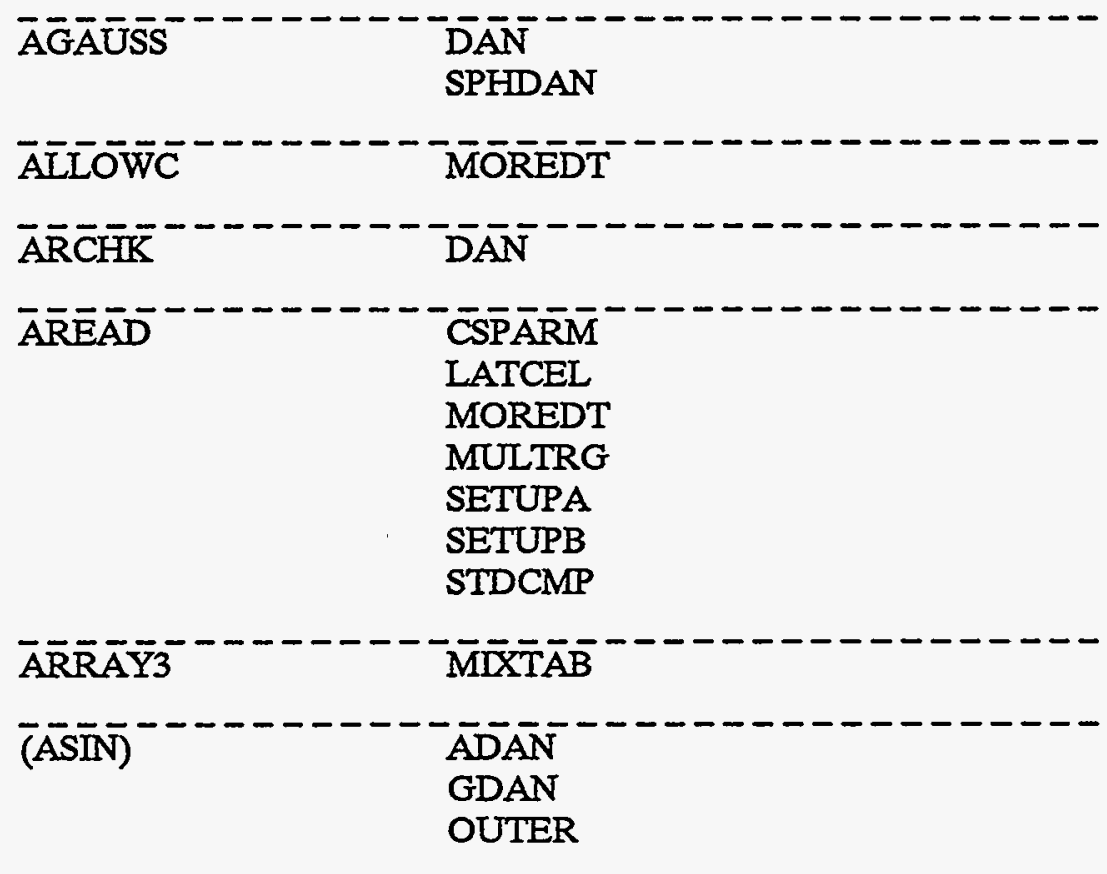


Table M7.B.1 (continued)

\begin{tabular}{|c|c|c|}
\hline $\begin{array}{l}\text { SUBROUTINE } \\
\text { CALLED }\end{array}$ & $\begin{array}{l}\text { CALLING } \\
\text { SUBROUTINE }\end{array}$ & $\begin{array}{l}\text { CALLED } \\
\text { SUBROUTINE }\end{array}$ \\
\hline$\overline{A V G B}$ & BOND & \\
\hline$\overline{\mathrm{A}} \overline{\mathrm{V}} \overline{\mathrm{G}} \overline{\mathrm{Y}}-\cdots---$ & $\overline{T W} \overline{\text { TOYS }}$ & $\begin{array}{l}\bar{M} \bar{G} \bar{C} \bar{W} \bar{R} \bar{D}^{---} \\
\text {STOP }\end{array}$ \\
\hline $\bar{A} \bar{V} \bar{G} \overline{1}$ & $\overline{C L A} \bar{P} \overline{S E}--$ & --------- \\
\hline $\bar{A} \bar{V} \bar{G} \overline{2}-\cdots---$ & $\overline{T W} \overline{O D X S}--$ & $\bar{M} \overline{\mathrm{G}} \overline{\mathrm{C}} \overline{\mathrm{W}} \overline{\mathrm{R}} \overline{\mathrm{D}} \overline{\mathrm{N}}^{---}$ \\
\hline$\overline{\mathrm{A}} \overline{\mathrm{X}} \overline{\mathrm{S}} \overline{\mathrm{DRN}}-\overline{-}$ & $\overline{\mathrm{C}} \overline{\mathrm{D}} \overline{\mathrm{A}} \overline{\mathrm{T}} \overline{\mathrm{A}}$ & --------- \\
\hline$\overline{\mathrm{B}} \overline{\mathrm{A}} \overline{\mathrm{L}} \overline{\mathrm{L}}-\cdots---$ & $\overrightarrow{D A N D A D}$ & $\begin{array}{l}\overline{(\mathrm{S}} \overline{\mathrm{Q}} \overline{\mathrm{R}} \overline{\mathrm{T}}) \\
\text { SPHDAN }\end{array}$ \\
\hline$\overline{\mathrm{B}} \overline{\mathrm{IN}} \overline{\mathrm{FIL}}$ & $\begin{array}{l}\text { ICE } \\
\text { XSDRN }\end{array}$ & \\
\hline$\overline{\mathrm{B}} \overline{\mathrm{INR}} \overline{\mathrm{C}} \overline{\mathrm{C}}^{-\cdots-}$ & $\begin{array}{l}\text { BONĀĀI } \\
\text { ICE } \\
\text { NITAWL } \\
\text { XSDRN }\end{array}$ & \\
\hline$\overline{\mathrm{B}} \overline{\mathrm{INR}} \overline{\mathrm{C}} \overline{\mathrm{X}}$ & $\begin{array}{l}\text { BONĀMI } \\
\text { ICE } \\
\text { NITAWL } \\
\text { XSDRN }\end{array}$ & \\
\hline$\overline{\mathrm{B}} \overline{\mathrm{O}} \overline{\mathrm{N}} \overline{\mathrm{A}} \overline{\mathrm{MI}}$ & $\bar{C} \overline{\mathrm{D}} \overline{\mathrm{A}} \overline{\mathrm{T}} \overline{\mathrm{A}}$ & $\begin{array}{l}\text { BINR } \overline{C F}--\cdots \\
\text { BINRCX } \\
\text { LCHKMX }\end{array}$ \\
\hline$\overline{\mathrm{BO}} \overline{\mathrm{N}} \overline{\mathrm{D}}^{----}$ & $\overline{C L A} \bar{P} \overline{P S E}$ & $\begin{array}{l}\bar{A} \bar{V} \overline{G B} \\
\text { FOLD } \\
\text { IO } \\
\text { UNFOLD }\end{array}$ \\
\hline$\overline{\mathrm{B}} \overline{\mathrm{O}} \overline{\mathrm{N}} \overline{\mathrm{D}} \overline{\mathrm{A}}$ & $\overline{\operatorname{RES}} \overline{\mathrm{D}} \overline{\mathrm{A}}$ & $(\mathrm{S} \overline{\mathrm{Q}} \overline{\mathrm{R}} \overline{\mathrm{T}})$ \\
\hline$\overline{\mathrm{CA}} \overline{\mathrm{L}} \overline{\mathrm{CM}} \overline{\mathrm{MS}}$ & $\overline{\mathrm{C} A \overline{\mathrm{D}} \overline{\mathrm{A}} \overline{\mathrm{T}} \overline{\mathrm{A}}}$ & ICHKM $\bar{M} \bar{X}$ \\
\hline$\overline{\mathrm{C}} \overline{\mathrm{E}} \overline{\mathrm{L}} \bar{L} \overline{\mathrm{M}} \overline{\mathrm{X}}$ & $\overline{\mathrm{C}} \overline{\mathrm{D}} \overline{\mathrm{D}} \overline{\mathrm{A}} \overline{\mathrm{T}} \overline{\mathrm{A}}---$ & $\overline{\mathrm{L}} \overline{\mathrm{CH}} \overline{\mathrm{K}} \overline{\mathrm{M}} \overline{\mathrm{M}} \overline{\mathrm{X}}^{-\cdots}$ \\
\hline$\overline{\mathrm{C}} \overline{\mathrm{IN}} \overline{\mathrm{I}} \overline{\mathrm{T}}-\cdots \cdot-\cdot$ & $\overline{\mathrm{C}} \overline{\mathrm{D}} \overline{\mathrm{DA}} \overline{\mathrm{T}} \overline{\mathrm{A}}$ & $\begin{array}{l}\text { CLEAR } \\
\text { INQUIR } \\
\text { OPENDA } \\
\text { RITE }\end{array}$ \\
\hline
\end{tabular}

NUREG/CR-0200,

Vol. 3, Rev. 4

M7.B.2 
Table M7.B.1 (continued)

\begin{tabular}{|c|c|c|}
\hline $\begin{array}{l}\text { SUBROUTINE } \\
\text { CAILED }\end{array}$ & $\begin{array}{l}\text { CALLING } \\
\text { SUBROUTINE }\end{array}$ & $\begin{array}{l}\text { CALLED } \\
\text { SUBROUTINE }\end{array}$ \\
\hline CLAPSE & C4DATA & $\begin{array}{l}\text { AVG1 } \\
\text { BOND } \\
\text { CLEAR } \\
\text { COPY } \\
\text { DEAN } \\
\text { IO } \\
\text { IO4 } \\
\text { STOP } \\
\text { TWODXS } \\
\text { TWODYS }\end{array}$ \\
\hline$\overline{\mathrm{C}} \overline{\mathrm{EAR}}$ & $\begin{array}{l}\text { CINIT } \\
\text { CLAPSE } \\
\text { CADATA } \\
\text { NITAWL } \\
\text { RESDA } \\
\text { SETUPB } \\
\text { TWODXS } \\
\text { TWODYS } \\
\text { XSDRN }\end{array}$ & -------- \\
\hline$\overline{C L O S D A}$ & $\begin{array}{l}\text { KNIIGHT } \\
\text { SHORTX }\end{array}$ & $---\cdots---1$ \\
\hline $\bar{C} \overline{O P Y} \bar{Y}^{-----}$ & $\begin{array}{l}\overline{C L A} \bar{P} \overline{S E}--- \\
\text { SHORTX } \\
\text { TWODXS } \\
\text { TWODYS }\end{array}$ & --------- \\
\hline$\overline{(\operatorname{COS})}-----$ & $\begin{array}{l}\text { ADAN } \\
\text { DAN } \\
\text { FINNER } \\
\text { GDAN } \\
\text { OUTER }\end{array}$ & \\
\hline$\overline{\mathrm{CSPA}} \overline{\mathrm{R}} \overline{\mathrm{M}}$ & $\overline{S E T U} \overline{P A}$ & $\begin{array}{l}\text { AREAD } \\
\text { LCOMPR } \\
\text { SMMTBA }\end{array}$ \\
\hline$\overline{\mathrm{C}} \overline{\mathrm{DAT}} \overline{\mathrm{TA}}$ & & $\begin{array}{l}\bar{A} \bar{X} \overline{S D} \bar{R} \bar{N} \\
\text { BONAMI } \\
\text { CALCMS } \\
\text { CELIMX } \\
\text { CINIT } \\
\text { CLAPSE } \\
\text { CLEAR } \\
\text { EPSIG }\end{array}$ \\
\hline
\end{tabular}

NUREG/CR-0200, 
Table M7.B.1 (continued)

\begin{tabular}{|c|c|c|}
\hline $\begin{array}{l}\text { SUBROUTINE } \\
\text { CALLED }\end{array}$ & $\begin{array}{l}\text { CALLING } \\
\text { SUBROUTINE }\end{array}$ & $\begin{array}{l}\text { CALLED } \\
\text { SUBROUTTNE }\end{array}$ \\
\hline C4DATA (continued) & & $\begin{array}{l}\text { ICE } \\
\text { KNIGHT } \\
\text { MIPCHK } \\
\text { NITAWL } \\
\text { PRELPS } \\
\text { SHORTX } \\
\text { SMMTBA } \\
\text { STOP } \\
\text { VERIFY } \\
\text { XSDRN } \\
\text { XSMESH }\end{array}$ \\
\hline$\overline{\mathrm{D} A} \overline{\mathrm{N}}^{-\cdots \cdots-\cdots}$ & $\overline{D A} \overline{N D} \overline{D A}$ & $\begin{array}{l}\bar{D} \overline{A N D A D} \\
\text { ADAN } \\
(A C O S) \\
(C O S) \\
\text { (SQRT) } \\
\text { AGAUSS } \\
\text { ARCHK } \\
\text { ERRSET }\end{array}$ \\
\hline$\overline{\mathrm{D} A} \overline{\mathrm{N}} \overline{\mathrm{C}} \overline{\mathrm{O} F} \overline{\mathrm{F}}$ & $\overline{\operatorname{RES}} \overline{\mathrm{A}} \overline{-}$ & $\begin{array}{l}\text { (EXP) } \\
\text { AFBSSQRT } \\
\text { DANDAD } \\
\text { E3 } \\
\text { SHELC } \\
\text { STOP }\end{array}$ \\
\hline$\overline{\mathrm{D}} \overline{\mathrm{A}} \overline{\mathrm{N}} \overline{\mathrm{D}} \overline{\mathrm{A}} \overline{\mathrm{D}}$ & $\overline{D A N C O F}$ & $\begin{array}{l}(\overline{E X} \bar{P}) \\
\text { BALI } \\
\text { DAN } \\
\text { SDAN }\end{array}$ \\
\hline$\overline{\mathrm{D}} \overline{\mathrm{E}} \overline{\mathrm{A}} \overline{\mathrm{N}}$ & $\overline{C L A} \overline{\mathrm{P}} \overline{\mathrm{S}} \overline{\mathrm{C}}-\overline{-}$ & $\overline{\mathrm{K}} \overline{\mathrm{A}} \bar{U}^{--\cdots--}$ \\
\hline$\overline{\mathrm{D}} \overline{\mathrm{T}} \overline{\mathrm{A}} \overline{\mathrm{SET}} \overline{\mathrm{T}}^{-\cdots-\cdots}$ & $\overline{\mathrm{SHOR}} \overline{\mathrm{R}} \overline{\mathrm{X}}^{---}$ & ------- \\
\hline$\overline{\mathrm{E}} \overline{\mathrm{PSI}} \overline{\mathrm{G}}-\cdots-\cdots-\cdot$ & $\overline{\mathrm{C}} \overline{\mathrm{D}} \overline{\mathrm{D}} \overline{\mathrm{A}} \overline{\mathrm{T}} \overline{\mathrm{A}}^{---}$ & $-\overline{(\mathrm{SQ}} \overline{\mathrm{R}} \overline{\mathrm{T}})$ \\
\hline$\overline{\mathrm{E}} \overline{\mathrm{R}} \overline{\mathrm{R}} \overline{\mathrm{SET}} \overline{\mathrm{T}}^{-\cdots \cdots}$ & $\overline{\mathrm{DAN}}-\cdots--$ & ------- \\
\hline$(\overrightarrow{\mathrm{EXP}})$ & $\begin{array}{l}\text { DANCOF } \\
\text { DANDAD } \\
\text { FINNER } \\
\text { NFLUX }\end{array}$ & \\
\hline
\end{tabular}

NUREG/CR-0200,

Vol. 3, Rev. 4

M7.B.4 
Table M7.B.1 (continued)

\begin{tabular}{|c|c|c|}
\hline $\begin{array}{l}\text { SUBROUTINE } \\
\text { CALLED }\end{array}$ & $\begin{array}{l}\text { CALIING } \\
\text { SUBROUTINE }\end{array}$ & $\begin{array}{l}\text { CALLED } \\
\text { SUBROUTINE }\end{array}$ \\
\hline $\mathrm{E} 3$ & $\begin{array}{l}\text { DANCOF } \\
\text { SDAN }\end{array}$ & \\
\hline$\overline{\mathrm{F}} \overline{\mathrm{A}} \overline{\mathrm{X}}-\cdots---$ & $\overline{\mathrm{STD}} \overline{\mathrm{CM}} \overline{\mathrm{P}}-\overline{-}$ & $\begin{array}{l}\text { FREAD } \\
\text { IREAD }\end{array}$ \\
\hline$\overline{\mathrm{F}} \overline{\mathrm{A}} \overline{\mathrm{X} P \mathrm{R} T}$ & $\overline{S T D} \bar{C} \bar{M} \bar{P}$ & -------- \\
\hline$\overline{\mathrm{F}} \overline{\mathrm{INN}} \overline{\mathrm{E}} \overline{\mathrm{R}}$ & $\overline{\text { OUTER }}$ & $\begin{array}{l}(\overline{A C O S}) \\
(\mathrm{COS}) \\
(\mathrm{EXP}) \\
(\mathrm{SIN}) \\
(\mathrm{SQRT})\end{array}$ \\
\hline$\overline{\mathrm{F}} \overline{\mathrm{X}} \overline{\mathrm{X}}^{------}$ & $\overline{\mathrm{STD}} \overline{\mathrm{C}} \overline{\mathrm{M}} \overline{\mathrm{P}}^{--}$ & ---------- \\
\hline $\overrightarrow{\mathrm{FO}} \overline{\mathrm{L} D}$ & $\overline{\mathrm{BOND}}-\cdots$ & - - - - - - - \\
\hline$\overline{\mathrm{F}} \overline{\mathrm{O}} \overline{\mathrm{X}}^{------}$ & $\overline{\mathrm{STD}} \overline{\mathrm{C}} \overline{\mathrm{M}} \overline{\mathrm{P}}^{--}$ & ------- \\
\hline$\overline{\mathrm{F}} \overline{\mathrm{R}} \overline{\mathrm{AD}}-\overline{-}$ & $\begin{array}{l}\text { FAX } \\
\text { LATCEL } \\
\text { MOREDT } \\
\text { MULTRG } \\
\text { SETUPA } \\
\text { STDCMP }\end{array}$ & \\
\hline$\overline{\mathrm{GA}} \overline{\mathrm{U}} \overline{\mathrm{SS}} \overline{\mathrm{S}}^{-}----$ & $\begin{array}{l}\text { ADAN } \\
\text { OUTER }\end{array}$ & \\
\hline$\overline{\mathrm{G}} \overline{\mathrm{DA}} \overline{\mathrm{N}} \overline{\mathrm{N}}-\cdots---$ & $\overline{\mathrm{ADAN}}$ & $\begin{array}{l}(\overline{A C O} \bar{S}) \\
\text { (ASIN) } \\
\text { (COS) } \\
\text { (SIN) } \\
\text { (SQRT) } \\
\text { KI3 }\end{array}$ \\
\hline \multicolumn{3}{|c|}{ 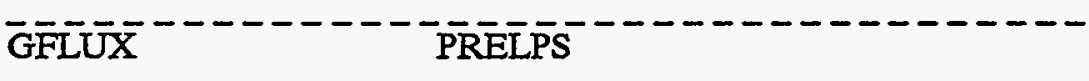 } \\
\hline$\overline{\mathrm{H}} \overline{\mathrm{OG}} \overline{\mathrm{GIE}}$ & $\overline{T W} \overline{O D Y S}$ & $\overline{\mathrm{STOP}}$ \\
\hline$\overline{\mathrm{I} C E}-----$ & $\overline{\mathrm{C}} \overline{\mathrm{D}} \overline{\mathrm{D}} \overline{\mathrm{A}} \overline{\mathrm{T}} \overline{\mathrm{A}}$ & $\begin{array}{l}\text { BINFIL } \\
\text { BINRCF } \\
\text { BINRCX } \\
\text { VOLFRC }\end{array}$ \\
\hline
\end{tabular}


Table M7.B.1 (continued)

\begin{tabular}{|c|c|c|}
\hline $\begin{array}{l}\text { SUBROUTINE } \\
\text { CAILED }\end{array}$ & $\begin{array}{l}\text { CALLING } \\
\text { SUBROUTINE }\end{array}$ & $\begin{array}{l}\text { CALLED } \\
\text { SUBROUTINE }\end{array}$ \\
\hline IDENTS & MTABLE & $\begin{array}{l}\text { ISCAN } \\
\text { NOFRAC }\end{array}$ \\
\hline$\overline{\mathrm{IN}} \overline{\mathrm{Q}} \overline{\mathrm{U}} \overline{\mathrm{U}} \overline{\mathrm{R}}$ & $\overline{\mathrm{CINIT}}$ & $-\cdots-\cdots-\cdots$ \\
\hline$\overline{\mathrm{IO}}^{-\cdots-\cdots-}$ & $\begin{array}{l}\text { BOND } \\
\text { CLAPSE } \\
\text { TWODXS } \\
\text { TWODYS }\end{array}$ & \\
\hline$\overline{\mathrm{I} O W} \overline{\mathrm{W}} \overline{\mathrm{T}}$ & $\overline{\mathrm{SHOR}} \overline{\mathrm{TX}}$ & ----- \\
\hline$\overline{104}$ & $\begin{array}{l}\text { CLAPSE } \\
\text { TWODXS } \\
\text { TWODYS }\end{array}$ & \\
\hline$\overline{\mathrm{IREA}} \overline{\bar{D}}----$ & $\begin{array}{l}\text { FAX } \\
\text { LATCEL } \\
\text { MOREDT } \\
\text { MULTRG } \\
\text { SETUPA } \\
\text { SETUPB } \\
\text { STDCMP } \\
\text { XSMESH }\end{array}$ & \\
\hline$\overline{\mathrm{ISCA}} \overline{\mathrm{N}} \overline{\mathrm{N}}$ & $\begin{array}{l}\text { IDENTSS } \\
\text { NITAWL } \\
\text { REORDR } \\
\text { SLNS } \\
\text { STDCMP }\end{array}$ & - - - - - - \\
\hline$\overline{\mathrm{K}} \overline{\mathrm{A}} \overline{\mathrm{U}} \overline{\mathrm{L}}^{--\cdots}$ & $\overline{\mathrm{DEA}} \overline{\mathrm{N}}-\cdots$ & $-\cdots-\cdots$ \\
\hline$\overline{\mathrm{K}} \overline{\mathrm{I}} \mathrm{3}-\cdots-\cdots$ & $\overline{G D A N}$ & ---- \\
\hline$\overline{\mathrm{K}} \overline{\mathrm{NIGH}} \overline{\mathrm{HT}}$ & $\overline{\mathrm{C} A \mathrm{D}} \overline{\mathrm{A}} \overline{\mathrm{T}} \overline{\mathrm{A}}$ & $\begin{array}{l}\text { CLOSDA } \\
\text { MESAGE } \\
\text { OPENDA } \\
\text { REED } \\
\text { SETUPA } \\
\text { STOP }\end{array}$ \\
\hline$\overline{\mathrm{L}} \overline{\mathrm{ATC}} \overline{\mathrm{CEL}}-$ & $\overline{\mathrm{SETUPB}}$ & $\begin{array}{l}\text { AREAD } \\
\text { FREAD } \\
\text { IREAD } \\
\text { LCOMPR } \\
\text { MIXERR }\end{array}$ \\
\hline
\end{tabular}

NUREG/CR-0200,

Vol. 3, Rev. 4

M7.B.6 
Table M7.B.1 (continued)

\begin{tabular}{|c|c|c|}
\hline $\begin{array}{l}\text { SUBROUTINE } \\
\text { CALLED }\end{array}$ & $\begin{array}{l}\text { CALLING } \\
\text { SUBROUTINE }\end{array}$ & $\begin{array}{l}\text { CALLED } \\
\text { SUBROUTINE }\end{array}$ \\
\hline LATCEL (continued) & & $\begin{array}{l}\text { SCANOF } \\
\text { SCANON }\end{array}$ \\
\hline$\overline{\mathrm{L}} \overline{\mathrm{C}} \overline{\mathrm{H} K \overline{\mathrm{M}} \overline{\mathrm{X}} \overline{\mathrm{X}}}$ & $\begin{array}{l}\overline{B O} \overline{N A} \bar{M}-- \\
\text { CALCMS } \\
\text { CELLMX } \\
\text { XSDRN }\end{array}$ & \\
\hline$\overline{\mathrm{L}} \overline{\mathrm{C}} \overline{\mathrm{O}} \overline{\mathrm{M}} \overline{\mathrm{PR}}$ & 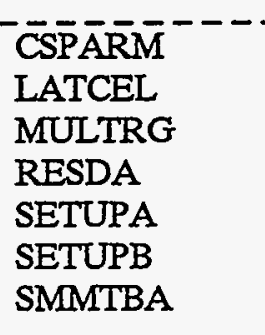 & -------1 \\
\hline$\overline{\mathrm{L}} \overline{\mathrm{O}} \overline{\mathrm{G}} \overline{\mathrm{ID}}$ & $\overline{\mathrm{SHOR}} \overline{\mathrm{T}} \overline{\mathrm{X}}^{--}$ & -------- \\
\hline$\overline{\mathrm{L}} \overline{\mathrm{R}} \overline{\mathrm{A} A \mathrm{D}} \overline{-}$ & $\begin{array}{l}\text { MUUTREG } \\
\text { SETUPA } \\
\text { STDCMP }\end{array}$ & \\
\hline$\overline{\mathrm{M}} \overline{\mathrm{E}} \overline{\mathrm{S}} \overline{\mathrm{A}} \overline{\mathrm{GE}} \overline{\mathrm{E}}$ & $\overline{\mathrm{K}} \overline{\mathrm{I}} \overline{\mathrm{G}} \overline{\mathrm{H}} \overline{\mathrm{T}}$ & -------- \\
\hline $\bar{M} \overline{\mathrm{G} C} \overline{\mathrm{WR}} \overline{\mathrm{D}} \overline{-\cdots}$ & $\begin{array}{l}\overline{A V G Y}-\overline{-} \\
A V G 2\end{array}$ & \\
\hline$\overline{\mathrm{MI}} \overline{\mathrm{PCHK}}$ & $\begin{array}{l}\overline{C A} \overline{\mathrm{D}} \overline{\mathrm{AT}} \overline{\mathrm{T}} \\
\text { WOT8 }\end{array}$ & \\
\hline $\bar{M} \overline{\mathrm{X} E R R}$ & $\begin{array}{l}\text { LATCEL } \\
\text { MOREDT } \\
\text { MULTRG }\end{array}$ & \\
\hline$\overline{\mathrm{M}} \overline{\mathrm{XT}} \overline{\mathrm{TA}} \overline{\mathrm{B}}-\cdots$ & SETUPB & $\begin{array}{l}\bar{A} \bar{R} \overline{R A Y 3}--- \\
\text { MODIFY } \\
\text { MTABLE } \\
\text { REORDR } \\
\text { STOP }\end{array}$ \\
\hline
\end{tabular}

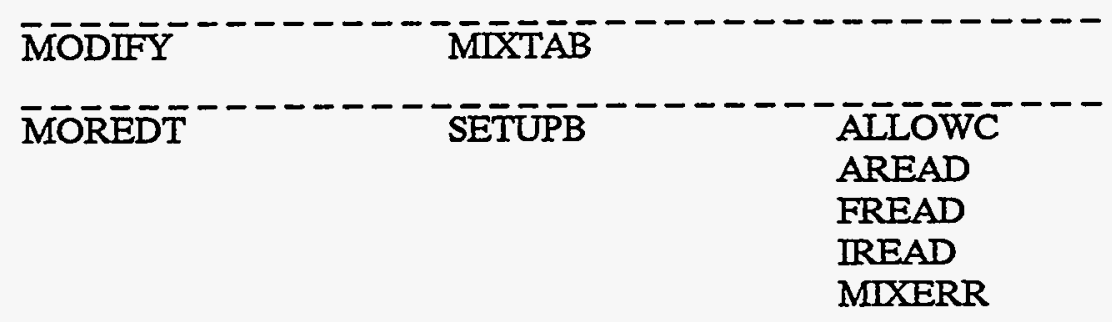


Table M7.B.1 (continued)

\begin{tabular}{|c|c|c|}
\hline $\begin{array}{l}\text { SUBROUTTNE } \\
\text { CALLED }\end{array}$ & $\begin{array}{l}\text { CALLING } \\
\text { SUBROUTINE }\end{array}$ & $\begin{array}{l}\text { CALLED } \\
\text { SUBROUTINE }\end{array}$ \\
\hline MOREDT (continued) & & $\begin{array}{l}\text { RESETC } \\
\text { SCANOF } \\
\text { SCANON }\end{array}$ \\
\hline \multicolumn{3}{|c|}{ 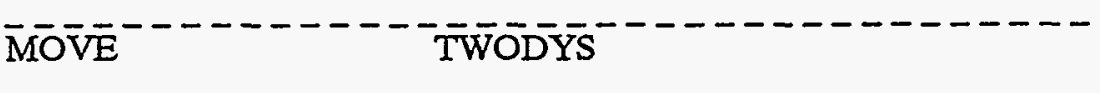 } \\
\hline$\overline{\mathrm{MT}} \overline{\mathrm{A}} \overline{\mathrm{B}} \overline{\mathrm{LE}}$ & $\begin{array}{l}\bar{M} \bar{X} \bar{T} \bar{A} \bar{B} \\
\text { IDENTS } \\
\text { STOP }\end{array}$ & \\
\hline$\overline{M U U L T R G}$ & SETUTB & $\begin{array}{l}\text { AREAD } \\
\text { FREAD } \\
\text { IREAD } \\
\text { LCOMPR } \\
\text { LREAD } \\
\text { MIXERR } \\
\text { SCANOF } \\
\text { SCANON }\end{array}$ \\
\hline $\bar{N} \bar{F} \bar{L} \overline{U X} \bar{X}^{-\cdots-\cdots-\cdots}$ & PRELPS & $\begin{array}{l}(\mathrm{EXX}) \\
(\mathrm{SQRT})\end{array}$ \\
\hline$\overline{\mathrm{NITA}} \overline{\mathrm{W}} \overline{\mathrm{L}}^{--\cdots-\cdots}$ & $\overline{\mathrm{C}} \overline{\mathrm{D}} \overline{\mathrm{D}} \overline{\mathrm{A}} \overline{\mathrm{T}} \overline{\mathrm{A}}-\overline{-}$ & $\begin{array}{l}\text { BINR } \bar{C} \bar{F} \\
\text { BINRCX } \\
\text { CLEAR } \\
\text { ISCAN }\end{array}$ \\
\hline $\bar{N} \bar{O} \overline{F R} \overline{A C}$ & $\overline{I D} \bar{E} \bar{N} \overline{T S}---$ & $\overline{\text { WTINVV }}$ \\
\hline$\overline{\mathrm{O}} \overline{\mathrm{P}} \overline{\mathrm{ENDA}} \overline{\mathrm{ND}}$ & $\begin{array}{l}\text { CINIT } \\
\text { KNIGHT } \\
\text { SHORTX }\end{array}$ & \\
\hline$\overline{\mathrm{O}} \overline{\mathrm{PN}} \overline{\mathrm{N}} \overline{\mathrm{II}}-\cdots---$ & $\overline{\mathrm{SHORTX}}$ & \\
\hline ÖUTER- & $\overline{S P} \bar{H} \bar{D} \bar{A} \bar{N}--$ & $\begin{array}{l}(\mathrm{ACOS}) \\
(\mathrm{ASIN}) \\
(\mathrm{COS}) \\
(\mathrm{SIN}) \\
(\mathrm{SQRT}) \\
\text { FINNER } \\
\text { GAUSS }\end{array}$ \\
\hline$\overline{\mathrm{PATCH}}$ & $\begin{array}{l}\text { TWODXS } \\
\text { TWODYS }\end{array}$ & \\
\hline
\end{tabular}

NUREG/CR-0200,

Vol. 3, Rev. 4

M7.B.8 
Table M7.B.1 (continued)

\begin{tabular}{|c|c|c|}
\hline $\begin{array}{l}\text { SUBROUTINE } \\
\text { CAILED }\end{array}$ & $\begin{array}{l}\text { CALLING } \\
\text { SUBROUTINE }\end{array}$ & $\begin{array}{l}\text { CALLED } \\
\text { SUBROUTINE }\end{array}$ \\
\hline POKE & SETUPB & (SQRT) \\
\hline$\overline{\mathrm{P}} \overline{\mathrm{REL}} \overline{\mathrm{P}} \overline{\mathrm{S}}$ & $\overline{\mathrm{C}} \overline{\mathrm{D}} \overline{\mathrm{A}} \overline{\mathrm{T}} \overline{\mathrm{A}}^{--}$ & $\begin{array}{l}\overline{G F L U X}- \\
\text { NFLUX }\end{array}$ \\
\hline $\bar{R} \bar{E} \bar{E} \bar{D}^{--\cdots--~}$ & $\begin{array}{l}\overline{K N} \overline{N I G \overline{H T}}--- \\
\text { SHORTX } \\
\text { STDCMP }\end{array}$ & -------- \\
\hline$\overline{\mathrm{R}} \overline{\mathrm{E}} \overline{\mathrm{O}} \overline{\mathrm{R}} \overline{\mathrm{DR}} \overline{\mathrm{R}}$ & $\overline{\mathrm{M}} \overline{\mathrm{X}} \overline{\mathrm{X}} \overline{\mathrm{A}} \overline{\mathrm{A}} \overline{\mathrm{B}}^{---}$ & $\overline{\mathrm{ISC}} \overline{\mathrm{C}} \overline{\mathrm{AN}} \overline{\mathrm{N}}----$ \\
\hline$\overline{\mathrm{R}} \overline{\mathrm{ESDA}}-\overline{\mathrm{A}}^{---}$ & SETUPB & $\begin{array}{l}\text { BONDA } \\
\text { CLEAR } \\
\text { DANCOF } \\
\text { LCOMPR }\end{array}$ \\
\hline$\overline{\mathrm{R}} \overline{\mathrm{SSETC}}-\overline{-}$ & $\overline{M O} \overline{\mathrm{REDT}}$ & -------- \\
\hline$\overline{\mathrm{R}} \overline{\mathrm{ITE}}^{------}$ & $\overline{\mathrm{CIN}} \overline{\mathrm{IT}}$ & --------- \\
\hline$\overline{\mathrm{S}} \overline{\mathrm{CANOF}}$ & $\begin{array}{l}\text { LATCEEL } \\
\text { MOREDT } \\
\text { MULTRG } \\
\text { STDCMP }\end{array}$ & \\
\hline $\bar{S} \overline{C A N O} \bar{N}--$ & $\begin{array}{l}\text { LATCEE } \\
\text { MOREDT } \\
\text { MULTRG } \\
\text { SETUPA }\end{array}$ & \\
\hline $\bar{S} \overline{D A N}----$ & $\overline{D A} \overline{N D A D}$ & $\overline{\mathrm{E} 3}$ \\
\hline$\overline{S E T U} \overline{P A}--$ & $\overline{\mathrm{K}} \overline{\mathrm{NI}} \overline{\mathrm{G}} \overline{\mathrm{HT}}$ & $\begin{array}{l}\text { A } \overline{R E A D} \\
\text { CSPARM } \\
\text { FREAD } \\
\text { IREAD } \\
\text { LCOMPR } \\
\text { LREAD } \\
\text { SCANON } \\
\text { SETUPB } \\
\text { STOP }\end{array}$ \\
\hline$\overline{\mathrm{SETU}} \overline{\mathrm{U}} \overline{\mathrm{B}}$ & SETUPA & $\begin{array}{l}\text { AREAD } \\
\text { CLEAR } \\
\text { IREAD } \\
\text { LATCEL } \\
\text { LCOMPR }\end{array}$ \\
\hline
\end{tabular}

NUREG/CR-0200, 
Table M7.B.1 (continued)

\begin{tabular}{|c|c|c|}
\hline $\begin{array}{l}\text { SUBROUTINE } \\
\text { CALLED }\end{array}$ & $\begin{array}{l}\text { CALLING } \\
\text { SUBROUTINE }\end{array}$ & $\begin{array}{l}\text { CALLED } \\
\text { SUBROUTINE }\end{array}$ \\
\hline SETUPB (continued) & & $\begin{array}{l}\text { MTXTAB } \\
\text { MOREDT } \\
\text { MULTRG } \\
\text { POKE } \\
\text { RESDA } \\
\text { STDCMP } \\
\text { STOP }\end{array}$ \\
\hline 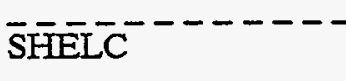 & $\overline{\mathrm{DANCOF}} \overline{-}$ & -------- \\
\hline $\bar{S} \bar{H} \overline{O R T X}-\cdots---$ & $\overline{\mathrm{C}} \mathrm{A} \overline{\mathrm{D}} \overline{\mathrm{T}} \overline{\mathrm{A}}$ & $\begin{array}{l}\overline{C L O S D} \bar{A}--- \\
\text { COPY } \\
\text { DTASET } \\
\text { IOWRT } \\
\text { LOGID } \\
\text { OPENDA } \\
\text { OPNFIL } \\
\text { REED }\end{array}$ \\
\hline$\overline{(\mathrm{SIN})}-\cdots-\cdots$ & $\begin{array}{l}\text { ADAN } \\
\text { FINNER } \\
\text { GDAN } \\
\text { OUTER }\end{array}$ & ------- \\
\hline $\bar{S} \bar{S} \overline{N A M E}$ & $\overline{\mathrm{STD}} \overrightarrow{\mathrm{C}} \overline{\mathrm{M}} \overline{\mathrm{P}}^{-\cdots}$ & $-\cdots--\cdots-\cdots$ \\
\hline $\bar{S} \overline{S L N S}-\cdots \cdots$ & $\overline{S T D} \overline{C M} \bar{M}^{---}$ & $\overline{\mathrm{IS}} \overline{\mathrm{C}} \overline{\mathrm{A}} \overline{\mathrm{N}} \bar{\cdots}$ \\
\hline $\overrightarrow{\mathrm{S}} \overline{\mathrm{M} M} \overline{\mathrm{T}} \overline{\mathrm{T}} \overline{\mathrm{A}}^{------}$ & $\begin{array}{l}\overline{C S P} \bar{A} \bar{R} \bar{M}^{---} \\
\text {CADATA }\end{array}$ & $\overline{\mathrm{LCOMPR}}$ \\
\hline$\overline{\mathrm{SPHDAN}} \overline{-}-\cdots$ & $\overline{\mathrm{BA}} \overline{\mathrm{I}} \overline{\mathrm{L}}$ & $\begin{array}{l}(\overline{A C O} \bar{O}) \\
\text { AGAUSS } \\
\text { OUTER }\end{array}$ \\
\hline$\overline{(\mathrm{SQ}} \overline{\mathrm{RT}} \overline{\mathrm{T}}^{-\cdots-\cdots-\cdots}$ & $\begin{array}{l}\text { ADAN } \\
\text { BALI } \\
\text { BONDA } \\
\text { DAN } \\
\text { DANCOF } \\
\text { EPSIG } \\
\text { FINNER } \\
\text { GDAN } \\
\text { NFLUX } \\
\text { OUTER } \\
\text { POKE }\end{array}$ & ------ \\
\hline
\end{tabular}

NUREG/CR-0200,

Vol. 3, Rev. 4

M7.B.10 
Table M7.B.1 (continued)

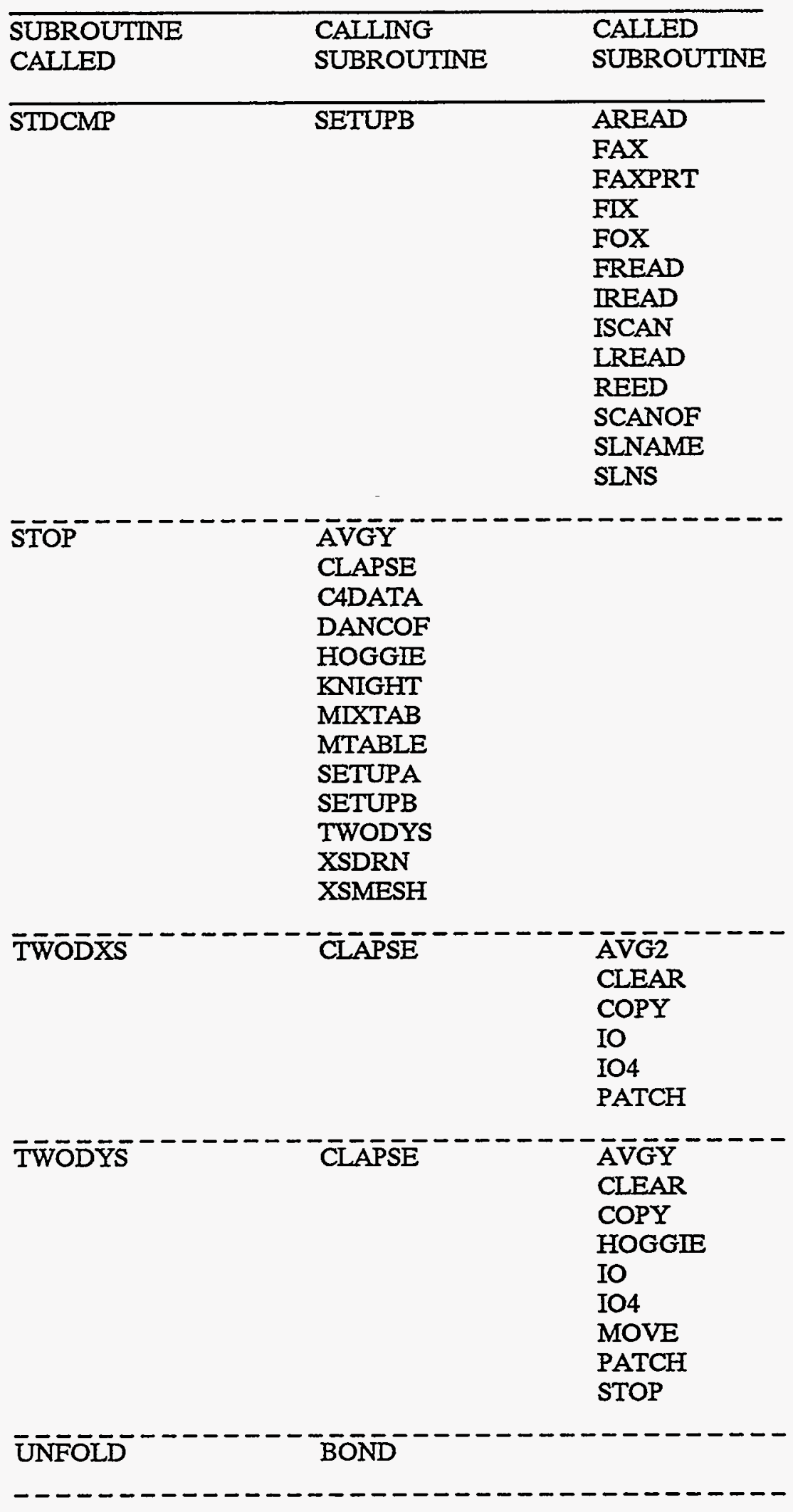

NUREG/CR-0200,

M7.B.11

Vol. 3, Rev. 4 
Table M7.B.1 (continued)

\begin{tabular}{|c|c|c|}
\hline $\begin{array}{l}\text { SUBROUTINE } \\
\text { CALLED }\end{array}$ & $\begin{array}{l}\text { CALLING } \\
\text { SUBROUTINE }\end{array}$ & $\begin{array}{l}\text { CALIED } \\
\text { SUBROUTINE }\end{array}$ \\
\hline$\overline{\text { VERIFY }}$ & CADATA & VOLJB \\
\hline \multicolumn{3}{|c|}{ 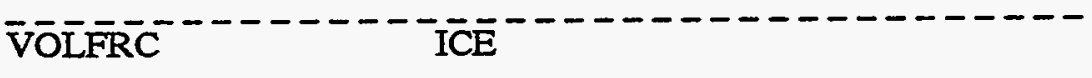 } \\
\hline \multicolumn{3}{|c|}{ 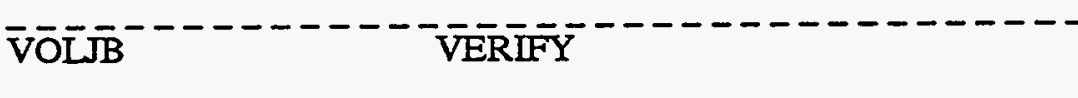 } \\
\hline \multicolumn{3}{|c|}{ 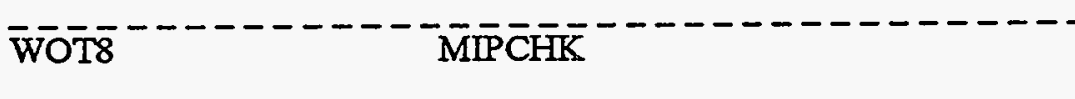 } \\
\hline \multicolumn{3}{|c|}{ 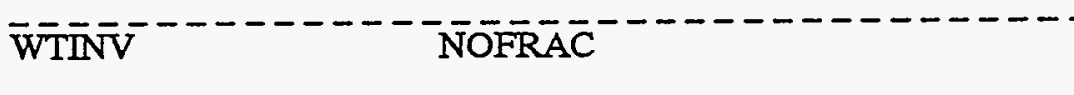 } \\
\hline$\overline{\mathrm{X}} \overline{\mathrm{S}} \overline{\mathrm{R}} \overline{\mathrm{RN}} \overline{\mathrm{N}}---$ & $\overline{\mathrm{C}} \overline{\mathrm{D}} \overline{\mathrm{D}} \overline{\mathrm{T}} \overline{\mathrm{T}} \overline{\mathrm{A}}$ & $\begin{array}{l}\text { BINFIL } \\
\text { BINRCF } \\
\text { BINRCX } \\
\text { CLEAR } \\
\text { LCHKMX } \\
\text { STOP }\end{array}$ \\
\hline $\bar{X} \bar{S} \bar{M} \overline{E S H}-\cdots$ & & $\begin{array}{l}\text { IREĀD- } \\
\text { STOP }\end{array}$ \\
\hline
\end{tabular}

NUREG/CR-0200,

Vol. 3, Rev. 4 
Table M7.B.2 lists the labeled common blocks used in the Material Information Processor and an alphabetical listing of the subroutines that reference them.

Table M7.B.2 Commons used in the Material Information Processor

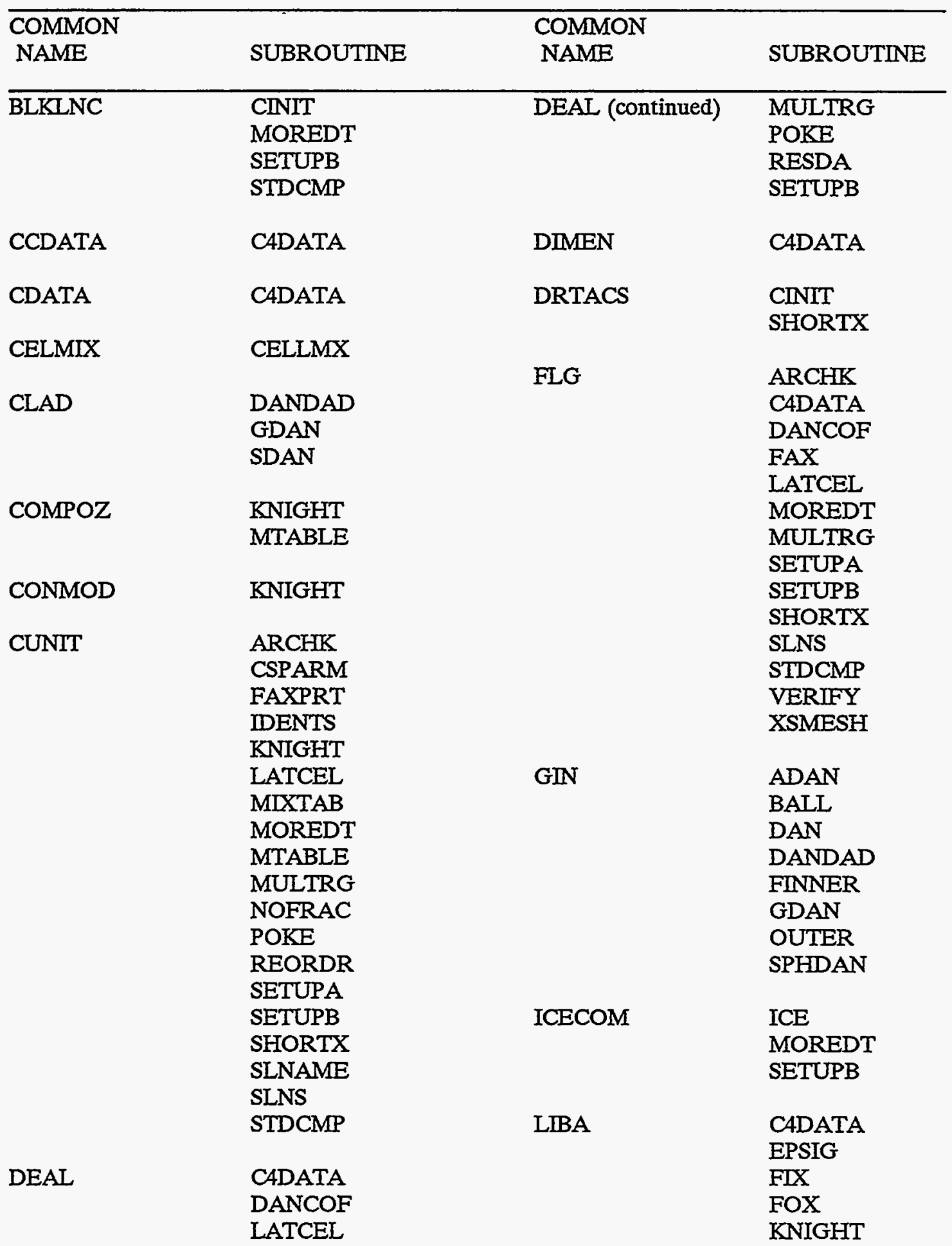

NUREG/CR-0200, 
Table M7.B.2 (continued)

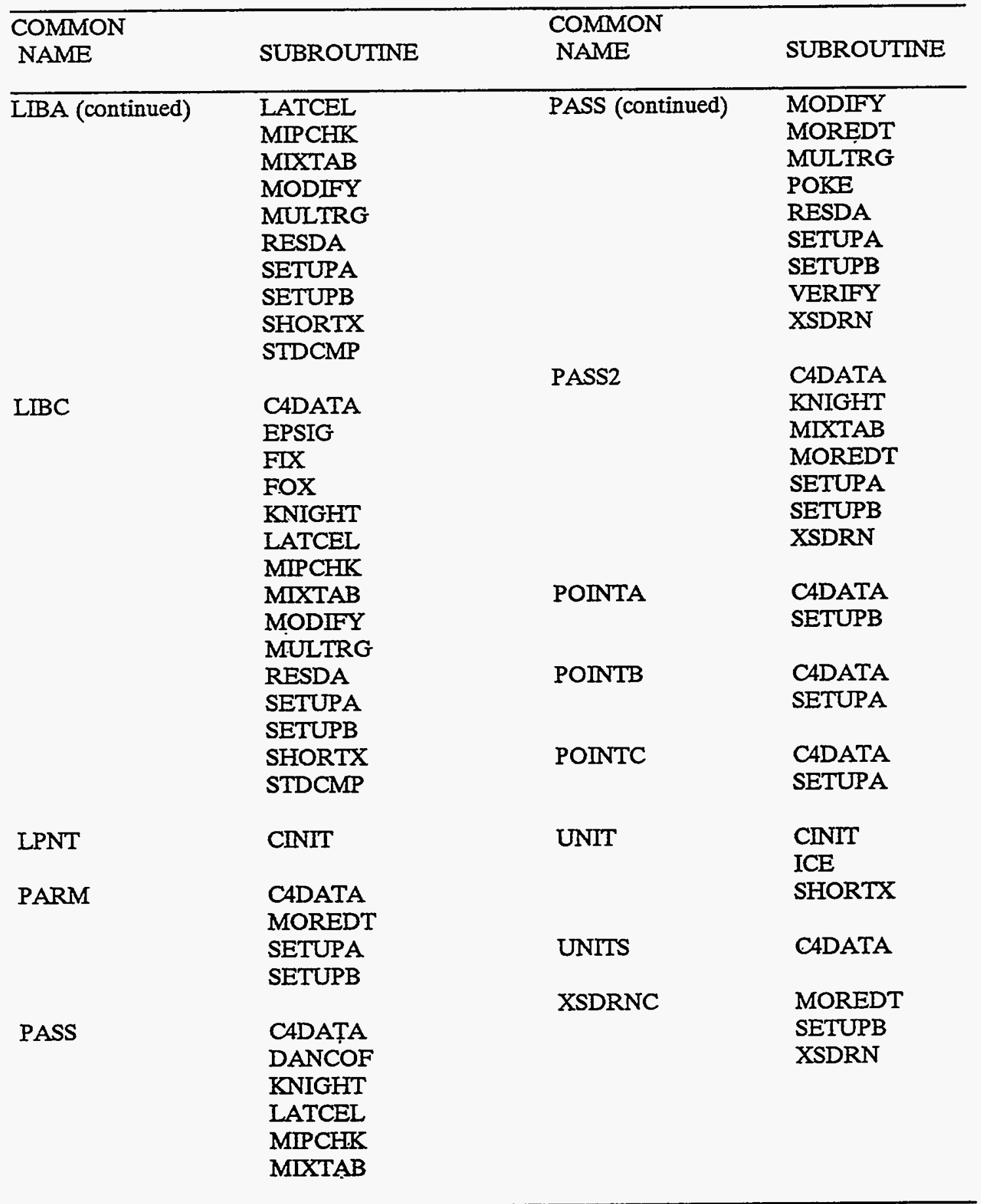

NUREG/CR-0200,

Vol. 3, Rev. 4

M7.B.14 
NUREG/CR-0200

Revision 4

Volume 3, Section M8

ORNL/NUREG/CSD-2/V3/R4

Computing Applications Division

STANDARD COMPOSITION LIBRARY
J. A. Bucholz
J. R. Knight
C. V. Parks
L. M. Petrie
J. C. Turner
R. M. Westfall

Previously Published: December 1984

Revised Manuscript Completed: November 1994

Date Published: April 1995

\author{
Prepared for the \\ Office of Nuclear Material Safety and Safeguards \\ U.S. Nuclear Regulatory Commission \\ Washington, DC 20555 \\ Under Interagency Agreement DOE 1886-8000-9B \\ NRC JCN No. B0009
}

Prepared by the

OAK RIDGE NATIONAL LABORATORY

managed by

MARTIN MARIETTA ENERGY SYSTEMS, INC.

for the

U.S. DEPARTMENT OF ENERGY

under contract DE-AC05-84OR21400 
This document provides a listing of the Standard Composition Library currently available within the SCALE system. A separate listing is also provided for available standard solutions as well as isotope distributions that may be specified. Available cross-section libraries for each standard composition are also provided. 
.

\section{'}




\section{TABLE OF CONTENTS}

Page

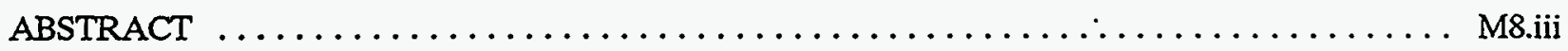

LIST OF TABLES $\ldots \ldots \ldots \ldots \ldots \ldots \ldots \ldots \ldots \ldots \ldots \ldots \ldots \ldots \ldots \ldots \ldots \ldots \ldots \ldots$

ACKNOWLEDGMENTS $\ldots \ldots \ldots \ldots \ldots \ldots \ldots \ldots \ldots \ldots \ldots \ldots \ldots \ldots \ldots \ldots \ldots \ldots \ldots$ M $\ldots \ldots \ldots$

M8.1 INTRODUCTION $\ldots \ldots \ldots \ldots \ldots \ldots \ldots \ldots \ldots \ldots \ldots \ldots \ldots \ldots \ldots \ldots \ldots \ldots \ldots \ldots \ldots \ldots .1$

M8.2 THE STANDARD COMPOSITION LIBRARY $\ldots \ldots \ldots \ldots \ldots \ldots \ldots \ldots \ldots \ldots \ldots . . \ldots \ldots$

M8.3 TABLE OF AVAILABLE SOLUTIONS $\ldots \ldots \ldots \ldots \ldots \ldots \ldots \ldots \ldots \ldots \ldots \ldots \ldots . .1$

M8.4 MULTIPLE-ISOTOPE MATERIALS $\ldots \ldots \ldots \ldots \ldots \ldots \ldots \ldots \ldots \ldots \ldots \ldots \ldots \ldots .1$ 


\section{LIST OF TABLES}

M8.2.1 The Standard Composition Library . . . . . . . . . . . . . . . . . . .

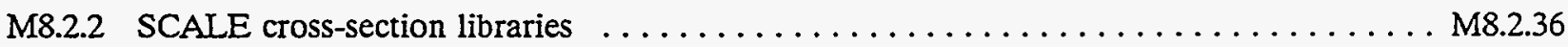

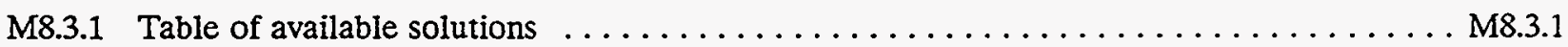

M8.4.1 Multiple-isotope distribution table $\ldots \ldots \ldots \ldots \ldots \ldots \ldots \ldots \ldots \ldots \ldots \ldots \ldots \ldots \ldots \ldots .4 .1$

Vol. 3, Rev. $4 \quad$ M8.vi 


\section{ACKNOWLEDGMENTS}

This work was funded by the U.S. Nuclear Regulatory Commission through the Office of Nuclear Material Safety and Safeguards and the Office of Nuclear Regulatory Research.

NUREG/CR-0200, 


\section{M8.1 INTRODUCTION}

The Standard Composition Library has been included within the SCALE system to provide the user with a simple and straightforward method of specifying the material mixtures for a given problem. The library consists of over 200 mixtures and isotopes commonly used within shielding and criticality problems. This library is tabulated in Sect. M8.2 with the various features of each composition. Additionally, a number of standard fissile solutions available for use are tabulated in Sect. M8.3. The user is also able to specify the isotopic distribution of boron, uranium, or plutonium by using the table provided in Sect. M8.4.

As the need arises, the Standard Composition Library will be updated to include an even greater selection of mixtures and solutions. However, if the user has a need to specify a mixture not currently in the library, this step may be achieved using the procedures described in Sect. M7.5.5. 


\section{M8.2 THE STANDARD COMPOSITION LIBRARY}

The Standard Composition Library describes the various compounds, alloys, elements and isotopes that can be used to define the material mixtures for a given problem." Typically, the alphanumeric description of one or more of these materials will be used to define a material mixture as noted in Sect. M7.4.4.

When formulating such a mixture, it is often necessary to know the density $(\mathrm{g} / \mathrm{cc})$ of the various constituent materials. For convenience, the reference values used by the code have been listed in Table M8.2.1. Note that the given reference values represent the actual theoretical density, except in the case of some individual nuclides where a default value of $1.0 \mathrm{~g} / \mathrm{cc}$ was used.

The temperature of a given material can be entered, but it is not required (cf. Sect. M7.4.4). However, the temperature probably should be entered if resonance data or Bondarenko data are available for the material, or if thermal-scattering data are available at more than one temperature. YES/NO flags for both conditions are given in Table M8.2.1. Note that the list of nuclides having resonance data differs from one master cross-section library to another. Table M8.2.1 indicates the nuclides having resonance data on each of the master cross-section libraries. The list of nuclides having thermal-scattering cross-section data at more than one temperature also differs from one library to another. Tables M4.2.4, M4.2.6, and M4.2.8 list those nuclides (and the associated temperatures) for each of the master cross-section libraries. Even though the user may find this information interesting and/or helpful, he should have no direct need of it.

Unfortunately, all nuclides are not presently available on all master cross-section libraries. Column 5 of Table M8.2.1 is designed to give a quick indication of which cross-section libraries (denoted by the reference numbers $1-8$ ) contain data for the specified nuclide. The reference numbers are matched to available SCALE libraries in Table M8.2.2. The 27BURNUPLIB library is based on ENDF/B-IV data and merely extends the 27GROUPNDF4 library to include several fission-product nuclides that are not typically used in criticality analyses.

Multiple sets of iron, nickel and chromium isotopes are in the Standard Composition Library. These sets correspond to different weighting functions used in generating the multigroup cross sections. The special weighting functions correspond to $1 / E \sigma_{t}(E)$, where $\sigma_{t}(E)$ is the total cross section of either SS-304 stainless steel or Inconel for use in mixing stainless steels or Inconel for use in mixing Inconel-like alloys. These weightings specifically apply to the 27- and 218-group libraries generated from ENDF/B-IV data. In order for the stainless-steel and Inconel standard composition identifiers to be usable with the Hansen Roach library, the 218-group library sets with the special weighting functions were collapsed to 16 groups and added to the Hansen Roach data set. For the 123-group library, the standard iron, nickel and chromium cross-section sets were reproduced with the identifiers of the specially weighted sets. This allows the user to specify stainless steel or Inconel when using the 123-group library, but the cross sections used will not have a special weighting.

The nuclide identifying numbers (ID) are listed in column 6 of Table M8.2.1. Typically, the ID number is $A+1000^{*} Z$, where $Z$ and $A$ are the charge and mass numbers for the nuclide (i.e., 1001 for hydrogen and 8016 for oxygen, etc.). Exceptions to this rule include metastable nuclides and nuclides whose cross sections have a special weighting. Also, elements with isotopic mixtures (typically natural abundance) have ID numbers of $Z^{*} 1000$. The nuclides in brackets are those for which the isotopic weight percent can be specified (or else default to the value given in Table M8.4.1).

To more fully document the composition of each material and/or to document the assumptions used in producing the associated cross-section data, a brief description of each material in Table M8.2.1 is included here:

In addition to the various materials listed here, one is also free to use any of the solutions found in Sect. M8.3. 


\section{LITHIUM \\ BORON \\ BROMINE \\ SIIVER \\ INDIUM \\ TUNGSTEN \\ RHENIUM \\ B4C \\ $\mathrm{H} 20$ \\ H20-X(E)-HR \\ D20 \\ ZIRCALLOY}

SS304

SS316

INCONEL

CARBONSTEEL

ORCONCRETE

RFCONCRETE

MGCONCRETE

REG-CONCRETE

BALSA

REDWOOD

OAK

PYREX

PLEXIGLASS

POLYETHYLENE

POLY(H2O)

PARA(H2O)

PARAFFIN

HNO3

HFACID
Lithium: natural isotopic distribution obtained by default

Boron: natural isotopic distribution obtained by default

Bromine: natural isotopic distribution obtained by default

Silver: natural isotopic distribution obtained by default

Indium: natural isotopic distribution obtained by default

Tungsten: natural isotopic distribution obtained by default

Rhenium: natural isotopic distribution obtained by default

Boron carbide: $\mathrm{B}_{4} \mathrm{C}$; natural isotopic distribution obtained by default

Water: cross-sections developed using $1 / E$ weighting everywhere

Water: cross sections developed using fission spectrum weighting at high energies and $1 / E$ at lower energies

Heavy water: $\mathrm{D}_{2} \mathrm{O}$

Zircaloy-2 as tabulated in ENDF/B-IV ( 297.91 wt \% zirconium, 1.59 wt \% tin, 0.5 wt \% iron); note the thermal-capture cross section and the resonance capture integrals of zirc-2 and zirc-4 are equal within the experimental measurement uncertainties and the variance on the contents of the alloying agents used in zirc-2 and zirc-4.

Stainless steel-304: 69.5 wt \% iron, 19 wt \% chromium, 9.5 wt $\%$ nickel, 2 wt \% manganese

Stainless steel-316: 65.42 wt \% iron, 17 wt \% chromium, 12 wt \% nickel, $2.5 \mathrm{wt}$ $\%$ molybdenum, 2 wt \% manganese, 1 wt \% silicon, 0.08 wt \% carbon

Inconel: $73 \mathrm{wt} \%$ nickel, $15 \mathrm{wt} \%$ chromium, $7 \mathrm{wt} \%$ iron, $2.5 \mathrm{wt} \%$ titanium, 2.5 wt \% silicon

Carbon steel: 99 wt \% iron, 1 wt \% carbon; cross sections developed using $1 / \mathrm{E}$ weighting

Oak Ridge Concrete: 41.02 wt \% oxygen, 32.13 wt \% calcium, 17.52 wt \% carbon, $3.448 \mathrm{wt} \%$ silicon, $3.261 \mathrm{wt} \%$ magnesium, $1.083 \mathrm{wt} \%$ aluminum, $0.7784 \mathrm{wt}$ \% iron, $0.6187 \mathrm{wt} \%$ hydrogen, $0.1138 \mathrm{wt} \%$ potassium, $0.0271 \mathrm{wt} \%$ sodium

Rocky Flats Concrete: 48.49 wt \% oxygen, 23 wt \% calcium, 15.5 wt \% silicon, $5.52 \mathrm{wt} \%$ carbon, $2.17 \mathrm{wt} \%$ aluminum, $1.37 \mathrm{wt} \%$ potassium, $1.25 \mathrm{wt} \%$ magnesium, $1.01 \mathrm{wt} \%$ iron, $0.75 \mathrm{wt} \%$ hydrogen, $0.63 \mathrm{wt} \%$ sodium, $0.19 \mathrm{wt} \%$ sulfur, 0.1 wt $\%$ titanium, 0.02 wt $\%$ nitrogen

Magnuson's Concrete: 49.94 wt \% oxygen, 22.63 wt \% calcium, 10.53 wt carbon, $0.9445 \mathrm{wt} \%$ potassium, $9.420 \mathrm{wt} \%$ magnesium, $4.210 \mathrm{wt} \%$ silicon, $0.7859 \mathrm{wl} \%$ aluminum, $0.5595 \mathrm{wt} \%$ iron, $0.3319 \mathrm{wt} \%$ hydrogen, $0.2483 \mathrm{wt} \%$ sulfur, $0.1488 \mathrm{wt}$ $\%$ titanium, 0.1411 wt \% sodium, 0.0523 wt \% chlorine, $0.0512 \mathrm{wt} \%$ manganese

Regular Concrete: $53.2 \mathrm{wt} \%$ oxygen, $33.7 \mathrm{wt} \%$ silicon, $4.4 \mathrm{wt} \%$ calcium, $3.4 \mathrm{wt}$ $\%$ aluminum, $2.9 \mathrm{wt} \%$ sodium, $1.4 \mathrm{wt} \%$ iron, $1.0 \mathrm{wt} \%$ hydrogen

Balsa wood: $\mathrm{C}_{6} \mathrm{H}_{10} \mathrm{O}_{5}, 0.125 \mathrm{~g} / \mathrm{cm}$

Redwood: $\mathrm{C}_{6} \mathrm{H}_{10} \mathrm{O}_{5}, 0.4485 \mathrm{~g} / \mathrm{cm}$

Oak wood: $\mathrm{C}_{6} \mathrm{H}_{10} \mathrm{O}_{5}, 0.75 \mathrm{~g} / \mathrm{cm}$

Pyrex: 53.5 wt \% oxygen, 37.7 wt \% silicon, 4.1 wt \% sodium, 3.7 wt \% boron, 1.0 wt $\%$ aluminum

Plexiglas: $\mathrm{C}_{5} \mathrm{H}_{8} \mathrm{O}_{2}, 1.18 \mathrm{~g} / \mathrm{cc}$

Polyethylene: $\mathrm{C}_{2} \mathrm{H}_{4}, 0.92 \mathrm{~g} / \mathrm{cc}$

Polyethylene: $\mathrm{C}_{2} \mathrm{H}_{4}, 0.92 \mathrm{~g} / \mathrm{cc}$ uses hydrogen in water thermal kernel

Paraffin: $\mathrm{C}_{25} \mathrm{H}_{52}, 0.93 \mathrm{~g} / \mathrm{cc}$, uses hydrogen in water thermal kernel

Paraffin: $\mathrm{C}_{25} \mathrm{H}_{52}, 0.93 \mathrm{~g} / \mathrm{cc}$

Nitric acid: HNO

Hydrafluoric acid: $\mathrm{HF}$

NUREG/CR-0200, 


\begin{tabular}{|c|c|}
\hline UO2 & Uranium dioxide: $\mathrm{UO}_{2}$ \\
\hline UO3 & Uranium trioxide: $\mathrm{UO}_{3}$ \\
\hline $\mathrm{U} 308$ & Uranium oxide (yellowcake): $\mathrm{U}_{3} \mathrm{O}_{8}$ \\
\hline UC & Uranium carbide: UC \\
\hline UN & Uranium nitride: UN \\
\hline UF4 & Uranium tetrafluoride: $\mathrm{UF}_{4}$ \\
\hline UF6 & Uranium hexafluoride: $\mathrm{UF}_{6}$ \\
\hline $\mathrm{UO} 2 \mathrm{~F} 2$ & Uranyl fluoride: $\mathrm{UO}_{2} \mathrm{~F}_{2}$ \\
\hline $\mathrm{UO} 2(\mathrm{NO} 3) 2$ & Uranyl nitrate: $\mathrm{UO}_{2}\left(\mathrm{NO}_{3}\right)_{2}$ \\
\hline URANIUḾ & $\begin{array}{l}\text { Uranium metal }(19.05 \mathrm{~g} / \mathrm{cc}) \text { having a variable isotope distribution (i.e., the user may } \\
\text { specify the actual isotope distribution or use the natural isotope distribution } \\
\text { supplied by default }\end{array}$ \\
\hline U(.27)METAL & $\begin{array}{l}\text { Depleted uranium metal }(19.05 \mathrm{~g} / \mathrm{cc}) \text { having a fixed isotope distribution: } 0.27 \mathrm{wt} \\
\%{ }^{235} \mathrm{U}, 99.73 \mathrm{wt} \%{ }^{238} \mathrm{U} \text {; to specify a different distribution, the user should use } \\
\text { URANIUM instead of } U(.27) \text { METAL }\end{array}$ \\
\hline PUO2 & Plutonium oxide: $\mathrm{PuO}_{2}$ \\
\hline PUC & Plutonium carbide: PuC \\
\hline PUN & Plutonium nitride: PuN \\
\hline PUF4 & Plutonium tetrafluoride: $\mathrm{PuF}_{4}$ \\
\hline $\mathrm{PU}(\mathrm{NO} 3) 4$ & Plutonium nitrate: $\mathrm{Pu}\left(\mathrm{NO}_{3}\right)_{4}$ \\
\hline PLUTTONIUMALP & $\begin{array}{l}\text { Plutonium metal }-\alpha \text { phase; has density of } 19.84 \mathrm{~g} / \mathrm{cc} \text { but is otherwise the same as } \\
\text { the } \Delta \text { phase }\end{array}$ \\
\hline PLUTONIUMDLT & $\begin{array}{l}\text { Plutonium metal }-\Delta \text { phase; has density of } 15.92 \mathrm{~g} / \mathrm{cc} \text { but is otherwise the same as } \\
\text { the } \alpha \text { phase }\end{array}$ \\
\hline ACTIVITIES & Available activity responses (see Table $\$ 1.4 .8$ ) \\
\hline FISP-1 & Short-lived lumped fission products \\
\hline FISP-2 & Long-lived lumped fission products \\
\hline 1/VABSORBER & $\begin{array}{l}\text { Fictitious material having a } 1 / \mathrm{v} \text { absorption cross section normalized to } 1.0 \text { at } 0.0253 \\
\mathrm{eV}\end{array}$ \\
\hline $\mathrm{H}$ & Hydrogen, cross sections developed using $1 /$ E weighting everywhere \\
\hline $\mathrm{H}-\mathrm{X}(\mathrm{E})-\mathrm{HR}$ & $\begin{array}{l}\text { Hydrogen, cross sections developed using fission spectrum weighting at high } \\
\text { energies and } 1 / E \text { weighting at lower energies }\end{array}$ \\
\hline H-POLY & $\begin{array}{l}\text { Hydrogen, cross sections developed using a thermal-scattering kernel for hydrogen } \\
\text { bound polyethylene }\end{array}$ \\
\hline HFREEGAS & Hydrogen, cross sections developed using a free gas thermal-scattering kernel \\
\hline $\mathrm{D}$ & Deuterium \\
\hline DFREEGAS & Deuterium, cross sections developed using a free gas thermal-scattering kernel \\
\hline H-3 & Hydrogen-3 \\
\hline HE-3 & Helium-3 \\
\hline $\mathrm{HE}$ & Helium: He \\
\hline LI-6 & Lithium-6 \\
\hline LI-7 & Lithium-7 \\
\hline $\mathrm{BE}$ & Beryllium, cross sections developed assuming a free atom \\
\hline BEBOUND & Beryllium, cross sections developed assuming $\mathrm{Be}$ atom bound in a crystalline lattice \\
\hline B & Natural boron \\
\hline B-10 & Boron-10 \\
\hline B-11 & Boron-11 \\
\hline C & Carbon: C \\
\hline $\begin{array}{l}\text { C-GRAPHITE } \\
N\end{array}$ & $\begin{array}{l}\text { Carbon, cross sections developed using a thermal-scattering kernel for graphite } \\
\text { Nitrogen: } N\end{array}$ \\
\hline
\end{tabular}

NUREG/CR-0200, 


\begin{tabular}{|c|c|}
\hline N-15 & Nitrogen-15 \\
\hline O & Oxygen \\
\hline $0-17$ & Oxygen-17 \\
\hline $\mathrm{F}$ & Fluorine: $F$ \\
\hline NA & Sodium: $\mathrm{Na}$ \\
\hline MG & Magnesium: $\mathrm{Mg}$ \\
\hline $\mathrm{AL}$ & Aluminum: $\mathrm{Al}$ \\
\hline SI & Silicon: Si \\
\hline SI-28 & Silicon-28 \\
\hline $\mathrm{P}$ & Phosphorous: $\mathrm{P}$ \\
\hline $\mathbf{S}$ & Sulfur \\
\hline S-32 & Sulfur-32 \\
\hline CL & Chlorine: $\mathrm{Cl}$ \\
\hline AR & Argon: $\mathrm{Ar}$ \\
\hline $\mathrm{K}$ & Potassium \\
\hline $\mathrm{K}-39$ & Potassium-39 \\
\hline $\mathrm{CA}$ & Calcium: $\mathrm{Ca}$ \\
\hline $\mathrm{CA}-40$ & Calcium-40 \\
\hline SC-45 & Scandium-45 \\
\hline $\mathrm{TI}$ & Titanium: Ti \\
\hline V & Vanadium \\
\hline V-51 & Vanadium-51 \\
\hline CR & Chromium, cross sections developed using $1 / \mathrm{E}$ weighting \\
\hline CR-ESIGT & $\begin{array}{l}\text { Chromium, cross sections developed using }\left[\mathrm{E} \sigma_{t}(\mathrm{E})\right]^{-1} \text { weighting, where } \sigma_{t}(\mathrm{E}) \text { is that } \\
\text { of chromium }\end{array}$ \\
\hline CRSS & $\begin{array}{l}\text { Chromium, cross sections developed using }\left[\mathrm{E} \sigma_{\mathrm{t}}(\mathrm{E})\right]^{-1} \text { weighting, where } \sigma_{t}(\mathrm{E}) \text { is that } \\
\text { of SS-304 }\end{array}$ \\
\hline CRINCONEL & $\begin{array}{l}\text { Chromium, cross sections developed using }\left[E \sigma_{t}(E)\right]^{-1} \text { weighting, where } \sigma_{t}(E) \text { is that } \\
\text { of Inconel }\end{array}$ \\
\hline $\mathrm{MN}$ & Manganese, cross sections developed using $1 / E$ weighting \\
\hline MNSS & $\begin{array}{l}\text { Manganese, cross sections developed using }\left[E \sigma_{t}(E)\right]^{-1} \text { weighting, where } \sigma_{t}(E) \text { is that } \\
\text { of SS-304 }\end{array}$ \\
\hline $\mathrm{FE}$ & Iron, cross sections developed using $1 / \mathrm{E}$ weighting \\
\hline FE-SIGT & Iron, cross sections developed using $\left[\mathrm{E} \sigma_{\mathrm{t}}(\mathrm{E})\right]^{-1}$ weighting, where $\sigma_{\mathrm{t}}(\mathrm{E})$ is that of iron \\
\hline FESS & $\begin{array}{l}\text { Iron, cross sections developed using }\left[\mathrm{E} \sigma_{t}(E)\right]^{-1} \text { weighting, where } \sigma_{t}(E) \text { is that of } \\
\text { SS-304 }\end{array}$ \\
\hline FEINCONEL & $\begin{array}{l}\text { Iron, cross sections developed using }\left[\mathrm{E} \sigma_{t}(\mathrm{E})\right]^{-1} \text { weighting, where } \sigma_{\mathrm{t}}(\mathrm{E}) \text { is that of } \\
\text { Inconel }\end{array}$ \\
\hline $\mathrm{CO}, \mathrm{CO}-59$ & Cobalt -59 \\
\hline NI & Nickel, cross sections developed using $1 / E$ weighting \\
\hline NI-ESIGT & $\begin{array}{l}\text { Nickel, cross sections developed using }\left[\mathrm{E} \sigma_{\mathrm{t}}(\mathrm{E})\right]^{-1} \text { weighting, where } \sigma_{\mathrm{t}}(\mathrm{E}) \text { is that of } \\
\text { nickel }\end{array}$ \\
\hline NISS & $\begin{array}{l}\text { Nickel, cross sections developed using }\left[\mathrm{E} \sigma_{\mathrm{t}}(\mathrm{E})\right]^{-1} \text { weighting, where } \sigma_{\mathrm{t}}(\mathrm{E}) \text { is that of } \\
\text { SS-304 }\end{array}$ \\
\hline NIINCONEL & $\begin{array}{l}\text { Nickel, cross sections developed using }\left[E \sigma_{t}(E)\right]^{-1} \text { weighting, where } \sigma_{t}(E) \text { is that of } \\
\text { Inconel }\end{array}$ \\
\hline $\mathrm{CU}$ & Copper: $\mathrm{Cu}$ \\
\hline $\mathrm{ZN}$ & Zinc: $\mathrm{Zn}$ \\
\hline $\mathrm{ZN}-64$ & Zinc-64 \\
\hline GA & Gallium \\
\hline
\end{tabular}




\begin{tabular}{|c|c|}
\hline GE-72 & Germanium-72 \\
\hline GE-73 & Germanium-73 \\
\hline GE-74 & Germanium-74 \\
\hline GE-76 & Germanium-76 \\
\hline AS -75 & Arsenic-75 \\
\hline SE-76 & Selenium-76 \\
\hline SE-77 & Selenium-77 \\
\hline SE-78 & Selenium-78 \\
\hline SE-80 & Selenium-80 \\
\hline SE-82 & Selenium -82 \\
\hline BR-79 & Bromine-79 \\
\hline BR-81 & Bromine- 81 \\
\hline KR-78 & Krypton-78 \\
\hline KR-80 & Krypton-80 \\
\hline $\mathrm{KR}-82$ & Krypton-82 \\
\hline KR-83 & Krypton-83 \\
\hline KR-84 & Krypton-84 \\
\hline $\mathrm{KR}-85$ & Krypton-85 \\
\hline $\mathrm{KR}-86$ & Krypton-86 \\
\hline $\mathrm{RB}-85$ & Rubidium-85 \\
\hline RB-86 & Rubidium-86 \\
\hline RB-87 & Rubidium-87 \\
\hline SR-84 & Strontium-84 \\
\hline SR-86 & Strontium-86 \\
\hline SR-87 & Strontiumi -87 \\
\hline SR-88 & Strontium-88 \\
\hline SR-89 & Strontium-89 \\
\hline SR-90 & Strontium-90 \\
\hline$Y-89$ & Yttrium-89 \\
\hline Y-90 & Yttrium-90 \\
\hline Y-91 & Yttrium-91 \\
\hline $\mathrm{ZR}$ & Zirconium: $\mathrm{Zr}$ \\
\hline ZR-90 & Zirconium-90 \\
\hline ZR-91 & Zirconium-91 \\
\hline ZR-92 & Zirconium-92 \\
\hline ZR-93 & Zirconium-93 \\
\hline ZR-94 & Zirconium-94 \\
\hline ZR-95 & Zirconium-95 \\
\hline ZR-96 & Zirconium-96 \\
\hline NB & Niobium: $\mathrm{Nb}$ \\
\hline NB-93 & Niobium-93 \\
\hline NB-94 & Niobium-94 \\
\hline NB-95 & Niobium-95 \\
\hline MO & Molybdenum: Mo \\
\hline MO-92 & Molybdenum-92 \\
\hline MO-94 & Molybdenum-94 \\
\hline MO-95 & Molybdenum-95 \\
\hline MO-96 & Molybdenum-96 \\
\hline MO-97 & Molybdenum-97 \\
\hline MO-98 & Molybdenum-98 \\
\hline MO-99 & Molybdenum- 99 \\
\hline
\end{tabular}




\begin{tabular}{|c|c|}
\hline MO-100 & Molybdenum-100 \\
\hline TC-99 & Technetium-99 \\
\hline RU-96 & Ruthenium-96 \\
\hline RU-98 & Ruthenium-98 \\
\hline RU-99 & Ruthenium-99 \\
\hline RU-100 & Ruthenium-100 \\
\hline RU-101 & Ruthenium-101 \\
\hline RU-102 & Ruthenium-102 \\
\hline RU-103 & Ruthenium-103 \\
\hline RU-104 & Ruthenium-104 \\
\hline RU-105 & Ruthenium-105 \\
\hline RU-106 & Ruthenium-106 \\
\hline RH-103 & Rhodium-103 \\
\hline RH-105 & Rhodium-105 \\
\hline PD-102 & Palladium-102 \\
\hline PD-104 & Palladium-104 \\
\hline PD-105 & Palladium-105 \\
\hline PD-106 & Palladium-106 \\
\hline PD-107 & Palladium-107 \\
\hline PD-108 & Palladium-108 \\
\hline PD-110 & Palladium-110 \\
\hline AG-107 & Silver-107 \\
\hline$A G-109$ & Silver-109 \\
\hline$A G-111$ & Silver-111 \\
\hline $\mathrm{CD}$ & Cadmium \\
\hline CD-106 & Cadmium-106 \\
\hline CD-108 & Cadmium-108 \\
\hline$C D-110$ & Cadmium-110 \\
\hline CD-111 & Cadmium-111 \\
\hline CD-112 & Cadmium-112 \\
\hline CD-113 & Cadmium-113 \\
\hline$C D-114$ & Cadmium-114 \\
\hline CD-115M & Cadmium-115 (metastable) \\
\hline CD-116 & Cadmium-116 \\
\hline IN-113 & Indium-113 \\
\hline IN-115 & Indium-115 \\
\hline SN & Tin: Sn \\
\hline SN-112 & Tin-112 \\
\hline SN-114 & Tin-114 \\
\hline SN-115 & Tin-115 \\
\hline SN-116 & Tin-116 \\
\hline SN-117 & Tin-117 \\
\hline SN-118 & Tin-118 \\
\hline SN-119 & Tin-119 \\
\hline SN-120 & Tin-120 \\
\hline SN-122 & Tin-122 \\
\hline SN-123 & Tin-123 \\
\hline SN-124 & Tin-124 \\
\hline SN-125 & Tin-125 \\
\hline SN-126 & Tin-126 \\
\hline SB-121 & Antimony-121 \\
\hline
\end{tabular}

NUREG/CR-0200, 


\begin{tabular}{|c|c|}
\hline SB-123 & Antimony-123 \\
\hline SB-124 & Antimony-124 \\
\hline SB-125 & Antimony-125 \\
\hline SB-126 & Antimony-126 \\
\hline TE-120 & Tellurium-120 \\
\hline TE-122 & Tellurium-122 \\
\hline TE-123 & Tellurium-123 \\
\hline TE-124 & Tellurium-124 \\
\hline TE-125 & Tellurium-125 \\
\hline TE-126 & Tellurium-126 \\
\hline TE-127M & Tellurium-127 (metastable) \\
\hline TE-128 & Tellurium-128 \\
\hline TE-129M & Tellurium-129 (metastable) \\
\hline TE-130 & Tellurium-130 \\
\hline TE-132 & Tellurium-132 \\
\hline $\mathrm{I}-127$ & Iodine-127 \\
\hline $\mathrm{I}-129$ & Iodine-129 \\
\hline $\mathrm{I}-130$ & Iodine-130 \\
\hline $\mathrm{I}-131$ & Iodine-131 \\
\hline $\mathrm{I}-135$ & Iodine-135 \\
\hline XE-124 & Xenon-124 \\
\hline $\mathrm{XE}-126$ & Xenon-126 \\
\hline XE-128 & Xenon-128 \\
\hline XE-129 & Xenon-129 \\
\hline $\mathrm{XE}-130$ & Xenon-130 \\
\hline $\mathrm{XE}-131$ & Xenon-131 \\
\hline XE-132 & Xenon-132 \\
\hline XE-133 & Xenon-133 \\
\hline $\mathrm{XE}-134$ & Xenon-134 \\
\hline $\mathrm{XE}-135$ & Xenon-135 \\
\hline $\mathrm{XE}-136$ & Xenon-136 \\
\hline CS-133 & Cesium-133 \\
\hline CS-134 & Cesium-134 \\
\hline CS-135 & Cesium-135 \\
\hline CS-136 & Cesium-136 \\
\hline CS-137 & Cesium-137 \\
\hline BA-134 & Barium-134 \\
\hline $\mathrm{BA}-135$ & Barium-135 \\
\hline BA-136 & Barium-136 \\
\hline BA-137 & Barium-137 \\
\hline BA-138 & Barium-138 \\
\hline BA-140 & Barium-140 \\
\hline LA-139 & Lanthanum-139 \\
\hline LA-140 & Lanthanum-140 \\
\hline CE-140 & Cerium-140 \\
\hline CE-141 & Cerium-141 \\
\hline CE-142 & Cerium-142 \\
\hline CE-143 & Cerium-143 \\
\hline CE-144 & Cerium-144 \\
\hline PR-141 & Praseodymium-141 \\
\hline PR-142 & Praseodymium-142 \\
\hline
\end{tabular}




\begin{tabular}{|c|c|}
\hline PR-143 & Praseodymium-143 \\
\hline ND-142 & Neodymium-142 \\
\hline ND-143 & Neodymium-143 \\
\hline ND-144 & Neodymium-144 \\
\hline ND-145 & Neodymium-145 \\
\hline ND-146 & Neodymium-146 \\
\hline ND-147 & Neodymium- 147 \\
\hline ND-148 & Neodymium-148 \\
\hline ND-150 & Neodymium-150 \\
\hline PM-147 & Promethium-147 \\
\hline PM-148 & Promethium-148 \\
\hline PM-148M & Promethium-148 (metastable) \\
\hline PM-149 & Promethium-149 \\
\hline PM-151 & Promethium-151 \\
\hline SM-144 & Samarium-144 \\
\hline SM-147 & Samarium-147 \\
\hline SM-148 & Samarium-148 \\
\hline SM-149 & Samarium-149 \\
\hline SM-150 & Samarium-150 \\
\hline SM-151 & Samarium-151 \\
\hline SM-152 & Samarium-152 \\
\hline SM-153 & Samarium-153 \\
\hline SM-154 & Samarium-154 \\
\hline EU & Europium \\
\hline EU-151 & Europium-151 \\
\hline EU-152 & Europium-152 \\
\hline EU-153 & Europium-153 \\
\hline EU-154 & Europium-154 \\
\hline EU-155 & Europium-155 \\
\hline EU-156 & Europium-156 \\
\hline EU-157 & Europium-157 \\
\hline GD & Gadolinium: Gd \\
\hline GD-152 & Gadolinium-152 \\
\hline GD-154 & Gadolinium-154 \\
\hline GD-155 & Gadolinium-155 \\
\hline GD-156 & Gadolinium-156 \\
\hline GD-157 & Gadolinium-157 \\
\hline GD-158 & Gadolinium-158 \\
\hline GD-160 & Gadolinium-160 \\
\hline TB-159 & Terbium-159 \\
\hline TB-160 & Terbium-160 \\
\hline DY-160 & Dysprosium-160 \\
\hline DY-161 & Dysprosium-161 \\
\hline DY-162 & Dysprosium-162 \\
\hline DY-163 & Dysprosium-163 \\
\hline DY-164 & Dysprosium-164 \\
\hline HO-165 & Holmium-165 \\
\hline ER-166 & Erbium-166 \\
\hline ER-167 & Erbium-167 \\
\hline TM-169 & Thulium-169 \\
\hline LU-175 & Lutetium-175 \\
\hline
\end{tabular}

NUREG/CR-0200, Vol. 3, Rev. 4 


\begin{tabular}{|c|c|}
\hline LU-176 & Lutetium-176 \\
\hline $\mathrm{HF}$ & Hafnium: Hf \\
\hline HF-174 & Hafnium-174 \\
\hline $\mathrm{HF}-176$ & Hafnium-176 \\
\hline $\mathrm{HF}-177$ & Hafnium-177 \\
\hline HF-178 & Hafnium-178 \\
\hline $\mathrm{HF}-179$ & Hafnium-179 \\
\hline $\mathrm{HF}-180$ & Hafnium-180 \\
\hline TA-181 & Tantalum-181 \\
\hline TA-182 & Tantalum-182 \\
\hline W & Tungsten \\
\hline W-182 & Tungsten-182 \\
\hline W-183 & Tungsten-183 \\
\hline W-184 & Tungsten-184 \\
\hline W-186 & Tungsten-186 \\
\hline RE-185 & Rhenium-185 \\
\hline RE-187 & Rhenium-187 \\
\hline IR-191 & Iridium-191 \\
\hline IR-193 & Iridium-193 \\
\hline$A U$ & Gold: Au \\
\hline $\mathrm{PB}$ & Lead: $\mathrm{Pb}$ \\
\hline BI-209 & Bismuth-209 \\
\hline TH-230 & Thorium-230 \\
\hline TH-232 & Thorium-232 \\
\hline $\mathrm{PA}-231$ & Protactinium-231 \\
\hline PA-233 & Protactinium-233 \\
\hline $\mathrm{U}-232$ & Uranium-232 \\
\hline U-233 & Uranium-233 \\
\hline U-234 & Uranium-234 \\
\hline U-235 & Uranium-235 \\
\hline U-236 & Uranium-236 \\
\hline U-237 & Uranium-237 \\
\hline U-238 & Uranium-238 \\
\hline NP-237 & Neptunium-237 \\
\hline NP-238 & Neptunium-238 \\
\hline PU-236 & Plutonium-236 \\
\hline PU-237 & Plutonium-237 \\
\hline PU-238 & Plutonium-238 \\
\hline PU-239 & Plutonium-239 \\
\hline PU-240 & Plutonium-240 \\
\hline PU-241 & Plutonium-241 \\
\hline PU-242 & Plutonium-242 \\
\hline PU-243 & Plutonium-243 \\
\hline PU-244 & Plutonium-244 \\
\hline$A M-241$ & Americium-241 \\
\hline $\mathrm{AM}-242$ & Americium-242 \\
\hline AM-242M & Americium-242 (metastable) \\
\hline AM-243 & Americium-243 \\
\hline CM-241 & Curium-241 \\
\hline CM-242 & Curium-242 \\
\hline CM-243 & Curium-243 \\
\hline
\end{tabular}




$\begin{array}{ll}\text { CM-244 } & \text { Curium-244 } \\ \text { CM-245 } & \text { Curium-245 } \\ \text { CM-246 } & \text { Curium-246 } \\ \text { CM-247 } & \text { Curium-247 } \\ \text { CM-248 } & \text { Curium-248 } \\ \text { BK-249 } & \text { Berkelium-249 } \\ \text { CF-249 } & \text { Californium-249 } \\ \text { CF-250 } & \text { Californium-250 } \\ \text { CF-251 } & \text { Californium-251 } \\ \text { CF-252 } & \text { Californium-252 } \\ \text { CF-253 } & \text { Californium-253 } \\ \text { ES-253 } & \text { Einsteinium-253 }\end{array}$

NUREG/CR-0200,

Vol. 3, Rev. 4 
Table M8.2.1 The Standard Composition Library

\begin{tabular}{|c|c|c|c|c|}
\hline $\begin{array}{l}\text { Alphanumeric } \\
\text { description } \\
\text { standard } \\
\text { composition }\end{array}$ & $\begin{array}{l}\text { Theoretical } \\
\text { density } \\
\text { oth in } \\
\text { grams/cc }\end{array}$ & $\begin{array}{l}\text { Resonance } \\
\text { data or } \\
\text { Bondarenko } \\
\text { data available }\end{array}$ & $\begin{array}{l}\text { Cross-section } \\
\text { libraries for this } \\
\text { standard composition } \\
\text { (see Table M8.2.2) }\end{array}$ & $\begin{array}{l}\text { List of nuclides in this } \\
\text { standard composition (with } \\
\text { isotopes the user may } \\
\text { specifiy shown in brackets) }\end{array}$ \\
\hline LITHIUM & 0.5340 & NO & 12345678 & {$\left[\begin{array}{lll}3006 & 3007\end{array}\right]$} \\
\hline BORON & 2.3730 & NO & 12345678 & {$\left[\begin{array}{lll}5010 & 5011\end{array}\right]$} \\
\hline BROMINE & 3.1200 & YES & $-2-45-78$ & {$\left[\begin{array}{lll}35079 & 35081\end{array}\right]$} \\
\hline SILVER & 10.5000 & YES & $12 \cdot 45 \cdot 78$ & [47107 47109] \\
\hline INDIUM & 7.3100 & YES & $12-45 \cdot 78$ & [49113 49115] \\
\hline HAFNIUM & 13.2700 & YES & $\ldots \ldots$ & $\begin{array}{c}{\left[\begin{array}{ll}72174 & 72176 \\
72177 & 72178 \\
72179 & 72180\end{array}\right]}\end{array}$ \\
\hline TUNGSTEN & 19.2300 & YES & $12-45-78$ & $\begin{array}{l}{\left[\begin{array}{l}741827418374184 \\
74186]\end{array}\right.}\end{array}$ \\
\hline RHENIUM & 21.0200 & YES & $12-45-78$ & {$\left[\begin{array}{lll}75185 & 75187\end{array}\right]$} \\
\hline $\mathrm{B} 4 \mathrm{C}$ & 2.5200 & NO & 12345678 & [5010 5011] 6012 \\
\hline $\mathrm{H} 2 \mathrm{O}$ & 0.9982 & NO & 12345678 & 10018016 \\
\hline $\mathrm{H} 2 \mathrm{O}-\mathrm{X}(\mathrm{E})-\mathrm{HR}$ & 0.9982 & NO & $1 \ldots \ldots$ & 13018016 \\
\hline $\mathrm{D} 20$ & 1.1053 & NO & $12345-78$ & 10028016 \\
\hline ZIRCALLOY & 6.4400 & YES . & $12345-78$ & 40302 \\
\hline SS304 & 7.9200 & YES & $12345-78$ & $\begin{array}{l}243042505526304 \\
28304\end{array}$ \\
\hline
\end{tabular}

NUREG/CR-0200, 
Table M8.2.1 (continued)

\begin{tabular}{|c|c|c|c|c|}
\hline $\begin{array}{l}\text { Alphanumeric } \\
\text { description } \\
\text { standard } \\
\text { composition }\end{array}$ & $\begin{array}{l}\text { Theoretical } \\
\text { density } \\
\rho \text { th in } \\
\text { grams/cc }\end{array}$ & $\begin{array}{l}\text { Resonance } \\
\text { data or } \\
\text { Bondarenko } \\
\text { data available }\end{array}$ & $\begin{array}{l}\text { Cross-section } \\
\text { libraries for this } \\
\text { standard composition } \\
\text { (see Table M8.2.2) }\end{array}$ & $\begin{array}{l}\text { List of nuclides in this } \\
\text { standard composition (with } \\
\text { isotopes the user may } \\
\text { specifiy shown in brackets) }\end{array}$ \\
\hline SS316 & 7.7500 & YES & $12345-78$ & $\begin{array}{l}60121400024304 \\
250552630428304 \\
42000\end{array}$ \\
\hline INCONEL & 8.3000 & NO & $12345-78$ & $\begin{array}{l}140282200024404 \\
2640428404\end{array}$ \\
\hline CARBONSTEEL & 7.8212 & YES & 12345678 & 601226000 \\
\hline ORCONCRETE & 2.2994 & YES & 12345678 & $\begin{array}{ccc}1001 & 6012 & 8016 \\
11023 & 12000 & 13027 \\
14000 & 19000 & 20000 \\
26000 & & \end{array}$ \\
\hline RFCONCRETE & 2.3210 & YES & $12345-78$ & $\begin{array}{l}1001601270148016 \\
1102312000130271400016000 \\
19000200002200026000\end{array}$ \\
\hline MGCONCRETE & 2.147 & YES & $12345-78$ & $\begin{array}{ccc}1001 & 6012 & 8016 \\
11023 & 12000 & 13027 \\
14000 & 16000 & 17000 \\
19000 & 20000 & 22000 \\
25055 & 26000 & 30000\end{array}$ \\
\hline REG-CONCRETE & 2.3000 & YES & 12345678 & $\begin{array}{lll}1001 & 8016 & 11023 \\
13027 & 14000 & 20000 \\
26000 & & \end{array}$ \\
\hline BALSA & 0.1250 & NO & 12345678 & 100160128016 \\
\hline REDWOOD & 0.4485 & NO & 12345678 & 100160128016 \\
\hline OAK & 0.7500 & NO & 12345678 & 100160128016 \\
\hline PYREX & 2.2300 & YES & 12345678 & $\begin{array}{lll}{\left[\begin{array}{ll}5010 & 5011\end{array}\right]} & 8016 \\
11023 & 13027 & 14000\end{array}$ \\
\hline
\end{tabular}

NUREG/CR-0200,

Vol. 3, Rev. 4

M8.2.12 
Table M8.2.1 (continued)

\begin{tabular}{|c|c|c|c|c|}
\hline $\begin{array}{l}\text { Alphanumeric } \\
\text { description } \\
\text { standard } \\
\text { composition }\end{array}$ & $\begin{array}{l}\text { Theoretical } \\
\text { density } \\
\text { pth in } \\
\text { grams/cc }\end{array}$ & $\begin{array}{l}\text { Resonance } \\
\text { data or } \\
\text { Bondarenko } \\
\text { data available }\end{array}$ & $\begin{array}{l}\text { Cross-section } \\
\text { libraries for this } \\
\text { standard composition } \\
\text { (see Table M8.2.2) }\end{array}$ & $\begin{array}{l}\text { List of nuclides in this } \\
\text { standard composition (with } \\
\text { isotopes the user may } \\
\text { specifiy shown in brackets) }\end{array}$ \\
\hline PLEXIGLASS & 1.1800 & NO & 12345678 & 100160128016 \\
\hline POLYETHYLENE & 0.9200 & NO & $\ldots . .7-$ & 19016012 \\
\hline POLY(H2O) & 0.9200 & No & 12345678 & 10016012 \\
\hline PARAFFIN & 0.9300 & NO & 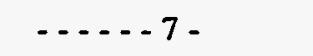 & 19016012 \\
\hline PARA(H2O) & 0.9300 & NO & 12345678 & 10016012 \\
\hline HNO3 & 1.0000 & No & 12345678 & 100170148016 \\
\hline HFACID & 1.0000 & NO & 12345678 & 10019019 \\
\hline UO2 & 10.9600 & YES & $12345-78$ & $\begin{array}{r}922339223492235 \\
9223692238] 8016\end{array}$ \\
\hline UO3 & 7.2900 & YES & 12345678 & $\begin{array}{c}922339223492235 \\
9223692238] 8016\end{array}$ \\
\hline U308 & 8.3000 & YES & $12345-78$ & $\begin{array}{c}922339223492235 \\
9223692238] 8016\end{array}$ \\
\hline UC & 13.6300 & YES & $12345-78$ & $\begin{array}{c}{[922339223492235} \\
9223692238] 6012\end{array}$ \\
\hline UN & 14.3100 & YES & $12345-78$ & $\begin{array}{c}{[922339223492235} \\
9223692238] 7014\end{array}$ \\
\hline UF4 & 6.7000 & YES & $12345-78$ & $\begin{array}{c}922339223492235 \\
9223692238] 9019\end{array}$ \\
\hline
\end{tabular}

M8.2.13

NUREG/CR-0200, Vol. 3, Rev. 4 
Table M8.2.1 (continued)

\begin{tabular}{|c|c|c|c|c|}
\hline $\begin{array}{l}\text { Alphanumeric } \\
\text { description } \\
\text { standard } \\
\text { composition }\end{array}$ & $\begin{array}{l}\text { Theoretical } \\
\text { density } \\
\rho \text { th in } \\
\text { grams/cc }\end{array}$ & $\begin{array}{l}\text { Resonance } \\
\text { data or } \\
\text { Bondarenko } \\
\text { data available }\end{array}$ & $\begin{array}{l}\text { Cross-section } \\
\text { libraries for this } \\
\text { standard composition } \\
\text { (see Table M8.2.2) }\end{array}$ & $\begin{array}{l}\text { List of nuclides in this } \\
\text { standard composition (with } \\
\text { isotopes the user may } \\
\text { specifiy shown in brackets) }\end{array}$ \\
\hline UF6 & 4.8500 & YES & $12345-78$ & $\begin{array}{c}{[922339223492235} \\
9223692238] 9019\end{array}$ \\
\hline $\mathrm{UO} 2 \mathrm{F2}$ & 6.3700 & YES & $12345-78$ & $\begin{array}{l}{[922339223492235} \\
9223692238] 8016 \\
9019\end{array}$ \\
\hline $\mathrm{UO} 2(\mathrm{NO} 3) 2$ & 2.2030 & YES & $12345-78$ & 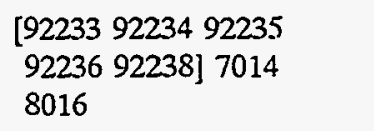 \\
\hline URANIUM & 19.0500 & YES & $12345-78$ & $\begin{array}{c}{\left[\begin{array}{ll}92233 & 9223492235 \\
92236 & 92238\end{array}\right]}\end{array}$ \\
\hline $\mathrm{U}(.27) \mathrm{METAL}$ & 19.0500 & YES & 12345678 & 9223592238 \\
\hline PUO2 & 11.4600 & YES & $12345-78$ & $\begin{array}{c}{[942389423994240} \\
9424194242] 8016\end{array}$ \\
\hline PUC & 13.6000 & YES & $12345-78$ & $\begin{array}{c}{[942389423994240} \\
9424194242] 6012\end{array}$ \\
\hline PUN & 14.2500 & YES & $12345-78$ & $\begin{array}{c}{[942389423994240} \\
9424194242] 7014\end{array}$ \\
\hline PUF4 & 7.0000 & YES & $12345-78$ & $\begin{array}{c}{[942389423994240} \\
9424194242] 9019\end{array}$ \\
\hline PU(NO3)4 & 2.4470 & YES & $12345-78$ & $\begin{array}{l}{[942389423994240} \\
9424194242] 7014 \\
8016\end{array}$ \\
\hline PLUTONIUMALP & 19.8400 & YES & $12345-78$ & $\begin{array}{l}{[942389423994240} \\
9424194242]\end{array}$ \\
\hline
\end{tabular}

NUREG/CR-0200,

Vol. 3, Rev. 4

M8.2.14 
Table M8.2.1 (continued)

\begin{tabular}{|c|c|c|c|c|}
\hline $\begin{array}{l}\text { Alphanumeric } \\
\text { description } \\
\text { standard } \\
\text { composition }\end{array}$ & $\begin{array}{l}\text { Theoretical } \\
\text { density } \\
\text { oth in } \\
\text { grams/cc }\end{array}$ & $\begin{array}{l}\text { Resonance } \\
\text { data or } \\
\text { Bondarenko } \\
\text { data available }\end{array}$ & $\begin{array}{l}\text { Cross-section } \\
\text { libraries for this } \\
\text { standard composition } \\
\text { (see Table M8.2.2) }\end{array}$ & $\begin{array}{l}\text { List of nuclides in this } \\
\text { standard composition (with } \\
\text { isotopes the user may } \\
\text { specifiy shown in brackets) }\end{array}$ \\
\hline PLUTONIUMDLT & 15.9200 & YES & $12345-78$ & $\begin{array}{l}{[942389423994240} \\
9424194242]\end{array}$ \\
\hline ACTIVITIES & 1.0000 & NO & $-23-5678$ & 900 \\
\hline FISP-1 & 1.0000 & NO & $\ldots \ldots$ & 901 \\
\hline FISP-2 & 1.0000 & NO & $\ldots \ldots$ & 902 \\
\hline 1/NABSORBER & 1.0000 & NO & $12345--8$ & 999 \\
\hline $\mathrm{H}$ & 1.0000 & NO & 12345678 & 1001 \\
\hline $\mathrm{H}-\mathrm{X}(\mathrm{E})-\mathrm{HR}$ & 1.0000 & No & $1 \ldots \ldots$ & 1301 \\
\hline H-POLY & 1.0000 & No & $\ldots . .7$ & 1901 \\
\hline HFREEGAS & 1.0000 & NO & $\ldots$ & 1801 \\
\hline$D$ & 1.0000 & NO & $12345-78$ & 1002 \\
\hline DFREEGAS & 1.0000 & NO & $\ldots \ldots$ & 1802 \\
\hline $\mathrm{H}-3$ & 1.0000 & NO & $\ldots .$. & 1003 \\
\hline $\mathrm{HE}-3$ & 1.0000 & NO & $\ldots .$. & 2003 \\
\hline $\mathrm{HE}$ & 1.0000 & NO & $12-45678$ & 2004 \\
\hline LI-6 & 1.0000 & NO & 12345678 & 3006 \\
\hline
\end{tabular}


Table M8.2.1 (continued)

\begin{tabular}{|c|c|c|c|c|}
\hline $\begin{array}{l}\text { Alphanumeric } \\
\text { description } \\
\text { standard } \\
\text { composition }\end{array}$ & $\begin{array}{l}\text { Theoretical } \\
\text { density } \\
\rho \text { th in } \\
\text { grams/cc }\end{array}$ & $\begin{array}{l}\text { Resonance } \\
\text { data or } \\
\text { Bondarenko } \\
\text { data available }\end{array}$ & $\begin{array}{l}\text { Cross-section } \\
\text { libraries for this } \\
\text { standard composition } \\
\text { (see Table M8.2.2) }\end{array}$ & $\begin{array}{l}\text { List of nuclides in this } \\
\text { standard composition (with } \\
\text { isotopes the user may } \\
\text { specifiy shown in brackets) }\end{array}$ \\
\hline II-7 & 1.0000 & NO & 12345678 & 3007 \\
\hline $\mathrm{BE}$ & 1.8480 & NO & 12345678 & 4009 \\
\hline BEBOUND & 1.8480 & NO & $\ldots . .$. & 4309 \\
\hline B & 2.3730 & NO & $1-3 \ldots 7-$ & 5000 \\
\hline B-10 & 2.1950 & NO & 12345678 & 5010 \\
\hline B-11 & 2.4130 & NO & 12345678 & 5011 \\
\hline C & 2.3000 & NO & 12345678 & 6012 \\
\hline C-GRAPHITE & 2.3000 & NO & $\ldots . .7$ & 6312 \\
\hline $\mathbf{N}$ & 1.0000 & NO & 12345678 & 7014 \\
\hline $\mathrm{N}-15$ & 1.0000 & NO & $\ldots \ldots$ & 7015 \\
\hline 0 & 1.0000 & NO & 12345678 & 8016 \\
\hline O-17 & 1.0000 & NO & $\ldots \ldots$ & 8017 \\
\hline $\mathrm{F}$ & 1.0000 & NO & 12345678 & 9019 \\
\hline $\mathrm{NA}$ & 1.0000 & YES & 12345678 & 11023 \\
\hline MG & 1.0000 & NO & 12345678 & 12000 \\
\hline AI & 2.6989 & No & 12345678 & 13027 \\
\hline
\end{tabular}

NUREG/CR-0200,

Vol. 3, Rev. 4

M8.2.16 
Table M8.2.1 (continued)

\begin{tabular}{|c|c|c|c|c|}
\hline $\begin{array}{l}\text { Alphanumeric } \\
\text { description } \\
\text { standard } \\
\text { composition }\end{array}$ & $\begin{array}{l}\text { Theoretical } \\
\text { density } \\
\text { pth in } \\
\text { grams/cc }\end{array}$ & $\begin{array}{l}\text { Resonance } \\
\text { data or } \\
\text { Bondarenko } \\
\text { data available }\end{array}$ & $\begin{array}{l}\text { Cross-section } \\
\text { libraries for this } \\
\text { standard composition } \\
\text { (see Table M8.2.2) }\end{array}$ & $\begin{array}{l}\text { List of nuclides in this } \\
\text { standard composition (with } \\
\text { isotopes the user may } \\
\text { specifiy shown in brackets) }\end{array}$ \\
\hline SI & 2.3230 & NO & 12345678 & 14000 \\
\hline SI-28 & 1.0000 & NO & $\ldots . . .$. & 14028 \\
\hline $\mathbf{P}$ & 1.0000 & NO & $12-45-78$ & 15031 \\
\hline$S$ & 1.0000 & No & $12345-78$ & 16000 \\
\hline S-32 & 1.0000 & No & $\ldots \ldots$ & 16032 \\
\hline CL & 1.0000 & No & 12345678 & 17000 \\
\hline AR & 1.0000 & No & $\ldots \ldots$ & 18000 \\
\hline $\mathbf{K}$ & 0.8595 & NO & 12345678 & 19000 \\
\hline K-39 & 1.0000 & No & $\ldots \ldots$ & 19039 \\
\hline $\mathrm{CA}$ & 1.545 & No & 12345678 & 20000 \\
\hline $\mathrm{CA}-40$ & 1.0000 & NO & $\ldots \ldots$ & 20040 \\
\hline SC-45 & 1.0000 & No & $\ldots . .7-$ & 21045 \\
\hline TI & 4.5400 & No & 12345678 & 22000 \\
\hline V & 6.1100 & No & $\ldots .$. & 23000 \\
\hline V-51 & 6.1100 & No & $12-45-78$ & 23051 \\
\hline CR & 7.1900 & YES & 12345678 & 24000 \\
\hline
\end{tabular}

NUREG/CR-0200,

Vol. 3, Rev. 4 
Table M8.2.1 (continued)

\begin{tabular}{|c|c|c|c|c|}
\hline $\begin{array}{l}\text { Alphanumeric } \\
\text { description } \\
\text { standard } \\
\text { composition }\end{array}$ & $\begin{array}{l}\text { Theoretical } \\
\text { density } \\
\rho \text { th in } \\
\text { grams/cc }\end{array}$ & $\begin{array}{l}\text { Resonance } \\
\text { data or } \\
\text { Bondarenko } \\
\text { data available }\end{array}$ & $\begin{array}{l}\text { Cross-section } \\
\text { libraries for this } \\
\text { standard composition } \\
\text { (see Table M8.2.2) }\end{array}$ & $\begin{array}{l}\text { List of nuclides in this } \\
\text { standard composition (with } \\
\text { isotopes the user may } \\
\text { specifiy shown in brackets) }\end{array}$ \\
\hline CR-ESIGT & 7.1900 & NO & $\ldots . .$. & 24301 \\
\hline CRSS & 7.1900 & No & $12345-78$ & 24304 \\
\hline CRINCONEL & 7.1900 & NO & $12345-78$ & 24404 \\
\hline $\mathbf{M N}$ & 7.4400 & YES & 12345678 & 25055 \\
\hline MNSS & 7.4400 & NO & $\ldots . . .$. & 25304 \\
\hline $\mathrm{FE}$ & 7.8740 & YES & 12345678 & 26000 \\
\hline FE-ESIGT & 7.8740 & No & $\ldots \ldots$ & 26301 \\
\hline FESS & 7.8740 & No & $12345-78$ & 26304 \\
\hline FEINCONEL & 7.8740 & No & $12345-78$ & 26404 \\
\hline $\mathrm{CO}$ & 8.9000 & YES & $12-45-78$ & 27059 \\
\hline CO-59 & 8.9000 & YES & $12-45-78$ & 27059 \\
\hline NI & 8.9020 & YES & 12345678 & 28000 \\
\hline NI-ESIGT & 8.9020 & NO & $\ldots \ldots$ & 28301 \\
\hline NISS & 8.9020 & No & $12345-78$ & 28304 \\
\hline NIINCONEL & 8.9020 & No & $12345-78$ & 28404 \\
\hline $\mathrm{CU}$ & 8.9600 & YES & 123456.8 & 29000 \\
\hline
\end{tabular}

NUREG/CR-0200,

Vol. 3, Rev. 4

M8.2.18 
Table M8.2.1 (continued)

\begin{tabular}{|c|c|c|c|c|}
\hline $\begin{array}{l}\text { Alphanumeric } \\
\text { description } \\
\text { standard } \\
\text { composition }\end{array}$ & $\begin{array}{l}\text { Theoretical } \\
\text { density } \\
\text { oth in } \\
\text { grams/cc }\end{array}$ & $\begin{array}{l}\text { Resonance } \\
\text { data or } \\
\text { Bondarenko } \\
\text { data available }\end{array}$ & $\begin{array}{l}\text { Cross-section } \\
\text { libraries for this } \\
\text { standard composition } \\
\text { (see Table M8.2.2) }\end{array}$ & $\begin{array}{l}\text { List of nuclides in this } \\
\text { standard composition (with } \\
\text { isotopes the user may } \\
\text { specifiy shown in brackets) }\end{array}$ \\
\hline $\mathrm{ZN}$ & 7.1330 & NO & $1 \ldots-7-$ & 30000 \\
\hline $\mathrm{ZN}-64$ & 1.0000 & NO & $\ldots$ & 30064 \\
\hline GA & 1.0000 & NO & $\ldots-$. & 31000 \\
\hline GE-72 & 1.0000 & YES & $\ldots \ldots 78$ & 32072 \\
\hline GE-73 & 1.0000 & YES & $\ldots \ldots 78$ & 32073 \\
\hline GE-74 & 1.0000 & YES & $\ldots \ldots 78$ & 32074 \\
\hline GE-76 & 1.0000 & YES & $\ldots-.78$ & 32076 \\
\hline AS-75 & 1.0000 & YES & $\ldots \ldots 78$ & 33075 \\
\hline SE-74 & 1.0000 & YES & $\ldots \ldots$ & 34074 \\
\hline SE-76 & 1.0000 & YES & $\ldots-78$ & 34076 \\
\hline SE-77 & 1.0000 & YES & $\ldots \ldots 78$ & 34077 \\
\hline SE-78 & 1.0000 & YES & $\ldots \ldots 78$ & 34078 \\
\hline SE-80 & 1.0000 & YES & $\ldots-.78$ & 34080 \\
\hline SE-82 & 1.0000 & YES & $\ldots-78$ & 34082 \\
\hline BR-79 & 1.0000 & YES & $-2-45-78$ & 35079 \\
\hline BR-81 & 1.0000 & YES & $-2-45-78$ & 35081 \\
\hline
\end{tabular}

NUREG/CR-0200, 
Table M8.2.1 (continued)

\begin{tabular}{|c|c|c|c|c|}
\hline $\begin{array}{l}\text { Alphanumeric } \\
\text { description } \\
\text { standard } \\
\text { composition }\end{array}$ & $\begin{array}{l}\text { Theoretical } \\
\text { density } \\
\text { pth in } \\
\text { grams/cc }\end{array}$ & $\begin{array}{l}\text { Resonance } \\
\text { data or } \\
\text { Bondarenko } \\
\text { data available }\end{array}$ & $\begin{array}{l}\text { Cross-section } \\
\text { libraries for this } \\
\text { standard composition } \\
\text { (see Table M8.2.2) }\end{array}$ & $\begin{array}{l}\text { List of nuclides in this } \\
\text { standard composition (with } \\
\text { isotopes the user may } \\
\text { specifiy shown in brackets) }\end{array}$ \\
\hline KR-78 & 1.0000 & YES & $\ldots . . . .$. & 36078 \\
\hline $\mathrm{KR}-80$ & 1.0000 & YES & $\ldots \ldots 78$ & 36080 \\
\hline $\mathrm{KR}-82$ & 1.0000 & YES & $\ldots 3 \ldots 78$ & 36082 \\
\hline KR-83 & 1.0000 & YES & $--3 \ldots 78$ & 36083 \\
\hline $\mathrm{KR}-84$ & 1.0000 & YES & $\ldots \ldots 78$ & 36084 \\
\hline$K R-85$ & 1.0000 & NO & $-\ldots .-8$ & 36085 \\
\hline $\mathrm{KR}-86$ & 1.0000 & YES & $\ldots .78$ & 36086 \\
\hline RB-85 & 1.0000 & YES & $\ldots .78$ & 37085 \\
\hline RB-86 & 1.0000 & No & $\ldots .78$ & 37086 \\
\hline RB-87 & 1.0000 & YES & $\ldots .78$ & 37087 \\
\hline SR-84 & 1.0000 & YES & $\ldots . . .$. & 38084 \\
\hline SR-86 & 1.0000 & YES & $\ldots \ldots 78$ & 38086 \\
\hline SR-87 & 1.0000 & YES & $\ldots$ & 38087 \\
\hline SR-88 & 1.0000 & YES & $\ldots . .78$ & 38088 \\
\hline SR-89 & 1.0000 & No & $\ldots \ldots 78$ & 38089 \\
\hline SR-90 & 1.0000 & NO & $\ldots \ldots 78$ & 38090 \\
\hline
\end{tabular}

NUREG/CR-0200,

Vol. 3, Rev. 4

M8.2.20 
Table M8.2.1 (continued)

\begin{tabular}{|c|c|c|c|c|}
\hline $\begin{array}{l}\text { Alphanumeric } \\
\text { description } \\
\text { standard } \\
\text { composition }\end{array}$ & $\begin{array}{l}\text { Theoretical } \\
\text { density } \\
\rho \text { th in } \\
\text { grams/cc }\end{array}$ & $\begin{array}{l}\text { Resonance } \\
\text { data or } \\
\text { Bondarenko } \\
\text { data available }\end{array}$ & $\begin{array}{l}\text { Cross-section } \\
\text { libraries for this } \\
\text { standard composition } \\
\text { (see Table M8.2.2) }\end{array}$ & $\begin{array}{l}\text { List of nuclides in this } \\
\text { standard composition (with } \\
\text { isotopes the user may } \\
\text { specifiy shown in brackets) }\end{array}$ \\
\hline Y-89 & 1.0000 & YES & $\ldots \ldots 78$ & 39089 \\
\hline Y-90 & 1.0000 & NO & $\ldots \ldots 78$ & 39090 \\
\hline$Y-91$ & 1.0000 & NO & $\cdots-78$ & 39091 \\
\hline ZR & 6.4400 & YES & 12345678 & 40000 \\
\hline ZR-90 & 1.0000 & YES & $\ldots . . .8$ & 40090 \\
\hline ZR-91 & 1.0000 & YES & $\ldots . . .8$ & 40091 \\
\hline ZR-92 & 1.0000 & YES & $\ldots-8$ & 40092 \\
\hline ZR-93 & 1.0000 & NO & $\ldots . . .8$ & 40093 \\
\hline ZR-94 & 1.0000 & YES & $\ldots . .-8$ & 40094 \\
\hline ZR-95 & 1.0000 & NO & $\ldots-8$ & 40095 \\
\hline ZR-96 & 1.0000 & YES & $\ldots . . .8$ & 40096 \\
\hline NB & 1.0000 & YES & $1-3-\ldots$ & 41093 \\
\hline NB-93 & 1.0000 & YES & $-2-45-78$ & 41093 \\
\hline NB-94 & 1.0000 & YES . & $\ldots . . .8$ & 41094 \\
\hline NB-95 & 1.0000 & NO & $-\ldots .-8$ & 41095 \\
\hline
\end{tabular}

M8.2.21

NUTREG/CR-0200, Vol. 3, Rev. 4 
Table M8.2.1 (continued)

\begin{tabular}{|c|c|c|c|c|}
\hline $\begin{array}{l}\text { Alphanumeric } \\
\text { description } \\
\text { standard } \\
\text { composition }\end{array}$ & $\begin{array}{l}\text { Theoretical } \\
\text { density } \\
\text { oth in } \\
\text { grams/cc }\end{array}$ & $\begin{array}{l}\text { Resonance } \\
\text { data or } \\
\text { Bondarenko } \\
\text { data available }\end{array}$ & $\begin{array}{l}\text { Cross-section } \\
\text { libraries for this } \\
\text { standard composition } \\
\text { (see Table M8.2.2) }\end{array}$ & $\begin{array}{l}\text { List of nuclides in this } \\
\text { standard composition (with } \\
\text { isotopes the user may } \\
\text { specifiy shown in brackets) }\end{array}$ \\
\hline MO & 10.2200 & YES & 12345678 & 42000 \\
\hline $\mathrm{MO}-92$ & 1.0000 & YES & $\ldots . . .$. & 42092 \\
\hline MO-94 & 1.0000 & YES & $\ldots \ldots-. .-8$ & 42094 \\
\hline MO-95 & 1.0000 & YES & $-3--8$ & 42095 \\
\hline MO-96 & 1.0000 & YES & $\ldots-.--8$ & 42096 \\
\hline MO-97 & 1.0000 & YES & $\ldots . . .8$ & 42097 \\
\hline MO-98 & 1.0000 & YES & $\ldots . . .-8$ & 42098 \\
\hline MO-99 & 1.0000 & NO & $\ldots-\ldots 8$ & 42099 \\
\hline MO-100 & 1.0000 & YES & $\ldots \ldots$ & 42100 \\
\hline TC-99 & 1.0000 & YES & $--3--78$ & 43099 \\
\hline RU-96 & 1.0000 & NO & $\ldots \ldots$ & 44096 \\
\hline RU-98 & 1.0000 & NO & $\ldots \ldots$ & 44098 \\
\hline RU-99 & 1.0000 & YES & $\ldots-\ldots 8$ & 44099 \\
\hline RU-100 & 1.0000 & YES & $--3 \cdots 78$ & 44100 \\
\hline RU-101 & 1.0000 & YES & $--3--78$ & 44101 \\
\hline RU-102 & 1.0000 & YES & $-3--78$ & 44102 \\
\hline
\end{tabular}

NUREG/CR-0200,

Vol. 3, Rev. 4

M8.2.22 
Table M8.2.1 (continued)

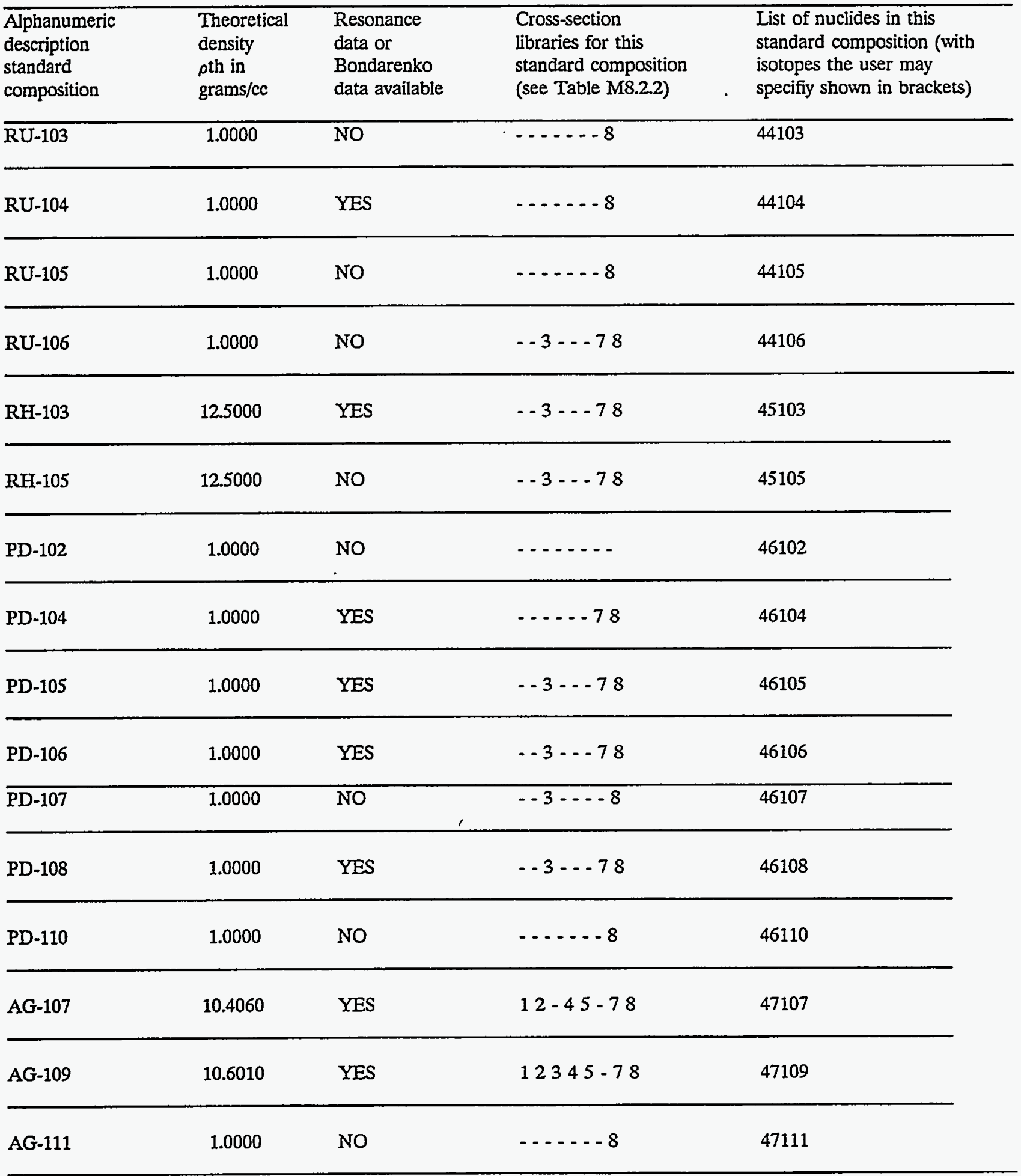


Table M8.2.1 (continued)

\begin{tabular}{|c|c|c|c|c|}
\hline $\begin{array}{l}\text { Alphanumeric } \\
\text { description } \\
\text { standard } \\
\text { composition }\end{array}$ & $\begin{array}{l}\text { Theoretical } \\
\text { density } \\
\rho \text { th in } \\
\text { grams/cc }\end{array}$ & $\begin{array}{l}\text { Resonance } \\
\text { data or } \\
\text { Bondarenko } \\
\text { data available }\end{array}$ & $\begin{array}{l}\text { Cross-section } \\
\text { libraries for this } \\
\text { standard composition } \\
\text { (see Table M8.2.2) }\end{array}$ & $\begin{array}{l}\text { List of nuclides in this } \\
\text { standard composition (with } \\
\text { isotopes the user may } \\
\text { specifiy shown in brackets) }\end{array}$ \\
\hline $\mathrm{CD}$ & 8.6500 & NO & $12-45-78$ & 48000 \\
\hline$C D-106$ & 1.0000 & NO & $\ldots . .$. & 48106 \\
\hline CD-108 & 1.0000 & NO & $\ldots . . .8$ & 48108 \\
\hline$C D-110$ & 1.0000 & YES & $\ldots . .8$ & 48110 \\
\hline$C D-111$ & 1.0000 & YES & $\ldots . . .8$ & 48111 \\
\hline $\mathrm{CD}-112$ & 1.0000 & YES & $\ldots . . .8$ & 48112 \\
\hline $\mathrm{CD}-113$ & 8.6500 & YES & $-3 \ldots 78$ & 48113 \\
\hline$C D-114$ & 1.0000 & YES & 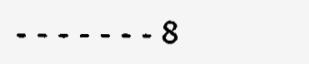 & 48114 \\
\hline CD-115M & 1.0000 & NO & $\ldots . . .8$ & 48601 \\
\hline CD-116 & 1.0000 & YES & $\ldots . .-8$ & 48116 \\
\hline $\mathbb{N}-113$ & 1.0000 & YES & $12-45-78$ & 49113 \\
\hline IN-115 & 1.0000 & YES & $12345-78$ & 49115 \\
\hline SN & 7.3100 & NO & $123456-8$ & 50000 \\
\hline SN-112 & 1.0000 & YES & $\ldots$ & 50112 \\
\hline SN-114 & 1.0000 & YES & $\ldots . .$. & 50114 \\
\hline
\end{tabular}

NUREG/CR-0200,

Vol. 3, Rev. 4

M8.2.24 
Table M8.2.1 (continued)

\begin{tabular}{|c|c|c|c|c|}
\hline $\begin{array}{l}\text { Alphanumeric } \\
\text { description } \\
\text { standard } \\
\text { composition }\end{array}$ & $\begin{array}{l}\text { Theoretical } \\
\text { density } \\
\text { oth in } \\
\text { grams/cc }\end{array}$ & $\begin{array}{l}\text { Resonance } \\
\text { data or } \\
\text { Bondarenko } \\
\text { data available }\end{array}$ & $\begin{array}{l}\text { Cross-section } \\
\text { libraries for this } \\
\text { standard composition } \\
\text { (see Table M8.2.2) }\end{array}$ & $\begin{array}{l}\text { List of nuclides in this } \\
\text { standard composition (with } \\
\text { isotopes the user may } \\
\text { specifiy shown in brackets) }\end{array}$ \\
\hline SN-115 & 1.0000 & YES & $\ldots . . .8$ & 50115 \\
\hline SN-116 & 1.0000 & YES & $\ldots \ldots-8$ & 50116 \\
\hline SN-117 & 1.0000 & YES & $\ldots . . .8$ & 50117 \\
\hline SN-118 & 1.0000 & YES & $\ldots \ldots 78$ & 50118 \\
\hline SN-119 & 1.0000 & YES & $\ldots .-.8$ & 50119 \\
\hline SN-120 & 1.0000 & YES & $\ldots \ldots-\ldots$ & 50120 \\
\hline SN-122 & 1.0000 & YES & $\ldots-\ldots 8$ & 50122 \\
\hline SN-123 & 1.0000 & NO & $\ldots-1$ & 50123 \\
\hline SN-124 & 1.0000 & YES & $\ldots . . .8$ & 50124 \\
\hline SN-125 & 1.0000 & NO & $\ldots . . .-8$ & 50125 \\
\hline SN-126 & 1.0000 & NO & $\ldots . . .8$ & 50126 \\
\hline SB-121 & 1.0000 & YES & $\ldots . . .8$ & 51121 \\
\hline SB-123 & 1.0000 & YES & $\ldots-\ldots 8$ & 51123 \\
\hline SB-124 & 1.0000 & NO & $\ldots \ldots 78$ & 51124 \\
\hline SB-125 & 1.0000 & No & $\ldots . . .-8$ & 51125 \\
\hline SB-126 & 1.0000 & NO & $\ldots . . .-8$ & 51126 \\
\hline
\end{tabular}

NUREG/CR-0200, 
Table M8.2.1 (continued)

\begin{tabular}{|c|c|c|c|c|}
\hline $\begin{array}{l}\text { Alphanumeric } \\
\text { description } \\
\text { standard } \\
\text { composition }\end{array}$ & $\begin{array}{l}\text { Theoretical } \\
\text { density } \\
\rho \text { th in } \\
\text { grams/cc }\end{array}$ & $\begin{array}{l}\text { Resonance } \\
\text { data or } \\
\text { Bondarenko } \\
\text { data available }\end{array}$ & $\begin{array}{l}\text { Cross-section } \\
\text { libraries for this } \\
\text { standard composition } \\
\text { (see Table M8.2.2) }\end{array}$ & $\begin{array}{l}\text { List of nuclides in this } \\
\text { standard composition (with } \\
\text { isotopes the user may } \\
\text { specifiy shown in brackets) }\end{array}$ \\
\hline TE-120 & 1.0000 & NO & $\ldots . . . .$. & 52120 \\
\hline TE-122 & 1.0000 & YES & $\ldots \ldots$ & 52122 \\
\hline TE-123 & 1.0000 & YES & $\ldots . . .8$ & 52123 \\
\hline TE-124 & 1.0000 & YES & $\ldots \ldots 8$ & 52124 \\
\hline TE-125 & 1.0000 & YES & 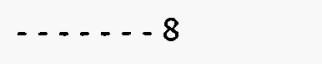 & 52125 \\
\hline TE-126 & 1.0000 & YES & $\ldots .78$ & 52126 \\
\hline TE-127M & 1.0000 & NO & $-\ldots .-8$ & 52601 \\
\hline TE-128 & 1.0000 & YES & $\ldots . . .8$ & 52128 \\
\hline TE-129M & 1.0000 & No & $\ldots-8$ & 52611 \\
\hline TE-130 & 1.0000 & YES & 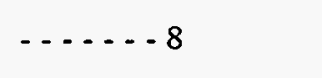 & 52130 \\
\hline TE-132 & 1.0000 & No & $\ldots . .-8$ & 52132 \\
\hline $\mathrm{I}-127$ & 1.0000 & YES & $\ldots . . .8$ & 53127 \\
\hline I- 129 & 1.0000 & YES & $\ldots 3 \ldots 78$ & 53129 \\
\hline I-130 & 1.0000 & NO & $\ldots . . .8$ & 53130 \\
\hline I-131 & 1.0000 & NO & $\cdots 3 \ldots 78$ & 53131 \\
\hline I-135 & 1.0000 & No & $\ldots \ldots$ & 53135 \\
\hline
\end{tabular}

NUREG/CR-0200,

Vol. 3, Rev. 4

M8.2.26 
Table M8.2.1 (continued)

\begin{tabular}{|c|c|c|c|c|}
\hline $\begin{array}{l}\text { Alphanumeric } \\
\text { description } \\
\text { standard } \\
\text { composition }\end{array}$ & $\begin{array}{l}\text { Theoretical } \\
\text { density } \\
\text { oth in } \\
\text { grams/cc }\end{array}$ & $\begin{array}{l}\text { Resonance } \\
\text { data or } \\
\text { Bondarenko } \\
\text { data available }\end{array}$ & $\begin{array}{l}\text { Cross-section } \\
\text { libraries for this } \\
\text { standard composition } \\
\text { (see Table M8.2.2) }\end{array}$ & $\begin{array}{l}\text { List of nuclides in this } \\
\text { standard composition (with } \\
\text { isotopes the user may } \\
\text { specifiy shown in brackets) }\end{array}$ \\
\hline XE-124 & 1.0000 & YES & $\ldots-7$ & 54124 \\
\hline $\mathrm{XE}-126$ & 1.0000 & YES & $\ldots-.-7$ & 54126 \\
\hline XE-128 & 1.0000 & YES & $\ldots .-78$ & 54128 \\
\hline $\mathrm{XE}-129$ & 1.0000 & YES & $\ldots-78$ & 54129 \\
\hline $\mathrm{XE}-130$ & 1.0000 & YES & $\ldots .-.78$ & 54130 \\
\hline$X E-131$ & 1.0000 & YES & $-3 \ldots-78$ & 54131 \\
\hline XE-132 & 1.0000 & YES & $\ldots .-78$ & 54132 \\
\hline XE-133 & 1.0000 & NO & $--3-\ldots 8$ & 54133 \\
\hline XE-134 & 1.0000 & YES & $\ldots \ldots 78$ & 54134 \\
\hline XE-135 & 1.0000 & NO & $-23-5-78$ & 54135 \\
\hline $\mathrm{XE}-136$ & 1.0000 & $\mathrm{NO}$ & $--3---78$ & 54136 \\
\hline CS-133 & 1.8730 & YES & $-23-5-78$ & 55133 \\
\hline CS-134 & 1.8730 & NO & $-.3-.78$ & 55134 \\
\hline CS-135 & 1.8730 & NO & $-.3-.-78$ & 55135 \\
\hline CS-136 & 1.0000 & YES & $\ldots .-. .8$ & 55136 \\
\hline CS-137 & 1.0000 & NO & $\ldots-.-.8$ & 55137 \\
\hline
\end{tabular}

NUREG/CR-0200, 
Table M8.2.1 (continued)

\begin{tabular}{|c|c|c|c|c|}
\hline $\begin{array}{l}\text { Alphanumeric } \\
\text { description } \\
\text { standard } \\
\text { composition }\end{array}$ & $\begin{array}{l}\text { Theoretical } \\
\text { density } \\
\text { oth in } \\
\text { grams/cc }\end{array}$ & $\begin{array}{l}\text { Resonance } \\
\text { data or } \\
\text { Bondarenko } \\
\text { data available }\end{array}$ & $\begin{array}{l}\text { Cross-section } \\
\text { libraries for this } \\
\text { standard composition } \\
\text { (see Table M8.2.2) }\end{array}$ & $\begin{array}{l}\text { List of nuclides in this } \\
\text { standard composition (with } \\
\text { isotopes the user may } \\
\text { specifiy shown in brackets) }\end{array}$ \\
\hline BA-134 & 1.0000 & YES & $-\ldots-8$ & 56134 \\
\hline BA-135 & 1.0000 & YES & $\ldots . .8$ & 56135 \\
\hline BA-136 & 1.0000 & YES & $\ldots .-8$ & 56136 \\
\hline BA-137 & 1.0000 & YES & $\cdots-8$ & 56137 \\
\hline BA-138 & 1.0000 & No & $12-45-78$ & 56138 \\
\hline BA-140 & 1.0000 & NO & - . - . 8 & 56140 \\
\hline LA-139 & 1.0000 & YES & $--3--78$ & 57139 \\
\hline LA-140 & 1.0000 & No & $\cdots . .-8$ & 57140 \\
\hline CE-140 & 1.0000 & No & 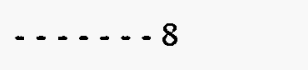 & 58140 \\
\hline CE-141 & 1.0000 & NO & 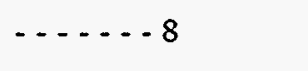 & 58141 \\
\hline CE-142 & 1.0000 & No & 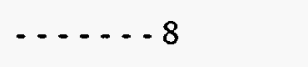 & 58142 \\
\hline CE-143 & 1.0000 & NO & 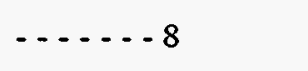 & 58143 \\
\hline CE-144 & 1.0000 & NO & $\ldots$ & 58144 \\
\hline PR-141 & 1.0000 & YES & $--3 \ldots 78$ & 59141 \\
\hline PR-142 & 1.0000 & No & $\cdots-.-8$ & 59142 \\
\hline PR-143 & 1.0000 & No & $--3--78$ & 59143 \\
\hline
\end{tabular}

NUREG/CR-0200,

Vol. 3, Rev. 4 
Table M8.2.1 (continued)

\begin{tabular}{|c|c|c|c|c|}
\hline $\begin{array}{l}\text { Alphanumeric } \\
\text { description } \\
\text { standard } \\
\text { composition }\end{array}$ & $\begin{array}{l}\text { Theoretical } \\
\text { density } \\
\text { pth in } \\
\text { grams/cc }\end{array}$ & $\begin{array}{l}\text { Resonance } \\
\text { data or } \\
\text { Bondarenko } \\
\text { data available }\end{array}$ & $\begin{array}{l}\text { Cross-section } \\
\text { libraries for this } \\
\text { standard composition } \\
\text { (see Table M8.2.2) }\end{array}$ & $\begin{array}{l}\text { List of nuclides in this } \\
\text { standard composition (with } \\
\text { isotopes the user may } \\
\text { specifiy shown in brackets) }\end{array}$ \\
\hline ND-142 & 1.0000 & YES & $\ldots . . .-8$ & 60142 \\
\hline ND-143 & 6.9600 & YES & $--3--78$ & 60143 \\
\hline ND-144 & 1.0000 & YES & $--3--78$ & 60144 \\
\hline ND-145 & 6.9600 & YES & $-3-\ldots 8$ & 60145 \\
\hline ND-146 & 1.0000 & YES & $\ldots . . .8$ & 60146 \\
\hline ND-147 & 1.0000 & No & $\ldots . . .8$ & 60147 \\
\hline ND-148 & 1.0000 & YES & $-.3-.78$ & 60148 \\
\hline ND-150 & 1.0000 & YES & $\ldots .-.-8$ & 60150 \\
\hline PM-147 & 1.0000 & YES & $-3 \ldots 78$ & 61147 \\
\hline PM-148 & 1.0000 & NO & $--3--78$ & 61148 \\
\hline PM-148M & 1.0000 & YES & ........ & 61601 \\
\hline PM-149 & 1.0000 & No &.---8 & 61149 \\
\hline PM-151 & 1.0000 & NO & $\ldots . . .8$ & 61151 \\
\hline SM-144 & 1.0000 & NO & $\ldots . . . . .$. & 62144 \\
\hline SM-147 & 1.0000 & YES & $--3 \ldots 78$ & 62147 \\
\hline SM-148 & 1.0000 & NO & $--3 \ldots-78$ & 62148 \\
\hline
\end{tabular}

NUREG/CR-0200, 
Table M8.2.1 (continued)

\begin{tabular}{|c|c|c|c|c|}
\hline $\begin{array}{l}\text { Alphanumeric } \\
\text { description } \\
\text { standard } \\
\text { composition }\end{array}$ & $\begin{array}{l}\text { Theoretical } \\
\text { density } \\
\text { oth in } \\
\text { grams/cc }\end{array}$ & $\begin{array}{l}\text { Resonance } \\
\text { data or } \\
\text { Bondarenko } \\
\text { data available }\end{array}$ & $\begin{array}{l}\text { Cross-section } \\
\text { libraries for this } \\
\text { standard composition } \\
\text { (see Table M8.2.2) }\end{array}$ & $\begin{array}{l}\text { List of nuclides in this } \\
\text { standard composition (with } \\
\text { isotopes the user may } \\
\text { specifiy shown in brackets) }\end{array}$ \\
\hline SM-149 & 7.7000 & YES & $--3 \ldots 78$ & 62149 \\
\hline SM-150 & 7.7000 & YES & $--3 \ldots 78$ & 62150 \\
\hline SM-151 & 7.7000 & YES & $--3--78$ & 62151 \\
\hline SM-152 & 7.7000 & YES & $--3 \ldots-78$ & 62152 \\
\hline SM-153 & 1.0000 & NO & $-\ldots-8$ & 62153 \\
\hline SM-154 & 1.0000 & YES & $--3 \ldots 78$ & 62154 \\
\hline EU & 5.2400 & YES & $\ldots . .$. & 63000 \\
\hline EU-151 & 1.0000 & YES & $\ldots .78$ & 63151 \\
\hline EU-152 & 1.0000 & YES & $\ldots .78$ & 63152 \\
\hline EU-153 & 5.2400 & YES & $--3 \ldots 78$ & 63153 \\
\hline EU-154 & 5.2400 & YES & $--3 \ldots 78$ & 63154 \\
\hline EU-155 & 5.2400 & NO & $--3--8$ & 63155 \\
\hline EU-156 & 1.0000 & NO & $-\ldots .-8$ & 63156 \\
\hline EU-157 & 1.0000 & NO & $-\ldots-8$ & 63157 \\
\hline GD & 1.0000 & YES & $12-45-78$ & 64000 \\
\hline GD-152 & 1.0000 & YES & $\ldots$. & 64152 \\
\hline
\end{tabular}

NUREG/CR-0200,

Vol. 3, Rev. 4

M8.2.30 
Table M8.2.1 (continued)

\begin{tabular}{|c|c|c|c|c|}
\hline $\begin{array}{l}\text { Alphanumeric } \\
\text { description } \\
\text { standard } \\
\text { composition }\end{array}$ & $\begin{array}{l}\text { Theoretical } \\
\text { density } \\
\text { pth in } \\
\text { grams/cc }\end{array}$ & $\begin{array}{l}\text { Resonance } \\
\text { data or } \\
\text { Bondarenko } \\
\text { data available }\end{array}$ & $\begin{array}{l}\text { Cross-section } \\
\text { libraries for this } \\
\text { standard composition } \\
\text { (see Table M8.2.2) }\end{array}$ & $\begin{array}{l}\text { List of nuclides in this } \\
\text { standard composition (with } \\
\text { isotopes the user may } \\
\text { specifiy shown in brackets) }\end{array}$ \\
\hline GD-154 & 1.0000 & YES & $-\ldots-8$ & 64154 \\
\hline GD-155 & 1.0000 & YES & $--3 \ldots-8$ & 64155 \\
\hline GD-156 & 1.0000 & YES & 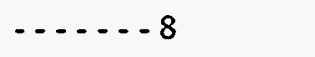 & 64156 \\
\hline GD-157 & 1.0000 & YES & $-3 \ldots 8$ & 64157 \\
\hline GD-158 & 1.0000 & YES & $\ldots-.-8$ & 64158 \\
\hline GD-160 & 1.0000 & YES & $\ldots-.-8$ & 64160 \\
\hline TB-159 & 1.0000 & YES & $\ldots \ldots 78$ & 65159 \\
\hline TB-160 & 1.0000 & NO & 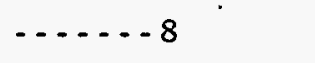 & 65160 \\
\hline DY-160 & 1.0000 & YES & $\ldots-. .-8$ & 66160 \\
\hline DY-161 & 1.0000 & YES & - . - - 8 & 66161 \\
\hline DY-162 & 1.0000 & YES & $\ldots-.-8$ & 66162 \\
\hline DY-163 & 1.0000 & YES & $\cdots-1$ & 66163 \\
\hline DY-164 & 1.0000 & YES & $12-45-78$ & 66164 \\
\hline HO-165 & 1.0000 & YES & $\ldots-78$ & 67165 \\
\hline ER-166 & 1.0000 & YES & $\ldots .78$ & 68166 \\
\hline ER-167 & 1.0000 & YES & $\ldots . .78$ & 68167 \\
\hline
\end{tabular}

NUREG/CR-0200, 
Table M8.2.1 (continued)

\begin{tabular}{|c|c|c|c|c|}
\hline $\begin{array}{l}\text { Alphanumeric } \\
\text { description } \\
\text { standard } \\
\text { composition }\end{array}$ & $\begin{array}{l}\text { Theoretical } \\
\text { density } \\
\rho \text { th in } \\
\text { grams/cc }\end{array}$ & $\begin{array}{l}\text { Resonance } \\
\text { data or } \\
\text { Bondarenko } \\
\text { data available }\end{array}$ & $\begin{array}{l}\text { Cross-section } \\
\text { libraries for this } \\
\text { standard composition } \\
\text { (see Table M8.2.2) }\end{array}$ & $\begin{array}{l}\text { List of nuclides in this } \\
\text { standard composition (with } \\
\text { isotopes the user may } \\
\text { specifiy shown in brackets) }\end{array}$ \\
\hline TM-169 & 1.0000 & YES & $\ldots . . .$. & 69169 \\
\hline LU-175 & 1.0000 & YES & $12-45-78$ & 71175 \\
\hline IU-176 & 1.0000 & YES & $12-45-78$ & 71176 \\
\hline $\mathrm{HF}$ & 13.2700 & YES & $12-45-78$ & 72000 \\
\hline HF-174 & 1.0000 & YES & $\ldots . .$. & 72174 \\
\hline $\mathrm{HF}-176$ & 1.0000 & YES & $\ldots . .$. & 72176 \\
\hline HF-177 & 1.0000 & YES & $\ldots . . .$. & 72177 \\
\hline $\mathrm{HF}-178$ & 1.0000 & YES & $\ldots . .$. & 72178 \\
\hline $\mathrm{HF}-179$ & 1.0000 & YES & $\ldots . .$. & 72179 \\
\hline HF-180 & 1.0000 & YES & $\ldots$ & 72180 \\
\hline TA-181 & 1.0000 & YES & $12-45678$ & 73181 \\
\hline TA-182 & 1.0000 & YES & ..... 7 - & 73182 \\
\hline w & 19.2300 & YES & $--3--6-$ & 74000 \\
\hline W-182 & 1.0000 & YES & $12-45-78$ & 74182 \\
\hline W-183 & 1.0000 & YES & $12-45-78$ & 74183 \\
\hline W-184 & 1.0000 & YES & $12-45-78$ & 74184 \\
\hline
\end{tabular}

NUREG/CR-0200,

Vol. 3, Rev. 4

M8.2.32 
Table M8.2.1 (continued)

\begin{tabular}{|c|c|c|c|c|}
\hline $\begin{array}{l}\text { Alphanumeric } \\
\text { description } \\
\text { standard } \\
\text { composition }\end{array}$ & $\begin{array}{l}\text { Theoretical } \\
\text { density } \\
\rho \text { th in } \\
\text { grams/cc }\end{array}$ & $\begin{array}{l}\text { Resonance } \\
\text { data or } \\
\text { Bondarenko } \\
\text { data available }\end{array}$ & $\begin{array}{l}\text { Cross-section } \\
\text { libraries for this } \\
\text { standard composition } \\
\text { (see Table M8.2.2) }\end{array}$ & $\begin{array}{l}\text { List of nuclides in this } \\
\text { standard composition (with } \\
\text { isotopes the user may } \\
\text { specifiy shown in brackets) }\end{array}$ \\
\hline W-186 & 1.0000 & YES & $12-45-78$ & 74186 \\
\hline RE-185 & 1.0000 & YES & $12-45-78$ & 75185 \\
\hline RE-187 & 1.0000 & YES & $12345-78$ & 75187 \\
\hline IR-191 & 1.0000 & NO & $\ldots .7$ & 77191 \\
\hline IR-193 & 1.0000 & NO & $\ldots . .7-$ & 77193 \\
\hline $\mathrm{AU}$ & 1.0000 & YES & $12345-78$ & 79197 \\
\hline PB & 11.3500 & NO & 12345678 & 82000 \\
\hline $\mathrm{BI}$ & 9.1780 & No & $\ldots . .$. & 83209 \\
\hline BI-209 & 9.1780 & No & $\ldots . . .$. & 83209 \\
\hline THL-230 & 1.0000 & YES & $\ldots \ldots$ & 90230 \\
\hline TH-232 & 1.0000 & YES & $12345-78$ & 90232 \\
\hline PA-231 & 1.0000 & YES & $\ldots$ & 91231 \\
\hline PA-233 & 1.0000 & YES & $12345--8$ & 91233 \\
\hline $\mathrm{U}-232$ & 1.0000 & YES & $\ldots \ldots$ & 92232 \\
\hline U-233 & 1.0000 & YES & $12345-78$ & 92233 \\
\hline U-234 & 1.0000 & YES & $12345-78$ & 92234 \\
\hline
\end{tabular}

NUREG/CR-0200,

Vol. 3, Rev. 4 
Table M8.2.1 (continued)

\begin{tabular}{|c|c|c|c|c|}
\hline $\begin{array}{l}\text { Alphanumeric } \\
\text { description } \\
\text { standard } \\
\text { composition }\end{array}$ & $\begin{array}{l}\text { Theoretical } \\
\text { density } \\
\text { pth in } \\
\text { grams/cc }\end{array}$ & $\begin{array}{l}\text { Resonance } \\
\text { data or } \\
\text { Bondarenko } \\
\text { data available }\end{array}$ & $\begin{array}{l}\text { Cross-section } \\
\text { libraries for this } \\
\text { standard composition } \\
\text { (see Table M8.2.2) }\end{array}$ & $\begin{array}{l}\text { List of nuclides in this } \\
\text { standard composition (with } \\
\text { isotopes the user may } \\
\text { specifiy shown in brackets) }\end{array}$ \\
\hline U-235 & 1.0000 & YES & 12345678 & 92235 \\
\hline $\mathrm{U}-236$ & 1.0000 & YES & $12345-78$ & 92236 \\
\hline U-237 & 1.0000 & YES & . . . & 92237 \\
\hline U-238 & 1.0000 & YES & 12345678 & 92238 \\
\hline NP-237 & 1.0000 & YES & $12345--8$ & 93237 \\
\hline NP-238 & 1.0000 & YES & $\ldots \ldots$ & 93238 \\
\hline PU-236 & 1.0000 & YES & $\ldots$ & 94236 \\
\hline PU-237 & 1.0000 & NO & $\ldots . . .$. & 94237 \\
\hline PU-238 & 1.0000 & YES & $12345-78$ & 94238 \\
\hline PU-239 & 1.0000 & YES & 12345678 & 94239 \\
\hline PU-240 & 1.0000 & YES & 12345678 & 94240 \\
\hline PU-241 & 1.0000 & YES & $12345-78$ & 94241 \\
\hline PU-242 & 1.0000 & YES & $12345-78$ & 94242 \\
\hline PU-243 & 1.0000 & YES & $\ldots . .$. & 94243 \\
\hline PU-244 & 1.0000 & YES & $\ldots \ldots$ & 94244 \\
\hline AM-241 & 1.0000 & YES & $12-45--8$ & 95241 \\
\hline
\end{tabular}

NUREG/CR-0200,

Vol. 3, Rev. 4

M8.2.34 
Table M8.2.1 (continued)

\begin{tabular}{|c|c|c|c|c|}
\hline $\begin{array}{l}\text { Alphanumeric } \\
\text { description } \\
\text { standard } \\
\text { composition }\end{array}$ & $\begin{array}{l}\text { Theoretical } \\
\text { density } \\
\text { oth in } \\
\text { grams/cc }\end{array}$ & $\begin{array}{l}\text { Resonance } \\
\text { data or } \\
\text { Bondarenko } \\
\text { data available }\end{array}$ & $\begin{array}{l}\text { Cross-section } \\
\text { libraries for this } \\
\text { standard composition } \\
\text { (see Table M8.2.2) }\end{array}$ & $\begin{array}{l}\text { List of nuclides in this } \\
\text { standard composition (with } \\
\text { isotopes the user may } \\
\text { specifiy shown in brackets) }\end{array}$ \\
\hline AM-242 & 1.0000 & YES & $\ldots$ & 95242 \\
\hline$A M-242 M$ & 1.0000 & YES & $\ldots . .$. & 95601 \\
\hline AM-243 & 1.0000 & YES & $12-45--8$ & 95243 \\
\hline CM-241 & 1.0000 & NO & $\ldots . .$. & 96241 \\
\hline CM-242 & 1.0000 & YES & $\ldots \ldots$ & 96242 \\
\hline CM-243 & 1.0000 & YES & $\ldots \ldots$ & 96243 \\
\hline CM-244 & 1.0000 & YES & $12-45--8$ & 96244 \\
\hline CM-245 & 1.0000 & YES & $\ldots \ldots$ & 96245 \\
\hline CM-246 & 1.0000 & YES & $\ldots \ldots$ & 96246 \\
\hline CM-247 & 1.0000 & YES & $\ldots \ldots$ & 96247 \\
\hline CM-248 & 1.0000 & YES & $\ldots$ & 96248 \\
\hline BK-249 & 1.0000 & YES & $\ldots . .$. & 97249 \\
\hline CF-249 & 1.0000 & YES & $\ldots \ldots$ & 98249 \\
\hline CF-250 & 1.0000 & YES . & $\ldots \ldots$ & 98250 \\
\hline $\mathrm{CF}-251$ & 1.0000 & YES & $\ldots \ldots$ & 98251 \\
\hline CF-252 & 1.0000 & YES & $\ldots$ & 98252 \\
\hline
\end{tabular}

NUREG/CR-0200, 
Table M8.2.1 (continued)

\begin{tabular}{|c|c|c|c|c|}
\hline $\begin{array}{l}\text { Alphanumeric } \\
\text { description } \\
\text { standard } \\
\text { composition }\end{array}$ & $\begin{array}{l}\text { Theoretical } \\
\text { density } \\
\rho \text { th in } \\
\text { grams/cc }\end{array}$ & $\begin{array}{l}\text { Resonance } \\
\text { data or } \\
\text { Bondarenko } \\
\text { data available }\end{array}$ & $\begin{array}{l}\text { Cross-section } \\
\text { libraries for this } \\
\text { standard composition } \\
\text { (see Table M8.2.2) }\end{array}$ & $\begin{array}{l}\text { List of nuclides in this } \\
\text { standard composition (with } \\
\text { isotopes the user may } \\
\text { specifiy shown in brackets) }\end{array}$ \\
\hline CF-253 & 1.0000 & YES & $\ldots \ldots$ & 98253 \\
\hline ES-253 & 1.0000 & YES & $\ldots$ & 99253 \\
\hline
\end{tabular}

NUREG/CR-0200,

Vol. 3, Rev. 4

M8.2.36 
Table M8.2.2 SCALE cross-section libraries

\begin{tabular}{lcc}
\hline $\begin{array}{c}\text { Alphanumeric } \\
\text { name }\end{array}$ & $\begin{array}{c}\text { Description } \\
\text { reference }\end{array}$ & $\begin{array}{c}\text { Reference number used } \\
\text { in Tables M8.2.1 } \\
\text { and M8.3.1 }\end{array}$ \\
\hline HANSEN-ROACH & Sect. M4.2.3 & 1 \\
27GROUPNDF4 & Sect. M4.2.2 & 2 \\
123GROUPGMTH & Sect. M4.2.4 & 3 \\
218GROUPNDF4 & Sect. M4.2.1 & 4 \\
27N-18COUPLE & Sect. M4.2.7 & 5 \\
22N-18COUPLE & Sect. M4.2.6 & 6 \\
18GROUPGAMMA & Sect. M4.2.5 & 7 \\
27BURNUPLIB & Sect. M4.2.8 & 8 \\
\hline
\end{tabular}

${ }^{a}$ SCALE allows some terse data specification. The user-supplied alphanumeric name need specify only as much of the name as is necessary for uniqueness. However, the terse name must match as many characters as are specified. For example, $\mathrm{H}, \mathrm{HA}, \mathrm{HAN}$, etc., are sufficient to specify the HANSEN-ROACH library. HAR is incorrect because three characters are specified and only two of them match. H-R is incorrect because three characters are specified and only the first one matches. 


\section{M8.3 TABLE OF AVAILABLE SOLUTIONS}

The Standard Composition Library (Table M8.2.1) describes the various compounds, alloys, elements, and isotopes one may use in defining the material mixtures for a given problem. In addition to the various materials listed there, one is also free to use any of the fissile solutions listed in Table M8.3.1. Indeed, the user is encouraged to treat the solutions listed in Table M8.3.1 as he would any other standard composition. Using empirical fits to experimental data, the code will then automatically calculate the volume fraction corresponding to the heavy metal, acid, and water components of the solution.

Table M8.3.1 Table of available solutions

\begin{tabular}{lcccc}
\hline $\begin{array}{c}\text { Alphanumeric } \\
\text { description of the } \\
\text { solution }\end{array}$ & $\begin{array}{c}\text { Resonance data } \\
\text { or Bondarenko } \\
\text { data available }\end{array}$ & $\begin{array}{c}\text { Scattering cross- } \\
\text { section data } \\
\text { available at } \\
\text { multiple } \\
\text { temperatures }\end{array}$ & $\begin{array}{c}\text { Cross-section } \\
\text { libraries for which } \\
\text { this solution is } \\
\text { available (see } \\
\text { Table M8.2.2) }\end{array}$ & $\begin{array}{c}\text { List of nuclides in } \\
\text { this fissile solution } \\
\text { (first nuclide } \\
\text { listed is a } \\
\text { variable isotope } \\
\text { nuclide) }\end{array}$ \\
\hline SOLNUO2F2 & YES & YES & $12345-78$ & 920001001 \\
SOLNUO2(NO3)2 & YES & YES & $12345-78$ & 90169019 \\
SOLNPU(NO3)4 & YES & YES & $12345-78$ & 90001001 \\
& & & & 940001016 \\
\end{tabular}




\section{M8.4 MULTIPLE-ISOTOPE MATERIALS}

Materials in the Standard Composition Library that contain multiple isotopes of a single element are denoted in Table M8.2.1. For materials containing lithium, boron, bromine, silver, indium, tungsten, rhenium, uranium, or plutonium, the user is free to specify the isotopic distribution using items $6 \mathrm{a}$ and $6 \mathrm{~b}$ of the Standard Composition Specification Card discussed in Sects. M7.4.4 and C4.4.4. Alternatively, the user may elect not to enter this data, thereby telling the code to assume the default values shown in Table M8.4.1. In all cases except plutonium, Table M8.4.1 lists the naturally occurring abundance of each isotope. In describing an arbitrary material, a multiple-isotope ID of $Z * 1000$ (where $Z$ is the nuclide charge number) can be used to denote the elements of Table M8.4.1. Then, if an isotope distribution other than the default values of Table M8.4.1 is desired, items $6 a$ and $6 b$ of the Standard Composition Specification Card (see Sect. M7.4.4) must be included.

Table M8.4.1. Multiple-isotope distribution table

\begin{tabular}{|c|c|c|c|c|c|c|c|}
\hline $\begin{array}{l}\text { Multiple- } \\
\text { isotope } \\
\text { ID }\end{array}$ & Material & ID & wt \% & $\begin{array}{l}\text { Multiple- } \\
\text { isotope } \\
\text { ID }\end{array}$ & Material & ID & wt $\%$ \\
\hline 3000 & Lithium & $\begin{array}{l}3006 \\
3007\end{array}$ & $\begin{array}{r}6.4996 \\
93.5004\end{array}$ & 75000 & Rhenium & $\begin{array}{l}75185 \\
75187\end{array}$ & $\begin{array}{l}37.1482 \\
62.8518\end{array}$ \\
\hline 5000 & Boron & $\begin{array}{l}5010 \\
5011\end{array}$ & $\begin{array}{l}18.3022 \\
81.6978\end{array}$ & 92000 & Uranium & $\begin{array}{l}92233 \\
92234 \\
92235\end{array}$ & $\begin{array}{l}0.0000 \\
0.0056 \\
0.7050\end{array}$ \\
\hline 35000 & Bromine & $\begin{array}{l}35079 \\
35081\end{array}$ & $\begin{array}{l}50.0650 \\
49.9350\end{array}$ & & & $\begin{array}{l}92236 \\
92238\end{array}$ & $\begin{array}{r}0.0000 \\
99.2894\end{array}$ \\
\hline 47000 & Silver & $\begin{array}{l}47107 \\
47109\end{array}$ & $\begin{array}{l}51.3771 \\
48.6229\end{array}$ & 94000 & Plutonium & $\begin{array}{l}94238 \\
94239 \\
94240\end{array}$ & $\begin{array}{r}0.0 \\
100.0 \\
0.0\end{array}$ \\
\hline 49000 & Indium & $\begin{array}{l}49113 \\
49115\end{array}$ & $\begin{array}{r}4.2283 \\
95.7717\end{array}$ & & & $\begin{array}{l}94241 \\
94242\end{array}$ & $\begin{array}{l}0.0 \\
0.0\end{array}$ \\
\hline 74000 & Tungsten & $\begin{array}{l}74182 \\
74183 \\
74184 \\
74186\end{array}$ & $\begin{array}{l}26.0571 \\
14.2496 \\
30.7262 \\
28.9671\end{array}$ & & & & \\
\hline
\end{tabular}


NUREG/CR-0200

Revision 4

Volume 3, Section M9

ORNL/NUREG/CSD-2/V3/R4

Computing Applications Division

MARS: A MULTIPLE-ARRAY SYSTEM USING COMBINATORIAL GEOMETRY

J. T. West*

M. B. Emmett

Previously Published: December 1984

Revised Manuscript Completed: November 1994

Date Published: April 1995

Prepared for the

Office of Nuclear Material Safety and Safeguards

U.S. Nuclear Regulatory Commission

Washington, DC 20555

Under Interagency Agreement DOE 1886-8000-9B

NRC JCN No. B0009

\author{
Prepared by the \\ OAK RIDGE NATIONAL LABORATORY \\ managed by \\ MARTIN MARIETTA ENERGY SYSTEMS, INC. \\ for the \\ U.S. DEPARTMENT OF ENERGY \\ under contract DE-AC05-84OR21400
}

Formerly with Oak Ridge National Laboratory. 


$$
\text { - }
$$




\begin{abstract}
MARS is a combinatorial geometry method for modeling a Multiple-ARray System. It allows the user the ability to model many unique rectangular arrays with unlimited array nesting. In this system, arrays may contain arbitrary vacancies and may be arbitrarily positioned in space. Geometry may be modeled around an array and optionally repeated with the array. Array repetition and array nesting does not require additional computer memory; hence, MARS can model very complicated geometry systems with a minimum of computer memory requirements.
\end{abstract}




\section{CONTENTS}

Page

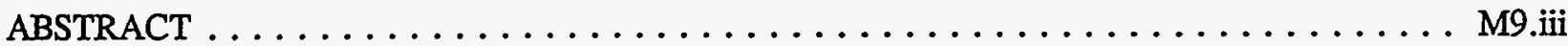

LIST OF FIGURES $\ldots \ldots \ldots \ldots \ldots \ldots \ldots \ldots \ldots \ldots \ldots \ldots \ldots \ldots \ldots \ldots \ldots$ M9.vii

LIST OF TABLES $\ldots \ldots \ldots \ldots \ldots \ldots \ldots \ldots \ldots \ldots \ldots \ldots \ldots \ldots \ldots \ldots \ldots \ldots \ldots \ldots$

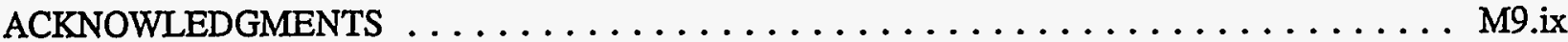

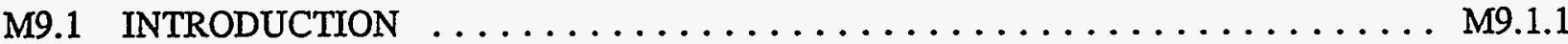

M9.2 COMBINATORIAL GEOMETRY THEORY AND TRACKING LOGIC $\ldots \ldots \ldots$. . . M M.2.1 M9.2.1 BODY DESCRIPTIONS . . . . . . . . . . . . . . . . . . M9.2.1

M9.2.1.1 Description of Body Types . . . . . . . . . . . . . M9.2.1

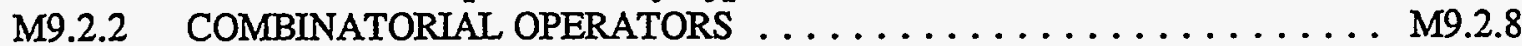

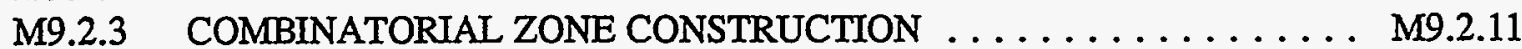

M9.2.4 COMBINATORIAL TRACKING LOGIC . . . . . . . . . . . . M9.2.12

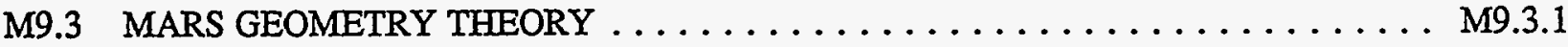

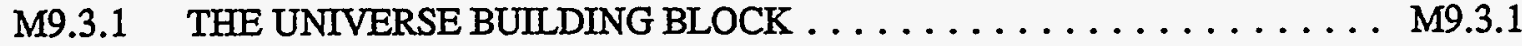

M9.3.2 MARS "ARRAY OF ARRAYS" CAPABILITY . . . . . . . . . . . M9.3.1

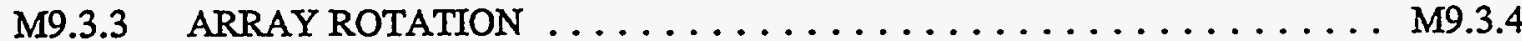

M9.3.4 MODEL CONSTRUCTION WITH MARS $\ldots \ldots \ldots \ldots \ldots \ldots \ldots \ldots$ M9.3.4

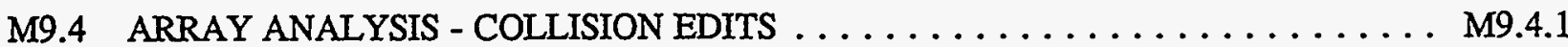

M9.4.1 ANALYSIS CRITERIA . . . . . . . . . . . . . . . . M9.4.1

M9.4.1.1 Location Criteria . . . . . . . . . . . . . . . . . . . . M9.4.1

M9.4.1.2 Media Criteria ..................... M9.4.2

M9.4.1.3 Response Criteria . . . . . . . . . . . . . . . M9.4.2

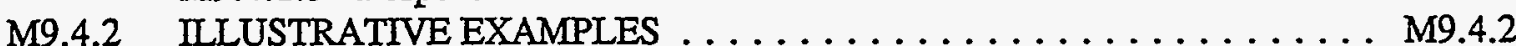

M9.5 COMBINATORIAL MARS OVERVIEW $\ldots \ldots \ldots \ldots \ldots \ldots \ldots \ldots \ldots \ldots \ldots$ M9.5.1

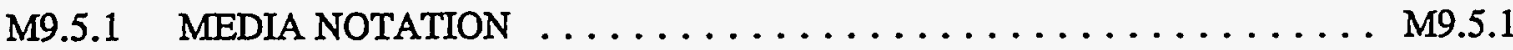

M9.5.2 TERMS AND DEFINITIONS $\ldots \ldots \ldots \ldots \ldots \ldots \ldots \ldots \ldots . \ldots \ldots . \ldots \ldots$

M9.5.3 RULES FOR ARRAY REPETITION . . . . . . . . . . . . . . M9.5.3

M9.6 MARS TRACKING LOGIC, SHORTFALLS, AND CORRECTIONS . . . . . . . . . M9.6.1

M9.6.1 PARTICLE NESTING TABLE FOR TRACKING . . . . . . . . . . . M9.6.1

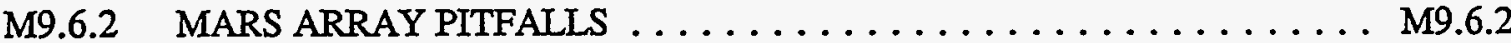

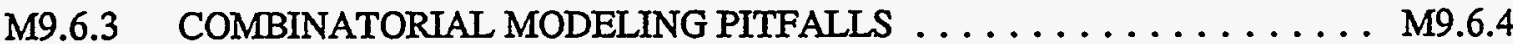

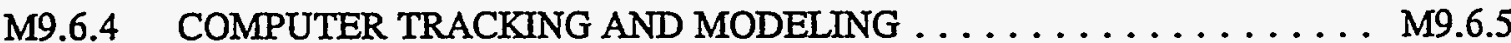

M9.A FREE-FORM COMBINATORIAL MARS INPUT INSTRUCTIONS $\ldots \ldots \ldots \ldots$. . . M9.A.1

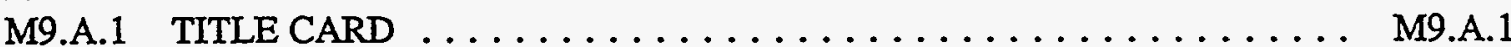

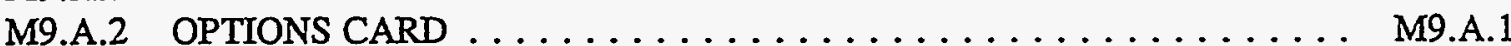

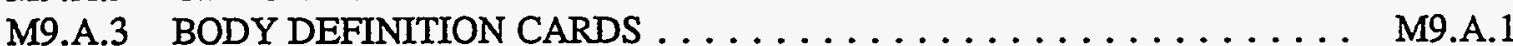

NUREG/CR-0200,

M9.v

Vol. 3, Rev. 4 


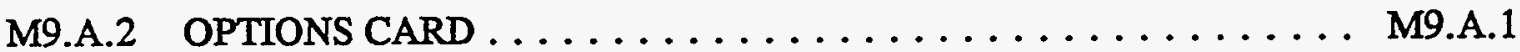

M9.A.3 BODY DEFINITION CARDS $\ldots \ldots \ldots \ldots \ldots \ldots \ldots \ldots$ M9.A.1

M9.A.4 INPUT ZONE DESCRIPTION CARDS $\ldots \ldots \ldots \ldots \ldots \ldots \ldots$ M9.A.1

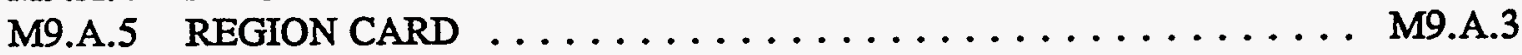

M9.A.6 UNIVERSE CARD $\ldots \ldots \ldots \ldots \ldots \ldots \ldots \ldots \ldots \ldots \ldots \ldots . \ldots \ldots$ M9.3

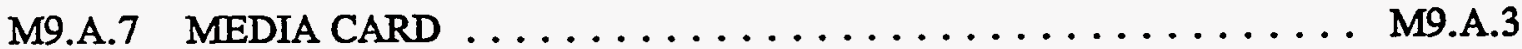

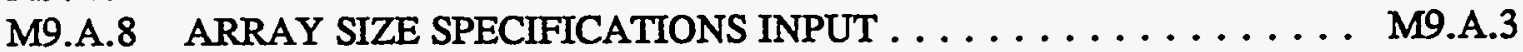

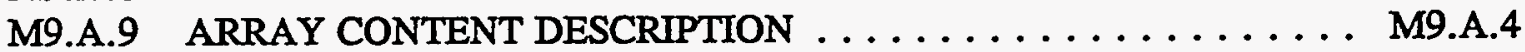

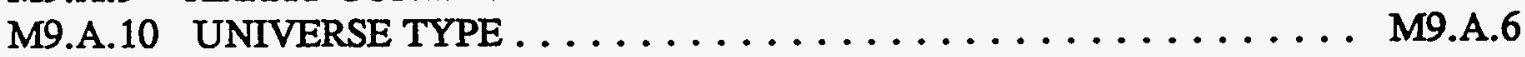

M9.B ILLUSTRATIVE EXAMPLES OF MARS GEOMETRY $\ldots \ldots \ldots \ldots \ldots$ M9.B.1

M9.B.1 AN UNCOMMON ARRAY SHAPE $\ldots \ldots \ldots \ldots \ldots \ldots \ldots \ldots$ M9.B.1

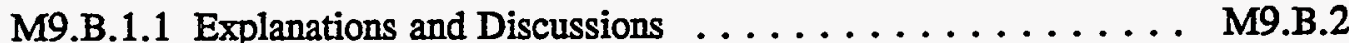

M9.B.2 OVERLAPPING PINS IN A $2 \times 2$ ARRAY $\ldots \ldots \ldots \ldots \ldots \ldots \ldots$ M9.B.7

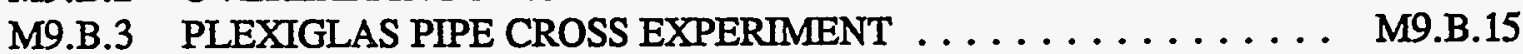

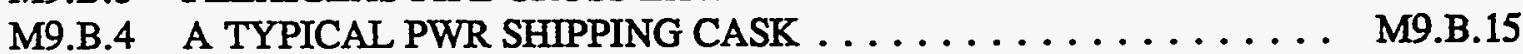

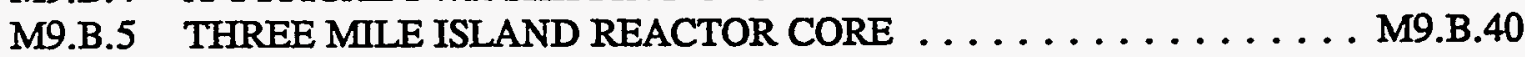

M9.B.6 INHERENTLY SUBCRITICAL INSERT DESIGN . . . . . . . M9.B.62

M9.C COMBINATORIAL GEOMETRY ZONE SUMMARY TABLE DESCRIPTION M9.C.1

M9.D INTERFACING THE MARS SUBROUTINES MODULE TO OTHER COMPUTER CODES $\ldots \ldots \ldots \ldots \ldots \ldots \ldots \ldots \ldots \ldots \ldots \ldots \ldots \ldots$ M9.D. 1

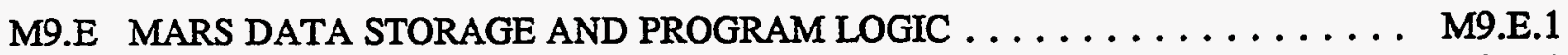

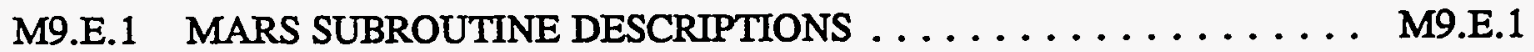

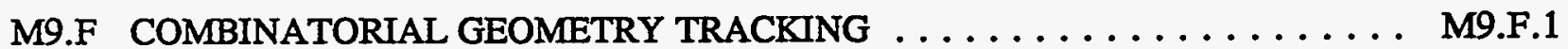

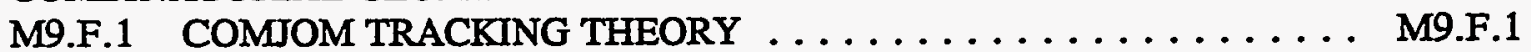

M9.G DIAGNOSTIC MESSAGES FROM MARS . . . . . . . . . . M9.G.1 M9.G.1 DIAGNOSTIC MESSAGES FROM MARS INPUT MODULE . . . . . M M.G.1 M9.G.2 DIAGNOSTIC MESSAGES FROM MARS TRACKING EVENTS . . M M.G.3

NUREG/CR-0200,

Vol. 3, Rev. 4

M9.vi 


\section{LIST OF FIGURES}

Page

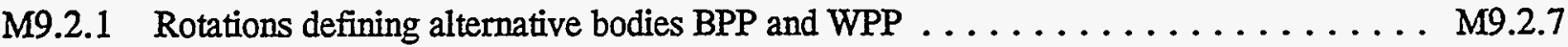

M9.2.2 Examples of combinatorial geometry method $\ldots \ldots \ldots \ldots \ldots \ldots \ldots \ldots \ldots . \ldots \ldots$

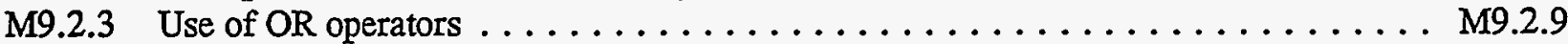

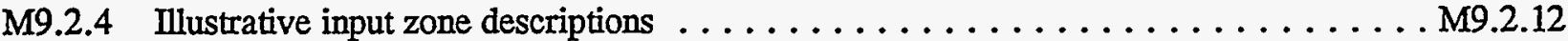

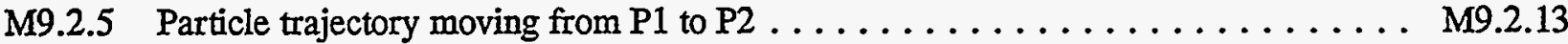

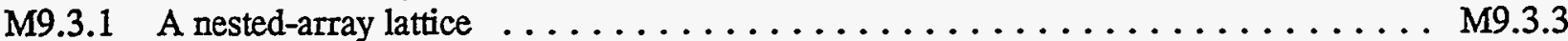

M9.B.1 Computer drawing of Sample Problem $1 \ldots \ldots \ldots \ldots \ldots \ldots \ldots \ldots \ldots \ldots . \ldots \ldots$. . . . . . . . . . . . .

M9.B.2 Computer input and output listing of Sample Problem $1 \ldots \ldots \ldots \ldots \ldots \ldots$. . . . . .

M9.B.3 Computer drawing of Sample Problem $2 \ldots \ldots \ldots \ldots \ldots \ldots \ldots \ldots \ldots . \ldots \ldots$

M9.B.4 Computer input and output listing of Sample Problem $2 \ldots \ldots \ldots \ldots \ldots \ldots$. . . . . . . . .

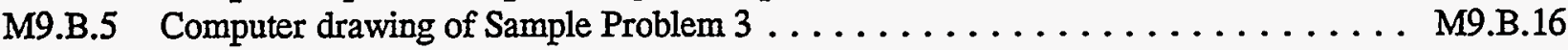

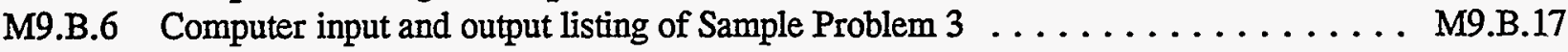

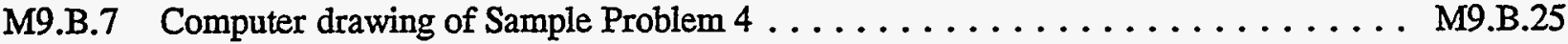

M9.B.8 Typical PWR shipping cask model construction $\ldots \ldots \ldots \ldots \ldots \ldots \ldots \ldots \ldots$. . . . . . . . . .

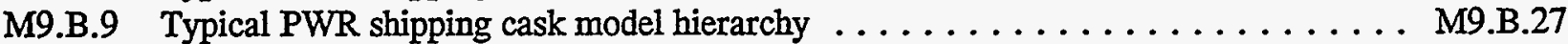

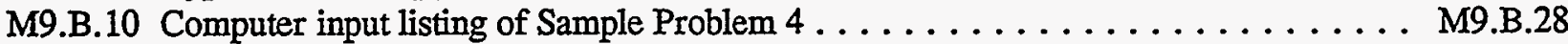

M9.B.11 Combinatorial MARS output listing of Sample Problem $4 \ldots \ldots \ldots \ldots \ldots \ldots$. . . . M9.B.30

M9.B.12 MARS array output listing for Sample Problem $4 \ldots \ldots \ldots \ldots \ldots \ldots \ldots$. . . . . . . . . . . . .

M9.B.13 Computer drawing of the Three Mile Island core

described by Sample Problem $5 \ldots \ldots \ldots$. . . . . . . . . M9.B.42

M9.B.14 Computer input and output listing of Sample Problem $5 \ldots \ldots \ldots \ldots \ldots \ldots$. . . . . . .

M9.B.15 Computer drawing of the inherently subcritical insert design . . . . . . . . . . . . M9.B.63

M9.B.16 Draftsman's drawing of the inherently subcritical insert design . . . . . . . . . M9.B.64

M9.B.17 Computer input and output listing of Sample Problem $6 \ldots \ldots \ldots \ldots \ldots \ldots$. . . . M9.B.65

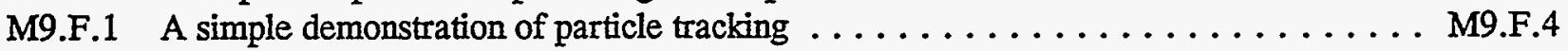




\section{LIST OF TABLES}

Page

M9.A.1 Input required for each body type $\ldots \ldots \ldots \ldots \ldots \ldots \ldots \ldots \ldots \ldots \ldots \ldots$. $\ldots \ldots$.2

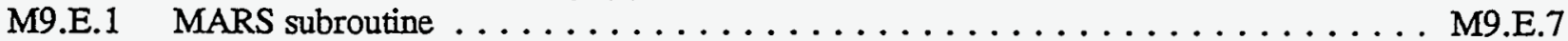

M9.E.2 MARS storage requirements $\ldots \ldots \ldots \ldots \ldots \ldots \ldots \ldots \ldots \ldots \ldots \ldots \ldots$ M9.E.8

M9.E.3 Layout of combinatorial geometry data in blank common . . . . . . . . . . . . M9.E.9

M9.E.4 Detailed layout of the FPD array in blank common . . . . . . . . . . . . . . M9.E.10

M9.E.5 Detailed layout of the MA array in blank common . . . . . . . . . . . . . M9.E.11

M9.E.6 Definitions of variables in common GOMLOC . . . . . . . . . . . . . . M9.E.13

M9.E.7 Definitions of variables in common PAREM as found

in combinatorial geometry . . . . . . . . . . . . . . . . .

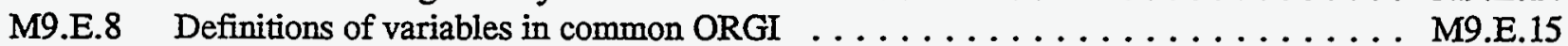

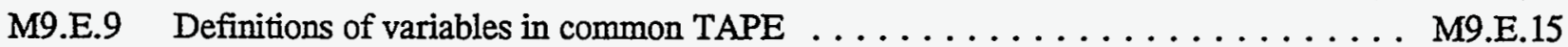

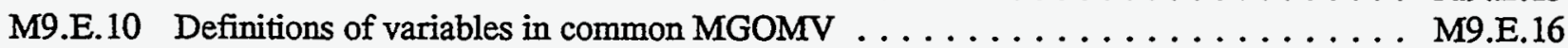

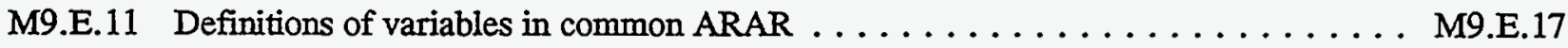

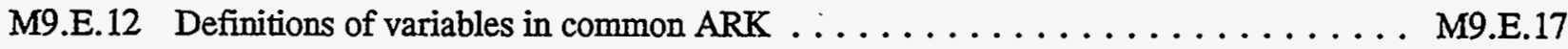

NUREG/CR-0200,

Vol. 3, Rev. 4

M9.viii 


\section{ACKNOWLEDGMENTS}

The direction and guidance of L. M. Petrie in developing the MARS system were invaluable. His patience and consultation aided in overcoming programming obstacles and spawning several fresh approaches to lattice modeling. This development is an offshoot of the array lattice modeling system originally developed by G. E. Whitesides in his KENO Monte Carlo program. The efforts of R. M. Westfall and R. H. Odegaarden, formerly of the U.S.Nuclear Regulatory Commission, are appreciated for their support and encouragement in funding this work. 


\section{M9.1 INTRODUCTION}

Rectangular lattice modeling demands as demonstrated by shipping casks, spent fuel pools, and reactor cores require a geometry system with a multiple-array capability and array manipulation techniques. The MARS geometry system has been developed to allow the nuclear analyst the ability to model complex lattice geometries efficiently and quickly with a minimum of geometric approximation and a minimum of computer memory requirements. The MARS system is a versatile system, meeting the most rigid modeling requirements in a flexible and general manner. The features the MARS system offers are as follows:

1. Many arrays may be modeled - each being unique.

2. Arrays may contain other arrays embedded in their lattice positions. The user may nest arrays inside arrays with no program limitation.

3. Arrays may be repeated by simple reference.

4. Arrays may have vacant lattice positions to model irregular array shapes. A particle may enter or exit an array from any cell in an array.

5. Geometry may be optionally modeled around an array and repeated with the array.

6. Arrays may be arbitrarily oriented. An array may be rotated as well as translated when it is repeated.

7. User geometry is modeled in simple coordinate systems called "universes," which are separate and independent from other parts of a geometry model.

8. Array input is verified for logical consistency and fit during input.

9. Basic geometry modeling uses combinatorial geometry for ease of input and flexibility. No restrictions are placed on the shape or complexity of individual cell content provided the outer shape of the cell is rectangular.

10. Efficient geometry data management minimizes the computer space requirements and has no external disk requirements. All geometry data reside in computer memory. Repeating a universe, repeating an array, and nesting arrays inside arrays do not require additional memory. Computer memory requirements are primarily a function of the number of unique arrays modeled and the size of each array. This feature allows complex models to be run on small computers.

11. MARS runs within MORSE-SGC. MORSE-SGC supergroups both the material cross sections and the particle tracking to minimize the computer memory requirements. Extensive effort has been placed on verifying and benchmarking this version of MORSE with the MARS geometry system. This version of MORSE is in the SCALE system and may run either in a stand-alone mode or in a SCALE control sequence. Further description of MORSE-SGC may be found in Sect. F9 of the SCALE manual. 
This document is intended to give a detailed description of the MARS geometry concepts and to illustrate some applications of the MARS modeling capability. Section M9.2 describes the rudiments of combinatorial geometry by introducing the concepts of material zone construction using basic combinatorial bodies. Section M9.3.1 discusses the MARS approach to lattice modeling and introduces the "universe concept," which is the link between combinatorial particle tracking and MARS lattice construction. In addition, Sect. M9.3.2 examines array nesting and the advantages nesting offers in lattice modeling. Section M9.3.3 recommends some broad procedures for the novice MARS user in model construction and development. Section M9.4 discusses the array analysis portion of MARS. The analysis part of MARS is a collision flux estimator with an edit feature that allows the user to obtain very specific and detailed reaction rate information from complicated models. Section M9.5 is a summary of the concepts introduced in Sects. M9.2 through M9.4. Section M9.6 discusses some subtle aspects of MARS tracking logic, including its weaknesses and some recommended corrective techniques for preventive modeling.

Appendices M9.A through M9.F give the mechanics for applying the MARS geometry system. Appendix M9.A gives the input requirements for both the combinatorial and array portions of MARS. Appendix M9.B gives five examples of problems modeled with MARS. Many of the MARS concepts are best understood in these applications. Appendix M9.C describes the combinatorial geometry zone transfer table printed at the completion of MARS tracking. Appendix M9.D describes how the MARS collection of subroutines may be interfaced into other Monte Carlo codes. Appendix M9.E discusses the MARS tracking logic and program flow. Appendix M9.F is presented as complementary information to the combinatorial ray tracing discussed in Sect. M9.2.4. A detailed numerical illustration of combinatorial tracking is given in Appendix M9.F. This appendix is a reprint of material presented in past MORSE workshops.

This document should orient the new MARS user to both combinatorial geometry modeling concepts and multiple nested-array concepts unique to the MARS system. The user should attempt to understand the geometry concepts developed in this document before generating MARS input. Users familiar with combinatorial geometry may wish to omit Sect. M9.2 and Appendix M9.C and concentrate on Sects. M9.3 and M9.6.

NUREG/CR-0200, Vol. 3, Rev. 4 


\section{M9.2 COMBINATORIAL GEOMETRY THEORY AND TRACKING LOGIC}

The combinatorial geometry package in the MARS system was obtained from earlier versions of the MORSE Monte Carlo code. Combinatorial geometry allows the description of physical structures by the combination of certain basic geometric shapes (bodies) such as rectangular parallelepipeds, right circular cylinders, etc. These basic shapes are combined using three logical operators-the AND operator using the " + " notation, the NOT operator using the "-" notation, and the OR operator using the "OR" notation. This section will introduce the concepts of simple geometric bodies, the operators to combine bodies into zones, and two types of zones-the input zone and its subset, the code zone.

\section{M9.2.1 BODY DESCRIPTIONS}

Combinatorial geometry (CG or COMJOM) describes general three-dimensional (3-D) material configurations by considering unions, differences, and intersections of simple bodies such as spheres, boxes, cylinders, etc. The description of material zones is accomplished by describing simple bodies and their relationships. This method allows space to be subdivided into unique zones of arbitrary shape. Each zone is the result of combining one or more of the following geometric bodies:

1. Rectangular Parallelepiped (RPP)

2. Box (an RPP arbitrarily rotated in space)

3. Sphere (SPH)

4. Right Circular Cylinder (RCC)

5. Right Elliptical Cylinder (REC)

6. Truncated Right-Angle Cone (TRC)

7. Arbitrary Convex Polyhedron of 4, 5, or 6 sides

8. Ellipsoid of Revolution (ELL)

9. Right-Angle Wedge (WED)

Body types 2-9 may be arbitrarily oriented with respect to the $x, y$, and $z$ coordinate axes. Body 1 , the RPP, must have its sides all parallel to coordinate planes. Alternative input descriptions for the BOX and the WED are described later in this section.

\section{M9.2.1.1 Description of Body Types}

The information required to specify each type of body is as follows: 
1. Rectangular Parallelepiped (RPP) - Specify the minimum and maximum values of the $\mathrm{x}$, $y$ and $z$ coordinates that bound the parallelepiped.

ORNL DWG 74-6762

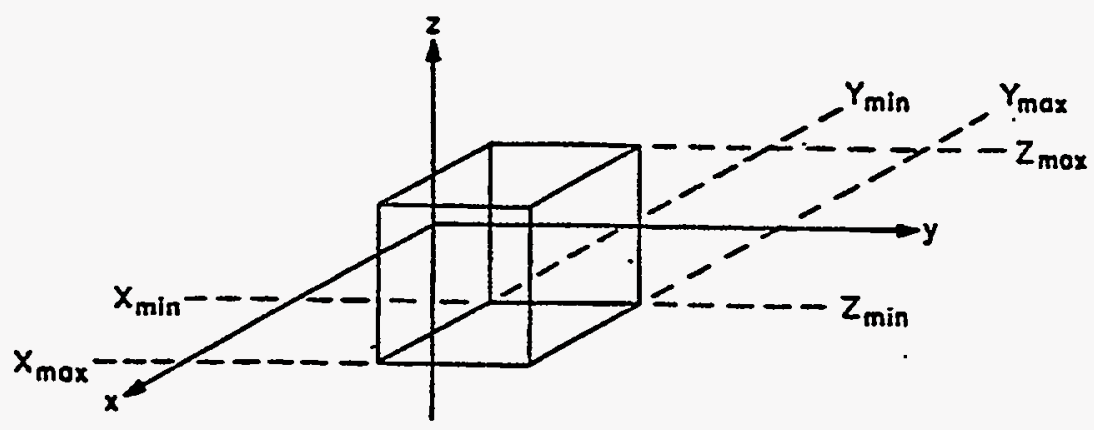

2. Sphere (SPH) - Specify the vertex, V, at the center and the scalar, $R$, denoting the radius

ORNL DWG 74-6763

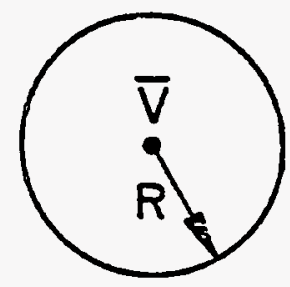

NUREG/CR-0200,

Vol. 3, Rev. 4

M9.2.2 
3. Right Circular Cylinder (RCC) - Specify the vertex, V, at the center of one base; a height vector, $H$, expressed in terms of its $x, y$, and $z$ components; and a scalar, $R$, denoting the radius.

ORNL DWG 74-6764

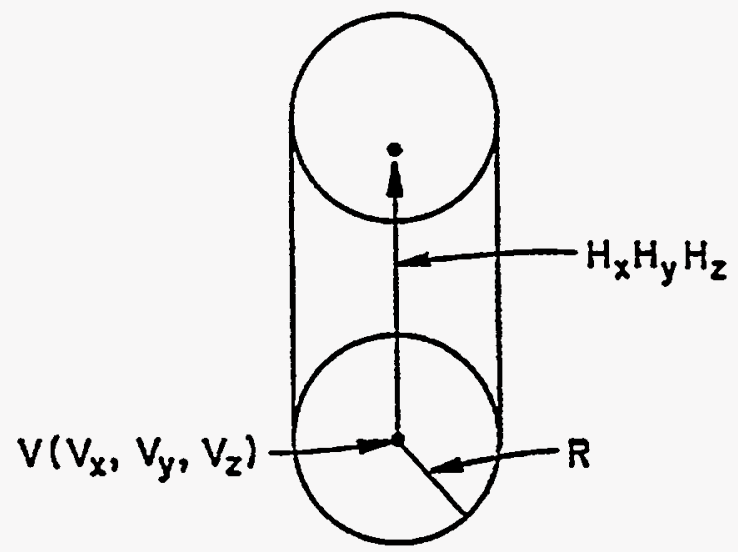

4. Right Elliptical Cylinder (REC) - Specify coordinates of the center of the base ellipse, a height vector, and two vectors in the plane of the base defining the major and minor axes.

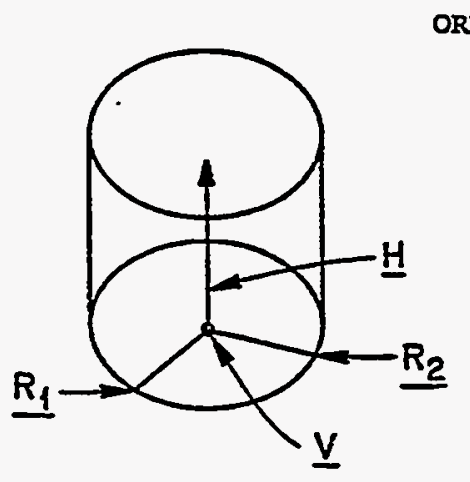


5. Truncated Right-Angle Cone (TRC) - Specify a vertex, V, at the center of the lower base; the height vector, $H$, expressed in terms of its $x, y$, and $z$ components; and two scalars, $R_{1}$ and $R_{2}$, denoting the radii of the lower and upper bases.

ORNL DWG 74-6766

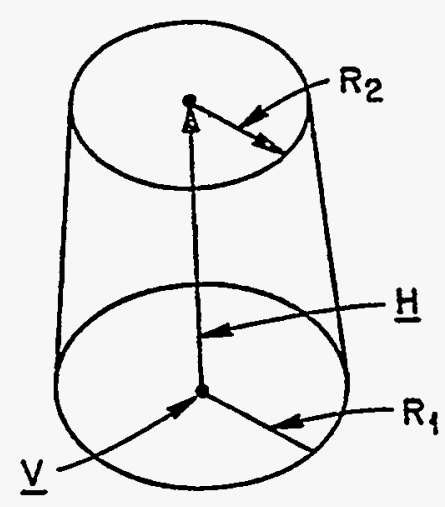

6. Ellipsoid (ELL) - Specify two vertices, $V_{1}$ and $V_{2}$, denoting the coordinates of the foci and a scalar, $R$, denoting the length of the major axis.

ORNL DWG 74-6767

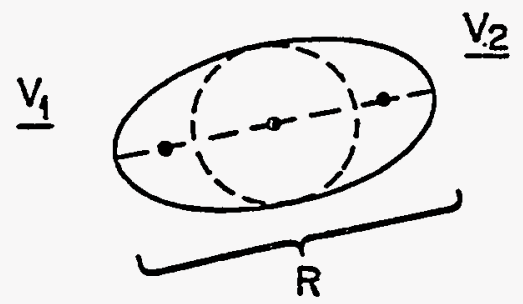


7. Right-Angle Wedge (WED) or (RAW) - Specify the vertex, V, at one of the corners by giving its $(x, y, z)$ coordinates. Specify a set of three mutually perpendicular vectors, $a_{i}$, with $a_{1}$ and $a_{2}$ describing the two legs of the right triangle of the wedge, that is, the $x, y$, and $z$ components of the height, width, and length vectors are given.

ORNL DWG 74-6768

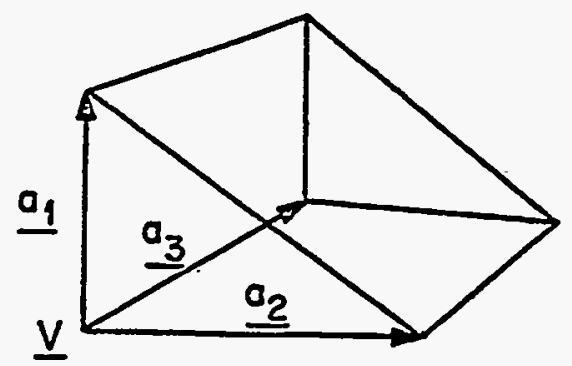

8. Box (BOX) - Specify the vertex, V, at one of the corners by giving its $(x, y, z)$ coordinates. Specify a set of three mutually perpendicular vectors, $a_{i}$, representing the height, width, and length of the box, respectively. That is, the $x, y$, and $z$ components of the height, width, and length vectors are given.

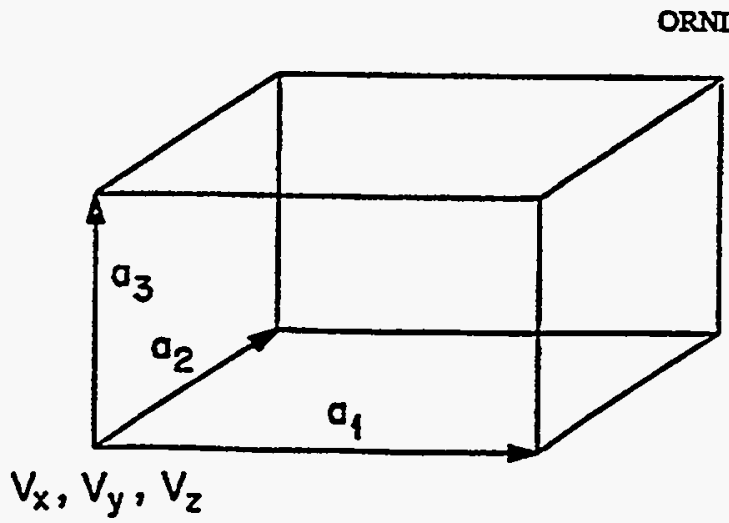

9. Arbitrary Polyhedron (ARB) - Assign an index (1 to 8) to each vertex. For each vertex, give the $x, y$, and $z$ coordinates. Each of the six faces is then described by a four-digit number giving the indices of the four vertex points in that face. For each face, these indices must be entered in either clockwise or counterclockwise order. 


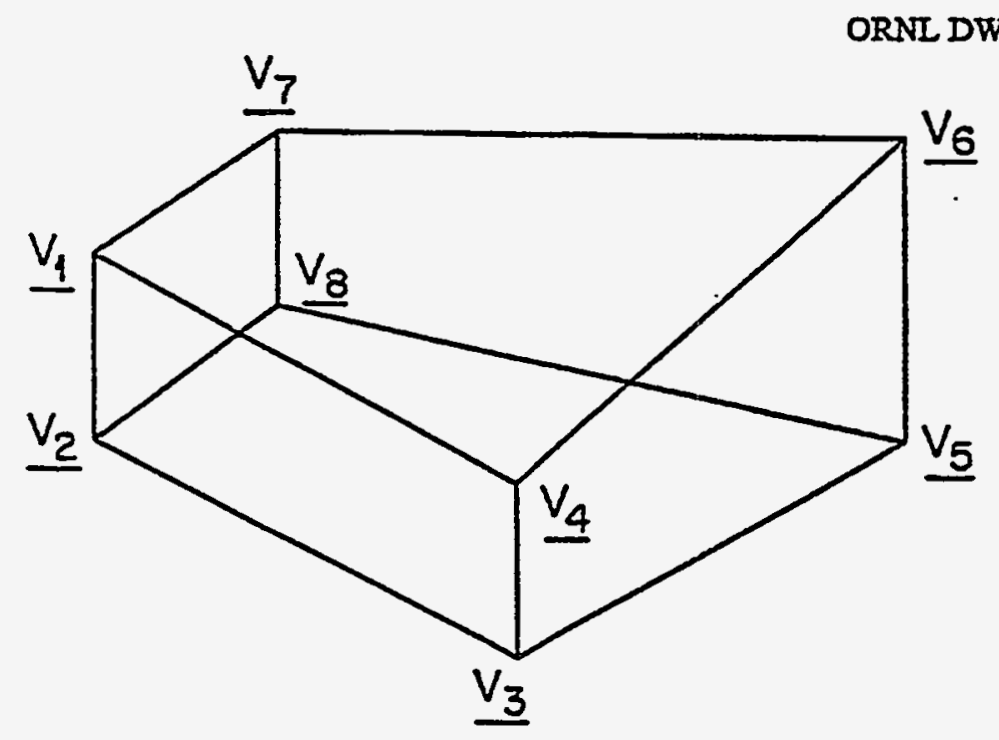

Alternative body descriptions for the BOX and the wedge (WED) are provided in the MARS version of combinatorial geometry. Presently the body data for the BOX and the WED (wedge) require the user to input a vertex and three displacement vectors for the axes of the body. An alternative method is available for entering these bodies. Very often the angle of rotation and the size of the body are known. The alternative body input is BPP for the BOX and WPP for the wedge. The "PP" refers to the parallelepiped input description used for the RPP. The BPP and WPP require the user to describe a rectangular parallelepiped, similar to the RPP, and then to enter three rotation angles. These angles are not simple Euclidean angles, but rather rotational angles. The first angle is an $X-Y$ rotation about the $\mathrm{Z}$ axis and is positive in the CLOCKWISE direction. This angle defines the first rotation of the RPP. The second angle is an $\mathrm{Y}-\mathrm{Z}$ rotation about the $\mathrm{X}$ axis and is positive in the CLOCKWISE direction. The second angle defines a rotation on the first rotation. The third angle input is an $X-Z$ rotation about the $\mathrm{Y}$ axis and is positive in the COUNTERCLOCKWISE direction. The third angle is a rotation on the second rotation. These three angles are input in degrees and may be either positive or negative. It is essential to remember that each angle defines a rotation that operates on the previous rotation. Figure M9.2.1 illustrates these rotations. The input for the BPP and the WPP is then translated into the BOX and WED input description for use by combinatorial geometry. The use of the BPP and WPP is optional, and the user should use the body description that is best understood.

NUREG/CR-0200, 


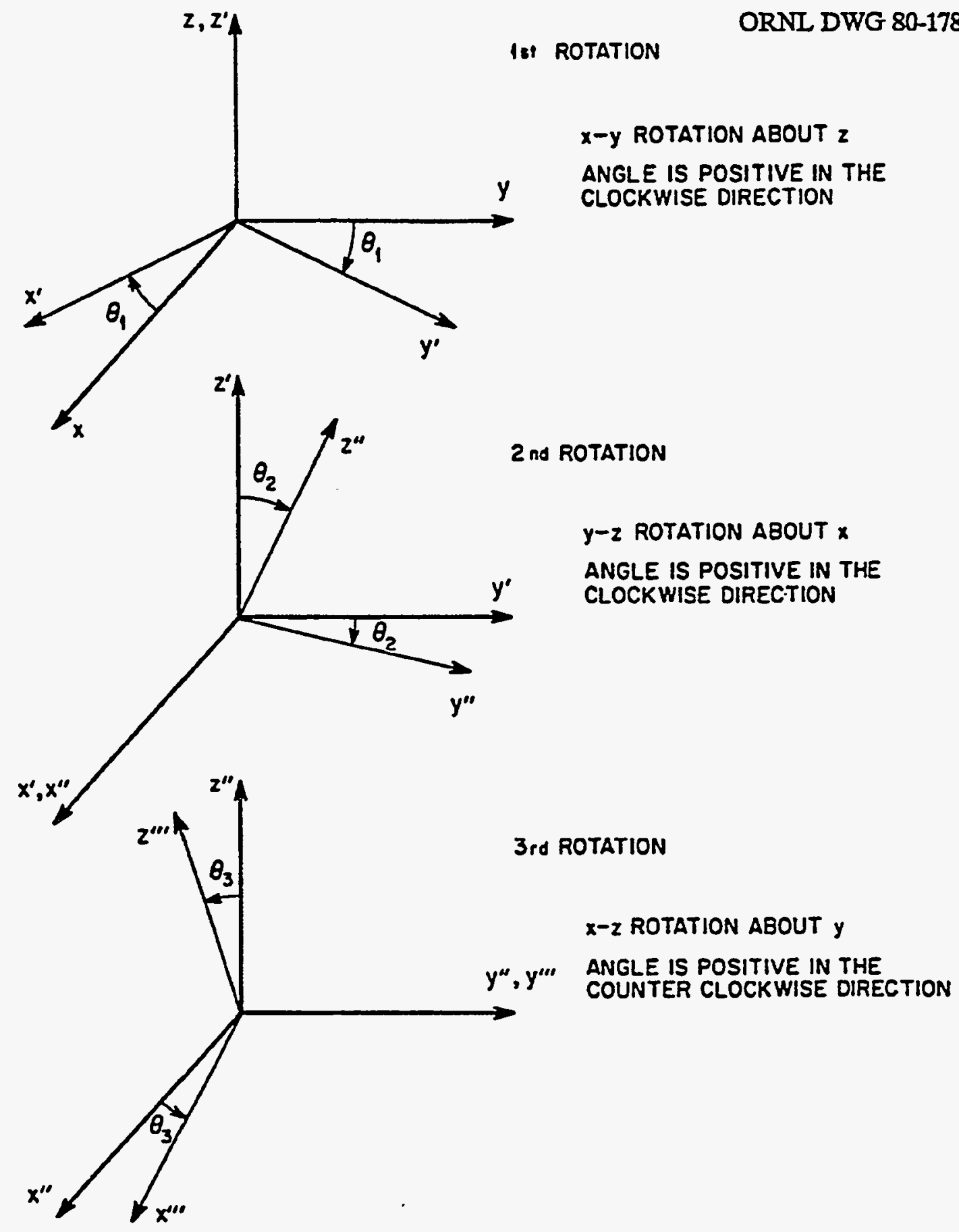

BPP AND WPP: $x \min , x \max , y \min , y \max , z \min , z \operatorname{mox}, \theta_{1}, \theta_{2}, \theta_{3}$

Figure M9.2.1 Rotations defining alternative bodies BPP and WPP 


\section{M9.2.2 COMBINATORIAL OPERATORS}

The basic technique for the description of the geometry consists of defining the location and shape of the various zones in terms of the intersections and unions of the geometric bodies. A special operator notation involving the symbols $(+),(-)$, and $(O R)$ is used to describe the intersections and unions. These symbols are used by the program to construct information relating material descriptions to the body definitions.

If a body appears in a zone description with a $(+)$ operator, it means that the zone being described is wholly contained in the body. If a body appears in a zone description with a $(-)$ operator, it means that the zone being described is wholly outside the body. If the body appears with an (OR) operator, it means that the input zone being described includes all points in the code zone following the "OR." OR may be considered as a union operator. In some instances, an input zone may be described in terms of subzones, called code zones, lumped together by (OR) statements. Body numbers after an "OR" describe a code zone. Code zones may be thought of as subsets of an input zone.

Techniques for describing a particular geometry are best illustrated by examples. Consider an object composed of a sphere and a cylinder as shown in Fig. M9.2.2. To describe the object, one takes a spherical body (2) penetrated by a cylindrical body (3) (see Fig. M9.2.2); if the materials in the sphere and cylinder are the same, then they can be considered as one zone, say Zone I (Fig. M9.2.2, Item c). The description of Zone I would be

$$
I=O R+2 \text { OR }+3
$$

This equation means that a point is in Zone I if it is either inside Body 2 or inside Body 3.

If different materials are used in the sphere and cylinder, then the sphere with a cylindrical hole in it would be given a different zone number (e.g., $J$ ) from that of the cylinder $(K)$.

The description of Zone J would be (Fig. M9.2.2, Item d):

$$
\mathrm{J}=+2-3
$$

This equation means that points in Zone $J$ are all those points inside Body 2 which are not inside Body 3.

The description of Zone $\mathrm{K}$ is simply (Fig. M9.2.2, Item e):

$$
\mathrm{K}=+3 \text {. }
$$

In other words, all points in Zone $\mathrm{K}$ lie inside Body 3.

Combinations of more than two bodies and similar zone descriptions could contain a long string of $(+),(-)$, and (OR) operators. It is important, however, to remember that every spatial point in the geometry must be located in one and only one zone.

As a more complicated example of the use of the (OR) operator, consider the system shown in Fig. M9.2.3 consisting of the shaded zone, A, and the unshaded zone, B. These zones can be described by the two BOXes, Bodies 1 and 3, and the RCC, Body 2. The zone description would be

$$
\mathrm{A}=+1+2
$$

NUREG/CR-0200, 
and

$$
\mathrm{B}=\mathrm{OR}+3-1 \mathrm{OR}+3-2
$$

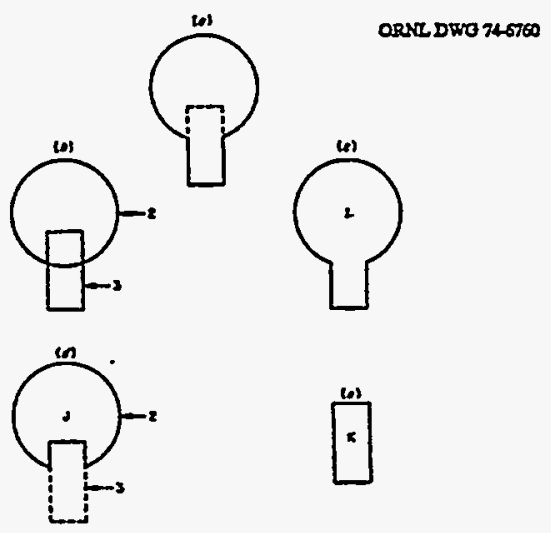

Figure M9.2.2 Examples of combinatorial geometry method

ORNL DWG 74-6761

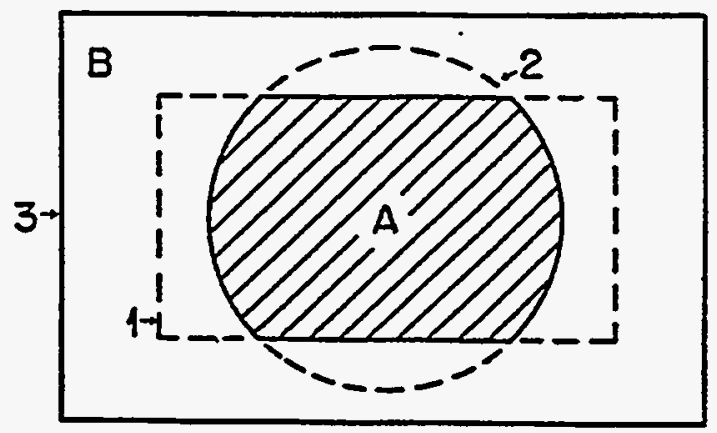

Figure M9.2.3 Use of OR operators

Notice that the OR operator refers to all following body numbers until the next OR operator is reached. For example, let Body 1 be a sphere with vertex $(-0.75,0.0,0.0)$ and radius 1.0. 


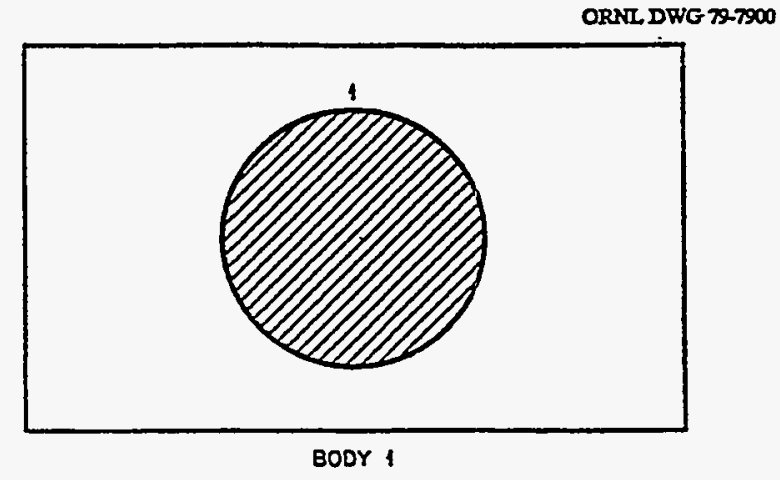

And let Body 2 be a sphere with vertex $(0.75,0.0,0.0)$ and radius 1.0 .

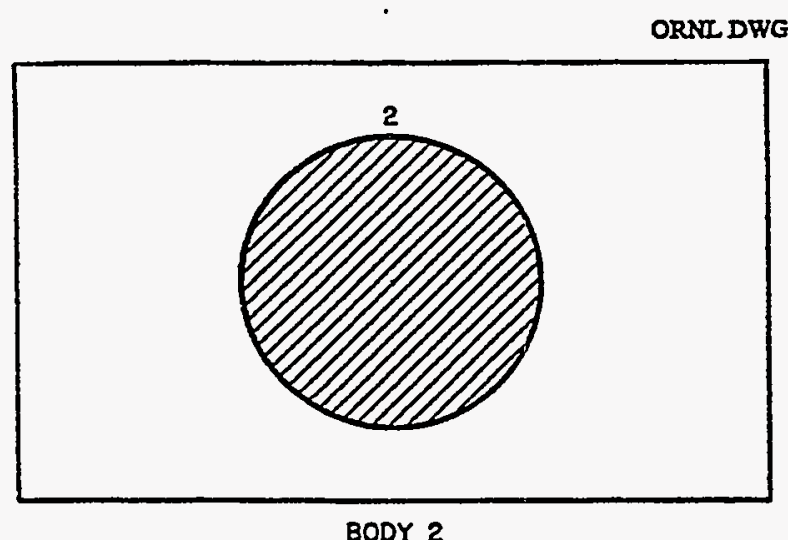

Then, "NOT 1" consists of all points that are not in Body 1.

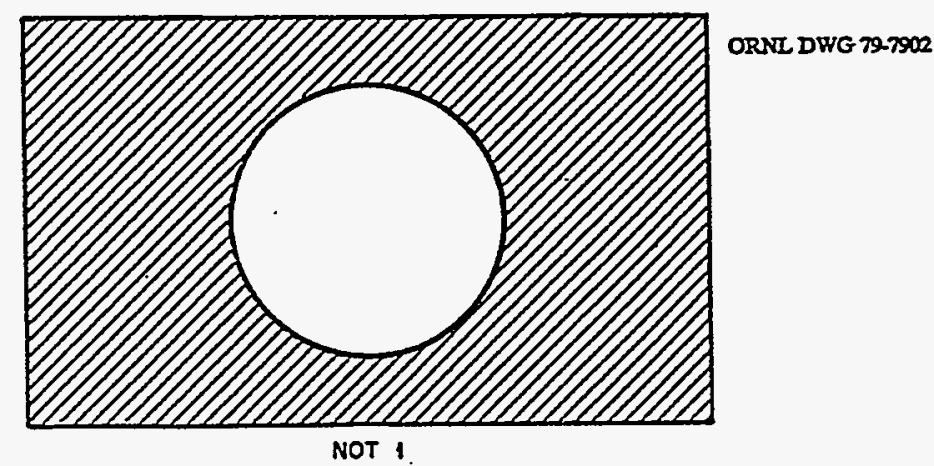

NUREG/CR-0200,

Vol. 3, Rev. 4

M9.2.10 


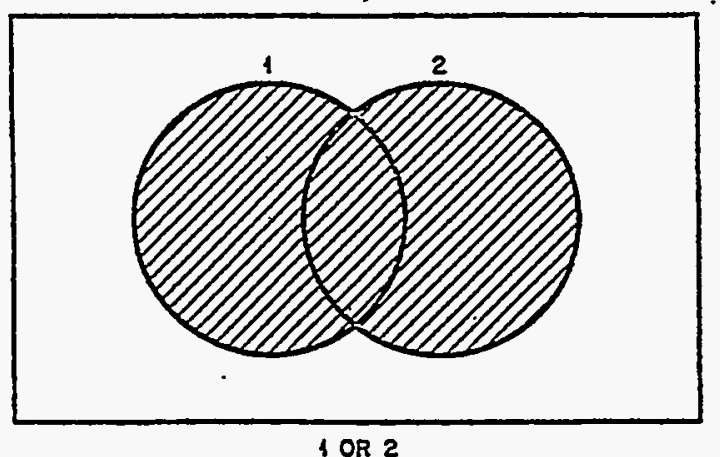

"1 OR 2" consists of all points that are in Body 1 or in Body 2 (or in both, the OR operation is not an exclusive or).

"1 AND 2" consists of all points that are in Body 1 and are also in Body 2.

ORNL DWG 79-7904

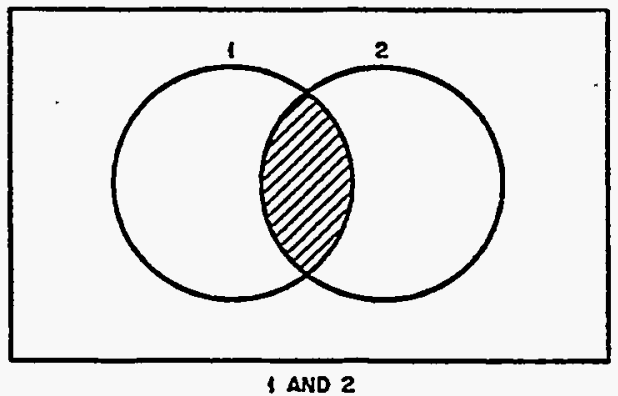

\section{M9.2.3 COMBINATORIAL ZONE CONSTRUCTION}

In combinatorial geometry the most elementary zone description is called a "code zone." The code zone description uses only the " + " and " $"$ " operators to describe a material zone. Code zones may be combined with the "OR" operator to define an "input zone" containing more than one code zone. An input zone may be composed of only one code zone. An input zone is a material zone of only one media, containing one or more code zones. An input zone may describe volumes of space that are not continuous. Figure M9.2.4 illustrates the difference between input zones and code zones.

Figure M9.2.4A shows the shaded zone, Input Zone 1, as all points in Body 1 "OR" all points in Body 2. Input Zone 1 in Fig. M9.2.4A contains two code zones. The first code zone is +1 , and the second code zone is +2 . Alternatively, this material zone could have been described as two input zones, 
each with only one code zone, as illustrated by Zones 2 and 3 of Fig. M9.2.4-A. In both methods, the set of points shared by Bodies 1 and 2 have been doubly defined; this is valid since both zones contain the same media. If Bodies 1 and 2 contained different material media, then the two bodies could not be combined into a single input zone; and the overlap between the two bodies would be erroneous. Figure M9.2.4-B's shaded zone represents all points in Body 1; and the clear zone represents all points in Body 2 which are "not" in Body 1. The shaded zone, Zone 1, is described as +1 . The clear zone, Zone 2, is described as $+2-1$. Figure M9.2.4-C's shaded area is all points in Body 2 and is the opposite description of Fig. M9.2.4-B. Figure M9.2.4-D's shaded zone is all points in Body 1, which are also in Body 2; that is, points which are common to both bodies. This zone is described as $+1+2$. Figure M9.2.4 demonstrates the use of the "OR," the " + ," and "-" operator. Note that the user is not required to use the "OR" operator (see Fig. M9.2.4-A). The "OR" operator gives the user a shorthand input notation to lump "code zones" logically together into a single "input zone." All combinatorial geometry tracking is done with "code zones." Tracking across code zones is transparent to the user. Program action occurs only when a particle track crosses an imput zone boundary. Input zones are a user convenience for consolidating code zones in a more logical, understandable manner.

ORNL. DWG 80-17841
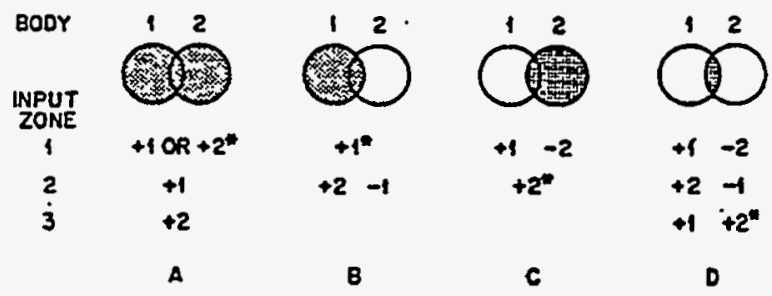

-indicates the shadeo zone

Figure M9.2.4 Illustrative input zone descriptions

\section{M9.2.4 COMBINATORIAL TRACKING LOGIC}

Tracking in combinatorial geometry depends on the following criteria:

1. Knowing the particle location in the geometry.

2. Knowing the particle trajectory in the current coordinate system.

3. Knowing the distance a particle can travel before having a collision.

4. Knowing the distance to enter and the distance to exit each body of the zone in which the particle is traversing.

NUREG/CR-0200, 
These four criteria determine whether the particle will undergo a collision or cross a zone boundary. If the distance to the next collision is less than the distance to exit the current input zone, then the particle will suffer a collision. If the distance to the next collision is greater than the distance to exit the current input zone, then the particle will encounter a boundary crossing and enter a new input zone. Only crossing an input zone boundary may constitute a possible change in material media. Changing code zones within the same input zone cannot constitute a media change. When combinatorial tracking determines that a boundary crossing has occurred, it then tries to determine the next zone of entry in its current universe. A universe is a collection of input zones sharing a unique coordinate system. It is necessary for MARS to compute the entrance and exit distances for bodies used in describing other input zones in the current universe. These entrance and exit distances used with the input zone descriptions determine the next zone the particle will enter. This procedure is demonstrated in Fig. M9.2.5.

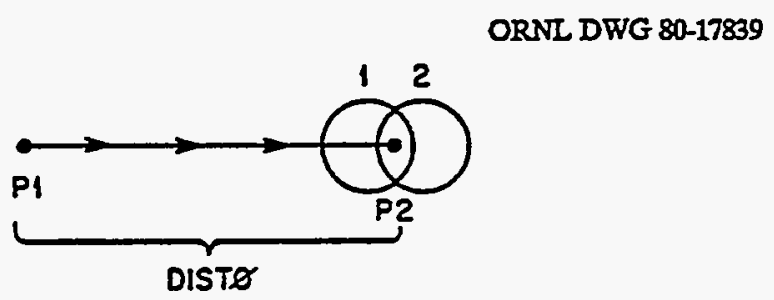

Figure M9.2.5 Particle trajectory moving from P1 to P2

In Fig. M9.2.5 a particle is emitted from point $\mathrm{P} 1$ and is traveling in the trajectory defined by direction cosines, $U, V$, and $W$. The distance to the next collision for the particle is known to be DIST0. From previous computation, the location of point P1 is known. The problem is to determine the input zone containing the particle collision site. From analytical geometry relations, the entrance and exit distances for the trajectory is computed for Body 1 and Body 2. The distance to enter Body $i$ will be RINi, and the distance to exit Body $i$ will be ROUTi. If RINi < DISTO < ROUTi, then the particle trajectory will terminate inside Body $i$. The relation of the RINis and ROUTis to DISTO may be used to construct a "truth table" to determine which bodies contain the collision site. Knowing the bodies containing the collision site, and the code zone descriptions, the code zone containing the collision is known. Assuming the zone description for Fig. M9.2.5 is given in Fig. M9.2.4-D, the following relations will exist:

$\begin{array}{llc}\text { BODY } & \text { [Relation of RINi to ROUTi] } & \text { Collision in Body } \\ 1 & \text { RIN1 < DIST0 < ROUT1 } & \text { YES } \\ 2 & \text { RIN2 < DIST0 < ROUT2 } & \text { YES }\end{array}$

Knowing the bodies containing the collision site, the zone containing the collision site can be determined. 


$\begin{array}{lccc}\text { ZONE } & \text { Description } & \begin{array}{c}\text { Collision } \\ \text { in Zone? }\end{array} & \text { Reason } \\ 1 & +1-2 & \text { NO } & \text { Collision is inside Body } 2 \\ 2 & +2-1 & \text { NO } & \text { Collision is inside Body } 1 \\ 3 & +1+2 & \text { YES } & \text { Collision is inside Body } 1 \text { and Body } 2\end{array}$

MARS can quickly determine the input zone containing a coordinate after all bodies containing the coordinate have been determined and a comparison with the zone description table has been performed. This method is efficient and effective provided (a) all space has been uniquely defined, and (b) all points in all bodies are satisfied by a given zone description with the correct relationship of bodies to each point. 


\section{M9.3 MARS GEOMETRY THEORY}

\section{M9.3.1 THE UNIVERSE BUILDING BLOCK}

A universe is a separate independent dimension in space defined by a collection of input zones bounded by a special boundary media. Every input zone resides in a universe. Every input zone description must include a universe number containing the zone. A particle can be in one and only one universe at a time. A particle may not change universes at a boundary crossing between input zones without first exiting the current universe. Each universe defines a unique coordinate system. Particle coordinates used while tracking through a universe are relative to the universe. This eliminates absolute coordinate space defined in a universe from conflicting with the same absolute coordinate space defined in other universes. Each universe is a microcosm with a separate unique geometry model. The most global universe in a model is Universe 0 , the absolute universe. Universe 0 must contain an array in order to enter other universes in a model. All universes with the exception of the absolute universe must be surrounded by a special boundary media, Media -1000 . This special -1000 media acts as a boundary flag to signify particle translation out of the current universe. The inner body of the zone containing the -1000 media then becomes the real outer boundary of the universe. This body is referred to as the universe reference body. The universe reference body may be either an RPP or a BOX. The reference body determines the absolute coordinate system inside the universe. The ability to differentiate universes makes the actual modeling construction of universes much simpler since they do not interact, interfere, or share space with any other zones not in the universe. After universes have been modeled, they may be combined arbitrarily into geometric arrays. The contents of a universe are arbitrary, and a universe may contain an array in one or more of its input zones. These concepts are illustrated in Appendix M9.B by several examples. Studying Appendix M9.B will make the universe concepts, array construction, and array nesting more comprehensible.

There are two types of universes: the combinatorial universe and the simple universe. The simple universe is composed of input zones analogous to KENO zones, where every zone completely encompasses the previous zone. Simple universe zone descriptions are composed of two or less bodies and do not reference any negative media numbers. A simple universe input zone may contain only one code zone. Universes erroneously declared simple containing input zones with more than one code

zone, or a code zone with more than two bodies, or an input zone with a negative media number will be correctly recognized by MARS as combinatorial universes, and the user will receive warning messages of the alteration. Tracking through simple universes is approximately $30 \%$ faster than tracking through combinatorial universes. The MARS user is encouraged to use simple universes in his model description wherever possible.

\section{M9.3.2 MARS "ARRAY OF ARRAYS" CAPABILITY}

MARS allows the user the ability to describe rectangular cells of arbitrary content and to combine these cells to form unique arrays. These arrays may subsequently be referenced for inclusion in a geometry model. The arrays could be referenced in an input zone in a universe, or they could be referenced in lattice cell positions in a larger array. Thus, there is a nested-array capability in the MARS system.

Arrays are assigned a numeric name as each array description is entered. Hence, the first array entered into the MARS input becomes Array 1; the second array entered becomes Array 2, etc. 
It is necessary in constructing a MARS model to distinguish array names from universe names. This is accomplished by referencing universe names as positive integers and array names as negative integers. Therefore, Array 1 would be referenced as -1 and Universe 1 would be referenced as +1 . Universes are referenced ONLY in array descriptions. Arrays may be referenced by TWO methods: (1) in the zone media input or (2) as the lattice cell content of other array descriptions.

One of the most important portions of the MARS input is the description of arrays - their dimensions and their content. The array input description in MARS combines the universes and other arrays into a complete model. Initially in the array input portion of MARS, the size of each array is entered. Array numbers (names) are assigned sequentially as each array size is entered. The size of an array is described by the number of lattice cells along each coordinate dimension, that is, the number of cells along the $\mathrm{X}$-axis, the number along the $\mathrm{Y}$-axis, and the number of cells along the $\mathrm{Z}$-axis. Next, the content of each lattice cell position in each array must be defined. MARS allows the user three different techniques for entering this information. The technique used is strictly based on individual user preference. These array description input techniques are described in detail in Appendix M9.A. Regardless of the method chosen by the user to describe the contents of each array, the contents of each lattice cell position of each array will be defined at the completion of the array description portion of the MARS input. A lattice cell position in an array may contain either a universe, entered with a positive integer; an array, entered with a negative integer; or a vacancy, entered with a zero. A zero in an array description defines a vacant lattice cell position and should not be confused with the absolute universe zero. Vacant lattice positions give the user flexibility in determining the shape of an array. Vacant lattice cell positions may be located either internally or on the periphery of an array.

Since the contents of a universe are arbitrary, a universe may contain an array. This arrangement allows geometry to be built around an array and then to be automatically repeated with the universe. An array is placed in a universe by describing a zone that snugly fits the nonvacant lattice cell positions of an array. The media for the input zone is given as a negative array number. This inserts by reference the array into the input zone. The array must fit snugly in the input zone; otherwise, a gap of undefined space may exist.

The simplest method to repeat an array is to directly reference a smaller array in a lattice cell position of a larger array. This method does not require any additional input to be specified, but wherever it is referenced, this method does require the smaller array to completely fill the lattice position of the larger array. Whenever a smaller array is referenced in a lattice cell position of a larger array, the smaller array may not contain vacant lattice positions.

Two methods for nesting an array have been described: (1) an array may be referenced in any input zone of any universe, and the universe may be referenced in any array description, and (2) an array may completely fill a lattice cell position of a larger array. A third technique is made possible through the use of arbitrarily located vacancies in a larger array. This technique is illustrated in Fig. M9.3.1.

NUREG/CR-0200,

Vol. 3, Rev. 4

M9.3.2 


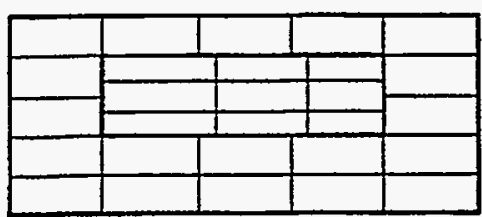

Figure M9.3.1 A nested-array lattice

The larger array shown in Fig. M9.3.1 is a $5 \times 5 \times 1$ array with a $3 \times 3 \times 1$ array embedded in its vacant lattice locations. The lattice cell description for the larger array could be

\section{$\begin{array}{lllll}12 & 1 & 2 & 1\end{array}$}

200002

20000.2

21212

Note the 1's and 2's are positive integers referencing Universes 1 and

$\begin{array}{lllll}12 & 12 & 1\end{array}$

2. The $0^{\prime} s$ are array vacancies.

The actual input zone containing the two arrays would be

ORNL. DWG 80-17838

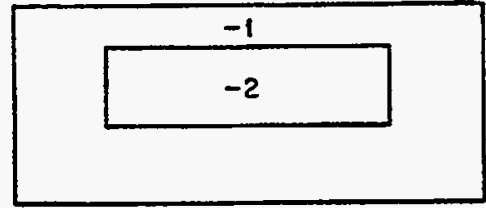

Every MARS model must contain one or more input zones in Universe 0 . The absolute universe in MARS contains the entire MARS model. Universe 0 may be bounded by a vacuum boundary, a reflected boundary, or an albedo boundary. These special boundaries are described in Sect. M9.5.1, Media Notation. Each input zone exists in a universe. Universe 0 is the beginning or top of the geometry hierarchy in the MARS system. Transfer into an array from the absolute universe is accomplished by entering an input zone defined in the absolute universe containing a negative media.

The term "level of geometry" represents the geometry hierarchy in MARS. The level concept is necessary to understand MARS model construction and MARS tracking logic. (See Sect. M9.6.1.)

The absolute universe is in the zeroth (0th) level of the geometry hierarchy. Any array referenced in an input zone defined in the absolute universe exists in the first level of the geometry hierarchy. The level 
The absolute universe is in the zeroth (0th) level of the geometry hierarchy. Any array referenced in an input zone defined in the absolute universe exists in the first level of the geometry hierarchy. The level of an array establishes the level of all universes referenced in the array. The universe level is the same as the array level, and all universes in an array exist at the same level. Any subarray referenced either directly in an array or in an input zone in a universe in an array is in the next level of the geometry nesting. There is no program limit to the extent of geometry nesting in the MARS system. Furthermore, array nesting in MARS is independent of computer memory requirements. The concept of a "geometry level" allows MARS to construct a nesting table which uniquely defines each point in a multilevel geometry model. Therefore, even though particle tracking utilizes a local universe coordinate system, the nesting table constructed during tracking allows MARS to uniquely define a particle location relative to any higher geometry level. The universe coordinate system utilized during particle tracking is always in the largest geometry level number (the most local) necessary to define the particle in an input zone containing a positive media number.

\section{M9.3.3 ARRAY ROTATION}

The Combinatorial MARS System has the ability to rotate an array arbitrarily in space. An array may be referenced either by a negative media notation for an input zone or by a negative entry in an array lattice description. When an array is referenced in an input zone, the first body of the input zone description becomes the reference body for the array. The reference body determines the coordinate translation and rotation for particles entering and exiting the array. The reference body for an array may be either an "RPP" or a "BOX" body type. If the reference body for an array is an "RPP" body type, then no rotation occurs and the boundaries of the array are parallel to coordinate planes. If the reference body for an array is a "BOX" body type, then the array will be oriented according to the definition of the BOX. Section M9.2.1 describes the combinatorial body types. The "BOX" is described as the eighth body type. In the figure accompanying this description, three displacement vectors, $A 1, A 2$, and $A 3$, are shown. For an array with a BOX reference body, vector $A 1$ defines the $X$ axis for the array, vector $A 2$ defines the $Y$ axis for the array, and vector $A 3$ defines the $Z$ axis for the array.

Arrays repeated with a BOX reference body may have arbitrary vacancies, just as an array referenced with an RPP reference body. The space external to the array inside the reference body must be defined by another input zone. The input zone containing the array must have the shape of the boundaries of the array. Sample Problem 6 in Appendix M9.B illustrates array rotation and array nesting.

All universes and/or arrays referenced in a rotated array are automatically rotated in space. Particle trajectories in a rotated array are in a rotated coordinate system. This requires particles entering a rotated array to have their coordinates translated and rotated and their direction cosines to be rotated. Particles exiting a rotated array must have their coordinates translated and undergo a reverse rotation and must have their direction cosines undergo the same reverse rotation. Each BOX body that is an array reference body has an orthogonal rotational matrix associated with it. The inverse rotation for an orthogonal matrix is the transpose of the original rotational matrix.

\section{M9.3.4 MODEL CONSTRUCTION WITH MARS}

Lattice array nesting is a different modeling technique from many of the conventional modeling schemes. Therefore, the following suggestions are presented to aid the novice MARS user in preparing his model.

NUREG/CR-0200, Vol. 3, Rev. 4

M9.3.4 
1. Examine your geometry for unique repeatable rectangular cells. These cells will be your universes. Decide how many unique cells exist in your model and identify each.

2. Define combinatorial bodies for each unique type of universe in your system. Bodies are numbered by the order in which they are entered in the combinatorial input. Make marginal notations in your notes of each body type and number. These notations will be convenient for future reference when describing input zones.

3. Identify a reference body for each universe. This determines the origin of each universe. All bodies used to model input zones in a given universe will have the same coordinate system as the universe reference body surrounding the universe. This body may be either an RPP or a BOX body. Always use the RPP as your reference body unless geometry rotation is required.

4. Determine the number of unique, simple arrays in your system. These arrays are composed entirely of universes. Assign universe numbers for these "building blocks" to be used in forming arrays. List your simple arrays noting the array description and array number.

5. Examine your system for the possibility of forming larger arrays that contain either the simple arrays and/or universes. This step may involve surrounding a simple array with its peripheral geometry features (such as a sheath surrounding a fuel assembly as in the typical PWR) to define a new universe. Then, the entire new universe can be referenced in the larger arrays as often as required. Remember to reference arrays with negative integers. Arrays may be inserted in combinatorial input zones with negative zone media designation. Arrays may be referenced in larger arrays with a negative array number for the content of a given cell in the larger array. Remember, universes are referenced with positive integers in array lattice descriptions.

6. In specifying the elements of the input, it is likely that further simplifications through array nesting as described in (5) will be recognized. It is difficult to adjust to the concept of examining a geometry model for the possibility of nesting arrays inside of larger arrays. In some models it may be apparent, but in most models nesting arrays is a subtle thought acquired after careful reflection. Thus, some iteration in the input zone and array content description may be desirable. For convenience, marginal notation of the actual description of the universe will be useful records for later reference. 


\section{M9.4 ARRAY ANALYSIS - COLLISION DEBTS}

In tracking through a complicated array, it is often necessary to obtain specific reaction rates dependent on location and/or media criteria. MARS has a generalized method of allowing the user to obtain this information without impacting on computer time requirements. MARS allows the user to specify both location criteria and media criteria to selectively sample specific collisions. The desired reaction rate is generated by multiplying the user-selected, collided flux times an arbitrary, user-defined response set. The combination of location criteria, media criteria, and response criteria allows the user to "edit" his collisions into special reaction rate bins. The criteria are general enough to cover many different lattice reaction rates of interest.

The order of the array analysis input is as follows:

1. The number of "edits" required is input in the first data block of the MORSE input.

2. For each "edit," the location criteria are entered.

3. For each "edit," the media criteria and the response criteria required are entered.

The location, media, and response criteria will be described in this section, along with some illustrative examples. It is important to remember that both the specified location and media criteria for each edit must be met before the collided flux is multiplied by the specified user response and banked in the appropriate edit bin.

\section{M9.4.1 ANALYSIS CRITERIA}

\section{M9.4.1.1 Location Criteria}

The location criteria are input in three parts, but only the first part is required. For each edit the location criteria input will be less than or equal to five entries. The three parts of the location criteria available for each edit are described below:

1. (1 REQUIRED ENTRY) The user may edit either an array or a universe. If the user is editing an array, the array name is entered as a negative entry. If the user is editing a universe, then the universe number is entered as a positive entry. If Universe " 0 ," the absolute universe, is specified, then no additional location criteria input for the edit is required.

2. (1 OPTIONAL ENTRY) A larger array in which the subarray or universe resides in may be entered. If zero is entered, then collisions for this edit will be tallied at all locations where the subarray or universe occurs. If a positive array number is entered, then collisions only in the specified subarray or universe occurring in the larger array will be tallied. The subarray or universe may occur in any sublevel of the larger array. The subarray or universe does not have to be directly referenced in the larger array.

NUREG/CR-0200, 
3. (3 OPTIONAL ENTRIES) A specific location in the larger array specified in Part 2 may be entered. If zero is entered, then the edit is not location-dependent in the larger array specified in Part 2. The location given is entered as the NX, NY, NZ coordinate of the lattice position in the larger array.

A zero input for any of the above entries terminates the location criteria for the edit being entered.

After the location criteria have been entered for all edits, then the media and response criteria will be input as a pair of entries for each edit.

\section{M9.4.1.2 Media Criteria}

The media criteria are specified by entering a media number to selectively bank collisions by material composition. All collisions meeting the location criteria occurring in the specified media for an edit will be banked. If zero is entered, then only the location criteria will be observed and the edit will not have any media dependence.

\section{M9.4.1.3 Response Criteria}

When a collision site has met both the location and media criteria for a given edit, the collided flux is calculated and multiplied times an arbitrary response set specified in the response input for the edit. MORSE allows the user to input arbitrary response functions (NRESP). These response functions are referenced in the response input to the array analysis. The MARS array analysis system computes only one reaction rate for each edit required by the user.

For each edit, the user inputs the media criteria and response criteria. At the end of the MORSE calculation each edit is output with the reaction rate and the fractional standard deviation. If the user edit is for a universe, then only one result and deviation is output. If the user edit is for an array, then results will be given for all lattice positions in the array. The contents of the lattice positions are arbitrary and independent of the array analysis performed. Therefore, the user may obtain array-averaged reactions by editing a larger array containing the arrays to be averaged.

\section{M9.4.2 ILLUSTRATIVE EXAMPLES}

The following free form input is given for six edits:

$$
\begin{aligned}
& -20,-230,-2312108,300,3020,302111 \text {, } \\
& 01,23,13,24,35,12
\end{aligned}
$$

The Location Criteria for each of the six edits were given first, followed by the Media and Response Criteria for each edit. Each edit is discussed below:

NUREG/CR-0200, 
Edit 1

Location Criteria: -20

Media/Response Criteria: 01

Bank all collisions in Array 2 wherever Array 2 occurs. No media dependence. Use Response Set 1 for this edit.

Edit 2

Location Criteria: -230

Media/Response Criteria: 23

Bank collisions in Array 2 whenever Array 2 occurs inside Array 3. Bank collisions in Media 2 only; use Response Set 3 for this edit.

Edit 3

Location Criteria: -2312108

Media/Response Criteria: 13

Bank collisions in Array 2, whenever Array 2 occurs in the 12108 position of Array 3. Array 2 may occur in any sublevel of Array 3. For example, Array 3 may reference Array 4 which references Array 2. Bank collisions only in Media 1; use Response Set 3 for this edit.

Edit 4

Location Criteria: 300

Media/Response Criteria: 24

Bank collisions occurring in Universe 30 wherever Universe 30 occurs. Bank collisions only in Media 2; use Response Set 4 for this edit.

Edit 5

Location Criteria: 3020

Media/Response Criteria: 35

Bank collisions in Universe 30 whenever it occurs in Array 2. Bank collisions only in Media 3 and use Response Set 5 for this edit.

Edit 6

Location Criteria: 302111

Media/Response Criteria: 12

Bank collisions in Universe 30 whenever it occurs in the 111 position of Array 2. Bank collisions only in Media 1; use Response Set 2 for this edit.

NUREG/CR-0200, 


\section{M9.5 COMBINATORIAL MARS OVERVIEW}

Sections M9.2 and M9.3 introduced the user to combinatorial geometry concepts and MARS array logic. This section is a summary of some of the important concepts developed in previous sections. The use of media input is introduced in this section with some discussion on special combinatorial MARS media notation.

\section{M9.5.1 MEDIA NOTATION}

The input to combinatorial MARS requires the user to input a media number for each input zone. This entry may have the following definition:

1. If positive, it refers to a valid cross-section mixture provided it is not equal to 1000 or to MEDALB.

2. If negative, it refers to an array residing in the input zone, provided it is not -1000 .

The absolute value of the entry is the array number. The following several special media are used in combinatorial geometry in the MARS system:

Media

0

1000

$-1000$

MEDALB
Description

External void - all particles entering Media 0 leak out of the system; their history is terminated.

Internal void - all particles traversing Media 1000 have no interactions; they simply pass through the input zone without any change in direction or energy.

Universe boundary flag - signals the exit of a particle from a universe. Translation and/or rotation occurs; no tracking is performed in Media -1000; this media is seen only on exiting a zone but never on entering a zone.

Reflection Media - can occur in any level of geometry model; specular reflection occurs; reflecting surface for MARS must be on an RPP or BOX. The body number of the RPP or BOX must be referenced both in the zone exiting and the zone entering.

\section{M9.5.2 TERMS AND DEFINITIONS}

1. Bodies - Nine basic geometric shapes with fully enclosed volumes. (Polyhedrals) RPP, BOX, BPP, WED, WPP, ARB (Revolved Surfaces) SPH, ELL, RCC, TRC, REC. BPP is an alternate specification for BOX; WPP is an alternative for WED.

2. Operators - + Include - Exclude OR Combine.

M9.5.1

NUREG/CR-0200, Vol. 3, Rev. 4 
3. Code Zones - One or more bodies used to describe a portion of problem space having a single media number.

4. Input Zones - One or more code zones used to describe a portion of problem space having a single media number. Code zones may be combined with the OR operator in forming input zones. The complete description for an input zone includes a media number, a region number, and a universe number.

5. Media Number - Explicitly specified in the media number list. In addition to designating a cross-section mixture number, the media number can be used for five other purposes.

Purpose
A
B
C
D
$\mathbf{E}$
F

6. Region Number - Explicitly specified in the region number list. Used to designate a set of weights (Russian roulette, splitting, pathlength stretching) for each input zone.

7. Universe Number - Explicitly specified in the universe number list. Used to designate a set of two or more input zones (in a single coordinate system) bounded by an outer input zone with the media number equal to -1000 . The simple Universe (analogue to KENO BOX-TYPE) is the basic "building block" for specifying an array; however, more complicated lattice geometry may be modeled in a universe. The contents of a universe is completely arbitrary. The outer shape of a universe must conform to an RPP or BOX.

8. Array Number - Implicitly determined from the order of arrays specified in the array size list. Explicitly referenced as a negative media number (see Purpose F under Definition 5) $\mathrm{OR}$ as a negative entry in the array content list. Thus, an array can contain another array. Positive entries in the array list are universe numbers. A ZERO entry in the array content list designates a vacancy described by other geometry specifications external to the array. 
9. MEDALB - Single variable specified in MORSE-SGC/S (SAS3) to designate a reflective boundary on an RPP surface or combination of RPP surfaces (see Purpose D under Definition 5).

10. Internal Void - Specified as Media 1000 (see Purpose $\mathbf{C}$ under Definition 5 listed above). All particles traversing Media 1000 have no interactions.

11. External Void - Specified as Media Number 0 (see Purpose B under Definition 5 listed above). All particles entering Media 0 leak out of the system. Their histories are terminated.

12. Levels - Depth of geometry nesting starting with the absolute or zero universe being Level 0 . Higher levels are defined by embedded arrays. The entire system is in Level 0 . Large portions of the system are in Level 1. Smaller portions are in Level 2, and so on. All universes within an array are at the same level as the array itself. Each array is at a lower level number than the level number of any arrays embedded in it. Hence, the lower the level number, the more global the level.

\section{M9.5.3 RULES FOR ARRAY REPETITION}

1. All arrays must fit snugly in the zone in which they are referenced.

2. The first body referenced in a zone containing an array is used as the array reference body. All translations for particles entering or exiting an array is performed relative to the reference body.

3. An array directly referenced in a lattice cell position of a larger array may not contain any vacant lattice cell positions.

4. A universe containing an array may not have the same reference body as the array it contains. 


\section{M9.6 MARS TRACKING LOGIC, SHORTFALLS, AND CORRECTIONS}

\section{M9.6.1 PARTICLE NESTING TABLE FOR TRACKING}

During tracking in the MARS geometry system, a particle frequently changes universes and arrays. With the ability to repeat and nest arrays in MARS, it is necessary to have a method of determining the particle location relative to the complete geometry model. As each particle tracks through the geometry, a "nesting table" is continually updated on the particle's present location. This nesting table gives detailed information on where the particle is relative to each level of the geometry model. The size of the table is $6 * \mathrm{NLEV}+4$, where NLEV is the total number of geometry levels in a given model. Six entries in the table are given for each geometry level:

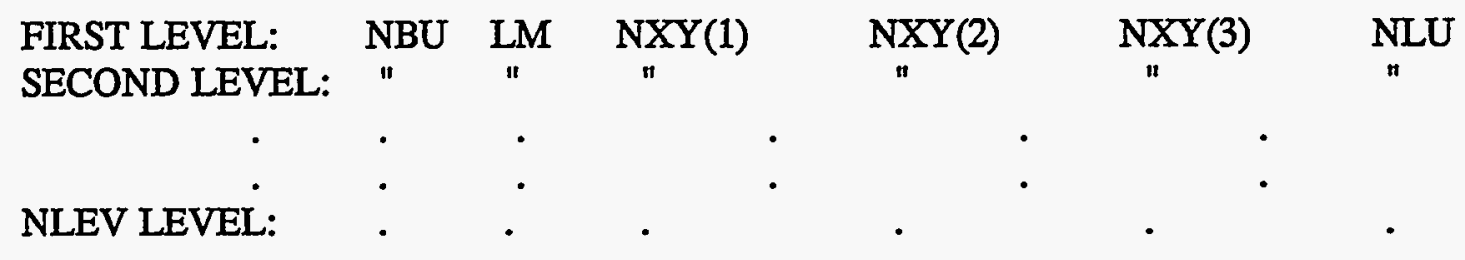

where

NBU is the reference body for the current array if the array was entered by a combinatorial input zone in a universe.

LM is the content of the lattice position of the current array. This value is positive for a universe and negative for an array. This value cannot be zero.

$\mathrm{NXY}$ is the current lattice position in Array NLU that is the $\mathrm{X}, \mathrm{Y}, \mathrm{Z}$ position of the lattice.

NLU is the current array number.

For example:

$\begin{array}{lcccccc}\text { FIRST LEVEL: } & 12 & -5 & 1 & 2 & 1 & 3 \\ \text { SECOND LEVEL: } & 0 & 6 & 3 & 1 & 1 & 5 \\ \text { THIRD LEVEL: } 21 & 1 & \mathbf{5} & \mathbf{7} & 1 & 1 & \end{array}$

This is the nesting table for a pin in the center assembly of the typical PWR Shipping Cask described in Example B-4. Refer to Sect. M9.B.

The particle location described in the above example is in the 571 position of the fuel assembly described as Array 1. Array 1 is in Universe 6 referenced at the 311 location of Array 5 . Array 5 is referenced explicitly in the array description of Array 3 in the 121 position. Array 3 was entered in Input Zone 28. The reference body for Array 3 is Body 12. Input Zone 28 occurs in the absolute universe. 
NBU is zero if the array for the current level was explicitly referenced in an array description for the next lowest level of the geometry. NBU cannot be zero for the first level description of the nesting array table. LM may either be positive or negative but not zero. It is positive if a universe is referenced at the NXY location of Array NLU, and it is negative if an array was referenced at the NXY location of Array NLU.

The last four locations in the nesting table after the level data are:

NL $\quad$...current level of the particle in the geometry.

NLO ...last effective level change. It is +1 if the particle Increased in level number; it is -1 if the particle decreased in level number; it is 0 if the particle changed array location without a change in level. For example, if the particle went from Level 2 to Level 3, NLO would be +1 . If a particle went from Level 3 to Level 2 , NLO would be -1 .

NLUOLD ...The last array the particle was inside before entering the current universe.

NLU ...The current array the particle is inside. This number will be the same as the $6 * \mathrm{NL}$ location in the nesting table.

\section{M9.6.2 MARS ARRAY PITFALLS}

By now the user is familiar with the concepts of MARS and combinatorial geometry. The relation between MARS and combinatorial geometry is important. MARS determines the universe and the universe location in a geometry model. After the universe is known, then combinatorial geometry determines the code zone and input zone in the universe in which the particle or particle trajectory resides. MARS handles the array bookkeeping and particle translation, as described in the previous section on the MARS-generated nesting table. Combinatorial geometry knows the correct universe number from MARS, and then performs the particle tracking in the universe. MARS logic involves arrays and does not involve zone descriptions. This relationship between MARS and combinatorial geometry is essential to user understanding of the tracking process and should be understood before he ventures forward into constructing a model. Input preparation is one element of building a complex geometry model; but by far, the most difficult part is model debugging. Even the most careful users will find themselves sooner or later examining a geometry dump. Geometry tracking errors are almost inevitable. The purpose of this section is to make the user aware of the pitfalls of MARS array modeling so as to minimize the number of geometry dumps. The success or failure of the MARS combinatorial geometry will depend on the ability of its users to master its many features with reasonable effort.

Before beginning a discussion of geometry model debugging it is imperative that the user have a basic understanding of the combinatorial geometry and MARS array tracking logic. The concepts of MARS universes, arrays, and geometry levels will be essential to understanding this section. The discussion of the nesting table concept introduced in the preceding section is important to interpreting the particle location in a geometry dump. This section will further discuss how MARS enters and exits an array during tracking. This is necessary in order to understand the failures that may occur during entering or exiting arrays.

NUREG/CR-0200,

Vol. 3, Rev. 4

M9.6.2 
Arrays are inserted into combinatorial input zones with negative media numbers. This insertion is more of a superpositioning of one geometry model, an array model, onto (not into) a combinatorial geometry input zone. Many warnings were given that the nonvacant lattice positions of an array must fit snugly in the combinatorial input zones where the array is referenced. More exactly, the array must completely fill and preferably slightly overflow the input zone boundary. This is necessary because of the method of entering and exiting arrays. The method of entering an array is described as follows:

1. A particle trajectory in combinatorial geometry encounters an input zone with a negative media number. The negative media number is not -1000 ; therefore, the particle is entering an array.

2. The particle coordinates must be translated into the array reference system in order to determine the lattice position in the array the particle is entering. The first body in the zone description is the array reference body. The coordinates of the origin of the reference body are subtracted from the particle coordinates, yielding the particle coordinates relative to the origin of the array.

3. Knowing the array being entered determines the lattice cell boundaries. The particle coordinates relative to the array origin must be within a valid nonvacant lattice cell position, or the particle cannot enter the array properly.

4. Next are translated the particle coordinates relative to the lattice cell being entered. The vertex, or the origin, of the lattice cell, XMIN, YMIN, ZMIN, is subtracted from the particle coordinates. This gives the coordinates of the particle relative to the lattice cell position.

5. If the lattice cell contains a universe, the particle coordinates are added to the reference body origin of the universe to give the absolute coordinates of the particle in the universe. Tracking then continues in combinatorial geometry.

6. If the lattice cell contains a subarray, the result of Step 4 is analogous to Step 2 for entering an array. Therefore, Steps 3, 4, and 5 are repeated for the subarray. When entering subarrays explicitly referenced in a larger array, no absolute coordinate relative to a universe is calculated. This is efficient but may lead to roundoff problems. Tracking into or out of universes helps to reduce roundoff error by translating relative to the universe reference body. This translation gives the particle a fresh update on its coordinates and tends to stabilize the tracking.

Frequently when a particle has made an incorrect entry into an array, the error is due to computer roundoff, or by an insignificant gap between the array lattice and the code zone referencing it. The size of each array and ALL lattice cell boundaries in each array are computed at input time. The size of an array and its lattice cell boundaries are calculated from the reference body of each universe composing each lattice position. The simple arrays, containing no subarrays, in the highest geometry level are computed first, then the larger arrays in the next lower level are computed until all arrays and their respective lattice positions have been calculated. A rigid test is performed to verify the proper fitting 
of universe reference bodies in lattice positions and the proper fitting of arrays in their reference bodies. If the "FIT Test" fails, then the job is terminated. The figure below illustrates an unintentional gap between an array lattice position and a combinatorial input zone.

The gap illustrated may be small, less than $1.0 \mathrm{E}-09 \mathrm{~cm}$, but it would be sufficient to cause a particle track to be lost. The correction is illustrated as the "overlap fix. "If the overlap is greater than $1.0 E-09 \mathrm{~cm}$, then Subroutine FINEFI will fatally warn the user, "THE ARRAY ... IN BODY ... REFERENCED IN CODE ZONE ... DOES NOT FIT." Therefore, the overlap applied should be small or it may itself be a fatal error. This is a rigid requirement. The overlap fix is beneficial in exiting the array correctly as well as entering the array correctly.

\section{M9.6.3 COMBINATORIAL MODELING PITFALLS}

Now that the user has some appreciation for the pitfalls in array tracking, it is necessary to discuss pitfalls in combinatorial geometry tracking. Whenever two floating-point numbers resulting from separate calculations are compared on a computer of finite precision, it is bad practice to test and depend on direct equality. In combinatorial tracking it is not always possible to avoid this problem. User input description is the best place to avoid ambiguity on zone boundaries. When two bodies share a common surface, the user should never assume the computer is capable of recognizing the two surfaces are actually a single surface.

ORNL DWG 80-17836

THE ZONE-ARRAY GAP PROBLEM
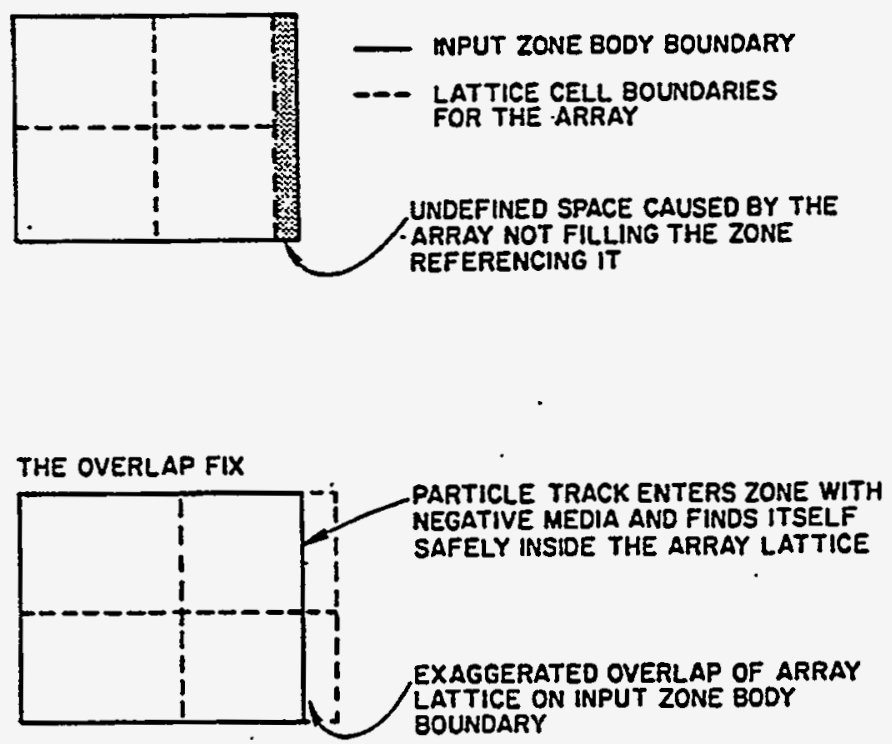

Furthermore, try to avoid having two bodies sharing a common surface occur on an input zone boundary, especially if the two bodies are referenced in both the adjacent input zone descriptions. In your geometry model, when constructing code zones, always attempt to describe your geometry with combinatorial logic, the union or intersection of bodies, without falling into the dangerous trap of defining bodies with 
common surfaces. When this is not possible, a less dangerous alternative exists. A small overlap between two body surfaces is preferable to a single surface. Combinatorial geometry will unwittingly let the user double-define space. Combinatorial tracking is always happy with the first definition for a portion of space it finds. It does not check to see if any other definitions exist. The danger comes in trying to leave the doubly defined space and in depending on which definition of the space is used.

\section{M9.6.4 COMPUTER TRACKING AND MODELING}

This section deals with the combinatorial MARS tracking logic and considerations involved in geometry model development. It is essential at this point that the user understand the following concepts and definitions before continuing:

A. how combinatorial logic determines in which code zone a particle is located,

B. the meaning of the following combinatorial variables: RIN, ROUT, DIST, DISTO (see Table M9.E.6 for label common /PAREM/),

C. the different roles of combinatorial geometry tracking and MARS array tracking (see Sect. M9.6.3). The complex modeling capabilities of combinatorial MARS are accompanied with a complex debugging output dump requiring user understanding of the tracking methods.

The most important questions combinatorial geometry and MARS must answer during tracking are the following:

MARS Tracking Questions:

A. In which universe is the particle located?

B. Will the particle exit the current universe? If so, then what will be the universe entered and in what array?

Combinatorial Tracking Questions:

A. In which input zone in the current universe is the particle located?

B. Will the particle exit the current input zone? If so, then what will be the next input zone the particle will enter?

These questions for MARS and combinatorial geometry are related in the following way. The first question in each system is asking the basic question:

Where is the particle located?

Each system, MARS and combinatorial, is answering the question from its own perspective. The second question in each system is asking the basic question: 
Where is the particle going?

This question cannot be answered without knowing the answer to the first question in both the combinatorial and MARS systems. In changing lattice locations in an array, the dialogue between combinatorial tracking and MARS tracking may go:

Combinatorial: The particle is entering Media -1000 ; therefore, the particle is exiting the current universe.

MARS:

The lattice cell being entered is in the same array as the current lattice cell location; therefore, the new universe being entered is NLU. The new coordinates are computed as $\mathrm{X}, \mathrm{Y}, \mathrm{Z}$ for the new universe.

Combinatorial: The particle is in input zone IR in the current universe. The particle will be entering input zone IRPRIM in the new universe.

MARS:

The lattice cell being entered is in the same array as the current lattice cell location; therefore, the new universe being entered is NLU. The new coordinates are computed as $\mathrm{X}, \mathrm{Y}, \mathrm{Z}$ for the new universe.

Combinatorial: The particle is in input zone IRPRIM in the new universe. The particle will be entering input zone $\mathbb{I R}$ in the new universe.

Computer tracking in the MARS/combinatorial geometry system is very often a combination of both questions in both systems. A very definite flow exists between the MARS and combinatorial tracking systems which is essential to a nested multiple-array geometry logic. This flow is best understood in the purpose of some of the more important subroutines in both systems. The MARS subroutines discussed will be CALI and PILOT. The combinatorial subroutines discussed will be LOOKZ, G1, and GG. Question A in MARS logic is answered by Subroutine CALI. It calls Subroutine LOOKZ to answer question A in combinatorial logic. Question B in MARS logic is answered by subroutine PILOT. It calls subroutine G1 in combinatorial logic to answer question B for the combinatorial system. MARS subroutines CALI and PILOT call combinatorial subroutines LOOKZ and G1. Combinatorial subroutines do not call MARS subroutines. Both MARS routines CALI and PILOT call LOOKZ, but only PILOT calls combinatorial routine G1. PILOT must call LOOKZ when a particle has entered a new universe to determine the particle input zone location.

Both combinatorial subroutines G1 and LOOKZ call subroutine GG to compute RIN, the distance to enter a body, and ROUT, the distance to exit a body. This information is stored in a floating point array called FPD for the body. This array contains the body definition data as well as the RIN and ROUT for each body. The address in the FPD array for each body information set is stored in the MA array. During a calculation RIN and ROUT are continually updated. The particle position and direction will be referred to as the particle trajectory. Many times during a particle track, the trajectory will change as a result of collisions and entering new universes. The RIN and ROUT computed in one universe are not valid in other universes. To know the current trajectory, a trajectory index is maintained called KLOOP. This index gives each trajectory a unique identifier. Each time RIN and ROUT are calculated for a body, a body trajectory variable called LOOP is updated. LOOP is set to KLOOP when

NUREG/CR-0200,

Vol. 3, Rev. 4

M9.6.6 
RIN and ROUT are reset in the FPD array. LOOP is stored in the MA array. The detailed description of the FPD and MA array is given in Tables M9.E.3 and M9.E.4 of Appendix E. These arrays will be dumped out whenever a particle gets lost. The combinatorial MARS user should thoroughly understand the contents of the MA and FPD arrays. Unfortunately, by the time a particle is lost in tracking, many important variables in the MA and FPD array have been destroyed by subsequent calculations. The MA and FPD array should be examined in a broad sense in a dump, for detailed information may not exist at the time of the dump.

The MARS subroutines determine the universe a particle is inside and the particle coordinates relative to that universe. The level nesting table in MARS gives the universe location relative to all lower levels of the MARS geometry. The nesting table is dumped when a particle is lost in tracking through array geometry. The combinatorial geometry routines are called from the MARS routines for tracking inside of a universe.

Most geometry errors fall into two broad categories:

A. undefined space, making it impossible to determine a particle location or impossible to determine the next zone of entry (a particle trajectory is trying to enter undefined space)

B. roundoff gap problems between arrays and lattice cells or between common surfaces of two or more bodies. The gap problem may create an undefined gap in a model.

Errors of type A are discovered in FINEFI (during array input), CALI, or LOOKZ. Errors of type B are discovered by PILOT or G1 during tracking. Whenever an error is discovered, eventually subroutine PR is called. PR dumps the MA and FPD arrays, a few label commons, and calls DIPR. Subroutine DIPR calls DUPR which dumps all relevant array storage information. The nesting table and the local particle coordinates are the last few lines DUPR dumps.

Most of the error messages indicate the subroutine calling for the error dump. It will be helpful to examine the subroutine listing to determine the initiating event causing the error dump. If the message is from PILOT, it probably relates to an array description error or reference. If the message is from G1, the error is probably due to a confusing or contradictory code zone description. The particle coordinates printed out in a geometry dump are either the coordinate of the last collision site or the coordinates where the particle entered the current universe. The value DIST is the trajectory distance from the coordinate site in the direction WB, where WB(1), WB(2), and WB(3) are the particle direction cosines. Examine KLOOP and all the bodies where LOOP is the same as KLOOP. These bodies were the last bodies where RIN and ROUT were computed. The only bodies combinatorial geometry considers the particle trajectory to be located in are those bodies in which RIN is negative and ROUT is positive. Combinatorial geometry considers the particle trajectory is external to all other bodies in which this combination of RIN and ROUT does not exist.

There are normally many combinations of bodies for describing a geometric material zone. Combinatorial logic makes body possibilities very flexible. Frequently, the quickest and most efficient attempt at correction may simply be to try another zone description. It is important to understand geometry errors, but frequently it is more important to obtain results from a geometry model. After examining RIN and ROUT for the current KLOOP, determine if a code zone exists fitting the combination of included and excluded bodies. If the body combination can exist, then an undefined volume of space may exist. If the body combination cannot exist, then G1 will have a roundoff problem in tracking. The user may correct this problem by describing a code zone with the nonexistent 
combination of bodies. Be careful not to doubly define the geometry model with a second contradictory zone description.

No danger exists in describing an input zone with a nonexistent body description that may not exist. If such a description is necessary to avoid a tracking error, it will not be encountered at any other time during the tracking process.

NUREG/CR-0200,

Vol. 3, Rev. 4 


\section{APPENDIXES}

NUREG/CR-0200,

Vol. 3, Rev. 4 


\section{MO.A FREE-FORM COMBINATORIAL MARS INPUT INSTRUCTIONS}

\section{M9.A.1 TITLE* CARD}

FORMAT (15A4)

M9.A.2 OPTIONS CARD (four entries required)

IVOPT - Volume option not implemented - enter 0.

IDBG - Debug print option if positive; otherwise, enter 0.

IBOD - Body numbers are assigned by the user if IBOD is greater than zero; otherwise, enter 0.

NAZ - Number of zones to be added to the data storage for next zone of entry memory table. Enter any large number if extra storage is required. Default value allows for five zones to be entered from any single code zone. This option is normally not required; enter 0 .

\section{M9.A.3 BODY DEFINITION CARDS}

Each new body must start on a new card. The allowable body types are given in Table M9.A.1 along with the required input variables to describe each body. An END card must be used to signify the end of the body definition cards. For each body, the following input is required:

ITYPE - Specifies the alphanumeric body type or END to terminate reading of body data (for example, BOX, RPP, ARB, RCC, etc.)

IALP - Body number assigned by the user if IBOD is greater than zero; otherwise, it is not entered.

FPD(I) - Real data required for the given body as shown in Table M9.A.1. These data must be in $\mathrm{cm}$.

\section{M9.A.4 INPUT ZONE DESCRIPTION CARDS}

Each new zone must start on a new card. A three-character title should be given for each new input zone (not necessarily unique) which must start with an alpha-type character. An END card must be used to signify the end of the input zone description cards. For each input zone, the data needed are the title and zone data. Input zone numbers are assigned sequentially. 
Table M9.A.1 Input required for each body type ${ }^{a}$

\begin{tabular}{|c|c|c|c|c|c|c|c|c|}
\hline \multirow{2}{*}{$\begin{array}{l}\text { Body type } \\
\text { Box }\end{array}$} & \multirow{2}{*}{$\begin{array}{l}\text { ITYPE } \\
\text { BOX }\end{array}$} & \multirow{3}{*}{$\begin{array}{l}\text { IALP } \\
\text { IALP is assigned } \\
\text { by the user or by } \\
\text { the code if left } \\
\text { blank. }\end{array}$} & \multicolumn{6}{|c|}{ Real data defining particular body } \\
\hline & & & $\begin{array}{l}\mathrm{Vx} \\
\mathrm{H} 2 \mathrm{x}\end{array}$ & $\begin{array}{l}\text { Vy } \\
\text { H2y }\end{array}$ & $\begin{array}{l}\mathrm{Vz} \\
\mathrm{H} 2 \mathrm{z}\end{array}$ & $\begin{array}{l}\mathrm{H} 1 \mathrm{x} \\
\mathrm{H} 3 \mathrm{x}\end{array}$ & $\begin{array}{l}\text { Hiy } \\
\text { H3y }\end{array}$ & $\begin{array}{l}\mathrm{H} 1 \mathrm{z} \\
\mathrm{H} 3 \mathrm{z}\end{array}$ \\
\hline Right parallelepiped & RPP & & $\mathrm{Xmin}$ & $X \max$ & Ymin & Ymax & Zmin & $\mathrm{Zmax}$ \\
\hline Sphere & SPH & & $\mathbf{v x}$ & vy & $\mathbf{v z}$ & $\mathbf{R}$ & - & - \\
\hline Right circular cylinder & RCC & & $\begin{array}{l}V_{x} \\
R\end{array}$ & $\begin{array}{l}\text { Vy } \\
-\end{array}$ & $\begin{array}{l}\nabla z \\
-\end{array}$ & Hx & $\begin{array}{l}\text { Hy } \\
-\end{array}$ & Hz \\
\hline Right elliptical cylinder & REC & & $\begin{array}{l}\text { Vx } \\
\text { Rix }\end{array}$ & $\begin{array}{l}\text { Vy } \\
\text { Riy }\end{array}$ & $\begin{array}{l}\text { Vz } \\
\text { R1z }\end{array}$ & $\begin{array}{l}\mathrm{Hz} \\
\mathrm{R} 2 \mathrm{x}\end{array}$ & $\begin{array}{l}\text { Hy } \\
\text { R2y }\end{array}$ & $\begin{array}{l}\mathrm{Hz} \\
\mathrm{R} 2 \mathrm{z}\end{array}$ \\
\hline Ellipsoid & ELI & & $\begin{array}{l}\text { V1x } \\
R\end{array}$ & $\begin{array}{l}\text { V1y } \\
-\end{array}$ & $\begin{array}{l}\text { V1z } \\
-\end{array}$ & $\begin{array}{l}\mathrm{v} 2 \mathrm{x} \\
-\end{array}$ & $\begin{array}{l}v 2 y \\
-\end{array}$ & $\begin{array}{l}\mathrm{V} 2 z \\
-\end{array}$ \\
\hline Truncated right cone & TRC & & $\begin{array}{l}\text { Vx } \\
\text { R1 }\end{array}$ & $\begin{array}{l}\text { Vy } \\
\text { RI }\end{array}$ & $\begin{array}{l}\mathrm{V}_{\mathrm{z}} \\
-\end{array}$ & Hix & Hy & Hz \\
\hline Right angle wedge & $\begin{array}{l}\text { WED or } \\
\text { RAW }\end{array}$ & & $\begin{array}{l}\text { Vx } \\
\text { H2x }\end{array}$ & $\begin{array}{l}\text { Vy } \\
\text { H2y }\end{array}$ & $\begin{array}{l}\mathrm{Vz} \\
\mathrm{H} 2 \mathrm{z}\end{array}$ & $\begin{array}{l}\mathrm{H} 1 \mathrm{x} \\
\mathrm{H} 3 \mathrm{x}\end{array}$ & $\begin{array}{l}\text { H1y } \\
\text { H3y }\end{array}$ & $\begin{array}{l}\mathrm{H} 1 \mathrm{z} \\
\mathrm{H} 3 \mathrm{z}\end{array}$ \\
\hline \multirow[t]{2}{*}{ Arbitrary polyhedron } & ARB & & $\begin{array}{l}\text { v1x } \\
\text { v3x } \\
\text { V5x } \\
\text { v7x }\end{array}$ & $\begin{array}{l}\text { V1y } \\
\text { v3y } \\
\text { V5y } \\
\text { V7y }\end{array}$ & $\begin{array}{l}\text { V1z } \\
\text { V3z } \\
\text { V5z } \\
\text { V7z }\end{array}$ & $\begin{array}{l}\text { V2x } \\
\text { V4x } \\
\text { V6x } \\
\text { v8x }\end{array}$ & $\begin{array}{l}\text { V2y } \\
\text { V4y } \\
\text { V6y } \\
\text { V8y }\end{array}$ & $\begin{array}{l}\text { V } 2 z \\
\text { V } 4 z \\
\text { V6z } \\
\text { V8z }\end{array}$ \\
\hline & & & \multicolumn{6}{|c|}{ Face descriptions (see note below) } \\
\hline Alternative body & BPP & & $\begin{array}{l}X \min \\
\theta_{1}\end{array}$ & $\begin{array}{l}X \max \\
\theta_{2}\end{array}$ & $\begin{array}{l}Y \min \\
\theta_{3}\end{array}$ & $Y \max$ & $Z_{\min }$ & $Z_{\max }$ \\
\hline Descriptions & WPP & & $\begin{array}{l}X \min \\
\theta_{1}\end{array}$ & $\begin{array}{l}X \max \\
\theta_{2}\end{array}$ & $\begin{array}{l}Y \min \\
\theta_{3}\end{array}$ & $Y_{\max }$ & $Z_{\min }$ & $Z_{\max }$ \\
\hline $\begin{array}{l}\text { Termination of body } \\
\text { imput data }\end{array}$ & END & & & & & & & \\
\hline
\end{tabular}

ANOTE: The arbitrary polyhedron input contains a four-digit number for each of the six faces of an ARB body.

NUREG/CR-0200,

Vol. 3, Rev. 4

M9.A.2 
IALP - The three-character title for the zone where the first character is a letter.

IIBIAS(I) - Specify the "OR" operator if required for the JTY(I) body.

JTY(I) - Body number with the $(+)$ or $(-)$ sign as required for the zone description.

$$
\begin{aligned}
& \text { Example: } \\
& \text { PEL +1 } \\
& \text { CLD +2 -1 } \\
& \text { H2O +3-2 } \\
& \text { END }
\end{aligned}
$$

\section{M9.A.5 REGION CARD}

One entry is required for each input zone. This entry specifies the importance region each input zone is inside. This step determines which set of weights for splitting, Russian roulette, and pathlength stretching to use in each zone during tracking.

\section{M9.A.6 UNIVERSE CARD}

This array specifies which universe each input zone is inside. One entry is required for each input zone. The entry must be either a zero or a positive integer. A negative entry is not valid. Each universe, with the exception of the absolute universe, must contain one and only one zone with a -1000 media. The absolute universe cannot contain any -1000 media zone.

\section{M9.A.7 MEDIA CARD}

This array specifies the media contained in each input zone. One entry is required for each input zone. If the entry is positive, it references a valid cross-section mixture or a reflected boundary, MEDALB. If the entry is negative, it references a valid array number as the absolute value of the entry. If the entry is -1000 , it references a universe external boundary media. If the entry is 1000 , it references an internal void. If the entry is 0 , it references an external void.

\section{M9.A.8 ARRAY SIZE SPECIFICATIONS INPUT}

An array is a regular rectangular lattice composed of rectangular cells of arbitrary content. The size of each array should be entered as NXMAX, NYMAX, by NZMAX. Arrays are sequentially named as they are entered, starting with 1 . The array size entered should include any vacant cells in the array, if any are present. After the size of the last array has been entered, a zero should be entered to terminate the entries. Zero is an illegal entry for an array size. After the zero terminator has been entered, a single integer parameter is entered to determine the means of entering the array specification list. If no array is to be described, only the zero terminator is required.

NXMAX - the number of cells along the $x$-axis of array $i$ 
NYMAX - the number of cells along the $y$-axis of array $i$

NZMAX - the number of cells along the z-axis of array i followed by a " 0 terminator"

IOP - $\quad$ array specification input option (required)

$=0$ Free-Form Input, FFREAD, type specification

$=1$ Standard KENO Mixed Cell (BOX) Orientation Cards

$=2$ Standard FIDO Integer Array Input Specification

Example: 15151655277100

This example describes three arrays. Array 1 will be a $15 \times 15 \times 1$ array. Array 2 will be a $6 \times 5 \times 2$ array. Array 3 will be a $7 \times 7 \times 1$ array. Zero terminates the array size entries. The last zero entered selects the free-form input specification method of describing the array contents.

--End of Geometry Input if no Arrays are Modeled-

\section{M9.A.9 ARRAY CONTENT DESCRIPTION}

The contents of each cell of each array must be defined. All contents of Array 1 are defined, then Array 2, etc. The method of entering these data is determined by IOP in Sect. M9.A.8 input. There are three possibilities for each cell entry. These numbers are distinguished by either a positive, zero, or negative entry. A positive entry is a universe number. The universe must fit snugly in the lattice cell position it is referenced inside. The contents of a universe are completely arbitrary. A negative entry is an array entry. The absolute value of the entry is the array being referenced. It must completely fill the lattice position in which it is referenced. It cannot contain any vacancies in its lattice cell positions. Repeating a subarray in a larger array in this manner does not require any additional input. The array must, however, fit snugly in the lattice cell position. The means of entering these data is selected by the user to give flexibility in describing his arrays. The options are the following:

1. IOP $=0-$ Free-Form Input Option

Free-form input is entered using the FFREAD notation. This allows an "*" repeat feature. Data are entered as:

DO $10 M=1$, NAR (NAR is the number of arrays entered)

DO $10 \mathrm{~K}=1$, NZMAX

DO $10 \mathrm{~J}=1$, NYMAX

DO $10 \mathrm{I}=1$, NXMAX

. . enter the contents of the $\mathrm{i}^{\text {th }}, \mathrm{j}^{\text {th }}$, and $\mathrm{z}^{\text {th }}$ cell location for array $\mathrm{m} .$.

NUREG/CR-0200,

Vol. 3, Rev. 4

M9.A.4 


\section{CONTINUE}

All entries must be separated by a blank, and data may be entered in all columns 1 through 80 . Entries of the form " $L * N$ " means enter the value $N$ into the input $L$ times. This could also be done with the "R" option by entering "LRN." In both cases blanks between entries are not allowed.

Example: $\begin{array}{lllllllll}2 & 1 & 2 & 2 & 1 & 2 & 12\end{array}$

This could be the description of a $3 \times 3$ array of the form,

212

212

212

2. IOP $=1-$ Mixed-Cell Orientation Cards

The first field contains the entry followed by three sets of three fields that are treated like FORTRAN DO loops, followed by a field that indicates whether another set of data is to be read. The arrangement of lattice cells may be considered as consisting of a 3-D matrix of numbers, with the cell position increasing in the positive $X, Y$, and $Z$ directions, respectively. Each set of orientation data consists of the following parameters, separated by one or more blanks.

LTYPE The cell entry. LTYPE may be negative (array \#), zero (empty cell), or positive (universe \#).

IX1 The starting point in the X direction. IX1 must be at least 1 and less than or equal to NXMAX.

IX2 The ending point in the X direction. IX2 must be at least 1 and less than or equal to NXMAX.

INCX The number of cells by which increments are made in the positive $\mathrm{X}$ direction. INCX must be greater than zero and less than or equal to NXMAX.

IY1 The starting point in the Y direction. IY1 must be at least 1 and less than or equal to NYMAX.

IY2 The ending point in the Y direction. IY2 must be at least 1 and less than or equal to NYMAX.

INCY The number of cells by which increments are made in the positive $Y$ direction. INCY must be greater than zero and less than or equal to NYMAX.

NUREG/CR-0200, 
IZ1 The starting point in the $\mathrm{Z}$ direction. IZ1 must be at least 1 and less than or equal to NZMAX.

IZ2 The starting point in the $\mathrm{Z}$ direction. IZ2 must be at least 1 and less than or equal to NZMAX.

INCZ The number of cells by which increments are made in the positive $Z$ direction. INCZ must be greater than zero and less than or equal to NZMAX.

ISTP $=0$, read another set of data,

$=0$, do not read any more mixed-cell orientation data.

An important feature of this type of data description is that, if any portion of an array is defined in a conflicting manner, the last card to define that portion will be the one that determines the array's cell type configuration. To utilize this feature, one can fill an entire array with the most prevalent cell type and then superimpose the other cell types in their proper places to accurately describe the array. The last set of mixed-cell orientation data must have a nonzero entry in the last field.

3. IOP $=2$ - Standard FIDO Array Input

The array being entered is integer; therefore, it is a " $\$$ " or " $\$$ " array. The array may be entered in the standard free-form FIDO format. The description for each lattice array is entered as a single array block with FIDO. The FIDO integer array number entered is the array number being described plus 100 . The data are entered, and each array description is terminated with a "T." All standard FIDO repeat options are available for entering the data. Array 1 would be entered as the "101\$\$" FIDAS array terminated with a "T." The process would continue until all array descriptions have been entered. The format for the data entry is the same as the description for free-form input. All $x$ entries for the first $y$ row and first $z$ level are entered, then all $x$ entries for the second $y$ row and first $z$ level are entered. This process continues until the entire first $z$ level has been described. Then the second $z$ level is described until the entire array has been described. Then the geometry array description or a given array is terminated with a "T."

\section{M9.A.10 UNIVERSE TYPE}

One entry is required for each universe modeled in the combinatorial geometry, starting with Universe 1. The entries should be either a zero or a 1: a zero if the universe is "combinatorial" and a 1 if the universe is "simple." A "simple" universe is a universe composed of concentric zones, where every zone completely surrounds the zone inside of it. Furthermore, input zones in a simple universe may be only one code zone and may be described by only one or two bodies. Tracking through "simple" universes is about $30 \%$ or more faster than through regular combinatorial geometry tracking, although the modeling capability is limited. Simple universes may be combined with regular combinatorial universes in arrays without any problems.

$$
\text { -.- End of Geometry Input -- }
$$

NUREG/CR-0200,

Vol. 3, Rev. 4

M9.A.6 


\section{M9.B ILUSTRATIVE EXAMPLES OF MARS GEOMETRY}

\section{M9.B.1 AN UNCOMMON ARRAY SHAPE}

Figure M9.B.1 illustrates the geometry being described. The input and some of the output edit are given in Fig. M9.B.2. The MARS input is Cards 2 through 27 in the input list. The remaining input is solely for the JUNEBUG graphics program, which is no longer distributed with the SCALE system. The following correspondence exists between the MARS input instructions and the card image list:

Card number

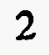

3

4-14

$15-21$

22

23

24

25

26

27
Input requirement

A.1, Title Card

A.2, Options Card

A.3, Body Definition Cards

A.4, Input Zone Description Cards

A.5, Region Card

A.6, Universe Card

A.7, Media Card

A.8, Array Size Specification Input

A.9, Array Content Description

A.10, Universe Type

The model consists of:

10 Bodies using

3 Body Types (RPP, RCC, and SPH)

6 Input Zones described by

12 Code Zones

1 Universe

1 Array of size $3 \times 3 \times 1$

1 Level of Geometry Nesting

Special attention should be given to:

1. Body 6 is the Reference Body 1 for Universe 1.

2. Input Zone 6 is the Universe 1 boundary zone with the -1000 media.

3. Body 1 is the reference body for Array 1 .

4. Input Zone 3 references Array 1 in the media list by a -1 media.

5. Input Zone 3 is described with two code zones, Code Zones 8 and 9.

6. Body 1 is the first body given in the zone description list for Code Zones 8 and 9 . 
7. Array 1 is a $3 \times 3 \times 1$ array with vacant cell positions on each corner.

8. Array 1 is described with FIDAS input because IOP is 2 on Card 25.

\section{M9.B.1.1 Explanations and Discussions}

Universe 1 consists of Input Zones 4, 5, and 6. Input Zone 6 is the universe boundary since it references Media -1000 . Zone 6 is described as " $+8-6$." The reference body for a universe is the first excluded body in the universe boundary zone description. No tracking occurs in a -1000 media. This acts only as a flag to signify exiting the universe. It is encountered only on exiting a universe. Body 6 not only is the reference body used to translate into and out of Universe 1, but it also defines the size of Universe 1. A universe cannot be referenced in array cells that do not correspond in length, width, and height to the universe's reference body.

Array 1 is referenced in Input Zone 3 which is made up of Code Zones 8 and 9 . The reference body for an array is always the first positive body mentioned in the code zone description where the array is referenced.

It must be a positive body reference. An array referenced in an input zone composed of more than one code zone can have only one reference body. Body 1 is the reference body for Array 1 . Notice it is the first body mentioned in the descriptions for Code Zones 8 and 9 of Input Zone 3. The reference body for an array must have the same delta $\mathrm{x}$ width, delta $\mathrm{y}$ depth, and delta $\mathrm{z}$ height as the full array. The reference body should be the size of the full array, even though vacancies may exist in the description of the array. The input zone where an array is referenced must fit snugly with the nonvacant lattice positions of the array. It is not necessary to combine Code Zones 8 and 9 into a single input zone as long as they both correctly reference the same reference body.

Notice that, since IOP is 2 on Card 25 of the A.8 input, the array content requirement, A.9, is accomplished with the FIDO input specifications on Card 26.

The nonmaterial media used in this model are the following:

Media number
1000
-1000
-1

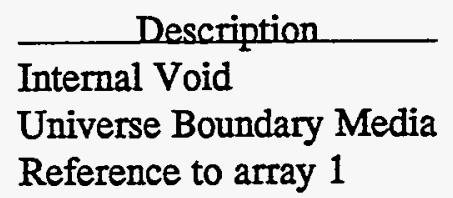

The absolute universe, Universe 0 , in this model is described with Input Zones 1, 2, and 3. Code Zones 1 through 5 were lumped together into Input Zone 1 since they all contained the same media. This zone definition was done with the "OR" operator. This step is not a requirement. It was done only for logical consistency in the input description. The best way to model any problem is in a manner that the user best understands.

NUREG/CR-0200,

Vol. 3, Rev. 4

M9.B.2 
Array 1 contents are

FOR $Z=1$
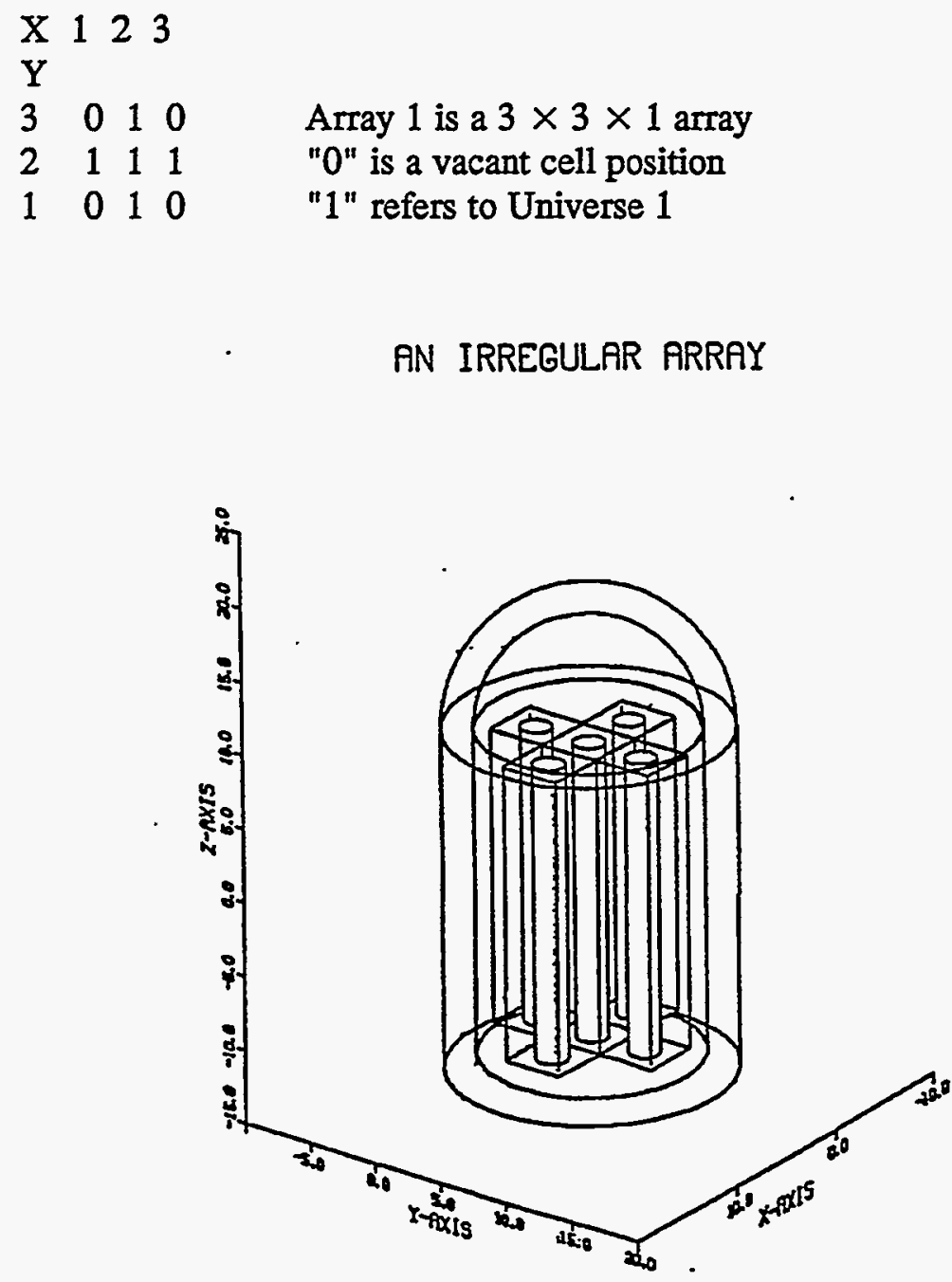

Figure M9.B.1 Computer drawing of Sample Problem 1 
THE FOLLOWING IS A LIST OF CARD IMAGE INPUT

CARD NO. C O L U M N N

1111111112222222222333333333344444444445555555555666666666677777777778 12345678901234567890123456789012345678901234567890123456789012345678901234567490

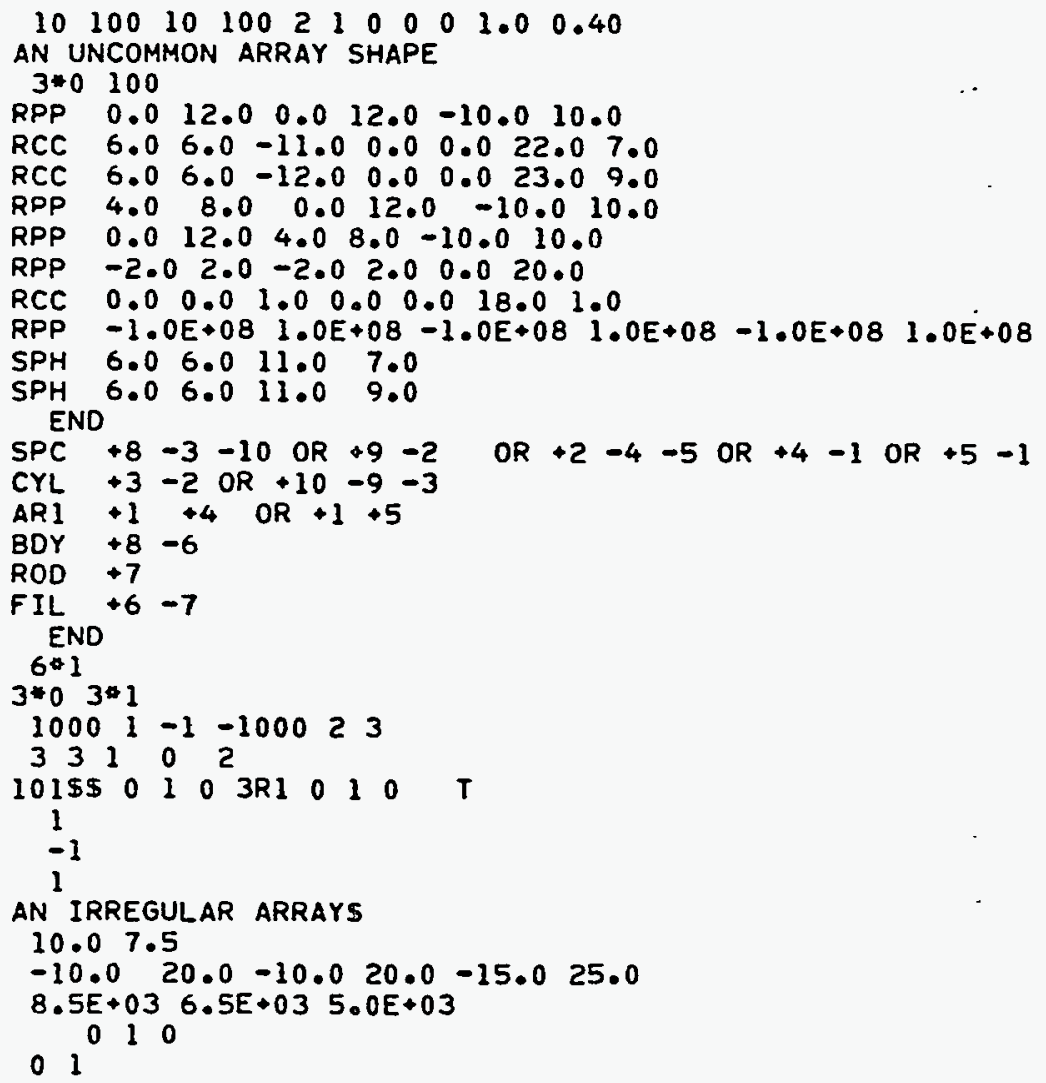

Figure M9.B.2 Computer input and output listing of Sample Problem 1

NUREG/CR-0200,

Vol. 3, Rev. 4

M9.B.4 
AN UNCOMMON ARRAY SHAPE

$$
\text { IVOPT }=0 \quad \text { IDBG }=0
$$

\begin{tabular}{|c|c|c|c|c|c|c|c|}
\hline RPP & 1 & 0 & $.1200000 E+02$ & BODY & $\stackrel{T A}{.1200000 E+02}$ & $-.1000000 E+02$ & $.1000000 E+02$ \\
\hline $\mathrm{RCC}$ & 2 & $\begin{array}{l}.6000000 E+01 \\
.7000000 E+01\end{array}$ & $.6000000 E+01$ & $-.1100000 E+02$ & 0. & 0. & $.2200000 E+02$ \\
\hline $\begin{array}{l}\text { RCC } \\
\text { RPP }\end{array}$ & 4 & $\begin{array}{l}.6000000 E+01 \\
.9000000 E+01 \\
.4000000 E+01\end{array}$ & $\begin{array}{l}.6000000 E+01 \\
.8000000 E+01\end{array}$ & $\begin{array}{l}-.1200000 E+02 \\
0 .\end{array}$ & $\begin{array}{l}0 . \\
.1200000 E+02\end{array}$ & $\begin{array}{l}0 . \\
-.1000000 E+02\end{array}$ & $\begin{array}{l}.2300000 E+02 \\
.1000000 E+02\end{array}$ \\
\hline RPP & 5 & 0. & $\because 1200000 E+02$ & $.4000000 E+01$ & $.8000000 E+01$ & $-.1000000 E+02$ & $.1000000 E+02$ \\
\hline RPP & 6 & $-.2000000 E+01$ & $.2000000 E+01$ & $-.2000000 E+01$ & $.2000000 E+01$ & 0 & $.2000000 E+02$ \\
\hline $\begin{array}{l}\text { RCC } \\
\text { RPP }\end{array}$ & 7 & $\begin{array}{r}0.1000000 E+01 \\
-.1000000 E+09\end{array}$ & $\begin{array}{l}0 . \\
.1000000 E+09\end{array}$ & $\begin{array}{r}.1000000 E+01 \\
-.1000000 E+09\end{array}$ & $\begin{array}{l}0 . \\
.1000000 E+09\end{array}$ & $\begin{array}{l}0 . \\
-.1000000 E+09\end{array}$ & $\begin{array}{l}.1800000 E+02 \\
.1000000 E+09\end{array}$ \\
\hline $\begin{array}{l}\text { SPH } \\
\text { SPH } \\
\text { NUMBER } \\
\text { LENGTH }\end{array}$ & $\begin{array}{l}9 \\
10 \\
\text { OF } \\
\text { of }\end{array}$ & $\begin{array}{rr}.6000000 E+01 \\
.6000000 E+01 \\
\text { BODIES } \quad 10 \\
\text { FPD-ARRAY } \quad 79\end{array}$ & $\begin{array}{l}.6000000 E+01 \\
.6000000 E+01\end{array}$ & $\begin{array}{l}.1100000 E+02 \\
.1100000 E+02\end{array}$ & $\begin{array}{l}.7000000 E+01 \\
.9000000 E+01\end{array}$ & & \\
\hline
\end{tabular}

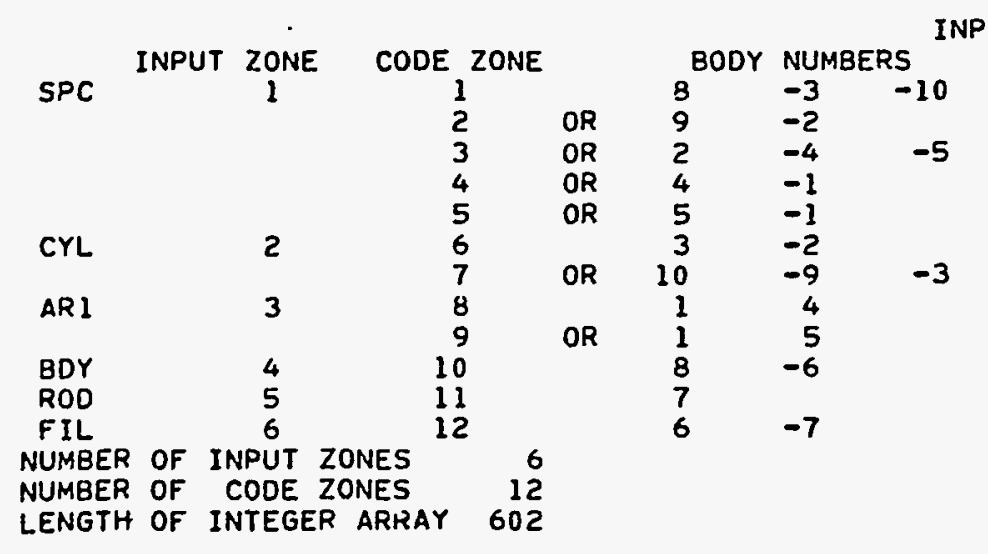

Figure M9.B.2 (continued)

M9.B.5

NUREG/CR-0200, Vol. 3, Rev. 4 


\begin{tabular}{|c|c|c|c|c|c|c|c|c|c|c|c|c|}
\hline $\begin{array}{c}\text { CODE ZONE } \\
1 \\
2 \\
3 \\
4 \\
5 \\
6 \\
7 \\
8 \\
9 \\
10 \\
11 \\
12\end{array}$ & $\begin{array}{c}\text { INPUT ZONE } \\
1 \\
1 \\
1 \\
1 \\
1 \\
1 \\
2 \\
2 \\
3 \\
3 \\
4 \\
5 \\
6\end{array}$ & ZONE & $\begin{array}{l}\text { DATA LOC. } \\
71 \\
87 \\
98 \\
114 \\
125 \\
136 \\
147 \\
163 \\
174 \\
185 \\
196 \\
202\end{array}$ & $\begin{array}{c}\text { NO. OF } \\
\text {. }\end{array}$ & $\begin{array}{l}\text { BODIES } \\
3 \\
2 \\
3 \\
2 \\
2 \\
2 \\
3 \\
2 \\
2 \\
2 \\
1 \\
2\end{array}$ & REGION & $\begin{array}{l}\text { NO. } \\
1 \\
1 \\
1 \\
1 \\
1 \\
1 \\
1 \\
1 \\
1 \\
1 \\
1 \\
1\end{array}$ & $\begin{array}{r}\text { HEOIA NO } \\
1000 \\
1000 \\
1000 \\
1000 \\
1000 \\
1 \\
1 \\
-1 \\
-1 \\
-1000 \\
2 \\
3\end{array}$ & Box & INPUT & $\begin{array}{c}\text { ZONE } \\
0 \\
0 \\
0 \\
0 \\
0 \\
0 \\
0 \\
0 \\
0 \\
1 \\
1 \\
1\end{array}$ & BOX CODE \\
\hline
\end{tabular}

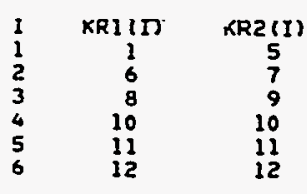

MORSE REGION IN INPUT ZONE(I) ARRAY (HRIZ(I),I×1,6)

$\begin{array}{llllll}1 & 1 & 1 & 1 & 1 & 1\end{array}$

MORSE MEDIA IN INPUT ZONE(I) ARRAY (HMIZ(I) \&I=1, 6)

$10001-1-1000 \quad 2 \quad 3$

Figure M9.B.2 (continued)

NUREG/CR-0200,

Vol. 3, Rev. 4

M9.B.6 


\section{M9.B.2 OVERLAPPING PINS IN A 2 X 2 ARRAY}

Figure M9.B.3 illustrates the geometry described. The input and some of the output edit are given in Fig. M9.B.4. The MARS input is Cards 2 through 55 in the input list. The remaining input is solely for the JUNEBUG graphics program which is no longer distributed with the SCALE system. The following correspondence exists between the MARS input instructions and the card image list:

\begin{tabular}{cl} 
Card number & \multicolumn{1}{c}{ Input requirements } \\
\cline { 2 - 2 } 2 & A.1, Title Card \\
3 & A.2, Options Card \\
$4-18$ & A.3, Body Definition Card \\
$19-45$ & A.4, Input Zone Description Cards \\
46 & A.5, Region Card \\
47 & A.6, Universe Card \\
$48-52$ & A.7, Media Card \\
53 & A.8, Array Size Specification Input \\
54 & A.9, Array Content Description \\
55 & A.10, Universe Type
\end{tabular}

The model consists of:

$\begin{array}{cl}14 & \text { Bodies using } \\ 2 & \text { Body Types (RCC and RPP) } \\ 26 & \text { Input Zones described by } \\ 26 & \text { Code Zones } \\ 4 & \text { Universes } \\ 1 & \text { Array of size } 2 \times 2 \times 1 \\ 1 & \text { Level of Geometry Nesting }\end{array}$

Special attention should be given to:

1. Body 11 is the reference body for Universe 1 .

2. Body 12 is the reference body for Universe 2 .

3. Body 10 is the reference body for Universe 3.

4. Body 9 is the reference body for Universe 4 .

5. Input Zone 6 is the universe boundary zone for Universe 1 .

6. Input Zone 12 is the universe boundary zone for Universe 2.

7. Input Zone 18 is the universe boundary zone for Universe 3. 
8. Input Zone 24 is the universe boundary zone for Universe 4.

9. This model has one code zone for each input zone.

10. The same bodies may be used in more than one universe description, thereby reducing the number of bodies needed to model a given geometry. Notice the cylinders overlap the universe boundaries and each cylinder is referenced in two universes.

11. This model has one array of size $2 \times 2 \times 1$.

12. The reference body for Array 1 is Body 13 .

13. The array content description on Card 54 used the free-form specification option with IOP set to 0 on Card 53.

The reference body for a universe is the excluded body in the universe boundary zone description. Everything inside the universe reference body comprises the universe model. This model demonstrates the importance of positioning the universes correctly in an array. If the array content input was reversed, what would the picture look like? Actually, for this model there was not a real need to use the array feature of MARS. This could have been modeled completely in the absolute universe. Notice in the output listing that the universes in this problem are combinatorial and not simple. The input declared the universes as simple, but MARS changed the input to combinatorial and issued warning messages accordingly.

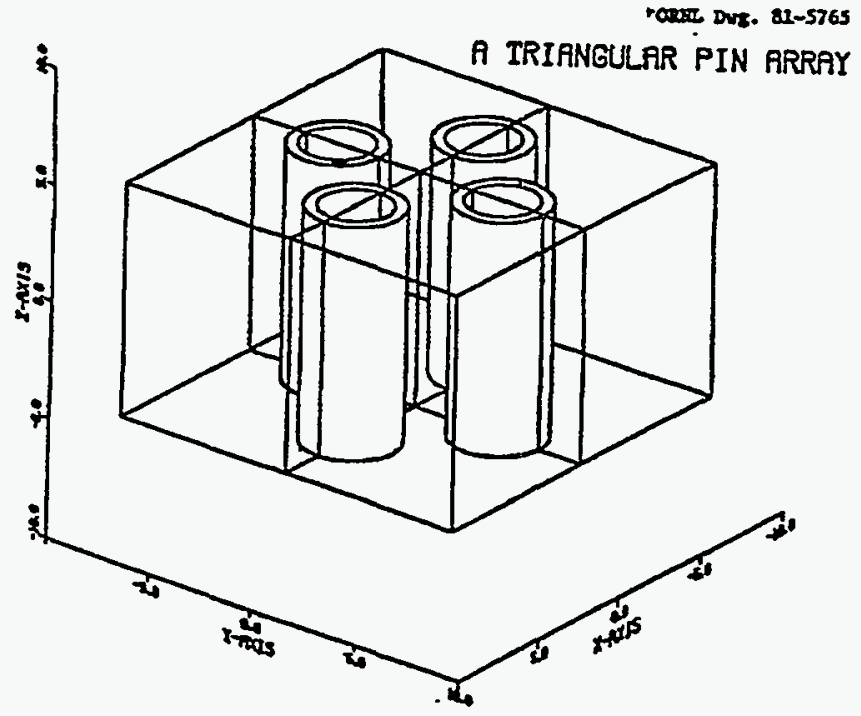

Figure M9.B.3 Computer drawing of Sample Problem 2

NUREG/CR-0200,

Vol. 3, Rev. 4 
THE FOLLOHING IS A LIST OF CARD IMAGE INPUT

CARD NO. C OLUMN NO.

1111111112222222222333333333344444444445555555555666666666677777777778 12345678901234567890123456789012345678901234567890123456789012345678901234567890

$\begin{array}{lllllllllllll}10 & 30 & 10 & 30 & 0 & 0 & 0 & 0 & 0 & 0.3 & 0.3\end{array}$

OVERLAPPING PINS IN A 2 BY 2 ARRAY, JIM WEST ORNL

$3 * 0 \quad 100$

RCC $8.0 \quad 12.0 \quad 0.0 \quad 0.0 \quad 0.0 \quad 10.0 \quad 1.5$

$\begin{array}{lllllllll}\text { RCC } & 8.0 & 12.0 & 0.0 & 0.0 & 0.0 & 10.0 & 2.0\end{array}$

RCC $12.08 .0 \quad 0.0 \quad 0.0 \quad 0.0 \quad 10.01 .5$

RCC $\quad 12.0 \quad 8.0 \quad 0.0$. $0.0 \quad 0.0 \quad 10.02 .0$

RCC $\quad 8.0 \quad 4.0 \quad 0.0 \quad 0.0 \quad 0.0 \quad 10.0 \quad 1.5$

RCC $\quad 8.0 \quad 4.0 \quad 0.0 \quad 0.0 \quad 0.0 \quad 10.0 \quad 2.0$

$\begin{array}{lllllllll}\text { RCC } \quad 4.0 & 8.0 & 0.0 & 0.0 & 0.0 & 10.0 & 1.5\end{array}$

$\begin{array}{llllllll}\text { RCC } \quad 4.0 & 8.0 & 0.0 & 0.0 & 0.0 & 10.0 & 2.0\end{array}$

$\begin{array}{llllllll}\text { RPP } & 0.0 & 8.0 & 0.0 & 8.0 & 0.0 & 10.0\end{array}$

RPP $\quad 8.0 \quad 16.0 \quad 0.0 \quad 3.0 \quad 0.0 \quad 10.0$

RPP $\quad \begin{array}{llllllll}0.0 & 8.0 & 8.0 & 16.0 & 0.0 & 10.0\end{array}$

RPP $\quad 8.0 \quad 16.0 \quad 8.0 \quad 16.0 \quad 0.0 \quad 10.0$

RPP $\quad-8.0 \quad 8.0 \quad-8.0 \quad 8.0 \quad-5.0 \quad 5.0$

RPP $-1.0 E+071.0 E+07-1.0 E+071.0 E+07-1.0 E+071.0 E+07$

END

PII + + +11

PCI + $-1+11$

$P[4+7+1]$

$\mathrm{PC}_{4}+8-7+11$

FII $+11-2-8$

$F B 1+14-11$

PII +1 +12

$P C 1+2-1+12$

PI2 +3+12

FC2 $+4-3+12$

FI2 $+12-2-4$

FB2 $+14-12$

$P I 2+3+10$

PC2 + $4-3+10$

PI3 $+5+10$

PC3 +6 $-5+10$

Figure M9.B.4 Computer input and output listing of Sample Problem 2 


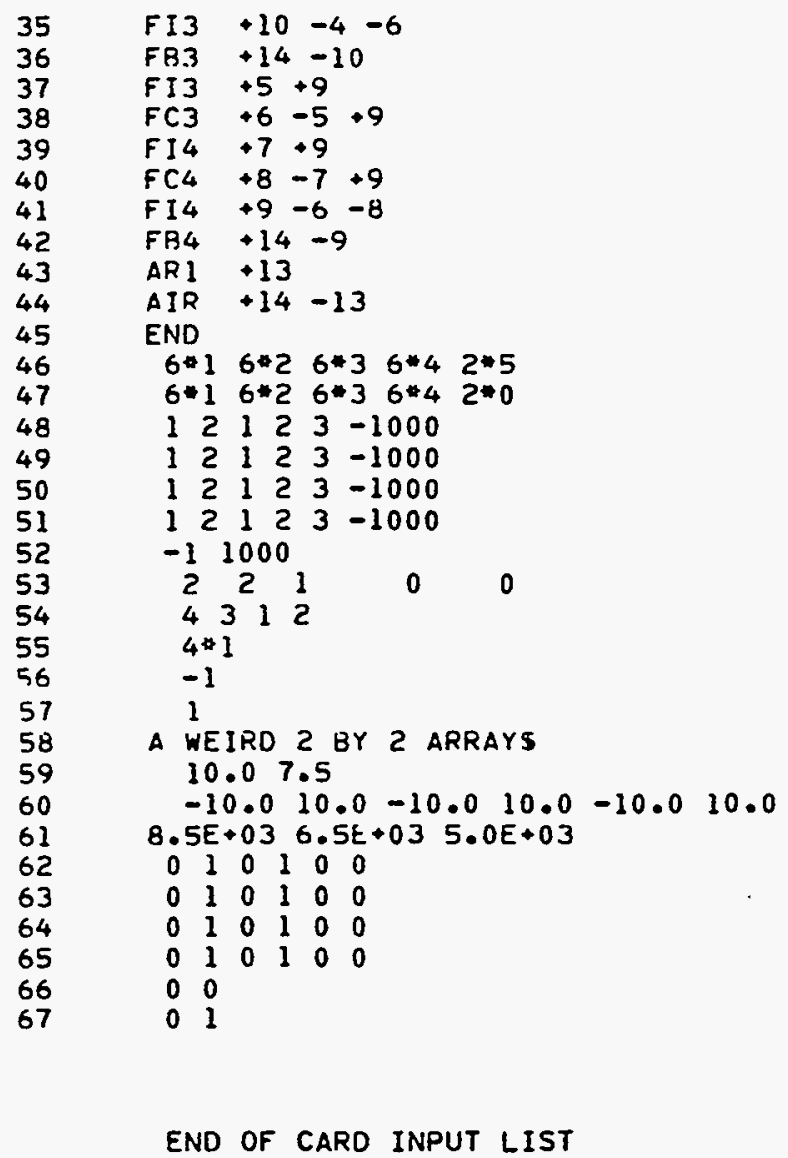

Figure M9.B.4 (continued)

NUREG/CR-0200,

Vol. 3, Rev. 4

M9.B.10 
OVERLAPPING PINS IN A 2 BY 2 ARRAY, JIM WEST ORNL

$$
\text { IVOPT }=0 \quad \text { IOBG }=0
$$

\begin{tabular}{|c|c|c|c|c|c|c|c|}
\hline $\mathrm{RCC}$ & 1 & - $8000000 E+01$ & $.1200000 E+02$ & BODY & $\begin{array}{l}\text { TTA } \\
0 .\end{array}$ & 0. & $.1000000 E+02$ \\
\hline $\mathrm{RCC}$ & 2 & $\begin{array}{l}.8000000 E+01 \\
.2000000 E+01\end{array}$ & $.1200000 E+02$ & 0 & 0. & 0. & $.1000000 E+02$ \\
\hline RCC & 3 & $\begin{array}{l}.1200000 E+02 \\
.1500000 E+01\end{array}$ & $.8000000 E+01$ & 0 & 0. & 0. & $.1000000 E+02$ \\
\hline $\mathrm{RCC}$ & 4 & $.1200000 E+02$ & $.8000000 E+01$ & 0 & 0. & 0. & $.1000000 E+02$ \\
\hline RCC & 5 & $\begin{array}{l}.8000000 E+01 \\
.1500000 E+01\end{array}$ & $.4000000 E+01$ & 0. & 0. & 0 & $.1000000 E+02$ \\
\hline RCC & 6 & $\begin{array}{l}.8000000 E+01 \\
.2000000 E+01\end{array}$ & $.4000000 E+01$ & 0. & 0. & 0 & $.1000000 E+02$ \\
\hline$R C C$ & 7 & $\begin{array}{l}.4000000 E+01 \\
.1500000 E+01\end{array}$ & $.8000000 E+01$ & 0. & 0. & 0 & $.1000000 E+02$ \\
\hline $\mathrm{RCC}$ & 8 & $\begin{array}{l}.4000000 E+01 \\
.2000000 E+01\end{array}$ & $.8000000 E+01$ & 0 & 0 & 0 & $.1000000 E+02$ \\
\hline RPP & 9 & 0 & $.80000 .00 E+01$ & 0. & $.8000000 E+01$ & 0. & $.1000000 E+02$ \\
\hline RPP & 10 & $.8000000 E+01$ & $.1600000 E+02$ & 0. & $.8000000 E+01$ & 0. & $.1000000 E+02$ \\
\hline RPP & 11 & 0 & $.8000000 E+01$ & $.8000000 E+01$ & $.1600000 E+02$ & 0 & $.1000000 E+02$ \\
\hline RPP & 12 & $.8000000 E+01$ & $.1600000 E+02$ & $.8000000 E+01$ & $.1600000 E+02$ & 0. & $.1000000 E+02$ \\
\hline RPP & 13 & $-.8000000 E+01$ & $.8000000 E+01$ & $-.8000000 E+01$ & $.8000000 E+0 l$ & $-.5000000 E+01$ & $.5000000 E+01$ \\
\hline RPP & 14 & $-.1000000 E+08$ & $.1000000 E+08$ & $-.1000000 E+08$ & $.1000000 E+08$ & $-.2000000 E+08$ & $.1000000 E+08$ \\
\hline $\begin{array}{l}\text { NUMBER } \\
\text { ENGTH }\end{array}$ & $\begin{array}{l}\text { OF } \\
\text { of }\end{array}$ & $\begin{array}{lr}\text { BODIES } & 14 \\
\text { FPD-ARRAY } & 120\end{array}$ & & & & & \\
\hline
\end{tabular}

Figure M9.B.4 (continued)

M9.B.11

NUREG/CR-0200, Vol. 3, Rev. 4 


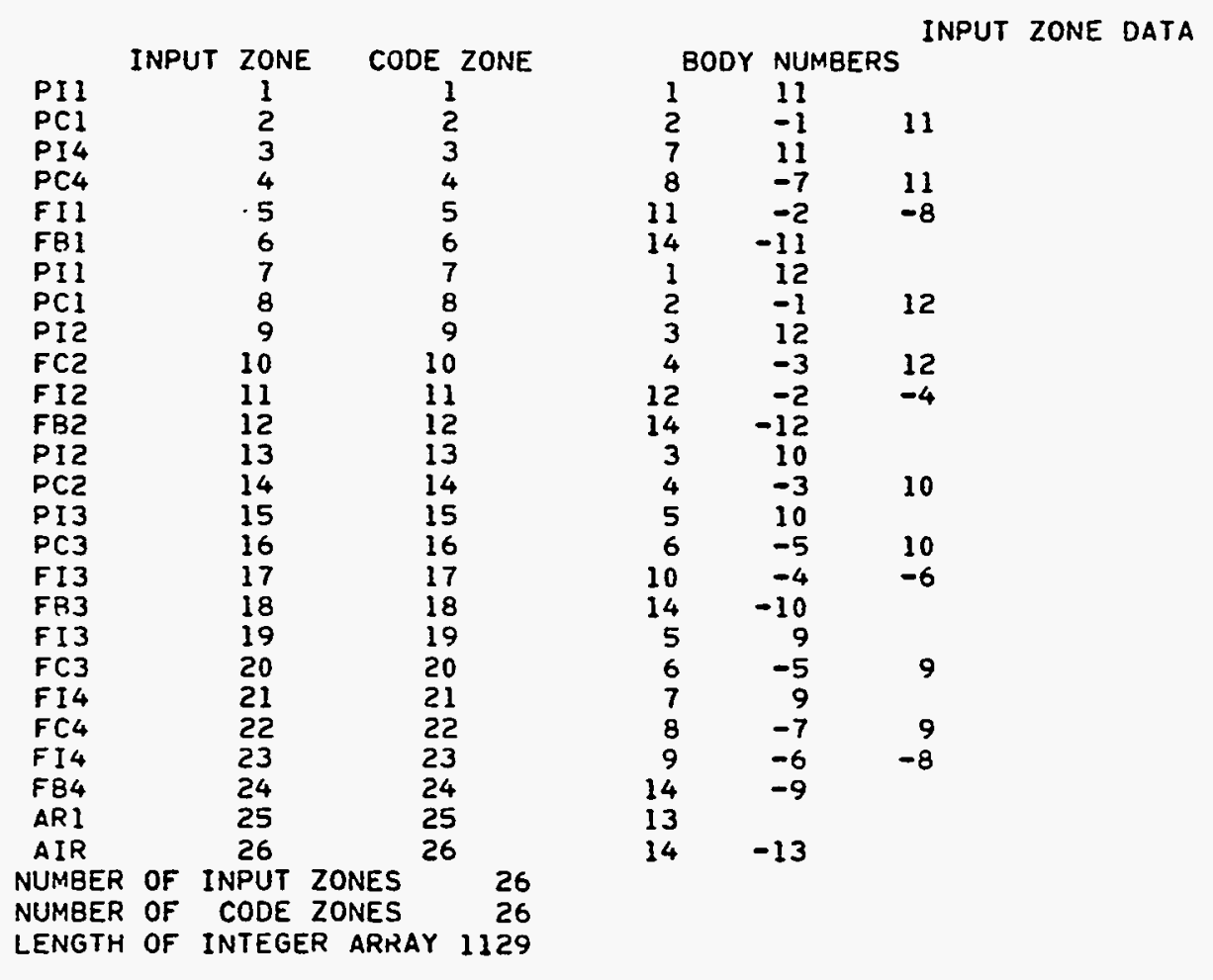

Figure M9.B.4 (continued)

NUREG/CR-0200,

Vol. 3, Rev. 4

M9.B.12 


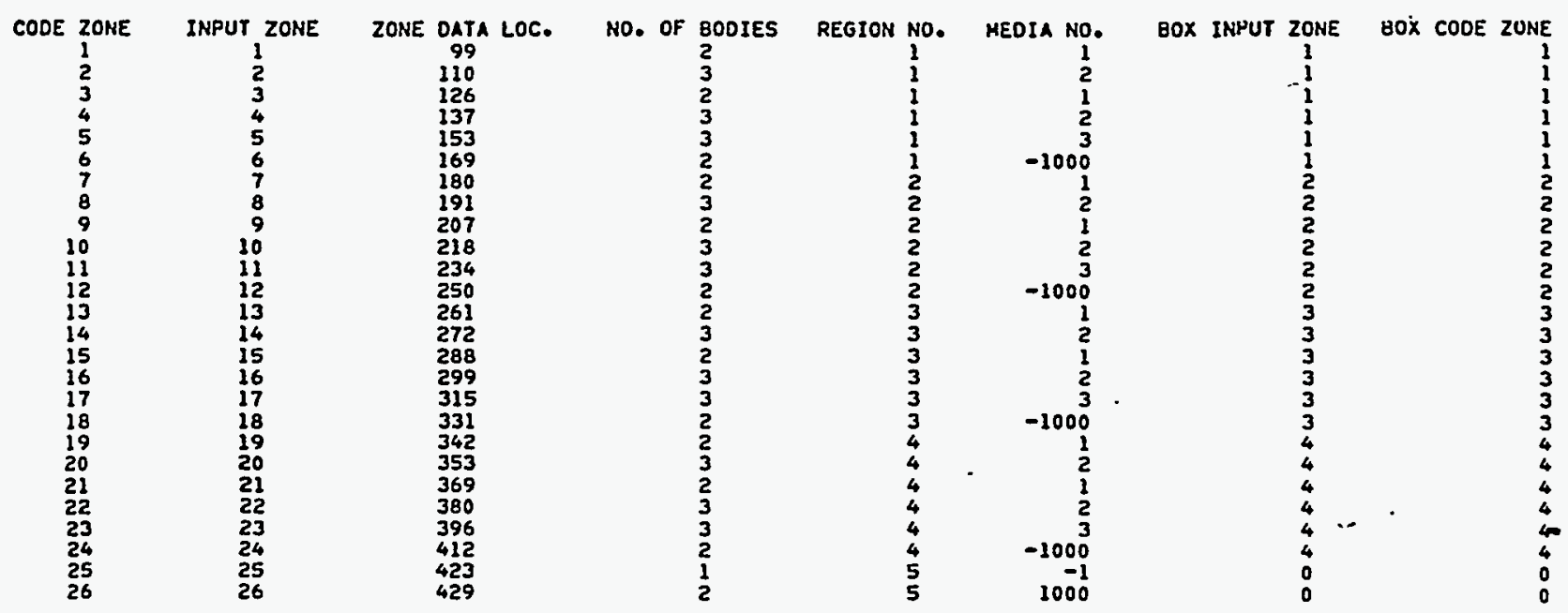

MORSE REGION IN INPUT ZONE(I) ARRAY (MRIZ(I),1=1,26)

$\begin{array}{lllllllllllllllllllll}1 & 1 & 1 & 1 & 1 & 1 & 2 & 2 & 2 & 2 & 2 & 2 & 3 & 3 & 3 & 3 & 3 & 3 & 4 & 4\end{array}$

MORSE HEOIA IN INPUT ZONE(I) ARRAY (MMIZII),I=1,26) :-
$12123-1000$
1.2
$123-1000 \quad-11000$

Figure M9.B.4 (continued)

M9.B.13

NUREG/CR-0200,

.Vol. 3, Rev. 4 


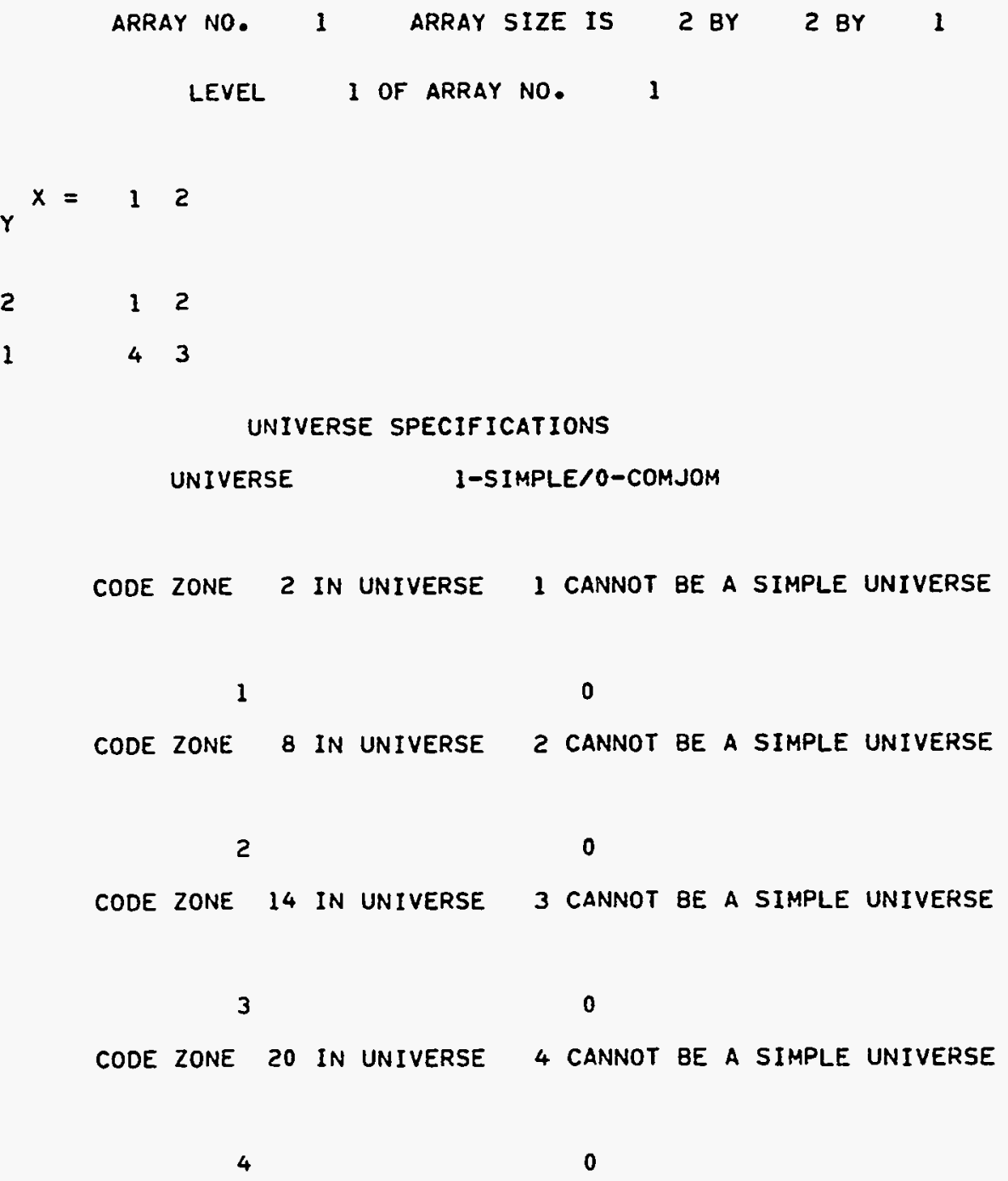

Figure M9.B.4 (continued)

NUREG/CR-0200,

Vol. 3, Rev. 4

M9.B.14 


\section{M9.B.3 PLEXIGLAS PIPE CROSS EXPERIMENT}

Figure M9.B.5 illustrates the geometry being described. The input and some of the output edit is given in Fig. M9.B.6. The MARS input is Cards 2 through 38 in the input list. The remaining input is solely for the JUNEBUG graphics program which is no longer distributed with the SCALE system. The following correspondence exists between the MARS input instructions and the card image list:

Card number Input requirements

$\begin{array}{cl}2 & \text { A.1, Title Card } \\ 3 & \text { A.2, Options Card } \\ 4-19 & \text { A.3, Body Definition Cards } \\ 20-34 & \text { A.4, Input Zone Description Cards } \\ 35 & \text { A.5, Region Card } \\ 36 & \text { A.6, Universe Card } \\ 37 & \text { A.7, Media Card } \\ 38 & \text { A.8, Array Size Specification Input } \\ & \text { Note: Since no arrays were specified, Input A.9 was not entered. }\end{array}$

The model consists of:

$15 \quad$ Bodies using

3 Body Types (RPP, RCC, \& BOX)

14 Input Zones described by

15 Code Zones

0 Universes

$0 \quad$ Arrays

$0 \quad$ Level of Geometry Nesting

Special attention should be given to:

1. This model does not use the MARS array feature; therefore, Input Requirement A.9 is not entered. Input A.8 consisted only of the terminating zero input.

2. All input zones are in the absolute universe, and no other input zones are described.

\section{M9.B.4 A TYPICAL PWR SHIPPING CASK}

Figure M9.B.7 illustrates the geometry being described. Figure M9.B.8a, M9.B.8b, and M9.B.8c demonstrate the array model nesting. Figure M9.B.9 gives a hierarchal view of the geometry model. It illustrates the order of geometry nesting and the level at which each segment of the model exists inside. The MARS input is shown in Fig. M9.B.10. The combinatorial output edit of the body data, the zone data, and the zone universe data is given in Fig. M9.B.11. The MARS output edit of each of the six arrays modeled is given in Fig. M9.B.12. The following correspondence exists between the MARS input instructions and the card image list: 


\section{PIPE CROSS EXP.}

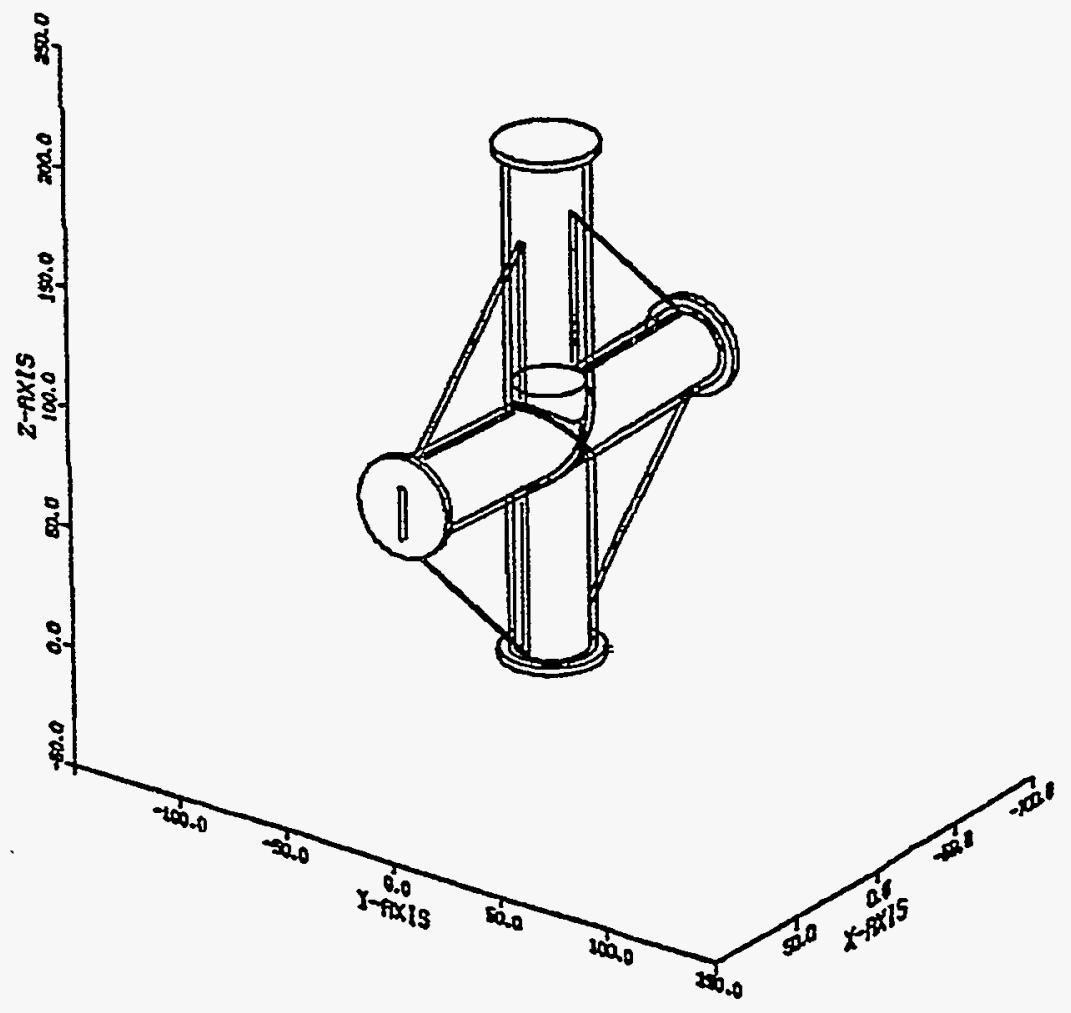

Figure M9.B.5 Computer drawing of Sample Problem 3

NUREG/CR-0200,

Vol. 3, Rev. 4

M9.B.16 
THE FOLLOWING IS A LIST OF CARD IMAGE INPUT

CARO NO. C O L U M N NO.

1111111112222222222333333333344444444445555555555666666666677777777778 12345678901234567890123456789012345678901234567890123456789012345678901234567890

$\begin{array}{llllllllllll}10 & 100 & 10 & 100 & 1 & 0 & 0 & 0 & 0 & 0.5 & 0.5\end{array}$ PLEXIGLAS PIPE CROSS CRITICAL EXPERIMENT $\begin{array}{llllll}0 & 0 & 0 & 10\end{array}$

RCC $0.0 \quad 0.0 \quad 3.175 \quad 0.0 \quad 0.0 \quad 207.01 \quad 13.97$

RCC $0.0 \quad 0.0 \quad 3.175 \quad 0.0 \quad 0.0 \quad 207.01 \quad 16.51$

RCC $0.0 \quad 0.0 \quad 91.44 \quad 88.160559 \quad 0.0 \quad 3.076759 \quad 13.97$

RCC $0.0 \quad 0.0 \quad 91.44 \quad 88.1605590 .0 \quad 3.076759 \quad 16.51$

RCC $0.0 \quad 0.0 \quad 91.44 \quad-88.1605590 .0 \quad 3.076759 \quad 13.97$

$\begin{array}{lllllllll}\text { RCC } & 0.0 & 0.0 & 91.44 & -88.160559 & 0.0 & 3.076759 & 16.51\end{array}$

RCC $0.0 \quad 0.0 \quad 0.0 \quad 0.0 \quad 0.0 \quad 3.17520 .32$

RCC $0.0 \quad 0.0 \quad 210.185 \quad 0.0 \quad 0.0 \quad 3.17520 .32$

RCC $88.150000 \quad 0.0 \quad 94.518635 \quad 3.173066 \quad 0.0 \quad 0.110806 \quad 20.32$

RCC $-88.160559 \quad 0.0 \quad 94.518635 \quad-3.173066 \quad 0.0 \quad 0.110806 \quad 20.32$

BoX $0.0-1.27-10.80102 .240 .0 \quad 102.240 .02 .540 .0-102.240 .0 \quad 102.24$

RPP $-300.0 \quad 300.0 \quad-300.0 \quad 300.0 \quad-300.0 \quad 113.175$

$R P P=350.0 \quad 350.0-350.0 \quad 350.0-350.0 \quad 350.0$

$R P P \quad-1.0 E+051.0 E+05-1.0 E+05 \quad 1.0 E+05-1.0 E+05 \quad 1.0 E+05$

RPP $-90.0 \quad 90.0-10.0 \quad 10.0 \quad 0.0 \quad 213.36$

ENO

$P G 1+2-1 \quad-4-6-7 \quad-8$

$P G 2+6-5-10-1$

$P G 3+4-3-9-1$

$P G 4+7$

Figure M9.B.6 Computer input and output listing of Sample Problem 3

M9.B.17

NUREG/CR-0200,

Vol. 3, Rev. 4 


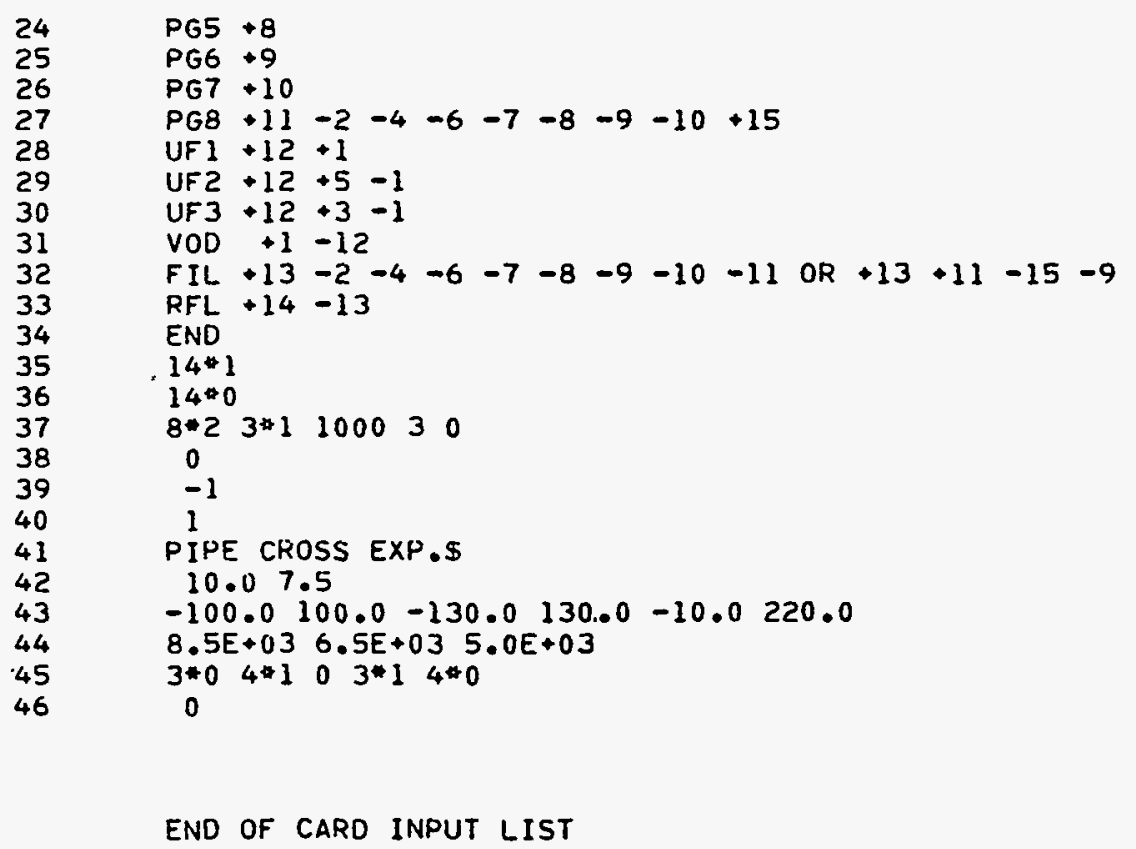

Figure M9.B.6 (continued)

NUREG/CR-0200,

Vol. 3, Rev. 4

M9.B.18 
PLEXIGLAS PIPE CROSS CRITICAL EXPERIMENT

$\begin{array}{ll}\text { IVOPT }=0 & \text { IDBG }=0\end{array}$

\begin{tabular}{|c|c|c|c|c|c|c|c|}
\hline \multirow{3}{*}{$\begin{array}{l}\text { RCC } \\
\text { RCC }\end{array}$} & \multirow{3}{*}{$\begin{array}{l}1 \\
2\end{array}$} & \multirow{2}{*}{$0.1397000 E+02$} & \multirow[b]{2}{*}{0.} & \multicolumn{2}{|c|}{ BODY DATA } & \multirow[b]{2}{*}{0 . } & \multirow{2}{*}{$.2070100 E+03$} \\
\hline & & & & $.3175000 E+01$ & 0. & & \\
\hline & & 0 . & 0. & $.3175000 E+01$ & 0. & 0 . & $.2070100 E+03$ \\
\hline RCC & 3 & 0. & 0. & $.9144000 E+02$ & $.8816056 E+02$ & 0. & $.3076759 E+01$ \\
\hline RCC & 4 & $0: 139+000$ e & 0. & $.9144000 E+02$ & $.8816056 E+02$ & o. & $.3076759 E+01$ \\
\hline RCC & 5 & 0. & D. & $.9144000 E+02$ & $-.8816056 E+02$ & o. & $.3076759 E+01$ \\
\hline$R C C$ & 6 & $0 \cdot$ & o. & $.9144000 E+02$ & $-.8816056 E+02$ & 0. & $.3076759 E+01$ \\
\hline RCC & 7 & $0.0032000 F+02$ & 0. & o. & 0. & n. & $.3175000 E+01$ \\
\hline RCC & B & 000 & 0. & $.2101850 E+03$ & o. & 0. & $.3175000 E+01$ \\
\hline RCC & 9 & $.8815000 E+02$ & 0. & $.9451864 E+02$ & $.3173066 E+01$ & 0 . & $.1108060 E+00$ \\
\hline$R C C$ & 10 & $\begin{array}{r}-.8816056 E+02 \\
.2032000 E+02\end{array}$ & 0 . & . $9451864 E+02$ & $-.3173066 E+01$ & o. & $.1108060 E+00$ \\
\hline$B 0 x$ & 11 & $\begin{array}{l}0 . \\
0 . \\
-.3000000 E+03\end{array}$ & $\begin{array}{r}-.1270000 E+01 \\
.2540000 E+01 \\
.3000000 E+03\end{array}$ & $\begin{array}{l}-.1080000 E+02 \\
0.3000000 E+03\end{array}$ & $\begin{array}{r}.1022400 E+03 \\
-.1022400 E+03 \\
.3000000 E+03\end{array}$ & $\begin{array}{l}0 . \\
0.3000000 E+03 \\
-.300\end{array}$ & $\begin{array}{l}.1022400 E+03 \\
.1022400 E+03 \\
.1131750 E+03\end{array}$ \\
\hline RPP & 13 & $-.3500000 E+03$ & $.3500000 E+03$ & $-.3500000 E+03$ & $.3500000 E+03$ & $-.3500000 E+03$ & $.3500 .000 E+03$ \\
\hline RPP & 14 & $-.1000000 E+06$ & $.1000000 E+06$ & $-.1000000 E+06$ & $.1000000 E+06$ & $-.1000000 E+06$ & $.1000000 E+06$ \\
\hline RPP & 15 & $-.9000000 E+02$ & $.9000000 E+02$ & $-.1000000 E+02$ & $.1000000 E+02$ & 0. & $.2133600 E+03$ \\
\hline $\begin{array}{l}\text { UMBER } \\
\text { ENGTH }\end{array}$ & $\begin{array}{l}\text { OF } \\
\text { OF }\end{array}$ & $\begin{array}{lr}\text { BODIES } & 15 \\
\text { FPD-ARRAY } & 136\end{array}$ & & & & & \\
\hline
\end{tabular}

Figure M9.B.6 (continued)

M9.B.19

NUREG/CR-0200, Vol. 3, Rev. 4 


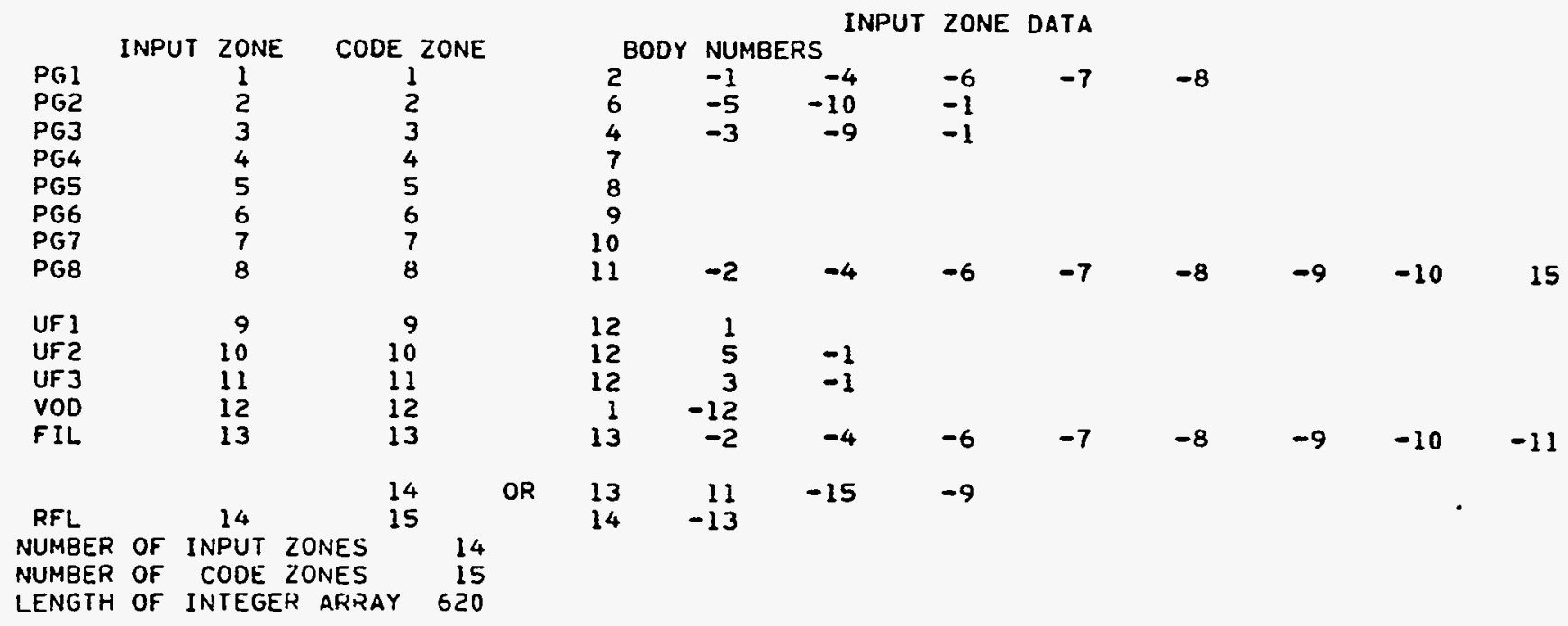

Figure M9.B.6 (continued)

NUREG/CR-0200,

Vol. 3, Rev. 4

M9.B.20 


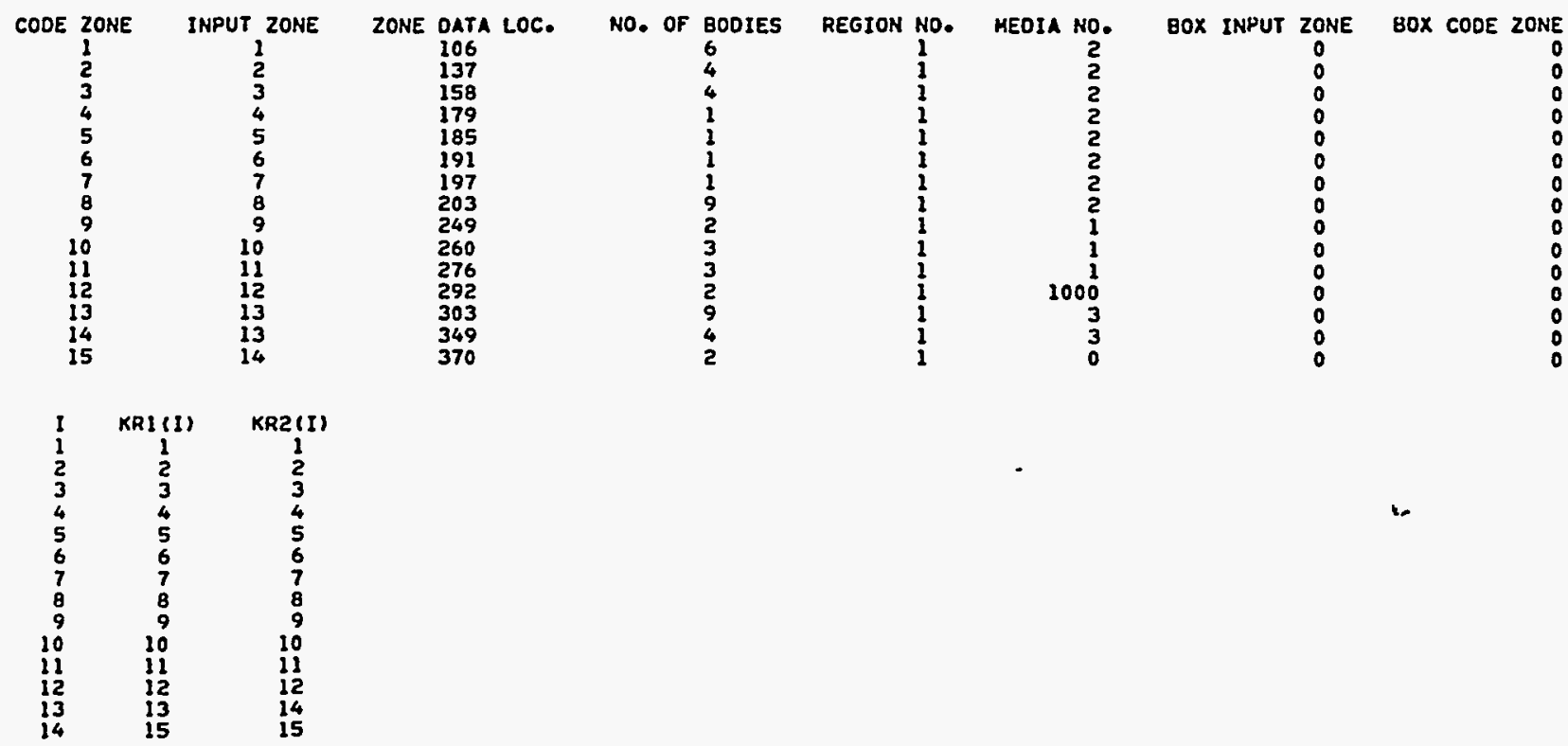

MORSE REGION IN INPUT ZONE(I) ARPAY (MRIZ(I),1=1,14)

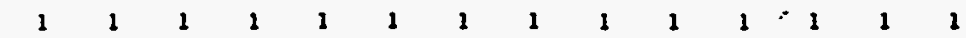

MORSE MEDIA IN INPUT ZONE(I) ARRAY (MMIZ(I), I=1,14)

$\begin{array}{llllllllllllllll}2 & 2 & 2 & 2 & 2 & 2 & 2 & 2 & 1 & 1 & 1 & 1000 & 3 & 0\end{array}$

Figure M9.B.6 (continued) 


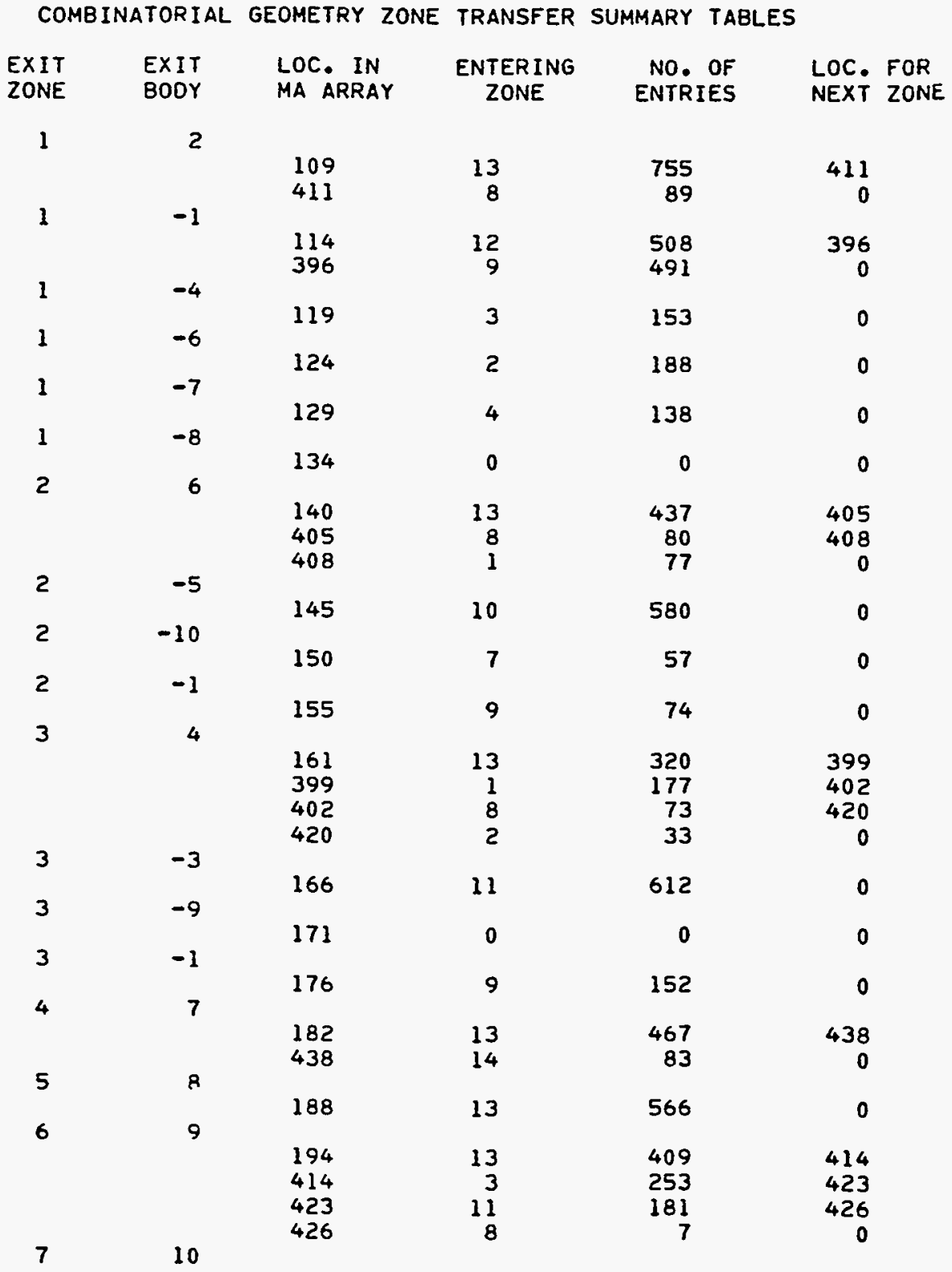

Figure M9.B.6 (continued)

NUREG/CR-0200,

Vol. 3, Rev. 4

M9.B.22 


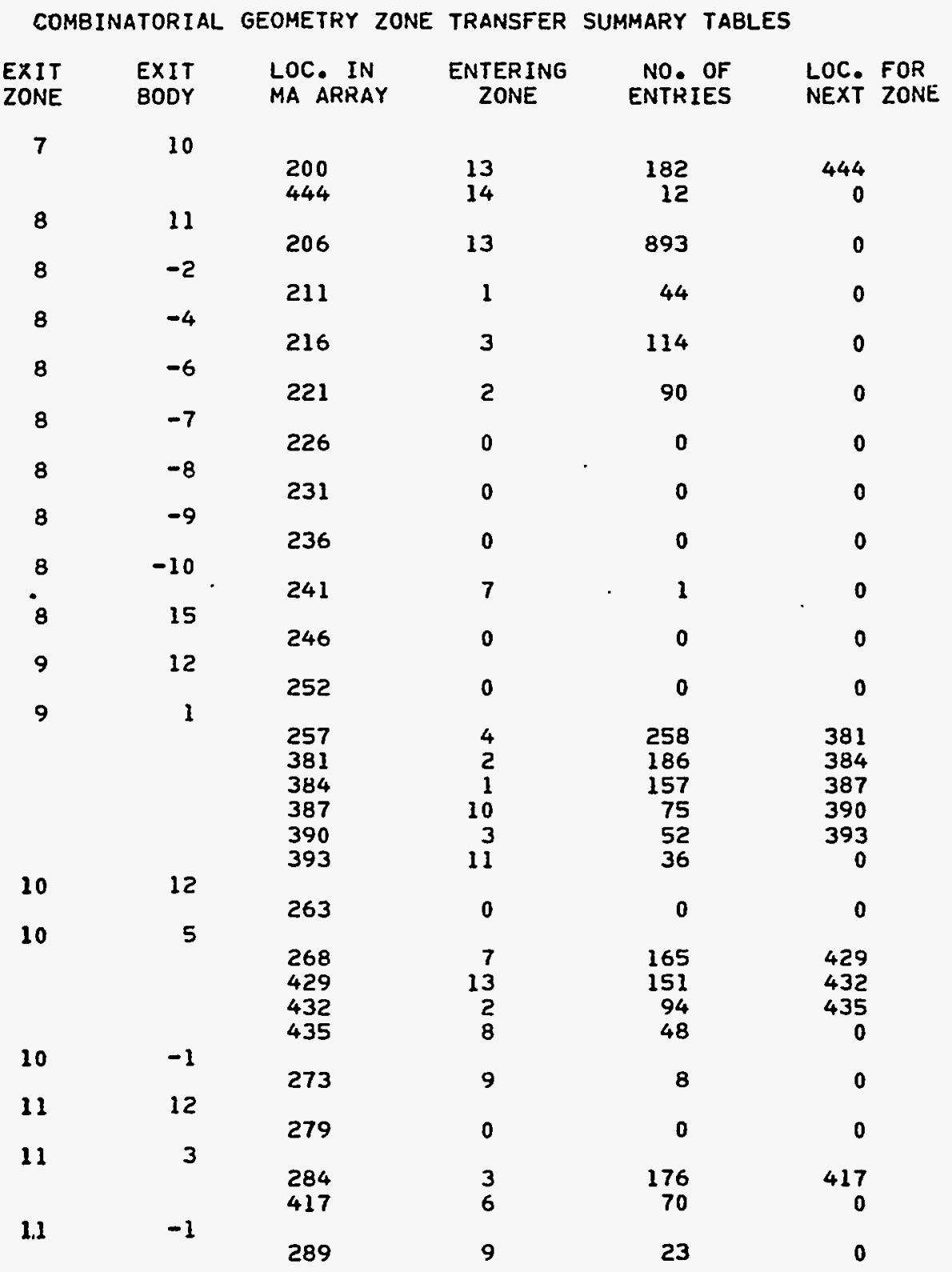

Figure M9.B.6 (continued)

M9.B.23

NUREG/CR-0200, Vol. 3, Rev. 4 
COMBINATORIAL GEOMETRY ZONE TRANSFER SUMMARY TABLES

\begin{tabular}{|c|c|c|c|c|c|}
\hline $\begin{array}{l}\text { EXIT } \\
\text { ZONE }\end{array}$ & $\begin{array}{l}\text { EXIT } \\
\text { BODY }\end{array}$ & $\begin{array}{l}\text { LOC. IN } \\
\text { MA ARRAY }\end{array}$ & $\begin{array}{l}\text { ENTERING } \\
\text { ZONE }\end{array}$ & $\begin{array}{l}\text { NO. OF } \\
\text { ENTRIES }\end{array}$ & $\begin{array}{ll}\text { LOC. } & \text { FOR } \\
\text { NEXT } & \text { ZONE }\end{array}$ \\
\hline 12 & 1 & 295 & 1 & 218 & 0 \\
\hline 12 & -12 & 300 & 9 & 241 & 0 \\
\hline 13 & 13 & 306 & 15 & 300 & 0 \\
\hline 13 & -2 & 311 & 1 & 2033 & 0 \\
\hline 13 & -4 & 316 & 3 & 1016 & 0 \\
\hline 13 & 0 & 321 & 2 & 1050 & 0 \\
\hline 13 & -7 & 326 & 4 & 377 & 0 \\
\hline & -0 & 331 & 5 & 509 & 0 \\
\hline 13 & & 336 & 6 & 939 & 0 \\
\hline 1,3 & -10 & 341 & 7 & 334 & 0 \\
\hline 13 & -11 & $\begin{array}{l}346 \\
447\end{array}$ & $\begin{array}{r}8 \\
14\end{array}$ & $\begin{array}{r}1504 \\
147\end{array}$ & $\begin{array}{r}447 \\
0\end{array}$ \\
\hline 14 & 13 & 352 & 0 & 0 & 0 \\
\hline 14 & 11 & $\begin{array}{l}357 \\
441\end{array}$ & $\begin{array}{r}13 \\
7\end{array}$ & $\begin{array}{r}176 \\
17\end{array}$ & $\begin{array}{r}441 \\
0\end{array}$ \\
\hline 14 & -15 & 362 & 0 & 0 & 0 \\
\hline 14 & -9 & 367 & 6 & 11 & 0 \\
\hline 15 & 14 & 373 & 0 & 0 & 0 \\
\hline 15 & -13 & 378 & 13 & 6976 & 0 \\
\hline
\end{tabular}

Figure M9.B.6 (continued)

NUREG/CR-0200,

Vol. 3, Rev. 4

M9.B.24 


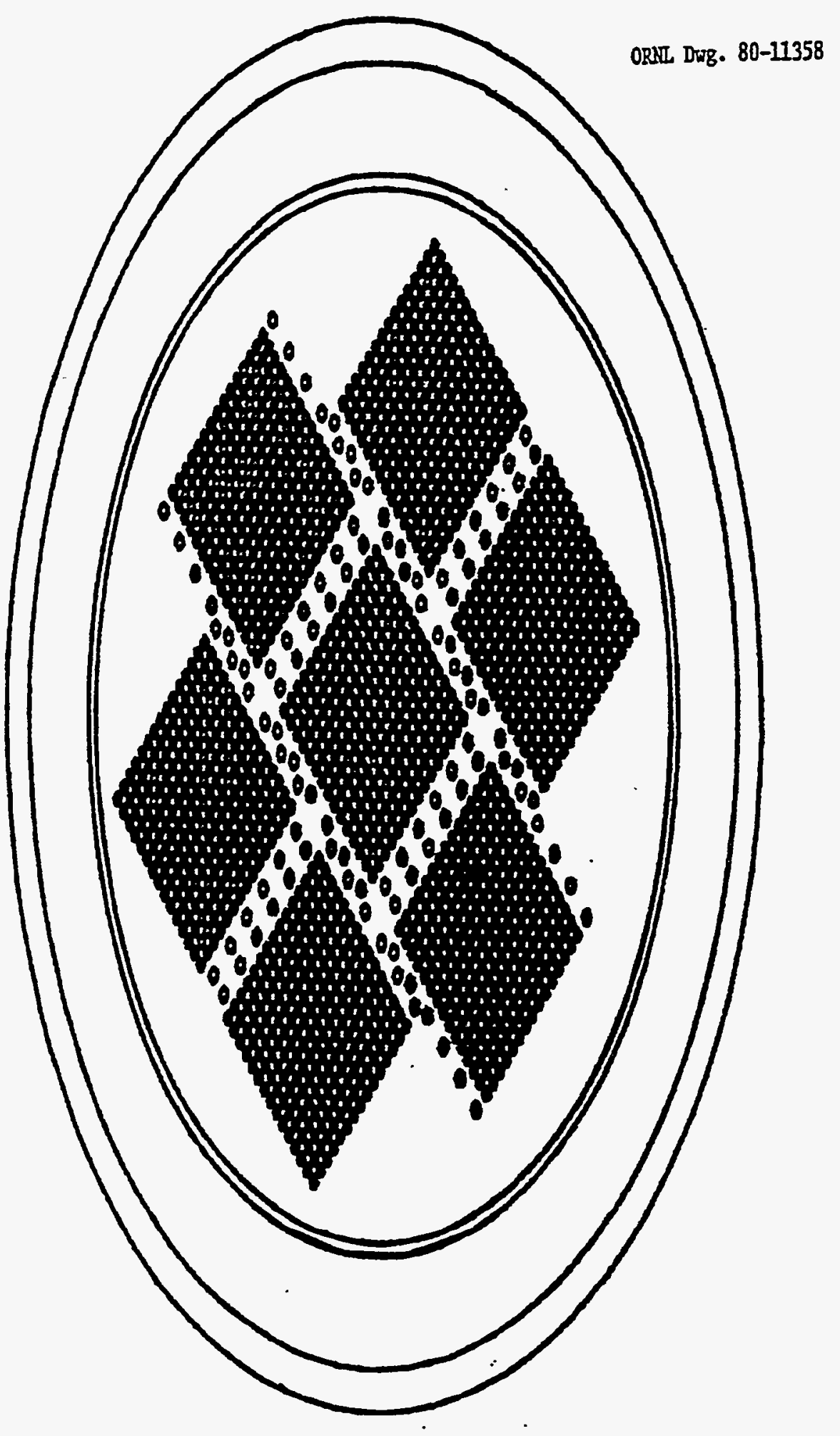

Figure M9.B.7 Computer drawing of Sample Problem 4 


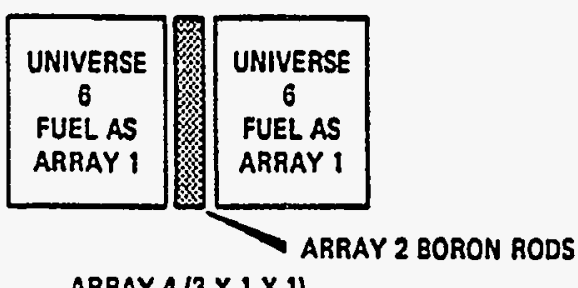

ARRAY $4(3 \times 1 \times 1)$

FIGURE B.8A

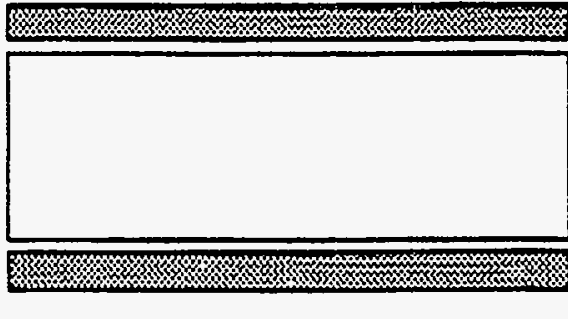

ARRAY

(STAGGERED BORON RODS)

\begin{tabular}{|l|l}
\hline \\
UNIVERSE
\end{tabular}

ARRAY 5

UNIVERSE 7 CONTAINS

ARRAY 6 INVERTED

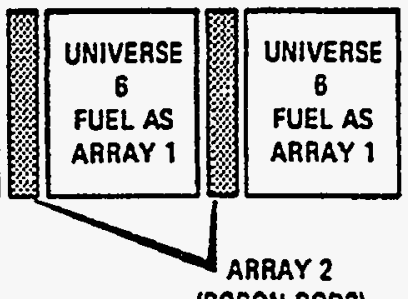

ARRAY $3\|\times 3 \times\|$

FIGURE B-8B

ARRAY $515 \times 1 \times 11$

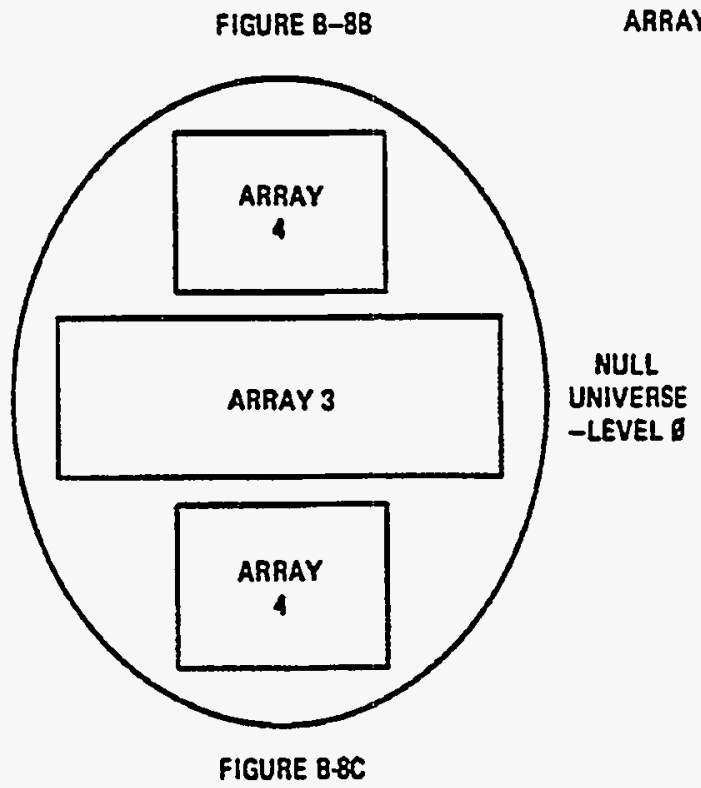

Figure M9.B.8 Typical PWR shipping cask model construction

NUREG/CR-0200,

Vol. 3, Rev. 4

M9.B.26 
PWR SHIPPING CASK MODEL HIERARCHY

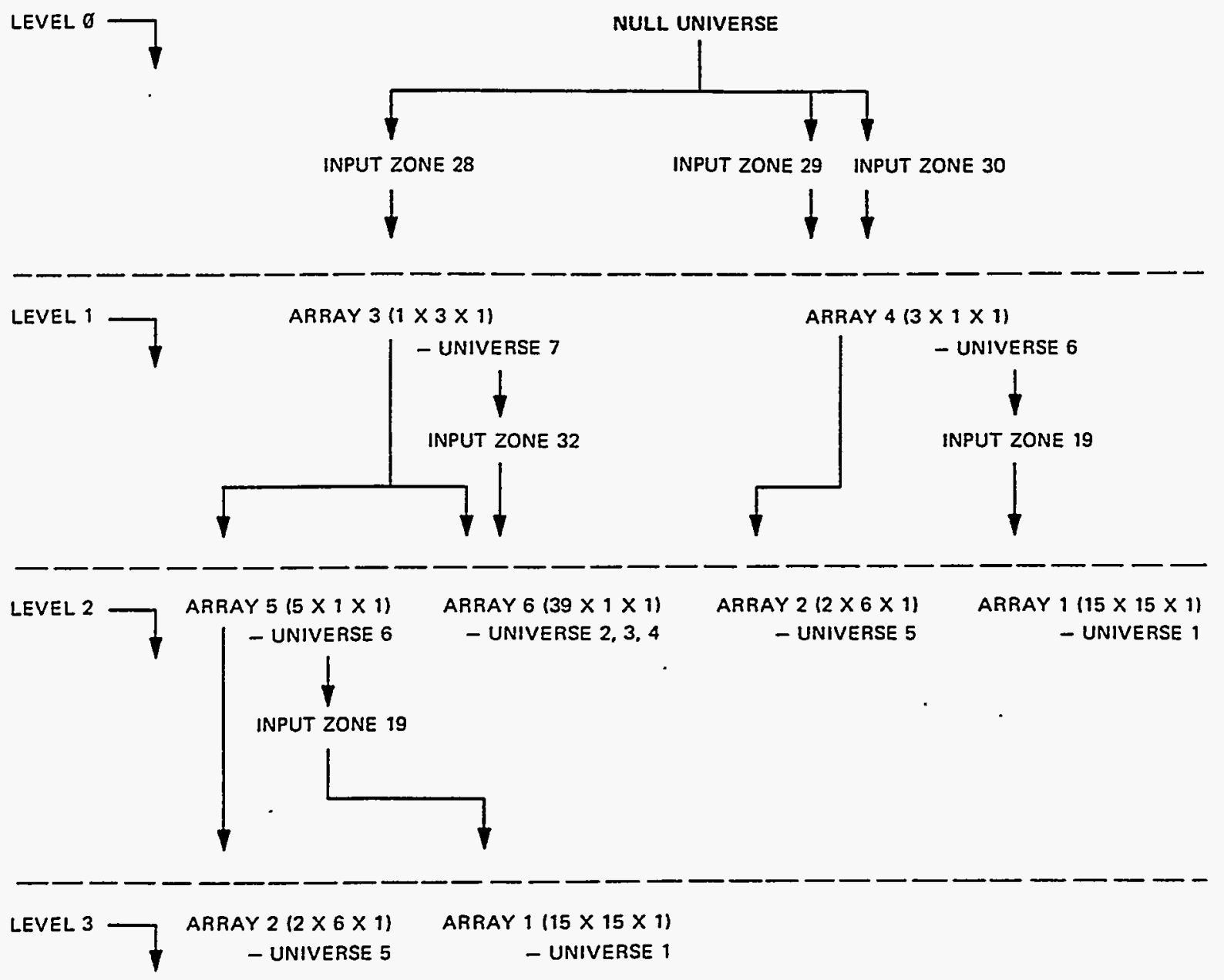

Figure M9.B.9 Typical PWR shipping cask model hierarchy 
THE FOLLOWING IS A LIST OF CARD IMAGE INPUT

CARD NO. COLUMN NO.

1111111112222222222333333333344444444445555555555665666666677777777778 12345678901234567890123456789012345678901234567890123456789012345678901234567890

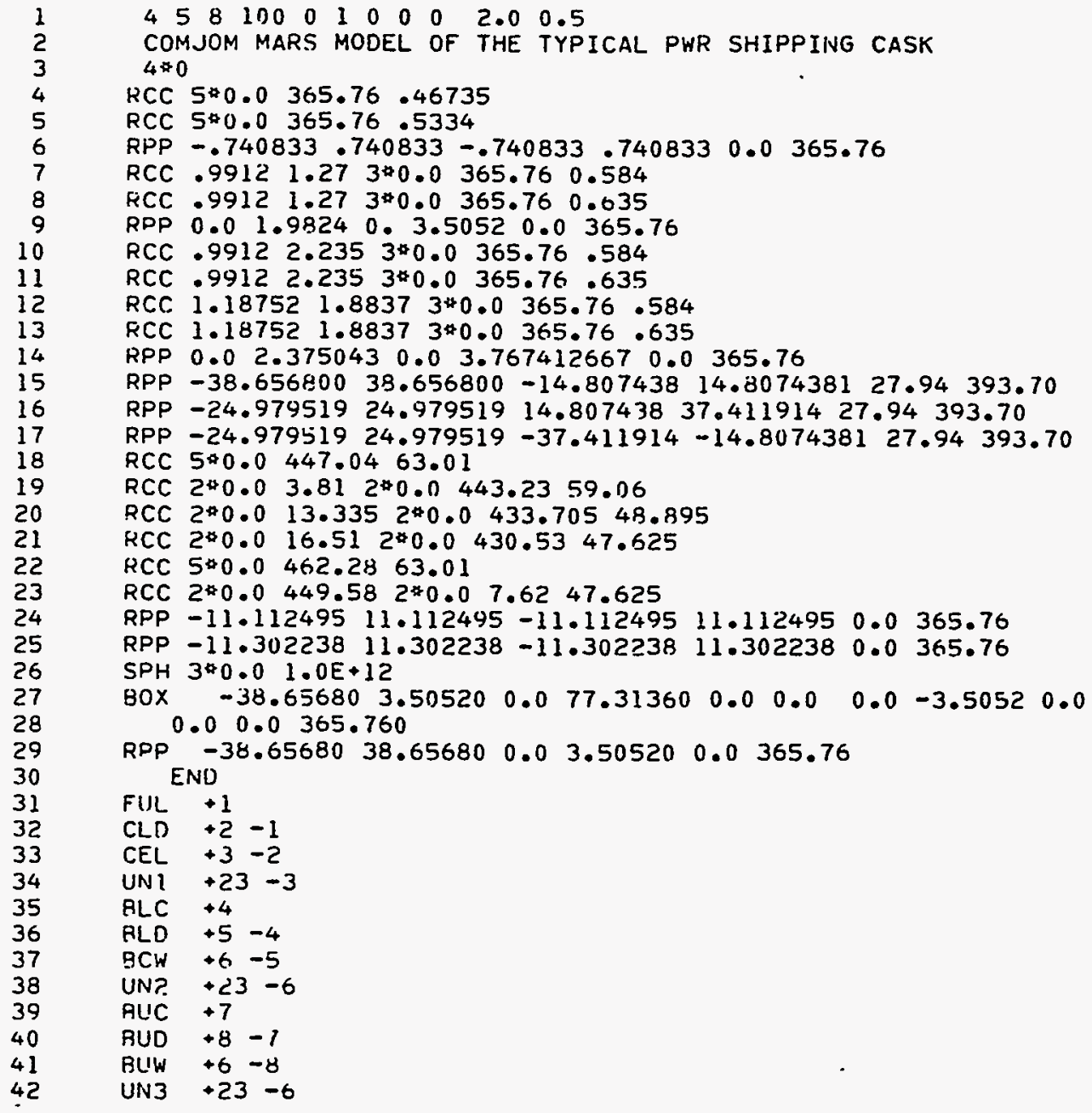

Figure M9.B.10 Computer input listing of Sample Problem 4

NUREG/CR-0200,

Vol. 3, Rev. 4

M9.B.28 


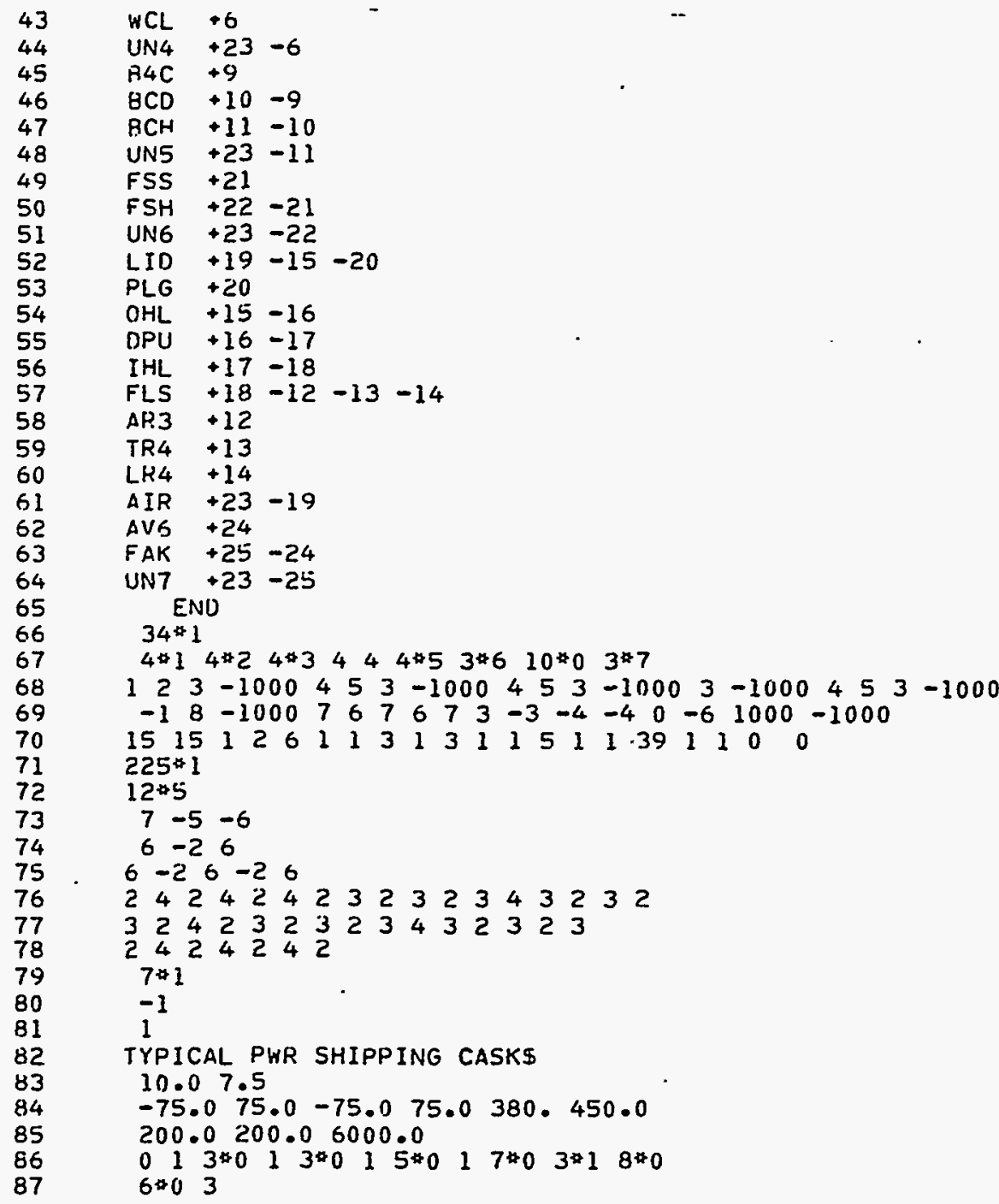

END OF CARD INPUT LIST

Figure M9.B.10 (continued)

M9.B.29 
COMJOM MARS MODEL OF THE TYPICAL PWR SHIPPING CASK

$$
\text { IVOPT }=0 \quad \text { IDBG }=0
$$

\begin{tabular}{|c|c|c|c|c|c|c|c|}
\hline \multirow[b]{2}{*}{$R C C$} & \multirow[b]{2}{*}{1} & \multirow[b]{2}{*}{$\begin{array}{l}0 . \\
.4673500 E+00\end{array}$} & \multicolumn{3}{|c|}{ BODY DATA } & \multirow[b]{2}{*}{0} & \multirow[b]{2}{*}{$.36576000+03$} \\
\hline & & & 0. & 0 . & 0 & & \\
\hline$R C C$ & 2 & $0.5334000 t+00$ & 0 & 0. & 0 & 0. & $.3657600 E+03$ \\
\hline RPP & 3 & $-.7408330 E+00$ & $.7408330 E+00$ & $-.7408330 E+00$ & $.7408330 E+00$ & 0. & $.3657600 E+03$ \\
\hline $\mathrm{RCC}$ & 4 & $\begin{array}{l}.9912000 E+00 \\
.5840000 E+00\end{array}$ & $.1270000 E+01$ & 0. & 0 . & 0. & $.3657600 E+03$ \\
\hline $\mathrm{RCC}$ & 5 & $\begin{array}{l}.9912000 E+00 \\
.6350000 E+00\end{array}$ & $.1270000 E+01$ & 0 . & 0 & 0. & $.3657600 E+03$ \\
\hline RPP & 6 & 0 & $.1982400 E+01$ & 0 & - $3505200 E+0 I$ & 0. & $.3657600 E+03$ \\
\hline$R C C$ & 7 & $\begin{array}{l}.9912000 E+00 \\
.5840000 E+00\end{array}$ & $.2235000 E+01$ & 0. & 0 . & 0. & $.3657000 E+03$ \\
\hline $\mathrm{RCC}$ & 8 & $\begin{array}{l}.9912000 E+00 \\
.6350000 E+00\end{array}$ & $.2235000 E+01$ & 0. & 0 . & 0. & - $3657600 E+03$ \\
\hline RCC & 9 & $\begin{array}{l}1187520 E+01 \\
.5840000 E+00\end{array}$ & $.1883700 E+01$ & 0 . & 0 . & 0. & $.3657600 E+03$ \\
\hline $\mathrm{RCC}$ & 10 & $\begin{array}{l}.1187520 E+01 \\
.6350000 E+00\end{array}$ & $.1883700 E+01$ & 0. & 0 . & 0 . & $.3657600 E+03$ \\
\hline RPP & 11 & 0 . & $.2375043 E+01$ & 0 & $\cdot 3767413 E+01$ & 0 & $.3657600 E+03$ \\
\hline RPP & 12 & $-.3865680 E+02$ & $.3865680 E+0 Z$ & $-.1480744 E+02$ & $.1480744 E+02$ & $.2794000 E+02$ & $.3937000 E ̈+03$ \\
\hline RPP & 13 & $-.2497952 E+02$ & $.2497952 E+02$ & $.1480744 E+02$ & $.3741191 E+02$ & $.2794000 E+02$ & - $3937000 E+03$ \\
\hline RPP & 14 & $-.2497952 E+02$ & $\cdot 2497952 E+02$ & $-.3741191 E+02$ & $-.1480744 E+02$ & $.2794000 E+02$ & $.3937000 E+03$ \\
\hline $\mathrm{RCC}$ & 15 & $0.6301000 E+02$ & 0. & 0. & 0. & 0. & $.4470400 E+03$ \\
\hline RCC & 16 & $.5906000 E+02$ & 0. & $.3810000 E+01$ & 0 . & 0. & $.4432300 E+03$ \\
\hline RCC & 17 & $0.4889500 E+02$ & 0. & $.1333500 E+02$ & 0. & 0. & .43370 \OE+03 \\
\hline$R C C$ & 18 & $0.4762500 E+02$ & 0. & $.1651000 E+02$ & 0 . & 0. & $.4305300 E+03$ \\
\hline$R C C$ & 19 & $.6301000 E+02$ & D. & 0. & 0. & 0. & $.4622800 E+03$ \\
\hline$R C C$ & 20 & $0.4762500 E+02$ & 0 . & $.4495800 E+03$ & 0 . & 0. & $.7620000 E+01$ \\
\hline RPP & 21 & $-.1111250 E+02$ & $.1111250 E+02$ & $-.1111250 E+02$ & $.1111250 E+02$ & 0. & $.365760 \underline{0 E}+03$ \\
\hline
\end{tabular}

Figure M9.B.11 Combinatorial MARS output listing of Sample Problem 4

NUREG/CR-0200,

Vol. 3, Rev. 4

M9.B.30 


\begin{tabular}{|c|c|c|c|c|c|c|}
\hline KPP & 22 & $-.1130224 t+02$ & $.1130224 E+02$ & $-.1130224 E+02$ & $.1130224 E+02$ & 0. \\
\hline $\begin{array}{l}\text { SPH } \\
\text { BOX }\end{array}$ & $\begin{array}{l}23 \\
24\end{array}$ & $\begin{array}{l}0 . \\
-.3865680 E+02 \\
0 .\end{array}$ & $\begin{array}{l}0 . \\
.3505200 E+01 \\
-.3505200 E+01\end{array}$ & $\begin{array}{l}0 . \\
0 . \\
0 .\end{array}$ & $\begin{aligned} .1000000 E+13 \\
.7731360 E+02 \\
0 .\end{aligned}$ & $\begin{array}{l}0 . \\
0 .\end{array}$ \\
\hline RPP & 25 & $-.3865680 E+02$ & $.3865680 \bar{E}+02$ & 0. & $.3505200 E+U I$ & 0 . \\
\hline $\begin{array}{l}\text { NUMBER } \\
\text { LENGTH }\end{array}$ & $\begin{array}{l}\text { OF } \\
\text { OF }\end{array}$ & $\begin{array}{lr}\text { BODIES } & 25 \\
\text { FPD-ARRAY } & 218\end{array}$ & & & & \\
\hline
\end{tabular}

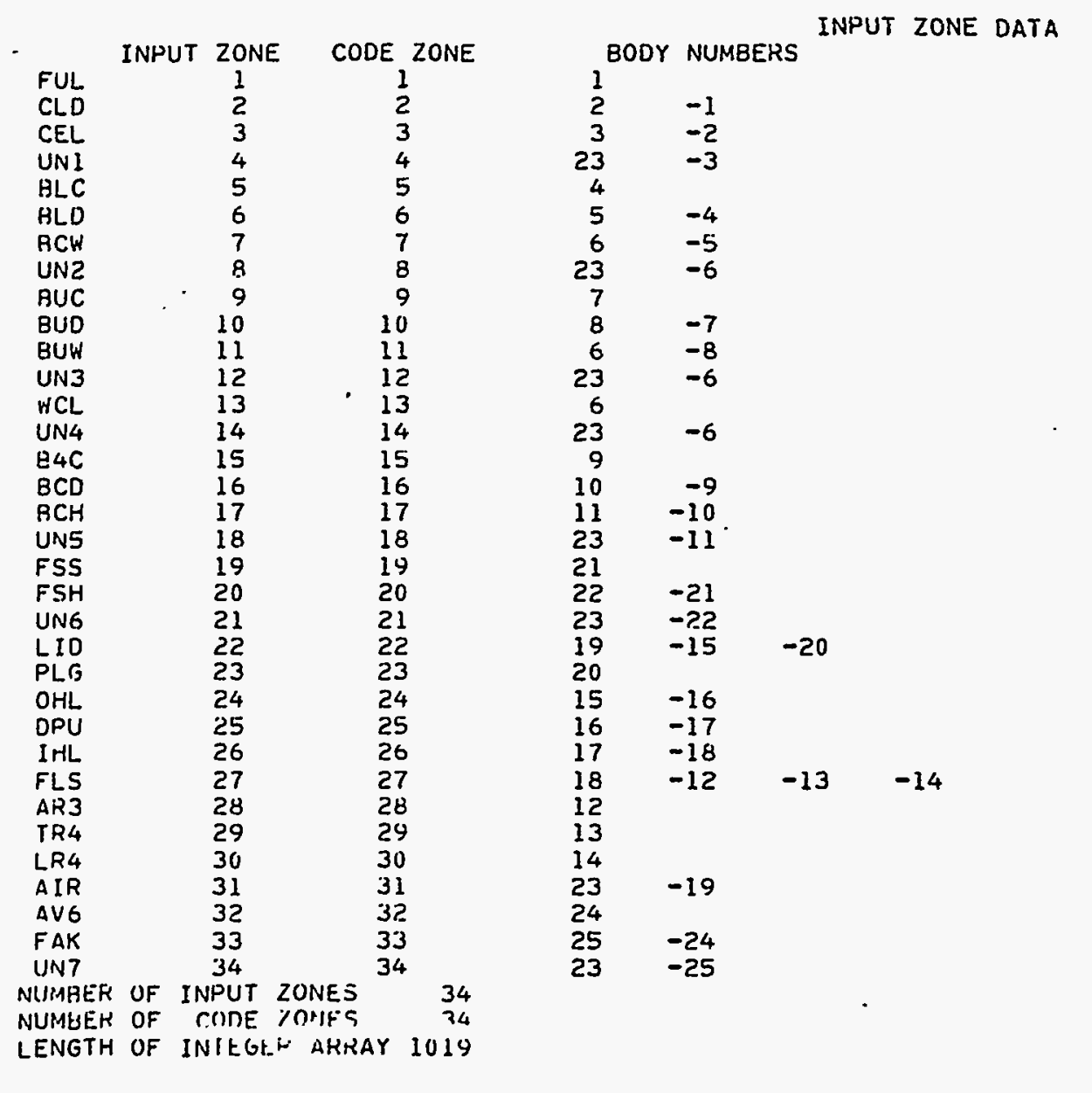

Figure M9.B.11 (continued) 


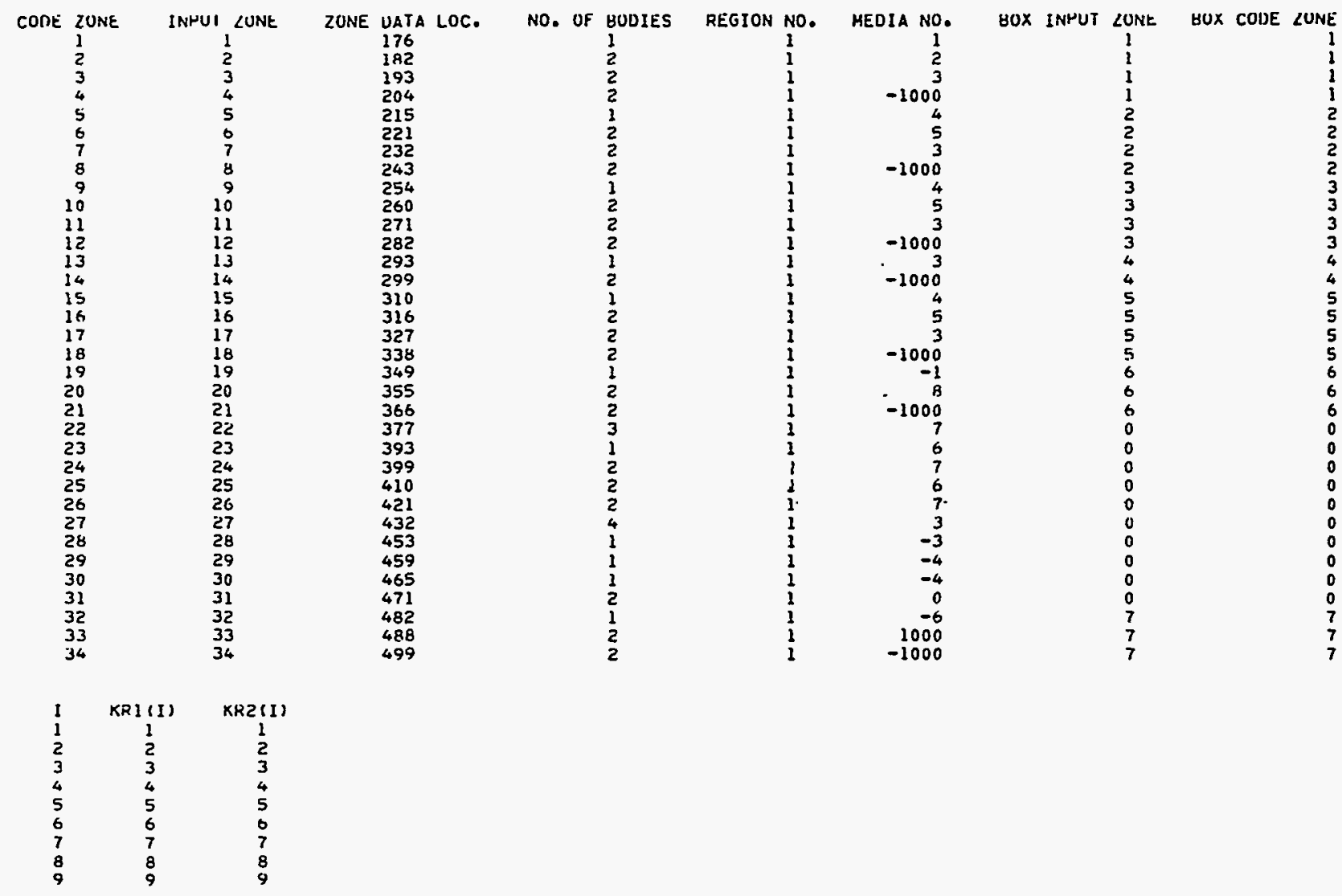

Figure M9.B.11 (continued)

NUREG/CR-0200,

Vol. 3, Rev. 4

M9.B.32 


$\begin{array}{lll}10 & 10 & 10 \\ 11 & 11 & 11 \\ 12 & 12 & 12 \\ 13 & 13 & 13 \\ 14 & 14 & 14 \\ 15 & 15 & 15 \\ 16 & 16 & 16 \\ 17 & 17 & 17 \\ 18 & 18 & 18 \\ 19 & 19 & 19 \\ 20 & 20 & 20 \\ 21 & 21 & 21 \\ 22 & 22 & 22 \\ 23 & 23 & 23 \\ 24 & 24 & 24 \\ 25 & 25 & 25 \\ 26 & 26 & 26 \\ 27 & 27 & 27 \\ 28 & 28 & 28 \\ 29 & 29 & 29 \\ 30 & 30 & 30 \\ 31 & 31 & 31 \\ 32 & 32 & 32 \\ 33 & 33 & 33 \\ 34 & 34 & 34\end{array}$

MORSE REGION IN INPUT ZONE(I) ARRAY (MRIZ(I), I=1,34)

$\begin{array}{llllllllllllllllllllll}1 & 1 & 1 & 1 & 1 & 1 & 1 & 1 & 1 & 1 & 1 & 1 & 1 & 1 & 1 & 1 & 1 & 1 & 1 & 1\end{array}$

MORSE MEOIA IN INPUT ZONE(I) ARRAY (MMIZ(I), I=1,34)

\begin{tabular}{|c|c|c|c|c|c|c|c|c|c|c|c|c|c|}
\hline 1 & 2 & $3-1000$ & 4 & 5 & $3-1000$ & 4 & 5 & $3-1000$ & $3-1000$ & 4 & 5 & $3-1000$ & -1 \\
\hline-1000 & 7 & 7 & 6 & 7 & -3 & -4 & -4 & -6 & $1000-1000$ & & & & \\
\hline
\end{tabular}

\footnotetext{
OPTION 0 WAS USED IN CALCULATING VOLUMES, FOR 1 REGIONS

$0-S E T$ VOLUMES $=1$, 1-CONCENTRIC SPHERES, 2-SLABS, 3-INPUTVOLUMES.

VOLUMES ( CC, USED IN COLLISIONS DENSITY AND TRACK LENGTH ESTIMATORS.

Figure M9.B.11 (continued)

M9.B.33 
ARRAY HO. 1 ARRAY SIZE IS 15 BY 15 BY 1

LEVEL 1 OF ARRAY NO. 1

$\begin{array}{rllllllllllllllll}X & X & 1 & 2 & 3 & 4 & 5 & 6 & 7 & 8 & 9 & 10 & 11 & 12 & 13 & 14 & 15\end{array}$

$\begin{array}{llllllllllllllll}15 & 1 & 1 & 1 & 1 & 1 & 1 & 1 & 1 & 1 & 1 & 1 & 1 & 1 & 1 & 1 \\ 14 & 1 & 1 & 1 & 1 & 1 & 1 & 1 & 1 & 1 & 1 & 1 & 1 & 1 & 1 & 1 \\ 13 & 1 & 1 & 1 & 1 & 1 & 1 & 1 & 1 & 1 & 1 & 1 & 1 & 1 & 1 & 1 \\ 12 & 1 & 1 & 1 & 1 & 1 & 1 & 1 & 1 & 1 & 1 & 1 & 1 & 1 & 1 & 1 \\ 11 & 1 & 1 & 1 & 1 & 1 & 1 & 1 & 1 & 1 & 1 & 1 & 1 & 1 & 1 & 1 \\ 10 & 1 & 1 & 1 & 1 & 1 & 1 & 1 & 1 & 1 & 1 & 1 & 1 & 1 & 1 & 1 \\ 9 & 1 & 1 & 1 & 1 & 1 & 1 & 1 & 1 & 1 & 1 & 1 & 1 & 1 & 1 & 1 \\ 8 & 1 & 1 & 1 & 1 & 1 & 1 & 1 & 1 & 1 & 1 & 1 & 1 & 1 & 1 & 1 \\ 7 & 1 & 1 & 1 & 1 & 1 & 1 & 1 & 1 & 1 & 1 & 1 & 1 & 1 & 1 & 1 \\ 6 & 1 & 1 & 1 & 1 & 1 & 1 & 1 & 1 & 1 & 1 & 1 & 1 & 1 & 1 & 1 \\ 5 & 1 & 1 & 1 & 1 & 1 & 1 & 1 & 1 & 1 & 1 & 1 & 1 & 1 & 1 & 1 \\ 4 & 1 & 1 & 1 & 1 & 1 & 1 & 1 & 1 & 1 & 1 & 1 & 1 & 1 & 1 & 1 \\ 3 & 1 & 1 & 1 & 1 & 1 & 1 & 1 & 1 & 1 & 1 & 1 & 1 & 1 & 1 & 1 \\ 2 & 1 & 1 & 1 & 1 & 1 & 1 & 1 & 1 & 1 & 1 & 1 & 1 & 1 & 1 & 1 \\ 1 & 1 & 1 & 1 & 1 & 1 & 1 & 1 & 1 & 1 & 1 & 1 & 1 & 1 & 1 & 1\end{array}$

Figure M9.B.12 MARS array output listing for Sample Problem 4 


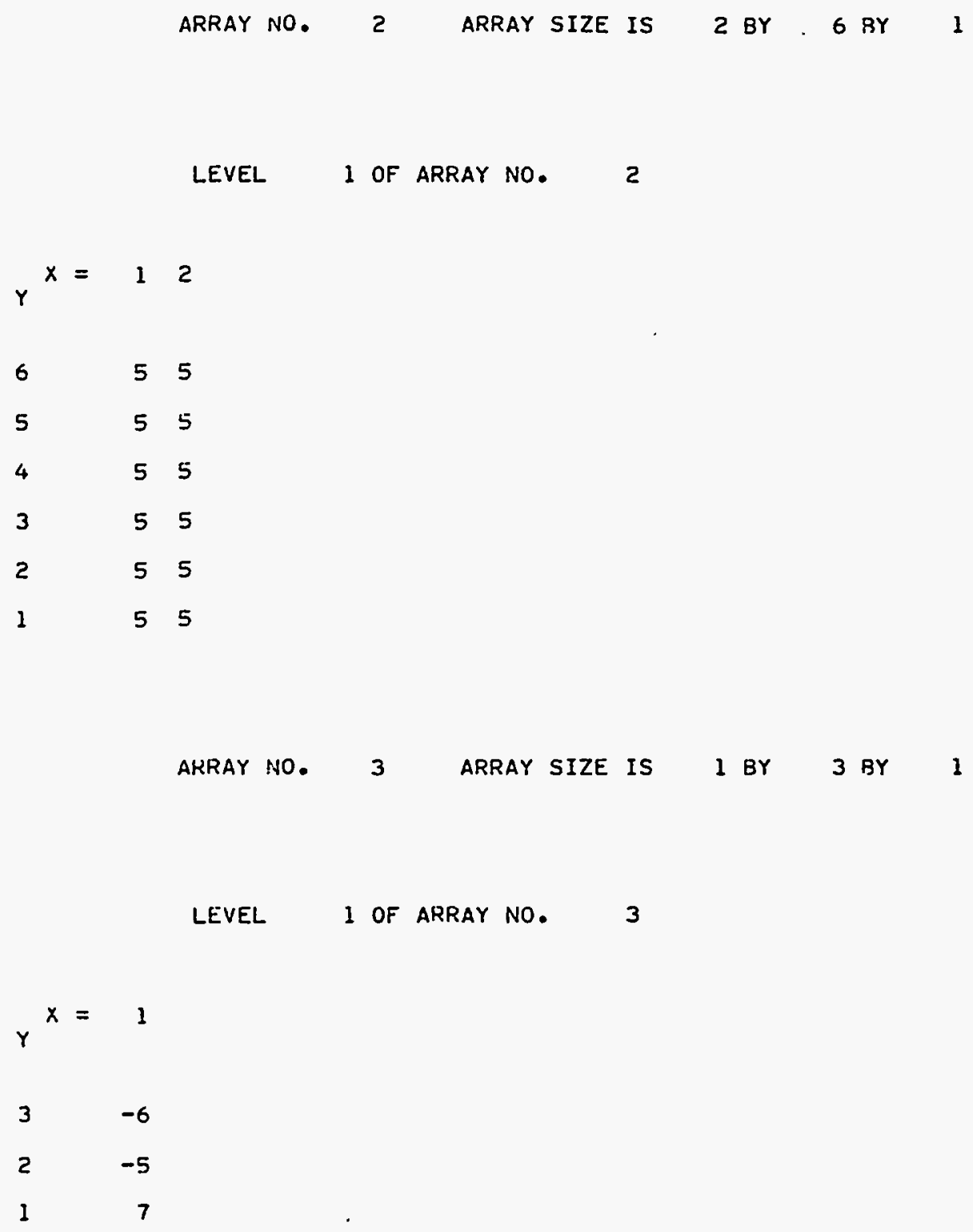

Figure M9.B.12 (continued) 


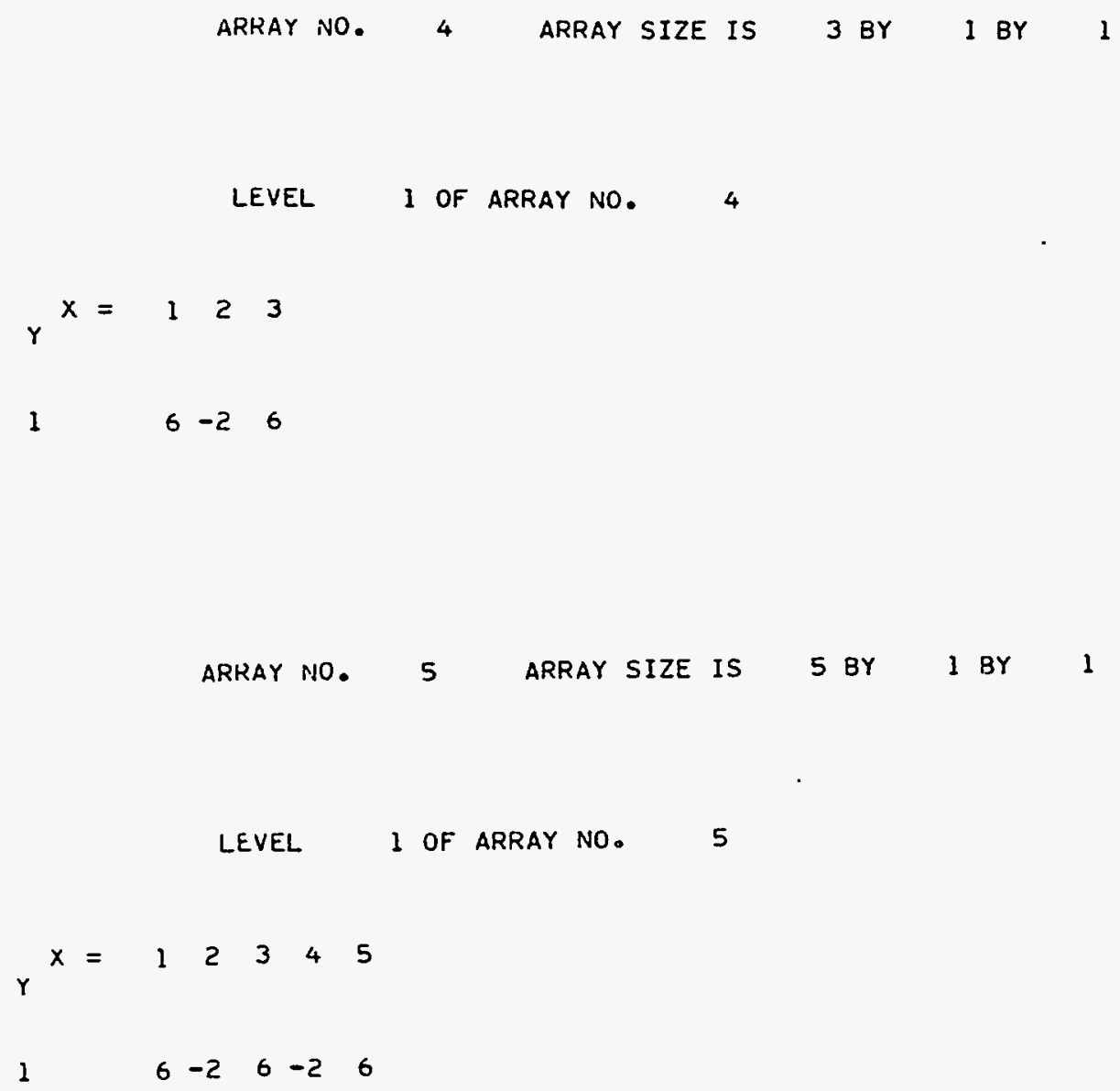

Figure M9.B.12 (continued)

NUREG/CR-0200,

Vol. 3, Rev. 4

M9.B.36 


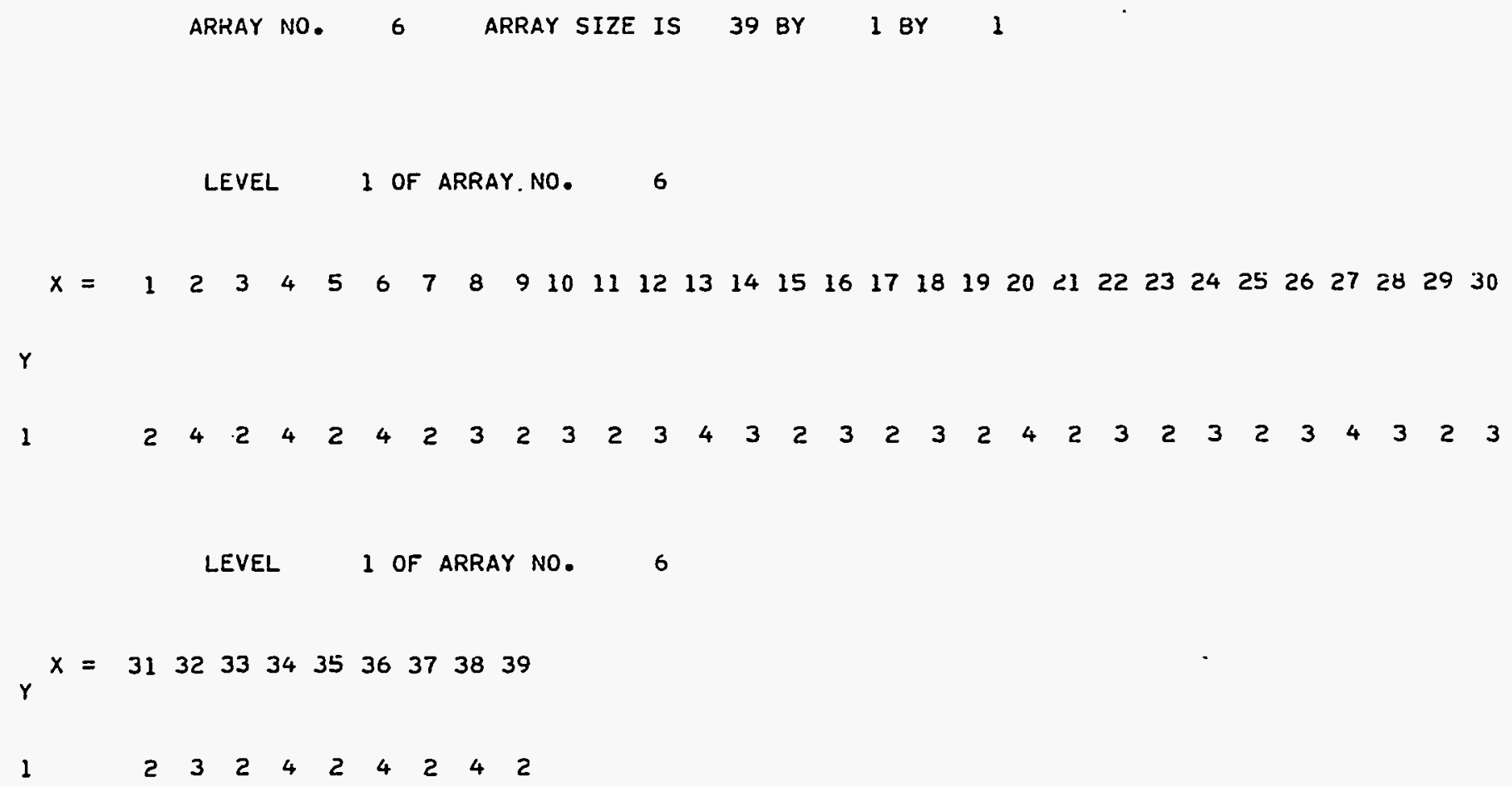

Figure M9.B.12 (continued)

M9.B.37 
UNIVERSE SPECIFICATIONS

UNIVERSE 1-SIMPLE/0-COMJOM

1

21

31

4

$5 \quad 1$

WARNING -- UNIVERSE 6 IS NOT SIMPLE

CODE ZONE 19 CONTAINS ARRAY

6

0

WARNING -- UNIVERSE 7 IS NOT SIMPLE

CODE ZONE 32 CONTAINS ARRAY 6

Figure M9.B.12 (continued)

NUREG/CR-0200,

Vol. 3, Rev. 4

M9.B.38 


$\begin{array}{cl}2 & \text { A.1, Title Card } \\ 3 & \text { A.2, Options Card } \\ 4-30 & \text { A.3, Body Definition Cards } \\ 31-65 & \text { A.4, Input Zone Description Cards } \\ 66 & \text { A.5, Region Card } \\ 67 & \text { A.6, Universe Card } \\ 68-69 & \text { A.7, Media Card } \\ 70 & \text { A.8, Array Size Specification Input } \\ 71-78 & \text { A.9, Array Content Description } \\ 79 & \text { A.10, Universe Type }\end{array}$

The model consists of:

$\begin{array}{cl}25 & \text { Bodies using } \\ 4 & \text { Body Types (RCC, RPP, BOX, \& SPH) } \\ 34 & \text { Input Zones described with } \\ 34 & \text { Code Zones (1 code zone per input zone) } \\ 7 & \text { Universes } \\ 6 & \text { Arrays } \\ 3 & \text { Level of Geometry Nesting } \\ 77 & \text { Cards used to describe the Geometry } \\ 1805 & \text { Total Words of Computer Memory Required to store the geometry } \\ & \text { data }\end{array}$

Special attention should be given to:

1. Universe references in Array Content Description use positive number references.

2. Array references in Array Content Description use negative number references.

3. Array references in Input Zone Descriptions are accomplished with negative media entries, where the absolute value of the negative media is the array number being referenced.

4. Bodies 12 and 14 are $1.0 E-06 \mathrm{~cm}$ smaller on the $Y$-axis than the $Y$-height of Array 4 which they contain. This causes no problem and prevents them from sharing common Y surfaces with Body 13.

5. Universe 1 was shortened by $0.02 \mathrm{~cm}$ from the actual length to prevent Universe 1 's $\mathrm{Z}$ boundary from being common with the $Z$ boundary of Body 21 where Array 1 is referenced. Array 1 is composed of Universe 1 only. Array 1 in Body 21 is referenced in Universe 6, which is further referenced in Array 4 and Array 5. If Universe 1 had not been shortened, then a particle track would go through three levels of geometry logic on one surface. Avoid common surfaces where 
possible. In most cases, a shift of a fraction of a centimeter in the position of a combinatorial geometry body will never be noticed in the final calculational results; but the shift may make the problem much less susceptible to roundoff error causing the particle tracking to get lost.

6. Notice that each of the seven universes has a -1000 boundary media zone.

7. Universe 7 contains Input Zone 32 which references Array 6 . This zone uses a BOX body to place the array inside. This is done to "flip" Array 6 over $180^{\circ}$ on its Y-axis. BOX 24 is the same size as Universe 7's reference body RPP 25. An RPP may be both the reference body for a universe and an array inside the universe, even though this would be a redundant practice. This redundancy is not allowed for a BOX. A BOX body cannot be the reference body for a universe and an array inside the same universe. This procedure is forbidden. It is not much of a restriction, but it is a restriction nonetheless.

\section{M9.B.5 THREE MILE ISLAND REACTOR CORE}

Figure M9.B.13 illustrates the geometry being described. Figure M9.B.14 gives the input list and some of the output list. The following correspondence exists between the MARS input instructions and the card image list:

Card number

Input requirements

$\begin{array}{cl}2 & \text { A.1, Title Card } \\ 3 & \text { A.2, Options Card } \\ 4-40 & \text { A.3, Body Definition Cards } \\ 41-134 & \text { A.4, Input Zone Description Cards } \\ 135 & \text { A.5, Region Card } \\ 136-137 & \text { A.6, Universe Card } \\ 138-143 & \text { A.7, Media Card } \\ 144-145 & \text { A.8, Array Size Specification Input } \\ 146-176 & \text { A.9, Array Content Description } \\ 177 & \text { A.10, Universe Type }\end{array}$

The model consists of:

$\begin{array}{cl}36 & \text { Bodies using } \\ 2 & \text { Body Types (RCC, RPP, BOX, \& SPH) } \\ 92 & \text { Input Zones described with } \\ 100 & \text { Code Zones } \\ 20 & \text { Universes } \\ 10 & \text { Arrays } \\ 2 & \text { Level of Geometry Nesting } \\ 175 & \text { Cards of Geometry Input } \\ 6000 & \text { Computer Memory Locations Required for Geometry Data }\end{array}$

NUREG/CR-0200,

Vol. 3, Rev. 4

M9.B.40 
Special attention should be given to:

1. The first nine arrays describe fuel assemblies composed of different universes.

2. The universes in this problem model three different fuel enrichments, two types of control rods, three different types of lump burnable poison rods, an instrument rod, and an orifice rod.

3. Each fuel assembly is placed in a universe so that the water gap between the fuel assemblies can be modeled.

4. Arrays 1 through 9 are placed in Universes 12 through 20. These universes are then referenced in Array 10. This is the actual reactor core. Array 10 is in Level 1 of the geometry. It is referenced in Input Zone 84 in the absolute universe. The core indentation has been modeled with Input Zone 84 so that Array 10 fits snugly.

5. Array 10, the reactor core, contains vacancies. The space in the array where the vacancies occur are external to Array 10 and the geometry is defined external to Input Zone 84.

6. Only the bodies in Input Zone 84 and the bodies used to describe Universes 12-20 are drawn in Fig. M9.B.13. The pin detail would not have been visible if they had been drawn in the figure.

7. The geometry data for this model took less than 6000 computer memory locations to store.

8. All universes were declared simple on Input Card 177. MARS changed many of the universetype descriptions to combinatorial and printed out warnings. 


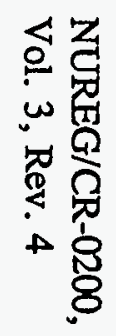

ORNL Dwg. 80-11359

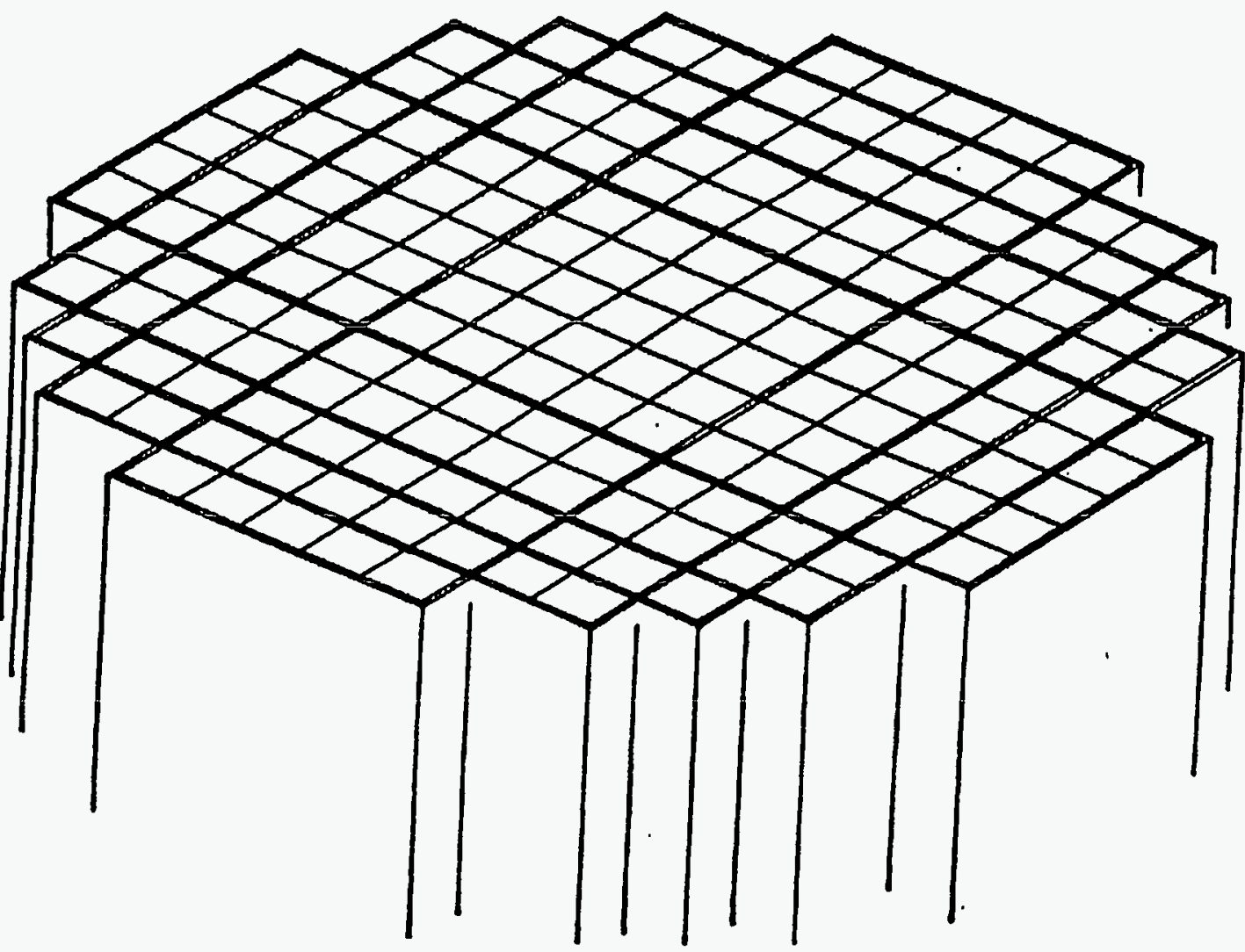

Figure M9.B.13 Computer drawing of the Three Mile Island core described by Sample Problem 5 
1111111112222222222333333333344444444445555555555666666666677777777778 12345678901234567890123456789012345678901234567890123456789012345674901234567890

$\begin{array}{lllllll}5 & 50 \quad 4 \quad 8 & 5 * 0 & 2.0 & 0: 5\end{array}$

TMI REACTOH CORE, JIM WEST, OKNL

3*0 100

RCC $5 * 0.0 \quad 365.76 \quad 0.46990$

RCC $\quad 5 * 0.0 \quad 365.76 \quad 0.47879$

RCC $5 * 0.0365 .760 .54610$

RPP $\quad-.72136 \quad .72136=.72136 \quad .721360 .0365 .76$

RPP $\quad-1.0 E+101.0 E+10-1.0 E+10 \quad 1.0 E+10-1.0 E+101.0 E+10$

RCC $5 * 0.0365 .760 .50165$

RCC 540.0365 .760 .54610

RCC $5 * 0.0340 .3600 .55880$

RCC $\quad 5 * 0.0340 .360 .61214$

RCC $5 * 0.0365 .76 \quad 0.61214$

RCC $5 * 0.091 .440 .5588$

RCC 5*0.0 365.76 0.60960

RCC $\quad 5 \% 0.0 \quad 365.76 \quad 0.63246$

HCC $\quad 5 * 0.0 \quad 365.76 \quad 0.67310$

RCC $\quad 5 * 0.0365 .76 \quad 0.56007$

RCC $\quad 5 \$ 0.0 \quad 365.76 \quad 0.62611$

RPP $-10.82040 \quad 10.82040-10.82040 \quad 10.82040 \quad 0.0 \quad 365.76$

RPP $-10.90549 \quad 10.90549-10.90549 \quad 10.90549 \quad 0.0 \quad 365.76$

RPP $\quad-163.58235163 .58235-163.58235 \quad 163.582350 .0365 .76$

RPP $\quad-165.48735165 .48735-165.48735165 .487350 .0 \quad 365.76$

RPP $\quad-163.58235163 .58235-54.5274554 .52745-100.0400 .0$

RPP $\quad-165.48735165 .48735-56.43245 \quad 56.43245 \quad 0.0365 .76$

RPP $\quad-141.77137141 .77137-98.1494198 .14941-100.0400 .0$

RPP $\quad-143.67637 \quad 143.67637-100.05441 \quad 100.05441 \quad 0.0 \quad 365.76$

RPP $\quad-119.96039119 .96039-119.96039119 .96039-100.0400 .0$

RPP $-121.86539121 .86539-121.86539121 .865390 .0365 .76$

RPP $\quad-98.1494198 .14941-141.77137141 .77137-100.0400 .0$

RPP $\quad-100.05441100 .05441-14 \$ .6763143 .67630 .0 \quad 365.76$

RPP $\quad-54.5274554 .52745-163.58235163 .58235-100.0400 .0$

RPP $\quad-56.43245 \quad 56.43245-165.48735165 .487350 .0365 .76$

RCC $0.00 .0-100.00 .00 .0600 .0 \quad 179.07$

RCC $\quad 0.0 \quad 0.0-100.00 .00 .0600 .0184 .15$

RCC $\quad 0.0 \quad 0.0-100.0 \quad 0.0 \quad 0.0 \quad 600.0 \quad 186.69$

HCC $\quad 0.0 \quad 0.0-100.00 .00 .0 \quad 600.0 \quad 191.77$

RCC $0.00 .0-100.000 .00 .0600 .0217 .17$

RCC $\quad 0.0 \quad 0.0-100.0 \quad 0.0 \quad 0.0 \quad 600.0 \quad 239.17$ END

FUA

$+2-1$

Figure M9.B.14 Computer input and output listing of Sample Problem 5 


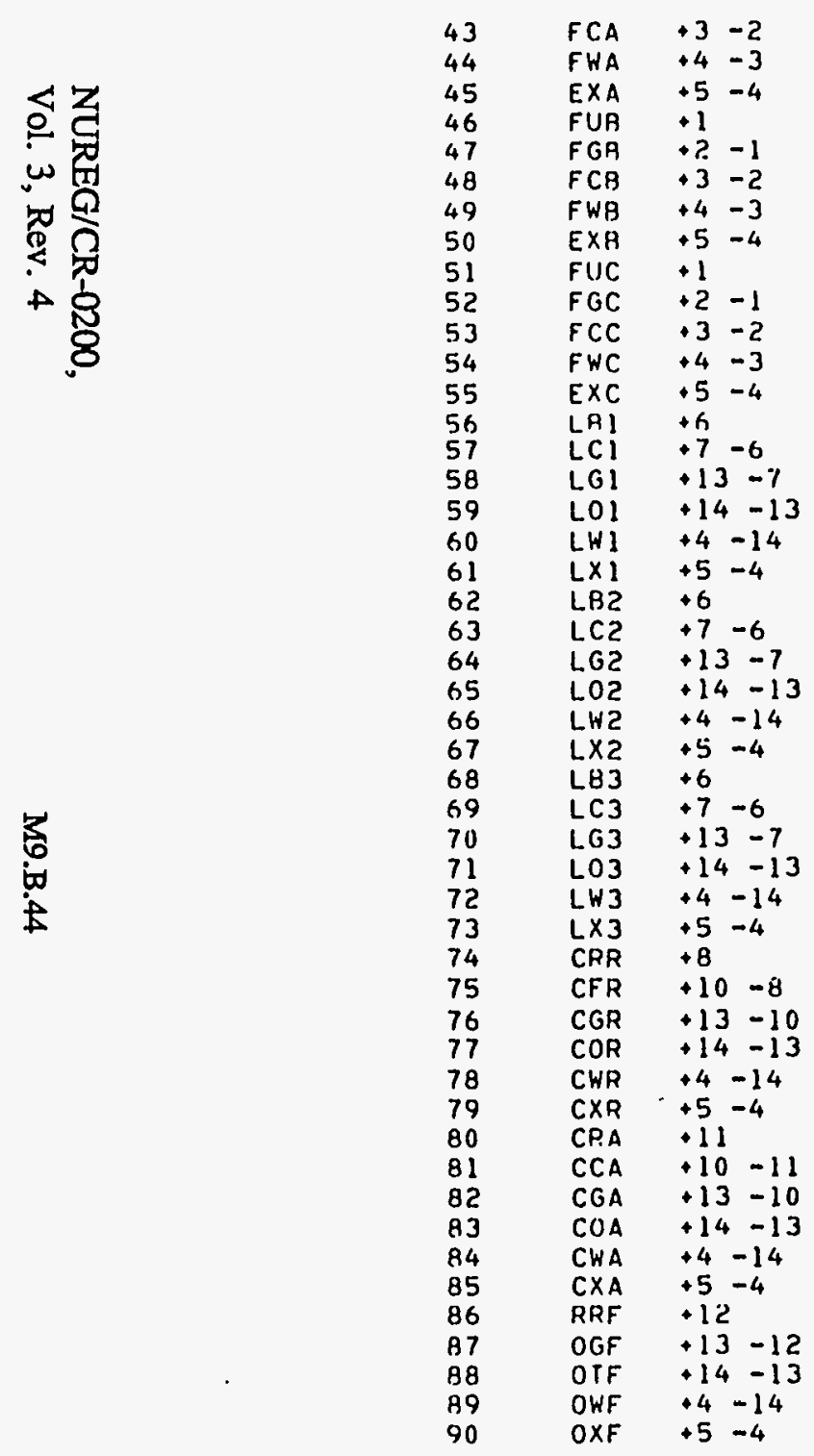

Figure M9.B.14 (continued) 


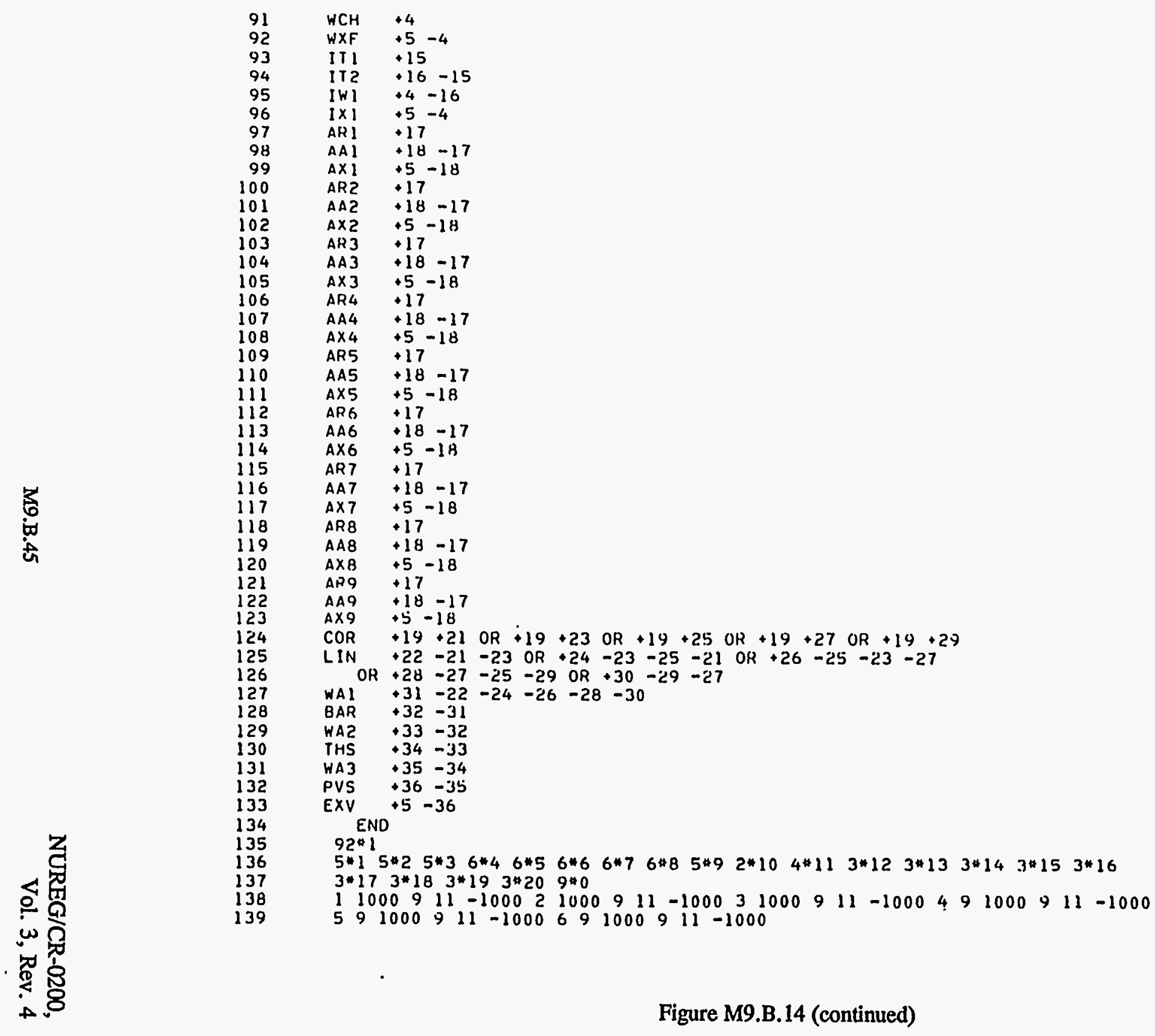




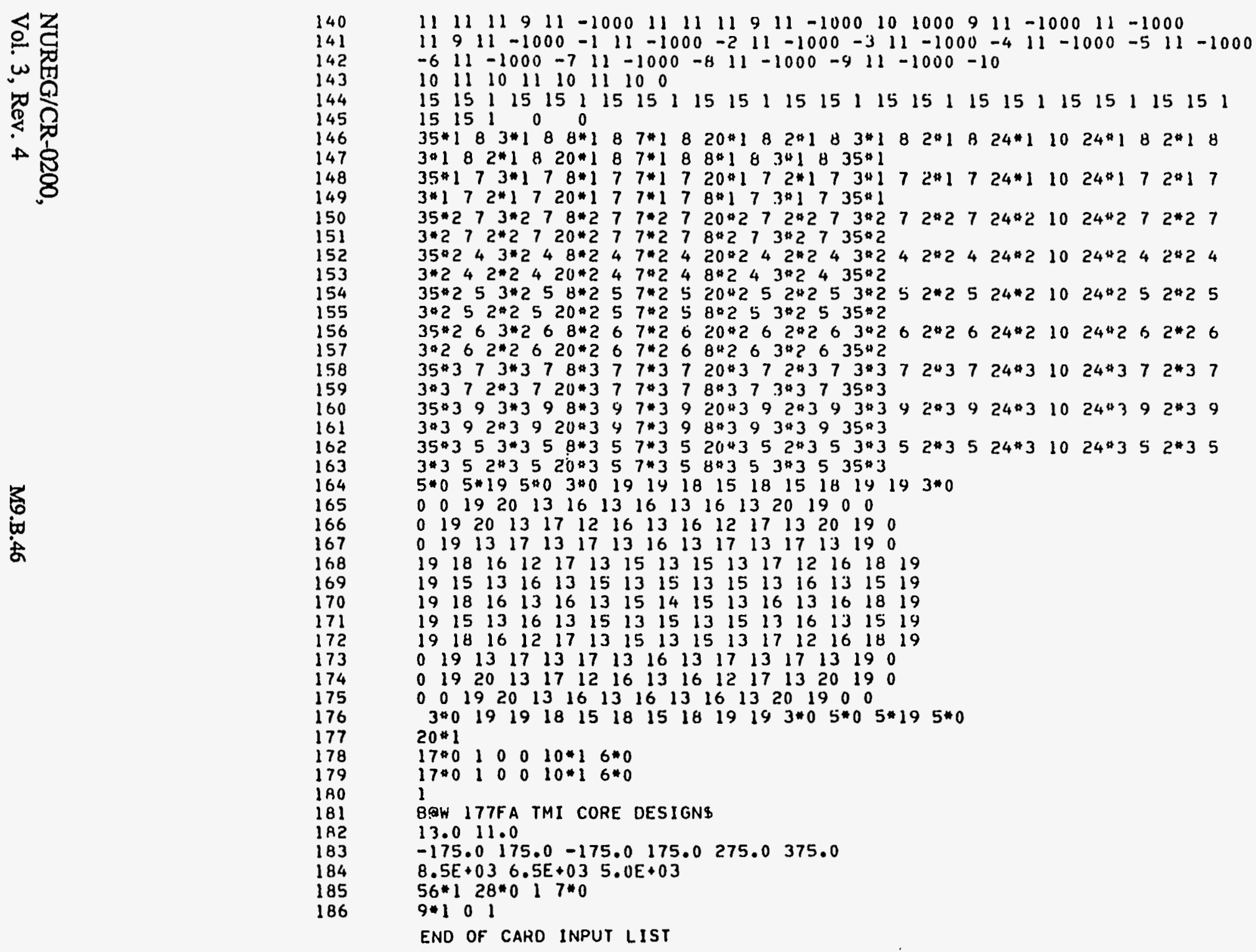

Figure M9.B.14 (continued) 
TMI REACTOR CORE, JIM WEST, ORNL

$\begin{array}{ll}\text { IVOPT }=0 & \text { IDBG }=0\end{array}$

\begin{tabular}{|c|c|c|c|c|c|c|c|c|}
\hline & & & & & 800Y D & ATA & & \\
\hline & RCC & 1 & $0.4699000 E+00$ & o. & 0. & 0 . & n. & $.3657600 E+03$ \\
\hline & RCC & 2 & $0.4787900 F+00$ & 0. & 0. & 0. & 0. & $.3657600 E+03$ \\
\hline & RCC & 3 & O. & o. & 0 . & 0. & 0 . & $.3657600 E+03$ \\
\hline & RPP & 4 & $-.7213600 \mathrm{E}+00$ & $.7213600 E+00$ & $-.7213600 E+00$ & $.7213600 E+00$ & 0 . & $.3657600 E+03$ \\
\hline & RPP & 5 & $-.1000000 E+11$ & $.1000000 E+11$ & $-.1000000 E+11$ & $.1000000 E+11$ & $-.1000000 E+11$ & $.1000000 E+11$ \\
\hline & RCC & 6 & 0. & 0 . & 0 . & o. & 0 . & . $3657600 E+03$ \\
\hline & RCC & 7 & 0 . & 0. & 0. & 0. & 0. & $.3657600 E+03$ \\
\hline & RCC & 8 & $0.5588000 E+00$ & 0 . & 0. & 0 . & 0. & $.3403600 E+03$ \\
\hline & RCC & 9 & 0. & 0 . & 0 . & 0 . & 0 . & $.3403600 E+03$ \\
\hline t. & RCC & 10 & $0.01214005+00$ & 0. & o. & 0 . & 0. & $.3657600 E+03$ \\
\hline & RCC & 11 & 0. & 0 . & n. & 0 . & 0. & $.9144000 E+02$ \\
\hline & RCC & 12 & 0 0 & 0. & 0. & 0 . & 0 . & $.3657600 E+03$ \\
\hline & RCC & 13 & 0.0 & 0. & 0. & 0. & 0 & $.3657600 E+03$ \\
\hline & RCC & 14 & 0. & 0. & 0. & 0 . & 0 . & $.3657600 E+03$ \\
\hline & RCC & 15 & 0. & 0 . & 0 . & 0 . & 0 . & $.3657600 E+03$ \\
\hline & RCC & 16 & $0.6261100 E+00$ & 0. & 0. & 0 . & 0. & $\cdot 3657600 E+03$ \\
\hline & RPP & 17 & $-.1082040 E+02$ & $.1082040 E+02$ & $-.1082040 E+02$ & $.1082040 E+02$ & 0 . & $.36576000 E+03$ \\
\hline & RPP & 18 & $-.1090549 E+02$ & $.1090549 E+02$ & $-.1090549 E+02$ & $.1090549 E+02$ & n. & . $3657600 E+0.3$ \\
\hline ב & RPP & 19 & $-.1635824 E+03$ & $.1635824 E+03$ & $-.1635824 E+03$ & $.1635824 E+03$ & 0. & $.36576000 E+03$ \\
\hline$\pi$ & RPP & 20 & $-.1654874 E+03$ & $.1654874 E+03$ & $-.1654874 E+03$ & $.1654874 E+03$ & o. & $.3657600 E+03$ \\
\hline$\omega \bar{\Omega}$ & RPP & 21 & $-.1635824 E+03$ & $.1635824 E+03$ & $-.5452745 E+02$ & $.5452745 E+02$ & $-.1000000 E+03$ & $.4000000 E+03$ \\
\hline
\end{tabular}

Figure M9.B.14 (continued) 


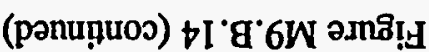

$50+30000009^{\circ}$

⿷. $0+30000009^{\circ}$

c $0.30000009^{\circ}$

E0. $30000009^{\circ}$

$\varepsilon 0+70000009^{\circ}$

$\varepsilon 0+30000009^{\circ}$

$\varepsilon 0+3009 \angle 59 \varepsilon^{\circ}$

$\varepsilon 0+30000007^{\circ}$

E $0+3009 L \mathrm{LQE}$.

$\varepsilon 0+3000000$ म

$\varepsilon 0+3009 L \mathrm{SQE}$.

$\varepsilon 0+30000007^{\circ}$

$0+.3009 L 59 \varepsilon^{\circ}$

$\varepsilon 0+30000007^{\circ}$

$\varepsilon 0+3009 \angle S 9 \varepsilon^{\circ}$

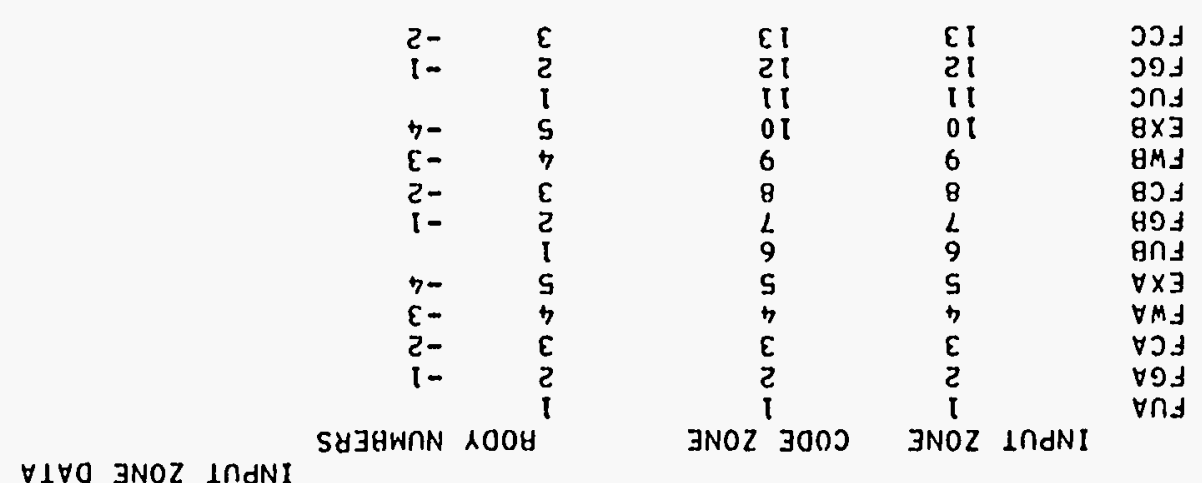

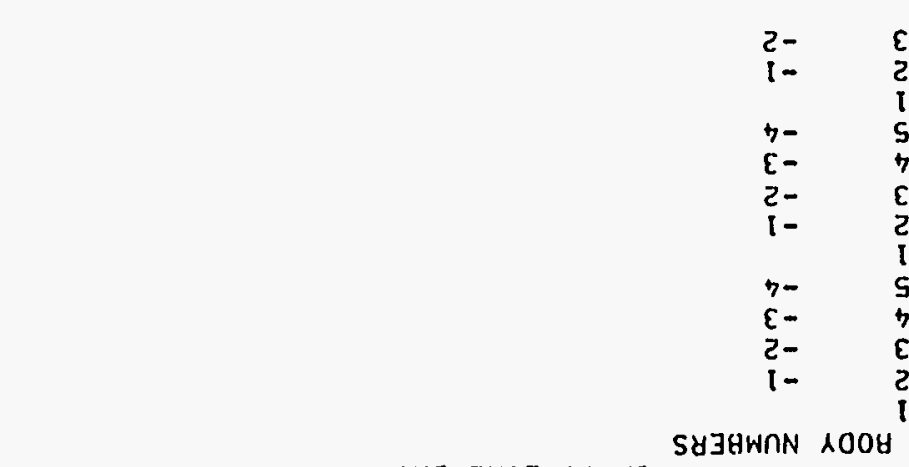

BOE A $\forall \forall Y \forall-O d J ~ J 0 ~ H I O N Z 7$

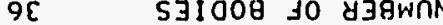

$\varepsilon 0+300 L 16 E 2$.

$10+300<1<12$.

$\begin{array}{lll}0 & 0 \\ 0 & 0\end{array}$

- $0 \varepsilon 0+30000001^{\circ-}$

- $0 \quad \varepsilon 0+30000001^{\circ-}$

- $0<0+30000001 \cdot-$

- $0 \varepsilon 0+3000000 I^{\circ-}$

- 0 . 0 E $\varepsilon 0+30000001^{\circ-}$

- je ja

$E 0+300 L 2161^{\circ}$

$\cdot 0$

० DE Jगע

$\varepsilon 0+3005 I+8 I^{\circ}$

टE गЈष

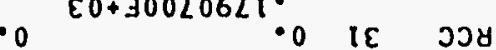

- $0 \quad 0+3 \mapsto \angle 8 \mapsto 591^{\circ}$

$\varepsilon 0+3 \pitchfork \angle 8 \mapsto 591^{\circ}-\quad 20+\exists S \pitchfork 2 \varepsilon \mapsto 95^{\circ}$

$20+35 \mapsto ? E \mapsto 95^{\circ}-$ OE dd

$20+35 \% \angle Z S+S^{\circ}-62$ dतम

ध0+3カサ50001- 82 ddע

- $0 \quad \varepsilon 0+\exists \varepsilon 9 \angle 9 E \mapsto I^{\circ}$

(1)

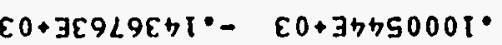

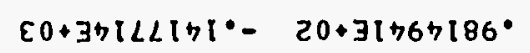

$20+3 โ \mapsto 6 \mapsto\left[86^{\circ}-L 2\right.$ ddy

- $0 \quad 60+3 \pitchfork \$ 98121^{\circ}$

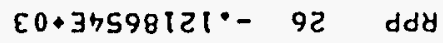

$\varepsilon 0+3000000 T^{\circ}-\varepsilon 0+370966 I^{\circ}$

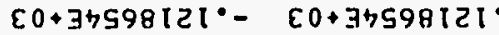

E0+ בด0966II- SZ ddy

- 0 C $0+3 \mapsto \mapsto 5000 T^{\circ}$

$10+30000001^{\circ}-20+3176+186^{\circ}$

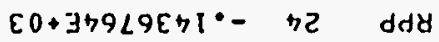

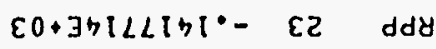

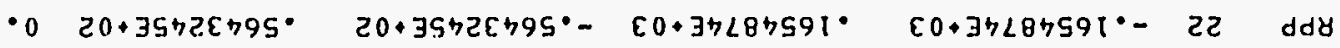




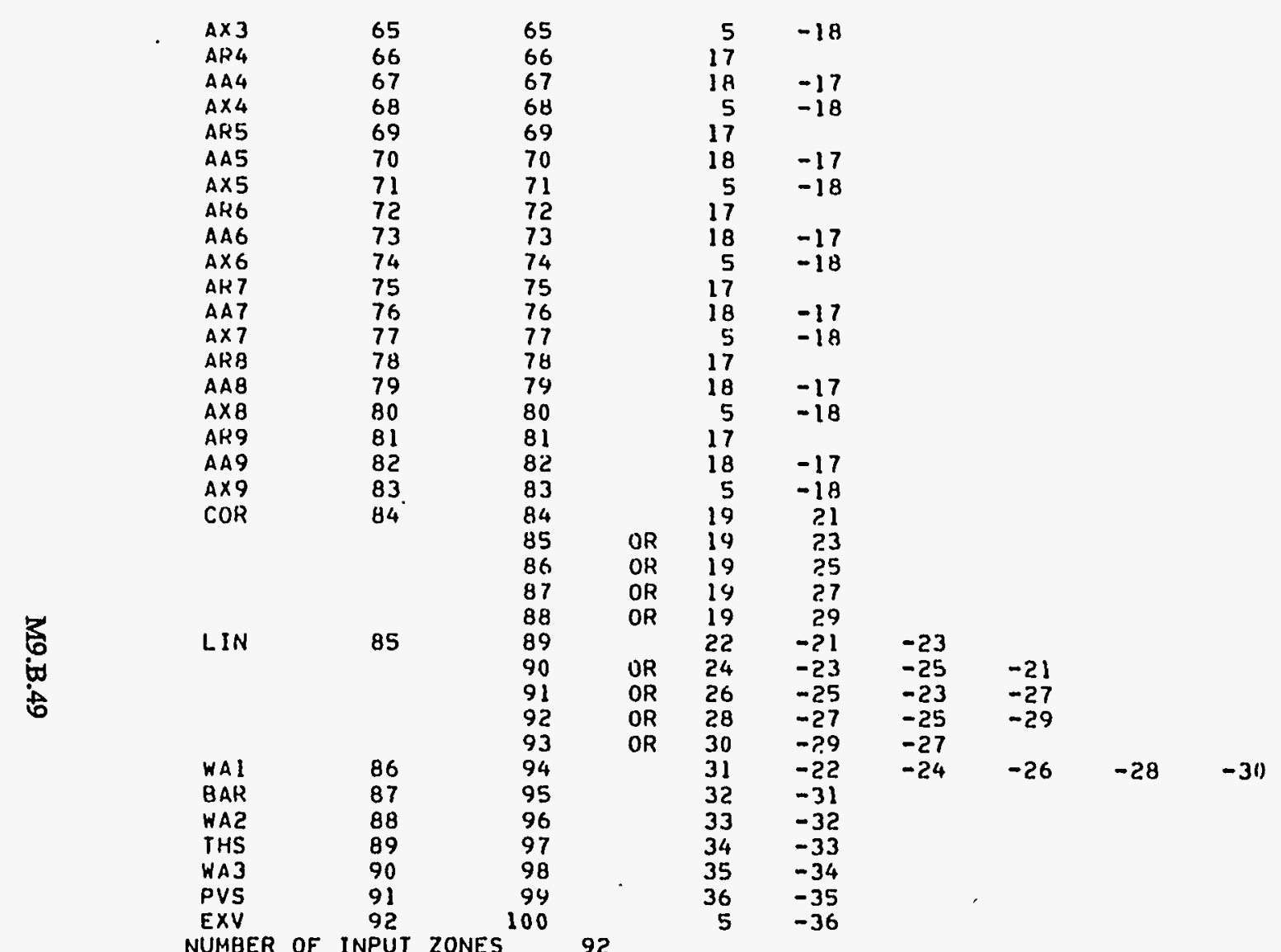

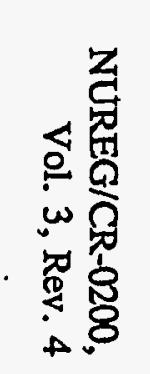

92

LENGTH OF INTEGER ARRAY 2992

CODE ZONE INPUT ZONE

ZONE DATA LOC.

NO. OF BODIES

REGION NO. MEDIA NO.

BOX INPUT ZONE

BOX CODE ZONE

253
259
270
281
202
303
309
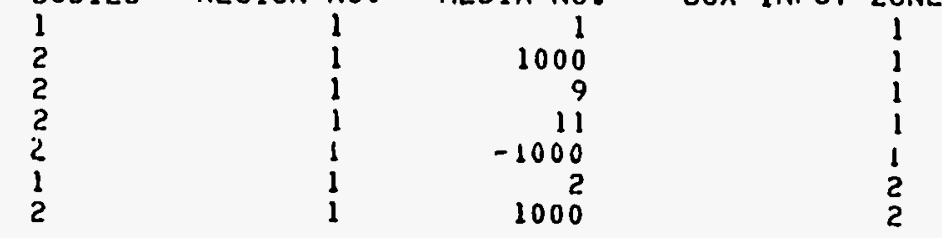

Figure M9.B.14 (continued) 


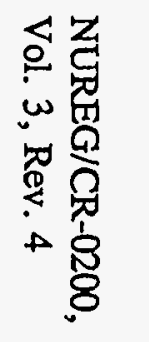

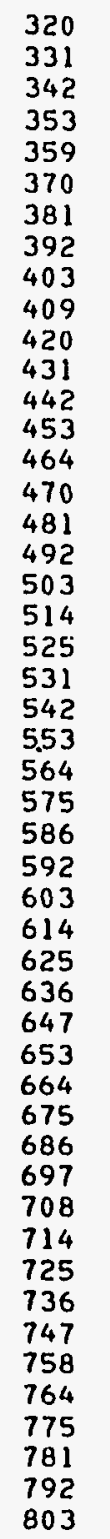

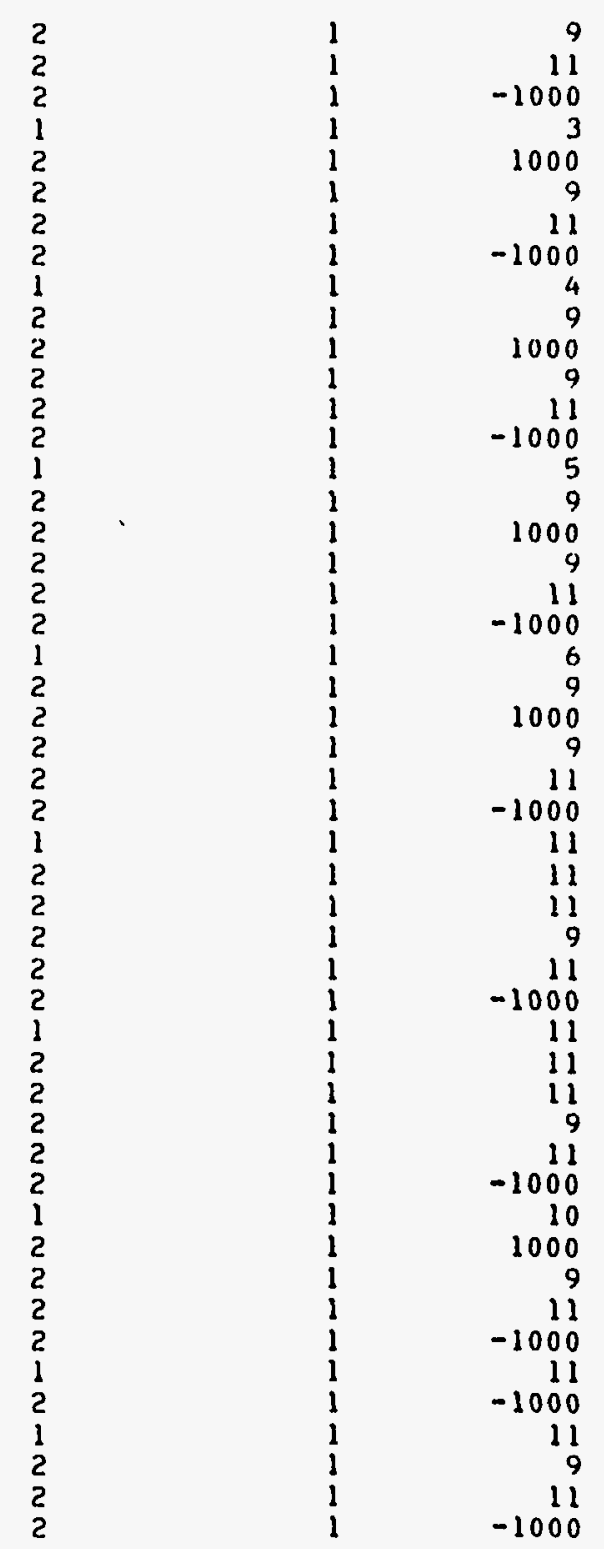

Figure M9.B.14 (continued) 


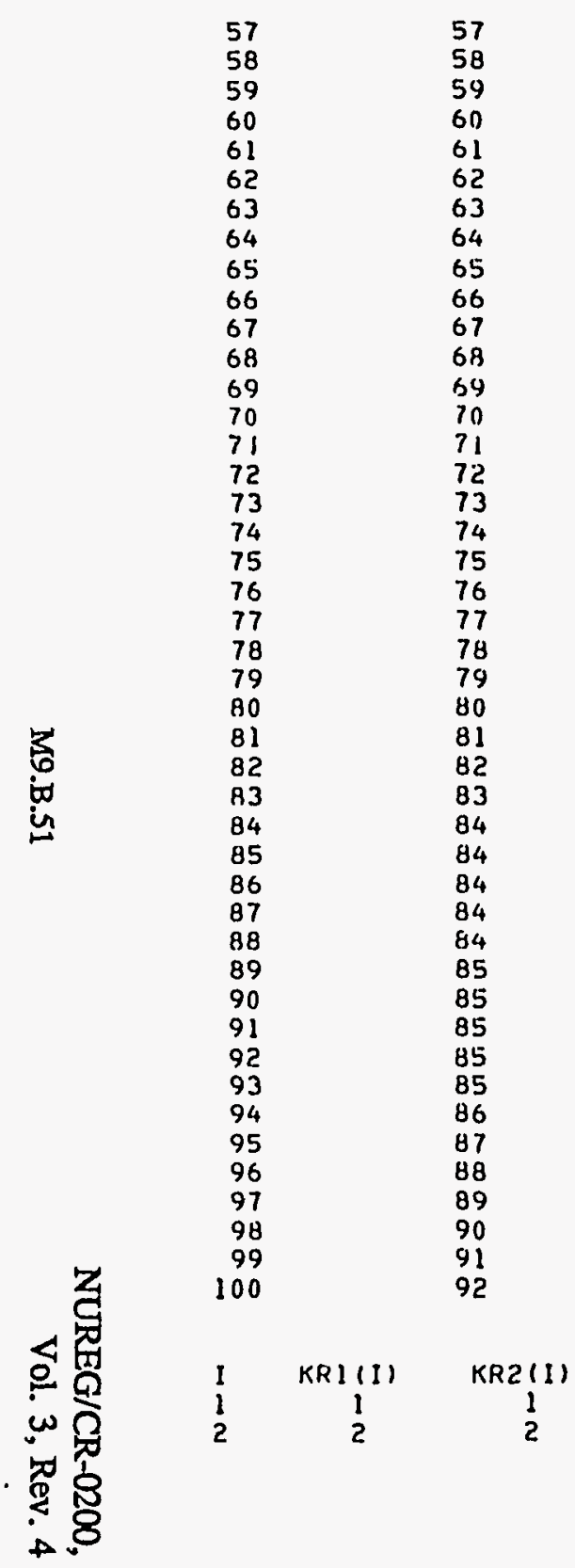

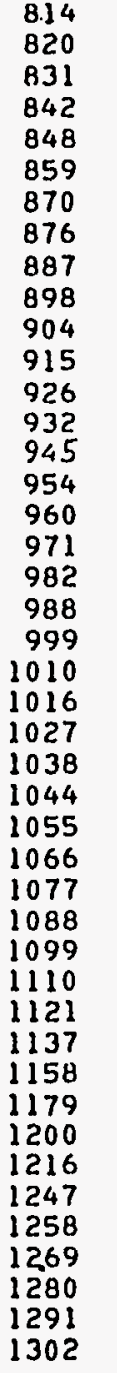

-1
11
-1000

-2
11

$-1000$

$-3$

$-4$

11
-1000

$-5$

$-1000$

$-6$

$-1000$

$-7$

11

$-8$

11

$-9$

11

$-1000$

$-10$

$-10$

$-10$

-10
-10

10

10

10

Figure M9.B.14 (continued) 


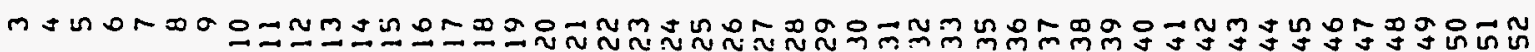

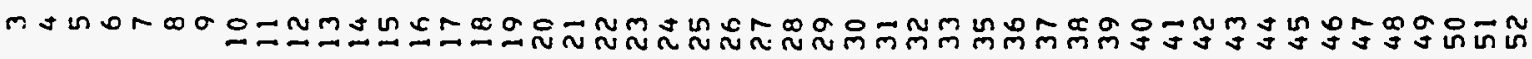

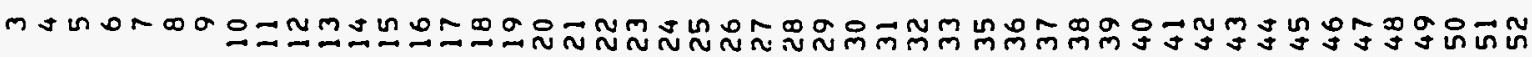




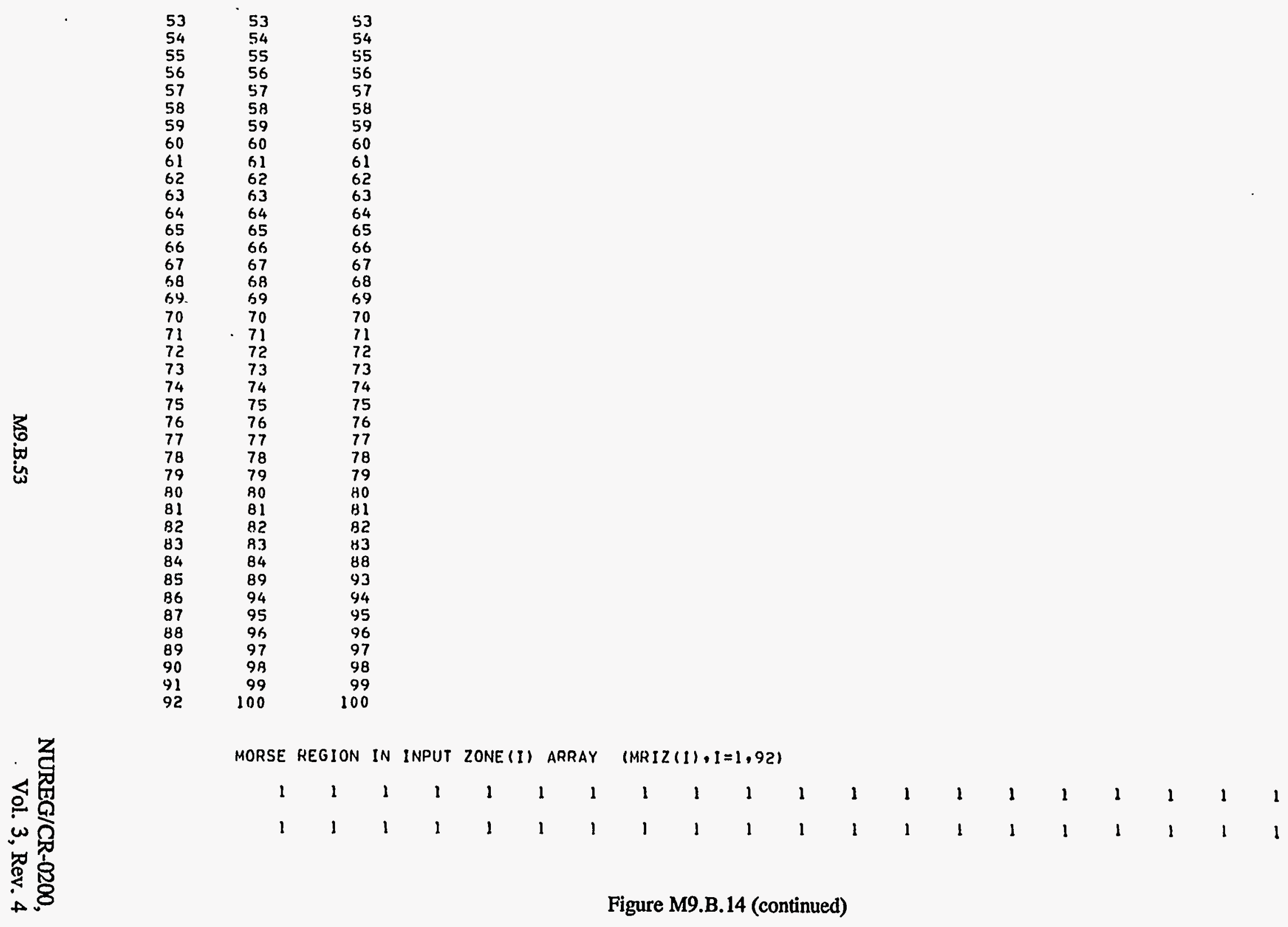



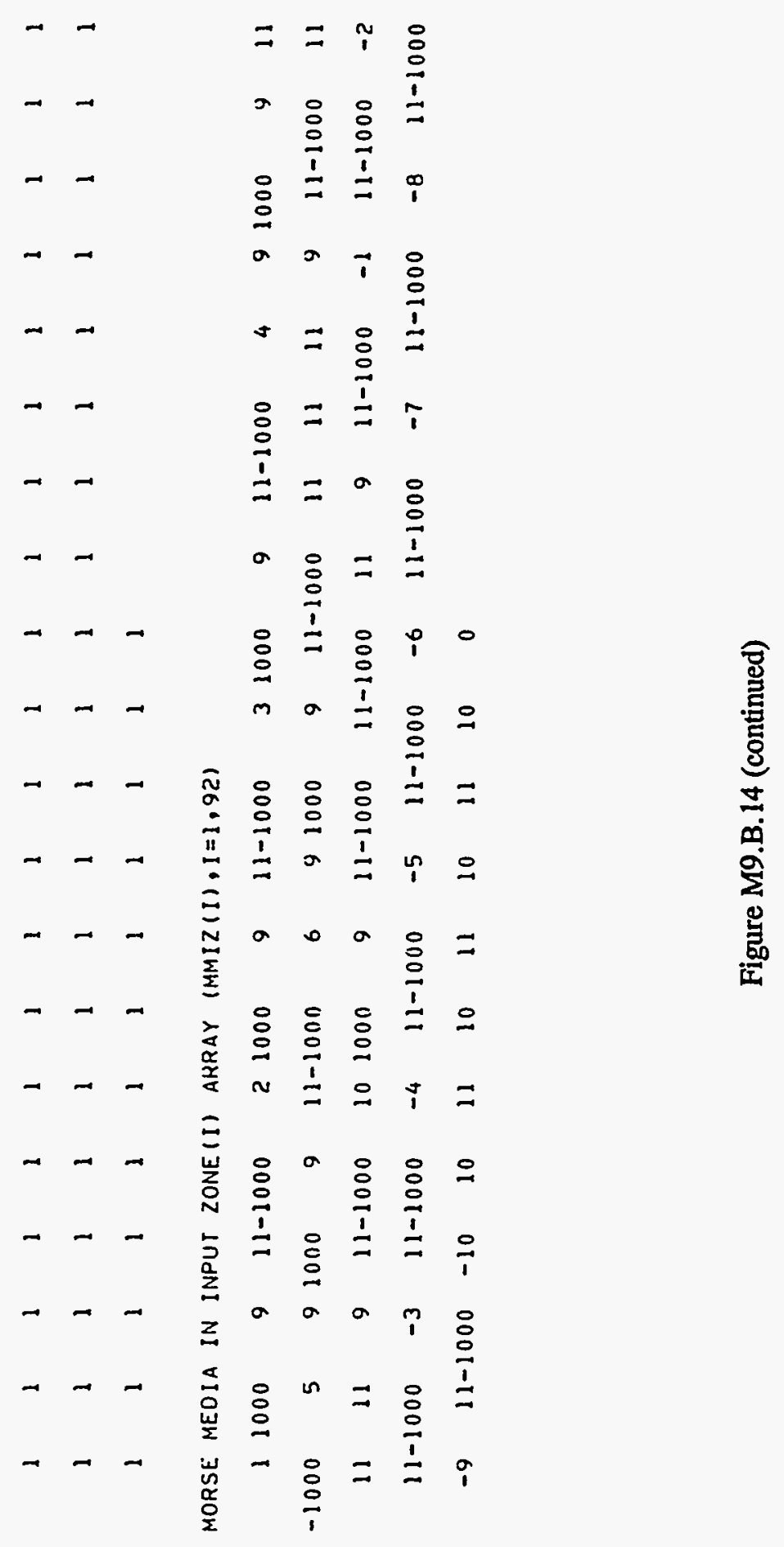

NUREG/CR-0200,

Vol. 3, Rev. 4

M9.B.54 


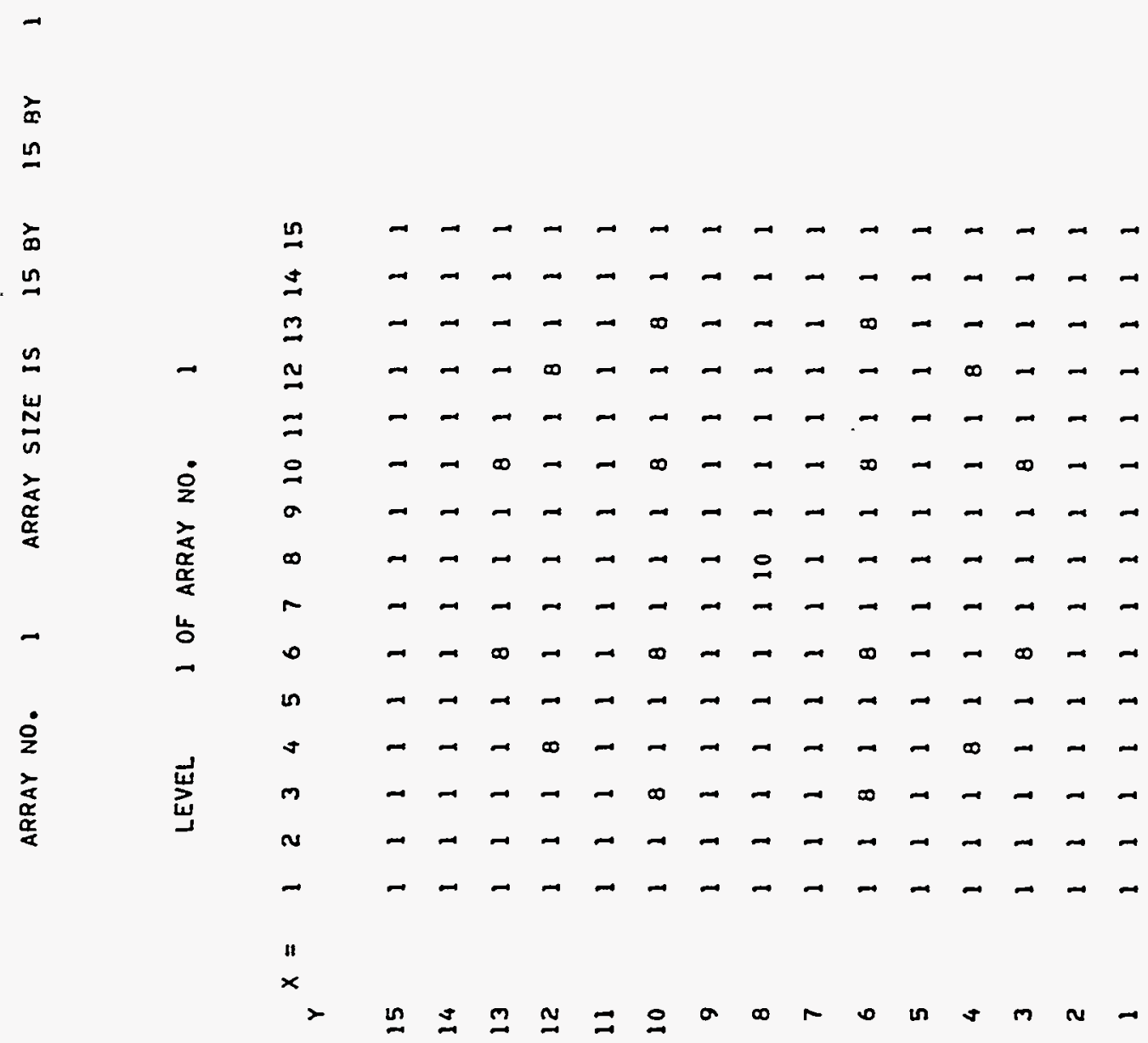

M9.B.55

NUREG/CR-0200, Vol. 3, Rev. 4 


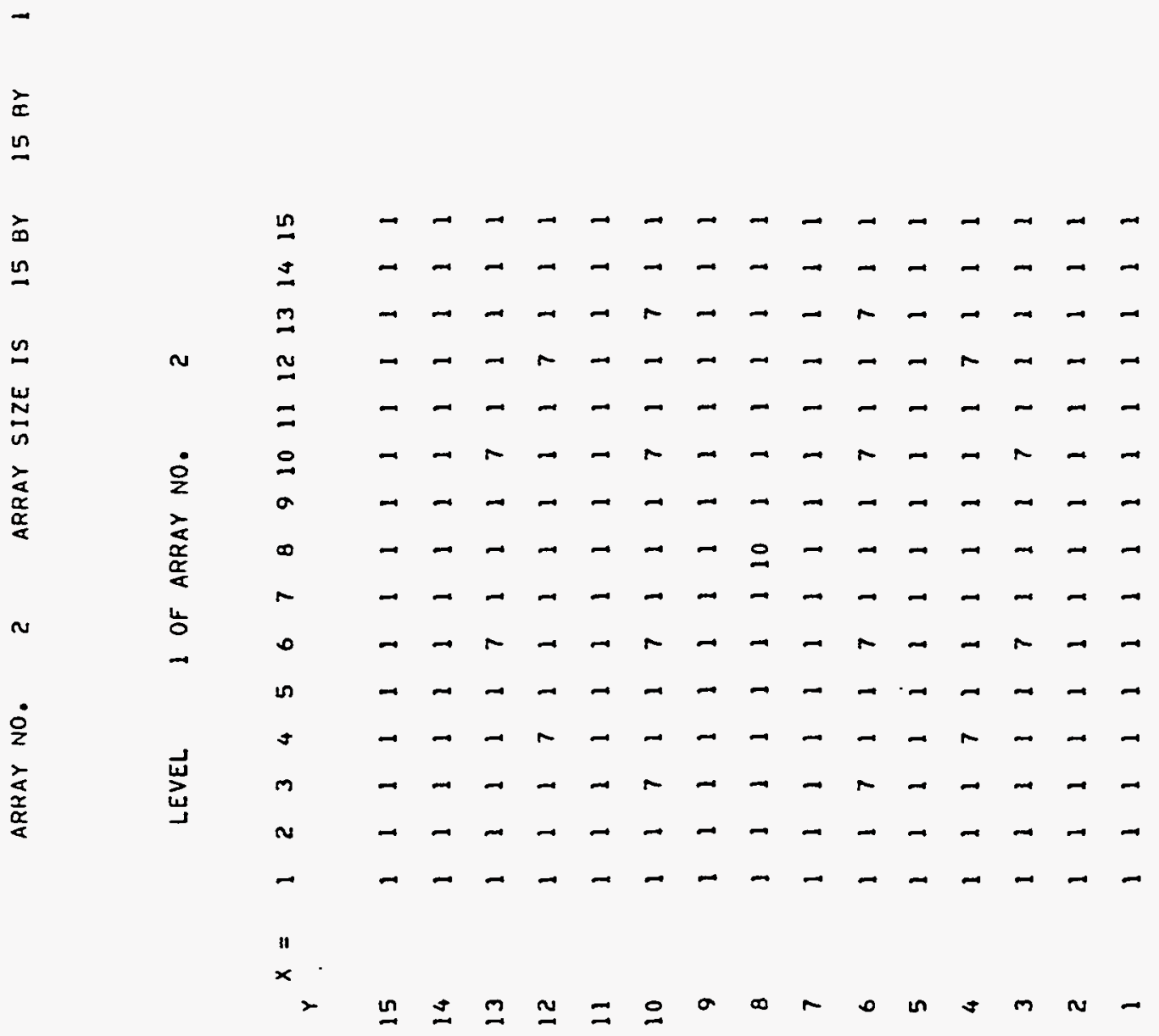

NUREG/CR-0200,

Vol. 3, Rev. 4 
ARRAY NO. 3 ARRAY SIZE IS 15 BY 15 RY 1

LEVEL 1 OF ARRAY NO. 3

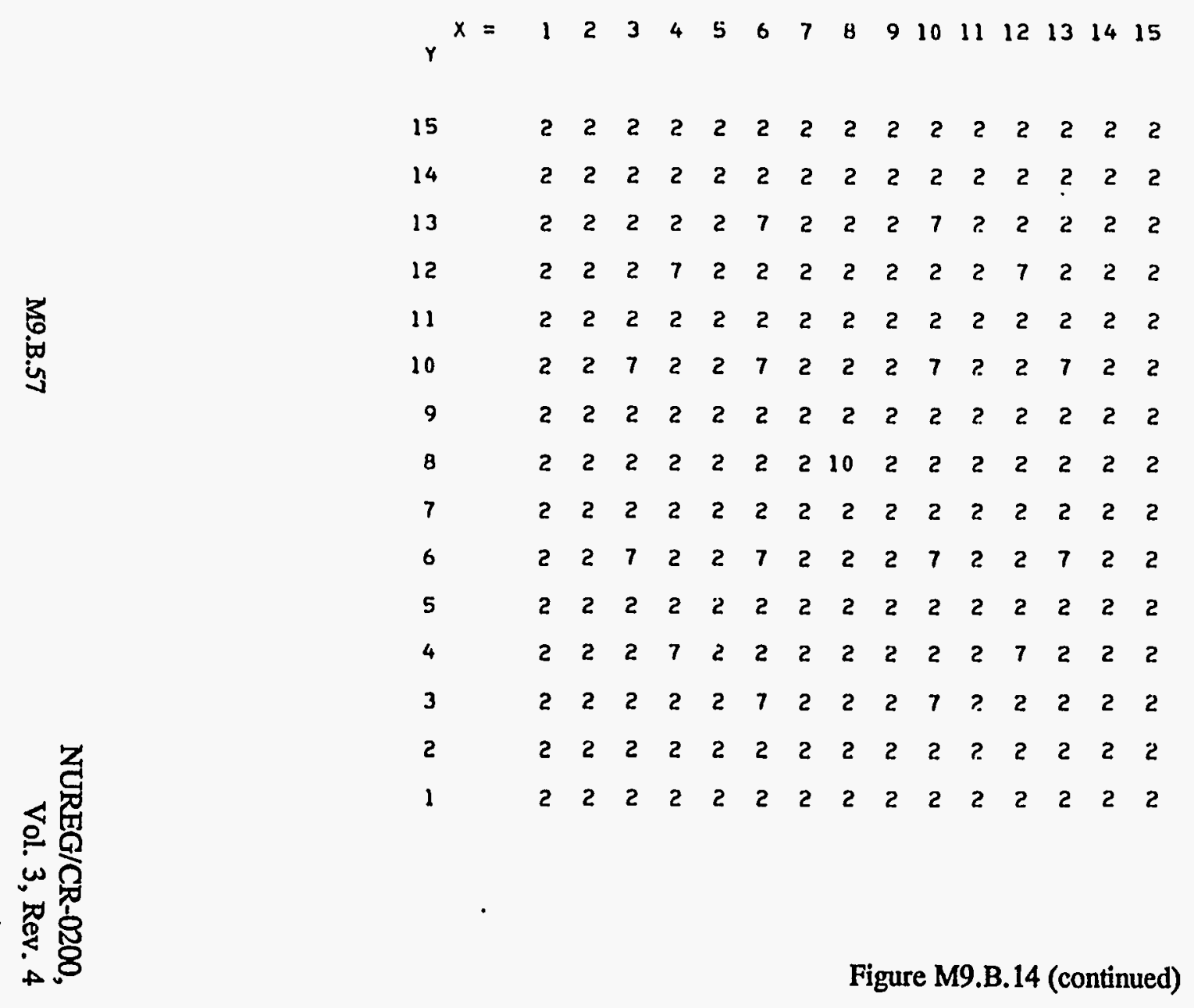




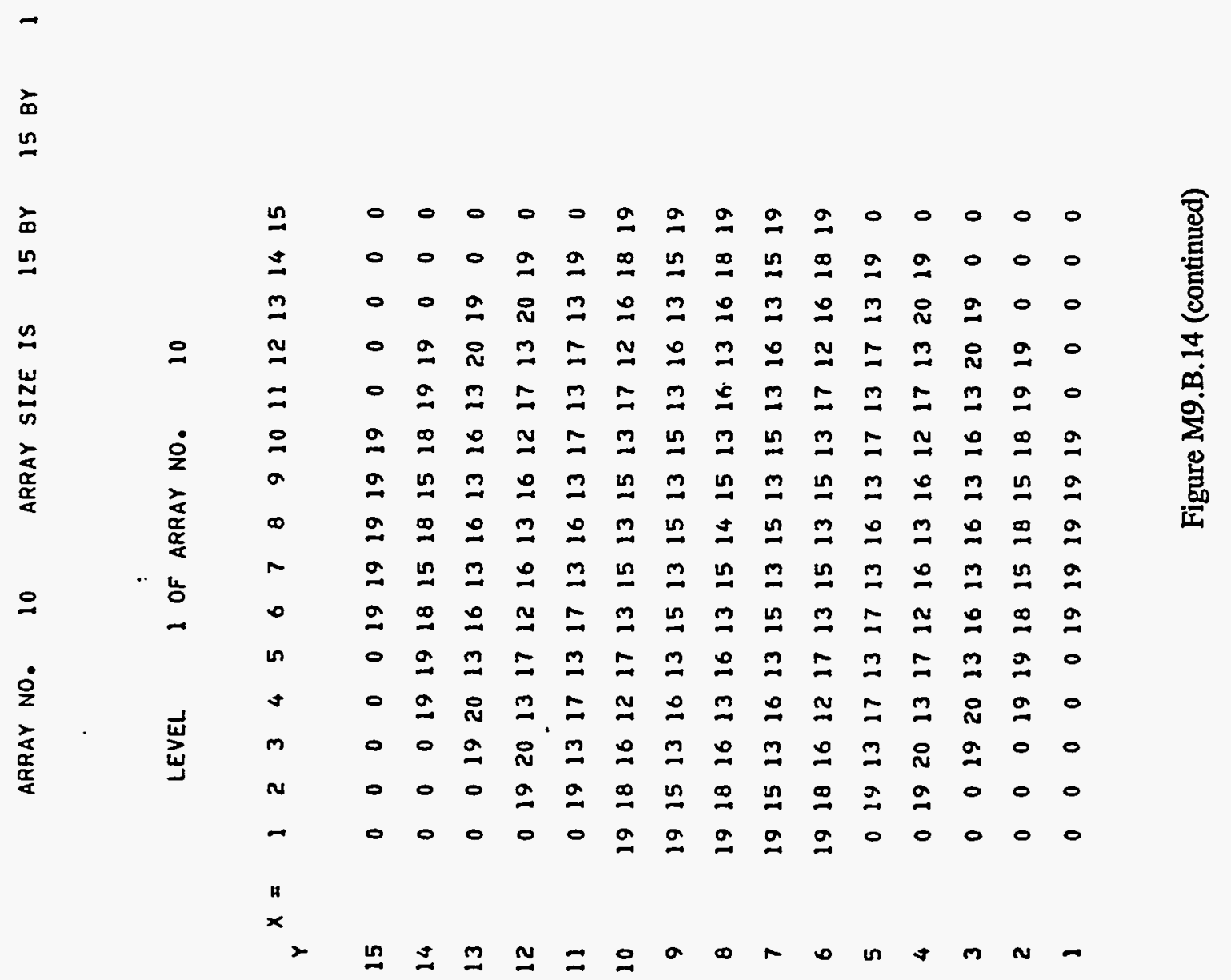


CODE ZONE 86CONTAINS AN ARRAY BUT IS DEFINED WITH MORE THAN ONE BODY - WARNING FIRST BOOY WILL BE REFERENCE HODY

CODE ZONE B7CONTAINS AN ARRAY BUT IS DEFINED WITH MORE THAN ONE BODY - WARNING FIRST BODY WILL BE REFERENCE BOOY

\section{UNIVERSE SPECIFICATIONS}

UNIVERSE

1-SIMPLE/O-COMJOM

2

3

Figure M9.B.14 (continued)
1 
WARNING -- UNIVERSE 12 IS NOT SIMPLE CODE ZONE 57 CONTAINS ARRAY I

WARNING -- UNIVERSE 13 IS NOT SIMPLE CODE ZONE 60 CONTAINS ARRAY 2

宅

13

WARNING -- UNIVERSE 14 IS NOT SIMPLE CODE ZONE 63 CONTAINS ARRAY 3

14

WARNING -- UNIVERSE 15 IS NOT SIMPLE CODE ZONE 66 CONTAINS ARRAY 4

WARNING -- UNIVERSE 16 IS NOT SIMPLE

Figure M9.B.14 (continued) 
WARNING -- UNIVERSE 17 IS NOT SIMPLE CODE ZONE 72 CONJAINS ARRAY 6

17

WARNING - UNIVERSE 18 IS NOT SIMPLE
COOE ZONE 75 CONTAINS ARRAY 7

18

WARNING -- UNIVERSE 19 IS NOT SIMPLE CODE ZONE 78 CONTAINS ARRAY

B

19

0

WARNING -- UNIVERSE 20 IS NOT SIMPLE

CODE ZONE 81 CONTAINS ARRAY 9

20

0

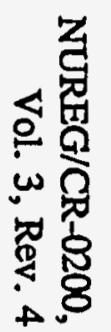

Figure M9.B.14 (continued) 


\section{M9.B.6 INHERENTLY SUBCRITICAL INSERT DESIGN}

Figure M9.B.15 illustrates the model being described. Figure M9.B.16 is a draftsman's drawing of the geometry being modeled. The external $x$ and $y$ boundaries for this problem are reflected to reproduce the model shown in Fig. M9.B.16. Figure M9.B.17 is a computer listing of the input and output edit for this problem. This problem demonstrates array rotation and array nesting. The model described was determined not to be subcritical. The following correspondence exists between the MARS input instructions and the card image input list:

\begin{tabular}{cl} 
Card number & \multicolumn{1}{c}{ Input requirements } \\
\cline { 2 - 2 } 2 & A.1, Title Card \\
3 & A.2, Options Card \\
$4-29$ & A.3, Body Definition Cards \\
$30-83$ & A.4, Input Zone Description Cards \\
84 & A.5, Region Card \\
$85-86$ & A.6, Universe Card \\
$87-90$ & A.7, Media Card \\
91 & A.8, Array Size Specification Input \\
$92-98$ & A.9, Array Content Description \\
99 & A.10, Universe Type
\end{tabular}

The model consists of:

$\begin{array}{cl}25 & \text { Bodies } \\ 3 & \text { Body Types (RCC, RPP, and BOX) } \\ 53 & \text { Input Zones } \\ 53 & \text { Code Zones } \\ 14 & \text { Universes } \\ 2 & \text { Levels of Geometry Nesting } \\ 98 & \text { Cards of Geometry Input } \\ 2300 & \text { Computer Memory Locations Required for Geometry Data }\end{array}$

Special attention should be given to:

1. Array 2 is referenced in Input Zones $23,25,28$, and 31 , corresponding to Universes 7, 8, 9, and 10 , respectively. It is rotated in Input Zones 25,28 , and 31.

2. There is no need for Universe 7. Array 2 could have been referenced directly in the $2,1,1$, position of Array 3.

3. Several bodies are reused in many different universes.

4. Array 1, the Fuel Assembly, is surrounded by a thin water gap described in Universe 3.

NUREG/CR-0200,

Vol. 3, Rev. 4

M9.B.62 
5. The alternative to rotating Array 2 in this model would have been to describe three additional arrays and three additional universes.

6. Universes 1 and 2 are SIMPLE, while Universes 3-14 are COMJOM.

OBSE D.r. 81-5764
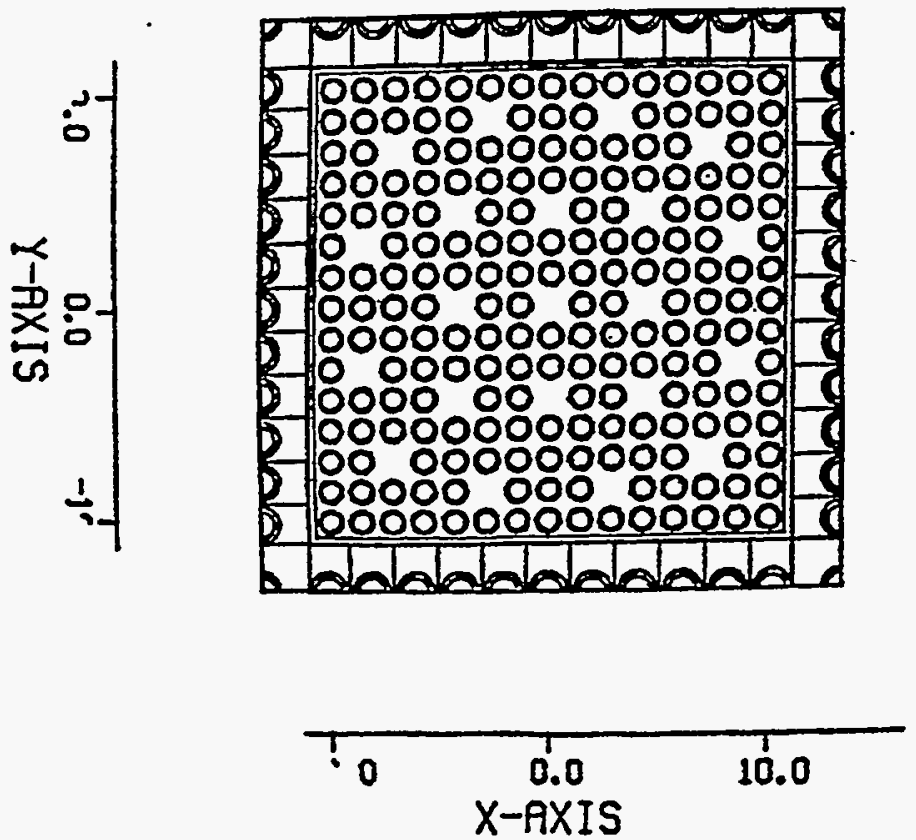

Figure M9.B.15 Computer drawing of the inherently subcritical insert design 


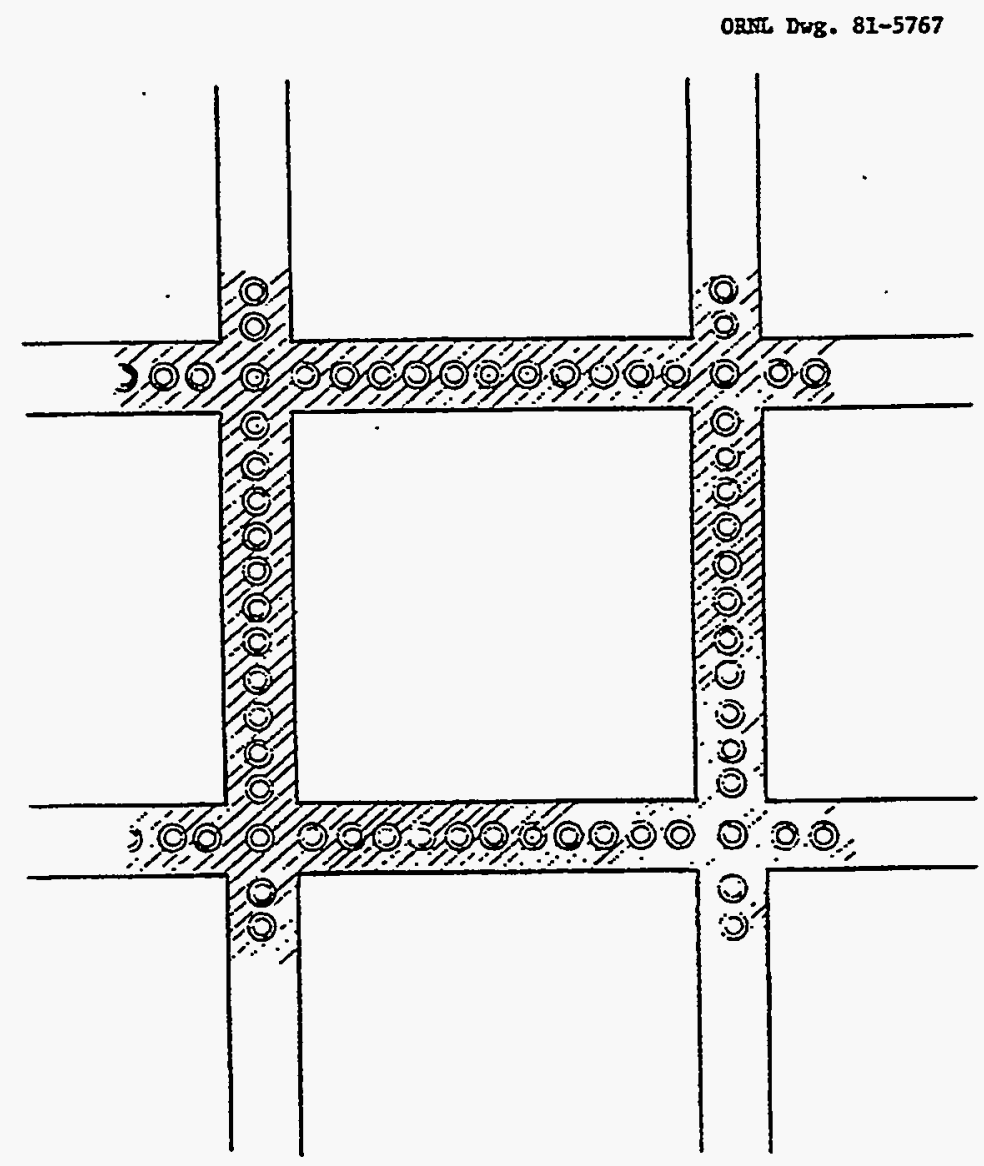

Figure M9.B.16 Draftsman's drawing of the inherently subcritical insert design 


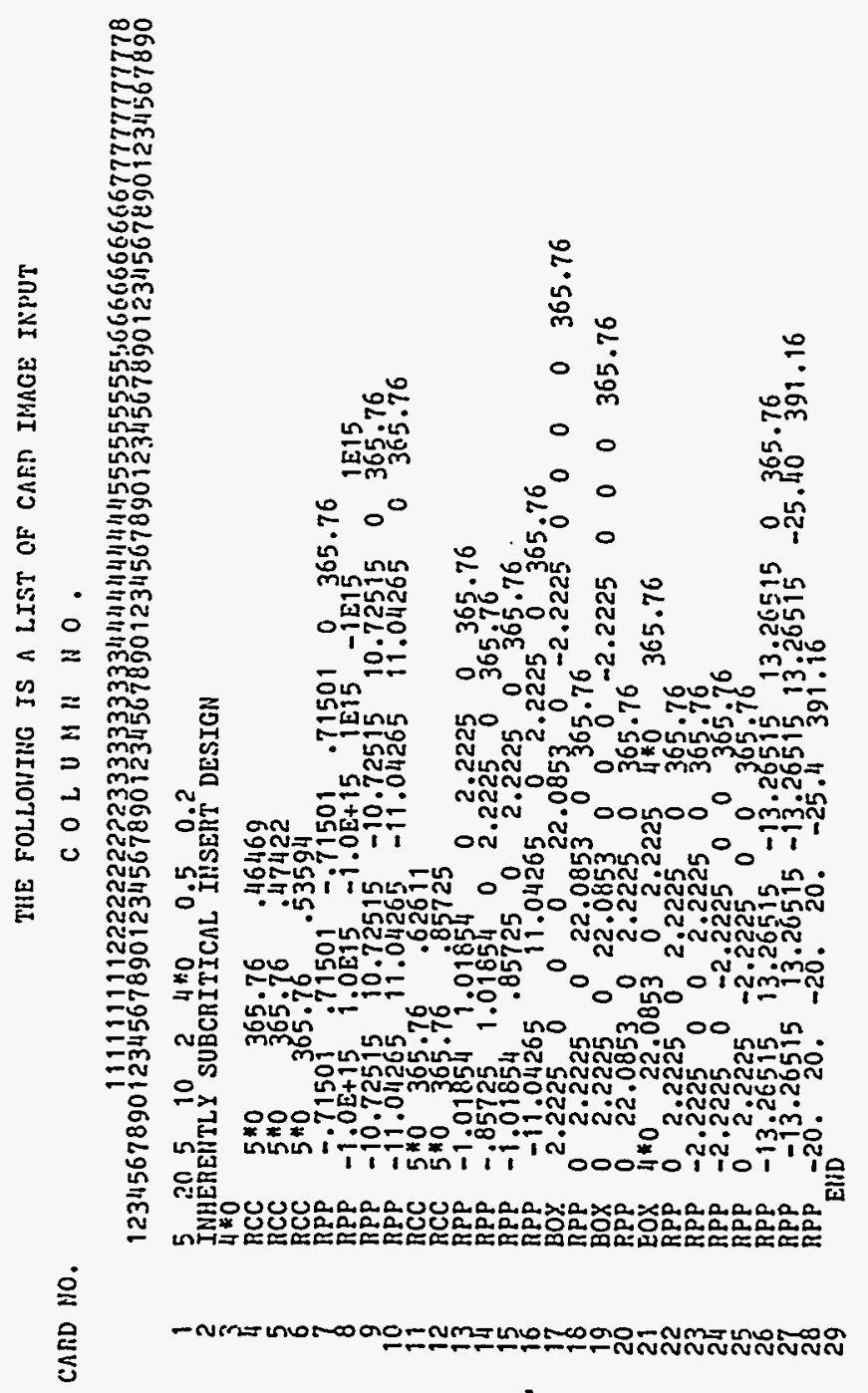

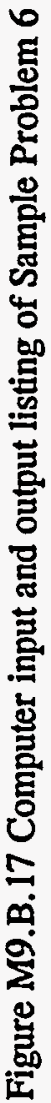




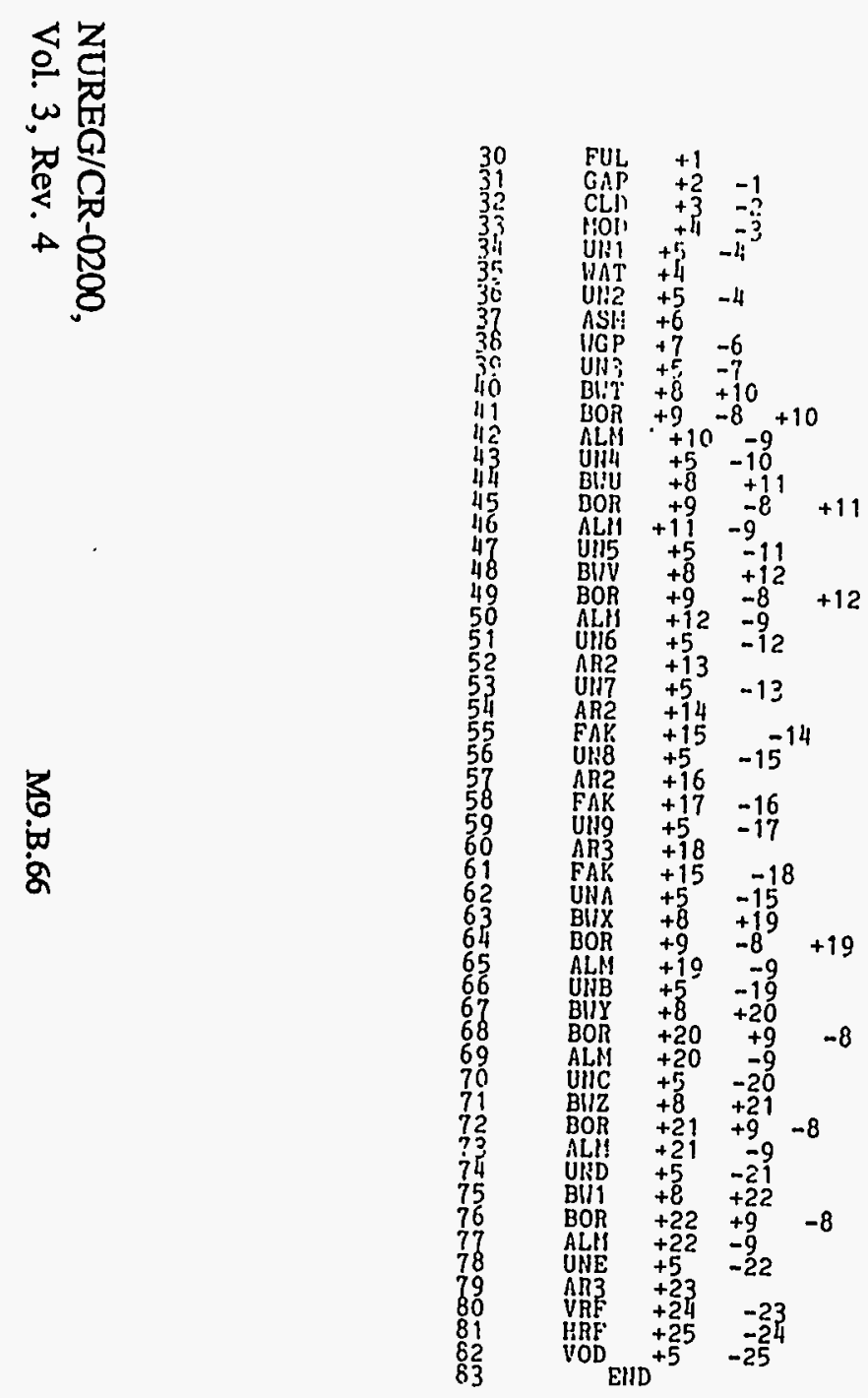

Figure M9.B.17 (continued) 


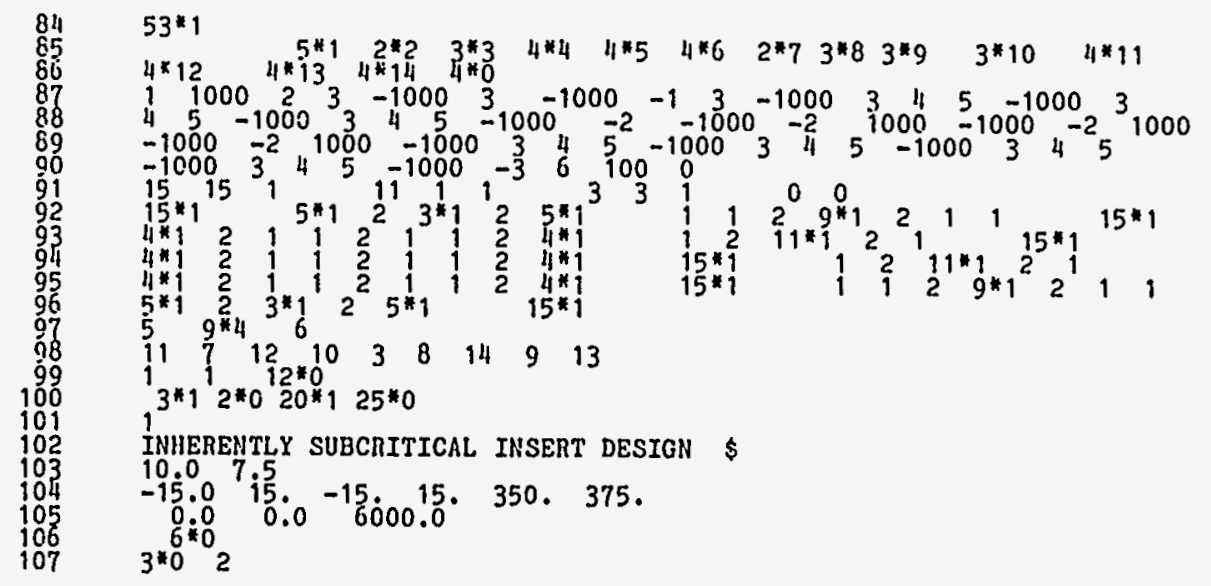

END OF CARD INPUT LIST 


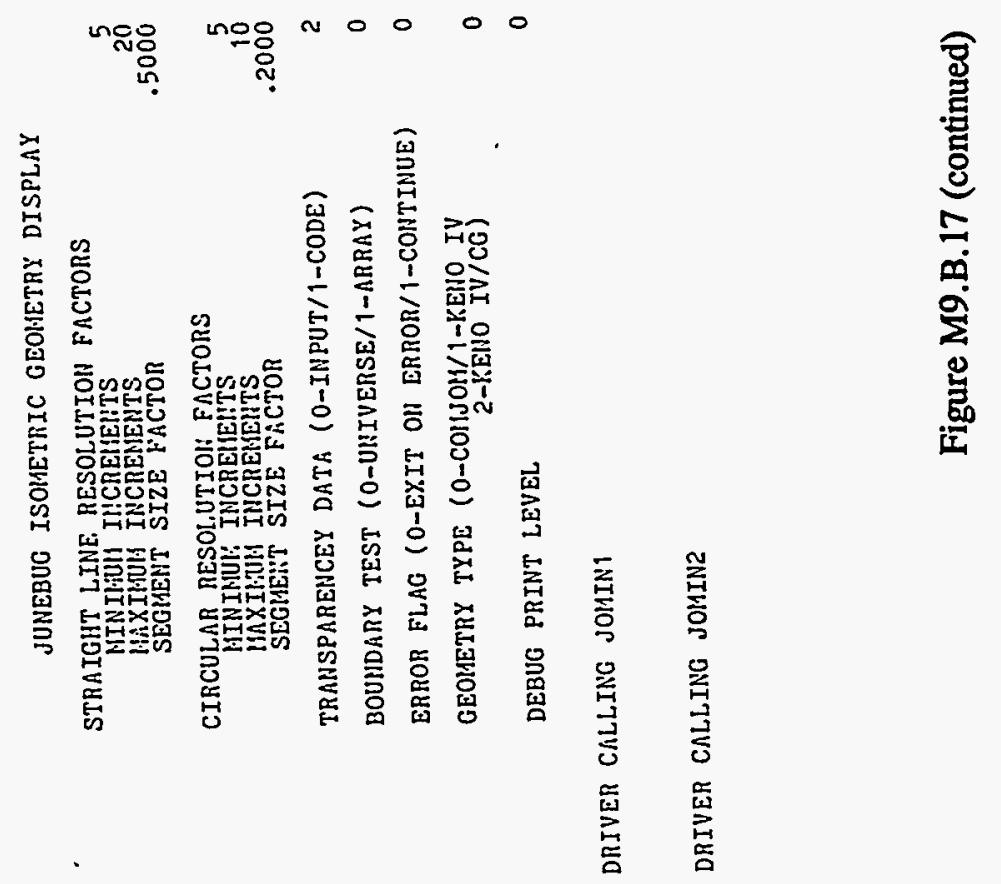

NUREG/CR-0200,

Vol. 3, Rev. 4

M9.B.68 


\begin{tabular}{|c|c|c|c|c|c|c|c|c|}
\hline & & & $\begin{array}{r}\text { MEREATLY SUBCRI } \\
\text { IVOPT = }\end{array}$ & $\begin{array}{l}\text { TICAL INSERT D } \\
0\end{array}$ & $\begin{array}{l}\text { ESIGH } \\
B G=0\end{array}$ & & & \\
\hline & EC: & 1 & c. & 0. & EODY 1 & $\begin{array}{l}n T h \\
0 .\end{array}$ & 0. & $.3657600 E+03$ \\
\hline & fe: & 2 & $\therefore: .4646900 E+00$ & 0. & 0. & 0. & 0. & $.3657600 \mathrm{E}+03$ \\
\hline & Res & 3 & $c .474<<00 t+00$ & 0. & 0. & 0. & 0. & $.3657600 E+03$ \\
\hline & REF & 4 & $\begin{array}{r}.5359400 \mathrm{E}+00 \\
-.7150100 \mathrm{E}+00\end{array}$ & $.7150100 \mathrm{E}+00$ & $-.7150100 E+00$ & $.7150100 \mathrm{E}+00$ & 0. & $.3657600 \mathrm{E}+03$ \\
\hline & RP: & 5 & $-.1000000 E+16$ & $.1000000 \mathrm{E}+16$ & $-.1000000 E+16$ & $.1000000 E+16$ & $-.1000000 E+16$ & $.1000000 E+16$ \\
\hline & $\mathrm{RPF}$ & 6 & $-.1072515 E+02$ & $.1072515 E+02$ & $-.1072515 E+02$ & $.1072515 E+02$ & 0. & $.3657600 E+03$ \\
\hline & RPP & 7 & $-.1104265 E+02$ & $.1104265 E+02$ & $-.1104265 E+02$ & $.1104265 E+02$ & 0. & $.3657600 \mathrm{E}+03$ \\
\hline & $\operatorname{scc}$ & 8 & c. $62611000+00$ & 0. & 0. & 0. & 0. & $.3657600 E+03$ \\
\hline & $\mathrm{RCC}$ & 9 & $0.6261100 \mathrm{E}+00$ & 0. & 0. & 0 . & 0. & $.3657600 \xi+03$ \\
\hline & RPS & 10 & $\begin{array}{r}.8572500 \mathrm{E}+00 \\
-.1016540 \mathrm{E}+01\end{array}$ & $.1018540 E+01$ & 0. & $.2222500 \mathrm{E}+01$ & 0. & $.3657600 \mathrm{E}+03$ \\
\hline & RPF & 11 & $-.8572500 \mathrm{E}+00$ & $.1016540 \mathrm{E}+01$ & 0. & $.2222500 \mathrm{E}+01$ & 0. & $.3657600 E+03$ \\
\hline 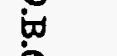 & $\mathrm{RPP}$ & 12 & $-.1018540 E+01$ & $.8572500 \mathrm{E}+00$ & 0. & $.2222500 \mathrm{E}+01$ & 0. & $.3657600 E+03$ \\
\hline & RE? & 13 & $-.1104265 E+02$ & $.1104265 E+02$ & 0. & $.2222500 \mathrm{E}+01$ & 0. & $.3657600 E+03$ \\
\hline & BC: & 14 & $.2222500 \mathrm{E}+01$ & 0 & 0. & 0. & $.2208530 \mathrm{E}+02$ & \\
\hline & R.PP & 15 & $\tilde{0}^{-2222500 E+01}$ & $.2222500 \mathrm{E}+01$ & o: & $2208530 \mathrm{E}+02$ & o: & $: 3657600 \mathrm{E}+03$ \\
\hline & BOX & 16 & 0. & $.222500 \mathrm{E}+01$ & 0. & $.2208530 \mathrm{E}+02$ & 0. & \\
\hline & R.PP & 17 & 0 & - & 0 & $.2222500 \mathrm{E}+01$ & $0:$ & \\
\hline & $\mathrm{BCO}$ & 18 & $0.02325000+01$ & o. & 0. & 0 & $0^{.2208530 \mathrm{E}+0 ?}$ & \\
\hline & RPP & 19 & $0:^{.2222500 \mathrm{E}+01}$ & :2222500E+01 & $0:$ & $.2222500 \mathrm{E}+01$ & $0:$ & $: 3657600 \mathrm{E}+03$ \\
\hline & EPP & 20 & $-.2222500 \mathrm{E}+01$ & 0 & 0. & $.2222500 \mathrm{E}+01$ & 0. & $.3657600 E+03$ \\
\hline & $\mathrm{KPP}$ & 21 & $-.2222500 \mathrm{E}+01$ & 0. & $-.2222500 E+01$ & 0 & 0. & $.3657600 E+03$ \\
\hline & RP? & 22 & 0 & $.2222500 \mathrm{E}+01$ & $-.2222500 \mathrm{E}+01$ & 0. & 0. & $.3657600 E+03$ \\
\hline & RPp & 23 & $-.1326515 E+02$ & $.1326515 E+02$ & $-.1326515 E+02$ & $.1326515 E+02$ & 0 & $.3657600 \varepsilon+03$ \\
\hline & EPP & 24 & $-.1326515 E+02$ & $.1326515 E+02$ & $-.1326515 E+02$ & $.1326515 E+02$ & $-.2540000 \mathrm{E}+02$ & $.3911600 E+03$ \\
\hline 息 & EPF & 25 & $-.2000000 \mathrm{E}+02$ & $.2000000 \mathrm{E}+02$ & $-.2000000 \mathrm{E}+02$ & $.2000000 \mathrm{E}+02$ & $-.2540000 \mathrm{E}+02$ & $.3911600 E+03$ \\
\hline 20 & $\begin{array}{l}\text { P!U!:SE } \\
\mathrm{LE}: \mathrm{BTT}\end{array}$ & 0 & $\begin{array}{lr}\text { ECDIES } & 25 \\
\text { FPD }-A R R A Y & 223\end{array}$ & & & & & \\
\hline
\end{tabular}

Figure M9.B.17 (continued) 


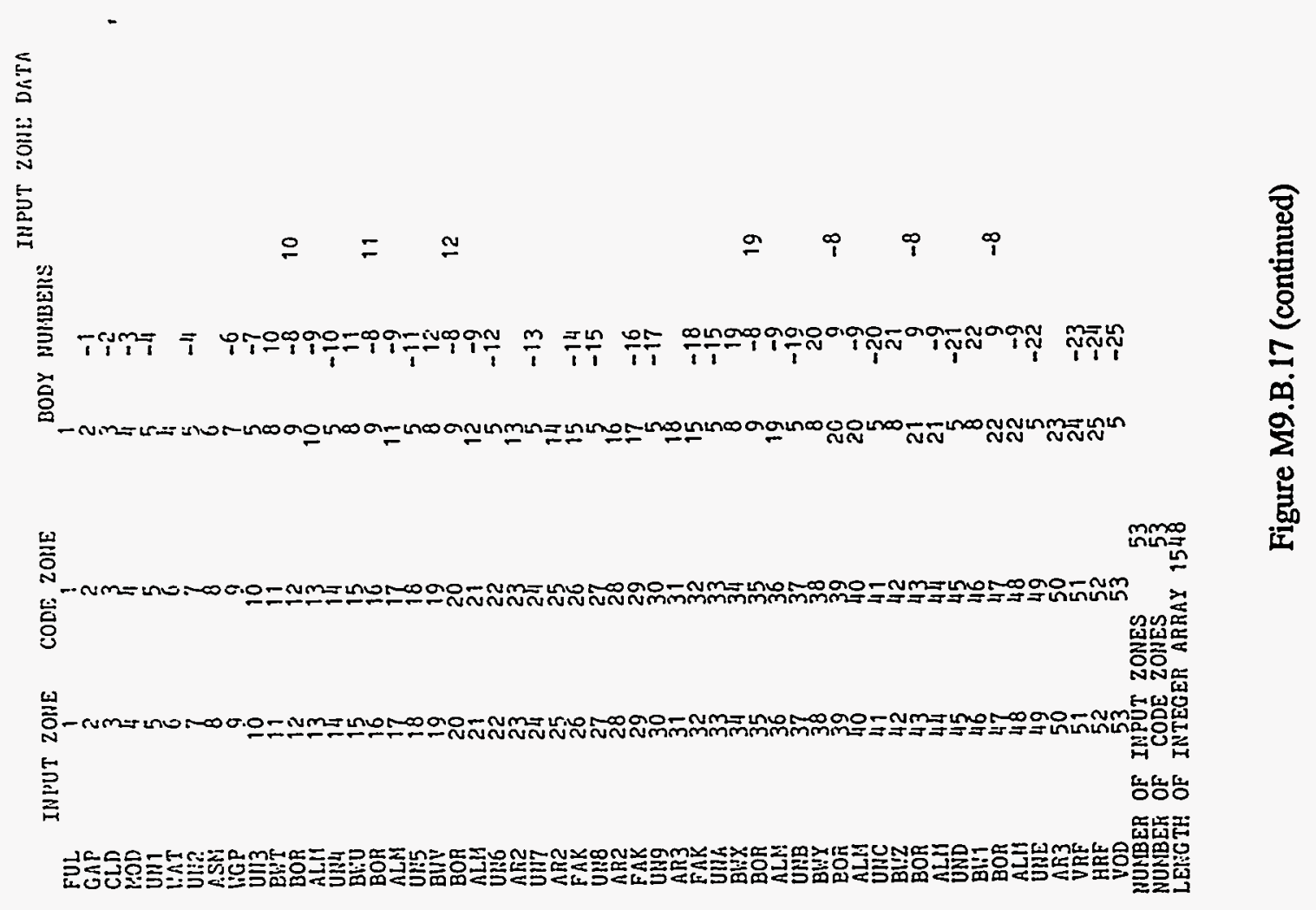

NUREG/CR-0200,

Vol. 3, Rev. 4

M9.B.70 


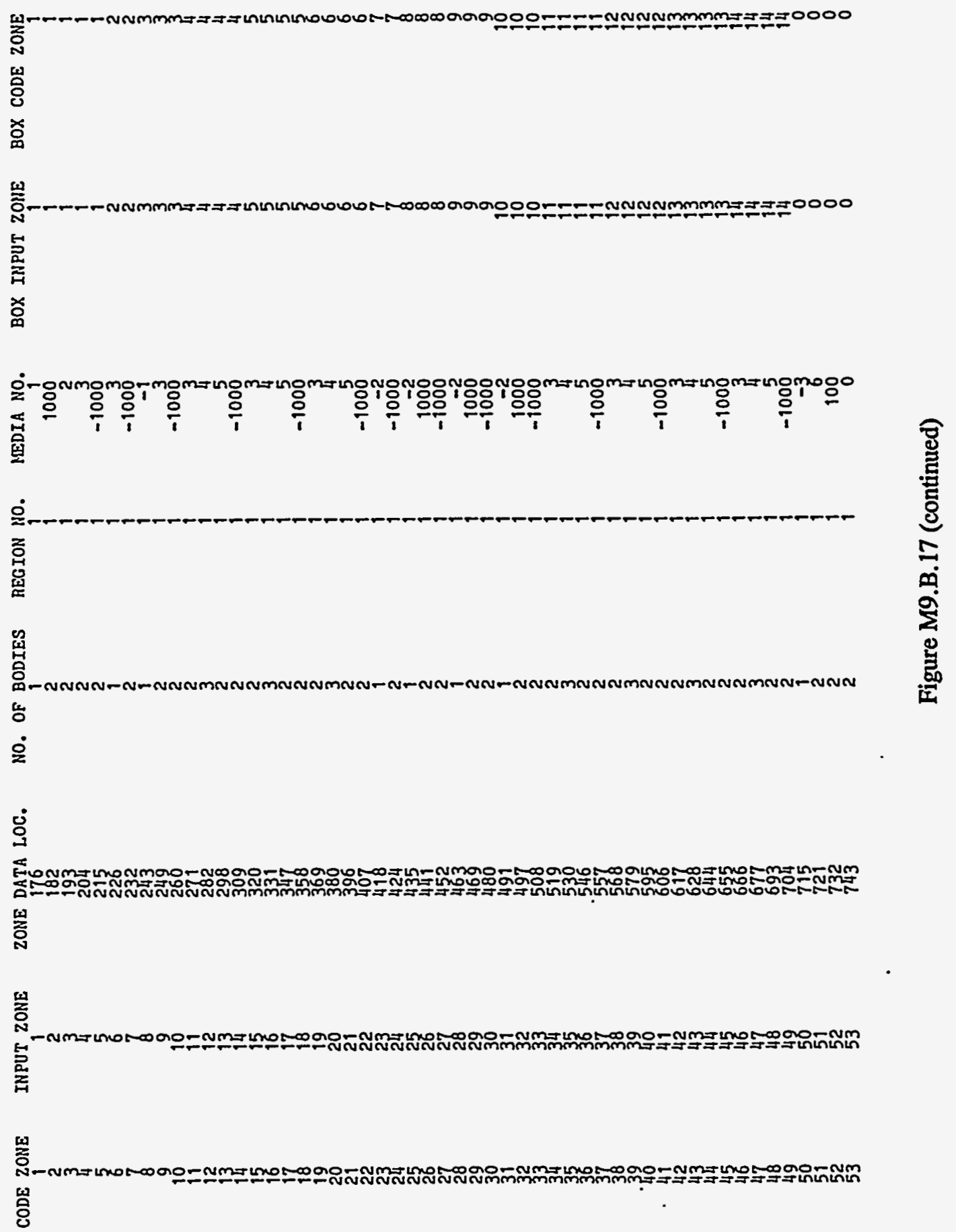




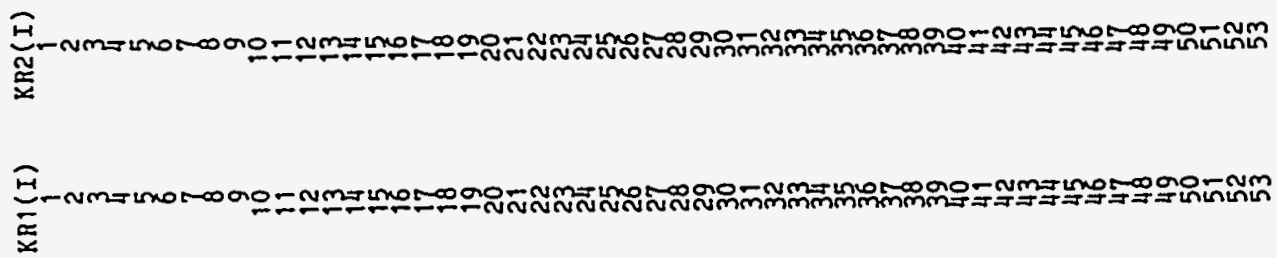

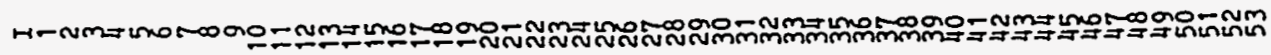

NUREG/CR-0200,

Vol. 3, Rev. 4 M9.B.72 


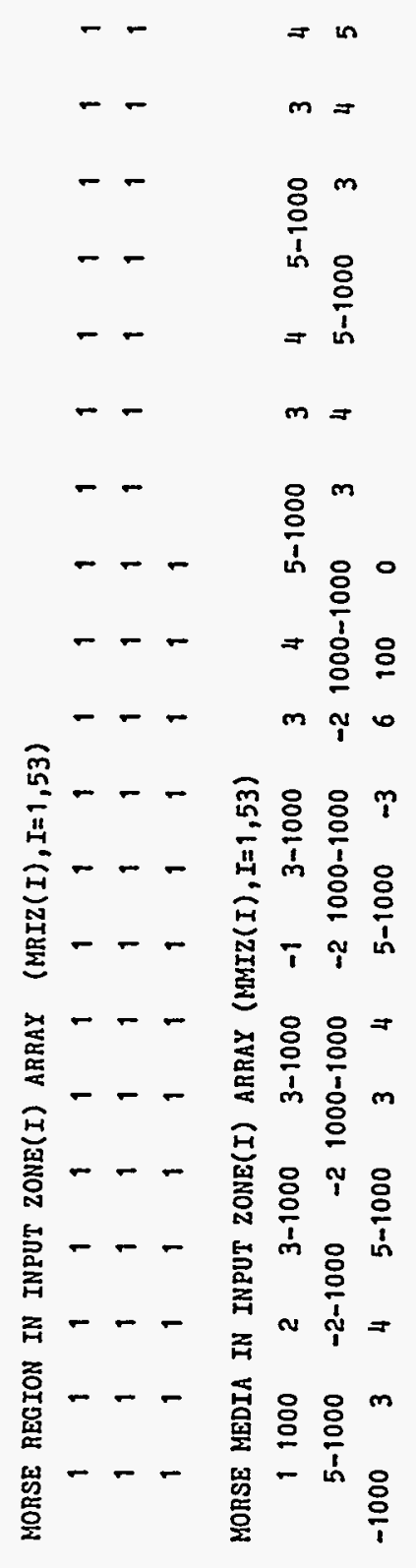

NUREG/CR-0200,

M9.B.73

Vol. 3, Rev. 4 


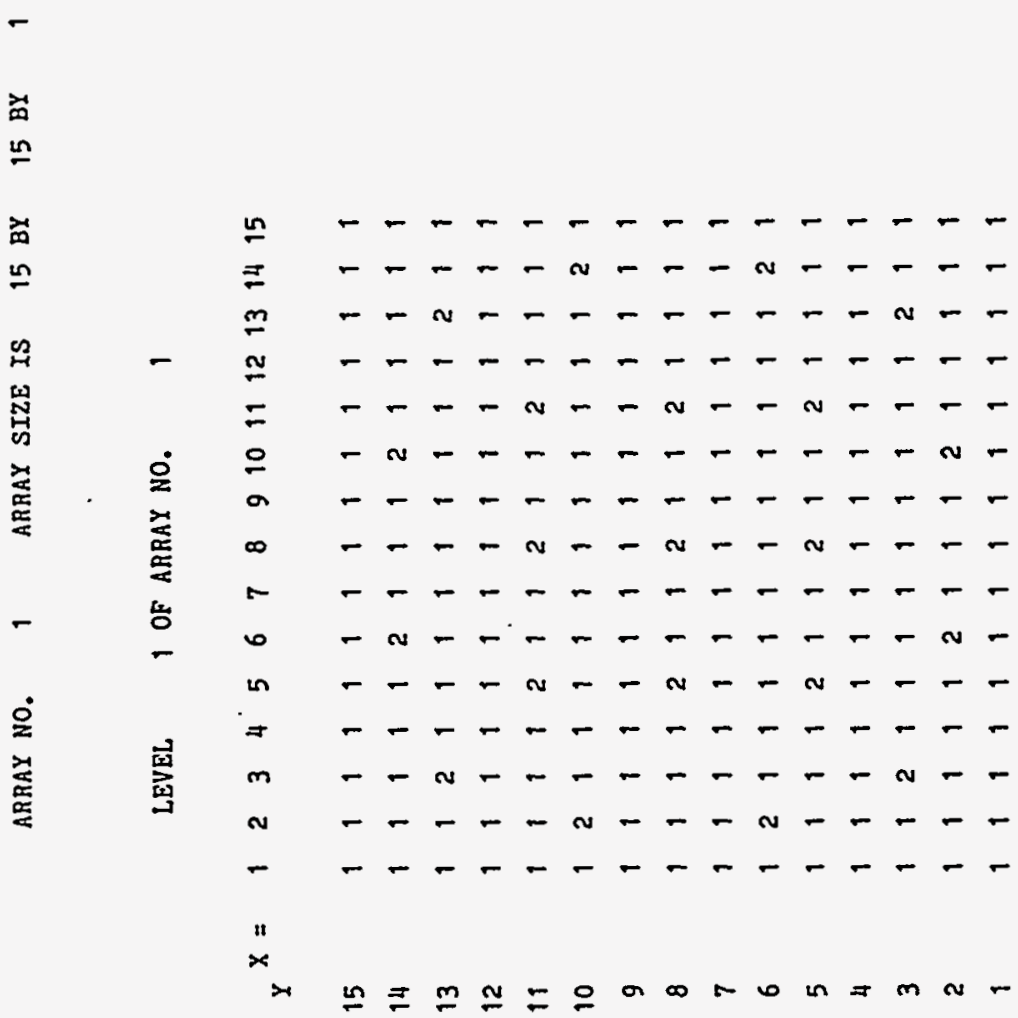




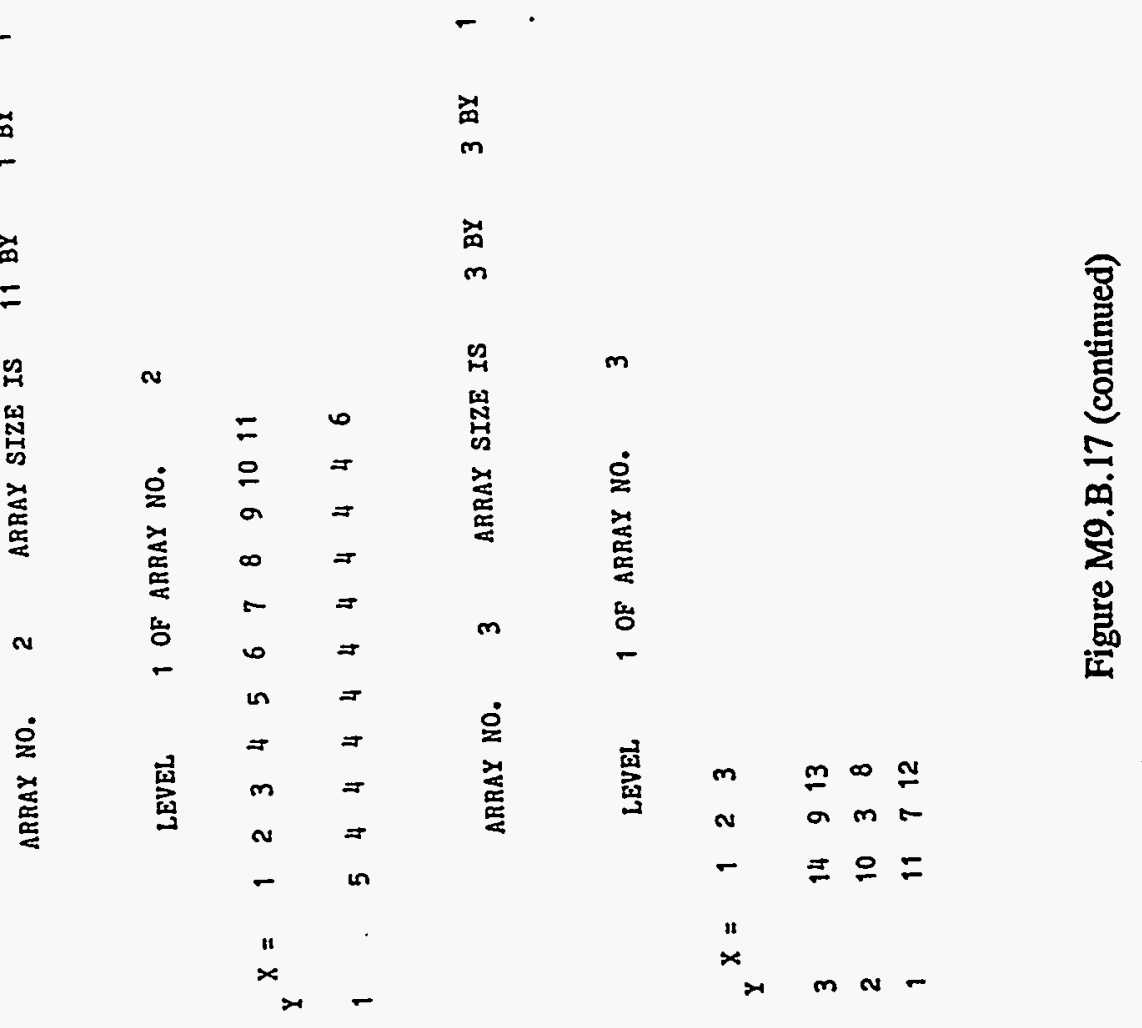




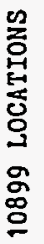

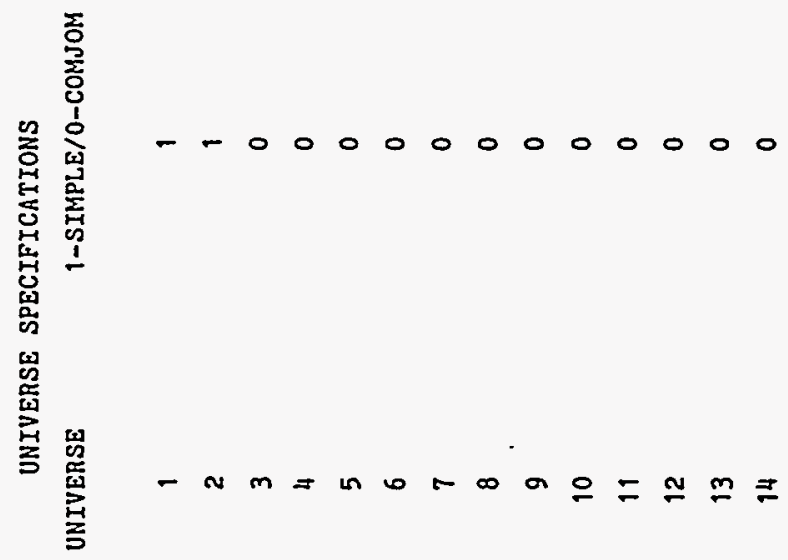

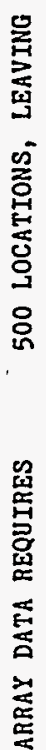

NUREG/CR-0200,

Vol. 3, Rev. 4 M9.B.76 


\section{M9.C COMBINATORIAL GEOMETRY ZONE SUMMARY TABLE DESCRIPTION}

Input zones are described by one or more code zones. The code zone description consists of the union or the intersection of bodies. If a body is totally included in a code zone, then a particle could exit the zone by exiting the body. If a body is an excluded body referenced with a negative sign in a code zone description, then a particle could exit the zone by entering the body. Every time a particle exits a zone, it does so by entering or leaving one or more bodies used in the zone description. To save time in determining the next zone of entry, combinatorial geometry builds a table of the zones entered when a particle exits a given zone by way of a specific body in the zone description. To make this process more useful, combinatorial geometry counts the number of times it enters a given zone from a given body in an adjacent zone. At the end of a batch or generation of particles, this table is sorted in order of the most frequent zone of entry. This sorting enables the geometry tracking system to check the more probable zones of entry before checking the less probable zones of entry. For most problems, this process will not accelerate the tracking significantly. It will, however, provide the user with a detailed account of where his tracking took place and with how much frequency. The zone transfer summary table is printed out at the end of each calculation. It is a good way to check geometry models for inconsistencies. The zone summary table gives the frequency of each zone transfer and by what body the zone transfer took place.

The following zone transfers are from the plexiglas pipe (Sect. M9.B.3). The exit and entry zone refers to code zones. We shall discuss the transfers out of Code Zone 3. This code zone's body description is 4-3-9-1. For each body in Zone 3's description, there will be an exit table giving the zones entered upon exiting Zone 3 from each body and the frequency each was entered. For example, histories exiting Code Zone 3 by way of Body 4 entered Code Zone 13320 times; Zone 1 was entered 177 times; Zone 8 was entered 73 times; Zone 2 was entered 33 times. All of these entries were exits from Code Zone 3 by way of exiting Body 4 . The user should examine his zone summary table and decide if the transfers were correct for the model he intended to design. Very often the intended model is not the model input. It is easy in three-dimensional (3-D) geometry modeling to leave a small crack in the model. The code zone transfer summary table is designed to verify and assist in the proper construction of a geometry model. 


\section{M9.D INTERFACING THE MARS SUBROUTINES MODULE TO OTHER COMPUTER CODES}

MARS has been developed in a mocularized system so that it may be easily adapted with minimal effort into other computer codes. There are only a very few subroutines the user needs to communicate with inside the MARS system. For input the user will have to call subroutines JOMIN1, JOMIN2, and AZIP in MARS. Examples of this may be found in Subroutine RINPUP in the SCALE SAS3 control program, and in Subroutine RINPU1 in MORSE-SGC/S. For asking the location of a particle given a coordinate in the absolute universe, Level 0 of the geometry model, the user needs to call Subroutine CALI. Examples of this can be found in Subroutines SOURCE and GETNT in MORSE-SGC/S. Knowing a particle location, trajectory, and distance it may travel, the user needs to call Subroutine PILOT to determine the next zone of entry. Examples of calls to PILOT may be found in Subroutines GOMST and EUCLID in MORSE-SGC/S. Notice that labeled common ARAR contains NAR, the number of arrays in a model and NLEV, the number of geometry levels present in a model. Occasionally, the user will have the nesting table for a particle and need the particle coordinate either in a lower or higher geometry level. Subroutine RISK in the JUNEBUG code (3-D graphics program no longer available in SCALE) was written to take a particle coordinate in Geometry Level NL1 and translate it to Geometry Level NL2, given the nesting array. For calling RISK, NL2 must be greater than or equal to NL1. The opposite may be accomplished by calling Subroutine CLEV. That is, CLEV takes a coordinate in Level NL1 and translates the coordinate to Level NL2. CLEV is in the MARS subroutine library. PILOT in MARS and GETNT in MORSE call CLEV.

The user should be careful in using MARS to protect the particle nesting table during tracking. The user should be aware that, when a particle enters a rotated coordinate system, the particle direction cosines, WB in labeled common PAREM, are automatically rotated. 


\section{M9.E MARS DATA STORAGE AND PROGRAM LOGIC}

Subroutine CAII answers the question: What is the particle location? It is given particle coordinates, usually in the absolute universe, although this is not a requirement. It proceeds to determine if the particle is in an array or in a valid material media. If the particle is in a valid media, it determines this and returns. If the particle is in an array, it then checks the next level of the geometry as described in the array description. It repeats the process until it determines a valid positive material media the particle coordinates are inside. In this process, it starts from a lower, more global level of the geometry hierarchy, and checks from there to a higher, more local geometry level. The process is completed when the particle is located in a positive real media.

During the process of checking successive levels of a geometry model, the nesting table is always updated as the particle coordinates are translated. Therefore, as MARS goes from a lower global level to a higher, local geometry level, MARS always maintains the knowledge of where the particle is located relative to the lower, more global geometry levels.

Subroutine PILOT goes through the same process during tracking, except it has the logic to translate from higher levels to lower levels as well as from lower levels to higher levels. This is necessary for tracking. PILOT uses the nesting table generated by CALI when the particle initial location was determined. Both PILOT and CALI call Subroutine STORA to update the nesting table.

\section{M9.E.1 MARS SUBROUTINE DESCRIPTIONS}

ABEND - ABEND is called for an abnormal termination of a calculation. It gives a traceback of where it was called and calls EXIT.

$A B O X$ - ABOX is called from JOMIN1. It reads the BPP and WPP body data and converts the data to the BOX and WED body input format. The BPP and WPP are alternative ways of describing the BOX and WED.

ALBERT - ALBERT is called from GENI to construct the floating-point data to be stored in the FPD table for the ARB body, the arbitrary polyhedron body.

ARGEN - ARGEN is called from AZTP. It generates the size of each array from the array content tables and NLV table. It must compute the size of the simplest arrays first. These arrays are the arrays that contain only universes that do not contain subarrays. ARGEN comes from the term "array generator." The $x$-width, $y$-length, and $z$-height of each array is stored in the WLH array. This array is not needed in tracking or particle locating. It is needed to verify the fit of each array in each reference location.

AZIP - AZIP reads the combinatorial MARS array size and content input. It calls several other subroutines and generates a series of tables from the input data that are needed for MARS array tracking. It is called after JOMIN2 and GENI have set up the combinatorial data tables in memory. It uses much of the combinatorial input data from memory to construct the MARS data tables. 
BOD - BOD is called from CELL after the lattice cell position of a particle has been determined. It returns the cell contents. If the contents of a cell is vacant, it sets a flag. This is legal for exiting an array but fatal for entering an array. A particle cannot enter a vacant lattice position of an array.

CAII - CALI is called from outside the MARS subroutine module to determine a particle location. It first determines the universe and array the particle is inside. Frequently this requires checking several levels of the geometry model. CALI calls LOOKZ to determine the combinatorial geometry input zone a particle is inside for each universe or array. When CALI has checked several levels of geometry logic and determines the positive media the particle is inside, it then returns the information in labeled common PAREM, with the nesting table set by calls to STORA.

CELL - CELL is called from both CALI and PILOT. It is the guts of entering or exiting an array. It is called for a particle inside of or moving through an array. It returns the lattice cell position and content for the current particle position. CELL serves a dual role. It indicates the location of a particle in an array when the particle is not moving, and it says the next cell the particle will enter when the particle is moving. CELL calls subroutines SORT and BOD.

CLEV - CLEV is called from PILOT to translate a particle coordinate from a larger level, more local coordinate system to a lower, more global geometry level number given the nesting table. Because of the presence of several labeled commons in CLEV, it changes quite a few variables in a few commons. The user should be careful before calling CLEV so as not to inadvertently change some important information needed for tracking.

CORNER - CORNER is called from TRENTE and RTEXIT. It returns the origin or vertex for a reference body. This information is essential to particle translation for both entering and exiting a universe or an array.

CTRAN - CTRAN is called to determine the particle coordinate relative to either a lattice cell in an array or given the lattice position and the particle coordinate, it can determine the coordinate of the particle relative to the origin of the array. It requires the array number, the lattice position, and the particle coordinate to perform the proper translation. The argument NX determines the proper translation to perform.

DELTA - DELTA is called from ARGEN. It computes the size of each dimension of each lattice cell from the reference body of the cell. This dimension is summed in ARGEN to compute the total array size on each dimension.

DIPR - DIPR is called from several subroutines to dump MARS array information after an error has been detected. It calls DUPR. DIPR is called to simplify the call to DUPR from the error detecting coding.

DUPR - DUPR is called from DIPR. It dumps the MARS array tables from memory and the nesting table of the current particle location. It generates quite a bit of output and should not be called frequently during debugging. The argument IXD in DUPR can suppress much of the geometry dump to allow frequent printouts of the nesting array during model debugging.

NUREG/CR-0200, 
FINEFI - FINEFI is called from AZIP. It checks the MARS array input with the combinatorial input for snug fit. Most of the MARS input error messages regarding array content, reference, or fit comes from FINEFI. It is essential to have exact geometry fits before successful tracking can be initiated.

GENI - GENI is called from JOMIN2. It reads the binary file generated by JOMIN1 and stores the data into memory in the combinatorial geometry array tables. It edits and prints the output edit of the combinatorial input.

GG - GG is called from LOOKZ and G1. It is the guts and essence of the combinatorial geometry system. It computes, given the body number, the RIN and ROUT for the body.

GTVLIN - GTVLIN is called from JOMIN2 to calculate input zone volumes. The present version of GTVLIN is next to useless and is normally never used.

G1 - G1 is called from PILOT to determine the next input zone a particle may enter. It is in three parts. The first part of G1 determines the distance to exit the present zone if the zone will be exited. The second part of G1 determines the next zone of entry by checking those previous zones the particles entered when exiting the current zone by way of the body causing the particle to exit. If a new zone of entry is not determined from this table, then the third part of G1 proceeds to check all other possible zones of entry in the current universe. Errors in combinatorial geometry tracking come from G1.

IPACK - IPACK is called from JOMIN1 to pack several integers into one integer.

JOMIN1 - JOMIN1 reads the free-form combinatorial input for the body data, zone description data, region data, universe data, and media data. The input is written on a scratch file for later use by GENI.

JOMIN2 - JOMIN2 is called during combinatorial geometry input processing. It sets up the combinatorial geometry array pointers from information determined by JOMIN1. It then calls GENI, and the input data are stored in the proper arrays. JOMIN2 can call GTVLIN but usually does not.

LEVEL - LEVEL is called from AZIP. It determines the highest level number each array is referenced inside. These data are placed in the NLV table for later use in AZIP. The NLV table is not used for tracking or locating a particle.

LOOKZ - LOOKZ is called from CALI and PILOT to determine the particle location in a universe. It calls GG to determine RIN and ROUT for each body in a zone description table. It then determines the code and input zone the particle is inside. This information is returned in labeled common PAREM.

ORTHOM - ORTHOM is called from AZIP. It computes the rotational matrices of each BOX body, which references either an array or a universe. A BOX can be arbitrarily positioned in space. When a particle enters a universe or an array and when the reference body is a BOX, then both the 
particle coordinates and direction cosines must be rotated. Subroutine ROTA is the only routine that makes use of these matrices constructed by ORTHOM.

PILOT - PILOT is called from outside the MARS subroutine module to determine the next input zone a particle may enter. The first zone the particle enters with a positive media number is retumed. PILOT cannot be called without first knowing the particle location as determined by calling CALI.

PR - PR is called from combinatorial geometry errors discovered in LOOKZ or G1. It generates even more output.

RESTOR - RESTOR is called by JOMIN when RINPU2 calls JOMIN. When executed in SCALE, the geometry and array data are written out on a binary file for later recovery. RESTOR reads labeled commons REPEAT, ARAR, GOMLOC, and PAREM. It also reads the MA, FPD arrays and all of the MARS array storage from the binary file. The file read by RESTOR is written by RINPUP in the SAS3 control module in SCALE or by RINPU1 in MORSE-SGC.

RISK - RISK translates coordinates defined on geometry level NL1 to geometry level NL2 using the nesting table stored in array LP. This translation is from a global coordinate to a local coordinate system. NL2 must be greater than NL1.

ROTA - ROTA performs particle and direction cosine rotation upon entering or exiting a coordinate system defined by a BOX reference body. It is called from TRENTE and RTEXIT. It uses the rotational matrices constructed by ORTHOM during input processing.

RTEXIT - RTEXIT is called on exiting either a universe or an array. The "RT" means rotate, then translate. The rotation must be performed first, and then the translation can occur. RTEXIT is given the reference body for the universe or the array. If the body is an RPP, only translation of coordinates is required. If the body is a BOX, then both rotation and translation are required.

SAZAR - SAZAR is called by JOMIN if NDSN, the number of array analysis collision edits (input in MORSE-SGC) required, is $>0$. SAZAR reads the location, media, and response criteria for each edit. This allows the user to selectively sample specific collisions.

SKPBLK - SKPBLK is called from JOMIN1 to skip blanks while reading free-form input cards.

SORCER - SORCER is called after completion of a batch of histories. It sorts the next zone of entry table in the order of most probable entry. This is a simple, fast routine used to speed up tracking through a complex geometry model.

SORT - SORT is called from CELL. It is called for each dimension of an array. It determines the cell position on each dimension for the particle location. It determines when a particle is exiting an array lattice and sets a flag for CELL to take appropriate action.

NUREG/CR-0200, 
STORA - STORA is called from CALI and PILOT. It updates the nesting table during array tracking and locating. This is one of the most important aspects of array nesting logic. It is essential to the MARS logic.

TRENTE - TRENTE is called on entering either a universe or an array. The "TR" means translate, then rotate. The translation of the particle coordinate must occur and then the rotation. TRENTE is the opposite of RTEXIT. It requires the reference body of the universe or the array to determine the appropriate coordinate transformation.

UNIS - UNIS is called by AZIP to read, to verify, and to edit the universe type input. If a universe is erroneously declared simple, UNIS changes the universe type specification to combinatorial and writes warnings to the user.

ZEXITS - ZEXITS is called to dump the combinatorial summary of zone transfers at the end of a calculation. In MORSE-SGC, it is called by NRUN.

Table M9.E.1 MARS Subroutine

Model

\begin{tabular}{llll}
\hline \multicolumn{2}{c}{ Input routines } & \multicolumn{2}{c}{ Tracking routines } \\
\hline Combinatorial & MARS array input & Combinatorial & MARS array tracking \\
\hline JOMIN1 & AZIP & LOOKZ & CALI \\
JOMIN2 & LEVEL & G1 & PILOT \\
GENI & ARGEN & GG & CELL \\
ABOX & DELTA & PR & SORT \\
GTVLIN & ORTHOM & SORCER & BOD \\
& FINEFI & ZEXITS & ROTA \\
& UNIS & ALBERT & CORNER \\
& SAZAR & NORML & RTEXIT \\
& & & TRENTE \\
& & & CTRAN \\
& & & STORA \\
& & & CLEV \\
& & & RISK \\
& & & DIPR \\
& & & DUPR \\
\hline
\end{tabular}




\begin{tabular}{|c|c|c|c|}
\hline $\begin{array}{l}\text { Address } \\
\text { pointer }\end{array}$ & $\begin{array}{l}\text { Array } \\
\text { name }\end{array}$ & Length of the array & Description \\
\hline IP(NP) & NLV & NAR & $\begin{array}{l}\text { Largest level each array is referenced inside; } \\
\text { there are NAR arrays in a model }\end{array}$ \\
\hline $\mathrm{IP}(\mathrm{NP}+1)$ & WLH & 3*NAR & $\begin{array}{l}\text { The width on } X \text {, the length on } Y \text {, and the } \\
\text { height on } Z \text { of each array }\end{array}$ \\
\hline $\mathrm{IP}(\mathrm{NP}+2)$ & - & INACTIVE & - \\
\hline $\mathrm{IP}(\mathrm{NP}+3)$ & NCMAX & $3 * \mathrm{NAR}$ & $\begin{array}{l}\text { The size of each array lattice NXMAX, by } \\
\text { NYMAX, by NZMAX, }\end{array}$ \\
\hline $\mathrm{IP}(\mathrm{NP}+4)$ & NI4 & NAR & $\begin{array}{l}\text { Pointer for the array content description for } \\
\text { each array }\end{array}$ \\
\hline $\mathrm{IP}(\mathrm{NP}+5)$ & NBN & $\sum_{j=1}^{N A R} N X M A X_{j} * N Y M A X_{j} * N Z M A X_{j}$ & $\begin{array}{l}\text { Lattice cell content for each array as pointed } \\
\text { to by NI4 }\end{array}$ \\
\hline $\mathrm{IP}(\mathrm{NP}+6)$ & NBOD & IBOD & $\begin{array}{l}\text { Body No. that defines each universe; there } \\
\text { are IBOD universes }\end{array}$ \\
\hline $\mathrm{IP}(\mathrm{NP}+7)$ & NCN & NAR*3 & $\begin{array}{l}\text { Address for the cell boundaries for each } \\
\text { array in each dimension }\end{array}$ \\
\hline $\mathrm{IP}(\mathrm{NP}+8)$ & RBY & $\sum_{j=1}^{N A R} N X M A A X_{j}+N Y M A X_{j}+N Z M A X_{j}+3$ & $\begin{array}{l}\text { The lattice cell boundary for each array as } \\
\text { pointed to by NCN }\end{array}$ \\
\hline $\mathrm{IP}(\mathrm{NP}+9)$ & NBA & NUMB & $\begin{array}{l}\text { Address for BOX rotation matrices for all } \\
\text { BOX bodies that reference either arrays or } \\
\text { universes }\end{array}$ \\
\hline $\mathrm{IP}(\mathrm{NP}+10)$ & ORT & NF & Rotation matrices as pointed to by NBA \\
\hline IP(NP+11) & LP & $6 * \mathrm{NLEV}+4$ & Particle nesting table for tracking \\
\hline
\end{tabular}

NUREG/CR-0200,

Vol. 3, Rev. 4

M9.E.6 
Table M9.E.3. Layout of combinatorial geometry data in blank common

\begin{tabular}{|c|c|c|}
\hline Starting location & Information & Size \\
\hline $\mathrm{NGEOM}=\mathrm{NADD}$ & Length of geometry array & 1 \\
\hline KFPD & MA - Integer array & LTMA \\
\hline KLCR & FPD - Floating point array & LFPD \\
\hline KNBD & $\begin{array}{l}\text { LOCREG - Indices to correlate MA array data with } \\
\text { code zone data }\end{array}$ & NUMR \\
\hline KIOR & NUMBOD - Number of bodies for each code zone & NUMR \\
\hline KRIZ & IROR - Indices to correlate input zone to code zone & NUMR \\
\hline $\mathrm{KRCZ}$ & $\begin{array}{l}\text { MRIZ - Indices to correlate MORSE region to input } \\
\text { zone }\end{array}$ & IRTRU \\
\hline KMIZ & $\begin{array}{l}\text { MRCZ - Indices to correlate MORSE region to code } \\
\text { zone }\end{array}$ & NUMR \\
\hline $\mathrm{KMCZ}$ & $\begin{array}{l}\text { NMIZ - Indices to correlate MORSE media to input } \\
\text { zone }\end{array}$ & IRTRU \\
\hline KKR1 & $\begin{array}{l}\text { NMCZ - Indices to correlate MORSE media to code } \\
\text { zone }\end{array}$ & NUMR \\
\hline KKR2 & $\begin{array}{l}\text { KR1 - Indices to correlate first code zone to input } \\
\text { zone }\end{array}$ & IRTRU \\
\hline KNSR & $\begin{array}{l}\text { KR2 - Indices to correlate last code zone to input } \\
\text { zone }\end{array}$ & IRTRU \\
\hline \multirow[t]{2}{*}{ KVOL } & $\begin{array}{l}\text { NSOR - Indices of code zones in which source } \\
\text { particles have been found }\end{array}$ & NUMR \\
\hline & VNOR - Volume of each MORSE region & NIR \\
\hline $\operatorname{IP}(1)$ & Array storage for MARS & $\mathrm{IP}(12)-\mathrm{IP}(1)$ \\
\hline
\end{tabular}


Table M9.E.4. Detailed layout of the FPD array in Blank Common ${ }^{a}$

\begin{tabular}{|c|c|c|c|}
\hline $\begin{array}{l}\text { Position in } \\
\text { Blank Common }\end{array}$ & Information stored & Size & Description \\
\hline KFPD & RIN for Body 1 & 1 & $\begin{array}{l}\text { Path length data for last } \\
\text { traiectory in Body } 1\end{array}$ \\
\hline $\mathrm{KFPD}+1$ & ROUT for Body 1 & 1 & \\
\hline KFPD +2 & $\begin{array}{l}\text { First six words of real data for } \\
\text { Body } 1\end{array}$ & 6 & $\begin{array}{l}\text { Read from first card of } \\
\text { Body } 1 \text { card set }\end{array}$ \\
\hline $\mathrm{KFPD}+8$ & $\begin{array}{l}\text { Remaining words of real data } \\
\text { for Body } 1\end{array}$ & $\mathbf{N}_{1}$ & $\begin{array}{l}N_{1} \text { depends on body type } \\
\text { (see Table } 4.3 \text { ) }\end{array}$ \\
\hline \multirow[t]{3}{*}{$\mathrm{KFPD}+8+\mathrm{N}$} & RIN for Body 2 & 1 & \\
\hline & ROUT for Body 2 & 1 & $\begin{array}{l}\text { Same information as } \\
\text { above but for Body } 2\end{array}$ \\
\hline & $\begin{array}{l}\text { Remaining data for Body } 2 \text { ( } \mathrm{n}_{2} \\
\text { words) } \\
\text { Repeat for NUMB bodies }\end{array}$ & $\mathbf{N}_{2}$ & \\
\hline
\end{tabular}

${ }^{a}$ NOTE: Eight words are set aside at the end of the FPD array but are not used. 


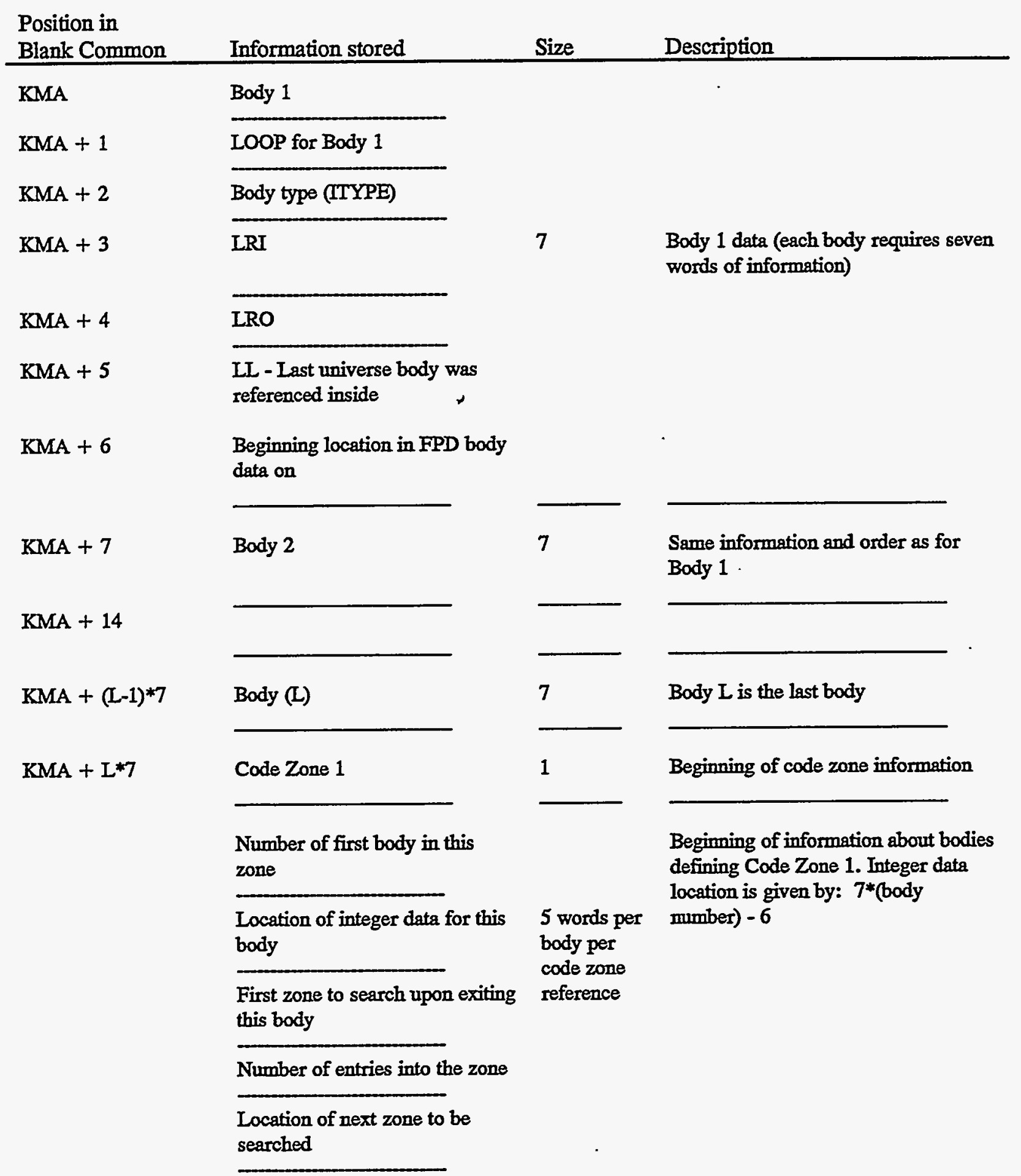

NUREG/CR-0200, 
Table M9.E.5 (continued)

\begin{tabular}{|c|c|c|c|}
\hline $\begin{array}{l}\text { Position in } \\
\text { Blank Common }\end{array}$ & Information stored & Size & Description \\
\hline & $\begin{array}{l}\text { Data on second body in this } \\
\text { zone }\end{array}$ & 5 & $\begin{array}{l}\text { The last three words in each set } \\
\text { of body data initiate the "leap } \\
\text { frog" process by which the code } \\
\text { stores possible zones which can } \\
\text { be entered upon exiting this body } \\
\text { in that particular zone. These } \\
\text { zones are checked by the code } \\
\text { when the next zone entered is } \\
\text { being determined. If the next } \\
\text { zone is not located from this }\end{array}$ \\
\hline & $\begin{array}{l}\text { Data on last body is the } \\
\text { zone }\end{array}$ & 5 & $\begin{array}{l}\text { stored data, all zones are } \\
\text { searched. }\end{array}$ \\
\hline & Zone 2 & 1 & \\
\hline & Body information & & except for Code Zone 2 \\
\hline & Zone data of the last zone & & $\begin{array}{l}\text { Code zone information about the } \\
\text { last zone input on cards }\end{array}$ \\
\hline $\mathrm{KMA}+\mathrm{LDATA}$ & $\begin{array}{l}\text { Code search information } \\
\text { KMA + LTMA - } 1\end{array}$ & $2 * \mathrm{NAZT}$ & $\begin{array}{l}\text { Storage set aside for determining } \\
\text { the zone to be searched and } \\
\text { where the next zone number is } \\
\text { located }\end{array}$ \\
\hline
\end{tabular}

NUREG/CR-0200,

Vol. 3, Rev. 4

M9.E.10 
Table M9.E.6 Definitions of variables in common GOMLOC

\begin{tabular}{|c|c|}
\hline Variable & Definition \\
\hline KMA & Starting location for the array MA containing integer data for each code zone \\
\hline KFPD & Starting location for the array FPD containing real data for each code zone \\
\hline $\mathrm{KLCR}$ & $\begin{array}{l}\text { Starting location for the array LOCREG(I) that contains the starting location in the MA array for the Ith } \\
\text { code zone data }\end{array}$ \\
\hline KNBD & Starting location for the array NUMBOD(I) that contains the number of bodies for the Ith code zone \\
\hline KIOR & $\begin{array}{l}\text { Starting location for the array IROR(I) that contains the index of the corresponding input zone for the Ith } \\
\text { code zone }\end{array}$ \\
\hline KRIZ & $\begin{array}{l}\text { Starting location for the array MIRZ(I) that contains the index of the MORSE region corresponding to the } \\
\text { Ith geometry input zone }\end{array}$ \\
\hline $\mathrm{KRCZ}$ & $\begin{array}{l}\text { Starting location for the array MRCZ(I) that contains the index of the MORSE region corresponding to the } \\
\text { Ith geometry code zone }\end{array}$ \\
\hline KMIZ & $\begin{array}{l}\text { Starting location for the array MMIZ(I) that contains the index of the MORSE media corresponding to the } \\
\text { Ith geometry input zone }\end{array}$ \\
\hline KMCZ & $\begin{array}{l}\text { Starting location for the array MMCZ(I) that contains the index of the MORSE media corresponding to the } \\
\text { Ith code zone }\end{array}$ \\
\hline KKR1 & $\begin{array}{l}\text { Starting location for the array KR1(L) contains the first code zone which was made from the Lth input } \\
\text { zone }\end{array}$ \\
\hline KKR2 & Starting location for the array KR2(L) contains the last code zone which was made from the $L$ th input zone \\
\hline KNSR & Starting location for array NSOR that contains the code zones in which source particles have been found \\
\hline KVOL & Starting location for the array VNOR(I) which contains the volume for MORSE region (I) \\
\hline NADD & $\begin{array}{l}\text { Starting location for the geometry data and changed in JOMIN2 to the total number of words required for } \\
\text { geometry data }\end{array}$ \\
\hline LDATA & Length of the integer data in the MA array excluding the words set aside for zone search information \\
\hline LTMA & Total length of the MA array \\
\hline LFPD & Length of the FPD array \\
\hline NUMR & Number of code-produced zones \\
\hline IRTRU & Number of input zones \\
\hline NUMB & Number of bodies \\
\hline NIR & Number of MORSE geometry regions \\
\hline
\end{tabular}


Table M9.E.7 Definitions of variables in common PAREM as found in combinatorial geometry

\begin{tabular}{|c|c|}
\hline Variable & Definition \\
\hline $\mathrm{XB}(3)$ & Coordinates of the starting point of the present path. Changed in EUCLID, GOMST, and LOOKZ \\
\hline WB(3) & $\begin{array}{l}\text { Direction cosines of particle trajectory. Equal to U, V, and W. Changed in EUCLID, GOMST, } \\
\text { and LOOKZ }\end{array}$ \\
\hline WP(3) & Temporary storage of WB(3) \\
\hline $\mathrm{XP}(3)$ & Temporary storage of XB(3). Changed in NORML \\
\hline RIN & Distance to entry calculated in $G G$ \\
\hline ROUT & Distance to exit calculated in GG \\
\hline PINF & Machine infinity $(1.0 \mathrm{E}+20)$ \\
\hline DIST & Distance from $\mathrm{XB}(3)$ to present point \\
\hline $\mathbf{I R}$ & Combinatorial zone of present particle position \\
\hline IDBG & Set nonzero to initialize a debug printout \\
\hline IRPRIM & Next region to be entered after a call of $\mathrm{G} 1$ \\
\hline NASC & $\begin{array}{l}\text { Body number of last calculated intersection. Set negative to indicate source or collision point not on } \\
\text { a body surface }\end{array}$ \\
\hline LSURF & $\begin{array}{l}\text { Surface of body NASC where intersection occurred. Positive if particle is entering the body and } \\
\text { negative when exiting }\end{array}$ \\
\hline NBO & $\begin{array}{l}\text { Body mumber and a sign used to define zones. Input in zone description as positive when zone is } \\
\text { contained in body and as negative if zone is outside body }\end{array}$ \\
\hline LRI & Entry surface calculated in GG \\
\hline LRO & Exit surface calculated in GG \\
\hline KLOOP & Trajectory index of present path incremented in $G 1$ \\
\hline LOOP & $\begin{array}{l}\text { Index of last trajectory calculated for body NBO. If LOOP is equal to KLOOP, GG returns } \\
\text { immediately with old vahues in RIN, ROUT, LRI, and LRO }\end{array}$ \\
\hline ITYPE & Body type of Body NBO (indicated BOX, SPH, etc.) \\
\hline NOA & Not used \\
\hline
\end{tabular}

NUREG/CR-0200,

Vol. 3, Rev. 4

M9.E.12 
Table M9.E.8 Definitions of variables in common ORGI

\begin{tabular}{|c|c|}
\hline Variable & Definition \\
\hline DISTO & $\begin{array}{l}\text { Distance from point } \mathrm{XB}(3) \text { to next scattering point. Used in } \mathrm{Gl} \text { to avoid calculating } \\
\text { the next zone if a scattering event occurs before the intersection }\end{array}$ \\
\hline MARKG & $\begin{array}{l}\text { Set } 1 \text { in G1 if trajectory end point is reached before next intersection. Otherwise set } \\
\text { to } 0\end{array}$ \\
\hline NMEDG & Input zone number for current collision from a LOOKZ call \\
\hline NBLZ & $\begin{array}{l}\text { Packed word containing both input zone and code zone numbers for current collision } \\
\text { stored in LOOKZ }\end{array}$ \\
\hline BLZOLD & Packed word containing code and input zone numbers for previous collisions \\
\hline IRPOLD & Input zone number for previous collision \\
\hline
\end{tabular}

'Variable names are not the same in all routines. Also, on non-IBM-360 machines, the order of the variables is MARK, DIST, NMEDG. Reordering resulted from the conversion of the IBM- 360 version to double precision.

Table M9.E.9 Definitions of variables in common TAPE

\begin{tabular}{ll}
\hline Variable name & \multicolumn{1}{c}{ Definition } \\
\hline INT & Logical number of standard input unit \\
IOT & Logical number of standard output unit \\
IOUT & $\begin{array}{l}\text { Logical number of scratch unit for geometry } \\
\text { data }\end{array}$ \\
IOU2 & Logical number of second scratch unit \\
IDM(4) & Not used at present \\
\hline
\end{tabular}


Table M9.E.10 Definitions of variables in common MGOMV

\begin{tabular}{ll}
\hline Variable & \multicolumn{1}{c}{ Definition } \\
\hline MUS & Pointer for array indicating type of universe - simple or comjom \\
MUZ & Pointer for array indicating last zone for a given universe \\
LI & Current universe number \\
IPRET & $\begin{array}{l}\text { Signal - when }=1 \text { PILOT returns at every boundary crossing rather than } \\
\text { tracking until media changes }\end{array}$ \\
IFLOW & Signal indicating direction of crossing. Inward if $=0$, outward if $=1$ \\
IECT & $\begin{array}{l}\text { Error counter - prints messages first } 10 \text { times. MORSE-SGC abends on error } \\
\text { number } 11\end{array}$ \\
NLO & $\begin{array}{l}\text { Signal when changing levels - } \\
=0 \text { means same level } \\
=-1 \text { means down one level } \\
=+1 \text { means up one level }\end{array}$ \\
& $\begin{array}{l}\text { Signal indicating entry to array if } 0, \text { or exit from array if } 1 \\
\text { IGX }\end{array}$
\end{tabular}

NUREG/CR-0200,

Vol. 3, Rev. 4 
Table M9.E.11 Definitions of variables in common ARAR

\begin{tabular}{ll}
\hline Variable & \multicolumn{1}{c}{ Definition } \\
\hline NBY & Body number \\
NLEV & Number of geometry levels \\
NAR & Number of arrays \\
NQ & $=1$ for MORSE \\
IAW & Number of universes \\
IAY & Length of lattice cell array \\
NF & $\begin{array}{l}\text { Maximum size of array } \\
\text { lattice }\end{array}$ \\
NX1(1) & Current $x$ lattice position \\
NX1(2) & Current $y$ lattice position \\
NX1(3) & Current $z$ lattice position \\
& NX1(1-3) = 0 if outside of \\
\hline
\end{tabular}

Table M9.E.12 Definitions of variables in common ARK

\begin{tabular}{ll}
\hline $\begin{array}{l}\text { Variable } \\
\text { LM }\end{array}$ & \begin{tabular}{l}
\multicolumn{1}{c}{ Definition } \\
Content of lattice position of current array $>0$ for a \\
universe; $<0$ for an array
\end{tabular} \\
NLU & $\begin{array}{l}\text { Current array number } \\
\text { NBB }\end{array}$ \\
NZY(1-3) & $\begin{array}{l}\text { Reference body for current array } \\
\text { position) }\end{array}$ \\
$\mathrm{XD}(1-3)$ & Current $\mathrm{X}, \mathrm{Y}, \mathrm{Z}$ of particle \\
\hline
\end{tabular}




\section{M9.F COMBINATORIAL GEOMETRY TRACKING}

\section{M9.F.1. COMJOM TRACKING THEORY}

Tracking a particle in MARS consists of:

1. determining the array, universe, and code zone in which a point is located,

2. finding the distance along a given direction to the exit point from this code zone,

3. determining the next code zone the ray will enter in the same universe, and

4. finding the distance to the exit point of this code zone.

This process is continued until the next collision point is encountered, the particle leaks from the system, or an albedo surface is encountered.

Given a starting point $(x, y, z)$ a direction (specified by direction cosines $u, v$, and $w$ ) and a body (one of the basic geometric shapes mentioned earlier), the basic tracking Subroutine GG in the combinatorial geometry package will determine whether the ray from the starting point and the specified direction will intersect the given body. If it does, the subroutine will calculate RIN, the distance to the entry point into the body, and ROUT, the distance to the exit point from the body. A number of orientations are possible:

1. The ray starts at a point outside the body and intersects the body in the positive direction.

ORML Drg. 79-7906

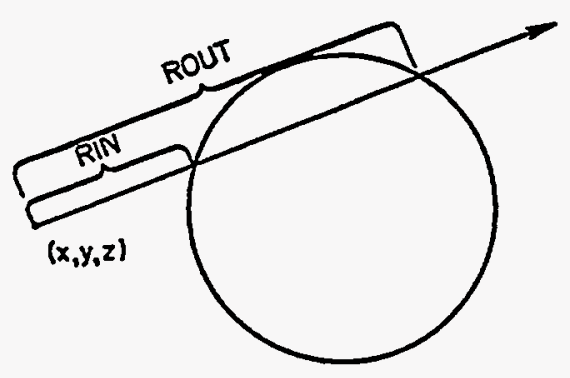

In this case, ROUT $\geq$ RIN $>0$. (ROUT) may equal RIN if the ray grazes the body. 
2. The ray starts at a point outside the body and intersects the body in the negative direction.

ORNL Dwo. 79-7907

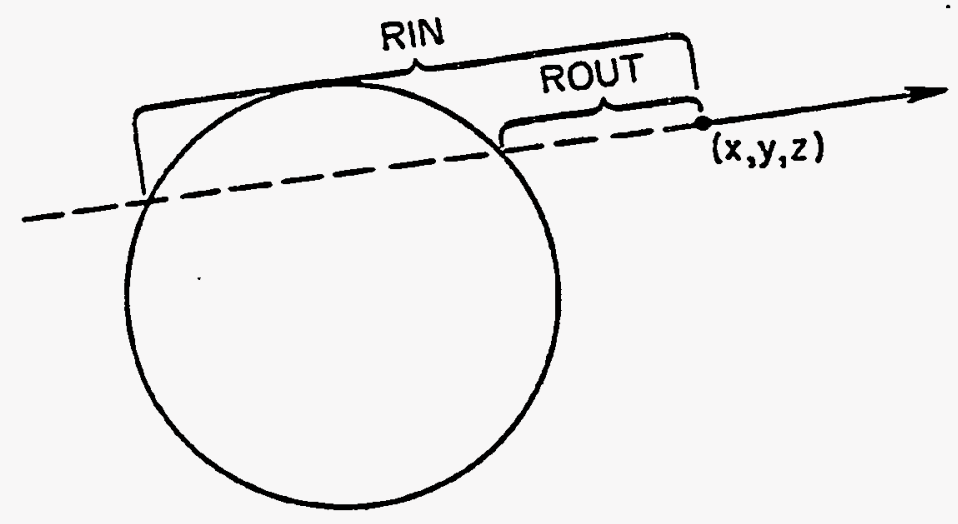

In this case, $0>$ ROUT $\geq$ RIN.

3. The ray starts at a point inside the body.

ORNL Dwg . 79-7908

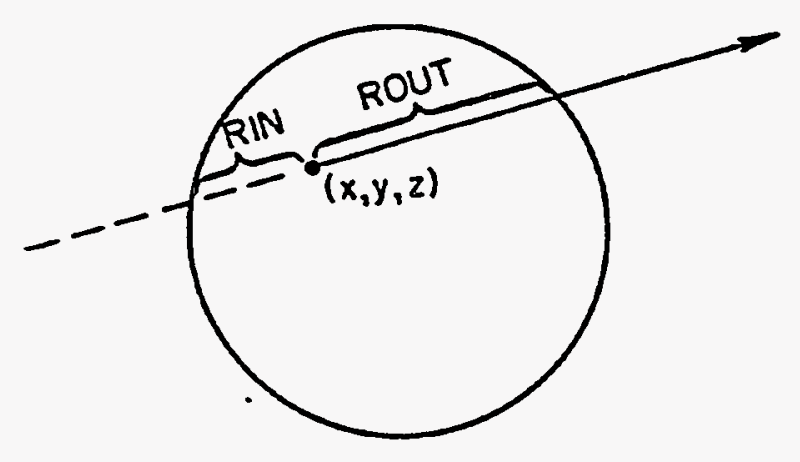

In this case, ROUT $>0>$ RIN.

NUREG/CR-0200,

Vol. 3, Rev. 4

M9.F.2 
4. The ray misses the body.

ORNL Dwg. 79-7909

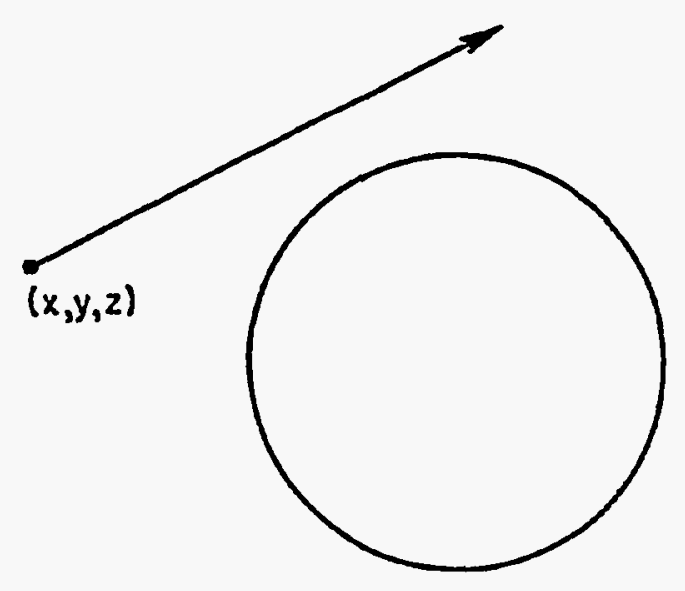

In this case, ROUT is set equal to -PINF, and RIN is usually set equal to PINF, where PINF is a large number (the computer's approximation of infinity).

To demonstrate how tracking is performed, as shown in Fig. M9.F.1, consider the following description:

\section{Bodies}

1. RPP $-1.0 \leqslant x \leqslant 0.5,-1.0 \leqslant y \leqslant 1.0,-1.0 \leqslant z \leqslant 1.0$

2. RPP $-0.5 \leqslant x \leqslant 1.0,-1.0 \leqslant y \leqslant 1.0,-1.0 \leqslant z \leqslant 1.0$

3. RPP $-2.0 \leqslant x \leqslant 2.0,-2.0 \leqslant y \leqslant 2.0,-2.0 \leqslant z \leqslant 2.0$

4. RPP $-3.0 \leqslant x \leqslant 3.0,-3.0 \leqslant y \leqslant 3.0,-3.0 \leqslant z \leqslant 3.0$

\section{Input Zones}

1. $1-2$, media 1 , region 1

2. $2+1$. media 2, region 1

3. $-1+2$, media 3, region 1

4. $3-1-2$, media 1000 , region 1

5. $4,-3$, media 0 , region 1 
ORNL Dwg. 79-7910

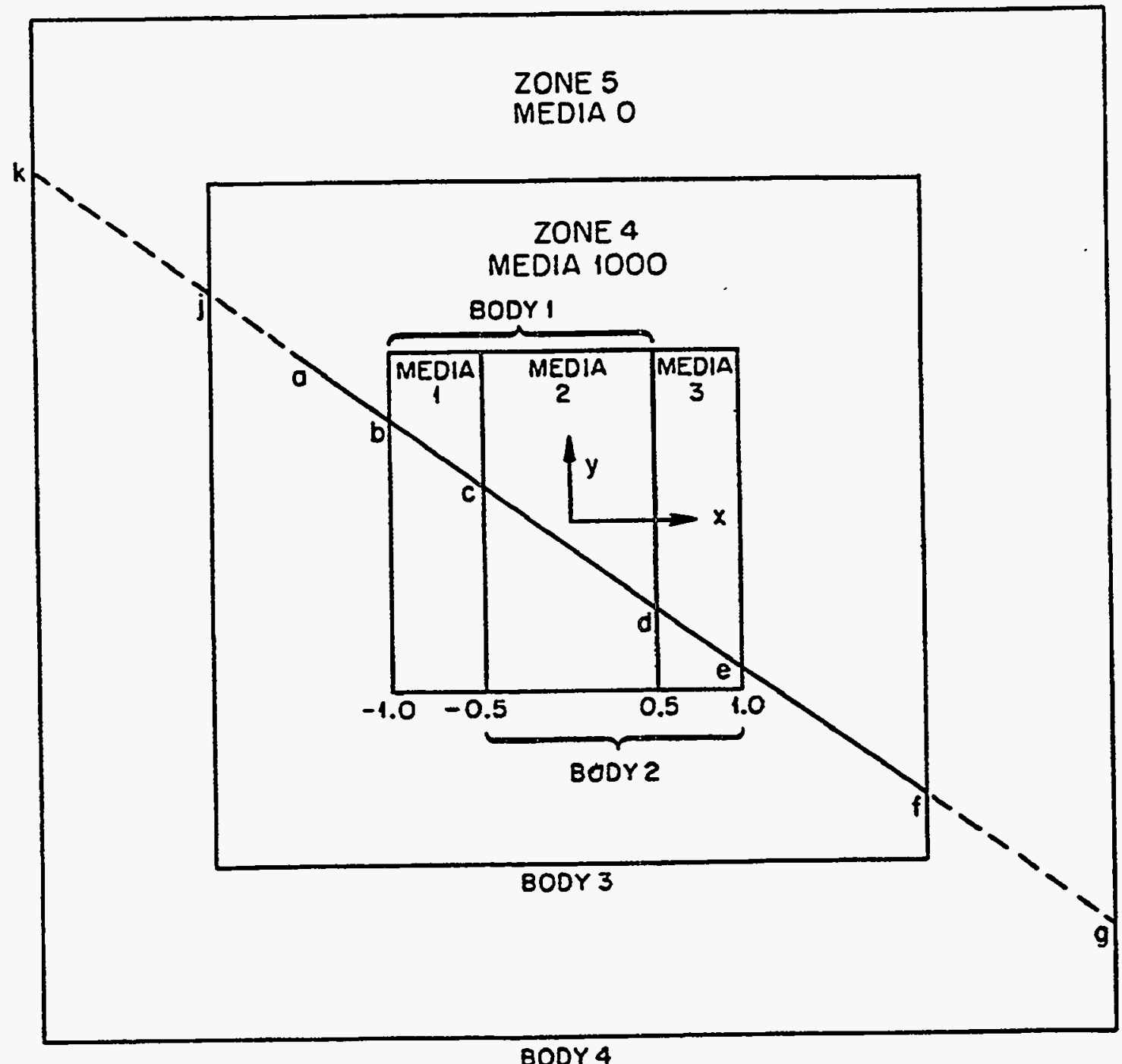

Figure M9.F.1 A simple demonstration of particle tracking

NUREG/CR-0200,

Vol. 3, Rev. 4 
Since all input zones in this example are described without OR operators, the input zones and code zones will be the same. Let ' $a$ ' be the starting point $(-1.5,1.0,0.0)$ with direction cosines $(.8,-.6,0)$.

The determination of the location of the starting point is made by attempting to calculate an exit distance for each code zone. If a valid distance is found for a code zone, then the point is in that code zone. The code zones are initially examined in the order of their description.

To see if the starting point is in Code Zone 1, the bodies in the zone are tested. Body 1 is the first body in Zone 1. RIN and ROUT for Body 1 are calculated giving

$$
\mathrm{RIN}=.625, \mathrm{ROUT}=2.5
$$

Since RIN > 0, the point is not in Body 1 and therefore cannot be in Zone 1 . The next body in Zone 1 does not need to be checked. To check Zone 2, the first body is Body 2. (The bodies are checked in the order given in the input description.) RIN and ROUT for Body 2 are calculated giving

$$
\mathrm{RIN}=1.25, \mathrm{ROUT}=3.125 \text {. }
$$

Again, RIN $>0$, and the point is not in Body 2 and cannot be in Zone 2. To check Zone 3, the first body is Body -1 . RIN and ROUT are retrieved for Body 1 giving

$$
\mathrm{RIN}=.625, \mathrm{ROUT}=2.5
$$

Since RIN $>0$, the point is not in Body 1 and therefore is in Body -1 . The next body in Zone 3 must then be checked. The data for Body 2 are retrieved giving

$$
\mathrm{RIN}=1.25, \mathrm{ROUT}=3.125 \text {. }
$$

Since RIN > 0, the point is not in Body 2 and is not in Zone 3. To check Zone 4, the first body is Body 3. RIN and ROUT for Body 3 are calculated giving

$$
\mathrm{RIN}=.625, \mathrm{ROUT}=4.375
$$

Since RIN $<0$ and ROUT $>0$, the point is in Body 3. The next body in Zone 4 is Body -1 . RIN and ROUT are retrieved for Body 1 giving

$$
\mathrm{RIN}=.625, \mathrm{ROUT}=2.5
$$

Since RIN > 0, the point is not in Body 1 and therefore is in Body -1 . The next body in Zone 4 is Body -2 . RIN and ROUT are retrieved for Body 2 by giving

RIN $=1.25$, ROUT $=3.125$

Since RIN > 0 , the point is not in Body 2 and therefore is in Body -2 . The point is in all the bodies in Zone 4 and therefore is in Zone 4.

NUREG/CR-0200, 
At the same time that the RINs and ROUTs are checked to see if the point is in the various bodies of a zone, the exit distance, DIST, is also calculated. The exit distance from the zone is the smallest of the distances to leave Body 3 (ROUT $=4.375$ ); to enter Body $1(\mathrm{RIN}=.625$ ), or to enter Body 2 (RIN $=1.25$ ); therefore,

$$
\text { DIST }=.625 \text {. }
$$

Once the exit distance for a given zone is found, the number of mean-free paths that the particle travels in the zone is calculated to see if a collision occurs in the zone, and if so, at what point. The total number of mean-free paths traveled to the next collision point will have previously been selected. For this example, it will be assumed that the number of mean-free paths selected is large enough so that a collision will not occur, and the particle will leak from the system.

The next step then is to determine which code zone the particle enters next. Zone 1 will be checked first. The first body in Zone 1 is Body 1. RIN and ROUT are retrieved for Body 1 giving

$$
\text { RIN }=.625, \text { ROUT }=2.5
$$

If the particle is to be in (or enter) Body 1 after traveling this far, then DIST 2 RIN and DIST < ROUT. Since DIST $=$ RIN $=.625$ and DIST $=$ RIN $<$ ROUT, the tests are passed and the particle has entered the Body 1. The next body in the zone is Body -2 . RIN and ROUT are retrieved for Body 2 giving

$$
\mathrm{RIN}=1.25, \text { ROUT }=3.125 \text {. }
$$

If the particle is to be in Body -2 (not in Body 2), then either DIST $<$ RIN or DIST $\geq$ ROUT. Since DIST < RIN, the particle is in Body -2 . The particle has therefore entered Zone 1.

The exit distance from Zone 1 is found next by picking the smallest of the ROUTs for the positive bodies and the RINs of the bodies which are negative. For Body 1 ROUT $=2.5$, and for Body 2 (which is negative in the zone) RIN $=1.25$. Therefore, the exit distance from Zone 1 is

$$
\text { DIST }=1.25 \text {. }
$$

The total distance in mean-free paths is again calculated and compared against the predetermined number of mean-free paths which the particle is to travel to see if a collision occurs in Zone 1. If not, then tracking continues as above to determine the next zone the particle enters and the exit distance from that zone. When the particle reaches Zone 5 , the medium number of 0 is used as a flag to indicate that the particle has leaked, and the tracking can be terminated. If a collision occurs, then the weight of the particle will be multiplied by the nonabsorption probability, a new energy is selected, a new direction is selected, etc. The tracking of the particle then continues from this point in the new direction if it has not been killed by some process such as Russian roulette or an energy cutoff (where the particle has scattered down to an energy range that is not of interest in the problem). If an albedo surface is encountered during tracking (this is determined by specifying a special medium number to indicate an albedo surface), then a problem-dependent subroutine will be called which will specify the new particle parameter needed for continuation of the tracking.

NUREG/CR-0200,

Vol. 3, Rev. 4

M9.F.6 


\section{M9.G DIAGNOSTIC MESSAGES FROM MARS}

Numerous error messages are printed out by the MARS geometry package. These messages aid the user in determining the cause of the trouble when an error is detected by MARS during the input step or during particle tracking. Sections M9.G.1 and M9.G.2 give the actual message that is printed, the subroutine name where the error was detected, and an explanation of the message and/or its cause.

\section{M9.G.1 DIAGNOSTIC MESSAGES FROM MARS INPUT MODULE}

\begin{tabular}{|c|c|c|}
\hline $\begin{array}{l}\text { Subroutine } \\
\text { printing } \\
\text { message }\end{array}$ & Message & Meaning \\
\hline ARGEN & $\begin{array}{l}\text { ARRAY NO IS IMPROPERLY DEFINED - } \\
\text { FATAL ERROR IN ARGEN }\end{array}$ & $\begin{array}{l}\text { The array size exceeds the size of the array } \\
\text { lattice (NCMAX) }\end{array}$ \\
\hline ARGEN & $\begin{array}{l}\mathrm{ARGEN} I X Y=-I X=-M R=-N A=\ldots \mathrm{NE}= \\
-\mathrm{NMAX}=-\end{array}$ & $\begin{array}{l}\text { Error was detected in DELTA. See } \\
\text { message from DELTA. }\end{array}$ \\
\hline AZIP & $\begin{array}{l}\text { FATAL ERROR - UNIVERSE NO. _ IS NOT } \\
\text { DEFINED }\end{array}$ & $\begin{array}{l}\text { Either the universe number is incorrect or } \\
\text { the media number is not }-1000 \text {. }\end{array}$ \\
\hline DELTA & 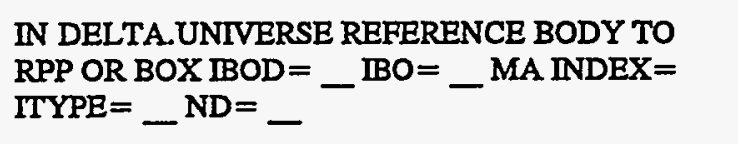 & $\begin{array}{l}\text { Self-explanatory. Check the input data. } \\
\text { IBO is body number. }\end{array}$ \\
\hline FINEFI & $\begin{array}{l}\text { WARNING - IN FINEFI NO REFERENCE WAS } \\
\text { MADE TO ARRAY NO. - }\end{array}$ & $\begin{array}{l}\text { One of the arrays specified is not } \\
\text { referenced. }\end{array}$ \\
\hline FINEFI & $\begin{array}{l}\text { IN FINEFI INVALID ARRAY REFERENCE IN } \\
\text { ARRAY _ POSITION — TO NONEXISTENT } \\
\text { ARRAY_- }\end{array}$ & Array number exceeds maximum (NAR). \\
\hline FINEFI & $\begin{array}{l}\text { FINEFI FATAL ERROR - ARRAY POSITION } \\
\text { REFERS TO AN INVALID OR UNDEFINED } \\
\text { UNIVERSE - }\end{array}$ & $\begin{array}{l}\text { Universe number exceeds number of } \\
\text { universes (IBOD) in system. }\end{array}$ \\
\hline FINEFI & $\begin{array}{l}\text { IN FINEFI ARRAY NO. POSITION } \\
\text { TO UNIVERSE DEFERS } \\
\text { IS NOT AN RPP OR BOX_FATAL ERROR }\end{array}$ & $\begin{array}{l}\text { The reference body for an array must be } \\
\text { either a BOX or an RPP. Check input data. }\end{array}$ \\
\hline FINEFI & $\begin{array}{l}\text { FINEFI - FATAL ERROR IN ARRAY _ ELEMENT } \\
\text { POSITION } \overline{\text { CONTAINS UNIVERSE _ MISFIT }} \\
\text { IN POSITION }\end{array}$ & Self-explanatory. Check input. \\
\hline FINEFI & $\begin{array}{l}\text { IN FINEFI ARRAY HAS NO VALID } \\
\text { ELEMENTS - VERY FATAL }\end{array}$ & $\begin{array}{l}\text { This message is usually in addition to one of } \\
\text { the others from FINEFI. All lattice cell } \\
\text { positions have been checked for fits prior to } \\
\text { this message. }\end{array}$ \\
\hline
\end{tabular}

NUREG/CR-0200, 


\begin{tabular}{|c|c|c|}
\hline $\begin{array}{l}\text { Subroutine } \\
\text { printing } \\
\text { message }\end{array}$ & Message & Meaning \\
\hline FINEFI & $\begin{array}{l}\text { FINEFI - CODE ZONE CONTAINS ARRAY } \\
\text { BUT IS DEFINED WITH MORE THAN ONE BODY } \\
\text { WARNING - FIRST BODY WILL BE } \\
\text { REFERENCE BODY }\end{array}$ & Self-explanatory. Check input. \\
\hline FINEFI & $\begin{array}{l}\text { FINEFI FATAL ERROR - CODE ZONE } \\
\text { REFERENCES AN INVALID ARRAY - }\end{array}$ & $\begin{array}{l}\text { The array number is }>\text { number of arrays } \\
\text { (NAR) in the system. }\end{array}$ \\
\hline FINEFI & $\begin{array}{l}\text { FINEFI FATAL ERROR - CODE ZONE } \\
\text { CONTAINS ARRAY INSIDE BODY } \overline{-} \\
\text { REFERENCED BODY IS NOT AN RPP OR BOX }\end{array}$ & $\begin{array}{l}\text { The reference body for an array must be } \\
\text { either a BOX or an RPP. Check input data. }\end{array}$ \\
\hline FINEFI & $\begin{array}{l}\text { FINEFI FATAL ERROR - ARRAY _ IN BODY } \\
\text { REFERENCED IN CODE ZONE_ _DOES NOT FIT }\end{array}$ & $\begin{array}{l}\text { The overlap of lattice cell boundary and } \\
\text { input zone boundary is too large. }\end{array}$ \\
\hline FINEFI & $\begin{array}{l}\text { FINEFI FATAL ERROR - YOU HAVE AT LEAST } \\
\text { ONE ARRAY BUT NO ARRAY WAS } \\
\text { REFERENCED IN A LEVEL ZERO ZONE }\end{array}$ & Self-explanatory. Probable input error \\
\hline GTVLIN & $\begin{array}{l}* * * * * * * * * * \text { ERROR IN VOLUME } \\
\text { CALCULATION*********} \\
\mathrm{JF}=\ldots \mathrm{NIR}=\end{array}$ & $\begin{array}{l}\text { The number of regions for which volumes } \\
\text { were calculated does not equal the number } \\
\text { in the geometry. }\end{array}$ \\
\hline JOMIN1 & $\begin{array}{l}\text { ITYPE DOES NOT EQUAL ANY OF THE } \\
\text { FOLLOWING }\end{array}$ & $\begin{array}{l}\text { The body type given does not exist in the } \\
\text { code. }\end{array}$ \\
\hline JOMIN1 & $\begin{array}{l}\text { EXCEEDED CORE DURING CG INPUT ISTR }=- \\
\text { N= NADD }=\text { LIM }= \\
\text { LTMA }=\text { LFPD }= \\
\text { NUMR }=\text { IRTRU = } \\
\text { NAZT }=\text { _IBODT }=\text { - }\end{array}$ & $\begin{array}{l}\text { The space allocated for the data is } \\
\text { insufficient. ISTR }+N+1 \text { is amount } \\
\text { required up to this point. LIM is space } \\
\text { available. }\end{array}$ \\
\hline SAZAR & $\begin{array}{l}\text { NMOST INCREASED TO _ BY SUBROUTINE } \\
\text { SAZAR }\end{array}$ & $\begin{array}{l}\text { An array edit was requested, but there was } \\
\text { inadequate space to save it. Space was } \\
\text { added. }\end{array}$ \\
\hline UNIS & $\begin{array}{l}\text { WARNING - UNIVERSE _ IS NOT SIMPLE } \\
\text { CODE ZONE _ CONTAINS ARRAY _ }\end{array}$ & $\begin{array}{l}\text { A negative media number was found in a } \\
\text { simple universe. UNIS changes it to } \\
\text { combinatorial universe. }\end{array}$ \\
\hline UNIS & $\begin{array}{l}\text { CODE ZONE IN UNIVERSE } \\
\text { SIMPLE UNIVERSE }\end{array}$ & $\begin{array}{l}\text { The number of bodies in this code zone is } \\
>2 \text {, so it is not simple. UNIS changes it. }\end{array}$ \\
\hline UNIS & $\begin{array}{l}\text { BODY IN UNIVERSE. IS NOT REFERENCED } \\
\text { POSITIVE IN THE UNIVERSE }\end{array}$ & Fatal error. \\
\hline
\end{tabular}

NUREG/CR-0200,

Vol. 3, Rev. 4

M9.G.2 


\begin{tabular}{|c|c|c|}
\hline message & Message & Meaning \\
\hline CAII & CALI NL,NLU,IR,IRPRIM,NMED,NLEV _ & $\begin{array}{l}\text { Printed only if debug switch IDBG is on } \\
(>0) \text {. }\end{array}$ \\
\hline CALI & $\begin{array}{l}\text { ERROR IN CALI FROM CELL } * I Z=\ldots L U=- \\
\text { IER }=\text { - }\end{array}$ & $\begin{array}{l}\text { Either CELL has set the error signal } \\
\text { IER }>0 \text { or lattice cell is vacant }(L Z>0) \text { on } \\
\text { entering array. }\end{array}$ \\
\hline CALI & $\begin{array}{l}\text { ERROR IN CALI * } \\
\text { NMED,IPS,LZ,IER,LU,IR,IRPRIM,LM,LL,NL - }\end{array}$ & $\begin{array}{l}\text { When this message follows one above see } \\
\text { that explanation. If IPS }>2 \text {, there is error } \\
\text { on exiting array. }\end{array}$ \\
\hline CLEV & ERROR IN CLEV *NL1= ${ }^{\mathrm{NL} 2}=\ldots \mathrm{NGY}=$ & $\begin{array}{l}\text { Level NL1 is lower than level NL2. It } \\
\text { should be higher because code translates } \\
\text { from a higher to a lower level. }\end{array}$ \\
\hline G1 & $\begin{array}{l}\text { NO VALID DISTANCE IN GI * IR,XB,WB,DIST }= \\
-\end{array}$ & $\begin{array}{l}\text { G1 could not determine the next body that } \\
\text { the ray will intersect. There is a probable } \\
\text { error in user's geometry specifications, or } \\
\text { he may have written over his geometry data. }\end{array}$ \\
\hline G1 & $\begin{array}{l}* * * * * * * * * * * * * * * * * * * * * * * * * * * * * * * * * * * * * * * * * * * * * * * \\
\text { GEOMETRY SEARCH ARRAY FULL } \\
* * * * * * * * * * * * * * * * * * * * * * * * * * * * * * * * * * * * * * * * * * * * * *\end{array}$ & $\begin{array}{l}\text { In order to same some computer time, user } \\
\text { may want to increase the value of NAZ in } \\
\text { his input. Only harm done is an increase in } \\
\text { computer time which is often insignificant. }\end{array}$ \\
\hline G1 & 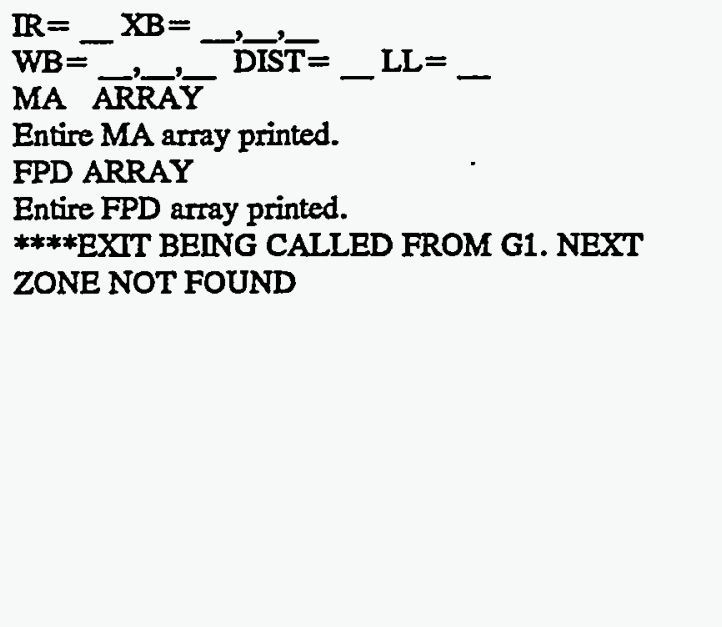 & $\begin{array}{l}\text { G1 could not find the next zone that the } \\
\text { particle would enter. It checked all zones } \\
\text { and is saying that the particle won't enter } \\
\text { any of them. } \\
\text { Probable error in zone specifications. } \\
\text { Subroutine PR called to print values from } \\
\text { commons GOMLOC, DBG, and PAREM. } \\
\text { Among the variables printed the following } \\
\text { apply to the maximum body number and } \\
\text { therefore have no significance - } \\
\text { NBO,N,NUM,ITYPE,SIN,IRP, and } \\
\text { LOCAT. The most important variable is } \\
\text { NASC which is the number of the next body } \\
\text { the ray will intersect. That is, the code } \\
\text { cannot find what zone this body is in. Check } \\
\text { zone specification for this body. }\end{array}$ \\
\hline
\end{tabular}




\begin{tabular}{|c|c|c|}
\hline $\begin{array}{l}\text { Subroutine } \\
\text { printing } \\
\text { message }\end{array}$ & Message & Meaning \\
\hline GG & $\begin{array}{l}\text { IN GG } \\
\mathbb{I R}=-\end{array}$ & $\begin{array}{ll}\text { ITYPE }= & \text { ITYPE is not one of the } \\
\text { NBO }=\ldots & \text { body types (1-9) allowed. } \\
\text { User has either overstored } \\
\text { MA array or has used a } \\
\text { body number out of range } \\
\text { in the zone description. }\end{array}$ \\
\hline LOOKZ & $\begin{array}{l}\mathrm{IR}= \\
\text { WB=- } \\
\text { DIST }=-\mathrm{LL}=- \\
\text { MA ARRAY } \\
\text { Entire MA array printed. } \\
\text { FPD ARRAY } \\
\text { Entire FPD array printed. } \\
\text { ****EXIT BEING CALLED FROM LOOKZ }\end{array}$ & $\begin{array}{l}\mathrm{XB}=\text {, - Zone has not been found. } \\
\text { Check the zone } \\
\text { specifications for error. }\end{array}$ \\
\hline NORML & $\begin{array}{l}\text { INVALID REGION OR BODY IN NORMAL. } \\
\text { IR= _ NASC }=\text { - }\end{array}$ & $\begin{array}{l}\text { NASC is not in region IR. Check whether } \\
\text { IR or NASC has been overwritten. }\end{array}$ \\
\hline NORML & $\begin{array}{l}\text { ROUND-OFF ERROR IN NORMAL NBO= } \\
\text { LSURF = _XP= }\end{array}$ & $\begin{array}{l}\text { Self-explanatory. Applies only to ELL and } \\
\text { BOX. }\end{array}$ \\
\hline PILOT & $\begin{array}{l}\text { PROBLEM ENCOUNTERED IN ARRAY } \\
\text { PROCESSING, PARTICLE WILL BE } \\
\text { TERMINATED AS ESCAPE. }\end{array}$ & $\begin{array}{l}\text { Printed when PILOT is in a loop when } \\
\text { processing an array. Particle is probably } \\
\text { unable to enter or leave an array. May be } \\
\text { input error. }\end{array}$ \\
\hline PILOT & PILOT CRASH & $\begin{array}{l}\text { Printed only if debug switch } \mathrm{DBG} \text { is on } \\
(>0) \text {. }\end{array}$ \\
\hline PILOT & ERROR IN PILOT ON ENTERING ARRAY & $\begin{array}{l}\text { If IER }>0 \text {, previous error message from } \\
\text { SORT explains error. If } L Z>0 \text { or } L M=0 \text {, } \\
\text { lattice cell is vacant or cell position is out of } \\
\text { range ( }<0 \text { or }>\text { maximum). }\end{array}$ \\
\hline PILOT & ERROR IN PILOT ON EXITING ARRAY & $\begin{array}{l}\text { If IER }>0 \text {, previous error message from } \\
\text { SORT explains error. IF IEXIT }=1 \text { or } \\
\mathrm{LM}=0 \text {, lattice position is out of range. } \\
\mathrm{NL}<0 \text { means error in level number. }\end{array}$ \\
\hline SORT & $\begin{array}{l}\text { FATAL ERROR IN SORT *** PARTICLE LOST ON } \\
\text { ENTERING OR EXITING ARRAY. } \\
\text { M,NMAX,IGX,LX1,LX2,NXY - } \\
\text { XB,RBY(LX2),SML,SMALL }\end{array}$ & $\begin{array}{l}\text { On entering array, particle position is ot at a } \\
\text { lattice cell boundary (RBY) for array; on } \\
\text { exiting array, either lattice position is }> \\
\text { size of array lattice or is }<0 \text { or particle } \\
\text { position is not at lattice cell boundary. }\end{array}$ \\
\hline STORA & $\begin{array}{l}\text { IN STORA EITHER AN IILEGAL LEGAL } \\
\text { TRANSFER WAS ATTEMPTED OR AN } \\
\text { INCORRECT ARRAY REQUEST WAS MADE } \\
{ }^{*} \mathrm{NLO}=\mathrm{NL}=\text { NLU }=\text { LM }=\end{array}$ & $\begin{array}{l}\text { The level number NL is wrong. Either it is } \\
\text { greater than the number of levels (NLEV) or } \\
\text { it is } 0 \text {. }\end{array}$ \\
\hline
\end{tabular}

NUREG/CR-0200,

Vol. 3, Rev. 4

M9.G.4 
Computing Applications Division

\section{FIDO INPUT SYSTEM}

L. M. Petrie

Previously Published: December 1984

Revised Publication Date: April 1995

Prepared for the

Office of Nuclear Material Safety and Safeguards

U.S. Nuclear Regulatory Commission

Washington, DC 20555

Under Interagency Agreement DOE 1886-8000-9B

NRC JCN No. B0009

Prepared by the

OAK RIDGE NATIONAL LABORATORY

managed by

MARTIN MARIETTA ENERGY SYSTEMS, INC.

for the

U.S. DEPARTMENT OF ENERGY

under contract DE-AC05-84OR21400 



\begin{abstract}
This document provides a description of the FIDO input system being used in conjunction with several SCALE functional modules. The FIDO system is a widely used method of entering or modifying large data arrays with minimum effort. Special advantage is taken of patterns of repetition or symmetry whenever possible.
\end{abstract}




\section{.}




\section{CONTENTS}

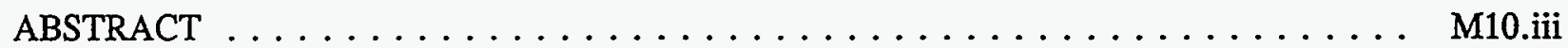

ACKNOWLEDGMENTS ....................... M10.vii

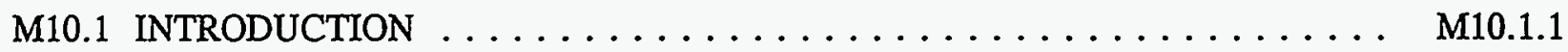

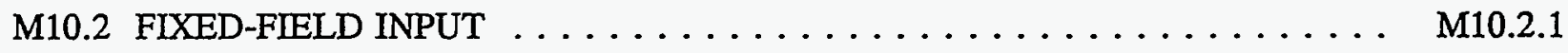

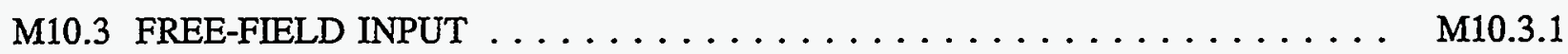

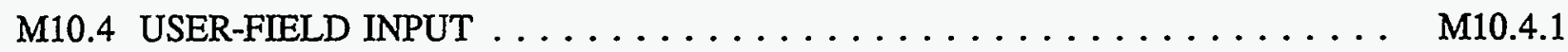

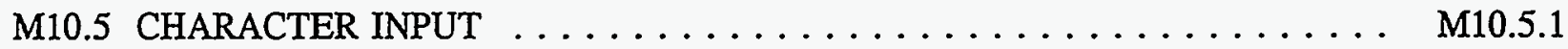




\section{ACKNOWLEDGMENTS}

This document was funded by the Storage and Transport Systems Branch, within the Office of Nuclear Material Safety and Safeguards, U.S. Nuclear Regulatory Commission, for inclusion within the SCALE manual. 


\section{M10.1 INTRODUCTION}

The FIDO input method is specially devised to allow entering or modifying large data arrays with minimum effort. Advantage is taken of patterns of repetition or symmetry wherever possible. The FIDO system was patterned after the input method used with the FLOCO coding system at Los Alamos and was first applied to the DTF-II code. Since that time, numerous features requested by users have been added, a freefield option has been developed, and the application of FIDO has spread to innumerable codes.

The data are entered in units called "arrays." An array comprises a group of contiguous storage locations that are to be filled with data at the same time. These arrays usually correspond on a one-to-one basis with FORTRAN arrays used in the program. A group of one or more arrays read with a single call to the FIDO package forms a "block," and a special delimiter is required to signify the end of each block. Arrays within a block may be read in any order with respect to each other, but an array belonging to one block must not be shifted to another. The same array can be entered repeatedly within the same block. For example, an array could be filled with " 0 " using a special option, and then a few scattered locations could be changed by reading in a new set of data for that array. If no entries to the arrays in a block are required, the delimiter alone satisfies the input requirement.

Three major types of input are available: fixed-field input, free-field input, and user-field input. 


\section{M10.2 FIXED-FIELD INPUT}

Each card is divided into six 12-column data fields, each of which is divided into three subfields. The following sketch illustrates a typical data field. The three subfields always comprise 2, 1, and 9 columns, respectively.

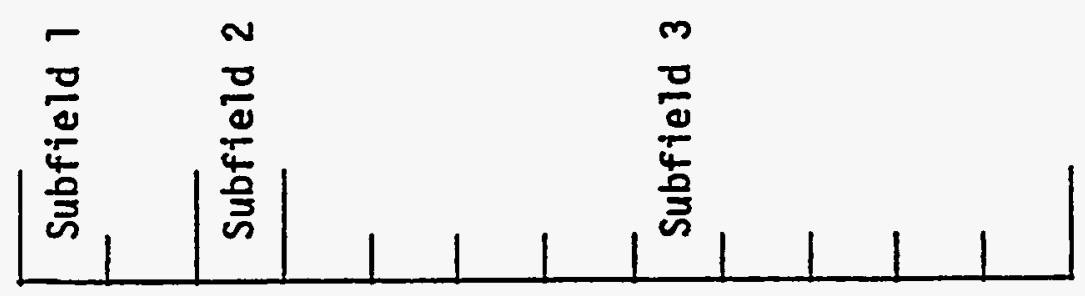

To begin the first array of a block, an array originator field is placed in any field on a card:

Subfield 1: $\quad$ An integer array identifier $<100$ specifying the data array to be read in.

Subfield 2: An array-type indicator:

"\$" if the array is integer data

$" * n$ if the array is real data

"\#" if the array is double-precision data

\section{Subfield 3: $\quad$ Blank}

Data are then placed in successive fields until the required number of entries has been accounted for. A sample data sheet shown in Table M10.1.1 illustrates this point.

In entering data, it is convenient to think of an "index" or "pointer" as a designator that is under the control of the user and which specifies the position in the array into which the next data entry is to go. The pointer is always positioned at array location \#1 by entering the array originator field. The pointer subsequently moves according to the data operator chosen. Blank fields are a special case in that they do not cause any data modification and do not move the pointer.

A data field has the following form:

Subfield 1: The data mumerator, an integer $<100$. We refer to this entry as $N_{1}$ in the following discussion.

Subfield 2: $\quad$ One of the special data operators listed below.

Subfield 3: A nine-character data entry, to be read in F9.0 format. It will be converted to an integer if the array is a " $\$$ " array or if a special array operator such as $Q$ is being used. Note that an exponent is permissible but not required. Likewise, a decimal is permissible but not required. If no decimal is supplied, it is assumed to be immediately to the left of the exponent, if any; and otherwise to the right of the last column. This entry is referred to as $\mathrm{N}_{3}$ in the following discussion. 
Table M10.2.1 General example of FIDO input

Name General Example of Fido Input

Charge

Date

Poge _

\begin{tabular}{|c|c|c|c|}
\hline & & IDENTIFICATION & REMARKS (DO'NOT PUNCH) \\
\hline$\perp \underline{1} \$$ & $\begin{array}{lllll}-1 & 1 & 1 & 1 & 1\end{array}$ & & Begin the 1 S array, fixed-field, integral \\
\hline $13 \quad 1$ & $L-1-L \perp L-1-1 / 1$ & & Enter 1 \\
\hline${ }^{28}+\mathrm{F}$ & $1+1+1+1+2$ & & Fill array with 2 \\
\hline${ }^{37} 1^{2} \perp^{*}$ & $\begin{array}{lllllll}1 & 1 & 1 & 1 & 1 & 1 & 1\end{array}$ & & Begin the $2^{*}$ array, ftxed-field, real \\
\hline${ }^{40} i_{1}$ & $1, \cdot, 2,3,4,1,1$ & 73 & Enter 1.234 \\
\hline${ }^{01} \quad 1 \quad 1$ & $1,2, \cdot, 3,4,1,-11$ & 1,0 & $" \quad "$ \\
\hline $151=$ & $1 \_L 2,3 \perp 4 \perp \perp \perp+10 \_2$ & & $"$ \\
\hline${ }_{1}^{3} 3_{1}=$ & $11 ; 1,11,2,3,4$ & & " \\
\hline $1+1$ & $1,1,1,1,1,7$ & & 7.0 \\
\hline 1 & $\begin{array}{llll}-1 & 1\end{array}$ & & A blank fleld is always ignored \\
\hline $49 \quad 1 \quad T$ & $1 \quad 1 \quad 1 \quad 1 \quad 1 \quad 1 \quad 1$ & 73 & Terminate this block \\
\hline $\begin{array}{lll}1 & 1 \\
\end{array}$ & $111,1,1,1$ & & No entries may follow $\mathrm{T}$ on a card \\
\hline $3,3, *$ & $\begin{array}{llll}1 & 1 & 1 & 1\end{array}$ & & Begin $3 *$ array, fixed-field real \\
\hline $9,9, I$ & 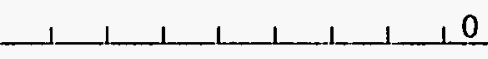 & & Enter $0,1,2,3,4,5,6,7,8,9,10,10,10$ \\
\hline $38,3, R$ & $1+1-1+1,1$ & & as real numbers \\
\hline $3, *, *$ & $1,1,0, S_{1}, 1,0$, & & Repeat $3 *$ in free-field, skip \\
\hline 1,1 & $1,2,1,1,1,1$ & & to 11 th entry, correct sequence to \\
\hline${ }^{01}+1$ & $1,1,1,1,1,1$ & 3,0 & $f_{---9,10,11,12}$ \\
\hline $4+\frac{4}{13} *$ & $2.1 I-111 \quad 1.141 \cdot 101$ & & Begin 4* array, free-fleld, real \\
\hline$\frac{2}{25} \perp Q \underline{L}$ & 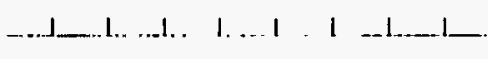 & & Enter $1,2,3,4,1,2,3,4,1,2,3,4$ \\
\hline$\frac{1}{37}+1$ & $\ldots$ & & End reading this array; remainder of array unchanged \\
\hline$x_{1}$ & 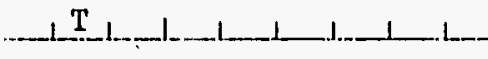 & & erminate this block \\
\hline 90 & $1 \perp 1-1<1-1$ & 73 & \\
\hline $0^{\circ 1}+1$ & $\begin{array}{llllllll}1 & 1 & 1 & 1 & 1 & 1 & 1 & 1\end{array}$ & $1,1,1,1,4,0$ & \\
\hline
\end{tabular}

$R$ - REPEAT

1. INTERPOLATE

S. SKIP

T - TERMINATE 
A list of data operators and their effect on the array being input follows:

"Blank" indicates a single entry of data. The data entry in the third subfield is entered in the location indicated by the pointer, and the pointer is advanced by one. However, an entirely blank field is ignored.

" + " or " - " indicates exponentiation. The data entry in the third field is entered and multiplied by $10^{ \pm N_{1}}$, where $N_{1}$ is the data mumerator in the first subfield, given the sign indicated by the data operator itself. The pointer advances by one. In cases where an exponent is needed, this option allows the entering of more significant figures than the blank option.

" $\&$ " has the same effect as " + ".

" $R$ " indicates that the data entry is to be repeated $N_{1}$ times. The pointer advances by $N_{1}$.

"I" indicates linear interpolation. The data mumerator, $\mathrm{N}_{1}$, indicates the number of interpolated points to be supplied. The data entry in the third subfield is entered, followed by $\mathrm{Nj}$ interpolated entries equally spaced between that value and the data entry found in the third subfield of the next nonblank field. The pointer is advanced by $\mathrm{N}_{1}+1$. The field following an "I" field is than processed normally, according to its own data operator. The "I" entry is especially valuable for specifying a spatial mesh. In "\$" arrays, interpolated values will be rounded to the nearest integer.

" $L$ " indicates logarithmic interpolation. The effect is the same as that of " $I$ " except that the resulting data are evenly separated in log-space. This feature is especially convenient for specifying an energy mesh.

" $Q$ " is used to repeat sequences of numbers. The length of the sequence is given by the third subfield, $N_{3}$. The sequence of $N_{3}$ entries is to be repeated $N_{1}$ times. The pointer advances by $N_{1}^{*} N_{3}$. If either $N_{1}$ or $N_{3}$ is 0 , then a sequence of $N_{1}+N_{3}$ is repeated one time only, and the pointer advances by $N_{1}+N_{3}$. This feature is especially valuable for geometry specification.

The " $N$ " option has the same effect as " $Q$," except that the order of the sequence is reversed each time it is entered. This feature is valuable for the type of symmetry possessed by $S_{n}$ quadrature coefficients.

"M" has the same effect as "N," except that the sign of each entry in the sequence is reversed each time the sequence is entered. For example, the entries

\section{$1232 \mathrm{M} 2$}

would be equivalent to

\section{$123-3-223$.}

This option is also useful in entering quadrature coefficients.

" $Z$ " causes $N_{1}+N_{3}$ locations to be set at 0 . The pointer is advanced by $N_{1}+N_{3}$.

" $\mathrm{C}$ " causes the position of the last array entered to be printed. This is the position of the pointer, less 1. The pointer is not moved.

" $O$ " causes the print trigger to be changed. The trigger is originally off. Successive " 0 " fields turn it on and off alternately. When the trigger is on, each card image is listed as it is read.

" $S$ " indicates that the pointer is to skip $N_{1}$ positions leaving those array positions unchanged. If the third subfield is blank, the pointer is advanced by $\mathrm{N}_{1}$. If the third subfield is nonblank, that data entry is entered following the skip, and the pointer is advanced by $N_{1}+1$.

"A" moves the pointer to the position, $\mathrm{N}_{3}$ specified in the third subfield.

"F" fills the remainder of the array with the datum entered in the third subfield. 
"E" skips over the remainder of the array. The array length criterion is always satisfied by an $\mathrm{E}$, no matter how many entries have been specified. No more entries to an array may be given following an "E," except that data entry may be restarted with an "A."

The reading of data to an array is terminated when a new array origin field is supplied, or when the block is terminated. If an incorrect number of positions has been filled, an error edit is given; and a flag is set which will later abort execution of the problem. FIDO then continues with the next array if an array origin was read. Otherwise, control is returned to the calling program.

A block termination consists of a field having " $\mathrm{T}$ " in the second subfield. XI entries following " $\mathrm{T}$ " on a card are ignored, and control is returned from FIDO to the calling program.

Comment cards can be entered within a block by placing an apostrophe (') in column 1 . Then columns 2-80 will be listed, with column 2 being used for printer carriage control. Such cards have no effect on the data array or pointer.

NUREG/CR-0200,

Vol. 3, Rev. 4 


\section{M10.3 FREE-FIELD INPUT}

With free-field input, data are written without fixed restrictions as to field and subfield size and positioning on the card. The options used with fixed-field input are available, although some are sightly restricted in form. In general, fewer data cards are required for a problem, the interpreting print is easier to read, a card listing is more intelligible, the cards are easier to keypunch, and certain common keypunch errors are tolerated without affecting the problem. Data arrays using fixed- and free-field input can be intermingled at will within a given block,

The concept of three subfields per field is still applicable to free-field input; but if no entry for a field is required, no space for it need be left. Only columns 1-72 may be used, as with fixed-field input. A field may not be split across cards.

The array originator field can begin in any position. The array identifiers and type indicators are used as in fixed-field input. The type indicator is entered twice to designate free-field input (i.e., "\$\$, " $* *$," or "\#\#"). The blank third subfield required in fixed-field input is not required. For example,

$31^{* *}$

indicates that array 31, a real-data array, will follow in free-field format.

Data fields may follow the array origin field immediately. The data field entries are identical to the fixed-field entries with the following restrictions:

1. Any mumber of blanks may separate fields, but at least one blank must follow a third subfield entry if one is used.

2. If both first- and second-subfield entries are used, no blanks may separate them (i.e., 24S, but not 24 S).

3. Numbers written with exponents must not have imbedded blanks (i.e., 1.OE+4, 1.0-E4, $1.0+4$, or even $1+4$, but not $1.0 \mathrm{E} 4$ ). A zero should never be entered with an exponent. For example, $0.00-5$ or $0.00 \mathrm{E}-5$ will be interpreted as $-5 \times 10^{-2}$.

4. In third-subfield data entries only 9 digits, including the decimal but not including the exponent field, can be used (i.e., 123456.89E07, but not 123456.789E0T).

(5) The $Z$ entry must be of the form: $738 Z$, not $Z 738$ or $738 \mathrm{Z}$.

(6) The + or - data operators are not needed and are not available.

(7) The $Q, N$, and $M$ entries are restricted: $3 Q 4,1 N 4, M 4$, but not $4 \mathrm{Q}, 4 \mathrm{~N}$, or $4 \mathrm{M}$. 


\section{M10.4 USER-FIELD INPUT}

If the user follows the array identifier in the array originator field with the character " $U$ " or "V," the input format is to be specified by the user. If " $U$ " is specified, the FORTRAN FORMAT to be used must be supplied in columns 1-72 of the next card. The format must be enclosed by the usual parentheses. Then the data for the entire array must follow on successive cards. 'The rules of ordinary FORTRAN input as to exponents, blanks, etc., apply. If the array data do not fill the last card, the remainder must be left blank.

"V" has the same effect as " $U$," except that the format read in the last preceding " $U$ " array is used. 


\section{M10.5 CHARACTER INPUT}

If the user wishes to enter character data into an array, at least three options are available. The user may specify an arbitrary format using a " $U$ " and reading in the format. The user may follow the array identifier by a "/". The next two entries into subfield 3 specify the beginning and ending indices in the array into which data will be read. The character data are then read starting with the next data card in an 18A4 format.

Finally, the user may specify the array as a free-form "*" array and then specify the data entries as " $\mathrm{nH}$ " character data where $\mathrm{n}$ specifies how many characters follow $\mathrm{H}$. 
Computing Applications Division

\title{
PICTURE: A PRINTER PLOT PACKAGE FOR MAKING 2-D
} PICTURES OF MARS GEOMETRIES

\author{
Margaret B. Emmett
}

Manuscript Revised: February 1991

Date Published: April 1995

Prepared for the

Office of Nuclear Material Safety and Safeguards

U. S. Nuclear Regulatory Commission

Washington, DC 20555

Under Interagency Agreement DOE 1886-8000-9B

NRC JCN No. B0009

Prepared by the

OAK RIDGE NATIONAL LABORATORY

managed by

MARTIN MARIETTA ENERGY SYSTEMS, INC.

for the

U.S. DEPARTMENT OF ENERGY

under contract DE-AC05-84OR21400 


\begin{abstract}
The PICTURE program was written to provide aid in preparing correct input data for the MARS geometry package, which is a multiple-array system using combinatorial geometry. It provides a printed view of arbitrary two-dimensional slices through the geometry. By inspecting these pictures one may determine if the geometry specified by the input cards is indeed the desired geometry. This report describes PICTURE, its options, and its input.
\end{abstract}


、 
CONTENTS

Page

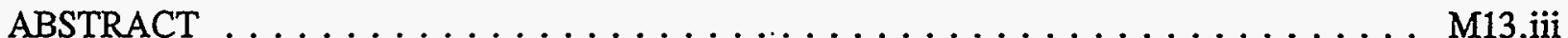

LIST OF FIGURES $\ldots \ldots \ldots \ldots \ldots \ldots \ldots \ldots \ldots \ldots \ldots \ldots \ldots \ldots \ldots$ M13.vi

LIST OF TABLES $\ldots \ldots \ldots \ldots \ldots \ldots \ldots \ldots \ldots \ldots \ldots \ldots \ldots \ldots \ldots \ldots \ldots \ldots \ldots$ M13.vii

ACKNOWLEDGEMENTS $\ldots \ldots \ldots \ldots \ldots \ldots \ldots \ldots \ldots \ldots \ldots \ldots \ldots \ldots \ldots \ldots$ M13.ix

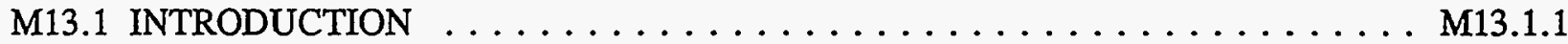

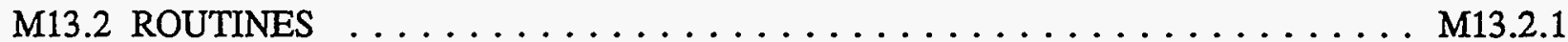

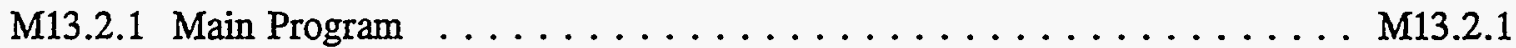

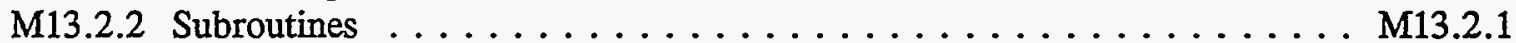

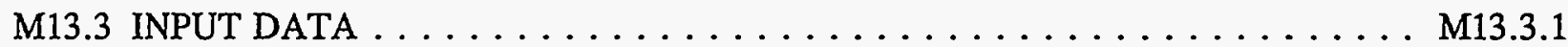

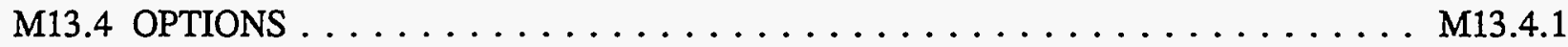

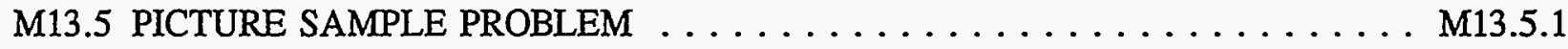




\section{LIST OF FIGURES}

Eigure

Page

M13.5.1 Input Data for PICTURE Sample Problem . . . . . . . . . . . . . M13.5.2

M13.5.2 Output of Combinatorial Geometry Tank Sample Problem . . . . . . . . . . M13.5.3

NUREG/CR-0200,

Vol. 3, Rev. 4

M13.vi 


\section{LIST OF TABLES}

Tahle

Page

M13.2.1 Definition of variables in common PICT

M13.2.4 


\section{ACKNOWLEDGMENTS}

The funding for this update to the PICTURE code was provided by NRC's Office of Nuclear Material Safety and Safeguards. Special thanks to Lindy Norris for typing this manual. 


\section{M13.1 INTRODUCTION}

The PICTURE program was written to help the user determine whether his MARS input data correctly describe his geometry. PICTURE displays, as printed output, two-dimensional (2-D) slices through the specified geometry. A regularly spaced array of points is generated, and each point is plotted as a symbol related to either media, region, or zone, depending on the option selected by the user. By printing out this array, a rough picture of one view of the geometry is produced. The user may then look at the picture and determine if the geometry is as intended. A sample problem is described in Sect. M13.5.

Running PICTURE requires the routines described in this report plus those making up the MARS geometry package described in Sect. M9. MARS also uses routines from the SCALE subroutine library. 


\section{M13.2 ROUTINES}

\section{M13.2.1 Main Program}

The executive routine for the PICTURE program sets the dimension for blank common, the I/O unit mumbers, and the ratio of the number of characters per inch down the page to the number across the page, and calls subroutine PICTUR.

Subroutines called: PICTUR

Commons required: Blank

Variables changed: INT, IOT, RAYX, NDIM

Significant internal variables:

INT - input logical unit $(=5)$,

IOT - output logical unit $(=6)$,

RAYX - ratio of mumber characters/inch down to mumber characters/inch across page (default $=0.8$ for $14 \times 81 / 2$ paper; user should use 0.6 for $14 \times 11$ paper).

\section{M13.2.2 Subroutines}

\section{Subroutine PRINT (KXX, KYY, ATABLE, IOT)}

This routine controls the printing of the picture. First it is determined if the picture is to be more than one "page" (130 columns) wide, and then for each line of the picture on the first page the information to be printed is determined by calling MESH and printed with a 130A1 format. The next lines are then calculated and printed until that "page" is finished. Note that a page refers to width, not length. Thus, as much detail may be obtained as necessary in both directions by piecing together the output.

\section{Called from: PICTUR}

Subroutine called: MESH

Commons required: PICT

Variables required:

KXX - $\quad$ number of intervals in the $U$ direction (direction of paper movement through the printer),

KYY - $\quad$ number of intervals in the V direction (line), 
ATABLE - table of characters to be printed,

IOT - $\quad$ output logical unit.

Significant internal variable:

NPAGES - number of subpictures required to cover the width of the total picture,

NV - $\quad$ number of characters per line (characters/page width).

Subroutine MESH (XS, YS, ZS, NV)

Subroutine MESH is used by the PICTURE package to set up one line of print in the array NSTOR. Both for efficiency and to debug the MARS array geometry data, this version has been modified to work exactly like particle tracking. CALI is first called to determine the zone of the first grid point. A trajectory to the last grid point is then initialized, and successive calls to PILOT, which calls 'G1,' "track" a particle to the last point, setting the region of each grid point in NSTOR. By setting IRG negative, zero, or positive, either NREG, IR, or NMED will be stored in the print array NSTOR.

Called from: PRINT

Subroutines called: CALI, RESET, PILOT

Commons required: PICT, GOMLOC, PAREM, ORGI, REPEAT, ARAR, MGOMV, SS, JOMN2, blank. Variables required:

XS, YS, ZS - coordinates of first grid point,

NV - $\quad$ number of grid points,

DELV - distance between grid points,

IRG - $\quad$ flag to print NREG, IR, or NMED if IRG is negative, zero, or positive, coordinates of width (in direction $V$ ) of picture in geometry units.

Variables changed: NSTOR - print array.

Significant internal variables:

J - grid point index,

ISTOR - value to be stored in NSTOR between successive boundary crossings,

IROLD - present input zone number,

SUMS1 - distance traveled on current line (DIST),

NUREG/CR-0200,

Vol. 3, Rev. 4

M13.2.2 
DLINE - total distance to end of current line (DISTO).

\section{Subroutine PICTUR (INT, IOT, NDIM, RAYX)}

Subroutine PICTUR reads in the input, calculates the coordinates of the picture to be plotted, and controls the calls to other routines. There are several different ways in which a 2-D slice through the geometry may be obtained. These different options are discussed in Sect. M13.4 with discussions of the input. The characters to be printed for corresponding media or regions may be changed by altering the values in ATABLE as given in the data statement.

Called from: Main Program

Subroutines called: JOMIN, PRINT

Commons required: PICT, MGOMV

Variables required: Several input cards are read.

INT - input logical unit,

IOT - output logical unit.

Variables changed: All variables in common PICT (see Table M13.2.2.1)

\section{IPRET in MGOMV*}

Significant internal variables:

NADD(1) - first location in blank common for storage of geometry data,

NCK - $\quad$ flag to indicate which set of input options was used to define the 2-D slice.

'See Table M9.E.8. 
Table M13.2.1 Definition of variables in common PICT

\begin{tabular}{|c|c|}
\hline Variable & Definition \\
\hline $\mathrm{X} 0, \mathrm{YO}, \mathrm{ZO}$ & $\begin{array}{l}\text { The coordinates in geometry units defining the first point (upper-left-hand } \\
\text { corner) of the picture. }\end{array}$ \\
\hline $\mathrm{X} 1, \mathrm{Y} 1, \mathrm{Z} 1$ & $\begin{array}{l}\text { The coordinates in geometry units defining the last point (lower-right-hand } \\
\text { corner) of the picture. }\end{array}$ \\
\hline $\mathrm{XU}, \mathrm{YU}, \mathrm{ZU}$ & The length (in direction $U$ ) of the picture in geometry units. \\
\hline $\mathrm{XV}, \mathrm{YV}, \mathrm{ZV}$ & The width (in direction $V$ ) of the picture in geometry units. \\
\hline DELU & The increment in geometry units between lines in the picture in the $U$ direction. \\
\hline DELV & The increment in geometry units between lines in the picture in the $\mathrm{V}$ direction. \\
\hline IRG & $\begin{array}{l}\text { A flag indicating that region, zone, or medium geometry parameter should be } \\
\text { printed if IRG is negative, zero, or positive, respectively. }\end{array}$ \\
\hline NU & Number of intervals to print along $U$ axis. \\
\hline NV & Number of intervals to print along $V$ axis. \\
\hline ICNT & $\begin{array}{l}\text { A flag indicating whether this is last plot (and if not, whether next plot is of a } \\
\text { different geometry). }\end{array}$ \\
\hline NSTOR(130) & $\begin{array}{l}\text { An array used to store the medium, region, or zone number for one line of the } \\
\text { picture. }\end{array}$ \\
\hline
\end{tabular}

NUREG/CR-0200,

Vol. 3, Rev. 4

M13.2.4 


\section{M13.3 INPUT DATA}

The format of the input data for PICTUR has been revised to use free form with a system of keywords to identify the variables. Following is a description of the data.

1. Card PA:

NUSE: The mumber of characters to be read on Card B to replace the standard values of ATABLE. Specify a 0 and omit Card B if the standard ATABLE is desired. NUSE $\leq 50$.

2. Card PB: Format (50A1) (omit if NUSE =0)

ATABLE(I), I=1, NUSE: The list of characters that are to be printed for each medium. For medium $\mathrm{N}, \mathrm{ATABLE}(\mathrm{N}+1)$ is printed. If $\mathrm{N} \geq 47$, ATABLE (48) is printed. The standard values of ATABLE are:

Medium Number

0 (external void)

1 through 9

10 through 35

36 through 46

247 (including

internal voids)
Character Printed

1 through 9

A through $\mathbf{Z}$

Various special characters

(blank)

3. GEOM input: MARS combinatorial geometry input."

4. Remaining data uses keywords, and multiple values can appear on a line.

$$
\begin{aligned}
& \text { TTL }=\text { title in } 18 \mathrm{~A} 4 \text { format } \\
& \text { TITLE(I),I=1,18 } 72 \text { characters to be printed as a title. }
\end{aligned}
$$$$
=-1 \text { There is only one plot. Default. }
$$

$=0$ After this picture, return to step 4 for another picture with the same geometry.

$$
\begin{array}{ll}
\text { ICN = inam(18) } \quad \text { ICNT } & =1 \text { After this picture, read in a new GEOM input. } \\
\text { (step } 3 \text { above) }
\end{array}
$$

Enter $\mathrm{X0}, \mathrm{YO}$, and $\mathrm{ZO}$ the $\mathrm{X}, \mathrm{Y}$, and $\mathrm{Z}$ coordinates in the combinatorial geometry of the upper left corner of the picture. Data must be entered for all three coordinates unless all three values from the previous plot are to be used. 


$$
\begin{aligned}
& \text { XUL }=\text { fnam(1) } \\
& \text { YUL }=\text { fnam(2) } \\
& \text { ZUL }=\text { fnam(3) }
\end{aligned}
$$

Enter $\mathrm{X} 1, \mathrm{Y} 1$, and $\mathrm{Zl}$ the $\mathrm{X}, \mathrm{Y}$, and $\mathrm{Z}$ coordinates in the combinatorial geometry of the lower-right corner of the picture.

$$
\begin{aligned}
& X L R=\text { fnam(4) } \\
& Y L R=\text { fnam(5) } \\
& Z L R=\text { fnam(6) }
\end{aligned}
$$

Note: These six coordinates partially describe the plane of the slice by defining two points in the plane and designate the top, bottom, left and right sides of the picture. Default values are those from the previous plot.

Enter XU, YU, and ZU the direction numbers proportional to the direction cosines for the $U$ axis of the picture. The $U$ axis points down the printed page in the direction the page moves through the printer.

$$
\begin{aligned}
& \mathrm{UAX}=\text { fnam(7) } \\
& \mathrm{VAX}=\text { fnam(8) } \\
& \mathrm{WAX}=\text { fnam(9) }
\end{aligned}
$$

Enter XV, YV, and ZV the direction numbers for the $\mathrm{V}$ axis of the picture. The $\mathrm{V}$ axis points to the right across the page.

$$
\begin{aligned}
& \text { UDN = fnam(10) } \\
& \text { VDN }=\text { fnam(11) } \\
& \text { WDN }=\text { fnam(12) }
\end{aligned}
$$

Note: These values complete the description of the plane of the slice by giving a line in the plane and also specify the orientation of the picture on the output.

Enter DELU, DELV, NU, and NV the spacing and number of intervals.
$\operatorname{DLX}=$ fnam(13)
DELU: Spacing (in GEOM units) of intervals along the $U$ axis.
DLD $=$ fnam(14)
DELV: Spacing (in GEOM units) of intervals along the $V$ axis.
NAX $=$ inam(15)
NU: $\quad$ Number of intervals to print along the $U$ axis (overrides
$\mathrm{NDN}=\operatorname{inam}(16)$
NV:
Number of intervals to print along the $\mathrm{V}$ axis (overrides DELV).

NUREG/CR-0200,

Vol. 3, Rev. 4

M13.3.2 
Note: All four entries are not required as input; see Sect. M13.4 for an explanation.

Signal the end of data for this plot.

\section{END}

If there are more plots, set up the data according to the value of ICNT and specify parameters that need changing. 


\section{M13.4 OPTIONS}

1. $X_{L R}=Y_{L R}=Z_{L R}=0$.

For this case NU and NV must be specified. In addition, either DELU or DELV must be specified. If the other is left blank, the code will produce an undistorted picture. If both DELU and DELV are specified, the picture is likely to be distorted. The standard printers give 10 characters to the inch across a line but only 6 lines per inch down the page. Because of this, DELV $=0.6 * \mathrm{DELU}$ is necessary to produce an undistorted picture.

2. $X_{L R}$ or $Y_{L R}$ or $Z_{L R}=0$.

If any one variable on Card PD is specified, the code will calculate the others to produce an undistorted picture.

If both NU and DELU (or both NV and DELV) are specified, DELU (or DELV) will be ignored.

The $U$ and $V$ axes may have arbitrary orientation. (If they are not orthogonal, the resulting picture will be distorted.) In Option 1 , the first point will be at $(X, Y, Z)_{U L}$, and the remaining points in the directions and at the distances specified. In Option 2, the range from $X_{\mathrm{UL}}$ to $X_{\mathrm{LR}}$ is divided into intervals and the calculated points will be at the midpoints of the intervals. The first point will be $1 / 2$ interval past $(X, Y, Z)_{L R}$ and the final point will be within $1 / 2$ interval of $(X, Y, Z)_{I R}$. If $(X, Y, Z)_{L R}$ does not lie on the U-V plane, or if the $U$ and $V$ axes are not orthogonal, the location of the final point is not readily predictable.

The simplest method to obtain the correct results is to specify two diagonal corners of the plane of the slice on Card PD, with the top having the short dimension. Then, on Card PE, specify the U axis to be parallel to the edge of the slice with the large dimension (left or right side), and the $V$ axis to be parallel to the edge of the slice with the small dimension (top or bottom). Finally, let the only entry on Card PF be NV equal to maximum number of characters per line on your printer; this arrangement will provide the largest undistorted picture. 


\section{M13.5 PICTURE SAMPLE PROBLEM}

This problem illustrates the use of the PICTURE program for looking at the geometry of a given problem. The geometry being illustrated is a tank. This tank model was constructed purely as an illustration of the combinatorial geometry and is in no way accurate or detailed. The use of the OR operator and the ARB body is demonstrated. The input data are listed in Fig. M13.5.1. The output and picture produced by the problem are shown in Fig. M13.5.2. 


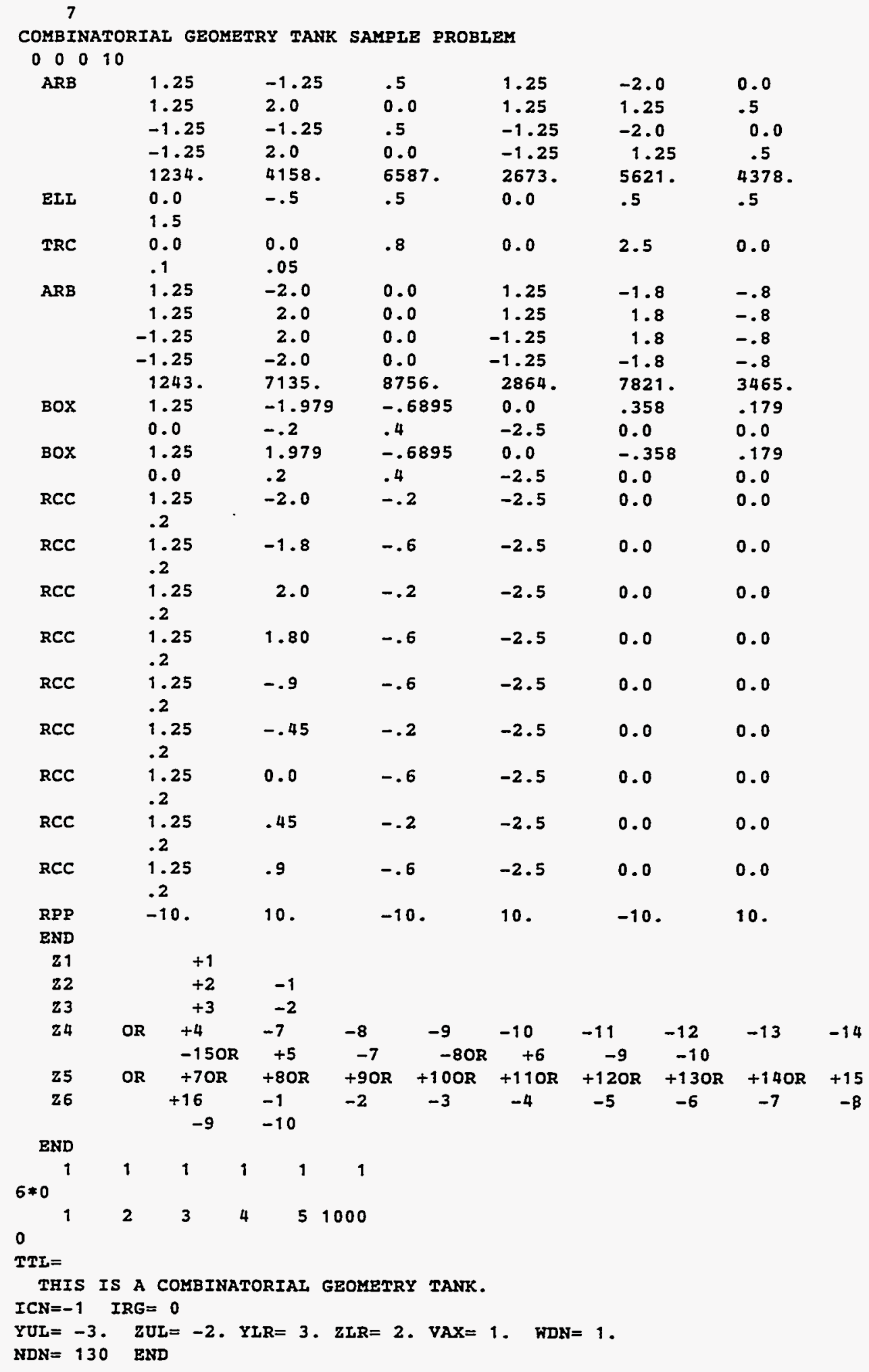

Figure M13.5.1 Input data for PICTURE sample problem

NUREG/CR-0200,

Vol. 3, Rev. 4

M13.5.2 
COMBINATORIAL GEOMETRY TANK SAMPLE PROBLEM

IVOPT $=0$

12

ARB

$0.1250000 \mathrm{D}+0 \mathrm{I}$

$0.1250000 \mathrm{D}+01$

$-0.1250000 \mathrm{D}+0$

$-0.1250000 \mathrm{D}+01$

$0.1234000 \mathrm{D}+04$

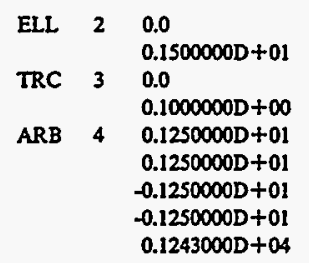

$-0.1250000 \mathrm{D}+01$
$0.2000000 \mathrm{D}+01$
$-0.1250000 \mathrm{D}+01$
$0.2000000 \mathrm{D}+01$
$0.4158000 \mathrm{D}+04$
$-0.1000000 \mathrm{D}+01$
0.0
$0.1000000 \mathrm{D}+01$
0.0
0.0
0.0
$0.9013878 \mathrm{D}+00$

$-0.5000000 \mathrm{D}+\infty$

$0.5000000 \mathrm{D}-01$

$-0.2000000 \mathrm{D}+01$

$0.2000000 \mathrm{D}+01$

$0.2000000 \mathrm{D}+01$

$-0.2000000 \mathrm{D}+01$

$0.7135000 \mathrm{D}+04$ $-0.1000000 \mathrm{D}+01$

0.0

$0.1000000 \mathrm{D}+01$

0.0

0.0

0.0

$0.8246211 \mathrm{D}+\infty$
IDBG $\boldsymbol{~ - ~} 0$

BODY DATA

\begin{tabular}{|c|c|c|c|}
\hline $0.5000000 \mathrm{D}+00$ & $0.1250000 \mathrm{D}+01$ & $-0.2000000 \mathrm{D}+01$ & 0.0 \\
\hline 0.0 & $0.1250000 \mathrm{D}+01$ & $0.1250000 \mathrm{D}+01$ & $0.5000000 \mathrm{D}+00$ \\
\hline $0.5000000 \mathrm{D}+\infty$ & $-0.1250000 \mathrm{D}+01$ & $-0.2000000 \mathrm{D}+01$ & 0.0 \\
\hline 0.0 & $-0.1250000 \mathrm{D}+01$ & $0.1250000 \mathrm{D}+01$ & $0.5000000 \mathrm{D}+00$ \\
\hline $0.6587000 \mathrm{D}+04$ & $0.2673000 \mathrm{D}+04$ & $0.5621000 \mathrm{D}+04$ & $0.4378000 \mathrm{D}+0.4$ \\
\hline 0.0 & 0.0 & $0.1250000 \mathrm{D}+01$ & \\
\hline 0.0 & $-0.1000000 \mathrm{D}+01$ & $0.5000000 \mathrm{D}+00$ & \\
\hline 0.0 & 0.0 & $0.1250000 \mathrm{D}+01$ & \\
\hline 0.0 & $0.1000000 \mathrm{D}+0 \mathrm{l}$ & 0.0 & \\
\hline $0.5547002 \mathrm{D}+\infty 0$ & $-0.8320503 \mathrm{D}+00$ & $0.1109400 \mathrm{D}+01$ & \\
\hline $\begin{array}{r}-0.5547002 \mathrm{D}+\infty 0 \\
0.6000000 \mathrm{D}+01\end{array}$ & $-0.8320503 \mathrm{D}+\infty$ & $0.1109400 \mathrm{D}+01$ & \\
\hline $0.5000000 \mathrm{D}+\infty$ & 0.0 & $0.5000000 \mathrm{D}+\infty 0$ & $0.5000000 \mathrm{D}+00$ \\
\hline $0.8000000 \mathrm{D}+\infty 0$ & 0.0 & $0.2500000 \mathrm{D}+01$ & 0.0 \\
\hline 0.0 & $0.1250000 \mathrm{D}+01$ & $-0.1800000 D+01$ & $-0.8000000 \mathrm{D}+00$ \\
\hline 0.0 & $0.1250000 \mathrm{D}+01$ & $0.1800000 \mathrm{D}+01$ & $-0.8000000 \mathrm{D}+00$ \\
\hline 0.0 & $-0.1250000 \mathrm{D}+01$ & $0.1800000 \mathrm{D}+01$ & $-0.8000000 \mathrm{D}+\infty$ \\
\hline 0.0 & $-0.1250000 \mathrm{D}+01$ & $-0.1800000 D+01$ & $-0.8000000 \mathrm{D}+00$ \\
\hline $0.8756000 \mathrm{D}+04$ & $0.2864000 \mathrm{D}+04$ & $0.7821000 D+04$ & $0.3465000 \mathrm{D}+04$ \\
\hline 0.0 & 0.0 & $0.1250000 \mathrm{D}+01$ & \\
\hline 0.0 & $-0.1000000 \mathrm{D}+01$ & 0.0 & \\
\hline 0.0 & 0.0 & $0.1250000 \mathrm{D}+01$ & \\
\hline 0.0 & $0.1000000 \mathrm{D}+01$ & $0.8000000 \mathrm{D}+\infty$ & \\
\hline $0.9701425 \mathrm{D}+\infty$ & $0.2425356 \mathrm{D} \div 00$ & $0.1940285 \mathrm{D}+01$ & \\
\hline$-0.9701425 \mathrm{D}+00$ & $0.2425356 \mathrm{D} \div 00$ & $0.1940285 \mathrm{D}+01$ & \\
\hline
\end{tabular}

$-0.1800000 \mathrm{D}+01$

$-0.9000000 \mathrm{D}+\infty$

$-0.2500000 \mathrm{D}+01 \quad 0.0$
$-0.1979000 \mathrm{D}+01 \quad-0.6895000 \mathrm{D}+\infty \quad 0.0$ $-0.2000000 \mathrm{D}+00$

$0.4000000 \mathrm{D}+00$

$0.6895000 \mathrm{D}+\infty 0$

$0.4000000 \mathrm{D}+\infty 0$

0.2000

$0.2000000 \mathrm{D}+00$

$-0.2000000 \mathrm{D}+01$

$-0.2000000 \mathrm{D}+\infty 0$

$-0.250$

001

$-0.2500000 \mathrm{D}+01$

$-0.2500000 \mathrm{D}+01$

$0.3580000 \mathrm{D}+\infty 0$

0.0

$-0.3580000 \mathrm{D}+\infty 0$

0.0

0.0

0.0

$0.2000000 \mathrm{D}+0$

$-0.2500000 \mathrm{D}+01$

$-0.2500000 \mathrm{D}+01$

0.0

0.0

$-0.2000000 \mathrm{D}+00$

$-0.2500000 \mathrm{D}+01$

0.0

$-0.6000000 \mathrm{D}+00$

$-0.2500000 \mathrm{D}+01$

$-0.2500000 \mathrm{D}+01$

0.0

$-0.6000000 D+\infty 0 \quad-0.2500000 D+01 \quad 0.0$

$-0.2500000 \mathrm{D}+01 \quad 0.0$

$0.1000000 \mathrm{D}+02$

$-0.1000000 \mathrm{D}+02$

$0.1790000 \mathrm{D}+\infty 0$ 0.0

$.1790000 \mathrm{D}+\infty 0$

0.0

0.0

0.0

0.0

0.0

0.0

0.0

0.0

0.0

0.0

$0.1000000 \mathrm{D}+02-0.1000000 \mathrm{D}+02$

$0.1000000 \mathrm{D}+02$

NUMBER OF BODIES

Figure M13.5.2 Output of combinatorial geometry tank sample problem 


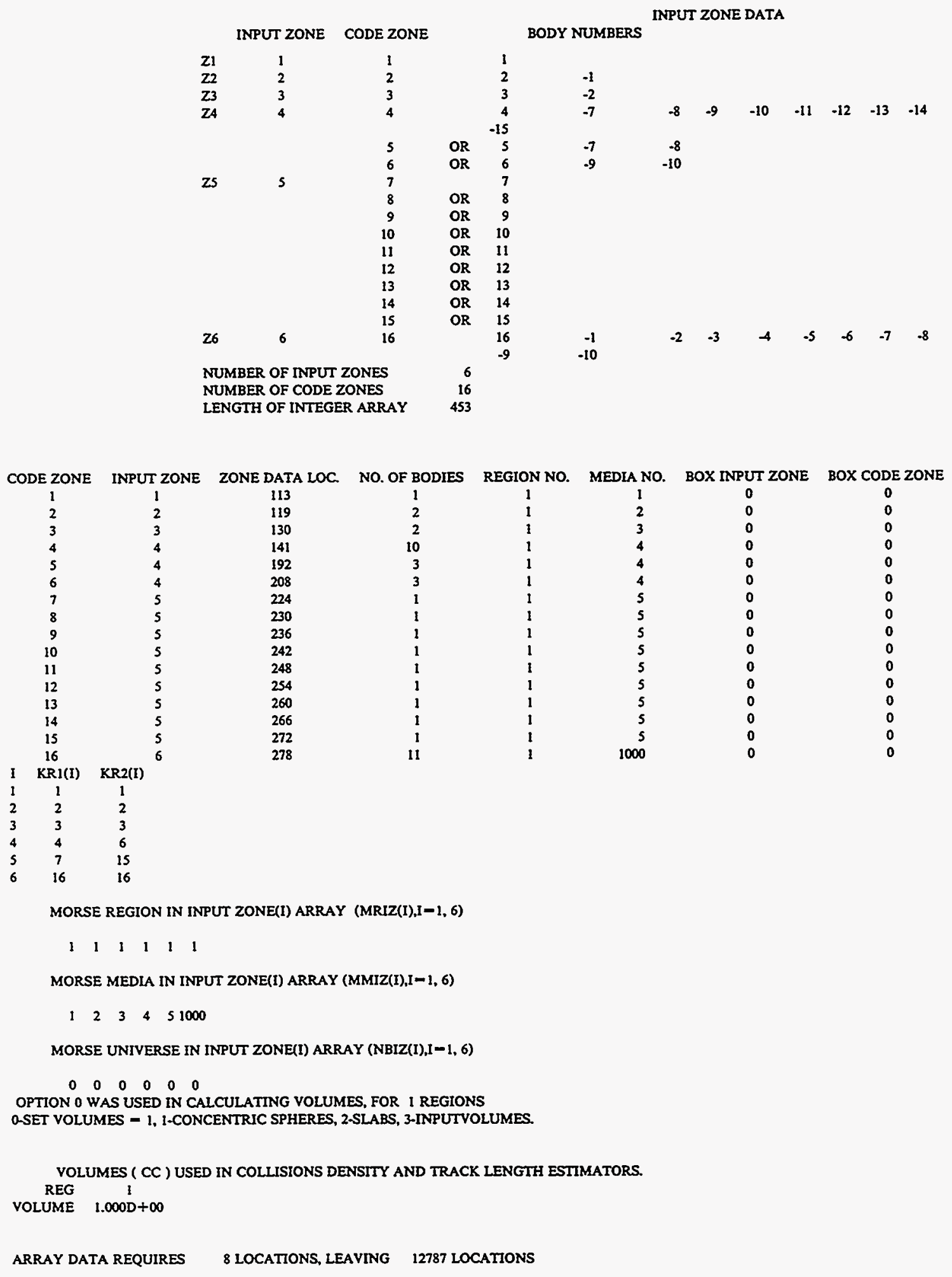

Figure M13.5.2 (contimued)

NUREG/CR-0200,

Vol. 3, Rev. 4

M13.5.4 


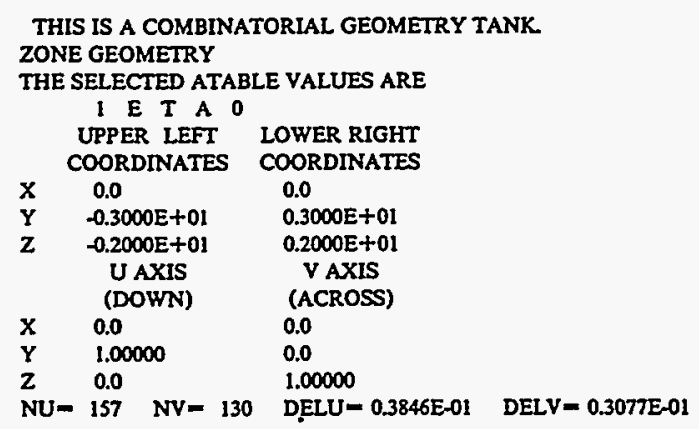

Figure M13.5.2 (continued)

M13.5.5

NUREG/CR-0200, Vol. 3, Rev. 4 
000000000000014000000000 AAIII

O000000000000AAAAAAAAAAAAALI II

0000000000000AAAAAAAAAAAAALIIIII

\$00000000000AAAAAAAAAAAAAALI IIII

IA40000000AAAAAAAAAAAAAAAAIIIIIIII

A4AAAAAAAAAAAAAAAAAAAAAAAALI1111111

AA AAAAAAAAAAAAAAAAAAAAAAAIIIIIIIII

ARAAAAAAAAAAAAAAAAAAAAAAAIIII2111112

AAAAAAAAAAAAAAAAAAAAAAAAAALI1111111111

14AAAAAAAAA AAAAAAAAAAAAAAA1111111111111

AAAAAAAAAAAAAAAAAAAAAAAAAAII 11111111111

14AAAAAAAAAAAAAAAAAAAAAAAAL111111111111111

AAAAAAAAAAAAAAAAAAAAAAAAAAL111111111111111

AAAAAAAAAAAAAAAAAAAAAAAAAA1111111111111111

AAA OOOOOODAAAAAAAAAAAAAAAA11 12112111111111

100000000000 AAAAAAAAAAAAAA1112111111111111

0000000000000AAAAAAAAAAAAA1111111111111111 0000000000000 AAAAAAAAAAAAAII 11111111 IIIIII 0000000000000 AAAAAAAAAAAAA 1111111221112111 A00000000000AAAAAAAAAAAAAA 111111111111111 A ODODODODOAAAAAA AAAAAAAAALI IIIIIIIII AAAOODOOAAAAAAAAAAAAAAAAA11 I11111111111ILEEEEEE AAAAAAAMAAAAAAAAAAAAAAAARAII1111111111121EEEEEEEEE 14AAAAAAAAAAAAAA0000000AAA1111111111111112EEEEEEEEEEE AAAAAAAAAAAAAAODO00000000A1111111111111111EEEEEEEEEEEE AAAAAAAAAAAAA00000000000001111111111111111EEEEEEEEEEEEEE AaAaAaAaAaAaA0000

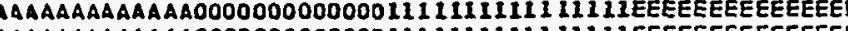
AAAAAAMAAAAAAO000000000000112111211111111EEEEEEEEEEEEEEE

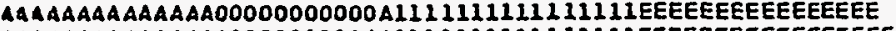
AAA AAAAAAAAAAAAODO000000AAIII 11111111111 EEEEEEEEEEEEEEEEE AAAAAAAAAAAAAAAAA 000 AAAAALI111111111111EEEEEEEEEEEEEEEEE AAA AAAA AAAAAAAAAAAAAAAAAAAII 111111121212 EEEEEEEEEEEEEEEEEE 14000000000 AAAAAAAAAAAAAAAA 1111111111111111 EEEEEEEEEEEEEEEEEE OOOOO0000000AAAAAAAAAAAAAA11111111111111EEEEEEEEEEEEEEEEEE

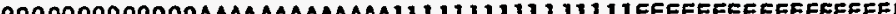
AA111111112 11211EEEEEEEEEEEEEEEEEE 0000000000000AAAAAAAAAAAAAA11121111111 11111 EEEEFEEEEEEEEEEEEEE A O0000000000AAAAAAAAAAAAAA1111111111111111EEEEEEEEEEEEEEEEEE A 000000000 AAAAAAAAAAAAAAA1111111111111111EEEEEEEEEEEEEEEEE AAAAAAAAAAAAAAAAAAAAAAAAAAI11111111111111EEEEEEEEEEEEEEEEE AAAAAARAAAAAAAAAAAOOO AAAAAL111111111111111EEEEEEEEEEEEEEEEE AAAAAAAAAAAAAAAOO0000000AAI111111111111111EEEEEEEEEEEEEEEEE AAAAAAA AAAAAA AAAAAAAAAAAAAO000000000000111111111111111EEEEEEEEEEEEEEE AAAAAAAAAAAAAO000000000000111111112111112EEEEEEEEEEEEEE AAAAAAAAAAAAAAOOODO000000A1111111111111111EEEEEEEEEEEE AAAAAAAAAAAAAARAO000000 AAAI111111111111111EEEEEEEEEEET AAAAAAAAAAAAAAAAAAAAAAAAAALII1111111111111EEEEEEEEETTT AAAAOOODOAAAAAAAAAAAAAAAAA1121111121111111EEEEEE TTTTTT M 000000000AAAAAAAAAAAAAAI111111111111111 TTTTT

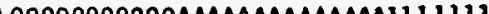
400000000000AAAAAAAAAAAAAIII 111211111111! rTTT OOOODOQ000000AAAAAAAAAAAAALII111111111111 TTTT 000000000000AAAAAAAAAAAAII11111111111112 TTTTT 0000000000000AAAAAAAAAAAAAL221111111111111 TTTTT 400000000000AAAAAAAAAAAAAA1111111111111111 AAA0000000A AAAAAAAAAAAAAAAI111111111111111 AAAAAAAAAAAAAAAAAAAAAAAAAAI111111111111111 TTTTT A4AAMAAA AAAAAAAAAAAAAAAAAAI111111111111111 AAA A TITT AALAAAAAAAA TT AAAAAAAMAAAAAAAAAAAAAAAAAAIIII111111111 TTT AAAAAAAAAAAAAAAAAAAAAAAAAAIL1111111111 TTT AAAAAAAAAAAAAAAAAAAAAAAAAA11111111111 AAAAAAAAAAAAAAAAAAAAAAAAAAII11111111 AAAMAAARAAAAAAAAAAAAAAAAAALAIIIIIIII A4A O0O0000AAAAAAAAAAAAAALI1111111 1 O000000000AAAAAAAAAAAABAL

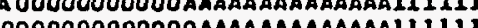
ODO0O0000000AMAAAAAAAAAAALIIII ODO0000000000AAAAAAAAAAAAALI I OO00000000000AA000000000AALI I OOOOOOOOOOOAA00000000000AL

OOOOODOOAAMO000000000D AAAAA0000000000000 AAO0000000000 000000000

TTTT

itrT

TTtT

TTTT

TTT

TTTt

TTT

TTT

TTT

TITT

TTTT

TTT

TTTI

TTT
TTT

Figure M13.5.2 (continued)

NUREG/CR-0200,

Vol. 3, Rev. 4

M13.5.6 
Computing Applications Division

\title{
COMPOZ DATA GUIDE
}

J. R. Knight and L. M. Petrie

Previously Published: December 1984

Revised Manuscript Completed: November 1994

Date Published: April 1995

\author{
Prepared for the \\ Office of Nuclear Material Safety and Safeguards \\ U.S. Nuclear Regulatory Commission \\ Washington, DC 20555 \\ Under Interagency Agreement DOE 1886-8000-9B \\ NRC JCN No. B0009
}

\author{
Prepared by the \\ OAK RIDGE NATIONAL LABORATORY \\ managed by \\ MARTIN MARIETTA ENERGY SYSTEMS, INC. \\ for the \\ U.S. DEPARTMENT OF ENERGY \\ under contract DE-AC05-84OR21400
}




\begin{abstract}
The COMPOZ program used to create the Standard Composition Library is described. Of particular importance is documentation of the COMPOZ input data file structure. Knowledge of the file structure allows users to edit the data file and subsequently create their own site-specific composition library.
\end{abstract}




\section{CONTENTS}

ABSTRACT $\ldots \ldots \ldots \ldots \ldots \ldots \ldots \ldots \ldots \ldots \ldots \ldots \ldots \ldots \ldots \ldots \ldots \ldots \ldots \ldots$ M $\ldots \ldots \ldots$

ACKNOWLEDGMENT $\ldots \ldots \ldots \ldots \ldots \ldots \ldots \ldots \ldots \ldots \ldots \ldots \ldots \ldots \ldots \ldots \ldots$

M14.1 INTRODUCTION . . . . . . . . . . . . . . . . . . . M14.1.1

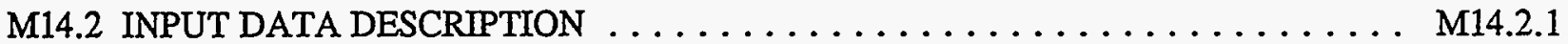

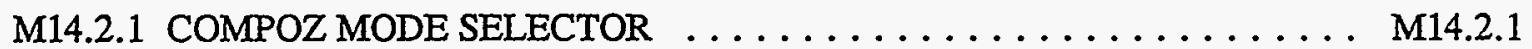

M14.2.2 LIBRARY HEADING INFORMATION . . . . . . . . . . . . . . . . . . M14.2.1

M14.2.3 STANDARD COMPOSITION TABLE . . . . . . . . . . . . . . M14.2.2

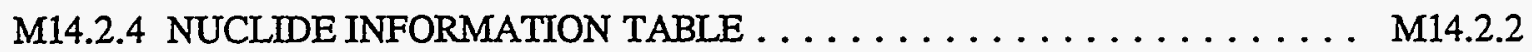

M14.2.5 ISOTOPIC DISTRIBUTION TABLE . . . . . . . . . . . . . M14.2.2 


\section{ACKNOWLEDGMENT}

This work was funded by the Storage and Transport Systems Branch, Office of Nuclear Material Safety and Safeguards, of the U.S. Nuclear Regulatory Commission. 


\section{M14.1 INTRODUCTION}

COMPOZ is the program that creates (writes) the SCALE Standard Composition Library (see Sect. M8). Data are input in free form using the AREAD, FREAD, and IREAD functions in SCALE (see Sects. M2-M3). A card-image data file containing the input to COMPOZ (and the Standard Composition Library) is available with the SCALE system. Execution of COMPOZ using this data file creates the Standard Composition Library currently available with the SCALE package. This section provides documentation of the data file structure. Knowledge of the data file structure allows users to edit the data file and subsequently create their own site-specific or user-specific composition library.

COMPOZ is intended to create or make permanent changes to and/or to print the composition library and should not be used for any other purpose. To avoid confusion with the Standard Composition Library provided with SCALE, it is strongly recommended that only new keywords and compositions be used in any site-specific or user-specific library. 


\section{M14.2 INPUT DATA DESCRIPTION}

COMPOZ imput data are entered in free form (see Sect. M3). All data must be followed by at least one blank. The COMPOZ input data file contains five data records or blocks:

1. COMPOZ mode flag selects whether a new standard composition library will be created, or an old standard composition library will be listed. Only if a new library is being created are the following data records entered.

2. The head record contains the library identification, a set of parameters describing the size of the library, and a three-line library title with 80 characters per line.

3. The standard composition table contains the name, theoretical density, number of elements, and other information about each standard composition. Individual nuclides, mixtures, and compounds are all included in the table.

4. The muclide information table contains the nuclide identification number, atomic mass, resonance energy cross sections, and a resonance flag for each nuclide.

5. The isotopic distribution table contains the muclide identification number and the atom percent of each isotope used in specifying the default enrichment.

Note that for executing COMPOZ via SCALE, an $=$ COMPOZ is required in the first eight columns of a record preceding the mode flag, and an END is required in the first three columns of a record inserted after the last data record.

\section{M14.2.1 COMPOZ MODE SELECTOR}

1 LGEN $=0$ - create a new library and list it

1 - list an existing library

If LGEN is 0 , then input the following data to create a new standard composition library.

\section{M14.2.2 LIBRARY HEADING INFORMATION}

$1 \mathrm{IDT}$ - library identification number

2 NSC - number of standard compositions

3 NNUC - number of entries in the Nuclide Information Table

4 NELV - number of variable isotope definitions

5 MXXELSC - maximum number of elements in a standard composition 
6 MXISEL - maximum number of isotopes in a variable isotope element definition

7 AVOGAD - Avogadro's constant (atoms/b-cm)

8 TITLE - $\quad 3$ lines of 80 characters used to identify the library

\section{M14.2.3 STANDARD COMPOSITION TABLE}

1. SCID Composition name, maximum of 12 characters.

2. NEL Number of elements.

3. ROTH Theoretical density, $\mathrm{gm} / \mathrm{cm}^{3}$.

4. IVIS Does first element have variable isotope distribution?

0 , no;

1 , yes.

5. ICP 0 for a mixture,

1 for a compound.

6. IRS 0 for no resonance data,

1 for resonance data in any constituent.

7. NCZA Element or nuclide ID

8. ATPM Weight percent if ICP $=0$. Number of atoms per molecule if ICP $=1$.

For each composition, items 7 and 8 are repeated until all components of the composition are described. There should be NEL pairs of entries. Items 1 through 8 are entered in a similar fashion for all compositions. There should be a total of NSC composition descriptions. If IVIS $=1$, the first NCZA for that composition must be one of the NZN values from the isotopic distributions directory. Only one isotopic distribution element per composition is allowed.

Nuclides are entered first, in order of increasing nuclide ID, followed by mixtures and compounds in arbitrary order.

\section{M14.2.4 NUCLIDE INFORMATION TABLE}

1. NZA Nuclide ID. This should be the mass number $+1000 *$ the atomic number.

2. AM Atomic mass, $\mathrm{C}-12$ scale.

3. SIGS Resonance energy scattering cross section, barns.

4. SIGT Resonance energy total cross section, barns.

NUREG/CR-0200,

Vol. 3, Rev. 4

M14.2.2 
5. JRS Resonance nuclide identification.

0 , no resonance data;

1 , resonance data.

6. MTS Multiple thermal scatter identifier. Enter 1.

The resonance energy cross sections are averaged over the appropriate energy range for the nuclide. Items 1-6 are repeated for all nuclides. There should be a total of NNUC sets of entries. Entries should be made in order of increasing nuclide ID.

\section{M14.2.5 ISOTOPIC DISTRIBUTION TABLE}

1. NZN $1000 *$ atomic number of variable isotope elements.

2. NISO Number of isotopes in the default abundance.

3. ISZA Isotope ID.

4. ABWP Default abundance, atom percent.

The default abundance is generally the naturally occurring abundance. For each element, items 3 and 4 are repeated until $100 \%$ total abundance is described, making a set for this element. The next element is described in the same fashion in the next set, etc. There should be a total of NELV sets. These sets must be in the same order as the NZN element entries in the isotopic distribution directory. The number of isotopes per element cannot exceed MXISEL. 
Computing Applications Division

USER'S GUIDE FOR UTILTYY MODULES

N. M. Greene

Manuscript Completed: November 1989

Date Published: April 1995

Prepared for theOffice of Nuclear Material Safety and Safeguards

U.S. Nuclear Regulatory Commission

Washington, DC 20555

Under Interagency Agreement DOE 1886-8000-9B

NRC JCN No. B0009

\author{
Prepared by the \\ OAK RIDGE NATIONAL LABORATORY \\ managed by \\ MARTIN MARIETTA ENERGY SYSTEMS, INC. \\ for the \\ U.S. DEPARTMENT OF ENERGY \\ under contract DE-AC05-84OR21400
}




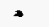

- 


\begin{abstract}
The purpose of this section is to document selected AMPX-77 modules that can benefit the analyst interested in editing, converting, or combining cross-section libraries normally used by the SCALE system modules.
\end{abstract}




\section{CONTENTS}

Page

ABSTRACT $\ldots \ldots \ldots \ldots \ldots \ldots \ldots \ldots \ldots \ldots \ldots \ldots \ldots \ldots \ldots \ldots \ldots \ldots \ldots$

M15.1 INTRODUCTION $\ldots \ldots \ldots \ldots \ldots \ldots \ldots \ldots \ldots \ldots \ldots \ldots \ldots \ldots \ldots \ldots \ldots \ldots$ M15.1.1

M15.2 AIM-MODULE TO CONVERT MASTER CROSS-SECTION LIBRARIES

FROM BCD TO BINARY FORMAT (OR VICE VERSA) $\ldots \ldots \ldots \ldots \ldots \ldots \ldots$ M15.2.1

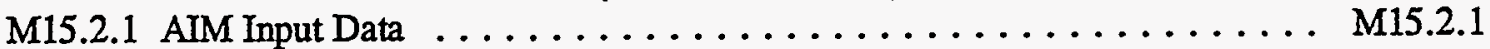

M15.3 AJAX-MODULE TO MERGE, COLLECT, ASSEMBLE, REORDER,

JOIN, AND/OR COPY SELECTED DATA SETS FROM

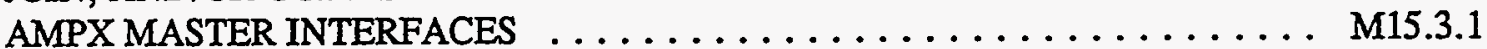

M15.3.1 AJAX Input Data . . . . . . . . . . . . . . . . . M15.3.1

M15.3.2 AJAX Input/Output Specifications . . . . . . . . . . . . M15.3.2

M15.4 ALE-MODULE TO LIST INFORMATION FROM MASTER

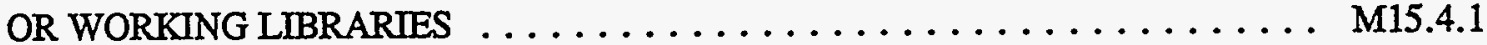

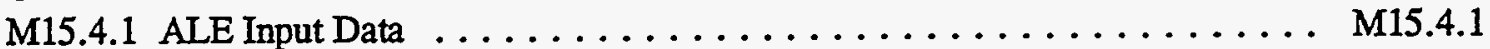

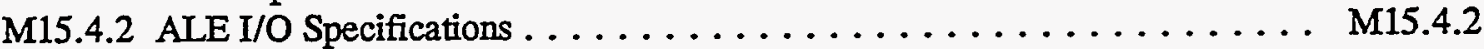

M15.5 ALPO-ANISN LIBRARY PRODUCTION OPTION $\ldots \ldots \ldots \ldots \ldots \ldots \ldots \ldots$ M15.5.1

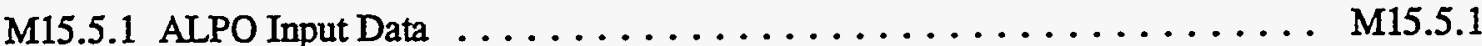

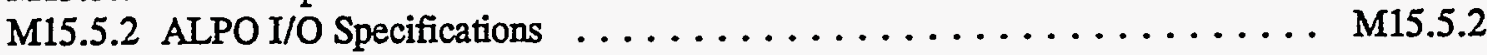

M15.6 CORECTOL-MODULE TO CONVERT PRE-AMPX-77 MASTER

LIBRARIES TO THE AMPX-77 FORM . . . . . . . . . . . . . . . . . . . M15.6.1

M15.6.1 CORECTOL Input Data . . . . . . . . . . . . . . . . M15.6.1

M15.6.2 CORECTOL $1 / O$ Specifications $\ldots \ldots \ldots \ldots \ldots \ldots \ldots \ldots . \ldots \ldots . \ldots \ldots$ M15.6

M15.7 LAVA-AMPX MODULE TO MAKE AN AMPX WORKING LIBRARY

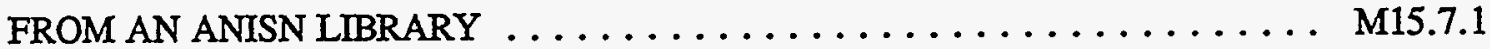

M15.7.1 LAVA Input Data . . . . . . . . . . . . . . . . . M15.7.1

M15.7.2 LAVA I/O Specifications $\ldots \ldots \ldots \ldots \ldots \ldots \ldots \ldots \ldots \ldots \ldots \ldots \ldots . \ldots \ldots$

M15.8 PERFUME-MODULE TO CORRECT LEGENDRE POLYNOMIAL FITS

TO SCATTERING MATRICES $\ldots \ldots \ldots \ldots \ldots \ldots \ldots \ldots \ldots \ldots \ldots$. . . . . . . . . . . . .

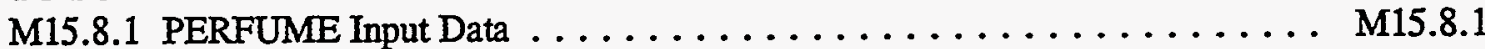

M15.8.2 PERFUME I/O Specification . . . . . . . . . . . . . M15.8.1

M15.9 RADE-MODULE TO CHECK AMPX MASTER CROSS-SECTION

LIBRARIES . . . . . . . . . . . . . . . . . . . . . . . M15.9.1

M15.9.1 RADE Input Data . . . . . . . . . . . . . . . . M15.9.1

M15.9.2 RADE I/O Specifications ................... M15.9.3

M15.v

NUREG/CR-0200, Vol. 3, Rev. 4 
M15.10 WAX-MODULE TO MERGE, COLLECT, ASSEMBLE RE-ORDER, JOIN, COPY SELECTED NUCLIDES FROM AMPX

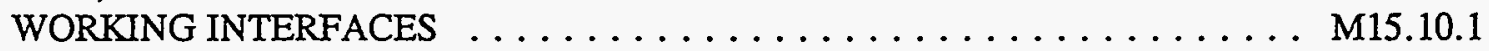

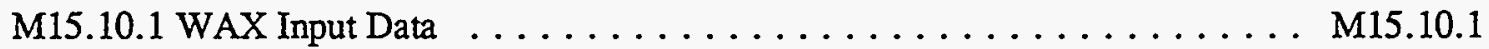

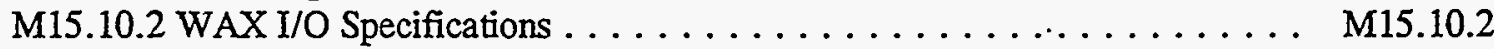

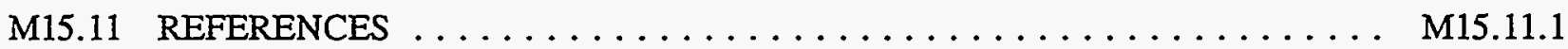

NUREG/CR-0200,

Vol. 3, Rev. 4

M15.vi 


\section{M15.1 INTRODUCTION}

Previous releases of the SCALE system did not include the utility modules discussed in this section, although in practice they perform invaluable operations for edit and special use of cross-section libraries. For example, AIM is absolutely necessary to move the binary-formatted cross sections between different computer hardware. AJAX and WAX are modules to extract and combine sets of data from different libraries. ALE produces listings of data on cross-section libraries. ALPO converts SCALE cross sections to ANISN formats, whereas LAVA performs the reverse operation. RADE is a cross-section checking module that makes simple tests on SCALE cross-section libraries.

All of the modules in this section are shared by the SCALE and AMPX systems. Their input uses the FIDO procedures described in Sect. M10. In the descriptions on the following pages, the number of items to be input into an array is given in square brackets, $\square$; the default values for parameters are given in parentheses, 0 . 


\section{M15.2 AIM-MODULE TO CONVERT MASTER CROSS-SECTION LIBRARIES FROM BCD TO BINARY FORMAT (OR VICE VERSA)}

AIM (AMPX Interchangeable Masters) is a module whose primary purpose is to be able to pass AMPX master cross-section libraries between computers. All AMPX cross-section files are written in binary formats, which are not movable between machines of different manufacturers. AIM has the capability to either read a binary-formatted master library and to "unload" it to the card image format or to read a file written in this same card image format and create a master library. Because all machines can read card image files, this file serves to transmit data between computers. Alternatively, it is possible, though not necessarily efficient, to use AIM to create a master library using card image input because a user can independently create data in the special card image format.

\section{M15.2.1 AIM Input Data}

\section{Block 1}

0\$ Logical Unit Assignments [2]*

1. MBIN - Binary master (1)**

2. $\mathrm{MBCD}-\mathrm{BCD}$ master (18)

$1 \$$ Option Selection Trigger [1]

1. IOPT

0 - Binary to $\mathrm{BCD}$ conversion

$1-\mathrm{BCD}$ to binary conversion

$2 \$$ Data Edit Triggers [4]

1. IP1D (0)

0 - No 1-D edit

$1-$ Edit 1-D cross sections

2. $\operatorname{IP} 2 \mathrm{D}(-1)$

-1 - No 2-D edit

$\mathrm{L}-$ Edit through $\mathrm{P}_{\mathrm{L}}$ of 2-D arrays

3. IPRES (0)

0 - FIDAS print master library data as processed

1 - FIDAS print suppressed

4. IPBOND Not used, enter zero (0)

T Terminate Block 1.

"The number of entries in the array is given in square brackets.

-Default values are given in parentheses. 
If, and only if, the BCD data are to be read from cards, continue with the following input; otherwise, the input to AIM is complete. Note that the following input corresponds to the AMPX master interface specification (see Sect. F2.3.8).

\section{Block M1}

$2 \$$ Tape Identification [10]

1. IID - Library identification number

2. NNUC - Number of nuclides in this library

3. IGM - Number of neutron energy groups

4. IFTG - First thermal group

5. MSN - Nordheim treatment revision level required for this library. A value of 2 is used when the cross sections are intended for NITAWL-II.

6. IPM - Number of gamma-ray energy groups

7. 17 - Zero

8. 18 - Zero

9. 19 - Zero

10. 110 - Zero

T Terminate Block M1.

Five Title Cards, each in (20A4) format. The five cards of Hollerith information can be used to describe the library.

\section{Block M2}

Input Block M2 NNUC times.

TITLE card in (18A4) format. This information is the title for the nuclide.

$3 \$ \mathrm{ID}(19-50) \quad$ Refer to the following table for a description of the $\mathrm{ID}(19), \mathrm{ID}(20, \ldots, \mathrm{ID}(50)$ entries. Note that floating-point entries can be entered using the $3^{*}$ designation, whereas the integers are input in a $3 \$$ array. Simply input both $3 \$$ and $3 *$ arrays, and use the "skip" or "address" options to make the input to the proper place in the array.

Word(s) Item

1-18 18 words of text describing the set

19 Identifier of the set

20 Number of 6-parameter sets of resolved resonance data

21 Number of energies at which to evaluate unresolved values (NITAWL-II does not perform an unresolved resonance calculation and expects this value to be zero.)

22 Number of 1-D neutron processes (temperature independent)

23 Number of 2-D neutron processes

$24 \quad$ Zero

25 Number of 1-D gamma processes

26 Number of 2-D gamma processes

NUREG/CR-0200,

Vol. 3, Rev. 4

M15.2.2 


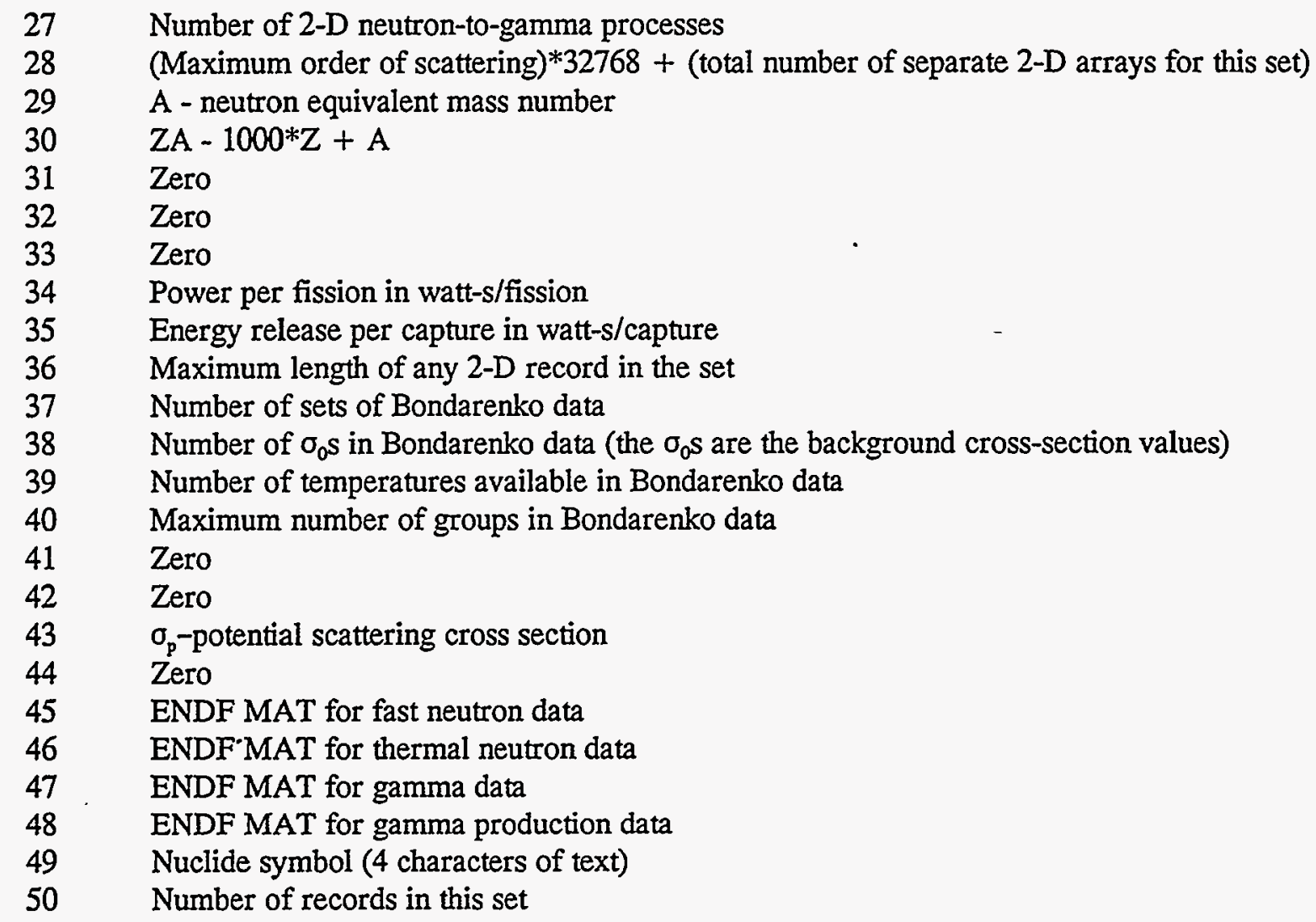

$\mathrm{T}$ Terminate Block M2.

\section{Block M3}

7* Neutron energy group boundaries. [IGM +1$]$ The group boundaries are input high to low in eV.

8* Gamma-ray group boundaries. [IPM +1$]$ The group boundaries are input high to low in $\mathrm{eV}$.

T Terminate Block M3.

Follow with NNUC sets of Blocks M4-M15 data described as follows:

\section{Block M4}

TITLE card in (18A4) format. Use the same title card entered in data block M2 above for the nuclide title.

3\$ ID(19-50) Enter the same data for the appropriate nuclide as described in block M2 above.

T Terminate Block M4. 


\section{Blocks M5, M6. Bondarenko data}

If $\operatorname{ID}(37)>0$, enter the Bondarenko data.

In the following arrays, the array dimensions are taken from the ID values ( $3 \$$ array).

$\mathrm{ID}(37) \equiv \mathrm{NBOND}$, nwnber of Bondarenko processes

$\mathrm{ID}(38) \equiv \mathrm{NSIGO}$, number of $\sigma_{0}$ values

$\mathrm{ID}(39) \equiv \mathrm{NTEMP}$, number of temperatures

Block M5

9* Bondarenko Table Ordinates [NTEMP + NSIGO + 2]

Include NSIGO $\sigma_{0}$ values (high-to-low), followed by NTEMP temperatures in K (low-to-high), followed by ELO and EHI, the lower and upper limits of the energy range for which Bondarenko factors apply.

\section{$10 \$$ Bondarenko Table Directory [6* NBOND]}

The directory array consists of six strings of numbers, arranged one after the other. The first NBOND numbers are the process identifiers (MT-numbers); for example, 2 for elastic scattering and 18 for fission. (See Sect. F3.B for list of MT identifiers.) The next NBOND numbers are the first energy groups for which Bondarenko factors are given for each of the processes; the next NBOND numbers are the last energy group for which the factors are given. The fourth string will contain all zeroes, except for the case of self-shielding transfer matrices, in which case it contains the order of scattering for the process (i.e., 0 for $P_{0}$ terms, 1 for $\mathrm{P}_{1}$, etc.). The fifth string will contain all zeroes except for transfer matrix shielding, in which case it contains the position of the term to be shielded, relative to the "magic word" in the transfer matrix array (e.g., for the case of only downscatter, a 1 would normally point to the within-group term, a 2 to the first downscatter term). The sixth string contains zeroes.

T Terminate Block M5.

\section{Block M6}

This data block will be repeated NBOND times. It consists of two arrays: the infinite dilution values for the process and the corresponding Bondarenko factors. Let NF be the first group for which Bondarenko data are given and NL be the last group. (These groups are taken from the second and third strings from the directory array discussed earlier.)

11* Infinite Dilution Cross Sections [NL - NF + 1]

$\left(\sigma_{\mathrm{ID}}(\mathrm{i}), \mathrm{i}=\mathrm{NF}, \mathrm{NL}\right)$

12* Bondarenko Factors [NSIGO*NTEMP*(NL - NF + 1)] $(((B F(i, j, k), i=1, N S I G O), j=1, N T E M P), k=N F, N L)$

T Terminate Block M6.

NUREG/CR-0200,

Vol. 3, Rev. 4

M15.2.4 


\section{Block M7. Resonance Parameter and Other Neutron Cross-Section Data}

In this block, the following definitions are used:

$\mathrm{NRES} \equiv \mathrm{ID}(20)=$ number of resolved resonances

NUNR $\equiv \operatorname{ID}(21)=$ number of energy points at which to calculate "average" unresolved cross sections (this is zero for NITAWL-II)

$\mathrm{N} 1 \mathrm{D} \equiv \mathrm{ID}(22) \quad=$ number of temperature-independent averaged neutron cross sections

$\mathrm{N} 2 \mathrm{D} \equiv \mathrm{ID}(23) \quad=$ number of neutron-neutron scattering processes

13* Resonance data array; enter if NRES or NUNR is nonzero [6*NRES + NUNR + 9]

The first nine words contain parameters used in both the resolved and unresolved resonance calculations:

1. A, the mass ratio for the isotope or mixture of isotopes

2. $\sigma_{\mathrm{p}}$, the potential scattering cross section

3. $g$, the average statistical factor in the unresolved region

4. NRES, the number of six-parameter resonance sets

5. s, a factor used in the Nordheim calculation to determine the range over which the calculation will be made

6. $\langle D>$, the average level energy spacing for the $\ell=0$ unresolved sequence which will be calculated

7. $\left\langle\Gamma_{n}^{0}\right\rangle$, the average unresolved neutron width

8. $\left\langle\Gamma_{Y}\right\rangle$, the average unresolved gamma width

9. $\left\langle\Gamma_{\mathrm{f}}\right\rangle$, the average unresolved fission width

The next 6 *NRES words consist of six-word sets of data used in the Nordheim calculation. The first six words are:

1. Zero

2. NBLK, the number of blocks of resolved data

3. Zero

4. Zero

5. TREF, the reference temperature at which the infinite dilution arrays on this library were calculated

6. Zero

Following these six words are NBLK six-word groups that are used to specify information concerning blocks of resonance data that apply to, for example, different isotopes, different energy regions, different kinds of data (s-wave or p-wave resonances), etc. These groups are stacked as follows:

1. AWRI, the mass ratio associated with the block of data

2. ABUN, the abundance for the block of data

3. NRE, the number of resonances in the block

4. $\ell$, the value of spin for the resonances in the block

5. EL, the low-energy cut-off for resonances in the block 
6. $\mathrm{EH}$, the upper-energy cut-off for resonances in the block

After these NBLK groups of six words, the six-word sets of resonance parameters are arranged as follows:

1. $E_{0}$, the resonance energy

2. $\Gamma_{n}$, the neutron width of the resonance

3. $\Gamma_{\gamma}$, the gamma width of the resonance

4. $\Gamma_{f}$, the fission width of the resonance

5. $\mathrm{r}$, a factor used in the Nordheim treatment for determining the range of calculation

6. $\mathrm{g}_{\mathrm{J}}$, the statistical factor for the resonance

The following chart illustrates the structure just described schematically:

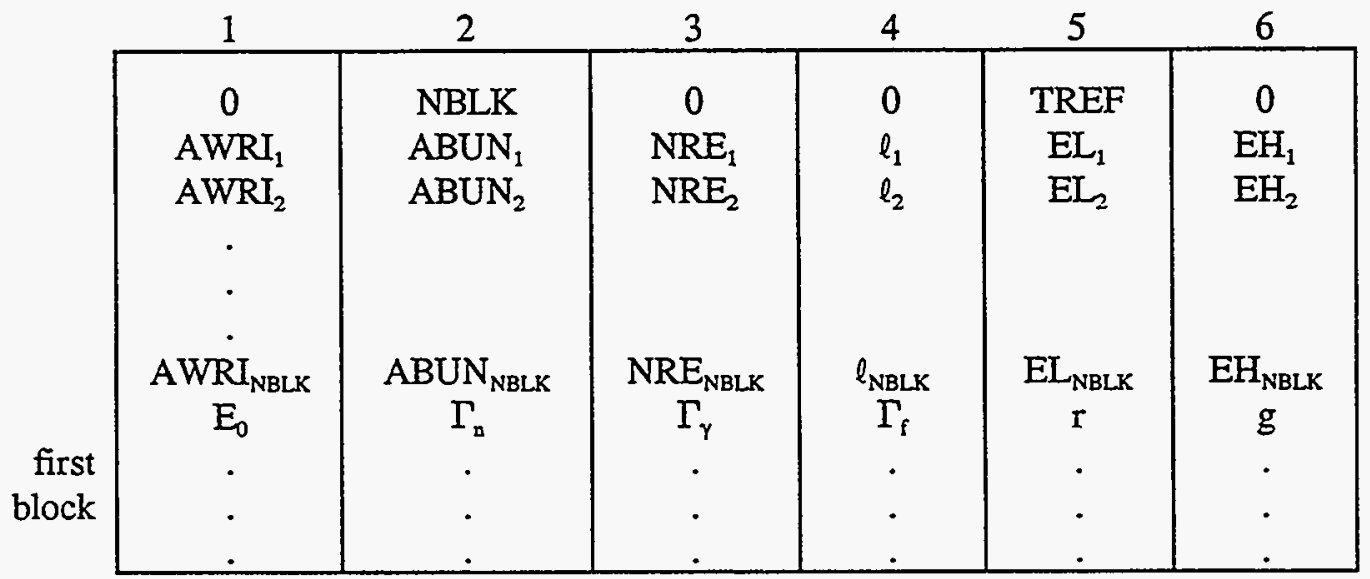

After the resolved resonance parameters, the points at which the unresolved cross section should be evaluated are specified. There are NUNR of these points arranged low to high in energy:

$$
(\operatorname{EUNR}(\mathrm{I}), \mathrm{I}=1, \mathrm{NUNR})
$$

14* Temperature-independent averaged neutron cross sections [N1D*(IGM +1$)]$

Enter process identifier for first process followed by averaged cross sections for all groups (highest energy group to lowest). Enter second process identifier followed by its cross sections, etc.

NUREG/CR-0200,

Vol. 3, Rev. 4

M15.2.6 
Enter the process identifiers for all processes, followed by the corresponding length of the "magic-word" (Sect. M9) compressed arrays, followed by the order of the Legendre fit to each process, followed by the number of temperatures at which the cross sections for each process are given; that is,

$$
\begin{aligned}
& \left(\mathrm{MT}_{\mathrm{i}}, \mathrm{i}=1, \mathrm{~N} 2 \mathrm{D}\right), \\
& \left(\mathrm{L}_{\mathrm{i}}, \mathrm{i}=1 \mathrm{~N} 2 \mathrm{D}\right), \\
& \left(\mathrm{NL}_{\mathrm{i}}, \mathrm{i}=1, \mathrm{~N} 2 \mathrm{D}\right), \\
& \left(\mathrm{NT}_{\mathrm{i}}, \mathrm{i}=1, \mathrm{~N} 2 \mathrm{D}\right) .
\end{aligned}
$$

T Terminate Block M7.

\section{Blocks M8 and M9. Neutron-Neutron Scattering Matrices}

Each scattering process has an M8 and M9 block. Processes where NL is greater than zero have NL + 1 repeats. When NT $\geq 1$, the number of repeats is $N^{*}(N L+1)$. Data for all arrays for the first temperature are given first, etc.

\section{Block M8. Parameters and Temperatures}

17* Temperatures at which the cross sections are given [NT]

$18 \$$ Parameters [2]

1. NMW-number of "magic words" embedded in the transfer matrix

2. LPL - length of the compressed scattering matrix (including space for magic words)

T Terminate Block M8.

\section{Block M9. Scattering Matrix}

$19 \$$ Magic Words [NMWI Specify the "magic words" that are included in the transfer matrix.

20* Scattering Matrix [LPL] Specify the transfer matrix as in the master library format described below. Include zeroes in the positions that will contain magic words.

T Terminate Block M9.

\section{Scattering Matrix Structure}

This record type is used to store scattering matrix data (sometimes called 2-D data). As will be illustrated, it has provisions for truncating zero and/or impossible elements from the array. It exists in two forms: (1) a self-defining form used for gamma production data on a master library and (2) a form that is not self-defining. The only difference is that the self-defining form has the array length as the first word in the record, while the other does not; that is, 


$$
\mathrm{L},(\mathrm{X}(\mathrm{I}), \mathrm{I}=1, \mathrm{~L})
$$

or

$$
(\mathrm{X}(\mathrm{I}), \mathrm{I}=1, \mathrm{~L}) \text {. }
$$

The structure of the X-array is as follows:

magic word for a group,

terms for scattering to the group,

magic word for the next group,

terms for scattering to this group,

etc.

In some cases, a negative or zero magic word is used to specify the end of data in the record.

A magic word is used to define:

1. the sink group number, III,

2. the first group number, JJJ, which scatters to group III, and

3. the last group number, $\mathrm{KKK}$, which scatters to group III.

The magic word is then defined as

$$
\mathrm{MW}=1000000 * \mathrm{JJJ}+1000 * \mathrm{KKK}+\mathrm{III}
$$

such that it is composed of three 3-digit integers:

\section{MW: JJJKKKIII}

The scattering terms below a magic word are in reverse order (following typical practice for transport theory programs); that is, the scattering term for scattering from the last group is first, etc.

$$
\begin{gathered}
\text { MW for group III } \\
\sigma(\mathrm{KKK}-\mathrm{III}) \\
\sigma(\mathrm{KKKK}-1-\mathrm{III}) \\
\cdot \\
\cdot \\
\sigma(\mathrm{JJJ}-\mathrm{III})
\end{gathered}
$$

The scattering matrix record will contain one $\mathrm{P}_{\ell}$ matrix for a process.

Consider an elastic scattering matrix for hydrogen that will be a full triangular matrix and assume three energy groups. The scattering matrix will look as follows:

1001001

$\sigma(1-1)$

1002002

$\sigma(2-2)$

NUREG/CR-0200,

Vol. 3, Rev. 4

M15.2.8 


$$
\begin{aligned}
& \sigma(1 \rightarrow 2) \\
& 1003003 \\
& \sigma(3 \rightarrow 3) \\
& \sigma(2 \rightarrow 3) \\
& \sigma(1 \rightarrow 3)
\end{aligned}
$$

Note that the record is a mixture of integer and floating-point terms.

\section{Data Blocks M10, M11, M12. Gamma-Production Data}

These blocks are required only when $\mathrm{N} 2 \mathrm{DY}[\equiv \operatorname{ID}(27)]$ is greater than zero, where N2DY is the number of processes requiring gamma production data.

\section{Block M10. Gamma-Production-Data Directory}

$21 \$$ Enter the gamma-production process identifiers, followed by the maximum length of the scattering matrices for a process, followed by the order of scattering for the processes, followed by a trigger (0/1cross sections/yields) that specifies whether the gamma-production matrices are in cross section or yield units; that is,

$\left(\mathrm{MTY}_{\mathrm{i}}, \mathrm{i}=1, \mathrm{~N} 2 \mathrm{DY}\right)$,

$\left(L Y_{i}, \mathrm{i}=1, \mathrm{~N} 2 \mathrm{DY}\right)$,

$\left(N L Y_{i}, i=1, N 2 D Y\right)$,

$\left(N_{T Y}, i=1, N 2 D Y\right)$.

T Terminate Block M10.

\section{Blocks M11, M12. Gamma-Production Data}

These blocks are repeated NLY +1 times for each gamma-production (N2DY) process. (Note that NLY is a function of the process.)

\section{Block M11. Parameters}

$22 \$$ Gamma-Production Matrix Parameters [2]

1. NWDY - number of magic words in the scattering matrix.

2. LPLY - length of the scattering matrix.

T Terminate Block M11.

Block M12. Scattering Matrix

$23 \$$ Magic Words [NMWY]

Specify the magic words that will be part of the scattering matrix. 
Specify the scattering matrix. Use zeroes in the positions that will contain magic words.

T Terminate Block M12.

\section{Blocks M13, M14, M15. Gamma-Ray Cross Sections}

These blocks will only be used if either of the following two parameters is a nonzero value.

$\mathrm{N} 1 \mathrm{DZ} \equiv \mathrm{ID}(25)=$ number of gamma-ray averaged cross sections

$\mathrm{N} 2 \mathrm{DZ} \equiv \mathrm{ID}(26)=$ number of gamma-gamma scattering processes

\section{Block M13. Gamma Cross Sections and Directories}

25* Gamma Averaged Cross Sections [N1DZ*(IPM + 1)]

Specify the identifier for the first process, followed by its cross sections, followed by the second process identifier and its cross sections, etc.

26* Gamma-Gamma Scattering Directory [N2DZ*4]

Specify the identifiers of all scattering processes, followed by the lengths of the scattering matrices for the corresponding processes, followed by the orders of scattering for the processes, followed by a zero for each process; that is,

$\left(M T Y_{i}, \mathrm{i}=1, \mathrm{~N} 2 \mathrm{DZ}\right)$

$\left(L Y_{i}, \mathrm{i}=-1, \mathrm{~N} 2 \mathrm{DZ}\right)$

$\left(N L Y_{i}, i=1, N 2 D Z\right)$

$\left(\mathrm{NTY}_{\mathrm{i}}, \mathrm{i}=1, \mathrm{~N} 2 \mathrm{DZ}\right)$

T Terminate Block M13.

Block M14, M15. Gamma-Gamma Scattering Matrices

These blocks are repeated NLZ +1 times for each of the gamma-ray scattering processes.

\section{Block M14. Gamma Parameters}

$27 \$$ Gamma-Gamma Matrix Size and Order

1. NMW2 - number of magic words in the scattering matrix

2. LPL2 - length of scattering matrix

NUREG/CR-0200,

Vol. 3, Rev. 4

M15.2.10 
T Terminate Block M14.

Block M15. Gamma Scattering Matrix

28\$ Magic words [NMW2]

Specify the magic words from the scattering matrix.

29* Scattering Matrix [LPL2]

Specify the scattering matrix.

T Terminate Block M15. 


\section{M15.3 AJAX-MODULE TO MERGE, COLLECT, ASSEMBLE, REORDER, JOIN, AND/OR COPY SELECTED DATA SETS FROM AMPX MASTER INTERFACES}

AJAX (Automatic Ioining of AMPX X-Sections) is a module to combine data from AMPX master interfaces. Options are provided to allow merging from any number of files such that the user is able to determine the final nuclide ordering. Any form of master interface (neutron, gamma-ray, or neutron-gamma) can be accessed.

\section{M15.3.1 AJAX Input Data}

Block 1

$-1 \$$ Core Size [1]

1. LENG - Number of words to allocate to AJAX $(100,000)$

0\$ Logical Unit Assignments [2]

1. MMT - Logical number of new library (default $=1$ )

2. NMAX - Not used

$1 \$ \quad$ Number of Files [1]

1. NFILE - Number of files to be used in constructing the new library. (When "reordering" operations are performed that required the same file to be accessed several times, each access is counted in determining the value of NFILE.)

T Terminate Block 1.

Blocks 2 and 3 are stacked, one after the other, NFILE times.

Block 2

$2 \$ \quad$ File and Option Selection [2]

1. NF - Logical unit number of file considered

2. IOPT - N Delete $N$ nuclides from those on logical NF and add the remainder to the new file.

$=0 \quad$ Add all nuclides on logical NF to the new file.

$=+N$ Add $N$ nuclides from logical $N F$ to the new file.

T Terminate Block 2.

Block 3 Enter only when IOPT $\neq 0\}$

$3 \$$ Nuclides Selected [|IOPT $\mid]$

Identifiers of nuclides that are to be added or deleted from NF.

$4 \$$ New Identifiers [|IOPT $\mid$ ] Enter only if an identifier is to be changed.\} 
This array allows changing the identifier given in the $3 \$$ array for the set of data on the new library.

T Terminate Block 3.

Note that AJAX operates sequentially to construct the new library. Once an identifier is selected for a nuclide on the new file, the occurrence of a set of data with that identifier on any new library will be ignored. Normally, the identifiers will remain the same as those used on the libraries from which data are selected. The $4 \$$ array provides a way to override these identifiers.

\section{M15.3.2 AJAX Input/Output (I/O) Specifications}

The following devices are normally needed to execute AJAX:

\begin{tabular}{|c|c|}
\hline Logical_No. & Purpose \\
\hline 5 & Card input \\
\hline 6 & Standard output \\
\hline 15 & Scratch device \\
\hline 16 & Scratch device \\
\hline 18 & Scratch device \\
\hline 19 & Scratch device \\
\hline $\operatorname{MMT}(1)$ & Master file to be created \\
\hline NF & File(s) to be merged onto MMT \\
\hline
\end{tabular}

NUREG/CR-0200,

Vol. 3, Rev. 4

M15.3.2 


\section{M15.4 ALE-MODULE TO LIST INFORMATION FROM MASTER OR WORKING LIBRARIES}

ALE is a module that will produce listings of information contained on an AMPX master or working library. It also has provisions for controlling the spacing of the output.

\section{M15.4.1 ALE Input Data}

\section{Block 1}

0\$ Logical assignments [2]

1. MMT - master library

2. MWT - working library

$1 \$$ Selection option [1]

1. NEDIT - number of nuclides for which listings are to be produced (a zero selects all nuclides on a library).

$2 \$$ Block edit option [10]

(A nonzero value selects editing the data.)

1. NLDN - 1-D neutron arrays

2. NLDG - 1-D gamma arrays

3. NRES - resonance data

4. IOPT4 - not used

5. IOPT5 - not used

6. IOPT6 - not used

7. IOPT7 - not used

8. IOPT8 - not used

9. IOPT9 - not used

10. ICORE - number of words allocated to this module (default 50000)

$3 \$$ Block carriage control characters [25]

The entries have the following effect on how the header line for a particular kind of data is printed: all values are 0 , by default, which says to skip a line before printing the block; a 1 can be used to start a block on a new page.)

1. Nuclide directory information

2. One-dimensional cross sections (absorption, fission, etc.)

3. Two-dimensional cross sections (scattering matrices)

4. Bondarenko data

5. Unassigned

6. Unassigned

7. Unassigned

8. Unassigned

9. Unassigned 

10. Unassigned
11. Unassigned
12. Unassigned
13. Unassigned
14. Unassigned
15. Unassigned
16. Unassigned
17. Unassigned
18. Unassigned
19. Unassigned
20. Unassigned
21. Unassigned
22. Unassigned
23. Unassigned
24. Unassigned
25 . Unassigned

$4 \$$ Scattering Matrices to be edited [100]

Enter the MT numbers of the processes for which edits are desired.

$5 \$$ Order of Scattering Matrices to be edited [100]

The $4 \$$ and $5 \$$ arrays are entered in one-to-one correspondence. The entries in the $5 \$$ array give the maximum order of Legendre coefficient to be listed (e.g., a value of 2 would cause the $P_{0}, P_{1}$, and $P_{2}$ scattering matrices to be listed).

T Terminate Block 1 .

Block 2 (Enter only if NEDIT $>0$ )

$11 \$$ Nuclide identifiers [NEDIT]

These are the identifiers for the nuclides for which listings are to be made.

T Terminate Block 2.

\section{M15.4.2 ALE I/O Specifications}

ALE requires the following I/O devices.

NUREG/CR-0200,

Vol. 3, Rev. 4 


\begin{tabular}{cl} 
Logical No & \multicolumn{1}{c}{ Purpose } \\
5 & Standard input \\
6 & Standard output \\
MMT & Master library \\
MWT & Working library
\end{tabular}

M15.4.3

NUREG/CR-0200, Vol. 3, Rev. 4 


\section{M15.5 ALPO (ANISN LIBRARY PRODUCTION OPTION)}

ALPO is a module for producing ANISN libraries from AMPX working libraries. Several working libraries can be accessed in a given run. The ANISN library can be produced in either binary or BCD format.

\section{M15.5.1 ALPO Input Data}

\section{Block 1}

$-1 \$$ Process Identifiers by Position in the ANISN Library [100].

This array can be used to override the normal arrangement of cross-section types in ANISN $^{1}$-formatted libraries or can be used to produce special cross-section sets; for example, dose factor sets that contain several processes. The identifier for the process to be placed in row 1 of the ANISN tables is input first; row 2, second; etc. Note that nuclides that do not contain the processes noted in this table will revert to the normal ANISN ordering, namely, $\sigma_{\mathrm{T}}$ in position IHT, $\overline{v \sigma}_{\mathrm{f}}$ in position IHT-1, etc.

$0 \$ \quad$ Logical Assignments [2]

1. MAN - logical unit for ANISN library (Use a 7 when a punched card output is desired.) (default $=20$ )

2. MAX - not used

$1 \$ \quad$ Primary Options [8]

1. NFILE - number of working libraries to be accessed

2. IHT - position of the total cross section in the ANISN tables (3)

3. IHS - position of the within-group cross-section in the ANISN tables

IHT + IGM - IFTG + 1, where IGM is the number of neutron energy groups; IFTG is the first thermal group

4. ITL - table length of the ANISN tables, IHS + IGM + IPM - 1, where IPM is the number of gamma-ray groups

5. MAXPL - the maximum order of scattering to be written on the ANISN library (20)

6. IOPT1D - option to print group averaged cross sections (0). A 1 selects printing

7. IOPT2D - option to print scattering matrices $(O)$. A 1 selects printing

8. ITRANS - transport correction option (0)

$-N$, truncate $P_{N}$ and above matrices and correct all lower ordered within-group terms by $2(2 \ell+1) \times \sigma_{\mathrm{N}}\left(\mathrm{g} \rightarrow \mathrm{g}^{\prime}\right) /(2 \mathrm{~N}+1)$

0 , no transport correction

1 , replace $\sigma_{\mathrm{t}}$ with $\sigma_{\mathrm{tr}}=\sigma_{\mathrm{a}}+(1-\mu) \sigma_{\mathrm{s}}$, where $\mu$ is calculated by summing the $\mathrm{P}$, matrix and dividing by the $P_{0}$ sum or by $2 /(3 \times A)$ when $P_{1}$ is not given. (The within-group term is also adjusted.)

T Terminate Block 1.

Data Blocks 2 and 3 are repeated NFILE times. 


\section{Block 2}

$2 \$ \quad$ File Selection Options [2]

1. NF - logical number of the working library

2. IOPT - nuclide selection

$-\mathrm{N}$, accept all nuclides from the working library except the $\mathrm{N}$ designated in the $3 \$$ array below.

0 , accept all nuclides from the working library

$+\mathrm{N}$ accept all the $\mathrm{N}$ nuclides from the working library that are designated at the $3 \$$ array below.

$\mathrm{T}$ Terminate the data block.

\section{Block $3\{$ IOPT $\neq 0\}$}

$3 \$ \quad$ Nuclides to be selected or ignored [ $\mid$ IOPT $\mid]$

T Terminate the data block.

\section{M15.5.2 ALPO I/O Specifications}

The following devices are normally needed to execute ALPO:

\begin{tabular}{|c|c|}
\hline Logical No. & Purpose \\
\hline 5 & Card input \\
\hline 6 & ard output \\
\hline 7 & Punched card output \\
\hline 14 & Scratch device \\
\hline MAN(20) & ANISN binary library \\
\hline MAX( & AMPX working librar \\
\hline
\end{tabular}




\section{M15.6 CORECTOL-MODULE TO CONVERT PRE-AMPX-77 MASTER LIBRARIES TO THE AMPX-77 FORM}

Prior to AMPX-77, the implementation of the Nordheim Integral Treatment in the NITAWL module assumed that the cross sections in the master library would be split into two cases:

1. cross sections for the bodies of the resonances (weighted over a reference), and 2. wing cross sections, which included correction values, values for $\ell=1,2$, etc., resonances (i.e., everything in the cross sections which the Nordheim calculation was not going to calculate)

This arrangement allowed one to simply add these pieces together if an infinite dilution set was desired, or to perform a resonance self-shielding calculation and add to the second set noted above to obtain self-shielded values. This procedure required that the basic processing code be required to know exactly where the bodies of the resonances would be calculated, and, thereby, precluded the use of the Nordheim treatment with libraries not based on this knowledge.

It was recognized that a better way to implement the Nordheim treatment would be to reference the self-shielded values to infinite dilution values. The Nordheim calculation, therefore, would really be two calculations: (1) the regular calculation, just as before, and (2) a calculation where the cross-section values are simply weighted over a $1 / \mathrm{E}$ flux. The difference in the two values could then simply be added to the reference set to obtain shielded values. This new approach has several advantages: (1) it allows the Nordheim calculation to be performed with any library that used $1 / \mathrm{E}$ weighting in the resonance range, a commonly used scheme; (2) it allows one to always refine (or unrefine) a calculation by adding (for example, $\ell=1$ ) or deleting resonance parameters; and (3) it allows for increased accuracy in the analysis.

Clearly, the base library needed by the two approaches is different. The task of taking the earlier AMPX master libraries and converting them to the new format by adding together the resonance body values and the wing values and discarding the wing values is the purpose of the CORECTOL (CORrECT Old Libraries) module. It is a very simple module to use and requires essentially that the user define where the files are located. Obviously, CORECTOL has no counterpart module for converting newer libraries to the older form, as it is this complicated task that the newer procedures have been designed to eliminate.

\section{M15.6.1 CORECTOL Input Data}

\section{Block 1.}

$-1 \$ \quad$ Core Assignment [1]

1. ICORE - Number of words of core to assign to this module (100000)

$0 \$ \quad$ Logical Assignments [4]

1. NT1 - Old AMPX master (1)

2. NT2 - New AMPX master (2)

3. NS - Scratch device (18)

4. NT - Scratch device (19)

T Terminate Block 1. 


\section{M15.6.2 CORECTOL I/O Specifications}

CORECTOL uses the following I/O devices:

\begin{tabular}{ll} 
LogicalNo & \multicolumn{1}{c}{ Purpose } \\
\cline { 2 - 2 } 5 & Card input \\
6 & Printed output \\
NT1(1) & Old AMPX master library \\
NT2(2) & New AMPX master library \\
NS(18) & Scratch device \\
NT(19) & Scratch device
\end{tabular}

NUREG/CR-0200,

Vol. 3, Rev. 4 


\section{M15.7 LAVA-AMPX MODULE TO MAKE AN AMPX WORKING LIBRARY FROM AN ANISN LIBRARY}

LAVA (Let ANISN Visit AMPX) is a module that can convert an ANISN library (neutron, gamma, or coupled neutron-gamma) to an AMPX working library that can be used in XSDRNPM. ANISN cross sections can be input on cards (fixed- or free-form FIDO format) or on a binary library.

\section{M15.7.1 LAVA Input Data}

\section{Block 1}

$-1 \$$ Core Allocation [1]

1. NWORD - number of words to allocate to LAVA (50000)

0\$ Logical Definitions [6]

1. N1 - ANISN library (20)

2. N2 - AMPX working library (4)

3. N3 - Scratch (18)

4. N4 - Scratch (19)

5. N4 - Input (5)

6. N6 - Output (6)

$1 \$$ ANISN Library Parameter Data [8]

1. NNUC - Number of isotopes to be put on new library

2. IGM - Number of neutron groups

3. IHT - Position of $\sigma_{\mathrm{t}}$

4. IHS - Position of $\sigma_{\mathrm{g}-\mathrm{g}}$

5. IHM - Table length

6. IFTG - First thermal group

7. IPM - Number of gamma groups

8. IFM - Format of ANISN library

-1 , binary

0 , free-form $B C D$

1 , formatted $B C D$

9. IFLAG - Flag that selects the method for calculating scattering cross sections from scattering matrices -0 or 1 (default $=1$ ). ANISN matrices are the sum of all the individual scattering matrices (elastic, inelastic, $\mathrm{n} 2 \mathrm{n}, \mathrm{n} 3 \mathrm{n}$, etc.) for processes possible for the particular nuclide. LAVA attempts to arbitrarily determine values for an elastic (MT = 2 ) and an $n 2 n(M T=16)$ cross section, recognizing that elastic scattering is generally the most dominant scattering process and that $n 2 n$ is the most common scattering process that yields more than a single exit neutron. To accomplish this, the absorption cross section in the ANISN data must be the true absorption value (not an energy absorption cross section as in some older gamma-ray sets or whatever alternative value). When IFLAG $=1$, requiring the correct absorption, the elastic value is taken as 


$$
\sigma_{\ell}^{g}=\sigma_{a}^{g},
$$

but the $\mathrm{n} 2 \mathrm{n}$ is taken from

$$
\sigma_{\mathrm{n}, 2 \mathrm{n}}^{\mathrm{g}}=\sum_{\mathbf{g}^{\prime}} \sigma_{0}\left(\mathrm{~g}^{\prime}\right)-\sigma_{l}^{\mathrm{g}}
$$

When IFLAG $=0$, no attempt is made to calculate an $\mathrm{n} 2 \mathrm{n}$ value and the elastic value is simply

$$
\sigma_{\ell}^{\mathrm{g}}=\sum_{\mathbf{g}^{\prime}} \sigma\left(\mathrm{g}^{\prime}\right)
$$

T Terminate Block 1.

\section{Block 2}

$2 \$$ Identifiers of $\mathrm{P}_{0}$ Block of Data for the Nuclide on the ANISN Library (see Ref. 1) [NNUC]

$3 \$$ Order of Scattering For the Nuclides on the ANISN Library [NNUC]

If an order of scattering for a nuclide is negative, the $P_{d}(\ell>0)$ matrices for the nuclide will be multiplied by $(2 \ell+1)$ to account for differences in the way different installations normalize the matrices.

4\$ AMPX Identifiers for the Nuclides Selected From ANISN Library [NNUC]

$5 \$$ MT of each 1-D position in the ANISN Library [IHT]

The order is from position IHT to position 1. Note, MT numbers of frequently used data appear in the 1-D positions and are as follows:

6* Fission Spectrum [IGM]

If a nuclide has a nonzero fission cross section and either no fission spectrum (MT $=1018$ ) is specified in the 1-D positions of the ANISN library or the fission spectrum flag for that nuclide has been appropriately set in the $9 \$$ array, then the fission spectrum specified by the $6 *$ array is included for that nuclide.

7* Neutron Energy Group Boundaries* [IGM + 1]

8* Gamma-Ray Energy Group Boundaries* [IPM + 1]

Read high-to-low in energy (eV).

NUREG/CR-0200,

Vol. 3, Rev. 4

M15.7.2 
$9 \$$ Nuclide CHI Flags [NNUC]

$0 / 1$ - Use the fission spectrum from 1-D's/use the fission spectrum from the $6^{*}$ array

T Terminate Block 1.

\section{M15.7.2 LAVA I/O Specifications}

The following devices are normally needed in running the LAVA module:

\begin{tabular}{cl} 
Logical No & \multicolumn{2}{c}{ Purpose } \\
\cline { 2 - 2 } N2 & AMPX working library written by LAVA (4) \\
N5 & Card input (5) \\
N6 & Standard output (6) \\
N3 & Scratch device (18) \\
N4 & Scratch device (19) \\
N1 & ANISN library (20)
\end{tabular}




\section{M15.8 PERFUME-MODULE TO CORRECT LEGENDRE POLYNOMIAL FITS TO SCATTERING MATRICES}

PERFUME (PERmute EaUlly Moment Expansions) is a module that examines scattering matrices to locate those matrices that yield nonphysical fits and adjusts them to produce acceptable distributions. The procedure involves an examination of the moments of the cross section, as described in Appendix F9.D.2 of the SCALE documentation. With these prescriptions, a range of possible coefficients is determined, after which PERFUME arbitrarily picks the value at the midpoint of the range.

\section{M15.8.1 PERFUME Input Data}

$-1 \$$ Core Assignment [1]

1. NWORD - Number of words to allocate to PERFUME (100000)

0\$ Logical Assignments [3]

1. NTP - Input master library (23)

2. NOP - Output master library (1)

3. NER - Error message output file (6)

Assign this to a unit other than 6 to suppress the voluminous error message listing that may be produced by some libraries, if you do not wish to view this information.

$1 \$ \quad$ Output Suppression Factor [1]

1. EPS - Information concerning bad moments is edited when the zeroeth moment of the transfer term (i.e., $\sigma_{0}$ ) satisfies the following expression (default $=0.0001$ ):

$$
\sigma_{0}>\epsilon * N^{3}
$$

where $\mathrm{N}$ is the order of Legendre fit to the cross section. [Warning: For a library with a large number of energy groups and nuclides, the amount of output can be substantial.]

T Terminate Block 1.

\section{M15.8.2 PERFUME I/O Specification}

PERFUME uses the following I/O assignments:

Logical No.

5

6

$\mathrm{NTP}(23)$

NOT(1)
Purnose

Card input

Printed output

Input master library

Output master library 


\section{M15.9 RADE-MODULE TO CHECK AMPX MASTER CROSS-SECTION LIBRARIES}

RADE (Rancid AMPX Data Exposer) is provided to check AMPX-and ANISN-formatted multigroup libraries. It will check neutron, gamma, or coupled neutron-gamma libraries.

Some of the more important checks are made to ensure that:

1. $\sigma_{\mathrm{t}}=\sigma_{\mathrm{a}}+\sigma_{\mathrm{s}}$

2. $\sigma_{\text {in }}=\Sigma \sigma_{\text {in }}^{\text {partial }}$

3. $\sigma_{\mathrm{a}}=\sigma_{\mathrm{c}}+\sigma_{\mathrm{f}}$

4. $\sigma_{c}=\sigma_{\mathrm{ny}}+\sigma_{\mathrm{n} \alpha}+\sigma_{\mathrm{ng}}+\sigma_{\mathrm{nd}}+\ldots$

5. $\quad \sigma_{\mathrm{el}}^{\mathrm{g}}=\Sigma_{\mathrm{g}^{\prime}} \sigma_{\mathrm{el}, 0}\left(\mathrm{~g}^{\prime}\right)$ (also made on any process with a scattering matrix)

6. $\sigma_{0\left(\mathrm{~g}^{\left.-g^{\prime}\right)}\right.}>0$

7. $\sigma_{\imath}, \sigma_{\mathrm{a}}, \sigma_{\mathfrak{f}}, \sigma_{\mathrm{ny}}, \sigma_{\mathrm{pp}}, \ldots>0$

8. $f_{\ell}^{\min } \leq f_{\ell}\left(g \rightarrow g^{\prime}\right) \leq 1.0$

where $f\left(g \rightarrow g^{\prime}\right)=\frac{\sigma_{\ell}\left(g \rightarrow g^{\prime}\right)}{(2 \ell+1) \sigma_{0}\left(g \rightarrow g^{\prime}\right)}$

and $f_{\ell}^{\min }=-1.0$ for all odd $\ell$, and is given in the following table for even $f$ :

\begin{tabular}{|c|c|}
\hline$\ell$ & $f_{l}^{\min }$ \\
\hline ? & -0.5 \\
\hline & -0.433 \\
\hline 6 & -0.419 \\
\hline 8 & -0.414 \\
\hline
\end{tabular}

In addition to these checks, the code will compute an estimate of the capture-binding energy for each neutron group in a coupled neutron-gamma set. On option, one can request a display of differential cross sections.

\section{M15.9.1 RADE Input Data}

\section{Block 1}

$-1 \$ \quad$ Core Assignment [1]

1. NWORD - number of words to allocate RADE (100000) 
1\$ Checking Commands [4]*

1. MMT - Check the AMPX Master Interface on logical MMT. This can be a neutron, gamma, or a coupled neutron-gamma library.

2. MWT - Check the AMPX Working/Weighted Interface on logical MWT.

3. MAN - Check the ANISN binary-formatted library on logical MAN.

4. IFM - -1, ANISN library is binary formatted.

0 , ANISN library is BCD free form.

1 , ANISN library is BCD fixed form.

$2 \$ \quad$ Options [20]

1. IOPT1 - Number of angles at which a display of differential cross sections is desired. These angles will be equally spaced in the cosine range, -1 to +1 . These edits are for the groupintegrated cross sections and not for each group-to-group transfer.

2. IOPT2 - The $\epsilon$, in $1 / 1000$ of a percent, to which checks are made (e.g., IPT $2=1$ ) is equivalent to $0.001 \%$ checking. This is the default value when IOPT2 is not input or when a zero value is input.

3. IOPT3

. Future checking options; skip or input zeros

20. IOPT20

$3 \$$ ANISN Options [7] \{MAN $\neq 0\}$

1. NSET - Number of ANISN sets to check

2. IHT - Position of $\sigma_{\mathrm{t}}$

3. IHS - Position of $\sigma_{g 8}$

4. ITL - Table length

5. NL - Maximum order of scattering

6. IGM - Number of neutron groups

7. IPM - Number of photon groups

T Terminate Block 1 .

Block 2

$\{$ Input only when MAN $>0\}$

$4 \$$ Identification Numbers of $P_{0}$ Sets on ANISN Binary Library on Logical MAN [NSET]

$5 \$$ Order of Scattering of Sets of ANISN Data on Logical MAN [NSET]

7* Neutron Group Structure, high-to-low in eV [IGM + 1]

Number of entries in the array.

NUREG/CR-0200,

Vol. 3, Rev. 4

M15.9.2 
8* Gamma Group Structure, high-to-low in eV [IPM + 1]

T Terminate Block 2.

M15.9.2 RADE I/O Specifications

RADE requires the following $I / O$ assignments:

\begin{tabular}{cl} 
Logical unit & \multicolumn{1}{c}{ Purpose } \\
\cline { 2 - 2 } 5 & Card input \\
6 & Printed output \\
18 & Scratch device \\
19 & Scratch device \\
MMT & Master library \\
MWT & Working library \\
MAN & ANISN library
\end{tabular}




\section{M15.10 WAX-MODULE TO MERGE, COLLECT, ASSEMBLE, RE-ORDER, JOIN, COPY SELECTED NUCLIDES FROM AMPX WORKING INTERFACES}

WAX (Working Libraries AJAX) is a module to combine data on AMPX working libraries. Options are provided to allow merging from any number of files in a manner as to allow the user to determine the final nuclide ordering, if desired.

\section{M15.10.1 WAX Input Data}

\section{Block 1}

$-1 \$$ Core assignment $[1]$

1. NWORD - Number of words to allocate to VEL (5000)

0\$ Logical assignments [2]

1. MWT - Logical number of new library (default $=1$ )

2. NWAX - Not used

$1 \$$ Number of files [1]

1. NFILE - Number of files which will have data selected from them

T Terminate Block 1.

Blocks 2 and 3 are stacked, one after the other, NFILE times.

\section{Block 2}

$2 \$ \quad$ File and option selection [2]

1. NF - Logical number of file considered

2. IOPT $^{*}=-\mathrm{N}$ Delete $\mathrm{N}$ nuclides from $\mathrm{NF}$ to create the new file on $\mathrm{MWT}$

$=0$ Add all nuclides to the new file on MWT

$=\mathrm{N}$ Add $\mathrm{N}$ nuclides from $\mathrm{NF}$ to create the new file on MWT

T Terminate Block 2.

Block 3 (Enter only when IOPT $\neq 0$ )

$3 \$$ Nuclides selected [|IOPT |]

Identifiers of nuclides which are to be added or deleted from NF

-Sets with duplicate identifiers will not be entered on MWT. The first occurrence of an identifier selects that set for the new library.

M15.10.1

NUREG/CR-0200, Vol. 3, Rev. 4 
$4 \$$ New identifiers [|IOPT $\mid]$

This array allows changing the identifier given in the $3 \$$ array when it is selected for the new library.

T Terminate Block 3.

\section{M15.10.2 WAX I/O Specifications}

The following devices are normally needed to execute WAX.

Logical No.
5
6
15
16
18
19
MWT(1)
NF

Purpose
Card input
Standard output
Scratch device
Scratch device
Scratch device
Scratch device
Working file to be created
File(s) to be merged onto MWT

NUREG/CR-0200,

Vol. 3, Rev. 4

M15.10.2 


\section{M15.11 REFERENCE}

1. W. W. Engle, Jr., A User's Manual for ANISN, USAEC Report K-1693, Union Carbide Corp., Nucl. Div., Oak Ridge Gaseous Diffusion Plant, March 1967. 
NUREG/CR-0200

Revision 4

Volume 3, Section M16

ORNL/NUREG/CSD-2/V3/R4

Computing Applications Division

COMMENT DATA GUIDE

L. M. Petrie

Manuscript Completed: February 1993

Date Published: April 1995

\author{
Prepared for the \\ Office of Nuclear Material Safety and Safeguards \\ U.S. Nuclear Regulatory Commission \\ Washington, DC 20555 \\ Under Interagency Agreement DOE 1886-8000-9B \\ NRC JCN No. B0009
}

\author{
Prepared by the \\ OAK RIDGE NATIONAL LABORATORY \\ managed by \\ MARTIN MARIETTA ENERGY SYSTEMS, INC. \\ for the \\ U.S. DEPARTMENT OF ENERGY \\ under contract DE-AC05-84OR21400
}




\section{$\cdot$}




\begin{abstract}
The COMMENT program is a utility program that selectively tailors FORTRAN source code for different machines and operating systems.
\end{abstract}


CONTENTS

Page

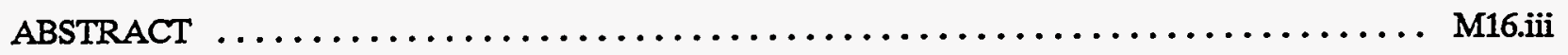

M16.1 INTRODUCTION $\ldots \ldots \ldots \ldots \ldots \ldots \ldots \ldots \ldots \ldots \ldots \ldots \ldots \ldots \ldots \ldots \ldots \ldots \ldots \ldots \ldots \ldots .1$

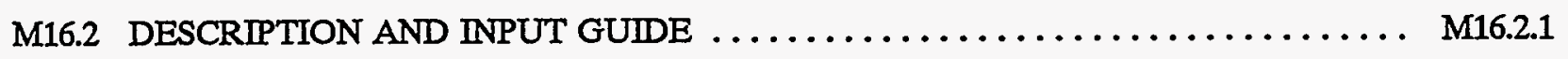

NUREG/CR-0200,

Vol. 3, Rev. 4 


\section{M16.1 INTRODUCTION}

The COMMENT program is used to selectively tailor FORTRAN source code for different machines and operating systems. 


\section{M16.2 DESCRIPTION AND INPUT GUIDE}

The COMMENT program is a utility program that selectively comments and uncomments lines of FORTRAN source code to provide a source code tailored to different machines and operating systems.

A list of comments and conversion types is given in Table M16.1.

Table M16.1. COMMENT language flags

\begin{tabular}{|c|c|c|c|c|c|c|c|c|}
\hline \multirow[b]{2}{*}{ Comment } & \multicolumn{8}{|c|}{ Conversion type } \\
\hline & IBM & VAX & MFE & LANL & UNIX & UNICOS & ULTRIX & AIX \\
\hline CSHR & $\mathrm{X}$ & $\mathrm{X}$ & & & $X$ & & $\mathrm{X}$ & $\mathbf{x}$ \\
\hline CLNG & & & $\mathbf{X}$ & $\mathbf{X}$ & & $\mathbf{x}$ & & \\
\hline CIBM & $\mathrm{X}$ & & & & & & & \\
\hline CUNI & & & & & $\mathrm{X}$ & $\mathrm{X}$ & $X$ & $\mathrm{X}$ \\
\hline CULT & & & & & & & $x$ & \\
\hline CUCS & & & & & & $\mathrm{X}$ & & \\
\hline CADX & & & & & & & & $\mathrm{X}$ \\
\hline CLANL & & & & $x$ & & & & \\
\hline CMFE & & & $\mathrm{X}$ & & & & & \\
\hline CRAY & & & $\mathrm{X}$ & $\mathrm{X}$ & & $\mathrm{X}$ & & \\
\hline CVAX & & $\mathbf{X}$ & & & & & & \\
\hline CQOT & Protec & the cas & of quot & 1 strings & tween $\mathrm{p} z$ & $s$ of CQOT & ines. & \\
\hline
\end{tabular}

The input/output $(I / O)$ files utilized by COMMENT are listed below:

I/O File

sysprint

sysin

input

output
Function

Dataset containing error messages

Dataset specifying conversion type, (type)

Dataset to be converted

Converted dataset

type is the desired conversion type, chosen from the following list:

\begin{tabular}{l}
\multicolumn{1}{c}{ type } \\
\hline IBM \\
VAX \\
MFE \\
LANL \\
UNIX \\
UNICOS \\
ULTRIX
\end{tabular}

AIX
Result

- Produces upper-case source tailored for MVS systems

- Produces upper-case source tailored for VAX

- Produces lower-case source tailored for CTSS on LLNL Cray

- Produces lower-case source tailored for CTSS on LANL Cray

- Produces lower-case source tailored for UNIX

- Produces lower-case source tailored for UNICOS

- Produces lower-case source tailored for ULTRIX

- Produces lower-case source tailored for AIX 
To utilize COMMENT, compile and load the program into an executable and assign the $\mathrm{I} / \mathrm{O}$ files as appropriate for the operating system.

The Nuclear Engineering Applications Section at Oak Ridge National Laboratory (ORNL) utilizes COMMENT via a CLIST on the IBM mainframe by entering a TSO command. This requires creating an input dataset containing a FORTRAN source deck (usually by selecting the desired module or modules from a SCALE Librarian Master). The input dataset should be of the form name.FORT where name is a valid name supplied by the user. This input dataset is processed by COMMENT to produce a tailored dataset, name.DATA. The IBM TSO command is given below:

\section{\% convert name ype}

COMMENT can also be utilized via a script on the local workstations at ORNL. The workstation command to utilize COMMENT is:

convert type input_file_name output_file_name

where the user must specify the existing input file name and can specify any valid output file name.

NUREG/CR-0200,

Vol. 3, Rev. 4 


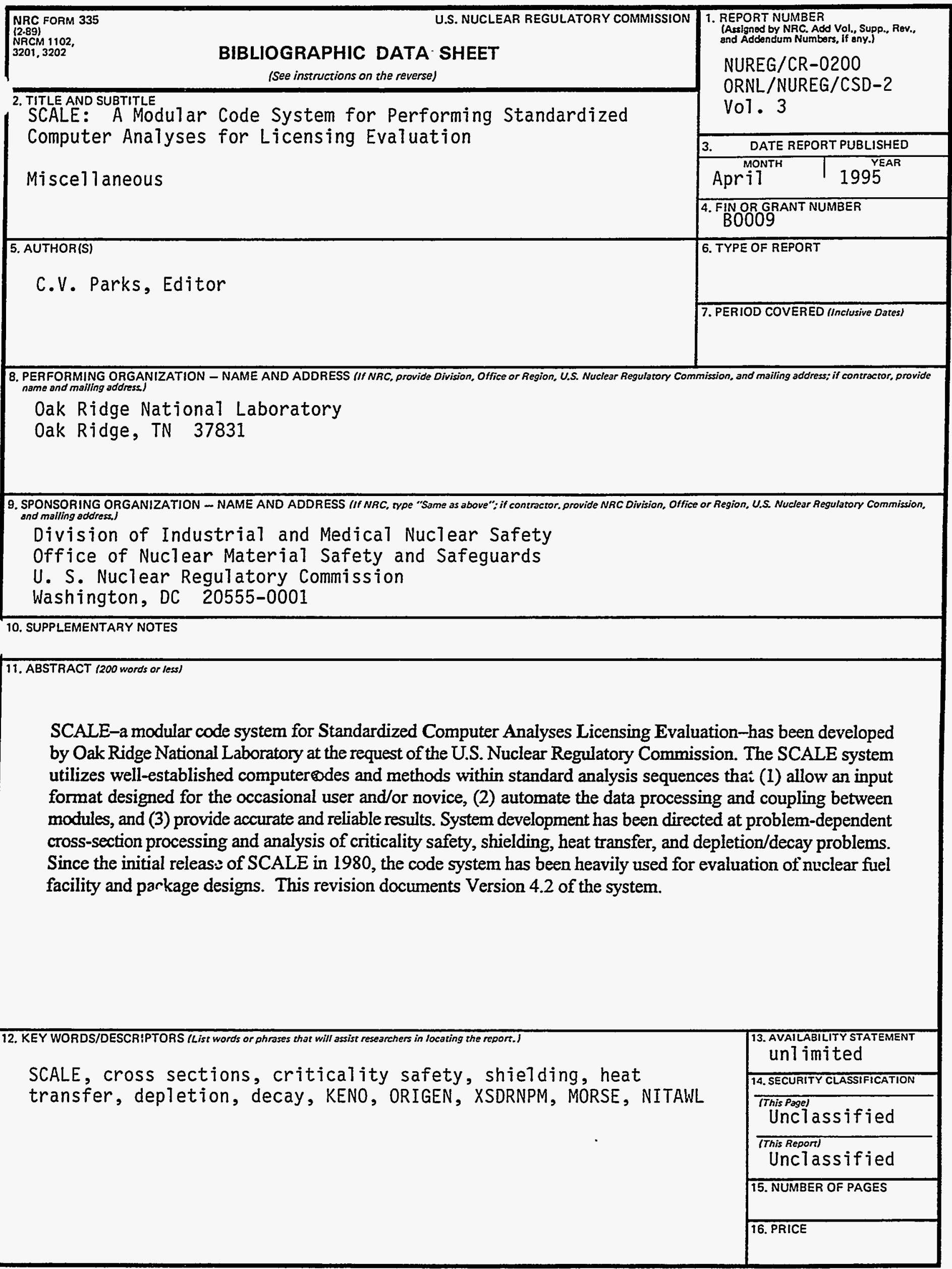

